les planies 


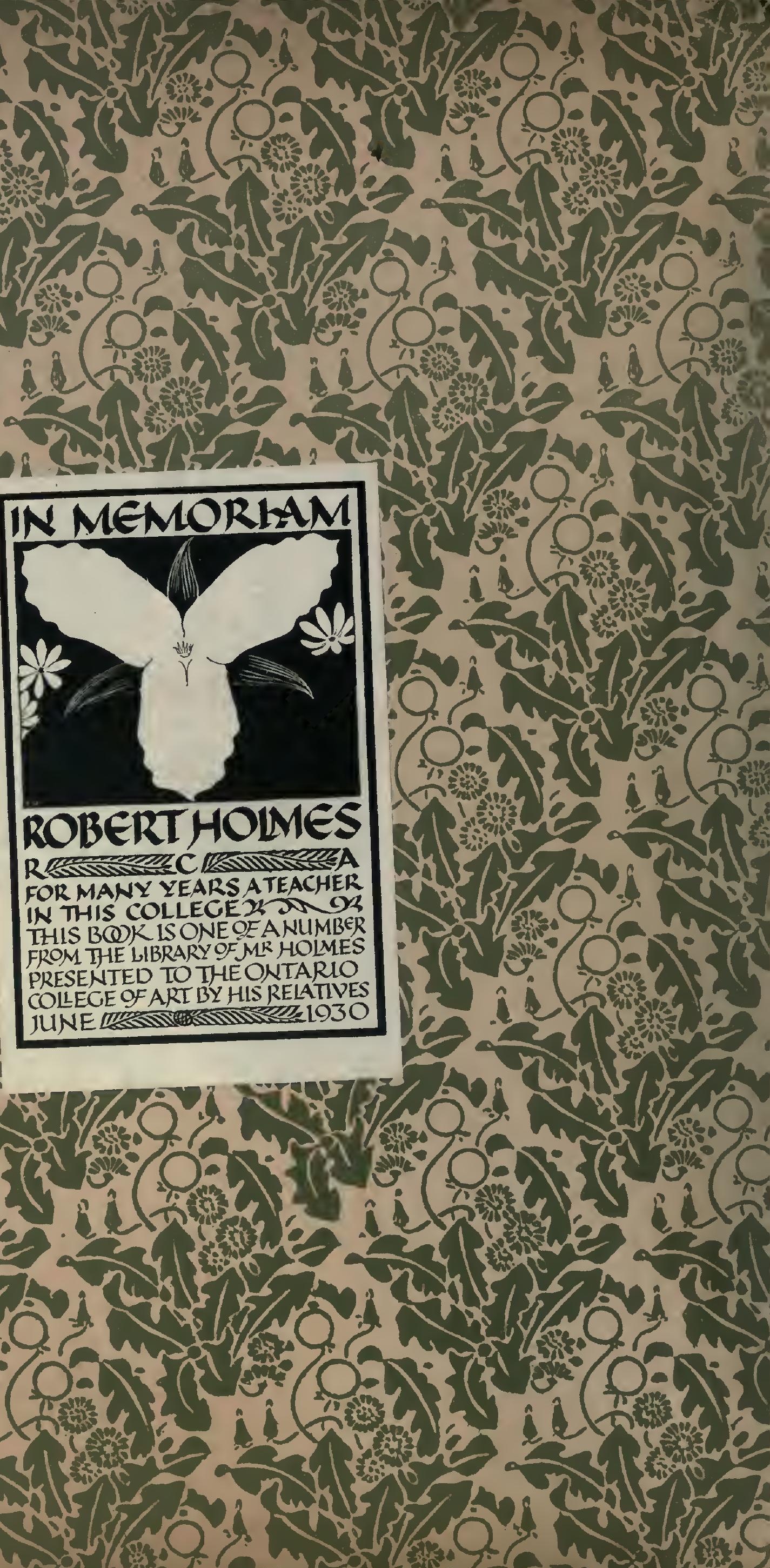






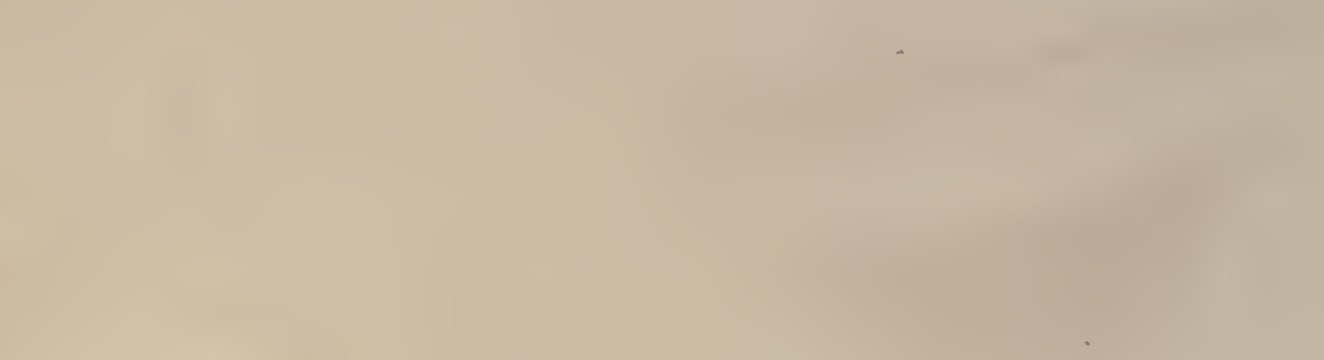


\section{LES \\ PLANTES}


TOUS DROITS DE REPRODUCTION

DE TRADUCTION, DAADAPTATION ET D’EXÉCUTION RÉSERVÉS POUR TOUS PAYS

COPYRIGHT 1922, BY THE LIBRAIRIE LAROUSSE, PARIS 


\section{HISTOIRE NATURELLE ILLUSTRÉE}

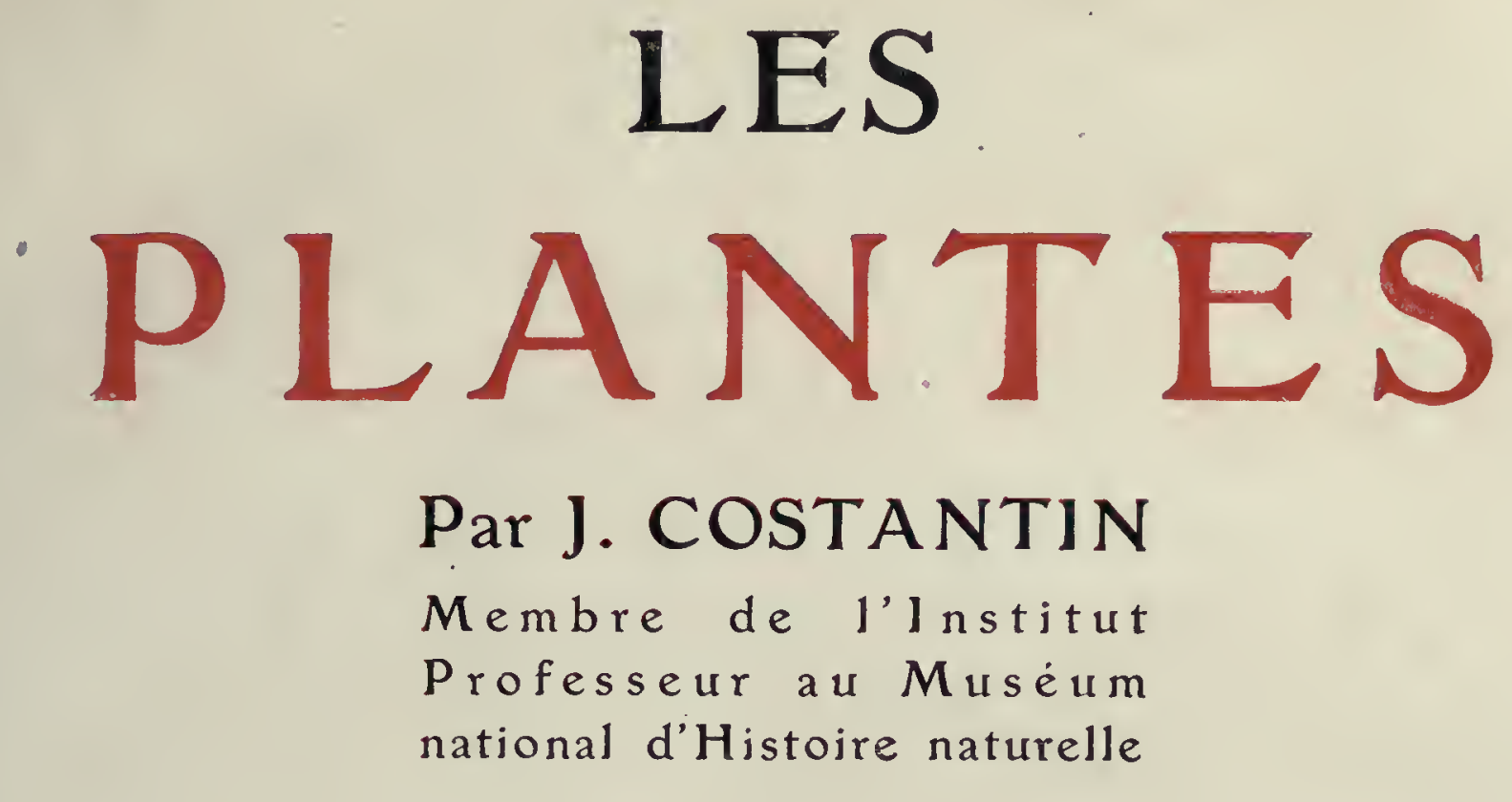

ET

\section{F. FAIDEAU}

Professeur de Sciences naturelles
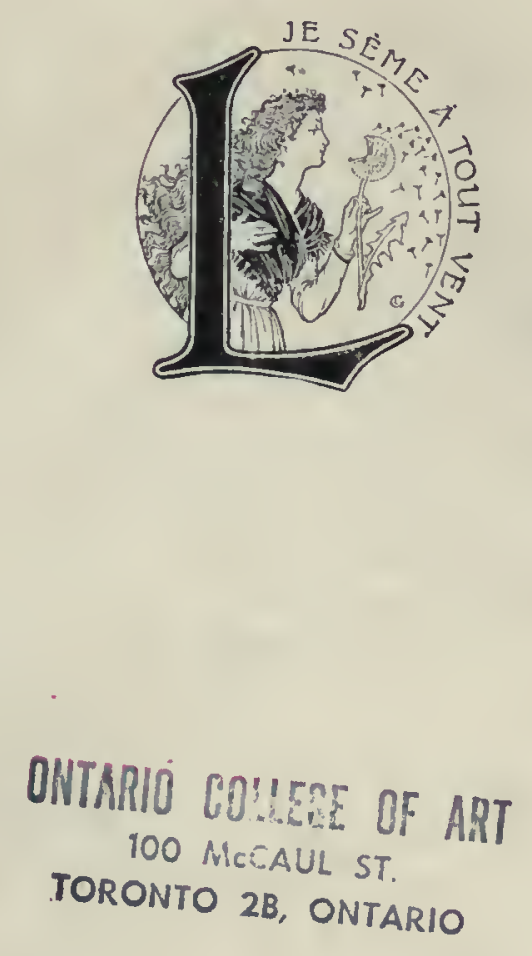

PARIS - LIBRAIRIE LAROUSSE 
732

$\$ 743.7$ 


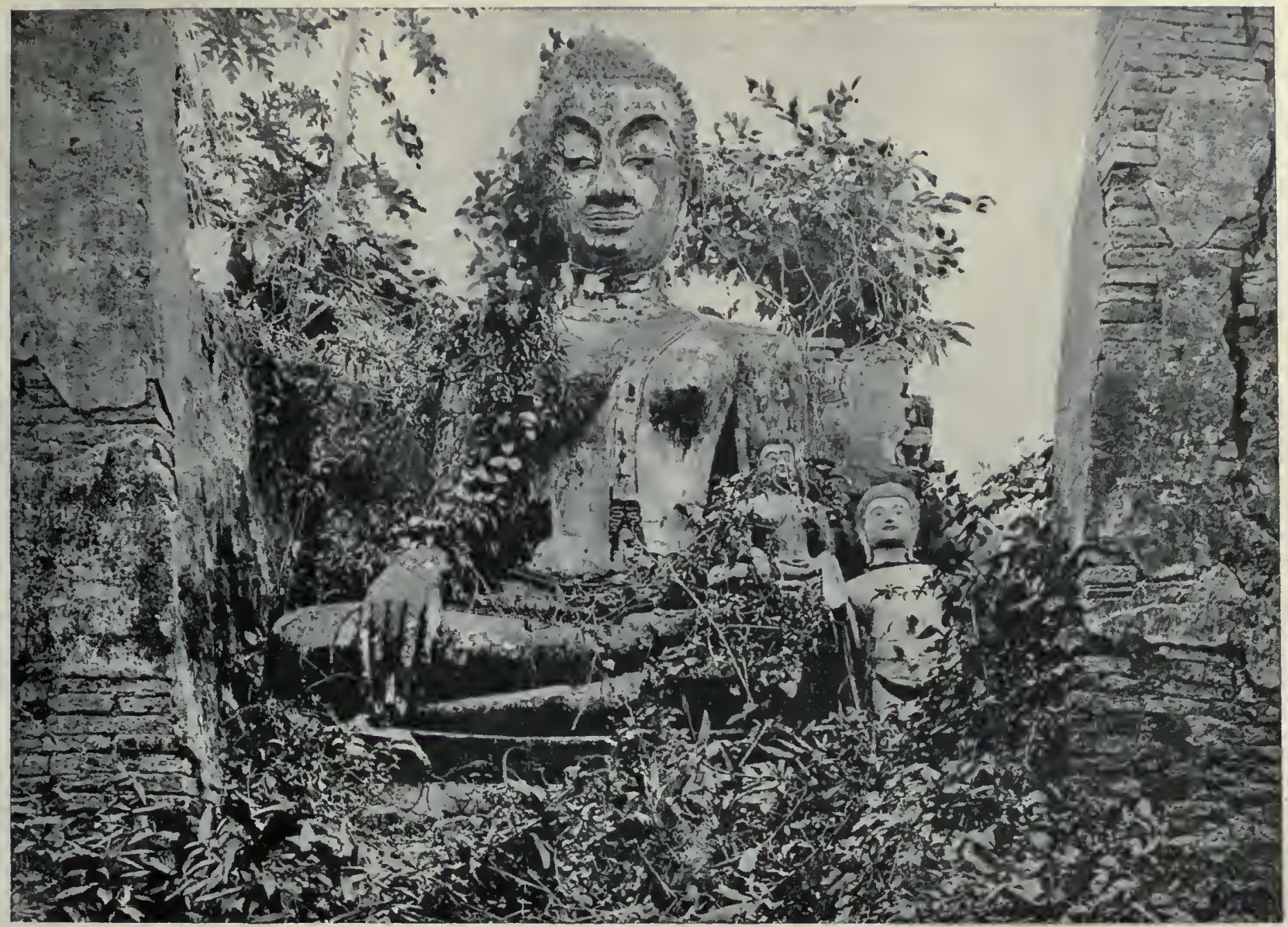

L'AGONIE D'UN BOUDDHA; RUINES DE PHITSANULOK (SIAM).

Cl. de M. L. Fournereau.

\section{LES PLANTES}

INTRODUCTION

\section{LA CIVILISATION ET LES PLANTES}

T ORSQUE l'homme civilisé se promène à travers les rues des grandes capitales, il observe partout les traces de l'activité de ses semblables, et la végétation semble avoir disparu totalement de son voisinage; le sol est recouvert de pavés ou de bitume et la terre nourricière des plantes est complètement supprimée : les maisons, les usines, les palais, les temples apparaissent à tous les coins de l'horizon et le végétal paraît absent ou dompté. Cependant, de-ci de-là, quelques arpents de sol sont demeurés libres et transformés en jardins pour rappeler au souvenir de l'observateur qu'au delà des fortifications des villes se pressent des légions d'arbres et d'herbes prêts à livrer l'assaut. A la moindre défaillance de la civilisation, de partout affluent des semences qui s'insinuent entre les pierres des édifices pour les disjoindre, les renverser et pour reprendre possession d'un empire qui a été traîtreusement enlevé aux vrais possesseurs du sol. On pouvait voir, il y a quelques années, à la Cour des Comptes, une telle expérience faite en plein Paris, par la volonté du gouvernement et du parlement. C'était une ruine bien étrange et bien curieuse. Le monument tel qu'il était sorti des mains des fédérés de la Commune, dévasté par l'incendie, ses balcons tordus, ses pans de murs à moitié écroulés, ses pièces à jour au travers desquelles on voyait le ciel, avait été abandonné à l'invasion du monde végétal. Les plantes avaient pullulé, les herbes folles, les arbres s'étaient installés en maîtres, et, après dix années, leur œuvre avait été extraordinaire.

La civilisation humaine est donc une simple tache, une moisissure à la surface de l'écorce terrestre que les hommes entretiennent et défendent par une lutte de tous les instants, avec un acharnement inlassable. Dans nos climats du Nord, la lutte est déjà intense, mais dans les pays chauds, le combat est plus âpre encore : Le lecteur pourra contempler le Bouddha majestueux et résigné représenté par notre première gravure; ce dies, habillé de végétations, coiffé de lianes, assiste à son propre émiettement dans les solitudes du Siam; là, les monuments abandonnés disparaissent rapidement, engloutis sous la forêt vierge voisine, et cela peut être un moyen de conservation partielle. Tel est le cas pour les ruines d'Angkor, au Cambodge, où les palais merveilleux de cette ville enchantée et mystérieuse ont été ensevelis pendant des siècles, ignorés des humains, sous la forêt qui avait repris possession du sol. 
L'homme a d'ailleurs porté la lutte sur le territoire ennemi, et partout, surtout dans les pays septentrionaux, le monde des plantes est soumis à sa sévère discipline, domestiqué pour son usage. Chaque année, sur d'immenses territoires, la végétation est enlevée, le sol nettoyé par un labour patient, et la semence féconde est déposée en terre " par le geste auguste du semeur ". C'est grâce à ces grandes plaines cultivées et aux récoltes qu'elles produisent que le civilisé, voyant son pain assuré, peut scruter le ciel ou descendre en Jui-même et créer la science, l'art, la poésie et tout le magnifique édifice de la civilisation.

Si en Europe notre aliment fondamental est obtenu grâce an Blé, c'est à l'aide du Riz que les immenses populations asiatiques se nourrissent dans les contrées chaudes, et la culture en est faite en terrains inondés. Lhumidité abondante fournie aux plantes, jointe à la chaleur intense du soleil, peut permettre deux récoltes en une année; aussi ne devons-nous pas être étonnés de savoir

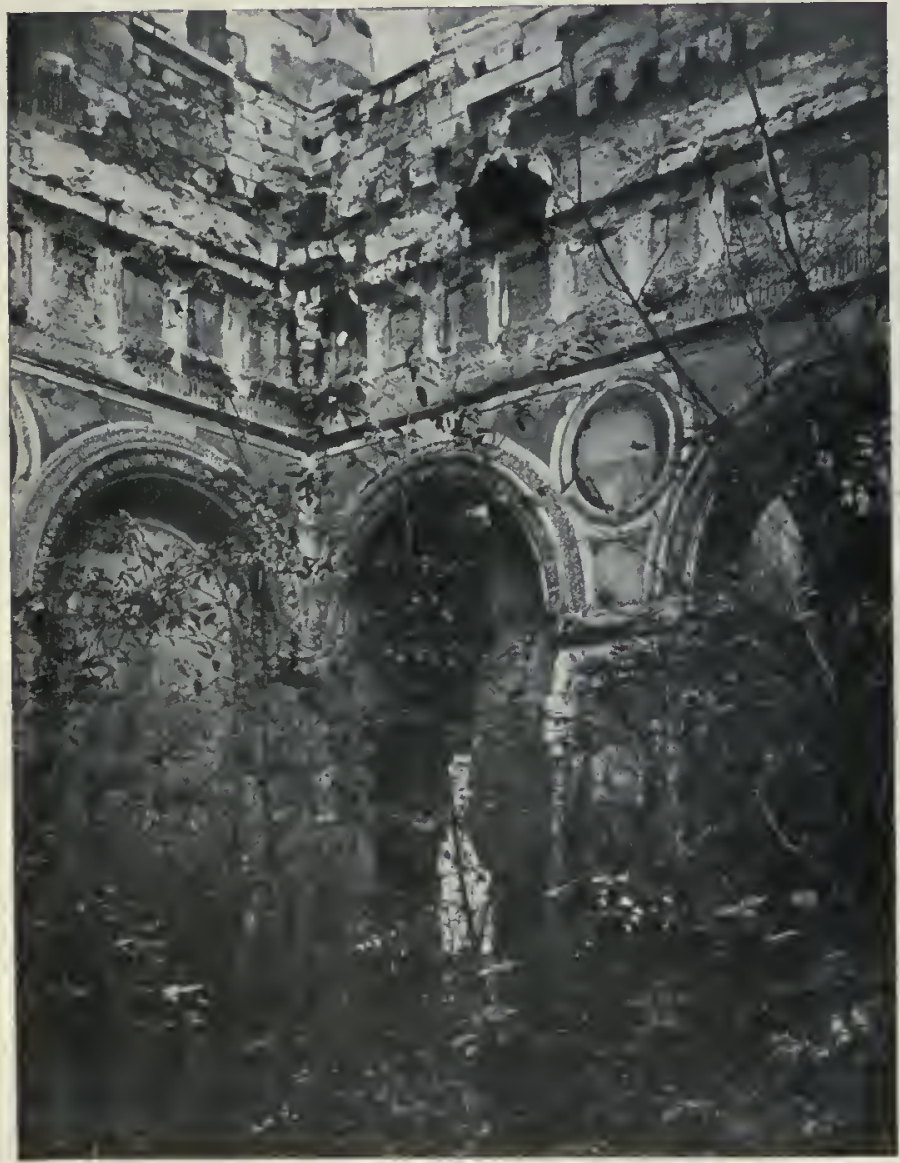

Ruines de la Cour des Comptes, en 1898.

que l'Asie a été le berceau des grandes civilisations de l'antiquité, qui se sont toujours épanouies là où l'eau abondait dans les pays chauds, comme le long du Nil dans l'ancienne Égypte ou de l'Euphrate et du Tigre dans la Chaldée où naquit la culture du Blé.

Pascal a comparé l'humanité à un homme qui vivrait toujours et toujours progresserait. Sa tâche primitive, à l'aube de l'histoire, a été de lutter contre les plantes et de les utiliser. On peut comparer cet homme-humanité qui ne meurt jamais à un laboureur ou à un jardinier dont la vie entière est occupée aux soins qu'il donne à la végétation. Depuis le lever du soleil jusqu’à son coucher il vit avec les plantes, i] les soigne, i] les arrose, il les plante, i] les repique, il les arrache, il les récolte, il les vend. Il consacre un certain temps chaque jour à nettoyer le sol, à ratisser les allées afin d'arrêter l'invasion des herbes folles, mais ses principaux efforts sont consacrés aux grands champs cultivés ou aux plantes du potager qui doivent le nourrir. Il ne néglige cependant pas le jardin d'agrément qu'il inonde d'une pluie bjenfaisante, car les belles fleurs réjouissent le regard, éloignent la tristesse et contribuent puissamment à l'embellissement de la vie en jouant un rôle si important dans l'art et dans l'ornementation.

L'homme des champs, laboureur ou viticulteur, n'a point d'autre pensée que celle de faire fructifier son champ, et c'est avec une attention inquiète qu'il surveille la levée de son Blé, l'éclosion des fleurs de sa Vigne; chaque jour amène une occupation nouvelle et un souci nouveau; tantôt c'est la gelée qu'il redoute, la grêle, l'orage; à un autre moment il se lamente sur la sécheresse ou bien il gémit sur l'absence du soleil, sur la lenteur avec laquelle mûrissent ses moissons. Par contre, à d'autres heures, quelle acti-

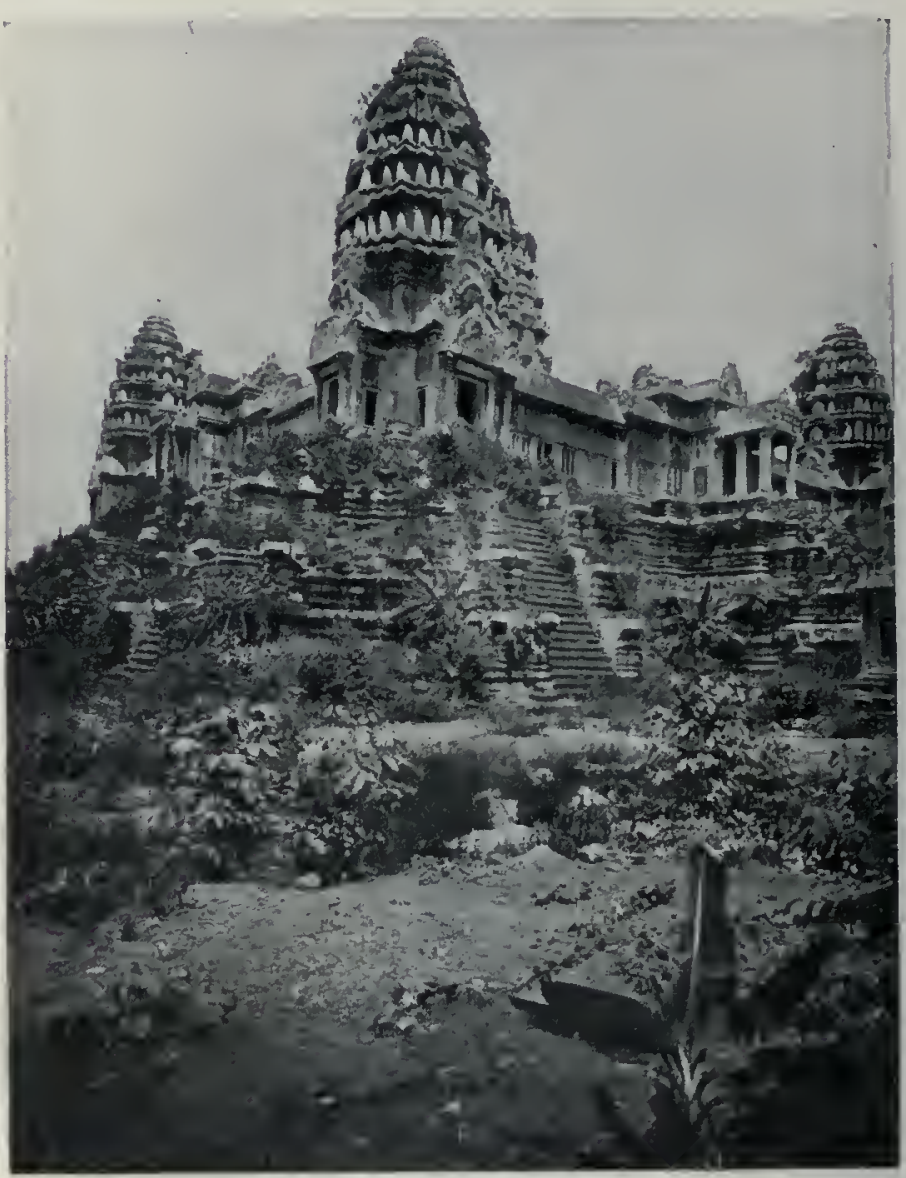

$\mathrm{Cl}$. de l'office colonial,

Ruines d'Angkor-Vat (Cambodge).

vité il déploie, par exemple à l'époque du jaunissement des champs de Blé, au temps de la vendange. Il n'a qu'une idée en tête, celle de ses plantes et de la récolte quil en attend.

Le citadin n'a pas de pareilles pensées et il oublie volontiers quelle place importante le monde végétal tient dans son existence. Il lui suffit cependant, pour s'en rendre compte, d'aller se promener un matin sur un marché, par exemple sur le carreau des Halles, pour voir l'immense variété de tout ce que consomme chaque jour une grande capitale comme Paris. Dans le roman d'Émile Zola, "le Ventre de Paris", cette description est faite d'une manière puissante et c'est une obsession pour le lecteur que de voir réapparaître à tous les chapitres cette énumération formidable de ce qu exige la vie de plusieurs millions d'hommes en légumes, en fruits de toutes sortes : carottes, oignons, navets, pommes de terre, fraises, cerises, pommes, poires, pêches forment des amoncellements énormes et multicolores, qui, chaque matin, sont happés avec une rapidité merveilleuse. Il suffit d'imaginer une cause quelconque mettant obstacle à l'arrivée de tontes les denrées végétales, une grève de chemins de fer, l'apparition d'une armée ennemie, un siège, une inondation, pour voir tout à coup la vie sociale s'arrêter et l'homme civilisé, endormi par le bien-être, disparaître pour faire place au barbare sauvage et affamé qui constituait les hordes primitives de l'humanité.

Le laboureur, le jardinier, dont toute l'existence est consacrée aux soins à donner aux plantes, a tout intérêt à les bien connaître et cela à tous les points de vue. Il doit d'abord savoir les distinguer les unes des autres. Il est bien évident qüil ne confondra pas un Chou avec une Pomme de terre, mais il devra s'efforcer de discerner des différences plus délicates, de distinguer, par exemple, les particularités infimes qui séparent les variétés de Céréales. Il devra rassembler des séries de plantes voisines appartenant à une catégorie à laquelle il se consacrera particulièrement. Celui-là soi- 
gnera les légumes, et la culture maraîchère n'aura plus de secrets pour lui; cet autre s'attachera aux plantes ornementales de jardins : les Roses, les Dahlias, les Chrysanthèmes seront l'objet de ses efforts; un troisième se consacrera à la culture des serres et des merveilles qu'on y rassemble : Orchidées, Fougères, plantes grasses, etc., car un seul type de ces plantes mérite une attention
Les besoins de notre espèce sont innombrables; l'homme ne doit pas seulement se nourrir, il faut qu'il fabrique ses vêtements, qu il se construise des habitations, qu il alimente en matière première les innombrables industries créées par son esprit inventif.

Les plantes textiles, comme le Cotonnier, le Lin, le Chanvre ont depuis un grand nombre de siècles une place conșidérable

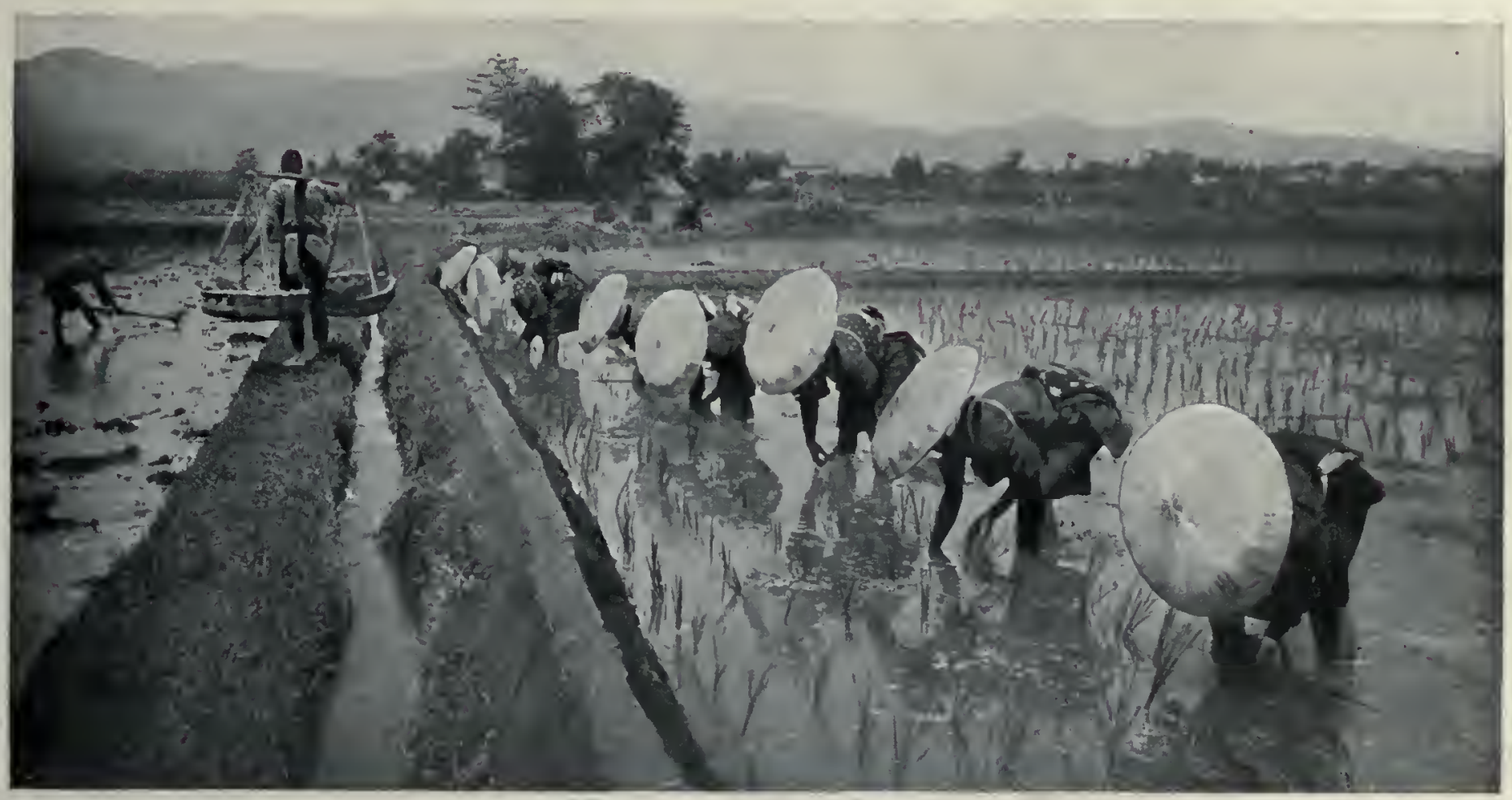

Culture du Riz an Japon : la Plantation.

de tous les instants de la part d'un praticien. Chacun a intérêt à avoir une spécialité, à la condition de trouver le moyen de communiquer sa manie à son semblable, de le convaincre qu'il a acquis une maîtrise dans un art difficile et qu'il est intéressant de conserver un trésor rassemblé avec beaucoup de peine. Mais le goût de la collection n'est pas le seul que doive avoir celui qui vit des plantes; il doit aussi connaître leurs mours, leurs propriétés, leur manière de vivre; il a besoin de savoir comment elles naissent, comment elles se reproduisent, comment elles meurent. Un exemple montrera, mieux que toute autre chose, la portée d'un pareil renseignement obtenu par un homme habile. Dans les serres de la maison Veitch, qui, en Angleterre, sont depuis plus d'un demi-siècle consacrées à la culture des Orchidées, il y avait vers 1850 un jardinier émérite nommé Dominy qui cultivait ces plantes avec beaucoup de méthode et d'attention; ayant appris d'un médecin, le Dr Harris, le mécanisme de la fécondation pour ces fleurs, il réussit l'hybridation de Cypripèdes ou Sabots de Vénus et ces croisements furent féconds. Il fut assez habile pour réaliser la germination très difficile des semences ainsi obtenues et, après des années d'efforts, les premiers hybrides artificiels d'Orchidées firent leur apparition sur la place, et ils trouvèrent des amateurs qui les payèrent au poids de l'or; cette expression n'est pas une métaphore, car on a vu un seul pied payé parfois jusquà 10000 francs. Evidemment la culture faite de cette façon devient un art extrêmement délicat et l'on conçoit que la maison qui possède un pareil artiste fasse les plus grands efforts pour conserver sa collaboration.

L'homme-humanité de Pascal, auquel nous faisions allusion plus haut, a été amené, de même que le jardinier auquel nous le comparions, à se perfectionner dans le cours des siècles, à étendre ses connaissances, à multiplier et à. varier ses cultures. L'homme ne vit pasque de pain, il a besoin de légumes, de fruits. Ces derniers occupent une place prépondérante dans son alimentation : chercher des fruits comme les poires, les pommes, les cerises, et de plus en plus gros, de plus en plus succulents, de plus en plus précoces ou de plus en plus tardifs a été une tâche importante. La découverte de types de culture supérieurs à ceux qui existaient a été un problème de premier ordre qui a contribué à l'enrichissement des contrées où les bonnes variétés ont pu se propager.

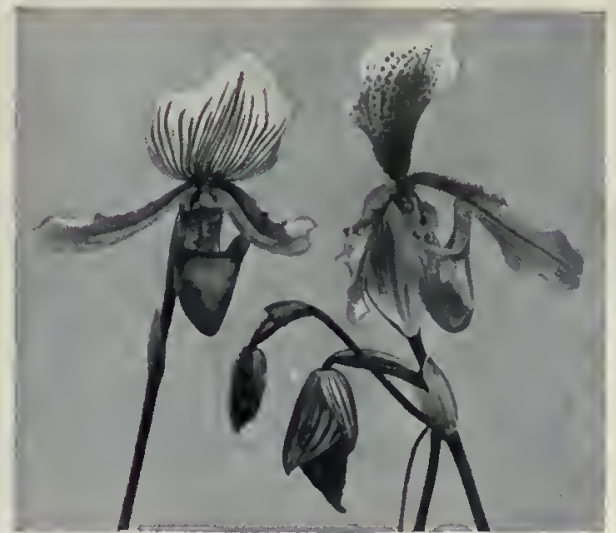

dans les cultures humaines. Les transformations de ces matières premières ont été le point de départ de toutes les inventions de machines quj font la gloire de l'Europe.

L'évolution de lindustrie a été aussi provoquée et accélérée par la nécessité d'extraire les matières grasses ou olćagineuses d'un grand nombre de

graines: Palmier à huile, Cocotier, Lin, Colza, Pavot, Arachide, Ricin, Cotonnier, Aleurite ou Abrasin, etc.

Dans ces dernières années, les applications multiples du caoutchouc, notamment pour les bandages des roues des bicyclettes, des automobiles, de toutes les voitures, ont eu comme conséquence la nécessité de récolter ou de produire une quantité énorme de cette matière première qui s'extrait en saignant diverses plantes, surtout des grands arbres du bassin de l'Amazone. On croyait les réserves des immenses forêts vierges du Brésil inépuisables, mais l'industrie de la locomotion a pris un tel essor qu'il a fallu exploiter les plantes à caoutchouc de l'Afrique tropicale et que les Anglais ont installé d'immenses cultures dans les Straits settlements de la presquî̀le de Malacca et dans l'île de Ceylan.

De même, l'industrie des câbles sous-marins n'a pu se développer que grâce à la gutta-percha, et l'exploitation des arbres producteurs a été faite avec une intensité si barbare dans les forêts de l'archipel de la Sonde que des espèces précieuses ont complètement disparu; ce serait une perte sans remède si heureusement le jardin 
botanique de Buiten zorg, à Java, n'avait pris soin de sauver les types les plus rares et de la plus haute valeur qu'une exploitation féroce allait faire disparaître.

L'industrie du bois de construction est beaucoup plus importante et plus ancienne. C'est par l'exploitation des forêts que l'homme a de tout temps extrait les matériaux dont il a besoin pour la construction de ses maisons, de ses meubles, de ses parquets et de tous les menus objets fabriqués par le menuisier, le tour neur, et dont on ne peut se passer. L'exploitation se fait d'une manière intense dans la montagne, et les troncs d'arbres, précipités dans les lacs,

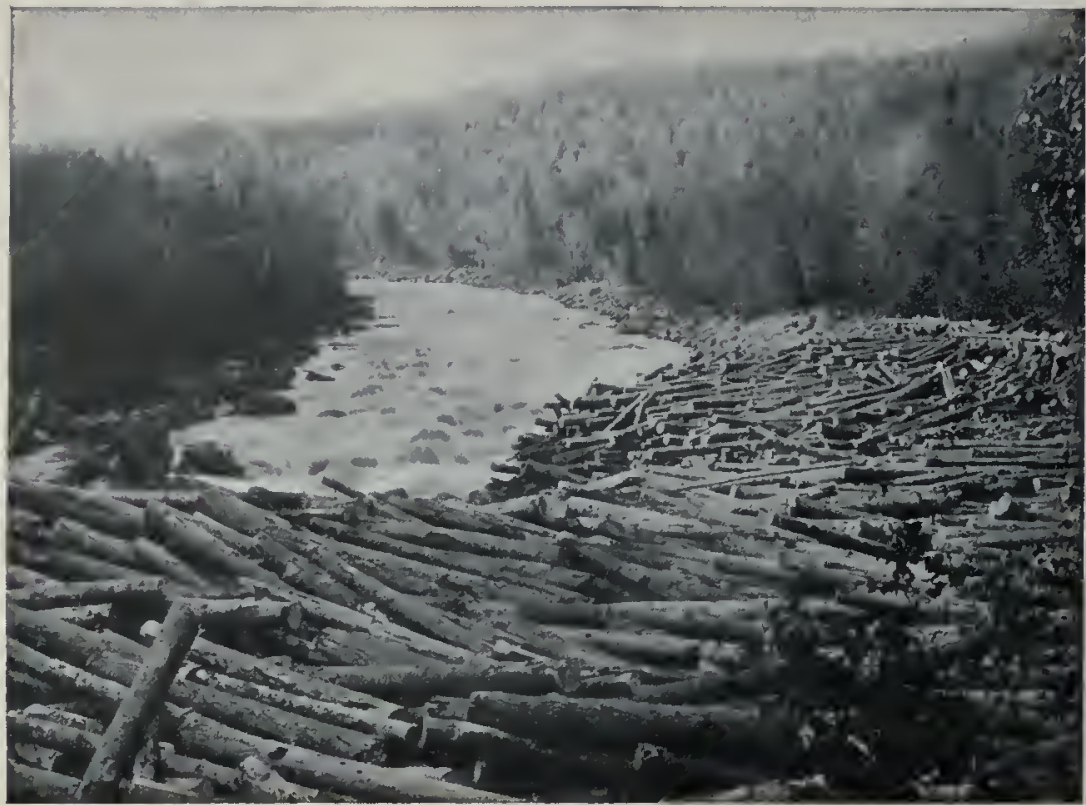

Le flottage du bois au Canada. fournit la quinine) qui ont rendu d'immenses services à l'humanité.

Enfin, l'homme n'a pas seulement à s'occuper de ce qui peut l'intéresser lui-même, il doit encore songer aux animaux qu'il a domestiqués et qui lui rendent des services si grands dans toute son existence. Le perfectionnement de l'industrie tend à réduire leurs services : le développement prodigieux de l'automobilisme n' arrivera peut-être pas à supprimer le cheval, mais certainement à réduire beaucoup son emploi. Cependant l'homme n'est pas près de se passer du bouf de labour, de la vache à lait, du mouton de boucherie. Il faut nourrir tout ce bétail, et l'alimentales rivières, sont amenés par flottage, ce qui réduit singulièrement les frais de transport.

L'industrie de la teinture est depuis longtemps extrêmement florissante : dans tous les temps et chez tous les peuples, les étoffes aux couleurs vives ont toujours été appréciées et les matières colorantes comme l'indigo, la garance, pour ne citer que les plus connues, peuvent s'extraire de certaines plantes. Les espèces à tanin qui servent au tannage des peaux sont également indispensables pour l'industrie et partout on recherche avec soin les plantes nouvelles qui peuvent en fournir, car ce n'est pas seulement de l'écorce de Chêne que l'on peut l'extraire, et la Canaigre notamment, qui pousse à l'état sauvage et en grande abondance dans les terres basses et sablonneuses de l'Arizona, du Mexique, a dans ces derniers temps beaucoup attiré l'attention des tanneurs.

Les plantes narcotiques, comme le Tabac, le Pavot à opium, occupent une place malheureusement trop grande dans la vie humaine, car sil y a des plantes indispensables, il en est un certain nombre, comme l'Absinthe ou celles qui produisent le haschisch, dont on pourrait avec avantage se passer.

Beaucoup de plantes sont bienfaisantes et le nombre des plantes médicinales est considérable. Si, pour certaines d'entre elles, les propriétés curatives qu'on leur attribue ne sont pas toujours aussi effectives que veulent bien le dire ceux qui les préconisent et sil y a des modes dans les médicaments comme en toutes choses, il y a par contre des plantes (comme le Quinquina, qui

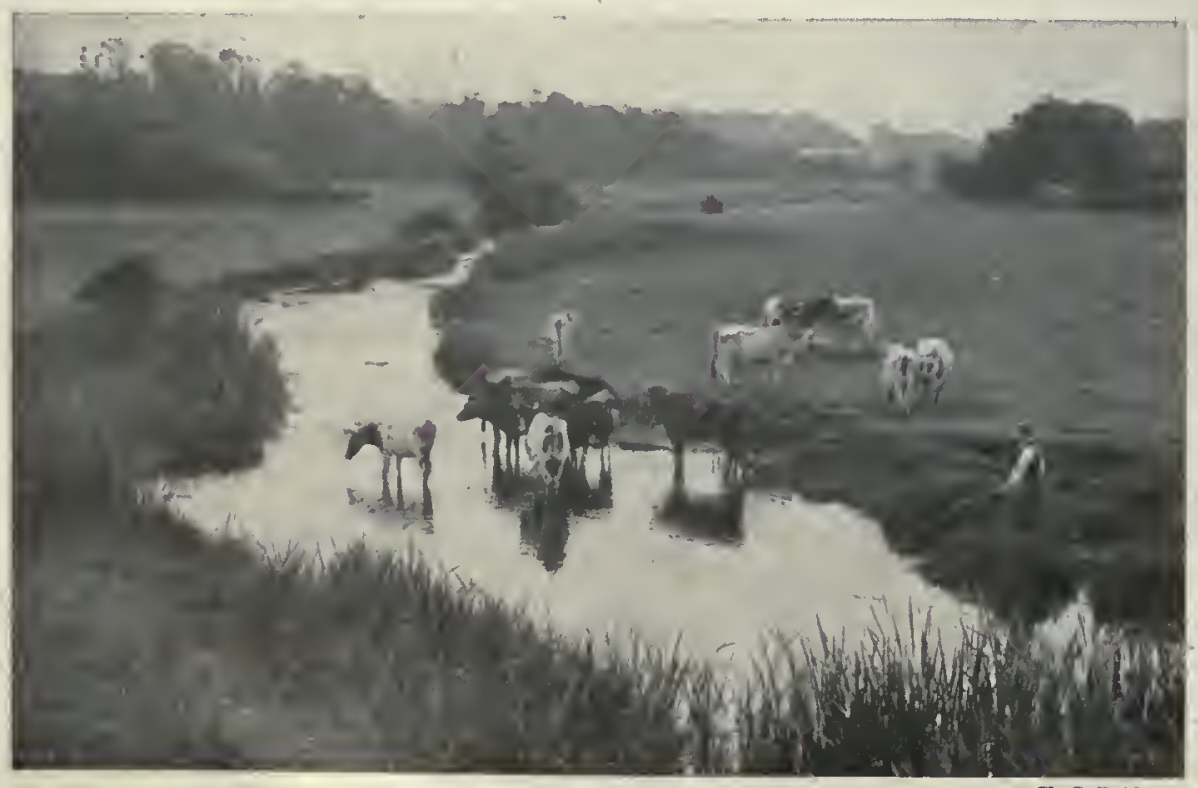

Bestiaux dans un pâturage. tion de tous ces animaux est l'origine de très grandes cultures fourragères. Dans les pays du Nord, la constitution des pâturages est facile; mais dans les régions désertiques il n'en est plus ainsi et la question de l'élevage du bétail devient une des grandes préoccupations de l'agriculteur. Les plantes des pays très secs où la végétation est restreinte sont d'ailleurs armées contre la dent des ruminants par des épines qui les protègent très efficacement. II faut donc trouver des espèces ou des variétés que la nature et l'art du sélectionneur sont parvenus à rendre lisses et qui peuvent servir à l'alimentation des animaux domestiques.

Cette rapide revision suffit pour nous faire entrevoir l'importance immense des plantes pour l'homme et le rôle considérable qu'elles jouent dans les civilisations. Ne négligeons pas de rappeler qu'elles servent à embellir l'existence humaine, si souvent attristée ; quelques fleurs à la fenêtre de Jenny l'ouvrière lui donnent un peu de joie et de gaieté. L'élégance des fleurs et leur beauté les rendent extrêmement intéressantes pour l'artiste et la place qu'elles occupent dans l'art moderne est considérable.

Elles ont d'ailleurs unc autre tâche, moins apparente celle-là, mais non moins efficace, c'est de purifier l'atmosphère que la vie animale vicie d'une manière intense par la respiration; sans les plantes qui régénèrent l'oxygène et qui absorbent l'anhydride carbonique, l'atmosphèrc deviendrait bientôt irrespirable et la vie disparaitrait de la surface du globe. On peut se rendre compte de leur utilité quand, dans un appartement, dans un laboratoire, on veut avoir un aquarium pour y élever des petits poissons, il est indispensable d'y mettre des plantes d'eau afin de régénérer l'oxygène; sinon il faut faire circuler dans le liquide un courant de bulles d'air. La plante joue donc un grand rôle dans les harmonies naturelles; sans le végétal, l'animal ne peut exister, non seulement parce que le premier fabrique l'air respirable, mais parce qu'i] lui donne les éléments de sa nourriture. La plante se contente pour vivre de l'air, de la lumière et du sol. On a pu dire que c'est " un rayon de soleil condensé ".

Un autre rôle des plantes ne peut pas être passé sous silence, celui des infiniment petits sous forme de poussière dans l'atmosphère et qui constituent les microbes dont les immortels travaux de Pasteur ont révélé l'immense importance. Les Champignons microscopiques ont un rôle presque aussi grand dans le monde ; ils pullulent partout sous forme de moisissures, de parasites, et les maladies contagieuses qui s'étendent à toutes les plantes cultivées d'un pays pour le ruiner manifestent ainsi l'étendue de leur domaine. 


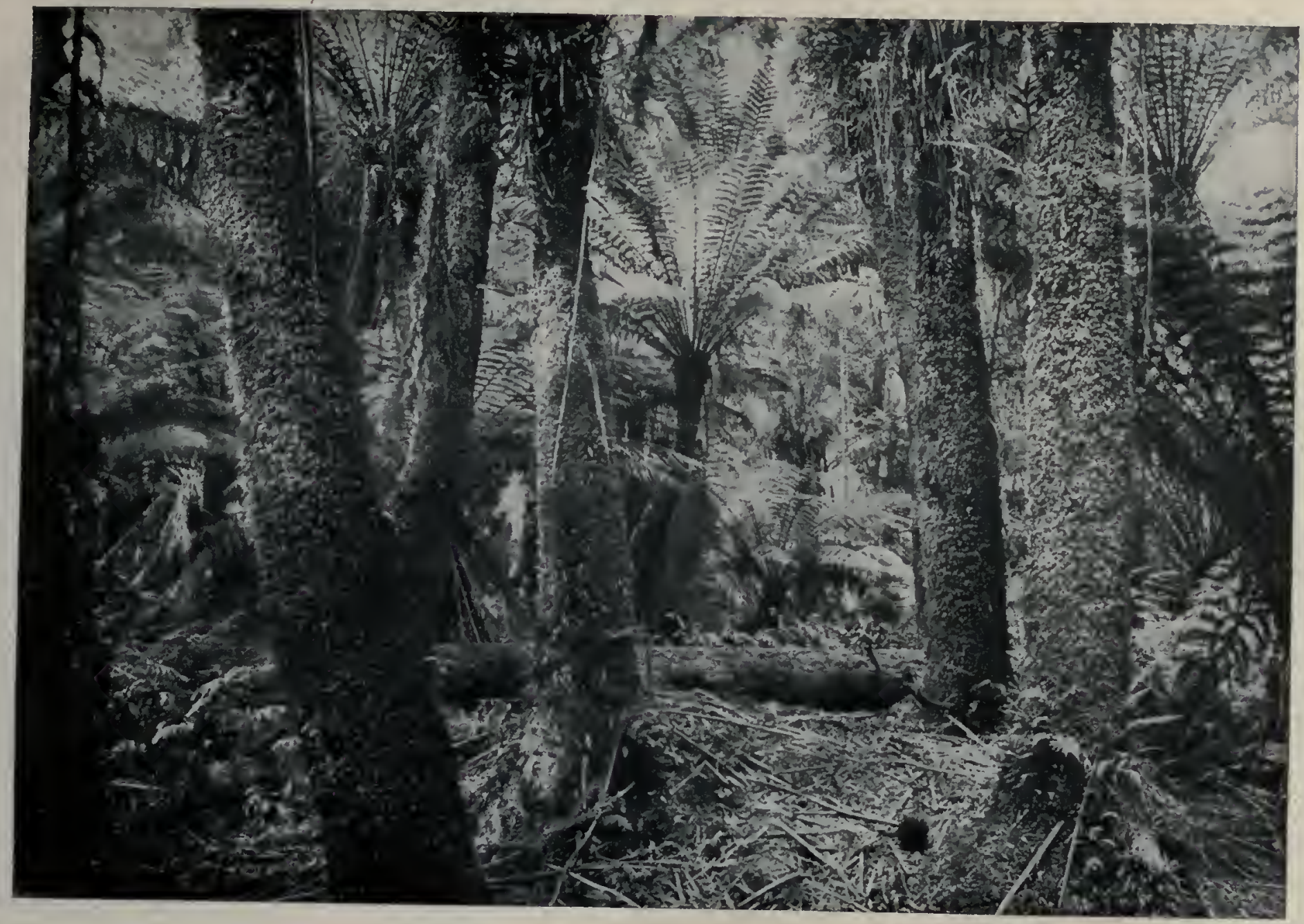

Forét de Fougères arborescentes en Australie.

\section{LES ASPECTS DE LA VÉGÉTATION}

Le vent, les eaux, le feu central, creusent les vallées, sculptent les rivages, créent les reliefs. Les grandes lignes du paysage résultent du travail incessant de ces forces qui modèlent les roches composant l'écorce terrestre. Cette ossature de roches compactes, massives, n'apparaît qu'en un petit nombre de points; partout ailleurs, elle est recouverte d'une riche parure de plantes qui puisent leur nourriture dans le sol superficiel ou terre végétale.

La terre végétale. - Comment se forme la terre végétale? Les premiers artisans en sont les Lichens, plantes inférieures qui, sous la forme de lames ou de croûtes blanchâtres, grises, jaunes ou brunes, sont répandues partout sur l'écorce des arbres, les murs, le sol. Les Lichens prennent possession du roc nu, s'y cramponnent, attaquent sa surface et, de leurs débris accumulés, joints aux débris de la roche, forment une mince couche de matière organique dans laquelle se développent bientôt les germes de Mousses quapporte le vent. Celles-ci continuent l'attaque, ajoutent à l'épaisseur de la couche d'humis et préparent le terrain dans lequel vivront plus tard des végétaux d'un ordre plus élevé.

La durée d'une existence humaine suffit à l'accomplissement de ce travail. Des vieillards vous diront quau temps de leur enfance ils ont connu, blanc et net, dans la nouveauté de sa pierre, le mur de ce jardin de village dont les parois disjointes sont maintenant mouchetées de Lichens, tapissées de verdure et de fleurs, et dont le faîte disparaît sous une végétation adventice de Coquelicots, de Giroflées, de Sédums ou Orpins et de.Joubarbes.

Certaines tranchées de chemins montrent comment la roche cède à l'action des racines (fig. l). En bas, elle est intacte; plus haut,

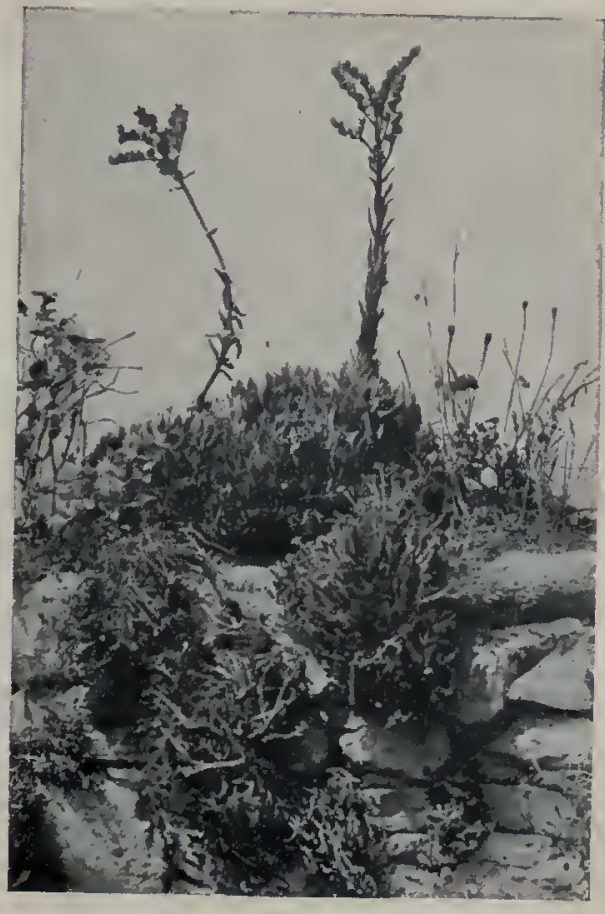

Orpins et Joubarbes sur un mur. craquelée, puis formée d'éléments séparés, de pierrailles disséminées dans une substance déjà terreuse; elle disparaît complètement dans la partie superficielle qui supporte les végétaux.

Les flores naturelles ou modifiées par l'homme sont un des éléments importants du paysage. Tous les lieux où les plantes ne peuvent vivre : déserts, régions polaires, sommets glacés, sont l'image même de la mort et de la désolation. Combien, grâce aux végétaux, sont admirablement variés les spectacles de la nature!

Au cours de cet ouvrage, nous étudierons l'action du milieu sur les plantes, ainsi que les lois qui président à leur distribution à la surface du globe. Nous voulons seulement, pour l'instant, appeler l'at' tention sur leurs physionomies si diverses, sur leurs modes de groupement, et contem. pler en amis du beau quelques paysages botaniques.

Qu on se serve du gros bout ou du petit bout de la lorgnette, qu'on contemple du haut d'une colline un vaste ensemble de pays ou qu'on se penche sur le moindre tapis de verdure, le spectacle offert par le monde végétal est toujours magnifique.

"Je n'ai jamais observé la simple corolle de la plus petite fleur, dit Bernardin 
de Saint-Pierre, que je ne l'aie vue composée d'une matière admirable, parsemée de brillants et teintée des plus vives couleurs. "1

La flore d'un talus. - Voulezvous que, pour commencer, nous regardions ensemble un paysage en miniature : le talus de ce chemin creux. $C^{\prime}$ est l'hiver : l'herbe est rare et les fléurs sont absentes, mais des Lichens barbus, étalés, ramifiés de dix façons montrent les singularités de leur végétation; le sol est recouvert des étranges frondaisons des Peltigères, des cornets menus des Cladonies et de la minuscule forêt des Mousses aux tiges élégantes et aux feuillés diaphanes. Au printemps; le spectacle change : les Mousses se surmontent de leurs mignonnes capsules, des fleurettes se dressent partout et, par larges plaques, le tapis des herbes disparaît sous les Pâquerettes étalant au soleil leurs rayons blancs et leur cour d'or. Puis, c'est la poussée des hautes herbes: Graminées aux nuances ternes, mais gracieuses quand même par la disposition de leurs inflorescences, Millepertuis aux corolles dorées, Coquelicots écarlates, Bouillon blanc à la colonne de fleurs jaune pâle érigée sur un imposant piédestal de feuilles épaisses et cotonneuses, et bien d'autres plantes encore que des semis de hasard apportèrent en ce lieu.

L'automne amène la déchéance des plantes à fleurs; leur tige se dessèche, leurs feuilles jaunissent, se flétrissent, senvolent à tous les vents. Les humbles végétaux, Mousses et Lichens, enfouis sous la forêt des herbes hautes, reparaissent au jour et reprennent, avec l'humidité croissante, le cycle interrompu de leur végétation.

Les saisons qui se renouvellent et qui, comme on l'a dit justement, sont les climats qui voyagent et nous viennent trouver, font de cet étroit espace de terrain un tableau changeant. La vie y est active, la lutte intense pour la conquête de la lumière et la possession du sol; des espèces succombent, d'autres dominent,

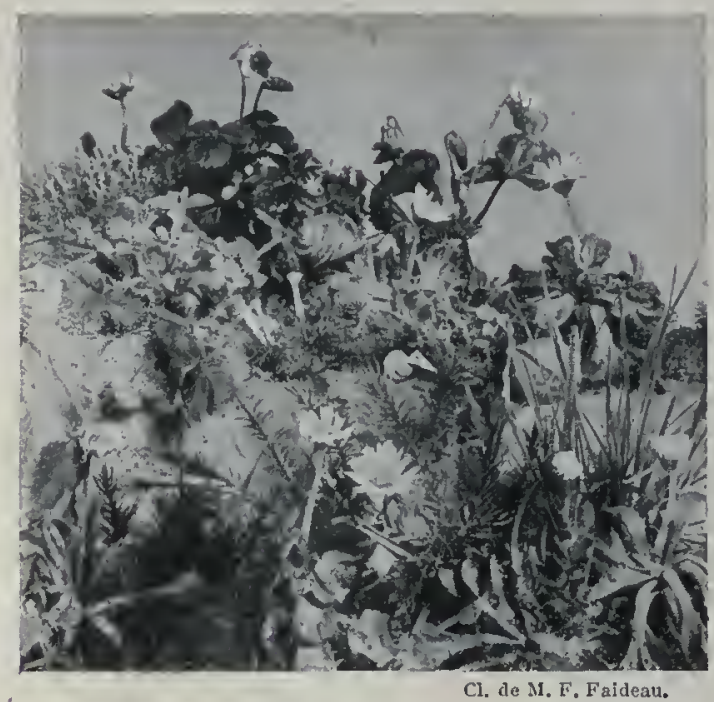

Petite flore d'un talus.

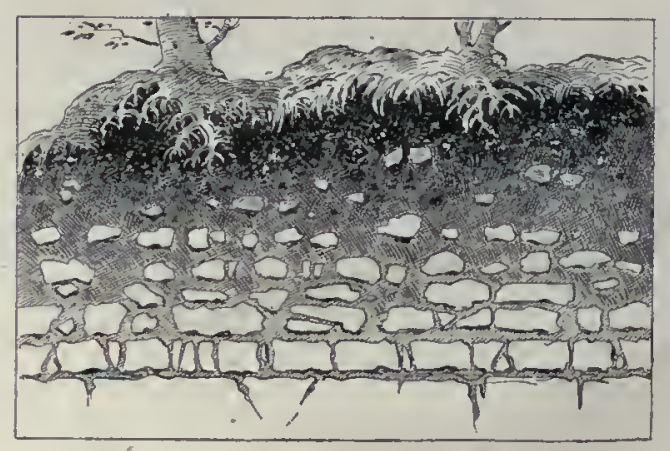

Fig. 1. - Formation de la terre végétale. jusquà ce quiune nouvelle plante mieux douée vienne arrêter leur marcho envahissante ou même les éliminer complètement. C'est, sur une scène restreinte, toute la vie du monde végétal.

La forêt en France. - Mais quittons ce minuscule coin de terre. La forêt est là toute proche et qui nous attire, infiniment variée dans ses aspects, avenante et gaie dans ses clairières, inquiétante et hostile dans ses vallons sombres, émouvante partout.

Chaque arbre a sa beauté, ses caractères, sa physionomie et produit une impression particulière rendue beaucoup plus saisissante par le groupement. Le Chêne, roi de nos forêts, est robuste, majestueux; de son écorce crevassée, de ses branches tordues, se dégage une impression de grandeur. Le Hêtre, tout aussi puissant, est plus élégant, avec son tronc droit, son écorce lisse, ses feuilles minces et régulières. Le Bouleau est gracieux, délicat; son écorce est d'un blanc d'argent; ses branches sont légères, flexibles, ses feuilles s'agitent au moindre vent. Les Conifères, enfin, ont un feuillage sombre et serré qui les rend lourds, massifs; leurs troncs cylindriques, égaux et tous pareils, ont un aspect monotone et triste.

Au printemps, lorsque le feuillage encore léger laisse filtrer de larges nappes de lumière, le sol des bois se pare. Perce-neige, Anémone sylvestre, Narcisse jaune, Jacinthe sauvage, $\mathrm{Mu}$ guet, Sceau-de-Salomon, qui couvrent souvent d'immenses espaces, fleurissent à peu près en même temps et pendant une courte période. Plus tard, la frondaison śépaissit, la lumière manque; le sous-bois ne s'égaie que de quelques fleurs rares et peu brillantes.

L immensité du sujet nous déborde et nous trouble. Où trouver la place de décrire la fougeraie, les Bruyères, la si jolie flore des clairières avec ses Violettes, ses Pervenches, ses Véroniques, ses Lamiers, ses Stellaires, et celle, si curieuse, qui apparaît pendant les périodes successives d'exploitation des taillis. C'est un fait bien connu que dans l'année qui suit la coupe d'un bois, toute une flore s'épanouit dont aucune trace n'existait auparavant. Des Ronces aux tiges férocement armées arrêtent le promeneur; la Douce-amère s'enroule autour des jeunes arbres çà et là oubliés dans la coüpe précédente, un épais tapis de Fraisiers couvre le sol; les Digitales, en terrain siliceux, dressent orgueilleusement leurs hampes garnies de corolles tubulées. L’année suivante, le taillis a poussé; la végétation herbacée est moins variée; elle disparaît peu à peu à mesure que l'ombre s'accroît, pour reparaître dix à quinze ans plus tard quand les jeunes arbres tomberont de nouveau sous la cognée du bûcheron. Y a-t-il là apport de graines venues d'endroits situés hors de la coupe ou germination de graines restées inactives dans le sol depuis la dernière exploitation? C'est un point fort discuté.

La végétation tropicale. Nos forêts paraissent vides et nues, si on les compare à la forêt tropicale, telle qu'on peut l'admirer dans l'Inde, au Congo, au Brésil. C'est une masse solide et compacte de verdure composée 


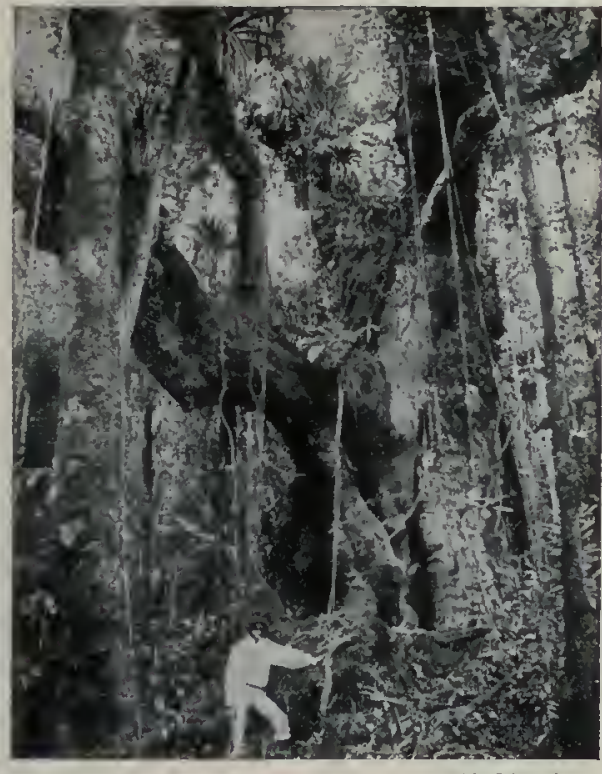

La végétation en forêt tropicale.

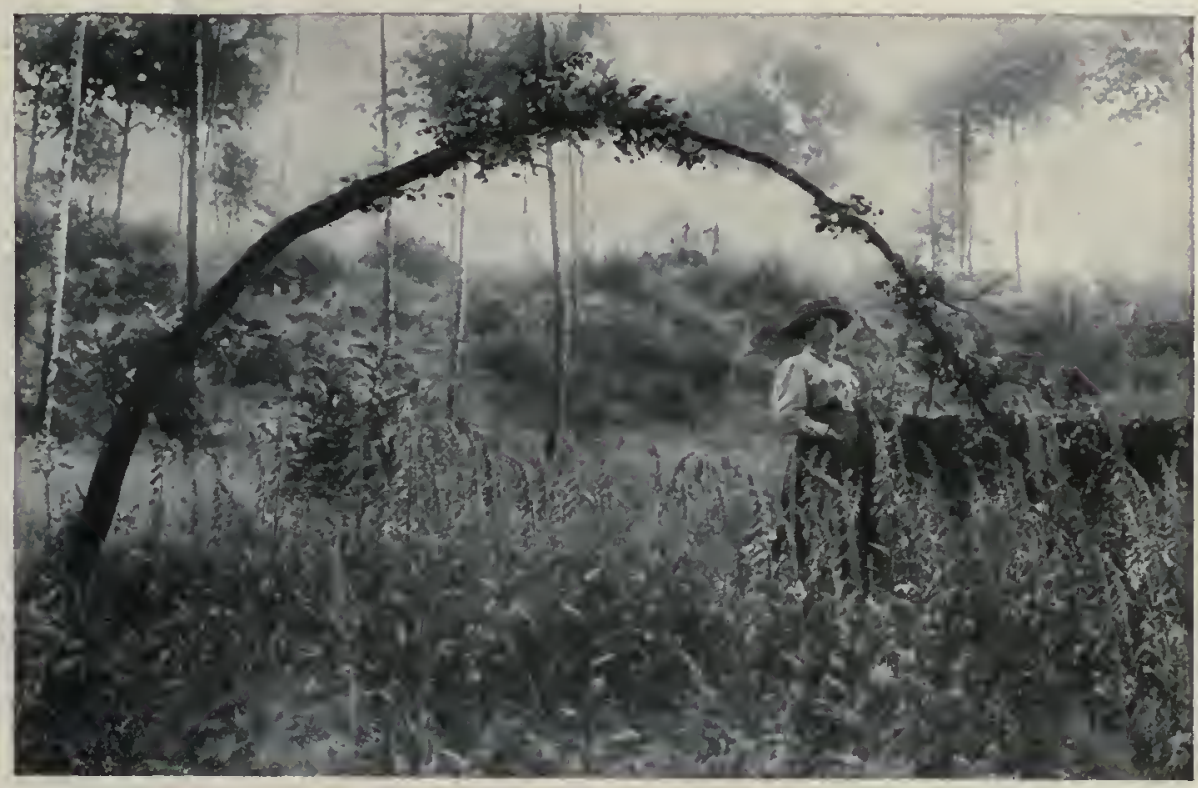

Cl, de M F. Faideau. de centaines d'espèces d'arbres très différents. Les fleurs de ces arbres n'apparaissent pas toutes ensemble, comme sous nos climats; elles se succèdent pendant toute l'année, sont souvent petites et leurs couleurs ne frappent pas les yeux par leur masse. Partont le voyageur admire ou sétonne. Certains arbres ont des fruits étranges, tel ce curieux Kigelia, l'Arbre à saucissons du Victoria-Nyanza, dont les fruits cylindriques, suspendus à l'extrémité de leur long pédoncule, évoquent, sur ces terres lointaines, de vagues souvenirs dc la foire aux jambons.

Les Palmiers forment une des particularités les plus saillantes de la région tropicale; les Fougères y abondent, les espèces arborescentes constituent des groupes importants dans les forêts de l'Amérique, de l'Australie, de Java, de l'Afrique tropicale, etc. Les Bambous, dans les terrains un peu frais, atteignent une grosseur et une taille extraordinaires. Après les grands arbres, ce qui frappe le plus dans la forêt tropicale, $c^{\prime}$ est la profusion de plantes grimpantes qui vont fleurir au sommet des arbres, en pleine lumière. Les plantes épiphytes, Orchidées, Broméliacées, Fougères, recouvrent les branches, et chaque arbre devient lui-même une petite forêt.

Pour consoler ceux qui n'ont pas vu et ne verront jamais les splendeurs de la forêt tropicale, ajoutons avec le naturaliste Wallace : "Cette richesse de végétation devient, à la longue, monotone, oppressive, et on regrette parfois les teintes de lautomne, si riches et si variées, des régions tempérées, le froid sommeil de l'hiver et le charme du réveil de la nature au printemps. "

Le contraste est extraordinaire entre ce monde végétal exubérant, touffu, formidable et la maigre végétation des régions désertiques ou semi-désertiques. Quels arbres étranges que ces Dracana qui se dressent sur les plateaux de l'île Socotora, non loin de la côte des Somalis. Combien sont curieux certains aspects de Madagascar, montrant ces bosquets d'énormes Baobabs au tronc renflé à la base, ou les vallées du Natal, couvertes d'herbes rudes et d'Aloès géants, colonnes cylindriques terminées par une rosace de feuilles épineuses.

Les prés et les moissons. La flore de la prairie, composée de plantes vivaces, amies du plein soleil, est abondante et variée. Les conditions d'humidité, la nature du terrain qui favorisent telle ou telle espèce, le rythme saisonnier font de la prairie un parterre où se modifient constamment le décor floral et la nuance du fond, c'est-à-dire le vert des Graminées. Quelques Pâquerettes égaient seules le court gazon de l'hiver. Véroniques, Primevères, Cardamines, Boutons d'or apparaissent au printemps, bientôt suivis du blanc Narcisse des poètes, dans les prairies de montagnes. Au début de juin, sous la triple action de la chaleur, de la lumière et de l'humidité, tout un jardin jaillit du milieu des herbes : les grappes bleues des Sauges se dressent; les Scabieuses et les Jacécs forment des nappes violettes et les Grandes Marguerites de larges taches blanches; cà et là fleurissent des Plantains, des Salsifis, des Orchidées; plus tard, cest le tour des Liserons, de l'Aigremoine, de la Tanaisie, du Millefeuille, de la Carotte sauvage et des Campanules. Dans les prés humides, septembre tait apparaítre les larges corolles du Colchique d'automne, messager de l'hiver prochain.

Dans les Blés, croissent trop abondamment nos plus belles fleurs sauvages: Bleuet, Coquelicot, Nielle, Souci, Matricaire, Spéculaire miroir de Vénus, Pied-d’alouette, Chrysanthème des moissons, Nigelle, Scandix peigne de Vénus et cent autres. Cette fore élégante, venue d'Orient avec les céréales, comprend surtout des

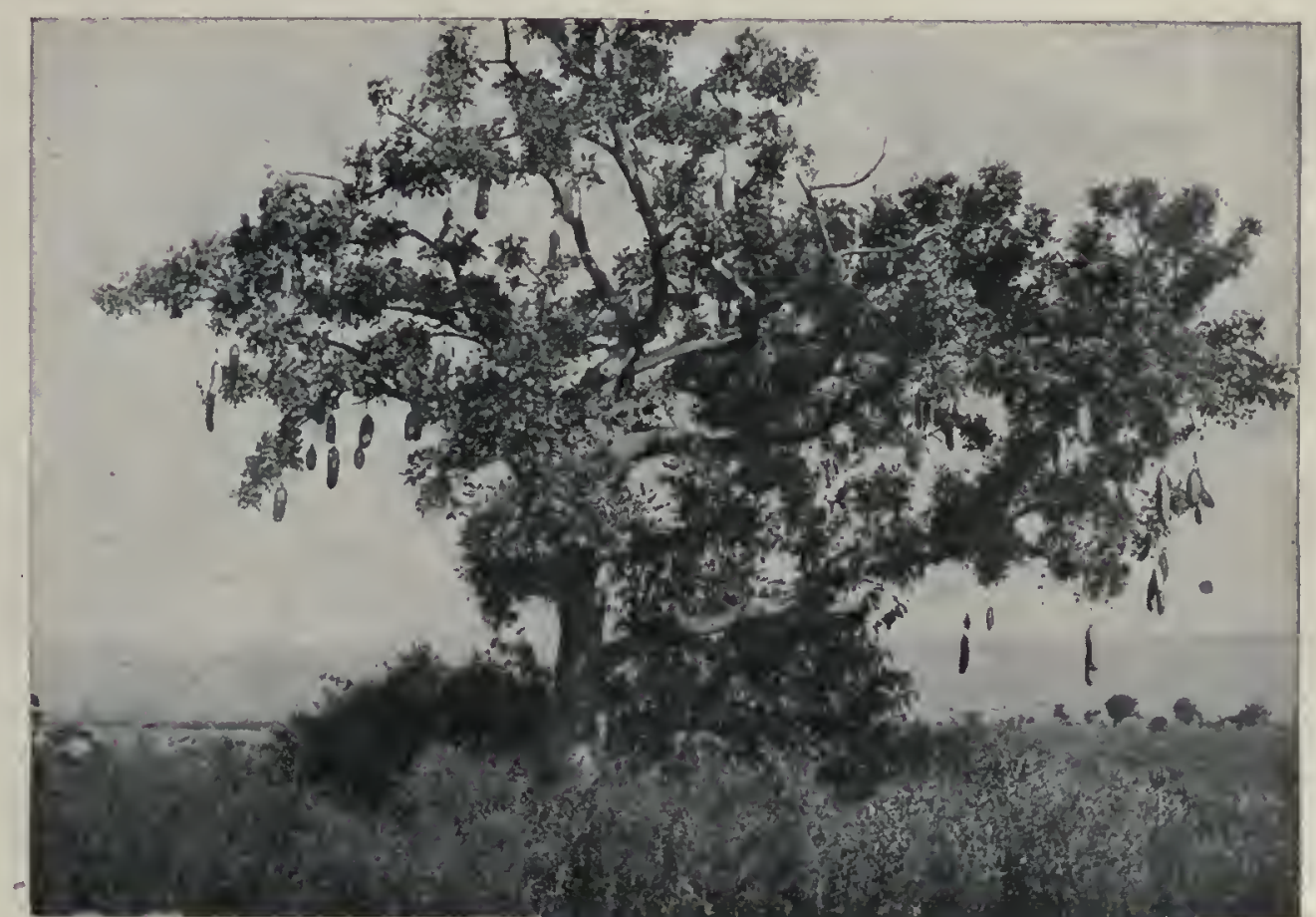

Cl. de \$l. Alluaud.

Kigelia d'Afrique ou arbre à saucissons (région du Victoria-Nyanza 


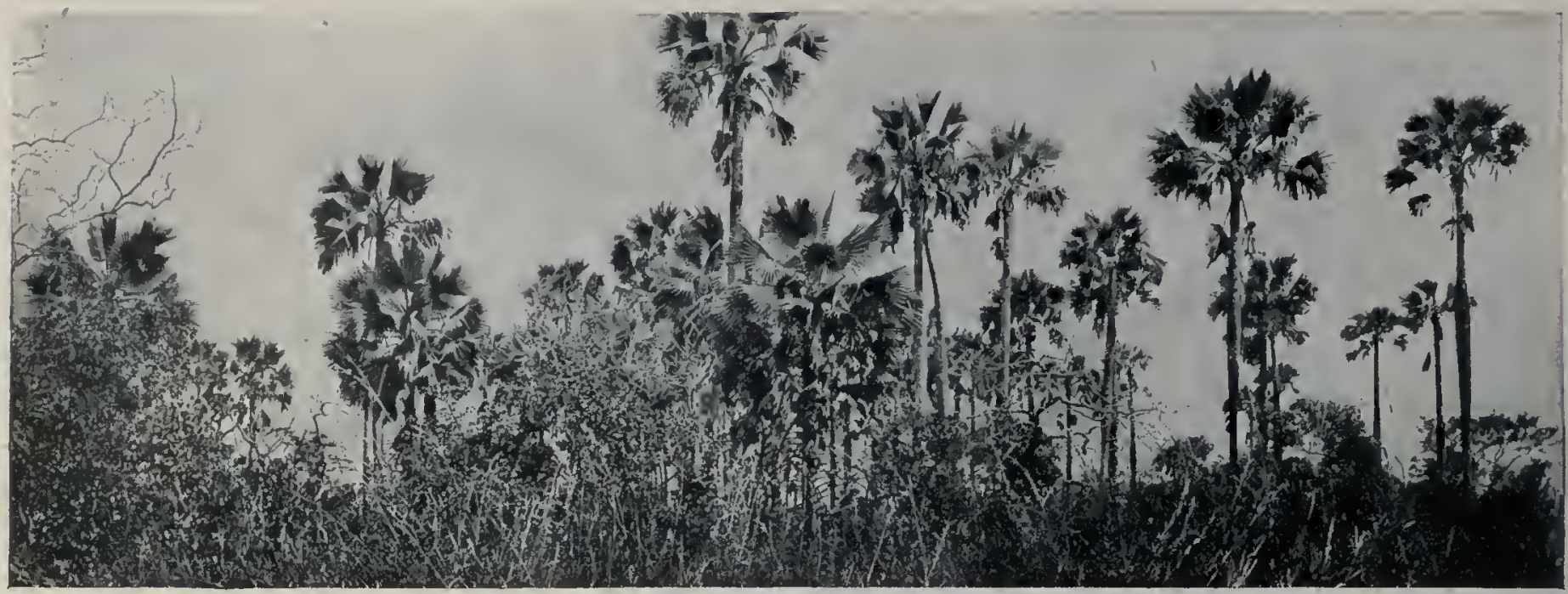

Groupe de Palmiers (Borassus flabelliformis) [Ancien Togoland].

C1. G. Fischer (Tegetationsbilder).

végétaux annuels qui sont semés avec elles, grandissent en même temps que les chaumes, et mûrissent la plupart de leurs graines, avant que, de sa faucille, le moissonneur ne les couche sur le sol.

La haie. - Evoquōns, en passant, la splendide floraison printanière des arbres fruitiers de nos vergers et arrêtons-nous quelques instants au pied de la haie. Pour protéger son domaine, l'homme l'enclôt surtout de plantes épineuses. Dans la haie, le Prunellier et l'Aubépine étalent leurs rameaux pointus comme des alênes; les aiguillons des Ronces et ceux de l'Eglantier renforcent cette ligne de défense et la rendent impénétrable. Par un curieux contraste, ces plantes, si peu accueillantes, ont d'admirables floraisons qui s'échelonnent du printemps à la fin de l'été. L'hiver à peine fini, le Prunellier ouvre la marche et dissimule ses piquants sous l'éphémère parure de ses fleurs délicates; en mai, l'Aubépine lui succède et entremêle de blancs bouquets la verdure de ses feuilles ; en juin et durant une partie de l'été, l'Églantier épanouit ses grandes fleurs rosées au si doux parfum; la Ronce le suit de près et garde jusqu’à l'arrière-saison quelques rameaux fleuris.

Au pied de la haie, vit tout un monde d'herbes qui profite de l'abri de son feuillage et de la fraîcheur qu'il entretient; autour de ses rameaux épineux s'enroulent des Liserons, des Chèvrefeuilles, s'accrochent des Bryones et des Clématites.

$Q$ uand les derniers pétales sont tombés, que les feuilles commencent à jaunir, puis à tournoyer sous le vent d'automne, la haie est encore superbe sous sa parure de fruits ; mûres et prunelles aux nuances sombres qui font ressortir le rouge éclatant des cenelles des Aubépines, des cynorrhodons des Eglantiers et la blanche cascade des longues aigrettes plumeuses des Clématites.

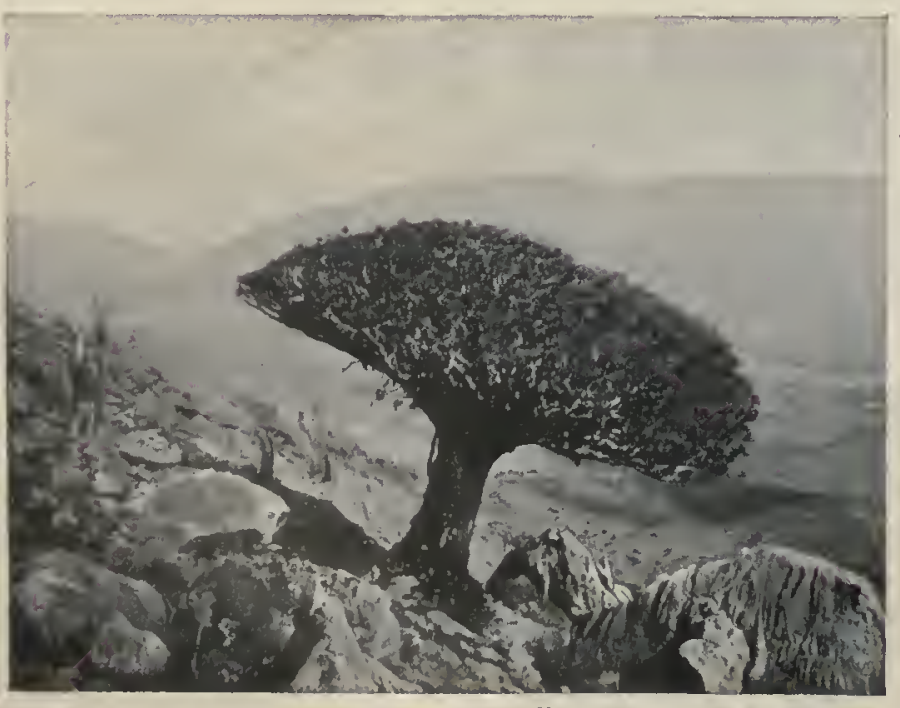

Cl. G. Fischer (Vegelationsbilder).

Dracena Cinnabari, de l'ile Socotora (Océan Indien).
La montagne et les eaux. - En montagne, la tempêrature s'abaisse d'environ un' degré tous les 200 mètres, de sorte que, sur quelques kilomètres, tous les climats se superposent. On peut dire de toutes les montagnes ce que Labillardière a dit du Liban : elles portent l'hiver sur leur tête, le printemps sur leurs épaules et l'automne dans leur sein, tandis que l'été dort à leur pied. En quelques jours ou même quelques heures, le voyageur qui fait l'ascension d'une haute montagne en région tropicale voit passer sous ses yeux toute la végétation d'un hémisphère de l'équateur au pôle. Aucune montagne n'est plus intéressante à ce point de vue que le Kilimandjaro, situé sous l'équateur et haut de 6000 mètres. Liun de ses explorateurs, Alluaud, a rapporté de son voyage d'impressionnantes photographies. Nous publions ici l'une d'elles, représentant le val de Buamba. Ces arbres étranges chargés de plantes épiphytes prospèrent à 3500 mètres d'altitude.

En gravissant nos Alpes, le touriste traverse d'abord des forêts où il voit disparaitre successivement le Chêne, le Hêtre, le Charme et le Frêne; puis, plus haut, les Pins et les Mélèzes eux-mêmes. Ensuite, il ne rencontre plus que des arbustes nains, rabougris : Saules, Bouleaux et autres, et les jolies plantes alpines : Silènes, Saxifrages, Androsaces, Draves, Armoises, Primevères, Soldanelles, Linaires, Gentianes, Linnées, etc. Leurs touffes basses, serrées, compactes, aux feuilles menues, disparaissent, la saison venue, sous les larges corolles innombrables, admirablement belles et si vivement colorées!

Les pentes sèches et ensoleillćes sont garnies de plantes velues et laineuses dont l'Edelweiss (Gnaphale pied de lion) est le type le plus connu. Dans les lieux frais vivent des plantes à feuilles molles et vertes : Fougères (Woodsia et autres), Pédiculaires,

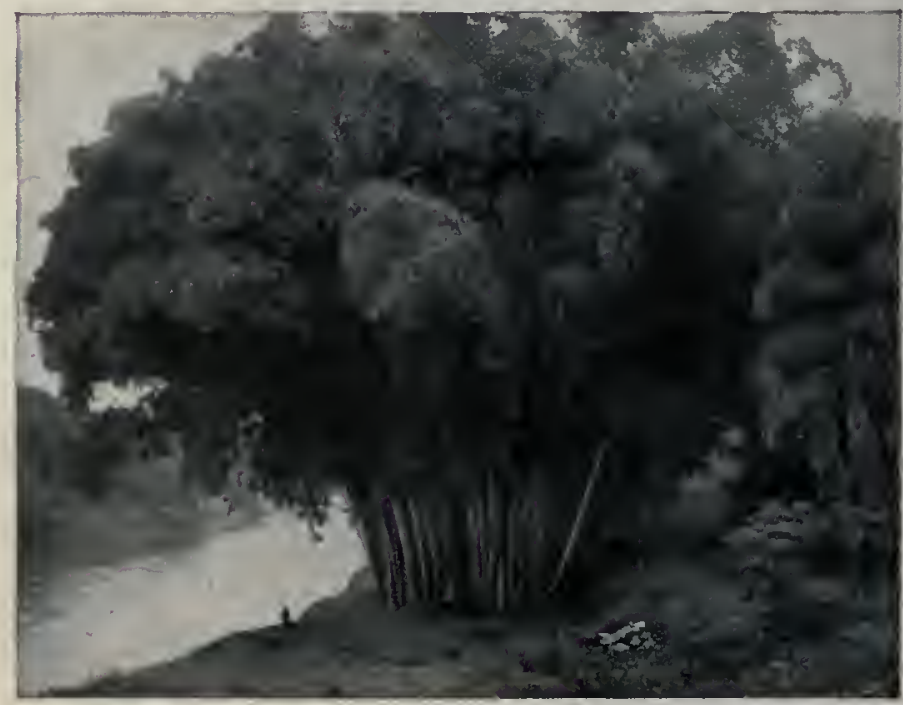

Un bouquet colossal de Bambous, dans l'île de Ceylan. 


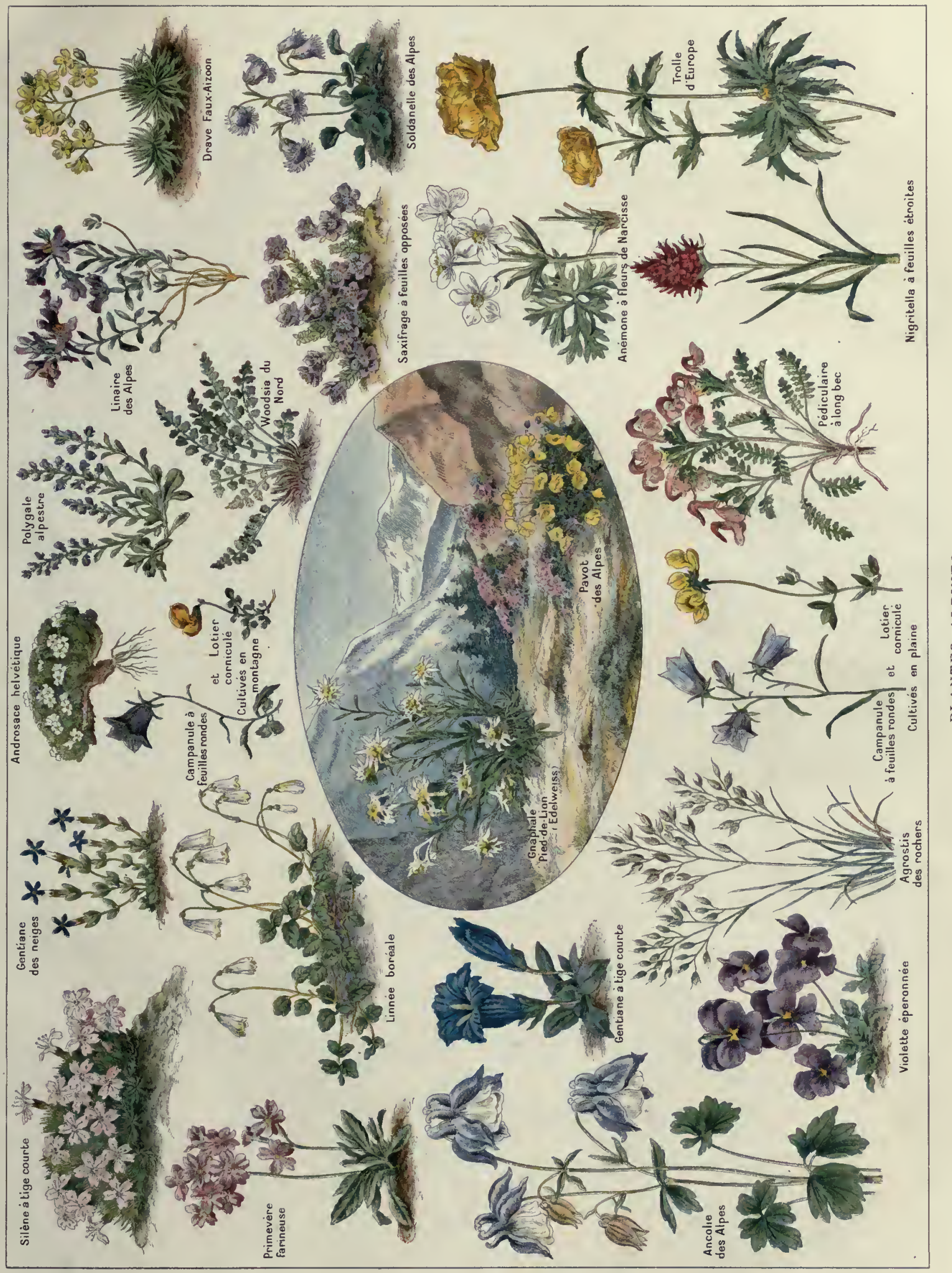



Anćmone à fleur de Narcisse, des Orchidées (Nigritella), l'Ancolie alpine, le Trolle d'Europe, la si jolie Violette éperonnée, etc.

Les expériences de Gaston Bonnier ont mis en évidence l'influence du climat de la montagne sur la végétation des espèces. Des graines provenant d'une même plante étaient semées dans des sols de même composition, les unes à Fontainebleau ou à Pierrefonds, les autres dans les Alpes, de 1050 à 2400 mètres de hauteur. II a vu ainsi que l'altitude développe les parties souterraines, tandis que les organes aériens se réduisent. Cette réduction est visible sur notre Planche en couleurs dont le haut est occupé par des plantes de fortes altitudes, et le bas par des plantes vivant en des lieux moins élevés. Avec l'altitude, le coloris des fleurs s'accentue : les Campanules sont d'un bleu plus intense ; la couleur jaune des Lotiers tourne presque au rouge.

Plus haut encore, des Mousses et des Lichens persistent seuls. De place en place cependant, jusqu'à 3000 mètres et au delà, de petits espaces qui se trouvent favorisés par l'exposition sont couverts des plus charmantes fleurs de la région alpine : ce sont les jardins des glaciers, oasis de ces déserts de glace.

Nous navons pas encore parlé des groupes de végétaux formant la flore aquatique; ils sont cependant parmi les plus beaux qui se puissent rencontrer. Sur les bords croissent des Joncs, des Carex et un peuple de roseaux (Arundo, Phragmites et autres),

puis les plantes amphibies aux fleurs élégantes : Rumex, Jonc fleuri, Sagittaire; enfin les plantes d'eau proprement dites, dont les plus apparentes sont les Nénuphars, qui parent superbement nos étangs et nos rivières. Mais combien plus somptueux encore le décor des eaux dans les régions chaudes, avec sa profusion de larges feuilles flottantes ou dressées et les admirables fleurs du Lotus ou de la Victoria regia.

La flore maritime. - Sur le littoral maritime, une flore spéciale couronne le sommet des falaises, s'insinue entre les galets du rivage, fixe les grains de sable des dunes ou transforme en un parterre fleuri les talus des marais salants. Là se rencontrent les étonnantes Salicornes, épaisles, charnues et rigides; se Perce-pierre, aux

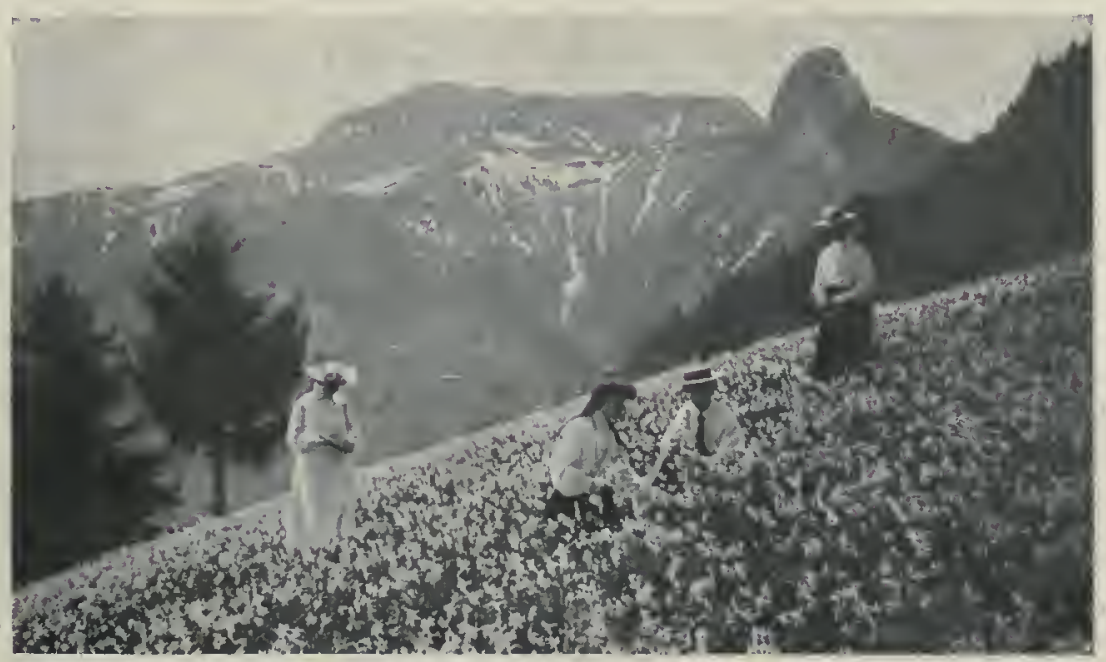

Cl. E. Nossier.

couvrant les rochers du bord ou parant de leurs nuances vives le fond des petites mares que laisse la mer en se retirant. Tandis que les Ulves ou Laitues de mer ont des tissus d'une délicatesse extrême, les Laminaires semblent de longues lanières de cuir et les roses Corallines incrustées de calcaire sont dures comme du corail.

La course rapide que nous venons d'accomplir à travers les paysages végétaux nous a permis d'en admirer la variété et la beauté. C'est maintenant un long voyage d'exploration que nous vous proposons d'entreprendre avec nous à travers le monde végétal. Sans rien sacrifier de l'exactitude et de la précision scientifiques, nous nous appliquerons à vous en rendre les étapes agréables. Voici d'ailleurs l'itinéraire du voyage, c'està-dire le plan de ce livre. 


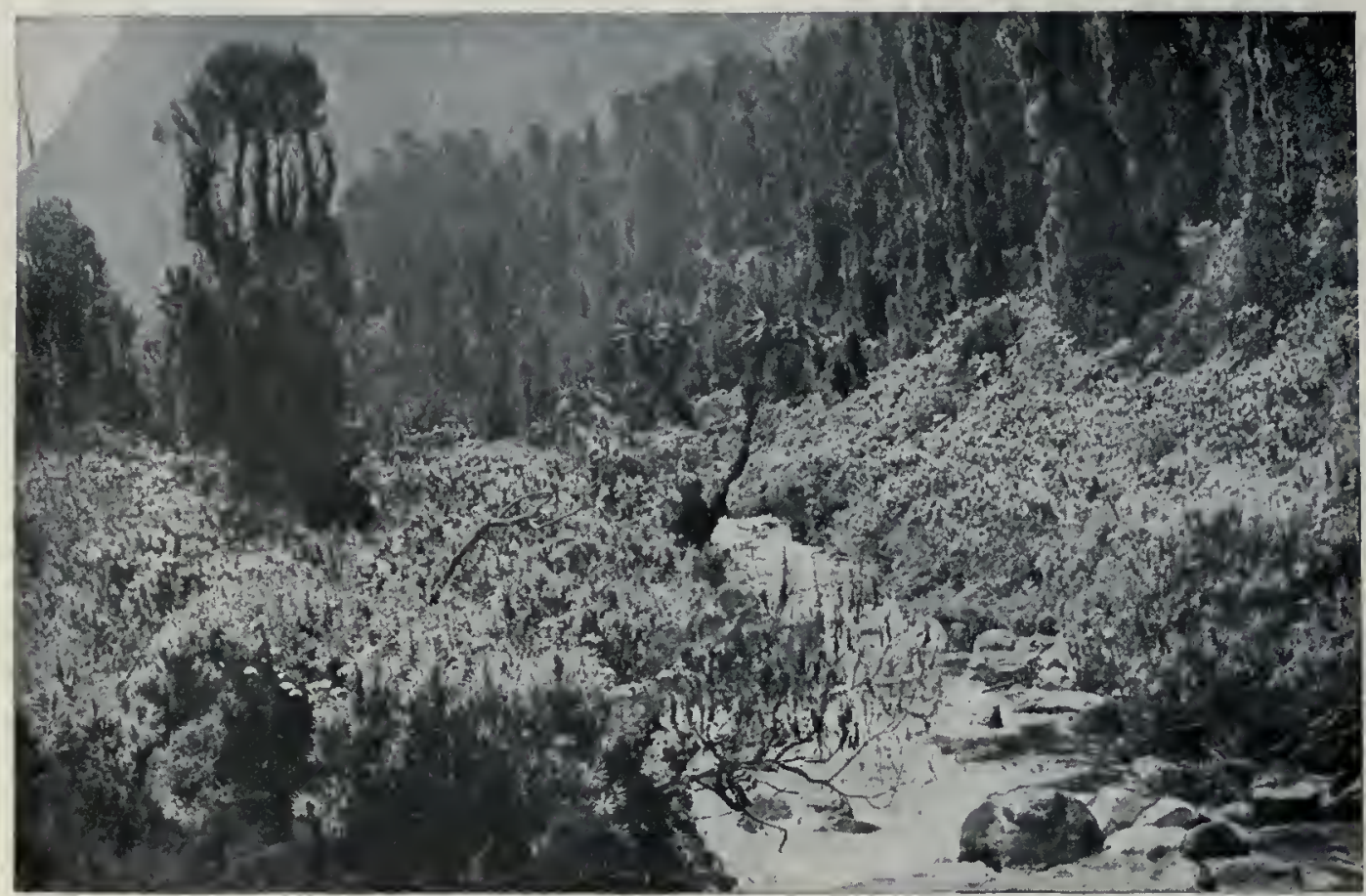

La végétation dans le val de Buamba (Kilimandjaro).

Nous venons plus haut de comparer le végétal à une montre, mais nous savons qu il y a des montres très diverses les unes des autres par le méta! de la boîte, qui peut être en or, en argent, ou même en une matière moins précieuse. Elles se différencient par le mécanisme, par le mode de fabrication, suivant quelles sont anciennes ou modernes, enfin par le pays qui les produit, et il y aura intérêt à réunir une collection de ces objets. Nous ferons de même pour le monde des plantes. En les comparant entre elles, nous nous apercevrons qu'elles sont très nombreuses, et il sera de toute nécessité de les classer. Comme il s'agit d'une multitude, la Classification n'est pas une petite tâche. C'est à cette besogne que s'est illustré le génie lumineux de Linné. Nous remarquerons de suite avec lui quil y a des plantes à fleurs et des plantes sans fleurs; les premières sont les Phanérogames, les secondes les Crypto-

\section{DIVISIONS DE LA BOTANIQUE}

La plante n'est pas un être inerte et endormi, comme on est tenté de le penser après un examen superficiel des choses; c'est un être vivant et, à ce titre, très intéressant à étudier de près. Cette étude constituera la première partie de cet ouvrage. Si l'on veut avoir une idée d'une montre, que fait-on? On l'examine d'abord de l'extérieur, puis on l'ouvre, on la démonte, isolant une à une les parties qui la composent, puis on rajuste les pièces disjointes et on met la machine en marche. Nous ferons de même pour le végétal : nous isolerons un à un ses éléments constitutifs, racine, tige, feuille, fleur, fruit, graine; nous nous efforcerons de préciser pour chacun d'eux le rôle qui lui incombe, puis nous ferons nos efforts pour comprendre la machine en activité.

Les végétaux ne sont d'ailleurs pas isolés dans la nature; ils s'y trouvent partout au contact des animaux et face à face avec le monde minéral sur toute la surface du globe terrestre. Comment se comportent-ils les uns par rapport aux autres? Ce sont là des questions d'un grand intérêt qu'il nous faudra aussi examiner. A mesure que notre horizon s'agrandira, s'accroitra notre soif d'aborder des questions plus vastes, et celle de l'origine des plantes et du transformisme se posera inévitablement à nous. Nous serons amenés ainsi à examiner les notions mystérieuses de l'hérédité et de la naissance des variétés par les moyens que l'homme a en son pouvoir.

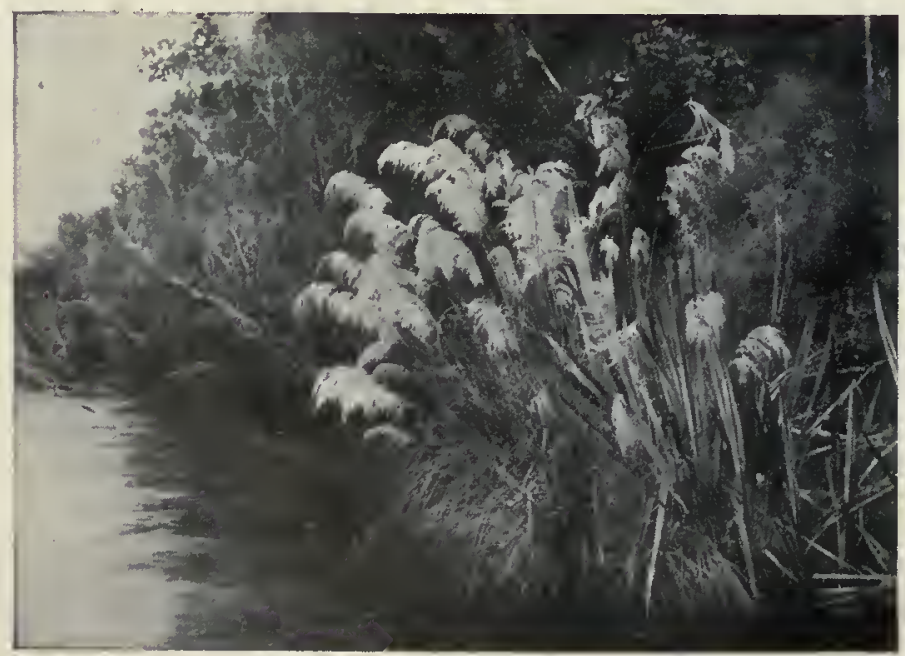

Arundo conspicua, en Nouvelle-Zélande. games : le premier mot venant de deux mots grecs voulant dire à sexes apparents, visibles; le second, au contraire, à sexes cachés. Les Phanérogames attirent tout de suite l'attention par leur grande taille, par leur beauté, par leurs applications nombreuses; ce sont elles aussi qui ont d'abord été étudiées. Les Cryptogames (Algues, Champignons, etc.) sont plus humbles, elles n attirent pas les regards : aussi ont-elles été longtemps méconnues; mais on a fini par se convaincre qu'elles étaient extrêmement nombreuses et que leur rôle dans la nature était très important, souvent même capital.

Quand nous serons parvenus à nous reconnaître au milieu de cette immensité d'êtres divers, nous nous demanderons pourquoi nous nous sommes donné cette peine. Si l'homme civilisé cherche à connaître d'une manière approfondie le monde qui l'entoure, c'est afin d'en tirer parti pour l'amélioration de son sort. Quand il se place à ce point de vue, il s'aperçoit aisément qu'il ny a pas d'étude plus utile : le nombre des espèces végétales qui ont des applications est immense. Nous les grouperons en plusieurs chapitres, suivant qu'il s'agira des plantes alimentaires, fourragères, industrielles, médicinales ou ornementales. Quelques pages finales seront consacrées à l'utilisation artistique de la plante, puis aux légendes et aux mythes auxquelles elle a donné lieu.

En résumé, Anatomie et Biologie des plantes, Classification botanique, Applications des végétaux, telles sont donc les trois grandes divisions qui se partageront à peu près également l'ouvrage.

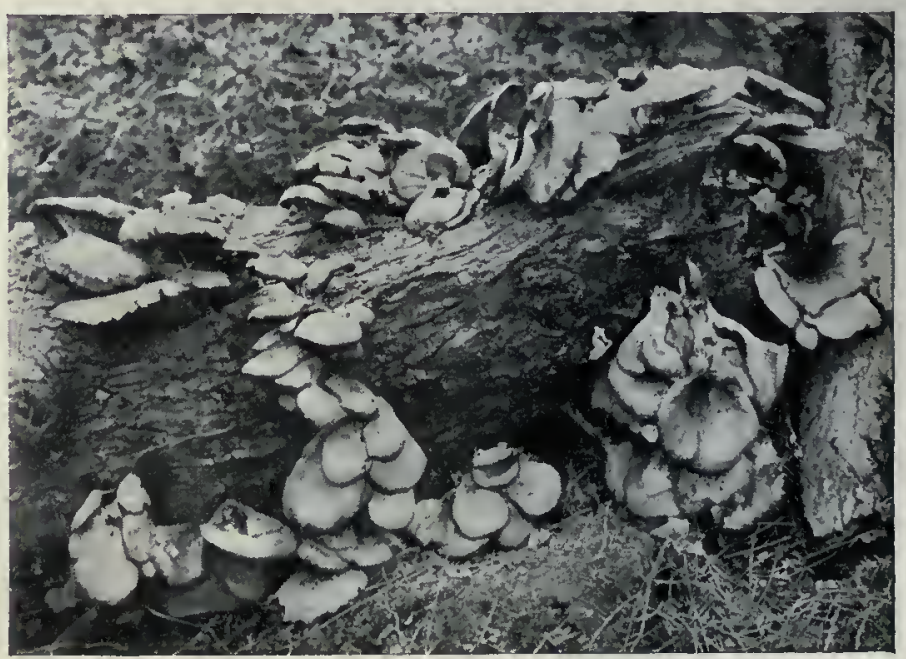

Pleurote corne d'abondance sur du bois mort. 


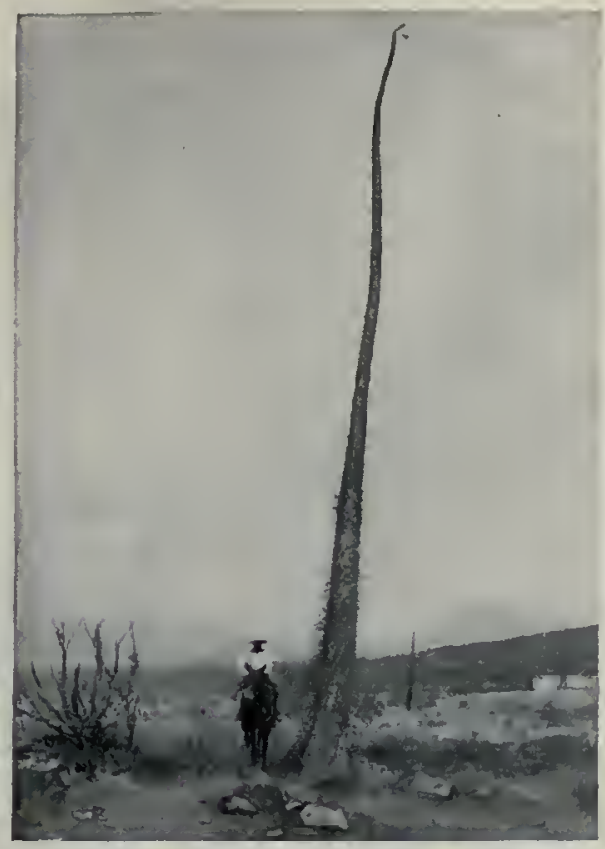

C). de M. Diguet.

IDRIA COLUMNARIA.

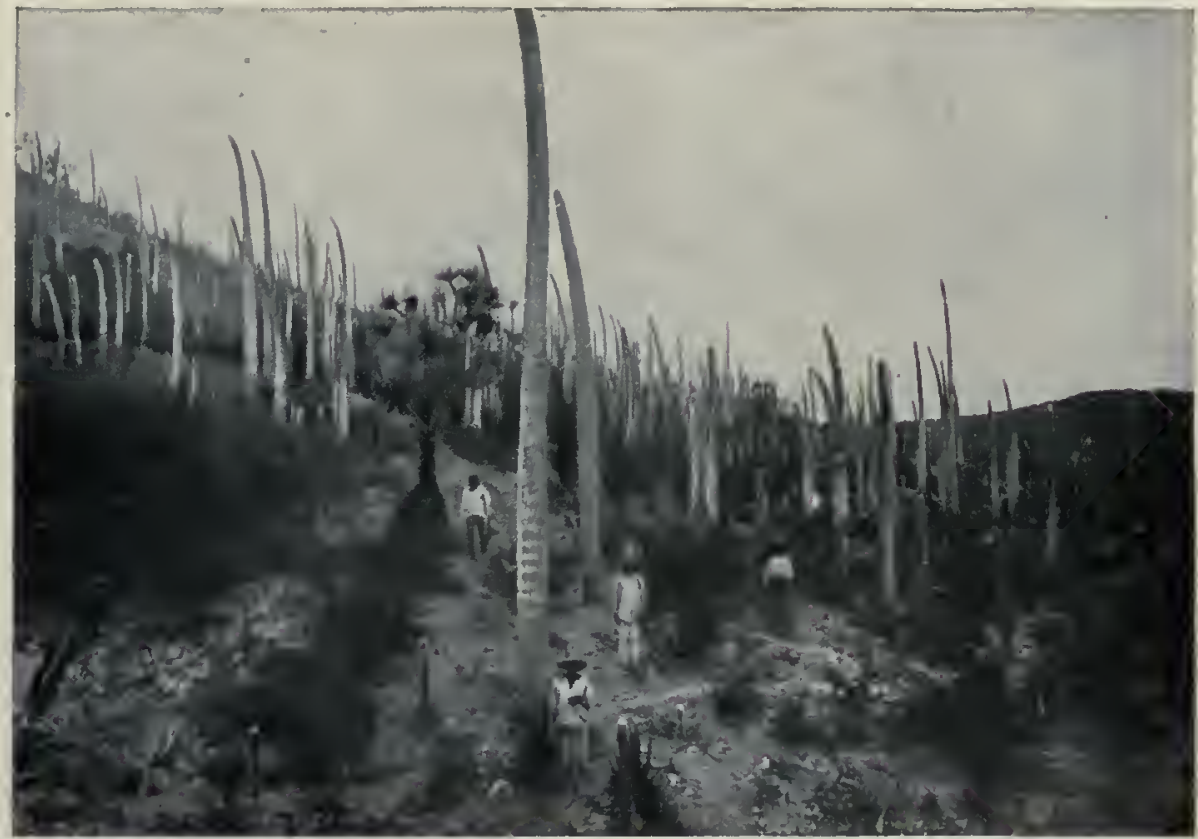

PILOCEREUS LATERALIS, CIERGES DU MEXIQUE.

\section{LA VIE VÉGÉTALE}

\section{I. - LES ORGANES DE LA PLANTE}

\section{LES CELLULES ET LES TISSUS}

$\mathrm{L}$

E végétal est un être vivant. Qu'entend-on par vie? On a essayé, vainement d'ailleurs, de donner une définition de ce mot: "La vie est le contraire de la mort, " a dit Bichat, célèbre médecin qui vivait à l'époque de Napoléon ler ; $c$ 'est là, il faut l'avouer, une définition qui n' est guère explicite, car elle suppose une connaissance de la mort que nous ne possédons pas. La définition bien connue de Béclard : " La vie, c'est l'organisation en action, " ne nous renseigne pas davantage. Une autre défnition qui n'est guère meilleure est celle de Cuvier : "La vie est une force qui résiste aux lois qui régissent la matière brute. La mort est la défaite de ce principe de résistance; le cadavre n'est autre chose que le corps vivant retombé sous l'empire des forces physiques. "En réalité, la conception de Cuvier est inexacte et c'est l'inverse qui est vrai. Nous ignorons à proprement parler ce qu'est la vie, mais nous savons avec certitude qu'elle ne s'oppose pas aux lois physico-chimiques qui règlent toutes choses. Tout phénomène vital exige pour s'accomplir des conditions déterminées : une graine ne germe que si on lui donne une certaine quantité de chaleur, d'humidité et de l'oxygène. De même, si l'on place une Sensitive sous une cloche où l'on ajoute un peu de chloroforme ou d'éther, les phénomènes si curieux de sensibilité qui caractérisent cette plante sont abolis.

La force vitale ne s'oppose donc pas aux forces extérieures ; elle est, au contraire, déterminée par celles-ci. C'est là le grand fait mis en lumière dans le cours $\mathrm{du} X t \mathrm{X}^{\mathrm{c}}$ siècle par l'illustre Claude Bernard, fondateur de la doctrine fameuse du déterminisme.

Renonçons donc à la tentative vaine de définir la vie, mais essayons cependant d'en préciser et d'en délimiter les caractères. Ils sont susceptibles de se rattacher à quatre conceptions : $1^{\circ}$ la croissance; $2^{\circ}$ l'organisation; $3^{\circ}$ la nutrition $4^{\circ}$ la reproduction. Examinons-les successivement.

Croissance. - Le premier fait le plus frappant à signaler quand on examine un être vivant, c'est qu'il n'est pas constamment identique à lui-même. Pour l'animal, cette chose saute aux yeux, parce qu'il se meut, parce qu'il s'agite, parce qu'il change de forme à chaque instant. Chez le végétal, les choses sont moins frappantes, car il est immobile, attaché au sol et, pour ainsi dire, figé dans son attitude; mais ne nous hâtons pas de conclure, soyons patients dans nos observations et nous verrons quau bout d'un certain temps il a grandi, que ses bourgeons se sont épanouis, que ses

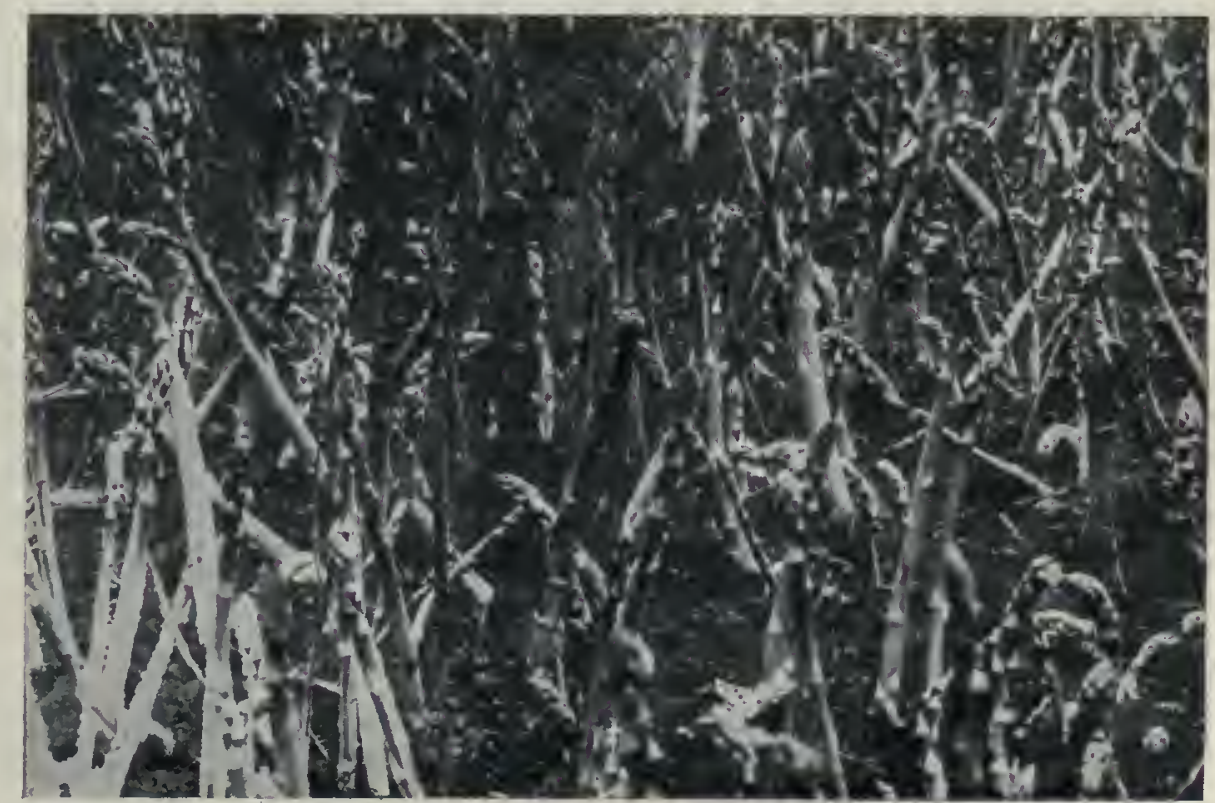

Une culture d'Asperges forcées.
Cl, de M, F, Faldeau. 


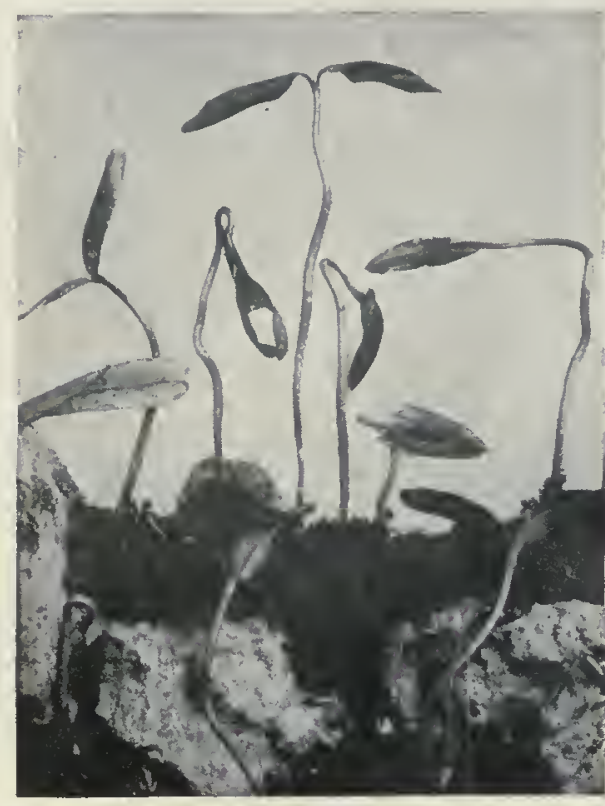

Plantules du Frêne. fleurs se sont ouvertes. $L$ ion a eu l'idée, par la cinématographie, d"abréger la durée de chacun de ces phénomènes et on les a fait passer sous nos yeux avec promptitude. On a eu a!ors le spectacle étrange d'une plante qui grandissait à vue d'oil, qui étalait ses feuilles, qui changeait de forme pour s'abriter du soleil, qui faisait mouvoir ses organes les plus divers; sur l'écrán, en quelques secondes, le bouton floral apparaît, grossit; le pédoncule penche bien-

tôt sous le poids de la fleur dont les pétales s'épanouissent, puis se flétrissent et tombent. Le caractère d'être vivant pour le végétal devient alors saisissant.

Ce phénomène de la croissance a des conséquences très importantes au point de vue de la forme quaffecte le végétal. On peut dire que ce sont ces lois de croissance qui constituent le fait primordial pour chaque être vivant. Le cas le plus simple est celui où la croissance a lieu dans une direction déterminée et constante : le corps sallonge; sa forme devient cylindrique et la plante affecte l'aspect d'un bâton qui s'accroît par l'extrémité ou par une grande partie de sa longueur. Chacun dira : mais nous n avons jamais vu de plantes ayant cet aspect; il en existe cependant et ces végétaux contribuent à donner au paysage des contrées où on les observe un aspect inoubliable: les Idria et les Cierges du Mexique sont des plantes qui'se développent ainsi en une colonne qui peut atteindre de très hautes dimensions, se dressant droite au-dessus du sol. La rectitude est même si parfaite que l'on utilise dans ce pays ces plantes en les semant côte à côte pour faire des clôtures.

Nous ne sommes pas habitués évidemment à une telle végétation, mais suivons la croissance d'une jeune plantule; faisons abstraction des cotylédons ou premières feuilles, qui d'ailleurs peuvent parfois

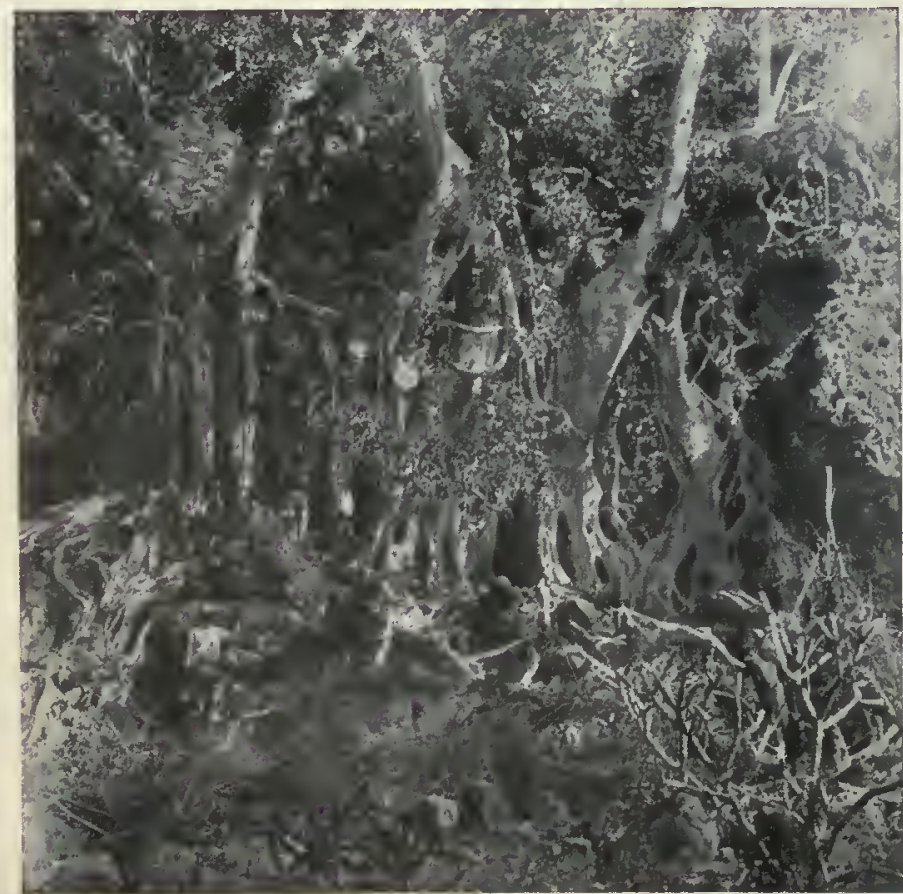

Cl. de M. Diguet.

Soudures du Figuier de Palmer (Californie) un peu tarder à s'épanouir,et nous aurons un aspect assez analogue. Donc, au moins au début de la vie de presque tous les végétaux (Asperge, etc.), la croissancc dans une direction est le type prédominant. L'une des moitiés s'accroít vers le haut, l'autre vers le bas; liune devient la tige, l'autre la racine.

Il est vrai que cette formc sim ple, primordiale, est en général de bien courte durée. car la ramification se manifeste.

Mais le rameau a

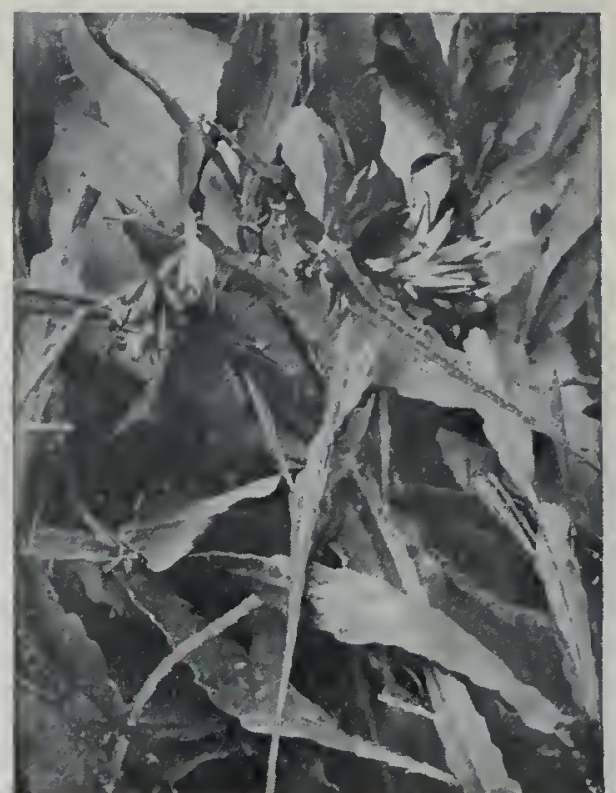

Phyllocactus fleuri. le même aspect que la tige mère et la ramification, à vrai dire, n'est qu'une manifestation de la même loi. Au point de vue du résultat et de l'aspect, tout est changé, mais la loi de croissance reste au fond la même. La direction, la grosseur et le nombre des rameaux ont également une grande importance pour changer l'aspect.

Un autre phénomène, d'ailleurs purement accidentel celui-là, peut également contribuer à donner au végétal un aspect très bizarre; nous voulons parler des soudures qui se produisent assez fréquemment entre organes aériens rapprochés les uns des autres. Quand deux branches de Hêtre se rencontrent, elles se soudent: parfois ce sont deux arbres voisins qui fusionnent ainsi, et lorsqu $i$ s'agit de deux plantes d'essence différente, comme un Chêne et un Charme (Chêne charmé de la forêt de Fontainebleau), on peut admettre qu'une telle observation faite par des êtres primitifs ait pu paraître bien étrange. Si les soudures se multiplient comme dans le Figuier de Rumph, aux Indes, ou dans les racines du Figuier de Palmer, on a un aspect tout à fait singulier.

Dans tous les exemples que nous venons de citer, le développement a lieu dans un "sens, mais il n'en est pas toujours ainsi : il y a des plantes ou des parties de plantes pour lesquelles la croissance a lieu dans deux directions : le corps prend alors une forme aplatie;

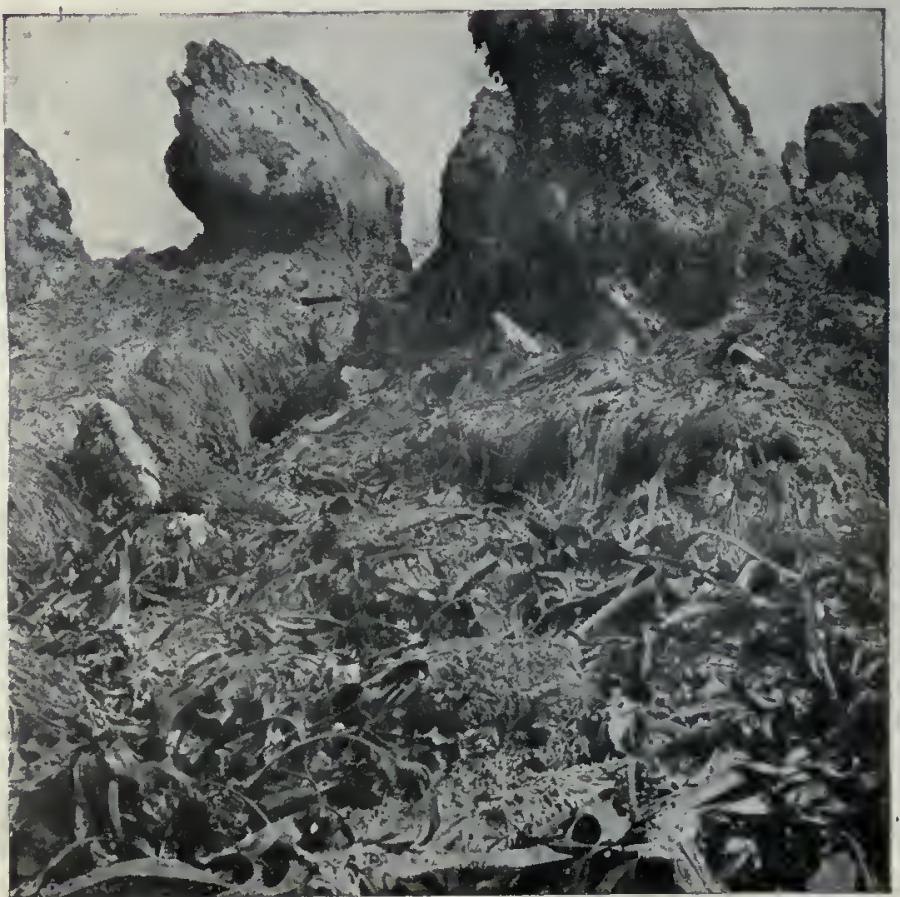

Laminaires, Himanthalia et Fucus, à Roscoff. W
C1. de M. Pruvot. 
c'est ce qui se manifeste dans les Laminaires, les Himanthalia, parmi les Algues, et chez les Epiphyllum, les Phyllocactus, parmi les plantes à fleurs. C'est ce quion voit pour les feuillesquis attachent sur la tige de la plupart des plantes supérieures. de croissance, nous devons en ajouter un

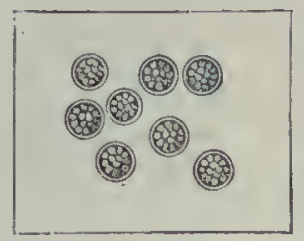

Fig. 2.

Pleurocoques très grossis.
A ces deux types
Buisson d'Échinocactus, au Mexique.

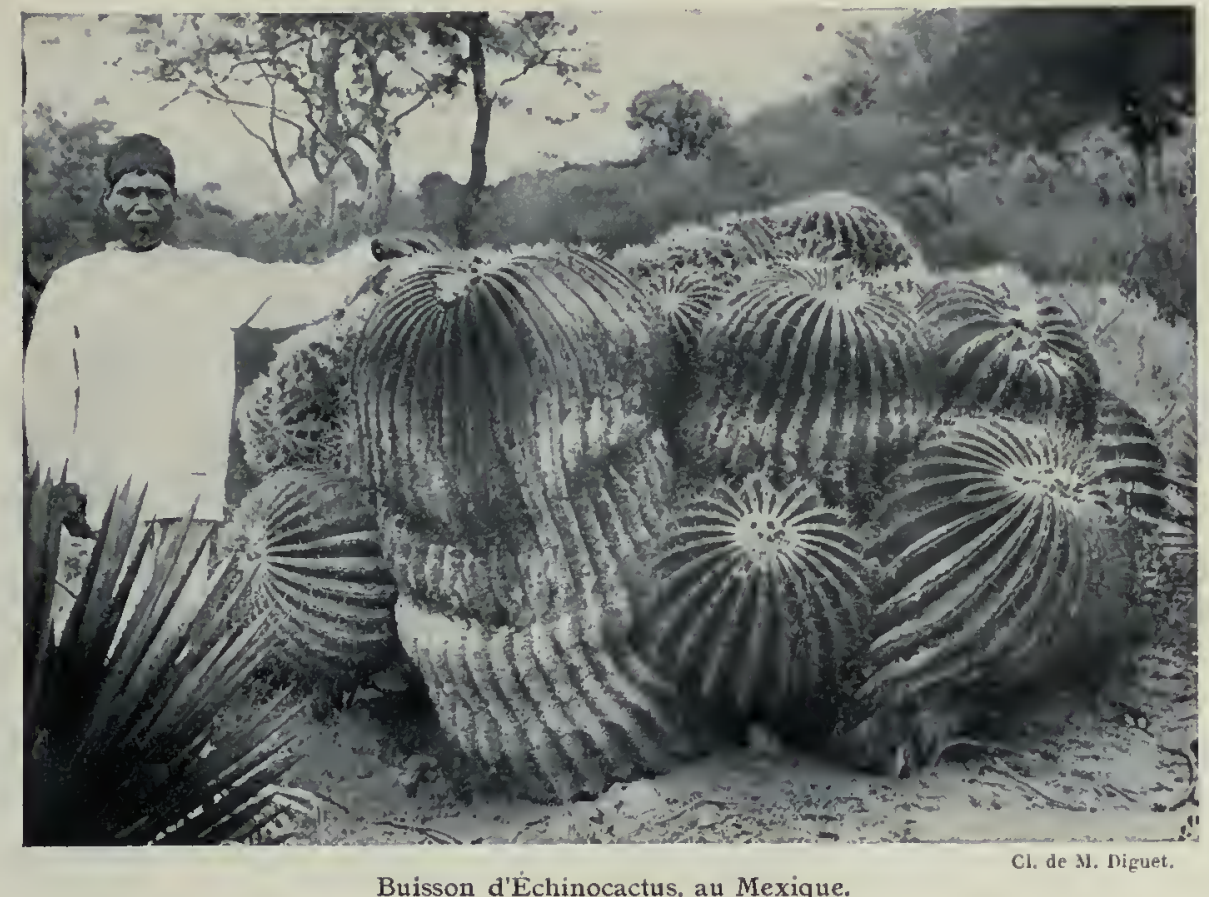

très dissemblables la forme plane, la forme sphérique et la forme filamenteuse ou cylindrique. Les derniers essais nous montrent notamment un changement très notable, accompagné de la fixation d'une plante qui, de sphérique, devient cylindrique arborescente. Ce résultat éclairetrès vivement les causes profondes de la morphologie des a nimaux fixés ou libres et mobiles. C'est une remarque très intéressante à faire qué les animaux attachés au sol-affectent très communément l'aspect de petits arbres; cest ce que l'on voit notamment dans le corail et beaucoup

troisième, qui peut être le plus simple et le plus primitif, et qui se rencontre chez les êtres les plus inférieurs; nous voulons parler de la croissance uniforme dans toutes les directions. L'être prend alors une forme sphérique. C'est ce que l'on observe par exemple sur cette poussière verte développée sur l'écorce des arbres du côté du nord, que l'on appelle Pleurocoque vert ( $f \mathrm{gg} .2)$, ou encore sur la neige rouge, Algue microscopique (Sphérelle de la neige) qui tache d'une teinte sanglante d'immenses étendues sur les névés; cest ce qu'on voit aussi chez les Mamillaires, les Échinocactus.

On peut se demander si les trois formes primitives du corps que nous venons d'indiquer sont subordonnées à des conditions particulières d'existence. C'est là évidemment une question beaucoup trop complexe pour pouvoir être résolue d'une manière générale. Cependant, dans un cas particulier, il semble que nous soyons renseignés sur l'origine des formes primitives d'un être. II s'agit d'une série d'expériences qui ont été tentées sur un Champignon (Stérigmatocyste) par M. Ray. I] a fait pousser cette plante de trois manières : $\left.\right|^{\circ}$ dans les conditions normales, il dépose les semences sur un liquide placé dans un cristallisoir et la moisissure forme une croûte à la surface du liquide, le Champignon affecte une forme plane; $2^{\circ} \mathrm{si}$, au contraire, il fait la culture dans un tube soumis à un mouvement de trépidation, grâce à l'intervention d'un électro-aimant dans lequel passent des courants alternati-

d'autres zoophytes (animaux-plantes) constituant, dans la classification de Cuvier, le grand groupe d'animaux inférieurs qui ressemblaient, selon lui, d'une façon frappante à des plantes, et cette ressemblance tient bien certainement à la fixation de l'animal.

Ce qui précède éclaire tout de suite notre route d'une manière éclatante et nous fait entrevoir une conséquence d'une portée considérable pour l'étude du règne végétal : c'est que la fixation au sol est un des facteurs primordiaux de la forme arborescente des plantes. Il y a plus : les lois qui règlent la position des branches d'un arbre sont analogues à celles qui président à la ramification des coraux. Pour ne citer qu'un exemple, nous mentionnerons les Flustres, animaux fixés dont toutes les branches se manifestent dans un même plan, et comme les ramifications sont répétées, très nombreuses, tous les rameaux finissent par se rencontrer, se souder ensemble en un réseau, par suite de l'existence ici dans un plan d'une propriété qui existe pour certains Figuiers exotiques (Figuier de Rumph) pour toutes les branches réparties dans tout l'espace.

Organisation. - Une autre propriété essentielle de la vie qu'il nous faut maintenant mentionner est celle qui résulte de l'organisation interne. Si l'on coupe un fragment d'un être vivant quelconque et si on l'examine au microscope, on voit qu il est vement contraires, il peut faire osciller régulièrement le liquide et lc Stérigmatocyste prend l'aspect de petites boules régulièrement sphériques; $3^{\circ} \mathrm{en}$ fin, sil ajoute un morceau de bois à l"intérieur du tube de culturc précédent agité de la même manic̀rc, les germes s'attachent au substratum et le corps de la plante cryptogame devient filamenteux et ramifié.

Ainsi donc cette recherche curieuse nous laisse entrevoir comment naissent trois formes

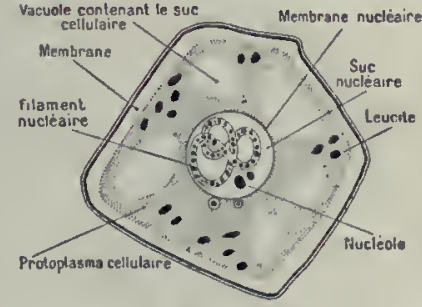

Fig. 3. - Cellule végétale.

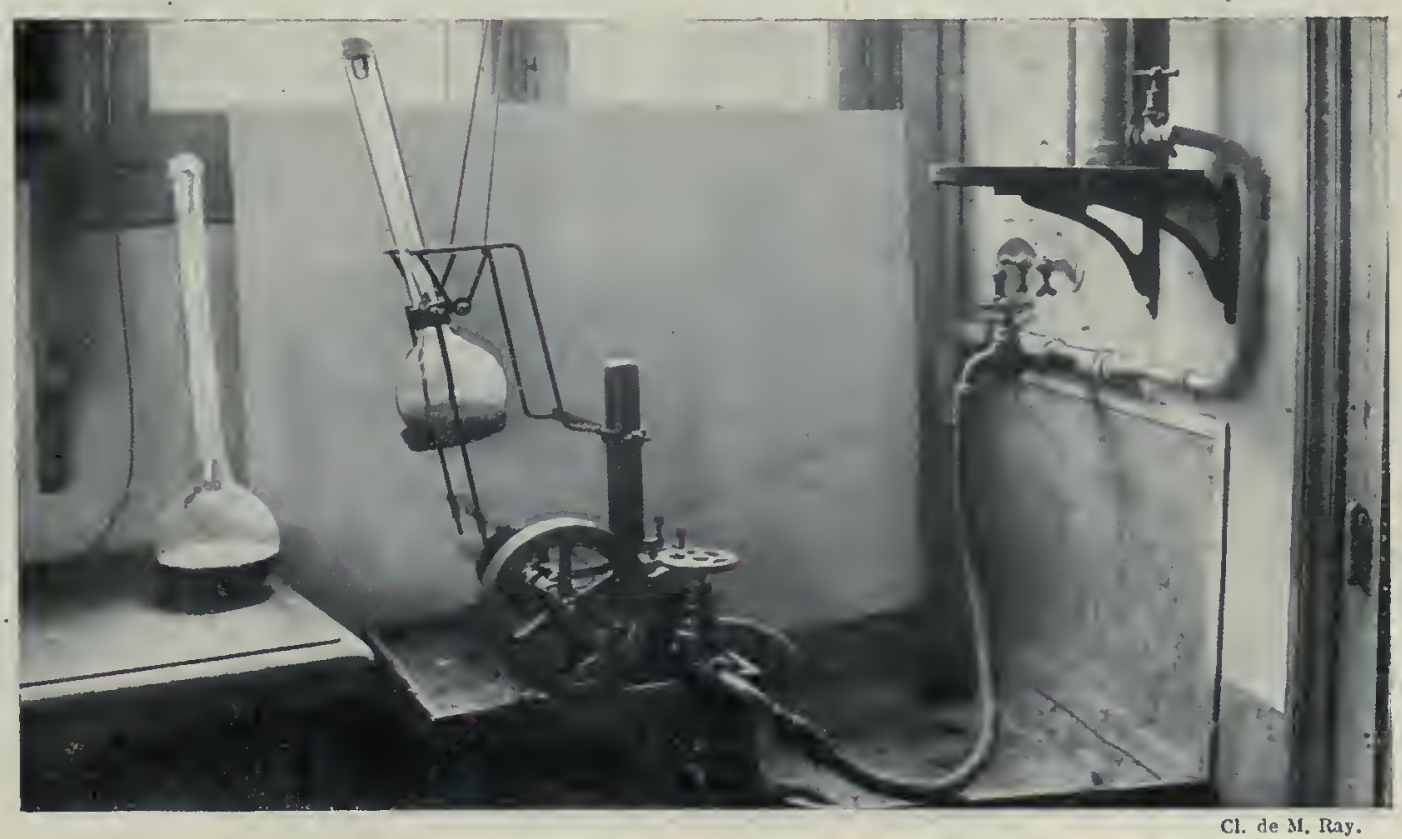

Appareil ayant servi aux expériences de M. Ray 


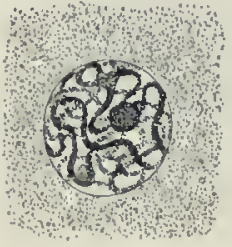

A

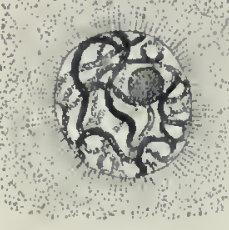

B
$\mathrm{C}$

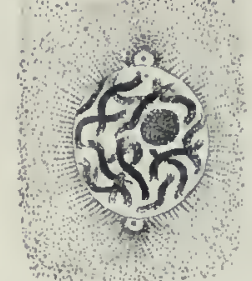

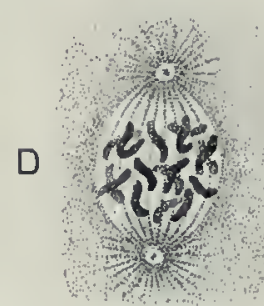
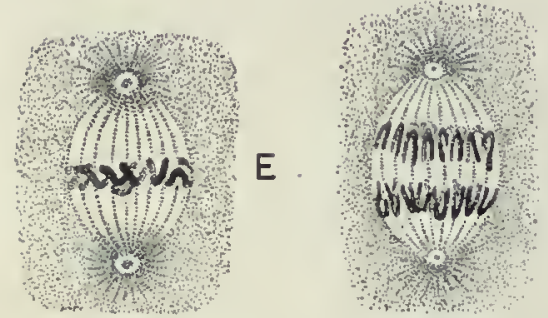

F

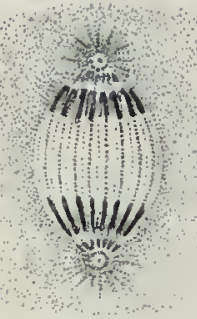

Fig. 4. - Division cellulaire.

A, noyau : $B$, début de la division ; $C$ et $D$, division des chromosomes et disparition de la membrane nucléaire : E, phase du fuseau et plaque équatoriale :

$F$ et $G$, attraction des chromosomes vers les póles; $H$; formation des noyaux-filles. un filament pelotonné sur lui-même, capable d'être le lieu d'élection de la matière colorante, un nucléole, du suc nucléaire et une membrane.

Les propriétés vitales de l'activité de ce noyau ont pu se révéler notamment par les phénomènes de division qui se manifestent dans toutes les cellules végétales et même, pouvons-nous ajouter, dans toutes les cellules animales, par le même processus compliqué et étrange ( $f g .4)$. Le filament nucléaire se contracte, se divise en un nombre déterminé de morceaux qui ne tardent pas à s'orienter suivant une plaque disposée à l'équateur du noyau dont la membrane s'évanouit; on voit alors deux figures coniques formées par des granules, disposés en files qui partent des deux pôles qui se sont constitués en deux points opposés de la surface de l'ancien noyau; ces deux cônes sont opposés par leur base commune qui est la plaque équatoriale. Bientôt chacune des anses chromatiques de cette plaque se divise en deux, longitudinalement, et les deux moitiés glissent, pour ainsi dire, le long des génératrices des deux cônes, de manière à se rapprocher des deux sommets

formé de petites loges contenant un corps semi-fluide, granuleux, que l'on appelle le protoplasma, et le petit compartiment est désigné, depuis Hooke, Grew et Malpighi, sous le nom de cellule ( $f$ g. 3). Chez les végétaux, la carapace de la loge est rigide et formée surtout d'une substance que l'on appelle la cellulose, qui a la même composition chimique que le linge et le papier. La rigidité de l'enveloppe cellulaire a une grande importance au point de vue du végétal; c'est elle, en effet, qui l'immobilise et qui lui impose une propriété caractéristique qui le distingue tout de suite de l'animal, dont le mouvement est une des propriétés primordiales. En fait, le mouvement existe chez la plante, mais il est caché, silencieux; il se passe à l"intérieur de chacune des petites loges : cest le mouvement du protoplasma. Pour le déceler, il faut des observations patientes faites au microscope. Si l'on place l'œil sur l'oculaire de cet instrument, quand on a mis devant l'objectif une préparation d'un poil d'Ortie faite dans une goutte d'eau posée sur une lame de verre, le tout recouvert d'une lamelle ou couvre-objet, on peut assister aux mouvements du protoplasma, qui ne sont autres que les frémissements de la vie végétale. Ces mouvements, on peut les abolir en tuant cette substance à l'aide d'un courant électrique; on peut enfin les suspendre à l'aide d'un anesthésique. Le protoplasma est donc la matière vivante, et cela est si vraj qu'on retrouve cette même substance, avec des propriétés identiques, chez tous les êtres doućs de vie.

Au milieu de la cellule est un globule beaucoup plus gros que les granules protoplasmiques, qui a été découvert d'assez bonne heure et observé pour la première fois chez les plantes par Robert Brown. On est parvenu à déceler la structure complexe de ce noyau à l'aide de méthodès très délicates qui ont permis de le tuer en le coagulant et de le colorer, de manière à pouvoir en distinguer nettement toutes les parties constituantes. On voit qu'il présente

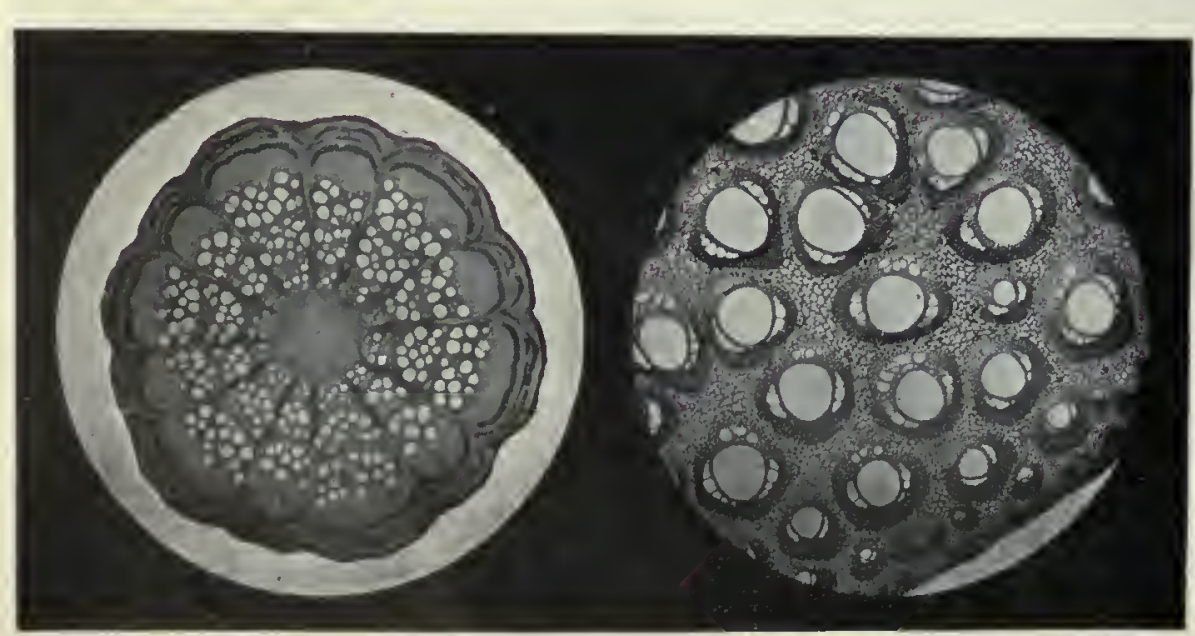

Tige de Clématite et tige de Jonc (Coupes grossies). ou pôles. Quand elles sont groupées en ce point et rapprochées alors les unes des autres, elles se ressoudent à nouveau en deux pelotons qui s'entourent d'une membrane nucléaire nouvelle, et deux jeunes noyaux sont ainsi constitués, identiques au noyau mère primitif. Ces deux noyaux restent pendant quelque temps unis entre eux par des files de granules qui sont bombées de manière à figurer, par leur ensemble, l'aspect d'une sorte de petit tonneau ou tonnelet. On remarque bientôt sur la région équatoriale du tonnelet, à l'endroit où était précédemment la plaque des anses, une accumulation de granules qui se rapprochent les uns des autres et se multiplient d'une manière notable. D'abord de constitution protoplasmique, ils ne tardent pas à s'jmprégner de cellulose et la membrane apparaît alors tout à coup, parce que tous ces éléments se sont fusionnés simultanément en une lame. La cellule est divisée en deux : une cellule primitive a donné naissance à deux cellules filles qui lui ressemblent. Ces phénomènes de la division du noyau, très complexes, qui ont été retrouvés avec les mêmes caractères dans les deux règnes, végétal et animal, sont évidemment une des manifestations les plus singulières de la vie. Schwann a pu énoncer cette loi qui porte son nom : que tous les êtres vivants sont formés de cellules; loi qui peut être complétée par la suivante, grâce aux grands et beaux travaux de Strasburger, Flemming, Guignard, etc.: que les noyaux sont constitués et se divisent de la même façon.

L'organisme végétal est une sorte de fédération dans laquelle les cellules s'associent pour concourir à la tâche commune. La tâche étant souvent très complexe, chaque cellule ne peut travailler pour son compte, faisant successivement toutes les besognes. La division du travail a été la condition de perfectionnement des êtres vivants, comme elle a été la raison des progrès de l'industrie humaine; à chaque cellule est dévolu un rôle déterminé et uniquement celui-là. On cite souvent l'exemple de la fabrication d'une épingle qui doit, pour arriver à son état final, passer dans soixante mains : chaque ouvrier, qui ne fait constamment qu' une opération très restreinte et très déterminée, arrive à la faire avec un haut degré de perfection et de rapidité. La nature a opéré de même, mais comme bien souvent la besogne à accomplir exige de grands efforts, ce n'est pas une cellule isolée qui accomplit un acte précis, mais un grand nombre d'unités identiques entre elles. Or, de même que tous les travailleurs qui font le même geste, qui vivent dans le même milieu, qui ont le même costume, finissent par, se ressembler, de même les cellules qui ont la même fonction finissent par être semblables, et c'est leur cnsemble qui constitue ce que l'on appelle les tissus.

Là, lcs travailleurs de la grande fédération végétale se contentent d'un costume mince et souple; chacun d'eux reste dans une petite loge dont la paroj est transparente, de façon à 
laisser pénétrer la lumière, ce rayon de soleil qui est le grand bienfaiteur du végétal, sans lequel il ne pourrait vivre, et la petite cellule fabrique à l'intérieur des petits globules verts appelés grains de chlorophylle, à l'aide desquels elle utilise l"énergie solaire pour décomposer l'acide carbonique de l'air qui circule entre toutes les cellules. Ailleurs, les lilliputiens épaississent leur manteau considérablement, le durcissent de façon

à former un squelette résistant qui soutient la plante. Le corps protoplasmique se fait petit au fond de la cavité, qui se réduit de plus en plus pour augmenter l'épaisseur de la paroi ; il finit par se réduire presque à rien et même par mourir et, lorsqu il a disparu, c'est la charpente qui reste pour soutenir l'édifice.

Nutrition. - Tous les êtres vivants se nourrissent, c'est-à-dire qu'ils empruntent au milieu extérieur un certain nombre d'éléments chimiques simples ou composés qu'ils incorporent dans leur substance. On a objecté, il est vrai, que la nutrition n'est pas l'apanage seulement des êtres vivants, car on peut nourrir un cristal d'alun en le plongeant dans une dissolution sursaturée. Il est bien certain que beaucoup de phénomènes vitaux ont leurs analogues dans l'histoire des corps bruts, mais ce qui n'arrive jamais pour ces derniers, cest quils aient à la fois tous les caractères que nous venons d'énumérer. Jetons quelques menus cristaux de sulfate de fer dans une solution étendue de silicate de soude : i] se produit, par la réaction des deux sels, un précipité tubulaire de silicate de fer, qui sallonge, s'élève jusqu'au sommet du vase, sous forme de filaments verts qui ont une vague ressemblance avec des Algues. C'est ce qu'on a pompeusement appelé des pscudo-plantes. II niy a là, on le conçoit, rien de comparable aux phénomènes de la vie chez les végétaux.

C'est peut-être l'assimilation des matières extérieures au corps animé qui constitue l'acte le plus important et le plus caractéristique de la vie, selon Le Dantec. Déposons un globule de levure dans un moût de bière et regardons ce qui se produit; au bout d'un certain temps, nous avons 100 globules, de sorte qu'on peut écrire l'équation:

Un globule + moût de bière $=100$ globules + excreta.

A l'aide du moût de bière qui est l'aliment, le globule en a fabriqué 100 autres identiques à lui-même : il a disloqué pour cela les molécules du moût, è ce qui reste non utilisé ce sont les excreta. Cette formule si simple est, on peut dire, l'équation de la vie. Elle nous fait saisir ce qu'est la nutrition.

Reproduction. - Une des plus frappantes propriétés des êtres vivants est d'émettre des cellules qui, en grandissant et en se divisant d'une manière répétée en cellules nouvelles, redonnent une autre plante. Tantôt c'est une cellule nommée spore qui, sans secours étranger, possède cette propriété (reproduction asexuée), tantôt au contraire (cas de la fécondation) elle ne la possède qu'après fusion avec une autre cellule, et le produit de cette union constitue l'cuf. C'est de 1844 à 1855 que la notion de la reproduction s'est précisée, et cela, grâce à l'étude des plantes inférieures. Decaisne et Thuret ont récolté des Fucus ou Varechs sur les bords de la mer; ils ont plongé les extrémités des frondes dans un cristallisoir contenant de l'eau de mer; comme les sexes sont séparés dans cette plante, ils ont pu aisément avoir dans un cristallisoir uniquement des petits corpuscules pyriformes, agiles, mobiles grâce à deux petits cils insérés de côté que l'on appelle anthérozoïdes. Abandonnés à eux-mêmes, ces pelits corps ne tardent pas à se flétrir et à se décompo-

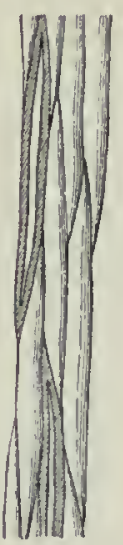

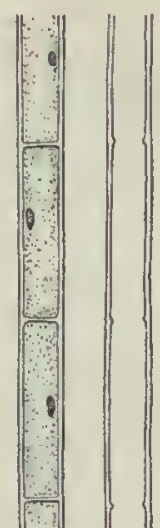

B $\mathrm{C}$

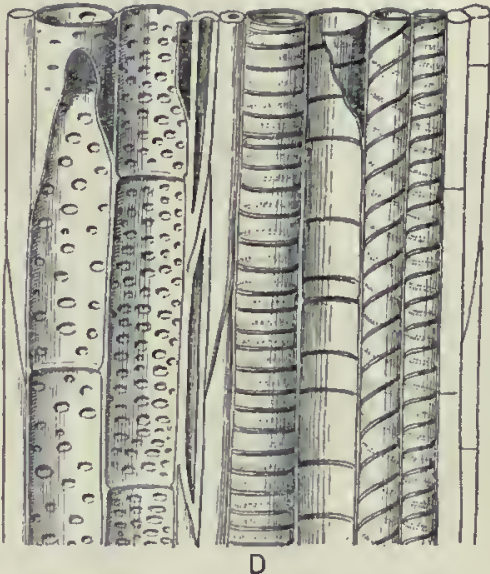

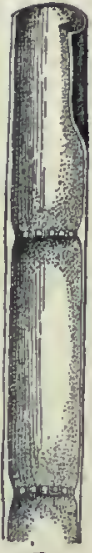

Fig. 6. - Etéments d'une plante vus au microscope.

A, groupe de fibres du bois ; $B$, vaisseau jeune: $C$, vaisseau parfait : $D$, groupc de vaisseaux du bois ponctués, annelés, spiralés: $E$, tube criblé.

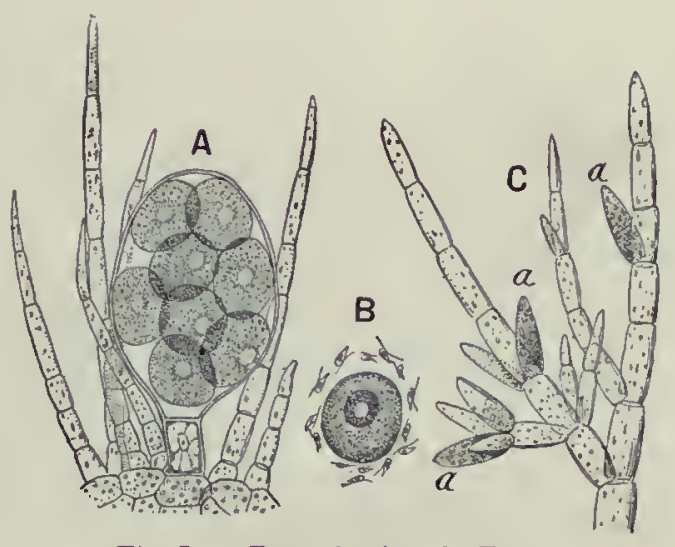

Fig. 7. - Reproduction du Fucus,

A, oosphères dans leur enveloppe; B. oosphère libre, entourée d'anthérozoïdes; $C$, poils rameux avec anthéridies $a$ a a (ou se produisent les anthérozoïdes) trés grossis. ser. Les autres corpuscules, appelés oosphères, dont les deux botanistes ont fait une décoction, sont les éléments femelles; ils sont beaucoup plus gros, arrondis et non mobiles; maintenus seuls dans le cristallisoir, ils pourrissent de même et se détruisent. Il n'en est pas ainsi si on mélange les deux liquides contenus dans les deux cristallisoirs. On peut alors, en prélevant une goutte de liquide résultant de ce mélange, assister à un phénomène extraordinaire : les anthérozoïdes entourent la boule femelle, s'y attachent, la font tourner, puis, brusquement, le mouvement s'arrête, une membrane de cellulose se montre : l'œuf est formé; il entre de suite en activité et, par ses bipartitions répétées, commence à ébaucher un corpuscule qui deviendra bientôt un Fucus nouveau ( $f \mathrm{~g} g .7)$.

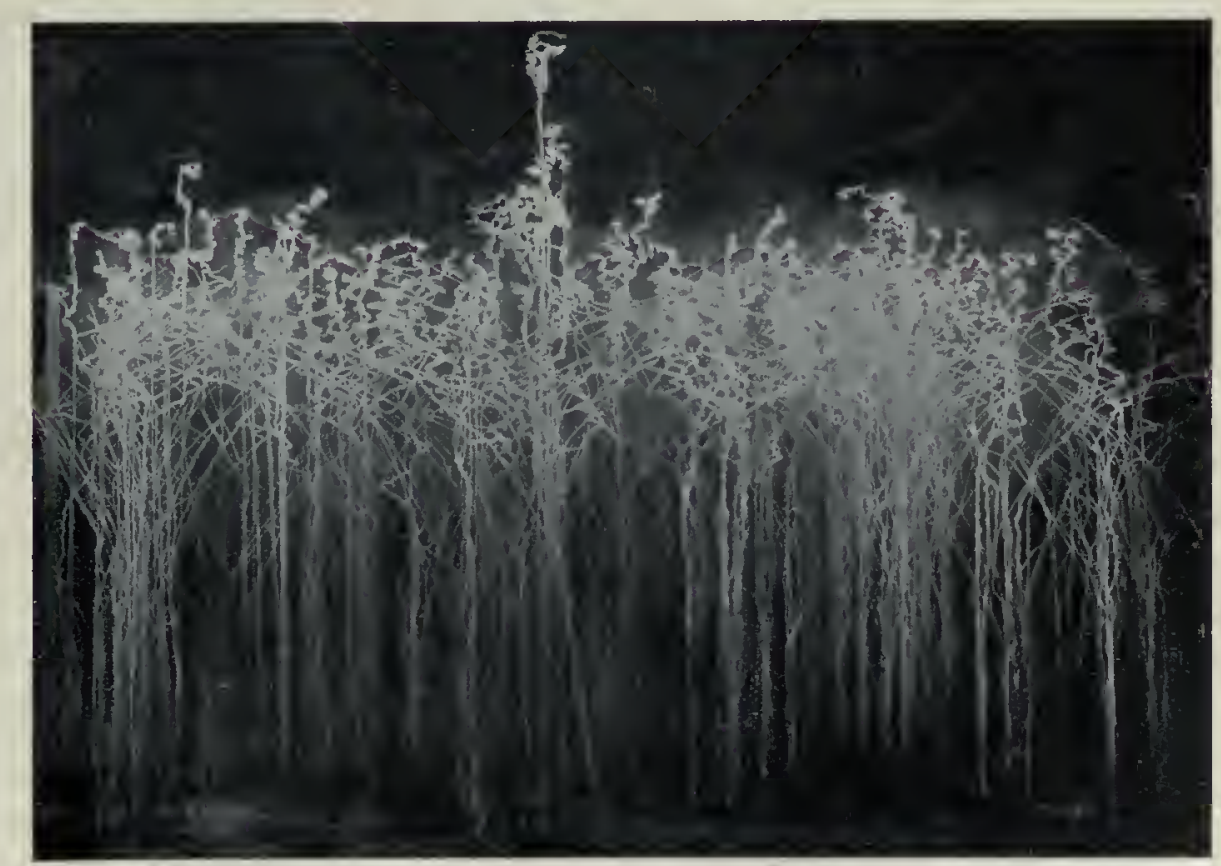

Cl. do N1, Fiaidenu.

Précipité chimique produisant des pseudo-plantes. 


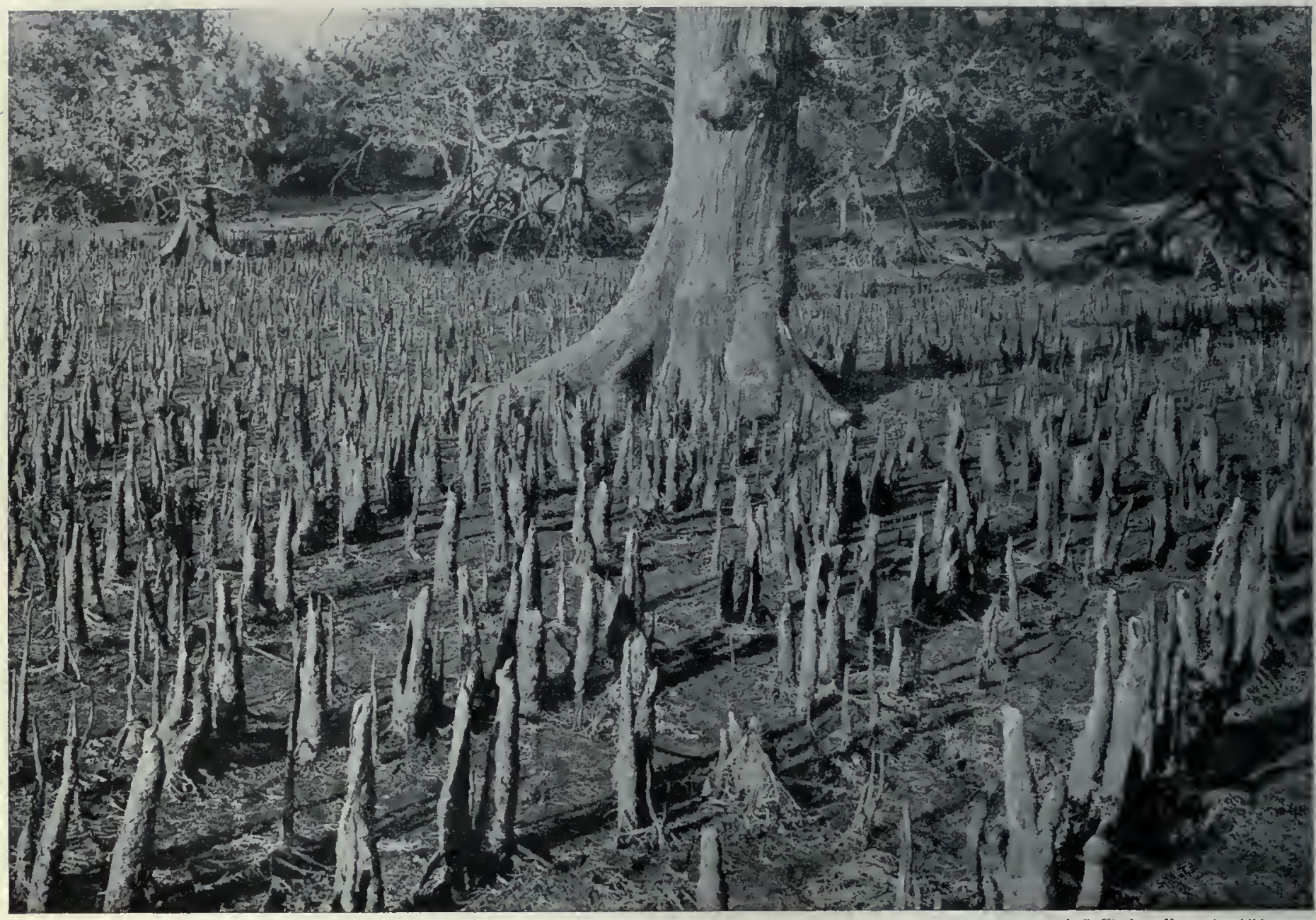

Racines-asperges de Sonneratia, au Siam (ile Koh Chang). Au fond : Palétuviers.

\section{LA RACINE}

"La vie, c'est la nutrition ", a dit Aristote. La plante a une vie fixée; elle puise sur place les éléments de sa nourriture, tandis que l'animal doit se déplacer pour la rencontrer; la racine est donc d'importance primordiale; elle fixe la plante et la nourrit; suivant la torte expression de Sully Prudhomme, "elle dispense la plante de penser pour subsister $"$.

Absorption de la sève. - La racine est un organe cylindrique qui se développe d'ordinaire dans le sol. Elle croît par son extrémité, car c'est sous la partie terminale appelée coiffe qu'existent les cellules qui, par leur activité et leurs divisions, édifient peu à peu tous les tissus de cet organe. La coiffe qui recouvre ces éléments jeunes et délicats en voie de prolifération est donc un organe protecteur; c'est ëlle qui empêche toutes les parties dures du sol de nuire à la racine. Un peu au-dessus de la coiffe se trouve la région des poils radicaux ou poils absorbants (fig. 8); ce sont eux qui sont chargés de puiser dans le sol toutes les

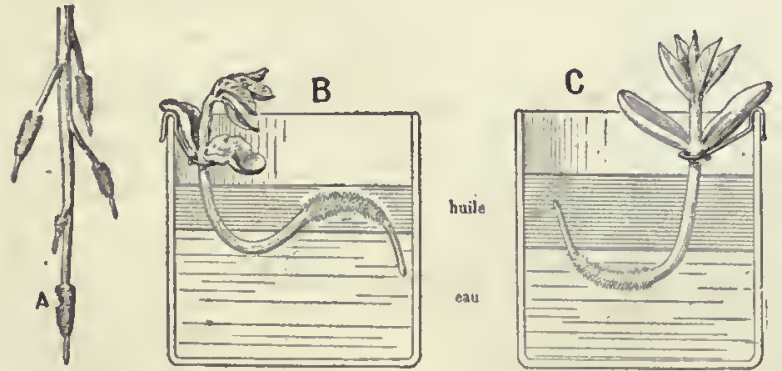

Fig. 8. - Expérience montrant l'absorption.

$A$, racine et ses radicelles avec leurs poils absorbants; $B$, la plante dont les poils absorbants sont dans l'huile se flétrit; $C$, celle dont les poils absorbants sont dans l'eat reste fraîche. substances liquides qui doivent pénétrer dans le végétal pour sa nutrition. On met en évidence cette fonction des poils par des expériences très simples: on fait plonger une racine d'une jeune plante dans un récipient contenant de l'eau surmontée d'une couche d'huile ( fig. 8) ; sil'on s'arrange de façon à ne laisser plonger dans l'eau que la coiffe, la plante se fane; si l'on fait plonger la région des poils seulement, la plante reste fraîche et non fanée. Labsorption ne se produit pas au-dessus des poils radicaux.

Ce phénomène de l'absorption s'opère d'après les lois de l'osmose qui se manifestent par l'expérience de la vessie de porc. On prend un cristallisoir dans lequel on met de l'eau pure et l'on y plonge un tube fermé à sa base par une vessie et rempli d'eau sucrée, légèrement teintée par une matière colorante (fig. 9); l'eau pure traverse très rapidement la membrane, plus rapidement que l'eau sucrée en sens inverse, et l'on voit le liquide monter dans le petit tube. Les liquides traversent donc les membranes et avec des vitesses inégales : l'eau pure traverse plus vite que l'eau sucrée. Toutes les solutions salines ont des vitesses variables. Cette expérience explique le mode de pénétration des liquides dans la plante. La membrane des différents poils radicaux fonctionne comme la vessie précédente et se laisse traverser par les

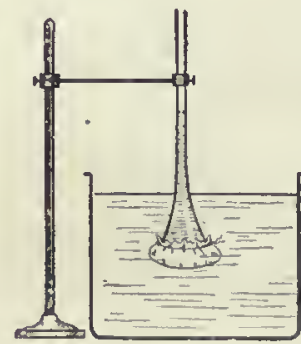

Fig. 9. - Osmomètre.

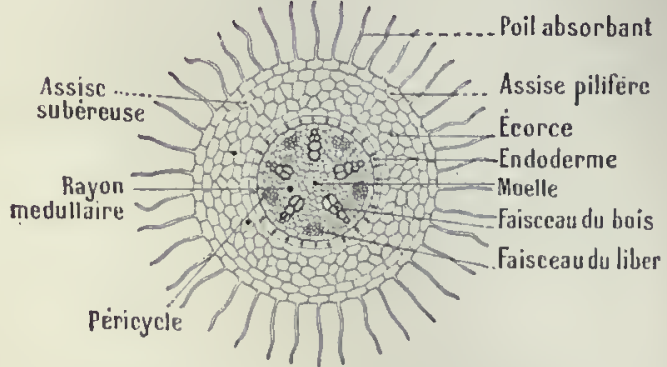

Fig. 10. - Section d'une jeune racine. 


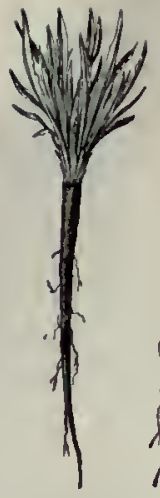

Fig. 11. pivotante de Salsifis.

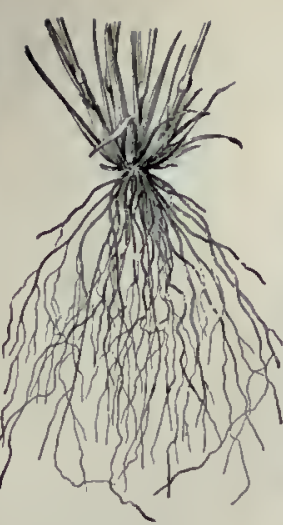

Fig. 12

Racine fasciculée du Bté.

substances salines dissoutes par l'eau de pluie dans le sol. C'est là le point de départ du grand et rapide mouvement ascensionnel de la sève.

Le poil radical est une cellule qui contient du protoplasma, c' est-à-dire une matière albuminoïde tout à fait com-

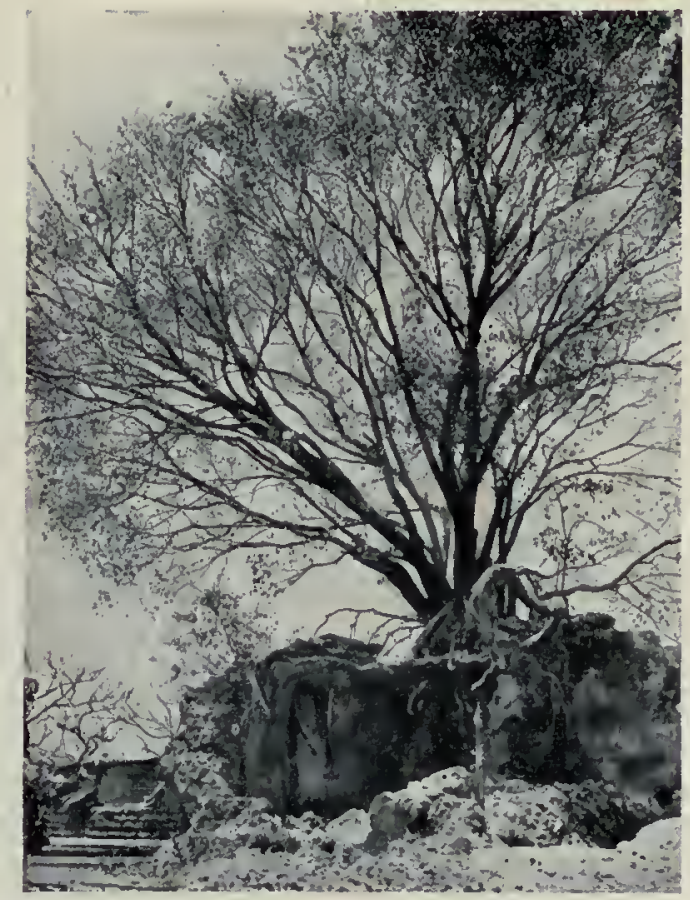

Cl. de M. Diguet.

Racines-ceintures d'un Ficus.

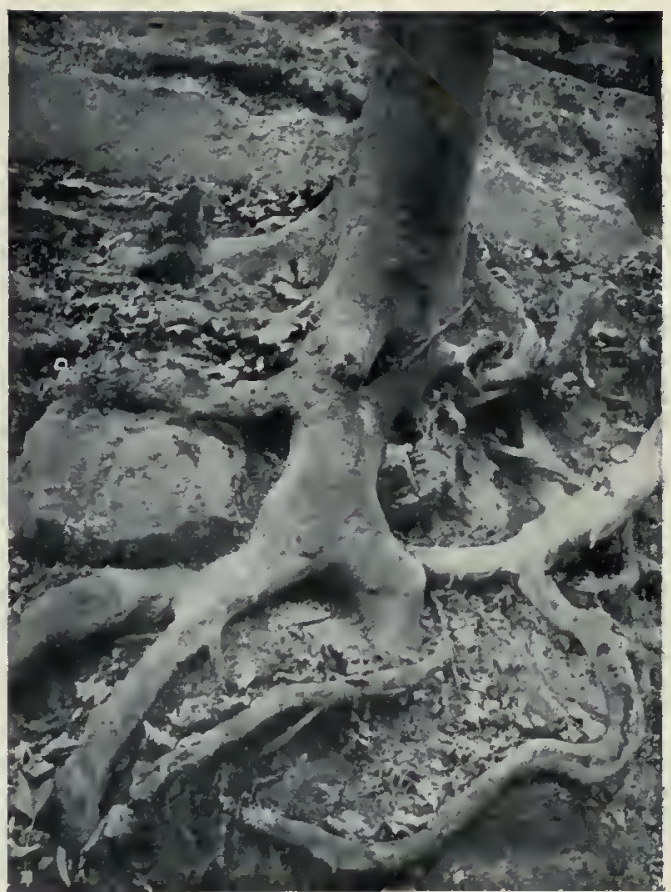

Cl. de M. Atget. parable au blanc d'œuf. Or,

si, dans l'expérience précédente, on avait mis de l'albumine d'un cut dans le petit tube, ce blanc y serait resté intégralement sans traverser la membrane. Il était absolument indispensable de faire cette remarque, parce que l'on ne s'expliquerait pas pourquoi la matière vivante ne sortirait pas de la plante en même temps que les liquides extérieurs y pénètrent.

Structure interne. - Quelques mots suffiront à indiquer quelle est la structure interne de l'organe radical. Si l'on coupe en long et au milieu une racine de Fève, par exemple, on distingue vers la pointe trois cellules qui engendrent par leur division successivement tous les tissus; ils se groupent en deux régions : l'écorce et le cylindre central ( $f$ ig. 10 ), ce dernier contenant des faisceaux du bois, formés de vaisseaux spiralés et annelés, ponctués, qui alternent avec les faisceaux du liber. Quand la racine vieillit, il apparaît en dedans du liber, en dehors du bois, une assise génératrice qui, par ses divisions répétées, engendre le bois secondaire et le liber secondaire de la racine et tous les tissus qui contribuent à la croissance en épaisseur.

Ramification. - Nous avons supposé, dans ce qui précède, que nous avions affaire à un organe jeune, non encore divisé. En vieillissant, la racine se ramifie; la racine principale est le pivot. Il apparaít à sa surface, suivant des génératrices déterminécs, des sortes de petits boutons qui ne tardent pas à crever et, par l'orifice, sortent des petites racines secondaires ou radicelles, sur lesquelles nous retrouvons tous les caractères de la racine principale ( $f$ g. $8, A$ ).

Une racine est dite pivotante quand la racine principale est beaucoup plus grosse que les autres (fig. II) ; si la racine principale s'arrête de bonne heure dans son développement, les racines secondaires prédominent : on dit alors que les racines sont fasciculées (fig. 12); ce sont celles qui sont superficielles et qui épuisent le sol en surface, tandis que les premières l'épuisent en profondeur.

Quand on déterre une plante qui est dans un terrain meuble, on extrait le chevelu, c'est-à-dire l'ensemble de toutes les fines racines et radicelles, mais les poils absorbants attachés aux particules du sol sont déchirés et non visibles; pour voir ces poils radicaux, il faut faire germer les graines sur de la

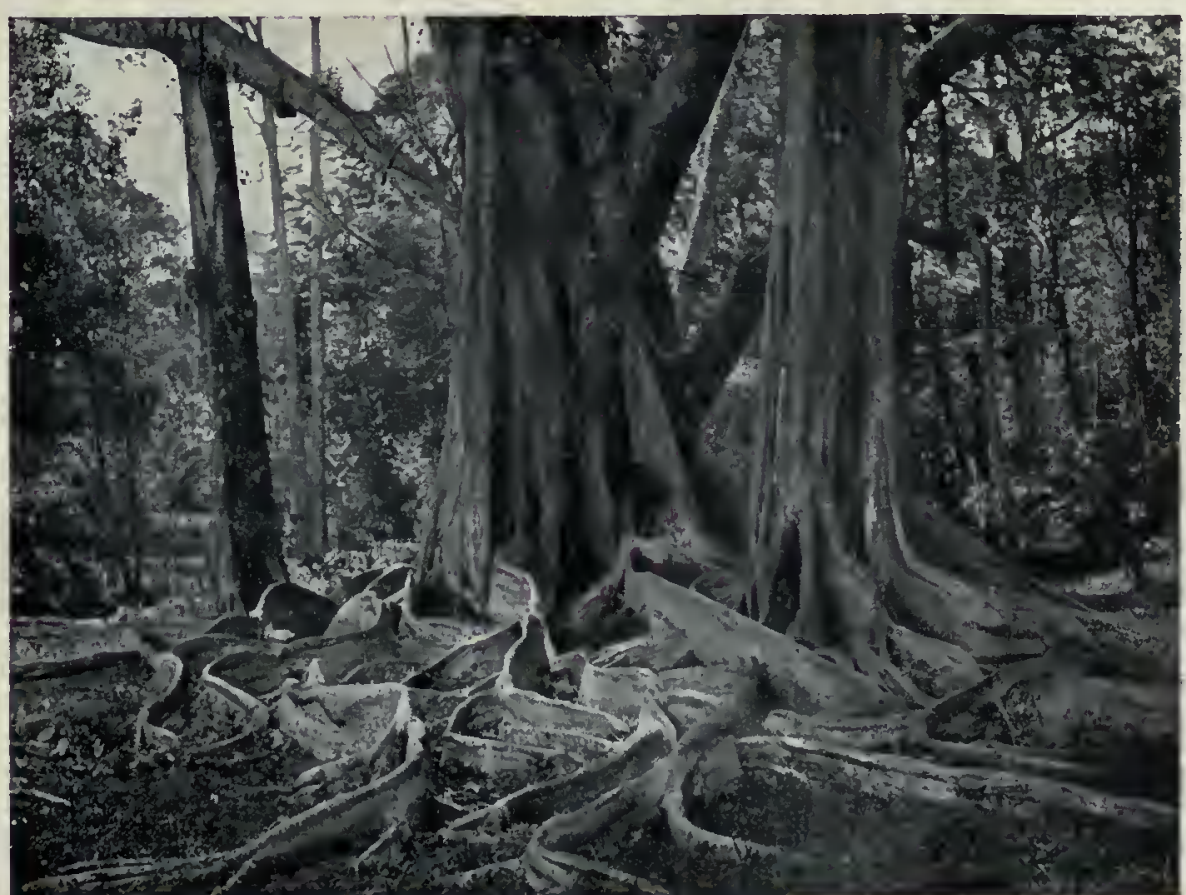

Racines-patettes d'un Figuier à caoutchouc. mousse humide. Sur un terrain meuble en pente, l'érosion montre fréquemment combien est puissant le système radiculaire des plantes.

Croissance en longueur. - La croissance en longueur des racines est continue et souvent remarquable. Les racines de Vigne peuvent s'enfoncer jusqu'à 10 ou 15 mètres de profondeur. Les racines adventives de certains Figuiers des pays chauds, comme le Figuier tueur d'arbres, peuvent sinsinuer entre les pierres des habitations voisines et exercer des pressions capables d'en amener la destruction.

L'accroissement en longueur de la racine ne se fait que dans une courte région située dans le voisinage de sa pointe; coupe-t-on cette dernière, la croissance en longueur cesse presque aussitôt. Toutes les génératrices du cylindre radical deviennent, à tour de rôle, le siège d'un plus fort allongement; la pointe de la racine pénètre donc dans la terre, non comme un clou qu'on enfonce, mais par un mouvement de vis, beaucoup plus puissant. 
Adaptations fixatrices. - La racine sert à fixer la plante à l'aide des radicelles. La racine principale et la tige qui la surmonte peuvent être comparées à un mât tendu par des cordes obliques enfoncées dans le sol qui sont les racines secondaires; par suite de l'adhésion très intime des poils radicaux avec les particules solides du sol, par suite de contractions qui se produisent dans les tissus internes de toutes les racines, les cordelettes précédentes tirent fortement sur le mât tout autour et le consolident.

Une autre pro-

priété des racines est très importante à considérer. Fait-on germer une graine sur de la mousse, on voit que la pointe se courbe pour s'enfoncer verticalement dans le sol. Au bout de quelques jours, si on sort la plantule de la mousse et si l'on place la racine horizontalement, la pointe s infléchit à nouveau et reprend la direction verticale. C'est la pesanteur qui produit ces flexions, et l'on désigne sous le nom de géotropisme cette singulière propriété. On a pu le démontrer en faisant germer une graine sur une roue, soit verticale, soit horizontale; en imprimant à la première roue un mouvement rapide, on provoque le développement d'une force suivant le rayon, qui est la force centrifuge : c'est cette direction, s'éloignant du centre de la roue, que prend alors la racine.

L'obliquité des racines secondaires, si importante pour la consolidation de la tige, est aussi sous la dépendance de l'action de la pesanteur, qui est alors moins forte que pour la racine principale. Le géotropisme disparaît dans les radicelles d'ordre plus élevé, qui croissent à l'aventure. La direction verticale conduit plus rapidement que toute autre la racine principale aux couches profondes qui sont des Monocotylédones, il n'y a pas d’épaississement secondaire; les racines adventives restent cylindriques.

Les actions mécaniques auxquelles sont soumises les racines peuvent être moins intenses que celles qui résultent de l'action des tornades, mais plus fréquemment répétées. $C^{\prime}$ est ce qui arrive au bord de la mer, dans les régions tropicales, pour les Palétuviers. La partie ordinairement souterraine des plantes est ici presque complètement sortie de la vase, et les racines, en longs arceaux, sont alternativement dans l'air et dans l'eau de mer, suivant que le flux ou le refux ramène ou éloigne le flot. Il faut évidemment à la racine, dans ce cas, à la fois de la ténacité, de la flexibilité et de l'élasticité, car les paquets de mer qui frappent contre elle exercent leur action dans tous les sens. L'ensemble de la tige atrophiée dans le bas et des racines adventives rappelle une sorte d'araignée gigantesque aux pattes multiples (racines-échasses).

La sortie de la racine de son milieu normalement souterrain a eu ici des conséquences très manifestes. Il en sera de même lorsque cet organe se développera d'une manière analogue dans une ambiance nouvelle. Le Lierre développe dans l'air sur ses tiges des racines rapprochées les unes des autres, restant courtes, qui s"insinuent dans les anfractuosités du support et y adhèrent fortement par leur gangue ou leurs poils ( $r a$ cines-crampons).

Adaptations nutritives. - Les racines ont aussi un rôle nourricier des plus importants. Elles penvent non seulement s agripper après les objets, mais sincruster en eux; elles $y$ parviennent en les corrodant. On s'en rend compte en faisant germer une graine sur une plaque de marbre. Au bout d'uncertain temps, la racine, les radicelles, les poils radicaux y ont dessiné leurs contours, car la plaque a été attaquée par un acide produit par les racines.

Cette corrosion se produit évidemment dans les parasites comme le Gui, qui vit sur les Pommiers, 


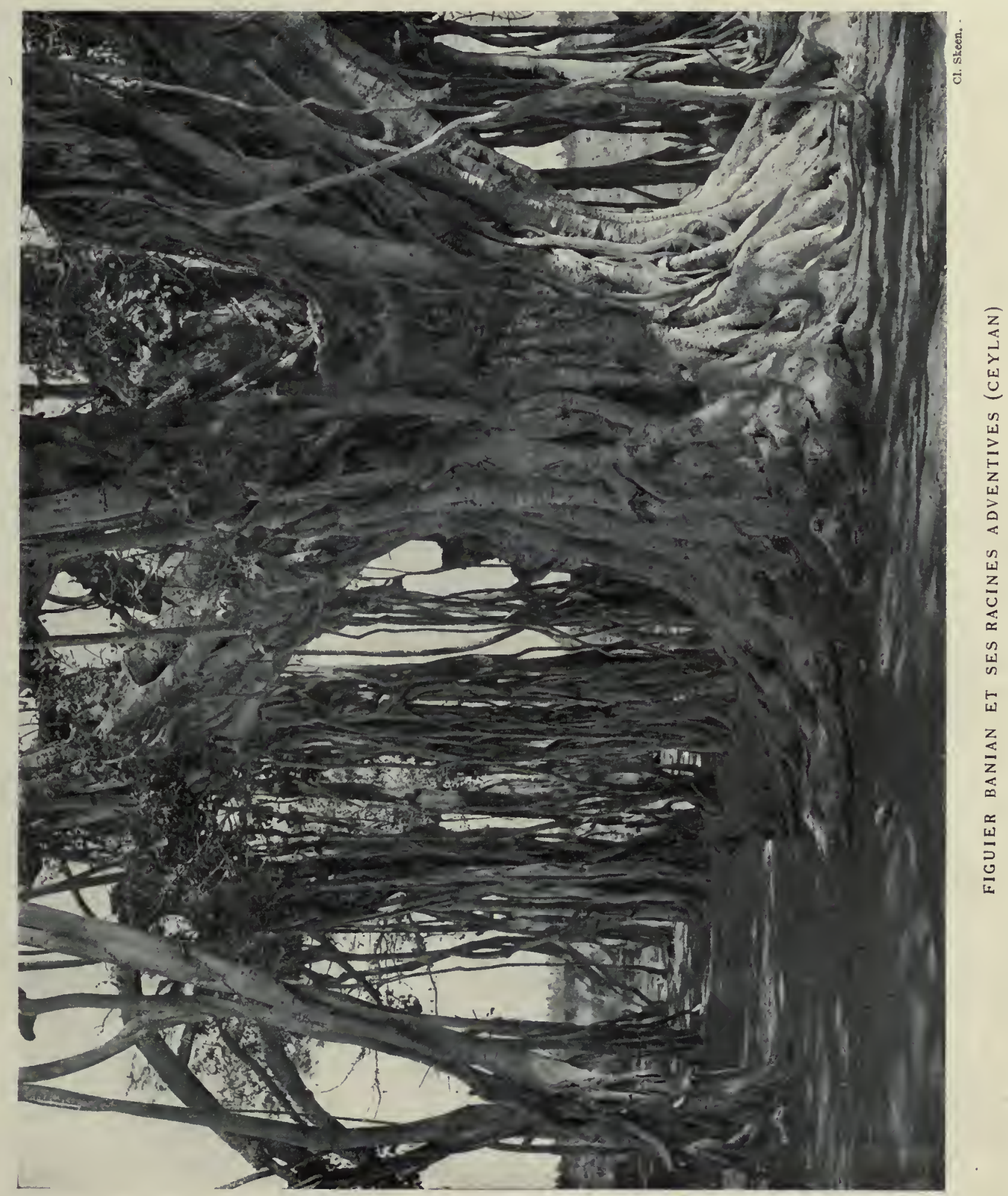





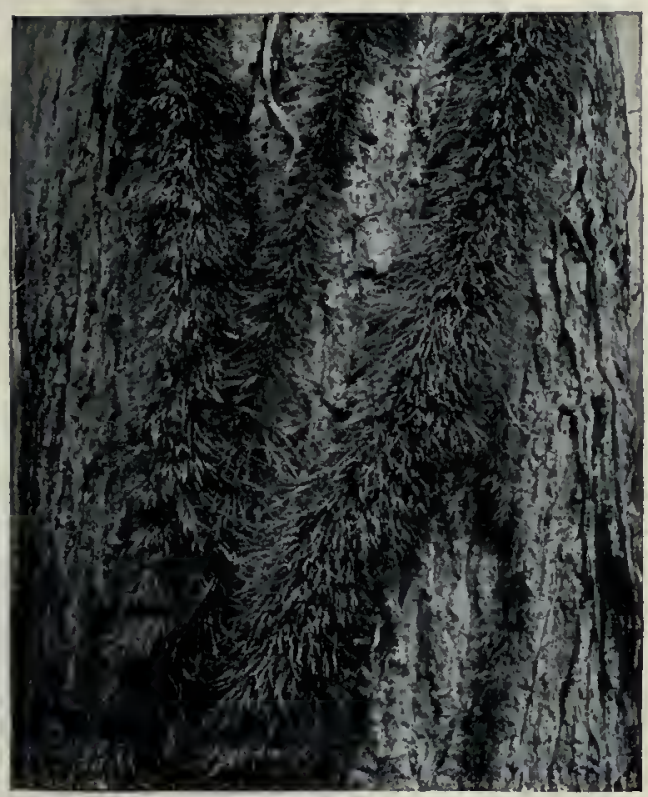

Racines-crampons de Lierre.

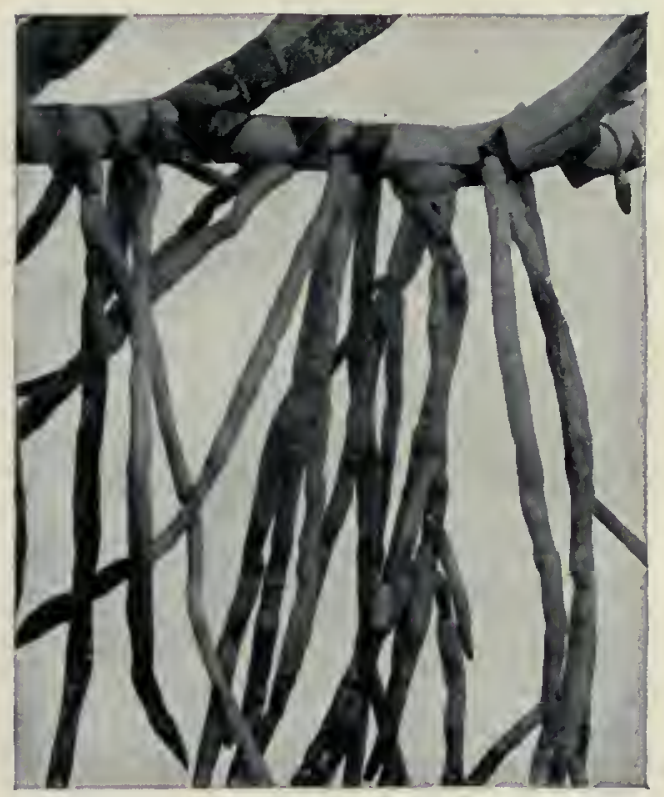

Racines à voile des Orchidées.

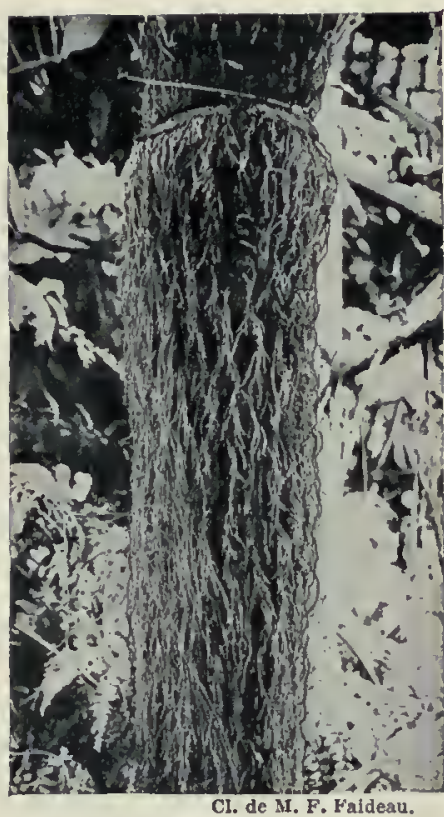

Racines en balai de Fougères. les Peupliers; la racine rencontre une résistance souvent très grande à sa pénétration; aussi se déforme-t-elle, et elle produit ce que l'on appelle un suçoir. La nutrition de la racine s'opère dans le cas des parasites à l'aide de la sève de la plante hospitalière.

L'humidité favorise l'apparition des racines; il suffit d'enterrer une branche en son milieu dans le sol maintenu humide, pour en voir naître. Les traumatismes ont aussi un rôle favorable : le bouturage consiste, en effet, à plonger par sa base un fragment de tige coupée dans le sol, et il se forme en ce point des racines nouvelles, dites adventives. Dans les régions tropicales, la chaleur et l'humidité réunies font naître par milliers des racines adventives aériennes, qui pendent partout des branches, absorbent l'humidité de l'air et contribuent à la nutrition et souvent aussi à la fixation, comme chez les Orchidées et les Aroïdées épiphytes. Le voile des Orchidées épiphytes est un tissu blanc plein d'air, qui entoure l'extrémité de leurs racines et absorbe l'eau aussi facilement que $\mathrm{d} u$ papier buvard. Le tronc des Fougères arborescentes est souvent couvert d'une multitude de petites racines noires qui lui donnent à la base l'aspect d'un balai dont le tronc serait le manche. Chez le Figuier banian de l'Inde, les branches émettent des racines adventives (racines-supports) qui sallongent, se fixent au sol et forment un pilier qui soutient les grosses branches et contribue à les nourrir. Quelques autres espèces de Figuiers tropicaux produisent des racines aériennes.

L'humidité attire d'ailleurs les racines, dont l'hydrotropisme est si puissant qu îl triomphe du géotropisme. Cette attirance pour l'eau cause l'envahissement des tuyaux de drainage par les racines des plantes qui y forment d'énormes tampons ou queues de renard.
Respiration. - En plongeant une racine dans une atmosphère limitée renfermant de l'oxygène, on peut voir, en faisant l'analyse des gaz au début et à la fin de l'expérience, qu il y a eu absorption d'oxygène et dégagement d'anhydride carbonique. C'est là un phénomène capital connu sous le nom de respiration; il est commun à tous les êtres animés : c'est une des caractéristiques de la vie; Pour tous les organes du végétal qui plongent dans l'air, la respiration se fait évidemment sans difficulté; il n'en est pas de même pour les organes souterrains. Les arbres des villes, malgré le grillage entourant leur pied, souffrent beaucoup de la présence de l'asphalte; souvent l'asphyxie se produit pour leurs racines, qui ne tardent pas à fermenter et à périr.

Quand le sol devient compact, l'air n'y pénètre plus, et le danger d'asphyxie devient redoutable; c'est ce qui arrive pour les plantes qui vivent dans la vase, et notamment pour celles de la région côtière des pays chauds. Les racines d'Avicennia, de Sonneratia pointent verticalement hors du sol pour aller chercher l'air; aussi les appelle-t-on racines-asperges.

Racines tuberculeuses. - Les racines peuvent se souder: on a des racines fasciées; cela est normal chez nos Orchidées indigènes, comme les Orchis; la fasciation peut même y être complète et l'ensemble forme un tubercule arrondi. D'autres fois, au contraire, le tubercule est palmé et la paume de cette sorte de main est la partie fasciée, tandis que les doigts sont les racines distinctes.

$11 \mathrm{y}$ a d'autres types de racines tuberculeuses (tuméfiées) : c'est ce qui arrive pour les Carottes, les Dahlias, etc. C'est dans les parties âgées que les matériaux nutritifs s'accumulent le plus souvent et sont utilisés par la plante pour le développement ultérieur.

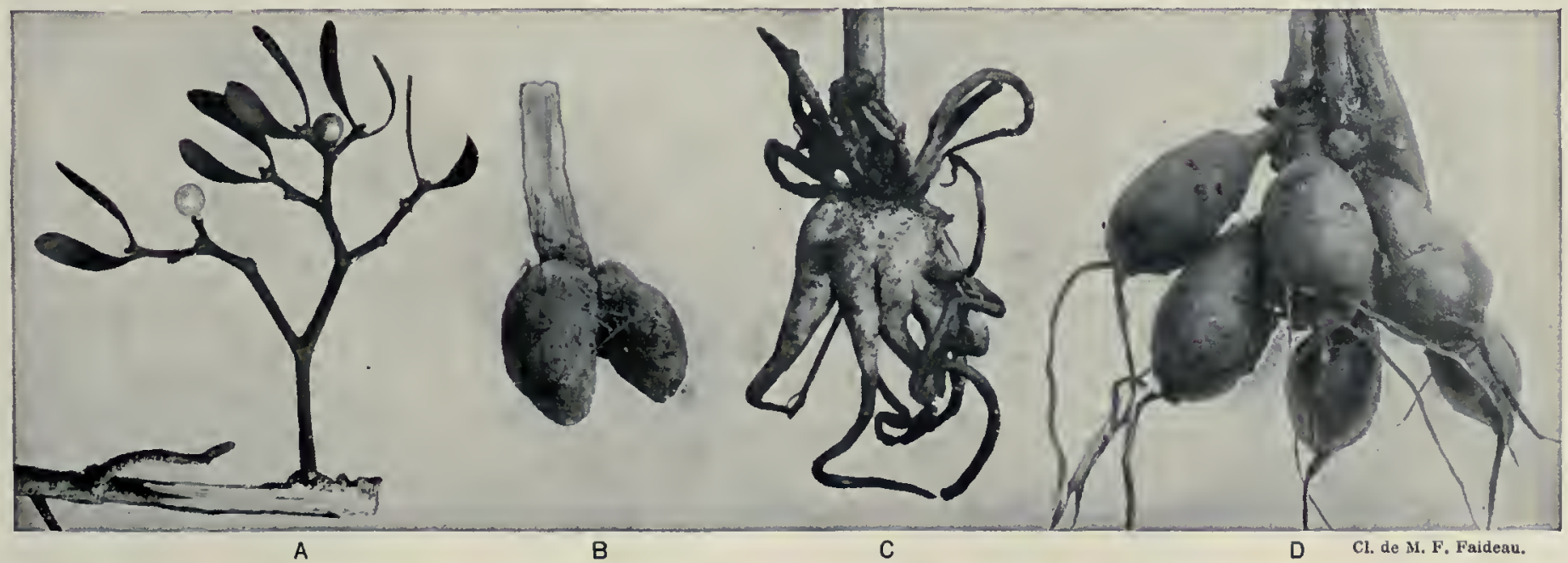

A Suçoirs du Gui; B, Racines arrondies de Loroglosse; C, Racines digitées d'Orchis moucheron; D, Racines tuberculeuses de Dahlia. 


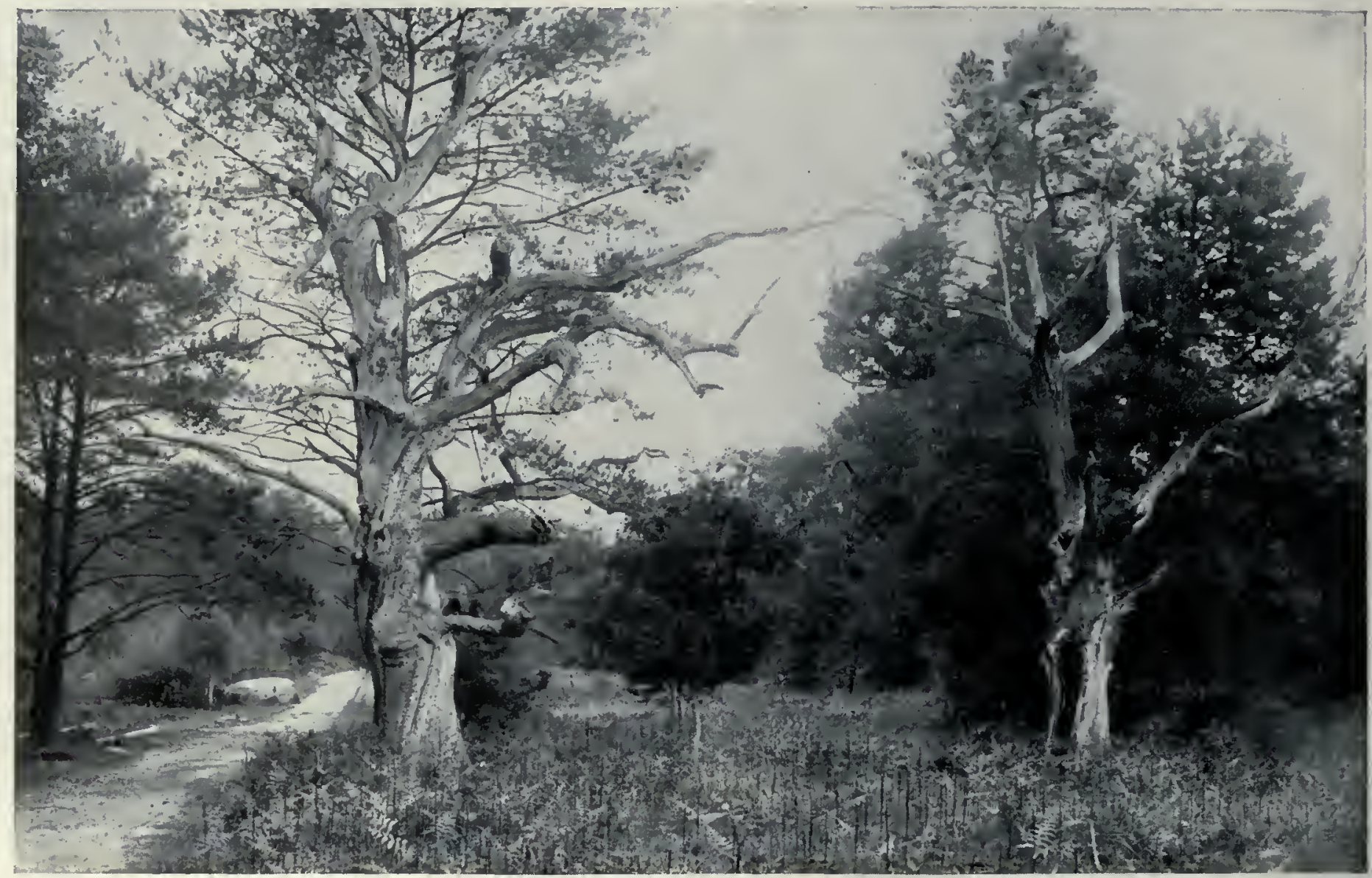

Vienx Chênes de la forèt de Fontainebteau.

\section{LA TIGE}

La tige est l'organe de la plante destiné à la soutenir dans l'air: c'est elle qui se dresse et se ramifie quelquefois d'une manière puissante pour permettre aux feuilles et aux fleurs de s'épanouir à la lumière. Son rôle fondamental est donc de produire et de porter ces deux derniers organes, de les soutenir et de les nourrir en leur conduisant la sève, aliment dont elles ne sauraient se passer.

Bourgeons. - A l'extrémité de la jeune tige encore simple se trouve le bourgeon terminal, formé par une série d'écailles imbriquées et emboîtées les unes sur les autres, qui recouvrent à l'intérieur des ébauches de feuilles de plus en plus jeunes. Ce bourgeon éclate et s'épanouit ( $f$ ig. 13 ); les écailles externes, qui sont souvent imprégnées de matière cireuse ou gommeuse, s'étalent, tombent, et les petites feuilles internes suivent le mouvement d'épanouissement et grandissent. Les espaces entre les petites feuilles saccroissent et on distingue ainsi dans la tige les noeuds et les entre-nœuds : les premiers correspondent aux plans perpendiculaires à l'axe de la tige suivant lesquels se fait l'attache des feuilles; les entre-nouds correspondent aux régions beaucoup plus grandes de la tige entre les premiers. Si l'on mesure sur une tige adulte la longueur des entre-nœuds successifs, on voit, en partant du haut, qu'ils sont de plusen plus grands jusqu'à une région moyenne de la tige, puis que leur longueur diminue dans la partie inférieure de l'organe aérien. Cette remarque renseigne donc sur le mode de croissance des tiges qui n'est pas subterminal comme dans la racine, mais s'opère sur toute la longueur et est intercalaire.

Rarement la tige reste simple : c'est le cas cependant des Fougères arborescentes et des Palmiers. Exceptionnellement ces derniers se ramifient, et le Doum ou $\mathrm{Hy}_{y}$ phane thebaica est un exemple que l'on cite à cause de sa rareté. Les avantages et les inconvénients qui découlent de la simplicité de ces tiges se comprennent aisément. Un fût de colonne parfaitement cylindrique permet à l'arbre de consacrer toute sa vigueur à la recherche de la partie supérieure la plus éclairée des forêts. Dans les forêts vierges tropicales, extrêmement denses, où croissent surtout ces deux catégories de végétaux, cette propriété est de grande importance, car la lutte pour la lumière y est une des manifestations les plus intenses de la lutte pour la vie.

Ramification et port. - D'ordinaire, la tige est ramifié, et c'est en général à l'aisselle d'une feuille et au-dessus d'elle qu'un bourgeon latéral apparait, formé dans la partie extérieure de l'écorce et constitué exactement comme le bourgeon terminal;

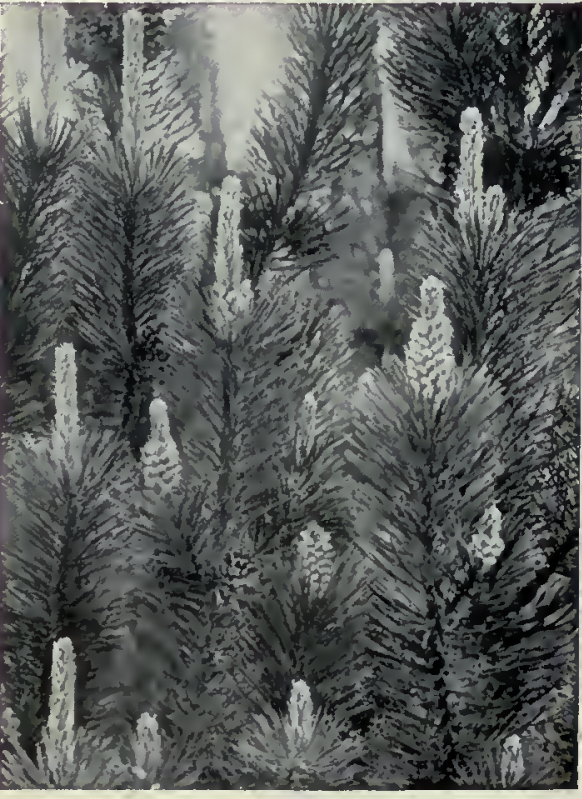

Bourgeons et inflorescences du Pin. par son développement, il engendre une branche qui est absolument identique à la tige primitive. Les branches sont, le plus souvent, d'au-

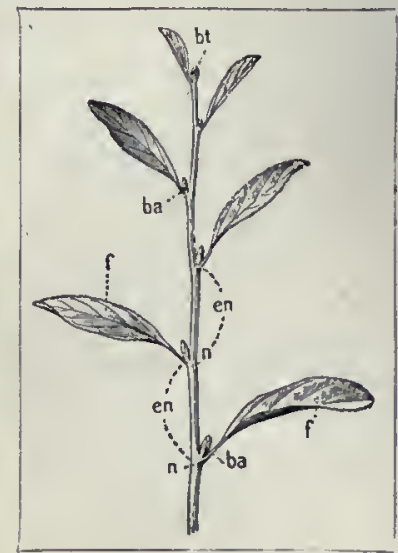

Fig. 13. - Tige.

$f$, feuille; $b a$, bourseon axillaire $b \boldsymbol{t}$, bourgeon terminal; $n$, noud, e $n$, entre-noeud. 


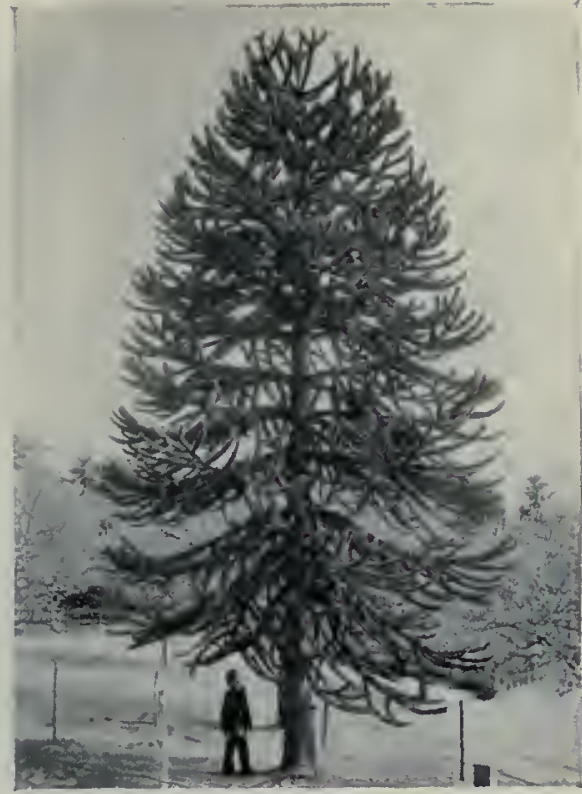

Araucaria imbricata.

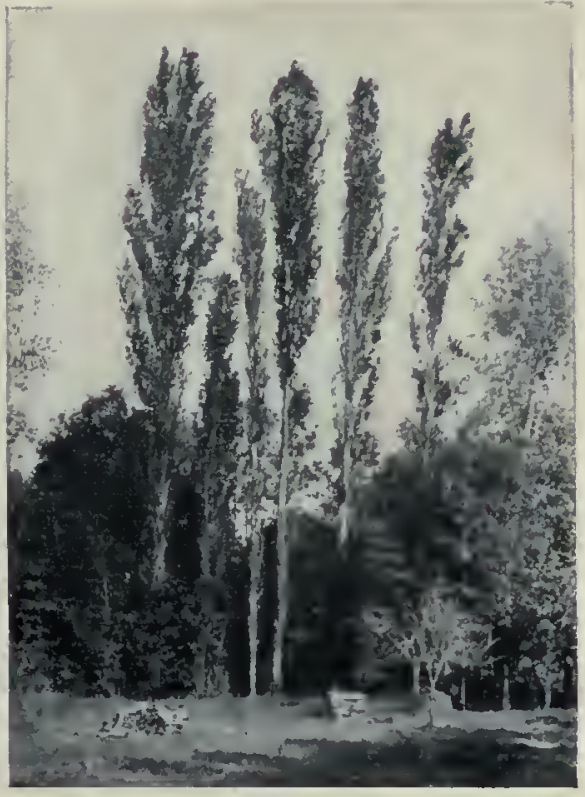

Peuplier pyramidal ou d'Italie.

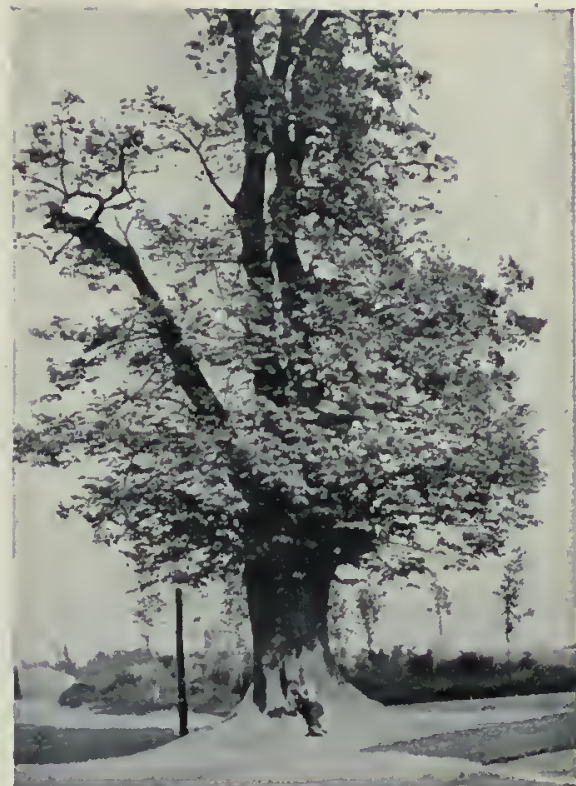

Titleul centenaire de Laeken. tant plus jeunes quelles sont plus près du haut de la tige; il en résulte que leur taille va en grandissant du sommet à la base, et que l'ensemble de l'arbre ramifié a l'aspect d'un cône, ce que lon voit très bien dans les Sapins, dans les Sequoia, les Araucaria. Ce cône peut devenir très aigu dans les Thuya, par suite de la faible croissance des branches inférieures, et ce cas sert de transition vers celui du Peuplier pyramidal, dans lequel le tronc principal est seul bien apparent, toutes les branches restant grêles et courtes et cela sur toute la longueur de la tige, qui est dite fastigiée. Parfois les branches retombent vers le bas: on a les arbres pleureurs, dont le Saule de Babylone, dit Saule pleureur, est lexemple le plus connu. Si, au contraire, l'activité de la croissance varie pendant l'allongement de l'arbre, modérée au début et maximum au milieu de la vie, il en résulte qu il prend régulièrement une forme en boule, comme on peut le voir dans les Pommiers.

Tiges herbacées et tiges ligneuses. - Cette tige change de consistance et de nature avec l'âge. Si elle est restée petite et molle, aqueuse, on dit que la plante est herbacée, parce que cette particularité sobserve pour les herbes de nos prairies: ailleurs, la tige sallonge notablement et les tissus se durcissent : on dit que la plante est ligneuse, et l'on a affaire, dans ce cas, à ce qu'on désigne couramment sous le nom d'arbre ou d'arbuste. Ces différences si fondamentales d'aspect et de taille en entraînent une autre relativement à la durée du végétal. Les plantes herbacées sont, en général, éphémères; elles ne vivent souvent qu'une année; rarement elles survivent à l'hiver; moins fréquemment encore elles persistent plusieurs saisons de suite sans péricliter. grâce à leurs parties souterraines : de là découle la distinction des plantes annuelles, bisannuelles et vivaces. Les plantes ligneuses sont beaucoup mieux armées pour résister aux frimas de nos hivers, et les arbres peuvent vivre pendant des siècles. La durée de l'existence de quelques-unes de ces espèces est parfois prodigieuse; il n'est pas impossible de rencontrer des Chênes de plus de 500 ans : le Jupiter de la forêt de Fontainebleau a plus de 700 ans ; en 1812 , on abattit à Bordza, dans les provinces baltiques de la Russie, un Chêne qui avait près de 1000 ans; c'est l'âge vénérable du Châtaignier de Sancerre. On a signalć des Baobabs de près de 6000 ans, et le Dragonnier d'Orotava de Ténériffe, qui a été abattu par un orage, il y a quelques années, ne paraissait pas avoir sensiblement grossi depuis $] 402$, époque où les Européens, en arrivant dans l'île, ont commencé à l'observer et à le mesurer, et son âge pouvait être aussi extraordinaire. On voit, d'après cela, que l'édification d'un arbre et d'une forêt d'essences ligneuses peut prendre la valeur d'un phénomène presque comparable, pour la durće, aux périodes géologiques.

On admettra aisément qu'une plante, qui a devant elle des siècles pour s accroître, pourra atteindre en hauteur des dimensions très remarquables. Les espèces que nous venons de mentionner ne sont pas, cependant, parmi celles de plus haute taille. Les arbres géants de 50 à 60 mètres ne sont pas rares dans la forêt équatoriale (Altingia), mais c'est en Australie et en Californie que l'on observe actuellement les arbres les plus hauts. Les Sequoia, de cette dernière contrée, atteignent plus de 100 mètres (115 mètres); les Eucalyptus, de la première région, vont jusquà 165 mètres de haut.

Croissance en épaisseur. - L'accroissement en longueur des arbres n'est pas le seul point intéressant à signaler dans leur histoire; l'accroissement en diamètre mérite également d'attirer notre attention. Quand on scie un billot transversalement, obtenu diun tronc d'arbre, on remarque aisément une série de zones concentriques dans la région centrale, formant ce que l'on appelle vulgairement bois. L'expérience apprend que ces zones sont annuelles, et que leur nombre permet de déterminer l'âge d'un arbre (fig. 18). Lorsqu'on examine à la loupe la constitution de ces zones, on voit qu'elles sont caractérisées par un changement brusque du calibre des vaisseaux, éléments constitutifs du bois dans lesquels circule la sève : les vaisseaux formés pendant le printemps et l'été sont très larges, à membrane relativement mince; ceux qui se produisent pendant l'automne sont, au contraire, à cavité étroite et à membrane épaisse. Cet épaississement continu des tiges est produit par le jeu d'une assise qui existe d'une manière permanente à la périphérie du bois (fig. 16); elle engendre, d'une façon presque continue, ralentie cependant pendant les grands froids, vers l'intérieur de la tige, les éléments du bois et, vers l'extérieur, les éléments libériens qui s'aplatissent les uns sur les autres, car ils 
sont mous, de manière à avoir été comparés aux feuilletsd'un livre (liber). La considération des couches ligneuses et de leur constitution est une question de la plus grande importance pratique, à cause de l'utilisation des bois en menuiserie et en ébénisterie.

Transforma tions du bois. Lorsque le bois vieillit, il subit des modifications notables dans sa dureté, sa consistance et sa couleur, qui sont d'importance pour l'industrie. La partie centrale d'une tige devient d'une couleur en général plus

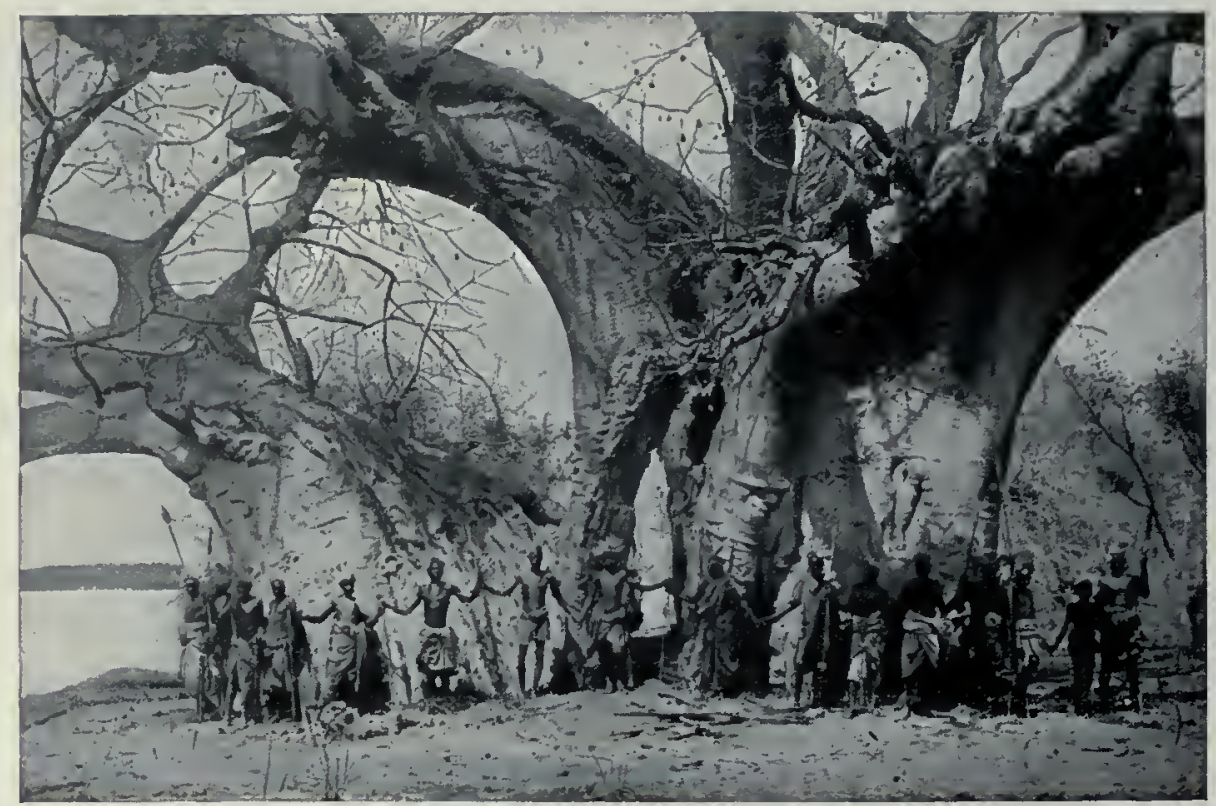

Baobab géant, dans le Centre africain. tée parl'unité, tandis que le cœur varie : diamètre 30 centimètres, le cœur vaut 3; diamètre 60 centimètres, le coeur vaut 4 .

L'élasticité d'un bois est une propriété souvent importante, qui a un rôle notable dans diverses circonstances, en particulier pour la constitution de la mâture des navires. Comme l'élasticité est en raison inverse de l'épaisseur des couches annuelles, les Pins, qui sont, comme on le sait, des arbres à croissance lente, conviennent bien pour le but précédent. Mais la latitude a une influence sur cette croissance reté et d'une densité plus grandes. Cette transformation est le début d'une série de modifications successives dont le terme ultime est la destruction du bois; elle se produit progressivement de l'intérieur vers l'extérieur, mais elle progresse sans lien régulier avec la marche des saisons. La couleur est foncée dans cette partie centrale; clle constitue le cœur du bois. Les régions ligneuses périphériques, dans lesquelles ces métamorphoses ne sont pas opérées, constituent l'aubier. Il peut arriver que le bois conserve une coloration peu intense et une faible densité dans toute l'épaisseur du tronc; on a affaire alors aux bois blancs, peu durables, donnant peu de chaleur comme combustibles. Les bois qui se colorent sont les bois durs et la partie ainsi transformée forme dans un arbre le bois parfait qu'utilise l'ébéniste. La couleur du cœur est variable avec les espèces : le Noyer est brun, le Plaqueminier ébénier est noir et donne le bois d'ébène, le bois des Hematoxylon est rouge violacé et fournit lc bois de Campêche employé comme colorant.

La constitution du bois parfait d'un arbre est d'ailleurs sous la dépendance des conditions de végétation. Dans un sol maigre, le cœur se forme mal; dans un terrain fertile, au contraire, les couches annuelles sont plus épaisses, et il y a beaucoup de bois parfait. L'âge intervient également dans la différenciation du bois et les progrès du cœur : la proportion de cœur augmente avec les années. Dans un Chêne de 20 centimètres de diamètre, l'épaisseur du cœur est l, et l celle de l'aubier; pour des épaisseurs croissantes du diamètre, l'épaisscur de l'aubier restc à peu près la même et est représen-

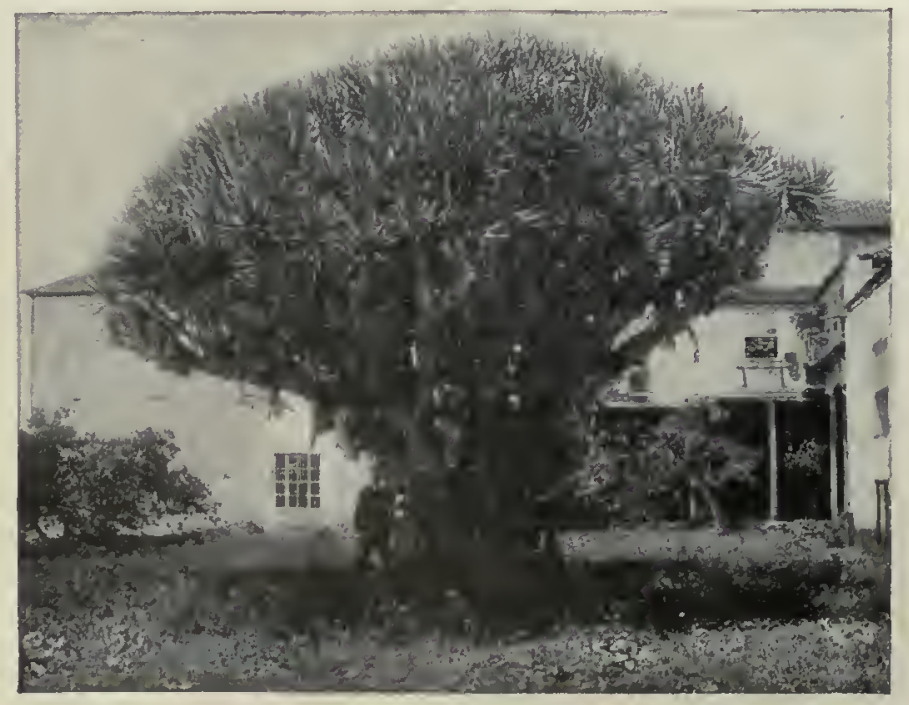

Dragonnier, à Ténériffe (Canaries). et, dans les recherches de Bravais et Martins, il a été établi que c'était vers $64^{\circ}$ de latitude, dans la presqu'île Scandinave, que se rencontraient les conditions les plus favorables pour le développement des tiges destinées à faire des mâts.

Le bois parfait peut parfois se différencier prématurément sous l'influence de blessures produites d'une manière régulière en des points déterminés suivant certaines génératrices, ct alors le bois se montre en section transversale, comme orné d'une sorte de croix de Malte qui dérive des traumatismes. C'est là un fait singulier qui résulte notamment du traitement auquel sont soumises les tiges de certains arbres et arbustes à Maule, en vue de la fabrication des cannes et des manches de parapluies.

Structure des jeunes tiges. - Nous venons d'envisager la structure des arbres; celle des herbes est beaucoup plus simple, et celles-ci présentent, à l'état persistant, la structure des arbres au début. On y trouve constamment, comme dans la racine, un épiderme qui est pourvu de petits orifices appelés stomates, par lesquels s'opèrent les échanges gazeux entre la plante et l'atmosphère; on y distingue une ćcorce ct un cylindre central (fig. 15), dans lequel on remarque des faisceaux qui sont à la fois liberriens et ligneux : libériens à l'extérieur, ligneux à l'intérieur (fig. 14). Par la juxtaposition de ces faisceaux, la tige se distingue donc nettement de la racine dans laquelle ces éléments sont séparés. La pointe des faisceaux du bois est vers l"intérieur et les éléments qui existent en

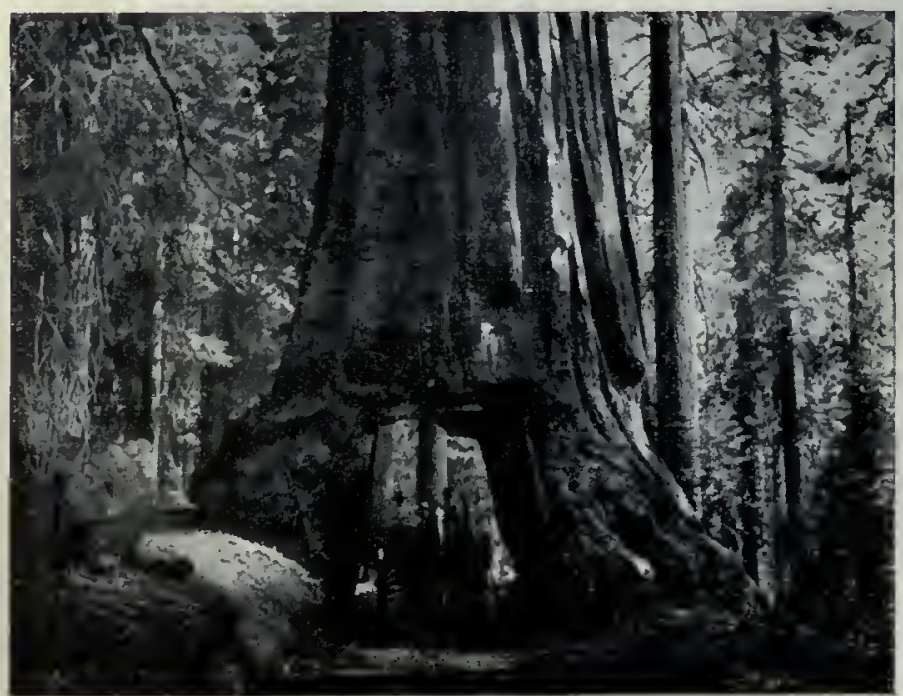

Sequoia gigantea, en Californic. 


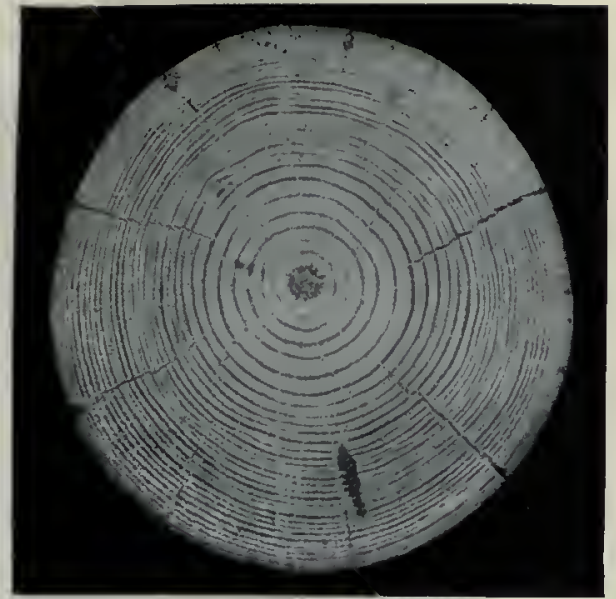

Zones annueltes d'un tronc de Pin.

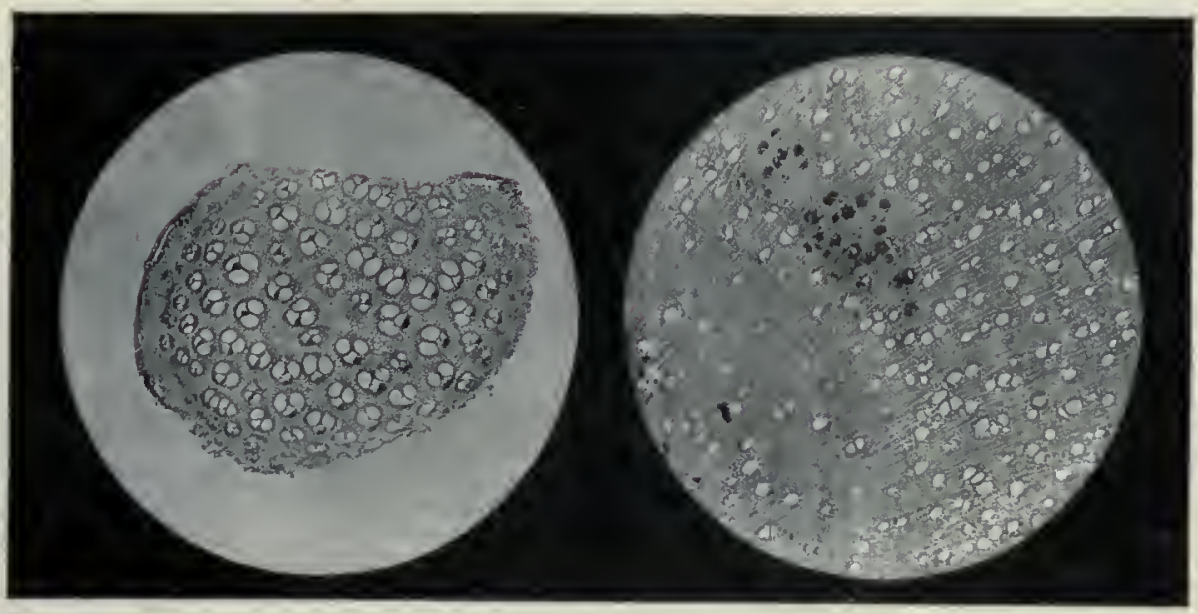

Tige de Smilax et tige de Grenadier (coupes grossies).
Cl. E. Dejrolle,

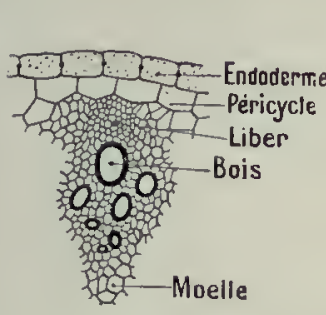

Fig. 14.

Détail d'un faisceau libéro-ligneux.

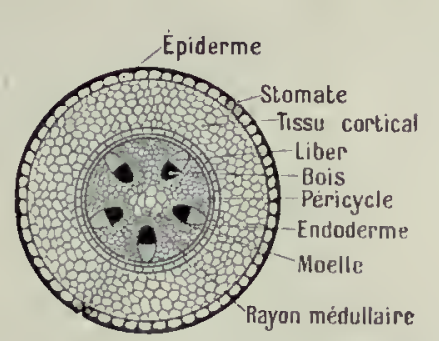

Fig. 15. - Coupe de Dicotylédone montrant ta structure primaire.

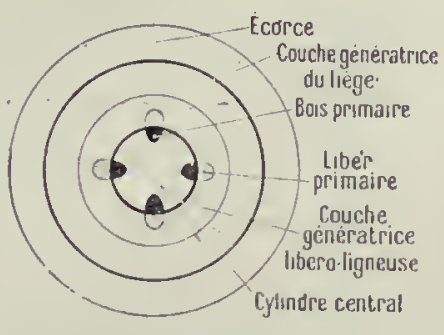

Fig.16. - Formations secondaires de Dicotylédones couches génératrices.

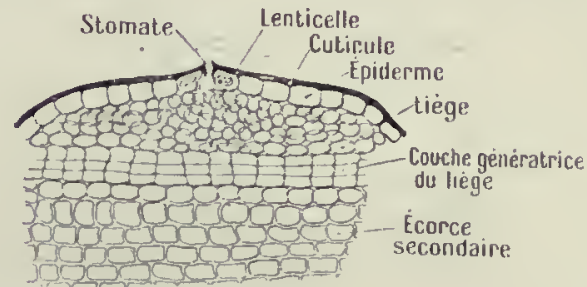

Fig. 17. - Fonctionnement de la couche génératrice du tiége. ce point sont constitués par des vaisseaux spiralés et annelés, tandis que, vers la périphérie de la partie ligneuse, les vaisseaux sont surtout ponctués. Il y a, d'ailleurs, des fibres et du tissu ligneux mélangés à ces divers éléments vasculaires. Dans le liber, c'est le tube criblé (fig. 6, E) qui est vraiment caractéristique, et qui doit ce nom aux plages criblées des parois transversales. La moelle est beaucoup plus développée que dans la racine, et elle est souvent réduite à une large cavité occupant le centre de la tige.

Les écorces. - En même temps que la partie interne des tiges se constitue et se différencie suivant les modes variés qui viennent d'être mentionnés, les parties périphériques subissent également des changements notables dans les tissus corticaux. Tandis que l'assise génératrice interne produit, par ses divisions répétées sur ses deux faces, le bois et le liber, une assise analogue, mais externe, se constitue à des profondeurs variées dans les tissus corticaux, qui engendre par ses cloisonnements, vers l'extérieur, le liège et, vers l'intérieur, l'écorce secondaire (fig. 17). Le liège est formé de cellules aplaties parallélépipédiques, très intimement soudées les unes avec les autres, à membrane imprégnée de subérine. Les cellules subéreuses périssent rapidement, perdent leur noyau et leur protoplasma, se remplissent d'air, forment une sorte de matelas mauvais conducteur de la chaleur à la périphérie des tiges et constituent un organe de protection, d'autant plus appréciable que les cellules imprégnées de subérine résistent à l'attaque des bactéries, qui détruisent les membranes purement cellulosiques. Grâce au jou de l'assise subéreuse, tous les tissus qui lui sont extérieurs ne tardent pas à être mortifiés et s'exfolient en forme d'écailles, de plaques variées. La tige continuant à sépaissir, des fentes tendent à se produire dans l'écorce, et

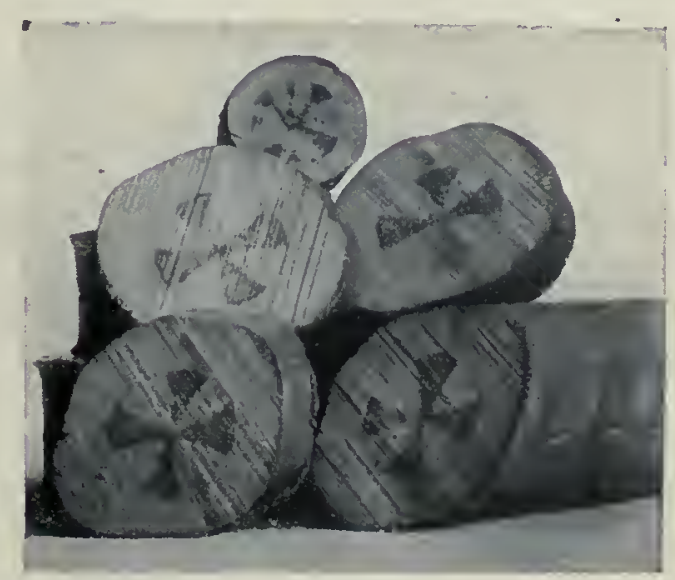

Croix de Malte naturelles sur sections de bois pour cannes, de nouvelles assises de liège naissent dans ses régions plus profondes. Il se forme ainsi à la surface des vieux troncs ce qu'on appelle l'écorce crevassée ou rhytidome, qui varie beaucoup dans son aspect suivant les tiges et fournit des caractères utiles pour reconnaître les arbres.

Tandis que l'écorce du Hêtre reste lisse, celle du Peuplier noir présente de longues crevasses; celles du Châtaignier sont plus longues encore; les crevasses du Chêne sont plus courtes. Le Cerisier se fend surtout horizontalement et son écorce s'enlève en plaques transversales minces, qui servent à faire ces boîtes à tabac que l'on connaît vulgairement sous le nom de queues de rat. Le Platane se dépouille par larges plaques qui tombent d'un coup et qui mettent à nu une partie jeune lisse et d'une teil e plus claire, de sorte que le tronc de cet arbre est maculé d'une manière curieuse par le rapprochement des parties vieilles et des parties jeunes de l'écorce.

Tiges souterraines. - La tige est susceptible, comme la racine, de variations notables qui sont en relation avec les fonctions diverses auxquelles cet organe doit s'adapter.

Les tiges vivant dans le sol constituent ce quel'on appelle les rhizomes; elles sont décolorées, blanches, dépourvues de feuilles vertes, garnies seulement d'écailles (fig. 19). Dans un Sceau-de-Salomon, par exemple, il y a un rhizome sur lequel on observe une série de cicatrices correspondant aux traces laissćes par les tiges aériennes dressées, après leurs chutes successives: on peut, $d$ après le nombre de ces cicatrices, déterminer depuis combien d'années la tige chemine silencieusement dans le sol; en réalité, elle relève chaque année son extrémité vers le haut, de façon à sortir de terre, et ne continue sa croissance souterraine que par un bourgeon de remplacement qui se forme à la base et qui se trouve en prolon- 


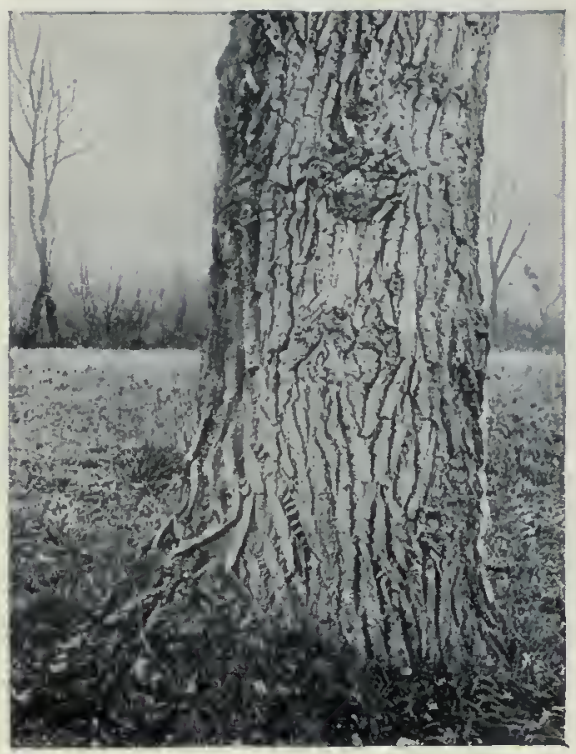

Écorce du Peuplier noir.

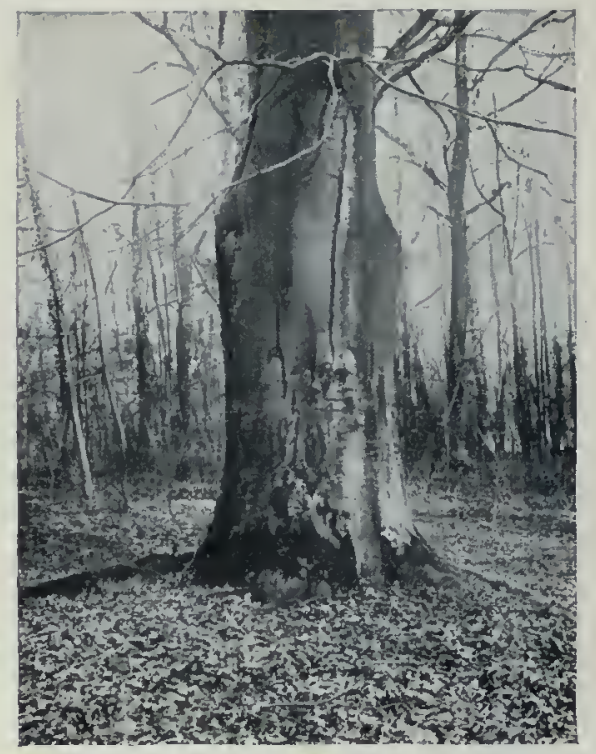

Ecorce du Hêtre.

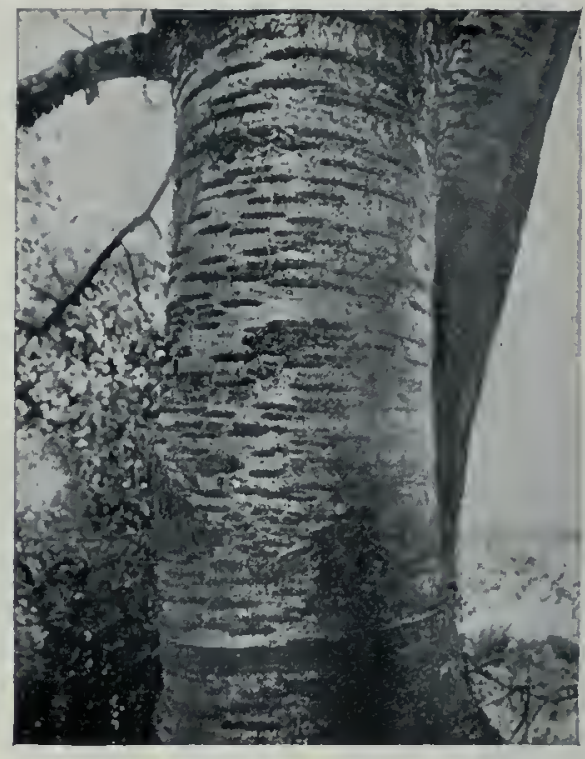

Cl. de M. F. Faideau.

Écorce du Cerisier.

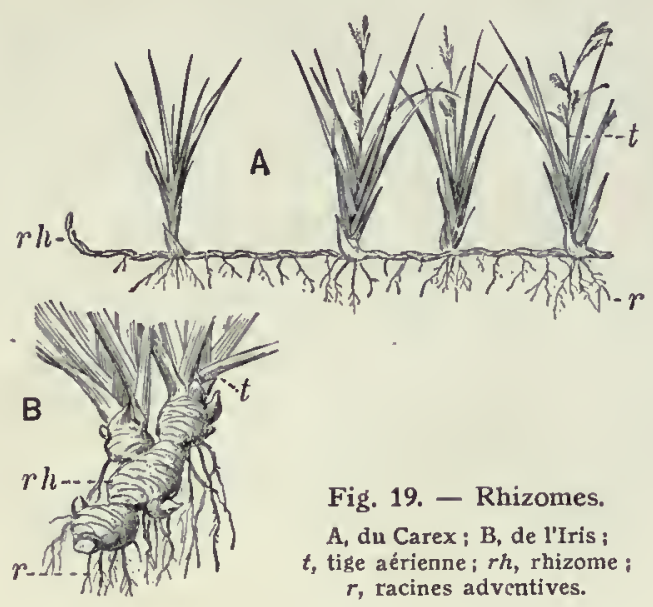

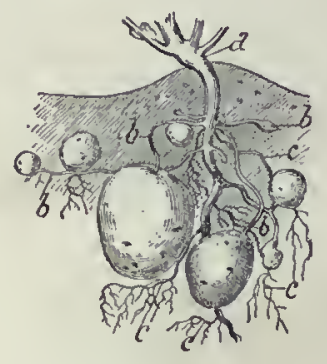

Fig. 20.

Tubercules

de la Pomme de terre. $a$, tige aérienne: $b$, rhizome portant des tubercules; $c$, racines adventives.

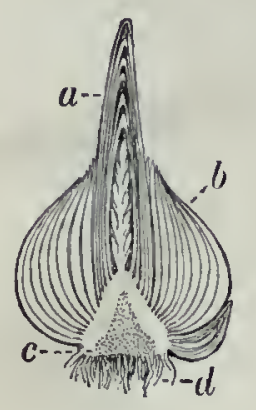

Fig. 21.

Conpe d'un butbe.

$a$, tige aérienne : $b$, écailles; $c$, plateau on rhizome; $d$, racines adventives.

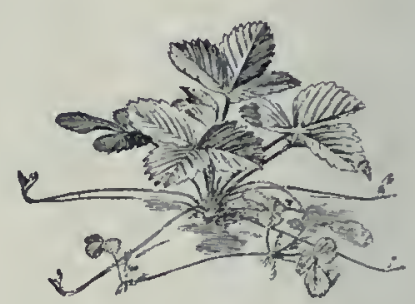

Fig. 22. - Coutants du Fraisier.

le tubercule est formé de plusieurs entre-nœeuds.

Si les cordons souterrains qui constituent le rhizome sortent accidentellement du sol et continuent à se développer à sa surface, on a ce que l'on appelle gement du rhizome. Ce dernier est donc, en réalité, formé d'une série de branches d'ordres différents: c'est ce que l'on appelle un sympode. Les tissus de ces tiges souterraines sont gorgés d'eau, remplis de matière féculente ou de diverses autres substances de réserve. Quelquefois le gonflement et la tuméfaction des tissus s'accusent plus encore et l'on voit de véritables tubercules se former, qui peuvent être constitués d'articles successifs renflés en chapelet comme dans les Crosues du Japon (Stachys affinis). Ailleurs, comme dans la Pomme de terre (Solanum tuberosum [fig. 20]), la tubérisation n'a lieu que sur une faible longueur des cordons incolores souterrains; sur le tubercule, on observe des yeux qui naissent à l'aisselle d'écailles, indiquant que

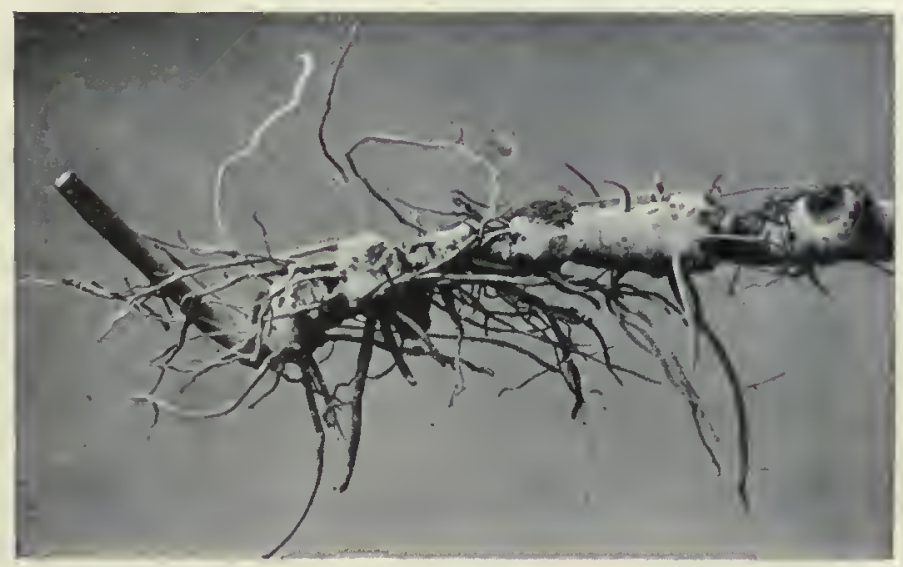

Rhizome du Sceau-de-Satomon avec cicatrices. des stolons ou drageons, ou des tiges rampantes que l'on observe aisément dans le Lierre terrestre (Glechoma hederacea), et surtout dans les Fraisiers (fig. 22), où ils forment ces coulants qui, après avoir rampé sur une assez grande longueur à la surface du sol, y produisent, près de l'extrémité, des racines qui s'enfoncent dans le sol et provoquent l'apparition de nouvelles feuilles et bientôt d'un nouveau plant de Fraisier; ce dernier se comporte comme le pied mère et la plante s'étend sur toute la surface du champ de culture.

Les bulbes ou oignons ( $f$ ig. 2l) sont des bourgeons souterrains comprenant un court rhizome ou plateau qui porte à sa face inférieure des racines adventives et, sur ses flancs, des écailles blanchâtres. A l'aisselle de chaque écaille est un bourgeon latéral. Dans certains bulbes, comme l'Oignon ordinaire, les écailles, très développées, se recouvrent complètement (bulbes tuniqués); dans le Lis, elles sont moins développées (bulbe écailleux); dans le Safran, elles sont très réduites : le plateau forme presque à lui seul le bulbe, qui est dit plein.

Tiges grimpantes. - Les tiges qui courent ainsi sur le sol appartiennent à la catégorie des plantes rampantes. Chez certaines il végète dans les endroits découverts, dans une prairie, par exemple. Mais si cette même plante crôit au milieu des Blés, dans un endroit où la lumière est atténuée, et où elle rencontre partout des tiges dressées qui peuvent lui servir de support, elle sə comporte d'une façon tout à fait différente : elle s'enroule autour des chaumes et devient une plante grimpante volubile.

Les tiges grimpantes ne sont pas toujours organisées sur ce dernier type. Nous avons vu, en effet, que la tige du Lierre grimpe le long des murs à l'aide de milliers de racines-crampons, et nous verrons ultérieurement que beaucoup se fixent aux tuteurs à l'aide d'organes enroulables nommés vrilles. espèces, comme le Liseron, cette propriété est très accusée quand 
Les tiges en pays désertiques. - En opposition à ces végétaux, nous pouvons citer ceux qui croissent dans les régions très sèches et désertiques, où les plantes sont peu nombreuses et la lumière intense. Les tiges s'y modifient dans une direction très différente. Les Cierges (Cereus) peuvent nous permettre d'apprécier l'amplitude de la variation des organes caulinaires. La tige reste d'ordinaire simple, elle ne se ramifie pas; elle est réduite à une colonne dépourvue de tous appendices, de feuilles et de branches; on remarque que sa surface est ailée et épineuse, que sa structure est charnue et aqueuse. Toutes ces particularités sont en rapport avec l'adaptation à un climat sec, qui permet au végétal de réduire au minimum le danger résultant pour lui de la transpiration. Les moyens que les plantes désertiques ont employés dans le cours des siècles pour arriver à ce résultat ont été les mêmes dans les pays les plus divers, mais ayant des conditions climatériques analogues. Cela est si vrai que des plantes très différentes les unes des autres, comme des Cactées, des Euphorbes grasses, des Asclépiadacées charnues ont subi des transformations si manifestement dans une même direction quelles sont arrivées, à l'heure actuelle, à se ressembler d'une ćtrange manière. Dans ces trois groupes, on a des tiges grasses et simples, couvertes de piquants, des tiges en boule ou des raquettes aplaties. Ce sont là les trois stades d"une même évolution qui s'est opérée dans le même sens pour trois groupes différents.

Fonctions de la tige. - La physiologie de la tige résulte, pour ainsi dire, de sa position dans l'ensemble du corps de la plante. C'est un organe qui sert de squelette, et qui a un double rôle de support et de conduction. C'est la tige, en effet, qui porte les feuilles, les fleurs et les fruits; ces diverses parties du végétal sont parfois extrêmement nombreuses, comme cela arrive dans un arbre élevé; il faut, pour porter cette riche frondaison et floraison, un système richement ramifié, solide, qui se dresse dans l'air où ses ramifications multiples permettent aux feuilles et aux fleurs de ne pas sétouffer les unes au-dessus des autres. Le squelette est surtout formé dans la tige par le tissu ligneux; déjà les vaisseaux ont leur membrane un peu épaissie et incrustée d'une matière dure appelée lignine, mais cette constitution intime se retrouve dans les fibres et le parenchyme ligneux. Ce sont d'ailleurs les fibres ligneuses qui constituent la partie essentielle et caractéristique du système squelettique. A ces fibres du bois s'ajoutent fréquemment les fibres libériennes qui forment des paquets plus ou moins développés, disséminés dans le liber ou agglomérés au dos des faisceaux. L importance de ces fibres est très grande, car c'est grâce à elles que beaucoup de plantes sont employćes comme textiles. Parle rouissage, les éléments parenchymateux sont sćparés, détruits, et les fibres peuvent être isolćes pour constituer l'étoupe qui servira au tisseur.

Le Chanvre, le Lin, le Jute, la Ramie sont parmi

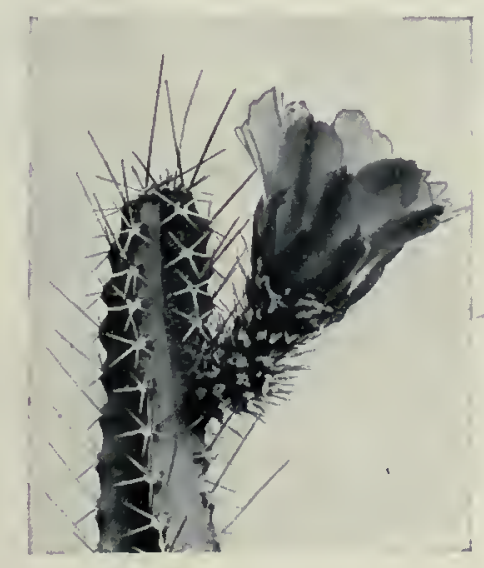

Cereus Blanckii (Cactée). les plantes les plus utiles à ce point de vue.

La seconde fonction fondamentale des tiges est de conduire la sève. C"est à travers son énorme système ligneux et vasculaire que circule la sève ascendante qui vient des racines et qui continue sa marche ascensionnelle vers les feuilles. Ce torrent vertical se maniteste quelquefois au dehors quand, par suite de blcssures, la sève s'écoule : on observe alors des pleurs. On peut encore trancher la partie supérieure d'une plante et le suc qui s'écoule en abondance est utilisé dans certaines contrées; soumis à la fermentation et à la distillation, il peut donner soit un vin (vin de Palme), soit un alcool, par exemple le mescal de l'Agave Salmiana.

Il ny a d'ailleurs pas que la sève ascensionnelle qui circule dans la tige ; il y a aussi la sève élaborée qui revient des feuilles et qui est d'ordinaire descendante. Seulement, au licu de passer par les vaisseaux du bois, elle descend par les tubes criblés du liber.

Evidemment, pour que la tige remplisse ces deux rôles essentiels, il faut qu'elle se dresse dans l'air et qu'elle soit orientée vers le haut. C'est ce qui arrive pour les tiges de la plupart des plantes, et cest la pesanteur qui contribue à cette orientation, grâce à cette propriété qui a été désignée sous le nom de géotropisme négatif. Pour la tige principale, le géotropisme est absolu; pour les branches obliques, le géotropisme est limité. Il est une catégorie de plantes pour lesquelles cette propriété disparaît : ce sont celles dont la tige est rampante ou celles dont la tige est souterraine. On dit alors qu il y a plagiotropisme. Les espèces dont la tige préscnte cette propriété anormale sont vouées à rester dans le sol ou à

Cl. de M. Diguet. au contraire, se réduit. L'absence de lumière fait, en outre, disparaître la matière verte et l'on a ces tiges souterraines, qui parfois se renflent en tubercules et il s'y accumule des matières alimentaires de réserve comme dans un grenier. Il en résulte que la plante peut séparer ces tubercules; grâce aux matériaux qu ils contiennent, ils peuvent germer comme une graine. Ces tubercules dégagent de la chaleur, et si l'on enfonce en eux le réservoir d'un thermomètre très sensible, on voit qu il marque une température supérieure à celle du sol. Ce dégagement cason voisinage. Si elles s introduisent dans la terre, que leur transpiration est modifiée, rendue plus difficile; elles se
tuméfient, leur écorce augmente d'épaisseur, leur cylindre central, lorique, d'abord faible, passe par un maximum, puis décroit.

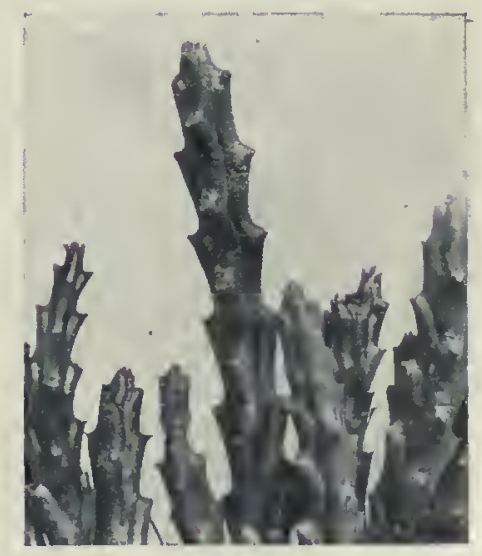

Euphorbia splendens (Euphorbiacée).

Stapelia (Asclépiadée grasse).

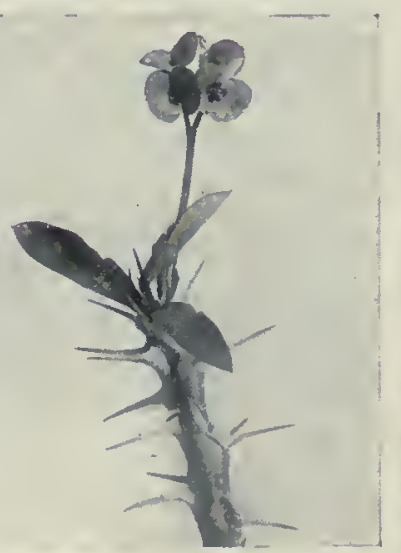




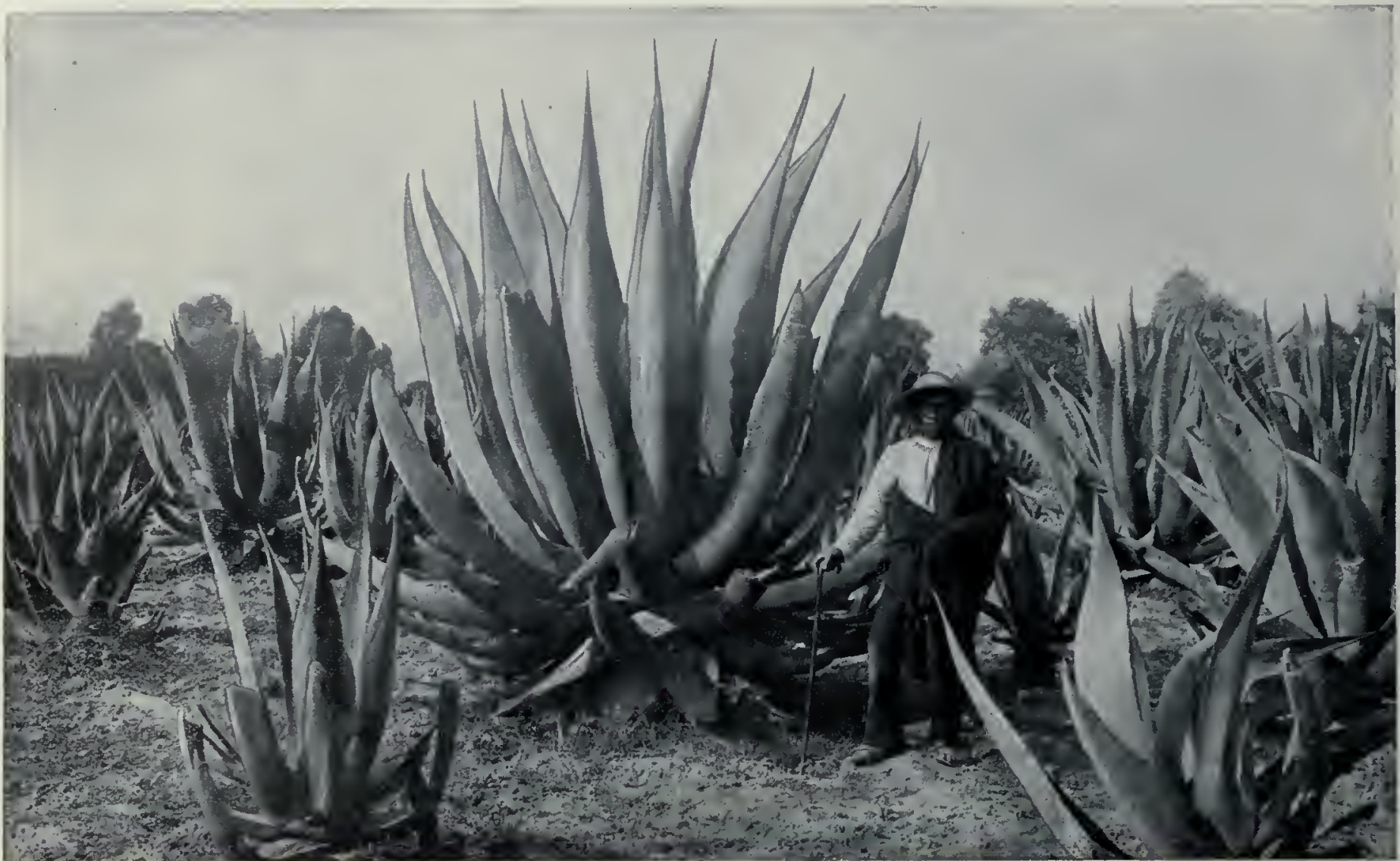

Une plantation d'Agaves, an Mexique.

Cl. A. Briquet.

\section{LA FEUILLE}

La feuille est le troisième organe de la plante qui se distingue des deux précédents par sa forme aplatie : la racine et la tige sont cylindriques et symétriques par rapport à un axe, tandis que la feuille est bilatérale ou symétrique par rapport à un plan. Une seconde différence saute aux yeux : la feuille est en général un organe petit, dont la croissance est restreinte, tandis que la tige et la racine sont des organes qui croissent presque indéfiniment. Certaines feuilles atteignent cependant des dimensions considérables, comme celles des Dracuntium, du Ravenala, de divers Palmiers. Les feuilles du Manicaria saccifère, de la forêt amazonienne, ont plus de 10 mètres de long.

La feuille (fig. 23) est formée, en général, de trois parties qui peuvent d'ailleurs l'une ou l'autre faire défaut : le limbe, la partie élargie, aplatie; le pétiole, ou queue de la feuille; la gaine, région un peu élargie entourant la tige à la base du pétiole. Les feuilles d'Arum, d'Ombellifères, nous montrent nettement les trois régions que nous venons d'indiquer, mais dans les feuilles de Hêtre, de Chêne, la gaine manque; au contraire, les feuilles de Graminées nont pas de pétiole, leur gaine fendue est trèsgrande et le limbe étroit et allongé est très développé. Dans quelques plantes, aux parties dépendant de la feuille, s'ajoutent les stipules (fig. 24), constituées par deux petites lames placées de part et d'autre du pétiole à sa base; on voit des stipules d'assez notables dimensions dans le Sarrasin et les Pensées. Parfois (dans le Hêtre par exemple), les stipules sont caduques et tombent au moment où se développe le bourgeon

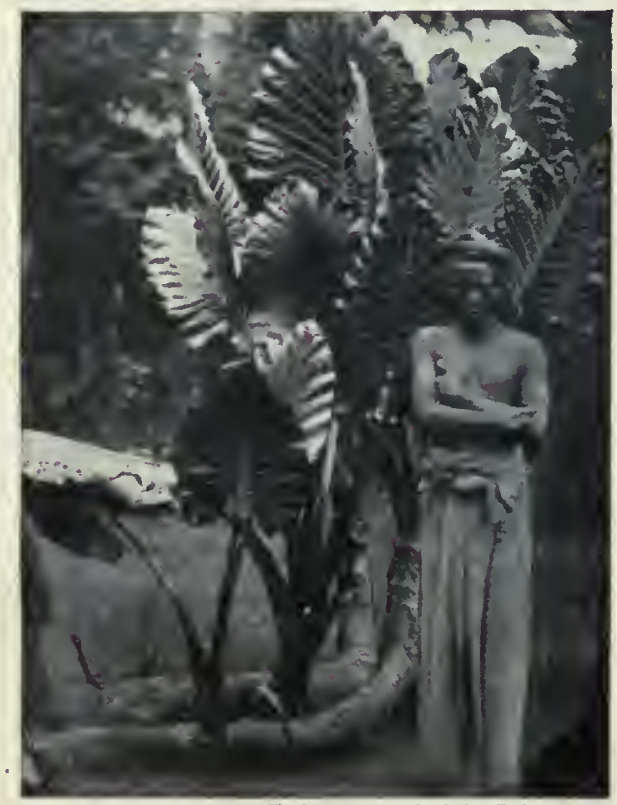

Cl. de M. Rraul do Saint-Pol T_lag.

Un Caladium, à Sumatra. qu'elles servaient à protéger. Bien que d'ordinaire indépendantes du pétiole, les stipules peuvent quelquefois se souder à lui; c'est ce qui arrive pour les Trèfles : les pointes qui font saillie au sommet de ces petits organes et leur position ne permettent pas de les confondre avec des gaines.

Nervation. - Le limbe est la partie la plus importante de la feuille; c'est celle qui joue le rôle prépondérant au point de vuc de la nutrition de la plante par l'air qui l'environne. On y distingue le parenchyme et les nervures, ces dernières formant une dentelle, souvent bien délicate, que l'on peut apercevoir lorsque les feuilles (de Peuplier, par exemple) ont séjourné pendant un certain temps dans l'eau. En plus de la nervure principale ct des nervures secondaires, on distingue un réseau véritablement rcmarquable de nervures tertiaires en fine dentelle, qui permettent de saisir comment se fait la répartition des aliments dans toutes les parties de la feuille. Le mode de distribution des nervures est tout à fait caractéristique et mérite d'être connu (fig. 25). Rarement les feuilles ont une seule nervure : cest cependant le cas des Pins, des Bruyères, du Tamarix, dont les feuilles sont en aiguilles ou aciculaires. Dans les Graminées et, d'une manière presque générale, dans les Monocotylédones, les nervures sont à peu près parallèles. Dans les plantes supérieures Dicotylédones, les nervures sccondaires s insèrent sur la nervure principale, en faisant avec elle un angle variable; si elles partent de diverses hauteurs sur elle, la nervation est dite pennée (comme dans les plumes); si elles partent toutes de la base, sirradiant de ce point comme les doigts d'un canard, on dit

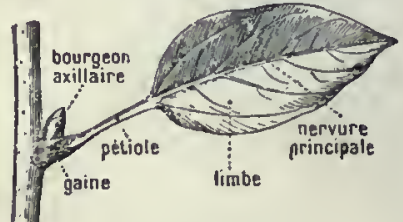

Fig. 23.

Parties de la feuille.

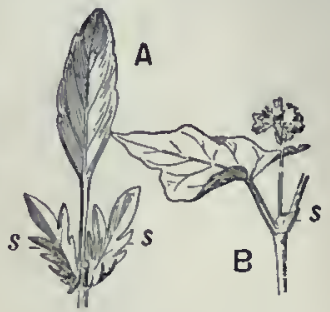

Fig. 24. - Stipules (s).

$A$ de Pensée; B, de Sarrasin. 


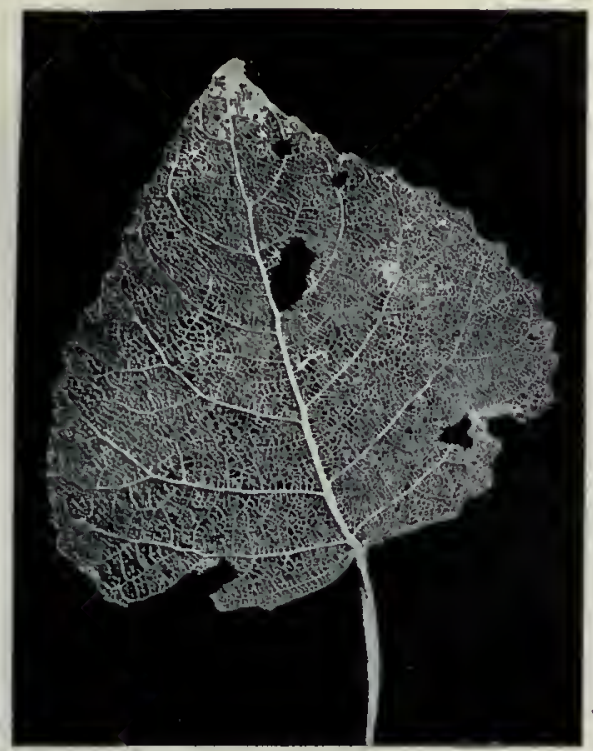

Feuilte de Peuplier réduite à ses nervures.

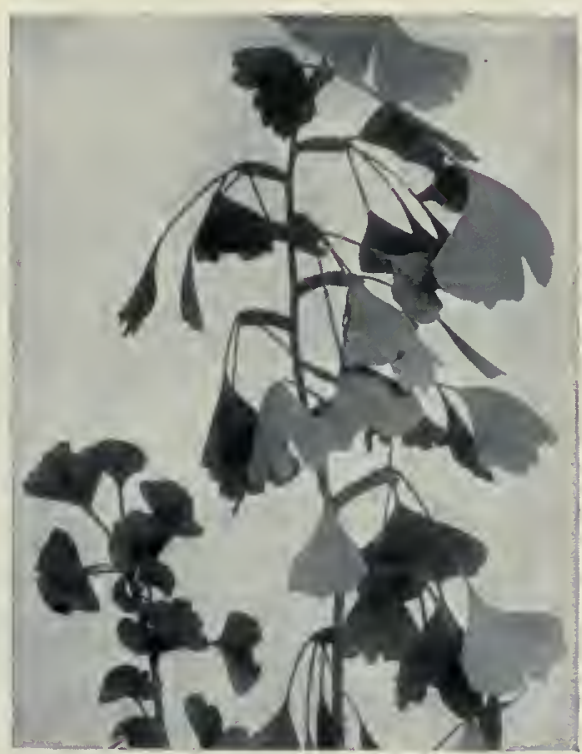

Feuilles flabellées de Ginkgo biloba. १?

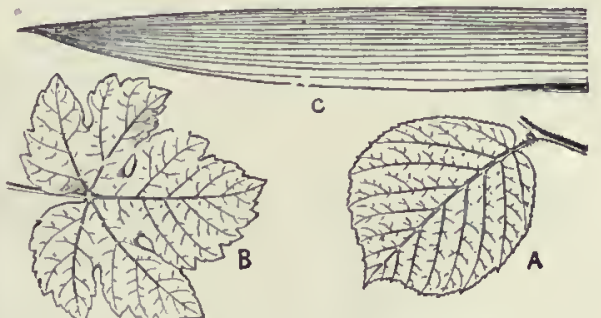

Fig. 25. - Nervation des feuitles.

$A$, de Noisetier; $B$, de Vigne; $C$, de Blé.

Vigne, etc., ou pennidentées, pennilobées, penniséquées, etc.

Les entailles peuvent être plus profondes encore que celles que nous venons de décrire; des folioles tout à fait semblables à de petites feuilles apparaissent, chacune pourvue d'un petit limbe et d'un pétiolule; on dit alors que les feuilles sont composées. Elles peuvent être composées-pennées comme dans le Robinier faux-Acacia ou composéespalmées comme dans le Marronnier d'Inde. que la nervation est palmée. La nervation est dite flabellée, ou en éventail, dans le Ginkgo; les nervures se divisent successivement en fourche, en suivant l'élargissement progressif de la feuille. En général, le pétiole s"insère à la base du limbe; cependant, dans une feuille de Capucine, il n'en est pas ainsi : il s'attache au-dessous du limbe et excentriquement; de ce point partent alors les nervures dans toutes les directions : on a ce que l'on appelle une nervation peltée (en bouclier).

Feuilles simples et feuilles composées. - Le parenchyme, ensemble des tissus qui s'étendent entre les nervures, peut également présenter des variations frappantes qui contribuent à changer complètement l'aspect des feuilles. Le bord du limbe peut être sans découpures, la feuille est alors entière; parfois i] est découpé en un grand nombre de petites denticulations, la feuille est dentée; si les échancrures sont en festons arrondis, la feuille est crénelée, et quand ces festons deviennent un peu profonds et les divisions moins nombreuses et plus grandes, la feuille est dite lobée ; la feuille est dite partite quand les entailles vont jusquà la nervure principale sans y atteindre ; elle est au contraire séquée quand la division du limbe la met à nu, comme, par exemple, chez le Fenouil. Comme de juste, les entailles plus ou moins profondes du parenchyme que nous venons de décrire peuvent accompagner des nervations de différents types et on a, suivant les cas, des feuilles palmidentées, palmilobées comme dans la

Disposition des feuilles sur les tiges. - Le mode d'insertion des feuilles sur les tiges se fait suivant des règles qui sont très remarquables par leur caractère mathématique (fig. 26 et 27), car ce n'est pas seulement dans le domaine céleste que tout est réglé par des nombres.

Il y a deux cas à distinguer, suivant que les feuilles sont isolées, insérées solitairement chacune sur un noud (feuilles alternes) ou qu'elles sont au contraire groupées par deux (feuilles opposées) ou plusieurs (feuilles verticillées). Occupons-nous d'abord du cas des feuilles alternes.

Si l'on s'élève sur la tige en suivant la ligne, en forme d'hélice, qui passe par les points successifs d'insertion des feuilles, on remarque que les divergences sont constantes pour passer d'un de ces points au point suivant.

On désigne sous le nom de divergence l'angle dièdre formé par deux plans passant par l'axe de la tige et par les deux points d'insertion de deux feuilles successives et voisines. Cet angle est mesuré de la façon suivante : on mène la circonférence passant par le point inférieur $(\mathrm{A})$ qui correspond à un plan perpendiculaire à l'axe de l'organe; par le point d'insertion de la feuille supérieure, on mène une génératrice qui rencontre la circonférence.précédente (en B) : l'arc $\mathrm{AB}$ mesure la divergence.

Non seulement la divergence est constante, comme nous venons de le dire plus haut, mais elle est représentée par une fraction simple de la circonférence $1 / 2,1 / 3,2 / 5$, etc. D'une façon générale, les fractions que l'on observe le plus couramment sont celles de la

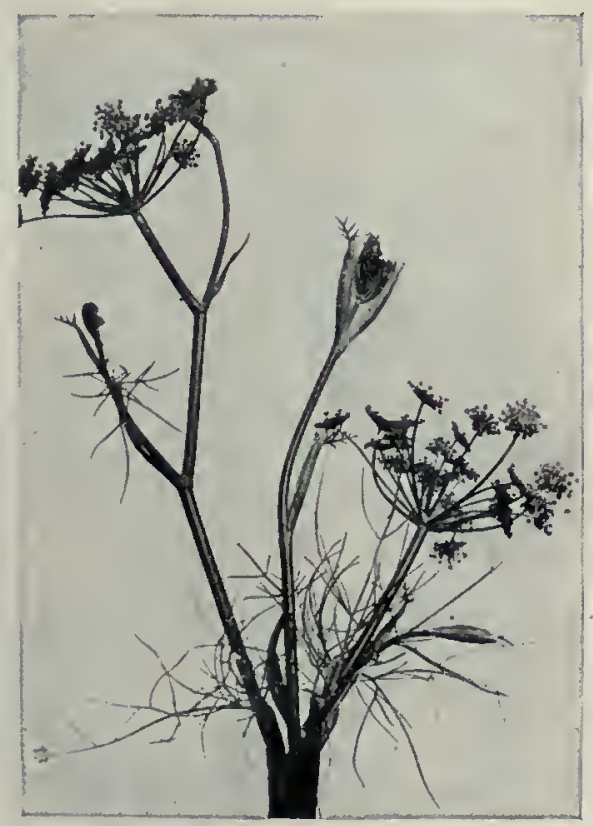

Feuittes séquées du Fenouil.

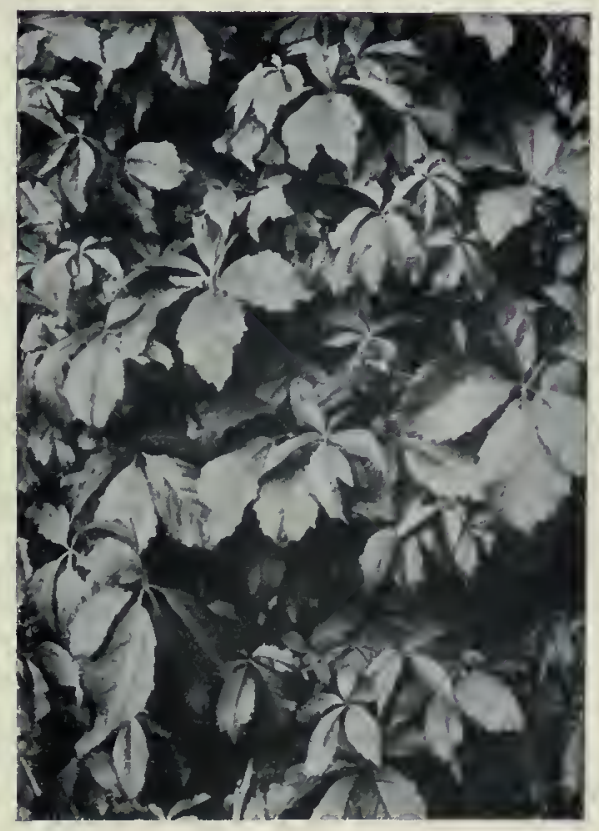

Feuilles palmées-composées de la Vigne vierge.

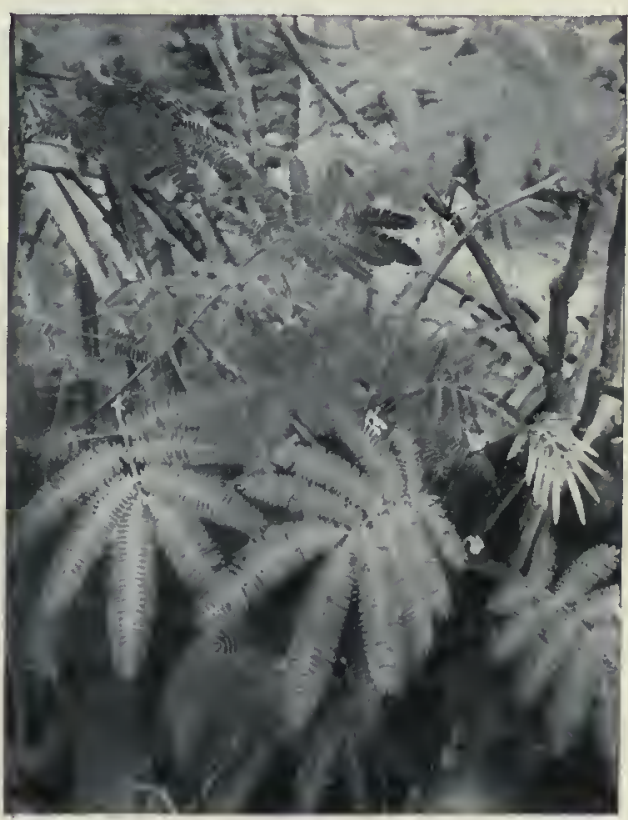

Feuitles bipennées du Calliandra. 

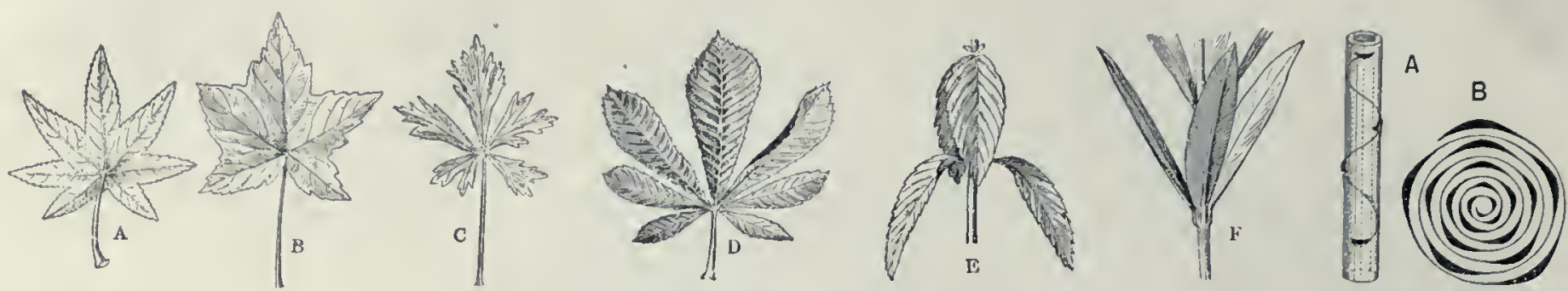

Fig. 26. - Feuiltes. Fis. 27. - Disposition
des feuilles atternes. A, lobée de Ricin, B, d'Érable, C, d'Aconit; D, composée-palmée du Marrontier; E, opuosces de Menthe; F, verticillées de Laurier-rose.

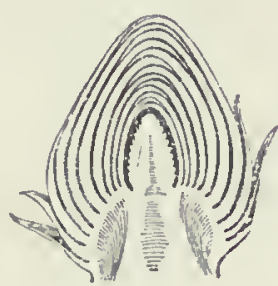

Fig. 28. - Coupe d'un bourgeon.

série que l'on obtient en additionnant les numérateurs et les dénominateurs entre eux des deux dernières fractions de la série précédente, ét en procédant toujours ainsi pour obtenir de nouveaux termes. Dans le Ravenala, l' " Arbre du voyageur n, de Madagascar, la divergence est de $1 / 2$, les feuilles sont distiques et on voit bien sur la photographie queelles sont insérées dans un même plan.

Lorsqu il s"agit de feuilles opposées ou verticillées,

la loi la plus simple, et qui sobserve le plus communément, est la suivante : la ligne médiane d'une feuille d'un verticille supérieur se projette exactement suivant la bissectrice de l'angle compris entre deux feuilles du verticille inférieur.

Telles sont les règles les plus simples et les plus générales qui président d'ordinaire à la phyllotaxie, c'est-à-dire à l'insertion des organes foliaires. Il est très remarquable de constater là des règles mathẻmatiques très simples qui indiquent évidemment que l'édification des plantes s'est faite suivant des lois logiques et naturelles qui se trahissent ainsi.

Bourgeons et préfoliation. - L'étude des bourgeons et de leur mode d'épanouissement révèle également des particularités assez curieuses (fig. 28 et 29). Les petites feuilles y sont disposées de

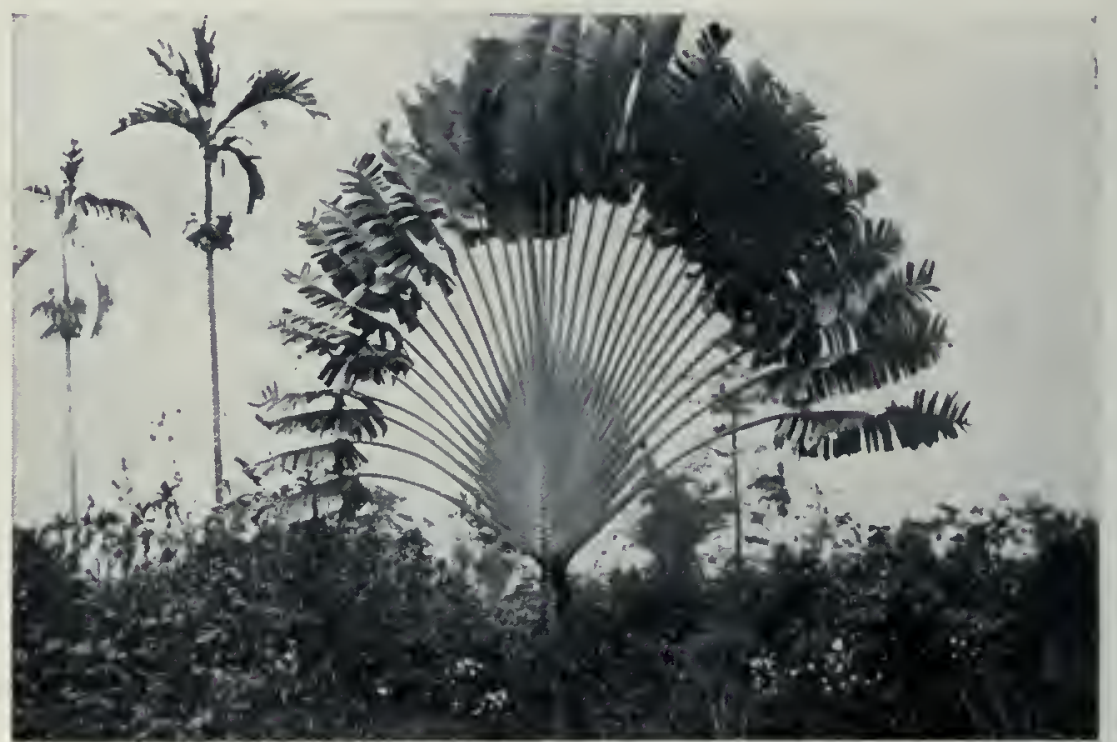

Le Ravenala ou Arbre du voyageur, à Madagascar.

manière à occuper le moins de place possible et à s"intercaler les unes entre les autres. Parfois, ce qui est rare, les feuilles sont plancs: c'est ce qui arrive chez les Lilas. Fréquemment elles sont pliées en deux suivant la nervure médiane : c'est ce qui arrive dans les Chênes (condupliquées). Dans les bourgeons de Fougères, elles sont roulées en crosse (circinées), et ceci se manifeste non seulement pour le pétiole principal, mais aussi pour les pétioles secondaires et les folioles, qui se développent d'ailleurs peu à peu au fur et à mesure de l'épanouissement. Chez les Bouleaux, les feuilles sont plissées en éventail ; dans les Peupliers, les bords sont enroulés en dedans; enfin, dans les Pruniers, l'enroulement est en cornet ou convoluté. C'est ce qui a lieu également pour le Muguet, et le déroulement se produit peu à peu.

Lorsque les feuilles sont pliées, la feuille extérieure peut

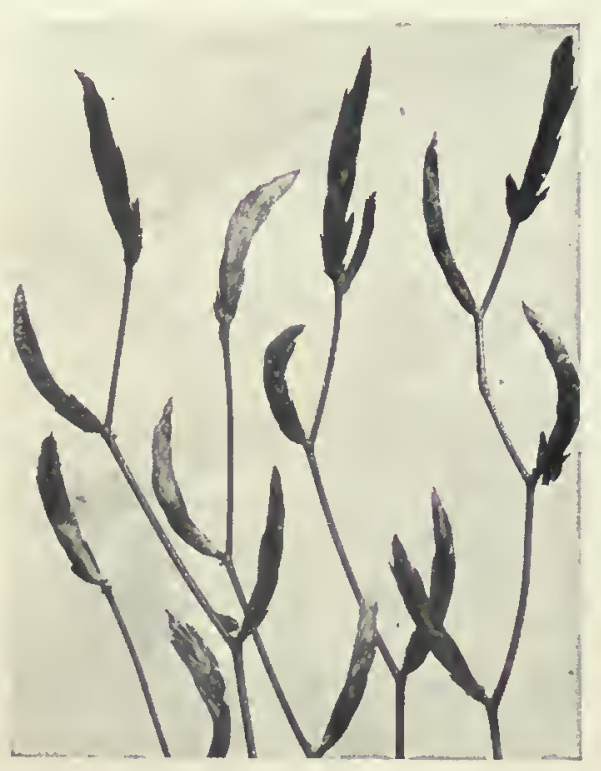

Bourgeons du Hêtre.

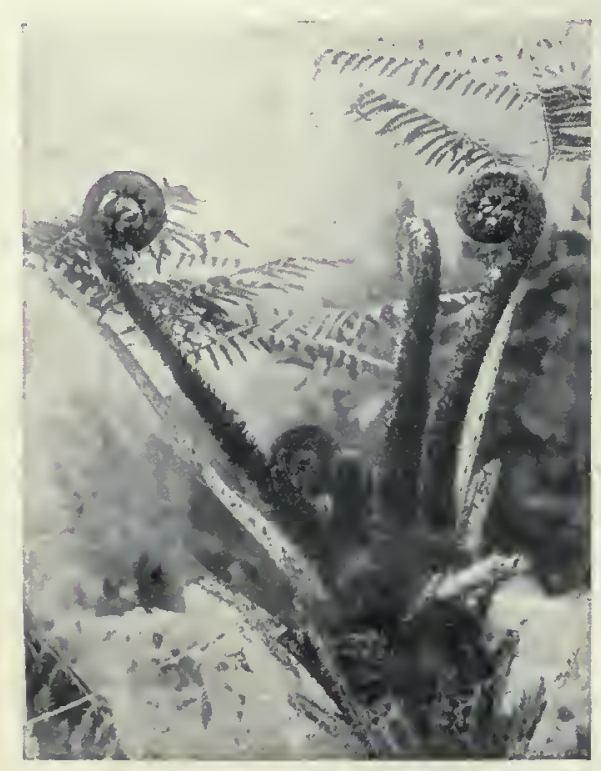

Crosses d'uue Fougère.

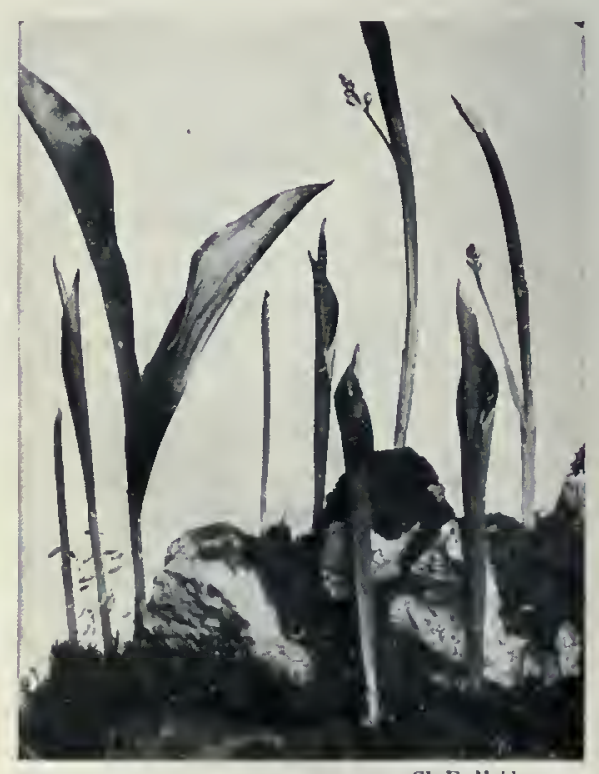

Développcmeut du Muguct. 


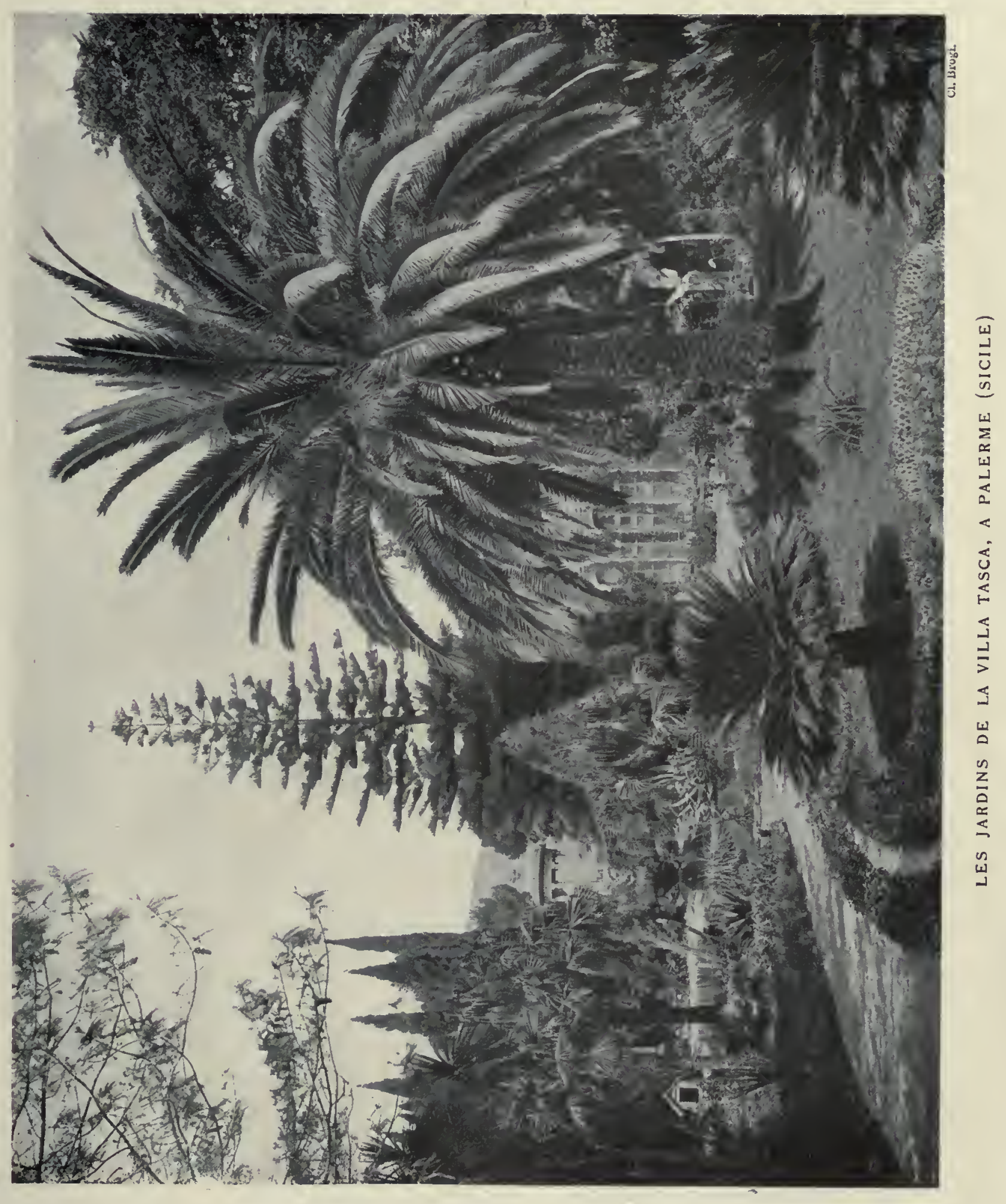



recouvrir complètement et emboitter la feuille plus interne et plus jeune, les plis étant opposés et se regardant : on a affaire au type équitant, que l'on remarque dans l'Iris. Si, au contraire, c'est seulement la moitié d'une feuille qui esi recouverte, on a un type semi-équitant : tel est le cas de l'Eillet. Enfin, lorsque les bords se rapprochent sans se recouvrir, on dit qu il y a préfoliation valvaire. Le limbe, entier au début, peut se perforer dans le cours du développement; c'est ce qui a lieu pour les Monstera délicieux : les perforations s'élargissent, gagnent les bords, et la feuille devient lobée ; en même temps d'autres perforations apparaissent, ce qui rend l'aspect de la feuille très singulier.

Durée. - La feuille, avons-nous dit plus haut, est un organe à faible croissance : cette propriété est liée à sa faible durée. Tandis que la tige et la racine subsistent pour ainsi dire indéfniment, la feuille est destinée à une chute plus ou moins rapide. Les herbes perdent en général leurs organes aériens par le froid; quand les feuilles persistent pendant l'hiver, elles ne tardent pas au bout d'un certain temps à se détruire. Mais c'est surtout pour les arbres que la caducité des feuilles se manifeste d'une manière nette quand, à la fin de l'automne, les forêts se dépouillent. On remarque alors deux sortes d'essences, celles que l'on appelle à feuilles persistantes et celles à feuilles caduques. En fait, dans les arbres toujours verts, comme les Pins,

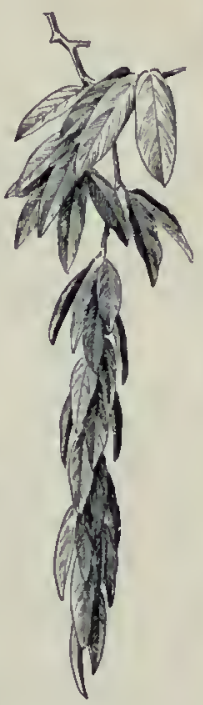

Fig. 30. Feuitlage pendant d'Amherstia nobilis.

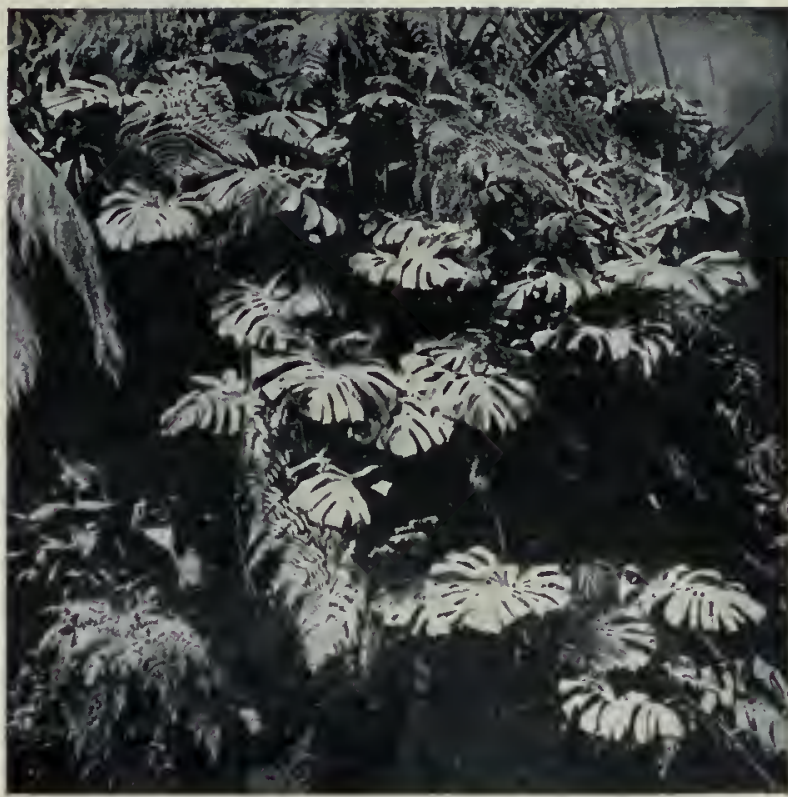

Feuilles perforées du Monstera délicieux. les Sapins, les feuilles durent un certain nombre d'années, parfois sept à huit, et finissent par tomber. Dans les Chênes, au contraire, la caducité du feuillage est liée à l'apparition de l'hiver. Ce lien est si manifeste que l'on peut, quand on se transporte dans un climat moins rude, où l'hiver est plus court, voir l'époque de la chute des feuilles retarder de plus en plus. Dans le midi de l'Europe, on peut assister à ce phénomène et M. Flammarion a cultivé dans le jardin d'hiver, ou grande serre, du Muséum de Paris, un Chêne rouvre de notre pays qui s'y était transformé en un arbre gardant ses feuilles toute l'année. On ne doit pas s'étonner, d'après cela, que dans les régions chaudes où l'hiver n'existe plus, avec son froid intense, toutes les espèces de Chênes soient à feuilles persistantes. Dans les continents comme l'Amérique du Sud, où l'on peut passer sans interruption de mer de la pointe extrême de la Patagonie jusqu'à des régions tout à fait tropicales, on rencontre des variations de même nature. Le cas des forêts de Hêtres (Nothofagus) de ces régions est tout à fait intéressant ; tandis que dans les régions froides on a des types à feuilles caduques, quand on s'élève vers le Chili les feuilles peuvent devenir persistantes. Mais l'hérédité vient compliquer le problème et, dans les climats intermédiaires, on peut avoir les types les plus

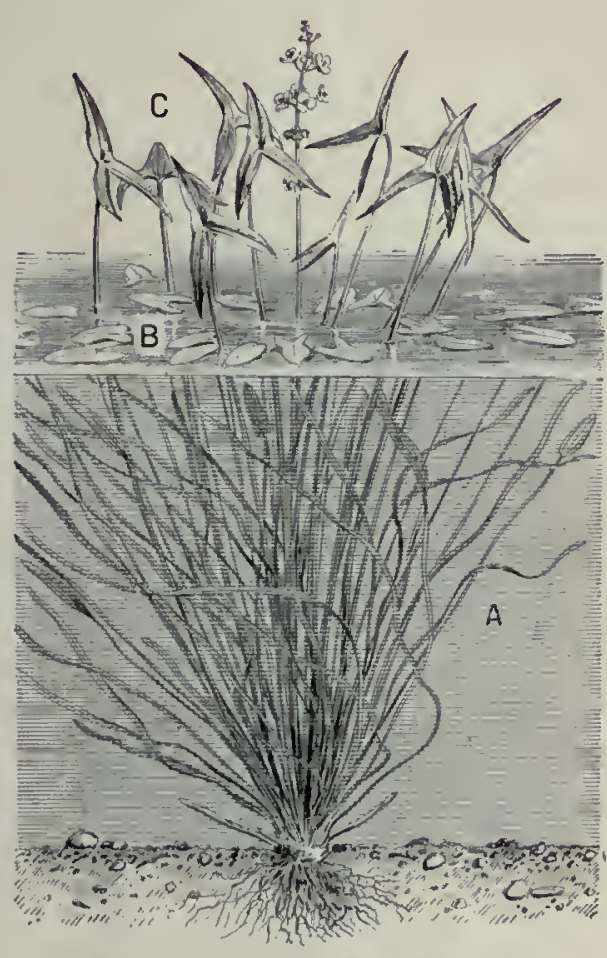

Fig. 31. - Sagittaire avec ses feuilles.

A, submersées: B, flottantes: C, aériennes. complexes. C'est ainsi que le $P$ soralea glanduleux, dans un pays où l'hiver existe, perd une grande partie de ses feuilles quand

arrive le froid, mais il se dépouille plus on moins de feuilles, suivant les localités. Ces exemples divers nous servent évidemment à expliquer le cas des arbres des régions tropicales pour lesquelles la forêt reste toujours verte; les feuilles tombent peu à peu, mais sans rythme saisonnier.

$\mathrm{Si}$ les feuilles s'altèrent et tombent successivement, il n'en résulte pas que leur apparition ne soit pas liée à la recrudescence de l'humidité qui, au début de la saison des pluies, redonne une activité nouvelle à la végétation. C'est à cette époque de l'année que la forêt tropicale s'orne d'une merveilleuse parure grâce aux nuances variées et tendres, jaunes, roses, pourpres, des jeunes feuillages. Les bourgeons ne se développent pas comme dans les pays froids, où la plante paraît comme craintive et hésite à émettre au dehors ses jeunes pousses qu'un retour offensif du froid peut geler et détruire. Il n'y a pas tous ces moyens de défense et de protection que nous connaissons dans les arbres de nos pays : cette viscosité des écailles du bourgeon qui en retarde l'éclosion, ces zones cotonneuses qui enveloppent frileusement toutes les jeunes feuilles. Dans les pays chauds, les bourgeons ne souvrent pas, ils se déversent : c'est l'expression consacrée; ils se développent avec une promptitude qui tient presque du prodige. Il se forme alors ce que l'on appelle les feuillages pendants ( $\mathrm{fg}$. 30 ), qui ne sont autres que des jeunes pousses avec ces feuillages déversés, et qui atteignent en un espace très court de temps une longueur très notable (parfois plus d'un mètre). Ce sont ces parties qui se teintent de jaune, de vert pâle, de rose, qui égaient d'une manière si heureuse ces forêts denses dont le feuillage a d'ordinaire des teintes d'un vert sombre. L'orientation pendante et les pigments qui se trouvent dans les

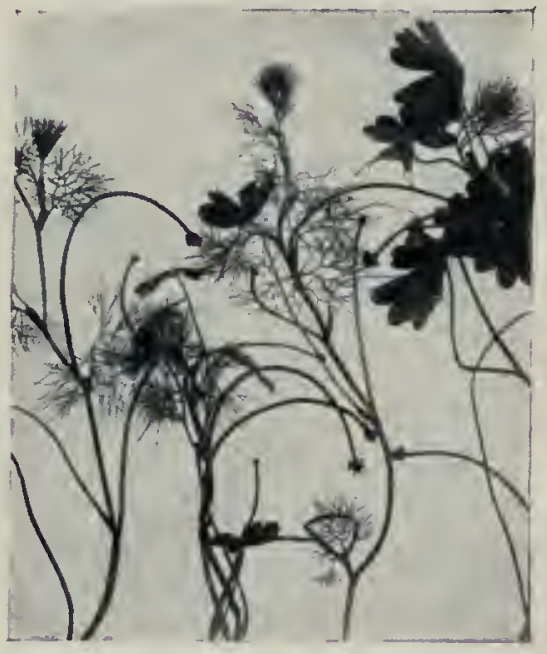

Renoncule aquatique.

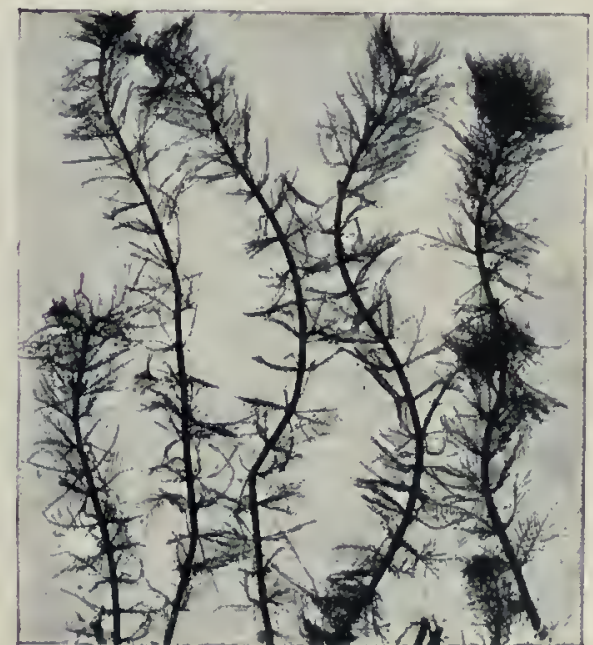

Myriophylle verticillé. 


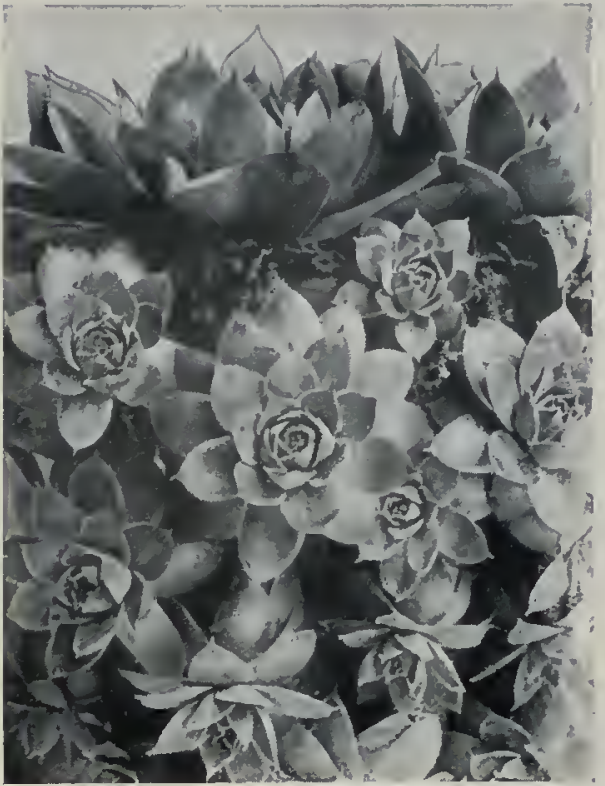

Joubarbe dcs toits.

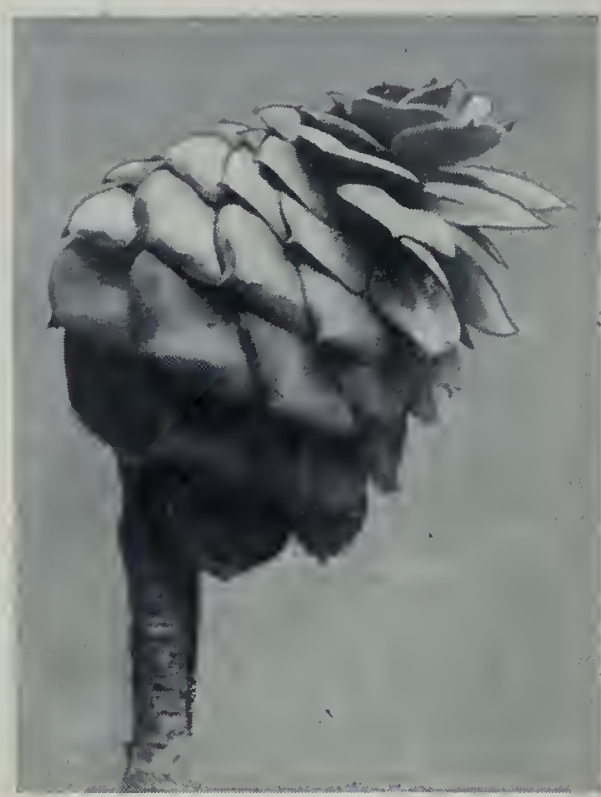

Feuitles épaisses dủ Cotyledon gibbiflora.

Dans les Myriophylles, qui sont exclusivement submergées, il ny a que des feuilles dćcoupées et rćduites à leurs nervures. Il arrive cependant que la partie supérieure des pousses sorte de l'eau; les feuilles sont alors plus épaisses, raccourcies, mais gardent toujours leur cachet aquatique.

Une autre adaptation remarquable est celle que l'on observe dans les plantes grimpantes, où l'extrémité des feuillcs peut se transformer en filaments délicats ou vrilles qui sont susceptibles de senrouler autour des objets. On voit une pareille organisation chez les Cucurbitacées, les Vesces, les Pois, etc.

L'exposition d'une plante dans une station sèche, sur un rocher dénudé, sur les tuiles d'un toit, place un végétal dans des conditions difficilcs d'existence dont il ne peut se tirer qu en usant d'artifices variés et assez. curieux. Si nous examinons une Joubarbe des toits (Sempervivum tectorum), nous voyons que la plante forme une grosse rosette de feuilles qui sont serrées les unes contre les autres et toutes épaisses, charnues, aqueuses. Grâce

feuilles servent à protéger les tissus jeunes et tendres contre l'ardeur des rayons du soleil. Quand les tissus ont pris de la consistance, le feuillage se redresse peu à peu et la teinte change.

Adaptations diverses des feuilles. - L'étude précédente nous a révélé d'une manière manifeste une accommodation évidente de la feuille au climat. Une pareille harmonisation de l'organe foliaire et du milieu extérieur s'observe partout dans la nature. La durée de la feuille étant très courte, il faut que cet organe soit, pour ainsi dire, adapté dès la première minute de son développement : c'est pourquoi la feuille est l'organe par excellence à étudier pour la connaissance de l'action des facteurs extérieurs.

Les plantes d'eau nous montrent des variations très remarquables et d'observation facile. Il suffit de se promener le long d'un cours d'eau pour remarquer les changements curieux de la Sagittaire ou Fléchière (fig. 31): les feuilles qui pointent hors de l'eau ont la forme de fèche $(C)$ supportée par un pétiole bien caractérisé, tandis que celles qui sont dans l'eau (A) ont la forme de longs et étroits rubans de très mince épaisseur, ondulant dans le milieu liquide. Entre ces deux feuilles, l'une aérienne, l'autre aquatique, il y a des feuilles amphibies ou nageantes (B), pourvues d'un pétiole, mais dont le limbe a une forme de cœur. C'est bien le milieu qui provoque ainsi la modification des feuilles, et lorsqu'une crue survient et submerge une feuille aérienne, ou bien elle meurt, si elle est trop âgée, ou bien elle s'allonge démesurément et prend une forme rubanée, ne gardant de sa structure en flèche que deux petites cornes qui se retrouvent à la base de son limbe, lequel se confond presque avec le pétiole.

On voit encore un autre exemple de transformations semblables en étudiant la Renoncule d'eau, qui a des feuilles aériennes pourvues d'un limbe plus ou moins profondément découpé, tandis que les feuilles submergées sont, au contraire, tout à fait divisées et réduites pour ainsi dire à leurs nervures. Il n'est pas rare d'observer des feuilles à limbe plongeant partiellement dans le liquide et se réduisant, par exemple, sur un bord, à leurs nervures comme dans une feuille laciniée.

Un pareil exemple est tout à fait frappant et montre bien l'action toujours manifeste des facteurs extérieurs qui altèrent pro$=0$ fondément la forme des êtres. à cette circonstance, grâce à cette disposition en gros bourgeons à demi épanouis, la plante atténue les dangers résultant de sa station sèche sur un toit exposé au soleil ardent et sur un milieu dépourvu de terre où les racines ne peuvent pas plonger profondément pour aller puiser l'humidité qui leur manque. Les feuilles se recouvrant les unes les autres, la transpiration se trouve par cela même diminuée; la plante peut donc traverser les semaines et lcs mois de sécheresse en perdant le minimum d'humidité; par contre, pendant la saison pluvieuse, les cellules charnues se gonflent d'eau et constituent une réserve de liquide importante, permettant aux feuilles de résister pendant la période suivante à une dessiccation prolongée.

11 est évident d'après cela que la carnosité des feuilles constitue un caractère d'une extrême importance pour les végétaux des pays très secs. On voit sur une des photographies l'aspect particulier que présentent certaines feuilles de plantes grasses.

Les Agaves, de même, sont des plantes mexicaines d'un très grand intérêt et d'un aspect tout à fait caractéristique qui ne réussissent, dans des régions tout à fait dépourvues d'eau, que grâce à leur rosette de grosses feuilles, extrêmement épaisses, dentées et pointues au bout. Ces dents leur sont utiles pour résister aux Ruminants et aux autres herbivores qui se jettent sur toutes les feuilles qu'ils rencontrent, comme la misère sur le monde, dans un pays où la végétation est très rare et l'alimentation difficile.

Évidemment cette question de la lutte contre les animalix acquiert dans les régions désertiques une importance capitale ; aussi les plantes à piquants s'y multiplient-elles d'une manière tout à fait extraordinaire. Ce caractère devient frappant dans les Cactées, dans les Cierges qui sont les plantes de désert par excellence. Ces végétaux sont si bien adaptés à ces stations désolées qu'ils ont supprimé complètement le limbe foliaire, organe dangereux pour des plantes qui redoutent surtout de transpirer, et la feuille n'est plus représentée que par des épines qui sont des armes puissantes contre l'attaque des ennemis.

Structure. - L'organisation intime des plantes est susceptible de révéler les mêmes adaptations que leur forme extérieure. Si

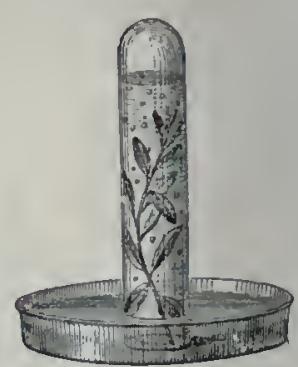

Fig. 34. - Expérience chtrant la fonction

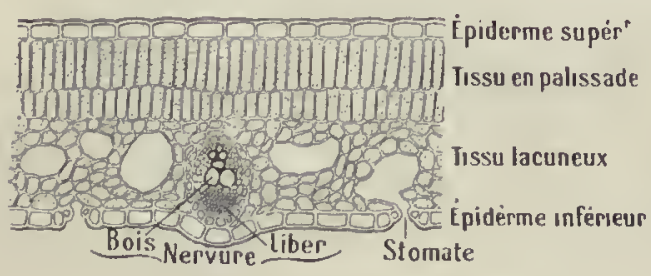

Fig. 32. - Coupe du limbe d'une feuille.
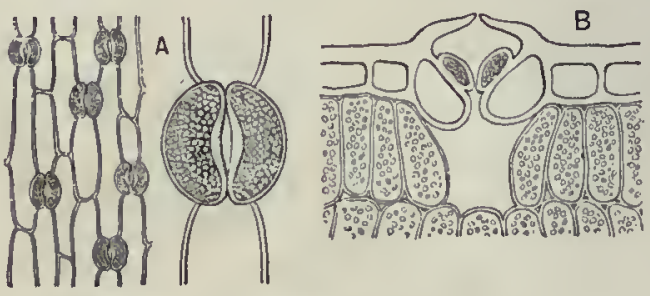

Fig. 33. - Stomates. A, vus de face; B, coupe.

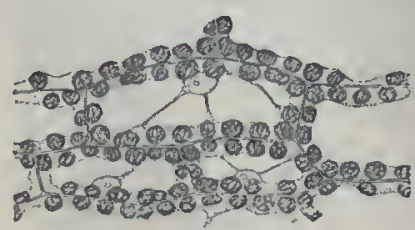

Fig. 35. - Corps chlorophylliens. (Trés grossis.) 
nous examinons l'épiderme d'une feuille aérienne, nous verrons que les cellules sont incolores, intimement liées entre elles, recouvertes par une cuticule épaisse (fig. 32 et 33); il y a cependant des orifices, appelés stomates, qui permettent les échanges gazcux entre la feuille et l'atmosphère; ce sont deux petites cellules vertes en forme de rein laissant entre elles un espace pour la sortie des gaz et de la vapeur d'eau. Dans les feuilles aériennes, les stomates sont à la partie inférieure; dans les feuilles submergées où la transpiration est abolie, ils disparaissent ; dans lesfeuilles nageantes, ils n existent qu’ à la face supérieure

Au-dessus de l'épiderme supéricur, il y a un tissu appelé palissadique, parce que les cellules sont allongées comme des palissades; elles sont bourrées de matière verte; au-dessous se trouvent des cellules laissant entre elles de grands espaces d'air qui sont en relation avec les stomates : c'est ce que l'on appelle le tissu lacuneux.

Certaines feuilles de Fougères et de Caladium sont translucides, à cause de la réduction du parenchyme à une faible épaisseur de cellules; elles ont un intérêt particulier pour l'horticulteur. Chez d'autres feuilles, la couleur verte manque complètement en plusieurs points; elles sont alors marbrées, panachées, rayées de blanc; quelquefois même il se forme, à côté des grains de chlorophylle, d'autres matières colorantes et la feuille peut prendre des teintes aussi vives qu'une fleur. C'est ce qu'on peut observer chez divers Bégonia, Crotons, Caladium, etc., à feuillage ornemental.

Dans ces tissus sont plongées les nervures qui présentent des faisceaux libéroligneux; les faisceaux ligneux apportent la sève venant des racines et de la tige, et les faisceaux libériens remportent la sève élaborée par les feuilles.

C'est, en effet, dans les feuilles que se passent les fonctions essentielles de la nutrition de la plante: fonction chlorophyllienne, transpiration, et aussi respiration; cette dernic̀re existe partout.

Physiologie de la feuille. - La physiologie principale de la feuille résulte de sa couleur, qui est verte et liée à la présence du pigment que l'on appelle la chlorophylle (fig. 35). Si lon cherche à dissoudre dans l'alcool cette matière colorante, en desséchant des feuilles à l'étuve, on voit que le dissolvant se colore en vert intense et, en ajoutant de la benzine au liquide, on voit se séparer deux liquides : l'un jaune à la partie inférieure, l'autre vert intense à la partie supérieure; le premier contient la xanthophylle, le second la chlorophylle. La xanthophylle est la matière jaune qui colore les feuilles des plantes poussées à linbscurité; en exposant ces plantes à la lumière, on voit rapidement, même à un éclairement faible, la teinte se modifier et la nuance verte apparaître. Ainsi le verdissement est, en général, le résultat de l'action de la lumière. Il y a cependant quelques plantes, en petit nombre, qui peuvent verdir à l'obscurité, comme les Fougères, etc. La chlorophylle une fois constituée dans la plante, la lumière a une action merveilleuse.

C'est grâce à la radiaticn solaire, en effet, que l'anhydride carbonique qui se trouve en petite quantité dans l'air est décomposé, l'oxygène mis en liberté et le carbone fixé. Si l'on met donc une
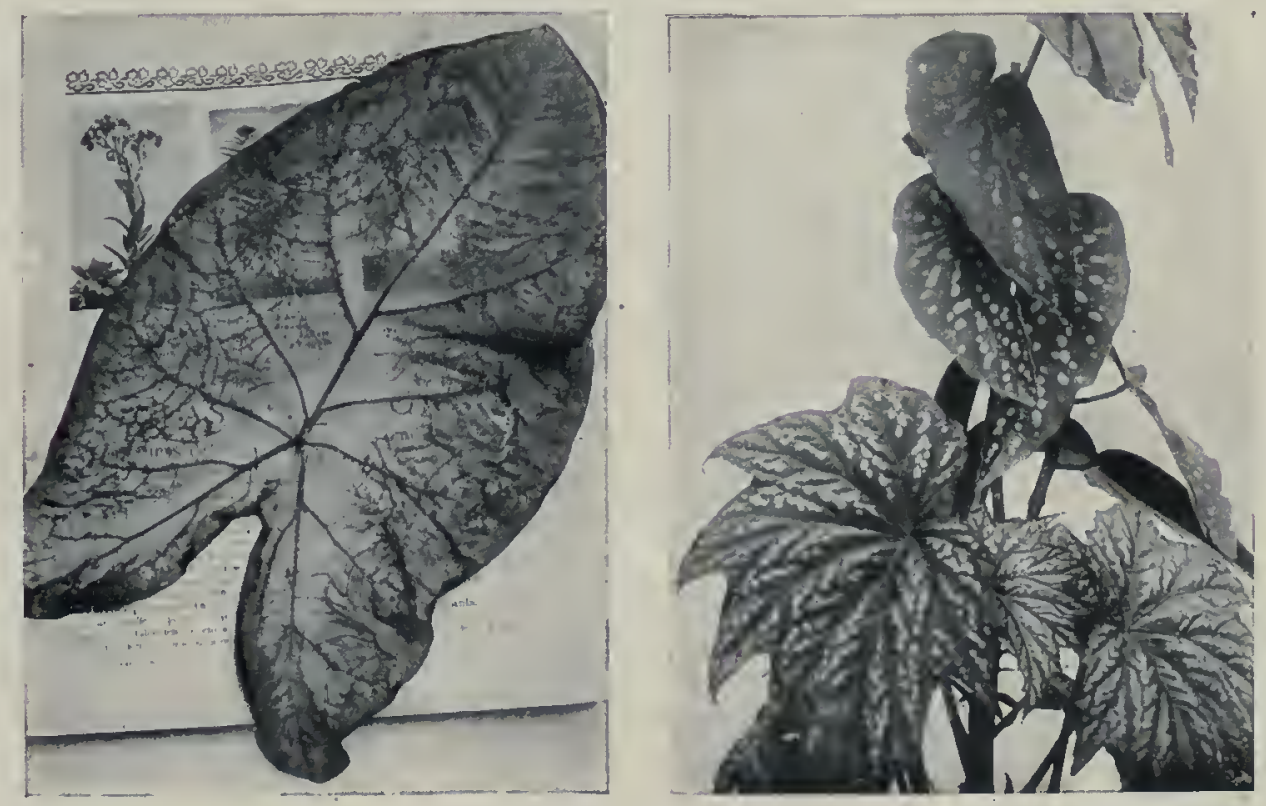

Feuilte transtucide d'un Caladium. plante sous une éprouvette (fig. 34) contenant de l'eau de Seltz (saturée de gaz carbonique), on voit des bulles gazeuses se rassembler peu à peu à la partie supérieure de l'éprouvette, quand la plante est exposée au soleil, et l'on constate que le gaz est de l'oxygène pur. Le célèbre physio!ogiste Priestley a donné à cette expérience une forme saisissante. Il introduisait sous une cloche un animal, une souris; au bout de peu d'heures, par suite de la respiration de l'animal, l'air est vicié et si on y introduit une bougic enflammée elle s'y éteint. Vient-on à mettre sous la cloche une souris et une plante, on constate que l'air ne s'altère pas et la bougie, introduite au bout d'un certain temps, y brûle avec le plus vif éclat. L'air vicié par l'animal a été purifié par les feuilles et régénéré par elles.

La fonction chlorophyllienne est donc la fonction capitale des feuilles. Elle est d'ailleurs liée à une série d'autres actes essentiels de la nutrition du végétal dont il nous faut maintenant parler; mais remarquons avant le caractère mystérieux et merveilleux de la chlorophylle qui capte l'énergie solaire. Quand on étudie le spectre de cette substance, on y voit des bandes d'absorption; or ce sont justement ces rayons absorbés qui disloquent le gaz carbonique. 


\section{NUTRITION DU VÉGÉTAL}

Transpiration. Respiration. - La feuille a une autre fonction capitale, qui est la transpiration. Un Maïs étiolé, placé à la lumière, transpire deux fois plus qu'à l'obscurité, tandis que, si la chlorophylle a fait son apparition dans les feuilles, la transpiration à la lumière peut être cent-fois plus grande qu'à l'obscurité.

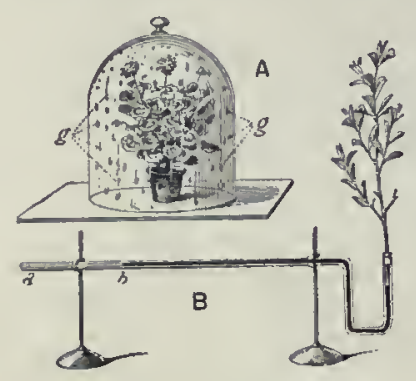

Fig. 36. - Transpiration.

A, cloche avec plante: g g, gouttes d'eau; $B$, mesure de ta lranspiration : l'eau, en $a$ au début, n'arrive plus qu'én $b$ au bout d'un moment. quantité de vapeur d'eau. Les différences qui existent entre le Maïs vert et le Maìs étiolé ne tiennent pas à la chlorophylle. En opérant sur des feuilles panachées ou décolorées en pleine lumière, on voit qu'elles transpirent exactement comme des feuilles vertes, parce que leurs membranes ont la même sensibilité vis-à-vis de la lumière et de la température. Les membranes d'une feuille étiolée ont une perméabilité beaucoup moindre.

L'intensité de la transpiration croît avec la chaleur, la sécheresse de l'air et son agitation (fig. 36). Elle a lieu surtout par les stomates, c'est-à-dire qu'elle est beaucoup plus abondante par la face inférieure des feuilles que par la face supérieure. Pendant la nuit, l'eau en excès peut s'échapper de la plante sous forme de se produit alors, non par les stomates ordinaires, mais par des orifices spéciaux, les stomates aquifères (fig. 37).

Le grand rôle de la feuille se manifeste autrement et a un retentissement lointain sur tous les autres organes. Cette transpiration intense qui a lieu dans les feuilles entraîne un certain nombre de conséquences.

La quantité d'eau rejetée par les feuilles dans l'air est considérable : on a calculé qu'un Chêne, en une période végétative, déversait dans l'atmosphère plus de 100000 kilogrammes d'eau. C'est donc un phénomène d'une extrême intensité. Il faut que l'eau, à mesure qu'elle est volatilisée au dehors, soit fournie à nouveau à la feuille pour une vaporisation ultérieure : la transpiration détermine donc un appel intense de liquide et c'est une cause de l'ascension de la sève dans les tiges. Par suite des lois de l'osmose, nous avons vu précédemmeṇt que la sève montait dans les racines et commençait cellules. A la lumière, les parois laissent passer une plus grande gouttelettes prises, à tort, pour de la rosée. Cette sortie de l'eau

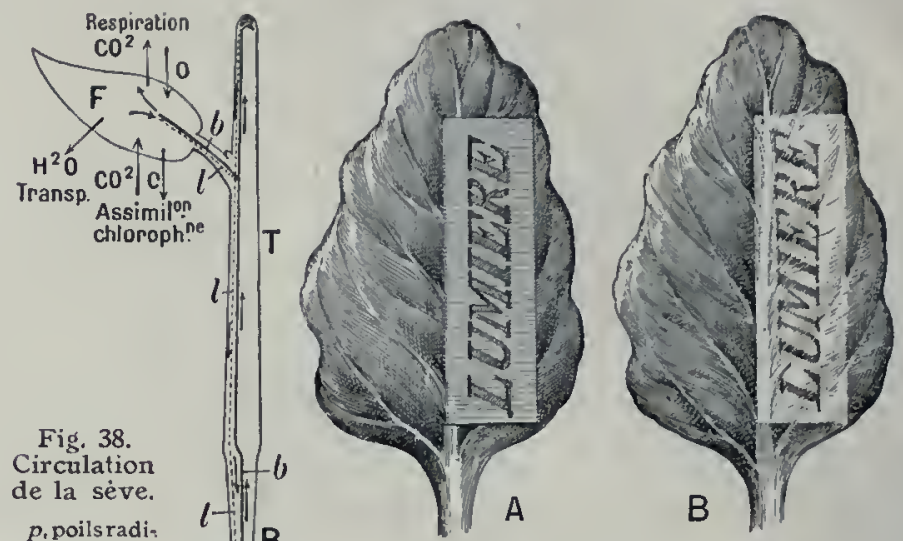

A, recouverte d'une feuille d'ètain ; $B$, la même, traitée par l'iode.
Fig. 39. - Feuille de Betterave.

à s'élever dans la tige, mais jamais cette poussée osmotique ne serait suffisante pour élever le liquide jusqu'en haut d'un grand arbre; c'est alors qu'intervient cet appel puissant, résultant de la transpiration des feuilles, qui achève cette ascension.

Une autre fonction non moins importante de la feuille est la respiration; elle respire activement comme la racine et la tige. Chez les plantes vertes, la respiration, qui consiste en une absorption d'oxygène et un dégagement de gaz carbonique, est masquée le jour par la fonction chlorophyllienne, beaucoup plus intense, qui dégage de l'oxygène et absorbe l'anhydride carbonique. Pendant la nuit, au contraire, la respiration existe seule et, en espace clos, les plantes, comme les animaux, vicient l'air.

Formation de la sève élaborée. - Dans les feuilles, la sève, essentiellement aqueuse, se trouve

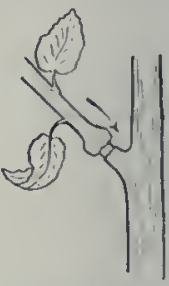

Fig. 40. Bourrelet formé la sẹve élaborée. par l'arrêt de profondément modifiée grâce à la fonction chlorophyllienne (fig. 38). Nous avons dit que l'anhydride carbonique était décomposé et que tout se passait comme si le carbone était fixé et l'oxygène mis en liberté. En réalité, les choses ne se passent pas ainsi; le carbone n'est pas mis en liberté, mais il rencontre la sève qui est très aqueuse et il se combine à l'eau de façon à faire des hydrates de carbone : glucose, sucre, amidon, cellulose.

On peut mettre en évidence ce résultat d'une manière saisissante. On recouvre une feuille d'une lame d'ćtain qui a été entaillée de façon à découper les lettres du mot "lumière " (fig. 39). On expose alors cette feuille sortant de l'obscurité au soleil; au bout d'un certain temps, on enlève la lame d'étain, on traite par l'alcool pour dissoudre la matière verte, puis on fait agir l'iode; on voit alors apparaître sur le fond décoloré de la feuille les lettres du mot "lumière " qui sont teintées en bleu intense. C'est que partout où la lumière a agi, il s'est lormé de l'amidon dans les grains de chlorophylle et cet amidon a été teinté

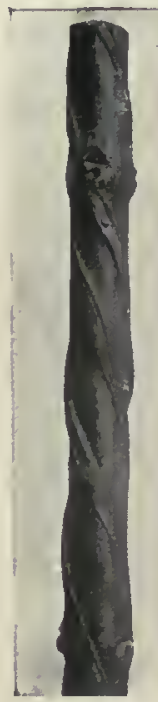

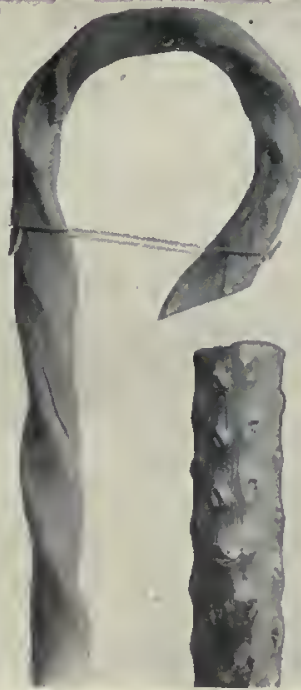
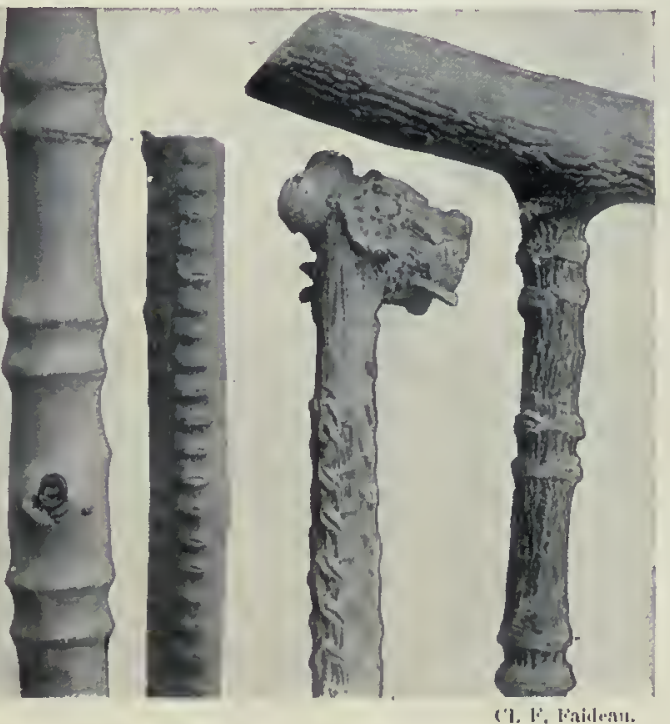
en bleu par l'iode.

Les traumatismes et la nutrition. - La sève élaborée circule dans les tubes criblés du liber. Si on enlève sur une branche d'arbre un anneau d'écorce jusqu'au cambium, on voit, après la cicatrisation, se former un bourrelet au-dessus de l'anneau (fig. 40 ); le sectionnement des tubes criblés a donc arrêté le passage de la sève élaboréc. Lorsqu'une liàne de Chèvrefeuille s'enroule" autour d'une jeune branche, elle agit de même et il se forme sur la branche, véritablement étranglée, un bourrelet hélicoïdal.

Cette propriété a été utilisée dans la curieuse culture des arbres et arbustes pour cannes, à Maule (Seine-et-Oise). Lornementation que portera la future canne est faite sur la jeune tige en végétation, à l'aide de fers spéciaux, de molettes, que l'on fait glisser sur toute la longueur de l'écorce. Il y a arrêt de la sève élaborée et prolifération des tissus aux points blessés; il se lorme un 


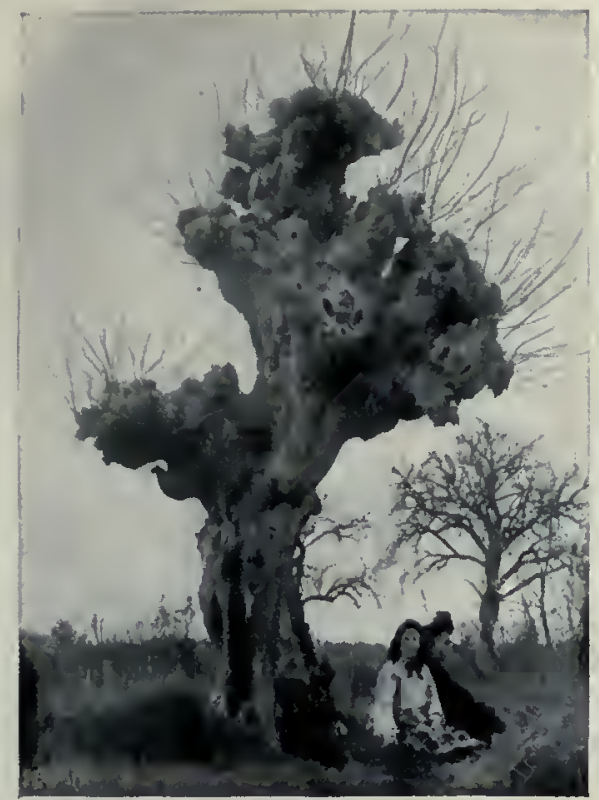

Vieil Orme taillé en têtard.

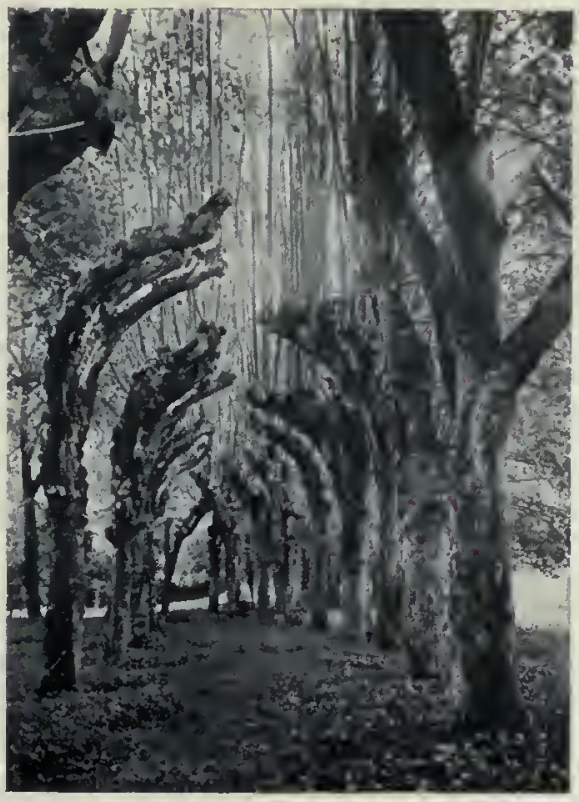

Tilleuls taillés en berceau.

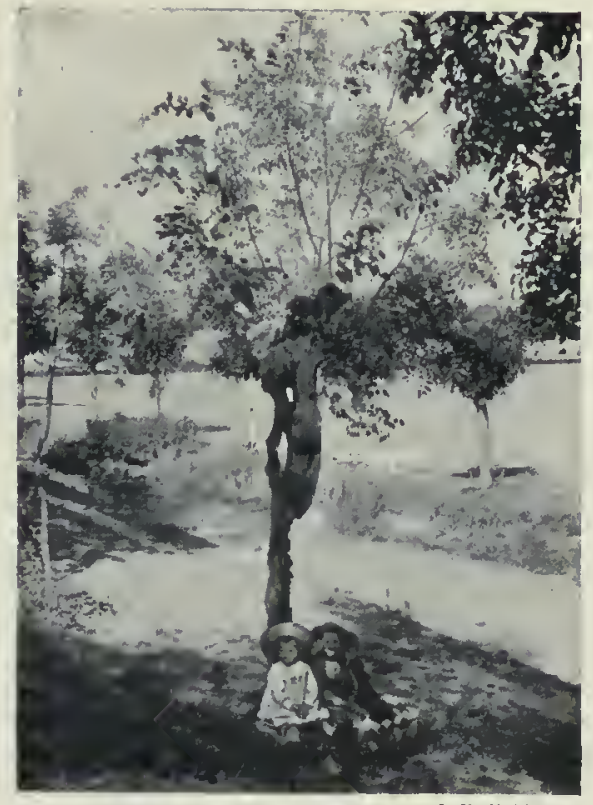

Cl. F. Wailean. bourrelet inflammatoire qui grave de façon indélébile l'ornementation choisie.

Beaucoup d'arbres sont exploités pour la production en bois de chauffage. On coupe toutes les branches par périodes régulières, sans toucher au tronc. C'est ce qu'on appelle exploiter en têtard, parce que la sève, montant toujours au même point du tronc, amène la formation d'une sorte de tête. La taille régulière des arbres d'une allée en vue de la formation d'un berceau conduit à des rćsultats analogues. Ces blessures périodiques produisent des tumeurs, le bois se pourrit et le tronc peut arriver à se réduire à une écorce, ainsi qu'on peut le voir sur l'une de nos gravures. Cette décrépitude du tronc n'empêche pas l'arbre de se couvrir de feuilles, car la sève circule dans une région voisine de l'écorce.

Les broussins, énormes tumeurs que l'on voit sur certains arbres, sont dus aussi à un arrêt provoqué par une série d'irritations, de blessures, un élagage trop sévère des bourgeons de base, ouvrant la porte à l'invasion des tissus ligneux par des Champignons inférieurs ou par des microbes.

\section{MULTIPLICATION VÉGÉTATIVE}

La feuille a des fonctions essentielles pour la plante, au point de vue de la reproduction, car les fleurs ne sont autre chose que des feuilles transformées. Mais avant d'aborder l'étude de ces organes fondamentaux, nous pouvons examiner le cas, plus simple, où la feuille s'essaye, pour ainsi dire, dans ce rôle nouveau qui lui incombe et parvient à multiplier le végétal. Si l'on examine les feuilles de certaines Fougères, par exemple celle de la curieuse Asplénie bulbifère, on voit d'abord une sorte de bouton y apparaître, qui donne naissance à un bourgeon d'où l'on voit sortir quelques jeunes feuilles et des racines, de sorte qu'une plantule naît sur la plante mère. Quand le développement est arrivé à cet état, on peut enlever cette jeune Fougère et la planter; au bout de peu de temps, on la voit prospérer et donner naissance à une Fougère nouvelle. Une autre espèce, l'Aspidium cicutaire, variété gemmifère, forme sur sa nervure principale des bulbilles capables de multiplier la plante. Dans l'inflorescence de l'Ail des vignes, les fleurs sont souvent remplacées par des bulbilles qui, lorsque l'année est humide, se développent sur la plante même, donnent une tige très apparente et senracinent rapidement, lorsqu'elles tombent sur le sol.

Bouturage. - Cette remarque conduit à la découverte du bouturage. Une bouture est un fragment de tige que l'on coupe, en ayant soin qu'il possède au moins un bourgeon; en plantant en terre ce tronçon du végétal, des racines adventives ne tardent pas à naítre au voisinage du point où la section a été opérée, et lorsque la nutrition est ćtablie grâce à elles, le bourgeon s accroît, étale ses feuilles, la tige grandit, se ramifie, donne de nouveaux bourgeons, puis bientôt des fleurs. C'est ainsi que l'on bouture les Pélargonium, qui jouent un rôle si important dans la confection des corbeilles dans tous les jardins. Tous les "Pelargo " ou Géranium des jardiniers sont dérivés de deux plantes du Cap, le Pelargonium inquinans et le Pelargonium zonale; on a obtenu par croisements des variétés extrêmement riches de formes, se distinguant par le feuillage, par le coloris des fleurs, par la rusticité, par le port, etc. Une fois ces variétés produites, on est certain de lés maintenir, grâce à la propriété qu elles ont de se bouturer. La bouture, en effet, donne une plante absolument identique à celle sur

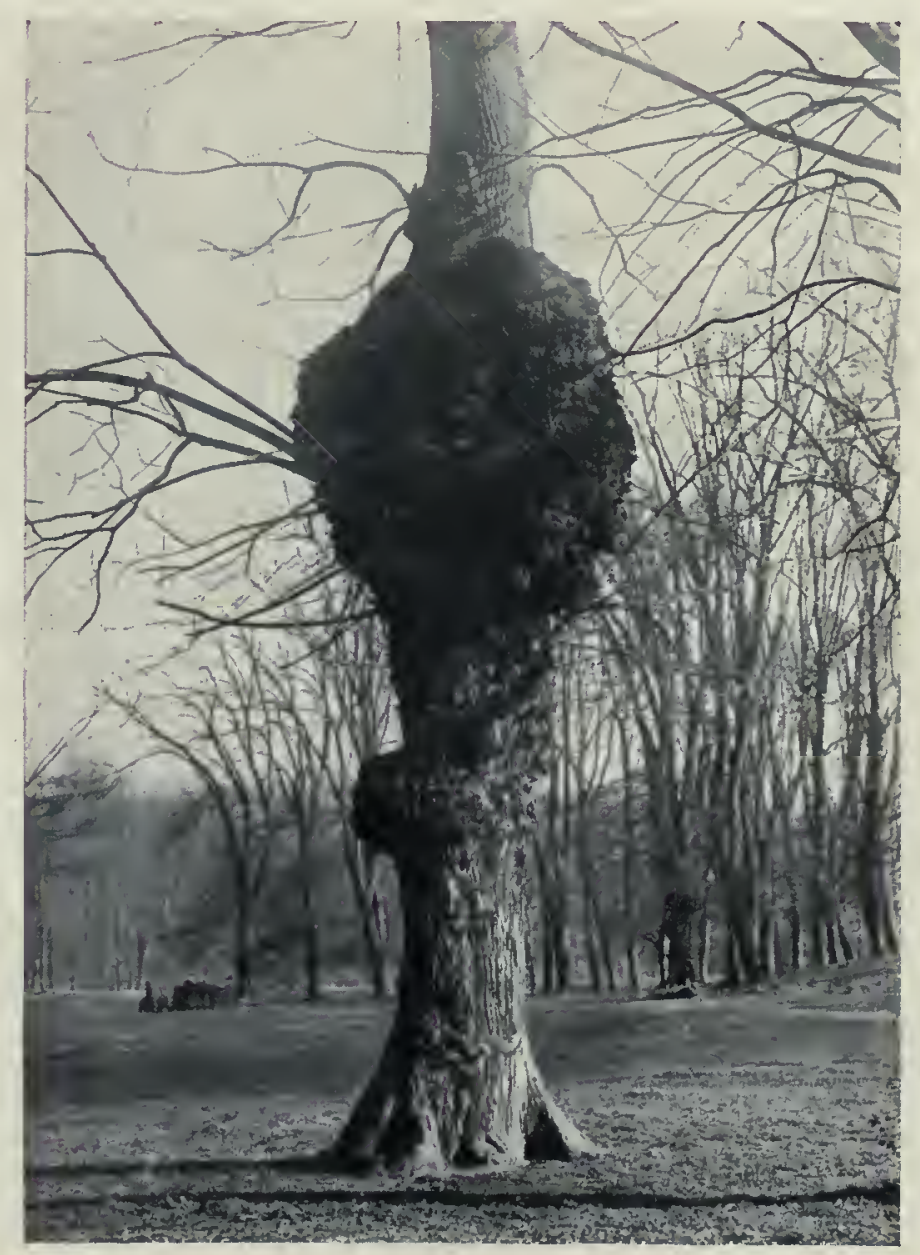

Orine portant un énorme broussiu. 


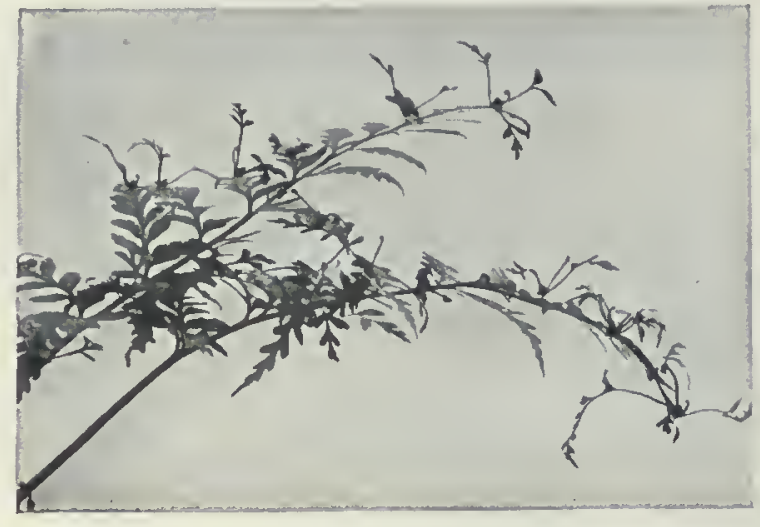

Asplénie bulbifere, avec bulbilles.

laquelle on vient de la couper, de sorte que, grâce à cette méthode simple, on conserve indéfiniment, avec une constance parfaite, une variation souvent très faible, très délicate : un léger changement de nuance, une faible modification du feuillage. C'est sur cette propriété qu'est fondée presque toute l'horticulture.

On conçoit - que pour.-la propagation des espèces aussi, cette particularité du bouturage soit également capitale. On découvre, dans un pays lointain, une espèce dont les propriétés intéressent l'agriculteur ou le commerçant, ou l'industriel. Si elle se bouture, on la coupe en tronçons et on la propage avec une extrême rapidité, sans attendre qu'elle donne des graines. Il y a, d'ailleurs, un autre cas où cette propriété est essentielle : c’est celui, par exemple, de la culture en serre. Supposons qu' on y cultive une espèce venant de terres exotiques, où des voyageurs intrépides ont été la chercher au péril de leur vie. La germination de ces graines a réussi et des plantes ont été obtenues. Mais la culture dans nos serres ne réalise pas toujours les conditions de la patrie d'origine des plantes, et la floraison, bien souvent, ne s'y produit pas ou ne s'y produit que très tardivement au bout d'un nombre parfois considérable d'années; d'ailleurs, même quand la floraison a lieu, les graines ne se forment pas toujours, de sorte que la propagation ne peut se faire que par bouturage. On connaît un certain nombre de plantes pour lesquelles le bouturage entraîne des variations de bourgeons.

Il y a un autre procédé de multiplication, l'éclatage, qui n'est, en fait, qu'une modification de celui-là s'appliquant surtout aux espèces herbacées qui sont pourvues d'une tige souterraine ou d'un rhizome : on sectionne la plante avant le départ de la végétation et, au lieu d'un pied, on peut en obtenir plusieurs.

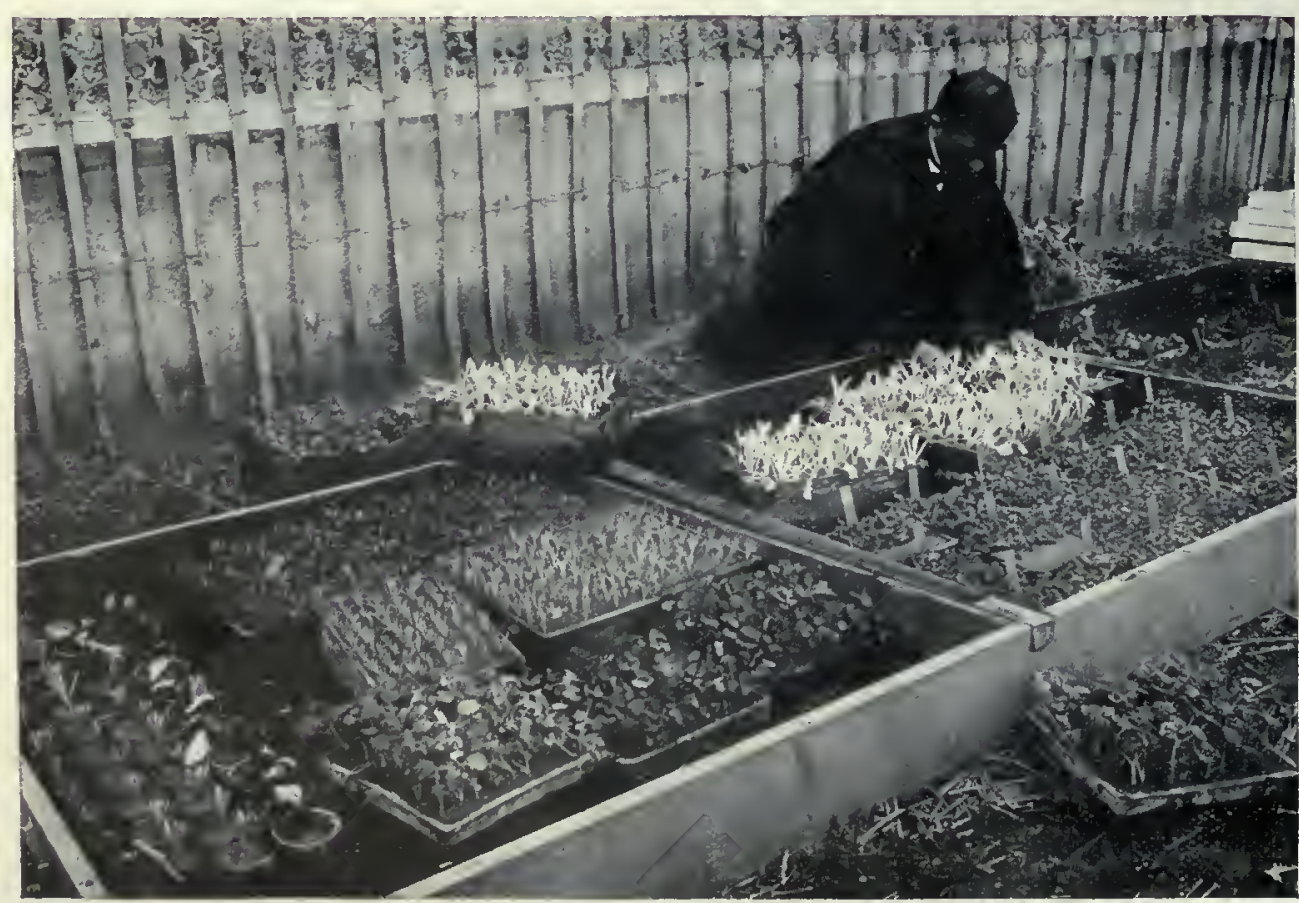

Jardinier soignant des boutures de variétés nouvelles non encore grainées.
Cl. J. Lojer.

Marcottage. - Parfois le bouturage ne réussit pas pour certaines espèces, et il faut employer d'autres artifices. La nature nous. apprend qu'il y. a d'autres méthodes de propagation des plantes, notamment le marcottage. Le Fraisier nous offre un exemple de marcottage naturel. La plante émet à la surface du sol des drageons ou coulants qui sont de minces tiges rampantes aériennes et dépourvues de feuilles à l'extrémité; elles s'enracinent à leur pointe, et, lorsque les racines adventives sont produites, le bourgeon se développe et donne une rosette de feuilles, puis bientôt des tiges dressées avec fleurs; c'est-à-dire qu'un nouveau plant de Fraisier est constitué ; il émettra de nouveaux coulants et propagera ainsi le Fraisier à la surface du champ de culture. Chacun de ces plants pourra s"isoler et se comporter comme un être distinct : en réalité, toute la surface envahie par la plante est couverte par un seul individu. Il est des cas où la notion d"individualité semble encore plus bizarre à comprendre : tous les Peupliers d'I talie cultivés sur d'immenses territoires, sur toute la France, par exemple, appartiennent à un seul et même individu, car on ne connaît qu'un sexe pour cette plante et jamais il ne s'y forme de graines, le bouturage étant le seul moyen de multiplication de cette espèce, au moins dans notre pays.

L'exemple du Fraisier a conduit le cultivateur à une méthode artificielle de multiplication, celle du marcottage (fig. 4l et 42). Quand le bouturage est difficile ou impossible, le jardinier entoure une branche de mousse, puis d'un pot contenant un peu de terre, de manière à provoquer la sortie de racines. Parfois encore, il infléchit la branche, de manière à l'obliger à s'enraciner, comme dans le cas de la Ronce. Si cet enracinement a eu lieu et sil voit la partie terminale du rameau pousser avec vigueur, il peut sevrer peu à peu la branche de sa sève primitive en entaillant progressivement la tige au-dessous du point où la marcotte a réussi. Lorsque la section est complète, on a une pousse qui semble être un individu nouveau, bien qu'en réalité ce soit la même plante qui continue à s'accroître.

Greffage. - Il existe un autre procédé qui permet la conservation des variétés et des boutures quand l'enracinement direct ne donne pas de résultat : c'est celui du greffage ( $f$ ig. 43 et 44). On coupe une bouture d'une variété très intéressante à conserver et on entaille la partie inféricure de la tige en biseau, de manière à pouvoir l'en- 


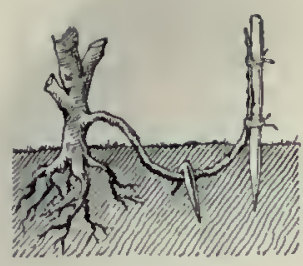

Fig. 41.

Marcotte simple.

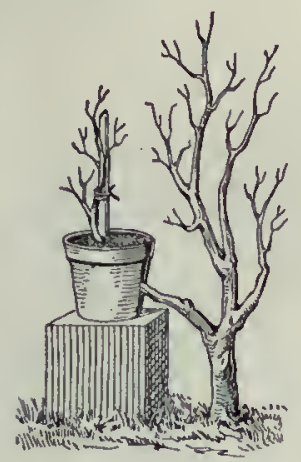

Fig. 42.

Marcotte en l'air.

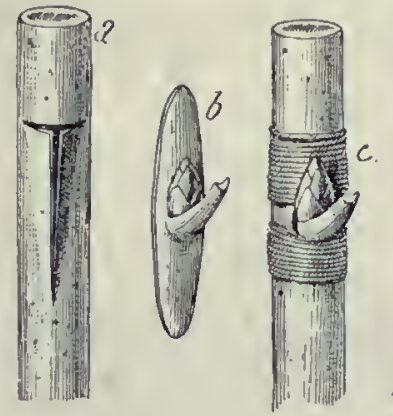

Fig. 43. - Greffe en écusson. $a$, sujet préparé ; $b$, écusson; $c$, greffe terminée.

foncer dans une tige d'une plante de même espèce, mais appartenant à une variété moins précieuse et de culture plus facile. Le tronc, dans ce dernier cas, a été sectionné transversalement, puis entaillé en long, de manière à ce qu'une fente s'y observe, dans laquelle on enfoncera le biseau précédent de la bouture. Une föis que les bois des deux plantes sont. en contact, que les assises génératrices sont en face l'une de l'autre, on ligature soigneusement l'ensemble des deux tiges et on recouvre les blessures d'un produit goudronneux, de manière à les empêcher de s'altérer. Au bout de peu de temps, la soudure s"établit entre les deux plantes, et la bouture supérieure ou greffon ne tarde pas à être complètement nourrie par le courant de sève qui vient du sujet ou tige inférieure.

On a pu réaliser différents types de greffe. La greffe par approche consiste à rapprocher deux plantes enracinées l'une de l'autre, après avoir fait des entailles dans leurs tiges en les liant ensemble. Lorsque la soudure entre les tissus est opérée, on coupe peu à peu la partie inférieure de la plante qui doit être le greffon, de manière à les priver peu à peu de communication avec le sol. Par ce moyen, on obtient à Maule, sur les arbustes cultivés en vue de la fabrication des manches d'ombrelles, des articles de fantaisie en forme d'anneau compliqué, de poignée de sabre, etc. La greffe par approche se produit souvent naturellement en forêt entre branches voisines. Citons encore les modes de greffage en fente, en écusson, en couronne, sur racine, etc.

Procédés divers. - Dans les plantes aquatiques, il est un autre moyen de propagation assez spécial qui mérite une mention. On l'observe notamment dans les Hydrocharis. Il s'y produit des bourgeons qui se sectionnent naturellement à leur base, puis se

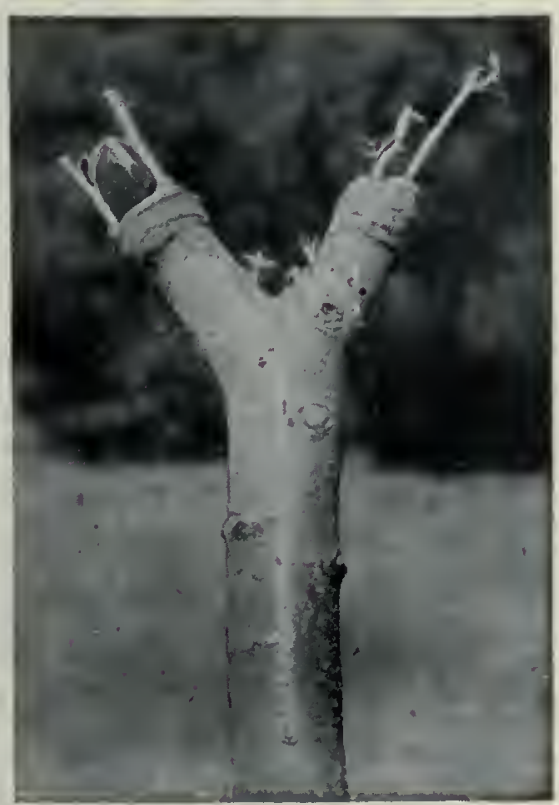

Greffe en fente du Pommier. détachent et tombent au fond de l'eau. Là, ils senracinent et ne tardent pas à reproduire la plante. On désigne sous le nom d'hibernacles ces bourgeons ainsi individualisés.

Dans les Cryptogames, en particulier

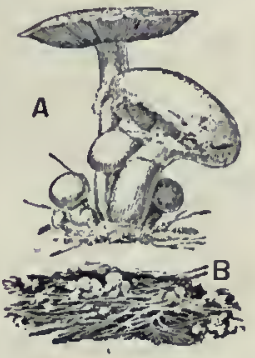

Fig. 45.

A. Champignon de conche: B. Mycélium ou blanc de champignon. dans les Muscinées et, principalement, dans les Hépatiques, il se forme ce que l'on appelle des propagules, qui apparaissent parfois dans des espèces de corbeilles qui se montrent à la surface du thalle. Ce sont de petits massifs cellulaires, arrondis ou ovoïdes, parfois pédicellés, qui sont souvent rapprochés en grand nombre.

Enfin, dans les Champignons, l'appareil végétatif est formé par de fins filaments: on le désigne sous le nom de mycélium. (fig. 45). Dans le cas du Champignon de couche, ce mycèle se propage dans le sol ou dans le fumier et, au bout d'un certain temps d'incubation, on y voit se former des agglomérations de filaments plus denses, arrondis, qui deviennent des fructifications, c'est-à-dire les chapeaux que tout le monde connaît et

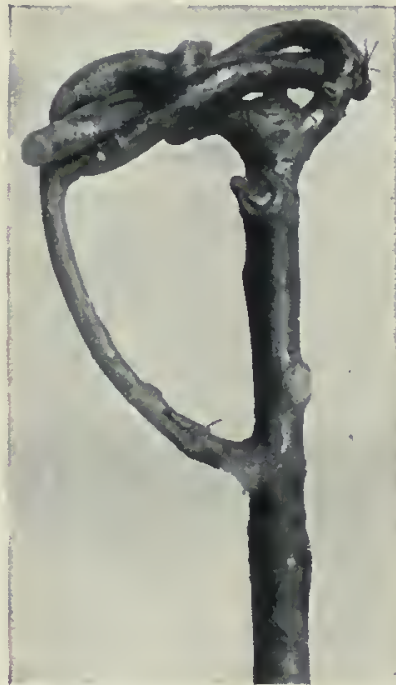

Bois de canne avec nceuds qui ont èté soudès sur le vif. qui constituent la partie alimentaire. Si l'on vient à enlevèr le mycélium un peu avant la formation des fructifications, on a ce que l'on appelle le " blanc de champignon ", qui sert à ensemencer les meules sur lesquelles on cultive le Psalliote champêtre. C'est par cette méthode qu'on se procure du blanc qualifié de vierge (rencontré dans les prairies, dans les tas de boue des routes, etc.) parce qu'il n'a pas été encore cultivé dans les carrières aù sont installées les immenses cultures de cette espèce, aux environs immédiats de Paris. En outre de ce blanc vierge, les cultivateurs utilisent le blanc levé sur fumier en cave fraîche et froide, ou bien ils se servent plutôt du blanc fabriqué en meule en plein air par les maraîchers l'hiver. L'avantage de cette méthode de propagation du blanc est d'éviter les maladies de toute nature qui pullulent dans le blanc cultivé en carrière.

Ce blanc est malheureusement rare, et les fraudeurs trompent souvent le champignonniste avec ce produit. On sait fabriquer du blanc vierge stérilisé très fécond, obtenu par les méthodes pastoriennes.

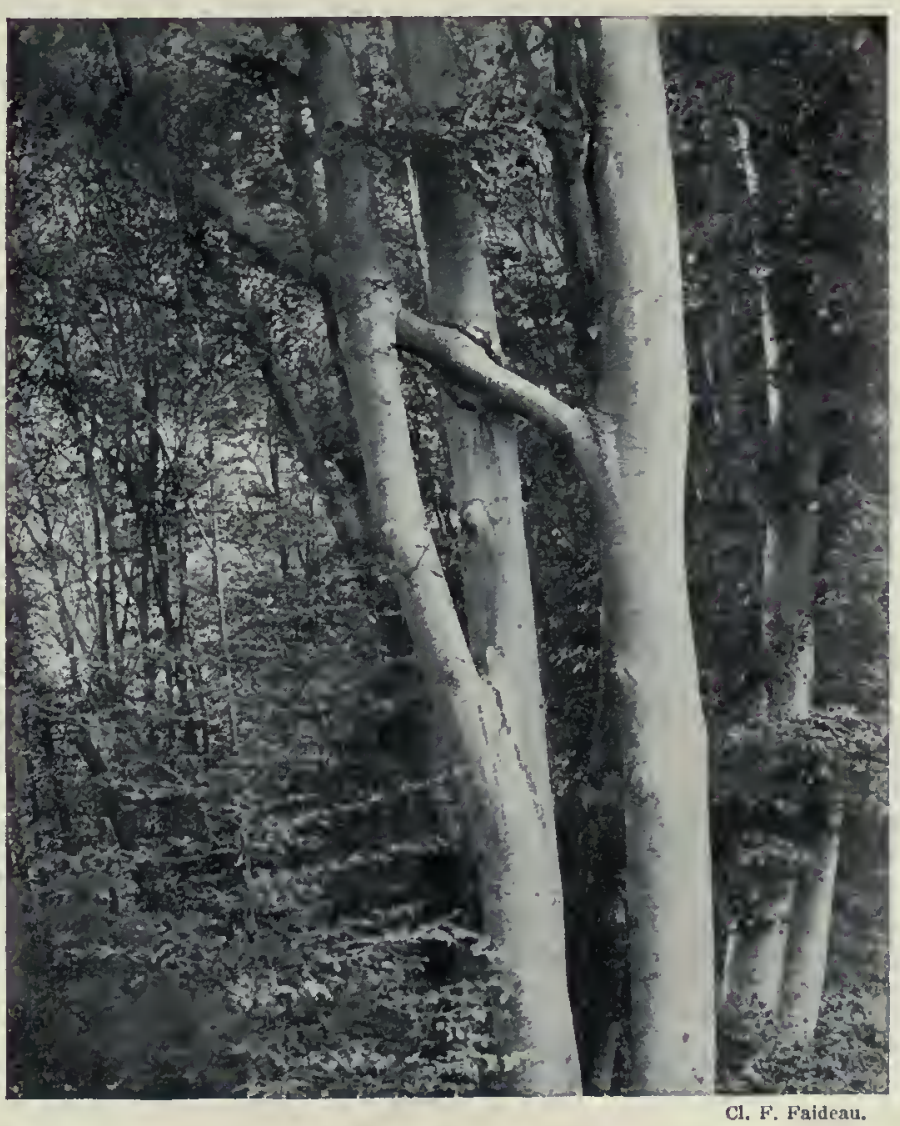

Greffe naturelte par approche entre deux branches de Hétre. 


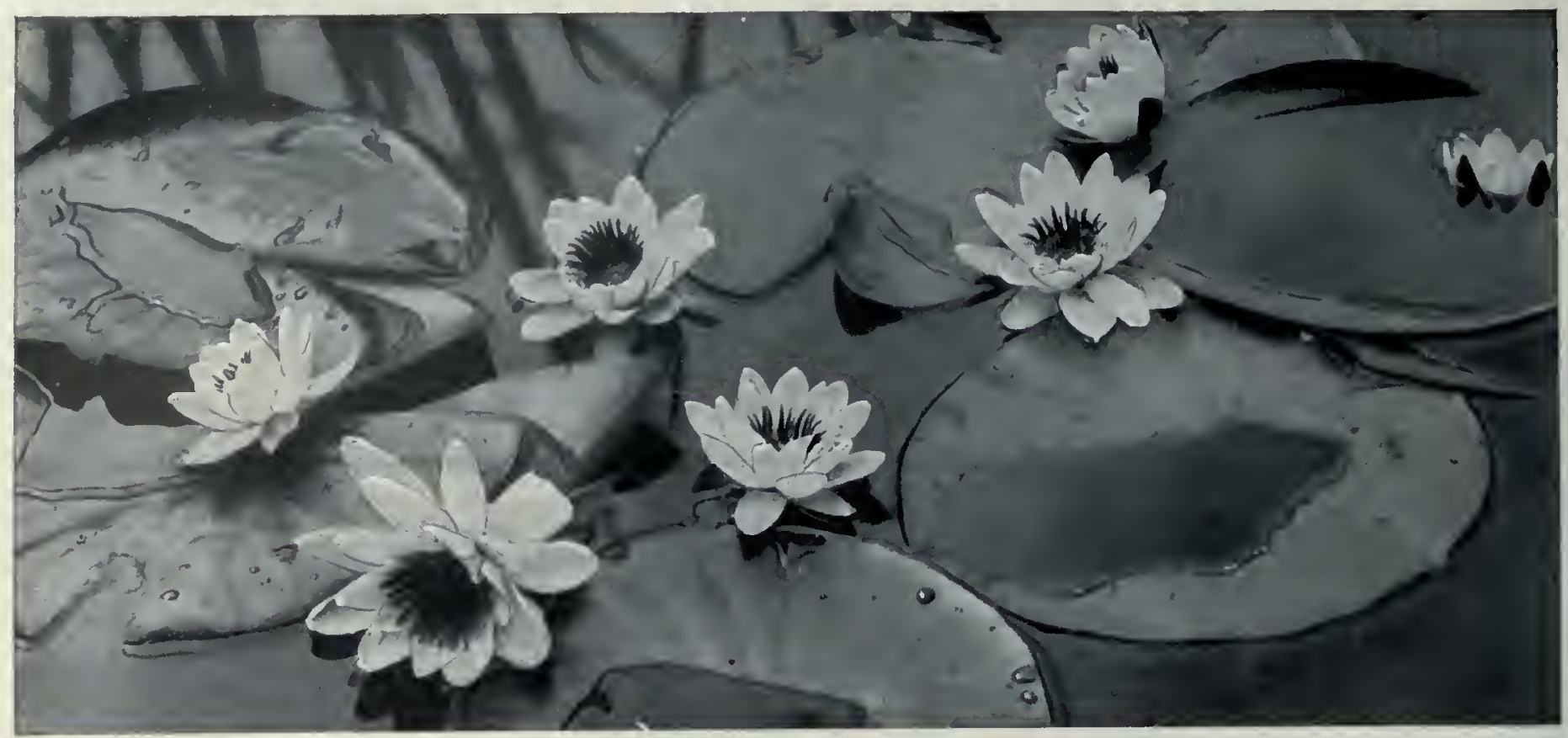

Nymphaea alba ou Nénuphar btanc des ètangs.

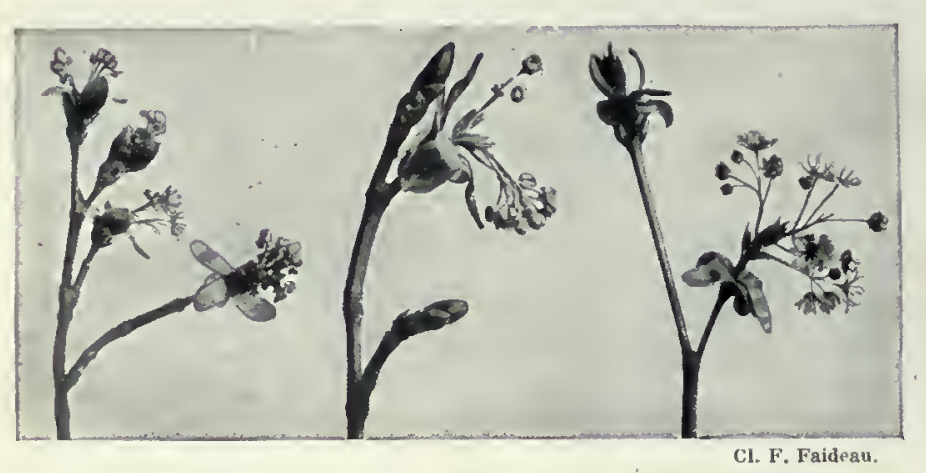

Epanouissement de l'inftorescence de l'Érable plane.

\section{LA FLEUR}

La formation des organes nommés fleurs vers l'extrémité des tiges est un phénomène de la plus haute importance, qui exige de la plante une dépense d'énergie vitale considérable; pour arriver à ce but, la plante utilise les matériaux qui préexistent en elle; elle transforme ou, pour mieux dire, elle métamorphose ses tiges et ses feuilles. La métamorphose des feuilles en organes floraux est une théorie des plus belles et des plus fécondes imaginée par le poète allemand Gœethe. Elle se relie d'ailleurs à la théorie plus vaste et plus générale de l'évolution, dont ce grand écrivain est un des précurseurs. En même temps que les feuilles se modifient, les tiges subissent des changements dans leurs groupements, dans leurs ramifications : ce sont ces agencements particuliers des tiges au voisinage des fleurs qui constituent les inflorescences.

Inflorescences. - Le principe assez général qui domine l'histoire des groupements floraux est le suivant: une tige qui a produit une fleur à son extrémité a d'ordinaire épuisé sa réserve de forces vitales pour l'édification de la fleur et ne peut plus s'accroître. De cette remarque, il résulte deux sortes d'inflorescences (fig. 46) : les inflorescences définies ou cymes et les inflorescences indéfinies ou grappes. Les premières ont leur tige terminée par une fleur et la croissance est arrêtée par cela même sur le rameau principal; elle ne peut reprendre que sur les rameaux secondaires; mais sur ceux-ci le même arrêt se produit s'il y a une fleur à l'extrémité, et le développement ne renaît que sur des rameaux tertiaires, etc. On peut avoir ainsi des cymes unipares, bipares, tripares, suivant qu'il y a chaque fois une, deux, trois branches secondaires nouvelles de remplacement. Les cymes unipares peuvent avoir leurs ramifications toutes du même côté; l'enroulement alors se produit en spirale à l'extrémité et l'on dit qu'on a une cyme en queue de scorpion ou cyme scorpioïde.
Les inflorescences indéfinies ou grappes sont également très répandues. Comme il n'y a pas de fleur à l'extrémité du pédoncule principal, il continue à croître pendant toute la période florale ; il se produit sur sa longueur des branches ou pédicelles qui étant, au contraire, terminées par des fleurs, sarrêtent rapidement dans leur allongement. C'est là le type de la grappe proprement dite (Lis à grande fleur, Groseillier). Mais cette inflorescence est susceptible de nombreuses variations. Les pédicelles latéraux secondaires peuvent s'allonger inégalement, ceux du bas
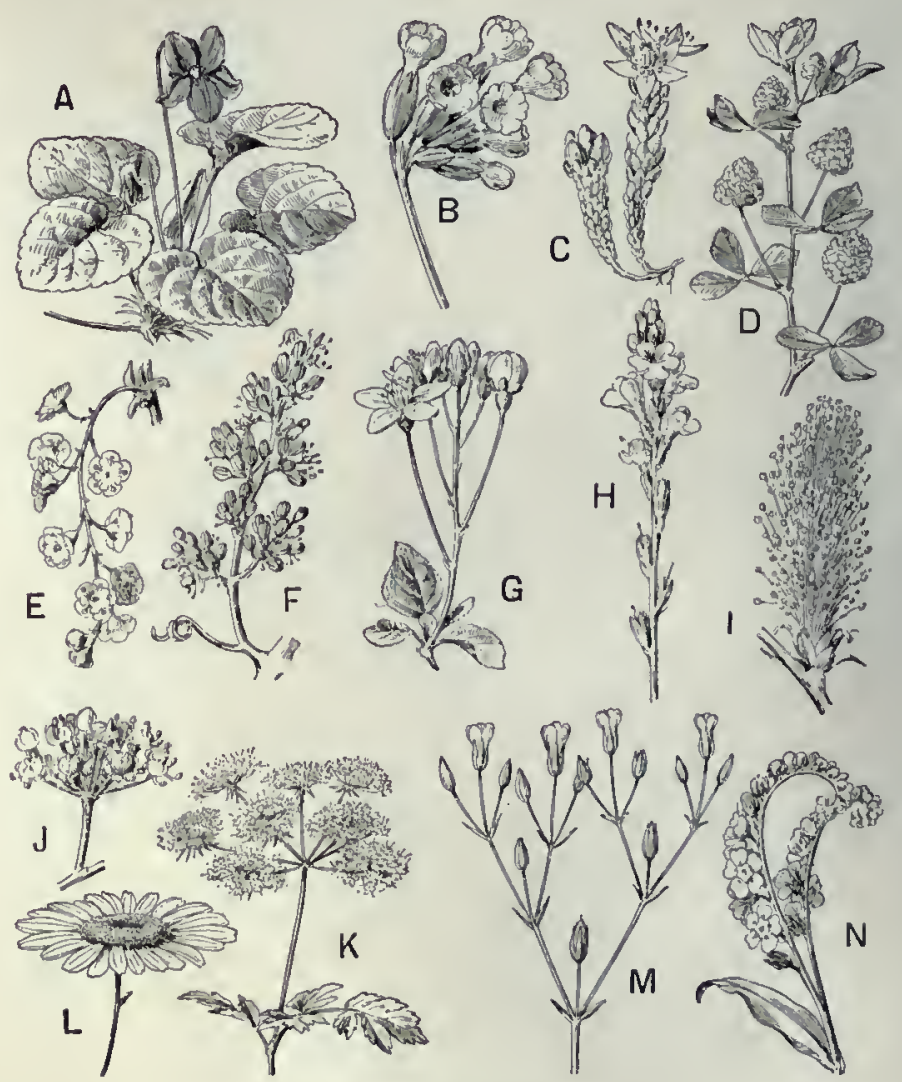

Fig. 46. - Inftorescences.

A. Uniflore (Violette) ; B. Pluriflore (Primevère) ; C. Terminale (Sedum) ; D. Axillaire (Lupuline); E. Grappe simple (Groseillier); F. Grappe composée (Vigne); G. Corymbe (Cerisier mahaleb); H. Épl (Verveine); I. Chaton ou épi unisexué (Saule) ; J. Ombelle simple (Lierre); K. Ombelle composée (Chorophylle) ; L. Capitule (Grande Marǵnerile): M. Cyme bipare ou dichotome (Céraiste): N. Cyme unipare ou scorpioïde (Myosotis). 


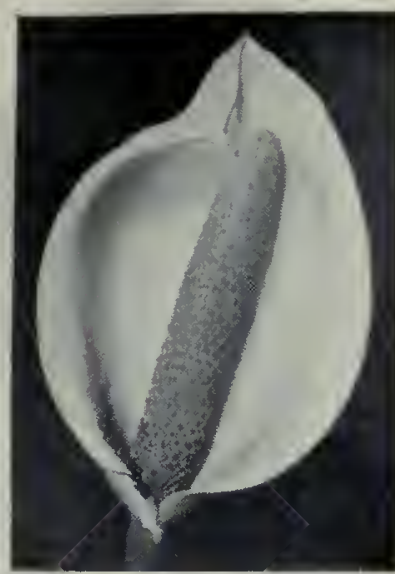

Inftorescence d'Anthurium. devenant beaucoup plus longs, il arrive alors que toutes les fleurs s'épanouissent à peu près dans un même plan et on a affaire à un corymbe (Poirier). Ailleurs, au contraire, tous les pédicelles secondaires restent courts, les fleurs sont comme insérées directement sur l'axe principal: on a l'épi, comme dans le Plantain; parfois il y a autour de l'inflorescence une grande bractée appelée spathe (Anthurium et autres Aroidées) et l'axe foral s'appelle spadice. Un troisième cas est celui de l'ombelle, dans lequel les ramifications partent à peu près du même point, de sorte que tous les pédicelles rappellent les rayons d'un parapluie, ainsi qu'on l'observe chez le Poireau. Le capitule, enfin, est une modification du cas précédent dans laquelle les pédicelles secondaires sont réduits à rien, et les fleurs s insèrent alors toutes au sommet de la tige : tels sont la Pâquerette, le Chrysanthème, etc.

Les divers types primitifs dinflorescences que nous venons d'énumérer peuvent se compliquer, et se combiner ensemble. On peut avoir des ombelles composées (Berce sphondyle), des épis de petits épis (Blé), des grappes de grappes (Vigne), des grappes d'ombelles (Lierre), des grappes composées ou panicules d'épillets (Avoine), des grappes dégénérant en cymes, etc.

La théorie de la métamorphose, à laquelle nous venons de faire allusion plus haut, se trahit surtout par l'étude des transformations des feuilles au voisinage des fleurs. On assiste, dans certains cas, aux modifications progressives qui permettent de passer, pour ainsi dire sans interruption, d'une feuille ordinaire à une bractée ou feuille florale, d'une bractée à un sépale ou pièce verte d'une fleur, d'un sépale à un pétale (pièce colorée), et même d'un pétale à une étamine (organe mâle) ou à un pistil (organe femelle). Le passage des feuilles aux bractées et aux sépales est très net dans l'Ellébore fétide.

Les étapes successives de la métamorphose florale sont donc au nombre de quatre : calice, corolle, androcée, gynécée.

Enveloppes florales. - Les enveloppes sont formées : $1^{\circ}$ par une partie externe, en général verte, appelée calice, qui est l'ensemble des sépales; $2^{\circ}$ par une partie interne colorée, appelée corolle, qui est l'ensemble des pétales (fig. 47 et 48). Parfois, l'une de ces parties manque, et celle qui subsiste peut changer de caractère : dans les Anémones, par exemple, il n'y a qu une seule enveloppe florale et elle est colorée; on pourrait être tenté de la regarder comme une corolle, d'autant plus qu'il y a

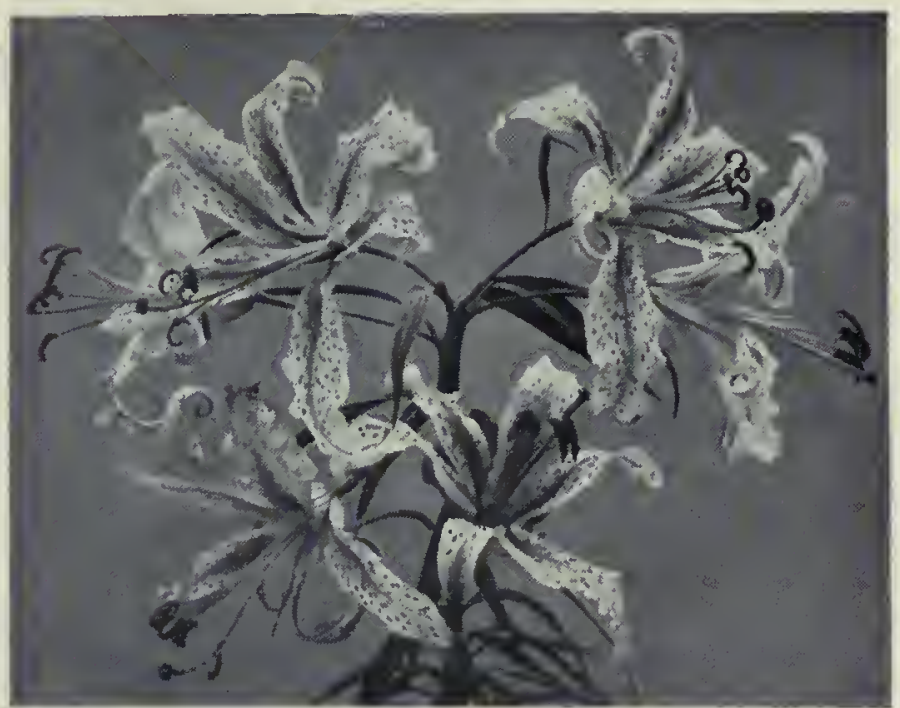

Lis tigrè.

des bractées dont l'ensemble forme ce que l'on appelle un involucre, qui semble simuler un calice; en réalité, il s'agit ici simplement d'un calice coloré. Ce cas se retrouve dans le Lis et dans beaucoup de plantes bulbeuses : calice et corolle sont colorés et se ressemblent. Parfois, comme chez le Pavot, la Heur ne paraît pas avoir de calice, parce que cet organe tombe de bonne heure: il est caduc. La corolle peut présenter la même propriété : dans la Vigne ( $f$ ig. $48, \mathrm{c}$ ), où les pétales restent rapprochés bords à bords en couvercle, cet organe se fend par le bas et tombe comme un chapeau soulevé par l'épanouissement des étamines. En général, quand le fruit se noue, les enveloppes se fanent. La corolle avec ses riches couleurs servirait, croyait-on, de porte-drapeau qui attire les insectes, grâce auxquels la fécondation croisée s'opère; nous verrons ce que l'expérimentation apprend sur ce point.

Les parties constituantes du calice et de la corolle peuvent être indépendantes ou soudées entre elles. Dans le premier cas, il y a calice dialysépale ou corolle dialypétale (Pois, fig. 48, e); dans le second cas, il y a calice gamosépale ou corolle gamopétale (Gloxinia). Une autre source de changements importants résulte de la croissance prépondérante de certaines pièces : le calice ou la corolle deviennent alors irréguliers; c'est surtout pour la corolle que ce fait acquiert de l'importance, car il contribue à donner à la fleur un aspect tout particulier. C'est ce que l'on voit, par exemple, dans un Pois ou un Lotier, où les cinq pétales portent des noms spéciaux : étendard, ailes et carène. L'irrégularité se trahit encore par l'existence de deux lèvres, comme chez la Sauge, ou par la présence d'éperons, comme dans les Angracum, les Linaires, etc.

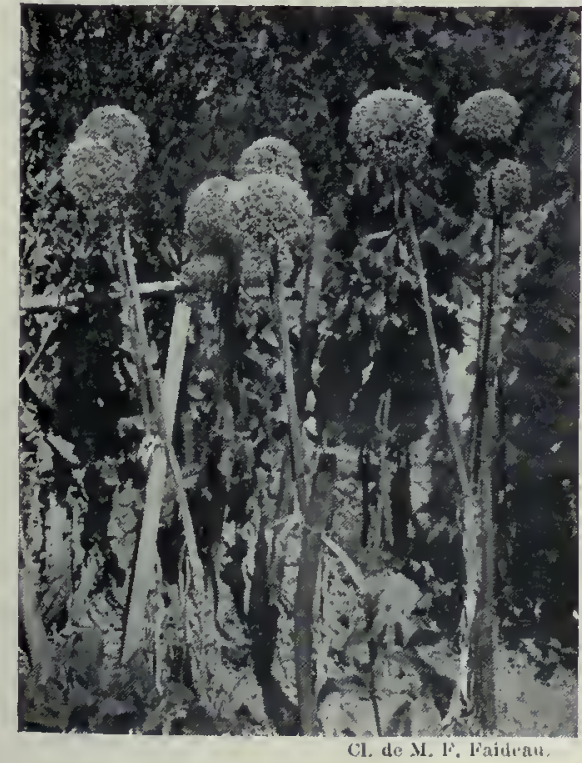

Ombelles du Poireau.

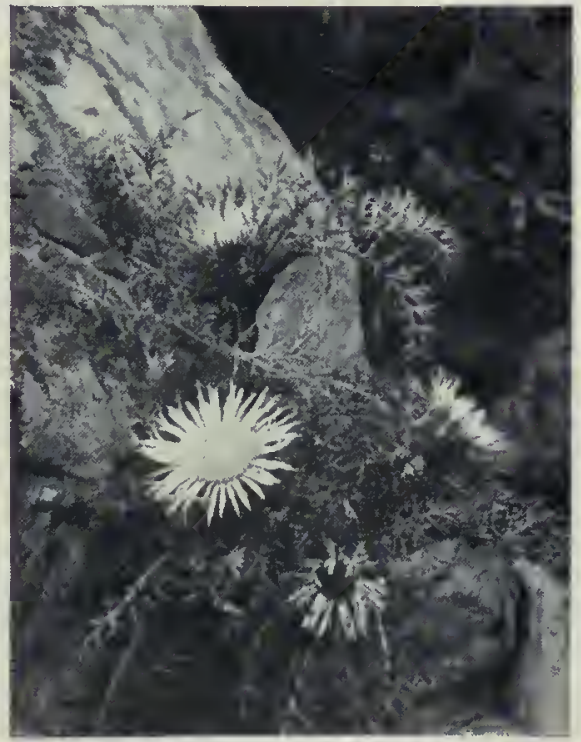

Capitute de la Carline.

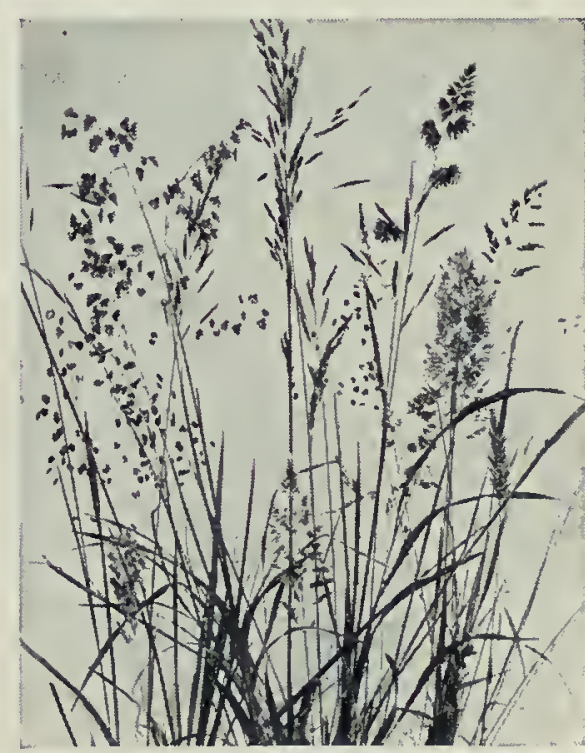

Épis des Graminées. 
Étamines. - L'étamine est formée d'un filament, en général grêle, le filet, surmonté d'une tête élargie, l'anthère ( fig. 49), présentant d'ordinaire quatre bosses, qui correspondent à quatre cavités, d'abord complètement pleines et closes, renfermant des grains de pollen qui ne tardent pas à être mis en liberté quand l'étamine arrive à maturité. Ces grains se forment quatre par quatre dans des cellules mères et. chez un certain nombre de plantes comme la Bruyère, cette union par quatre, en tétrades, subsiste indéfriment. Un autre cas plus rare, qui s'observe dans les Orchidées et les Asclépiadées, est celui où tout le contenu pollinique d'un sac, ou même de deux sacs voisins, se réunit en une masse unique : on dit alors qu il y a des pollinies ( $f$ g. 5]. B). En général, le pollen tombe en poussière : il est dit pulvérulent. Il est alors constitué d'une poudre microscopique, assez fréquemment jaune, qui est emportée au loin par le vent ou les insectes pour opérer la pollinisation des organes femelles. Ces grains sont remplis d'un protoplasma avec deux noyaux, l'un reproducteur, entouré de protoplasma différencié lenticulaire, et

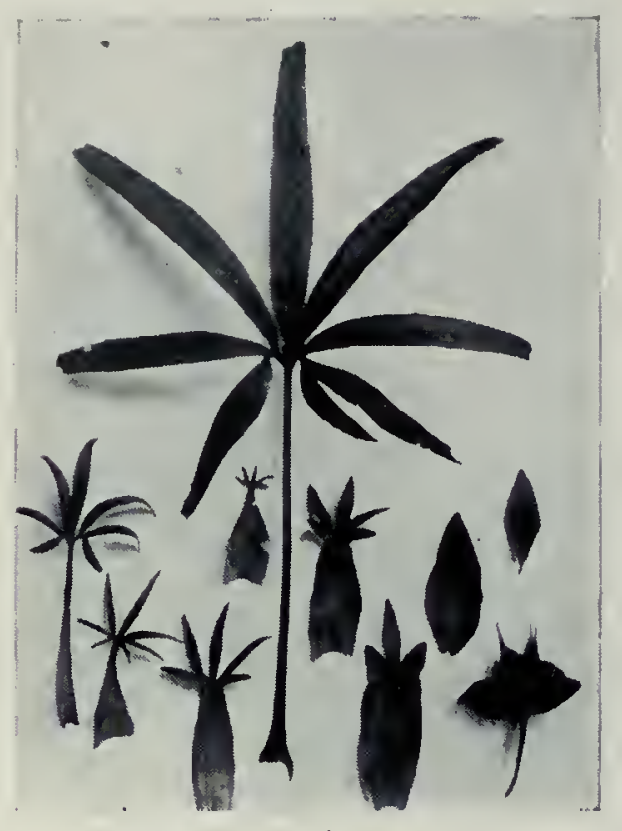

Ellébore fétide: passage de la feuille au sépale. certains cas, relativement rares, l'ouverture de l'anthère se produit par des pores : ainsi chez la Pomme de terre, ou par des clapets: par exemple chez le Laurier et l'Épinevinette (fig. 57 ).

Le nombre des étamines peut présenter des variations très importantes (fig. 53). Parmi les nombres les plus répandus dans les Dicotylédones, on peut citer cinq (Bourdaine, Pomme de terre), ou un multiple de cinq, notamment dix (Geranium). Par suite de la multiplication des étamines, on peut avoir des étamines nombreuses, chez le Poirier et le Rosier, par exemple ; enfin, les étamines, au lieu d'être disposées en cercles ou en verticilles, peuvent être très nombreuses et disposées en spirale, comme on l'observe chez les Renoncules, la Clématite à grande fleur, où les étamines sont extrorses, c'est-à-dire s'ouvrant à l'extérieur au lieu de s'ouvrir à l'intérieur comme d'ordinaire (Nénuphar blanc). Dans les Monocotylédones, c'est le type trois, ou plutôt six, qui prédomine, par deux verticilles de trois: ainsi chez le Lis à grande fleur, le Poireau. Le type quatre est rare, par exemple dans la Bruyère, où il $\mathrm{y}$ a huit

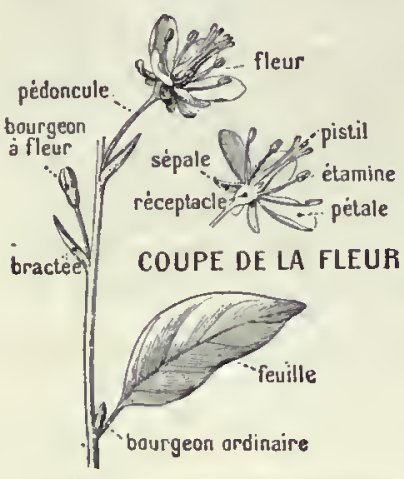

Fig. 47. - Origine de la fleur.

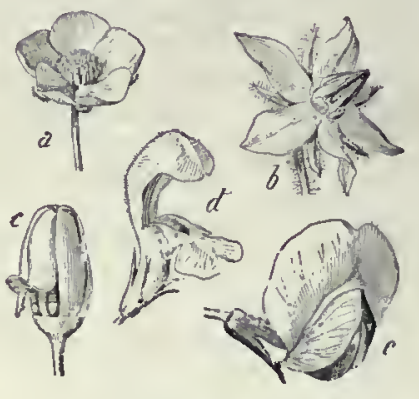

Fig. 48. - Corolle.

$a$, de Renoncule; $b$, de Bourrache : $c$ de Vigne ; $d$, de Lamier ; e, de Pois.

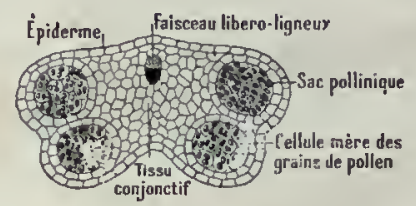

Fig. 49.

Coupe d'une anthère mùre.

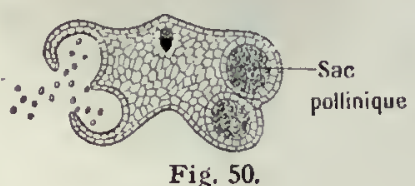

Déhiscence de l'anthère.

l'autre arrondi, qui est le noyau végétatif; la surface de ces grains est parfois recouverte de petites pointes, ou présente des parties visqueuses qui permettent l'adhérence aux corps étrangers, notamment aux insectes, ce qui assure leur transport ( $f$ ig. 51 et 52 ). Ils sont destinés à germer et ils ont, pour faciliter ce phénomène, des points où la membrane est plus mince, par où sortent les boyaux polliniques: c'est ce que l'on appelle les pores ou plis germinatifs.

Le pollen, étant destiné à réaliser la mystérieuse opération de la fécondation, doit donc d'abord être mis en liberté, dès qu'il est arrivé à un état de maturité convenable. Le mécanisme de la déhiscence de l'étamine est des plus curieux. Il sopère, en général, deux fentes en long sur les côtés entre les deux sacs polliniques voisins de l'anthère (fig. 50 ), qui se fusionnent en une seule loge. Il y a, par suite, deux fentes qui correspondent aux deux loges. Les bords de ces loges, par le jeu de la dessiccation des parois, se contractent et se rabattent soit en dzhors, soit en dedans. Dans

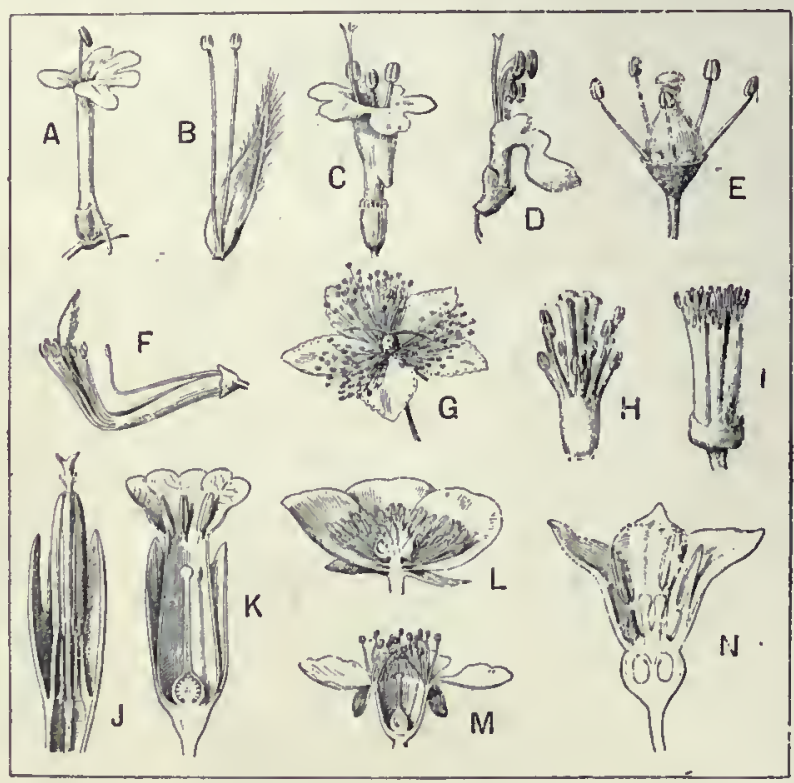

Fig. 53. - Androcèes.

$A$, à une étamine (Centranthe rouge) : $B$, à deux étamines (Saule); $C$, à trois étamines (Valériane); $\mathrm{D}$, à quatre étamines (Germandrée); $\mathrm{E}$, à cing étamines (Vigne) ; F, à étamines soudées par leurs filets en deux groupes (Pois) ; G, á nombreuses étamines (Millepertuis) ; $H$, à étamines soudées en un seul groupe (Oxalis) : I, soudées par leurs filets en plusieurs groupes (Oranger): J, soudées par leurs anthéres (Chardon);

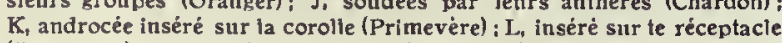
$\mathrm{K}_{\mathrm{t}}$ androcée inséré sur la corolie (Primevere) : $\mathrm{L}_{\text {inséré sur te réceptacle }}$
(Renoncule); $\mathrm{M}$, inséré sur le calice (Abricotier); $\mathrm{N}$, inséré sur l'ovaire (Garance).

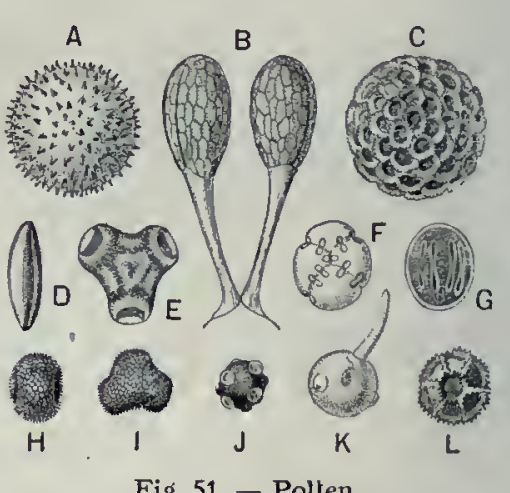

Fig. 51, - Pollen.

$A$, grain de pollen de Guimauve; $B$, Orchidée; $C$, de Cobea ; $D$, de Lis : $E$, de Clarkie: $F$, de Leschenaultie; $G$, de Bourrache; $H$ et I, de Pelargonium ; J, de Fumeterre: K, de Cerisier :

$\mathrm{L}$, de Chicoree (Rrossissement : 100 fois).

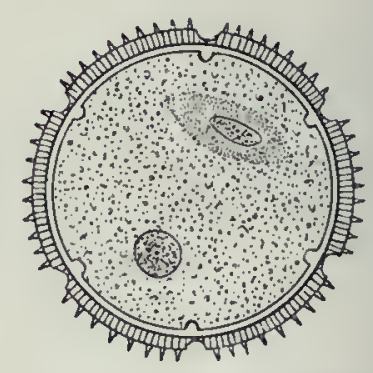

Fig. 52, - Grain de pollen vu an microscope.

étamines, ainsi que dans les Onagres et les Fuchsia.

Les dimensions des étamines sont aussi susceptibles de variations méritant d'être signalées; il y en a parfois quatre, dont deux longues et deux plus courtes, comme chez les Labiées, ou quatre grandes et deux petites, comme chez les Crucifères.

Les étamines peuvent, en outre, garder leur individualité ou se souder ensemble, et cette coalescence s'étend parfois aux anthères: ce sont les Synanthérées ou Composées, comme les Chrysanthèmes. Si elle s’étend aux 


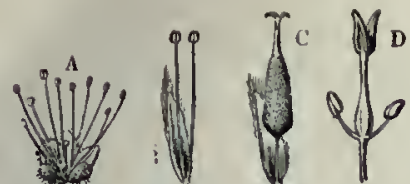
Fleur a pétale : $A$, de Chàtaignier. Fleurs nues : $B$, a étamines du Saule C, à pistil du Saule: D, du Frêne.

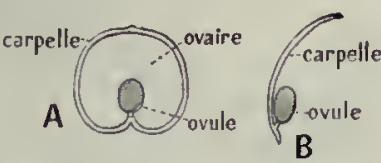

Fig. 55. - Feuille carpellaire

A, d'une Angiosperme: B, d'une Gymnosperme.

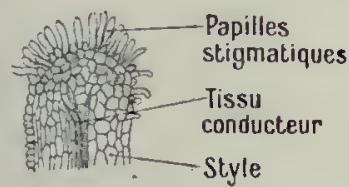

Fig. 59.

Coupe d'un stigmate.

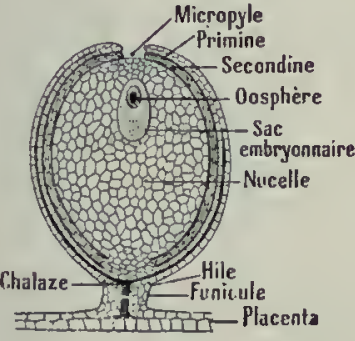

Fig. 61. - Coupe d'un ovule.

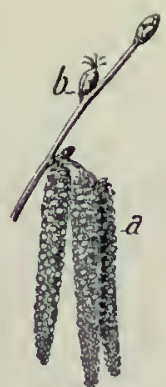

Fig. 56. Noisetier.

$a$, fleurs màles $b$, fleurs à pistil.

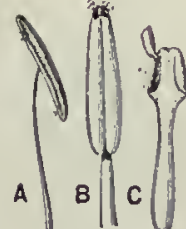
Déliscence.

A, longitudi nale du Lis

$B$, poricide de la Pomme de terre C, valvaire de

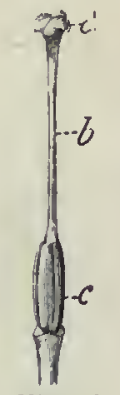

Fig. 58. Pistil du Lis. $a$, stigmate : $b$, style: c, ovaire.
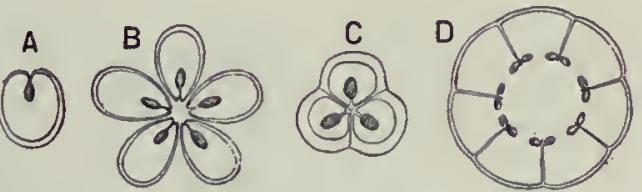

Fig. 60. -- Seclions transversales de pistils.

A, du Pois, à un seul carpelle; B, de l'Ancolie, à cinq carpelles séparés: $C$, du Lis, à trois carpelles soudés en un ovaire à trois loges: $\mathrm{D}, \mathrm{du}$ Pavot, à plusieurs carpelles soudés en un ovaire à une logie.

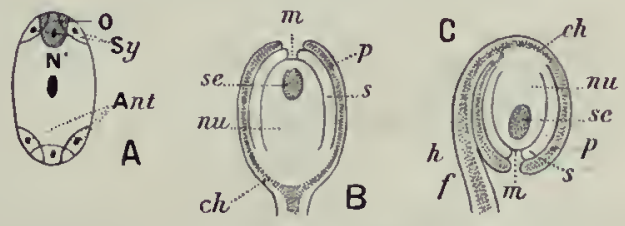

Fig. 62. - Ovules.

A, détail du sac embryonnaire se; $B$. ovule droit. C, ovule inverse.
Fig. 54. - Fleurs incomplètes.

Fig. 57

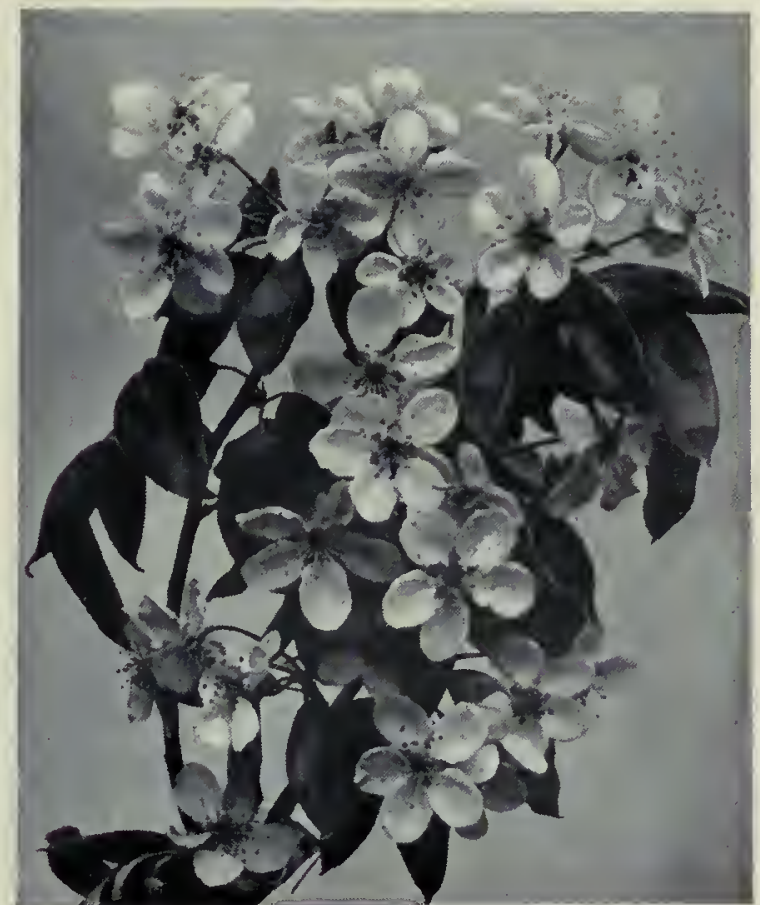

Fleurs du Poirier

on voit alors qu'elle présente à sa base deux petits corps ovoïdes que l'on appelle ovules (fig. 61 et 62 ); ces petits corpuscules se retrouvent aussi à l'intérieur de la cavité ovarienne du carpelle clos isolé que nous venons de décrire plus haut. Ces ovules sont les parties essentielles de l'organe femelle; ils méritent d'être considérés comme des lobes de feuilles dont la partie limbaire se serait creusée en forme d'une urne presque complètement close, ne laissant qu'un petit orifice terminal; cette partie

filets, les étamines forment soit un seul faisceau (Genêt), soit deux (Lotier), ou plusieurs, comme chez le Millepertuis (fig. 53, G). On dit qu'il y a gynostème, quand il y a soudure des étamines et du pistil, comme dans le cas des Orchidées.

Les étamines sont d'ordinaire rapprochées du pistil, mais non soudées à lui, sur une même feur qui est dite hermaphrodite: c'est ce qui arrive en particulier dans le cas de la fleur du Frêne ( $f$ ig. 54, D) où il y a simplement un pistil et deux étamines; mais il arrive que les sexes soient séparés : on a parfois des fleurs mâles et des fleurs femelles sur un même pied, et on dit que la plante est monoïque : tel est le cas du Noisetier ( $f$ ig. 56 ), ou sur deux pieds différents, et la plante est dite dioïque, comme le Chanvre, le Dattier, les Saules, etc.

Pistil. - Le pistil constitue l'organe le plus central de la fleur ( $f$ ig. 58 et 60 ). Il est formé de parties élémentaires que l'on appelle carpelles, et qui ne sont autre chose que des feuilles transformées (fig. 55). Ces feuilles sont, en général, dépourvues de pétiole, avec un limbe ventru dont les deux bords se rapprochent l'un de l'autre pour se souder, de manière à former une cavité close que l'on appelle l'ovaire; au-dessus de l'ovaire, la feuille carpellaire s'amincit et se transforme en une gouttière ouverte ou très souvent fermée, qui constitue le style, présentant à l'intérieur un tissu à moitié gélifié que l'on appelle tissu conducteur; enfin, tout à fait à l'extrémité du style, s'observe un épatement couvert de cellules papilleuses et visqueuses; cette région est la continuation du tissu conducteur interne : c'est sur cette partie appelée stigmate ( $f i g .59)$ que le grain de pollen est retenu et fixé, et c' est là qu'il germe.

La description que nous venons de donner d'un carpelle ne sapplique, en réalité, quaux carpelles clos et isolés. Il arrive très communément ou bien qu ils s'ouvrent, ou bien qu'ils se soudent entre eux. Un exemple de carpelles ouverts est fourni par les Conifères, où la feuille carpellairc est étalće (fig. 55, B);

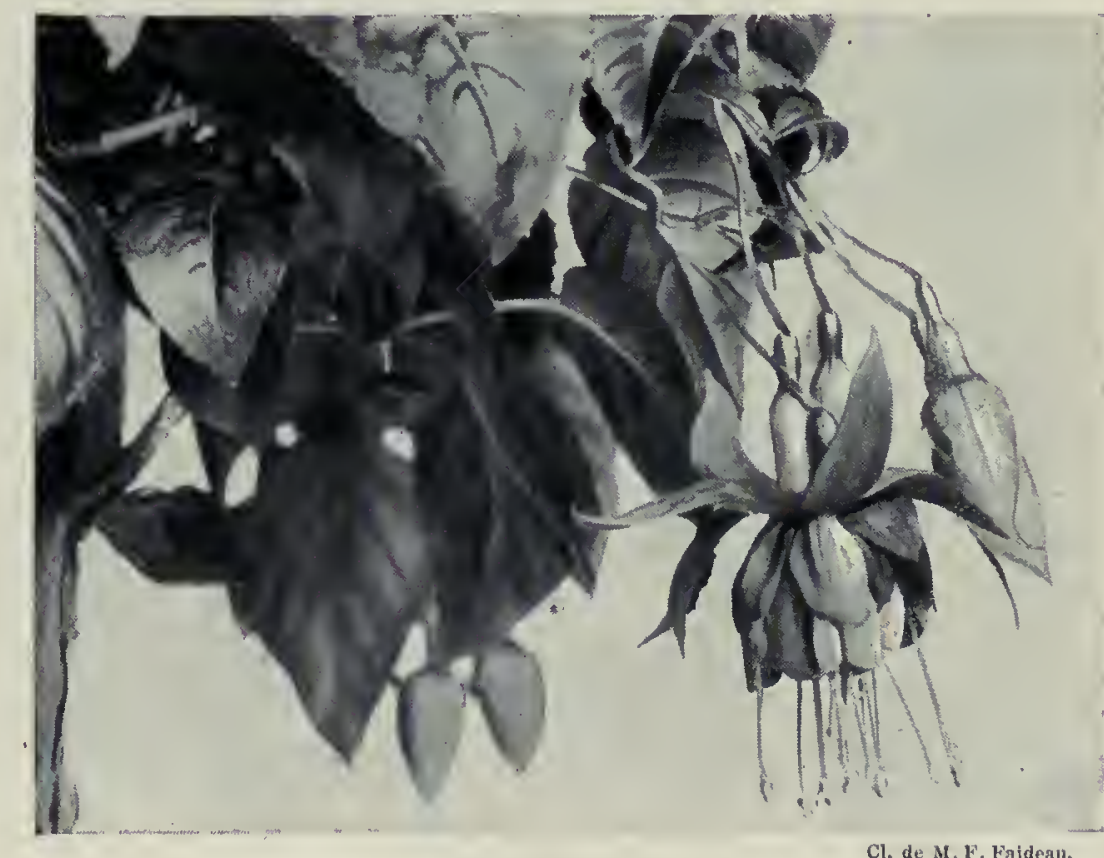

Fleurs de Fuchsia. réceptaculaire n'est, en réalité, que l'enveloppe de l'ovule, et on la désigne sous le nom de tégument. La partie la plus essentielle est à l'intérieur ; c'est une sorte de mamelon ovoïde pluricellulaire né à la surface du lobe foliaire et complètement entouré par lui ; cette partie porte le nom de nucelle, et c'est dans sa région interne et apicale que se trouve une grosse cellule, allongée suivant l'axe de l'ovule, qui est désignée sous le nom de sac embryonnaire (fig. 62 se et 63). C'est ce sac qui contient, à son pôle antérieur, la cellule femelle ou oosphère (o), dépourvue de membrane, située dans le plan médian et encadrée de chaque côté par une cellule semblable ou synergide, mais qui n'est pas destinée à l'imprégna- 


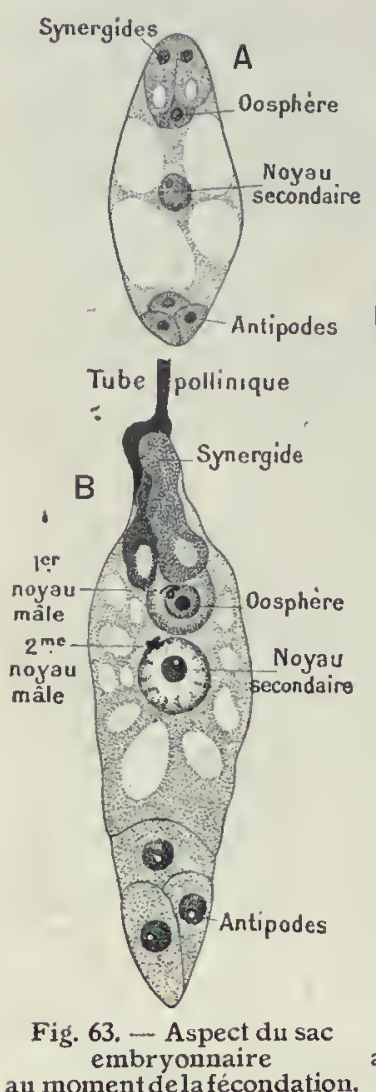

au moment del a fécondation.

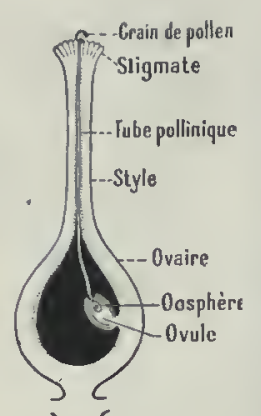

Fig. 64. - Péné-
tration du tube
pottinique
dans l'ovaire.

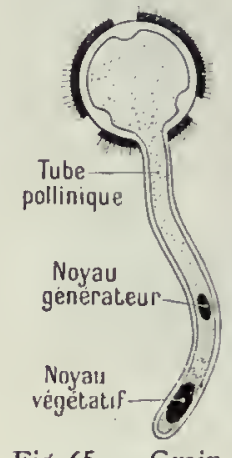

Fig. 65. - Grain de pollen, avec son long tube poltinique.

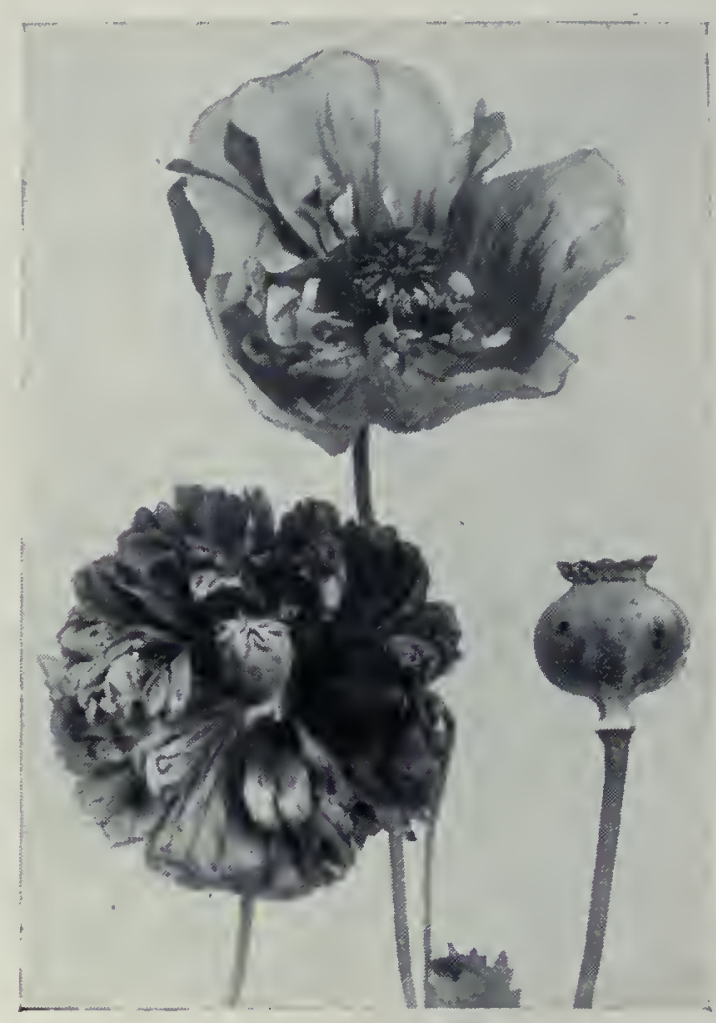

Pavot de jardin; ovaire libre.
Fécondation. - Nous venons de décrire la machine; voyons maintenant à quoi elle sert et comment elle fonctionne. Supposons le grain de pollen transporté sur le stigmate, soit directement, soit par le vent, les insectes, ou même par l'homme dans certaines cultures; nous reviendrons ultérieurement sur ces points en parlant des rapports des plantes et des animaux.

Grâce aux petits aiguillons qui existent parfois à la surface du grain de pollen ( $f$ g. $51, \mathrm{~A}$ ), grâce aux matières visqueuses des papilles stigmatiques, une adhérence intime s'établit entre cet organe femelle et le grain; ce dernier ne tarde pas à bénéficier de tous les afflux de matières nutritives qui viennent au pistil ou qui s'élaborent dans sa partie supérieure. Le grain germe et le tube ou boyau pollinique (fig. 64 et 65) sallonge, de manière à rechercher en s'avançant les matières nutritives dont il a besoin ; il suit ainsi le tissu conducteur qui est dans l'intérieur du style, et il arrive progressivement à la cavité ovarienne, qui offre à sa surface des arcs ou des méridiens de tissu conducteur analogue, de sorte que le tube pollinique cst conduit ainsi jusqu'à l'ovule; le

tion de la substance mâle ; à la base du sac sont les antipodes (Ant), ćgalement stériles; au milieu du sac il y a le noyau secondaire (N) résultant de la fusion des deux noyaux.

Les carpelles présentent des variations. Dans le Pin, ils sont ouverts et libres (fig. 55, B). Dans la Violette, il y a trois carpelles ouverts, mais soudés bords à bords. Il en résulte une cavité ovarienne unique avec trois lignes de suture ou placentas, sur lesquelles sont insérés les ovules par des cordons : on dit que la placentation est pariétale.

Il y a d'autres types de placentations. Dans le Lis, notamment (fig. 60, C), la placentation est dite axile : trois carpelles clos dont la section transversale est en forme de coin sont rapprochés et soudés de manière à former un ovaire à trois loges séparées, qui porte des ovules nombreux insérés sur la partie axiale. Dans la Primevère (fg. $53, \mathrm{~K})$, la placentation est centrale, ily a une seule cavité et les ovules sont insérés sur un mamelon central.

L'ovaire est dit libre ou supère, comme dans le Tilleul, l'Abricotier (fig. 53, M) quand il est isolé au milieu de la fleur et qu'en écartant la corolle on l'aperçoit en cntier. Il est adhérent ou infère quand, au contraire, il est soudé plus ou moins à la base des autres pièces florales et situé en apparence au-des sous de la fleur. Dans ce cas, qui est celui de l'Opuntia et de la Garance (fig. 53, N), la paroi de l'ovaire n'est pas formée seulement parle carpelle, mais encore par la base des étamines, despétaleset des sépales soudés ensemble.

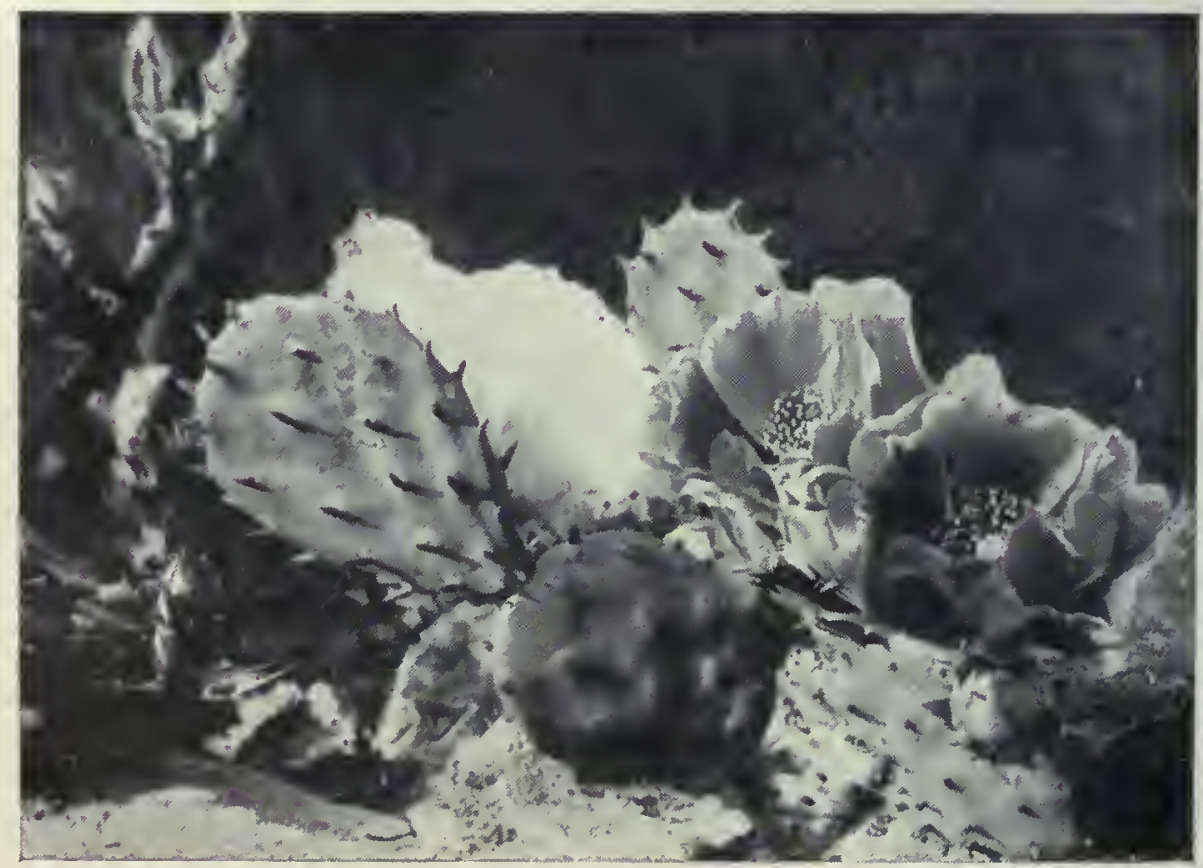

Opnntia en fleurs; ovaire infére on adhérent. sommet du boyau pénètre tout naturellement par son orifice, ou micropyle, et s avance, en digérant devant lui les membranes, jusqu'au sac embryonnaire. Pendant la marche, cachée aux yeux, du tube du pollen à travers l'organe femelle, les noyaux qu il contient cheminent également (fig. 65) : le noyau végétatif en avant, le noyau reproducleur en arrière, ce dernier entouré d'une petite masse de protoplasma nu, de manière à constituer une cellule mâle, qui ne tarde pas à se diviser en deux cellules; pendant que ce scindement s'opère, le noyau végétatif saltère et se résorbe peu à peu. Les deux cellules reproductrices mâles sont alors au plus complet voisinage de la cellule femelle ou oosphère. Tout est prêt pour l'acte fondamental de la fécondation, qui consiste dans la fusion intime de la cellule mâle et de la cellule femelle et dans la coalescence des deux protoplasmas. La première cellule passe dans l'oosphère et forme l'œuf, et le caractère de cellule mobile s'accuse par l'allongement du noyau en forme de virgule; la deuxième cellule mâle, à noyau également allongé et effilé, se rapproche du noyau secondaire du sac embryonnaire et se fusionne plus ou moins intimement avec lui. Ces deux fécondations simultanées donnent naissance à deux corps qui doivent avoir des rentes : le premicr devient l'embryon et, par les divisions répétées de ses cellules, se forme peu à peu la petite plantule nouvelle; le deuxième forme un tissu appelé à la nutrition de la plantule dans son développement ultérieur. destinées très diffél'albumen qui servira 


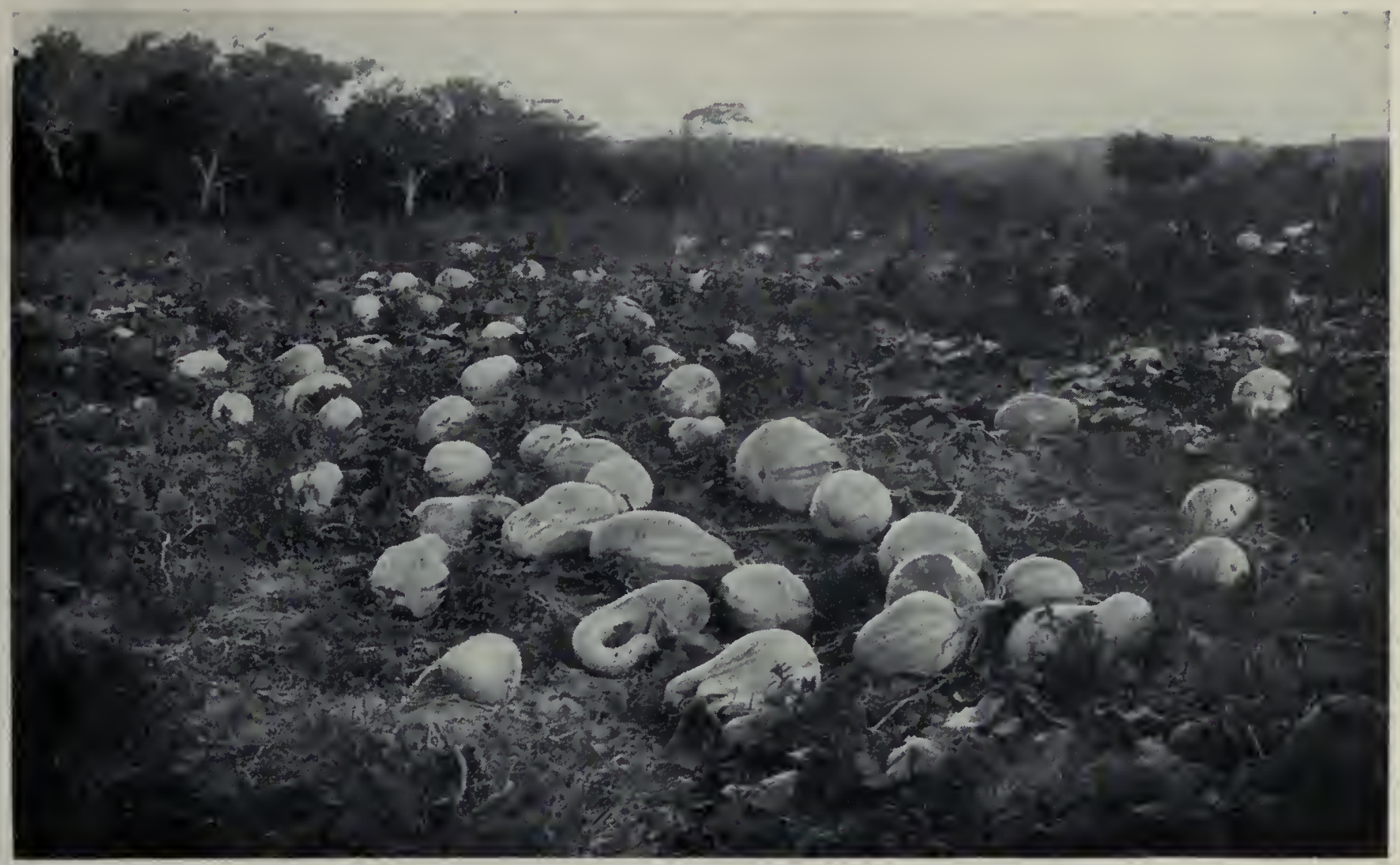

Champ de Courges, en Afrique du Sud.

\section{LE FRUIT}

Lorsque la fécondation a eu lieu, on voit commencer la maturation du fruit, et le développement de la graine se produire peu à peu. Le fruit résulte de la transformation de l'ovaire; la graine résulte du changement de l'ovule. En fait, le fruit comprend l'enveloppe; quand on mange un fruit, souvent on avale aussi sans $y$ faire attention la graine qu'il contient.

Les fruits sont de deux natures tout à fait différentes: les fruits charnus et les fruits secs. Les premiers sont surtout intéressants pour l'homme et un grand nombre de cultures sont entreprises pour les obtenir.

Fruits charnus. - Le premier type de fruits charnus est la baie (fig. 66): le grain de raisin ou de groseille, lorange ( $f$ g. 67) nous en donnent tout de suite une idée; on y distingue la peau, qui a une certaine consistance, et la pulpe, qui est un tissu à moitié aqueux au milieu duquel se trouvent plongés les pépins, yui ne sont autre chose que les graines. Ce sont évidemment les fruits les plus parfaits, puisque, pour ainsi dire, toute leur substance est mangeable. Certaines baies atteignent de grandes dimensions.

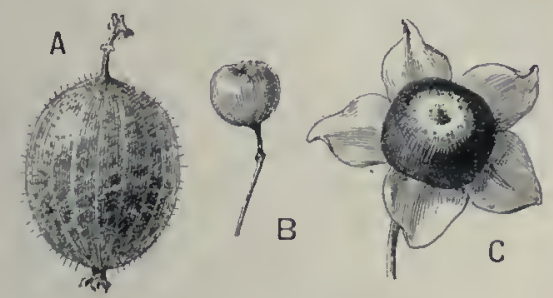

Fig. 66. - Baies.

$a$, de Groseillier a maquereau : $b$, d'Asperge; $c$, de Belladone.

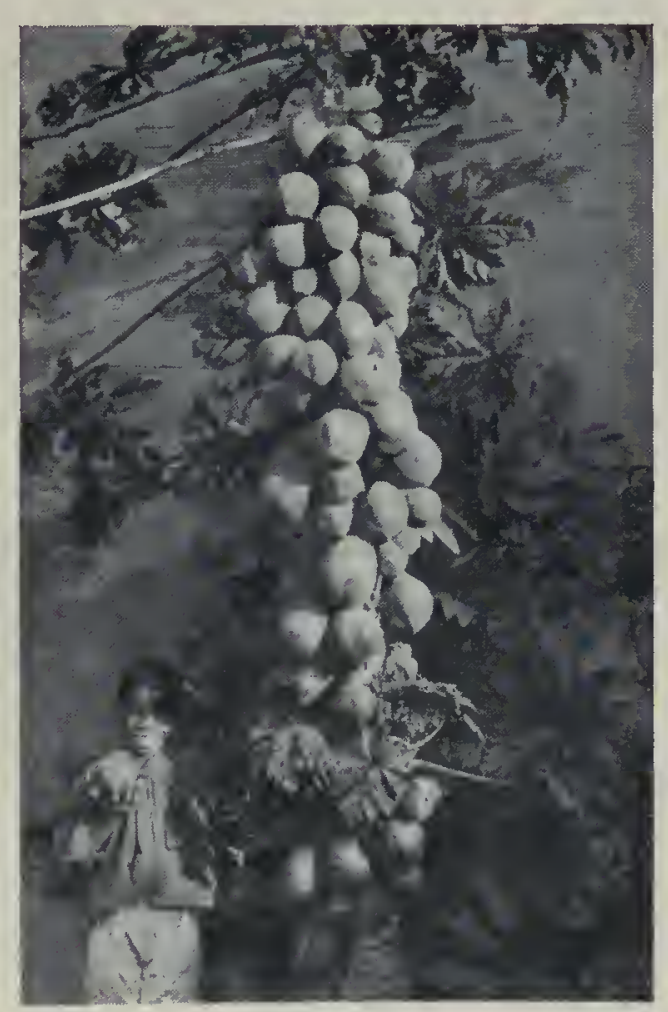

Papayes (Carica papay'a).

On peut citer la papaye, par exemple, qui est le fruit du Papayer, ou encore les fruits des Cucurbitacées, appelés parfois pépons : Courges, Potirons, Citrouilles, dont la couche externe est parfois très dure et pour lesquels la consistance du tissu interne va en diminuant de l'extérieur vers l'intérieur. La datte est une baie dont la graine, extrêmement dure, est souvent prise à tort pour un noyau.

Un second type de fruits nous est fourni parla drupe (fig. 68); ce sont les fruits à noyau : la cerise, la pêche, la prune, l'abricot, l'olive, nous dispensent de beaucoup insister. Il y a encore la peau du fruit et la chair comme dans les baies, mais la partie la plus interne est devenue dure comme du bois et constitue le noyau; en le cassant, on trouve la graine.

Les fruits charnus sont connus et appréciés des animaux aussi bien que des hommes. Dans notre pays, les loirs; dans les contrées tropicales, les singes, les chauves-souris sont des ennemis redoutables des plantes fruitières cultivées. Il faut leur faire une chasse très active ou protéger les fruits contre leurs dégâts. Ces mammifères, et surtcut les oiseaux, contribuent ainsi inconsciemment à propager les espèces sauvages produisant des fruits charnus. Nous parlerons de ce fait intéressant en étudiant les rapports des plantes avec les animaux.

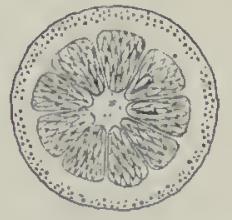

Fig. 67.

Coupe transversalc d'une urangc.

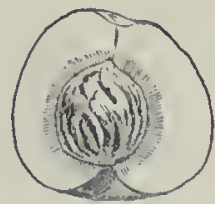

Fig.69. - Drupe ou fruit a noyau (Pêche). 


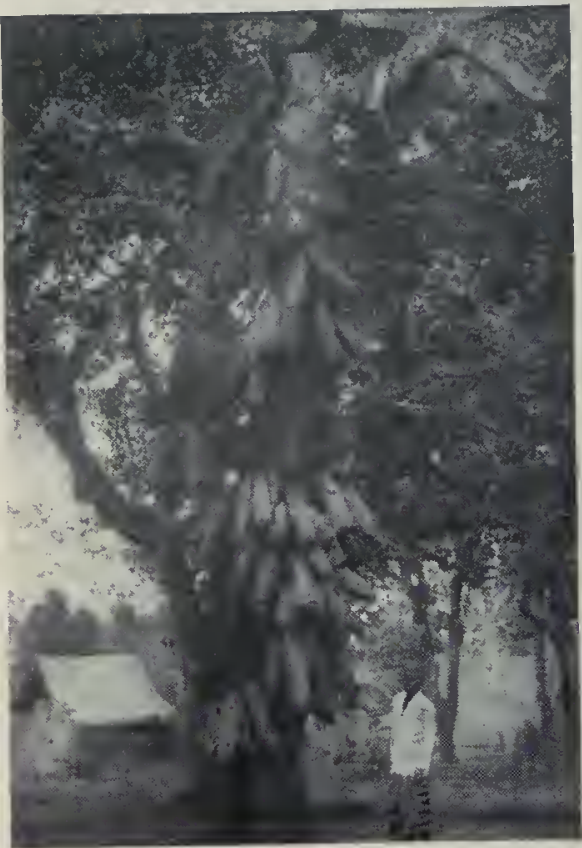

Protection des fruits du Jacquier.

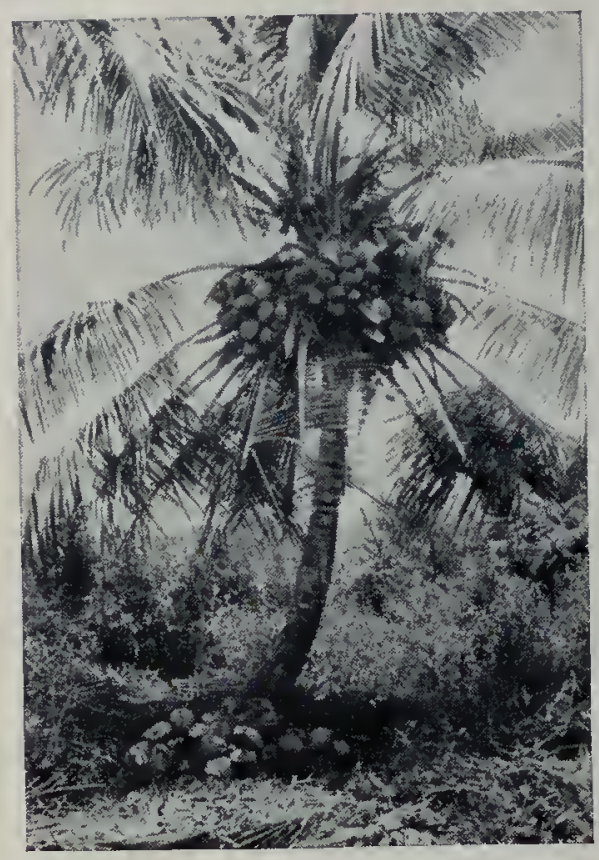

Un Cocotier à Tabasco (Mexique).

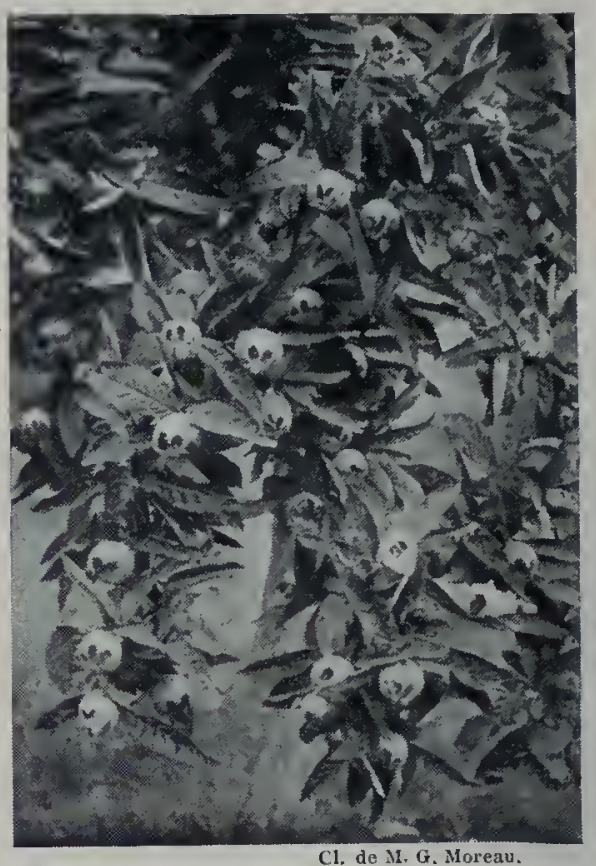

Néflier avec néfles.
Pour la baie comme pour la drupe, la graine n'est mise en liberté que par la destruction, la corruption de la pulpe du fruit ou par son ingestion par un animal. La nature $n$ avait donc pas intérêt à voir les graines contenues à l'intérieur de ces fruits se multiplier; en général elles sont peu nombreuses et, dans les drupes, il n'y en a qu'une.

L'amande, fruit de l'Amandier, est aussi rattachée aux drupes, bien que la partie charnue ne soit pas comestible. La noix de coco est, de même, une grosse drupe coriace, dont l'épais noyau est entouré 'par une substance fibreuse. A l'intérieur est l'énorme graine, dont le volumineux albumen est creusé en son centre, avant la complète maturité, d'une cavité remplie d'un liquide laiteux ou lait de coco.

La noix est un fruit assez yoisin de la drupe, dans laquelle la chair n'est plus comestible, mais constitue ce que l'on appelle le brou, qui est ferme, presque coriace; mais ici l'enveloppe peut, en vieillissant, éclater et produire une déhiscence imparfaite.

Fruits composés, fruits multiples, faux fruits. - La pomme, dont la poire ( fig. 69) est une légère variation, est d'une nature un peu différente de celle de la drupe. Elle présente à sa partie supérieure une partic creuse ombiliquée, où l'on aperçoit de petites feuilles desséchées qui sont les restes du calice, ou couronne, ou cil; à l'extrémité opposée se trouve la queue du fruit. Si on la coupe en long en deux, on aperçoit vers le milieu, et des deux côtés, des traces de loges de nature cornée, à l'intérieur desquelles se trouvent des pépins ou graines; cette constatation amène à pen-

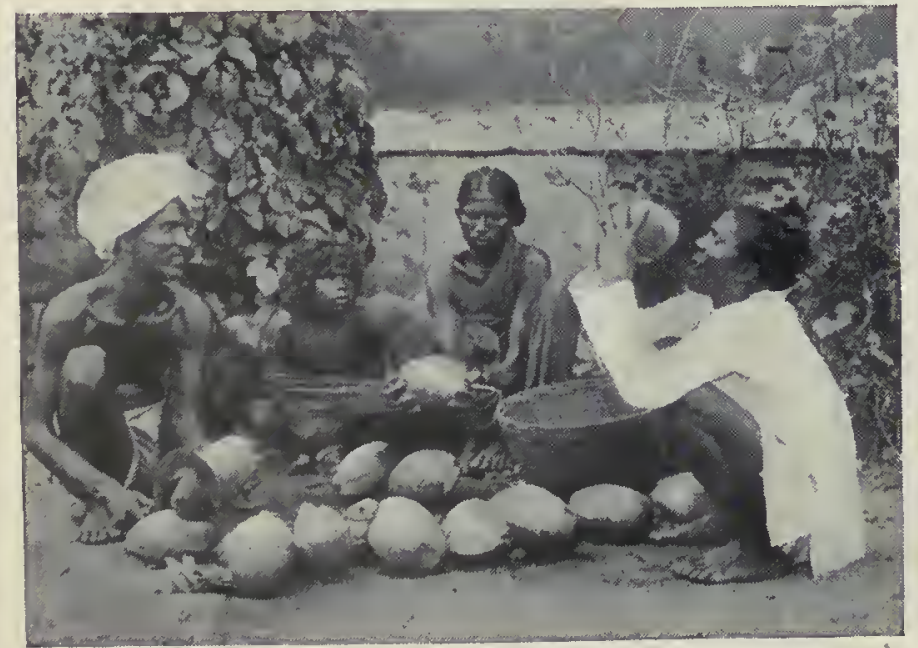

Buveurs de lait de coco, ser que l'on a affaire à un fruit complexe, formé de plusieurs drupes qui se seraient soudées par leurs parties internes au voisinage des noyaux. En réalité, les choses sont plus complexes encore, car non seulement il s'agit de fruits soudés ensemble, mais de drupes soudées à une sorte de coupe réceptaculaire qui existe aussi dans le Rosier, dont nous parlerons plus loin, et qui se fusionne intimement avec les parties précédemment mentionnées. La pomme est donc un des fruits les plus difficiles à comprendre que lon connaisse ( fig. $7 I)$ et, avec ses nombreuses variétés, on la considère comme un fruit composé.

La nèfle, fruit du Néfier, est, en somme, un fruit très voisin. Il y a une dépression plus accusée à sa partie supérieure, et on y voit des traces desséchées de toutes les parties de la fleur: calice, étamines et styles; cela indique bien que l'ovaire était infère et le calice très développé. La chair a une consistance particulière : elle est molle, et on dit que le fruit est blet; à l'intérieur de cette pulpe se trouvent des noyaux, ou osselets, de consistance ligneuse et très dure.

Il y a des cas où les petites drupes élémentaires se rapprochent sans se souder, comme dans le fruit de la Ronce, appelé vulgairement mûre (fruit multiple). Il succède à une seule fleur et l'on voit à la base le calice persistant; le réceptacle qui portait les carpelles était très saillant, conique ; chaque carpelle s'est accru en gardant son individualité; il est devenu charnu à l'extérieur; à l'intérieur. autour de chaque graine, il y a une petite coque parcheminée qui est l'analogue du noyau de la prune. La framboise (fig. 70) est dans le même cas, car le Framboisier est la Ronce du Mont Ida.

On désigne aussi sous le nom de mûres les fruits du Mûrier, qui ne doivent pas être confondus, en aucune façon, avec les fruits précédents. Les sexes sont séparés, le calice des fleurs femelles s'épaissit, devient charnu et forme ainsi uneenveloppe externe au fruit

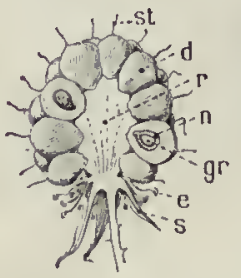

Fig. 70. - Coupe d'une framboise.

$s$, sépales flétris : c, étamines flétries st, style flétri; $r$, réceptacle; $n$, noyau; gr. graine.
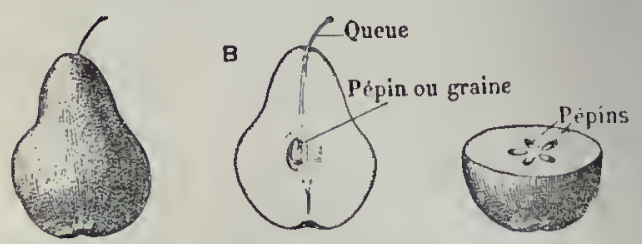

Fig. 69. - Fruit claruı à pépins (poire .

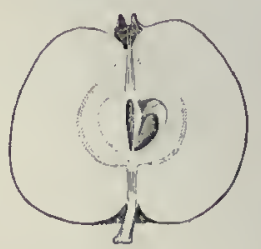

Fig. 71. Coupe d'une pounne.

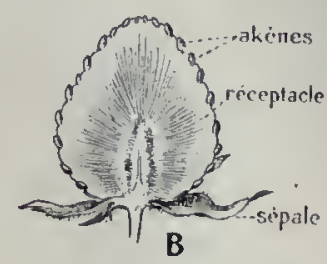

Fid. 72.

Coupe d'une fraise. 


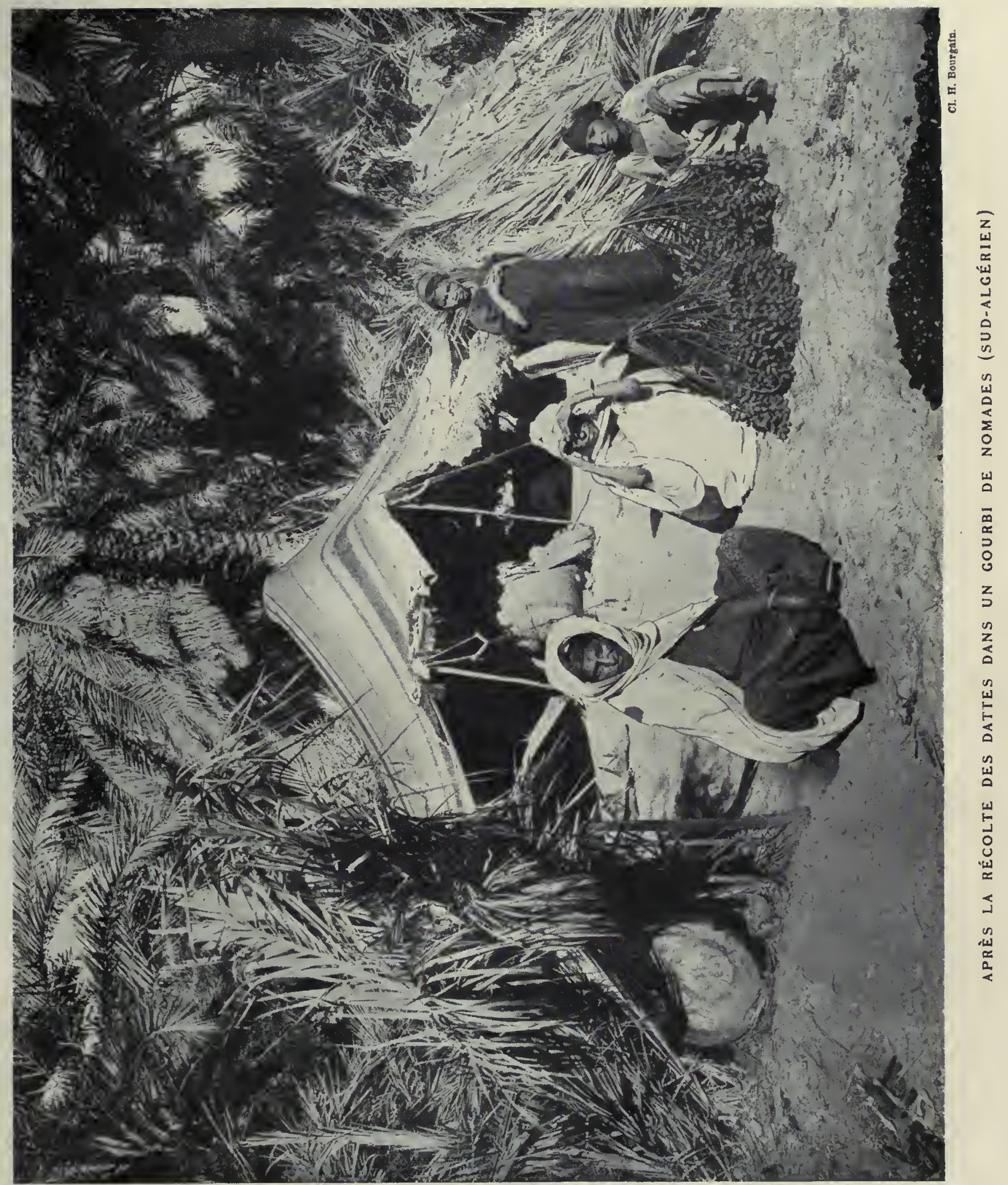



véritable, devenu lui-même également pulpeux à l'extérieur; l'enveloppe s'applique d'ailleurs sur le carpelle accru sans se souder à lui; chacun des fruits véritables est une petite drupe, et la mûre est formée par l'agglomération de plusieurs fruits pareils, de couleur blanche, ou rose, ou pourpre noir, suivant qu'il s'agit du Mûrier blanc ou du Mûrier noir (fruits composés).

Nous avons dit que dans la pomme la coupe réceptaculaire contenant les carpelles participait à la constitution du fruit. C'est quelquefois cette coupe qui constitue la plus grande partie des tissus comestibles : dans la figue, par exemple. Le réceptacle, en forme de poire renversée et ouvert à la partie supérieure (œil), contient au centre une série de pépins rougeâtres en très grand nombre : ce sont en réalité les fruits qui sont ici de petits akènes. L'énorme fruit de l'Arbre à pain est composé de fruits secs plongés dans la substance même du réceptacle, devenu charnu, amylacé. Ici le réceptacle est proéminent, sphérique. En somme, dans ces derniers cas, ce qui devient charnu ou alimentaire ce sont les parties extérieures du fruit véritable.

Il est un fruit bien connu qui se rattache à ce type, c'est la fraise (fig. 72). Ici c'est encore le réceptacle qui s'est gorgé de matières saccharines, mais il est en saillie au lieu d'être en forme de coupe comme dans la figue; à sa surface se trouvent un très grand nombre de petits pépins qui sont les fruits véritables; ils sont en réalité secs : ce sont des akènes, que nous allons définir cn étudiant cette deuxième catégorie de fruits. Très communé-

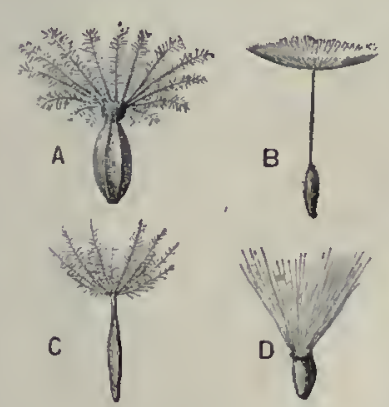

Fig. 73. - Akènes à aigrettes. A, Valériane: $\mathrm{B}$, Pissenlit ; ment, le vulgaire considère comme fruit ce réceptacle: c'est là une erreur qu'il ne faut pas commettre.

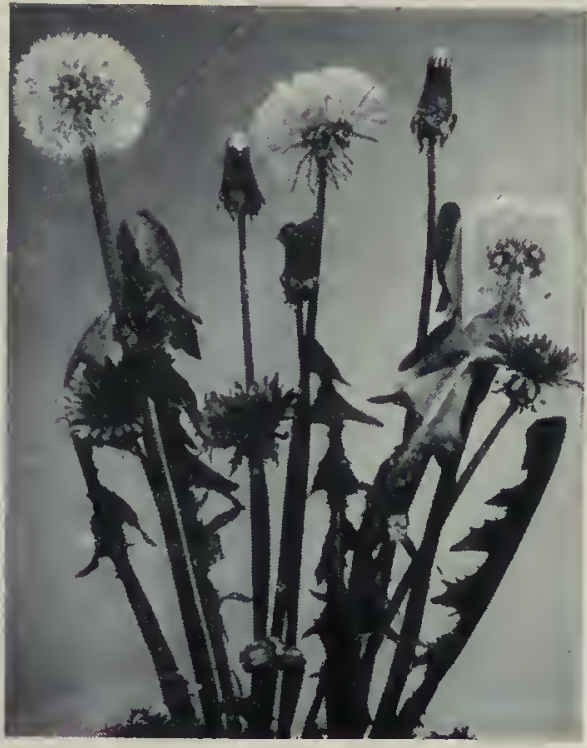

Pissentit ; fleurs et fruits.

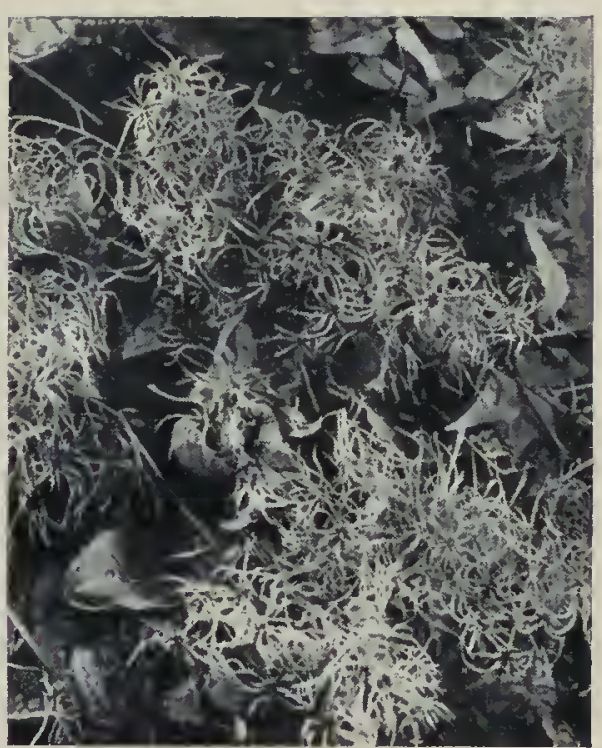

Clématite vigne blanche; fruits.

dicelle supportant en haut une aigrette rayonnante qui permet une dissémination facile. Les akènes des Clématites (fig. 76) sont prolongés de même par les styles accrus et devenus plumeux.

Il y a des akènes qui ne sont pas pourvus de tels appareils de vol et qui sont évidemment destinés à germer au plus proche voisinage de la plante mère. Le fruit du Tilleul est un akène ; tel est aussi le cas du Chêne (fig. 75) : en faisant sauter et tomber le gland, qui n'est autre chose que l'akène, on obtient une

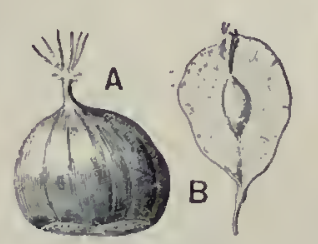

Fiğ. 74. - Akènes,

$A$, de Chàtaiónier ;

B, d'Orme (samare).

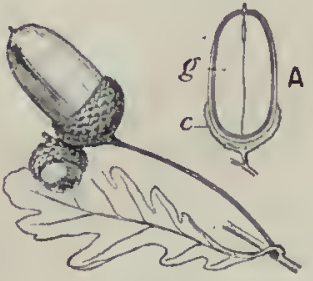

Fig. 75. - Gland duCliène. A, coupe : g, graine: c, cupule. petite coupe pédicellée que l'on appelle la cu-
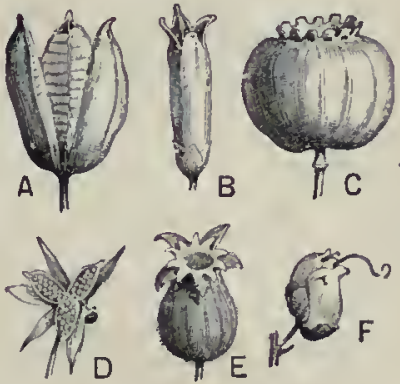
pule; elle est pourvue à sa surface d'un assez

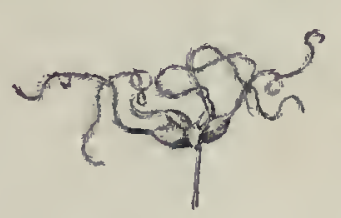

Fig. 76.
Akènes de Clématite.

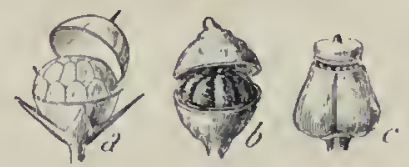

Fig. 77. - Capsules.

A. Iris : B, Eillet: C, Pavot: $a$. Mouron ; $b$, Pourpier ; $c$, Jusquiame. D, Violette; E, Lychnis; F, Muflier
Fruits secs. - Les fruits de ce type peuvent être séparés en deux groupes, suivant quils contiennent une ou plusieurs graines. S'ils contiennent une seule semence, on conçoit que leur dissémination puisse se faire sans aucune difficulté et que la dispersion au loin de la graine puisse être confondue avec le simple transport de l'enveloppe: la graine aura évidemment à percer, non seulement ses téguments, mais aussi la paroi durcie du fruit qui la contient. On nomme akène tout fruit qui ne souvre pas et qui ne contient qu'une graine. Il y en a de plusieurs variétés (fig. 73 à 76 ).

La graine peut être libre à l'intérieur de son enveloppe: c'est ce qui arrive par exemple pour les akènes des Composées, du Pissenlit (fig. 73, B) notamment. Tous les enfants se sont amusés à ramasser les grosses boules légères formées par ces plantes lorsque la fleur est passée; en soufflant dessus avec plus ou moins d'énergie, ils sont arrivés à mettre en liberté successivement chacun des petits fruits qui sont surmontés ici d'une sorte de pć-

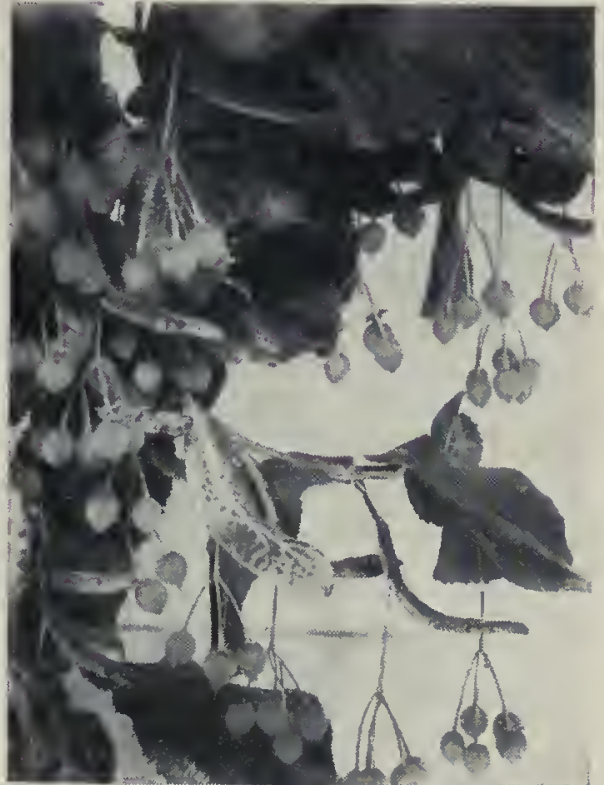

Tilleut; fruits ou akènes.

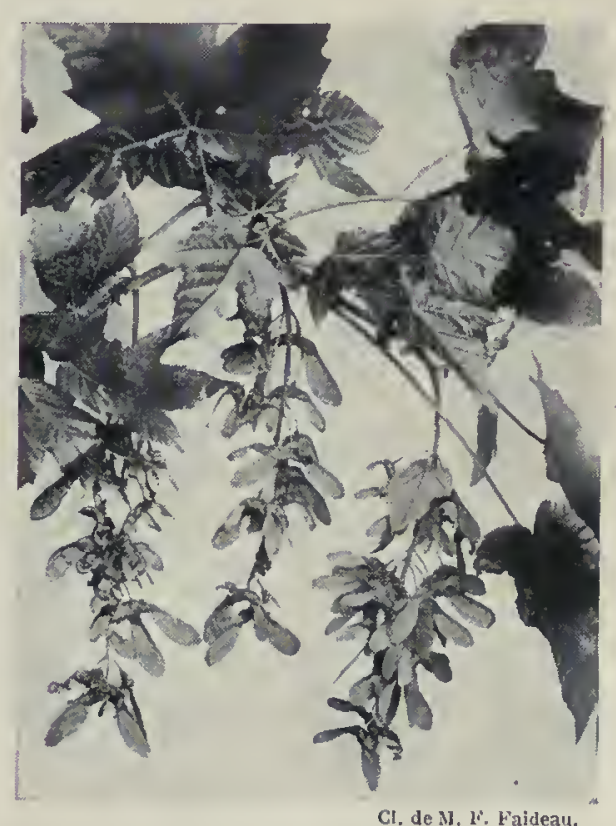

Érable sycomore; akènes ailés ou samares. 


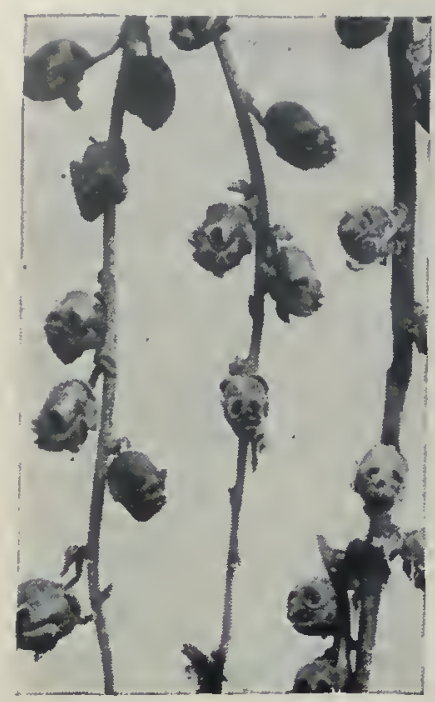

Capsules du Muflier.

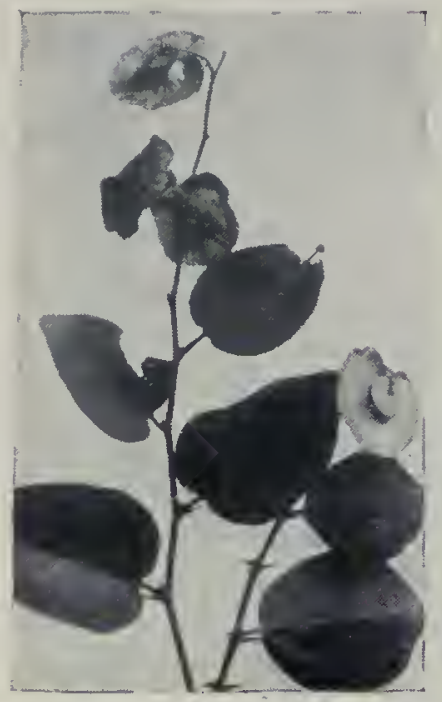

Paliure épineux.

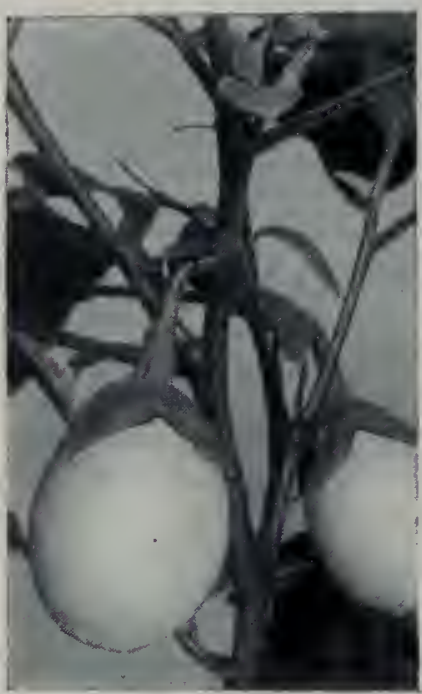

Plante aux œufs.

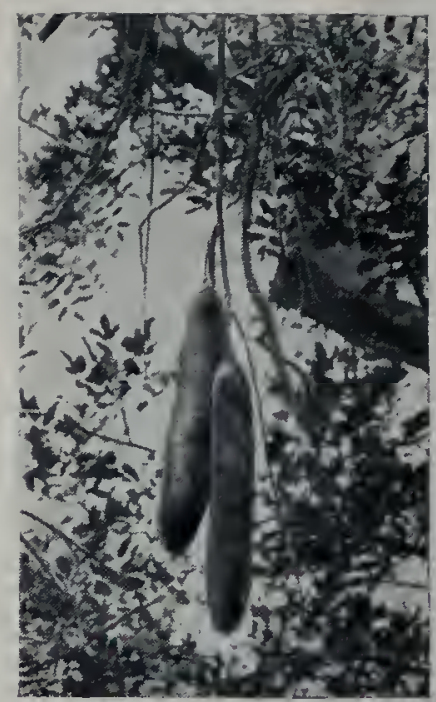

Fruits de Kigelia. grand nombre de petites écailles qui sont parfois très apparentes sur certaines espèces de Chêne. Cette cupule est formée d'un certain nombre de bractées soudées entre elles. On sait que, dans le Châtaignier, la cupule se hérisse de piquants, mais elle se fend en quatre valves en souvrant, mettant ainsi en liberté les deux fruits ou châtaignes qu'elle contient, et qui sont encore des akènes ( fig. 74, A). La constitution de la faîne du Hêtre est à peu près semblable. On voit donc ici que l'on a des fruits en apparence déhiscents: en réalité, ce qui s'ouvre ce n'est que l'enveloppe ou cupule. Cest donc une variation analogue à celle que nous citons plus haut pour la figue ou pour la mûre parmi les fruits charnus. Remarquons, en passant, que la ressemblance entre la châtaigne ct le marron d'Inde n'est quapparente : la première est un fruit, le second est une graine; autrement dit, la membrane brune et luisante qui entoure la châtaigne est un péricarpe, celle qui entoure le marron d'Inde est le tégument de cette graine.

Il y a un autre moyen de dissémination des fruits qui s'observe dans la samare; l'appareil de vol est ici une aile qui peut exister tout autour du fruit, par exemple dans l'Orme ( $\mathrm{ig}$. 74, B), et l'on peut voir tournoyer dans l'air ces fruits au printemps. Quand deux fruits ailés sont rapprochés l'un à côté de l'autre comme dans l'Érable, le développement des ailes ne peut évidemment pas avoir lieu tout autour et les deux ailes des deux fruits sont opposées.

Une autre modification importante de l'akène est le caryopse, qui peut être observé dans ce que l'on appelle improprement le "grain" de Blé, car en réalité il s'agit d'un fruit. Ces grains sont lourds: leur dissémination se fait à faible distance, comme dans le cas des Chênes, et de telles plantes sont évidemment destinées. à croître sur le sol qui les a vu naître et à constituer des associations comme les forêts ou les champs cultivés de Cćréales ou les prairies: la nature nous enseignant, en somme, comment il faut cultiver ces plantes. Dans le caryopse des Graminées, il y a soudure de la paroi de la graine, de sorte qu' à la germination, la plante, pour sortir au dehors, naura qu un obstacle à vaincre, ce qui est une condition favorable pour la réussite du développement.

Il y a une autre ca-

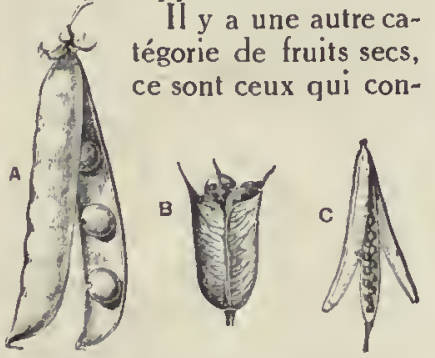

Fig. 78. - Fruits secs dehiscents. $\Lambda_{1}$, housse du Pois; $B$, follicules de l'A conit; C, sílique du Chou.

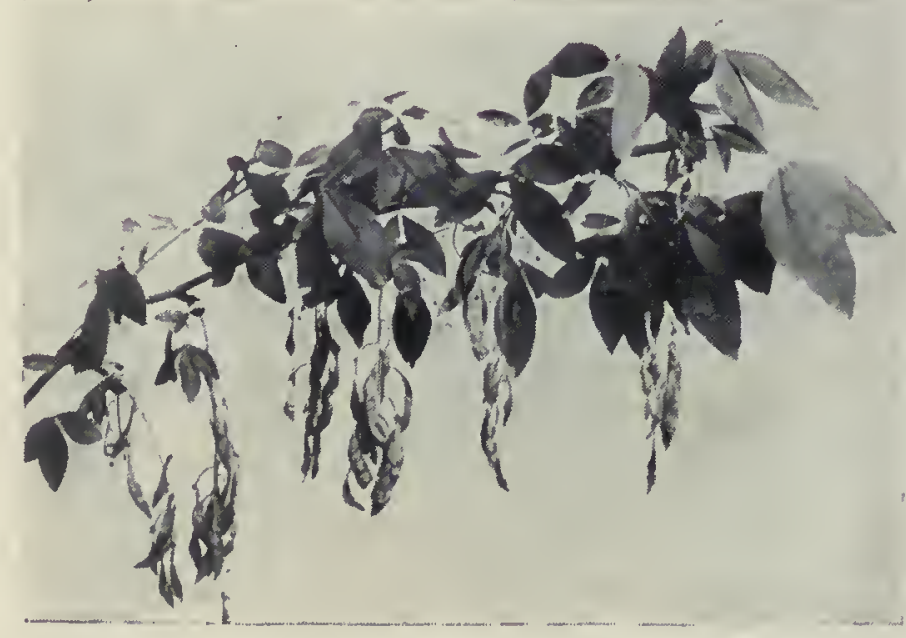

Cytise faux-ébéuicr, en fruits (gousses). tiennent plusieurs graines : leur nom générique est celui de capsule (fig. 77); il faut évidemment alors un mécanisme spécial pour ouvrir les enveloppes et permettre la mise en liberté des semences. Le plus ordinairement la capsule se fend en long et, sil s'agit d'un fruit à plusieurs loges, il pourra y avoir deux cas, suivant que la fente se manifestera au milieu des loges ou sur les cloisons qui les séparent entre elles: d'où les noms de capsule de loges ou loculicide et capsule de cloisons (septum) ou septicide. Le Lis, qui est loculicide, et le Colchique, qui est septicide, nous offrent des exemples de ces deux types. Ailleurs la capsule s'ouvrira par des pores au sommet ou sur le côté; tel est le cas des capsules poricides de Muflier et de Pavot. On connaît des exemples assez rares de capsules qui souvrent en travers : c'est ce qui arrive dans la Jusquiame, ou encore dans le Mouron rouge; le fruit porte alors le nom de pyxide ( $f$ g. $77, a, b, c$ ); cest le type de la boîte à savonnette, dont le couvercle senlève comme une calotte.

Remarquons, en passant, la bizarrerie de l'aspect de quelques fruits; celui du Muflier, lorsqu'il est ouvert et qu'on le regarde sens dessus dessous, rappelle une tête de mort; l'akène du Paliure épineux (Épine du Christ ou Porte-chapeau), entouré de son aile membraneuse, figure un chapeau; les baies de l'Aubergine ovigère (ou plante aux œufs) semblent des oufs de poule; les fruits allongés des Kigelia rappellent un saucisson pendu.

Au type de la capsule se rattachent trois modifications importantes dans le cas de déhiscence longitudinale. D’abord le légume ou gousse ( $f$ ig. 78, A), que l'on observe dans le Haricot et d'une façon plus générale dans la plupart des plantes de la famille des Légumineuses. On sait qu'il s'ouvre en deux valves qui se séparent au milieu et suivant la ligne placentaire.

Dans le follicule ( $f$ g. $78, \mathrm{~B}$ ), qui se rencontre dans la Pivoinc,

l'Aconit, c'est bien encore un seul carpelle isolé qui s'ouvre, mais seulement suivant la suture du placenta, de sorte quau moment de la déhiscence, il semble quc le carpelle se soit ćtalć et ait rcpris la forme plate de la feuillc qui lui a donnć naissance.

Enfin le fruit des Crucifèrcs mérite une mention spéciale; on lui donne le nom de silique (fig. 78, C). L'ovaire qui lui donne naissance est formé de deux loges, bien que la placentation soit sur la paroi; la loge devrait donc être unique; si elle se trouve divisée, c’est quil se forme une cloison surajoutée ou fausse cloison. La déhiscence a lieu suivant quatre lignes rapprochées deux à deux de part et d'autre de chaque placenta. Le fruit ouvert laisse apparaître au milieu la fausse cloison et deux valves. C'est là le fruit du Chou, cle. 


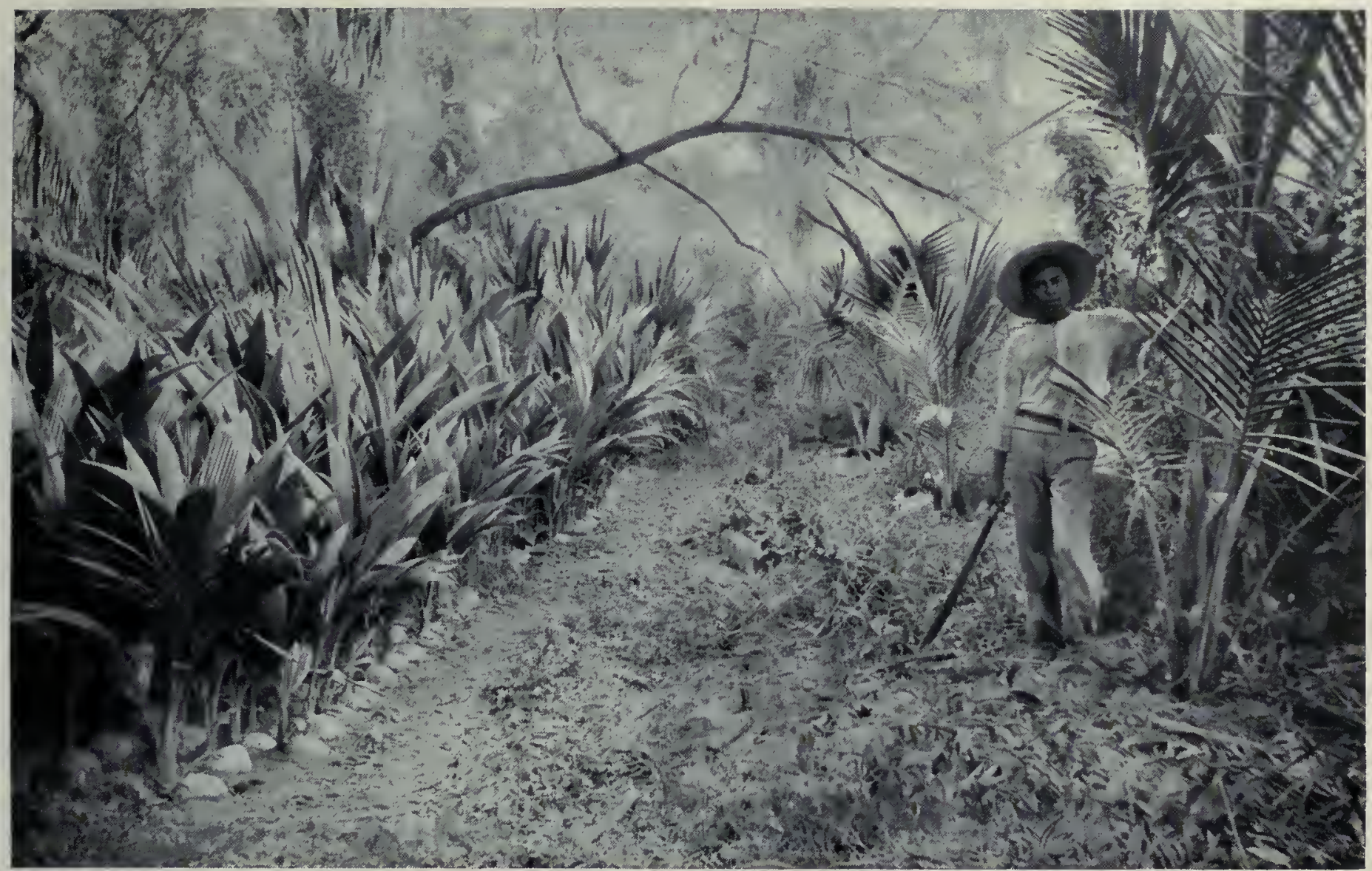

Une pépiniẻre de Cocotiers, à Tabasco (Mexique).

'hot, Waile, Mexico.

\section{LA GRAINE}

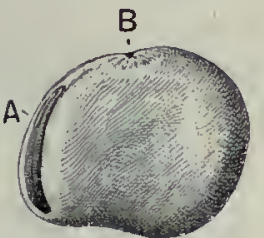

Fig. 79. - Fève montrant le hile $A$ et le micropyle $B$.
En même temps que l'ovaire grossit après la fécondation, de manière à donner le fruit, l'ovule se transforme à l'intérieur pour produire la graine. C'est elle qui constitue lorgane ultime et fondamental que la plante doit produire avant que la mort ne la fasse disparaître. Sa constitution nous importe donc grandement et nous devons en connaitre la structure interne et les propriétés mystérieuses.

Prenons d'abord une graine de Fève (fig. 79) et examinons sa surface : nous y remarquons une enveloppe assez dure que l'on appelle tégument; sur le côté, une large cicatrice ovalaire est visible, c'est le hile, par lequel s'attachait l'ovule au placenta, et lorsque la graine est devenue libre, c'est en ce point que la cicatrisation s'est općrée. A côté de cette tache s'observe une petite dépression, à peine visible, qui correspond à l'ancien orifice ou micropyle de l'ovule qui s'est fermé. Le tégument de la Fève est lisse. Examinons d'autres graines ( fig. 80$)$ : sur unè graine de Coquelicot, nous verrons à la surface du tégument un très joli réseau formé de parties saillantes qui se détachent
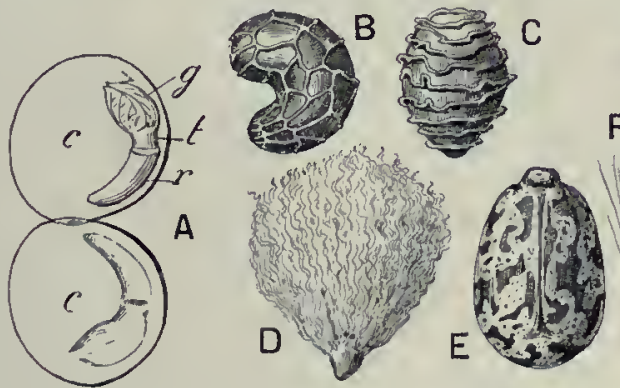

Fig. 80. - Graines.

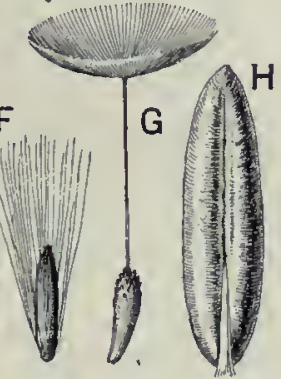

A, de Pois, ouverte: $c c$ cotylédons; $g$, Gemmule $t$, tigelle; $r$, radicule $B$, de Coquelicot (grossie); C, de Danphinelle (grossie); D, de Cotonnier; E, de Ricin; F, de Saule; $G$, fruit de Pissenlit; $H$, graine de Dattier.

du fond. La coloration du tégument n'est pas toujours uniforme; il y a souvent des taches colorées, extrêmement variées, chez le Haricot, le Ricin ; celte dernière graine est fort curieuse par sa ressemblance avec un insecte ( $f$ ig. 80, E).

Les téguments de certaines espèces sont pourvus de poils : ceux du Cotonnier, par exemple, acquic̀rent une très grande longueur et apparaissent sur toute la surface de la graine $\left(f_{g} g .80 \mathrm{D}\right)$; les anciens, qui connaissaient ce végétal, disaient de lui que c'est la plante " qui porte des toisons".

Les filaments nommés kapok, produits par l'Ériodendron anfractueux et utilisés pour le rembourrage, sont fixés à la paroi de la capsule et non sur la graine, comme chez le Cotonnier. Les poils, au lieu d'être disséminés sur toute la surface, peuvent être concentrés à une extrémité de la graine, à sa base près du hile chez les Asclépiadacées ou les Saules (fig. 80, F), les Peupliers; dans les Tillandsia, qui sont des Broméliacées épiphytes, la graine a la forme d'un filet grêle, dont la couche superficielle se désagrège en sortes de poils qui, réunis, forment une aigrette.

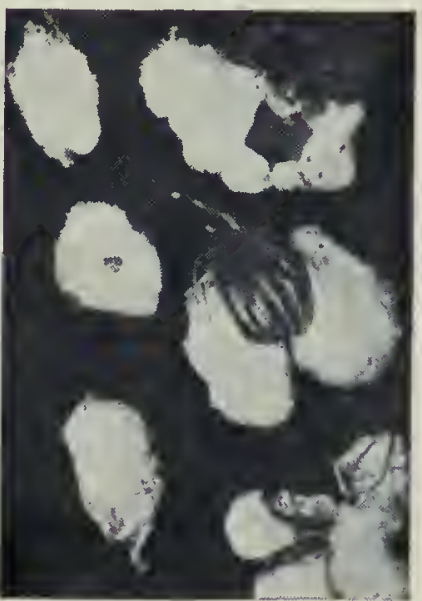

Cotonnier, fruits et graines.

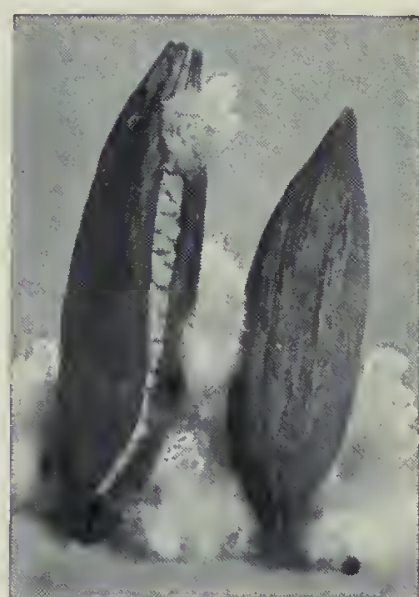

Ériodendron, fruits et graines. 


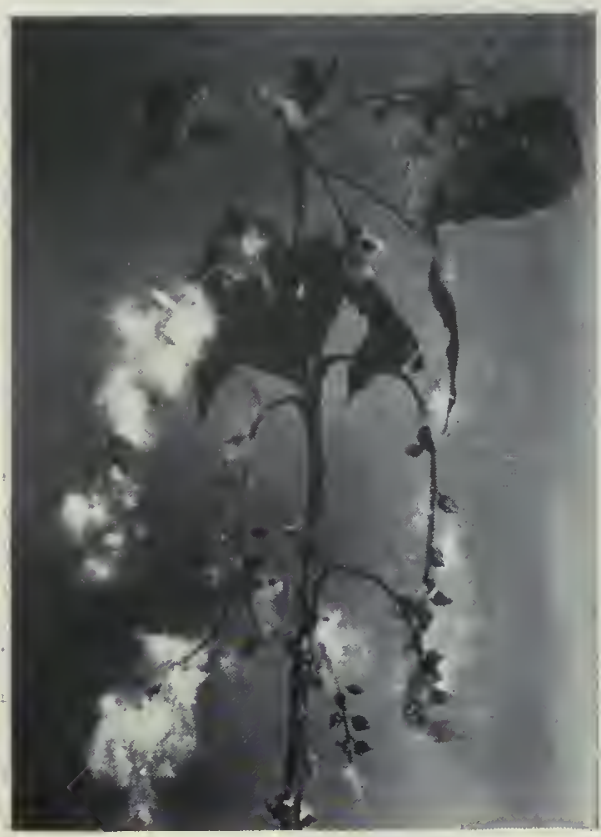

Peuplier noir avec fruits.
Dissémina tion des semences, - On entrevoit tout de suite le rôle important que doivent jouer de pareils appareils de vol pour la dissémination des semences; chacun a été gêné a u printemps par les graines aigrettées des Peupliers qui remplissent les jardins et la campagne, qui viennent parfois dans les yeux et sont très incommodantes, notamment pour les enfants très jeunes. Au lieu d'une aigrette de poils qui donne prise au vent et qui allège singulièrement la graine, il peut $y$ avoir une aile à sa surface qui fait tournoyer les semences dansl'air: $c^{\prime}$ est ce qui arrive notamment chez les Bignoniacées.

Les exemples que nous venons de citer sont très instructifs au point de vue de la dissémination des espèces. Quand le fruit contient une seule graine, c'est lui qui porte le parachute destiné à transporter au loin la semence féconde; mais quand le fruit contient plusieurs graines, $c$ est très souvent la graine qui est pourvue soit d'une aigrette, soit d'une aile.

La nature, il est vrai, peut employer d'autres ruses pour assurer la multiplication au loin d'une espèce : elle peut notamment rendre les graines collantes en provoquant la formation d'une sorte de matière gélatineuse à leur surface. Tel est le cas des graines de Lin, dont les cellules épidermiques du tégument ont la propriété de se gonfler et de se gélifier d'une manière extraordinaire au contact de l'eau. Les cataplasmes de farine de Lin sont une application bien connue de cette propriété. Déposées à la surface d'un objet quelconque, bouteille, vase, jardinière grotesque en terre poreuse, ces graines germent sur place et convrent l'objet d'une verdure tendre. L'aspect de ces germinations est si curieux, qu'elles forment la base d'un petit commerce de la rue.

Les fruits charnus sont ordinairement parés de couleurs vives, attirant le regard de l'oiseau qui avale la pulpe sucrée et dissémine les semences. La graine, cachée aux regards, n’a pas d'ordi-

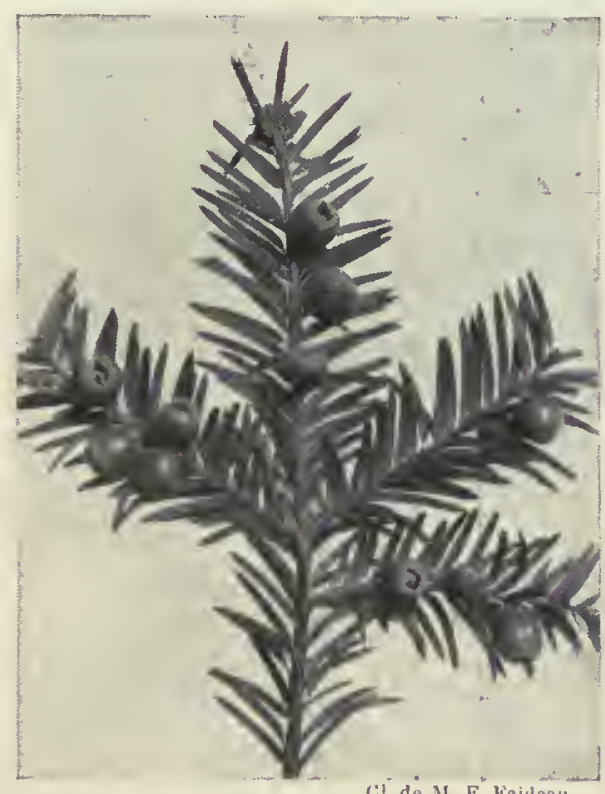

If (Taxus baccata) et fruits. naire évolué dans ce sens. Dans quelques cas cependant, elle peut être vivement colorée et charnue extérieurement et bénéficier du même mode de dissémination que les drupes et les baies. On cite la graine de Grenadier, dont le tégument est devenu charnu, rouge, de sorte que lorsquion ouvre le fruit, qui est sec et cloisonné, on trouve une série de petits corps qui ressemblent à des rubis. Il en est
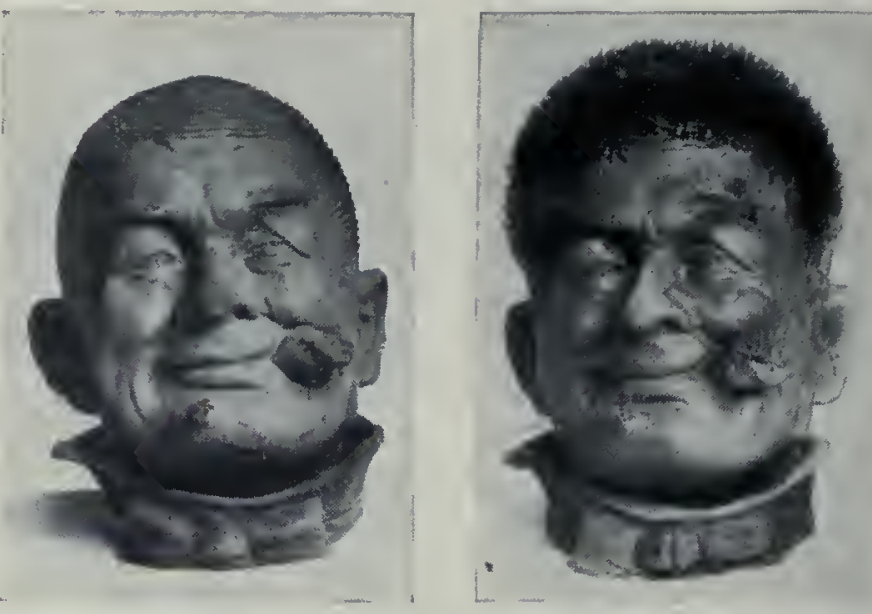

Jardinière poreuse avant et après la germination.

de même chez le Fusain. C'est pour la même raison que les graines de Passiflore et de la Figue d'Inde ou Opuntia sont comestibles.

Si par hasard, ce qui est très exceptionnel, la graine est nue, non enveloppée dans un ovaire, elle pourra alors devenir charnue comme un fruit. C'est ce qui arrive notamment pour un arbre curieux du Japon, que l'on appelle l'arbre aux quarante écus ou Ginkgo, dont les graines ressemblent à des drupes : elles sont dures à l'intérieur. ll en est de même des graines de l'If, entourées par un sac rouge supplémentaire. On voit donc que les mêmes fins ont été obtenues par l'emploi des mêmes moyens par d'autres organes.

Structure interne. - Passons maintenant à l'étude de la constitution interne de la graine ( $f \mathrm{~g}$. $8 \mathrm{l}$ ) et reprenons celle de la Fève ou du Haricot. Enlevons les téguments, opération qui se réalise assez aisément, et nous trouvons ce que l'on appelle l'embryon. Il est ici assez gros, et formé principalement par deux grosses masses charnues, planes sur les deux surfaces en contact, convexes sur les autres : ce sont les cotylédons ou encore les feuilles primordiales de la future plante. Si nous écartons ces cotylédons en les étalant et si nous observons le petit corps cylindrique qui se trouve entre eux, nous verrons qu'il est formé de trois parties : une partie cylindro-conique à une extrémité, c'est la petite racine ou radicule ; au-dessus sobserve une partie cylindrique qui est la tigelle; enfin, au sommet, de petites feuilles dont l'ensemble constitue la gemmulc. On voit donc, d'après l'énumération qui vient d'être faite, que les divers organes de la future plante sont déjà constitués.

Dans les deux exemples de Légumineuses que nous avons choisis, les cotylédons sont épais, charnus, gonfés et remplis de matière nutritive qui servira à l'alimentation de la future plante, qui a, pour ainsi dire, son grenier à l'intérieur d'elle-même.

Il n'en est pas toujours ainsi et, très communément, les cotylédons sont minces; la plantule entière est même souvent très petite et, tout autour d'elle, se développe un tissu nourricier que l'on
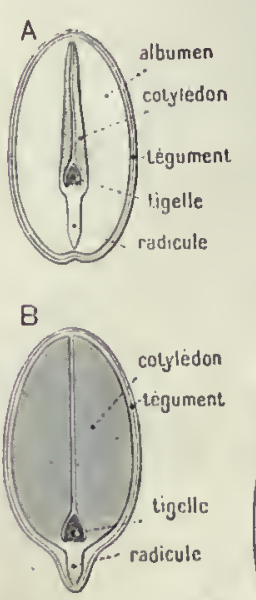

Fig. 81. - Coupes scliénatiques de graines.

$\Lambda, \dot{a}$ albumen ; $B$, sans albumen. appellel'albumen. Il est constitué par des cellules bourrées de matières de réserve, comme l'amidon dans l'albumen du Blé (fig. 82), par exemple, et c'est grâce à l'abondance de cette substance que cette plante est devenue alimentaire, objet de la convoitise de l'espèce
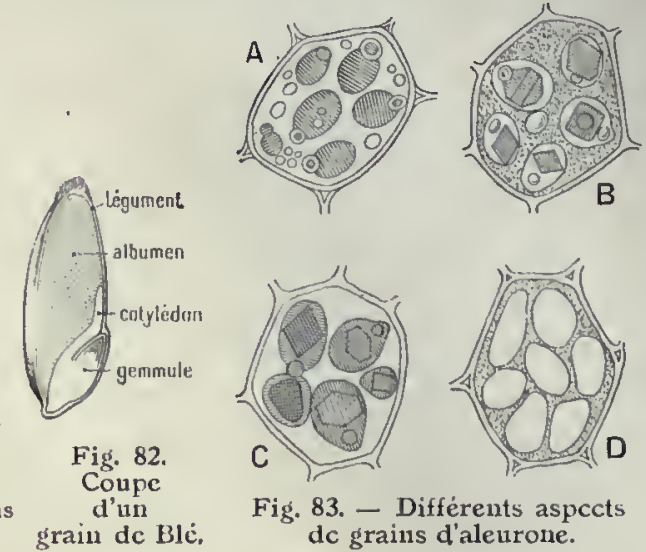

Fig. 83. - Différents aspccts dc grains d'aleurone. largement ouvert; mais ici ce sac est l'arille, sorte de tégument 
humaine, qui lui dérobe l'épargne qu'elle avait soigneusement amassée pour la nourriture de sa progéniture.

Il y a souvent dans l'albumen d'autres matériaux que l'amidon. Dans la graine de Ricin, il y a d'abord de I'huile et cest elle que l'on extrait et que l'on emploie en médecine pour ses propriétés purgatives: mais il $\mathrm{y}$ a en outre une réserve d'une autre nature, surtout formée de matières quaternaires ou albuminoïdes, qui s observe dans des globules que l'on désigne sous le nom de grains d'aleurone ( $f$ ig. 83 ) et dont la constitution est complexe. On y voit de la matière albuminoïde qui se présente sous forme d'un faux cristal, car ses angles sont variables, puis une petite masse sphé-

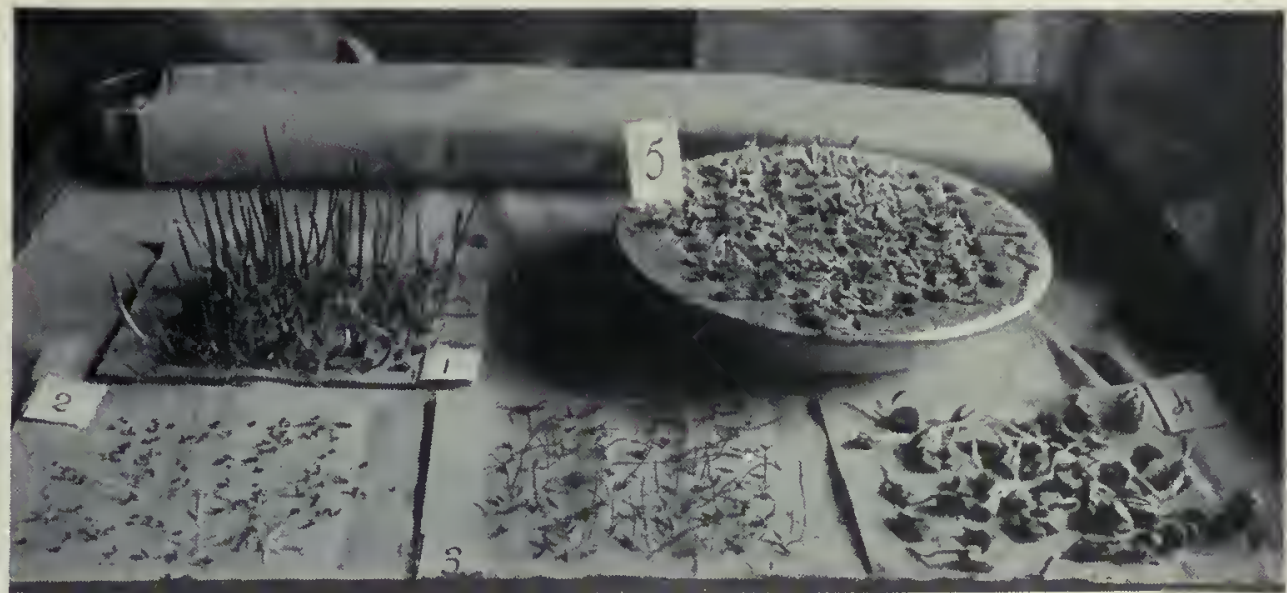

Graines germées. 1, de Seigle; 2, de Trèfle; 3, de Ray-grass; 4, de Maîs; 5 , de Betterave.

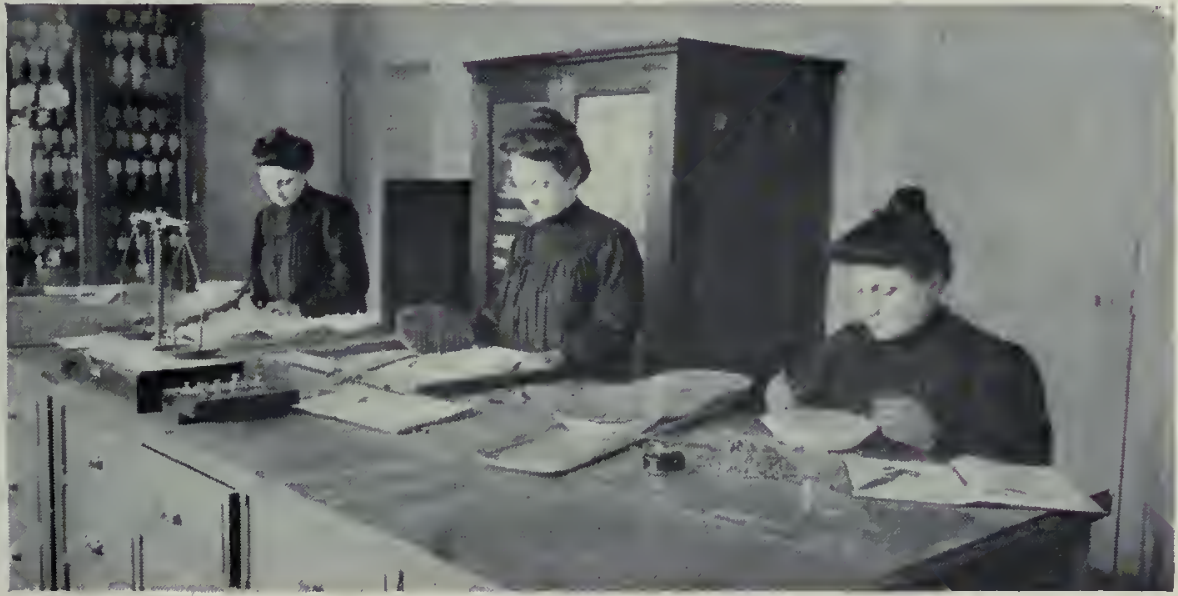

Préparation du sable et visite des graines germées.

des espèces précieuses. Parmi les plantes à graines perdant rapidement leur pouvoir germinatif, on peut citer l'Hevea, cet arbre à caoutchouc qui est l'une des principales richesses du Brésil.

Que faut-il en général pour qu'une graine manifeste à l'extérieur sa vitalité? II n'est pas nécessaire de lui donner grand'chose: il lui suffit d'un peu d'humidité et d'un peu de chaleur; il est cependant indispensable que la terre soit aérée, et c'est pour cela qu'avant d'y déposer la semence féconde, le laboureur doit retourner et ameublir le sol de manière que l'air y circule plus aisément. Si la graine est bonne, c'est-à-dire si elle n'a pas été mangée par les charançons ou rongée par la carie, maladie due à un Champignon, elle devra germer.

Il y a encore une autre catégorie dè semences qui ne germent pas: ce sont les graines trop vieilles.et, pour les ranimer, les prati-

rique qui est de nature calcaire; entre ces corps, il y a de la matière albuminoïde amorphe.

Conditions nécessaires pour la germination. - La graine abandonnée à elle-même demeure inerte et incapable de tout changement; c'est une sorte d'organe engourdi qui n'attendra qu'une occasion favorable pour se réveiller. Parfois cette occasion ne se présentera pas et la graine se sera endormie tout à fait : elle sera incapable de revivre, elle sera morte. Il y a une série de graines, surtout celles qui contiennent des matières oléagineuses, qui perdent aussi leur pouvoir germinatif avec la plus grande facilité. Cette proprićté importante est très fâcheuse quand les graines appartiennent à des espèces des colonies ou des contrées tropicales: les graines ne peuvent se conserver intactes pendant la traversée et, quand elles arrivent à destination, on essaie en vain de leur donner un regain de vitalité. Pour obvier à cet inconvénient, on est obligé d'avoir recours à l'artifice de la stratification. On place les graines isolées les unes des autres dans des boîtes en fer-blanc en lits successifs, en intercalant ces derniers de couches de sable, de terre pas trop humide, de poussière de charbon de bois. Il faut que les graines ne soient pas au contact des parois de la boite : le substratum ne doit pas être trop humide, pour éviter la pourriture; il ne doit cependant pas être trop $s e c$, pour que la dessiccation des graines nait pas lieu. On arrive, avec un peu de pratique, à trouver les conditions favorables; la germination commence souvent en cours de route, et, à l'arrivée, en ouvrant la boîte, on constate le bon état dans lequel sont les plantes, que lon s'empresse de mettre dans la serre à multiplication. On arrive ainsi à expédier au loin

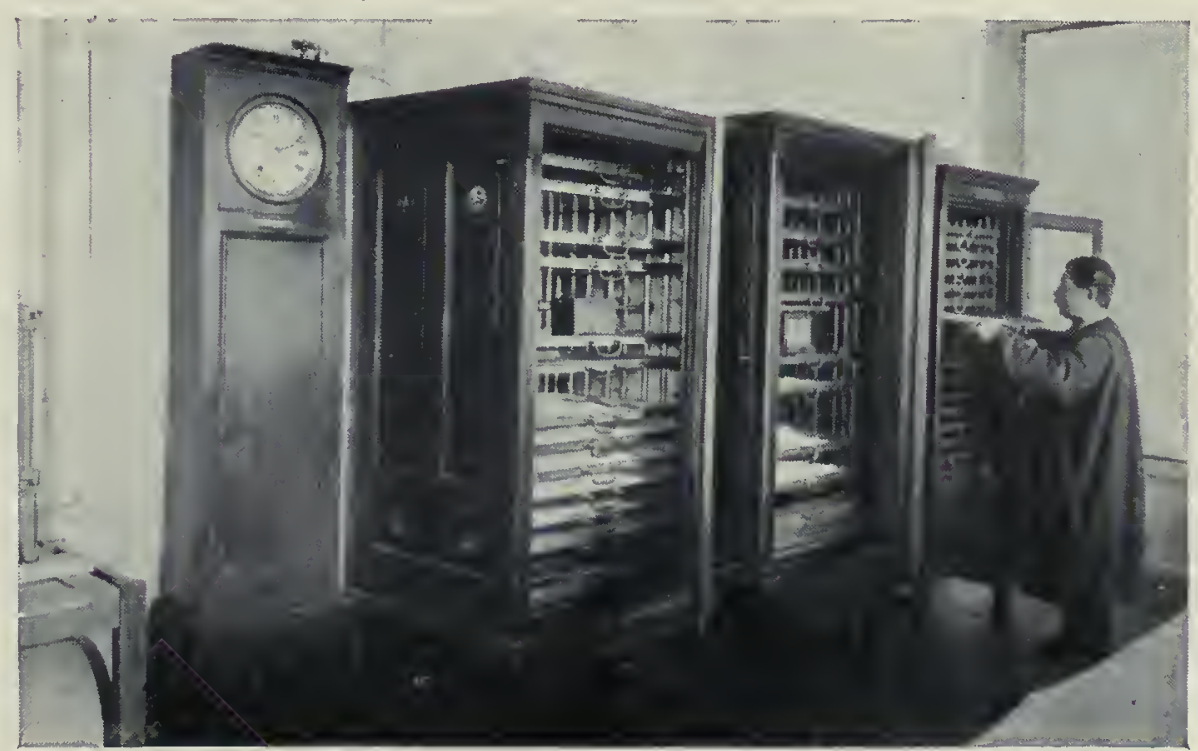

Étuves Sclıribanx pour l'étude du pouvoir germinatif des graines. 


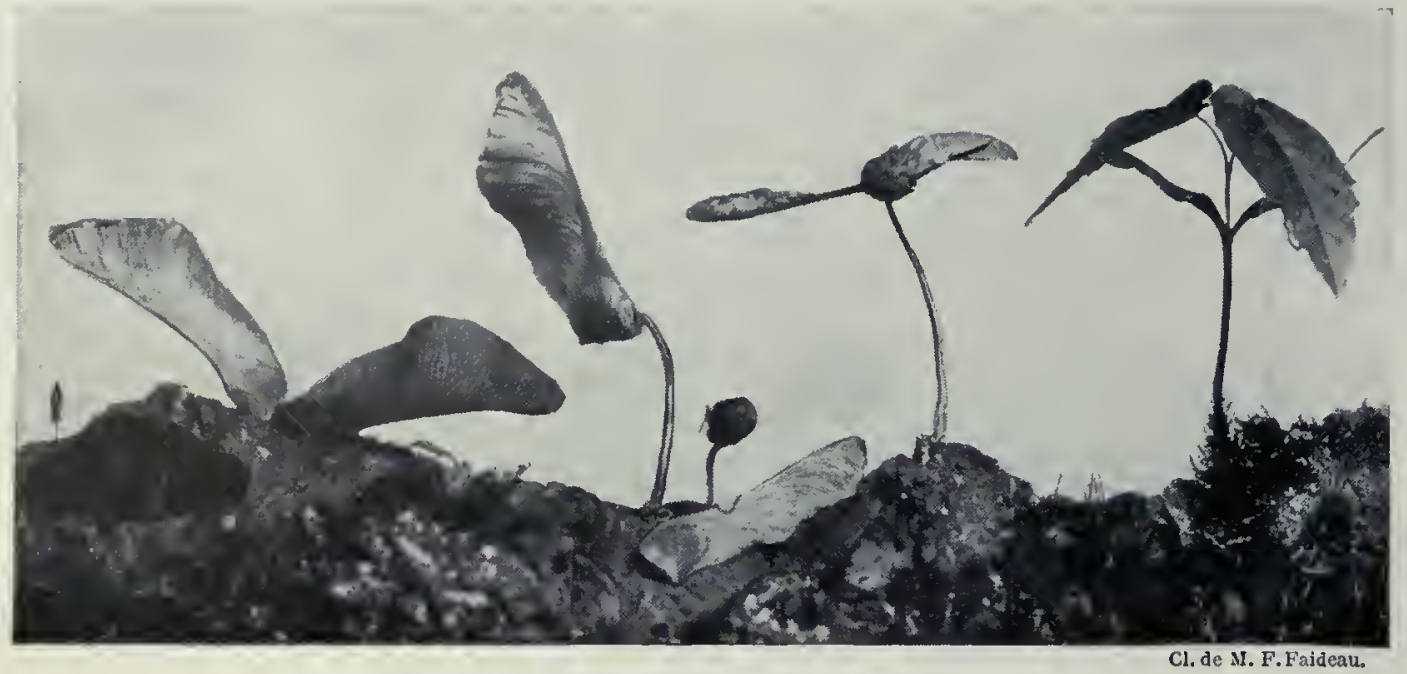

Phases snccessives de germination de l'Érable.

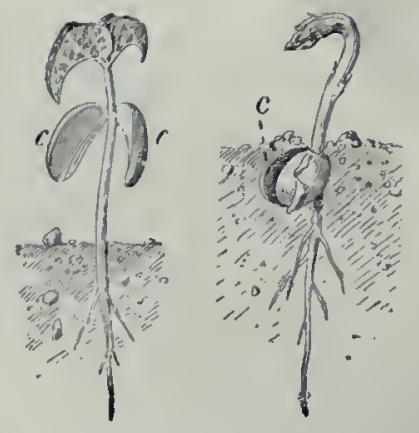

Fig. 84. Cotylédons épigés $(\mathrm{c}, \mathrm{c})$ du Haricot.

Fig. 85. Cotyledons hypogés (c)

Phénomènes externes de la germination. Dans les conditions normales, par exemple pour les graines de Haricot ou de Pois que

ne réussit pas avec les graines de Ricin, par exemple, parce qu'elles contiennent de l'huile dans l'amande; or l'huile, chacun le sait, est plus légère que l'eau.

Les grands établissements horticoles français apportent un soin méticuleux au choix des semences; aussi les graines sélectionnées coûtent-elles fort cher. Pour les obtenir, les fruits sont cueillis, à l'époque de leur maturité, par temps sec, mis au séchoir, puis battus et égrenés. Un premier triage élimine les graines insuffisamment mûres ou mal conformées. Dès leur arrivée dans le hall de réception de l'horticulteur, les semences subissent un nouveau triage, mécanique ou à la main, selon les espèces, et on prélève sur chaque sorte un échantillon qui servira de contrôle et permettra d'apprécier l'identité, la pureté, le pouvoir germinatif et la franchise d'espèce.

Le pouvoir germinatif est essayé dans les étuves Schribaux. Ce sont de grandes armoires à porte vitrée, chauffées au gaz et pourvues de régulateurs de température. Dans leur intérieur glissent des tablettes sur lesquelles sont les graines, simplement posées sur des feuilles de papier filtre maintenues humides. Une horloge, formée d'un cylindre faisant un tour complet en vingt-quatre heures, réalise automatiquement l'ouverture et la fermeture des robinets qui commandent les régulateurs; l'étuve, en effet, doit être réglée à $20^{\circ}$ pendant dix-huit heures et à $28^{\circ}$ pendant les six heures suivantes, afin d'imiter les variations analogues des températures diurne et nocturne ; des thermomètres enregistreurs très sensibles contrôlent la marche de la température. Au bout d'un certain temps, l'état des graines en germination est vérifié et noté. Ces essais sont complétés par d'autres en pleine terre ou sous abri. l'on a fait tremper dans l'eau pendant une nuit pour les bien imbiber, la germination se manifeste très nettement au bout d'un petit nombre d'heures ou de quelques jours.

Ces phénomènes sont très intéressants à suivre et ils frappent très vivement les enfants qui les étudient $d$ 'une manière attentive. Ce corps inerte qu'était la graine sort de sa torpeur et se réveille comme sous l'influence d'un coup de baguette magique, et la plantule apparaît avec une régularité merveilleuse, la même série de manifestations s'observant avec une constance rigoureuse. La paroi des téguments, à l'endroit de l'ancien orifice de l'ovule, se gonfle et ne tarde pas à crever, puis un petit corps conique apparaît : c'est la petite racine qui montre sa pointe. Elle sort bientôt plus résolument et tout de suite elle se courbe, de manière à prendre une direction verticale en se dirigeant vers la terre, et s'enfonce très rapidement. Dans cette première phase, le Haricot et le Pois se comportent de la même manière ( $f$ ig. 84 et 85 ), mais, peu de temps après, une différence se manifeste entre eux. Dans le premier, la graine ne reste pas dans la mousse ou la terre, elle est soulevée par le développement de la petite tige qui, maintenant, s'allonge dans une direction verticale, mais vers le haut; la tigelle est épicotylée. Avec le Pois, les choses se passent autrement : la graine reste à la surface du sol ou dans la terre; c'est que la tigelle ne sallonge pas; la germination est dite hypogée.

Au stade suivant du développement du Haricot, les enveloppes de la graine tombent et les cotylédons ou deux premières feuilles s'écartent et s'étalent, puis bientôt après, entre les deux grosses feuilles charnues, la gemmule pousse et donne ce qui deviendra la tige définitive pourvue de ses feuilles. Le Hêtre, le Cerisier.

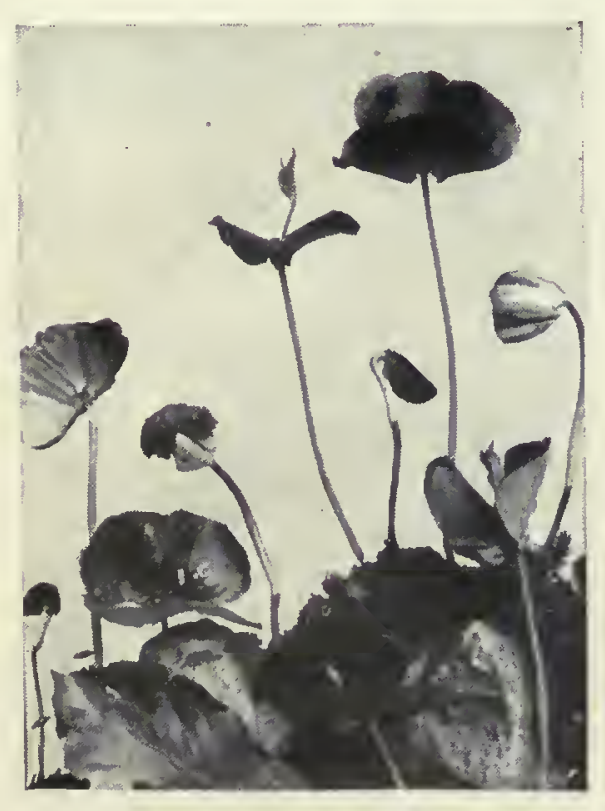

Germination du Hêtre.

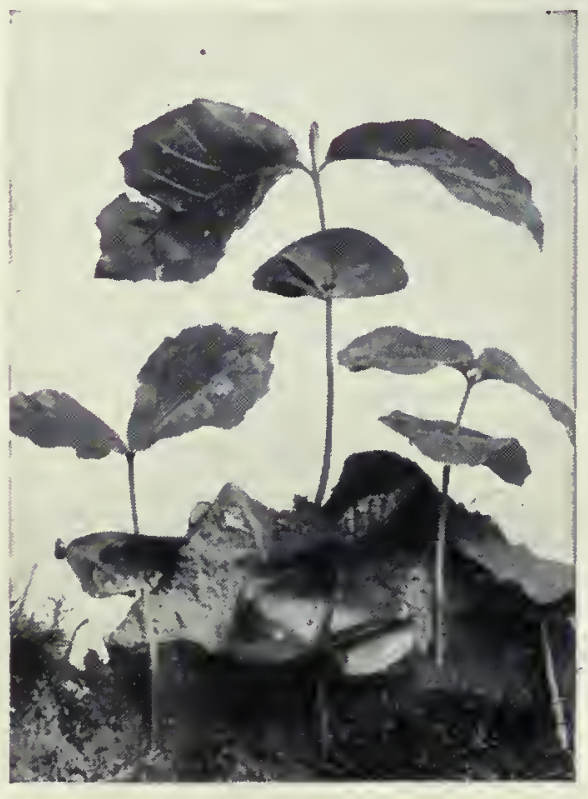

Plantules du Hètre.

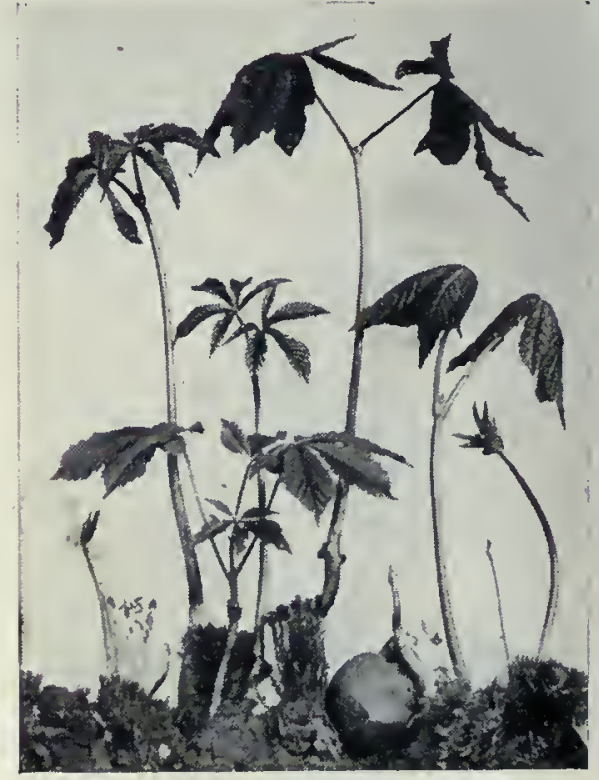

Jeunes Marronniers d'Inde. 
l'Érable et nombre d'autres Dicotylédones, ainsi que la pluzart des Conifères, ont une germination analogue.

Le Pois se comporte d'une manière différente, puisque la graine reste sur le sol, car la petite tige primitive ne sort pas; la tige définitive (axe épicotylé) apparaît cependant, mais plus tard; elle part de la graine au même point que la racine, mais a une orientation inverse. Le Chêne, le Marronnier d'Inde, le Noyer et la plupart la plantule entre en activité comme si elle allait accomplir toutes les phases de son développement; mais ce que veut le malteur, c'est provoquer l'apparition de la diastase ou substance digestive; une fois qu'elle est formée, il cherche à entraver son action sur les matières de réserve amylacées de la graine. Il sait que la germination est arrivée au stade qu'il désire, d'après la longueur du système des petites racines formant ce qu'il appelle la plumule. 11 porte

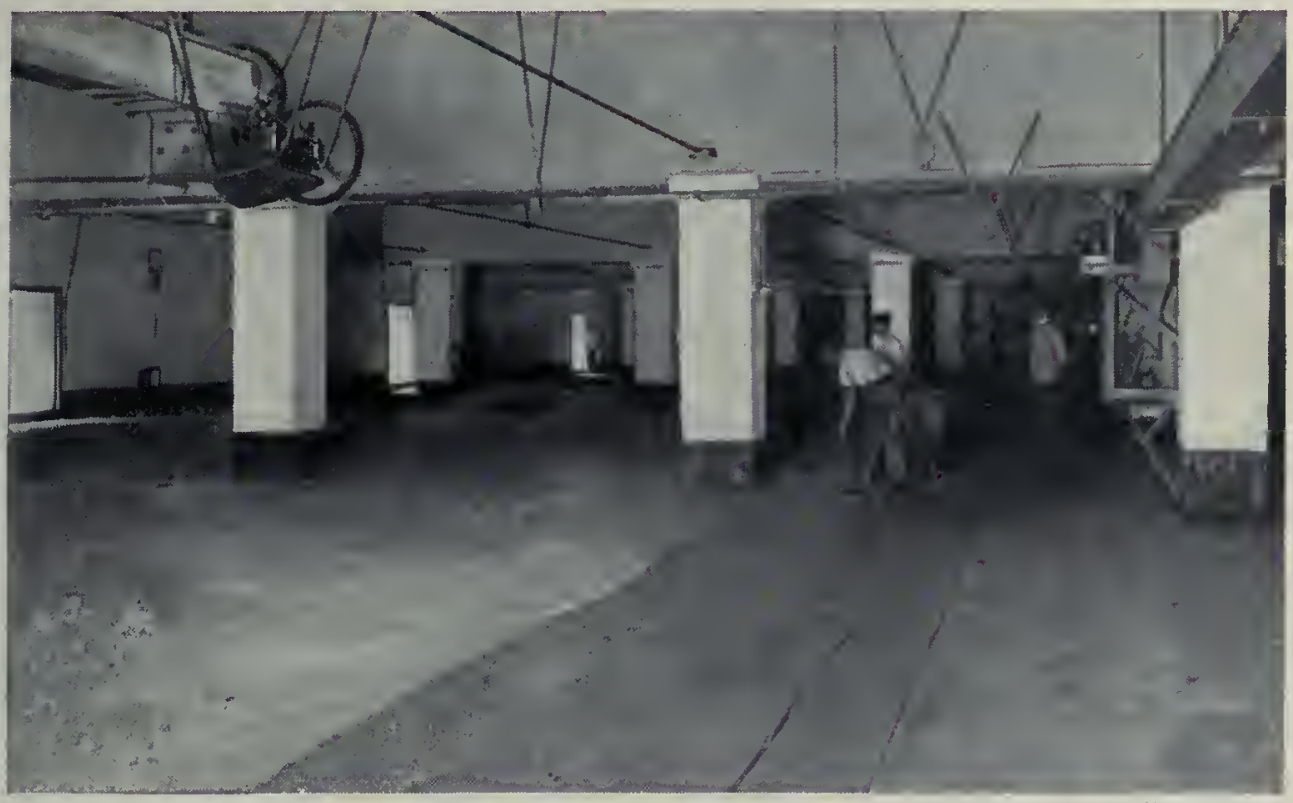

Caves dans lesquelles se fait la germination de l'orge.

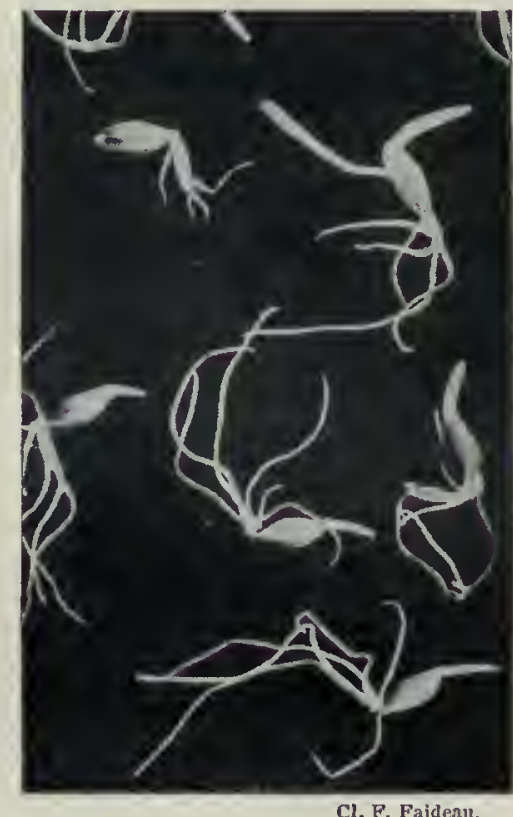

Orge germée pour la brasserie. des Monocotylédones germent comme le Pois. Chez le Cocotier, l'enveloppe ligneuse de la noix présente un orifice arrondi de moindre résistance du péricarpe par lequel la radicule sort.

Il y a d'autres types de germination, dont le Ricin nous offre un exemple. Les cotylédons sont ici minces, et l'embryon est aplati au milieu de la graine; les deux premières feuilles cotylédonaires sont appliquées sur la matière blanche de l'albumen. Quand la germination s'opère, on s'aperçoit, lorsque la graine souvre, que les téguments tombent : les cotylédons apparaissent, ils ont grandi, sont devenus verts. Lalbumen qui les enveloppait presque complètement a bien suivi, pendant un certain temps, leur accroissement, mais il a, pour ainsi dire, mauvais aspect ; cest à ses dépens que s'accroissent, en effet, la plantule et en particulier les cotylédons; de sorte que bientôt, quand les feuilles cotylédonaires acquerront une taille un peu plus grande, elles se libéreront tout à fait de ce tissu nourricier qui ne restera plus à leur base que sous forme de lambeaux d'un blanc sale, à moitié décomposés.

Phénomènes internes de la germination. - Que s'est-il passé pendant ce temps dans la graine? Des phénomènes internes très curieux s'y sont manifestés : la plantule $a$, pour ainsi dire, digéré l'albumen comme l'animal digère un morceau de viande qui est ingéré dans son estomac, et par un mécanisme chimique analogue, car la digestion est un des phénomènes les plus généraux qui existent. Pour en avoir une idée, nous étudierons la germination de l'orge, où le phénomène de la digestion des graines a été utilisé par les brasseurs et malteurs, sans qu'ils s'en doutent, depuis un temps immémorial, pour la fabrication de la bière. L'orge est introduite dans de grands bassins avec quatre fois son volume d'eau et agitée constamment, de façon à chasser les bulles d'air emprisonnées entre les grains. Les grains sains vont au fond du bassin, les vides surnagent et sont enlevés. L'orge se gonfle et simbibe d'eau. On la retire du liquide, puis on la porte sur des planches où elle doit être accumulée en couches de 50 centimètres d'épaisseur. La germination se manifeste, l'orge s'échauffe et, quand le germe commence à apparaître, on réduit successivement l'épaisseur de la couche de graines jusqu à 10 centimètres. La germination dure dix à douze jours en saison chaude, quinze à vingt en saison froide. La; saison favorable pour le maltage, c'est-à-dire pour l'obtention du malt ou orge germée, est le printemps (mars-avril), et les meilleures bières sont celles de mars. Pendant toute cette opération, on provoque le réveil de la graine: alors rapidement au séchoir, qui est une sorte de grenier aéré, puis dans une étuve à courant d'air ou touraille, et c'est l'opération du touraillage. Les graines, pour être desséchées rapidement, doivent être fréquemment retournées à la pelle; ces pelletages répétés amènent la rupture des radicelles devenues cassantes et qui peuvent être séparées par tamisage. Comme de juste, cette opération du touraillage doit être exécutée à une température suffisamment élevée pour qu elle soit rapide, mais assez basse, toujours inférieure à $55^{\circ}$, pour que la diastase ne soit pas atteinte, car c'est une substance qui se décompose aisément par la chaleur. Les grains concassés, déchirés et complètement secs constituent le malt, que le brasseur utilisera à sa convenance.

L'opération du brassage est très délicate, bien qu'elle consiste essentiellement dans le mélange du malt avec de l'eau chaude, mais la température ne doit osciller qu'entre les limites extrêmement restreintes de $60^{\circ}$ à $70^{\circ}$. Or, comme l'industriel opère sur de grandes masses, c'est une opération peu facile, d'autant plus, en fait, que de $70^{\circ}$ à $68^{\circ}$ on a des résultats très différents de ceux que l'on obtient de $64^{\circ}$ à $68^{\circ}$. Pour fixer les idées, par exemple, dans le premier cas, à la suite de l'action de la diastase sur l'amidon, on a I de maltose et 5 de dextrine; dans le second cas, 2 de maltose et 5 de dextrine. Or, le brasseur a intérêt à obtenir une certaine réaction, toujours la même, pour avoir une bière déterminée, exigée par le goût du consommateur ; c'est pour cela 'qu'il doit intervenir, et ne peut pas laisser la graine digérer comme elle l'entend.

Les Japonais utilisent ces pténomènes d'une autre manière : ils saupoudrent sur le riz, tué par la cuisson, une moisissure, l'Aspergille du riz, et c'est ce Champignon qui est chargé de trans* former la réserve, de manière à obtenir le koji, en vue de la fabrication du saké, liqueur nationale qui correspond à une production annuelle se chiffrant par millions. On mélange une toute petite mesure de spores d'Aspergille avec une certaine quantité de riz sec et on sème ce mélange sur le reste des graines. On replie les nattes et on agite le riz pour assurer la répartition. Le germoir est une cave où l'on peut maintenir l'humidité et une certaine constance de température. Il y a échauffement par la végétation du champignon. Le troisième jour, le riz a un aspect laineux. En été la fabrication du koji est interrompue. Le koji contient du glucose et de la dextrine. Le saké s'obtient en mélangeant 21 de koji, 68 de riz cuit, 72 d'eau; l'action a lieu à froid.

Voilà donc deux grandes industries qui sont fondées sur l'étude de la germination. Nous aurons occasion d'en signaler d'autres. 


\section{DU MOUVEMENT}

\section{CHEZ LES PLANTES}

Nous sommes habitués à considérer les plantes comme des êtres immobiles et ce caractère est même un de ceux qui nous frappent le plus et celui qui s'oppose de suite à la propriété la plus manifeste de l'animal. La fixité est cependant plus apparente que réelle, car le moindre souffle de vent fait bruire le feuillage et les branches et agite le Chêne aussi bien que le Roseau; en second lieu, la plante croit et la croissance est un mouvement d'une extrême lenteur. Nous avons dit, d'autre part, que les cellules dont se compose un végétal sont formées de petits compartiments à carapace rigide, à l'intérieur de laquelle s'agite la matière vivante qui est toujours en mouvement. Si les mouvements du protoplasma ne se trahissent pas au dehors, c'est que la cuirasse de cellulose de chaque cellule met obstacle à leur manifestation.

Mouvements protoplasmiques. - Cela est si vrai que si l"on imagine que l'on puisse extraire le globule protoplasmique de sa boite, il devra être mobile. C'est, en effet, ce qui se réalise parfois dans le règne végétal, lorsque les zoospores se produisent ou quand les anthérozoides sont mis en liberté (fig. 86). On voit, par exemple, dans les $\mathbb{E}$ dogones une cellule s ouvrir comme une boîte, de manière à permettre au contenu protoplasmique de s'échapper. Ce protoplasma nu est pourvu de petits appendices ciliaires, qui sont disposés à la partie antérieure du corps mobile en forme de couronne et, grâce à l'agitation continue de ces filaments extrêmement fins, qui battent l'eau comme des rames, le petit globule de matière vivante peut sagiter dans tous les sens dans le liquide ambiant. D'autres fois, les cils des zoospores, au lieu d'être disposés en couronne, sont répartis sur toute la surface de la masse mobile : c'est le cas des zoospores de Vauchérie ( fig. 87); mais le cas le plus ordinaire est celui où les cils se réduisent à deux : tous deux en avant, ou l'un en avant, long et flexible, qui

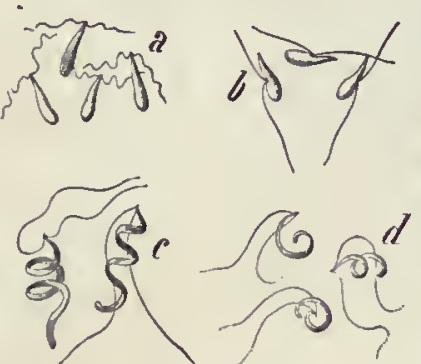

Fig. 86. Antherozoïdes.

$a$, Sphæroplea ; $b$, Fucus; $c$, Polytric d, Pellia.
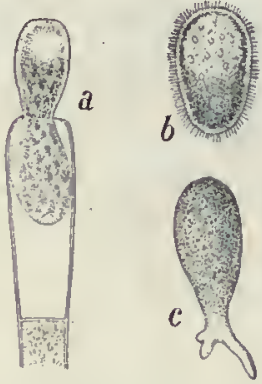

Fig. 87. - Zoospor
de Vauchérie. de Vauchérie. $a$, s'échappant; $b$, libre:
c, fixée et germant.

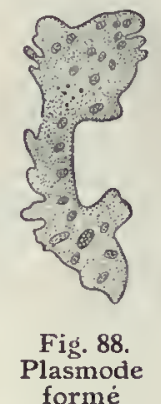

formé

par la fusion

jeunes
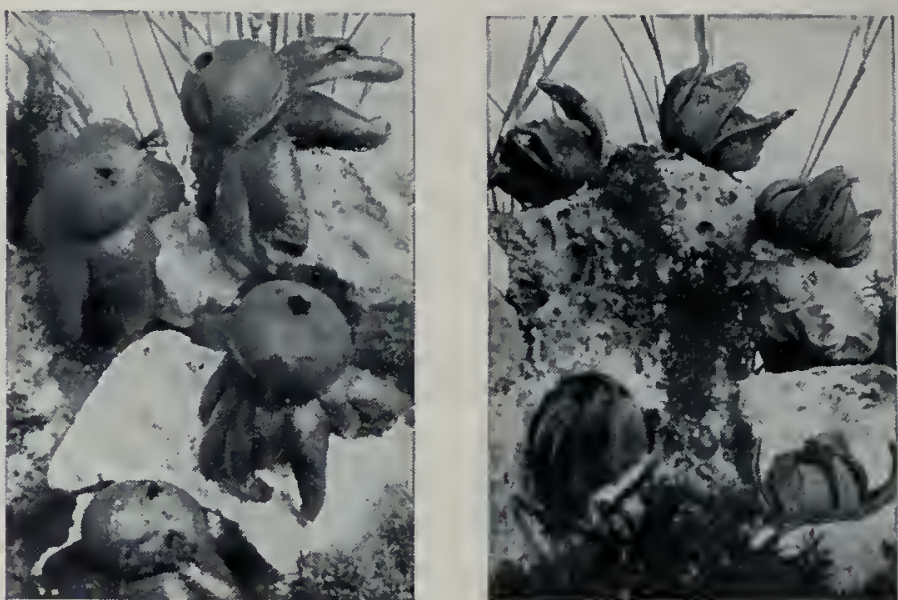

Cl. F, Faideau.

Geaster hygrométrique ouvert et contracté.

fonctionne comme une rame; l'autre en arrière, qui sert de gouvernail. Grâce à ces appendices, les mouvements de ce petit organisme sont prompts et rapides. Il peut arriver parfois, comme dans les anthérozoïdes des Mousses et des Fougères, que le corps mobile prenne une forme de tire-bouchon; il s'avance alors d'un mouvement de vis et arrive peu à peu à vaincre ainsi les obstacles qui se trouvent sur sa route.

Les mouvements du protoplasma ne sont d'ailleurs pas nécessairement liés à la présence de cils vibratiles, car dans les Myxomycètes (fig. 88) il existe des masses de protoplasma nu, appelées myxamibes, qui se déplacent comme les animaux inférieurs connus sous le nom d'amibes. C'est une sorte de mouvement de reptation, avec production, à la surface du protoplasma, de bourgeons qui grossissent et où, finalement, toute la masse vivante finit par se porter. Ces myxamibes, qui rampent ainsi dans le milieu, se rencontrent, se fusionnent, grossissent considérablement et donnent les plasmodes. Ce sont souvent d'énormes masses de protoplasma nu, ressemblant à une sorte de gelée qui se déplace sur les supports, qui grimpe même sur les arbres. Ces plasmodes s'observent dans les forêts; on les rencontre encore dans les tanneries, où ils forment des masses jaune d'or connues sous le nom de fleurs de tan.

On peut donc tirer de ce qui précède cette conclusion qu'il ne faut pas considérer comme absolus les caractères de l'animal et de la plante, tels que les donnait Linné, qui disait: "L'animal se meut, la plante est immobile. "La carapace cellulosique est, en général, l'obstacle principal au mouvement ou, du moins, à sa manifestation au dehors. Il existe cependant des cas, comme celui des Diatomées, où l'enveloppe dure n'empêche pas le mouvement; la cellule se meut tout d'une pièce, comme un guerrier couvert d'une forte armure, mais malgré cela très agile et très prompt.

Les déplacements des Algues mobiles sont provoqués et dirigés par les agents extérieurs, notamment la lumière, la pesanteur, etc. Pour une intensité lumineuse déterminée, les zoospores se dirigent vers la source, mais après avoir été attirées on 'les voit fuir, puis revenir en avant, revenir en arrière, cela par une série d'oscillations. Desroches a établi que les zoospores d'une Algue (Chlamydomonas), dans leurs mouvements sous l'influence de la lumière, suivent la loi de Weber-Fechner, loi trouvée par l'étude du système nerveux.

Ces mouvements alternatifs et oscillatoires, que nous venons de signaler pour les organismes libres et simples, se manifestent encore pour des organismes plus compliqués comme les Oscillaires, qui doivent leur nom à la particularité, que présente l'extrémité du filament qui les compose, d'osciller comme un pendule. Il s'agit, dans ce cas, d'Algues bleues qui sont constituées par des filaments très étroits et très longs. On les rencontre au pied des murs exposés au nord où elles forment un enduit crustacé d'un vert bleu 


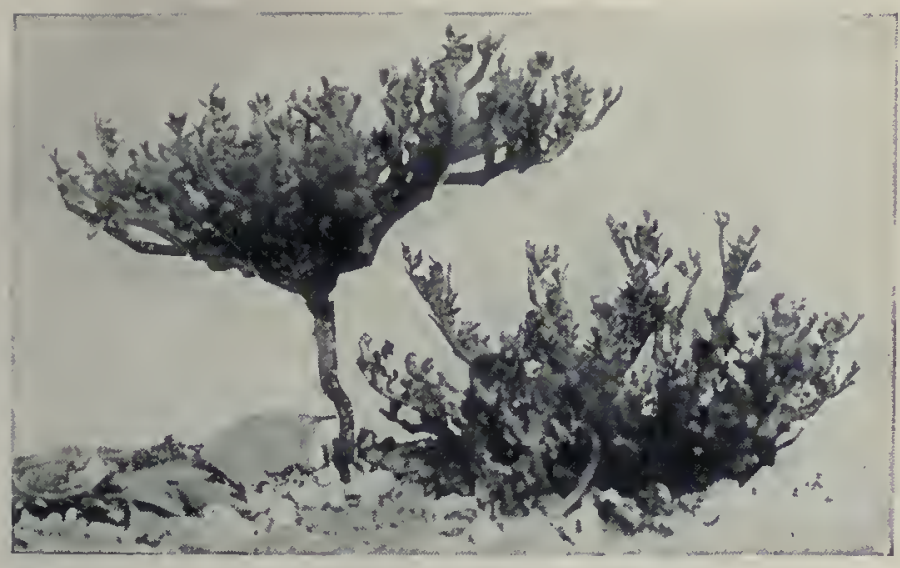

Rose de Jéricho ouverte par l'humidité.

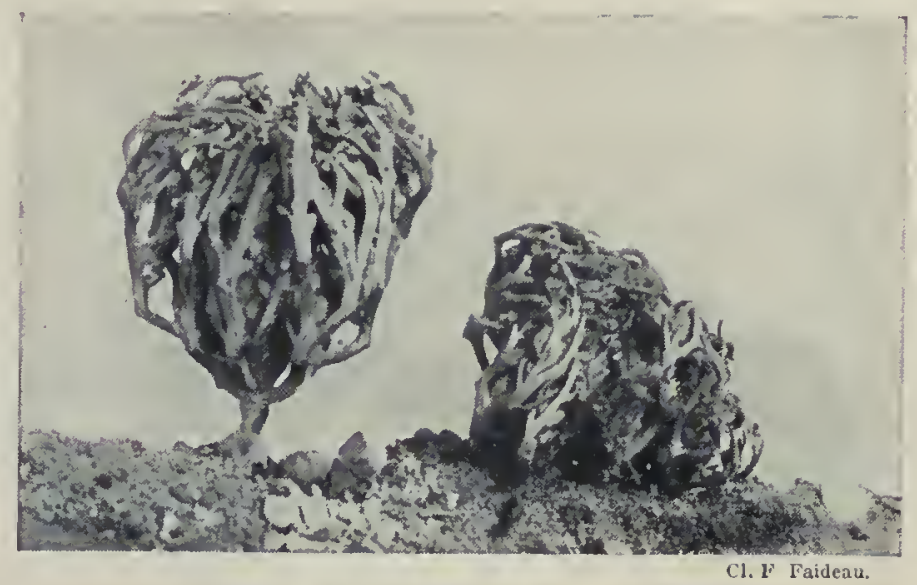

Rose de Jéricho contractée par la sécheresse.

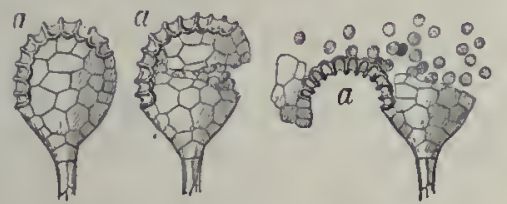
Fig. 89. - Déchirure des sporanges
des Fougères

par contraction de l'anneau $a$

noirâtre. Les Beggiatoa, qui leur ressemblent beaucoup, présentent des mouvements analogues, mais qui ne se manifestent pas seulement à l'extrémité; ce sont des Algues incolores, qui se rencontrent dans les eaux sulfureuses; elles ont, en effet, besoin d'hydrogène sulfuré, et le soufre résultant de la décomposition et de l'oxydation de ce gaz se dépose dans les cellules de cette Bactériacée sous forme de cristaux.

Mouvements hygroscopiques. - Par les temps secs, quelques plantes, comme les Mousses, les Fougères de rochers ou de murailles, semblent mortes; leur tige est rigide et fragile, leurs feuilles s'enroulent et se plissent. Que la pluie survienne, tout se redresse, s'étale et reverdit ; c'est une véritable reviviscence. Aucunc plante ne possède cette propriété à un plus haut degré que la Sélaginelle à feuilles écailleuses, vendue chez les horticulteurs sous le nom de Fougère de la résurrection. Beaucoup d'autres végétaux présentent simplement des mouvements hygrométriques dus à l'humidité ; nous citerons, parmi les plus connus, la Rose de Jéricho, qui est une petite Crucifère des déserts sablonneux d'Orient, et les Géasters, Champignons voisins des Vesses-de-Loup, qui étalent ou contractent leurs étoiles suivant l'état hygrométrique.

Les fruits manifestent aussi, à certaines époques de leur histoire, des mouvements analogues; ils souvrent par des dents au sommet,

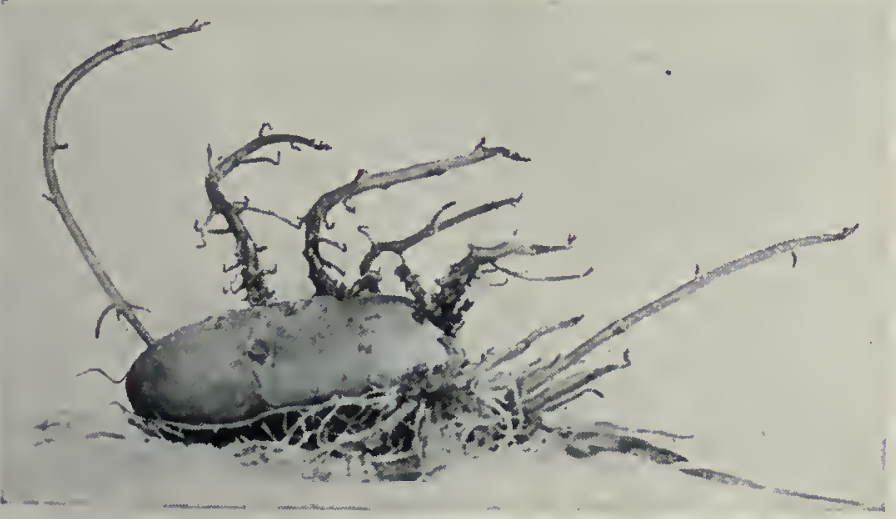

Plototropisme des tiges d'une pomme de terre.

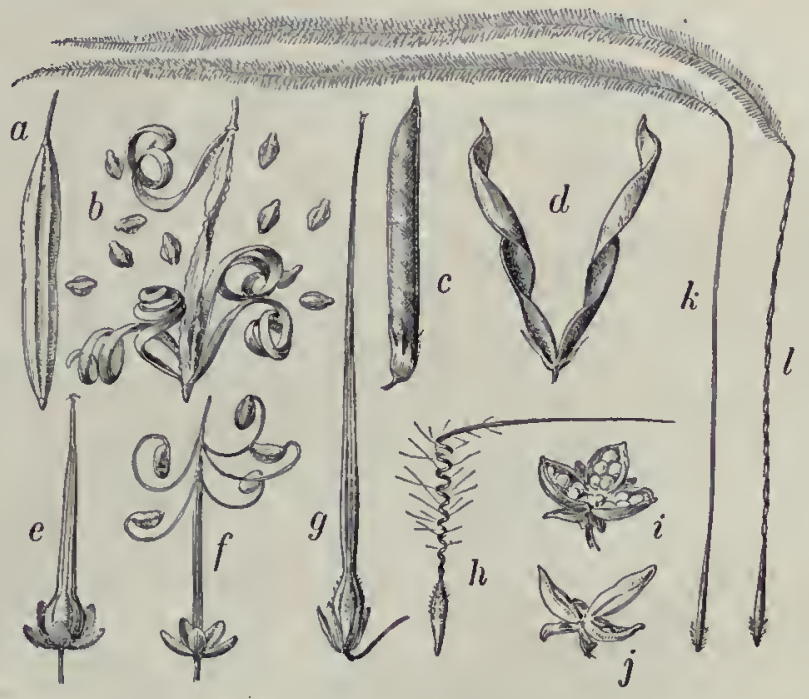

$a, b$, de l'Impatiens; $c, d$, du Vicia ;

$l$, de la Violelte; $k, l$, du Stipa. ligne de plus grande croissance: ce sont les mouvements de nuta tion qui favorisent sa pénétration dans la terre résistante; ainsi une vis s'enfonce dans du bois ou un tire-bouchon dans du liège. D'autres mouvements sont appelés des tropismes et, suivant qu'ils sont attribuables au soleil ou à la lumière, à la chaleur, à l'humidité, à la pesanteur, on les nomme héliotropisme, phototropisme, thermo tropisme, hydrotropisme, géotropisme.

Si l'on place, par exemple, des Pois chiches en train de germer devant une fenêtre, de manière que la lumière vienne sur le côté seulement, les plantes, au lieu d'être dressées verticalement comme à l'ordinaire, seront infléchies, et l'action directrice de la lumic̀re sera si

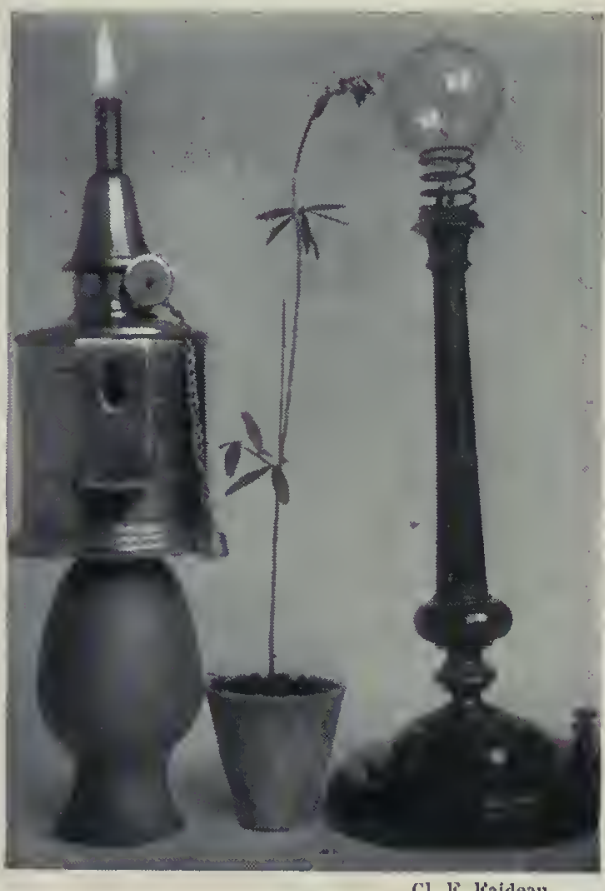

Jeune tige servant de photoncitre. par des fentes; c'est la dessiccation des parois qui amène des contractions et des déplacements. C'est la même cause qui provoque les déchirures des sporanges des Fougères, par la contraction des cellules à épaississement en fer à cheval qui constituent l'anneau (fig. 89). La contraction hygroscopique des fruits à bec de l'Erodium amène la séparation des graines portées au bout de filaments contractés en spirale, et cette propriété est utilisée pour fabriquer des hygromètres de prix de revient presque nul que l'on emploie dans les serres (fig. 90).

Mouvements de nutation, tropismes. - L'action des agents extérieurs, comme la Jumière, la chaleur, la pesanteur, peut également se traduire par des changements dans la croissance des organes. Chez la racine, la pointe décrit une spirale par suite des déplacements de la .

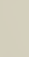




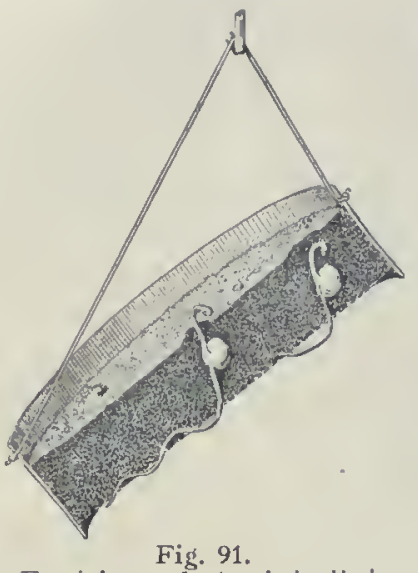

Expérience du tamis incliné.

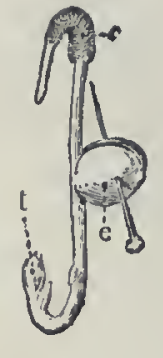

Fig. 92.

du Pois

retournée :

racine et tige

reprennent

leur

direction puissante que la tige sera horizontale, l'extrémité orientée vers la fenêtre. D'ordinaire l'action fléchissante de la source lumineuse n'est pas aussi forte et la direction de la tige est simplement oblique, inclinée vers la radiation, comme on peut le voir sur des tiges de Pomme de terre développées à une certaine distance d'une fenêtre. La sensibilité des jeunes tiges est si grande à l'action de la lumière qu'on peut les utiliser comme photomètre entre deux sources lumineuses inégales.

L'action de la chaleur se manifeste également pour la racine et il suffit d'une faible différence de températurc entre deux régions voisines du sol pour que la pointe de l'organe s'infléchisse d'un côté ct, suivant les cas, le sommet de la racine s infléchit vers la température la plus haute ou la plus basse: cela dépend de la courbe de croissance qui est en parabole. Tous ces mouvements trahissent, en fait, des inégalités de croissance des deux faces de l'axe souterrain exposées à des températures différentes et l'on sait que, pour une température appelée optimum, la croissance est la plus grande; à des températures au-dessous ef au-dessus, la croissance devient moindre.

Les flexions dues à des différences dans la répartition de l'humidité se manifestent clairement par l'expérience du tamis incliné (fig. 9l) qui forme le fond dune caisse contenant de la sciure de bois humide. Des graines qui y germent ont des racines qui sortent dans l'air, puis qui s'infléchissent vers la sciure humide, rentrent dans la caisse, puis en sortent verticalement (parce que la pesanteur reprend ses droits), et y rentrent à nouveau, et cela indéfiniment sous l'action successive de l'air sec et de la sciure humide.

Les tropismes dus à la pesan-
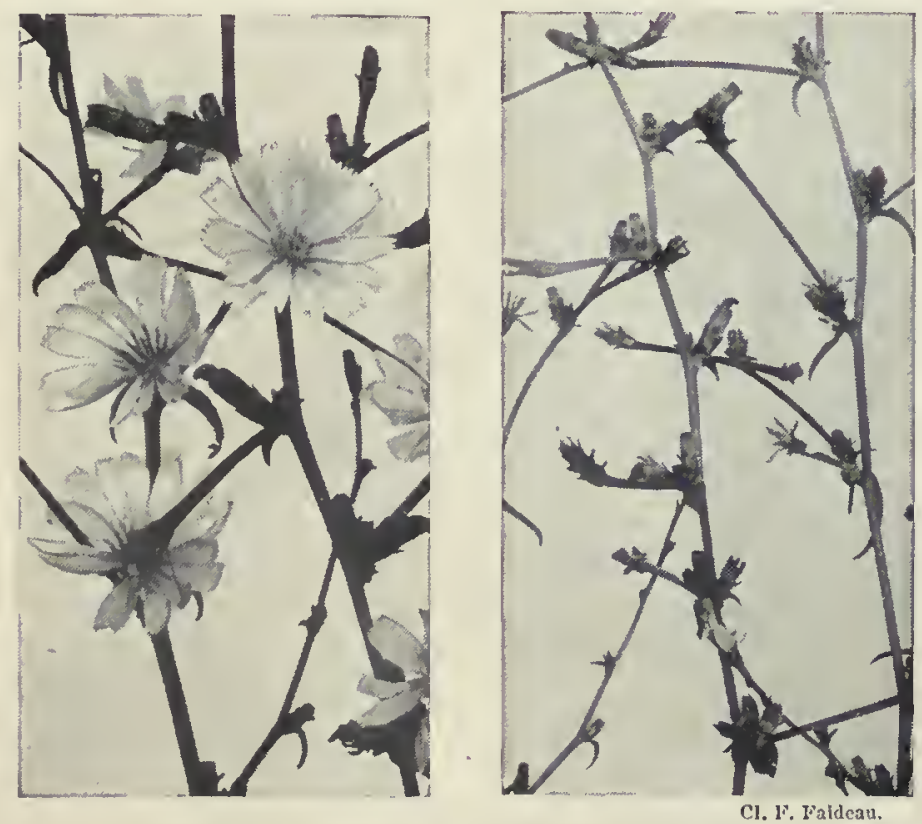

Chicorée sauvage; fleurs ouvcrtes et contractées. teur sont également très remarquables. Il suffit de placer une racine jeune horizontalement sur de la terre ou de la mousse: lagermination de la graine à laquelle la racine appartient continue ; on voit la pointe sinfléchir brus quement à angle droit pour reprendre la direction verticale. $\mathrm{Ce}$ phénomène est des plus accusés si le changement d'orientation est plus grand et, si la racine a été mise le sommet en l'air, elle retourne alors son extrémité de

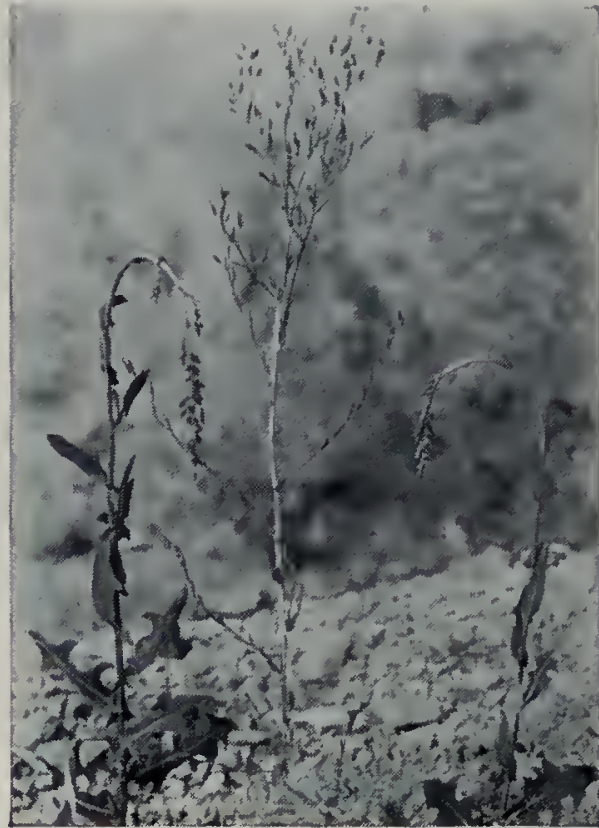

Cl. F. Faideau.

La Laitue scarote, plante boussole.
180 degrés, pour sorienter à nouveau vers le bas (fig. 92).

Mais c'est surtout pour les feuilles et les fleurs que ces mouve-

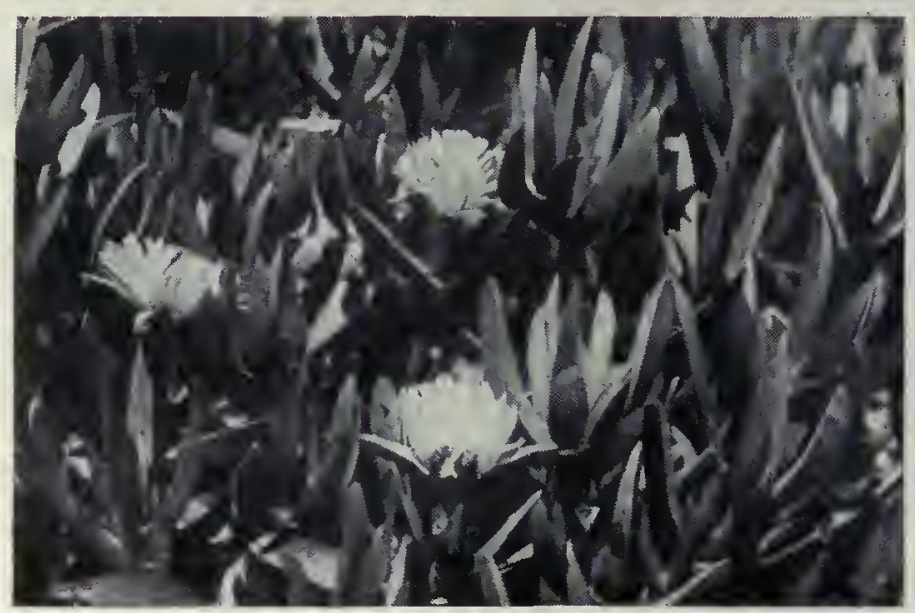

Mésembrianthéme pluviale en fleurs. ments à la lumière prennent une grande amplitude et un caractère particulièrement frappant. Certaines fleurs ou inflorescences suivent le soleil dans sa marche au cours d'une belle journće. Certaines espèces, comme la Laitue scarole, sont si sensibles, qu'à midi toutes leurs feuilles sont dressées et présentent leur tranche à la source lumineuse, de manière à recevoir le moins possible de ses rayons, alors quils atteignent leur maximum d'intensité ; l'aspect de ces plantes est tout à fait caractéristique à midi et, comme à cette heure précise, le plan de toutes les feuilles est celui du méridien du lieu, on qualifie ces végétaux du nom de plantes boussoles.

Le grand Soleil est également une plante sensible à l'action de l'astre dont il porte le nom, parce que ses larges capitules sont infléchis, non pas de manière à suivre le soleil, mais simplement à se tourner vers lui.

Mouvements de veille et de sommeil. - Les fleurs sont d'ailleurs particulièrement sensibles à l'action combince des causes externes; aussi a-t-on imaginé une horloge de Flore, à l'aide de diverses espèces qui s'épanouissent à des heures différentes:

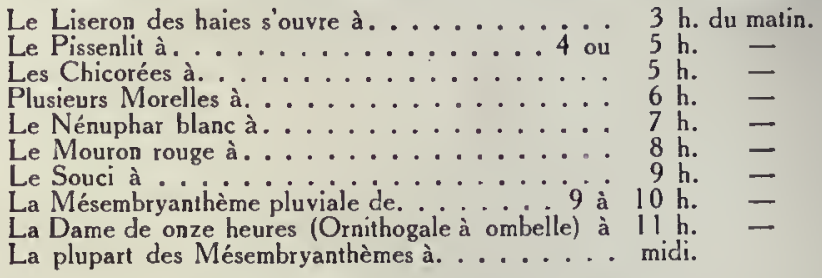

On observe des mouvements analogues chez les Bégonia. D'autres espèces, au contraire, s'ouvrent la nuit comme les Bellesde-nuit, les Cierges nycticalis.

Les mouvements dus à la lumière et à la nuit sont quelquefois si apparents, pour le feuillage notamment, qu ils peuvent contribuer à modifier tout l'aspect d'une plante : pendant le jour, les folioles d'un Trèfle ou d'un Oxalis. par exemple, étant étalées, épanouies, tandis que la nuit elles sont rabattues sur le pétiole, comme s'il s'agissait d'un parapluic fermé après avoir ćté ouvert 

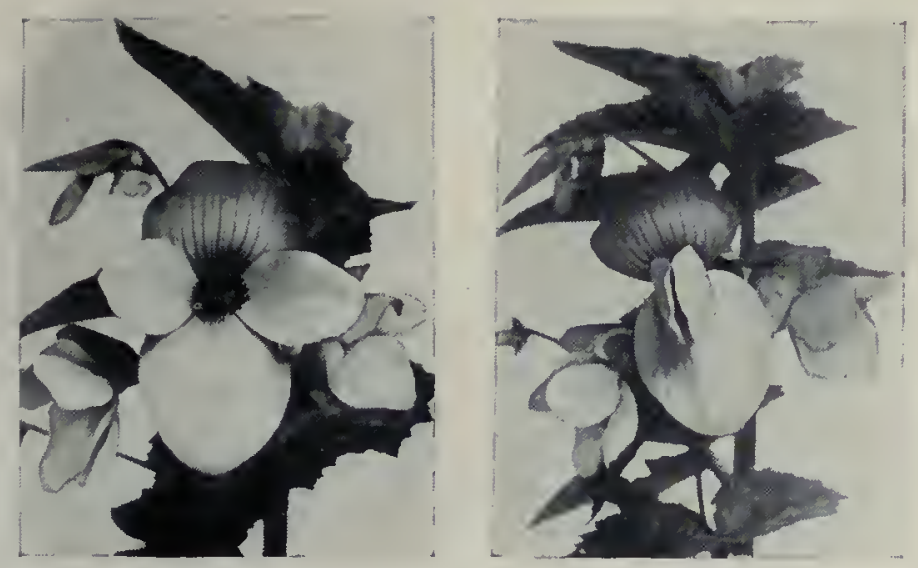

Begonia tubéreux; fleurs ouvertes et fermées.

pendant la journée. On conçoit que de tels changements d'aspect aient depuis longtemps frappé l'attention des observateurs et que l'on ait comparé la plante à ces deux états à un animal dans une période de veille ou dans une période de sommeil. C'est bien la lumière uniquement qui est la cause de ce changement, car il suffit, au milieu du jour, de transporter brusquement le végétal à l'obscurité pour le voir prendre instantanément son aspect nocturne. C'est à des changements brusques de transpiration et de répartition d'eau que ces phénomènes sont dus.

Mouvements spontanés et mouvements provoqués. - Il est des mouvements d'une autre nature qui se manifestent en dehors de l"intervention de cette cause et qui n'en sont pas moins curieux; ils sont d'ailleurs plus rares. Ils se manifestent notamment pour le Sainfoin oscillant (fig. 93) qui a des feuilles à trois folioles: une médiane très grande et deux basilaires très petites. La grande foliole exécute des mouvements de veille et de sommeil; les petites décrivent, au contraire, des mouvements inverses l'un par rapport à l'autre; l'une s'abaisse lorsque l'autre s'élève, et le sommet des deux décrit une ellipse. Ce sont les mouvements périodiques.

La Sensitive enfin présente des mouvements d'une nature plus extraordinaire encore. Ils se manifestent avec des caractères qui indiquent des propriétés tout à fait analogues à la sensibilité des animaux. Il suffit, avec un objet très délicat, de toucher une foliole pour la voir se rabattre immédiatement sur le pćtiole, ainsi que celle qui est en face; ce mouvement d'ébranlement, ainsi limité au début, s'étend progressivement de hauten bas

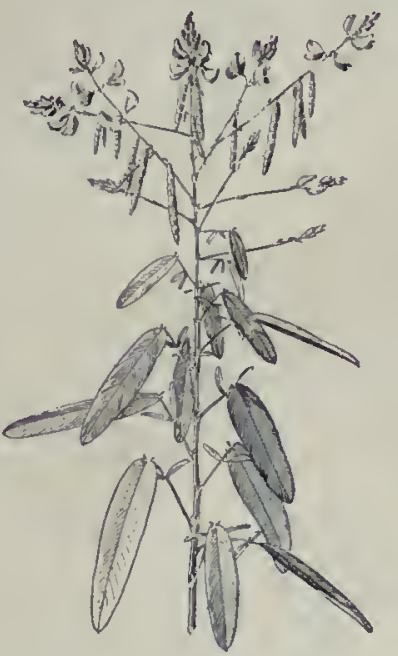

Fig. 93. - Desmodie ou

Sainfoin oscillant.

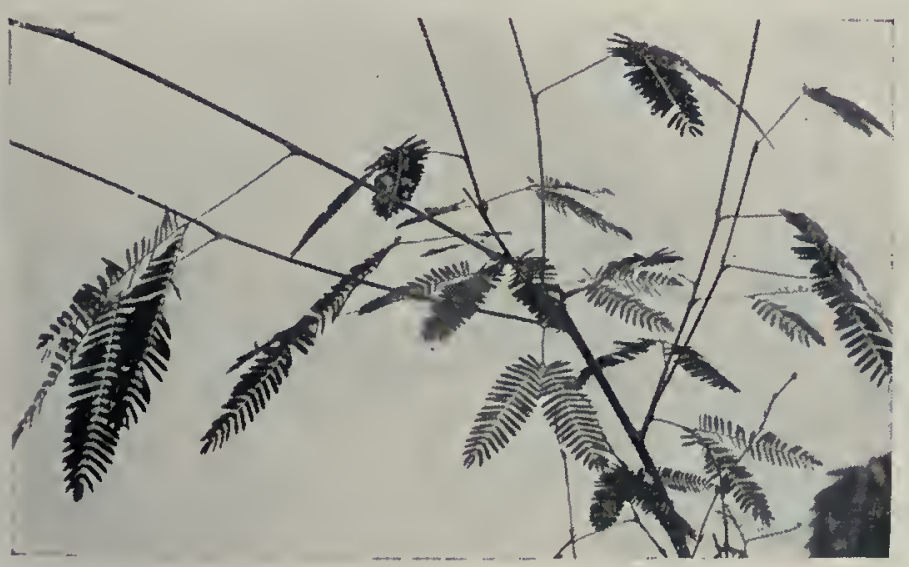

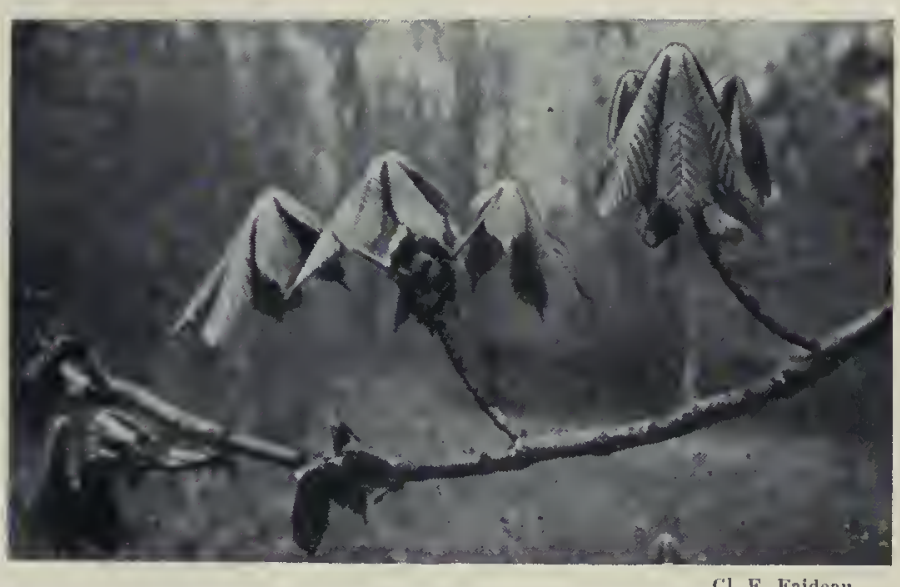

Feuiltes de Marronnier en ètat de sommeil.

et de bas en haut à toutes les folioles voisines insérées sur le même pétiole secondaire, puis aux pétioles voisins, et enfin à toute la feuille qui, en un temps très court, prend un aspect qui rappelle tout à fait celui du sommeil. D'ailleurs cette excitation bizarre ne se produit pas uniquement par contact; elle peut être provoquée par des substances caustiques, par le bruit du galop d'un cheval qui passe dans le voisinage d'un champ de Sensitive. Enfin, pour compléter la ressemblance avec les phénomènes de sensibilité, en plaçant une Sensitive en pot sous une cloche où l'on a mis une éponge imbibée de chloroforme, on peut anesthésier la plante et la rendre insensible à toutes ces actions mécaniques, comme l'on anesthésie un animal sur lequel on veut pratiquer une opération chirurgicale.

Un choc ou un ébranlement provoque, dans certaines fleurs, à l'époque de la maturité, un mouvement brusque des organes internes, surtout des étamines, qui favorise la dissémination du pollen. On a observé de semblables mouvements chez les Chardons, les Chicorées, les Mahonia, les Berberis (ou Épine-vinette) [fig. 94]. Chez cette dernière plante, dès qu'on touche avec la pointe d'une épingle l'une des six étamines à sa base, elle quitte brusquement le pétale contre lequel elle était appuyée pour venir appliquer son anthère contre le stigmate; en même temps l'anthère s'ouvre et le pollen en sort.

Chez le Mahonia, Dop a pu réaliser cette irritabilité avec un courant électrique. Dès que le courant est établi, le phénomène de contraction de l'étamine se produit; la continuation du cou-

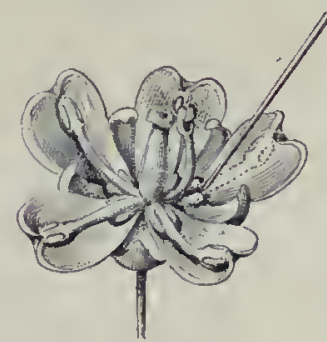

Fig. 94.

Fleur d'Epine-vinette irritabilité des étamines. rant $n$ agit pas et ne soppose pas au retour de l'étamine à l'état de repos. Si l'on a fixé un petit stylet très léger à l'étamine, l'autre extrémité pourra enregistrer le mouvement sur un cylindre. On constate qu'une étamine qui vient d'être excitée reste insensible pendant un certain temps ; après trois mouvements successifs, elle pperd toute sensibilité et est fatiguée.

Les mouvements des plantes dites carnivores se rattachent aux précédents ; nous les étudierons dans le chapitre des Rapports des animaux avec les plantes.

Une Sensitive (Mimosa Spegsazinii) en position de veitlc et ell position de sommeil.

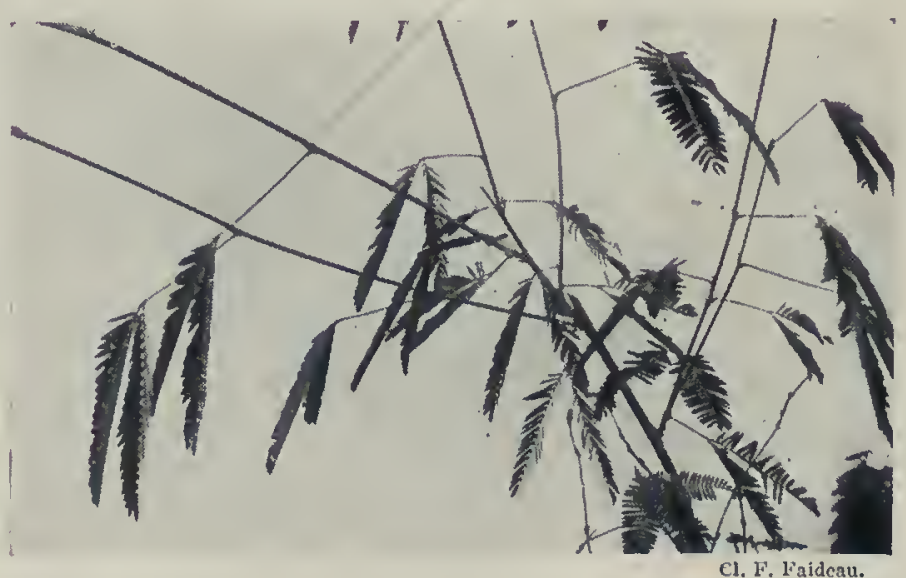




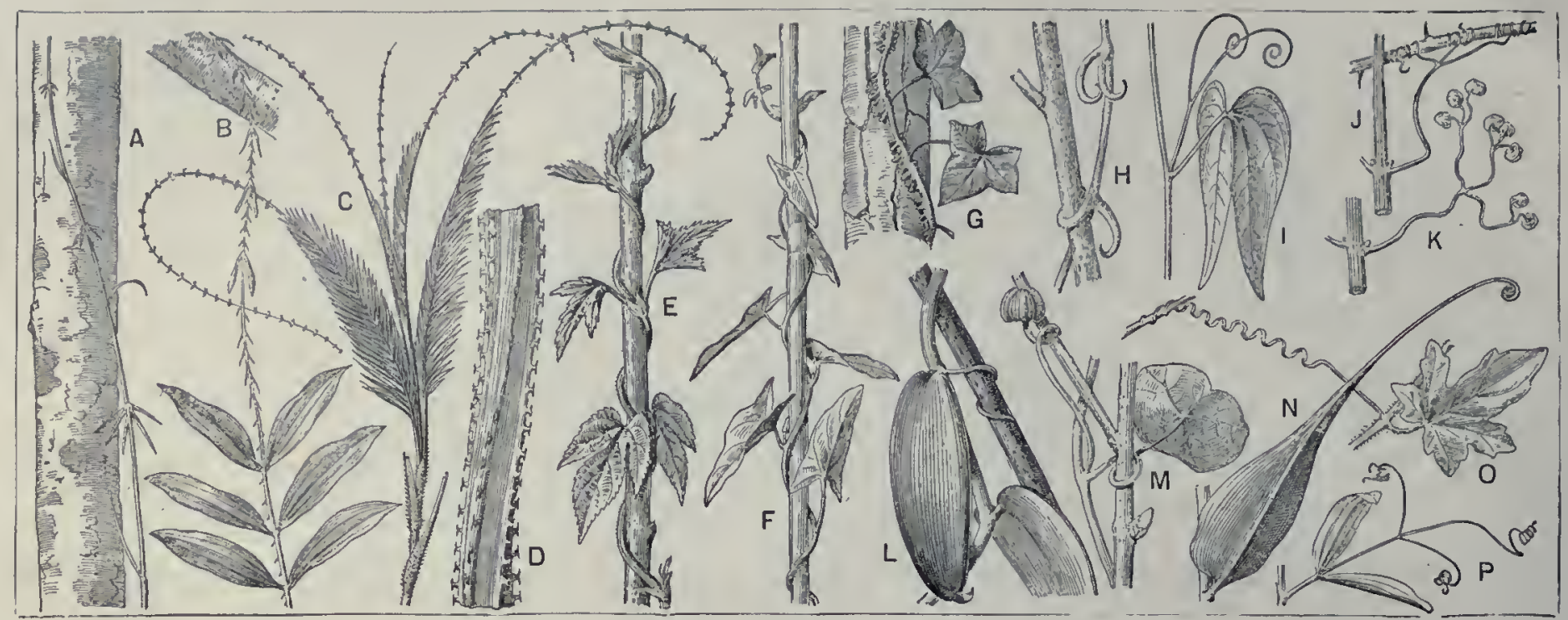

FIG. 95. - COMMENT GRIMPENT LES PLANTES.

A, Bambou grimpant ; B, Desmoncus; C, Rotang; D. Houblon (grossí) ; E, Volubilité du Houblon; F, Volıbilité du Liseron ; G, Cramoons du Lierre ; H, Vrille à crochet d'Uncaria; I, Vrille à ressorts đe Bauhinia; J, Vrilles spiralèes de Pithecotheńium; K, Vrilles à disques dı même; L, Vrille-racine de Vanille; M, Vrillepétiole de Capncine et vrille de fleur; N, Vrille-limbe de Gloriosa ; O, Vrille de Bryone; P, Vrille de Gesse odorante.

\section{II. - RAPPORTS DES PLANTES AVEC LES ORGANISMES}

\section{RAPPORTS \\ DES PLANTES ENTRE ELLES}

On peut diviser les plantes en deux groupes: $1^{\circ}$ les plantes autotrophes (du grec autos, soi-même, et trophé, nourriture) qui prennent directement leur nourriture dans la matière minérale : $\mathrm{cc}$ sont les plantes à chlorophylle, et $2^{\circ}$ les plantes allotrophes (du grec allos, autre) qui se nourrissent par l'intermédiaire d'un autre organisme. Certaines plantes autotrophes ont cependant besoin des autres végétaux, mais elles se bornent à leur demander un support: ce sont les plantes grimpantes et les épiphytes. Quant aux plantes allotrophes, on peut les répartir en trois groupes : les saprophyles, les mutualistes formant avec une autre plante une association à bénéfices réciproques ou symbiose, enfin les parasites.

Les plantes grimpantes. - Parmi les mouvements, sujet étudié au précédent chapitre, nous aurions encore à mentionner ceux qui ont pour but de permettre à une espèce de s'enrouler autour d'une autre : ce sont les mouvements de circumnutation, qui se manifestent à l'extrémité d'une tige qui, au lieu de s'accroître verticalement de bas en haut, décrit une spirale dont les

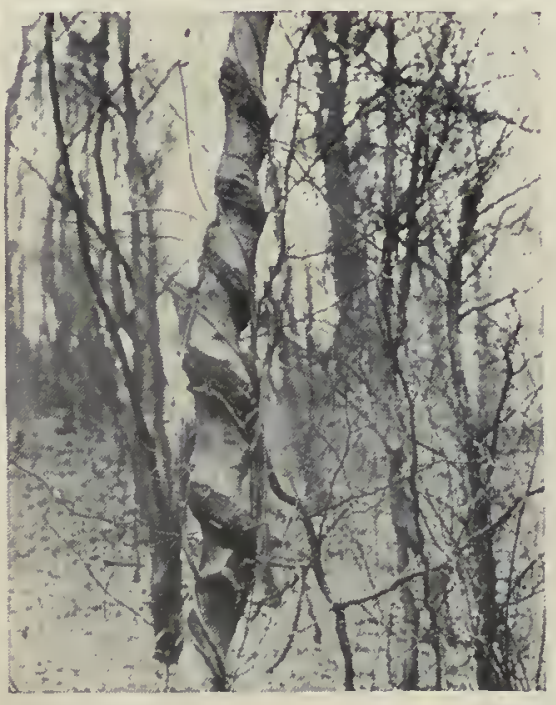

Jeune arbre enserré par une liane de Chévrefenitte.

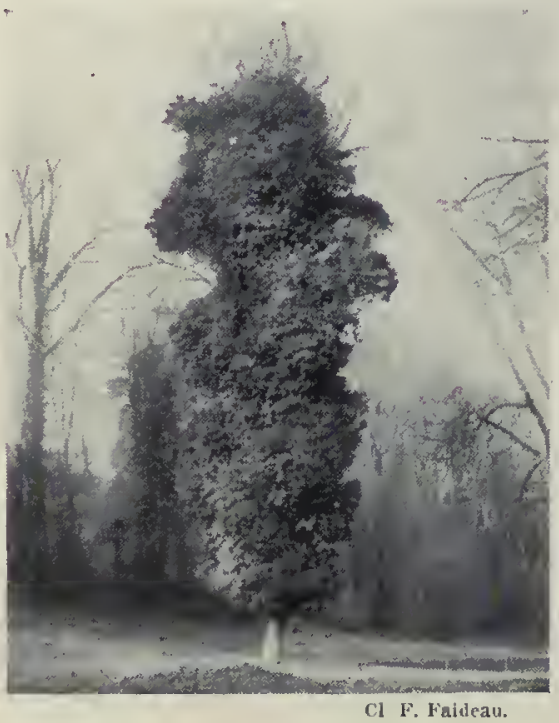

Erable sycomore envahi par un Lierre géant. tours sont très surbaissés et apparaissent comme des cercles ou des ellipses. Grâce à cette propriété, le sommet de la plante explore l'espace et peut s'enrouler autour d'un objet : bâton de bois, colonne de fonte ou tige d'une autre plante, qui lui sert de support et qui permet à une plante faible de s'élever dans l'air à une grande hauteur, tandis que seule elle tomberait à la surface du sol en se transformant en une plante rampante. Une fois que l'enroulement est produit autour de la tige d'une autre espèce, des rapports intimes, des actions réciproques s'établissent entre les deux êtres mis en présence l'un de l'autre. L'arbre qui sert de support continue à grossir et la liane enroulée autour de lui ne tarde pas à enfoncer ses tours de spire dans son écorce, qui se trouve fortement entravée dans sa croissance en cerlaines places; mais le tuteur réagit à son tour et, en continuant à croître, il aplatit la plante grimpante qui l'encercle et contribue ainsi à la déformer.

Dans le cas que nous venons d'envisager, les rapports entre les deux végétaux en contact sont aussi intimes que possible, mais ils peuvent être rendus presque aussi parfaits par d'autres procédés. Dans un Lierre, par exemple, il n'y a pas enroulement autour d'un arbre, mais accolement contre lui et adhésion puissante par une multitude de petites racines-crampons qui restent courtes et qui s'enfoncent dans toutes les anfractuosités de l'écorce du support. Comme ces organes d'adhérence sont extrêmement nombreux, la fixation est parfaite et l'arbre ainsi emprisonné à l'intérieur des ramifications du Lierre est fortement gêné dans sa croissance : il prend un air maladif; la rapidité avec laquelle les jeunes pousses du faux parasite s'accroissent sur l'écorce et la force de leur adhésion sont tout à fait merveilleuses, et quand on voit un arbre puissant aux prises avec cet ennemi qui l'étouffe, on constate par le ralentissement de sa croissance, par l'avortement de sa ramification, par le petit nombre de ses feuilles, qu il souffre grandement. Ce r est cependant pas un parasite qui l'attaque; l'emprisonnement est superficiel, les crampons ne pénètrent pas dans les tissus vivants de l'arbre et, malgré cela, quand le développement du réseau du Lierre est vigoureux, son action est redoutable.

On peut observer d'autres procédés d'adhćsion chez les plantes grimpantes (fig. 95). Elles peuvent avoir des organes réduits à l'état de simples filaments délicats, susceptibles de s'enrouler en spirale autour des objets à la façon de la queue prenante d'un singe. Lorsqu'une espèce, 


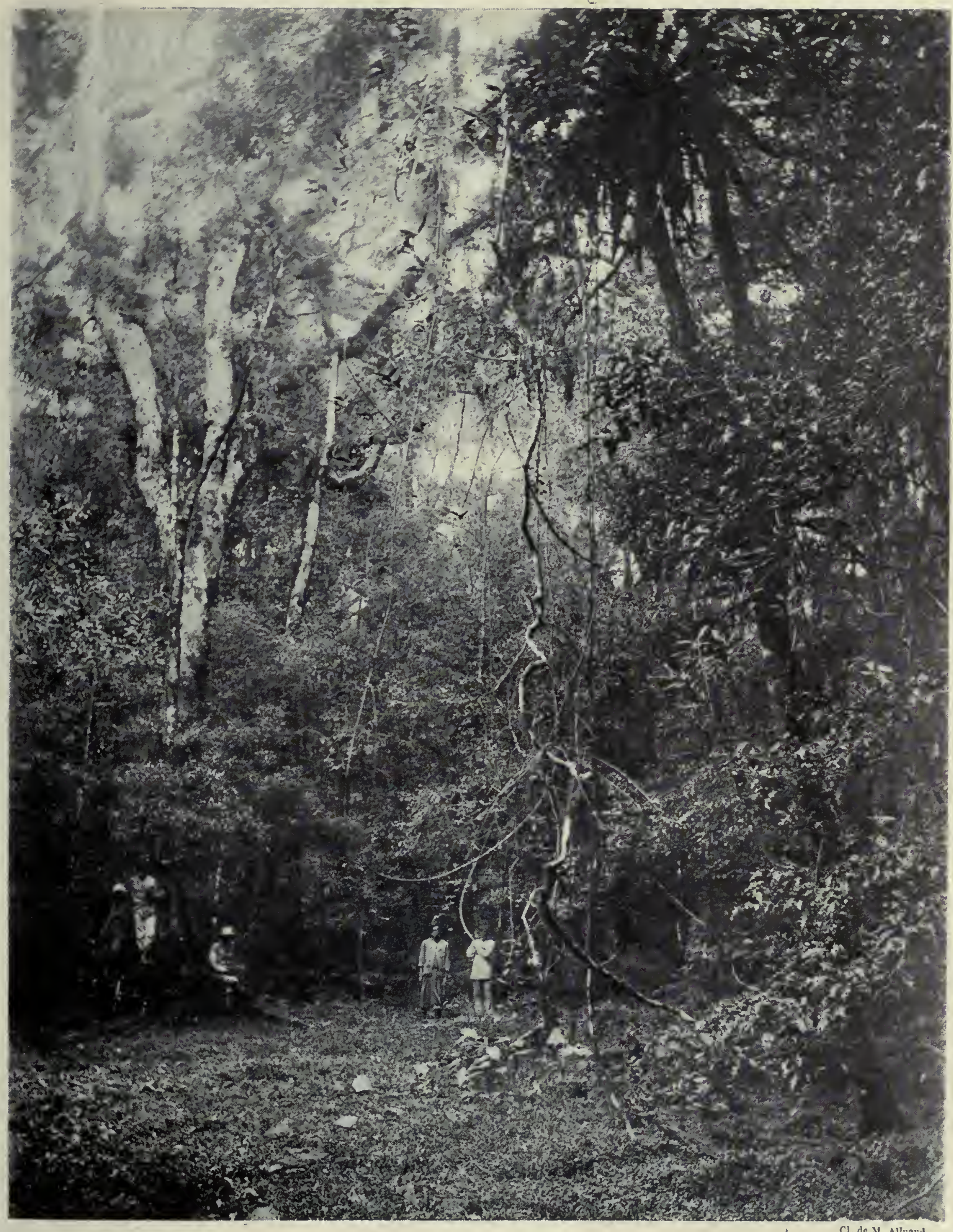

LIANES' EN FORÊT, A MADAGASCAR. 



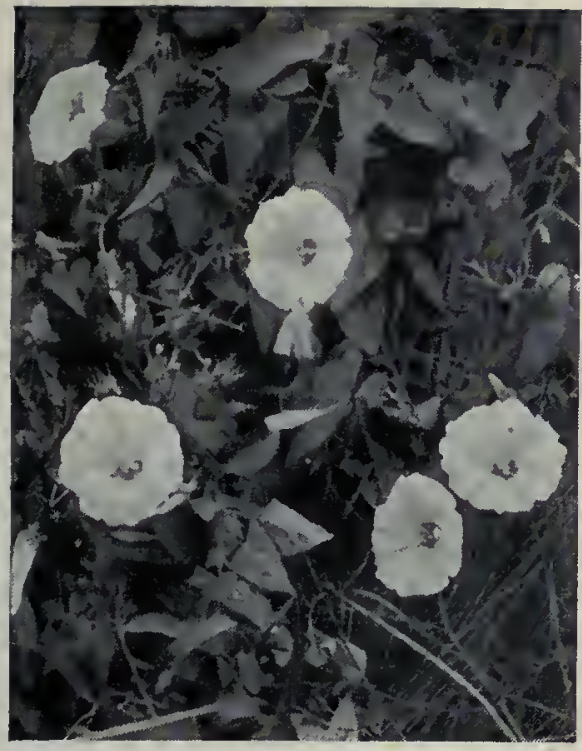

Liseron des haies.

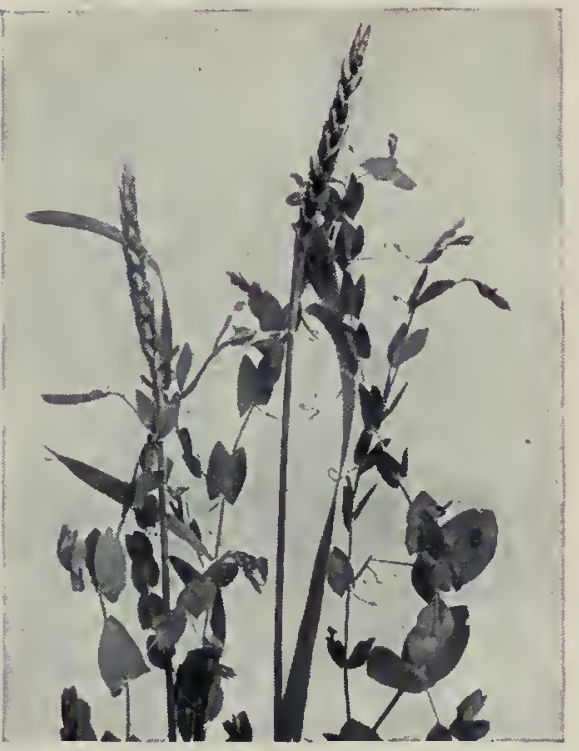

Gesse aphaca.

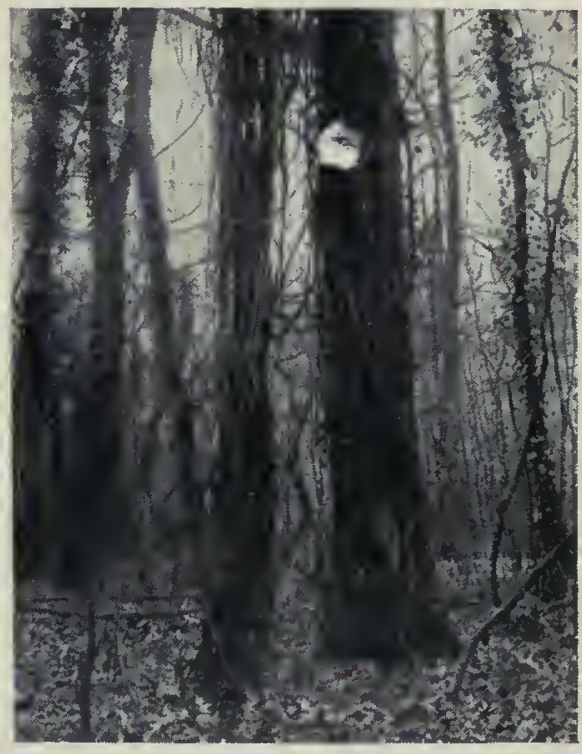

Cl. F. Faideau.

Lianes de Clématite. comme une Cucurbitacée par exemple, est armée d'un très grand nombre de ces fins organes, que l'on appelle des vrilles, elle devient très redoutable pour toutes les plantes qui se trouvent dans son voisinage, car elle s'accroche à elles de tous les côtés, et entrave ainsi leur croissance; la Citrouille ou le Melon s"étendent ainsi dans tout leur voisinage avec toutes les manifestations d'une puissance de végétation incomparable.

Si l'action des plantes grimpantes sur les végétaux quj les environnent est ainsi bien manifeste, la réaction de ces derniers n'est pas moins curieuse. Non seulement les lianes ont été amenées, par suite des conditions de la lutte, à varier les modes de grimpement (volubilité, adhésion par des crampons, fixation par des vrilles), mais toutes les particularités accidentelles de leur structure, qui pouvaient se trouver utilisées pour l'adhérence, trouvaient leur cmploi et assuraient à celles qui en étaient pourvues une prééminence pour s'élever sur les arbres : tels sont les aiguillons des Rosiers et des Ronces, les courtes branches inclinées vers le bas des Bambous grimpants, les lenticelles tuméfiées formant des papilles dans le Tinospora crispa, les crochets bien connus des Houblons ou du Caille-lait, les poils épineux des Delimopsis, lianes de la famille des Dilléniacées.

En étudiant attentivement tous ces exemples, on acquiert la conviction que la nature sait tirer parti de tout ce qui se trouve à sa portée : elle sait dévier les organes de leur rôle primitif pour les accommoder à un rôle nouveau; comme ce bon ouvrier dont parle Franklin, elle sait limer avec une scie et scier avec une lime et, peu à peu, elle fabrique et perfectionne les outils dont elle se sert pour arriver à ses fins. La distinction de deux sortes de branches, quj ne sobserve pas chez les plantes grimpantes inférieures, se manifeste, au contraire, quand on s adresse à des individus plus perfectionnés. Ces branches perdent leurs feuilles, elles s'effilent et finissent par devenir les organes délicats qui sont les vrilles de la Vigne. Ailleurs, dans les Légumineuses, en particulier dans les Vesces, cest la feuille qui se modifie et ce sont les extrémités des folioles qui perdent leur limbe et se transforment en fins filaments. La transformation progresse et devient plus complète dans la Gesse aphaca, où la feuille tout entière est métamorphosée en vrilles; il n'y a plus que les stipules pour assimiler l'anhydride carbonique de l'air. Dans les Smilax, c'est l'inverse qui a lieu: le limbe est intact et ce sont les stipules qui sont effilées en vrilles. La métamorphose est plus complète dans les Bignoniacées et dans les Cucurbitacées, où la feuille entière a perdu tout son limbe et est réduite à de simples filaments délicats, particulièrement aptes à la préhension. Evvidemment, toutes ces étapes diverses, qui trahissent les perfectionnements progressifs de l'adaptation des plantes à la vie grimpante, résultent des actions réciproques des lianes et de leurs divers supports. Il n'est pas rare, d'ailleurs, de voir parfois des retours en arrière dans la marche, en général, progressive de l'évolution. C'est ainsi, par exemple, que l'on a signalé des vrilles d'un Cucurbita où le limbe a fait à nouveau son apparition : la nature foliaire de ces organes filamenteux assez énigmatiques était ainsi mise en lumière, et l'on voyait alors l'enroulement se produire à la pointe, comme dans une Viciée ou comme dans certaines Liliacées, telles que les Uularia, les Gloriosa, ou dans certaines Flagellariées (Flagellaria); il peut aussi se produire à la base, dans le pétiole, comme chez une Clématite.

Les actions mécaniques, les tractions, les tensions, les pressions résultant du mode d'existence des lianes ont pour conséquences de profondes déformations de ces tiges. Ces altérations dans leur aspect sont certainement ce qu'il y a de plus curieux dans leur histoire; elles se manifestent, non seulement par les formes extérieures les plus extraordinaires, mais aussi par les structures internes les plus étranges et les plus inattendues. C'est surtout dans les forêts tropicales qu'abondent les plantes grimpantes; nous y reviendrons en étudiant la flore tropicale.

Dans ce qui précède, les contacts, quand il s'en établit entre

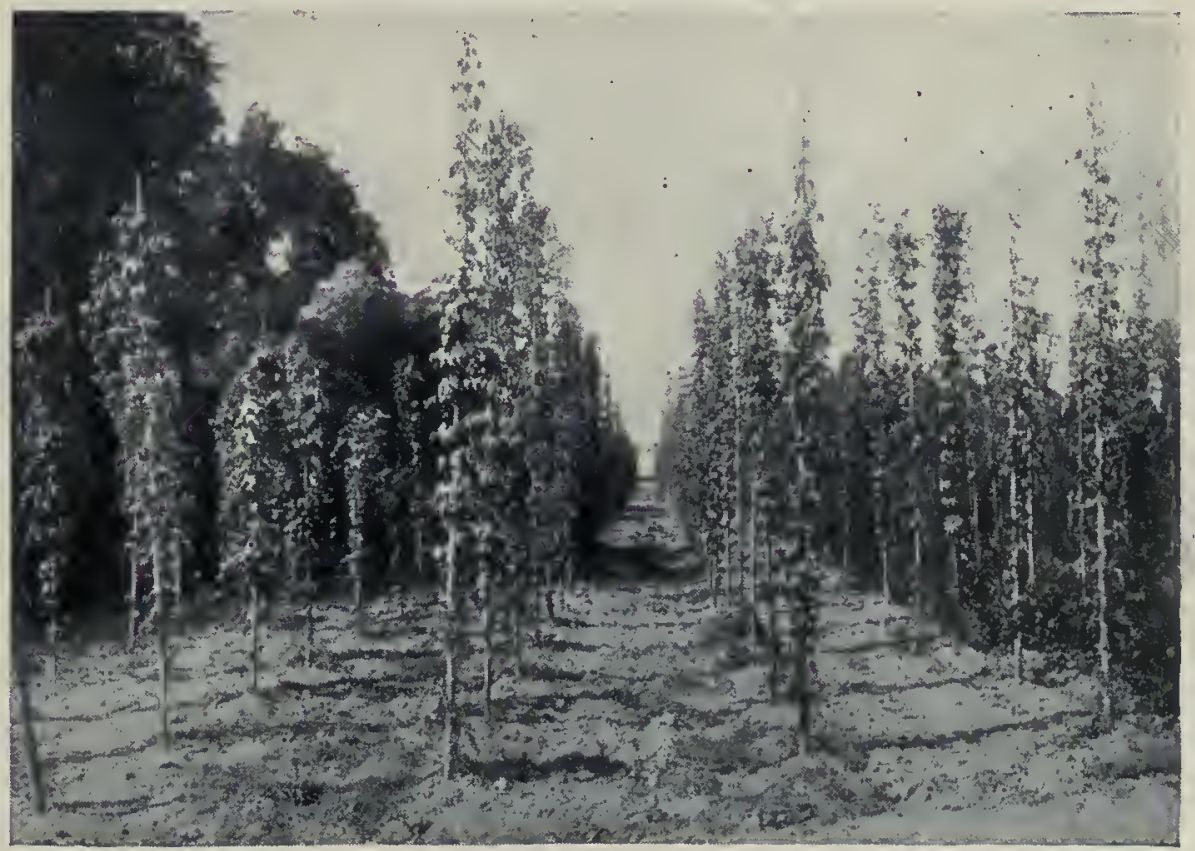

Aspect d'une houblonnière sur perches.
Cl. J. Boyer. 
la liane et le végétal qui sert de tuteur, sont toujours simplement superficiels; il n'y a jamais pénétration dans les tissus du support. C'est là ce qui différencie nettement les divers cas de la vie grimpante du parasitisme.

Le parasitisme. - Si nous prenons comme premier exemple celui de la Cuscule, qui semble au premier aspect se comporter exactement comme une liane, nous discernerons tout de suite les différences ( $f i g .9 .7$ ). Les débuts de cette plante parasite sont, en général, très difficiles; la jeune plantule issue de la germination de la graine est un corps cylindrique grêle, allongé, qui est dépourvu de radicule, et est, par cela même, incapable de croître aux dépens des éléments nourriciers du sol; comme, d'autre part, les feuilles font défaut, la nutrition est rendue impossible pendant les premières phases de l'existence; aussi la jeune plantule vit-elle aux dépens de ses réserves et elle ne peut s'accroître ainsi que faiblement ; cet allongement lui est cependant nécessaire, car elle a seulement ainsi, en explorant l'espace par de larges mouvements rotatoires, chance de rencontrer un objet voisin qui servira à la fois de support et de nourrice. Dès que cette rencontre a eu lieu, la situation change d'une manière complète; la tige s'enroule brusquement autour de la tige rencontrée par hasard, et sur la face internc des tours de spire apparaissent des boutons saillants, qui ne tardent pas à s'enfoncer dans l'écorce de l'hôte, la perforant profondément, de manière à aller puiscr les sucs nourriciers dans la sève. Pour cela, les sommets de ces suçoirs se dissocient et se transforment en poils qui se séparent au milieu des tissus de la plante hospitalière, s'insinuant entre les cellules de la partie profonde, autour des éléments lignifiés qui conduisent la sève. Cette sève déviée de son but normal est pompée par la Cuscute avec intensité; aussi, à partir de ce moment,' l'accroissement en longueur se fait avec

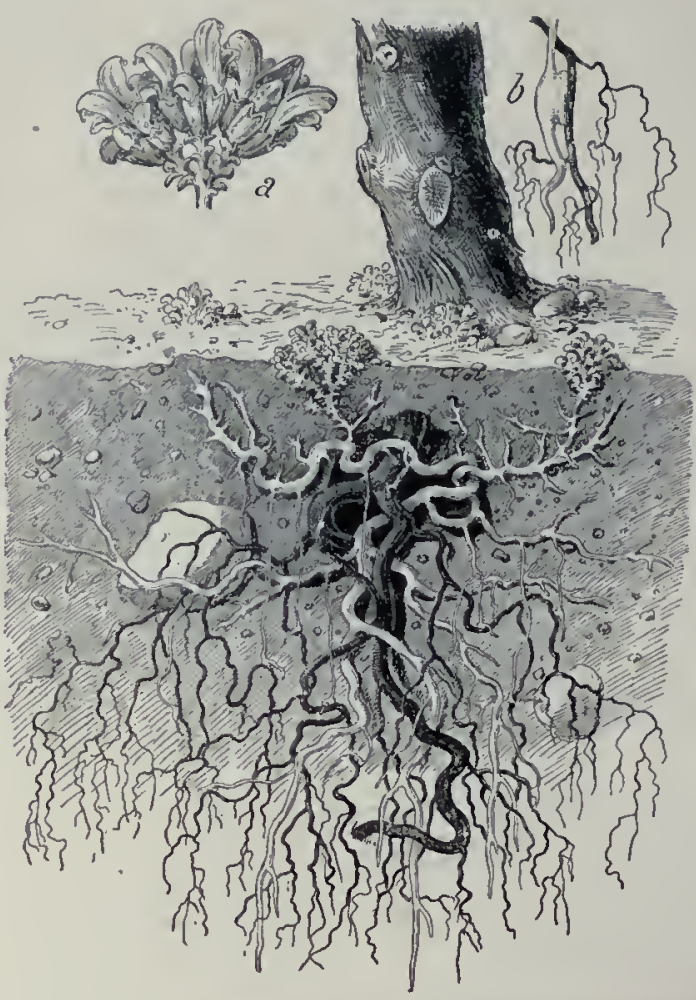

Fig. 96. - Clandestine (Lathroa Clandestina). $a_{1}$ Portion d'inflorescence; $b$, Suçoir sur une racine. une extrême promptitude : le parasite sétend de tous les côtés sur le champ de Luzerne, le couvre de ses fins filaments qui sont toujours dépourvus de feuilles et de chlorophylle. Tous les organes inutiles étant supprimés, la Cuscute consacre toute son activité à s'allonger et à s'enrouler autour des tiges, formant indéfiniment de nouveaux suçoirs qui épuisent peu à peu le champ de Luzerne. Autant les débuts du parasite ont été pénibles et difficiles, autant ensuite sa végétation est luxuriante; sa nutrition abondante étant assurée aux dépens de son hôte et la nécessité d'organes de nutrition propre ne se faisant plus sentir, feuilles et chlorophylle manquent : toute l'alimentation se fait par la sève de l'espèce attaquée.

Ce n'est, d'ailleurs, pas toujours en suivant la méthode que nous venons de décrire que les parasites procèdent à leurs attaques. Si nous prenons comme exemplc l'Orobanche, c'est exclusivement sur les organes souterrains de l'hôte que le parasite porte ses attaques. La germination de ses graines a lieu dans le sol, mais il faut que le contact s'établisse avec les racines d'une plante voisine, le Gaillet, par exemple. Au point de contact, il ne tarde pas à se produire superficiellement une sorte de renflement tuberculeux, dont la partie inférieure s'enfoncera dans la racine nourricière en $s^{\prime} y$ dissociant, tandis que la

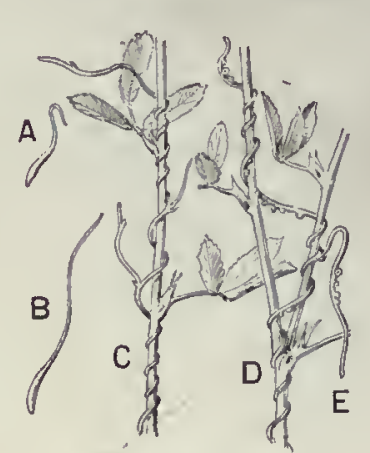

Fis. 97.

Germination de la Cuscute.

$A$ et $B$, premier et second stade ; C, enroulement; D, spires serrées ou läches; $E$, spire a vec suçoirs. partie supérieure donnera naissance à une tige qui se dressera dans lair, mais qui ne formera que de courtes écailles jaune brunâtre, insérées sur une tige de même couleur et incapable de se nourrir aux dépens de l'anhydride carbonique de l'air. Les Lathrćes sont des Orobanchacćes dont il existe deux espèces : la Squamaire (Lathraa Squamaria) et la Clandestine (L. Clandestina), qui vivent sur les racines des arbres forestiers et quelquefois sur celles de la Vigne (fig. 96).

Le cas des $R$ hinanthées, dans lesquelles se placent les Mélampyres, les Pédiculaires, les Euphraises, les Rhinanthes, est assez analogue, mais il $\mathrm{y}$ a un système de racines plus développé et ramifié dans le sol, partant d'un pivot; un certain nombre de ces racines rencontrent les organes souterrains d'une plante voisine, une Graminée par exemple, et, au contact, un suçoir se produit qui s'enfonce dans l'écorce- de la racine hospitalière et qui s'y met bientôt en communication avec le système ligneux, de sorte que le parasite peut alors pomper la sève dans les plantes voisines et se nourrir à leurs dépens. Le parasitisme est ici moins complet que dans les cas précédents, car les Rhinanthées ont des feuilles

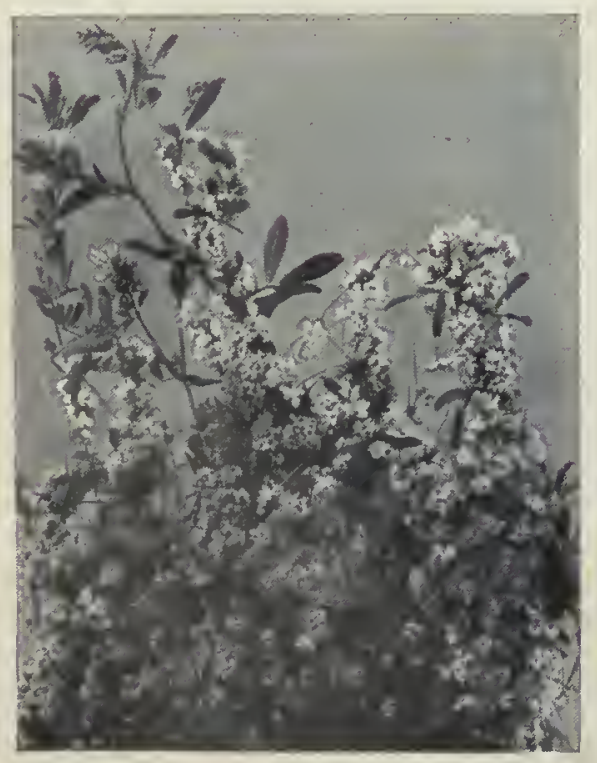

Cuscute de la Luzerne.

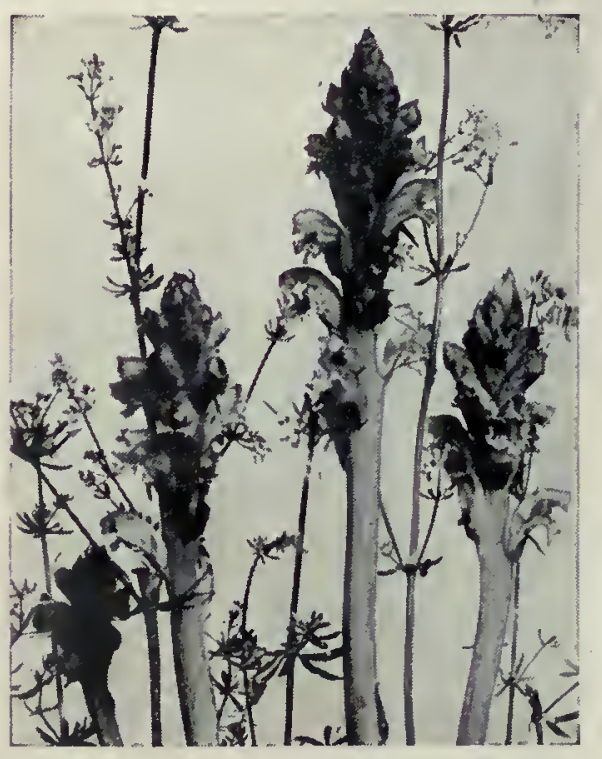

Orobanche du Gaillet.

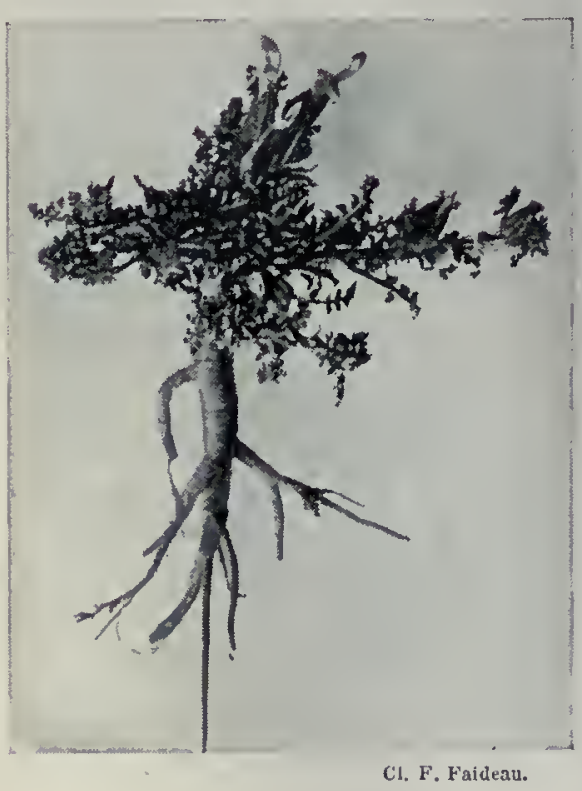

Pćdiculaire des marais 

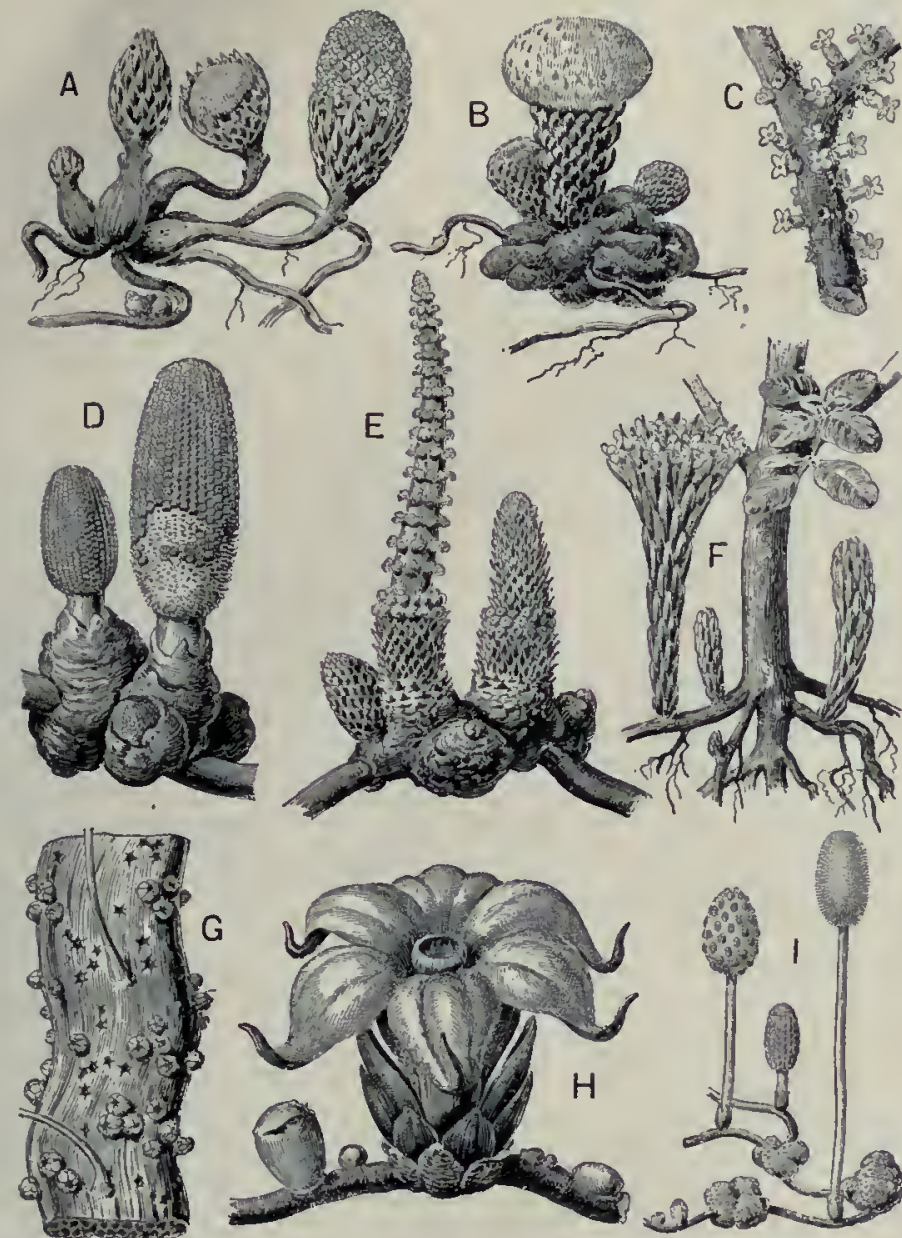

Fig. 98. - Balanoplıoracées ct Rafflésiacćes.

A, Landsdorffia hypogæa: B, Scybalium fungiforme; C, Apodanthes Flacourtiana; D, Rhopalocnemis phalloides; E, Lophophytum mirabile; F Cytinus hypocistis; G, Pilostyles Haussknechtii ; H, Brugmansia Zipellii ; I, Helosis guyanensis

vertes bien développées, et elles peuvent se nourrir non seulement aux dépens du gaz carbonique de l'atmosphère, mais aussi, partiellement, à l'aide des liquides du sol, car leurs racines peuvent présenter quelques poils radicaux, localisés au voisinage des suçoirs.

Dans les régions tropicales, les parasites se rattachant aux deux cas précédents, c'est-à-dire aux épirhizoïdes, sont tout à fait remarquables et méritent une mention spéciale. Ils constituent les groupes des Balanophoracées et des Rafflésiacées ( $f i g .98$ ).

Les Balanophoracées sont des plantes étranges qui ressemblent à des Champignons : elles manquent, en effet, de matière chlorophyllienne et ne sont formées, au point de vue vćgétatif, que d'une masse charnue irrégulière, sur laquelle se dresse une hampe florifère. Ces derniers organes reproducteurs devant, pour apparaître au dehors, percer un ćtui qui n'est pas sans rappeler la volve de certains Agarics des forêts de nos pays, on concoit que cettc ressemblance avec des masses fungiques ait frappé les premiers observateurs; analogie semblant plus justifiée encore par les couleurs vives des appareils végétatifs informes et des parties reproductrices de ces plantes, que les premiers observateurs avaient cru pouvoir rattacher aux Cryptogames. Il suffisait cependant d'examiner d'un peu près les appareils reproducteurs pour se convaincre que l'on avait affaire à des plantes à fleurs, assez élevées, par conséquent, en organisation. Ces fleurs, il est vrai, présentent des caractères assez particuliers : la partie femelle possède un pisti] qui est tellement rudimentaire (de 2 millimètres) qu'il n'est pas sans rap-

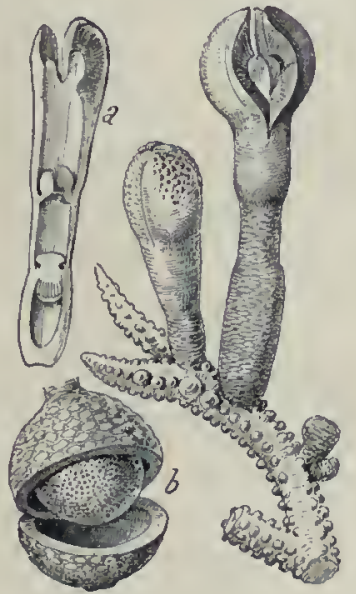

Fig. 99. - Prosopanche (Hydnoracée). (Balanophoracée).

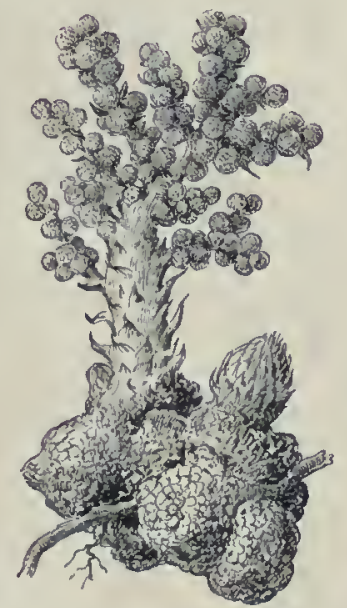

Fig.100. - Sarcophyte $a$, coupe de la fleur: $b$, fruit onvert.

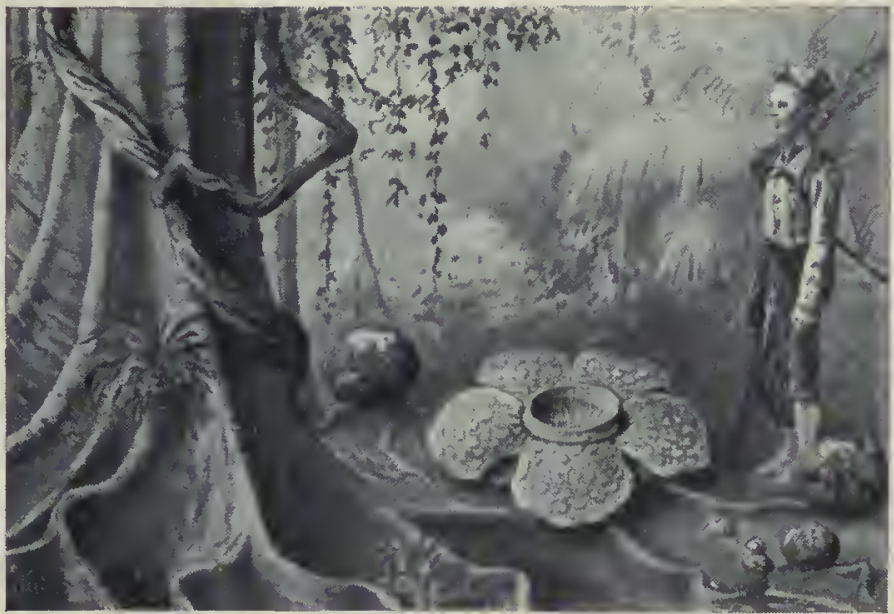

Rafflesia Arnoldi et sa fteur, à Sumatra.

peler les archégones des Mousses; l'ovule ne se différencie pas, il est soudé à l'ovaire : c'est ce que $\mathrm{V}$ an Tieghem appelle les Inovulées. Mais l'action du parasitisme ne se manifeste pas seulement sur la fleur avant la fécondation, elle se trahit encore après, car l'embryon dans la graine est indifférencié et formé d'un simple amas d'un petit nombre de cellules; il engendre l'appareil végétatif informe que nous mentionnions plus haut, et qui doit être percé pour laisser passer les hampes florifères.

La réduction du système végétatif est plus grande encore dans les Rafflésiacées, en particulier dans le genre Rafflesia. Ces plantes singulières se rencontrent dans les forêts tropicales sous la forme d'énormes boutons floraux, qui sortent des racines des arbres courant à la surface du sol. Ces boutons acquièrent de très grandes. dimensions et, quand ils s'épanouissent, ils constituent des fleurs qui sont parmi les plus grosses du règne végétal. Si l'appareil reproducteur a acquis un développement exagéré, le corps végétatif de la plante est, pour ainsi dire, réduit à rien : il n'apparaît au dehors ni tige, ni feuilles; il est réduit à de fins filaments qui se ramifient à l'intérieur des tissus de la racine de l'hôte, et se comportent absolument comme le mycélium d'un Champignon parasite, qui ramifie les fins filaments dont il se compose à l'intérieur d'une feuille, d'une tige ou d'une racine. Nous avons là un exemple extraordinaire des effets de la vie parasitaire sur les parasites : on connaît dans le règne animal, parmi les Crustacés, par exemple, des particularités analogues. Un être qui vit aux dépens d'un autre n'a plus besoin d'organes de nutrition, puisquil puise sa nourriture dans le corps des êtres voisins (fig. 99 et 100); il n'a plus quin seul souci, se re-

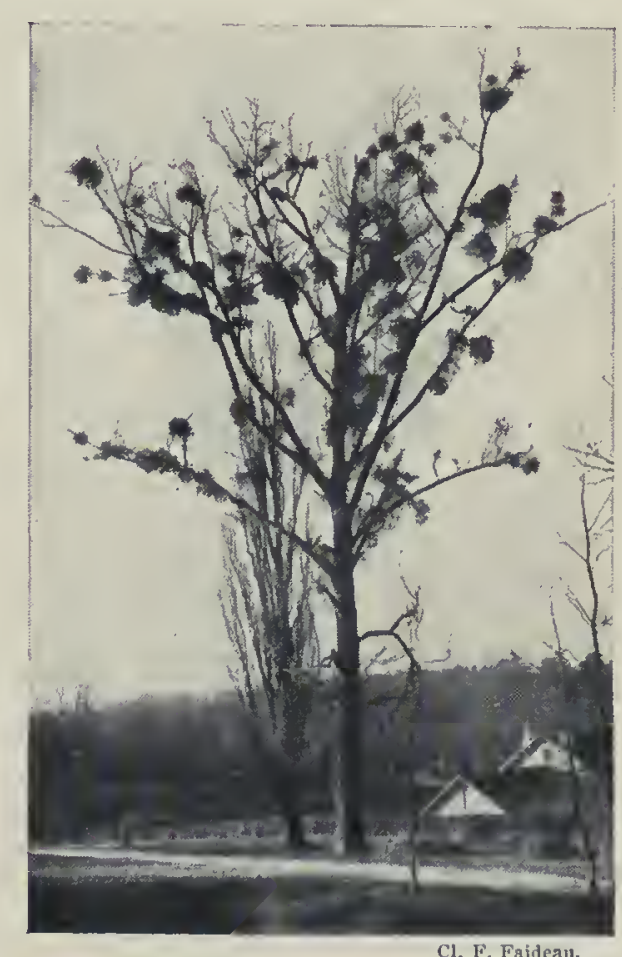

Touffes de Gui sur un Peuplier noir. 
produire, et, comme toute son activité se trouve orientée de ce côté, ses appareils de reproduction peuvent acquérir un développement remarquable. L'action du parasitisme se trahit encore pour les Raffésies, comme pour les Balanophoracées, comme pour les sont rares dans les pays septentrionaux, l'air y est trop sec; les Lichens sont à peu près les seuls représentants de ce mode d'existence; les épiphytes abondent, au contraire, dans les régions tropicales. On peut admettre que la vie épiphyte a commencé

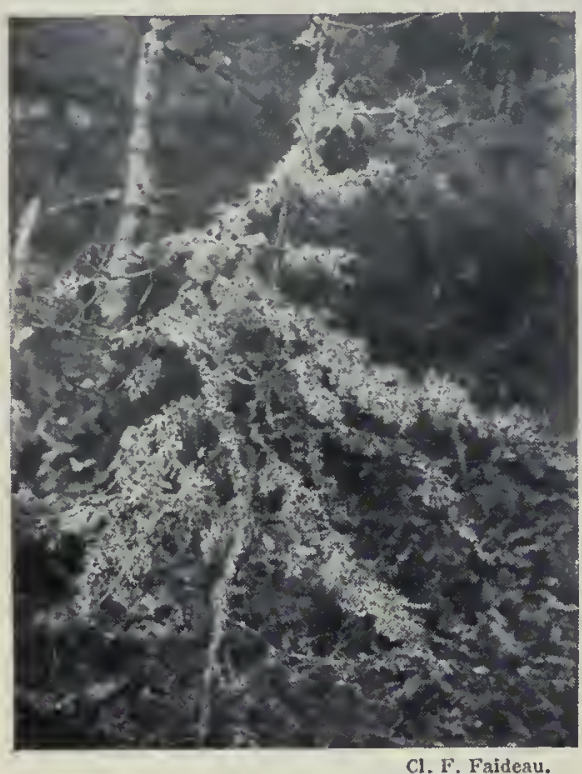

Lichens sur un jeune Pin.

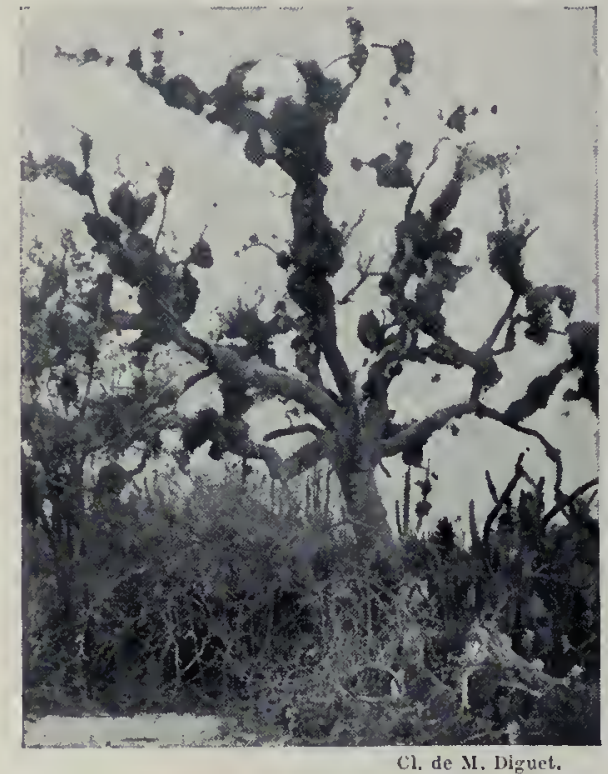

Titlandsia sur Bursera, au Mexique.

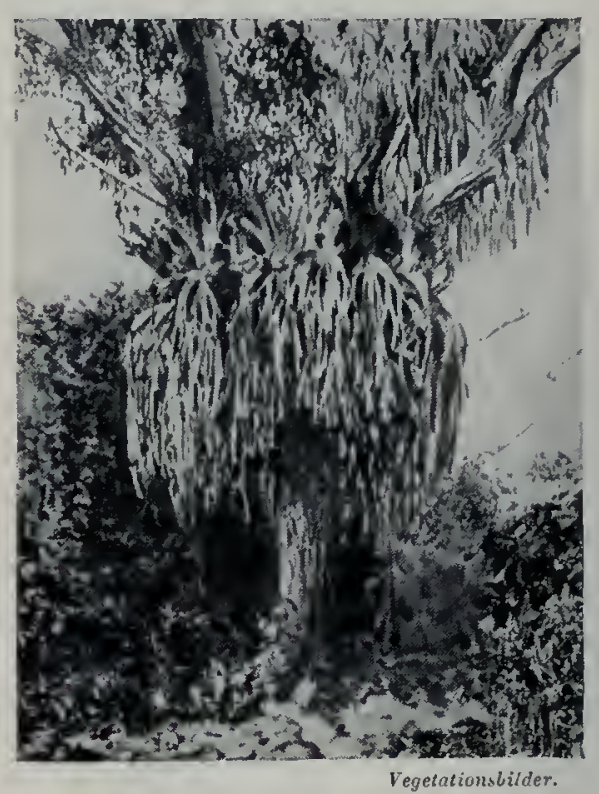

Un Platycerium dans les Andes.
Orobanches et la Cuscute, par une atrophie de l'embryon à l"intérieur de la graine.

En général, dans un groupe de parasites, le mode d'attaque de I'hôte est uniforme: toutes les Balanophoracées, par exemple, vivent sur les racines des plantes qui les nourrissent. Dans les Raffésiacées, il n'en est pas ainsi, car les Pilostyles sont des parasites qui vivent sur les écorces; ils sont d'ailleurs réduits à des boutons qui crèvent les parties superficielles des tiges et qui, en s'ouvrant, mettent à nu de petites fleurs; quant à l'appareil végétatif, il est filamenteux et interne comme celui des Rafflesia.

$\mathrm{Ce}$ cas nous conduit à envisager un dernier type de parasites, ceux qui vivent sur les écorces des tiges des arbres; ce sont les plus connus dans notre pays, car tout le monde a eu l'occasion d'observer les boules vertes que fait le Gui sur les tiges des Peupliers. Ici il y a une tige et des feuilles vertes opposées, mais cette plante s'enfonce à sa base dans l'écorce de l'arbre et, quand on vient à couper cette région, on s'aperçoit qu'il existe un suçoir qui cst entré profondément jusquà la partie ligneuse, où il s'épanouit, émettant de place en place des suçoirs secondaires qui se mettent en relation avec le corps du bois pour en absorber la sève. Évidemment, le Gui n'est pas un parasite aussi redoutable que tous ceux que nous venons d'énumérer plus haut et il est même établi qu'il n'est pas nuisible, au moins pendant l'hiver, au Peuplier, son hôte. Il lui est alors plutôt utile : en effet, ses feuilles vertes subsistent et il continue à assimiler le gaz carbonique de l'atmosphère, tandis que l'arbre hospitalier est dépourvu de feuilles. Le parasitisme a cependant un retentissement sur toute la plante; il se manifeste sur la fleur, dans laquelle l'ovule est indifférencié, de sorte que les Loranthacées, auxquelles le Gui appartient, sont des Inovulées; la dégradation s'accuse encore sur l'embryon, qui ne produit pas de radicule caractérisée.

Nous laissons de côté, pour le moment, l'étude des procédés par lesquels les Loranthacées sinstallent sur les arbres; nous y reviendrons en étudiant les rapports des animaux et des plantes.

L'épiphytisme. - Le cas du Gui nous amène à examiner celui des épiphytes. Il s'agit ici de plantes qui vivent sur les arbres, mais sans que leurs racines s'enfoncent dans l'ćcorce. Les épiphytes chez certaines plantes grimpantes étroitement liées à l'arbre, comme diverses Aroïdées (Monstère délicieux, Philodendre) ou Orchidées (Vanille), qui peuvent vivre soit reliées au sol, soit complètement séparées de lui, mais il est évident qu'en général la vie épiphyte résulte du transport sur les hautes branches de fruits charnus par les oiseaux ou de graines légères par le vent. La plupart des épiphytes possèdent des semences extrêmement légères (Orchidées, Fougères) ou pourvues d'un appareil de vol (Broméliacées); le vent les emporte facilement et les dépose sur les branches des arbres; elles y germent et donnent une végétation aérienne, solidement fixée par des racines adventives. Suivant la hauteur des rameaux sur lesquels la graine ou la spore est tombée, les problèmes à résoudre sont différents et il y a lieu de distinguer, parmi les plantes présentant ce mode d'existence, celles qui élisent domicile dans les parties basses, très humides, celles qui croissent dans les régions moyennes des forêts équatoriales et enfin celles qui végètent exclusivement à la partie supérieure des arbres.

Les premières ont les caractères de plantes aquatiques; on y constate la présence des Hyménophylles, des Trichomanes, qui sont des Fougères à feuillage mince et translucide.

Dans la partie moyenne croissent les Aroïdées, les Orchidées

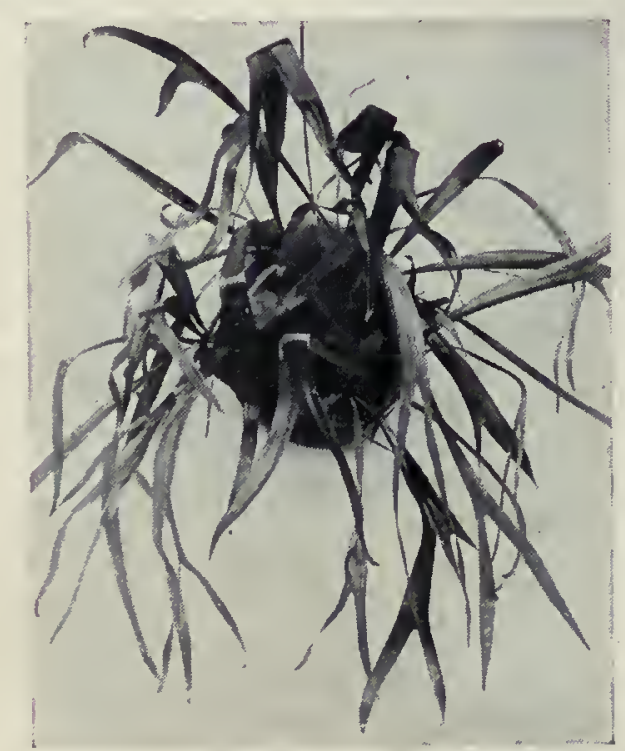

Platycère corne d'élan. à terreau, les Fougères comme les Platycères, qui différencient leurs feuilles en deux parties : les frondes stériles arrondies en forme de cornet, où s'accumulent les débris de feuilles, et les frondes fertiles ou reproductrices, ramifiées en fourche, qui pendent dans l'air. Chez les épiphyjtes à terreau, les inconvénients de la vie sur les arbres sont à peu près supprimés, puisqu'un sol artificiel formé par l'accumulation des débris végétaux et des poussières est à la disposition de leurs racines. Le réceptacle à terreau est soit un cornet formé par des feuilles spćcialement adaptées (Polypode à feuilles de Chêne, Platycère), soit une sorte de nid dû à l'enchevêtrement des racines (Orchidées) ou même à des feuilles en rosette. Chez la Doradille nid d'oiseau (Asplenium nidus), les longues feuilles sont groupées en couronne autour d'un centre, et bien que ces plantes sinstallent quelquefois sur des branches très ténues, elles peuvent acquérir une grande amplitude, jusqu' à 4 mètres de diamètre, et peser jusquà 20 kilogrammes avec la 
motte de terreau qui s'accumule au milieu de la couronne foliaire. Ces végétaux à terreau atteignent parfois un puissant développement : c'est le cas, en particulier, des Orchidées géantes dont les Grammatophylles de Java nous fournissent le type, qui peuvent,

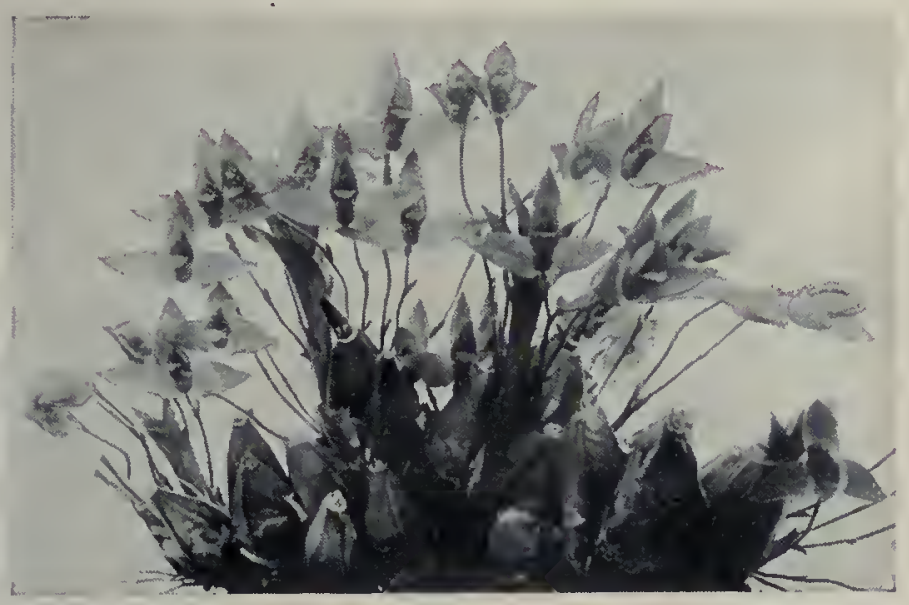

Lycaste aromatique (Orchidée épiphyte).

dans leur ensemble, représenter la charge d'une dizaine d'hommes et qui, en fleurissant tout d'un coup, donnent le merveilleux spectacle de milliers de fleurs $(3000$ à 4000$)$ de grandes dimensions ouvertes simultanément.

Pour les espèces qui poussent sur la couronne des arbres, les conditions d'existence sont tout à fait différentes, et l'exubérance que nous venons de signaler disparaît : l'appareil végétatif est rabougri, les tiges courtes, d'ordinaire charnues, fréquemment renflées en pseudobulbes; les feuilles sont épaisses, dures comme du cuir ou charnues, ce qui permet à ces espèces, qui présentent, en somme, des caractères presque désertiques, de résister à une excessive sécheresse. Ces difficultés, que rencontrent ces végétaux dans leur croissance, ne se manifestent que dans l'appareil végétatif, car l'appareil reproducteur est, au contraire, d'ordinaire puissamment développé et les Orchidées doivent en grande partie leur réputation justifiée au magnifique développement de leurs corolles. Il semble que la vie aérienne, qui a une action si complète sur les tiges et les racines, n’a pas de répercussion sur la fleur et l'on ne trouve pas ici de caractères généraux tirés de la graine, comme nous en signalions plus haut pour les parasites, du moins si l'on envisage l'ensemble des familles épyphites comme les Aroïdées. Broméliacées, etc. Cette dernière famille est caractéristique du Nouveau Monde, où elle est localisée.

On serait cependant tenté d'attribuer une partie des caractères héréditaires des Orchidées à la vie épiphyte, mais nous allons voir que c'est la vie symbiotique, ou associée à un Champignon, qui est primitive et la cause prédominante de l'organisation de ces plantes.

Le saprophytisme. - La plupart des Orchidées tropicales sont épiphytes, maisil y a un certain nombre d'entre elles qui végètent dans les parties basses et obscures des forêts et que l'on appelle, à cause de cela, plantes saprophytes. Elles paraissent vivre, comme les Champignons de nos prés et de nos bois, aux dépens des matières en décomposition dans le sol : substances organiques, feuilles mortes, etc. En réalité, il y a 'bien un Champignon, mais cest celui qui est dans leurs racines; il joue un rôle capital dans leur histoire physiologique et biologique, et tout d'abord la germination est impossible si le Champignon ne pénètre pas à l"intérieur de la graine dans les premiers stades de son développement. Ces résultats, étendus plus tard à toutes les Orchidées, ont été entrevus à l'origine par Noël Bernard pour les espèces comme la Néottic, qui vivent dans la partie sombre des forêts. Elles sont décolorées, sans chlorophylle, de sorte qu'on a été tenté de les confondre avec des plantes parasites. Comme chez ces dernières, leur embryon est indifférencié.

Cette dernière particularité est d'ailleurs un caractère général de toutes les Orchidées, et il est manifestement lié à la présence de Champignons dans les racines, particularité qui s'observe dans tous les représentants de cette famille, aussi bien chez les plantes épiphytes et fortement colorées en vert que chez les Orchidées terrestres qui habitent les prairies bien éclairées

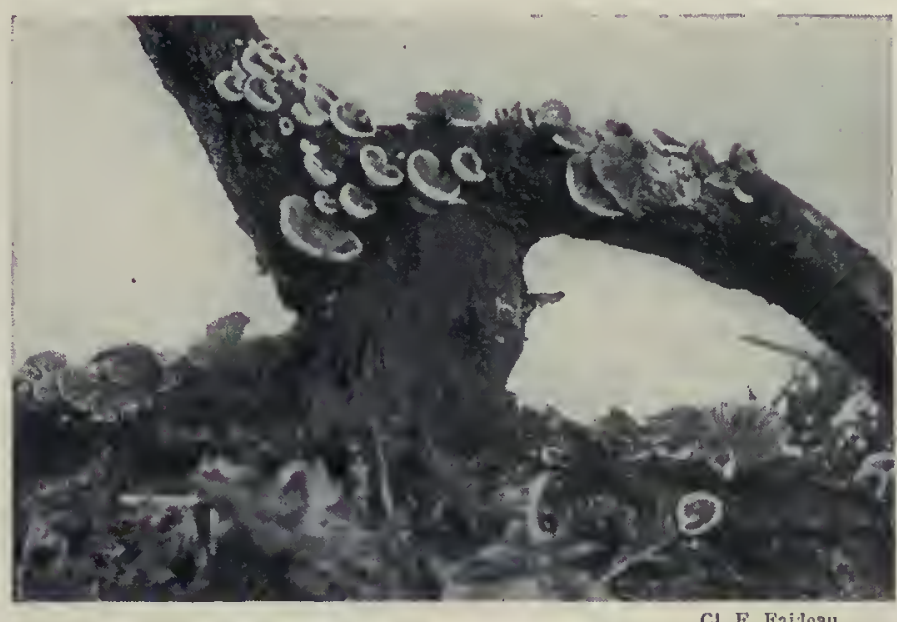

Octojuga variable, champignon de souche.

et les terrains humides, de manière que la chlorophylle puisse sy développer. Cette relation indubitable entre l'atrophie de l'embryon et la présence de mycorhizes internes dans les organes radiculaires est d'ailleurs confirmée par l'étude de toutes les familles analogues, comme les Triuriacées, les Burmanniacées et aussi par l'étude de certaines Gentianacées saprophytes, sans chlorophylle, comme les Voyria.

La nécessité de la présence de Champignons dans les organes souterrains de ces plantes est constante pendant toute la durée de la vie de la Néottie et elle se manifeste dès les premiers débuts de la germination. La graine d'une Orchidée tropicale épiphyte, comme un Cattlcya, est réduite à un petit embryon indifférencié non enveloppé d'un albumen, et emprisonné dans un tégument. Il n’y a d'ailleurs pas trace de Champignon dans ses cellules. Si l'on recueille aseptiquement ses graines, comme l'a fait Noël Bernard, dans une capsule non encore ouverte, de manière à les introduire dans un tube stérilisé, à l'abri de toutes les poussières atmosphériques et de tous les germes, la graine abandonnée à elle-même ne germe pas. Si, d'autre part, on est parvenu à extraire le Champignon de la racine d'un Cattleya pour en faire une culture pure, et si l'on vient à l'ensemencer dans les tubes où les graines de Cattleya sont inertes déjà depuis plusieurs mois, immédiatement la germination de l'Orchidée se manifeste avec une promptilude et une régularité surprenantes; et au bout d'un temps assez court, on a une plantule que l'on peut repiquer et qui est susceptible de continuer ensuite à se développer d'une manière normale et d'aller jusqu' à la foraison.

A chaque Orchidée, ou plutôt à chaque groupe ou série d'espèces d'Orchidées, correspond un Champignon spécial. Par exemple, le Champignon des racines du Phalanopsis n'est pas le même que celui des Odontoglossum, mais identique à celui des $V$ anda. Quand on inocule le Champignon d'une espèce d'Orchidée à une autre, d'un Odontoglossum à un Phalenopsis par exemple, il peut arriver ou bien que le Champignon pénètre et soit digéré ou phagocyté, ou bien, au contraire, qu'il mange et détruise la graine d'Orchidée. A l'association harmonique qui existe dans le cas normal, se substitue une association qui peut avorter ou qui peut être disharmonique et se traduire par la mort de la plantule.

La symbiose. - On connaît d'autres exemples d'associations dans le règne végétal. Les Lichens, par exemple, constituent une assocjation nécessaire d'un Champignon et d'une Algue. Le Champignon tire bénéfice de cette symbiose, parce qu'il utilise les produits hydrocarbonés que fabrique l'Algue à l'aide de son pigment vert. L'Algue, d'autre part, étant emprisonnée dans les flaments du Champignon, s'y trouve abritée contre une dessiccation rapide et les causes de 
destruction multiples qui existent dans le milieu ambiant. Cette association cst devenue nécessaire pour un certain nombre de Champignons qui ne se rencontrent dans la nature qu'associés à des Algues. Les Algues, au contraire, que l'on reconnaît dans le corps des $\mathrm{Li}$ chens, peuvent se trouver à l'état libre dans la nature. Bornet a pu d'ailleurs isoler les Algues par analyse, les cultiver purement et les faire reproduire. La culture des Champignons est un peu plus délicate. Moeller y est cependant parvenu et a obtenu des thalles d'un grand développement. La synthèse d'une Algue et d'un Champignon a été réalisée par Bonnier.

Un autre exemple très extraordinaire de symbiose est celui des Légumineuses qui présentent une association d'une sorte de Bactérie un peu aberrante (fixatrice de l'azote libre de l'air) et des racines des plantes de cette famille.

\section{Maladies cryptogami -} ques. - Les associations de deux êtres ne sont pas toujours à bénéfice réciproque: très sou-

vent l'un des deux pâtit du rapprochement; on conçoit aisément quil y ait toutes les transitions entre la symbiose et le parasitisme. Parmi les maladies dues à des Cryptogames, on doit d'abord citer les Rouilles des Céréales, affection déjà connue des Romains et qui cause des dégâts se chiffrant bon an mal an par des centaines de millions pour l'agriculture mondiale; on donne à ce Champignon le nom de Puccinie des Graminées ou Rouille, à cause des taches orangées qui se produisent sur les feuilles au printemps. L'ergotisme du Seigle a produit des désastres d'une autre nature : le grain est transformé sous l'influence du Champignon nuisible, le Claviceps purpurea, en un corps noir oblong qui fait saillie hors de l'épi. Au cours des famines qui ont sévi en France pendant tout le moyen âge jusqu'au milieu du $X v 1 I^{\theta}$ siècle, les paysans affamés ont à maintes reprises voulu faire moudre ces grains avec le seigle intact et il en est résulté des épidémies terribles; l'une d'elles a été signalée par Vétillard dans la Sologne, en $1770 ; 7000$ à 8000 personnes $y$ périrent.

Les ravages produits sur les plantes cultivées par les Champignons parasites sont extrêmement importants. En fait, la patholcgie végétale est très anciennement connue, puisqu'il est fait mention dans la Bible de la rouille et du charbon. Théophraste, le grand botaniste grec, qui était l'élève d'Aristote, mentionne également le charbon. En réalité, c'est au XVIII ${ }^{e}$ siècle que cette science s'est constituée par les études expérimentales très remarquables de Tillet, qui enroba les grains de Céréales dans la poussière charbonneuse, prise dans les épis malades. En semant en ligne, il constata que la rangée de grains

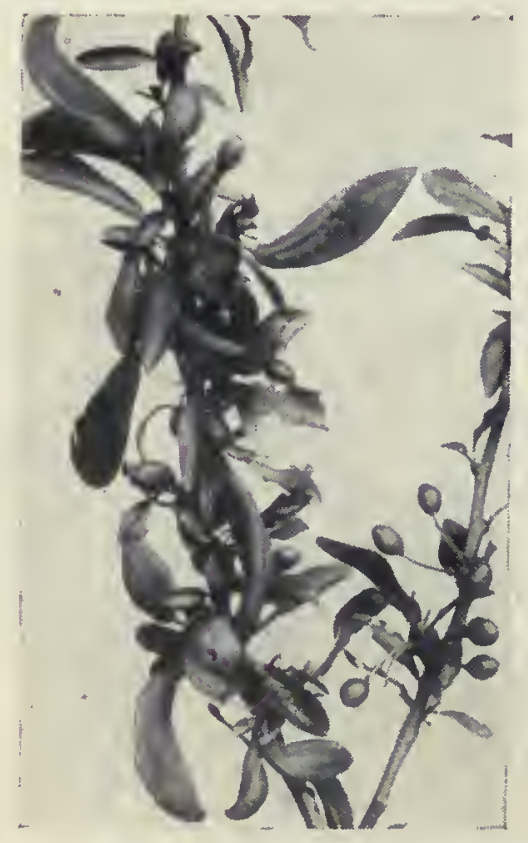

Fruits du Prunellier déformés par un Champignon : Exoascus pruni. pollués donnait un nombre énorme de pieds malades; la rangée suivante, qui n avait pas ćtć salie, était formée de plantes parfaitement saines. Cette expérience avait un caractère mystérieux et parut, en 1752 . presque un résultat de sorcellerie. Il y avait heureusement alors des philosophes très aptes à apprécier la portée très grande de pareils résultats; Louis XV. qui s'intéressait beaucoup aux plantes, vint visiter le champ d'expérience de Tillet, près de Versailles. Il fut tellementétonné du résultat qu'il avait sous les yeux qu'il jugea utile, pour le bien du royaume, de le faire connaître au public. A cette époque, il $y$ avait peu de journaux et le roi de France donna l'ordre à M. Lc Roy, son capitaine des chasses, de signaler à ses sujets lintérêt considérable de ces recherches agronomiques. Ce der= nier ne trouva pas de meilleur moyen que d'écrire une lettre à Diderot dans laquelle il relatait ce qu'il avait vu et qui l'avait intéressé.

Cette lettre est d'un ton très caractéristique de l'époque; cest un document historique assez curieux : "Nous avons souvent parlé, Monsieur, de la découverte de M. Tillet sur la Nielle des Blés. J'ai été souvent trompé sur ces matières, et sans penser que $\mathrm{M}$. Tillet voulait abuser des autres, je croyais qu'il pouvait s'en imposer à lui-même. Il est démontré que la poussière noire et fétide des grains niellés, cariés, ou comme vous voudrez les appeler, s'attache aux grains et les corrompt. Par là se perpétue cette peste qui ravage nos récoltes. ")

Cette date de 1752 de l'expérience de Tillet mérite d'être retenue, car elle correspond aux premières expériences de pathologie végétale, science qui était ainsi de plus de cent ans en avance sur la pathologie animale ( $188 \mathrm{I}$ avec Pasteur).

Les maladies cryptogamiques sont extrêmement nombreuses; nous pouvons mentionner parmi elles la maladie de la pochette ou de la cloque, due à des Exoasques, qui sévit sur le Pêcher. Une déformation analogue se manifeste également sur le Prunellier.

L'Uromyces du Pois est un parasite du même groupe que celui qui produit les Rouilles des Céréales. La photographie ci-jointe représente une Euphorbe petit Cyprc̀s déformée dans sa partie terminale par la présence de l'hôte nuisible. On s'aperçoit aisćment de l'existence du mal à l'aspect anormal du développement : l'inflorescence n'apparaît pas, les feuilles de l'extrémité de la tige sont petites, serrées les unes contre les autres dans le bourgeon terminal et, à leur face inférieure, on constate, par un examen attentif, la présence de petites pustules qui trahissent l'existence de l'organisme étranger. Le Champignon, après avoir rongé l'Euphorbe, ira porter ses dégâts sur un deuxième hôte, le Pois. 


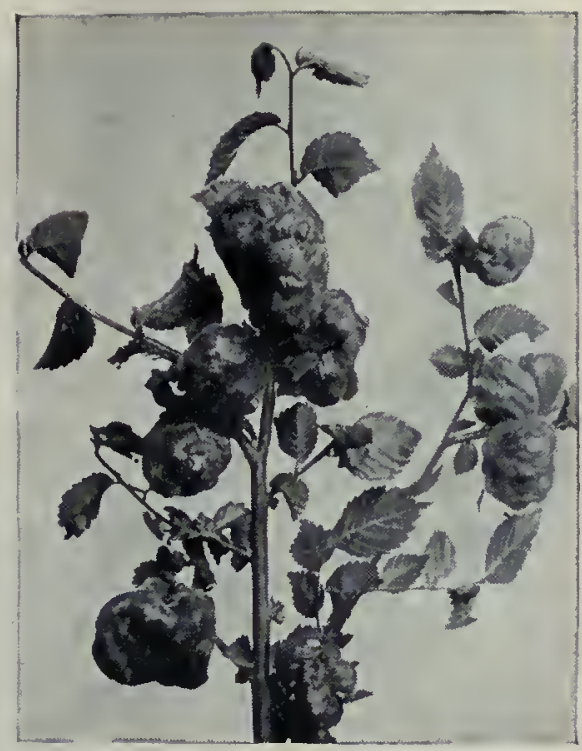

Galle de l'Orme (Schizoneura).

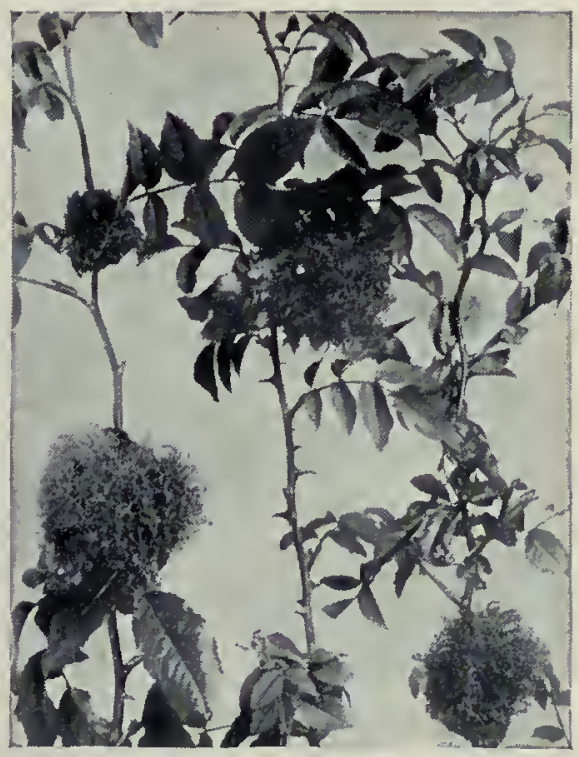

Galle de l'Egtantier, ou Bédéguar (Rhodites).

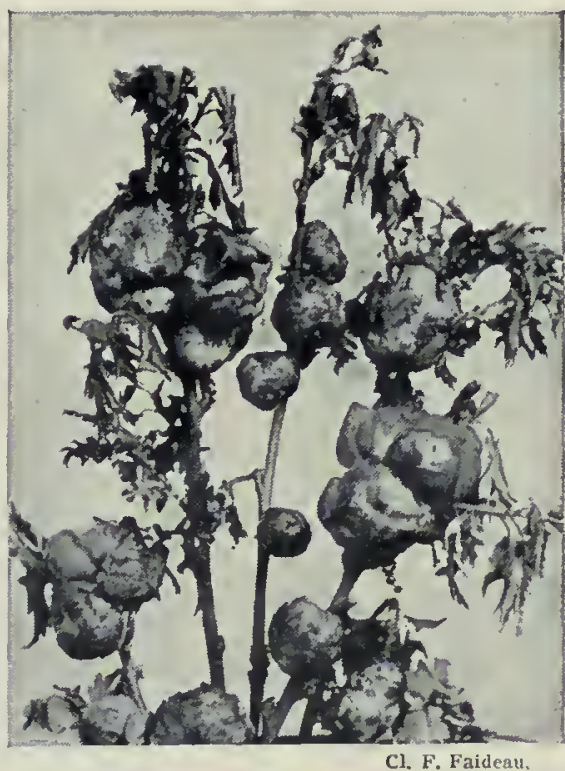

Galle dite pomme de Chêne (Biorhiza).

\section{RAPPORTS DES ANIMAUX ET DES PLANTES}

Nous venons d'envisager les rapports des plantes entre elles; les relations qui s'établissent entre les animaux et les plantes ne sont pas moins curieuses et variées; sil est de nombreux cas où les animaux nuisent aux plantes, il en existe aussi quelques-uns où ils rendent $\mathrm{d}$ 'importants services à ces dernières, quelquefois d'ailleurs à charge de réciprocité.

Fécondation. - Les animaux, et en particulier l'homme, peuvent intervenir dans la fécondation. Celle du Dattier, dans les oasis du désert, en Algérie, se fait de la façon suivante : l'inflorescence mâle est secouée ou découpée en petits tronçons, qui sont placés dans les spathes des individus femelles par les Arabes, qui grimpent sur les arbres. Grâce à ce procédé, la spathe femelle étant ficelée, la poussière mâle se dissémine sur les stigmates et assure la fécondation croisée. Cette opération a, comme de juste, une grande importance pour un Palmier tel que le précédent, où les sexes sont séparés sur des pieds distincts, et dont la fécondation est essentielle pour les habitants des oasis des déserts africains, car les dattes, qui sont ainsi produites, constituent la partie fondamentale de leur alimentation. La conservation du pollen doit se faire dans un endroit $\mathrm{sec}$, abrité du soleil et du vent, et, dans ces conditions, les caractères vitaux des cellules mâles peuvent se conserver pendant deux années. On conçoit que la possession de cette poussière fécondante soit considérée par les tribus arabes comme de première importance, et dans les guerres entre tribus hostiles, le premier effort de l'ennemi qui envahit une oasis est d'y détruire les pieds mâles, qui sont toujours en petit nombre : par ce procédé, l'adversaire se trouvera affamé, étant privé de sa récolte de dattes.

On voit, par l'exemple que nous venons de choisir, qu'il est des plantes pour lesquelles la pollinisation ne peut pas être directe, puisque les pieds mâles et femelles sont distincts (plante dioïque). Même dans le cas où la fleur est hermaphrodite, il peut arriver, et ceci est très fréquent, que la pollinisation ne puisse pas être directe; c'est, en particulier, ce qui survient dans les cas de dichogamie, c'est-à-dire quand la maturité des organes mâles et des organes femelles n'a pas lieu en même temps. Tantôt les étamines devancent les carpelles dans leur développement: on dit que la fleur est protandre; en réalité, au début, bien qu'elle soit hermaphrodite, la fleur de ces espèces se comporte comme une fleur mâle, et c'est seulement plus tard que ses parties femelles arrivent à point; mais à ce moment les étamines sont flétries et la fleur se comporte comme si elle était exclusivement femelle. La protandrie est extrêmement répandue dans un grand nombre de familles : Labiées, Campanulacées, Composées, Ombellifères; dans un assez grand nombre de genres, comme les Digitales, les Epilobes, etc.

Une plante qui présente la particularité précédente ne pourra évidemment pas se féconder elle-même. II en sera de même pour les fleurs protogynes; dans ce cas, c'est l'inverse qui a lieu; ce sont les parties femelles qui arrivent les premières à maturité : le stigmate d'une fleur devra être pollinisé par la poussière mâle d'une fleur plus âgée qu'elle; le pollen, au contraire, devra être transporté sur le pistil d'une fleur plus jeune. Ce cas s'observe dans les Plantains, dans les Scrofulaires, les Graminées. Dans ces divers cas, et aussi dans les plantes monoïques, la nécessité de l'intervention d'agents étrangers pour le transport du pollen se fait sentir.

Les agents principaux de la pollinisation croisée sont les insectes (fig. 101$)$ : ils viennent, en effet, visiter les fleurs pour y recueillir soit le nectar ou liquide sucré dont ils se nourrissent, soit le pollen dont ils ont besoin. L'insecte visiteur, en pénétrant dans la corolle
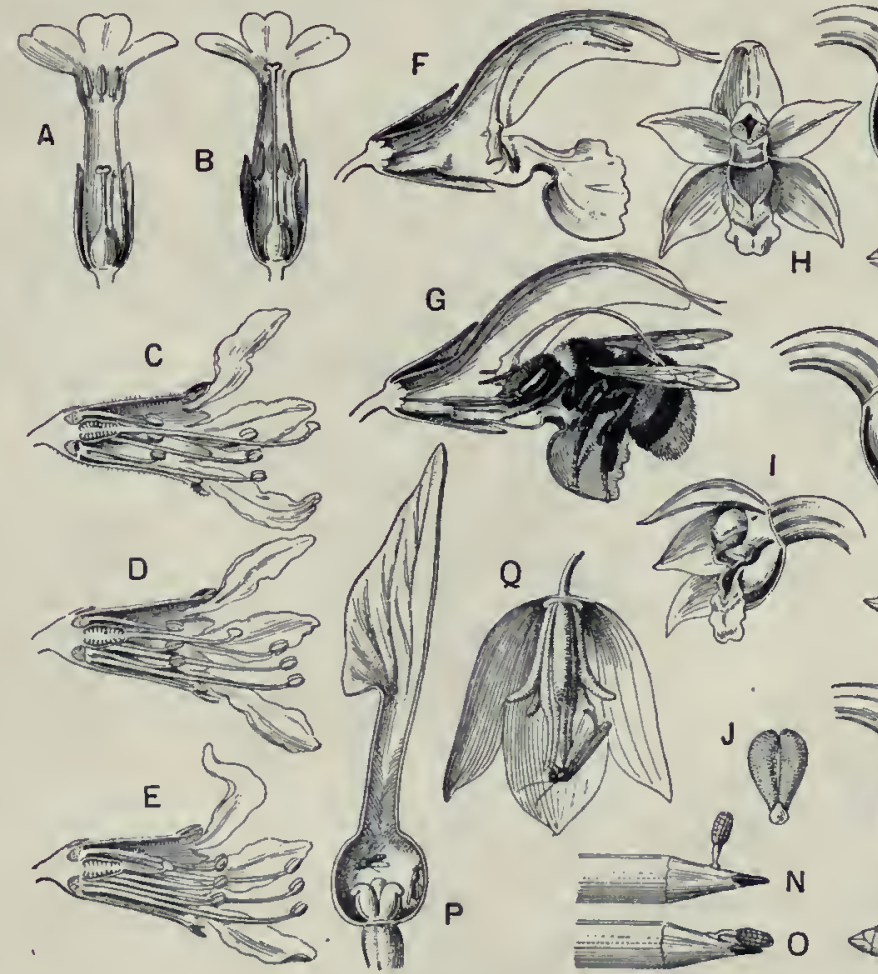

$\mathrm{G}$

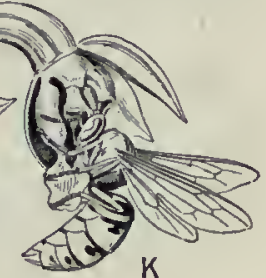


d'une fleur qui est à maturité, par suite de ses mouvements vient frotter les étamines, et, lorsquil s'envole pour aller visiter une fleur nouvelle, il emporte des grains de pollen en grand nombre qui sont attachés à sa trompe, à sa tête, à son dos, à ses pattes. Son corps est même souvent pourvu d'appendices qui fonctionnent comme de véritables brosses et qui retiennent ainsi aisément la poussière pollinique. Quand l'insecte, chargé ainsi inconsciemment de ces éléments fécondants, arrive sur une fleur de la même espèce dans laquelle les organes femelles sont à maturité, les parties de son corps chargées de pollen frottent contre le stigmate, qui est visqueux et qui agglutine et retient aisément les cellules mâles celles-ci peuvent alors germer et réaliser la fécondation.

Les insectes sont donc les grands agents de la fécondation croisée. Or, les expériences de Darwin ont établi que le croisement était avantageux pour les plantes, et que les individus ainsi produits étaient supérieurs par tous les caractères, à la fois végétatifs et reproducteurs (en particulier le poids des graines obtenues par fécondation croisée), aux individus issus d'autofécondation, cest-à-dire dans lesquels le pollen d'une fleur avait été employé à la fécondation du pistil de la même fleur. L intervention des insectes paraît donc utile pour le perfectionnement progressif des types, $c$ est-

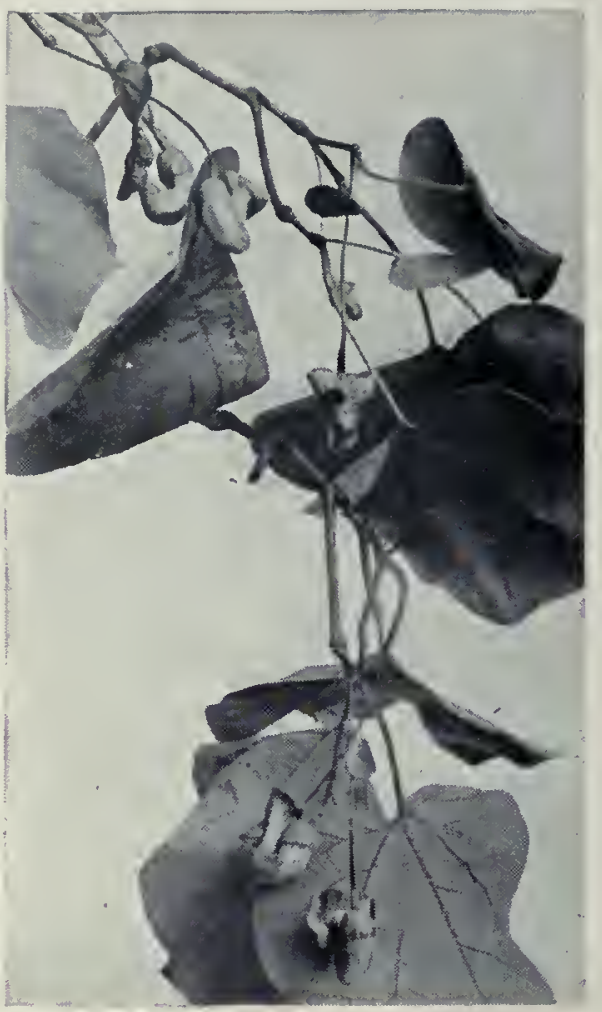

Aristoloche siphon stylées. Il existe plusieurs plantes, notamment les Primevères, qui présentent sur des pieds différents des fleurs au premier aspect identiques, mais qui sont dissemblables par les points où s'insèrent les étamines et par la longueur des styles (fig. 101. A et B). Les unes ont les étamines insérées très haut et les anthères sont à la gorge de la corolle; leur pistil est, par contre, très court et le stigmate est situé profondément dans le tube de la fleur. Les autres, au contraire. ont un style très long et le stigmate apparaît à l'orifice de la fleur; les étamines sont insérées très bas dans la corolle. Par suite de l'existence de ces deux sortes de fleurs, lout insecte qui visitera la première, simprégnera de grains de pollen sur certaines parties de son corps (par exemple son dos) qui viendront justement au contact du stigmate des fleurs de la deuxième catégorie quand il les visitera, puisque cet organe se trouve à la gorge de la corolle. Inversement, l'insecte qui enfoncera profondément sa tête dans la seconde fleur et qui visitera ensuite une fleur de la première catégorie transportera inconsciemment le pollen des étamines profondes de la deuxième fleur sur le pistil à stigmate profond de la première fleur. Les particularités florales des Primevères précédentes favorisent donc grandement la fécondation croisée par les insectes. Darwin a d'ailleurs prouvé qu'en transportant artificiellement le pollen d'une fleur sur le stigà-dire pour la production d'individus qui auront plus de chances de se maintenir que les autres, qui sont plus faibles et moins féconds.

Dispositions florales spéciales. - On peut d'ailleurs observer une série de dispositions florales, réalisées dans le cours des siècles chez un certain nombre de plantes et qui semblent très favorables à l'intervention des insectes dans la pollinisation (fig. 101).

Nous pouvons citer, en premier lieu, le cas des fleurs hétéro-

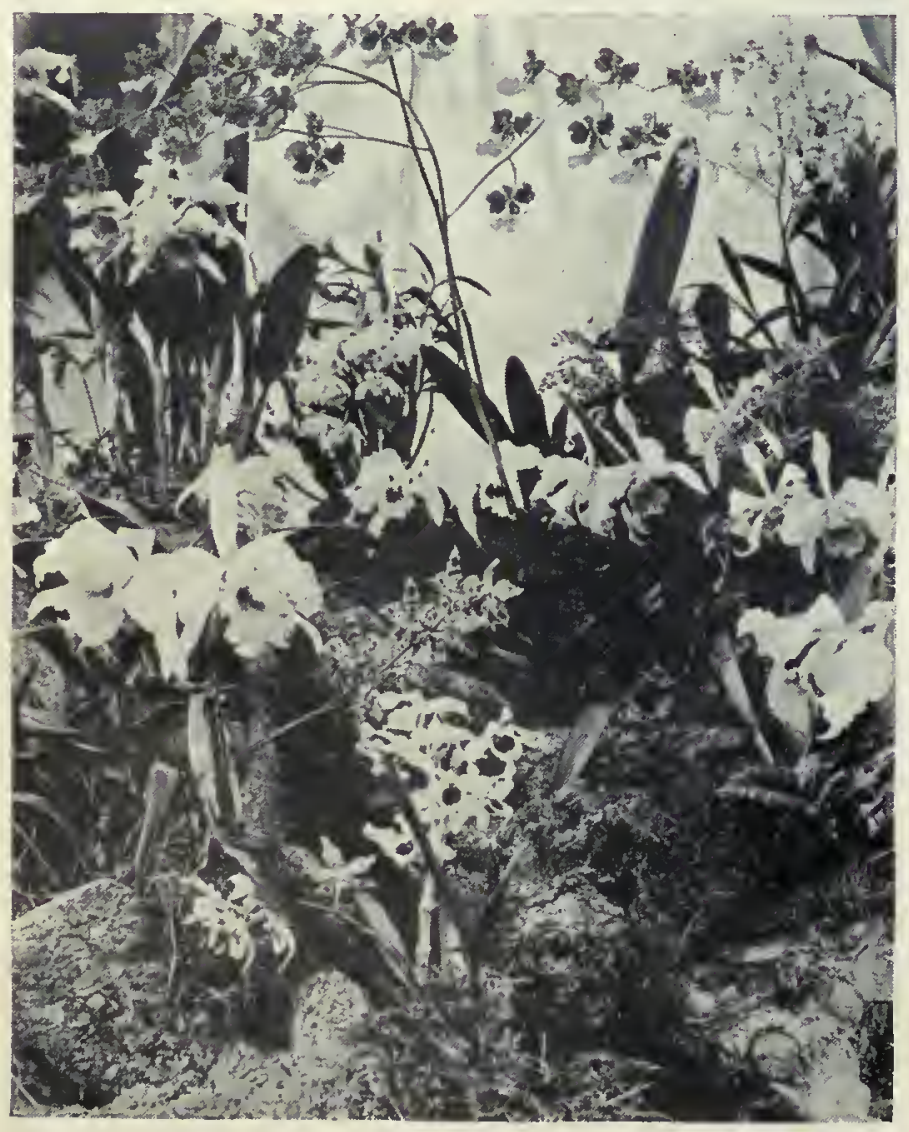

Cl F. Fraidean

Groupe d'Orchidées dans une serre. mate de la même fleur (fécondation illégitime), on n'avait dans les capsules qu'un très petit nombre de graines mal venues, et même souvent la fécondation avorte presque.

On connaît des plantes, comme les Salicaires, qui sont hétérostylées, mais qui, au lieu d'être simplement dimorphes comme les fleurs : les premières ont des styles très longs et deux sortes d'étamines, les unes à filets très courts, les autres à filets moyens; les secondes fleurs ont des styles de longueur moyenne et des étamines très longues et très courtes; les troisièmes fleurs ont des styles très courts et des étamines très longues et des étamines moyennes. Les stigmates des fleurs de la première catégorie à long style ne peuvent être fécondées (avec grande efficacité) qu avec le pollen des étamines à très longs filets des fleurs des deuxième et troisième types; de même pour les styles moyens et courts, les stigmates sont pollinisés par les étamines de longueur correspondante des autres fleurs.

Le cas de la Sauge ( $f$ ig. 101, F, G) nous permet d'entrevoir une disposition favorisant encore l'intervention des insectes par un mécanisme tout dissemblable. Les étamines ont la forme d'un fléau de balance à bras inégaux : le bras supérieur allongé, grêle, est infléchi sous la lèvre supérieure de la corolle et porte les anthères fertiles renfermant le pollen; les bras inférieurs sont courts et stériles; entre ces deux bras s'attache le support très court, qui n'est autre que le filet. Quand un bourdon arrive sur la fleur, il fait basculer avec sa trompe le bras inférieur de l'étamine, et le bras supérieur se rabat alors sur le dos de l'insecte fortement chargé de poils qui recueille le pollen, comme si une brosse frottait les anthères ouvertes. L'insecte s'envole ensuite chargé de poussière mâle; en pénétrant dans une autre fleur, il frottera inévitablement avec son dos le stigmate saillant hors de la lèvre supérieure de la corolle et opérera la fécondation croisée.

Dans les Aristoloches, on observe des phénomènes plus frappants encore. Le périanthe de ces fleurs a la forme d'un tube assez long, qui s'élargit à sa partie supérieure en entonnoir. Avant la fécondation, cet entonnoir est redressé vers le haut et semble par son orientation inviter les mouches à entrer dans le tube du périanthe. Ces insectes y pénètrent, en effet, et sans difficulté; ils rencontrent bien, il est vrai, le long du tube où ils s'enfoncent, une série de poils rapprochés les uns des autres, qui sembleraient devoir faire obstacle à leur marche en avant, mais comme ces poils sont orientés vers le bas, ils ne sopposent pas à la pénétration. La mouche arrive donc sans difficulté à la partie inférieure renflée, où elle rencontre à la fois les étamines et le stigmate de la partie femelle. Tant que la fécondation n'est pas opérée, l'insecte est enfermé dans cette prison, car les poils orientés vers le bas sont croisés Primevères, sont trimorphes. Elles ont en effet trois sortes de 
les uns sur les autres et forment un obstacle insurmontable pour lui. Lorsque la fécondation a été opérée par les mouvements de l'animal, les poils se flétrissent, et il peut sortir, mais il est alors barbouillé de pollen et il pourra se rendre dans une autre fleur pour l'y déposer. Il n'entrera pas dans les fleurs fécondées, parce que celles-là ont un aspect flétri: leurs périanthes sont flasques et rabattus. Burck plaide cependant le rôle de l'autofécondation.

Chez les Orchidées (fig. 101, H à M), il y a des dispositions très spéciales qui sont également curieuses. Le pollen de ces plantes est aggloméré en masses ou pollinies qui restent agrégées entre elles. Si un insecte vient visiter une de ces fleurs, il touche, avec sa tête ou avec sa trompe, un petit appareil appelé bursicule, qui s'ouvre et met à nu une masse gélatineuse; celle-ci est mise en liberté et s'attache à l'organe (tête ou trompe) de l'animal; cette masse gélatineuse est reliée à la pollinie par un pédicelle appelé cardicule. L'insecte s'envole donc en emportant, attaché après lui, tout un appareil complexe désigné sous le nom de pollinaire $(\mathrm{J})$; pendant le vol, la caudicule se contracte, change de direction, de sorte que lorsque l'animal arrive pour visiter une nouvelle fleur, la pollinie vient buter juste en face du stigmate et la fécondation croisée s'opère naturellement. Darwin a pu réaliser, d'ailleurs, les diverses phases de ce curieux mécanisme en introduisant un crayon dans une fleur $(\mathrm{N}, \mathrm{O})$ : le pollinaire qui s'y attache est transporté, avec contraction, sur la deuxième fleur, et il y a pollinisation.

Dans tous les exemples que nous venons de citer, la pollinisation est opérée par l'animal, mais d'une manière inconsciente. II ne semble plus en être de même dans le cas de la fécondation des Yucca, par le Pronuba yucasella (fig. 101, Q). La mère récolte le pollen et le rassemble pour le déposer sur le stigmate, et en même temps, à l'aide de sa tarière, elle enfonce ses oufs dans l'ovaire. Comme les larves, en se développant, se nourrissent des graines du Yucca, il faut que la fécondation ait eu lieu et la mère se charge de cette opération, dont elle a découvert la technique.

Expériences de Plateau. - Le travail de Darwin était destiné à avoir un grand retentissement. De nombreux disciples ont adopté immédiatement cette hypothèse que l'adaptation des fleurs aux insectes constituait un exemple frappant de la sélection naturelle, puis une réaction s'est produite. On a montré des exemples assez nombreux (sinon très nombreux) de cas d'autofécondation chez les Orchidées. Forbes notamment, qui a étudié les Orchidées exotiques à Java, en cite un certain nombre qui se fécondent elles-mêmes. Un petit nombre d'exemples dans les cultures de serre en Europe a confirmé ce résultat. Bonnier a montré d'autre part que les nectaires sont

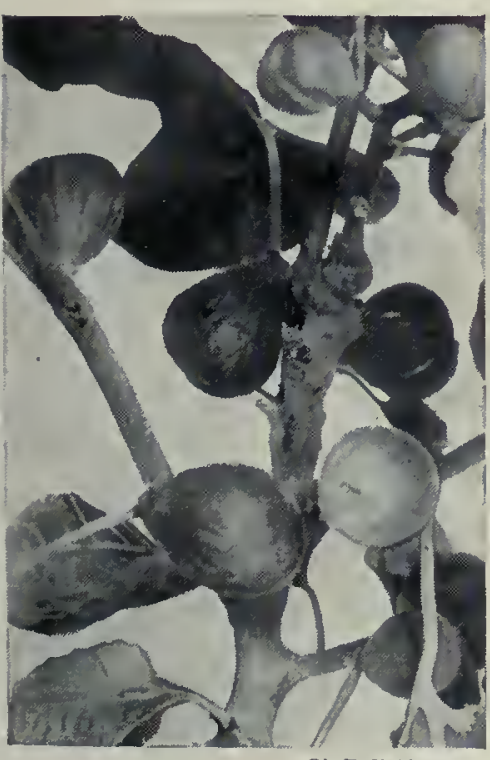

c1. F, Faideau.

Figuier commun avec fruits. fréquemment en dehors des fleurs dans d'autres familles, et que l'éperon des Orchidées (Orchis, Cephalanthera, etc.), très souvent, ne contient pas de nectar. La même fleur peut être visitée de façons différentes par un même insecte : ce qui semble indiquer que l'adaptation de la forme florale au corps de l'insecte n'est pas aussi complète qu' on le prétend.

Mais c'est surtout sur la question de l'utilité attractive de la couleur des fleurs que le combat s'est engagé et a été acharné. De très nombreuses expériences ont été entreprises par un grand nombre de savants (recherches de Lubbock, Forel, Bonnier, G. et E. Peckam, Wiist,
Dunhoff, Bethe, etc.) pour résoudre celte question délicate. Les uns se sont servis de papier ou d'étoffe colorés chargés de miel et ont étudié l'effet attractif des couleurs sur les guêpes, les abeilles. Selon Plateau, qui reprit toutes ces expériences, les résultats en sont illusoires et ne sont pas applicables aux façons de se comporter des insectes vis-à-vis des fleurs.

Plateau, dans une longue série de recherches, a essayé de se mettre à l'abri de toutes les causes d'erreur. Il a d'abord placé au milieu d'un Pêcher en floraison des fleurs artificielles extrêmement bien imitées; aucune d'entre elles n'a été visitée par les hyménoptères qui arrivaient en grand nombre sur les fleurs naturelles.

Une deuxième méthode met en présence d'une légion d'insectes deux variétés d'une même fleur de coloris différents. II faut que le nombre des fleurs soit le même à peu près dans les deux cas. Les insectes n'ont fait aucune différence dans leurs visites entre ces fleurs d'après leur coloris.

Une troisième méthode consistait à cacher la partie colorée d'une fleur avec un écran de papier ou un mor-

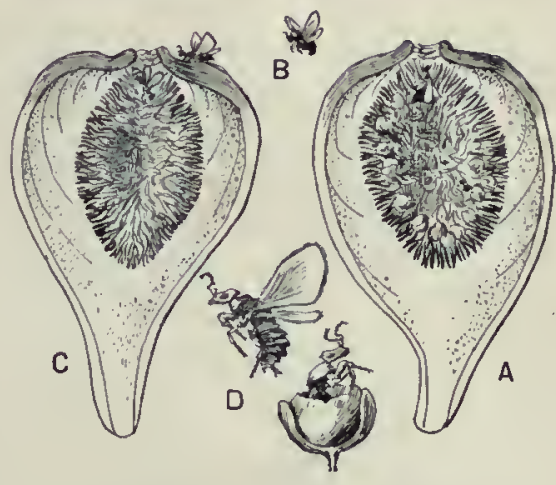

Fig. 102, - Caprification.

A, Cacrifigue avec insecte sur les fleurs mâles B, Insecte allant à la boune figue $\mathrm{C} ; \mathrm{D}$, Blastophago brossi insecte sortant de la galle (pistil).

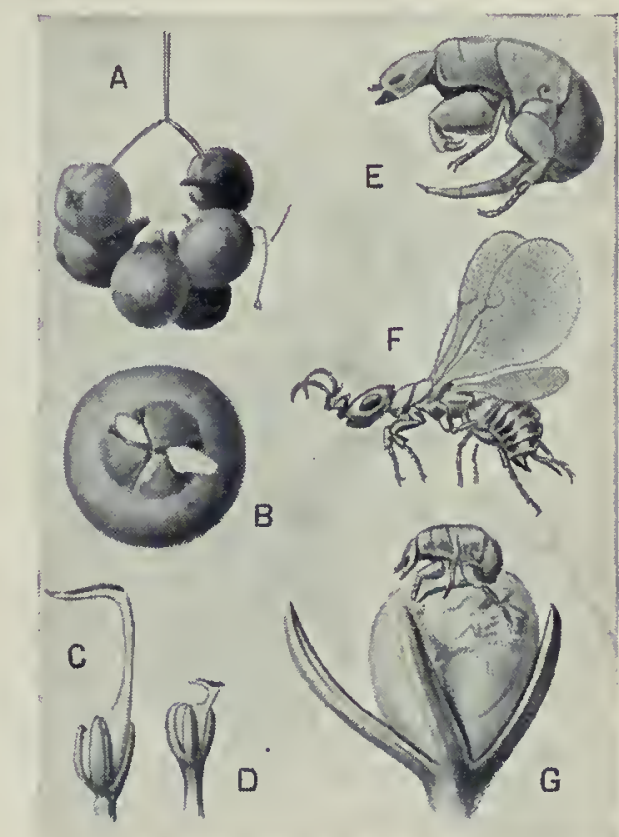

Fig. 103. - Caprification an moyen de dokkar.

A, Dokkar préparés pour la caprification: $B$, CEil d'une figue avec les ailes d'un Blastopha oa; C. Fleur femelle à style long; $D$, à style court; $E$, Blastophagta mâle; F, Bl. femelle; $G$, Mâle rampznt sur la galle. 


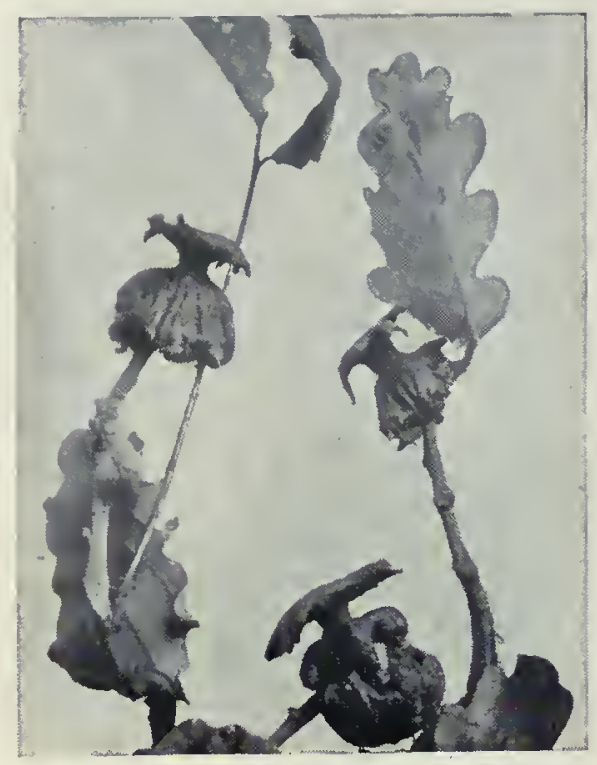

Galle en schapska du Chêne (Cynips Mayri).

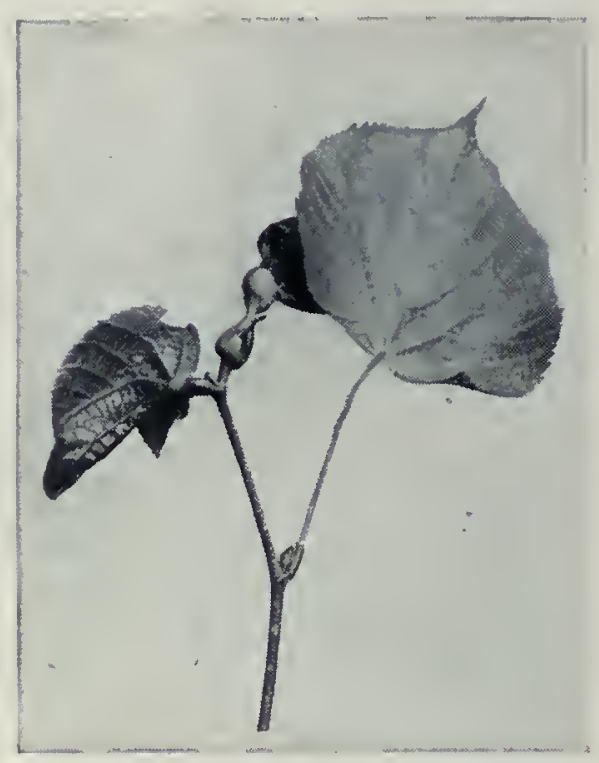

Galle de la feuille de Tilleul (Phytoptus).

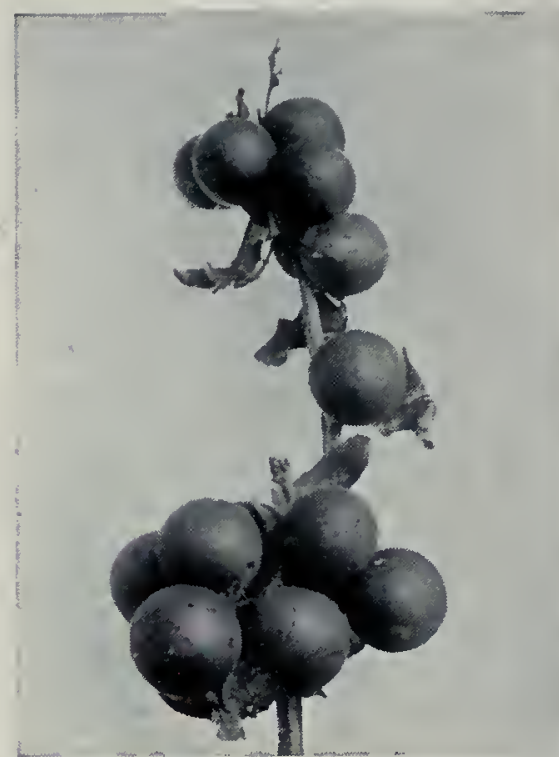

Galle en cerise du Chêne (Dryophante). ceau de limbe foliaire. Les insectes découvraient les fleurs sans être attirés par la couleur.

On peut, par exemple, dans une quatrième méthode, enlever la corolle d'une fleur ; cela n'empêche pas les visites des abeilles. Il faut cependant prendre la précaution de ne pas arracher les pétales avec des mains qui sentent la fumée, car cette odeur éloigne les insectes.

La conclusion de tout cet ensemble considérable de recherches longues et patientes est que les insectes ne sont guidés que d'une façon très imparfaite par la vue. Les recherches des physiologistes concluent d'ailleurs que les yeux à facettes donnent une vision assez confuse. Il semble bien plutôt que les insectes doivent être attirés par l'odorat, qui est extrêmement développé chez eux.

En somme, Plateau reconnaît, malgré toutes ces critiques, le rôle capital que " jouent les insectes dans la fécondation des fleurs". En ce qui concerne les Orchidées, l'importance de leur intervention s’affirme par le cas de la Vanille qui, à la Réunion, ne peut être fécondée, parce que les insectes fécondateurs du Mexique, patrie de cette plante, n'existent pas dans cette colonie. Il a fallu alors recourir à la fécondation artificielle, qui se pratique chaque arnée sur des centaines de millions de fleurs. Il en est de même

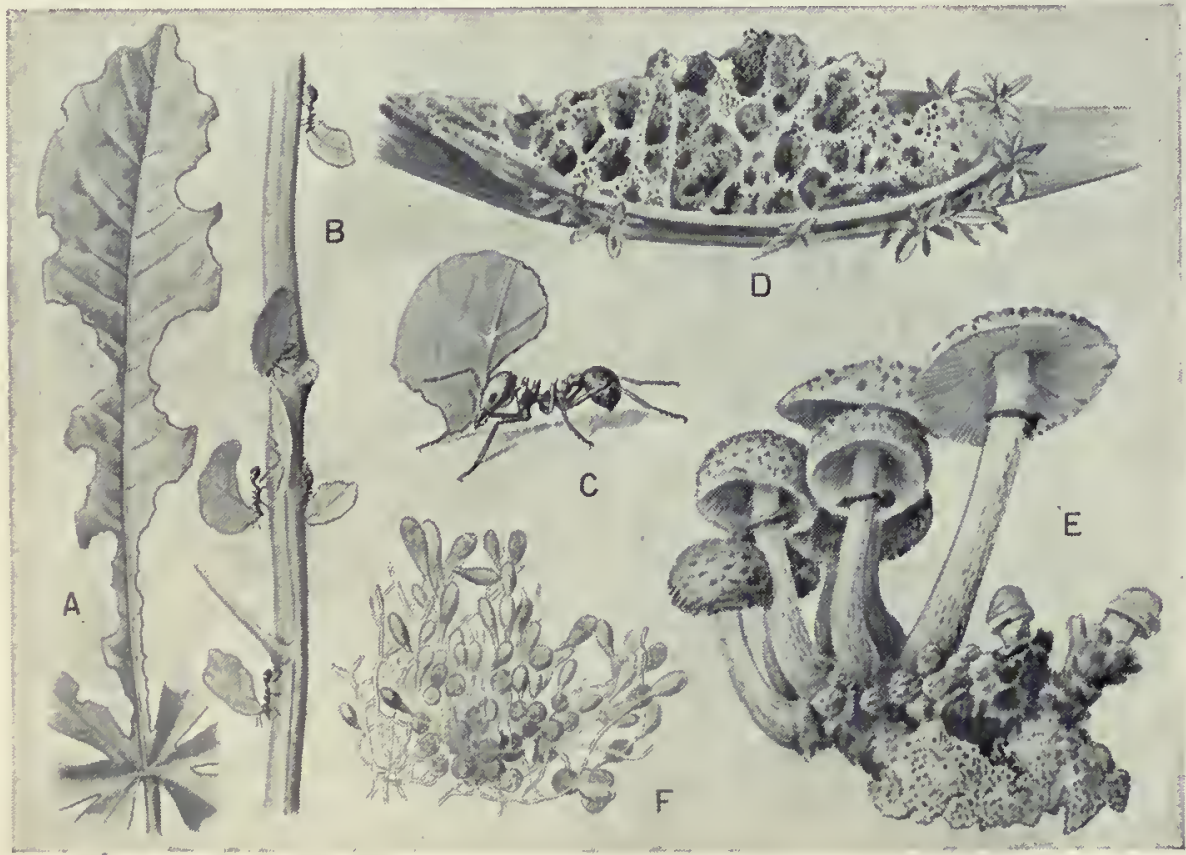

Fig. 104. - Culture de Champignons par l'Atta.

A. Fenille déconpée par les Alta discigera; B. Atta transportant des fraǵments de feuilles; C, Une Atta grossie; D. Nid; meule de Champignons; E, Rozites gongylophora; F, Mycelium de Rozites. pour bien des plantes d'ornement, comme les Gloxinia, les Pétunia, qu'on féconde en France dans les jardins ou dans les serres.

Caprification. - Les phénomènes qui se passent dans la caprification sont plus étranges encore que ceux que nous signalions plus haut à propos de la fécondation du Yucca. Il y a longtemps, dans le bassin méditerranéen, que l'on pratique l'opération désignée sous ce nom : elle était connue de Théophraste, botaniste grec, vivant à l'époque d'Alexandre le Grand; elle a été décrite par Pline l'Ancien, le célèbre naturaliste latin, et plus récemment par Tournefort, qui a eu l'occasion de l'observer dans son voyage en Orient, à l'époque de Louis XIV. On suspend, au milieu des cultures de Figuier, des caprifigues, c'est-à-dire des figues sauvages qui ne sont pas bonnes à manger et qui contiennent des moucherons (Blastophaga psenes : hyménoptères); ceux-ci s'envolent sur les Figuiers cultivés, pour y opérer la fécondation ( $f i g .102$ ). Les caprifigues sont des réceptacles qui contiennent deux sortes de fleurs : en haut des fleurs à étamines, en bas des fleurs à pistil à style court. Or, ces dernières ont été transformées en des galles, c'est-à-dire qu'au lieu de contenir des graines, elles renferment des œufs de Blastophaga, qui se développent dans l'ovaire et se métamorphosent en un insecte. Quand cet hyménoptère est sorti de l'ovaire et a rampé dans la caprifigue pour arriver à l'orifice, il s'est barbouillé de pollen, de sorte que lorsque la femelle s'envole hors de sa prison, elle est prête pour la pollinisation. Dès qu'elle a été fécondée elle-même par le mâle, elle s'envole vers les Figuiers comestibles et pénètre par l'orifice étroit, où elle laisse d'ordinaire ses ailes; une fois dans le conceptacle, elle cherche à l'aide de sa tarière à déposer ses oufs dans les ovaires, mais les fleurs femelles sont serrées les unes contre les autres et, comme les styles sont plus longs que les tarières, les œufs ne peuvent atteindre la cavité ovarienne; mais pendant que l'animal fait tous ces efforts, il dépose le pollen sur les stigmates et opère la fécondation, ce qui amène la maturation des figues et la production d'un fruit délicieux qui n'est obtenu, avec toutes ses qualités, que dans la région où la caprification est pratiquée. C'est une opération connue des Napolitains, et qui est pratiquée en Algérie; les "dokkar " ne sont autres que les chapelets de caprifigues que les Arabes suspendent au milieu de leurs plantations de Figuiers (fig. 103), et ils savent parfaitement que ces mauvaises figues sont remplies de moucherons. L'explication de la présence de ces insectes résulte de ce fait que ces caprifigues ont des fleurs femelles à pistil court et, lorsqu'elles sont visitées par la mouche 
mère, celle-ci peut déposer dans l'ovaire ses cuff, car sa tarière est assez longue pour cela : ce sont ses œufs qui se développent ensuite, comme il a été dit plus haut.

Les particularités que nous venons de signaler pour le Figuier cultivé sont d'ailleurs applicables à d'autres Figuiers, et on a pu les vérifier pour différentes espèces (Ficus hirla, diversifolia, ribes, canescens), mais, souvent, sous l'influence d'autres moucherons: par exemple, Blastophaga quadripes, au lieu de Blastophaga psenes. Il y a quelques années, les Américains ont cherché à obtenir des cultures de Figuier en Califoruie : ils avaient bien les arbres, mais ils ne parvenaient pas à obtenir les fruits, parce qu'ils n'avaient ni le Caprifiguier, ni le Blastophaga. C'est seulement à partir de 1899 que cette introduction ayant été faite, l'on a pu récolter des Figues du type de Smyrne ; c’est un grand événement agricole.

Les galles. - Le cas des galles que nous venons de citer nous amène à dire quelques mots des zoocécidies ou galles proprement dites. Toutes les personnes qui ont un peu herborisé ont souvent récolté des feuilles de Chêne, à la surface desquelles il y avait des sortes de boutons affectant des formes diversas. Quand on ouvre ces galles, on y trouve une larve d"insecte, notamment de Cynips. C'est la mère qui a piqué la feuille avec sa tarière en y déposant, en même temps que l'œuf, une substance chimique qui a provoqué une excitation des tissus et une multiplication des cellules produisant une région hypertrophiée qui affecte toujours la même forme, les mêmes dimensions et les mêmes couleurs. C'est une particularité extrêmement curieuse, car ce sont là des phénomènes en apparence héréditaires. La piqûre d'un insecte, en vue de nourrir son petit, amène des déformations d'une plante apparaissant avec des caractères constants, comme s'il s'agissait de caractères héréditaires normaux.

La noix de galle ou galle du Levant est la zoocécidie la plus connue; elle est due à un hyménoptère du groupe des Cynips, le Diplolepis galla tinctoria, qui pond ses oufs sur un Chêne d'Asie Mineure (Quercus infectoria) ; elle renferme une forte proportion de tanin. Le Chêne est le plus attaqué de tous les arbres; ses feuilles offrent souvent des galles sphériques, de la grosseur d'une cerise, dues à la piqûre d'un Dryophante, insecte du groupe des Cynips; elles ne renferment qu'une seule larve. Les pommes de Chêne, énormes nodosités irrégulières, bosselées et d'une belle couleur verte, sont dues à la piqûre d'un autre Cynips, le Biorhiza pallida. Chacune de ces grosses galles offre en son centre douze à quinze cellules, dont chacune est le logement d'une larve. Non moins curieuses sont les galles "en artichaut", qui semblent formées de petites touffes de feuilles écailleuses; elles sont encore l'œuvre d'un Cynipidé, l'Andricus fecondatrix. Il faudrait citer encore les galles "en chapeau ", sortes de lentilles situées à la facc inférieure des feuilles, et l'étrange galle " en schapska ", qui se développe sur les cupules des glands du Chêne pubescent quand la femelle du Cynips Mayri y a déposé ses œufs.

Les bédéguars ou galles chevelues des tiges d'Églantier naissent en mai, et ont en été la grosseur d'une nèfle; ils sont recouverts de longs poils à nuances vertes et rouges entremêlées. Dans cette galle habitent les larves d'un Cynips, le Rhodites de la rose, petit insecte mou et rougeâtre, qui vit exclusivement sur les rosiers.

Les Cynips ne sont pas les seuls insectes gallicoles. Un acarien, le Phytopte du Tilleul, amène, par ses piqûres continuelles, la formation de petites

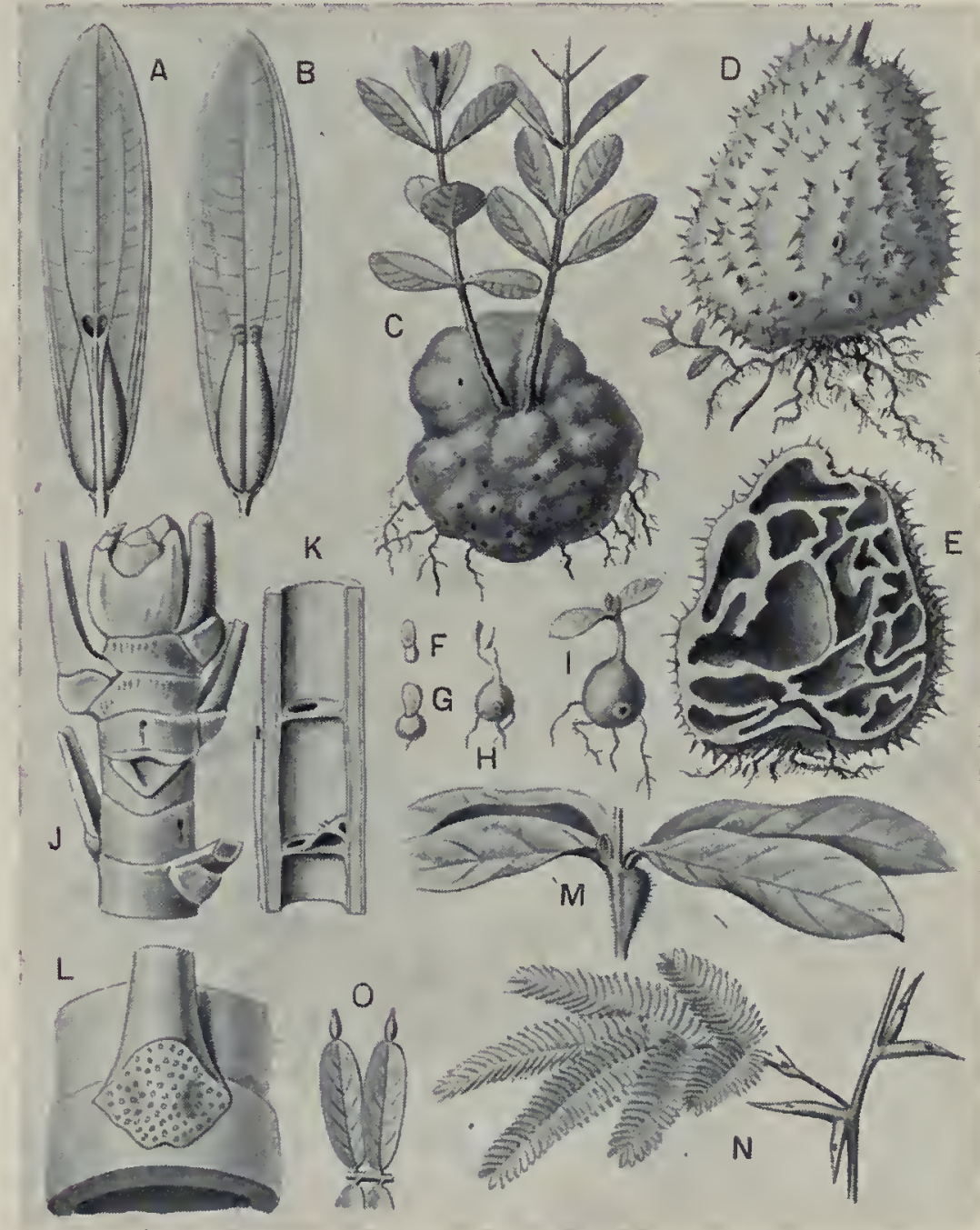

Fig. 105. - Organes hospitaliers aux fourmis.

A, B, Tococa lancifolia; C, Hydnophytum montanum; D, Myrmecodia echinata; $\mathrm{E}_{\mathrm{;}}$ Coupe du même ; F. G, H, I, Développement d'une graine de Myrnecodia; J, Sornmet dune jeune fide de Cccropia adenopus avec deux dépressions; $K$, Coupe d'une jeune tige; $L_{4}$ Attache de feuille de Cecropia, avec corpuscule de Müller; M, Cordia nodosa; N, Acacia spherocephala à stipules perforées: $O$, Ses folioles, avec corpuscules terminaux de Belt analoǵnes a ceux de Müller. 
dire, son aliment végétal par la culture : cest le cas pour les fourmis champignon nistes, qui fabriquent dans leur nid des meules à Champignons. Elles procèdent pour cela d'une façon singulière : elles commencent par saccager les plantations ou la végétation qu elles rencontrent; elles y parviennent en découpant les feuilles avec les pièces cour pantes de leur bouche : elles sont si destructrices qu'elles ont mérité le nom de coupeuses de feuilles. Ce sont des espèces du genre Atta, et notamment l'Aita histrix (fig. 104), qui sont de véritables féaux de divers districts, où elles rendent impossible la culture d'un certain nombre de plantes, comme l'Oranger, le Grenadier, les Rosiers, le Manguier, etc.

Cependant, ces animaux saccageurs ne se nourrissent pas des feuilles des plantes; on s'aperçoit qu'après les avoir fragmentées et broyées, ils en forment des boulettes qu'ils accumulent les unes à côté des autres, de manière à constituer des sortes de murs; en réalité, ce sont des meules à Champignons où ils "lardent " (c'est l'expression dont se servent les champignonnistes) le blanc ou mycélium, et le Champignon qüils cultivent avec une perfection remarquable est toujours le Rozites gongylophora. Ces petites bêtes ont acquis une telle maîtrise que leurs cultures sont plus parfaites que celles de leurs émules, les champignonnistes parisiens, car on ny observe jamais de maladie : le travail s'y fait avec une propreté, une pureté admirables. Ce résultat se comprend, quand on sait que ce Champignon est l'unique aliment de toute la colonie de fourmis. On ne peut donc pas voir une association plus intime

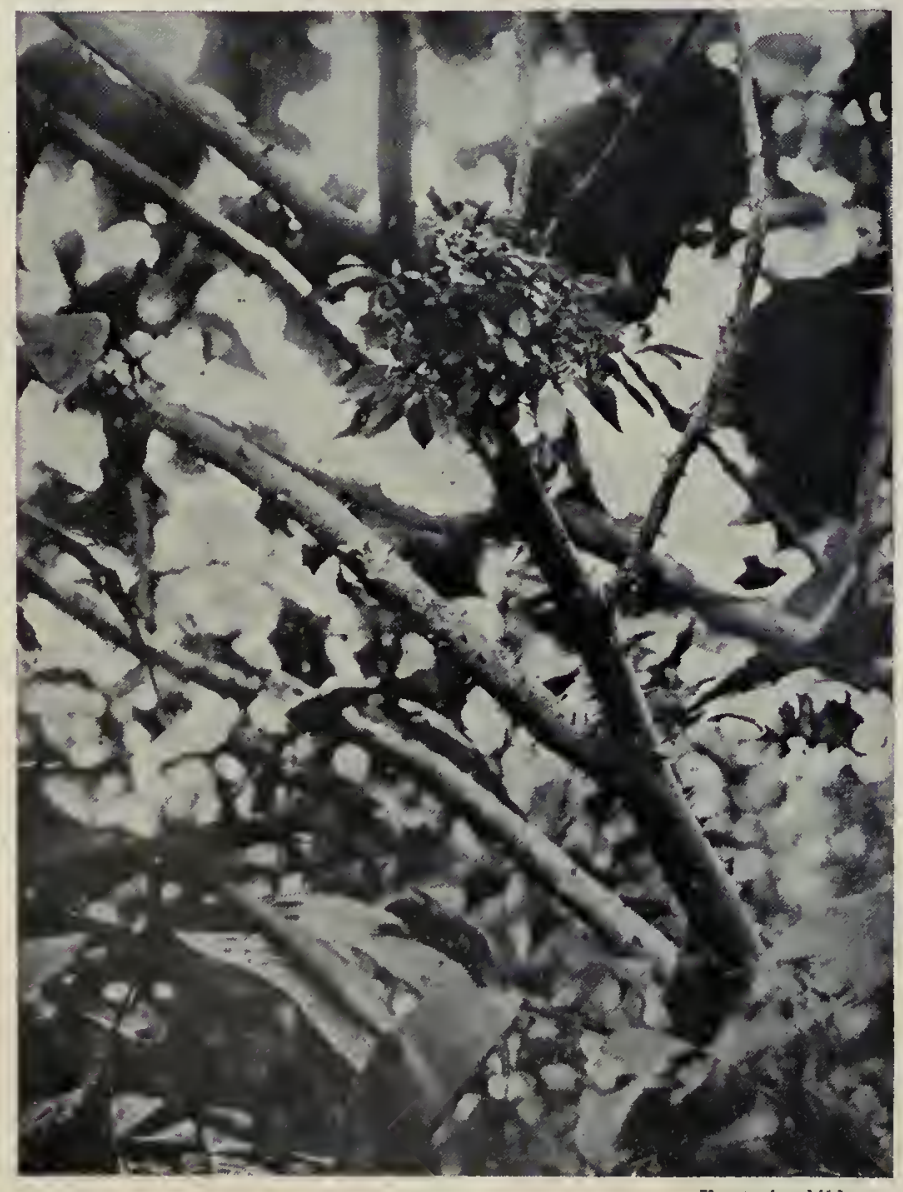

Jardin de fourmis (Camponotus femoratus), à Manaos.

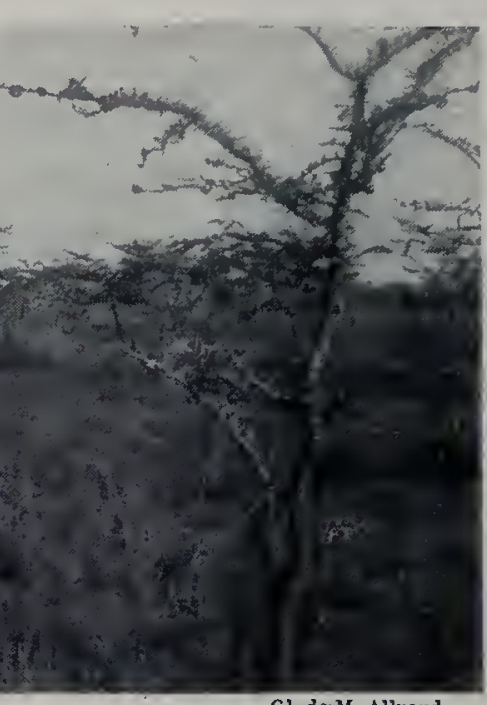

Cl. de M. Alluaud.

cacias à fourmis

Tirimainaro. d'une plante et d'un animal, car ils ne peuvent pas se passer l'un de l'autre. Les nids de termites, qui atteignent de si grandes dimensions, sont aussi remplis par le mycélium de Champignons qui poussent et fructifient souvent à leur surface.

L'association d'une fourmi et d'un végétal peut se présenter avec d'autres caractères, qui sont très différents des précédents et très singuliers. Dans les pays où pullulent les fourmis coupeuses de feuilles, dont il vient d'être question, la persistánce de certaines espèces attire tout de suite l'attention. Parmi ces espèces, on a signalé au Brésil, par exemple, les $\mathrm{Ce}$ cropia, qui sont des arbres de la famille des Urticacées. Quand on vient à secouer un de ces arbres, on comprend immédiatement la raison de l"immunité qu il possède vis-à-vis des fourmis saccageuses : aussitôt après les premières.secousses, on voit apparaître une armée de fourmis à la surface de l'arbre, qui se rassemblent en hâte et sur tous les points pour arrêter les attaques de tous les ennemis. Quand ces derniers sont formés par une troupe de coupeuses de feuilles, ils sont immédiatement repoussés avec perte. C'est à l"intérieur de l'arbre, dans les cavités de la moelle, que les fourmis protectrices appartenant au genre Azteca $(A$. instabilis, par exemple, vivant dans la moelle du Cecropia adenopus) font leur nid : chacune des logettes servant d'habitation est percée d'un orifice $(f i g .105, \mathrm{~J})$, qui est la porte de la chambre, permettant à la troupe d'Azteca d'apparaitre au dehors au moindre danger. On voit donc que les fourmis rendent à l'arbre un service signalé, mais l'arbre n'est pas ingrat avec ses défenseurs, car il leur donne le vivre et le couvert. Quand on observe la légion des fourmis dans une période de paix, au lieu du branle-bas guerrier que nous signalions plus haut, on voit les animaux cheminer le long de l'arbre, en se dirigeant vers la partie supérieure, où se trouvent les feuilles; d'autres fourmis reviennent vers leur nid en longues files et sont chargées de sortes de corpuscules ovoïdes ressemblant à de gros œufs qu' elles portent vers les logettes. C'est ce qu'on aopelle les corpuscules de Müller (fig. 105, L), qui ont été enlevés aux feuilles qui les produisent en grand nombre à la base du pétiole, sur une surface de quelques centimètres carrés, au milieu de poils effilés. Ces corpuscules, gorgés de matières albuminoïdes et oléagineuses, constituent un aliment très riche pour les fourmis qui ne vivent que de cela et ne sauraient s'en passer. Ce qu'il y a de plus curieux à constater, c'est que les organes de Müller n'existent que sur les espèces de Cecropia présentant des fourmis. On retrouve des arbres habités par des fourmis dans les régions tropicales, par exemple, les Acacia spherocephala (fig. 105, N). Les Acacia rencontrés sur la route du Kilimandjaro par Âlluaud sont curieux; Le Cerf y a vu une chenille de Lycénide (Lépidoptère) élevée dans les galles avec des feuilles d'Acacia par des fourmis du genre Crematogaster.

Il existe un certain nombre de végétaux appartenant à des familles diverses, qui sont susceptibles de donner asile à des fourmis (fig. 105) et qui présentent des cavités et des renflements dans la tige et dans la feuille, avec des fentes ou des orifices, qui mettent en communication ces nids avec le milieu extérieur; parmi eux, on peut citer les Myrmecodia, les Hydnophytum, les Duroia, qui sont des Rubiacées, les Tococa (Mélastomacées).

Parmi ces plantes myrmécophiles, mentionnons les Cordia nodosa (Borraginée) qui, dans l'Amérique du Sud, sont habités par les Azteca Ulei et Trailei dans de grands renflements en ampoule, à la base des dernières ramifications des branches. Comme les nids à l'intérieur de la plante ne suffisent pas, les fourmis en construisent au dehors et $y$ parviennent en devenant agriculteurs : elles accumulent de la terre sur les arbres et y déposent des graines de différentes plantes: Nidulaire myrmécophile, Figuier myrmécophile, Marckea de fourmis, Ectozoma d'Ule, Codonanthe de fourmis, Philodendron myrmécophile, qui y germent et, entre leurs racines, les Azteca construisent leur nid. Il est curieux de 
constater que ce sont toujours les mêmes espèces de plantes que l'on voit sortir de ces nids, et elles constituent ce que l'on appelle les " jardins feuris " de fourmis que l'on retrouve sur des territoires immenses, avec des caractères constants et composés d'espèces très distinctes. En outre, parmi ces espèces ainsi cultivées sur les arbres par les fourmis, la plupart sont épiphytes. On conçoit que le choix de ces animaux se soit porté vers des plantes qui devaient réussir dans les conditions où ils les plaçaient et qui, de plus, avaient un système de racines pas trop envahissant pour le nid : on ne s'étonnera pas de trouver, comme plantes de ces nids, des Aroïdées, des Broméliacées, des Pipéracées, des Moracées. Mais ce qui est plus curieux, c'est qu'il y ait aussi des espèces non aériennes qui ne vivent sur les arbres quavec les nids de fourmis : par exemple, le Phyllocactus phyllanthe, et surtout des Solanées (Marckea et Eclozoma) qui ne sont jamais épiphytes et qui ne le sont devenues que par l'intervention des $A z$ teca; il est bon d'ajouter que toutes les plantes des jardins fleuris de fourmis sont pourvues de baies qui, par leur succulence, doivent attirer les animaux. Enfin notons que les Azteca ne cultivent pas les mêmes espèces de plantes qu'un autre type de fourmis, le Camponotus temoratus du Brésil.

Faune bromélicole. - La température élevée qui règne dans les régions tropicales empêche l'existence de grandes mares permanentes dans les forêts, et cependant les moustiques y abondent, le paludisme et la filariose y règnent. D’intéressantes recherches de C. Picado ont montré le rôle important des Broméliacées épiphytes comme milieu biologique. La plupart de ces plantes ont, en effet, des feuilles engainantes, réunies à leur base, de manière à former de vastes godets dans lesquels s'accumulent les eaux provenant des pluies et de la condensation des brouillards nocturnes, et aussi toutes sortes de débris végétaux et animaux. Ces petites mares aériennes, innombrables dans les forêts des régions chaudes, constituent par leur ensemble un marécage permanent, suspendu, dans lequel viennent pondre une foule d'animaux : insectes, crustacés, vers, gastéropodes et même batraciens, dont les uns sont venus en volant, les autres en rampant le long des branches et des feuilles et dont plusieurs ont été transportés par le vent.

L'absence de pütréfaction dans ces mares, dont l'eau est toujours claire et sans odeur, serait due à la sécrétion par ces végétaux d'une gomme exerçant une action diastasique ; ces ferments seraient capables de digérer les débris animaux et végétaux du fond. Grâce à leurs

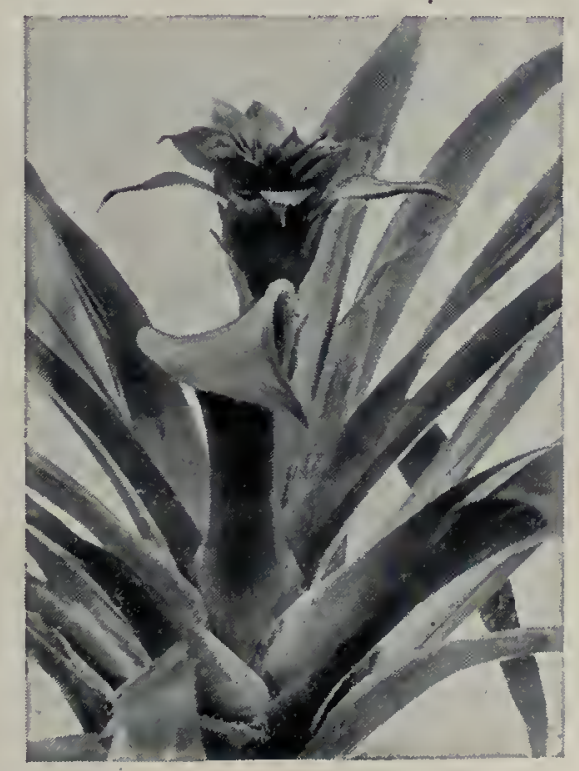

Caraguate cardinalis (Broméliacée).

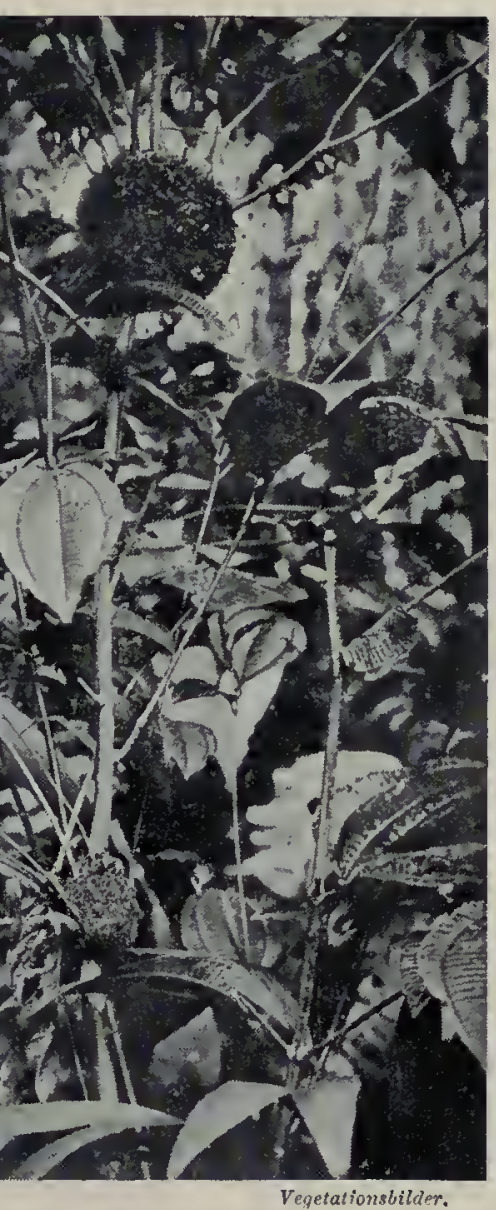

Vegetationsbilder.
(Mélastomacée)

écailles foliaires, les plantes absorbent les matières salines, ternaires ou albuminoïdes qui ont pris naissance dans ce milieu, dont la pureté est ainsi toujours maintenue.

Dissémination des fruits et des graines. - L'exemple que nous avons cité des plantes. rendues accidentellement épiphytes par l'intervention de fourmis nous amène à dire un mot du cas général des épiphytes et $\mathrm{du}$ rôle que les animaux jouent et ont joué dans la dissémination des graines de ces plantes. Lorsqu'on fait la récapitulation des modes de propagation des semences des végétaux qui vivent sur les arbres, on voit qu'ils se réduisent à deux essentiels : le vent et les animaux. Le vent explique la dissémination des spores impalpables des Fougères, des graines extrêmement petites des Orchidées. Ce sont au contraire les animaux qui interviennent pour la dissémination des fruits ou des graines charnus; ce sont les bêtes de la forêt vierge qui les transportent, les oiseaux, les singes, etc., et leur attention a été surtout fixée par les fructifications se distinguant par leur succulence.

Il est remarquable, en effet, que les fruits charnus, baies et drupes, sont toujours colorés de façon à ressortir au milieu du feuillage; leur épiderme est brillant, rouge ou violet foncé, parfois blanc. Leurs vives couleurs n'apparaissent qu'au moment de leur complète maturité ; élles attirent les oiseaux qui avalent les fruits mous, en digèrent la pulpe, tandis que les graines, pierreuses chez les baies, ou protégées par un noyau ligneux dans les drupes, traversent sans dommage le tube intestinal, sont rejetćes loin de la plante mère et germent. Ainsi, par un enchainement admirable de circonstances, les oiseaux assurent la perpétuité de l'espèce qui les rourrit. Dans nos pays, la carnosité des fruits des Ronces, du Prunellier, du Sureau, du Lierre, de l'Aubépine, du Houx, etc., assure la dissémination des graines de ces plantes; le passage de leurs semences à travers l'intestin des oiseaux expliquę pourquoi on les rencontre assez fréquemment au sommet d'un vieux mur ou

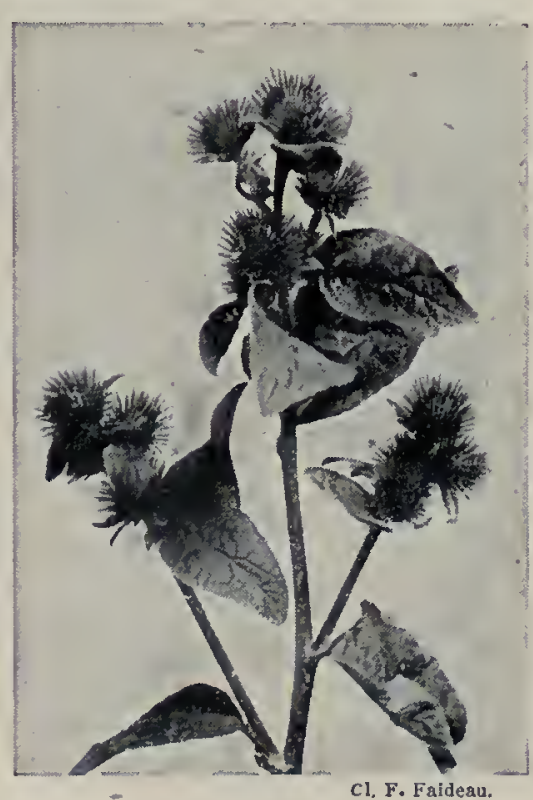

Fruits de la Bardane. dans une fourche d'arbre remplie de terre végétale. On trouve dans les régions chaudes de pareils fruits, destinés à traverser le tube digestif des animaux, chez les Astelia qui sont des Liliacées, chez les Schlegelia parmi les Bignoniacées, chez les Fuchsia parmi les Onagrariées.

La propagation des plantes qui vivent sur les arbres par les oiseaux est un fait d'ailleurs très anciennement connu pour le Gui, qui est, il est vrai, une plante parasite épiphy toïde et non une plante épiphyte.

L'origine des fruits charnus se manifeste assez nettement dans le cas des Liliacées à 


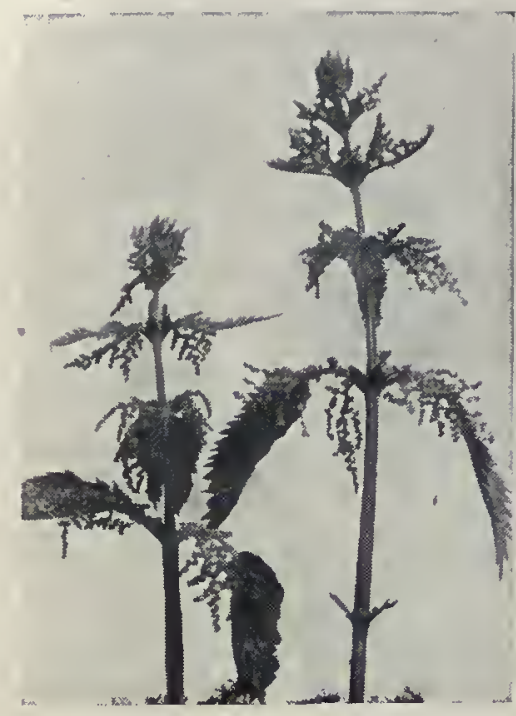

Ortie dioïque à poils urticants.

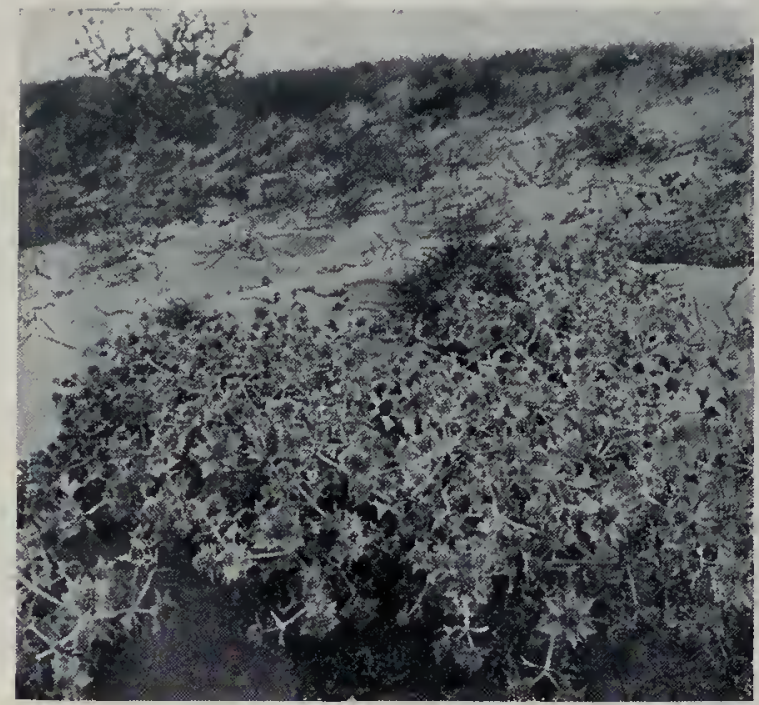

Panicaut maritime sur une dune.

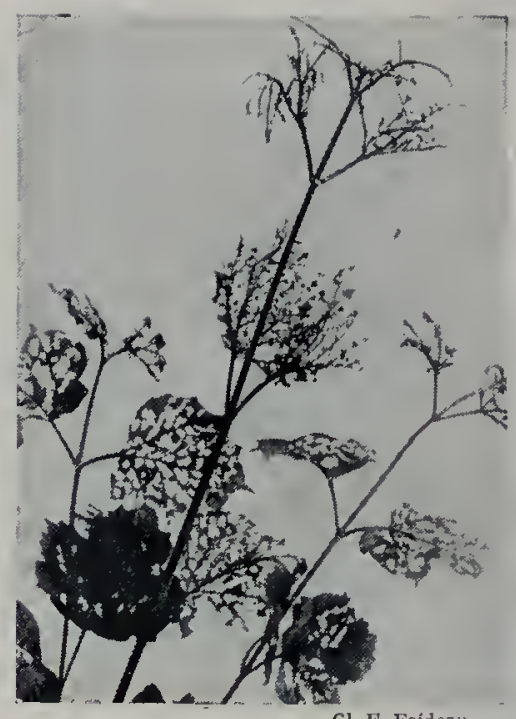

Cl, F. Faideal baies : si l'on rencontre des espèces de ce type dans les îles lointaines séparées des continents par d'immenses mers, c'est qu'elles ont été propagées par les oiseaux qui les avaient mangées et ont contribué à orienter leur évolution dans le sens de la carnosité du péricarpe. C'est ainsi que, dans les Yucca, plusieurs espèces à bajes existent dans les îles lointaines, tandis que la plupart des autres formes moins voyageuses ont pour fruit une capsule.

Les oiseaux jouent d'ailleurs un rôle important dans la dissémination des graines des plantes qui peuplent les archipels éloignés. Sur vingt-deux oiseaux d'origine continentale trouvés aux Açores, îles qui se trouvent à une distance de 1500 kilomètres du continent africain, la moitié est formée de mangeurs de fruits qui peuvent très bien contribuer à introduire des plantes nouvelles : les autres espèces de haut vol peuvent porter des semences diverses attachées à leur pattes, à leurs plumes. Darwin a recueilli des fragments de terre attachés à la patte d'un oiseau et il a vu germer et fleurir un Jonc bufonius; un autre fragment contenait les graines de quatre-vingt-deux plantes. L'étude de la flore des íles est tout à fait instructive au point de vue du rôle que jouent les oiseaux : surtout les grandes espèces de haute mer, puissants voiliers comme les frégates, les albatros, qui contribuent à modifier la végétation des îles les plus reculées. Nous reviendrons plus loin sur ce sujet.

Les animaux peuvent intervenir d'une autre manière dans la dissémination des plantes : quelques fruits sont pourvus de crochets, de dents, d'aiguillons, à l'aide desquels jls se fixent à la toison des mammifères. Tout le monde connaît les fruits de la Bardane: ce sont les teignes que les enfants s'amusent à lancer sur les vêtements, auxquels ils s'accrochent; lorsque ces fruits sont mûrs, ils se détachent au moindre contact et harponnent au passage les poils du chien, la laine du mouton et même le vêtement du berger. Les fruits de la Benoite, de l'Aigremoine, qui sont deux Rosacées; de la Carotte sauvage, qui est une Ombellifère; du Gaillet gratteron, qui est une $\mathrm{Ru}$ biacée, sont aussi pourvus de crochets et disséminés par la toison des mammifères; on voit donc des résultats semblables obtenus par les mêmes moyens. On peut dire, dans les divers cas que nous venons de citer. pour les espèces à fruits charnus ou à crochets, que les animaux rendent de grands services au règne végétal.
Défenses des plantes contre les herbivores. - Il n'en est pas toujours ainsi. Il s'établit souvent un véritable antagonisme entre le règne animal et le règne végétal et il semble que ce dernier soit obligé de s'armer pour résister aux mâchoires voraces qui le menacent. Cette lutte est surtout âpre dans les régions désertiques où la végétation est extrêmement rare, où par conséquent les animaux herbivores sont à la recherche du moindre rameau herbacé qu'ils peuvent se mettre sous la dent. La lutte pour l'existence, qui est dans ces contrées particulièrement intense, a orienté l'évolution d'une manière manifeste et a favorisé le développement de tous les organes piquants; aussi la flore des déserts est-elle caractérisée par le développement extraordinaire des épines à la surface de tous les organes des plantes vivant dans ces régions. Dans nos pays, l'Aubépine, le Prunellier, la Ronce, les Chardons ont aussi de formidables défenses externes. Les poils rudes qui recouvrent les Borraginacées : Bourrache, Vipérine, font respecter ces plantes, tout ou moins par les mollusques et par les moutons.

Les végétaux ont d'ailleurs des moyens de défense variés contre les attaques des animaux : parfois c'est un enduit cireux qui est un obstacle pour les fourmis qui veulent y grimper(Cecropia du Corcorvado); cest un suc amer qui se trouve dans leur tissu; c'est un liquide âcre, un poison ou un venin. Les Orties, et plusieurs Urticacées, surtout les Laportea, renferment des poils urticants qui sont des armes extrêmement redoutables contre l'homme et les animaux. Tous ces moyens de défense ne sont pas d'une efficacité absolue, mais ils suffisent parfois à éloigner quelques-uns des ennemis d'une plante, et un ennemi de moins c'est quelquefois le salut poúr l'espèce : le latex âcre des Euphorbes ne les protège pas contre les insectes, mais il fait respecter ces plantes par les ruminants.

\section{Les plantes carnivores. -} Quand un Drosera ou Rossolis est soumis à l'irritation produite par un jnsecte qui sabat sur une de ses feuilles, les poils (en réalité ce sont les lobes des feuilles, car il y a des vaisseaux) qui la couvrent se rabattent successivement sur l"insecte par la contraction de tout le limbe; puis l'ébranlement se communique au pétiole, le limbe contracté s'enroule sur ce dernier et I'animal capturé ne peut sortir; il ne tarde pas à périr, et sous l'influence de sucs digestifs 


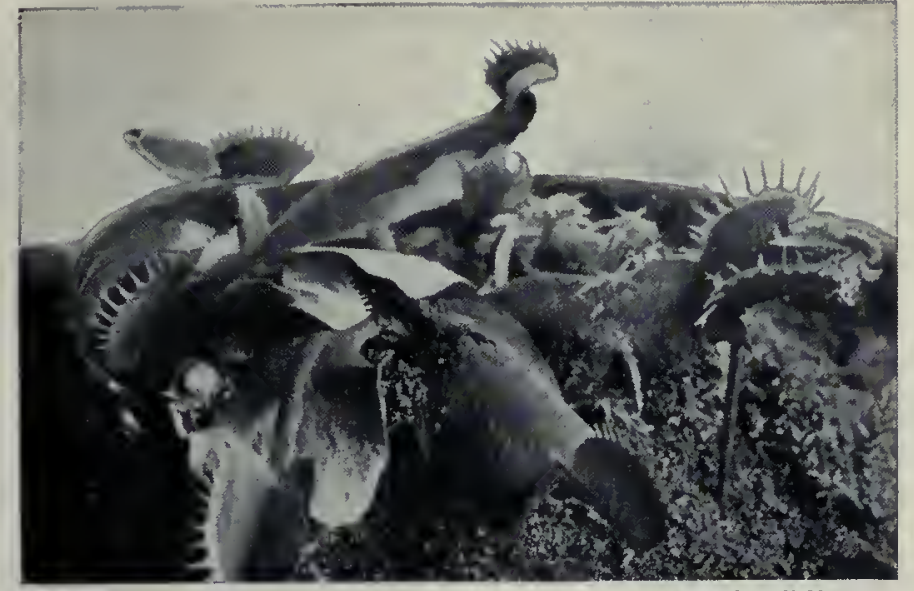

Dionée aftrape-mouche.

produits par la plante et peut-être aussi par des Bactéries, les tissus de l'animal sont digérés. Au bout d'un certain temps, la feuille reprend sa forme primitive. Après trois manœuvres analogues, une feuille est hors d'usage. Certaines particularités sont très curieuses: c'est ainsi que le contact d'un fragment de cheveu ne pesant que quelques millièmes de milligramme met les tentacules en mouvement, alors que la chute des plus grosses gouttes de pluie est sans effet sur eux.

La Dionée attrape-mouche ou Trappe-de-Vénus, ce miraculum nature, suivant l'expression de Linné, est une petite plante de la Caroline du Nord. Chacune de ses feuilles en rosette comprend un pétiole ailé qui se prolonge par deux lobes de 1 à 2 centimètres de long, mobiles autour de la nervure principale comme charnière et qui fonctionnent comme des panneaux d'oiseleur. Leur bord libre est hérissé de pointes aiguës; leur face supérieure présente des glandules rougeâtres et trois petits poils très irritables. Dès qu'un insecte frôle un de ces filaments, les lobes s'appliquent l'un contre l'autre, l'emprisonnent et les glandes sécrètent un liquide acide. Au bout de plusieurs jours, la prison s'ouvre lentement, mais on ne trouve plus que des débris du prisonnier. Selon Darwin, les lobes appliqués l'un contre l'autre ont fonctionné comme un " estomac temporaire " qui a digéré partiellement la proie et en a permis l'absorption.

Plusieurs autres genres de Droséracées, entre autres les Drosophylles, une petite plante voisine des Saxifrages, la Céphalote folliculaire, notre Grassette, commune dans les prairies tourbeuses, possèdent des propriétés analogues. Il en est de même de certaines plantes aquatiques, comme les Utriculaires et les Aldrovandies, dont les feuilles submergées présentent de petits pièges qui, chez les premières, rappellent une outre et, chez les secondes, les valves d'une coquille. On considère parfois aussi comme des pièges à insectes les ascidies des Sarracenia et des Darlingtonia (plantes de la famille des Sarracéniacées) et celles des Népenthacées; ce sont

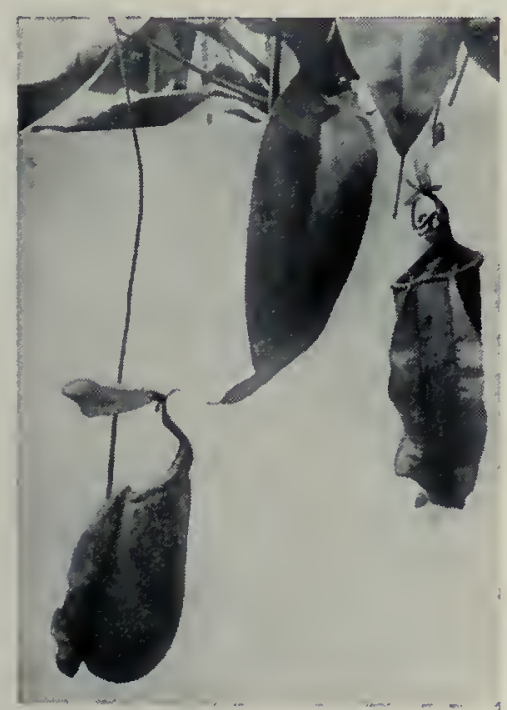

Nepenthes intermédiaire. des feuille's extrêmement curieuses, enroulées en cornet, en trompette, ou façonnées en urne. Elles contiennent toujours un liquide clair, dû à une sécrétion et accru de l'eau des pluies et de la rosée; peut-être sontelles surtout des réservoirs d'eau. Chez les Sarracéniacées, c'est la feuille entière qui forme le cornet; un lobe foliaire, ou couvercle, fixé sur le bord dorsal, en découvre plus ou moins l'ouverture; chez les Népenthès, la nervure médiane de la feuille se prolonge au delà du limbe en un long pédoncule, parfois vrillé, que termine une sorte de cruche à couvercle. Tous ces organes sont ornés de couleurs brillantes et en-

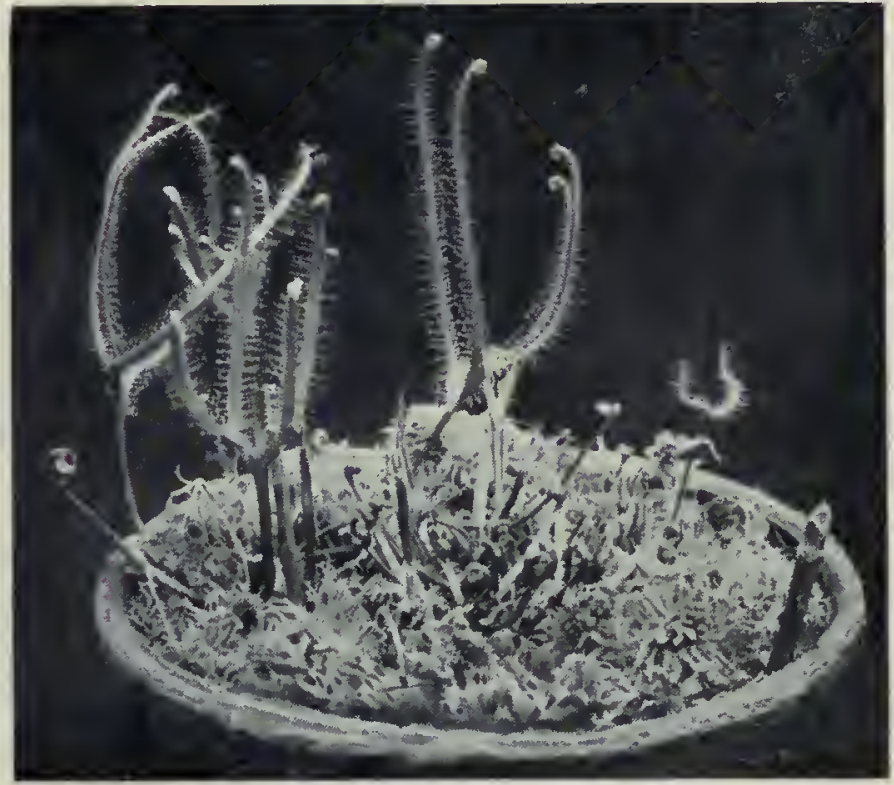

Drosera dichotoma d'Australie.

duits souvent d'un suc mielleux qui attire les insectes. Ceux-ci périssent en grand nombre dans le liquide que contient l'urne; les Bactéries interviennent dans la décomposition des animaux qui peuvent s'y trouver.

Un certain nombre de légendes circulent concernant ces plantes carnivores. On a prétendu que les urnes de Nepenthès étaient susceptibles de capter ou de digérer des petits oiseaux. Nous avons même eu l'écho d'une histoire plus fantastique encore qui a trouvé place dans certaines feuilles populaires des Etats-Unis. Il y était question d'une plante miraculeuse de Madagascar qui avait la propriété effroyable de saisir les hommes qui passaient dans son voisinage et de les emprisonner dans son bourgeon pour les digérer.

En laissant de côté de pareilles exagérations ridicules, il n’en subsiste pas moins le rôle sérieux de la capture d'animaux par des Drosera, par la Dionée gobe-mouche et par les Utriculaires.

Dans les urnes de ces dernières petites plantes aquatiques, on trouve régulièrement captés des animalcules d'eau qui, après s'être agités pendant un certain temps, finissent par cesser de se mouvoir et sont progressivement digérés et absorbés. La petite famille des Lentibulariacées, à laquelle appartiennent les Utriculaires, a d'ailleurs d'autres représentants carnivores : les Pinguiculaires et surtout les Genlisea. L'organisation de ces derniers est très extraordinaire. Les feuilles sont tubuleuses, avec deux ramifications à angle droit de la partie basilaire où se trouve une ampoule. Ces ramifications sont en forme de cornet, laissant ainsi des fentes qui sont des portes d'entrée par lesquelles s̈introduisent les animaux pris au piège; ils ne peuvent s'échapper, parce que les poils, bien orientés pour faciliter la pénétration, s'opposent tout à fait à la sortie. Un type très curieux est l'Utricularia neottioides (Amérique du Sud), sans utricules, mais pourvu de griffes servant à la capture des animaux.

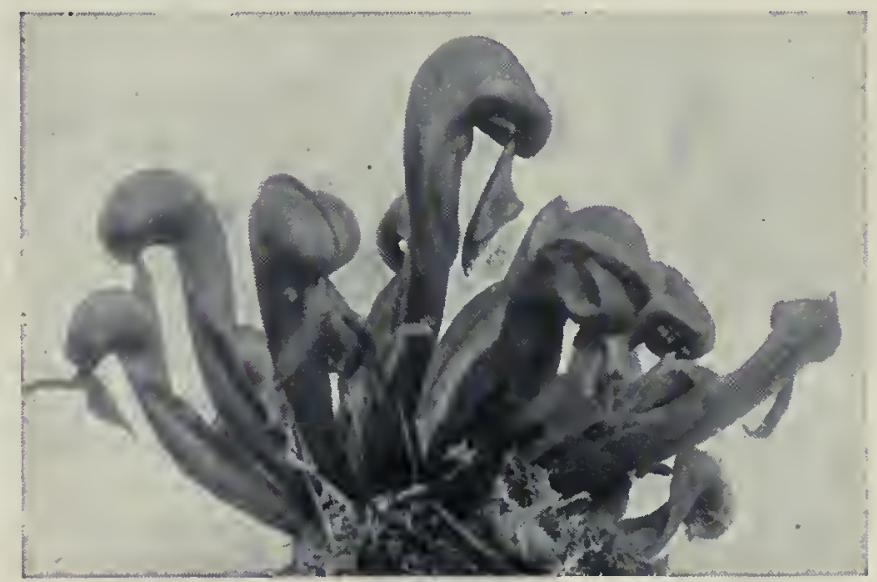

Darlingtonia de Californie. 


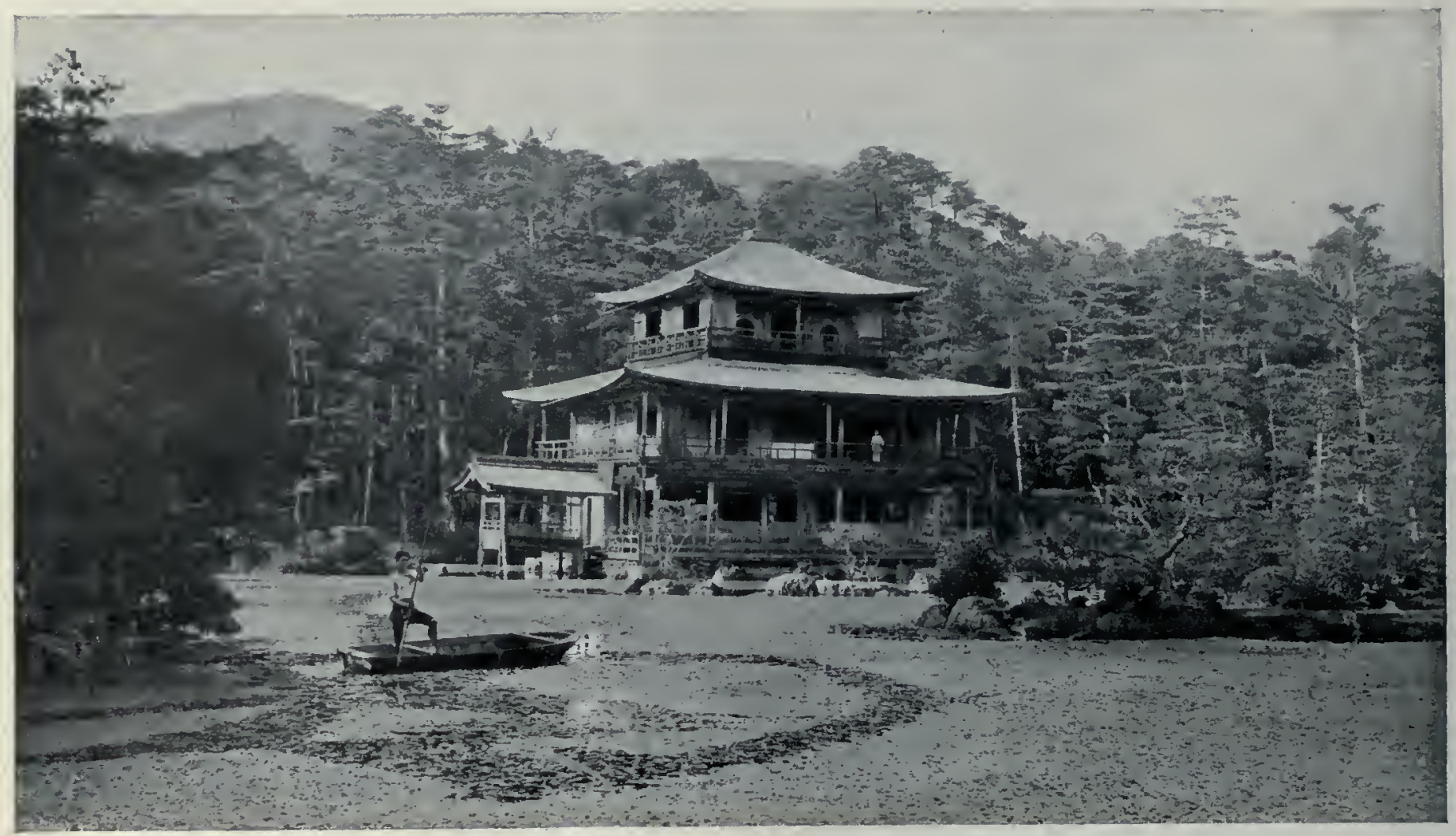

LAC DE KINKAKUJI, AVEC VEGETATION AQUATIOUE A FEUILES FLOTTANTES (JAPON).

\section{III. - RAPPORTS DES PLANTES AVEC LE MILIEU}

\section{INFLUENCE DU MILIEU}

L'action du milieu est beaucoup plus sensible sur les végétaux que sur les animaux; le mouvement est une des caractéristiques les plus essentielles du règne animal; la fixation, au contraire, la particularité fondamentale des plantes; la plupart des animaux, en effet, peuvent fuir un milieu dont les conditions sont contraires à leur organisation et à leurs besoins; la plante, par suite de son lien avec le sol, doit se transformer, s'adapter rapidement aux conditions que lui crée le milieu ou bien périr. Nous examinerons les milieux aquatique et souterrain, puis l'action du vent, celle du climat et des substances chimiques du sol.

\section{Action du milieu aquatique. -} Dans les eaux vit une flore extrêmement variée. Sur les bords des rivières et des lieux bas périodiquement inondés croissent des Joncs arrondis, des Cladium, des Carex anguleux, des Scirpes aux épillets menus, de jolies plantes aux larges fleurs vivement colorées : lris, Cardamine, Caltha ou Populage, Salicaire, Lysimaque, Spirée ulmaire, et tout un peuple de roseaux: Arondo, Phragmites, Baldingères, Typha ou Massettes qui bruissent et murmurent au moindre vent; leurs tiges longues et minces se heurtent, se froissent, se courbent sous l'action des tempêtes, mais se redressent toujours. En dedans de cette ceinture qui forme la flore des marécages sont les plantes amphibies des rives qui, dans l'eau, ont une moitié du corps, tandis que l'autre moitié est dans l'air. C'est là que se rencontrent la Renoncule longuc, le Rumex patience d'eau, la Renouée amphibie, les vénéneuses Enanthes, les Rubaniers, le Butome en ombelle ou Jonc fleuri, les Sagittaires, les Hottonies. Dans le milieu aquatique, on

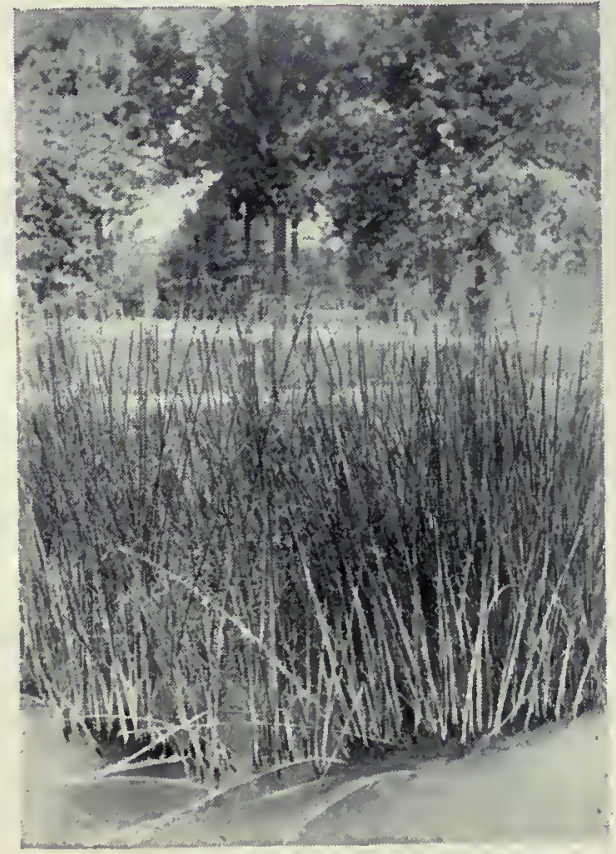

Jonc commun. trouve ensuite bien des catégories de végétaux : les plantes nageantes fixées au sol: Limnanthèmes, Potamots et Nénuphars de nos pays, Lotus et Victoria, Hydrocléis et Eichornia (Pontederia) des régions chaudes; les plantes submergées fixées au sol par la base : Vallisnérie, Hippuris, Myriophylle, etc.; les plantes flottantes comme la Mâcre ou Châtaigne d'eau, l'Utricuslaire, les Hydrocharis, les Cératophylles ou Cornifles, les Stratiotès, qui se tiennent entre deux eaux, puis montent à la surface pour fleurir et redescendent au fond pour mûrir leurs graines; enfin, les plantes nageantes libres, comme les Lentilles d'eau, qui sont des Phanérogames; les Salvinia et les Azolla, qui sont des Cryptogames. (Voir la PLANCHE EN COULEURS.)

L'action de l'eau sur les plantes se trahit par les formes diverses des feuilles submergées et nageantes qui sobservent dans une Sagittaire ou Flèche d'eau ; cette jolie plante a des feuilles aériennes en flèche, des feuilles submergées en ruban et des feuilles nageantes en cœur. Toutes les plantes amphibies présentent cette multiplicité de formes : les Renoncules aquatiques ont des feuilles submergées laciniées et des feuilles aériennes entières, comme aussi le Bidens Beckii; les Nymphea ont des feuilles submergées arrondies, translucides et minces, très différentes des feuilles nageantes fermes, mais de même forme, avec des stomates exclusivement à la face supérieure, tandis que les feuilles submergées n'en possèdent pas.

La vie nageante libre est un cas particulier de la vie aquatique dans laquelle les plantes restent au contact de l'air, mais sont détachées du sol; elles flottent librement à la surface de l'eau. La dégradation due à ce mode d'existence se manifeste surtout dans les Lentilles d'eau (fig. 106, B, C), dont l'appareil végétatif est si atrophić qu'on n'y 


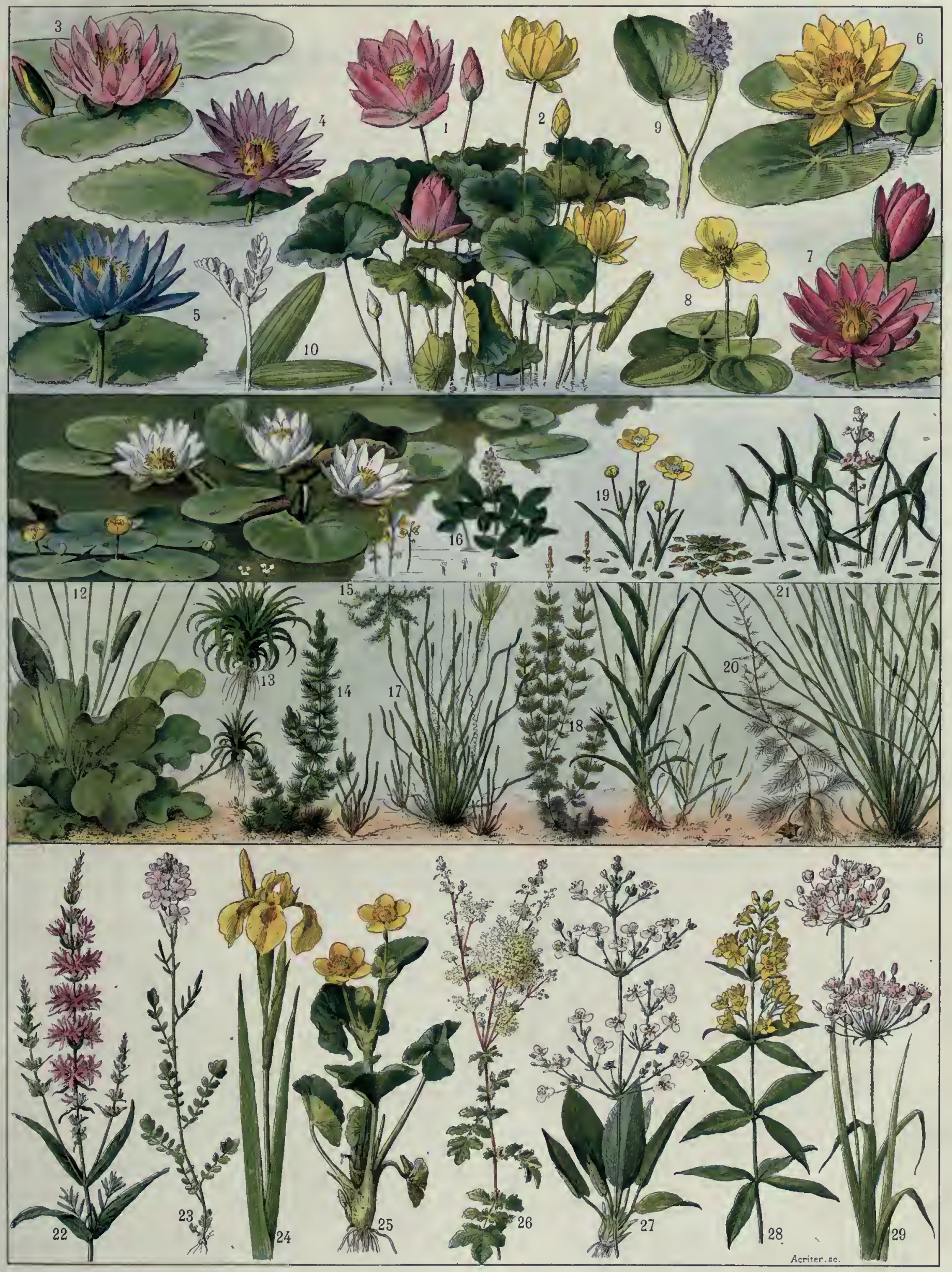

PLANTES D'EAU

1. Nelombo rose - 2. Nelombo janne. - 3. Nymphéa rose (Madame Paul Cazeneuve) - -4 . Nymphéa violet (Madame Abel Chatenay) - 5 . Nymphéa hybride bleu. 6. Ny mphea hybride jaune - 7. Nymphéa 13. Stratiote Faux-Aloès. - 14. Cornifle submersée - 15. Utriculaire, - 16. Ményanthe Tréfle d'eau, - 17. Vallisnérie. - 18. Myriophylle, - 19. Renoncule lan̊́ue. 20. Mâcre Châtaigne d'eau. -21 . Sagittaire, -22 . Salicaire, -23 . Cardamine. -24 . Iris faux-Acore on d'eau. -25 . Caltha des marais ou Populage, -26. Spiree Imaire - 27. Alisma Plantain d'ean. - 28. Lysimaque vulgaire. - 29. Butome en ombelle. 



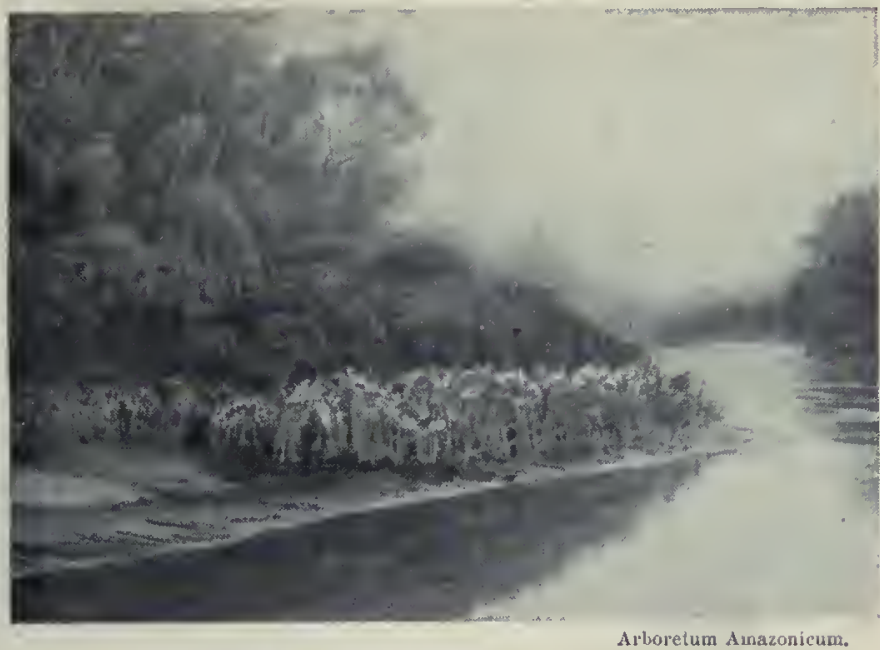

Végètation littorale du rio Couanany.

peut plus reconnaître des tiges et des feuilles : il n'y a plus qu'une sorte de thalle. Le caractère supérieur de ces plantes se manifeste cependant par les fleurs d'abord et par les racines qui restent courtes et plongent dans l'eau, servant de balancier pour maintenir la Lentille en équilibre à la surface du liquide. On connaît des Lentilles d'eau brésiliennes, les Wolffies arhizes (fig. 106, A), qui ont un corps arrondi et sont tout à fait dépourvues de racines; c'est seulement au moment de la reproduction, par la structure des fleurs. que l'on peut entrevoir des caractères de plante supérieure.

Une régression également accusće se manifeste dans les plantes entièrement submergées qui sont incapables de venir s'épanouir à la surface du liquide : elles nont que des feuilles minces, translucides et dépourvues de stomates. C'est ce qui arrive pour les Potamogetons, qui vivent dans les eaux courantes et sont attachées par leur base au sol. Parmi les plantes submergées il en est de plus dégradées encore : ce sont les espèces flottantes, qui ne sont jamais rattachées à la terre et qui restent libres dans les eaux. Ces plantes ont évidemment de grandes difficultés pour se nourrir, car, d'une part, elles ne peuvent plus rien emprunter au sol et elles sont entièrement dépourvues de racines; d'autre part, ne parvenant jamais à la surface de l'eau, elles ne sont exposées qu'à une lumière très atténuée et l'assimilation chlorophyllienne reste faible pour elles. Les espèces de ce groupe sont aussi peu nombreuses : c'est là que se placent les Cornifles ou Cératophylles, les Utriculaires, les Aldrovandies. On peut remarquer, pour ces deux dernières espèces, qu'elles obvient aux difficultés de la nutrition que nous venons de signaler en captant des animalcules aquatiques et en les digérant.

Parmi les plantes submergées fixées au sol par la base, on doit citer les fameuses Vallisnéries (fig. 107), dont les fleurs mâles, produites par des pieds distincts, se détachent et deviennent libres sous forme de petits boutons sphériques qui emprisonnent une bulle d'air, ce qui leur permet de s'élever dans l'eau jusqu'à la surface, où ils souvrent et naviguent comme de petits bateaux et entourent bientôt la fleur femelle qui est sur un deuxième pied.

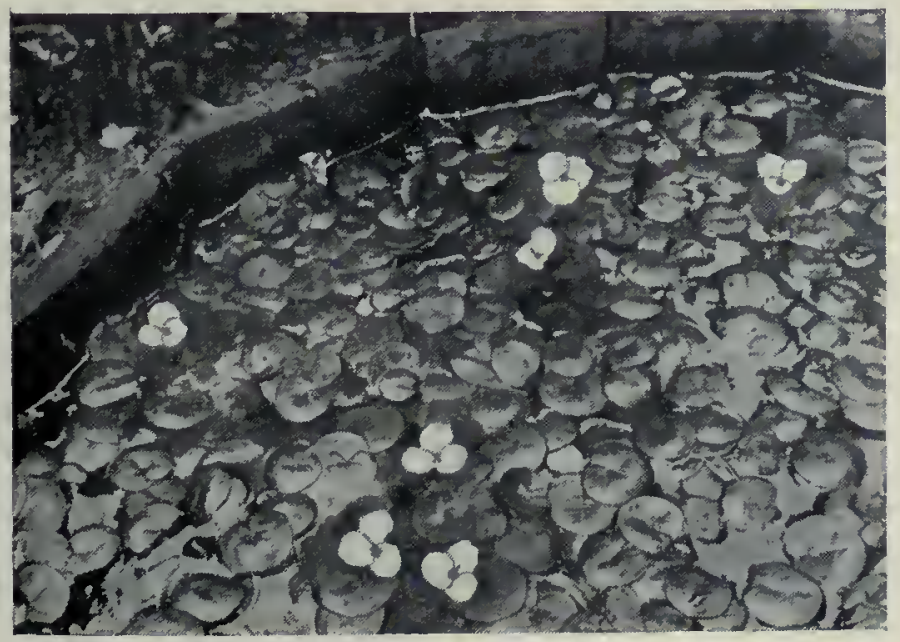

Hydrocharis morsus rance, en fleurs.

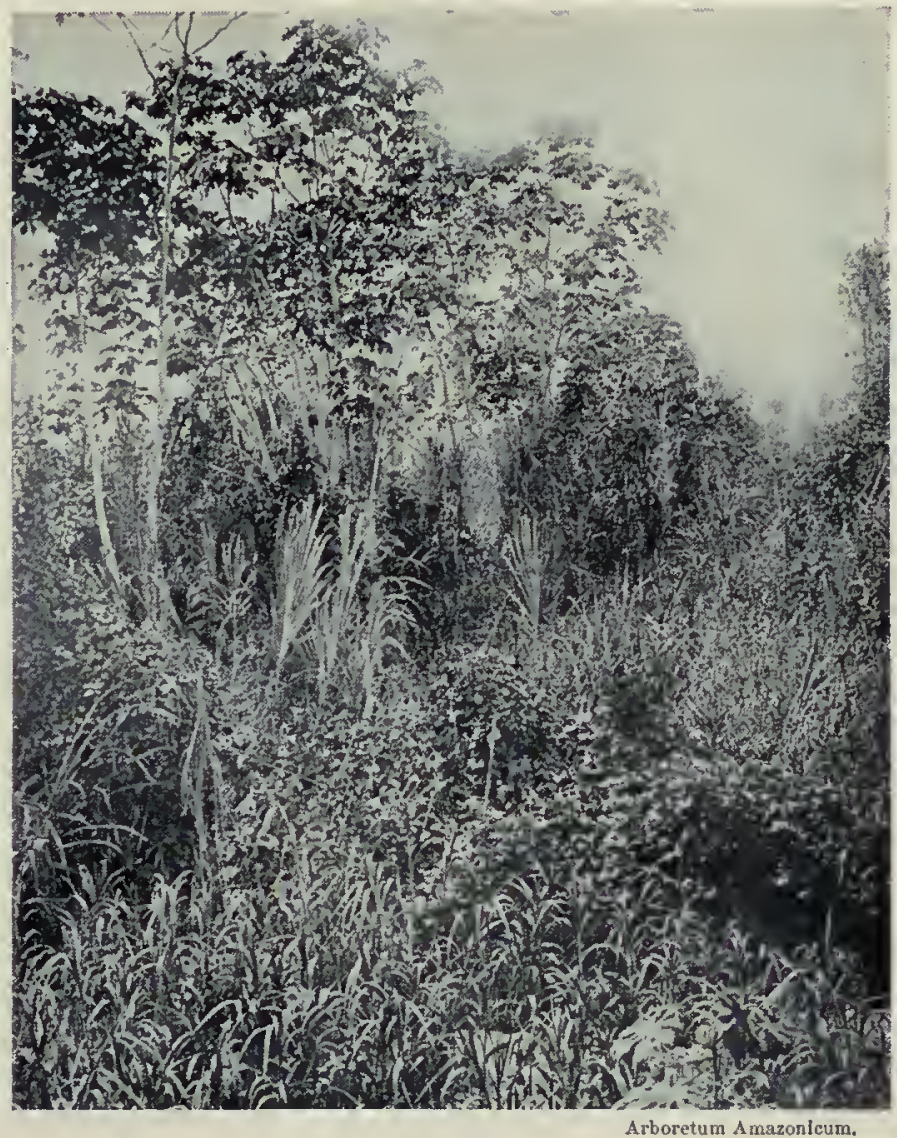

Végétation littorale du rio Ucayali.

Celle-ci, en déroulant son long pédicelle spiralé, est venue s'épanouir également à l'air. La pollinisation ne tarde pas à s'opérer et, quand elle est accomplie, le pédicelle de la fleur femelle contracte ses spires et la maturation du fruit s'achève au fond de l'eau.

Non moins merveilleux sont les phénomènes révélés par l'étude des plantes des cascades tropicales. Les Podostémacées (fig. 108), que l'on trouve attachées aux parois des rochers dans ces stations très limitées, se rencontrent partout dans les grands fleuves de l'Amérique du Sud, de l'Afrique et de l'Inde. Ce sont de toutes petites plantes, semblables en apparence à des Lichens et à des Mousses, mais qui sont cependant beaucoup plus élevées en organisation, car elles ont des fleurs qui les rapprochent des Saxifragacées. La dégradation intense manifestée par l'étude de ces plantes s'explique par les conditions spéciales de vie où elles se trouvent. Attachées à des rochers dans lesquels elles ne peuvent pas s'enfoncer, elles ont dû se modifier d'abord en vue de la fixation; elles produisent un long rhizome couvert de feuilles, attaché par des organes spéciaux appelés haptères, qui n'ont pas d'analogues dans les racines des autres Phanérogames : on serait tenté de regarder le long cordon cylindrique silicifié que nous venons de décrire comme une tige, mais la présence d'une coiffe à l'extrémité démontre nettement qu'i] s'agit d'une racine. C'est là une première adaptation, la plus commune et la plus naturelle, mais il s'en produit d'autres très extraordinaires. A côté des racines qui ont rampé sur le roc, d'autres ont pu flotter dans l'eau; celles-ci, par suite de l'action'mécanique du liquide toujours en mouvement, se sont aplaties et transformées en lames vertes susceptibles d'onduler dans l'eau. C'est ce que l'on voit dans les Dicrea, et l'on serait tenté de croire que l'on a affaire à une Algue plutôt qu'à une racine, si ce neétait la présence d'une coiffe à l'extrémité.

Action du vent. - L'agitation de l'air a une influence considérable sur la végétation : le vent est un
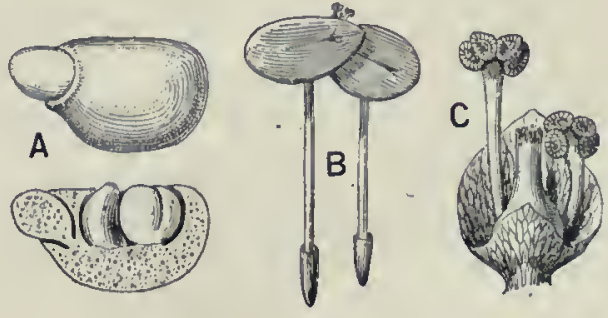

Fig. 106. - Lentilles d'eau.

A, Wolffia arhiza et conpe; B, C, Lemna minor et son inflorescence. 


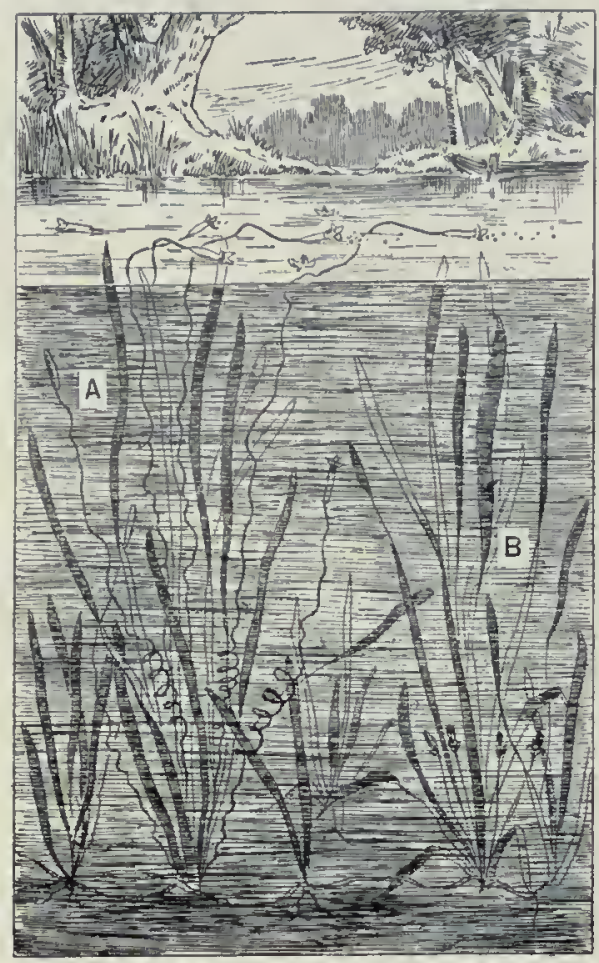

Fig. 107. - Vallisneria spiralis.

A, Pied femelle avec fleurs flottantes entourées de fleurs mâles échappées des spathes du pied mâle B. es arbres plantés au sommel des falaises maritiments dominants sur les déforme. J. Früh a classé ainsi les différentes formes arborescentes des endroits soumis à des vents réguliers: 10 le tronc est vertical, mais dépourvu de branches sur la partie faisant face au vent; $2^{\circ}$ le sommet du tronc est incliné suivant la direction du vent dominant; la couronne de l'arbre est asymétrique, comme élaguée du côté de la mer, plus développée à l'abri du vent; 30 l'arbre est complètement incliné et rabougri.

Action du milieu souterrain. - Un autre agent qui est susceptible de modifier profondément les végétaux, est le sol. La vie souterraine est caractérisée par l'absence de lumière et, par cela même, tous les organes qui croissent en terre rappellent les caractères des plantes étiolées que l'on obtient en faisant pousser des graines dans une armoire : on sait qualors il n'y a pas production de chlorophylle, les tiges restent blanches, les feuilles sont atrophiées et jaunes. Les rhizomes présentent ainsi les caractères des plantes privées de lumière, mais il y a cependant des différences très manifestes entre la vie étouffée dans le sol et la vie dans l'air à l'obscurité; la difficulté de la transpiration, la résistance des particules solides de la terre à la croissance, amènent un épaississement des tissus corticaux, une réduction du système central de la tige, ce qui est accompagné de l'atrophie de tout le tissu squelettique, c' est-à-dire les fibres, et de tout le système conducteur de la sève, c'est-à-dire les vaisseaux.

L'origine de la formation des tubercules des organes vivants dans le sol est encore assez obscure. On sait cependant d'une manière à peu près certaine que l'apparition des tubercules, ou racines fasciculaires des Ophrys et des Orchis, est liée à linvasion, dans les racines, d'un Champignon qui amène la tuméfaction des bourgeons et la formation de tumeurs. Ces tubercules, dans ce cas, paraissent être des excroissances trahissant l'existence d'une sorte de

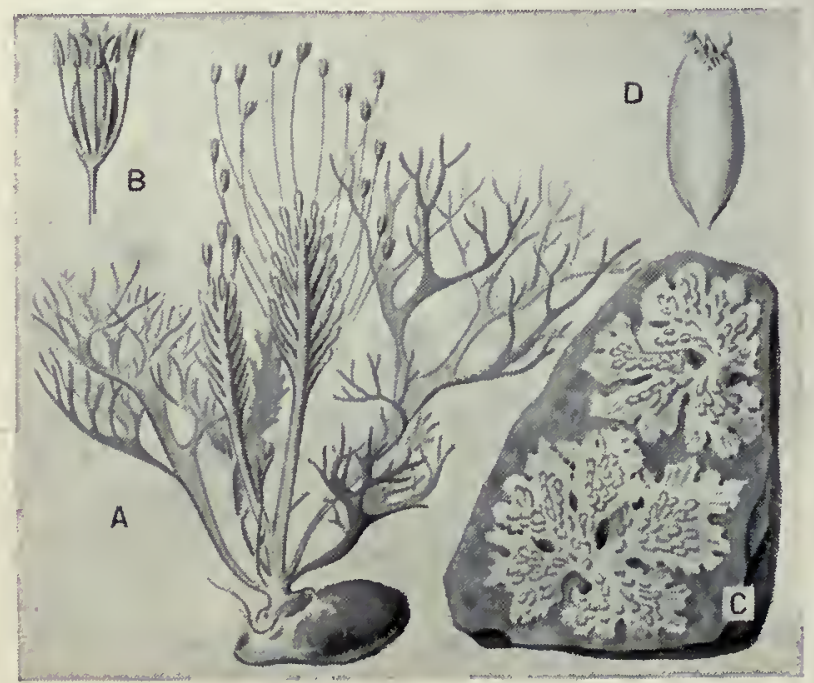

Fig. 108. - Pođostémacées.

A, Mourera Weddeliana;

B, Fleur grossie; C, Caslelnavia; D Fleur grossie maladie. Il est très vraisemblable d'admettre que quelque chose d'analogue a pu se passer autrefois pour la formation des tubercules de Pomme de terre, et Noël Bernard a formulé la théorie que les tubercules sont dus à des Champignons, ce qui a été confirmé par Magrou. Les Bactéries, dans le cas des racines de Légumineuses; les substances osmotiques sucrées, dans le cas du Radis (expérience de Molliard), produisent un effet semblable.

D'ailleurs, c'est par un autre procédé cultural que l'on est arrivé à accroître le volume des tubercules : la méthode préconisée par Louis de Vilmorin en 1832 consiste à faire des semis tardifs de Carotte, de façon à transformer une plante annuelle en une plante bisannuelle. En repiquant au début de l'année suivante, on a un bon choix de porte-graines qui peuvent donner des semences, et ces graines engendrent à la génération suivante des racines améliorées : "Quelques-unes, dit cet auteur, dépassèrent I kilogramme ; certaines égalaient les meilleures Carottes de jardin. "

Action du climat. - L'allongement de la vie et des modifications très profondes dans les caractères des végétaux peuvent aussi résulter du changement de climat.

Le changement d'altitude produit des effets importants (fig. 109). Bonnier a établi le rôle de ce facteur pour la Linaire alpine qui, par suite de la persistance de sa racine, peut être vivace aux hautes altitudes, tandis que dans les basses elle devient bisannuelle.

L'Arenaria à feuilles de Serpolet est annuel dans les plaines, tandis que sur les pics des Pyrénées il se maintient plusieurs années, grâce à son rhizome qui pénètre profondément en terre. $11 \mathrm{y}$ a d'ailleurs un résultat général qui établit bien l'exactitude du rôle de l'altitude, c'est que dans les Alpes, entre 200 et 600 mètres, la proportion des espèces annuelles et bisannuelles est de 60 pour 100 , tandis que de 1800 mètres jusqu'aux neiges éternelles, elle n'est plus que de 6 pour 100. La variation en latitude produit des effets analogues, car, tandis quaux environs de Paris, à $49^{\circ}$ de latitude, il y a 45 pour 100 de plantes annuelles et bisannuelles, il n'y en a plus du tout dans la zone polaire et toutes les espèces sont vivaces.

Cette question est d'ailleurs liée à celle du climat et à son effet sur la végétation. On sait, par exemple, pour le Lilas, qu'en le déplaçant vers le Nord on constate un retard de plus en plus accusé dans la floraison. Le retard dans l'épanouissement des bourgeons floraux qui se manifeste ainsi pour une espèces peut parfois devenir héréditaire et se maintenir même avec un changement de pays. On reconnaît dans un jardin des individus précoces et des individus hâtifs : tel est le cas du fameux Marronnier du 20 mars des Tuileries, qui fleurissait toujours beaucoup plus tôt que ses voisins. 


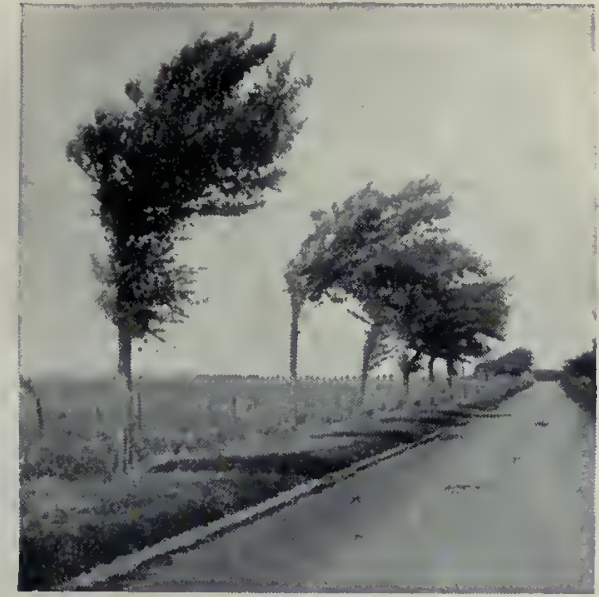

Ormes penchés par le vent de mer.

Ces faits conduisent à donner l'explication du dimorphisme saisonnier mis en évidence par de Wettstein. On a signalé pour cer taines espèces (Gypsophiles, Gentianes) l'existence d'individus tardifs et d'individus précoces. Or, on remarque que les petites espèces précoces carces particularités sont héréditaires, sont moins ramifiées que les espèces tardives et de port différent. Les caractères qui établissent les différences sont les mêmes pour les deux types de Gentianes (G. précoce, type hâtif; G. des Carpathes,

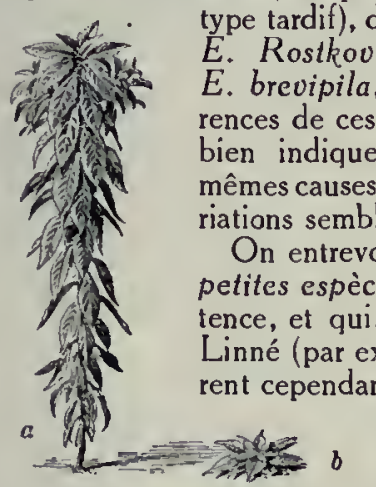

Fig. 109. - Topinambour. a, Semé en plaine: $b$, En montagne, par Bonnier, a 2300 métres.

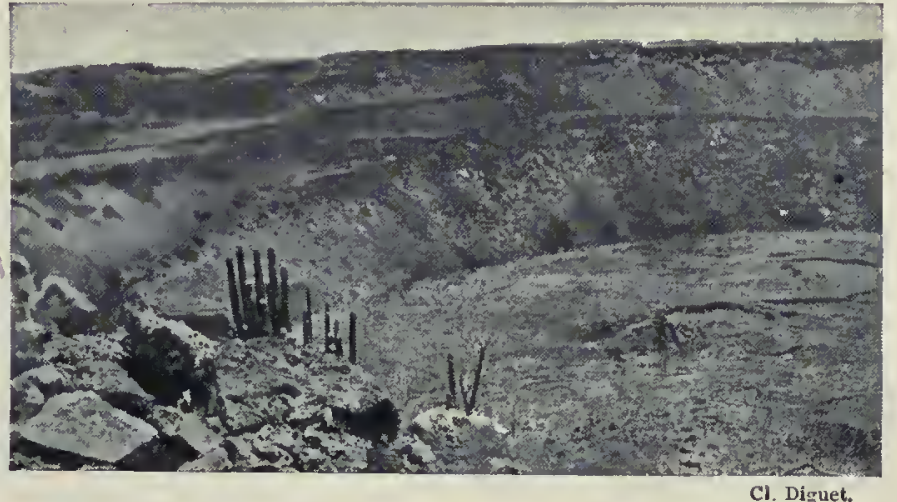

Cactées dans le cratère d'un ancien volcan du Mexique.

Géographie botanique. - L'extension des espèces est donc subordonnée au climat, et l'ensemble de la végétation d'une contrée prend des caractères particuliers qui peuvent être très distincts. L'aspect de la végétation d'un pays sans pluies notamment s'oppose d'une manière extraordinaire à l'aspect des forêts ou des régions arctiques. Il suffit de jeter un coup d'œil sur la photographie ci-jointe, prise au Mexique, pour s'en rendre compte. Les Cactées y dominent; la sécheresse amène chez ces plantes l'atrophie des feuilles, qui ne sont plus représentées que par des piquants à la surface de la tige, et celle-ci est remplie de tissus aquifères, de manière à pouvoir supporter de grandes privations d'eau; ainsi donc non seulement une réserve aqueuse est constituée, mais l'eau, une fois emmagasinée, se trouve indéfnniment conservée, puisque les feuilles, organes essentiels de transpiration, ont disparu.

Par ces quelques exemples on entrevoit ce qüil faut entendre par le facies de la végétation d'un pays : les actions de milieu s'y trahissent d'une manière frappante et l'effet du climat mérite d'être l'objet d'une étude spéciale dans les chapitres qui vont suivre sur la Géographie botanique.

A mesure qu'on s'éloigne de l'équateur, les rayons solaires frappent le sol de plus en plus obliquement; la température devrait donc décroître régulièrement de l'équateur vers les pôles, mais les circonstances locales, comme la proximité de la mer, la fréquence des vents secs ou humides, etc., diversifient les climats, de telle sorte que des régions de même latitude peuvent avoir un climat très différent. Nous distinguons cependant trois climats généraux avec des flores correspondantes : celui des zones glaciales, celui des zones tempérées froides (flore des forêts) ou chaudes (flore méditerranéenne), enfin celui des zones tropicales humides (forêts tropicales) ou sèches (savanes, déserts). causes de la naissance de toutes, car elles sont légion. Après dix années de culture du Draba de printemps, Jordan en avait trouvé dix; après trente années, il en avait deux cents. Depuis l'époque lointaine de la publication des travaux si curieux de ce botaniste français, qui pulvérisait les espèces linnéennes, beaucoup d'autres auteurs ont confirmé ses résultats : cette notion de la division des anciens types est devenue une des plus importantes de la science actuelle.

Action des substances chimiques du sol. - Il ne suffit pas de constater la division à l'infini des espèces, il faut encore découvrir le mode de naissance de ces petites formes. A ce point de vue, l'étude de l'inAuence des substances chimiques du sol est intéressante à envisager. On sait notamment que la présence du sel intervient pour faire apparaître une flore spéciale au bord de la mer et autour des marais salés. La présence de serpentine dans le sol, de minerais de zinc contribue à modifier certaines petites espèces et à leur donner des caractères particuliers tout à fait remarquables. On conçoit donc qu il puisse y avoir des plantes indicatrices du sol et que certaines associations végétales soient caractéristiques de certaines régions. Au voisinage des villages, notamment, il y a une flore rudérale qui se développe sur les décombres et qui suit l'espèce humaine dans toutes ses migrations. On a constaté, de même, que la végétation des cratères des volcans éteints, à Java, était bien caractérisée et que, dans le fond de la cuvette volcanique, poussait une flore très spéciale qui ne se retrouvait pas sur les pentes externes et internes de la montagne d'origine éruptive.

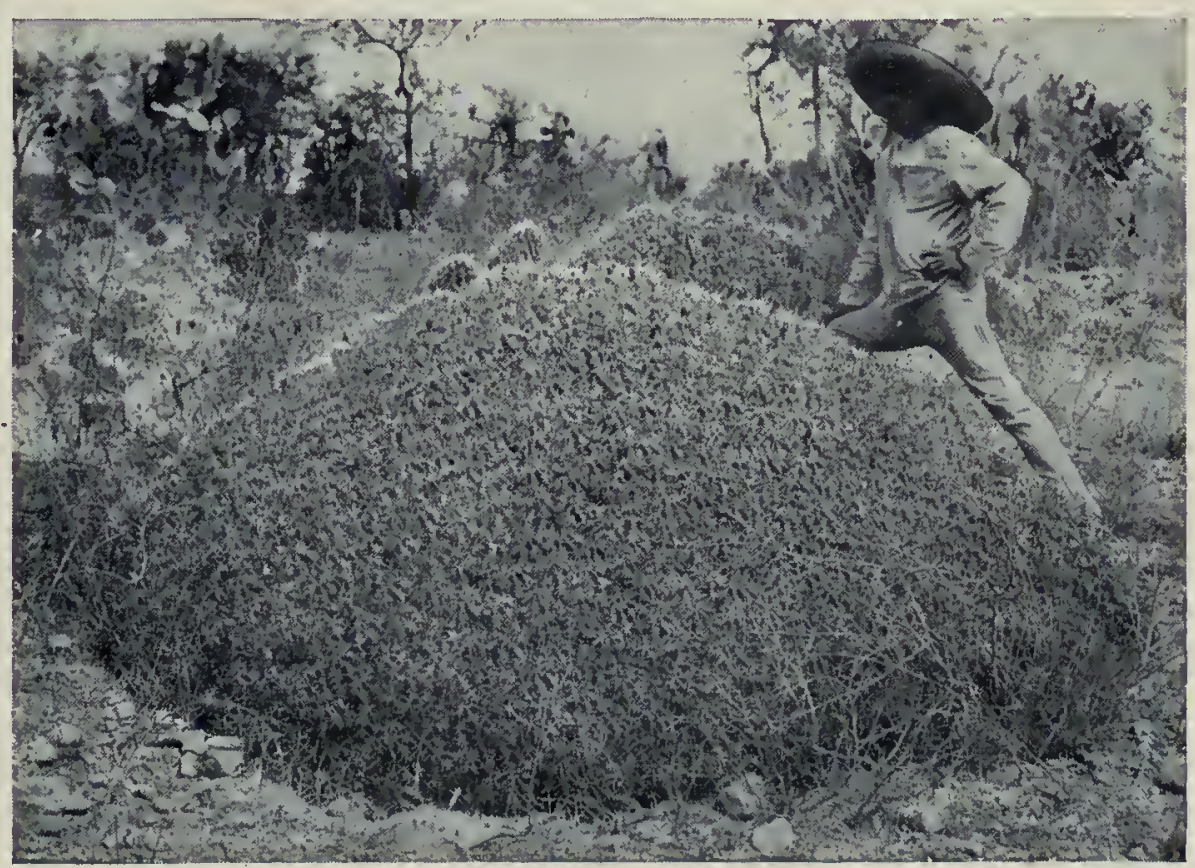

Echinocactus agglomeratus, à 1700 mètres d'altitude (Mexique). 


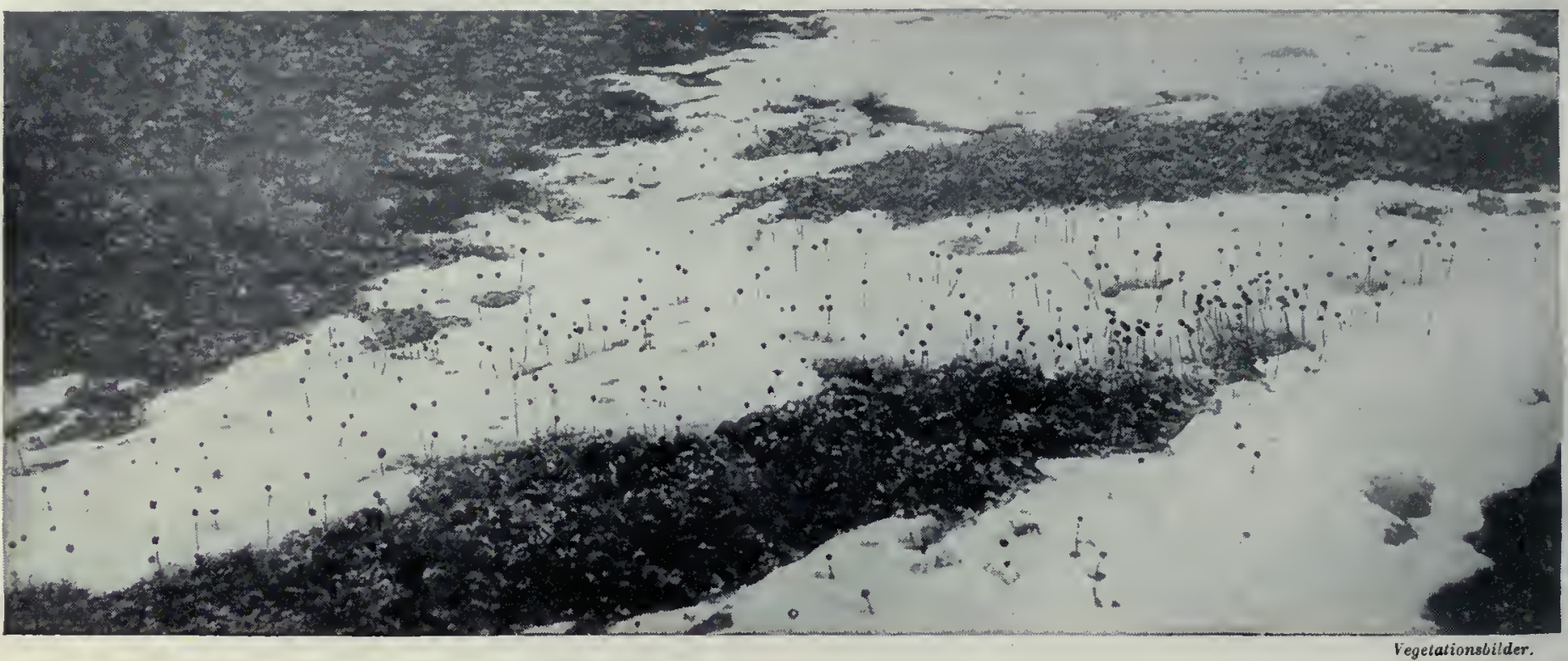

Acoena ascendens, des îles Falkland et de la Géorgie du Sud.

\section{FLORES ARCTIQUE ET ANTARCTIQUE}

Le climat arctique. - Les conditions climatériques des contrées polaires sont tellement spéciales qu il suffit de parcourir un tableau des températures et de l'humidité de ces régions pour entrevoir de suite quelles grandes conséquences doivent en découler pour les végétaux qui les habitent.

TABLEAU MÉTÉOROLOGIQUE DU SPITZBERG (MOSSEL-BAI, 7953' N.)

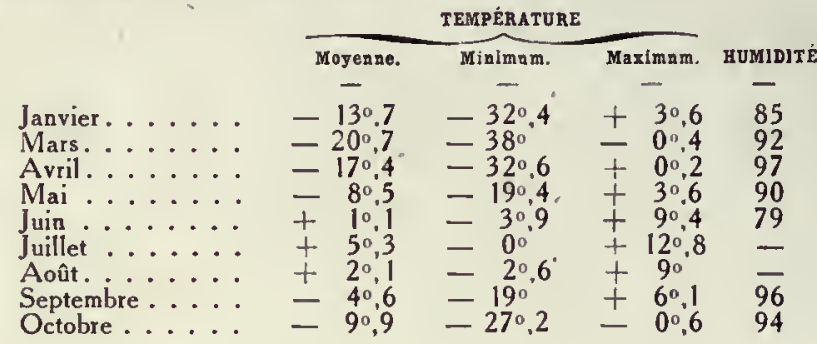

Ce qui caractérise le climat polaire, c'est, d'une part, le long hiver froid et, d'autre part, le très court été (juin, juillet, août); ce sont, en outre, les longues nuits continues d'hiver, pendant lesquelles le soleil reste caché au-dessous de l'horizon, et les jours d'été, pendant lesquels le soleil ne se couche pas. Le soleil est au-dessus de l'horizon d'une manière constante pendant 65 jours à $70^{\circ}$ de latitude, pendant 134 jours à $80^{\circ}$.

Ce ne sont pas tant les basses températures qui sont redoutables aux végétaux, car on peut en observer presque d'analogues dans les pays tempérés; ce sont surtout les tourmentes de vent et de neige, car elles ne permettent pas l'accumulation de la neige,

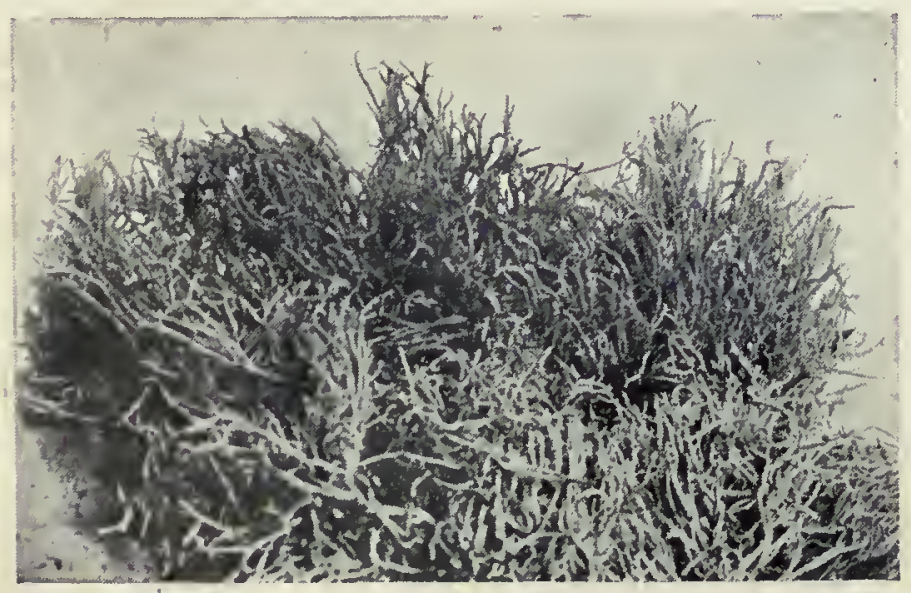

Lichens des rennes (Toundras sèches). dont le manteau protecteur contribue d'ordinaire puissamment à atténuer l'effet du froid.

Les températures d'été sont variables dans les diverses parties du domaine polaire, mais elles dépendent moins de la latitude que de l'existence ou de l'absence de courants d'eau chaude qui viennent réchauffer les terres arctiques : ainsi la température de l'air en juillet est seulement $3 \circ, 8$ dans le Groenland oriental; elle est de $13^{\circ}, 4$ sur la côte nord de l'Asie, à Ussjank, terre un peu échauffée par les eaux marines.

Il y a dans ces régions des différences de température souvent considérables entre l'air et les objets exposés au rayonnement direct. Par $78^{\circ}, 5$ de latitude nord, à Rensselærhafen, un thermomètre noirci (dans le vide) s'élève jusqu'à $21^{\circ}$, tandis que la température de l'air, au milieu de la journée, vers le 15 août, est $0^{\circ}$. Ailleurs, en mars, la température de l'air est de $-31^{\circ}$ à $-33^{\circ}$ et la neige commence à fondre au soleil.

Une question première doit se poser au sujet de la flore de ces terres désolées: $N^{*} y$ a-t-il place pour aucune végétation dans certaines régions arctiques? Le centre du Groenland est occupé par des glaciers; le Spitzberg, l'Islande, le nord de la Scandinavie, la Nouvelle-Zemble, le sud de l'Alaska, les terres de Baffin et de Grinne sont constitués par des régions montagneuses et les glaces. peuvent venir jusqu’à la mer, de manière à ne laisser, pour ainsi dire, aucune place à la végétation.

Même sil en était ainsi partout, et ce n'est pas le cas, toute trace de végétation ne serait pas exclue, car les champs de neige se couvrent parfois sur de vastes étendues d'Algues microscopiques (Chlamydomonas nivalis, etc.) et, à de grandes distances, le vaste manteau blanc apparaît maculé de rouge. En dehors de cette neige rouge, i] $\mathrm{y}$ a toujours quelques places dénudées où peuvent s installer quelques végétaux phanérogames ou cryptogames qui śépanouissent quand arrive la saison favorable.

Sur le sol ainsi mis à nu soit par les tourmentes pendant l'hiver, soit par la fusion des neiges au printemps, les plantes ne se fixent pas sans de grandes difficultés. D'abord souvent le sol reste glacé à une faible profondeur et la glace qui vient de fondre est arrêtée dans son écoulement par celle qui reste solide en dessous, de sorte qu'un marécage se forme inévitablement dont l'eau est toujours à une température très basse. Ces conditions sont évidemment très préjudiciables au développement de la vie organique et les plaines qu'on rencontre dans les contrées arctiques sont de véritables solitudes, inhabitables pour l'homme, incapables de fournir de la nourriture aux animaux.

Toundras. - Les régions où ceci s'observe portent le nom de toundras tremblantes ou marécageuses, et les seules plantes qui y croissent sont presque seulement les Sphaignes. Ce sont des plantes curieuses, dont les cellules perforées peuvent, suivant les circonstances, se gorger deau en s"imbibant comme des éponges, mais qui en se vidant restent remplies d'air et apparaissent avec une teinte vert très pâle, blanchâtre, caractéristique.

A côté des toundras humides, il peut $\mathrm{y}$ avoir des toundras 


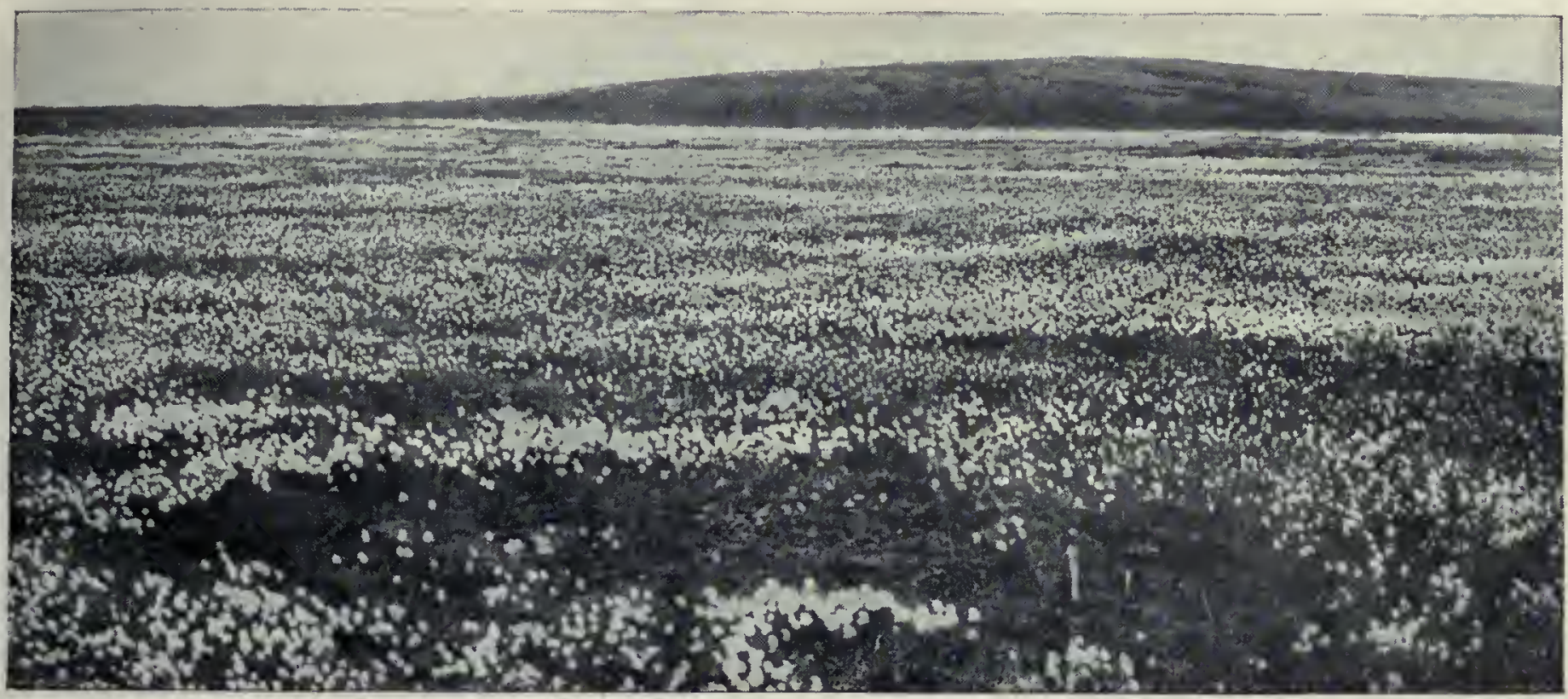

Eriophorum Scheuchzeri en fruits, près du lac Thomson (Nouvellc-Zemble).

sèches; ce sont des étendues arides couvertes sans fin de Lichens des rennes et de Mousses: Polytric, Dicrane (I), auxquels viennent se mêler divers Lichens, Luzules et Eriophorum, susceptibles de supporter pendant la saison estivale une dessiccation intense, après avoir reçu une humidité très grande à la fonte des neiges. Ces divers végétaux, notamment les Lichens, ont des propriétés physiologiques qui sont bien en harmonie avec les froids intenses quils supportent. Jumelle a soumis ces plantes à l'action d'une température de $-40^{\circ}$ en les plaçant dans un ballon renversé qui était contenu dans la caisse à parois feutrées d'une glacière. Le Lichen ainsi refroidi a continué à assimiler le carbone de l'atmosphère; à ces basses températures, la respiration était au contraire abolie. Une telle propriété physiologique est capitale pour des végétaux exposés à des froids intenses, car ils continuent à se nourrir tant qu'ils ont de la lumière en quantité suffisante.

Dans les mers arctiques il se passe quelque chose d'analogue pour les Algues qui vivent dans les eaux salées. Elles trouvent le moyen de se nourrir d'une manière remarquable, malgré les froids intenses, car elles ont parfois des dimensions véritablement colossales. C'est le cas des Macrocystis et des Nerocystis qui peuvent atteindre 200 mètres de long, des Lessonia et autres Algues gigantesques des régions arctiques ou antarctiques.

Les Macrocystes (fig. ]45, A) sont formées d'une sorte de tige, insérée sur les rochers par de très forts crampons; cette pseudolige s'ćtend horizontalement au niveau de la mer et émet des rangées de fausses feuilles étroites, avec flotteur à la base. Les Lessonies ont des tiges dressées et des ramifications qui retombent comme les branches d'un Saule pleureur.

Caractères de la flore arctique. - Pour les plantes terrestres Phanérogames, les propriétés physiologiques sont évidemment différentes et $\mathrm{il}$ est absolument impossible à toute végétation ligneuse et arborescente de sinstaller dans un pays où la durée de la végétation est très courte et les températures supérieures à $10^{\circ}$ très rares. Quelques Bouleaux rampants ou quelques Saules nains (Saule polaire, Bouleau nain) peurent cependant atteindre quelques centimètres au-dessus du sol et, en sunsinuant entres les anfractuosités des rochers, arrivent à donner des fleurs.

Les basses températures de l'air pendant le jour, et surtout pendant la nuit (quand il $y$ en $a$ ), constituent un obstacle très sérieux pour la croissance des pousses végétatives. Le froid qui règne également dans le sol est contraire au développement des organes souterrains et rend difficile l'absorption par les racines. On a comparé

(1) La mulliplicalion relative des Mousses par rapport aux plantes vasculaires dans le Nord résulte du bableau suivant:

\begin{tabular}{cc} 
Monsses. & $\begin{array}{c}\text { Plantes } \\
\text { vancalaires. }\end{array}$ \\
\hline 600 & 3000 \\
180 & 124 \\
262 & 386
\end{tabular}

les dimensions d'individus de la même espèce qui ont crû, les uns en Europe centrale, les autres dans les régions polaires :

\begin{tabular}{|c|c|c|}
\hline & $\begin{array}{l}\text { Enrope eentrale } \\
\text { et septentrionale. }\end{array}$ & $\begin{array}{l}\text { Rérgion } \\
\text { polairo. }\end{array}$ \\
\hline $\begin{array}{l}\text { lidago Virga-aurea } \\
\text { oitobium palustre. }\end{array}$ & $\begin{array}{l}30 \text { à } 60 \mathrm{~cm} . \\
30 \text { à } 60 \mathrm{~cm} .\end{array}$ & $\begin{array}{r}7 \text { à } 10 \mathrm{~cm} . \\
5 \mathrm{~cm} .\end{array}$ \\
\hline
\end{tabular}

Les pousses végétatives d'un Saule polaire en août, à une époque où la croissance de l'année va se terminer, atteignent en moyenne 1 à 5 millimètres, rarement 9 à 11 millimètres, et chacune d'elles porte deux feuilles très petites ( 7 à 1$]$ millimètres de long sur 5 à l] millimètres de large). L'épaississement est souvent encore plus faible et le gain annuel d'une tige d'Airelle se réduit à un vaisseau (Airelle uligineux).

La végétation polaire ne peut donc pas devenir ligneuse arborescente : elle est surtout formée de plantes herbacées, mais ce sont toujours des herbes vivaces, car les plantes annuelles manquent complètement : elles n'ont pas assez de temps pour mener à bien leurs fleurs et produire leurs graines; il faut les efforts soutenus de plusieurs années pour y parvenir. Une observation de Kjellmann, botaniste de l'expédition scandinave de la Véga, est intéressante à signaler à ce propos. Il eut l'occasion d'observer à Pittekoj, qui était la station d'hivernage, le Cochlearia tenestrata, à la fin de 1878. La plante avait bien fleuri dans l'été de 1878; ses inflorescences renfermaient des fleurs à divers états de développement, les unes en boutons, les autres en fruits, quand l'hiver revint brusquement et arrêta toute croissance. On aurait pu croire que toute la plante allait être détruite par le froid : il n'en fut cependant rien, malgré l'absence de manteau protecteur de neige,

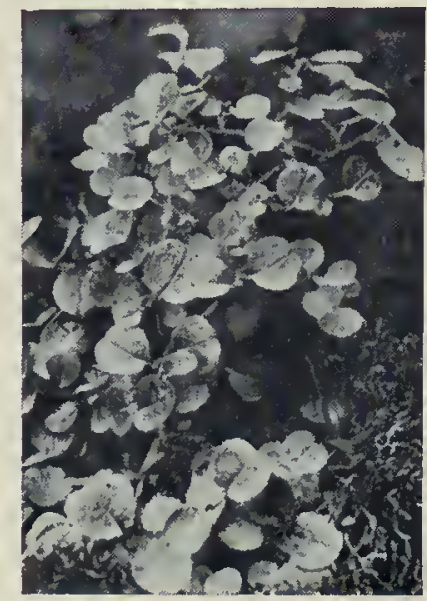

Saule polaire.

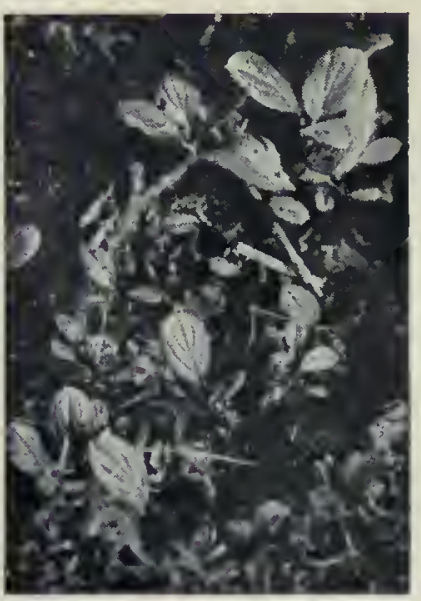

Saule réticulé. 


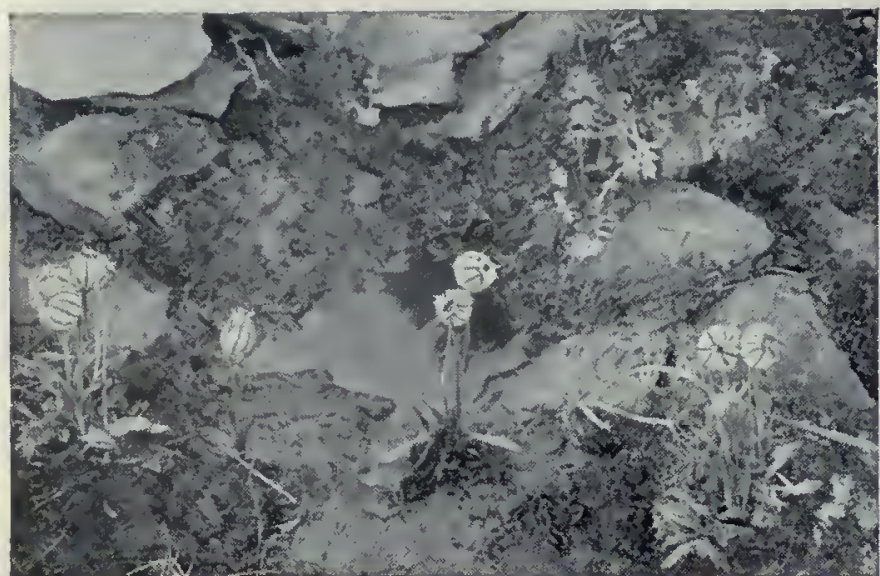

Melandrium apetale (Spitzberg).

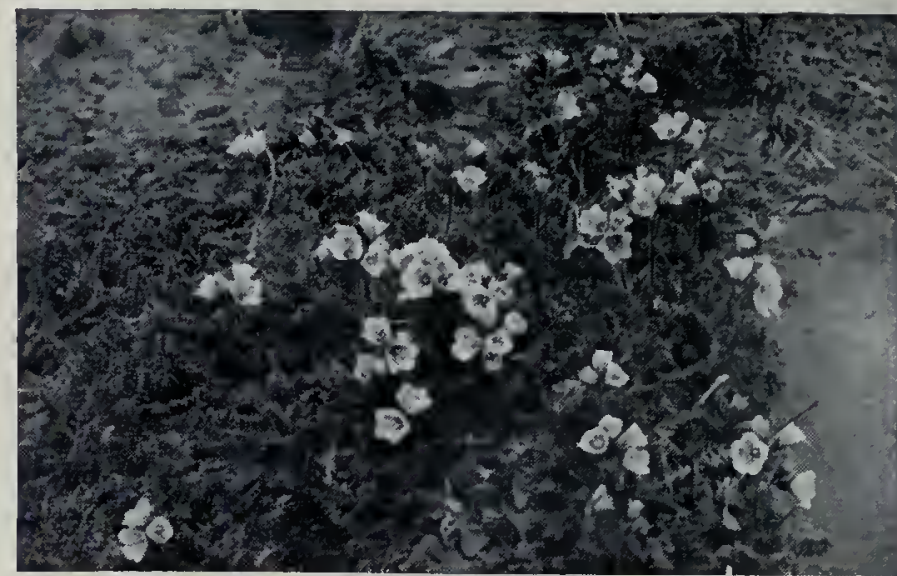

Polemonizm humile (Spitzberg). et, lorsque l'été de 1879 se manifesta, les boutons à fleur qui avaient été pétrifiés par le froid s'amollirent et s'ouvrirent comme par enchantement et, de l'aisselle des feuilles, partirent de nouvelles inflorescences ébauchées précédemment. Le travail d'une saison sert donc l'année suivante. Cela ne veut pas dire que le froid n'a pas d'action sur les fleurs; sil agit peu sur les boutons foraux quand ils sont bien protégés, il manifeste ses effets sur la fructification, qui avorte très communément, et sur les graines, qui ne se forment pas.

Nathorst a montré qu'au Spitzberg 75 pour 100 seulement des fruits arrivent à maturité. I] y a d'ailleurs surtout des plantes à floraison printanière dans les pays septentrionaux ; ce sont des plantes peu exigeantes au point de vue calorifique et ce sont celles qui ont le plus de chances de se maintenir. Si l'on rencontre, par hasard, quelques espèces que l'on peut qualifier d'estivales, celles-là, quand on s'élève trop vers le Nord, n'ont pas le temps de fleurir et elles restent réduites à leurs organes végétatifs. Le Rubus chamæmorus, par exemple, est stérile au voisinage de sa limite nord d'extension.

Steppe chaude d'été polaire. - Si l'été polaire est très court, si l'air est souvent froid, cela ne veut pas dire que les rayons solaires ne sont pas, à certains moments, très ardents, et l'activité de la radiation dans la zone glaciaire nord est aussi redoutable pour les végétaux que pour les voyageurs qui grimpent au mont Blanc et qui reviennent défigurés, la peau du visage pelée par les violents effets du soleil. Cette remarque est utile à rappeler pour faire comprendre quelques caractères de la végétation polaire qui peuvent, de prime abord, paraître étranges. Quoi de plus singulier, en effet, que de constater des points de ressemblance entre la flore polaire et celle des déserts ou des steppes les plus chaudes. C'est que, dans les deux cas, les plantes doivent se protéger contre une trop intense et trop rapide perte d'humidité. Warming a signalé déjà depuis longtemps le caractère désertique de la végétation du Groenland en été. Ceci se manifeste par le fort durcissement des feuilles qui sont à consistance de cuir, ou raides, ou en aiguille pour diminuer leur transpiration; ce dernier résultat est encore atteint par la tendance de la plante entière à former des coussinets arrondis

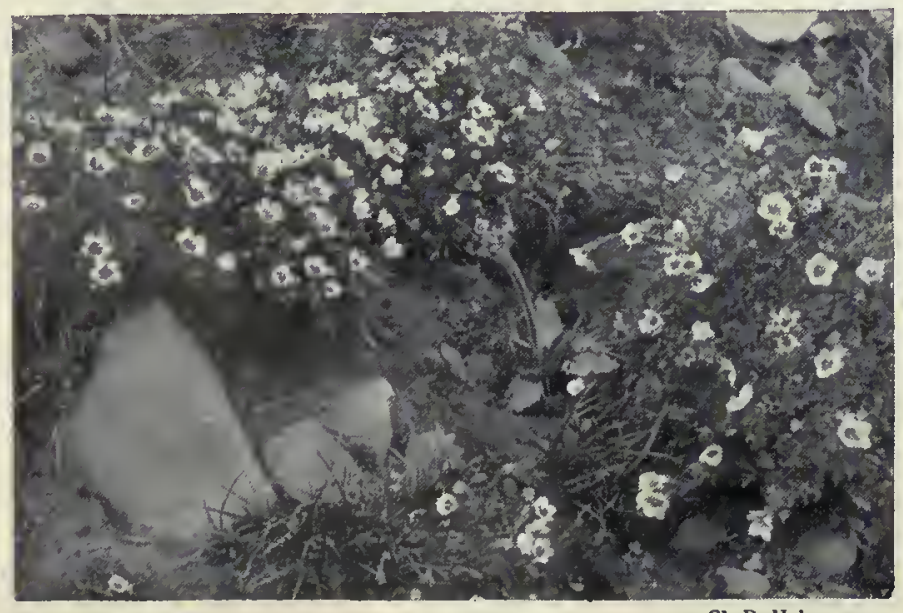

Saxifraga Groenlandica et nivalis (Spitzberg) de grande taille, particularité qui est extrêmement commune (Draba alpin, Coquelicot à tige nue, Saxifrage à feuilles opposées, etc.). Ailleurs, la protection est réalisée par l'enroulement de la feuille en dessous, cachant pour ainsi dire les stomates, appareils de transpiration; enfin la couche cireuse acquiert un grand développement et est très utile pour diminuer la perte d'eau (Saule glauque et réticulé).

D'ailleurs ces fortes chaleurs estivales peuvent favoriser parfois l'éclosion d'une végétation admirable, lorsqu'en un point où le sol est bombé, l'eau dégelée peut s'écouler complètement : c'est là que se rencontrent les meilleurs pâturages recherchés par les Samoyèdes et que l'on peut trouver des pays presque enchanteurs, si l'on se reporte au tableau célèbre tracé par Baer de la végétation de la Nouvelle-Zemble, quiil a comparée à celle d'un jardin.

I] nous reste à examiner quel est le rôle de ces jours polaires dont la durée peut être de plusieurs mois. Les expériences de Bonnier dans les caves des Halles, celles de Kjellmann dans les régions arctiques, ont appris qu'un éclairage continu produit une sorte d'étiolement vert pour les plantes d'Europe; mais les plantes polaires, comme la Cochléaire fenestrée, se développent bien mieux et produisent beaucoup plus de feuilles qu à un éclairage discontinu.

Caractères botaniques. - Nous avons signalé dans tout ce qui précède les caractères généraux et kiologiques de la flore arctique; il nous faut envisager maintenant ses caractères botaniques. La pauvreté de la flore arctique est très remarquable et plus profonde encore que ne semblerait l'indiquer le chiffre de 750 espèces, correspondant à l'ensemble de la population végétale de ce domaine qui s'étend cependant sur d'immenses territoires.

$\mathrm{Si}$ l'on examine comment ces plantes sont réparties, on voit que chaque île ou presqu'île ne contient qu'un nombre beaucoup plus restreint de types: 320 espèces pour le Groenland, 122 pour le Spitzberg, 193 pour la Nouvelle-Zemble, 124 pour la presqu'île de Taimyr. Sur les 320 espèces groenlandaises, 101 se trouvent seulement sur les deux côtes. Cette flore arctique est répartie entre 50 familles, parmi lesquelles il faut citer: Cypéracées 10 pour 100 , Graminées 10 pour 100, Crucifères 8 pour 100, Caryophyllacées 7 pour 100 , Renonculacées 5 pour 100 , Rosacées 5 pour 100, Saxifragacées 5 pour 100 , Ericacées 5 pour 100, Composées 4 pour 100. Une vingtaine d'espèces seulement sont spéciales à la flore polaire et ne se retrouvent nulle part ailleurssur le globe. Les espèces très caractéristiques de la flore arctique sont : Dryas octopetala, Silene acaulis, Melandrium apetale, Polemonium humile, Saxifraga Groenlandica, Lychnis apetala. Comme Graminées: Phippsia algidaet quelques genres mo- notypes: Dupontia et Pleuropogon.

Les terres antarctiques. Parmi les terres perdues dans les immensités de l'océan Antarctique, on peut citer l'ile de Kerguelen, explorée

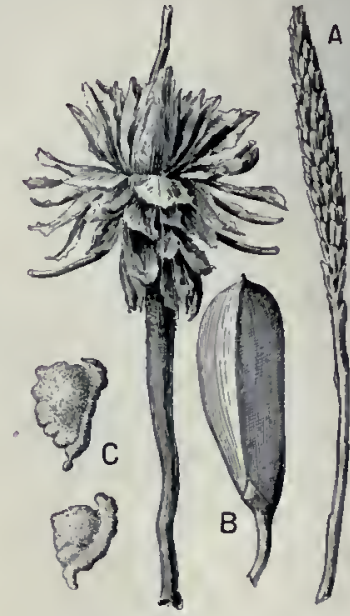

Fig. 110.

Chou de Kerguelen.

A, Inflorescence : $B$, Silique; C, Graines. 


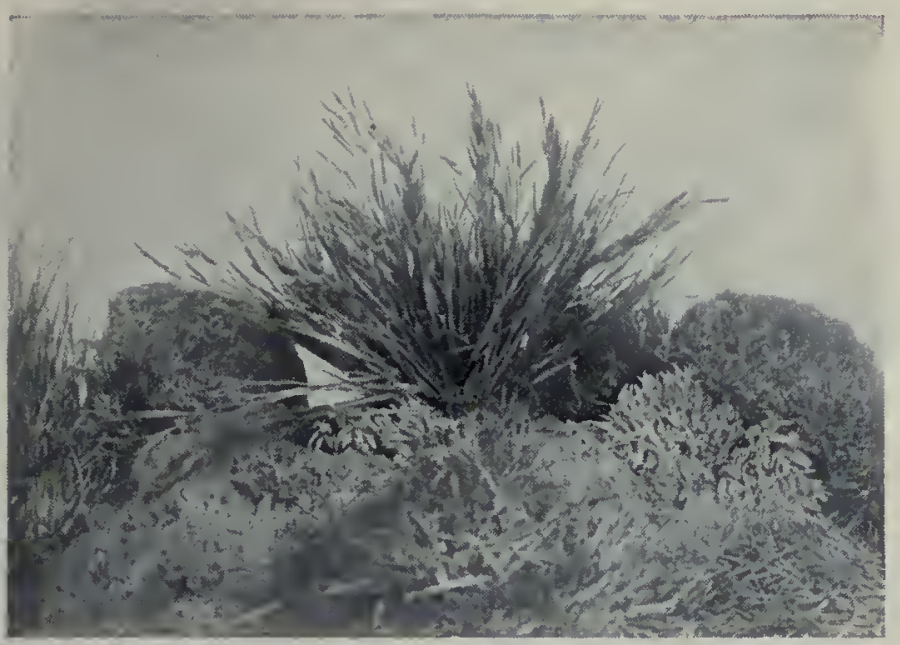

Flore antarctique : Graminées, Colobanthus et Mousses.

récemment par les voyageurs Boissière, qui ont rapporté au Muséum des échantillons de l'espèce la plus caractéristique de la flore phanérogamique de cette île (vingt et une espèces) qui est le Chou de Kerguelen (fig. IIO), Pringlea antiscorbutica, une Crucifère très intéressante. L'île de Kerguelen est située entre $48^{\circ}$ et $50^{\circ}$ de latitude sud; son plus grand diamètre atteint 20 kilomètres; elle a une chaîne de montagnes de hauteur moyenne de 1000 mètres (Mont Ross, 1900 mètres). Les sommets sont couverts de névés; il en descend des glaciers dont quelques-uns atteignent le niveau de la mer. Le climat de Kerguelen est franchement marin. La différence entre le mois le plus chaud (février) et le mois le plus froid (juillet) ne dépasse pas $6^{\circ}, 50$. Le minimum absolu est $10^{\circ}$, le maximum absolu $20^{\circ}$. La température moyenne de l'année est $3^{\circ}, 1$. L'humidité relative est grande et la précipitation atmosphérique abondante; il y a des chutes de neige toute l'année. Signalons comme végétaux remarquables une Rosacée, l'Acana ascendens, et une Ombellifère, l'Azorella Selago; cette dernière plante a été retrouvée à l'île Macquerie, à la Terre de Feu; elle manque à la Nouvelle-Zélande.

Dans la Géorgie du sud et les îles Malouines vivent deux Graminées, le Poa flabellata et l'Aira antarctica.

Cette dernière espèce a été rencontrée plus au sud par l'expédition française du Pourquoi-Pas de Jean Charcot (1908-1910); c'est la seule Phanérogame de cette région très froide, avec le Colobanthus crassifolius (Caryophyllacée), avec des Mousses (1) et des Lichens (2). La neige verte s'observe à l'île Petermann; la neige verte et la neige rouge sont abondantes en certaines régions de la côte ouest de la terre de Graham. Parmi les espèces d'Algues les plus remarquables de cette neige verte ou rouge, on doit citer Mycacanthococcus antarcticus et ovalis, Chlamydomonas antarcticus, Pscudotetraspora Gainii; cette dernière espèce est dédiée à Gain, le naturaliste de l'expédition Charcot. La neige rouge de l'île Wiencke forme de grandes plaques sur les falaises de glace et à la surface de la neige près des rookeries de pingouins: elle est composée de Rhaphidonema nivale, Stichococcus bacillaris, Ancylonema Nordcnskioldii, etc. On retrouve la neigé rouge à l'île Petermann. On peut mentionner, comme Algues d'eau douce dans ces régions des Schizophycées (Lyngbia, Oscillatoria, Nostoc), quelques Conjuguées (Cosmarium) et Chlorophycées (Ulothrix, Conferva, etc.)

Pendant l'hivernage à l'íle Petermann, les moyennes mensuelles de la température de l'eau de mer en surface et de l'air ont été :

\begin{tabular}{|c|c|c|c|c|c|}
\hline ANKÉE 1809 & MER & AIR & ATKE்E 1809 & MER & AIR \\
\hline $\begin{array}{l}\text { Janvier } \\
\text { l'évrier } \\
\text { Mars . } \\
\text { Avril . } \\
\text { Mai. . } \\
\text { Juin. . }\end{array}$ & $\begin{array}{r}-0,30 \\
=00,09 \\
=00,23 \\
=10,56 \\
=10,75 \\
=10,81\end{array}$ & $\begin{array}{r}+10,38 \\
+00,96 \\
-50,03 \\
-50,14 \\
-6^{0}, 46\end{array}$ & $\begin{array}{l}\text { Juillet.... } \\
\text { Août . } \\
\text { Septembre } \\
\text { Octobre. } \\
\text { Novembre. } \\
\text { Décembre. . }\end{array}$ & $\begin{array}{r}-10,83 \\
-10.84 \\
-10,76 \\
-10.22 \\
-00.99\end{array}$ & $\begin{array}{r}-6^{\circ}, 79 \\
-5^{\circ}, 66 \\
=50,90 \\
=2^{\circ}, 43 \\
-11^{0}, 13\end{array}$ \\
\hline
\end{tabular}

(1) Espèces les plus fréquentes: Webera Racovitza, Bryum pérangustidens, Patytrichum strictum, Drepanacladus uncinatus. La fore bryalagique antarctique comprend en taut cinquante à soixante espèces.

(2) Sphorophorus, Cladonia, Stereocauton, Usnea, Letharia, Potycantiana, Physcia, Lecarara, Lecidea.

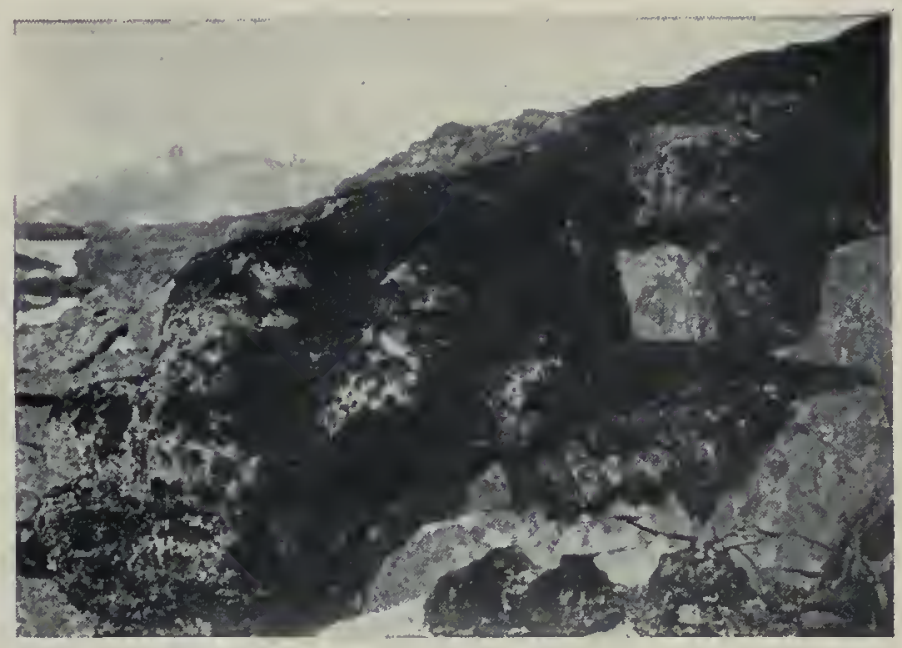

Mousses sur les rochers anx îles Argentines.

Les fonds marins sont balayés par des courants violents. Le long des côtes, partout où se trouvent des glaciers dont la base baigne directement dans la mer, il ne peut se produire, au moins dans les régions de faible profondeur, aucune végétation marine. C'est là où l'influence de la glace n'est pas continuelle que les Algues peuvent s'établir. En hiver, la vie végétale est presque suspendue; la banquise emprisonne les quelques Algues restées en place. La houle rabote les rocherset permet seulement aux Algues calcaires (Lithophyllum et Lithothamnion), grâce à leur dureté, à leur position sur les parois verticales rentrantes et les creux de rochers, de rester en place. Pendant les mois chauds, d'octobre à mars, la zone littorale se débarrasse peu à peu de la banquise et peut se couvrir d'une végétation assez abondante.

Gain a distingué la zone littorale comprise entre les niveaux de la haute mer et de la basse mer. Elle est peuplée d'Algues calcaires, avec Urospora penicilliformis, Monostroma Hariotii, Adenocystis Lessonii, Gracillaria simplex, etc. La zone sublittorale de la basse mer a environ 40 mètres de profondeur ; on y trouve des Desmarestia, accompagnées de Lessonia dubia, Plocamium coccinium, Callymenia antarclica. La région littorale jus qu à 150 mètres est encore peu connue et très pauvre. La végétation antarctique s'est adaptée au manque de lumière qui est dû à la nuit polaire de plus en plus longue (vers $66^{\circ}$ sud, au milieu de l'hiver, il y a à peine deux heures de jour d'une lumière très atténuée, plutôt crépusculaire) ct à l'épaisse couche de glace qui, dans la saison froide, recouvre la surface de la mer.

La comparaison des flores arctique et antarctique est intéressante. Si certaines espèces sont identiques, beaucoup sont différentes, et pour certaines familles il n'existe pas d'espèces communes aux deux régions. Chez les Laminariacées, Ecklonia, Lessonia, Macrocystis, Adenocystis, Phyllogigas, Phoeoglossum sont spéciaux aux régions polaires du Sud; Sacchorhiza, Chorda, Alaria. Laminaria, Agarum sont localisés dans les régions du Nord.

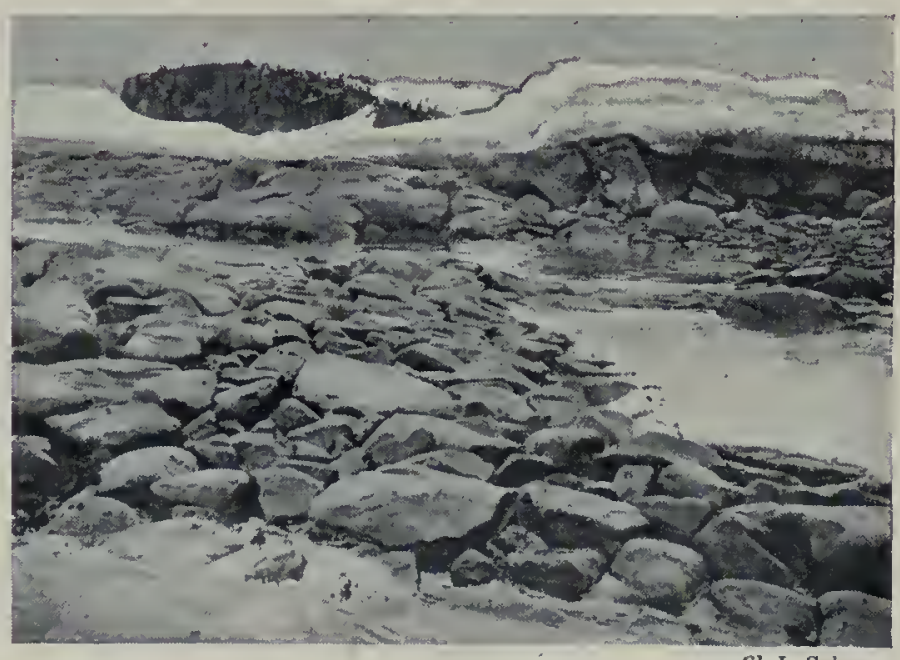

Algues croissant entre les pierres (ile Petermann). 


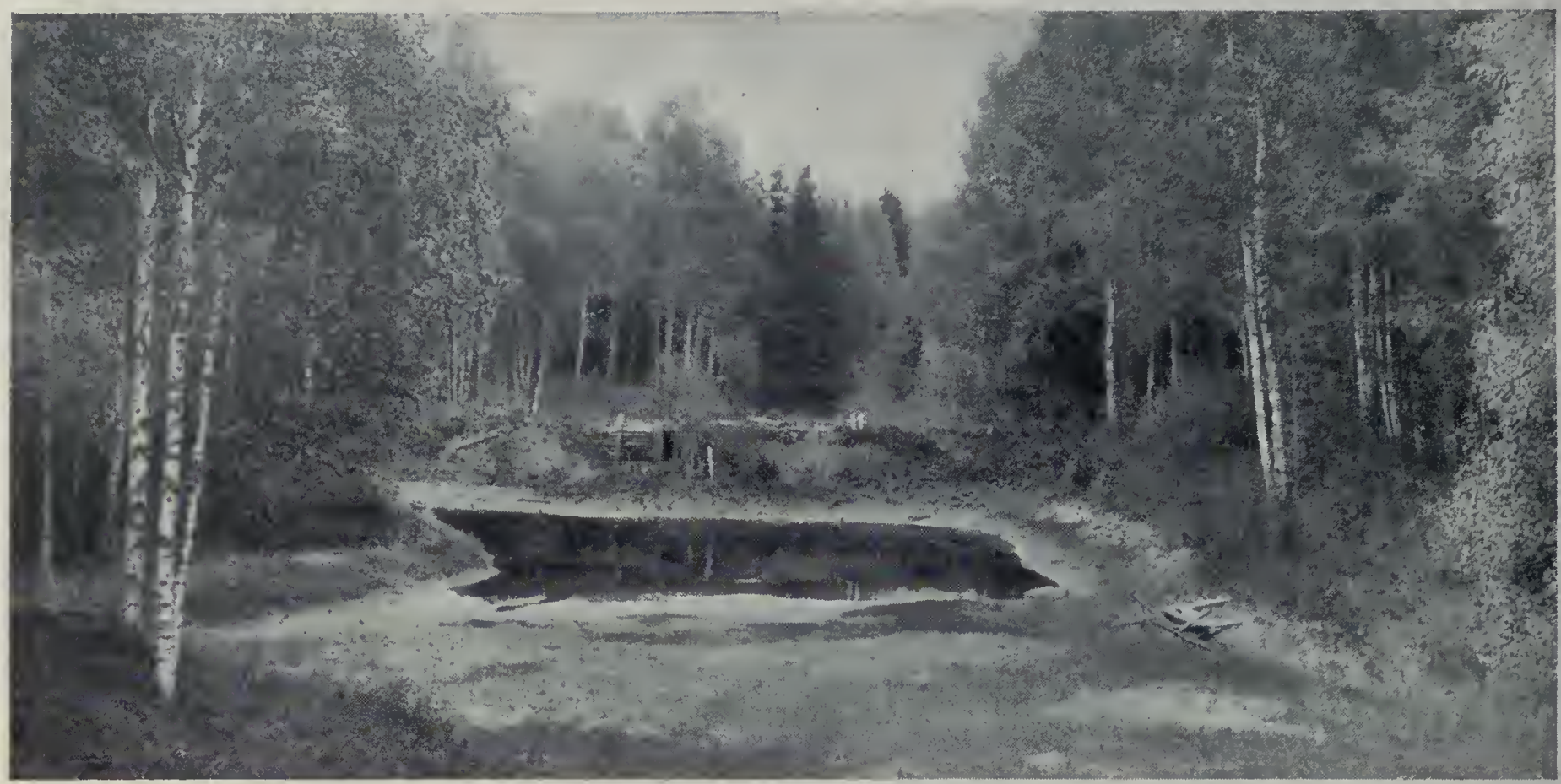

Une clairière dans la forêt russe.

\section{FORÊTS BOREALES \\ ET FORÊTS AUSTRALES}

Après avoir exploré les zones polaires, si l'on se dirige vers des régions moins désolées, on rencontre tout de suite un autre aspect de.paysage et une végétation dont le nombre des espèces est beaucoup plus élevé. Il faut évidemment, pour se rendre compte du facies de la végétation spontanée, parcourir des régions où la civilisation humaine n'est pas trop intervenue et où la nature règne encore en maîtresse.

Cette zone est surtout caractérisée par les forêts, et elle est développée principalement dans l'hémisphère boréal, dans le nord et le centre de l'Europe et de l'Asie, et dans le nord de l'Amérique du Nord. Dans l'hémisphère austral, l'absence de grands continents, étendus suivant les parallèles, ne laisse constater la présence d'une telle flore qu'à la pointe extrême de l'Amérique du Sud, ò̀ elle est surtout caractérisée par des Hêtres (Nothofagus).
Le climat. - Au point de vue du climat, il y a évidemment des variations notables à y signaler, mais ce qui caractérise ces contrées, c'est l'alternance nette de saison chaude estivale et de saison froide hivernale. L'humidité et la pluie sont assez abondantes toute l'année, surtout pendant les mois d'hiver, de printemps et d'automne, mais elles ne manquent pas au cours de l'été.

Les variations sont d'ailleurs très importantes, aussi bien quand on voyage vers l'est de l'Europe et en Asie que lorsqu'on traverse l'océan Atlantique pour aller dans l'Amérique du Nord.

La principale différence qui existe entre l'ouest et l'est de l'Europe, entre le climat de la Bretagne et celui de la Russie du Nord, tient principalement à l'influence de la mer qui se fait fortement sentir dans tout l'ouest de l'Europe, c'est-à-dire dans tous les pays qui sont réchauffés par le Gulf-stream. Ce fait se manifeste par l'avance qui y a lieu dans l'éclosion du printemps. On a dressé des cartes où sont représentées par une teinte uniforme les régions pour lesquelles un phénomène quelconque, par exemple la floraison du Lilas, se produit cn même temps (fig. 111$)$. On sait que lorsquion se déplace vers le Nord, cette floraison retarde, mais il y a un retard également appréciable quand on se dirige vers l'est de l'Europe.

Le retard dans l'éclosion du printemps est, par rapport à Paris, de 13 jours à Bruxelles, de 46 jours à Prague, de 52 jours à Varsovie, de 87 . jours à Pulkowa, en Russie. Il est vrai que si, dans ces dernières contrées, la chaleur est lente à venir, une fois qu'elle a commencé, elle progresse avec une très grande rapidité et, vers le milieu de la saison, les fleurs d'été sont fréquemment plus tardives à l'Ouest qu'à l'Est. Le long de l'Atlantique, il règne donc, en Europe occidentale, des températures moins froides pendant l'hiver que dans l'Est; par contre, la sécheresse y est beaucoup moins grande pendant l'été. Ces différences s'exazèrent à mesure que l'on s'avance vers l'est de l'Asie.

Si l'on compare maintenant les EtatsUnis et la France ou l'ouest de l'Europe, on voit que le climat des premiers, malgré des variations, est assez analogue au nôtre, mais les hivers y sont plus rigoureux et les étés plus chauds. A égalité de latitude, il y a une différence très

Fig. 111. - Carte de l'apparition de la floraison dn Lilas en Europe. 


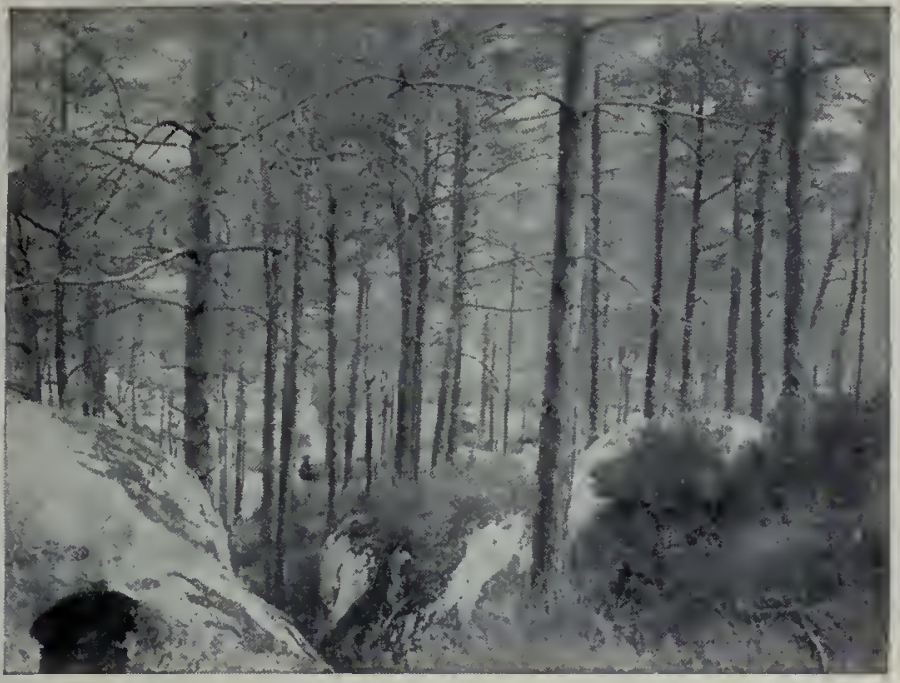

Pins sylvestres (Forêt de Fontainebleau).

notable dans l'apparition du printemps. Voici plusieurs villes américaines et européennes où le printemps se manifeste en même temps :

\begin{tabular}{|c|c|c|c|c|}
\hline méricaines. & Lstitude. & aropéentes & Lat tude. & $\begin{array}{l}\text { Difléretce } \\
\text { ds latitude }\end{array}$ \\
\hline $\begin{array}{l}\text { ew-York. } \\
\text { ew-Albany }\end{array}$ & $\begin{array}{l}40^{\circ} 42^{\prime} \\
30^{\circ} 17^{\prime}\end{array}$ & $\begin{array}{l}\text { Marbourg } \\
\text { Dijon }\end{array}$ & $\begin{array}{l}50^{\circ} 47^{\prime} \\
47^{\circ} 19^{\prime}\end{array}$ & $\begin{array}{l}10^{\circ} 05^{\prime} \\
9^{\circ} 02^{\prime}\end{array}$ \\
\hline
\end{tabular}

Les villes américaines sont plus au nord de $9^{\circ}$ à $10^{\circ}$ que les villes européennes correspondantes comme dates d'éclosion.

Caractères généraux de la flore forestière. - Ccs différences ne sont pas négligeables; elles expliquent bien des particularités de la végétation, mais elles sont compatibles avec le dćveloppement d'une flore qui partout affecte les mêmes caractères généraux. Ce qui la définit, cest l'existence de grandes forêts, dont nous pouvons prendre une bonne idée en parcourant les régions de Compiègne ou de Fontainebleau. Sans doute, en beaucoup de points, la civilisation a opéré le défrichement et les cultures ont pris la place des grandes étendues forestières d'autrefois, mais ces changements sont relativement récents, et on peut caractériser la flore naturelle qui nous occupe par la présence d'un grand nombre d'arbres tels que les Hêtres, les Chênes, les Pins sylvestres, les Bouleaux blancs, les Frênes, etc.

Quelles conditions assignent une limite à cette zone ? On pourrait être tenté de penser que c'cst le froid qui est le principal obstacle au développement de la végétation arborescente dans le Nord. Il ne semble cependant pas qu'il en soit ainsi, car Werschojansk, en Sibérie, point où l'on a observé les températures les plus basses à la surface du globe $\left(-64^{\circ}\right)$, est dans le domaine forestier et non dans la zone arctique. Le facteur le plus important qui tend à arrêter les Bouleaux et les Pesses au seuil de la toundra polaire est surtout le vent. Les tourmentes d'hiver ont une influence néfaste sur les arbres: elles enlèvent les branches et les dessèchent. Les froids tardifs du printemps sont aussi à redouter : ils surprennent la végétation au moment de son départ; aussi ontils comme effet de raccourcir encore la période d'activité utile du végétal, période déjà très courte normalement dans ces régions. On doit donc conclure que ce n'est pas la cha!eur, en valeur absolue, que réclame l'arbre pour se maintenir; ce sont des conditions secondaires (dérivant, il est vrai, de la température) qui sont, en fait, les vraies sources du mal dans lesquelles it faut chercher les causes de la disparition des arbres.

Les arbres des forêts boréales. - La forêt boréale peut affecter deux aspects principaux. Tout à fait dans le Nord, ce sont les arbres à aiguilles ou Conifères qui prédominent, caractérisés surtout par leurs feuilles persistantes; en outre, on y voit régner les mêmes espèces souvent sur d'énormes surfaces; dans les régions plus méridionales, ce sont les arbres à feuilles caduques qui deviennent plus nombreux. Ce n'est pas là, comme de juste, une division absolue; le Bouleau papyracé remonte très au Nord: par exemple, dans l'Alaska, il accompagne la Pesse blanche, qui marque la limite septentrionale des forêts dans cette région élevée vers le pôle. Enfin, parmi les Conifères, les Mélèzes se différencient par la caducité de leurs feuilles; malgré cela, ces plantes

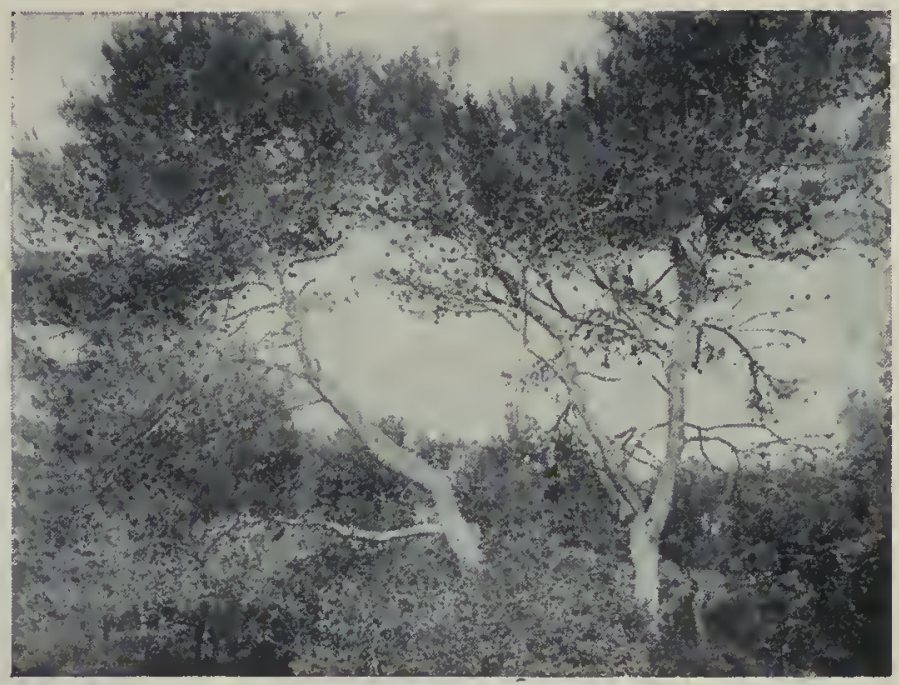

Pins maritimes (Sud-ouest de la France).

peuvent s'élever très haut; et dans le Labrador, le Mélèze américain accompagne la Pesse blanche à l'extrême bord septentrional du domaine forestier.

Les noms que nous venons de citer montrent que la flore n'est pas tout à fait semblable dans l'Amérique du Nord et dans le domaine correspondant de l'Ancien Monde. Les espèces sont assez voisines; ce sont des espèces représentatives et correspondantes. Le Mélèze américain remplace le Mélèze d'Europe; le Pin résineux correspond au Pin sylvestre; le Sapin baumier prend la place du Sapin pectiné; le Hêtre ferrugineux se substitue au Hêtre sylvestre. Il y a d'ailleurs des formes arborescentes qu'on 'ne trouve pas en Europe et qui sont caractéristiques de cette région américaine, comme le Tulipier de Virginie (Liriodendron), les Sassafras, les Magnolia.

Par les îles Aléoutiennes et le détroit de Behring, il s'établit

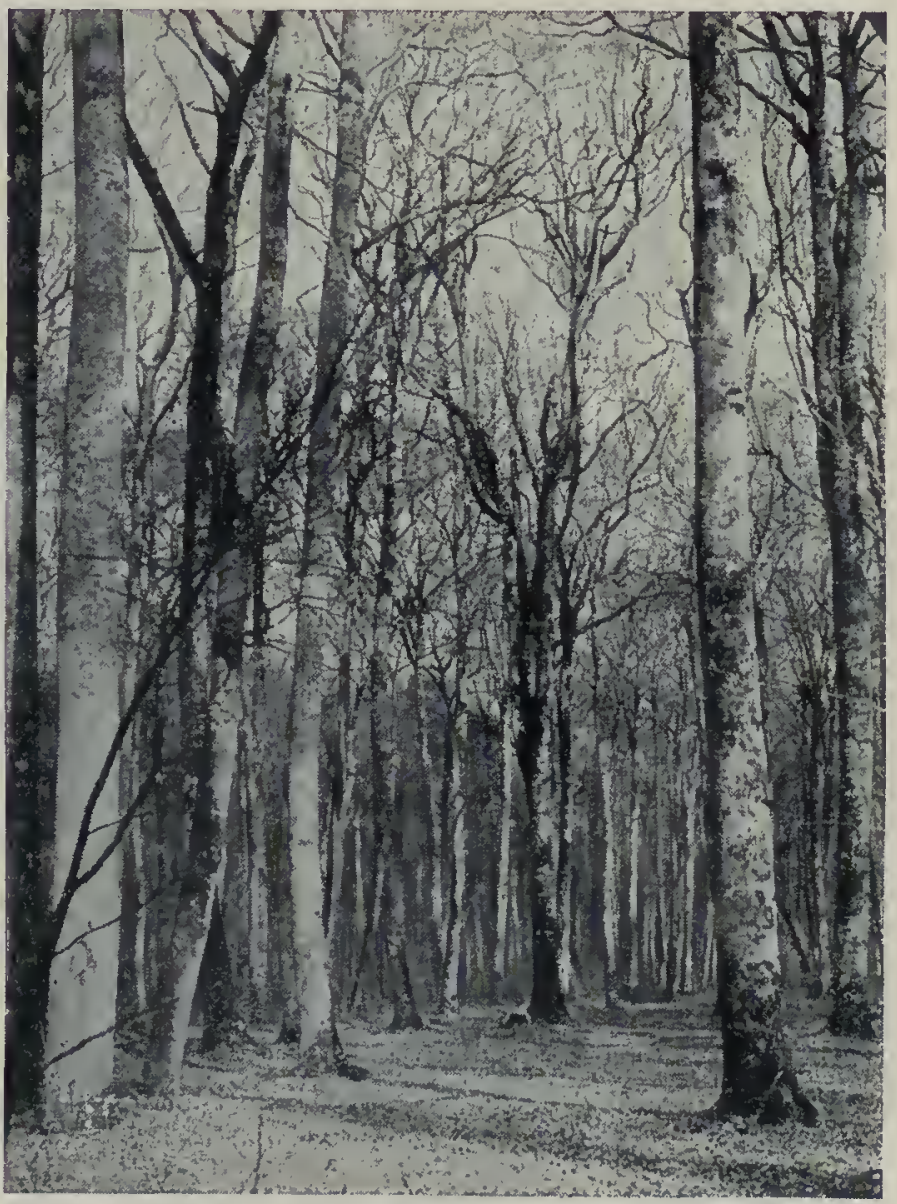

Futaie de Hêtres (Forêt de Fontainebleau). 


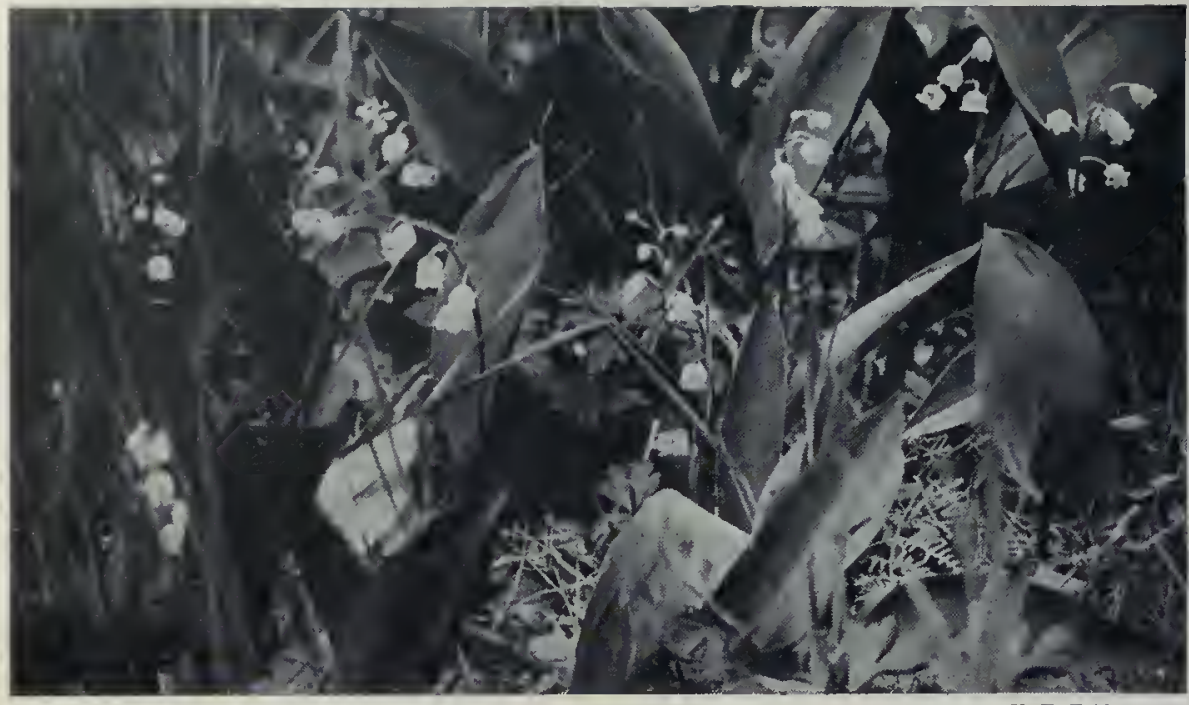

Le Muguet des bois (Environs de Paris).
Nord, le Fatsia horrida, les Myrica, etc.; en outre, il faut citer quelques types spéciaux : le Houx cassine qui correspond au Houx aquifolié, les Mahonia qui remplacent les Berberis, les Calycanthes, la Comptorie, l'Asiminier trilobé; à la place des Bruyères, les Camarines, les Menziésies.

Entre les arbres et les arbustes, et s'appuyant sur eux, peuvent se développer quelques liänes. mais elles ne sont pas ici bien nombreuses, telles que le Lierre, lié à la distribution du Hêtrc et surtout du Chêne ; les Clématites, les Ronces, les Rosiers, le Houblon. Mais jamais cette végétation adventive ne prend un grand développement, sauf dans les forêts japonaises, qui ne sont d'ailleurs rattachées au domaine actuellement étudié que d'une manière un peu détournée, car on les considère comme appartenant à une flore de type méditerranéen. On trouve les Schizandres dans le bassin de l'Amour et les Ménispermes dans l'Amérique du Nord.

Dans les forêts à feuillage caduc, la flore printanière est riche : les Muguets, les Jacinthes, une continuité de la flore de l'Asie et celle de l'Amérique du Nord, mais il y a de grandes différences entre les deux côtes américaine et européenne de l'Atlantique. Le voisinage de la mer modifie aussi souvent la flore; le Pin maritime, par exemple, rcmplace sur nos côtes le Pin sylvestre.

Le sous-bois. - Partout la forêt affecte les mêmes caractères généraux. Au-dessous des grands arbrcs, dans les forêts de Conifères, le sous-bois est très peu développé ; les aiguilles s'accumulent en grand nombre et couvrent le sol, qui ne peut nourrir qu'un petit nombre d'herbes, de Fougères et de Mousses, et, à l'arrière-saison, de Champignons à chapeau. Dans les forêts qui se dépouillent l'hiver, le sous-bois est plus riche : on y voit des arbustes, comme les Cornouillers, le Houx aquifolié, les Genévriers, l'Épinevinette, les Aubépines, les Pruniers épineux ; dans l'Amérique du

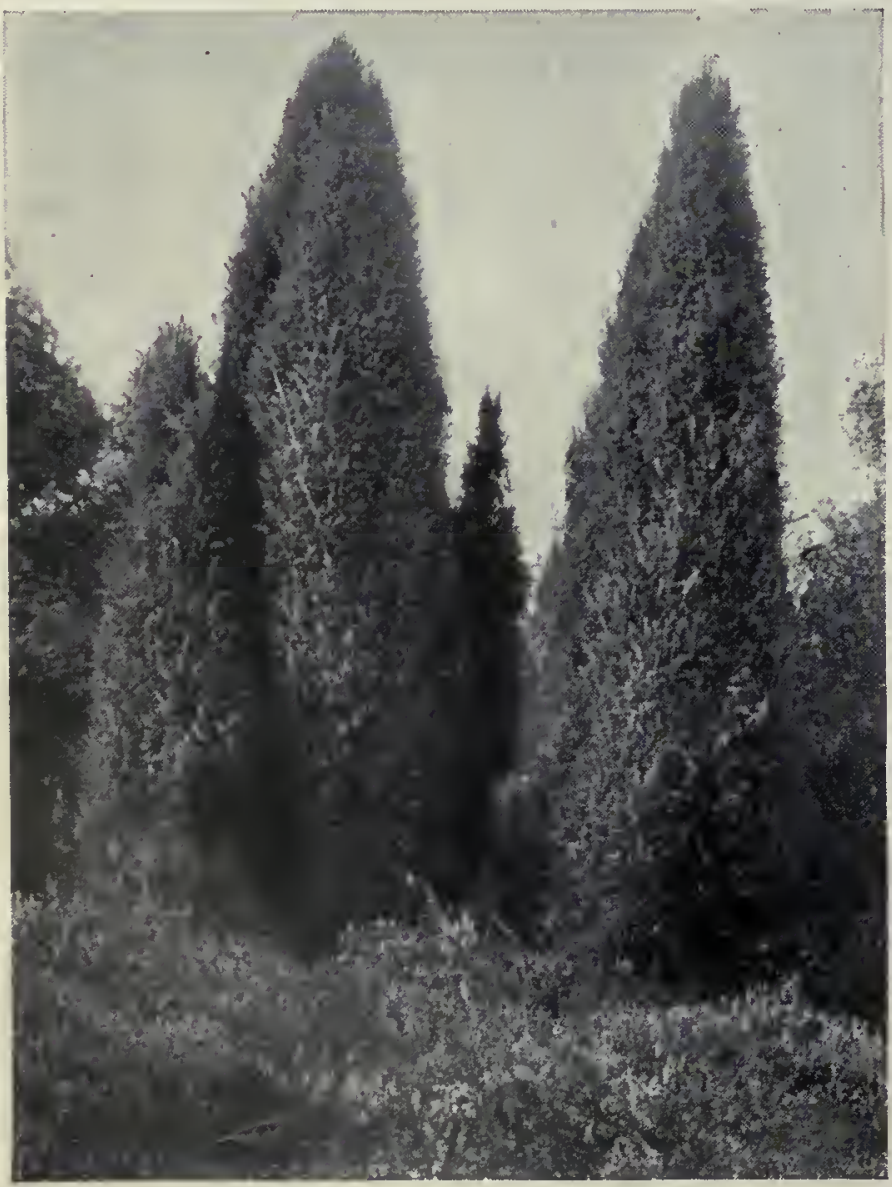

Genévriers aux cnvirons d'Arbonne (Seine-et-Marne).

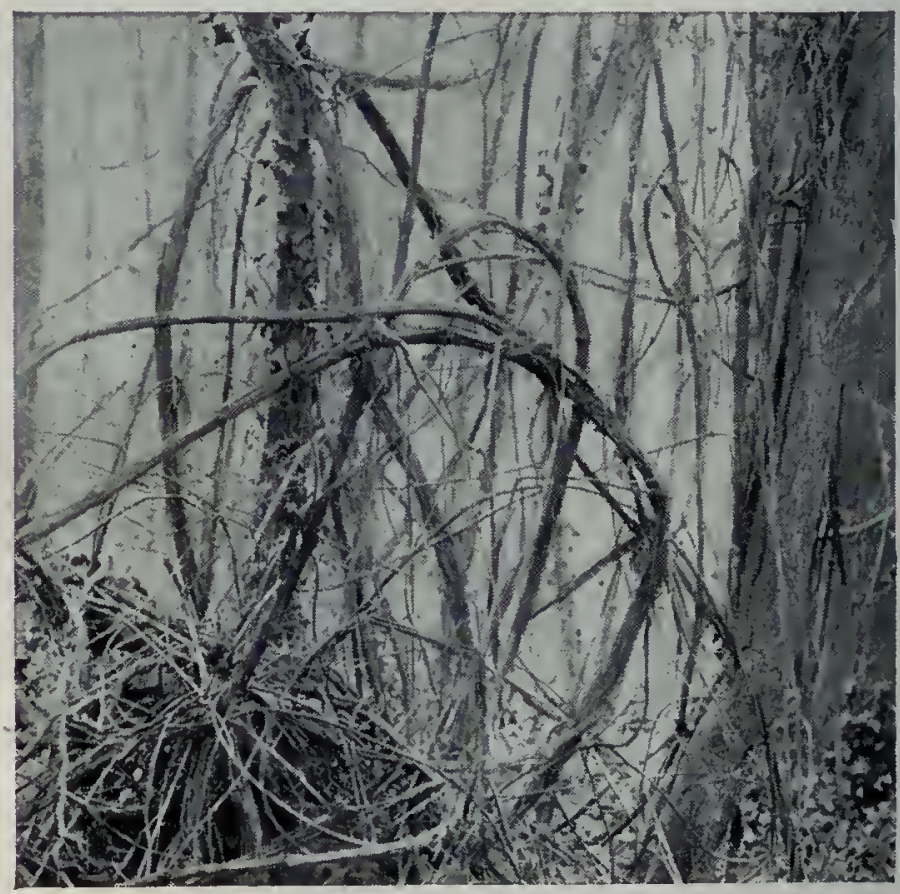

Lianes de Clématites dans les bois.

Cl. F. Faideau.

les Anćmones, ornent de leurs fleurs variées le sous-bois. Pendant l'été, les feuilles des arbres se développent, et la lumière qui arrive dans le fond des bois s'atténue fortement; il en résulte qu il n'y peut croître que des végétaux dont les exigences lumineuses sont très faibles, comme les Fougères herbacées : Polypode, Aspide, Fougère grand aigle (Pteris), et une série d'Orchidées saprophytes, comme la Néottie nid d'oiseau, les Épipogons, les Corallorhizes.

A l'aide de méthodes photométriques précises. Wiesner a pu déterminer la variation de l"intensité de la lumière à l'ombre de nos forêts, à mesure que se développaient les feuilles, et il a pu fixer ainsi quelles plantes pouvaient y réussir, et en suivre l'étiolement progressif à mesure que l'atténuation lumineuse devenait trop forte. Par exemple, pour l'Hépatique trilobée, le pétiole, qui a une longueur de 29 millimètres pour une lumière égale à l'unité, a une longueur de 108 millimètres pour une lumière égale à un sixième. En même temps que le pétiole s'allonge, le limbe diminue, et, à l'obscurité absolue, le pétiole a 174 millimètres et le limbe est presque complètement atrophié. Wiesner a fait des constatations analogues avec le Muguet, avec le Prenanthes purpurea, le $V$ incetoxicum officinale.

Clairières, prairies, montagnes. - L'atténuation de la lumière en été rend la végétation sous les forêts très pauvre et souvent stérile; mais à l'orće des bois ou dans les clairières, la lumic̀re 


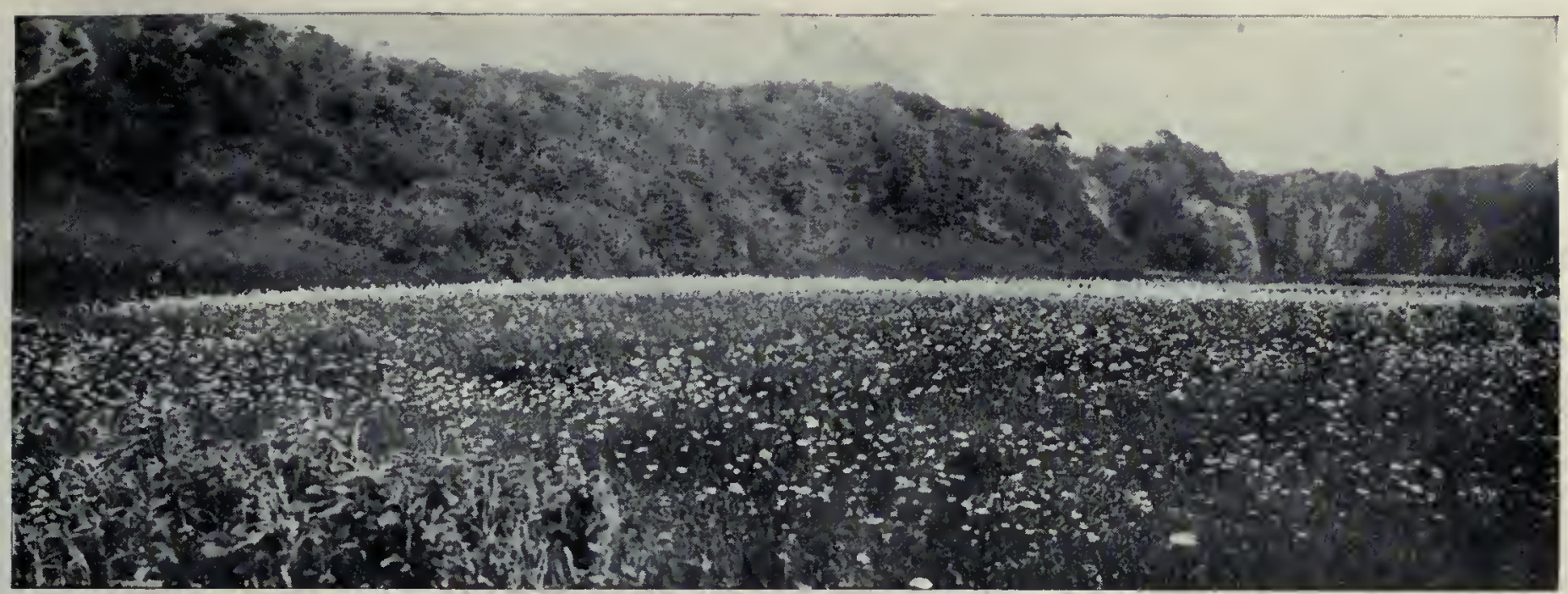

Prairies dans la valtée de la Belle-Rivière (Miquelon).

arrive plus aisément et le sous-bois se développe. Lorsque les clairières se parent au premier printemps, on y peut voir fleurir des plantes bulbeuses comme les Safrans ou Crocus; elles peuvent former les prairies sèches avec toute la légion des Graminées : Paturins, Ivraies, Flouves, Avoines, etc., ou les prairies humides, avec les Cypéracées et Joncacées: Laiches, Souchet, Ériophore, Clade et Joncs. Le long des rivières, on rencontre une flore spéciale de grandes Graminées et Cypéracées aquatiques : Phragmite commun et Scirpe lacustre.

Un autre type de végétation que l'on rencontre dans la flore boréale est celui des hautes montagnes, avec certaines plantes caractéristiques, comme l'Edelweiss. Concentrées sur les grandes chaînes, comme les Alpes, les Pyrénées et les Montagnes Rocheuses, ces espèces se répandent peu à peu, à mesure que l'on va vers le Nord, en Scandinavie, en Sibérie, et dans l'Alaska, dans l'Amérique du Nord. Au-dessous des prairies alpines, on observe la zone subalpine avec les Rhododendrons ferrugineux et hirsute; on retrouve plus bas sur les pentes des montagnes de l'Europe centrale la flore forestière, qui débute par la zone des Conifères.

D'autres variations sont à mentionner dans le domaine forestier

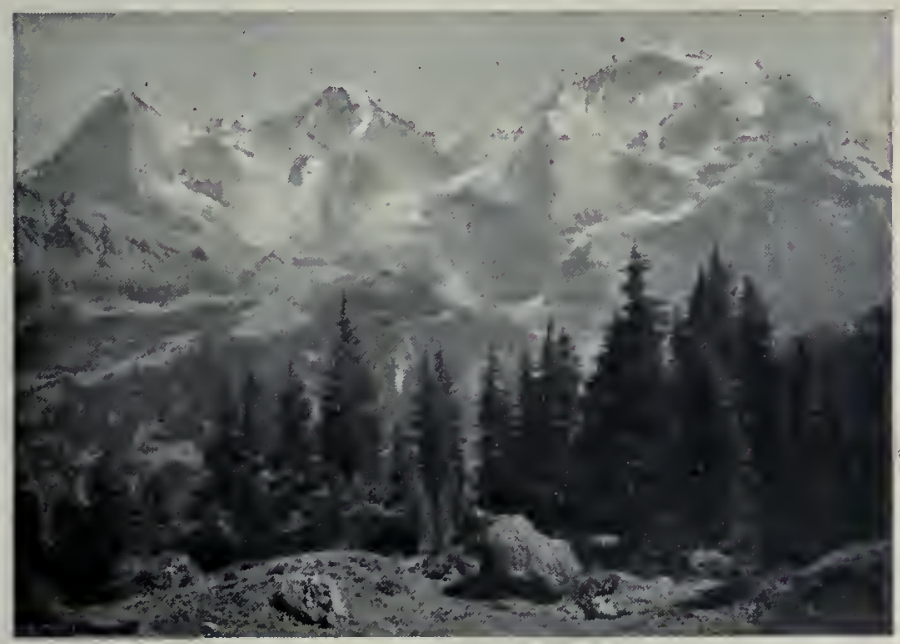

Forêt de montagne dans l'Oberland.

Cl. Wehrli.

proprement dit. Quand une rivière traverse une région humide, non seulement les lianes peuvent devenir plus nombreuses, mais les épiphytes peuvent apparaítre en petit nombre. Le long de la Trave, en Allemagne, les vieux Saules hébergent une fore adventice formée de plantes à graines légères transportées par le vent (Achillée millefeuille, Laiterons, Épilobes, Rumex), ou à fruits charnus transportés par les oiseaux ou les autres animaux, comme les Fraisiers, les Chèvrefeuilles, etc.

C'est là un fait très exceptionnel et très intéressant car, en règle, les épiphytes font presque complètement défaut dans les pays froids. Ils ne sont représentés que par quelques Mousses, Hépa-

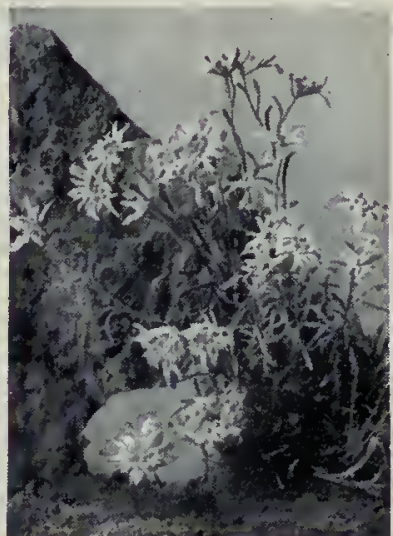

Edelweiss

(Gnaphalium Leontopodium). tiques et Lichens. Quant aux parasites, nous ne les connaissons que par le Gui et la Cuscute.

Adaptation aux variations saisonnières. - Si nous nous arrêtons aux caractères de la végétation arborescente, qui constitue le fond de la végétation du domaine forestier, on voit qu ils dépendent à la fois du froid de l'hiver et de la chaleur de l'été. Pendant l'hiver, l'arbre se dépouille, mais son tronc reste exposé aux intempéries et son écorce épaissie, rugueuse, crevassée, est bien propre à supporter, grâce à sa couche épaisse de liège qui constitue un véritable matelas d'air, un abaissement inusité de température. La

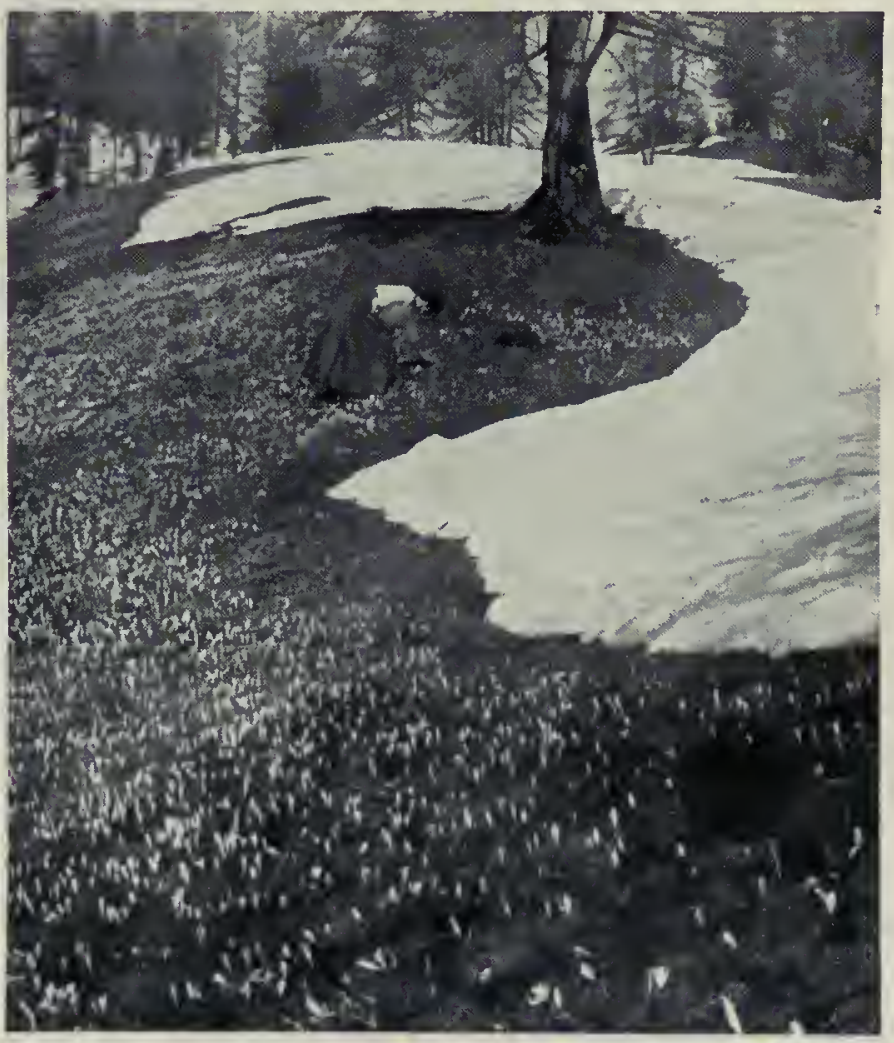

Les Crocus au printemps, en Suisse. 


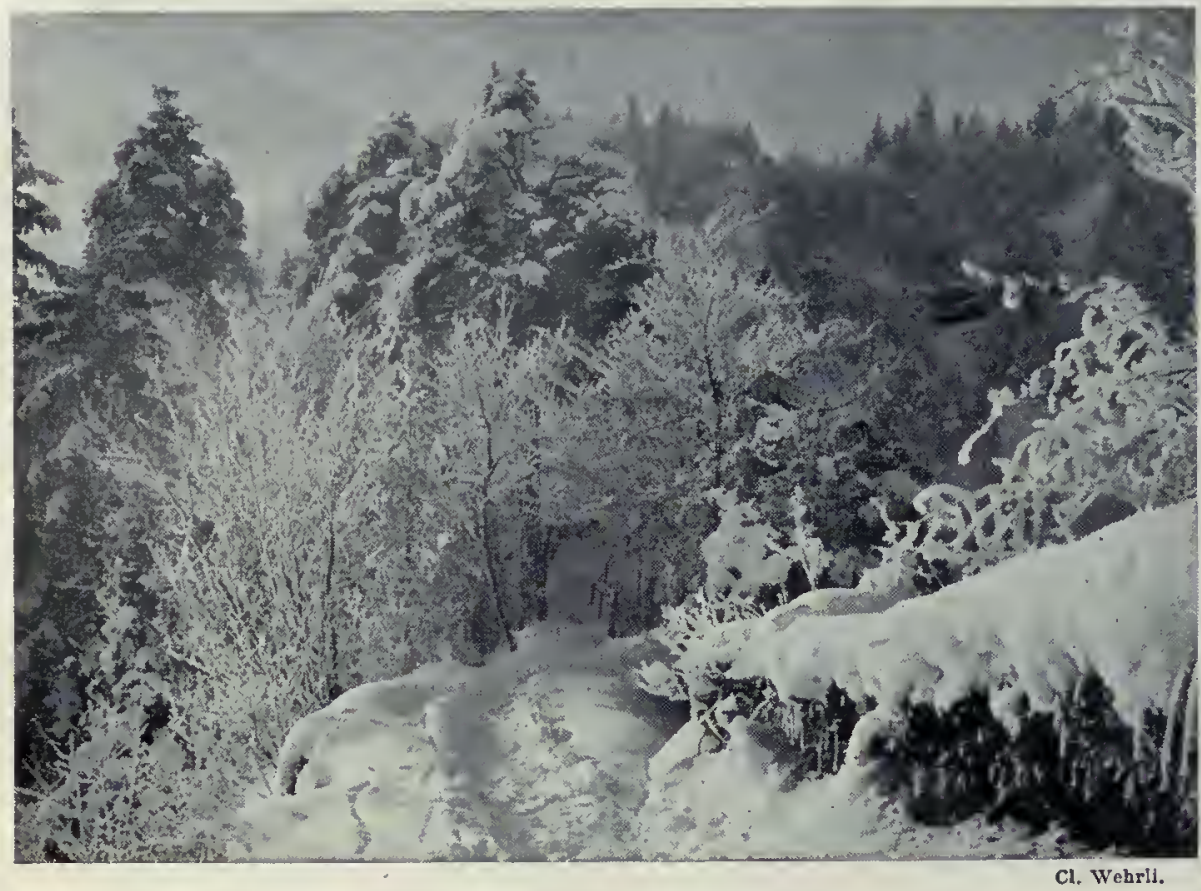

La neige et te givrc en forêt de montagne.

nord. Les parties continentales de l'hémisphère sud, où des conditions semblables se rencontrent, sont beaucoup plus restreintes et la zone forestière est limitée à la pointe sud de l'Amérique du Sud. Ce sont surtout des Hêtres qui abondent dans cette contrée, mais, assez communément, ils ont des feuilles persistantes, particularité liée à l'étroitesse et à l'extrême humidité de la pointe de l'Amérique du Sud, comprise entre deux grands Océans. A mesure que l'on va plus au Nord, le climat devient plus sec et les Hêtres à feuilles caduques apparaissent : tel est le cas du Nothofagus pumilio, représenté sur une photographie cicontre ; on remarque, en l'examinant, qu'il y a un parasite sur les branches, mais qui est spécial à cette région : c'est le Myzodendron. On voit un certain nombre de Hêtres de la Terre de Feu s'avancer au Chili jusqu'à $35^{\circ}$ de latitude : là on note un mélange d'espèces qui ont perdu leur feuillage persistant et d'autres qui l'ont gardé. Le Nothofagus obliqua et le $N$. procera ont un feuillage caduc au Chili, tandis quils sont toujours verts dans les forêts antarctiques. Une autre espèce, le $N$. Dombcyi, qui a ses feuilles toujours vertes dans les pays froids, garde ce caractère dans les régions plus tempérées. On conçoit également comment il peut arriver qu une plante

protection des bourgeons est également efficace et les matières gommeuses et la résine qui les couvrent, l'absence de stomates, sont évidemment propres à supprimer la transpiration en une saison où les racines ne fonctionnent pas, où la sève circule mal, et où toute cause qui tendrait à la mettre en mouvement porterait le plus grand trouble dans la plante.

Si pendant l'hiver le végétal redoute toute cause qui produirait la transpiration, il n'en est pas ainsi pendant l'été, et la délicatesse des feuilles ainsi qu'une série de particularités de leur structure sont bien en harmonie avec ces besoins. Ainsi donc, les arbres à feuilles caduques doivent concilier, pour ainsi dire, deux besoins opposés : transpirer beaucoup pendant l'été, transpirer très peu pendant l'hiver. Les arbres à feuilles persistantes, comme les Houx, les Conifères, ont un problème plus délicat à résoudre, car ils gardent leurs feuilles pendant l'hiver; ils n'échappent à ce danger qu'en épaississant et en durcissant la cuticule, grâce à laquelle ces végétaux diminuent fortement la perte d'eau pendant l'arrêt de la végétation. Cependant, la présence de feuilles, même très étroites, pendant l'hiver, permet l'accumulation des neiges et du verglas,

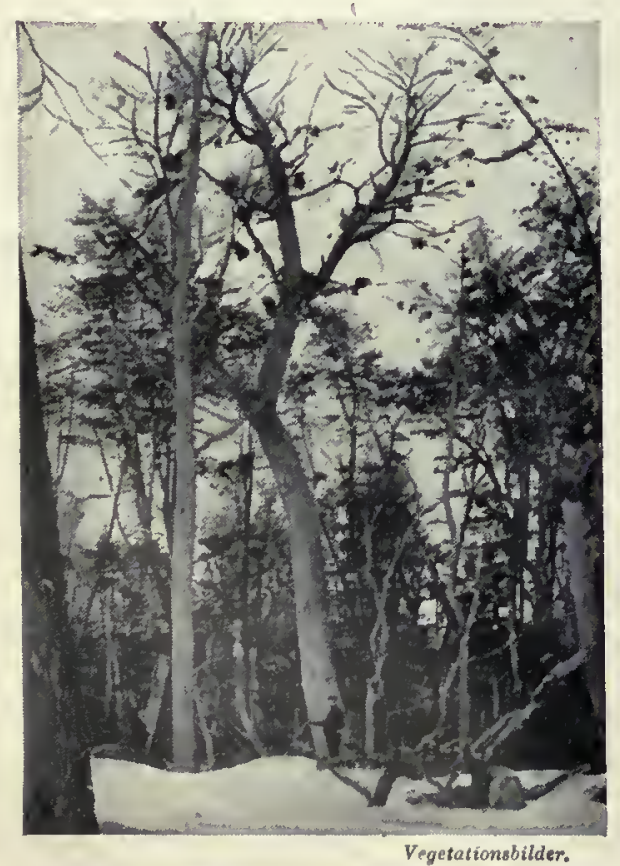

Hètres de la Terre de Feu

(Nothofagus pumilio) avec parasites (Myzodendron punctatum). sous le poids desquels les branches peuvent se rompre; danger rendu minimum précisément par l'étroitesse des aiguilles foliaires.

Le domaine forestier peut être envahi, non seulement par des espèces polaires dans les parties froides, mais aussi par les plantes de pays plus chauds: c'est la flore adventice ; on a signalé, notamment, 11 pour 100 d'espèces localisées surtout dans le domaine méditerranéen.

Forêts aus. trales. - Il y a donc une harmonie marquée entre l'arbre et le milieu où il se développe, dans l'hémisphère comme le $N$. antarctica, qui se dépouille de son feuillage au Chili, le perde également dans les forêts antarctiques. On explique ceci en disant que les arbres à feuilles persistantes ont leur centre de formation dans le Sud; les espèces à feuilles caduques, leur centre de différenciation dans le Nord.

Darwin a donné de l'aspect désolé des forêts de la Terre de Feu cette belle description : "Tout d'abord, c'est à peine si je puis faire quelques pas à cause des cataractes et des nombreux troncs d'arbres tombés qui barrent le passage; mais le lit du torrent sélargit bientôt, les inondations ayant emporté les bords. J'avance lentement pendant une heure en suivant les rives rugueuses et déchiquetées du torrent, mais la grandeur et la beauté du spectacle compensent bientôt toutes mes fatigues. La sombre profondeur du ravin concorde bien avec les preuves de violence que l'on remarque de toutes parts. De chaque côté, on voit des masses irrégulières de rochers et des arbres déracinés; d'autres arbres, encore debout, sont pourris jusqu'au couur et prêts à tomber. Cette masse confuse d'arbres bien portants et d'arbres morts me rappelle les forêts des tropiques, et cependant il y a une profonde différence : dans ces tristes solitudes, que je visite actuellement, la mort, au lieu de la vie, semble régner en souveraine. Le pays entier n'est qu'une énorme masse de rochers sauvages, de collines élevées, de forêts inutiles, le tout enveloppé de brouillards perpétuels et tourmenté de tempêtes incessantes. La terre habitable se compose uniquement des pierres du rivage. " Cette citation est bien propre à faire comprendre quelle impression profonde certains types de la végétation peuvent faire sur l'esprit de l'homme; elle met en lumière d'une façon saisissante l'action du climat.

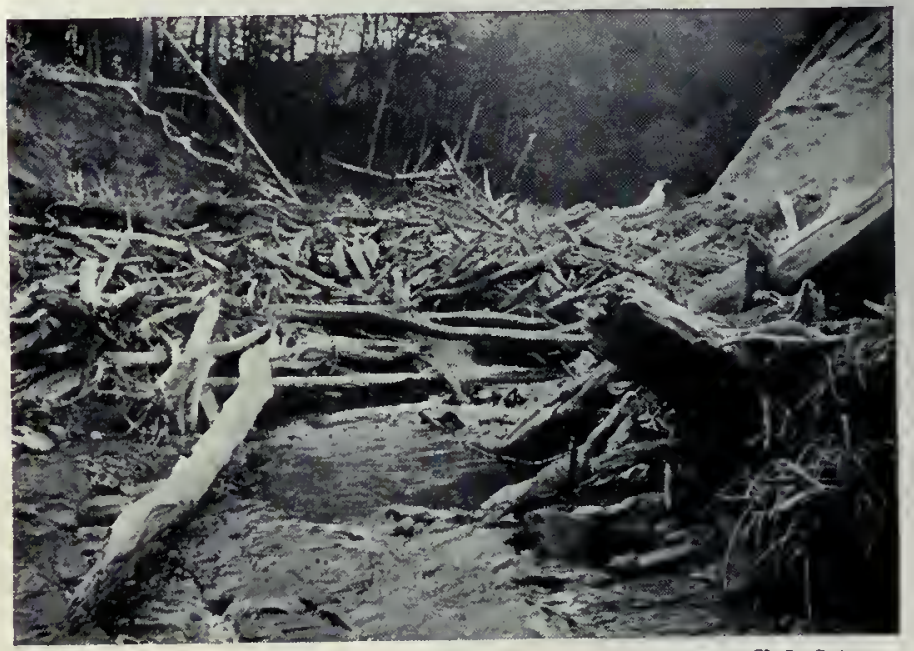

Cl. L. Gain.

Arbres entrainés par un torrent, près Punta Arenas (Chıli). 


\section{FLORE MÉDITERRANÉENNE}

Climat, caractères généraux de la flore. - Les bords de la Méditerranée sont caractérisés par un climat marin très spécial et très doux, qui diffère notablement de celui des contrées septentrionales de l"Europe; il se distingue par la brièveté de l'hiver, où le froid n'est, en général, pas persistant, sauf dans les pays montagneux, et par les pluies qui y sont fréquentes; la période chaude dure de huit à dix mois et la saison très chaude souvent de trois à cinq, et sans pluies. A ce domaine floral se rattachent trois régions assez distinctes: $1^{\circ}$ les îles et les côtes de l'Atlantique, les Açores et les Canaries qui, par suite de l'influence de la mer, ont un climat beaucoup plus uniforme; $2^{\circ}$ la zone méditerranéenne proprement dite, qui comprend tout le pourtour de la Méditerranée; $3^{\circ}$ la région qui s'étend à l'est de Damas, où les pluies sont beaucoup plus faibles $(20$ centimètres par an) : ce sont les steppes de l'Iran, qui font passage aux steppes de l'Asie centrale. Cet ensemble constitue un domaine très riche, avec 7000 plantes vasculaires, dont 4200 sont propres à cette région.

C'est le pays des plantes ligneuses de pays secs et toujours vertes; c'est la patrie de l'Olivier, de l'Oranger, du Laurier, du Chêne-liège, du Grenadier. Le Palmier nain ou Chamærops croît spontanément à Nicc et correspond à la limite nord de la famille des Palmiers en Europe $\left(44^{\circ}\right)$.

Les caractères de la végétation sont partout les mêmes: les arbres ne sont pas en général très élevés; leur tige est massive, leurs branches noueuses; leurs feuilles sont, d'ordinaire, fermes, entières, lancéolées ou linéaires, quelquefois très étroites, comme celles des Bruyères arborescentes. Les plantes tout à fait charnues, succulentes, sans feuilles, sont rares et, sil y a quelques Cactées, ce sont des plantes souvent acclimatées, comme les Opuntia ou Figuiersde Barbarie, qui sont d'origine américaine et propagées partout. Les lianes ligneuses à tige toujours mince n'abondent pas; les lianes herbacées sont, au contraire, plus répandues. Les plantes dressées herbacées sont rares et n'offrent rien de bien caractéristique. Les Mousses et les Lichens, sur l'écorce des arbres, manquent presque complètement, ainsi que les épiphytes appartenant aux Phanérogames.

La végétation est interrompue deux fois, d'une manière irrégulière : par le froid de l'hiver et par la sécheresse de l'été, et il ny a que de courtes périodes pendant lesquelles se rencontrent à la fois les conditions, optimales de température et d'humidité; en général, il y a séparation de ces deux facteurs.

Maquis, garrigue. - Le nombre des arbrisseaux toujours verts est considérable, et les buissons, qui constituent ce qu'on appelle le maquis, sont certainement les plantes les plus caractéristiques de cette flore. Là prédominent les Arbousiers, qui sont parés simultanément de leurs fleurs et de leurs fruits rouges et hérissés de petites aspérités qu' on a comparées, un peu à tort, à des fraises; là, se rencontrent le Pistachier Lentisque, les Bonnets d'évêques, les Bruyères arborescentes, Daphnés, Cistes, Oxyrides, etc.

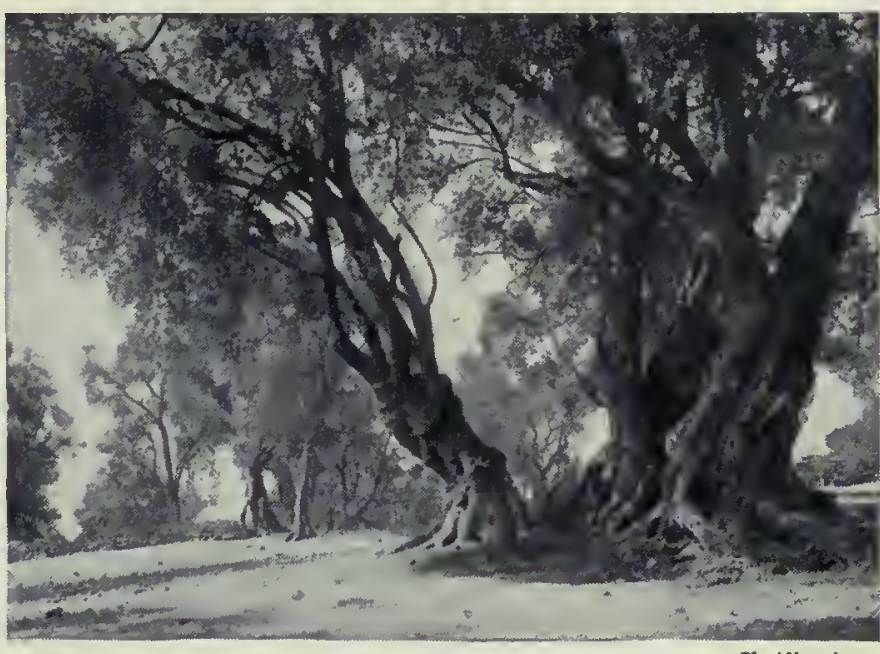

Bois d'Oliviers aux environs de Rome.

Le maquis proprement dit, dont on a une bonne idée en Corse, où il sert de refuge aux réfractaires à la loi, se rencontre surtout sur terrain siliceux. On le considère comme le sous-bois de forêts primitives qui ont disparu, sauf en quelques régions. C'est sur ce sol siliceux que l'on rencontre, dans le sud de la France, le Chêneliège et le Pin d'Alep. Lc Pin Pignon se rencontre çà et là sur terrain sablonneux; le Pin Laricio est aussi une espèce caractéristique de la flore méditerranéenne. Le maquis s étend quelquefois sur de très vastes espaces, avec une constitution très monotone : en Espagne, il est formé de Cistes; ailleurs, dans l'est de l'Europe, de Pistachiers Lentisques.

Dans les garrigues, qui s'observent dans le midi de la France, la végétation est plus basse encore et se développe surtout sur le terrain calcaire; là encore, on y voit les restes de forêts où le Chêne-Houx et le Pin d'Alep prédominaient. Le type principal de végétation est celui dont l'Olivier nous fournit un exemple important. Arbuste à l'état sauvage, en Orient, il est devenu par la culture dans tout le bassin méditerranéen un arbre massif, à tige ramifiée à une faible hauteur, à branches noueuses, à écorce épaisse, profondément fendue; il est caractérisé surtout par ses feuilles dures, petites, étroites, entières, à bords recourbés, qui, au-dessus, sont pileuses d'une manière éparse et d'un vert mat, mais qui, en dessous, ont des poils écailleux et un aspect argenté brillant. $\mathrm{Ce}$ type à feuilles dures entières se retrouve dans beaucoup d'autres plantes, dans les Chênes notamment, comme le Chêne-Houx, le Chêne-liège.

Les feuilles sont un peu plus grandes et verticillées dans le Laurier-rose et opposées dans les Lauriers, qui croissent aux Cana-

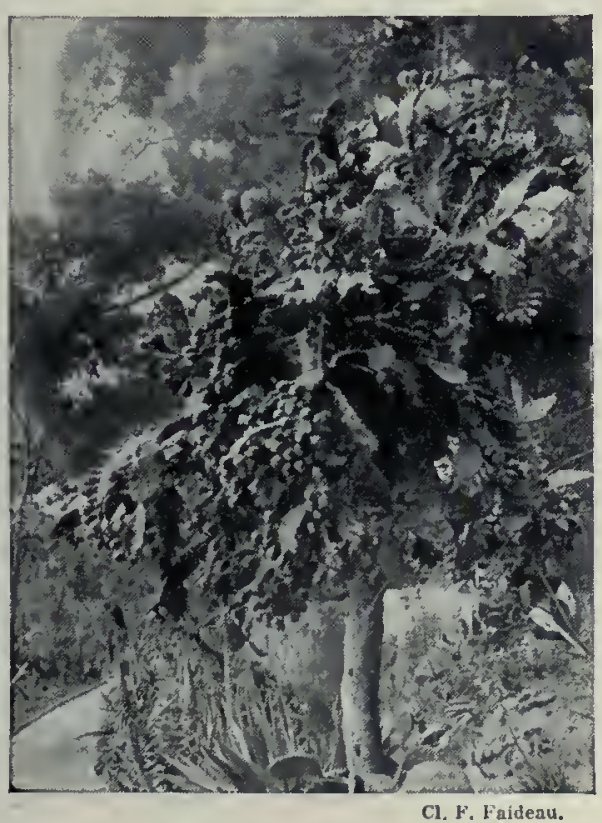

Opuntia monacantha (Monaco).

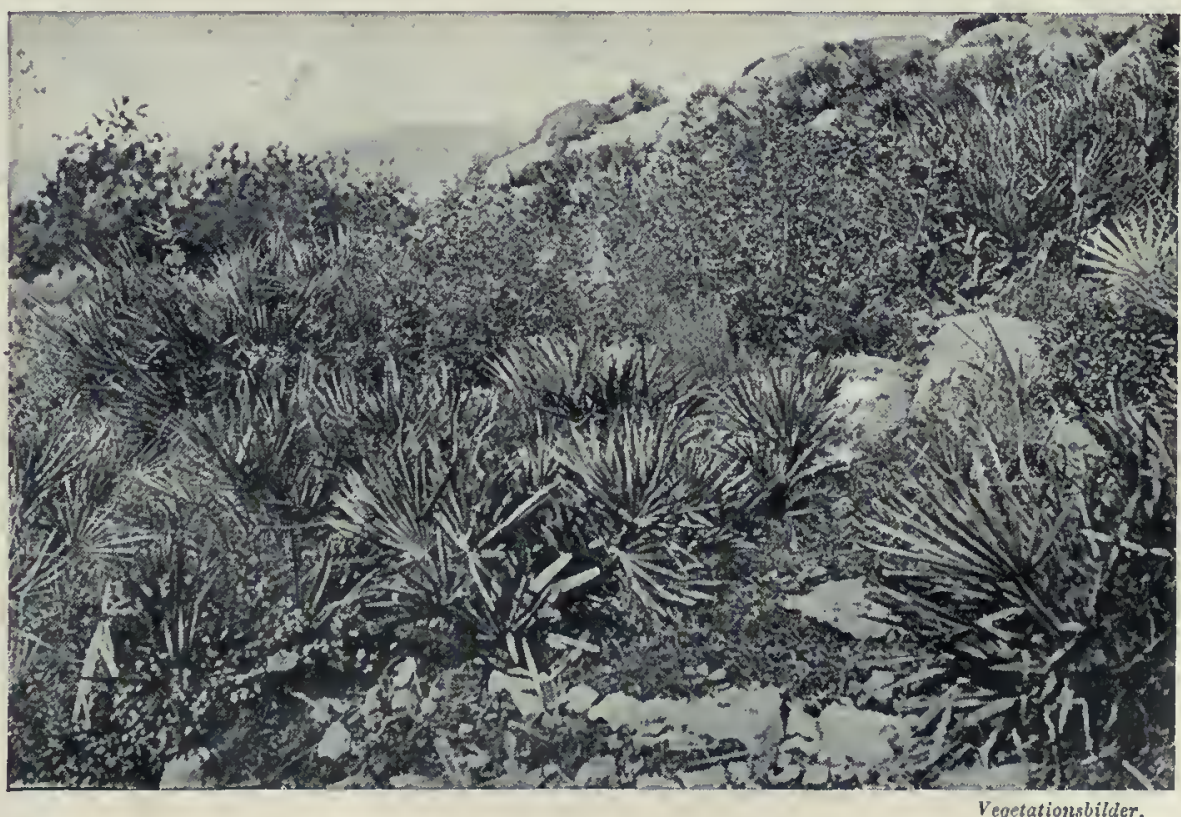

Chamcerops humilis et Pistacia Lcntiscus (Garrigues des Baléares). 


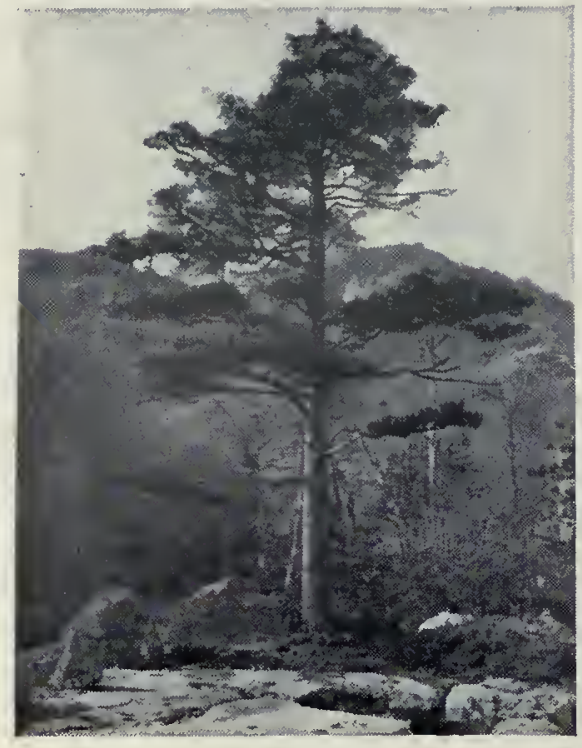

Pin Laricio (Corse).

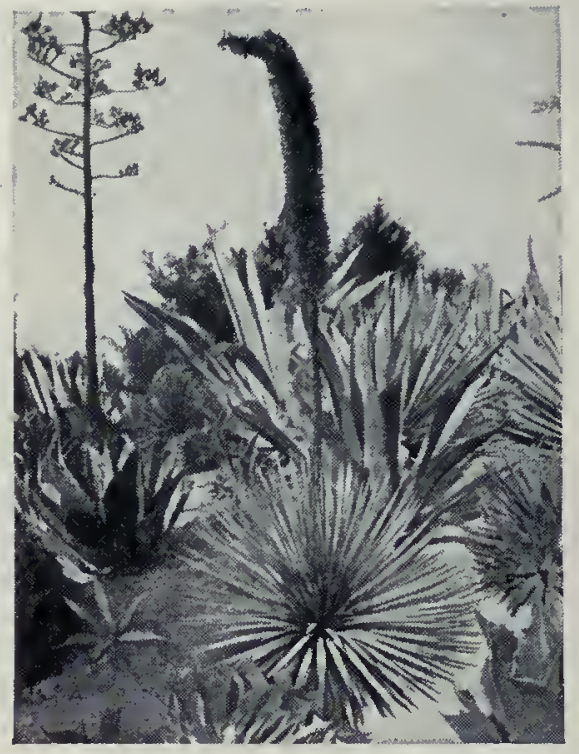

Eremurıs spectabilis (Espagne).

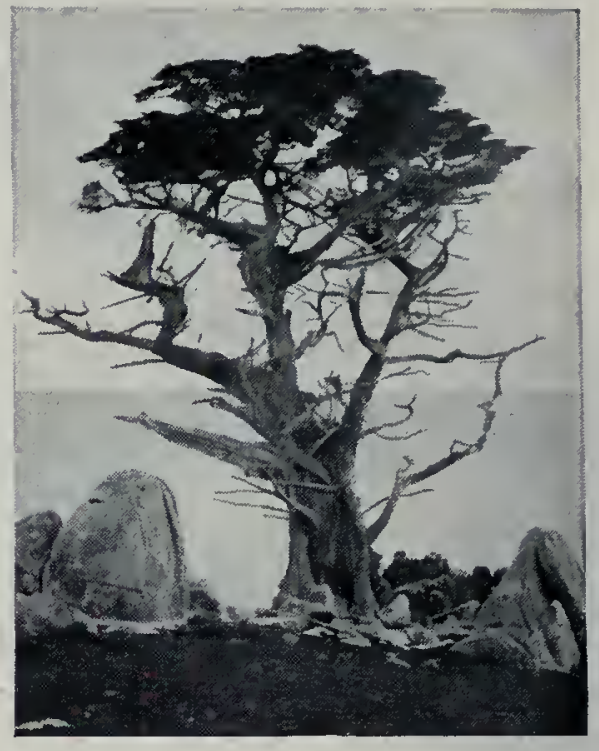

Cl. Faber.

Cyprès à gros fruits (Californie). ries. Aux îles Madère et aux Canaries, un arbre bien caractéristique est le Dragonnier.

Une autre plante typique du maquis est le Myrte commun, avec ses petites feuilles raides. Ces limbes étroits aromatiques se rencontrent aussi dans le Romarin officinal, la Lavande, le Thym vulgaire. Les feuilles presque en aiguilles sont caractéristiques des Bruyères, parmi lesquelles on peut signaler la Bruyère en arbre, la Bruyère de Portugal, etc. Un type rare est, au contraire, celui à feuilles composées pennées que l'on rencontre dans le Pistachier Lentisque. Comme plante grimpante par des vrilles stipulaires, on peut citer le Smilax âpre, aux feuilles persistantes et dures.

Enfin, la région méditerranéenne est extrêmement riche en plantes bulbeuses et tuberculeuses : c'est le royaume des Tulipes, des Narcisses, des Asphodèles, des Eremurus, des Muscari, des Glaïeuls, des Anémones. Là aussi abondent les Ophrys, les Orchis, les Arum ou Gouets.

Parmi les représentants d'un autre domaine, on peut rencontrer par exemple les Peupliers, les Frênes et autres arbres à feuilles caduques, qui s'observent seulement dans le voisinage de l'eau et dans un sol toujours humide; les Châtaigniers se montrent dans les contrées un peu montagneuses, au-dessus de l'Olivier.

Les Graminées annuelles abondent, tandis que les vivaces, très répandues dans le domaine forestier, sont ici assez rares.

Flore de Californie. - Le nord de la Californie forme une région dont le climat est très analogue à celui du domaine méditerranéen dans la zone maritime; on y trouve un hiver doux, des pluies assez abondantes, en février, et surtout les courants marins du Pacifique, venant du Nord, empêchant l'été d'être trop ardent.

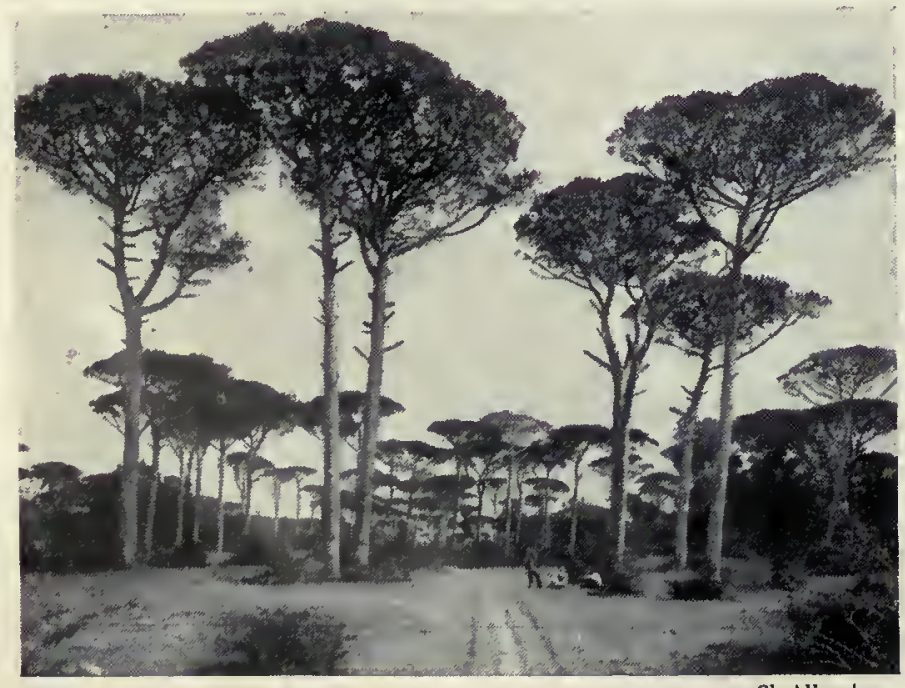

Pins pignons de la pineta de Ravenne.
C'est une contrée beaucoup plus restreinte que la région méditerranéenne; aussi ne devons-nous pas nous étonner dapprendre qu'elle ne comprend que mille espèces vasculaires spéciales.

Les buissons toujours verts y prédominent, au milieu desquels s'élèvent des arbres rares et isolés. Parmi les plus importants de ces derniers, on peut citer le Chêne à écailles dorées. Là encore dominent ces plantes toujours vertes, à feuilles dures, entières ou à dents épineuses au bord, comme le Prunier à fecuilles de houx, qui se rencontre sur les collines; les Ceanothus cuneatus, buissons de 2 mètres de haut, à fleurs blanches ou bleues en glomérules allongés denses. Les plantes grasses sont ici plus abondantes que d'ordinaire dans les domaines semblables et elles sont représentées par diverses Cactées.

Sur les pentes des régions montagneuses, là où les pluies deviennent plus abondantes, le sol se couvre de hautes forêts qui sont formées principalement de l'arbre au bois rouge ou Séquoier toujours vert, l'arbre Mammouth, ou d'un autre type analogue, le Wellingtonie gigantesque, dont l'aire est plus restreinte que celle de la précédente espèce; le sous-bois est composé de buissons à feuillage dur. Près de la mer, à San Francisco, dans les endroits découverts et très ensoleillés, se développe au milieu des rochers le Cyprès à gros fruits.

L'on désigne au Texas, sous le nom de chaparals, des prairies avec des buissons épineux. Parmi les plantes de cette région, on peut citer le Noyer nain, le Cercis occidental.

Dans un domaine qui s'étend sur de vastes territoires, il y a nécessairement des variations secondaires de climats. A côté des arbrisseaux à feuilles persistantes, il peut s'en rencontrer d'antres à feuilles caduques. Il peut y avoir des passages aux steppes, et les buissons épineux, les Salsolacées, les herbes vivaces et les plantes bulbeuses abondent. Si la contrée est arrosée par des pluies plus abondantes, les herbages à Graminées annuelles se multiplient, avec les Labiées et Composées odorantes et aromatiques.

Flore du Chili. - Dans l'Amérique du Sud, au Chili, on retrouve une flore homologue des deux précédentes; cela se concoit, car le climat est tout à fait comparable à celui de l'Espagne méridionale ou de la Sicile : cette similitude des conditions ambiantes se manifeste d'ailleurs par la facile acclimatation des plantes de la région méditerranéenne, comme l'Olivier, l'Oranger, etc. Un Palmier, le Jubéa remarquable, est à mentionner, car c'est l'espèce qui correspond à la limite méridionale de la famille des Palmiers dans l'Amérique du Sud ( $37^{\circ}$ de latitude australe). Il y a un certain nombre d'épiphytes dans la flore chilienne, notamment des Broméliacées et des Orchidées. On y trouve des Composées arborescentes et quelques Cactées. Ces dernières particularités tiennent évidemment à la forme du continent, dont les montagnes, orientées parallèlement à l'Océan, permettent l'extension au loin des espèces désertiques et épiphytes. Il y a lieu de remarquer les affinités de la flore littorale chilienne avec la flore littorale californienne; certaines espèces sont mêmes identiques dans les deux régions: Acène pinnatifide, Collomie grêle. 


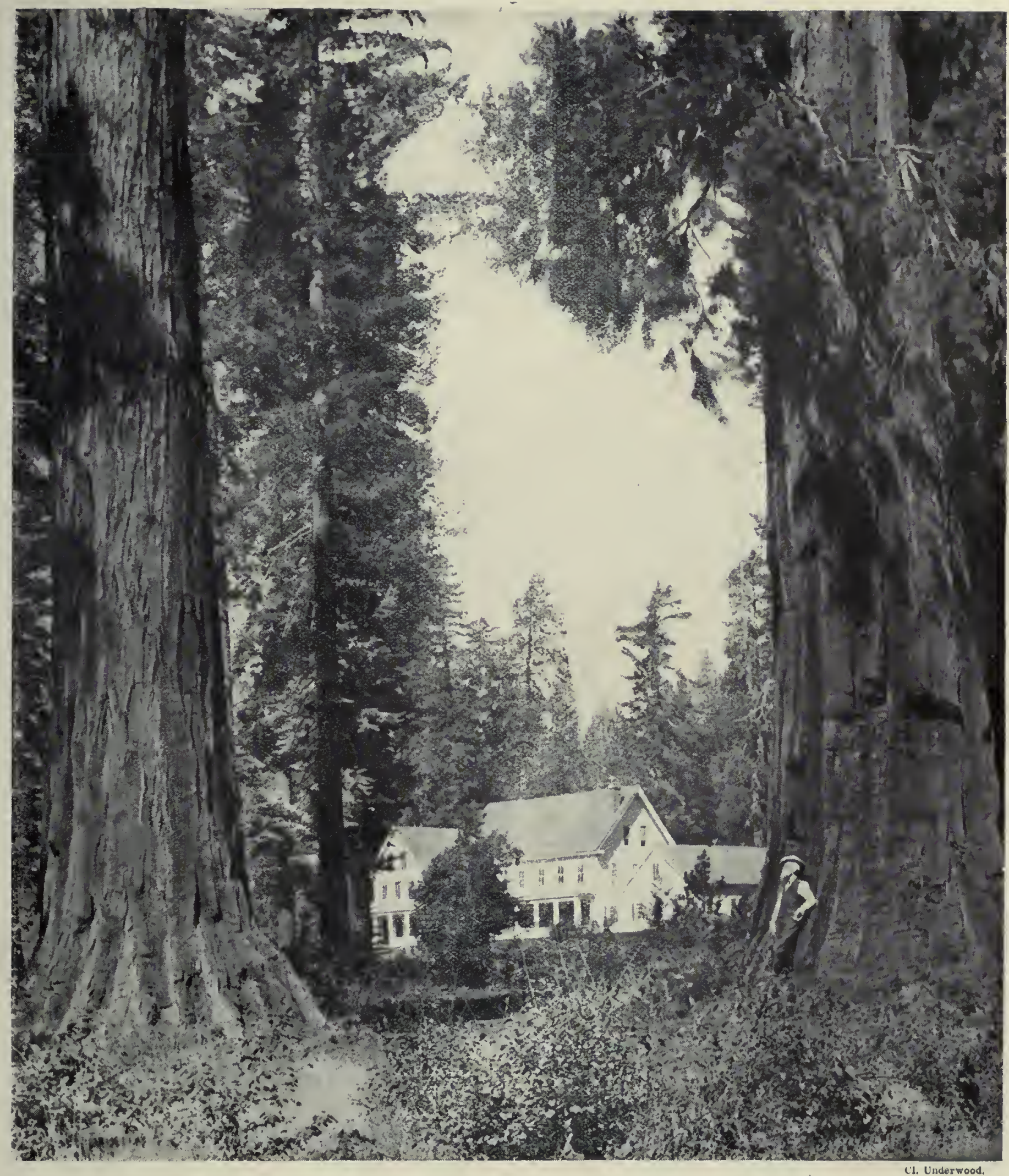

HOTEL DANS UNE FORET DE SEQUOIA GIGANTEA (CALIFORNIE). 



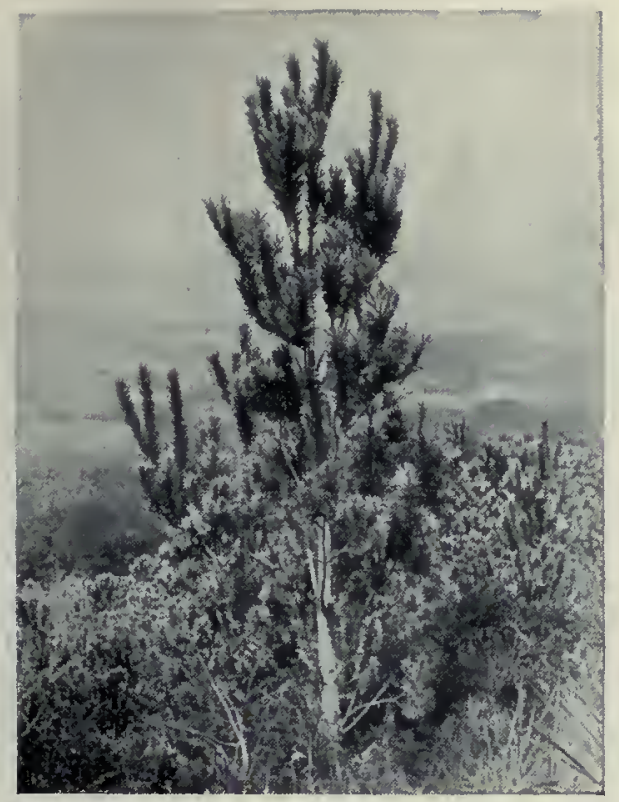

Protea argenté du Cap.

Flore du Cap. - Comme la flore du Chilj correspond, en Amérique, à celle de la Californie, de même, en Afrique, celle du Cap présente de grandes ressemblances avec celle de l'Afrique du Nord ou méditerranéenne. C'est une contrée d'une extrême richesse, qui renferme de très nombreuses plantes ornementales: on y compte huit millie espèces, dont beaucoup ont été introduites dans les jardins : Pélargonium, Bégonia, etc.

Ce qui la caractérise, c'est la prédominance des Bruyères en arbre et des plantes arborescentes rappelant les Myrtes et les Lauriers. Les affinités du nord et du sud de l'Afrique se trahissent, au point de vue de la végétation, par la présence d'un certain nombre de genres : Othonna, Hélichryse, communs à ces deux contrées. Il y a, d'ailleurs, d'autres affinités se manifestant avec la flore de l'Afrique tropicale, en particulier avec celle de Natal. D'autre part, il y a une analogie frappante avec la flore de l'Australie méridionale, et la présence d'une Protéacée, le Protea argenté, manifeste bien cette particularité, car cette famille est surtout abondamment représentée dans la grande île océanienne.

Flore sino-japonaise. - Il est enfin une dernière flore qui doit être mentionnée à côté de celles qui précèdent, c'est la végétation du Japon et de la Chine orientale. Le climat, cependant, présente certaines particularités qu'il ne faut pas négliger de signaler; il contribue à donner à la flore sino-japonaise des caractères un peu spéciaux : l'hiver est plus froid, surtout dans le Nord, de sorte qu'à certains égards ce domaine floral est intermédiaire entre la zone forestière et la zone méditerranéenne. D'autre part, la partie méridionale de ces contrées confine à des régions tout à fait

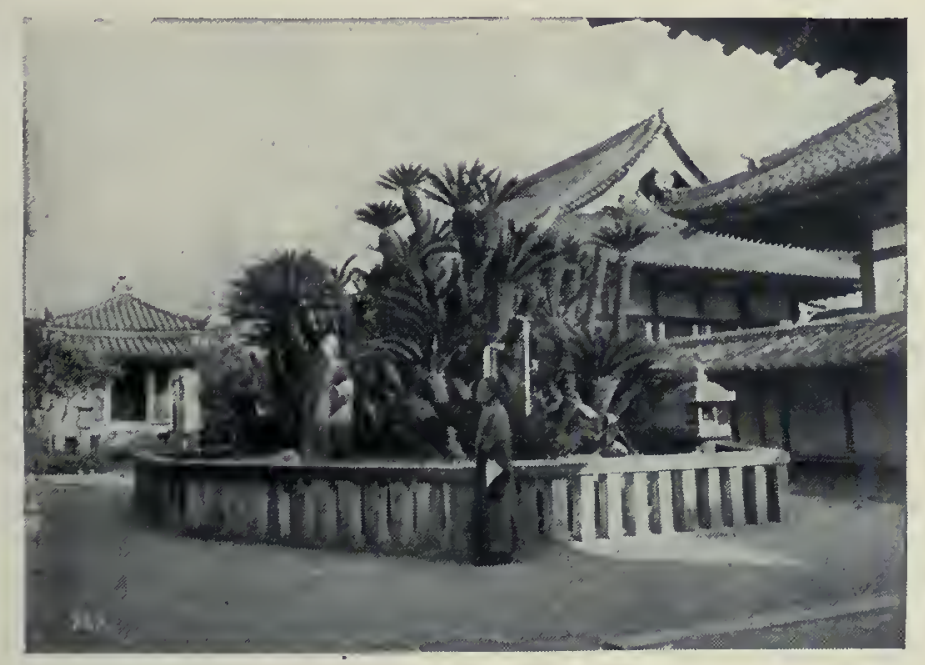

Cycas révolutés à Sakaï (Japon). chaudes et il n'y a pas lieu de s'étonner qu'on puisse observer des passages à la flore tropicale. Les différences avec la flore méditerranéenne s'accusent, notamment dans la comparaison des régions forestières : les espèces ligneuses représentent la moitié de la flore sino-japonaise, tandis qu'elles constituent seulement le cinquième de la flore méditerranéenne.

Les Gymnospermes sont particulièrement abondantes : non seulement il faut citer des Pins spéciaux (Pins chinois, de Bunge), mais aussi le Sciadopite verticillé, le Podocarpe de Chine et surtout le Ginkgo bilobé. Les Cycadées peuvent y prospérer, par exemple le Cycas révoluté et autres.

Les plantes Angiospermes sont nombreuses, avec beaucoup d'espèces à feuillage caduc appartenant à des genres bien connus dans les forêts de l'Europe : Hêtre de Siebold, Châtaignier japonais, Érables, Frênes, Tilleuls, etc.; il y a aussi des Planera, Platycarya, Carya, un grand nombre de Légumineuses et de $\mathrm{Ro}$ sacées en arbres.

A côté de cette végétation forestière, on y observe un grand nombre d'espèces dont le port est celui du Laurier et rappelle tout à fait la végétation méditerranéenne : le Camellia du Japon et l'arbre à Thé, le Cinnamome camphrier, le Néphèle Litchi, l'Aucuba du Japon, la Ketmie rose de Chine, le Broussonetia à papier ou arbre à papier, l'Aleurite à laque.

Les affinités avec la végétation tropicale s'accusent, surtout dans les parties méridionales du domaine sino-japonais, par la présence d'un certain nombre de Palmiers et de Graminées arborescentes ou Bambous. Les ressemblances de cette flore avec celle du domaine méditerranéen se montrent aussi avec celle de la Californie.

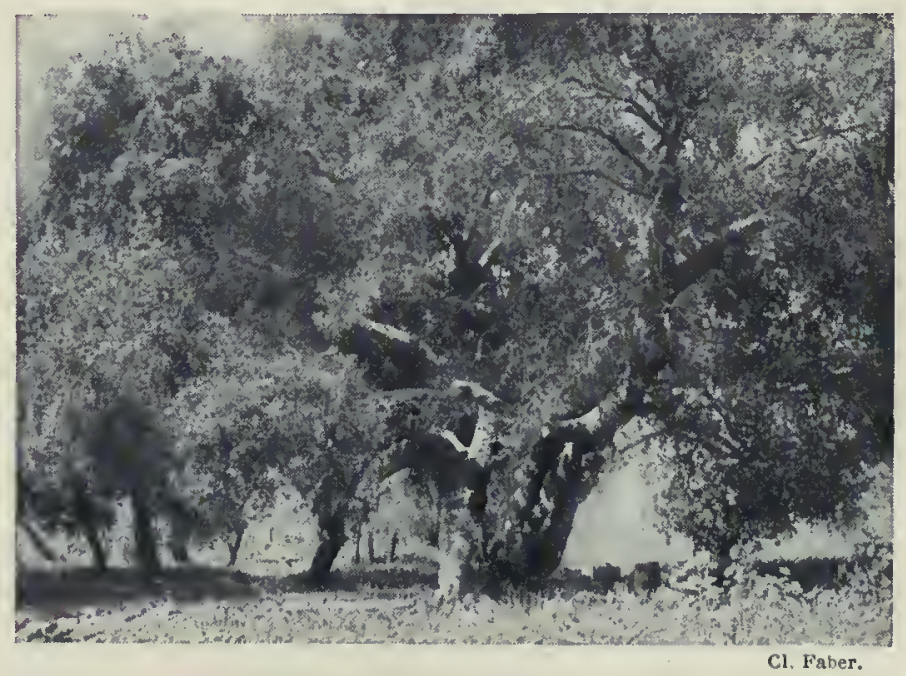

Chênes dorés de Californie. 


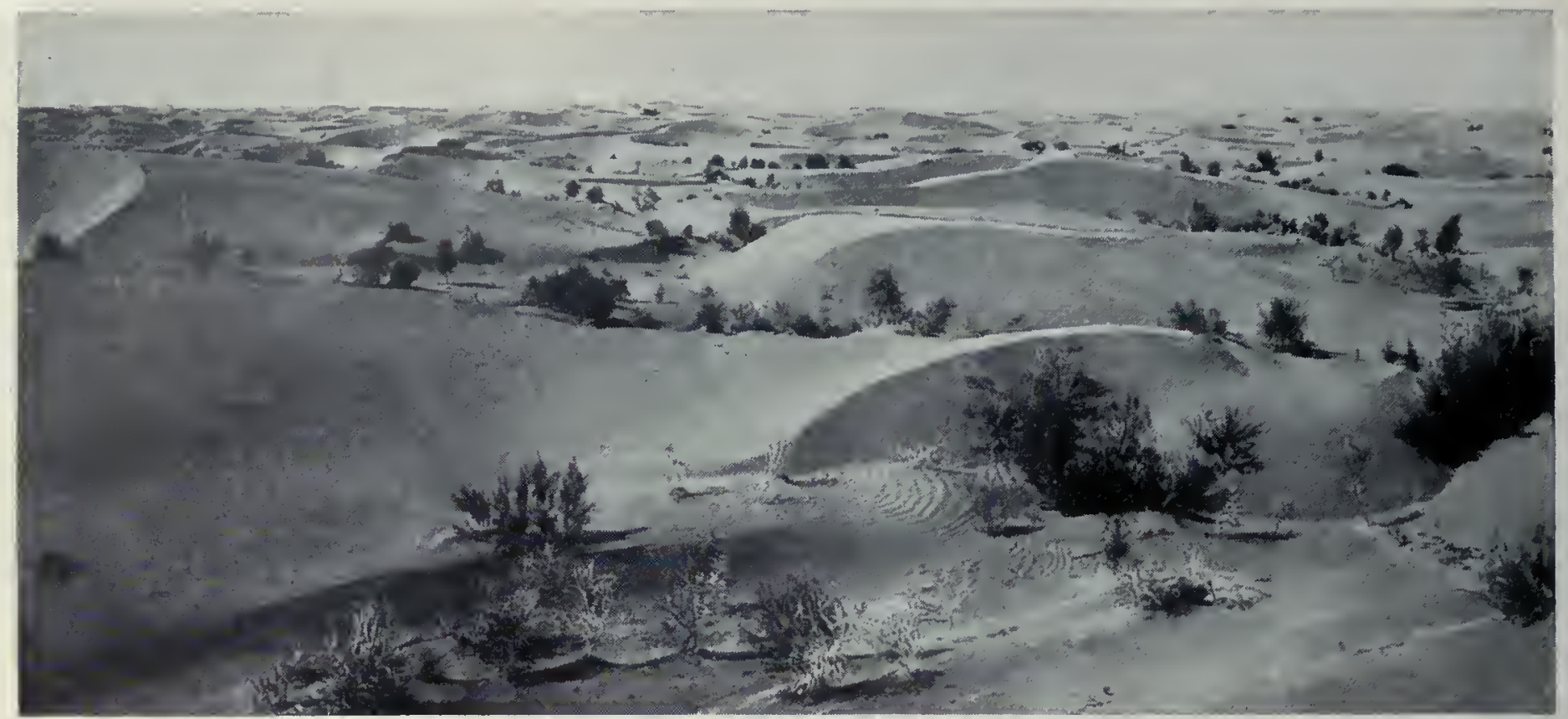

Dunes mobiles de la région de l'Amu Darja.

Vegetationsbilder.

\section{LE DÉSERT ET LES STEPPES}

Un autre aspect du globe, et non des moins importants, est celui dudésert, dont le Sahara africain est le type le plus remarquable et le plus étendu. Des régions désertiques se rencontrent en plusieurs autres parties du monde : le sud de l'Afrique nous offre le désert de Kalahari, caractérisé par le Welwitschia; en Asie, nous avons le désert de Gobi, du centre de la Chine, et le désert transcaspien, où il y a une région salée; enfin. l'Arabie. Le centre de l'Australie est aussi une région désertique; l'Amérique renferme également des déserts : d'abord, entre la sierra Nevada et les montagnes Rocheuses, l'Utah (avec une région à sel), l'Arizona, le sud de la Californie, puis la région désolée que l'on rencontre entre le Pérou et le nord du Chili.

Climat. - Dans tous ces pays, les pluies sont toujours très farbles et l'eau tombée annuellement ne dépasse pas 30 centimètres ; cest ainsi qu’à Copiapo, au Chili, on peut récolter I centimètre d'eau par an; 6 centimètres dans l'Arizona; 5 centimètres à Aden. Dans le Sahara, les pluies sont irrégulières; c'est surtout au printemps qu'elles prédominent. Le maximum d'humidité se manifeste en été en Australie, tandis qu'il a lieu en automne au Chili.
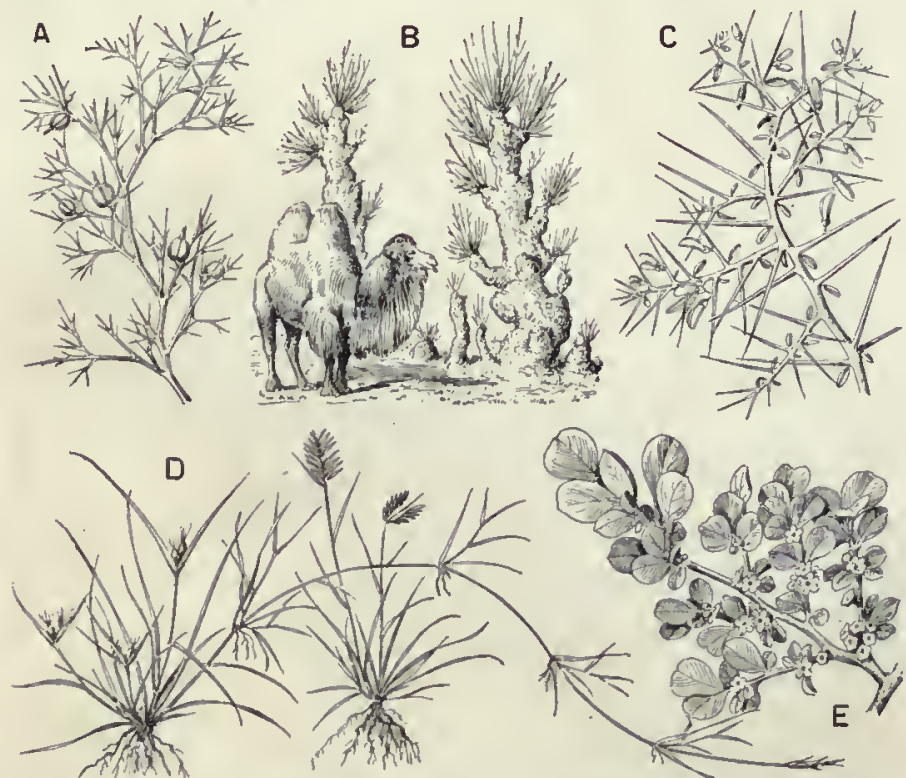

Fig. 112. - Plantes caracléristiques des déserts et des steppes. A, Zilla spinosa; B, Saxaoul (Haloxylon Hammodendrum):

C. Athagi Maurorum; D, Buffalo-Grass (Buchloe): E, Aizoon des Canaries.
Les quantités d'eau tombées au Caire, par exemple, sont les suivantes pour deux années consécutives d'observations :

\begin{tabular}{|c|c|c|c|c|c|}
\hline $\begin{array}{l}\cdots \\
\cdots\end{array}$ & $\begin{array}{l}6.4 \mathrm{~cm} . \\
8.3- \\
1.6- \\
0.5- \\
0.0- \\
0.0-\end{array}$ & $\begin{array}{r}3,9 \mathrm{~cm} . \\
4,4- \\
0,0- \\
6,2- \\
11,2- \\
1,2-\end{array}$ & $\begin{array}{l}\text { Report ... } \\
\text { Juillel .... } \\
\text { Aoûl. . . } \\
\text { Septembre. . } \\
\text { Octobre... } \\
\text { Novembre. . } \\
\text { Décembre... }\end{array}$ & $\begin{array}{l}16.8 \mathrm{~cm} . \\
0.0- \\
0.0- \\
0,0- \\
0.0- \\
0.1- \\
5.2-\end{array}$ & $\begin{array}{r}26.9 \mathrm{~cm} . \\
0.0- \\
0.0- \\
0.0- \\
0.0- \\
10.8- \\
4.8-\end{array}$ \\
\hline & & & & $\overline{20}$ & \\
\hline
\end{tabular}

C'est la quantité d'eau de pluie qui caractérise surtout ce climat : la sécheresse est parfois si grande que les lèvres se gercent, les ongles cassent comme du verre, les miroirs éclatent sous la pression de leur cadre. Les variations de température sont relativement étendues: elles atteignent plus de $50^{\circ}$.

Caractères de la végétation. - Le tableau précédent nous montre qu'au début de l'année les pluies sont assez fréquentes et il en résulte l'apparition d'une flore éphémère ou flore pluviale, qui disparaît peu après. Cette première végétation printanière est en partie formée de plantes annuelles qui ont une évolution rapide, qui fleurissent en peu de temps, donnent des graines et meurent dès que la période sèche commence. Telle est notamment la fameuse Rose de Jéricho (Anastatica de Jéricho), qui est susceptible, quand arrive la sécheresse, de se contracter en boule, mais sans rouler au loin dans le désert comme on le dit souvent, car elle est fixée par sa racine; elle s'étale en projetant ses graines quand arrive la pluie; aussi se développe-t-elle avec une rapidité merveilleuse quand la saison est favorable.

Dans aucune espèce du premier printemps, ni dans le Malcomia agyptiaca, ni dans le Matthiole livide, ni dans les Astragales, Composées, Borraginacées, Graminées, qui fleurissent avec promptitude à ce début de l'année, on ne voit apparaître aucun caractère indiquant une adaptation au climat sec. Ce sont simplement des espèces quelconques qui conviennent à ces régions par leur évolution rapide et qui réussissent, parce qu'elles peuvent fleurir et fructifier dans le minimum de tèmps. Évidemment ces espèces intéressent à ce point de vue l'horticulteur et, parmi elles, un certain nombre peuvent figurer dans les jardins où l'on désire avoir une floraison prompte.

A côté de ce premier groupe de végétaux, il y a à mentionner ceux qui, bien quannuels, durent un peu plus longtemps, mais qui sont nettement accommodés à la sćcheresse : la Ficoïde cristalline, l'Aizoon des Canaries ( $f$ g. $112, \mathrm{E}$ ), les Paronychiées, les Résédacées, les Crucifères. Il y a aussi quelques Dicotylédones persistantes, des Héliotropes, des Érodium et quelques plantes bulbeuses : par exemple, dans le Sahara égyptien, le Pancratium de Sickenberg, l'Urgine ondulé, l'Ail de Cramer, etc.

Sans doute ce n est pas seulement à cette flore printanière que servent les pluies du début de l'année, mais aussi aux végétaux 


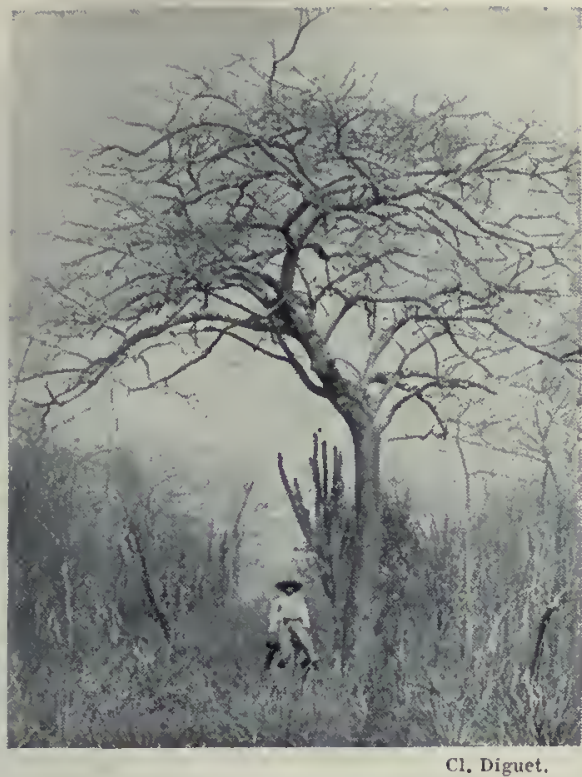

Pereskopuntia caliendriniafolia (Mexique).

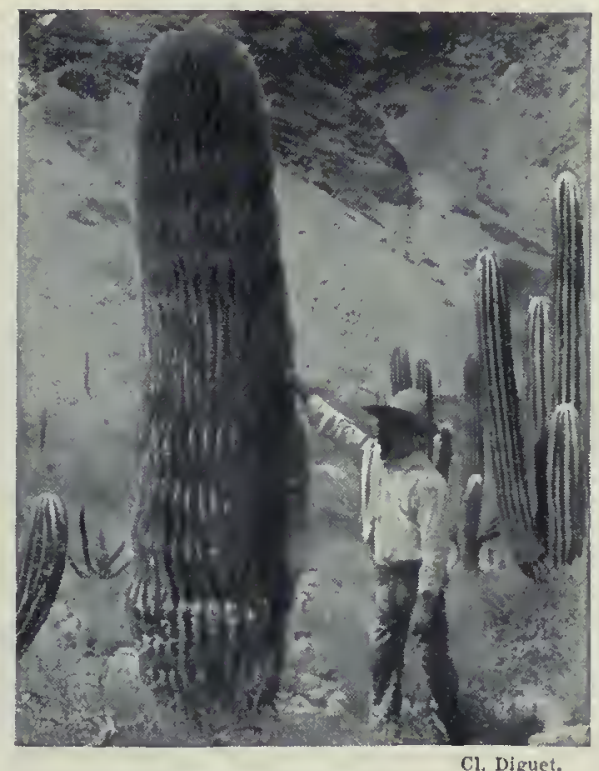

Echinocactus Digueti (Mexique).

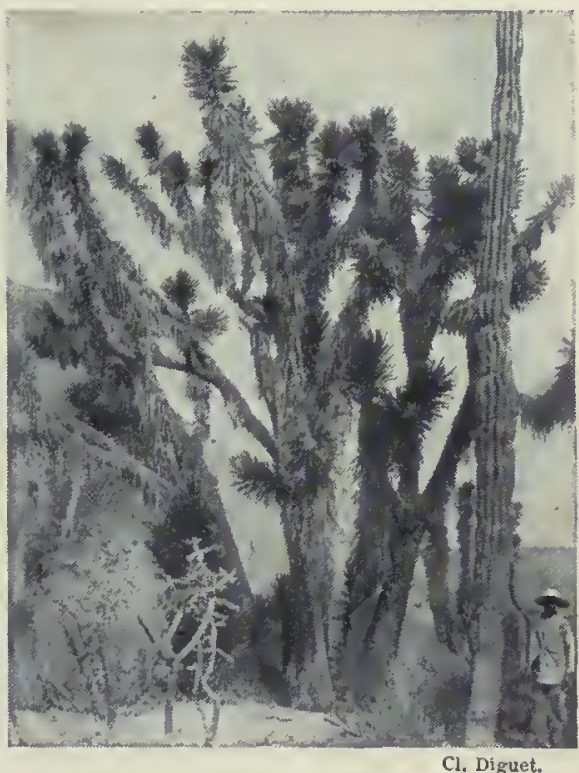

Yucca valida (Mexique). qui persistent et qui ont contre la sécheresse des moyens de défense qui n'existent pas dans la flore du début de l'année. Aussi les parties souterraines n'offrent aucun caractère particulier dans ces dernières espèces, tandis que, pour les formes durables, les racines acquièrent des dimensions considérables : c'est que ces plantes, ne trouvant plus l'humidité à la surface du sol, sont obligées d'aller la chercher dans les profondeurs (20 mètres parfois). II n'est pas rare dans les Acaciées, d'après Schweinfurth, que la racine ait vingt fois la longueur de la partie aérienne. Une plante haute comme la main aura une racine de $\mathrm{l}^{\mathrm{m}}, 50$ à 2 mètres. Il y a, en outre, une série d'autres caractères qui permettent à ces plantes de résister là où d’autres espèces péricliteraient inévitablement ; un grand nombre d'entre elles notamment ne sont pourvues de feuilles que pendant la période des pluies printanières.

Si l'on examine la végétation dans son ensemble, on voit qu'elle est formée d'individus épars; ce sont de petits buissons qui, à un examen superficiel, se ressemblent complètement. Il faut regarder de près les feuilles quand elles existent, et surtout les fleurs, pour distinguer, par exemple, une Légumineuse d'une Zygophyllée; un sous-buisson étalé sur le sol d'une Armoise ou d'un Tamaris, espèce qui apparaîtra surtout sur le sol sablonneux des ruisseaux desséchés, représentant ainsi la flore aquatique.

Cette similitude qui se manifeste entre toutes ces plantes se traduira, par exemple, dans les types épineux formant, dans le Sahara égyptien, des buissons arrondis de 1 mètre de haut et qui n'auront pas de feuilles : dans un Zille myagroide, dans les Astragales épineux, dans les Acacias tordus qui forment presque des petits arbres. L'Alhagi des Maures (fig. 112, C) est épineux, mais pourvu de petites feuilles; les piquants sont si acérés que la plante

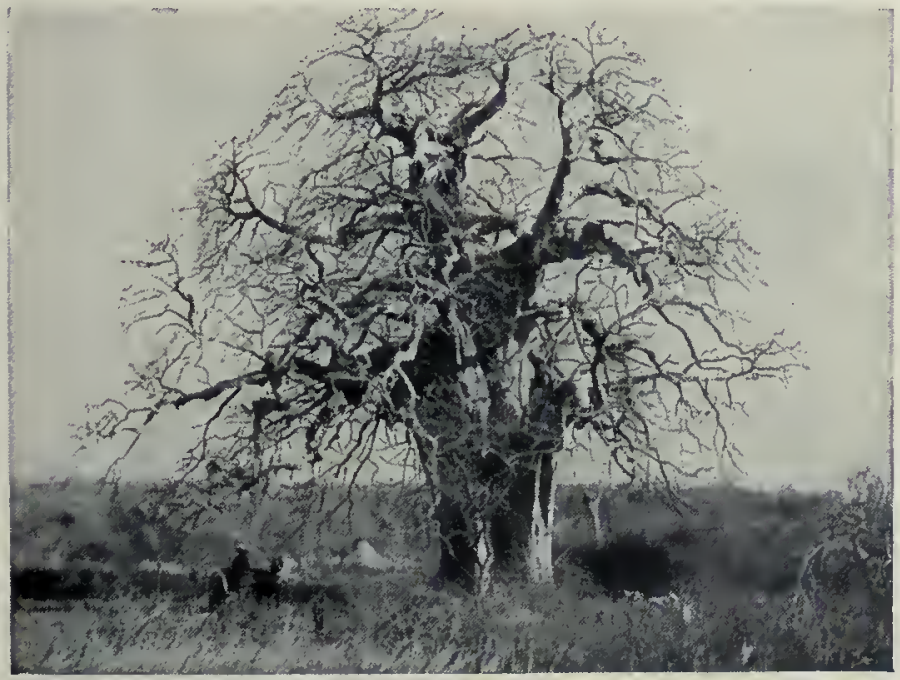

Un Baobab dans le Cayor (Sénégal). ne redoute pas l'attaque des ruminants. Ailleurs, quand les feuilles existent, pour atténuer les effets de la transpiration, ces organes sont couverts de poils filamenteux, comme chez le Liseron laineux et diverses Labiées. Certaines espèces sécrètent des sels déliquescents qui, pendant la nuit, attirent la vapeur d'eau et la condensent, même quand il y en a très peu. L'Arroche halime est couvert de poils renflés qui, par leur provision d'eau, permettent à cette espèce de demeurer verte par la plus forte sécheresse. Le même résultat est atteint par les Salsolacées à l'aide de tissu aquifère.

Flores désertiques spéciales. - Chaque région désertique a ses plantes caractéristiques et souvent étranges. Le sud de l'Afrique (Kalahari) et l'Angola ont la Welwitschie admirable ou Tumba, découverte en 1860 par Welwitsch, à Mossamèdes : c'est une Gymnosperme à grosse racine qui n'a que deux feuilles insérées l'une en face de l'autre sur une grosse tige, au-dessus des cotylédons, et qui peut vivre plus de cent ans sans engendrer d'autres feuilles; il est vrai que la base des feuilles se renouvelle constamment pendant que l'extrémité se dilacère et se détruit.

Une autre région de caractère désertique ou de steppe est celle qui sobserve entre le Kilimandjaro et la côte africaine orientale, riche en plantes succulentes comme l'Euphorbe Turicalli, et autres Euphorbes qui ressemblent à des Cactées; une Asclépiadée présente également le même phénomène de convergence : c'est la Stapélie carallume. C'est à cette région qu'appartiennent une série de plantes bizarres par leurs tiges tuberculeuses, par leurs branches épineuses, comme l'Adénie globuleuse ou le Pyrénacanthe à feuille de mauve. Mentionnons au Sénégal les Baobabs.

Il y a dans l'Amérique du Nord plusieurs contrées (nord du

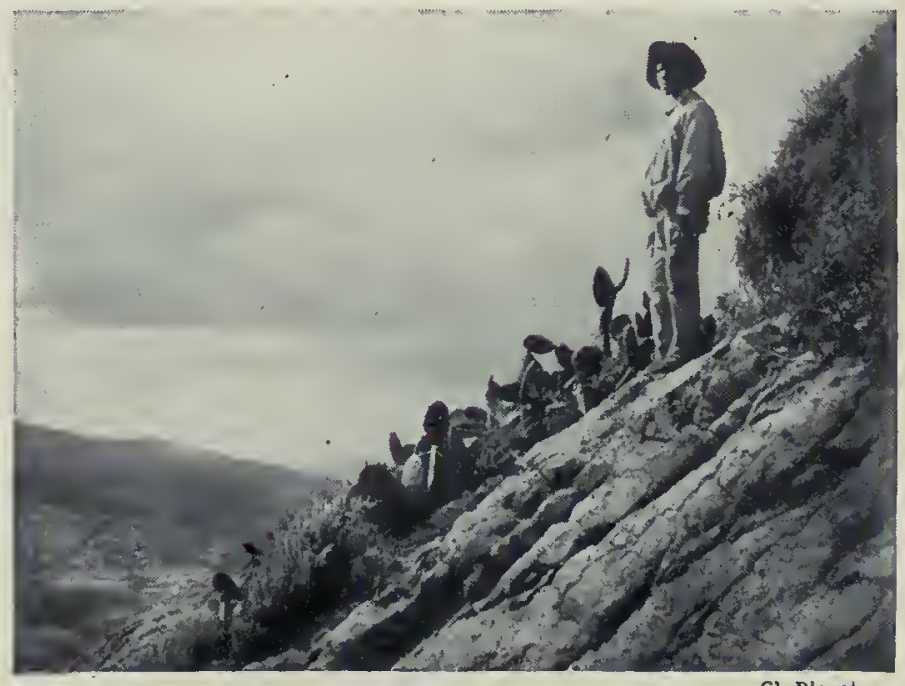

Nopals de la sierra Tlaljujalma (Mexique).
C1. Dlguet. 


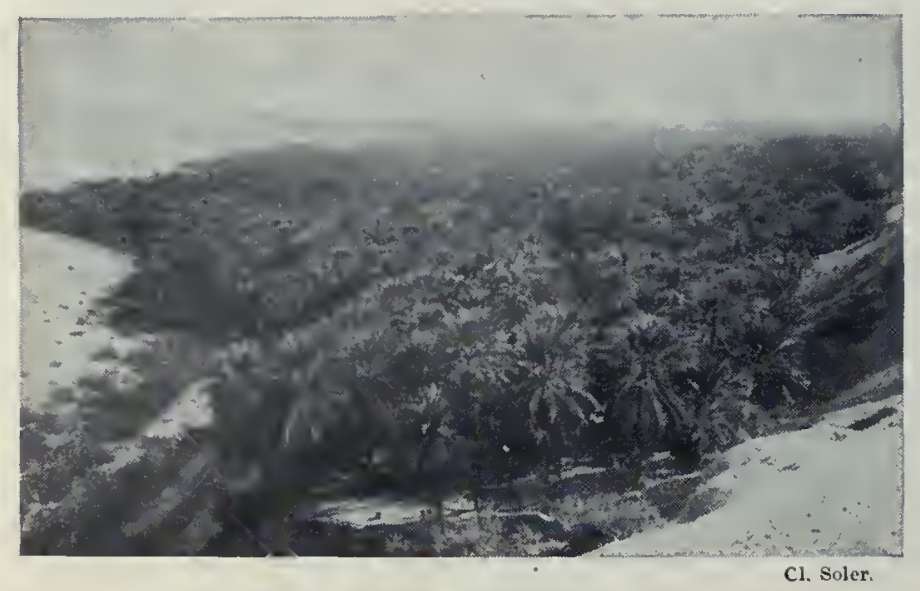

Corbeille de Nefta (Oasis tunisienne).

Mexique, Basse Californie, Texas, Arizona) très sèches, qui depuis longtemps ont été l'objet des études culturales des anciens Mexicains, qui y ont rassemblé un grand nombre de Cactées intéressantes au point de vue de la culture fruitière (ce sont les Cierges) et au point de vue de l'utilisation des pays privés d'eau. On y rencontre les Nopals, aussi les Pereskopuntia ou Pereskia, les Echinocactus, les Mamillaires. En Basse Californie, on doit mentionner les Yucca, notamment le Yucca valide et le Yucca de Trécul.

Au milieu des immensités désertiques et arides, on rencontre parfois des îlots de verdure: ce sont les oasis du sud de l'Algérie, par exemple, ou de la Tunisie; la richesse relative de végétation tient à la présence de sources qui sortent du sol en ces points.

Steppes. - Un autre type de paysage que nous ne pouvons omettre est celuj auquel se rattachent les steppes de la Russie, de l'Asie centrale et de la Perse, les prairies du sud des États-Unis, les pampas de l'Amérique du Sud, de la République argentine et de la Patagonie. Ce qui caractérise ces régions, c'est leur aspect monotone de végétation basse et herbacée; on n'y observe presque jamais d'arbre, jamais aucun buisson, bien que beaucoup de plantes soient un peu lignifiées à la base; les forêts manquent complètement. Par conséquent, cette zone florale se différencie avec la plus grande netteté, à la fois de la zone forestière et de la zone méditerranéenne et de ses analogues.

Le climat de ces contrées est assez sec et il est un terme de transition vers celui des déserts. 11 y a même deux stades très caractérisés dans ces étapes, suivant qu'il y a lieu de distinguer les steppes simples et les steppes salées. Dans ces dernières, les dangers qui résultent de la transpiration pour les plantes deviennent beaucoup plus grands, car l'accumulation de substances salines dans les cellules végétales peut en amener la mort. Les steppes salées s'étendent sur de vastes espaces dans le Turkestan. C'est là que se rencontrent un certain nombre de Salsolacées ou Chénopodiacées caractéristiques, entre autres notamment la Saxaoul ( $\mathrm{fg}$. 112, B), arbre informe ressemblant à une sorte de Saule têtard tout à fait tuberculeux, et qui ne peut donner qu'une ombre très faible, parce

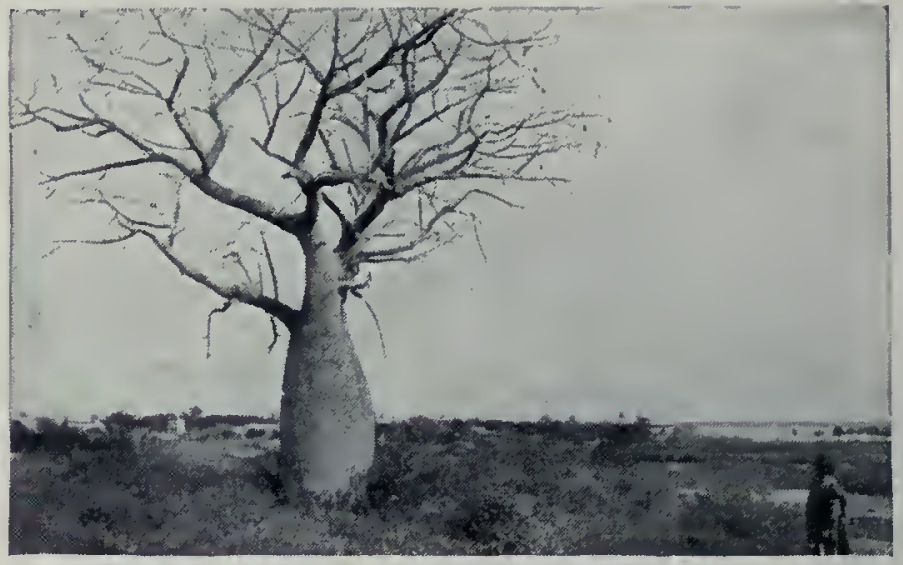

Eriodendron Samauma (Brésil).

qu'il n'a pas de feuilles; ses branches portent à la base des fruits roses, ainsi que Sorokine l’a décrit dans le Kizil-Koum; il se montre même là où il n'y a pas d'eau, comme dans ces dunes mobiles d'Amu Darja que reproduit notre gravure.

Dans les steppes ordinaires, les Graminées prédominent : parmi les plantes caractéristiques du sud de la Russie, on peut citer le Stipa pennata. L'Herbe des buffles ou Buffalo-grass (Buchloe dactylis ou Bulbilis, fig. 112, D) est typique des prairies du sud des EtatsUnis. Pendant l'hiver, la steppe est desséchée, ce qui n'arrive pas pour la prairie. Les plantes annuelles sont nombreuses; elles ont des feuilles molles et mûrissent leurs graines pendant la période humide. Les plantes bulbeuses abondent, car ces végétaux trouvent un abri dans le sol quand la sécheresse sévit. Les herbes vivaces communes sont dures, un peu ligneuses; les feuilles sont couvertes de poils, ou coriaces, ce qui leur permet de supporter sans graves inconvénients une saison sans pluies.

Lorsque les plantes ligneuses, qui sont rares, se multiplient, la steppe passe à la savane. En général, les arbrisseaux, quand ils existent, sont épineux; il y a beaucoup d'Astragales, de Tamaris, de Zygophyllées. On y trouve même certains Palmiers et quelques grands arbres, comme l'Eriodendron Samauma (au Brésil).

Cette fore des steppes peut avoir des représentants en dehors de son domaine propre. On retrouve des steppes salées au centre de l'Espagne, et sur 376 espèces de ces régions appartenant à 54 familles, ce sont les Composées, les Salsolacées, les Graminées et les Plombaginées qui prédominent : cette flore spéciale est formée d'un tiers de plantes annuelles, de deux tiers de plantes vivaces.

L'étude des contrées désertiques offre un intérêt tout spécial pour la France qui a dans ses colonies des surfaces immenses rentrant dans ce type de végétation (Algérie, Sahara, sud de Madagascar). Aussi pour notre pays l'étude de la civilisation mexicaine qui a su utiliser un grand nombre de plantes grasses (Cierges à fruits, Nopals à cochenille) présente un puissant intérêt. Le voyageur Diguet a contribué à faire connaître ces plantes.

Une végétation analogue se retrouve d'ailleurs autour des étangs salés et dans les régions les plus proches du bord de la mer.

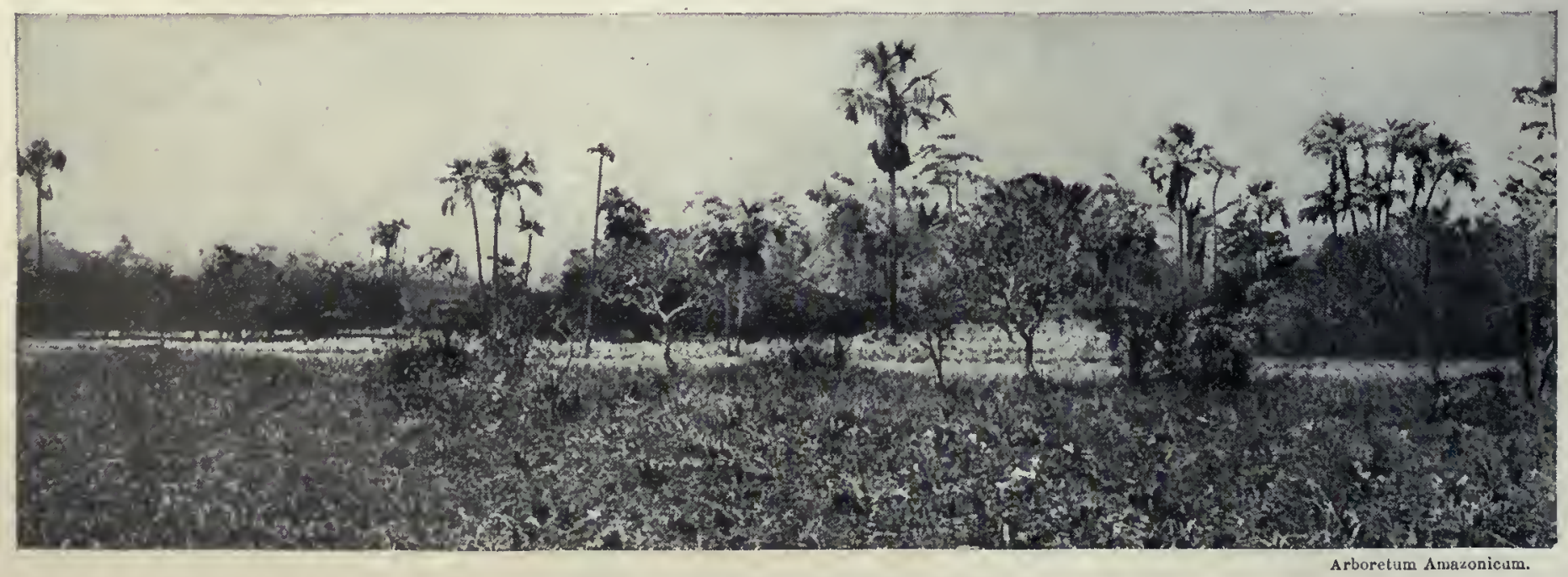

Savane avec palmiers Mauritia (Brésil). 


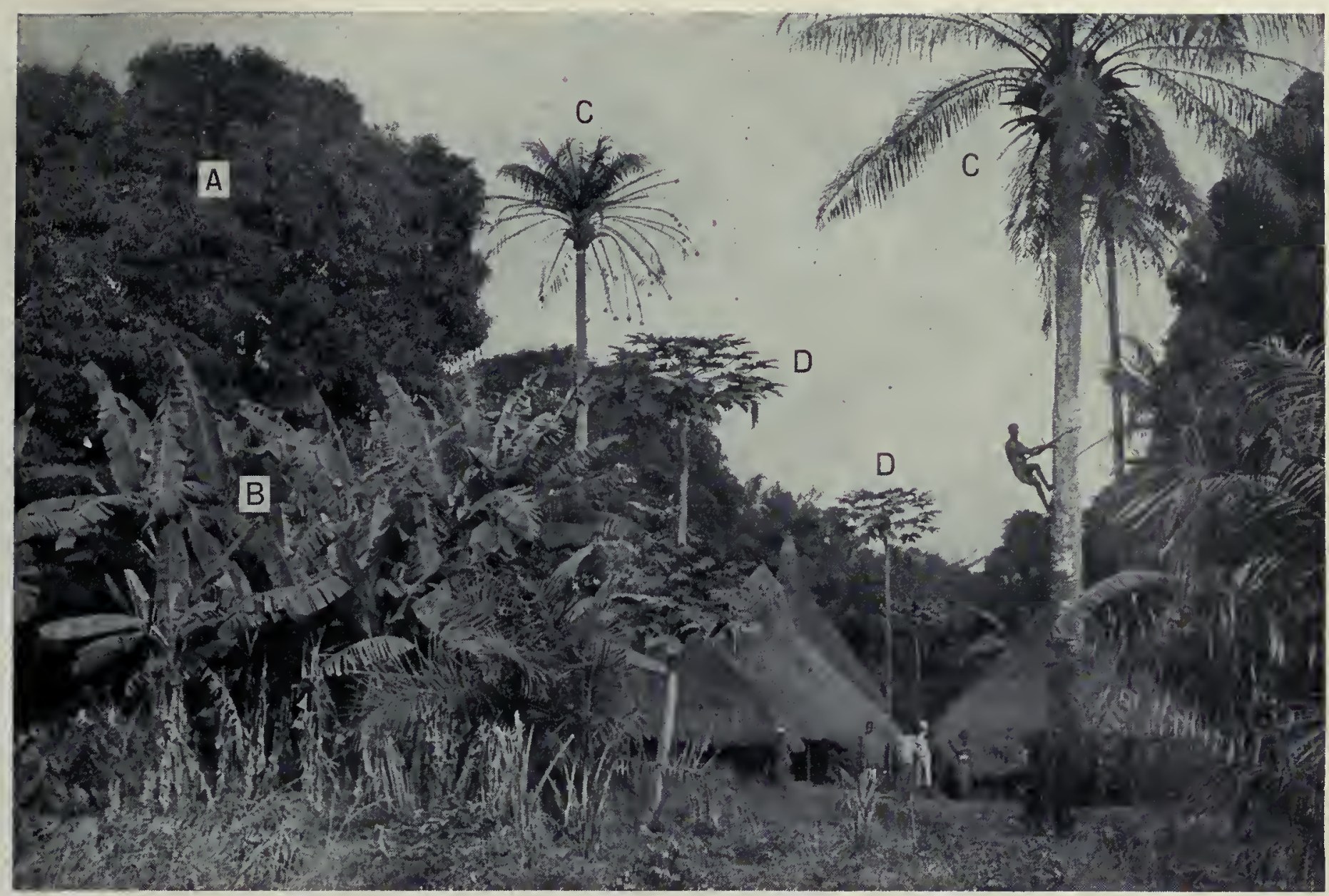

Végétation tropicate aux environs de Konakry. - A, Fromager; B, Bananiers; C, C, Palmiers à huile; D, D, Papayers.

\section{FLORE TROPICALE}

Le climat. - On serait tenté de penser que la chaleur est excessive dans les contrées tropicales; en fait, les hautes températures qu'on y observe ne sont pas plus élevées que dans nos pays septentrionaux en été : $30^{\circ}$ à $33^{\circ}$, tem. pératures moyennes de Java, de Ceylan, de Singapour. Ce qui caractérise donc les chaleurs tropicales, ce ne sont pas les hautes températures, mais leur constance. A Java (Batavia) la différence entre la moyenne du mois le plus chaud et le mois le plus froid est de $\mathrm{I}^{\circ}$; quant aux variations extrêmes, elles sont de $9^{\circ}, 2$ (par exemple, $20^{\circ}, 9$, température la plus basse, et $30^{\circ}, \mathrm{I}$, température la plus haute).

Si l'on ne tenait donc compte que de la température, le climat serait très uniforme; les grandes variations viennent de la répartition des pluies. En général, l'eau tombe abondamment chaque jour, et à Java, pendant le mois de janvier, il tombe, en moyenne, 475 millimètres d'eau; i] $\mathrm{y}$ a donc une époque où les pluies sont très abondantes. Au mois d'août, qui correspond à ce que l'on appelle la mousson sèche, on peut encore récolter 275 millimètres d'eau par mois, ce qui indique qu'il pleut encore beaucoup pendant cette saison, qui s'oppose à la période des pluies. Java (Buitenzorg notamment) est d'ailleurs un des points du globe où i] pleut le plus. Dans beaucoup de contrées tropicales, la différence entre la saison humide et la saison sèche est plus accusée. Au Brésil, dans l'Etat de Minas Geraës par exemple, la période des pluies s'étend d'octobre à mars, surtout de novembre à janvier, et il pleut abondamment de neuf à vingt jours par mois; d'avril jusqu'en septembre, la sécheresse est, au contraire, prédominante.

Forêt vierge. - Le climat dont nous venons de préciser brièvement les caractères a une influence profonde sur la végétation ; une chaleur uniforme accompagnée de pluies abondantes entraîne inévitablement un pullulement extraordinaire de la vie végétale et amène la formation de ce que l'on a appelé les forêts vierges, qui ont si profondément impressionné tous les voyageurs. La Jutte pour l'existence, et surtout pour la place, $y$ est tout à fait intense, et Stanley a pu dire avec juste raison que la forêt tropicale est si pleine que " si le sommet était plan, il serait facile de faire route par-dessus ». La puissance de cette végétation est extraordinaire; elle recouvre en quelques années les espaces défrichés par I'homme, puis laissés incultes, les monuments abandonnés. La forêt tropicale se compose de quatre parties principales: $1{ }^{\circ}$ les arbres; $2^{\circ} \mathrm{le}$ sous-bois; $3^{\circ}$ les lianes; $4^{\circ}$ les épiphytes et les parasites.

Étudions d'abord les deux premières parties qui constituent la 


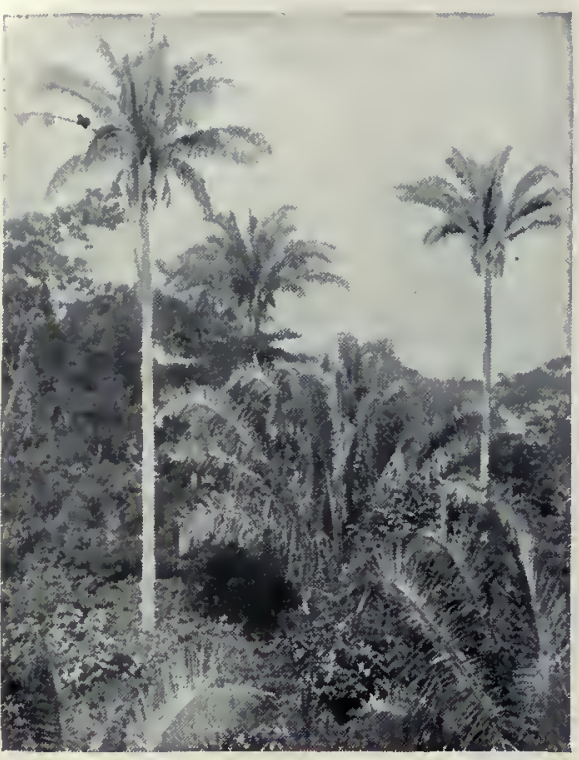

Cl. Waito,

Oreodoxa regia (Mexique).

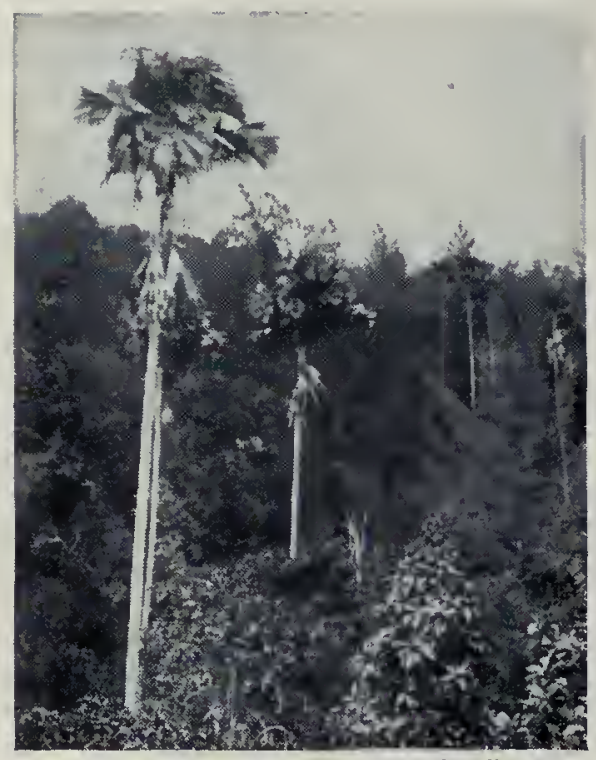

Cocotier des iles Seychelles.

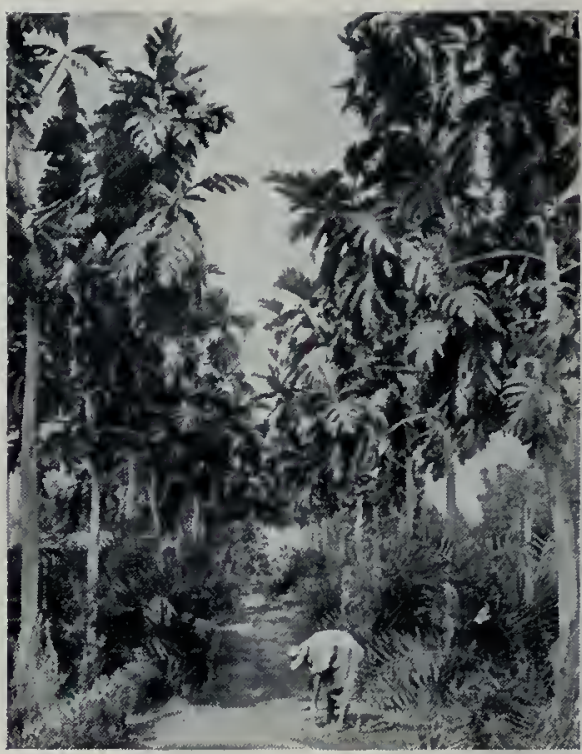

Arbre à pain (Madagascar). forêt proprement dite. Les arbres affectent une architecture assez particulière, qui est l"indice de la lutte intense pour la lumière. La ramification, quand elle se produit pour eux, est accompagnée fréquemment de redressement des branches parallèlement au tronc principal, de manière à former unc sorte de candélabre. Ailleurs, les rameaux se produisent à une grande hauteur sur le tronc principal, et les branches, en petit nombre, s'étalent obliquement, seulement vers la partie supérieure, affectant la forme d'un parasol. Enfin les ramifications peuvent avorter complètement et on a des arbres dont la tige reste simple : c'est le cas des Palmiers (sauf le Doum ou Hyphane, qui se ramifie exceptionnellement une fois), des Fougères arborescentes et des Cycadées, qui contribuent à donner à la végétation des tropiques son aspect caractéristique.

L'énumération des Palmiers que l'on rencontre dans la région tropicale est impossible, car il faudrait dénombrer la plus grande partie de cette famille considérable. Mentionnons cependant les types à feuilles en éventail, comme le Rondier dans l'Inde; d'autres à feuilles pennées, comme les Elæis de Guinée, qui abondent en Afrique, ainsi que le Raphia vinifère. En Asie, on peut citer l'Arec cachou, le Métroxyle de Rumph, qui fournit le sagou. En Amérique, on peut observer le Mauritie vinifère, qui joue un rôle économique important; le Céroxylon andicole, les Oreodoxa, le Lodoicea (ou Cocotier) des Seychelles.

Les Vaquois et types voisins sont également représentés dans toutes les flores des tropiques; ils ramifient très péu leur tige en fourche : en Asie, cest le Vaquois de Java; en Afrique, c'est le Vaquois candélabre. En Amérique, la famille des Pandanées, à laquelle appartiennent les plantes précédentes, est remplacée par le Carludovice palmé, qui a tout à fait l'aspect d'un Palmier, quoique d'une petite famille très distincte, celle des Cyclanthacées.

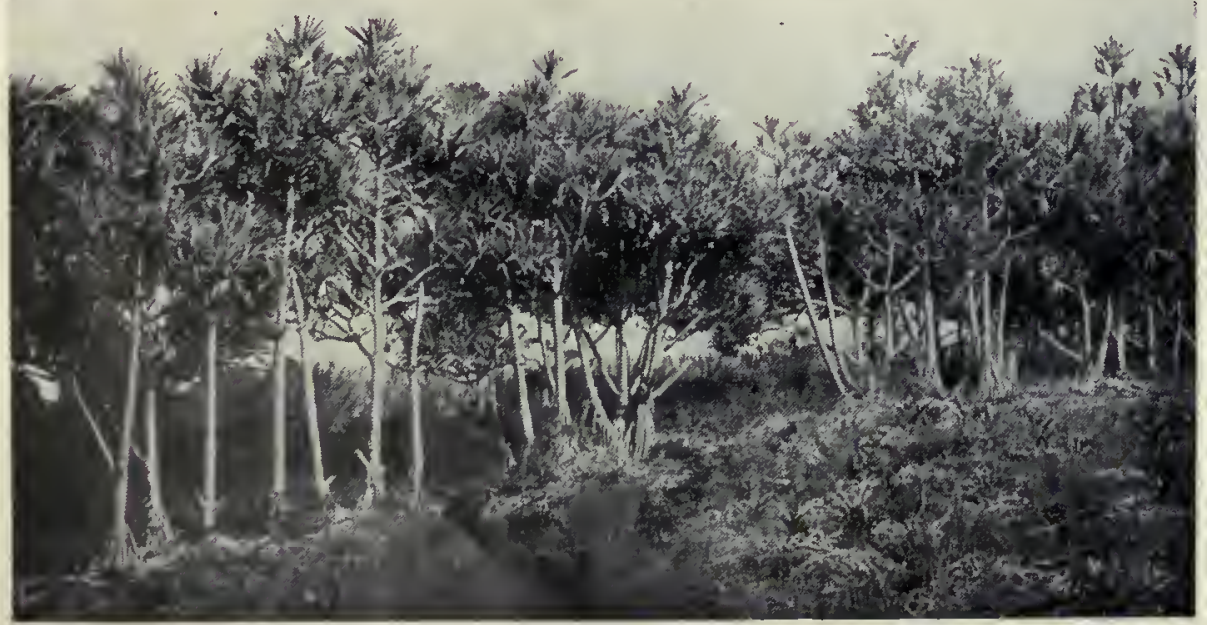

Vaquois (Pandanus utilis), dans l'Ile de la Réunion.
Les Cycadées ont aussi le port des Palmiers : Cycas d'Asie, Zamies d'Afrique et des Antilles, Cératozamies du Mexique.

Parmi les Fougères arborescentes, on peut mentionner les Alsophiles, les Cyathées, etc.

Un point essentiel à noter à l'occasion de ces forêts, c'est l'extrême variété des essences que l'on y observe. Il est très rare de rencontrer des régions où l'on ne voit que des individus appartenant tous à la même espèce comme dans les pays du Nord. Aussi l'inventaire des richesses forestières d'un pays représente-t-il un travail énorme, rendu très compliqué par la difficulté d'atteindre chaque arbre et de se procurer, en temps opportun, des fleurs et des fruits pour sa détermination. Ce travail commence seulement à être mené à bien à Java, pays où la botanique est étudiée avec ardeur depuis cent ans; on s'explique ainsi pourquoi la Flore forestière de l'Indo-Chine est restée inachevée par suite de la mort de son auteur; ce travail a été repris par M. Lecomte.

Parmi les arbres les plus célèbres des régions chaudes, on peut citer les Arbres à pain et le Jacquier, le Kolatier, les Papayers ; les Bananiers sont aussi des types très caractéristiques. Parmi les formes arborescentes les plus répandues, on peut nommer beaucoup de Légumineuses et surtout de Mimosées; en Asie et dans les îles de la Sonde, on rencontre des Albizzies, les Indigotiers, les Casses, les Hématoxyles de Campêche, les Figuiers, etc. Les Liliacées et les Amaryllidées arborescentes sont également célèbres: Dragonniers, Dasylirions, Fourcroyers, Barbacenies, etc.

Les arbres peuvent atteindre de très grandes tailles, et les $\mathrm{Ra-}$ samala ou Altingies que l'on rencontre à Java sont hauts comme des tours (60 mètres de haut). On conçoit que de pareils colosses, exposés aux tourmentes, aient besoin pour soutenir leur base de ces contreforts que nous avons désignés sous le nom de racinespalettes. Les Fromagers ou Ériodendrons présentent aussi des contreforls analogues.

Il arrive cependant que parfois les arbres s'étalent; c'est qu'il s'agit alors de ces lutteurs puissants qui écrasent peu à peu tous les concurrents se trouvant dans leur voisinage. Tel est le cas des Figuiers-Banians, notamment du Figuier des pagodes ou du Ficus Benjamina de Java. C'est grâce aux anastomoses de leurs branches, grâce aux mille racines adventives, qui forment autant de troncs nouveaux, que la plante peut s'étendre; elle atteint parfois jusqu'à 500 mètres de tour : l'arbre est devenu une forêt.

En général, la puissance de la vie végétale est moindre, et, malgré la lutte pour la lumière, il y a place pour un sous-bois. Il est formé de petits arbres, d'arbustes, qui ont des exigences moins impérieuses au point de vue de l'éclairement que les grands arbres. Leur nombre est parfois assez élevé, et dans le district de Lagoa-Santa, au Brésil, tandis que 


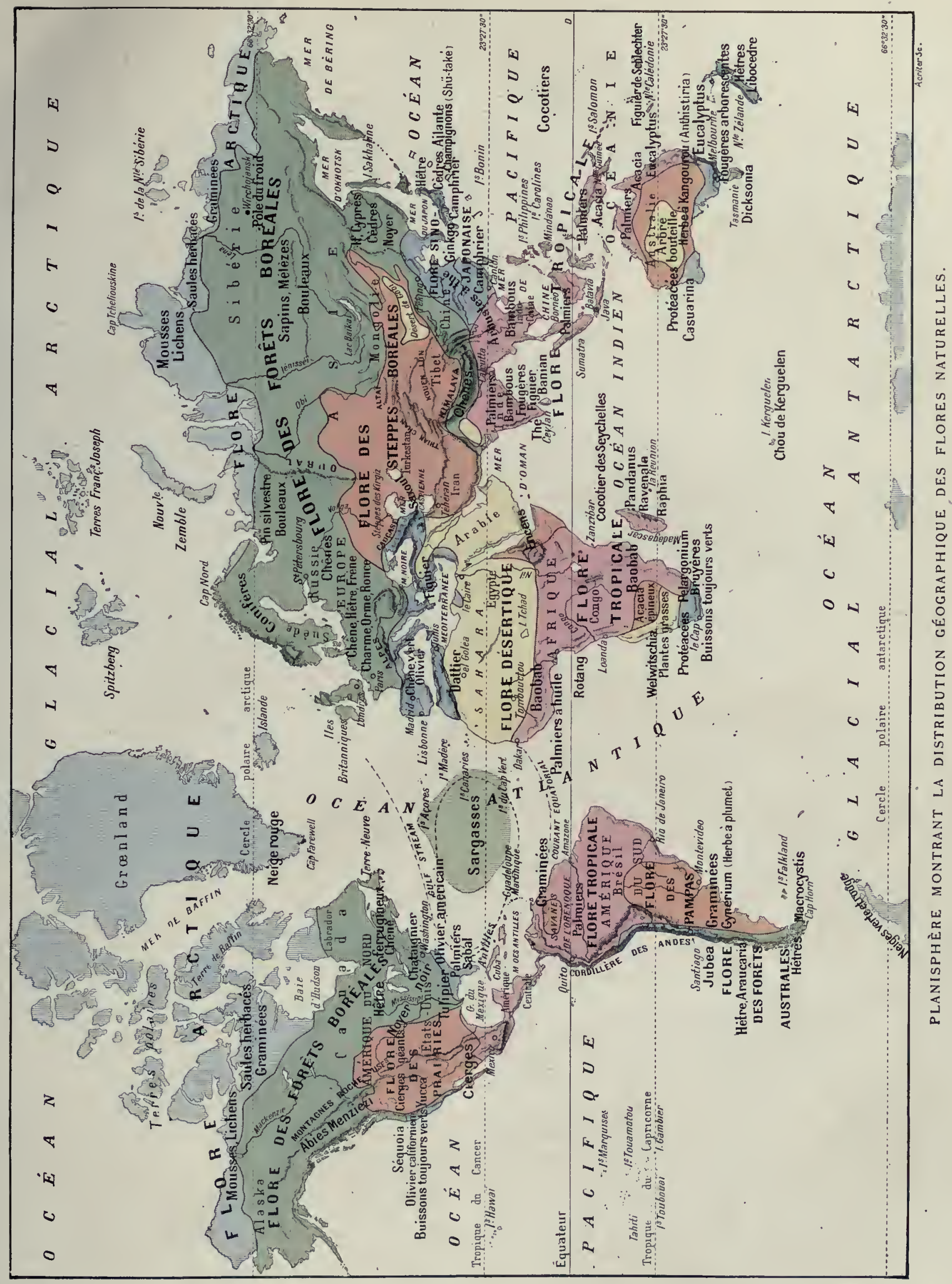

年 



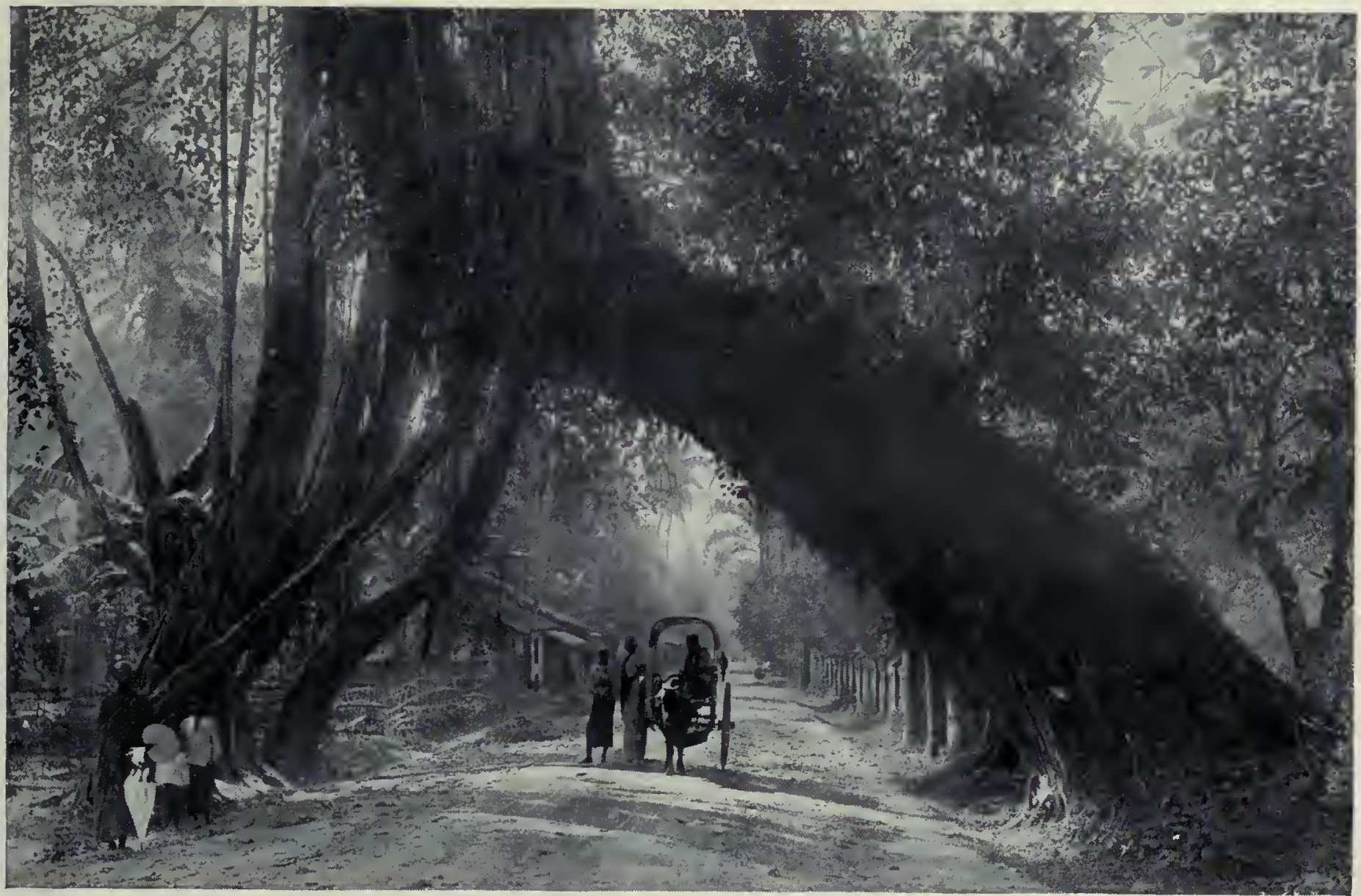

Figuier-Banian croissant au-dessus d'une route (Ite de Ceylan).

Cl. Skeen.

sur 2600 plantes Phanérogames il y a 380 espèces arborescentes, on compte 300 arbustes poussant dans ce petit district. Il y a aussi parfois des Fougères, et parmi elles on peut citer notamment les Gleichénies dichotomes qui sont herbacées, analogues à la Ptéride grand aigle de nos forêts, mais qui peuvent atteindre jusquà 12 mètres de hauteur.

Les Graminées, que nous sommes habitués à considérer comme formées surtout par des herbes dans les pays froids, sont représentées sous les tropiques par des plantes souvent magnifiques, comme les Bambous, qui sont de véritables arbres ayant jusqu à 30 mètres de haut et plus. Il y a aussi des Graminées herbacées, comme la Canne à sucre. Parmi les familles auxquelles appartiennent les herbes vivaces, on peut citer quelques Composées, Rubiacées, Labiées, Scrofularinées, Euphorbiacées, Lycopodiacées.

Les phénomènes phénologiques que manifeste la végétation arborescente sont évidemment en harmonie avec le climat; l'éclosion des bourgeons se produit au moment du retour de la saison des pluies, car sécheresse veut dire repos et arrêt de la végétation; cette éclosion des bourgeons et le développement des jeunes pousses aux feuillages pendants et vivement colorés contribuent à égayer la forêt vierge. Les feuilles formées sont, en général, grandes et de consistance épaisse, de couleur sombre à l'état adulte, avec la surface supérieure brillante, réféchissant la lumière. Ces organes ne tombent pas d'une manière régulière et, en général, dans les forêts humides, la plante est toujours verte. Il peut arriver cependant qu'elle se dépouille plus ou moins complètement pendant la saison sèche, et l'intensité de ce dépouillement devient d'autant plus grande que l'on passe à des contrées où la période sèche s'accuse. La floraison présente des variations analogues : par exemple à Java, sur 213 espèces arborescentes, 53 fleurissent toute l'année, 142 pendant la saison sèche, 18 pendant la saison des pluies. En général, c'est donc plutôt pendant la sécheresse que la floraison s'accuse.

Les lianes. - Le sous-bois est formé de végétaux qui se contentent de peu de lumière; il y a une autre catégorie de plantes qui sont aussi habituées à cette existence dans une demiobscurité : ce sont les lianes, et leurs caractères les plus étranges et

les plus remarquables découlent de cet état d'étiolement. La pullulation des espèces grimpantes est, en effet, tout à fait intense et contribue puissamment à rendre la forêt vierge inextricable. Une plante étiolée (on en donne aisément la preuve en enfermant une plante en germination dans une armoire) sallonge beaucoup et est incapable de se soutenir, par suite de la faiblesse de ses tissus; aussi retombe-t-elle sur le sol; mais si l'étiolement partiel a lieu dans un sous-bois épais, la plante étiolée ne retombera pas sur la terre, elle s'appuiera sur les branches des arbrisseaux voisins. On peut voir, par exemple, un $P$ uscetha scandens ramper pendant 25 mètres sur le sol, puis s'appuyer sur les plantes voisines pour grimper. La plante étiolée, n’ayant pas trouvé de support, est restée couchée sur le sol, mais dès qu'un appui a été rencontré, elle a pu acquérir un peu de vigueur pour se redresser vers le haut; à mesure qu'elle s'élève en rencontrant de nouveaux supports, sa vigueur s'accroît et elle tend de plus en plus à se rapprocher de la couronne de la forêt. Incapable d'abord de se ramifier, parce qu'elle

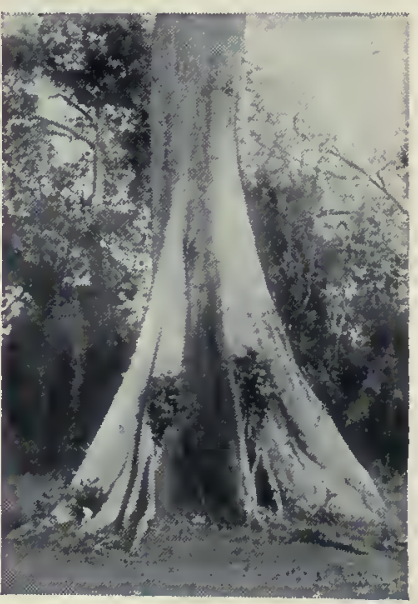

Fromager (Dahomey).

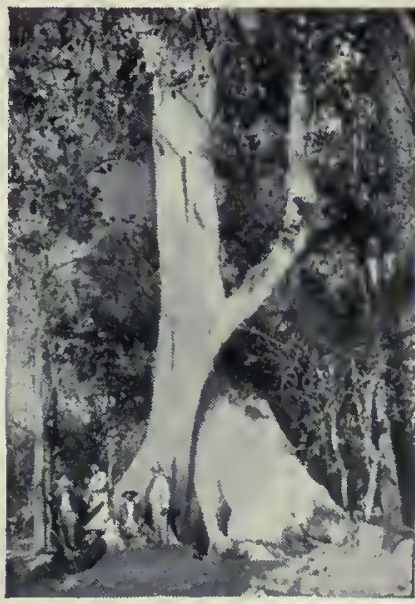

Figuier (Mexique) 


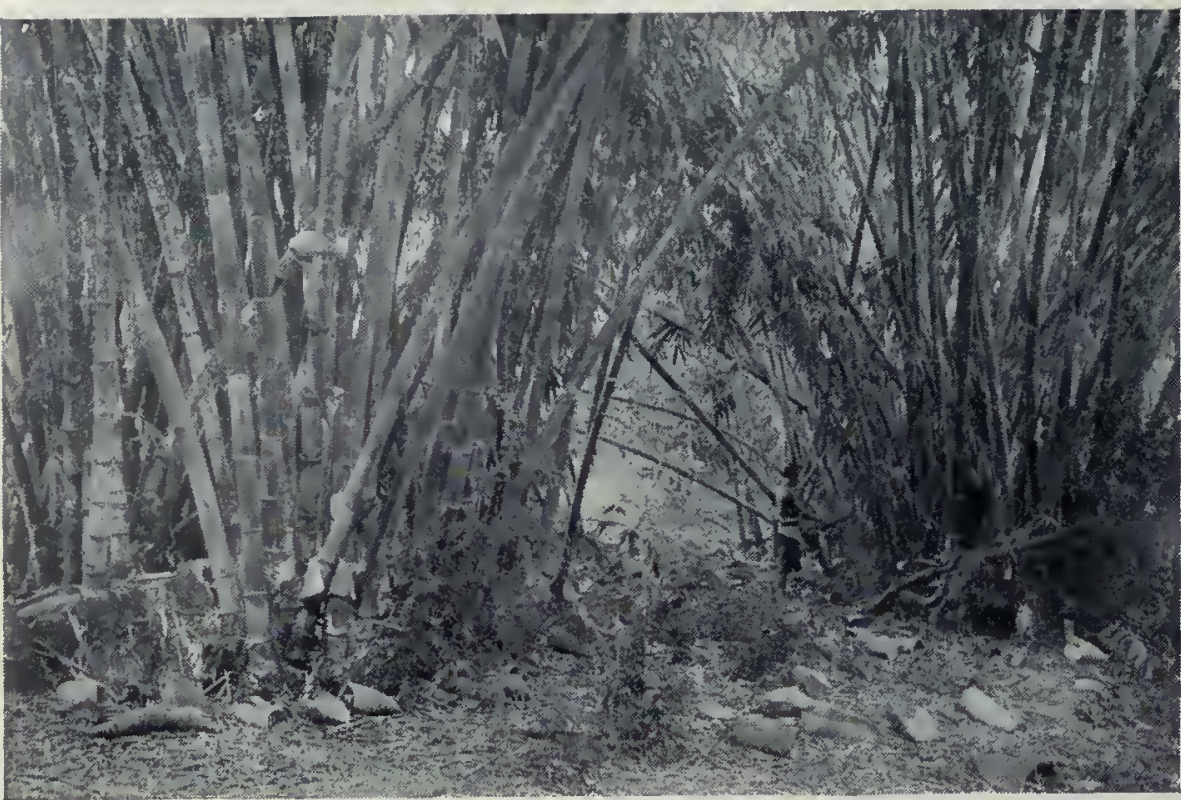

Bambous à Buitenzorg (Ite de Java).

n'en a pas la force, elle se divise au contraire abondamment dès qu'elle a atteint la couronne où elle peut fleurir. Cés lianes se déforment souvent d'une manière étrange en s'élevant sur les arbres : leurs tiges s'aplatissent, deviennent irrégulières à une ou plusieurs ailes; elles se tordent, elles se gondolent d'une façon bizarre, comme dans ces Bauhinia, que l'on appelle souvent des "escaliers de singe " (fig. 113$)$.

Une particularité de forme ou de structure, en apparence secondaire, peut assurer à certaines de ces plantes une supériorité incontestée sur leurs congénères. L'étude des Rotangs ou Palmiers grimpants est très instructive à cet égard. On en rencontre de plusieurs catégories, qui ont formé des aiguillons sur différents organes. Dans le Calamus extensus, qui vit dans l'Ancien Monde, c'est la tige qui est métamorphosée en un long fouet pourvu de piquants; dans les Raphiées, qui vivent dans des contrées semblables (Ancien et Nouveau Monde), c'est le pétiole qui est effilé en fouet et armé de pointes acérées. En Amérique, l'évolution des Palmiers vers la vie grimpante a pu s'effectuer dans une autre direction, car les Moréniées s'appuient simplement sur les branches, leurs pétioles orientés vers le bas formant crochet ; c'est évidemment là un des premiers stades de l'adaptation. Enfin chez les Bactridées américaines, dont les Desmuncus peuvent nous fournir un exemple, les folioles des feuilles pennées sont raccourcies et orientées vers le bas, à la manière de harpons qui, en s'enfonçant dans les objets voisins, assurent à ces Palmiers une maîtrise incontestable dans l'art de grimper. La puis-

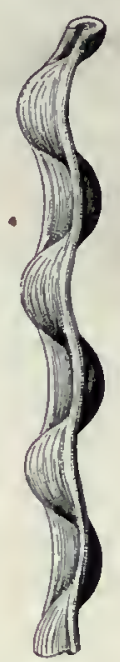

Fig. 113. Escalier de singe.

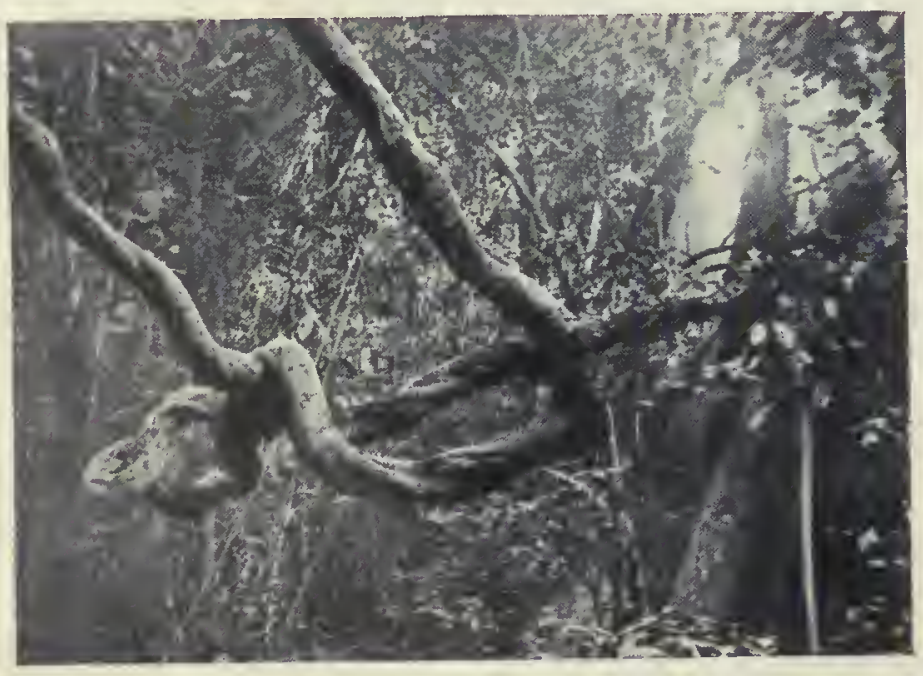

Nound de Lianes (Forêt du Soudan). sance de ces espèces pour s'élever dans la forêt est ainsi souvent tout à fait extraordinaire : on les voit s'élancer dans l'air avec leurs puissants fouets crochus qui explorent l'espace en quête de supports et, dès qu'ils en ont trouvé un, l'ascension devient rapide; mais, à mesure que la plante s'élève et grandit, son poids saccroît et bientôt le tuteur devient incapable de supporter son fardeau : tout s'écroule à la base; nouvel essor vers le haut, suivi plus tard d'une catastrophe semblable. Ces phénomènes d'ascension et de chute peuvent se multiplier tellement que l'on voit parfois de véritables cordages s'enrouler sur le sol, atteignant jusqu' à 200 et 300 mètres de long.

La forêt vierge est donc un lieu très propice au développement de la vie grimpante, et c'est dans les régions tropicales que se rencontrent les principaux types de lianes. La famille des Cucurbitacées, par exemple, est presque exclusivement tropicale; elle n'est représentée dans notre pays que par la Bryone diö̈que. Il peut y avoir des lianes en dehors des régions chaudes, mais c'est sous les tropiques qu'elles prédominent. En Europe, il y a 170 lianes sur 9400 espèces de végétaux supérieurs; ce qui correspond à 1,8 pour 100 de types grimpants. Dans l'Inde, les lianes représentent 8 pour 100 de la végétation phanérogamique.

Les lianes des forêts tropicales appartiennent surtout aux familles suivantes : Cucurbitacées, Vitées, Convolvulacées, Légumineuses, Pipéracées, Sapindacées, Mélastomacées. Parmi les Fougères, les Lygodium sont grimpants. En Amérique, il y a beaucoup de Passifforées, de Malpighiacées, de Smilacées, et, parmi les Orchidées, les Vanilles s'enroulent par leurs racines.

ll y a un autre type de végétaux, plus caractéristique encore des régions chaudes que les plantes grimpantes: nous voulons parler des épiphytes.

Épiphytes et parasites. - Les plantes épiphytes (voir p. 58) achèvent de remplir la forêt vierge. Ce sont là des hôtes très nombreux qui manquent à peu près complètement dans les pays froids. Parmi les plantes qui réussissent surtout dans ces conditions et qui méritent d'être appelées les " filles de l'air ", on peut citer d'abord les Fougères, et ce résultat s'explique aisément, étant donné la ténuité et la légèreté de leurs spores; parmi les Fougères épiphytes les plus remarquables, on peut citer les Trichomanes peltés, dans la partie basse, humide et sombre des forêts, puis les Fougères à terreau : Platycerium, Doradille en forme de nid, Polypode à feuilles de Berce dans la partie moyenne. Un second groupe également important parmi les plantes épiphytes est celui des Orchidées, tant les espèces à terreau de la partie moyenne, que les espèces à pseudo-bulbe de la couronne des arbres. C'est là que se développent toutes les espèces admirables que nous pouvons voir acclimatées dans nos serres : les Cattleya, les Lalia, les

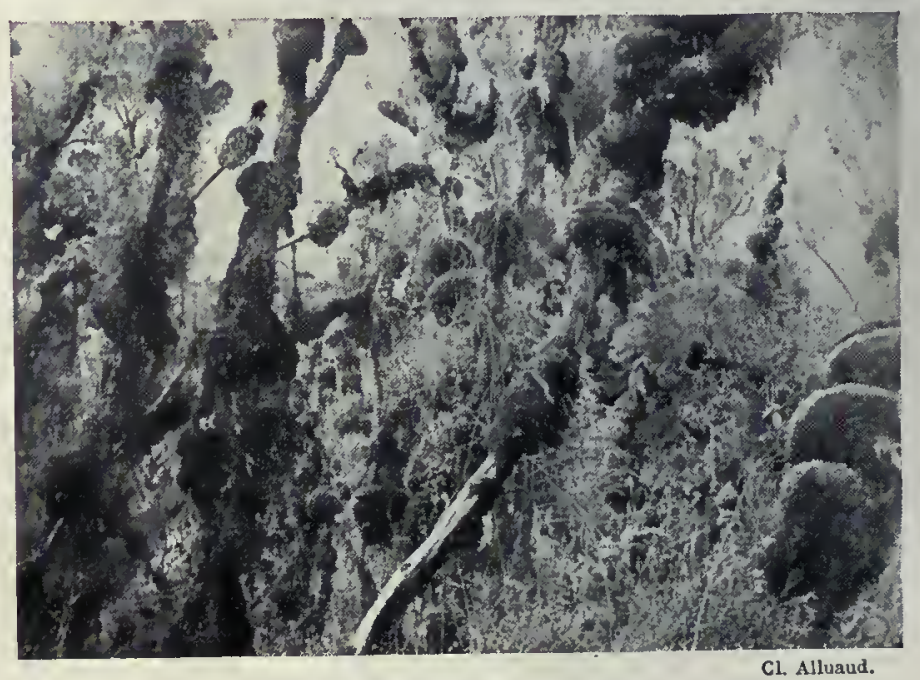

Végétations épiphytes (Mont Rouwenzori) 
Oncidies, les Odontoglosses, qui nous frappent par leurs caractères étranges de végétation, par leurs racines aériennes, leurs feuilles épaisses et charnues, leurs tiges à faux bulbes, autant que par la grandeur et la beauté de leurs fleurs. Une autre famille, qui a une place également importante dans les serres d'Europe et qui s installe sur les arbres, grâce aux aigrettes ou aux ailes de ses graines, est le groupe des Broméliacées. Les feuilles s'y disposent d'ordinaire en rosette, avec la partie inférieure creusée en cornets richement colorés de pourpre où l'eau de pluie s'accumule, de manière à constituer des réservoirs d'humidité pour la plante : c'est là ce qui caractérise les Nidulaires, dont les fleurs petites, mais aux couleurs vives, apparaissent au milieu de

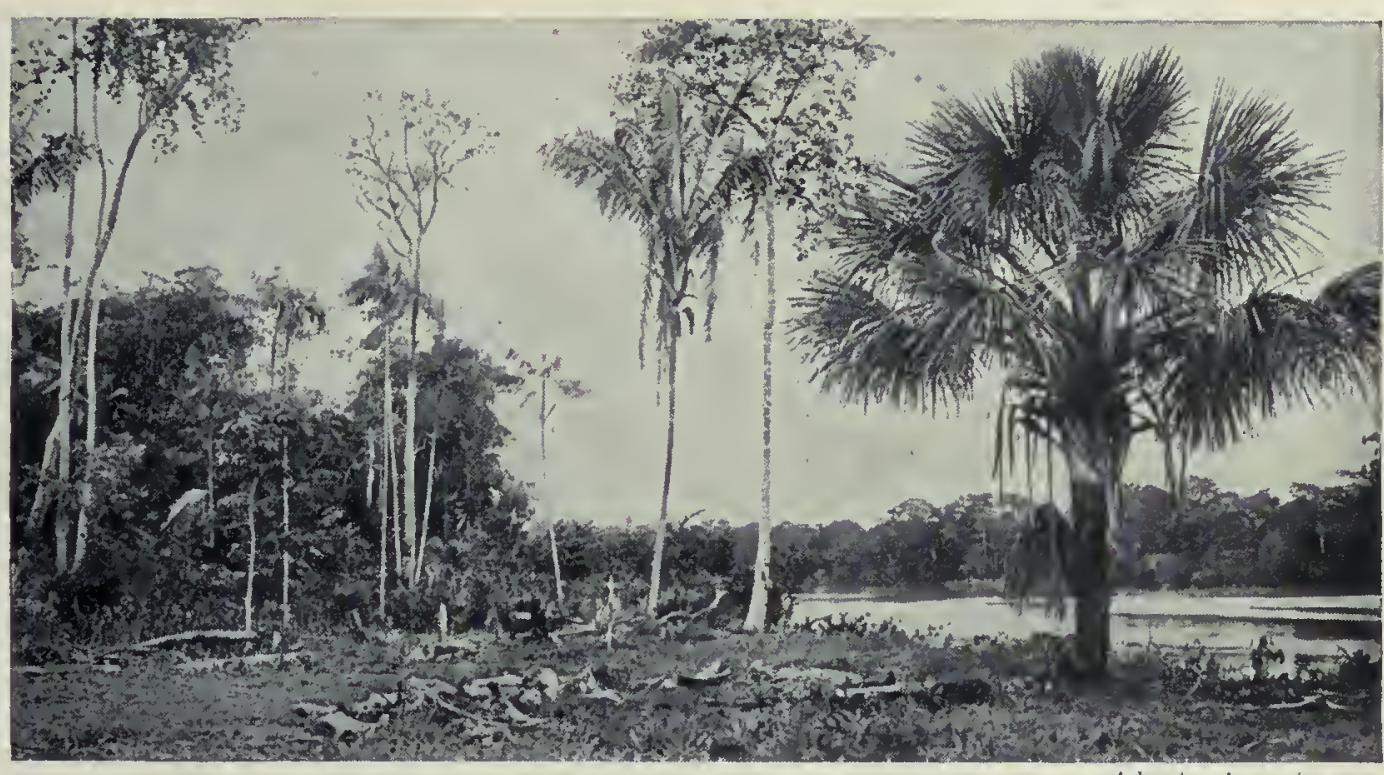

Végétation des bords du rio Arama (Brésil). ces cornets. Le port de ces Broméliacées est un peu raide; leur feuillage est souvent armé de piquants qui en rendent le maniement redoutable, mais leurs inflorescences sont colorées des plus vives nuances et les font apprécier des horticulteurs et des amateurs : c'est dans ce groupe que se placent les Tillandsies, les Vriesies, les Billbergies, etc. Les Aroïdées contiennent également un grand nombre de représentants adaptés à la vie sur les arbres, tels que les Philodendres, les Anthurium, les Monstères, et le feuillage, si curieusement perforé, de ces derniers, attire l'attention autant que leurs longues racines pendantes, semblables à des cordes atteignant plusieurs mètres de long.

A ces quatre groupes végétaux : Fougères, Orchidées, Broméliacées et Aroïdées, appartiennent presque toutes les plantes épiphytes, mais plusieurs autres familles : Liliacées, Gesnéracées, Asclépiadées, etc., en fournissent aussi quelques spécimens. En général, les épiphytes sont de petites plantes, plus ou moins rabougries, par suite de la faible quantité de nourriture qui est mise à leur disposition; mais parfois elles peuvent acquérir de grandes dimensions, comme c'est le cas des Clusies roses, qui sont des arbres qui s' installent sur d'autres arbres, ou comme les Orchidées géantes de Java, les Grammatophylles.

Toutes les plantes que nous venons de mentionner sont simplement posées sur les arbres; elles peuvent quelquefois les entourer, les encercler, mais jamais elles n enfoncent aucun suçoir dans leur écorce. Il n'en est pas de même des parasites, qui sont légion dans les régions chaudes et qui sont surtout représentés par des Loranthacées, famille innombrable dont une espèce, dans les pays froids, est le Gui. C'est tout un monde infiniment varié de parasites qui s' incruste sur les branches des arbres, qu'ils déforment et tuméfient d'une manière parfois très étrange, formant ce que l'on appelle la rose de Palo au Mexique, la rose de Madère au Guatémala. Parfois, le parasite sinsinue dans la plante hospita-

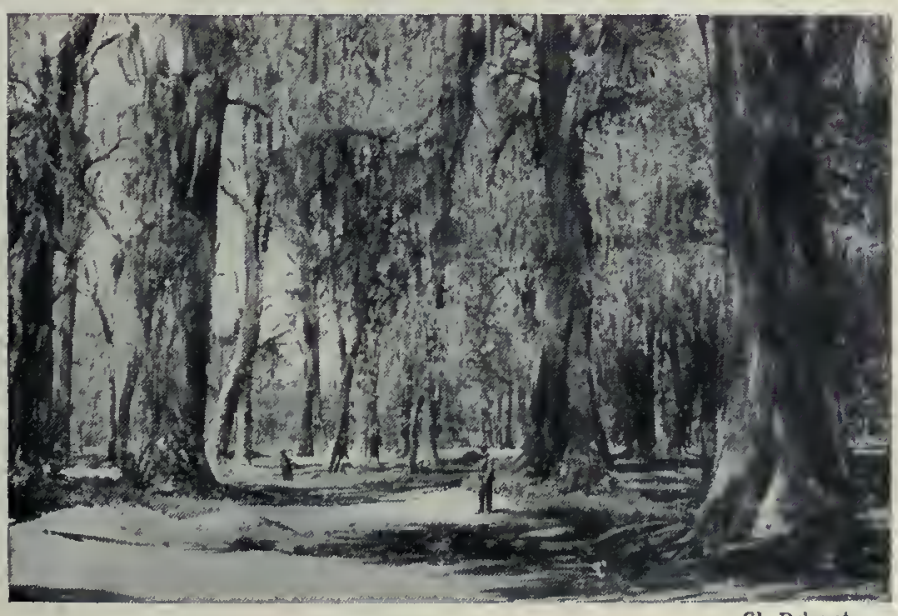

Arbres avec Tillandsia usneoides (Mexique) lière sans se trahir au dehors. Nous avons déjà parlé des Rafflésiacées et des Balanophorées, plantes informes, décolorées, souvent nauséabondes, dont les dernières jouent dans les forêts tropicales le rôle des Champignons de nos bois (voir page 57).

Types spéciaux de végétation tropicale. - La forêt igapo ou forêt marécageuse des bords de l'Amazone est composée presque exclusivement de Palmiers, avec un sous-bois riche en herbes et en arbustes. Comme Palmiers, des Astrocaryum, des Mauritia, des Euterpes, des (Enocarpes, etc., puis des Légumineuses (Campsiandra), des Euphorbiacées (Hevea), des Myristicées (Virola, sorte de Muscadier), des Sapotacées (Mimusops).

Au bord de la mer, en Asie et dans toutes les îles de l'Océanie, abonde le Cocotier. A noter aussi la flore des marigots, c'est-à-dire des lieux bas remplis d'eau par les pluies ou par les infiltrations d'un bras de fleuve; elle se compose d'une foule de hautes herbes, parmi lesquelles dominent les Graminées et les Cypéracées.

La flore du littoral, ou mangrove, est caractérisée dans les régions tropicales par des plantes très particulières qui frappent tout de suite le voyageur. A mer basse, les Rhizophores ou Palétuviers (fig. 114) se montrent comme de grandes araignées végétales, appuyées sur le sol par de nombreuses racines en arceaux. C'est le Rhizophora Mangle, qui est l'avant-garde de la végétation dans la mer. Aux branches de ces plantes pendent des fruits qui atteignent parfois plus de 1 mètre de long. En réalité, il s'agit de graines qui ont germé sur la plante mère et qui ont acquis sur l'arbre, par suite de l'humidité de l'atmosphère où vivent ces plantes, la propriété d'être' vivipares. Grâce à cette particularité, la graine qui, d'ordinaire, tombe dans la vase, fréquemment recouverte par la mer, a déjà germé et senfonce profondément dans ce sol mouvant; elle peut donc s'y installer avec une grande promptitude; c'est la raison pour laquelle ces végétaux se maintiennent là où tout autre serait immédiatement balayé par les courants marins.

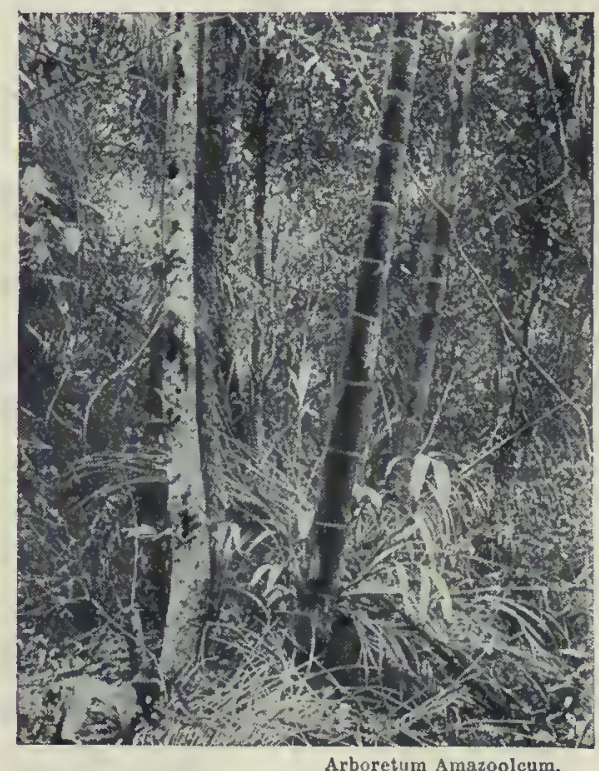

Un Campsiandra laurifolia et deux Astrocaryum Jauaryi (Amazone). 


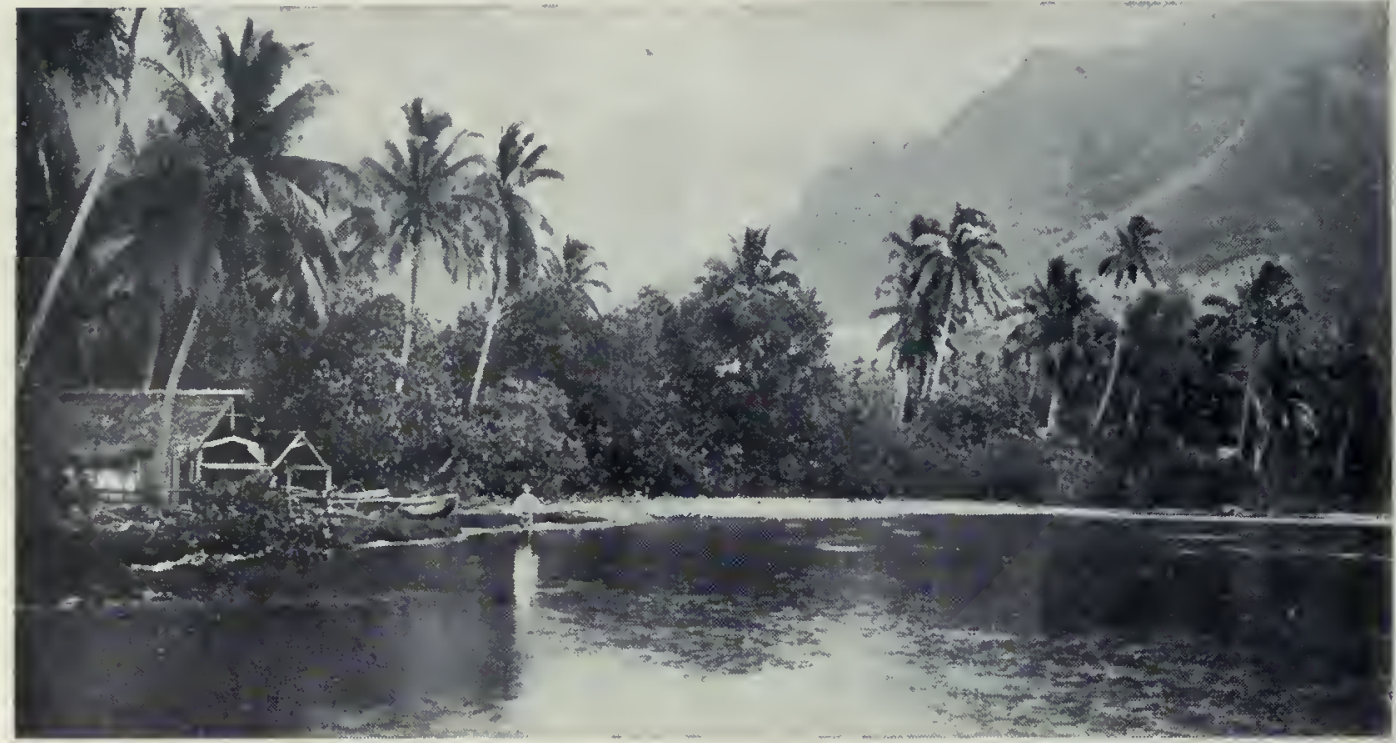

Le rivage à Papétoai (Tahiti).
3500 mètres par une série de zones de végétation, si bien décrites par Alluaud, et caractérisées par des Bruyères arborescentes, de grandes Immortelles, des Lobélia énormes à inflorescence en colonne, des Seneçons arborescents. Dans les forêts, à cette altitude, les arbres sont absolument surchargés de plantes épiphytes.

Les épiphytes, en particulier les Orchidées, ont beaucoup étonné les premiers voyageurs. La culturedes Orchidées, tentée à la fin du Xvirle siècle avait d'abord échoué, parce qu'on les traitait comme des plantes terrestres : c'était aussi absurde que de vouloir élever un poisson hors de l'eau. On finit par les cultiver sur bûches, en paniers suspendus, sur un compost de sphagnum et de
Cette flore littorale a quelques représentants particulièrement remarquables : les Avicennia, à racines respiratoires sortant vers le haut et pointant comme des asperges; les Bruguiera. (Rhizophoracée), les Lumnitzera (Combrétacée), qui ont des racines genouillées; les Carapa (Méliacées), qui ont une arête qui sort de la vase pour respirer.

La flore qui garnit les flancs des montagnes dans les régions tropicales est aussi des plus intéressantes à suivre en altitude. Sur le versant méridional de l'Himalaya, les Palmiers, les Bananiers, les Fougères arborescentes disparaissent vers 2000 mètres, puis les Lauracées vers 2600 mètres et les Magnoliacées vers 3000 mètres. Des arbres voisins de ceux de nos forêts boréales : Chênes, Bouleaux, Conifères, se rencontrent ensuite, mélangés à des essences tropicales (Bambou), et disparaissent vers 3700 mètres. Plus haut, et jusquà 4900 mètres, seétend la région alpine, avec des espèces analogues à celles de nos Alpes. Dans les Andes tropicales, ainsi que sur les hautes montagnes d'Afrique, il en est à peu près de même : les espèces seules diflèrent. En gravissant le Kilimandjaro, on passe, de 2900 à

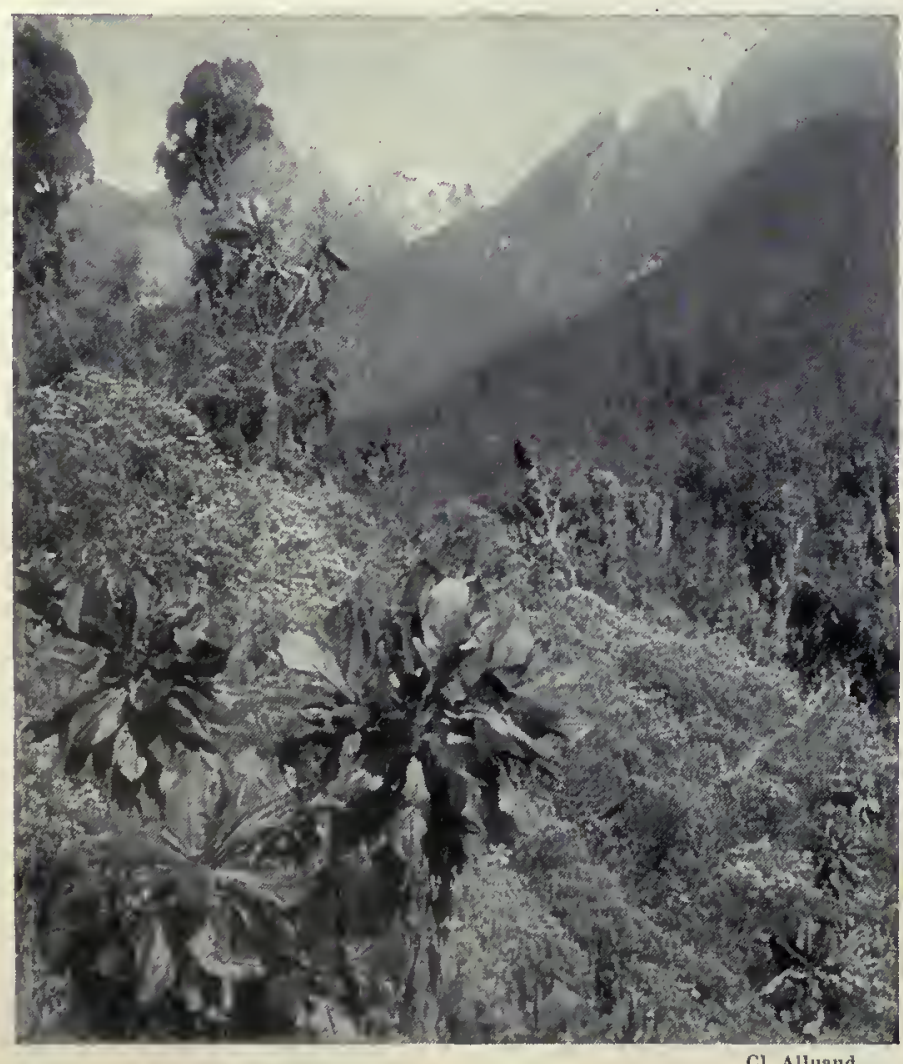

Flore tropicale du Kitimandjaro (Seneçons et Immortelles).

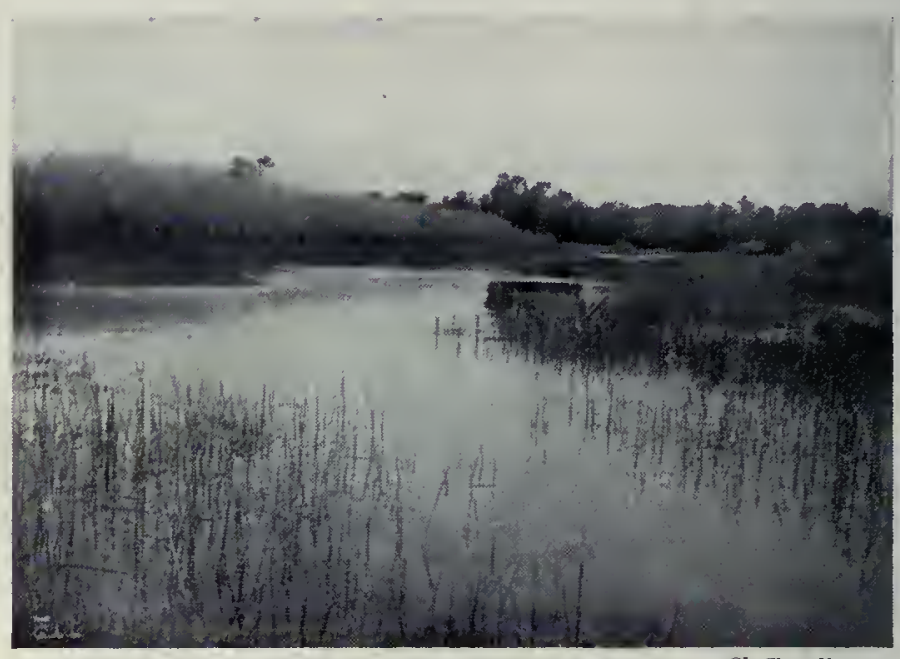

Les bords d'un marigot au Soudan.

Cl. Chevalier.

fibres de Polypode. Mais on exagérait, au début, la haute température et on calfeutrait trop. Malgré cela, ces premières cultures paraissaient très étranges. "Cette culture sans terre, ces racines aériennes, cette atmosphère lourde, vaporeuse, ces feuillages anormaux "), ces fleurs merveilleuses étonnaient les visiteurs. A partir de 1835, grâce au jardinier anglais Joseph Cooper, on parvint à cultiver les Orchidées de montagnes, à la suite des explorations des Cordillères de l'Amérique, des Khasia-Hills de l'Inde, des Monts des Orgues du Brésil. La serre froide permit la réussite de la culture de ces merveilleuses plantes que lon appelle: Odontoglossum crispum, Ada, Lalia majalis, etc.
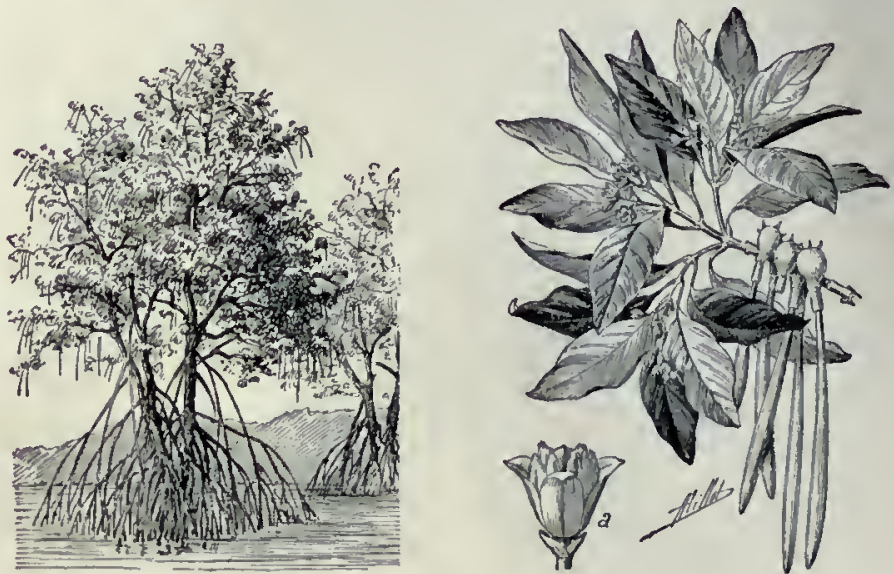

Fig. 114. - Rhizophore ou Palétuvier; détait du feuitlage et fleur $(\alpha)$. 


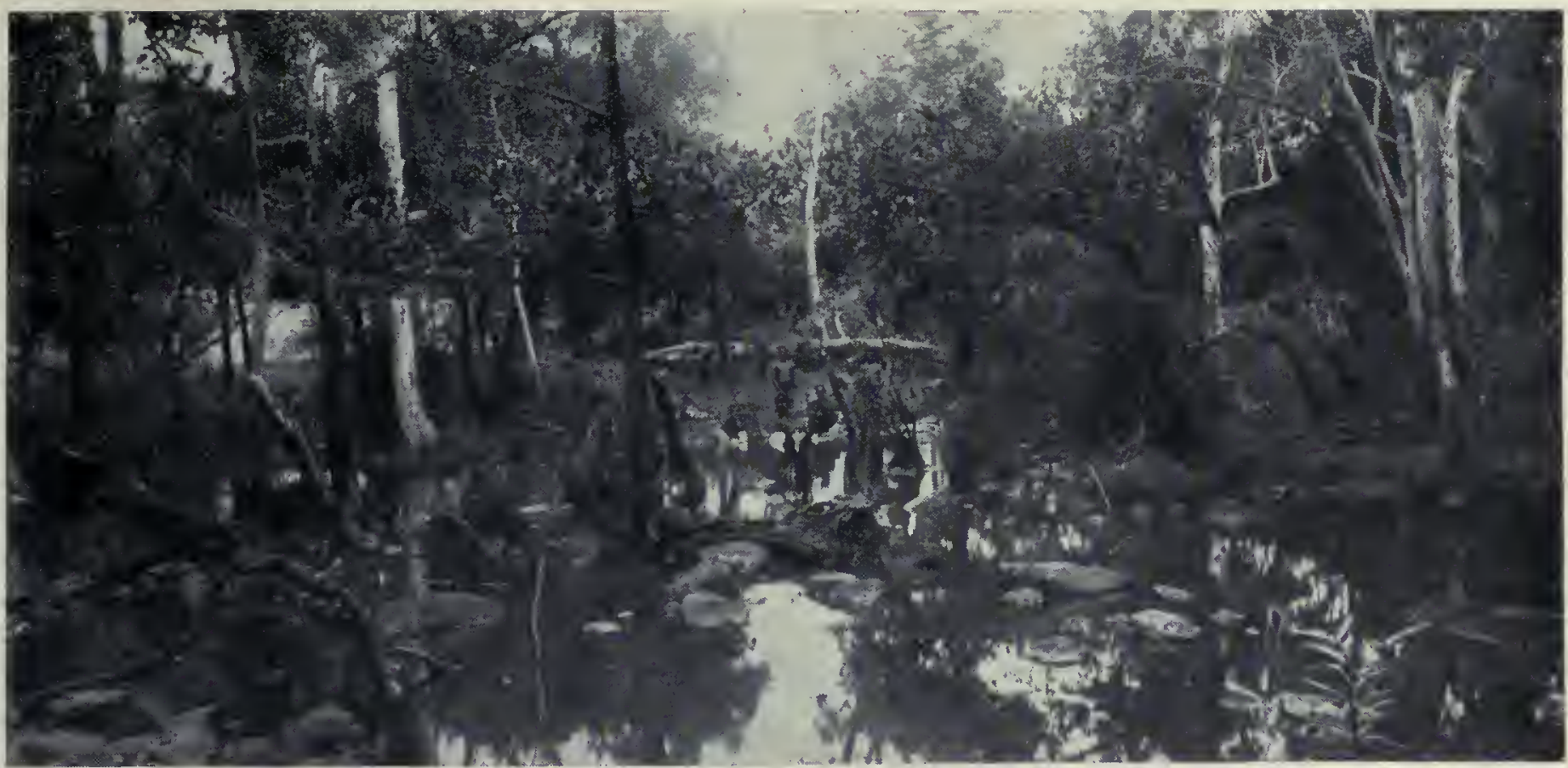

Un gué sur la rivière des Caïmans, à Diégo-Suarez (Madagascar).

G. Alluaud.

\section{FLORE DES ILES}

Caractères généraux. - Les flores insulaires offrent un intérêt tout particulier, parce qu'elles nous donnent souvent des étapes de l'évolution. C'est, en particulier, par l'étude de la flore et surtout de la faune des îles Galapagos que Darwin, en 1831, fut converti aux idées transformistes : i] remarqua, en effet, que les animaux qui peuplaient les îles de cet archipel avaient des caractères américains, mais qu'on ne trouvait aucun d'eux en Amérique; il constata, en outre, qu'il y avait des espèces spéciales dans chaque île, appartenant à des genres identiques qui n'existaient nulle part ailleurs sur le globe. C'était donc une preuve convaincante de la théorie de la transformation des êtres dans les temps passés.

Quelque chose d'analogue s'observe, par exemple, dans les îles Juan-Fernandez, qui se trouvent à 640 kilomètres en face de la côte du Chili : elles sont d'origine volcanique de la base au sommet et les éruptions qui leur ont donné naissance sont de l'époque tertiaire ou des périodes postérieures. A moins qu'il n'y ait eu génération spontanée, il faut donc admettre que cette flore dérive de celle des continents voisins, et c'est l'Amérique du Sud qui a dû contribuer surtout au peuplement de cet archipel; toute la flore, en effet, səmble d'origine américaine par ses affinités; il y a des espèces qui y paraissent transportées encore à l'heure actuelle : ce sont les types non endémiques, c'est-à-dire qui se retrouvent en Amérique ; 143 sont dans cette catégorie : ces plantes ont toutes été transportées par le vent, par les oiseaux marins ou par les courants marins. Nous pouvons d'ailleurs être renseignés sur la façon

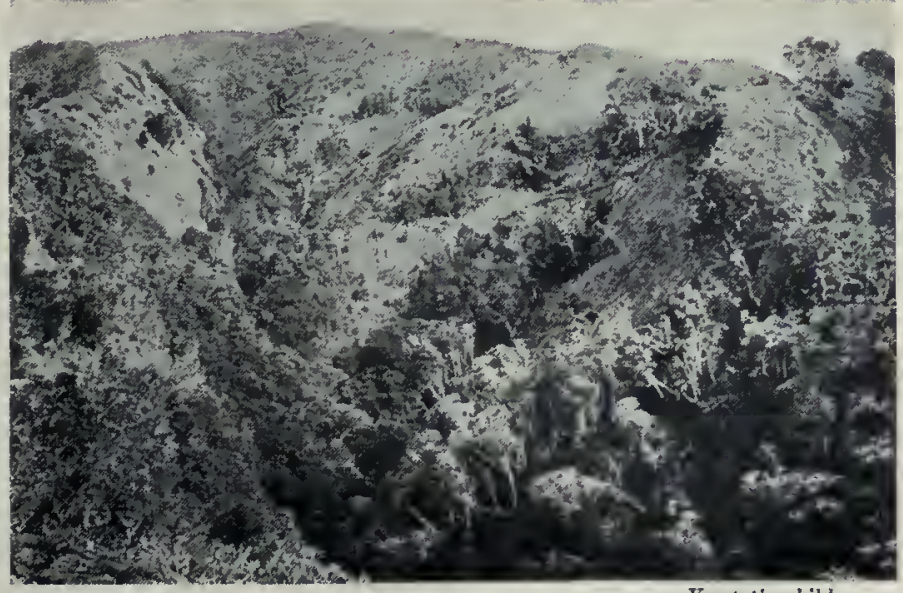

Vegetationsbilder.

Flore de Masafuera (Juan-Fernandez) : Myrceugenia Schultzei. dont se fait le peuplement d'une île nouvellement formée à l'heure actuelle : Treub, à Java, a suivi d’année en année la réapparition de la végétation dans l'île Krakatau, qui avait été presque complètement détruite après une épouvantable éruption volcanique. Quelques mois après l'éruption, il y eut peuplement surtout de Fougères par le vent, puis au bout de dix ans, de vingt ans, a dominé le rôle des courants marins pour la reconstitution de la flore du littoral. Aux Açores, sur 480 espèces, 439 ont été trouvées en Europe, à Madère, aux Canaries; parmi ces espèces, on en distingue 45 dont les fruits ou les graines ont un appareil de vol (aigrette, aile); 65 ont des graines très petites et très légères (transportées par le vent), 84 sont glumacées (transportées par le vent ou les courants), 38 ont des fruits charnus (transportés par les oiseaux qui les mangent). Ces données peuvent servir à expliquer la constitution de la flore endémique des îles Juan-Fernandez : sur 69 plantes de cette catégorie, il y en a 61 présentant les caractères suivants de leurs semences; 19 à drupes et baies ont pu être transportées dans les temps passés par les oiseaux de mer; 34 ont des graines petites ou à appareil de vol, qui ont été transportées par le vent ; 8 à graines ou fruits dans un périgone et transportables par les courants. Les espèces introduites dans cet archipel par ces procédés de propagation, qui sont ceux que nous connaissons à l'heure actuelle, s'y sont installées et y ont évolué : elles ont disparu du continent d'où elles venaient et on ne les trouve plus nulle part ailleurs sur le globe. Ce qui est plus extraordinaire, c'est que, pour certaines de ces espèces endémiques, l'évolution a eu lieu dans un sens déterminé dans chaque îlot de l'archipel : on

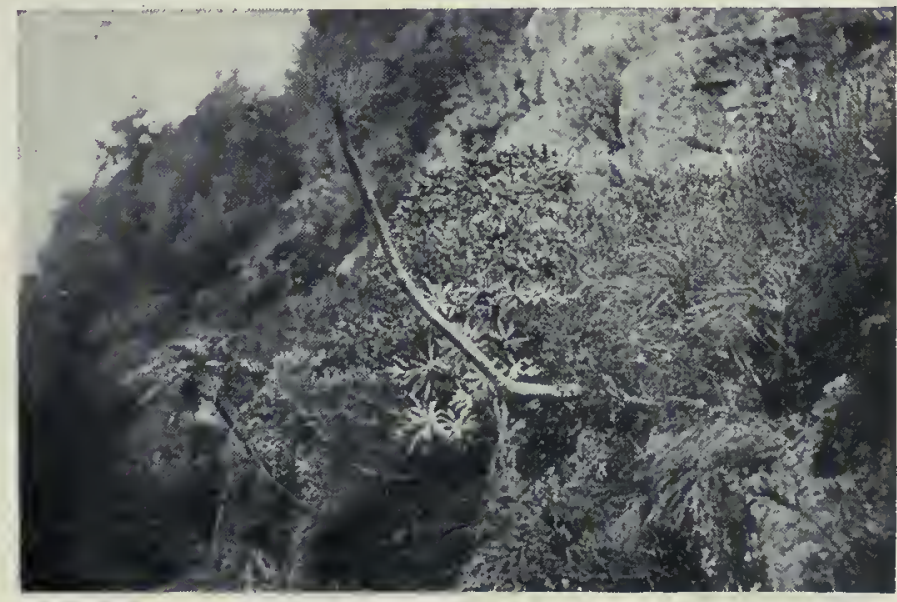

Flore de Juan-Fernandez : Dendroseris, Robinsoniả. 


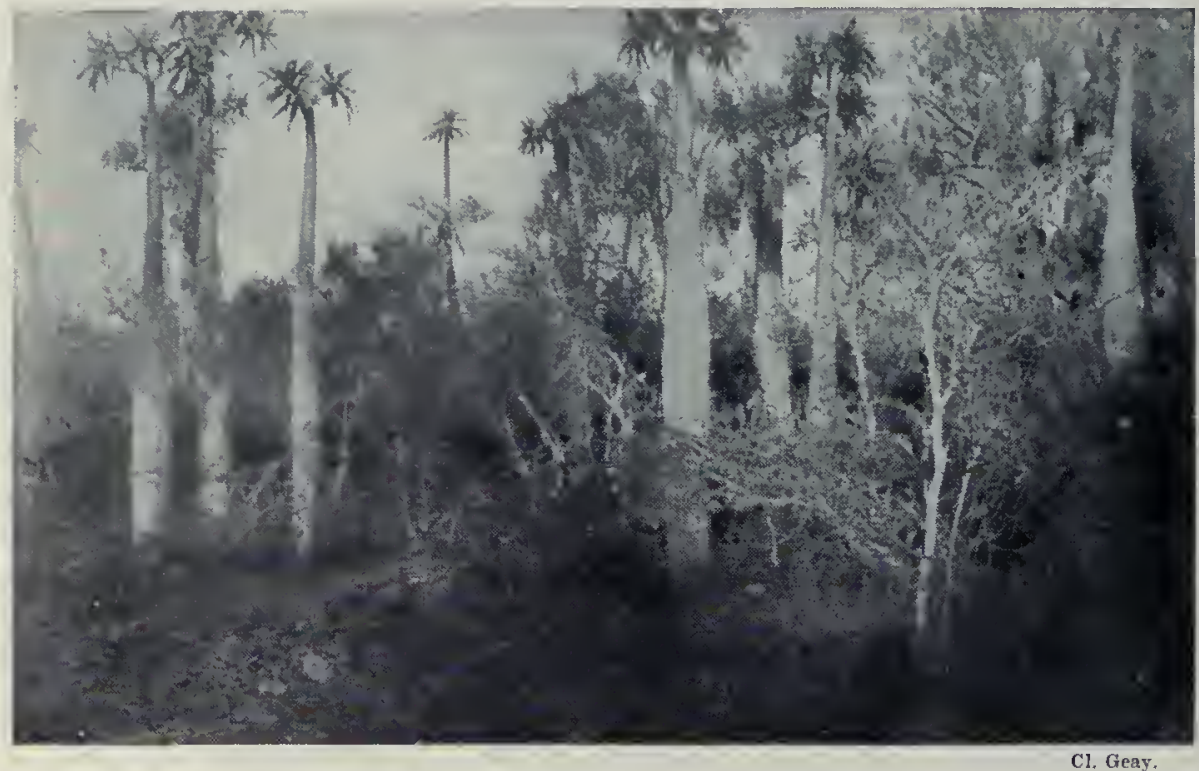

Groupe de Pachypodium Geayi (Madagascar).

Flore de Madagascar. - A Madagascar, il y a lieu de distinguer trois régions : celle de la forêt tropicale, sur la côte orientale; celle des savanes des contrées montagneuses du Centre et du Nord-Ouest; enfin celle du Sud-Ouest, qui est presque désertique et peuplée surtout par des plantes épineuses. La première région est caractérisée par des $\mathrm{Va}$ quois, en forme de candélabre, de 18 mètres de haut, à feuilles de 3 à 4 mètres de long, dont la tige atteint à sa base 1 mètre d'épaisseur; par l'Arbre du voyageur ou Ravenala de Madagascar; par le Raphia ruffia, quj est un Palmier. La présence d'une Lythracée endémique rare (Lagerslrœmia) indique bien une relation avec le domaine indien des moussons. C'est surtout la région du SudOuest, de caractère demi-désertique, qui est intéressante. C'est là que se trouvent des familles nouvelles, comme les Didiereacées (ayant des affinités avec les Polygonacées), composées de ces plantes épineuses curieuses, les Didiere $a$ et les Alluaudia, tel l'Alluaudia procera (A. élevé). On y trouve aussides Apocynacées remarquables, comme le Pachypode de Geay: une flore curieuse d'Asclépiadacées,

trouvera dans les deux îles Masa tierra et Masa fuera, de l'archipel de Juan-Fernandez, des espèces voisines, mais distinctes :

MASA TIERRA

Dendroseris pinnata.

Wahlenbergia Berteroi.

Eryngium bupleuroides.

Myrceugenia Fernandeziana.
MASA FUERA

Dendroseris gigantea.

Wahlenbergia tuberosa.

Eryngium sarcophyllum.

Myrceugena Schultzei.

Les flores des îles perdues dans les océans sont donc extrêmement intéressantes au point de vue de l'évolution de la vie sur le globe; malheureusement, depuis que l'Européen les a découvertes, il a contribué notablement à en détruire ou en altérer la végétation. L'île Sainte-Hélène était, en 1501, au moment de sa découverte, peuplée d'une flore très curieuse, mais des chèvres furent introduites en 1513, et leur nombre s'accrut avec une grande rapidité; en 1700 , les forêts avaient déjà beaucoup diminué et, à l'heure actuelle, beaucoup d'espèces qui n'existaient que là sur le globe ont disparu. A la Nouvelle-Zélande, l'arrivée du blanc a amené l'invasion de la Renouée aviculaire, du Laiteron potager et d'autres plantes européennes. Nous ne possédons plus qu'un fragment de la flore des Mascareignes, parce que la culture de la Canne à sucre a amené la destruction de la forêt vierge.

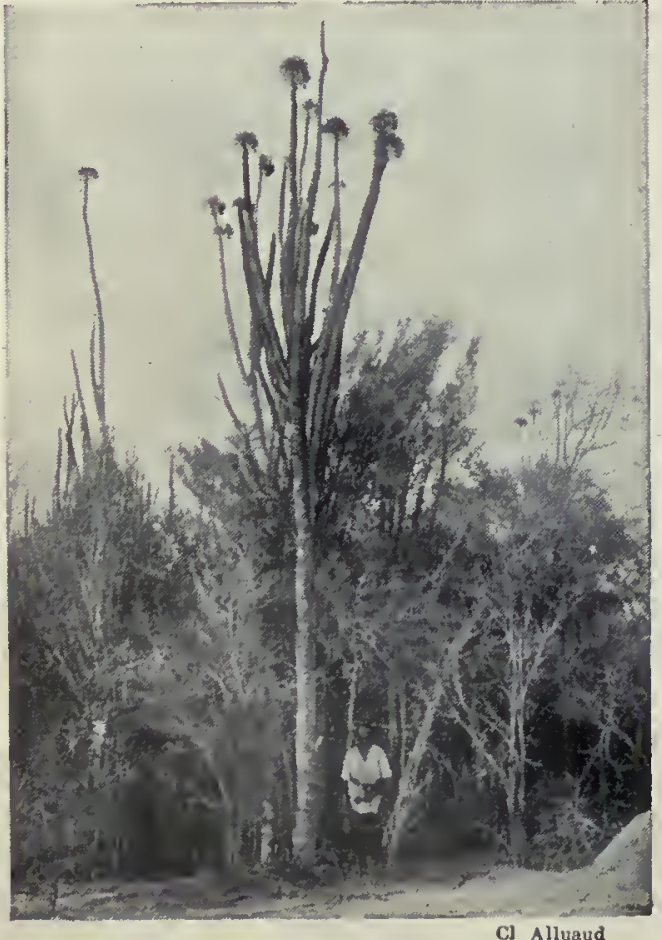

Alluaudia procera (Madagascar).

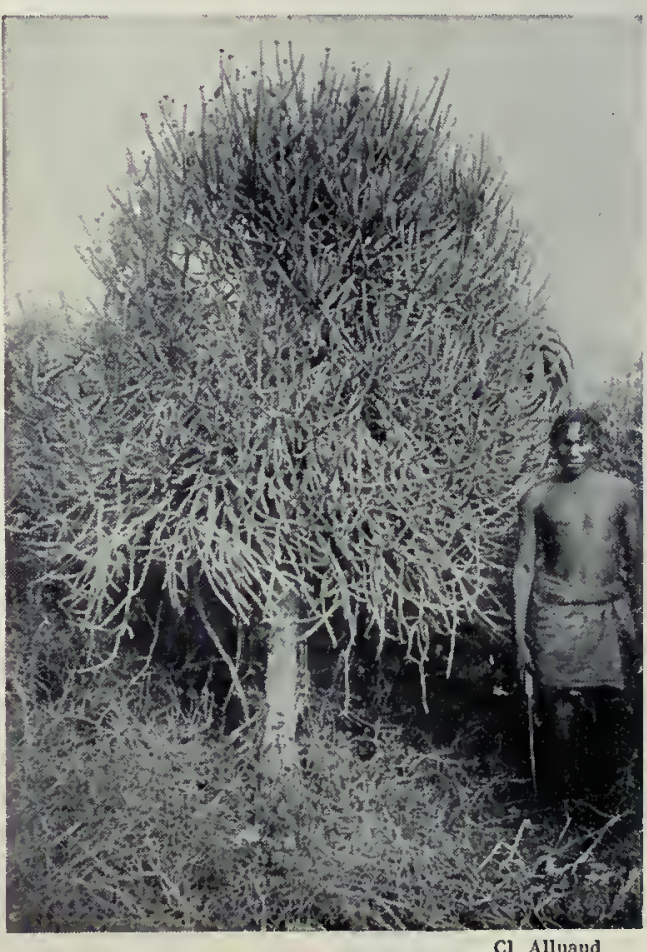

Euphorbia Laro (Madagascar) comme le Kompitsé, qui donne du caoutchouc (Gonocrypte de Greve), et une légion d'Euphorbes sans feuilles.

L'aspect de la végétation de Diego-Suarez permet de prendre une idée de la seconde flore du nord. La flore de Madagascar est d'ailleurs en accord avec sa faune (Lémuriens) pour montrer l'autonomie et l'antiquité de cette grande île.

Flore d'Australie. - L'Australie est de même renommée comme la patrie des marsupiaux. Cette île immense, qui est un véritable continent, n'a pas, comme de juste, un climat uniforme : elle possède, au Nord, un climat tropical et au Sud, un climat presque méditerranéen; en outre, il y a au centre un véritable désert. Il y a deux éléments étrangers principaux dans cette flore: l'élément malaisien et mélanaisien et l'élément antarctique; ils sont associés avec l'élément australien. La flore de l'Australie comprend environ 1400 genres, 8850 espèces; il y en a seulement 15 pour 100 qui se retrouvent ailleurs; toutes les autres et la majorité des genres sont endémiques; parmi les espèces spéciales (australes), 40 pour 100 se trouvent dans l'Australie occidentale. Sur la côte nord, soumise au climat tropical, se trouvent des bouquets de Palmiers (Kentia et Livistona), des formations de Vaquois, de Bauhinia, d'Arbres à thé, de Leptospermes. Sur la côte orientale du Queensland, on a de grandes forêts, à l'ombre desquelles croissent des Fougères en arbre et des $\mathrm{Pal}$ miers grimpants, comme le $\mathrm{Ca}$ lame austral; une Urticacée ( $L a$ porlea moroides), dont les piqûres produisent souvent des inflammations mortelles, notamment pour les chevaux; on y trouve aussi des Araucaria de Bidwell (BunyaBunya, fig. 115), à graines comestibles, à feuillage persistant, ainsi que les Livistona. Dans l'Australie méridionale se trouvent des forêts d'Eucalyptus (fig. 116), forêts sans ombre, d'arbres atteignant 100 mètres et plus; on peut trouver dans cette contrée et en Tasmanie des Fougères arborescentes (Cyathées, Dicksonia, Todea) qui forment le sous-bois. Il y a aussi quelques Protéacées (Grévillée, Hélicie), mais elles sont moins nombreuses que dans l'Ouest; dans la région alpestre des Alpes australiennes, entre I 200 et 2000 mètres, il y a des Hêtres antarctiques et des formes alpines d'Eucalyptus ( $E$. pauciflore, E. alpin), avecdes Ericacées 


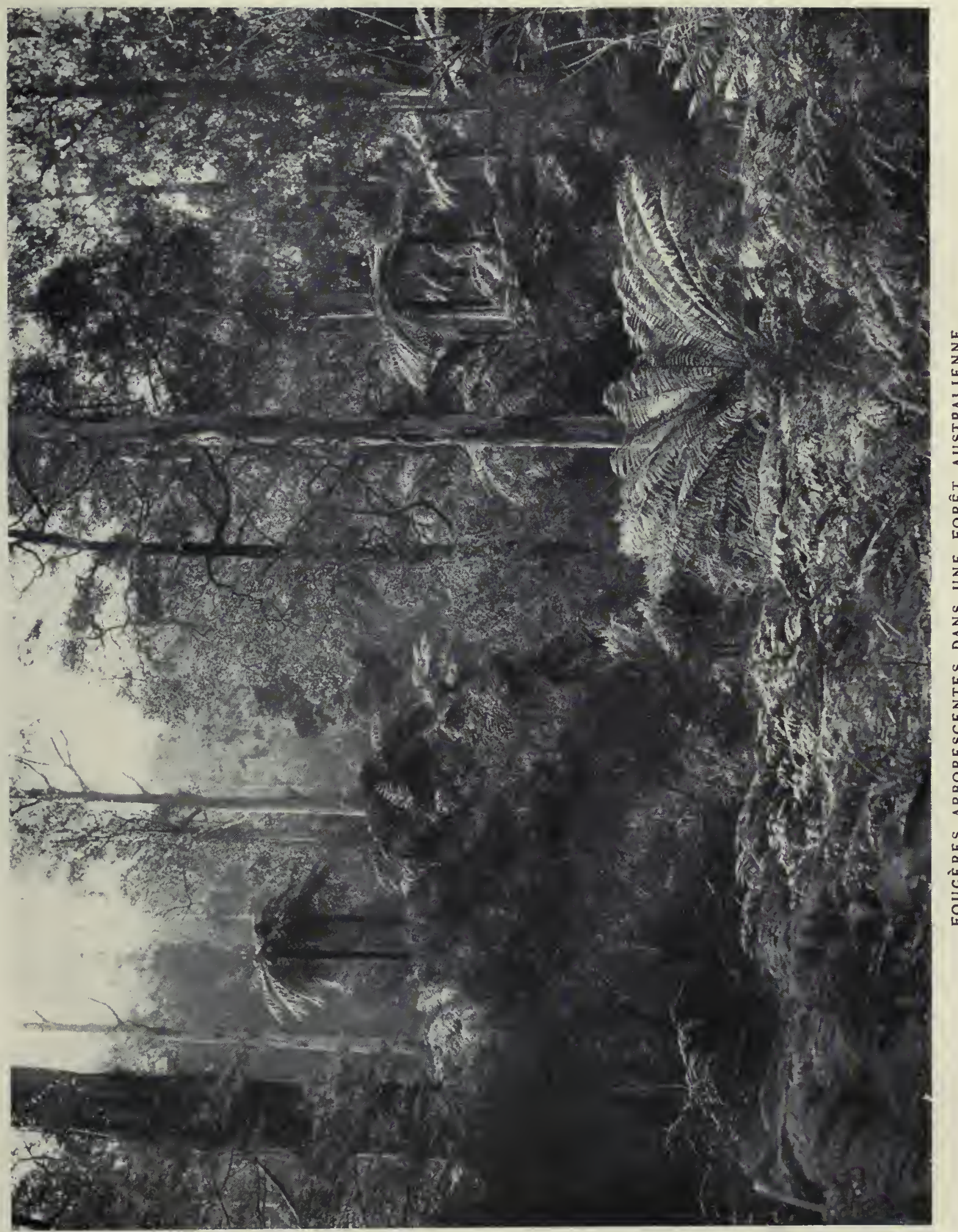





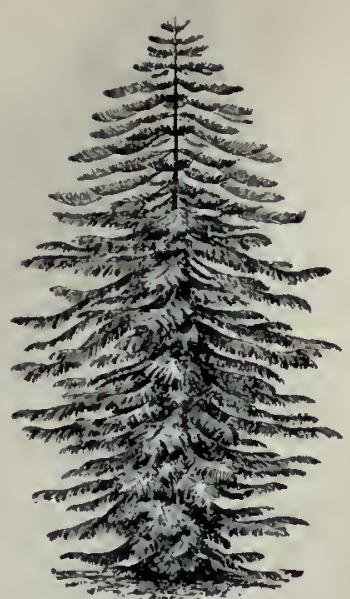

Fig. 115.

Araucaria.

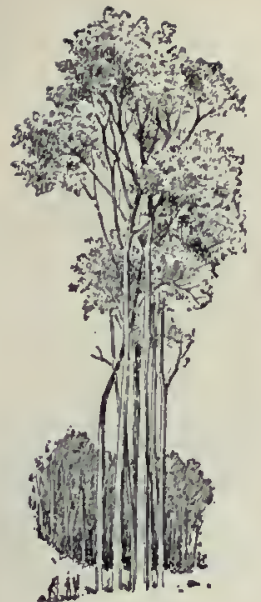

Fig. 116.

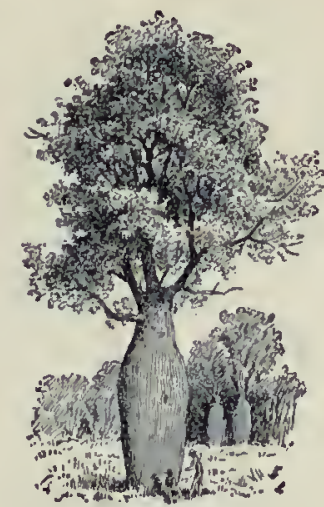

Fig. 117.

Arbre-bouteille.

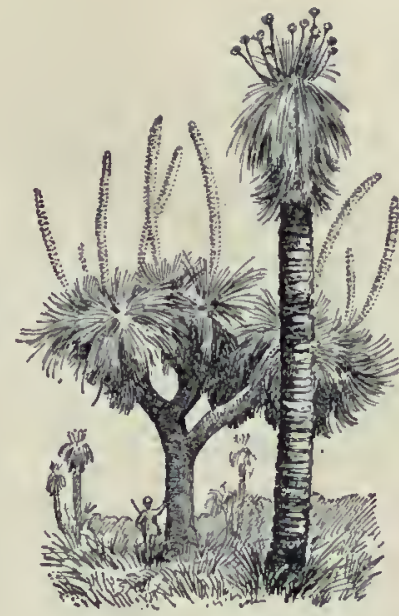

Fig. 118. - Xanthorrhée (à gauche) et Kingia.
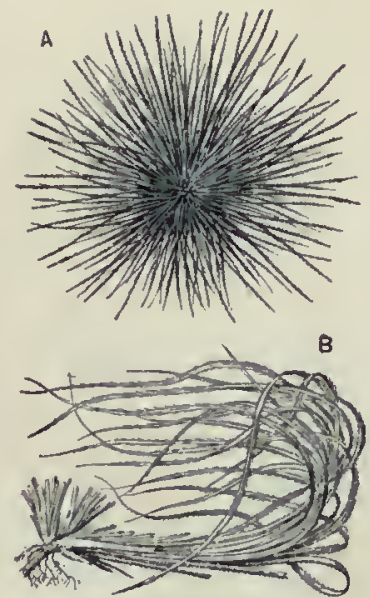

Fig. 119.

A, Triodie ; B, Spinifex. alpines (Wittsteinie) et des plantes analogues aux espèces européennes (Laiche, Alchimille, Botryche). La Tasmanie possède une région de Conifères remarquables, avec les Phylloclades, les Fitzroya, etc.

La région du Sud a une flore bien spéciale de Liliacées et de Protéacées (Swan River). Les Liliacées (ou Joncacées de certains auteurs) australiennes comprennent sept genres de plantes endémiques: Kingia (fig. 118), Johnsoniées, etc.; un intérêt véritable se rattache aux Xanthorrhées arborescentes (fig. 118) dont les étranges formes de végétation ont depuis longtemps frappé les colons anglais qui lesont désignées sous les noms de "Grass trees" ou "blackboys " (Xanthorrhée de Press); le Xerotes de Banks est commun à la fois à l'Australie et à la Nouvelle-Calédonie; c'est également la patrie du Dasypogon, des Brachychiton ou Arbre-bouteille (fig. 117). La famille des Protéacées est formée d'arbres généralement petits, rarement élevés, ou d'arbustes bas à feuilles persistantes, fleurissant très jeunes et ayant l'aspect de plantes annuelles; elles abondent dans l'Australie extratropicale (Persoonie, Grévillée, Banksie). L'intérieur de l'Australie est presque dépourvu de végétation sur de grandes étendues; il serait cependant peu exact de l'assimiler tout à fait à un désert; il y pleut en général un peu et on y trouve des buissons toujours verts formant les scrubs, et composés principalement de Brigalow (Acacia harpophylle); il y a - également, surtout dans les stations favorisées, quelques Graminées, comme l'Herbe au porc-épic ou Triodie et les Spinifex (fig. 119).

Flore de la NouvelleZélande. - La flore de la Nouvelle-Zélande comprend 950 espèces de Phanérogames, 130 Fougères: il y a plus de 60 pour 100 d'espèces endémiques, mais, sur 300 genres, il n'y en a que 24 de spéciaux à cette contrée. La végétation a des affinités avec celles de l'Asie tropicale, de l'Australie et des terres antarctiques. Les espèces qui existent à la fois en Nouvelle-Zélande et sur le grand continent australien sont rares; ce sont surtout des

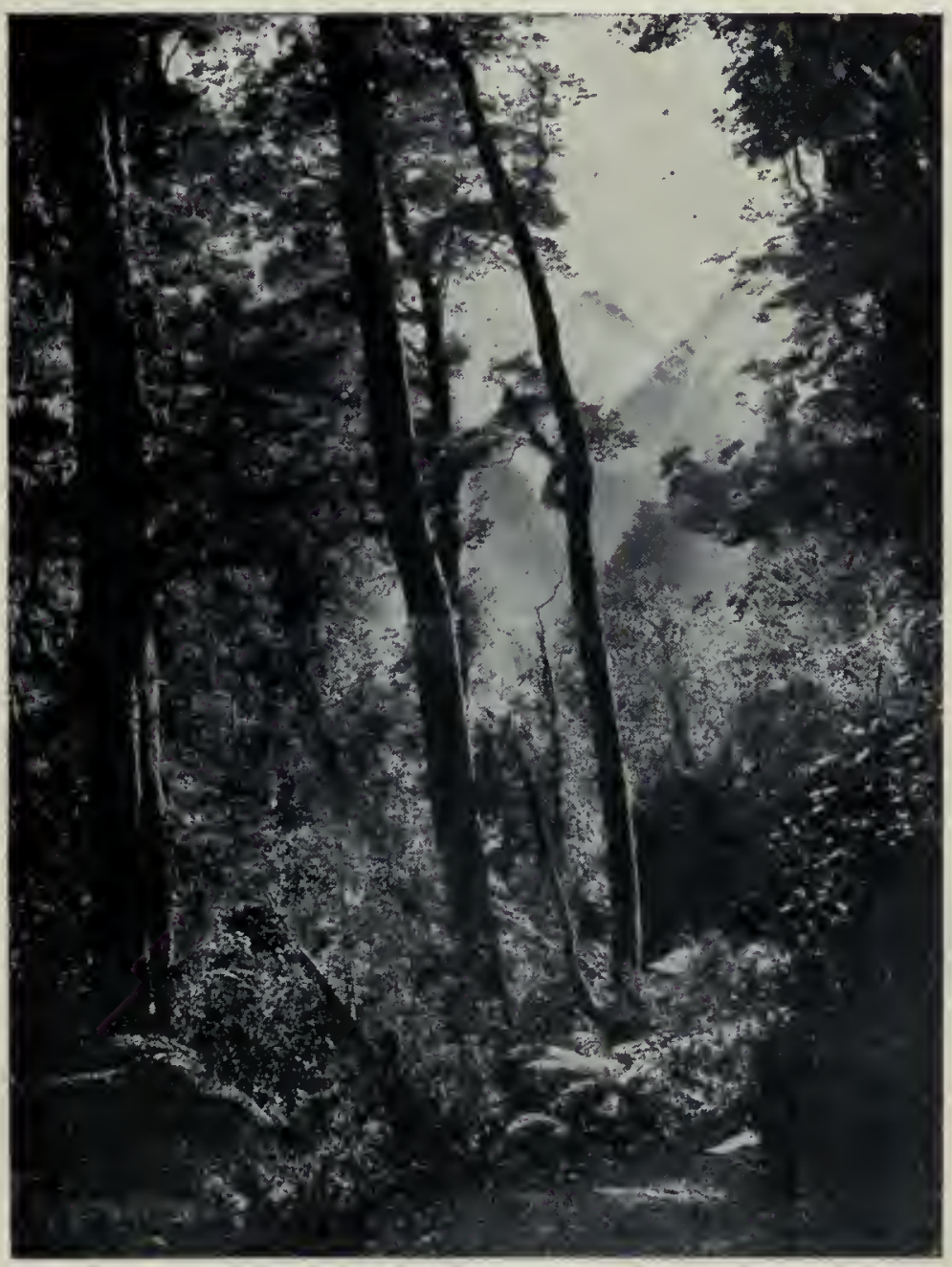

Paysage forestier de la Nouvelle-Zélande. types montagnards des Alpes australiennes et de Tasmanie. Les essences forestières de la Nouvelle-Zélande sont très remarquables et spéciales : on y observe des Conifères : Libocèdres, Phylloclades, Podocarpes, Dammara; les Hêtres, surtout le Hêtre de Solander, couvrent de grandes surfaces; il y a aussi le Cordyline austral qui est une Liliacée voisine des Dragonniers, puis des Protéacées, comme le Knightie élevé, des Homoxylées (Drimys axillaire); dans les grandes forêts, on retrouve des Myrtes, des Araliacées; les Fougères arborescentes, représentées surtout par les Cyathées, peuvent pousser jusque dans les montagnes au voisinage de la neige. La flore des montagnes est représentée par des espèces spéciales de Hêtres.

On a fait une remarque assez générale sur les fleurs des plantes néo-zélandaises : elles sont, pour la plupart, insignifiantes et verdâtres; on avait d'abord cru pouvoir expliquer ce fait par l'absence d'insectes dans cette contrée, mais une étude plus approfondie a montré que ces animaux ne sont pas du tout rares et un grand nombre d'entre eux opèrent la fécondation ; mais tandis quen Europe ce sont surtout les hyménoptères qui visitent les fleurs, en Nouvelle-Zélande, c'est surtout aux mouches et aux scarabées que cette fonction incombe.

La température dans cette région est très uniforme, comme dans les climats insulaires. C'est ce qui résulte du tableau suivant :

TEMPÉRATURE DE TARANAKI (ILE NORD)

Janvier. . . . 18 18 7

Février. ..... 18, 6

Mars. ..... 160,9

Avril. . . . . . 150

Mai . . . . 120 $12^{\circ}, 6$

Juin ..... 1 $11^{\circ}, 0$

Juillet ......... 10 10,4

Août. . . . . 10 $10^{\circ}, 0$

Septembrs.... $11^{\circ}, 8$

Octobre ... 13,2

Novembre.... $15^{\circ}, 1$

La quantité d'eau de pluie dans cette même contrée est de $1500^{\text {min }}$ à Taranaki (île Nord) [janvier $226^{\mathrm{m} m}$, mars 171, mai 161 , juillet 244 , septembre 149, novembre 322 , etc. $;$; elle s'élève à

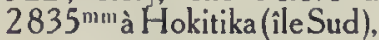
où la température $s$ abaisse jusqu'à $7 \circ, 3$ en juillet. 


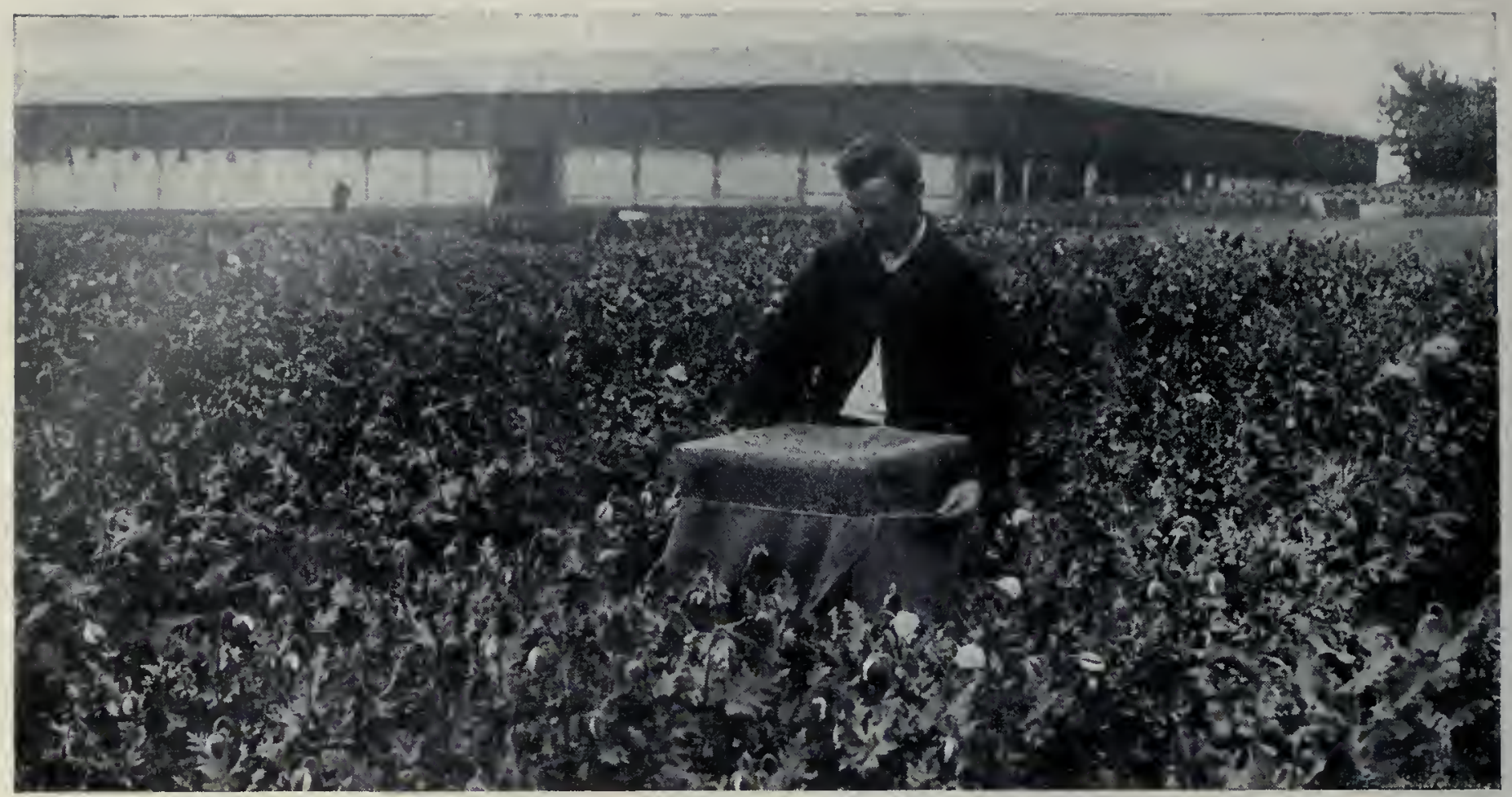

PROTECTION D'UN PAVOT FECONDÉ POUR EMPECHER LA FECONDATION PAR LES INSECTES.

\section{IV. - LE TRANSFORMISME}

\section{LE TRANSFORMISME}

Variabilité des espèces. - La variabilité est une propriété essentielle des êtres vivants; les plantes surtout la possèdent à un haut degré. Chacun a pu observer des modifications au type normal des plantes bien connues : folioles en surnombre, pétales supplémentaires, racines tuberculeuses ramifiées ou même volubiles, comme la curieuse carotte reproduite ci-contre, etc. Certaines de ces " monstruosités ") sont célèbres : citons la rose prolifère, dont la tige se continue au-dessus de la fleur; la poire prolifère, dont l'œil est traversé par une petite branche.

Tout le monde connaît les asperges fasciées qui, au lieu d'être rondes, sont plates, contournées. La fasciation est fort commune; on l'observe chez les végétaux les plus divers: Plantain, Chicorée, Cactées comme les Mamillaires, etc. La Célosie crête-de-coq ou
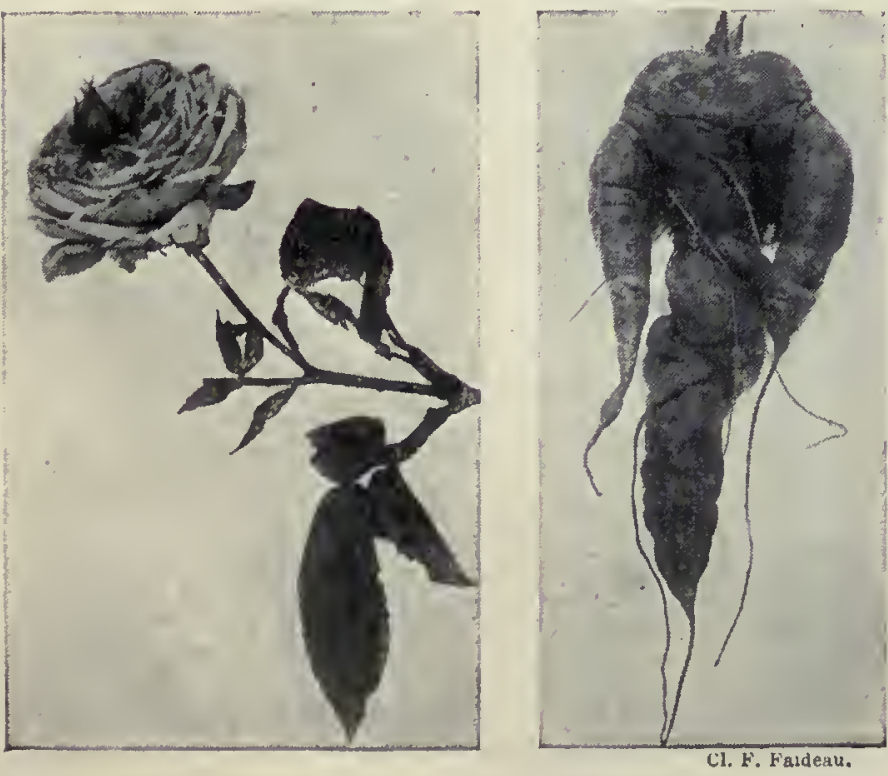

Rose prolifère et Carotte ramifiée et volubite.
Passe-velours, cultivée dans les jardins, présente une fascie tellement constante qu'clle peut être considérée comme l'état normal. La forme des inflorescences est aussi fort variable : les nègres cultivent, en Afrique, du Mil à épis en parasol et du Mil à épis droits.

La Massette ou Typha à feuilles larges, si commune au bord des eaux, porte des fleurs monoïques groupées en épis compacts ; l'épi mâle, au sommet de la hampe, tombe après la fécondation; il n'en reste que l'axe, plus ou moins flétri. Quant à l'épi femelle, situé au-dessous, il subsiste longtemps sous forme d'un cylindre de velours fauve. Au cours d'une promenade au bord de l'eau, on observe de nombreuses monstruosités de l'épi ; tantôt ce sont deux épis femelles se faisant suite et séparés par un faible intervalle, tantôt c'est une ramification anormale de l'axe en deux, trois ou quatre épis séparés dès la base ou plus ou moins complètement soudés. Ces anomalies peuvent provenir de la nutrition de la plante, de maladies cryptogamiques, de mutilations par des animaux parasites.

Un autre exemple bien curieux est celui des Trèfles à quatre feuilles (en réalité ce sont des folioles; il peut même y en avoir cing et six). Cette particularité exceptionnelle, qui est recherchée par les personnes espérant que ce fétiche leur portera bonheur, a pu être rendue assez fortement héréditaire par la culture et l'on peut avoir des champs de production, en vue de donner satisfaction aux personnes superstitieuses.

On pourrait multiplier beaucoup ces exemples, mais il y a lieu surtout d'insister sur ceux dont l'importance économique est considérable. Une plante nouvelle, une race jusque-là inconnue de Céréale qui se répand dans une province peuvent contribuer à l'enrichir; l'apparition d'un type de Betterave à grand rendement peut être quelquefois le point de départ d'un accroissement prodigieux de la richesse nationale.

L'exemple des variétés du Chou potager, qui sont connues de tous, peut servir de point de départ à notre examen de la question du transformisme. On connaît, en effet, la plante sauvage spontanée sur le littoral de la Manche, de la mer du Nord et de la Méditerranée; elle a donné naissance à ces types nombreux que nous rencontrons chez les cultivateurs et sur les marchés. La première année, le Chou sauvage débute par une rosette de grandes feuilles pennatiséquées lyrées, à lobe terminal large. C'est seulement l'année suivante que la tige se ramifie et fleurit. La douceur du climat marin favorise la persistance de la plante, qui vit trois ou 
quatre ans, fleurissant chaque année, mais n'ayant que des feuilles de petites dimensions. Ces caractères ne nous rappellent ni ceux du Chou pommé dont l'énorme bourgeon terminal est une grosse boule, ni le Chou cavalier dont la hauteur dépasse celle d'un homme, ni le Chou de Bruxelles qui possède une multitude de bourgeons comestibles, ni le Chou-rave à tige renflée, ni le Chou-navet à grosse racine, ni le Chou-fleur à inflorescence hypertrophiée formant, au miljeu des feuilles, une partie blanche si appréciée des consommateurs.

Le nombre des variétés de Choux paraît s'être multiplié beaucoup dans le cours des siècles. Théophraste, du temps d'Alexandre le Grand, n'en connaissait que 3; Tournefort, sous Louis XIV, en a signalé 20; De Candolle, 30; Lund et Kjaerkou, de nos jours, 122. On doit noter que toutes ces variations portent sur les feuilles, les tiges, les bourgeons, c'est-à-dire sur les organes que l'homme utilise pour son alimentation; la constitution de la fleur et celle du fruit sem-

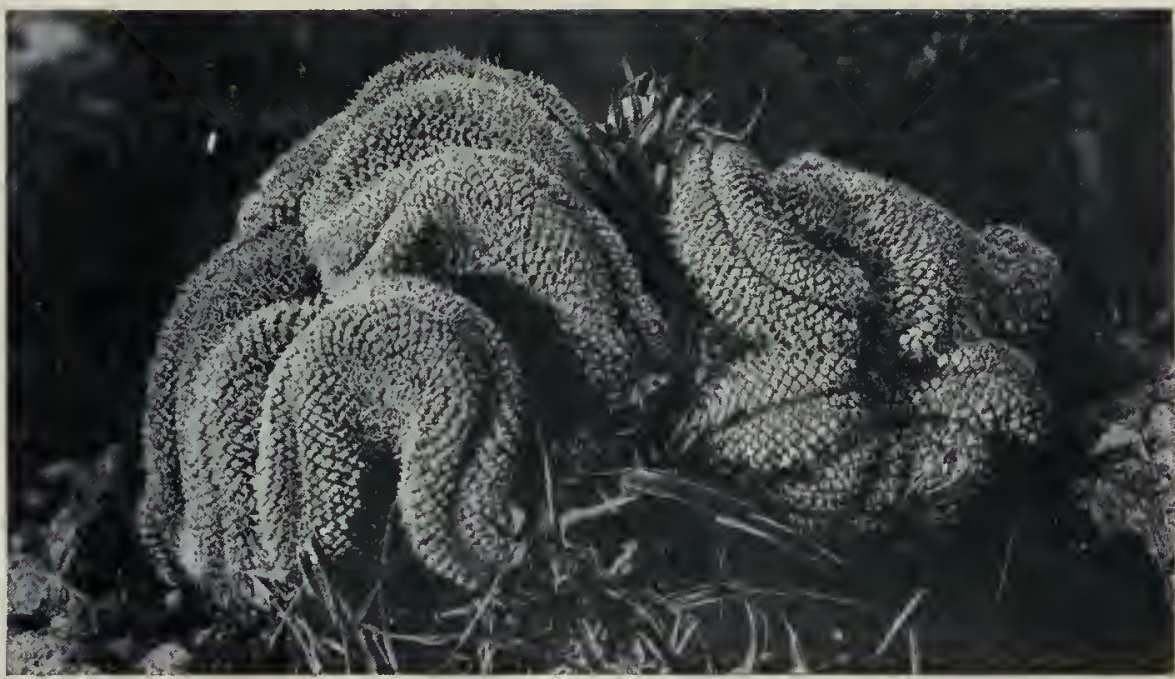

blent indiquer, au contraire, que ces organes sont parfaitement constants. Ce sont donc probablement les triages, involontaires ou conscients, qui orientent le perfectionnement des variétés; ils constituent ce que Darwin a appelé la sélection artificielle.

Sélection naturelle. - La sélection artificielle, quj s'opère par l'intervention de l'homme, s'oppose à la sélection naturelle, laquelle intervient d'une manière continue partout dans la nature. La concurrence vitale s'exerce sur une échelle immense. Une plante annuelle qui ne donnerait que deux graines par an aurait une descendance de plus d'un million d'individus en vingt ans, si tous ses rejetons survivaient. Mais on sait qu il est des animaux et des plantes (les Orchidées notamment), qui produisent des milliers de semences ou de graines. Il est évident que les descendants d'un seul de ces êtres prolifiques pourraient, en peu de temps, envahir la terre, sans laisser de place pour le développement d'aucune autre plante ou d'aucun autre animal.

11 est rare qu'un développement extraordinaire d'une espèce se produise ou, quand cela a lieu, comme pour la multiplication fantastique du pigeon voyageur aux États-Unis, tous les êtres voisins se livrent à une telle destruction que bientôt l'équilibre est rétabli, et le nombre des animaux et des plantes d'une région est à peu près constant pendant une série d'années.

La lutte pour l'existence entre les êtres a pour conséquence la survivance du plus apte, et ce résultat du combat se manifeste avec une netteté particulièrement frappante dans les phénomènes de mimétisme qui sont si saisissants quand on étudie le règne animal. Ils ont été mis en évidence par Wallace qui, par une voie tout à fait différente de celle suivie par Darwin, arrivait à des résultats analogues en même temps, car les découvertes fondamentales de ces deux savants ont été publiées le même jour ( $\mathbb{l}^{\mathrm{er}}$ juillet 1858) à la Société linnéenne de Londres. La mimique, c'est l'imitation qui se trahit par la fourrure ou le plumage des animaux polaires qui vivent sur la neige et qui sont blancs, afin de pouvoir
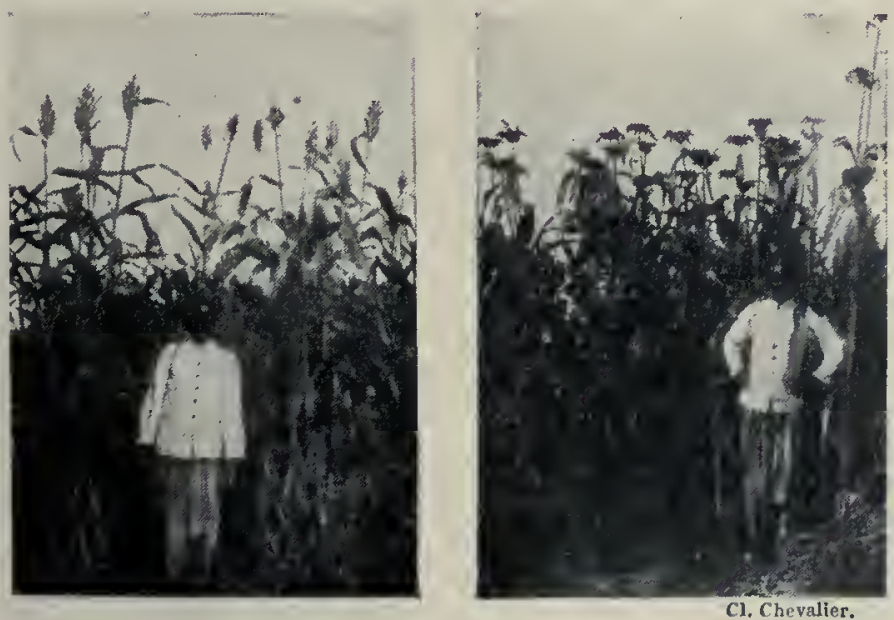

Mil à épis droits et à épis en parasol, au Soudan.

échapper à leurs ennemis (Lièvre polaire) ou s'approcher subrepticement d'eux (Ours polaire). C'est aussi l'imitation d'un autre animal ayant un moyen de défense déterminé : les Sésies, qui imitent d'une façon si singulière les Guêpes et les Frelons, dont l'aiguillon est redouté. D'autres parviennent à échapper à. leurs ennemis en ressemblant à des végétaux par leur forme, leur aspect, leur couleur.

Le fait le plus extraordinaire du mimétisme est celuj de ces curjeux papillons, les Kallima inachis, qui ressemblent à des feuilles lorsque leurs deux ailes sont rabattues, de manière à se toucher par leurs faces supérieures : les faces inférieures présentent les nervures principales et secondaires; fixés sur la branche et immobiles, ils ressemblent à s'y méprendre à des feuilles : ils offrent jusqu'aux taches, qui sont dues à des cryptogames. D'autres insectes, Phasmes et Chenilles, ressemblent à des brindilles de bois par leur forme et leur couleur. Ce sont là des phénomènes merveilleux quj ont été mis en lumière par Wallace et qui sont particulièrement propres à attirer l'attention des penseurs et des philosophes.

Les cas de mimétisme paraissent plus rares dans le règne végétal; cependant on a signalé comme assez frappantes les similitudes singulières du Lamier blanc ou Ortie blanche et de l'Ortie diö̈que; cette dernière possède, grâce à ses poils urticants, des moyens de défense fort énergiques et très efficaces. Ces deux plantes croissent souvent côte à côte, mélangeant leurs feuilles de même forme; seules, les fleurs diffèrent : celles du Lamier, grandes et blanches; celles de l'Ortie, petites et vertes.

Sélection artificielle. - La pratique de la sélection artificielle est employée pour perfectionner les animaux et les plantes depuis un temps immémorial. Charlemagne recommandait à ses officiers de surveiller les étalons et de rejeter ceux qui étaient vieux et mauvais. Darwin a étudié les effets de la sélection sur le pigeon, qui est issu du pigeon de roche ou bizet, et il a comparé

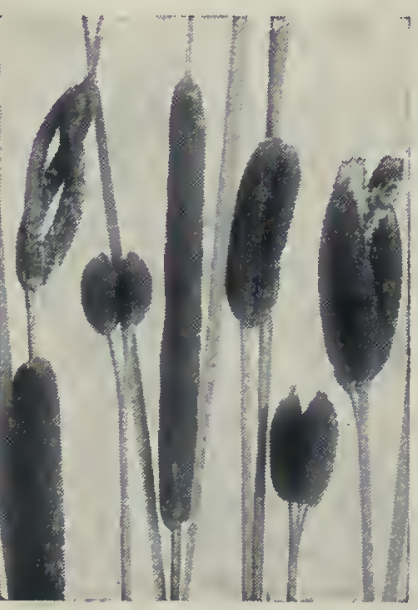

Monstruosités de la Massette.

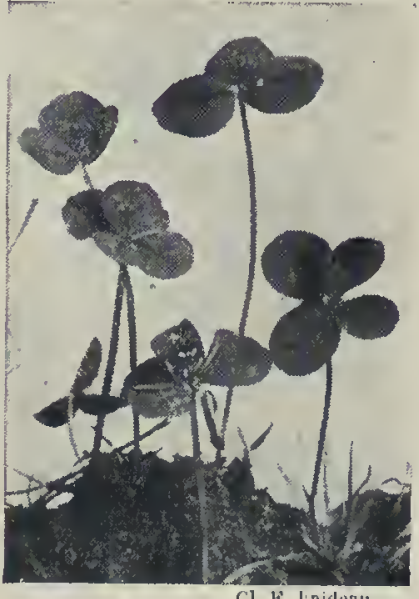

Trèfle à quatre folioles. 


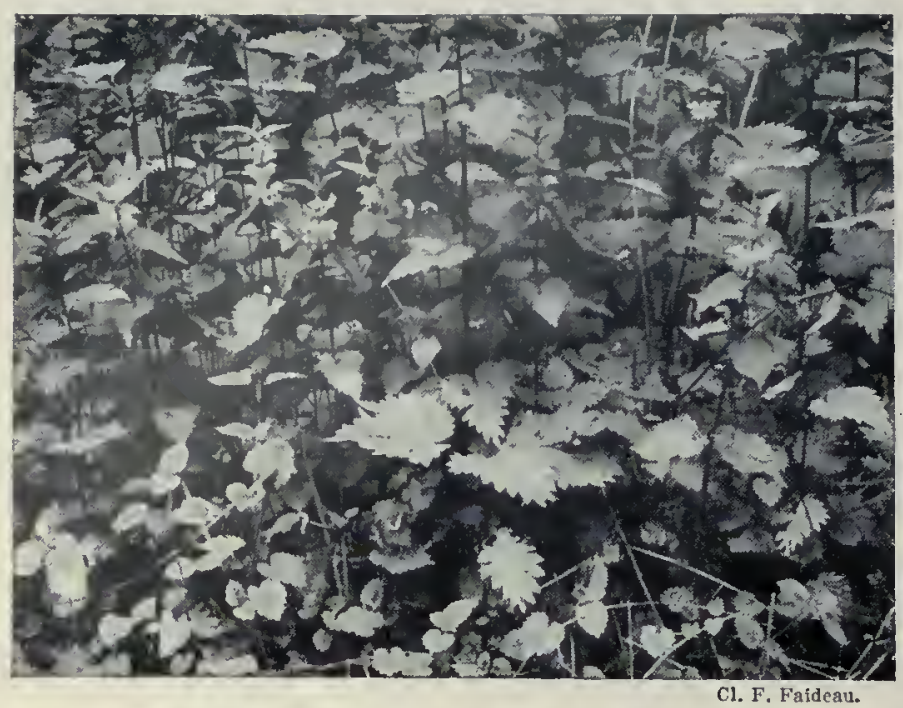

Mimétisme : Lamiers blanes et Orties dioïques.

toutes les races curieuses dérivant de cet animal : pigeon-paon, messager, culbutant, grosse-gorge, etc.

Le plus bel exemple à citer des résultats de la sélection artificielle est celui de la Betterave. Autrefois, on a commencé à trier ces plantes en tenant compte de la forme extérieure, en particulier de la grosseur et du poids des tubercules; on ne se préoccupait pas de la composition chimique, et la quantité de sucre ne dépassait pas 7 à 8 pour 100 . Au milieu du $X I X^{e}$ siècle, un triage rapide, en immergeant les racines dans une dissolution saline qui renseignait sur la densité des sucs, a permis d'augmenter la teneur en sucre. Mais, à partir de 1874 , l'emploi du polariseur a eu des conséquences importantes pour la culture de cette plante, et l'on vit la proportion de sucre s'élever progressivement de 14 à 18 pour 100 . Tous les individus ayant moins de 14 pour 100 ne sont pas conservés pour la graine et, pour déterminer les types d'élite, on fait des analyses portant parfois sur 300000 plantes. L'oiseau rare trouvé, il faut le multiplier, et on y parvient en le mettant en serre dès le mois de février; au bout de quelques jours, des ceilletons se développent au collet, on les détache et on les bouture ou on les greffe sur Betterave ( $f$ ig. 120). On peut ainsi récolter 5 kilogrammes de graines au lieu de 150 grammes. C'est donc par un travail incessant de sélection que l'industrie betteravière maintient ses hauts rendements, et les conséquences industrielles, économiques et commerciales de ces progrès ont été immenses. Un tel exemple suffit pour montrer la portée pratique de la méthode sélective dont le rôle a été si bien mis en lumière par les immortels travaux de Darwin. Linconvénient de cette méthode c'est que l'éleveur doit être constamment sur la brèche, et, à la moindre défaillance, tout le progrès réalisé s'évanouit, car les particularités chimiques, par exemple la teneur en sucre, qui caractérisent les individus d'élite ne sont pas héréditaires.

$\mathrm{De}$ Vries a suivi l'exemple très instructif de la naissance d'un Chrysanthème des moissons à cœur double (fig. 121). Il a tracé la courbe des individus plus ou moins nombreux ayant des languettes périphériques en

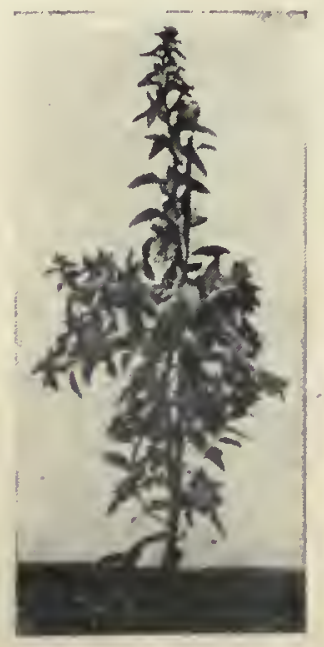
nombre de plus en plus grand. Il dressait chaque année des courbes telles que celle représentée ci-contre (fig. 122). Cette courbe est à plusieurs pointes; on voit

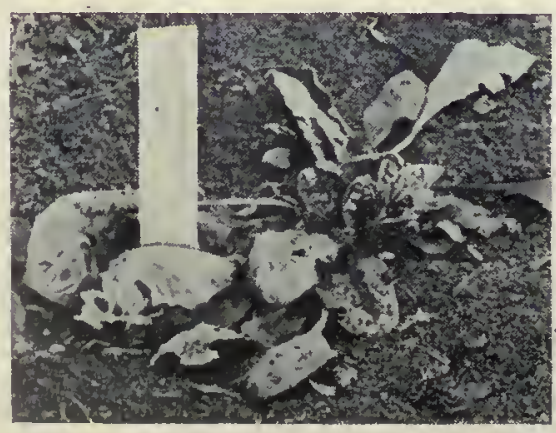

Onagre, variété rubrinervis et type nanella.
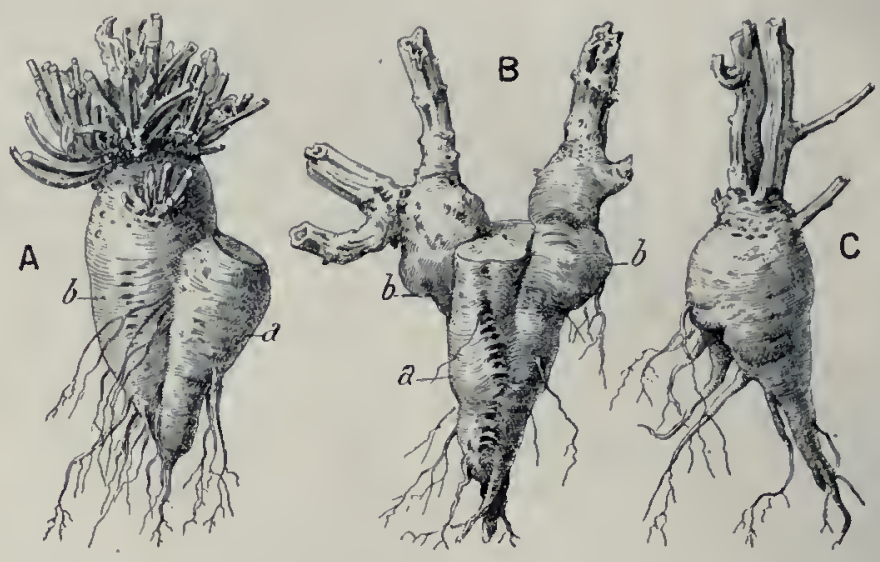

Fig. 120. - Betteraves greffees.

$\Lambda$, Greffe unique: $B$, Double; $C$, Bouture ayant fructifiè dès la preniére annéc: $a$, Porte-greffe; $b$, Greffon.

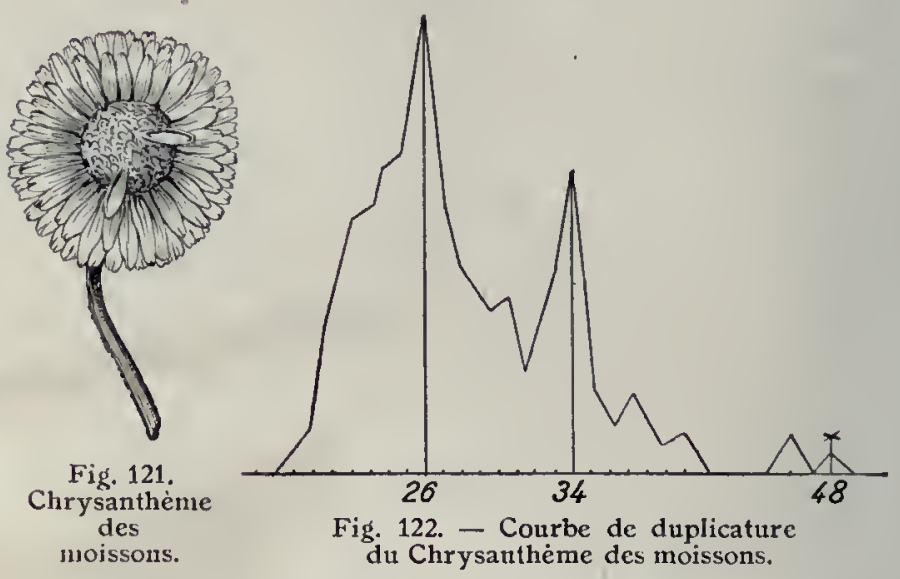

qu'il y a plusieurs maxima. Il y a, d'une part, des individus très nombreux à 26 languettes, un moindre nombre à 34, et enfin quelques-uns à 48 . On recueille les graines de ces derniers et, à la génération suivante, on voit la courbe changer d'aspect et les individus à nombreuses languettes se multiplier beaucoup. Ces recherches furent commencées en 1895; en 1899, on voyait 2 ou 3 languettes apparaître sur le disque et, en 1900, tout le disque était couvert de fleurs anomales. On voit, d'après cet exemple, "que l'horticulteur ne fait pas naître les variétés ", comme le disait Carrière; les propriétés sur lesquelles il opère sont des propriétés latentes," qu il faut " attendre attentivement et saisir avec empressement 1\%. Ceci explique également la réponse de Tegetmaier, éleveur de pigeons renommé, qui disait, à propos du caractère étrange de la queue démesurément longue des cogs de Corée (de plus d'un mètre de long): "Nous ne pouvons, certes, rien faire si la variation que nous désirons ne se présente pas à nous; mais si elle est une fois là, je crois que l'accroissement réussit aussi. "

Sélection horticole. - Il y a un autre type de sćlection, appelée horticole, qui soppose au précédent; cette dernière sćlection mérite d'être appelée agricole, car c'est surtout pour les plantes de grandes cultures qu'elle s'est manifestée. La sélection horticolc est caractérisée par l'apparition soudaine de variétés qui se maintiennent avec une stabilité parfaite et qui sisolent en un très petit nombre d'années. La nouveauté exige, en général, quatre ou cinq années pour sa purification ; on y parvient en supprimant, au moment de la floraison, les fleurs faisant retour à la forme primitive. Grâce à cette pratique, on évite les croisements et l'apparition de bâtards à la génération suivante. On arrive ainsi, en peu de temps, à avoir, à la levée d'un semis d'un type mis dans le commerce, 90 pour 100 , et plus, de plantes nouvelles. Le jardinier qui a découvert cette forme forale nouvelle et intéressante s'empresse de la vendre plusieurs milliers de francs et, comme elle est stable, elle se propage avec promptitude dans le commerce et perd alors une grande partie de sa valeur, à cause de sa fixité. Tout le monde peut l'avoir et la propager sans difficulté.

On commence à entrevoir comment les variétés stables prennent naissance. On sait que la mutation et l'hybridation peuvent présider à leur naissancc. 


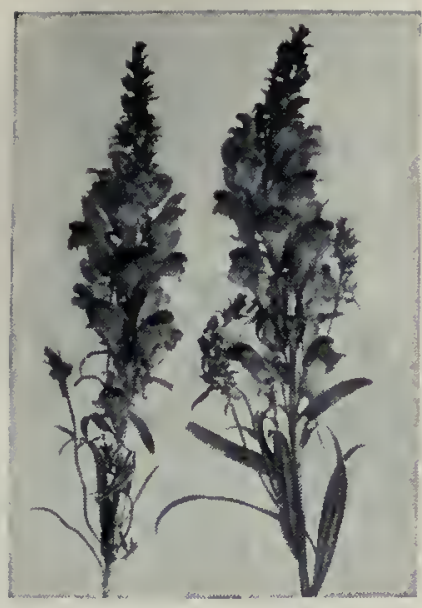

Linaire vulgaire.

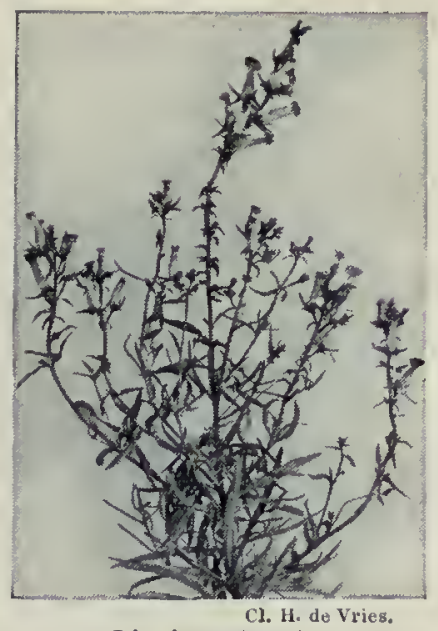

Linaire pétoriée.
Mutation. - Le phénomène de la mutation avait été entrevu déjà depuis longtemps, et l'on rapporte l'histoire d'un apothicaire d Hejdelberg qui, en 1590, vit apparaître dans son jardin une forme anomale de la grande Éclaire ou Chélidoine, le type à feuilles laciniées; en 1719, Marchant, membre de l'Académie des sciences, a vu apparaitre des Mercuriales annuelles à feuilles capillaires et à feuilles dilacérées, qui se maintinrent sans variations; en 176l, Duchesne signala le Fraisier monophylle, qui s'est maintenu jusquà nos jours avec une feuille. Mais c'est de Vries qui a véritablement découvert la mutation et qui en a fait une étude attentive et approfondie.

Ses recherches ont porté sur l'Onagre de Lamarck, espèce américaine, introduite depuis longtemps en Europe et naturalisée en certaines stations, notamment à Hilversum, non loin d'A msterdam, dans un champ de pommes de terre. Deux formes aberrantes nouvelles: l'une à style court (brevistylis), l'autre à feuilles lisses (leevitolia), attirèrent l'attention du savant hollandais; elles étaient accompagnées de fasciations de tiges, de déformations des feuilles qui présentaient notamment des ascidies ou urnes. Toutes ces plantes qui révélaient ainsi des phénomènes étranges furent soigneusement recueillies et transportées au jardin botanique d'Amsterdam, où elles furent cultivées avec soin pendant plusieurs années. C'est en 1886-87 que les essais culturaux commencèrent : 15000 échantillons authentiques d'Onagre de Lamarck furent récoltés de graines; mais à côté de ces formes normales, de Vries remarqua 10 individus aberrants : 5 appartenant à un type nain (nanella), 5 appartenant au type à feuilles larges (lata). Les graines des types nouveaux furent récoltées avec soin comme celles des types normaux, et l'on constata avec surprise que les graines de nanella ne donnaient que des nanella exclusivement : cette plante nouvelle avait une hérédité complète qui se maintenait indéfniment. Il en était de même du type lata. En semant les graines des individus normaux de l'Onagre de Lamarck, on avait encore une énorme proportion de plantes régulières, mais parmi elles, en petit nombre et à chaque culture nouvelle, réapparaissaient les deux formes irrégulières précédentes (nanella et lata), et d'années en années, à côté d'elles, on en vit naître d'autres, non signalées dans les campagnes précédentes. Ainsi, en 1897, l'auteur observa 1800 Lamarckiana, 9 nanella, 5 lata, I scintillans, 3 rubrinervis, 29 oblonga, 11 albida. Toutes ces petites espèces, car elles méritent réellement ce nom, se sont produites à plusieurs reprises (seul le gigas n'avait fait d'abord son apparition qu'une fois); leur stabilité est réellement

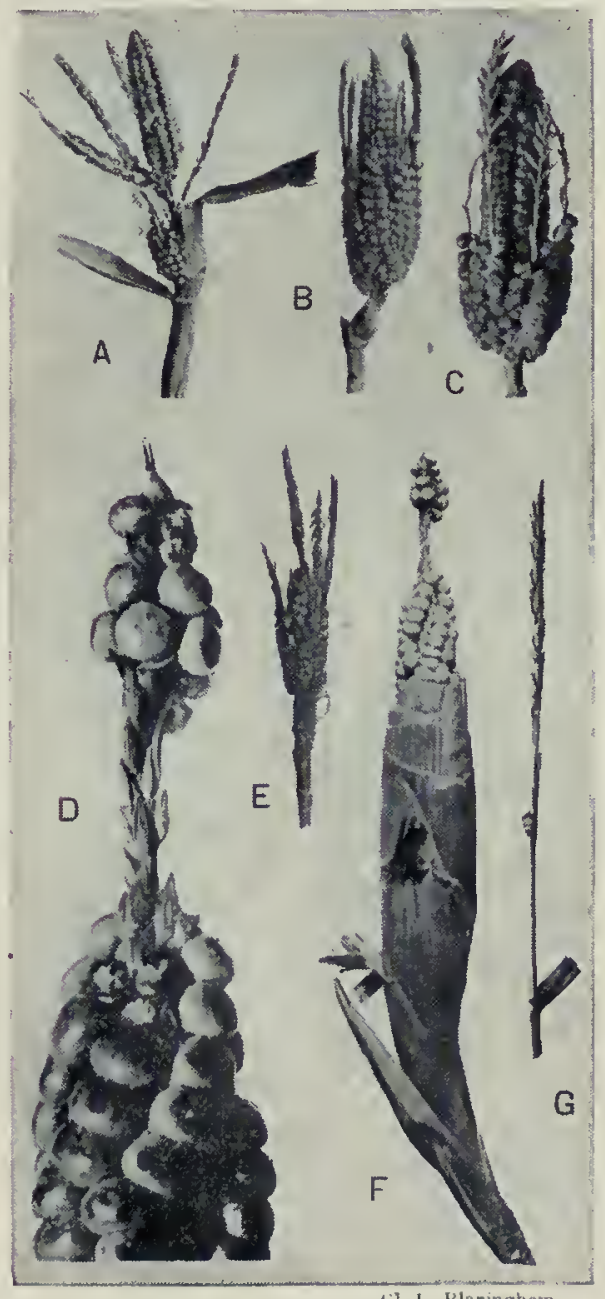

Fig. 123. - Métamorphose sexuelle des inflorescences de Maís.

A, B, E, G, Transformation incomp'ète de la panicule mâl, , plète; F, Femelle devenue mâle; $D$, Sommet grossi de F. extraordinaire, à la condition de les autoféconder de manière à éviter l'intervention d'un pollen étranger. Ces petites espèces nouvelles ont été distribuées aux jardins botaniques et ont été cultivées de 1903 à 1905 au Muséum de Paris. L'Onagre nain (nanella) n'est pas seulement caractérisé par sa petitesse (comme beaucoup de plantes naines, Giroflée naine, Eillet nain), il se distingue dès sa deuxième feuille, qui est très différente de celle de l'Onagre de Lamarck; on a obtenu, au Muséum, des plantes qui avaient, au moment de la floraison, 23 centimètres. Un autre type, rubrinervis, également cultivé au Jardin des Plantes, était bien différent par sa taille, qui atteignait $l^{m}, 50$. Ainsi donc la variation ne se produit pas, comme l'avaient indiqué Darwin. Wallace et leurs émules, d'une manière lente et à petits pas, mais par sauts brusques.

Au point de vue de la lutte pour l'existence, il se peut que ces petites espèces soient plus ou moins aptes à survivre; il semble que plusieurs d'entre elles soient assez bien armées, mais les autres paraissent, au contraire, destinées à disparaître. Il y a enfin des types comme le scintillans qui n auraient qu'une hérédité partielle : c'est-à-dire que, par autofécondation, on voit dans sa descendance trois types: des scintillans (33 pour 100), des oblonga et des Lamarchiana.

Un exemple de variation brusque quj est anciennement connu, puisqu'il a été observé déjà par Linné, est celui de la Linaire péloriée : la fleur, au lieu d'être irrégulière avec un éperon et symétrique par rapport à un plan, devient régulière et symétrique par rapport à un axe. Cette propriété singulière n'est pas, en général, intégralement transmissible à la descendance; ce n'est donc pas une mutation analogue à la précédente; mais de Vries a pu, par triages poursujvis plusieurs années, arriver à obtenir une hérédité de 90 pour 100 .

La mutation est un phénomène encore trop nouvellement décrit pour qu'il y ait beaucoup d'exemples à citer; cependant il a été retrouvé par Raunkiaer, dans le Pissenlit; par Nilsson, dans les Céréales; par Wettstein, dans les Sedum, et par Blaringhem, dans les Maïs.

Les traumatismes et la mutation. - Avec ces dernières plantes, un pas nouveau a été fait dans la voie du progrès par ce dernier auteur; il a pu déterminer les conditions expérimentales dans lesquelles la mutation a pris naissance. Il a soumis ses Maïs à des traumatismes divers : sections, torsions, pressions, et il a vu ainsi se produire en grand nombre des anomalies forales ( $\mathrm{fg} .123$ à 126). On sait que dans le Maïs il y a régulièrement à l'extrémité de la plante une panicule mâle et, de côté, des épis femelles. Or, dans la panicule mâle, à la

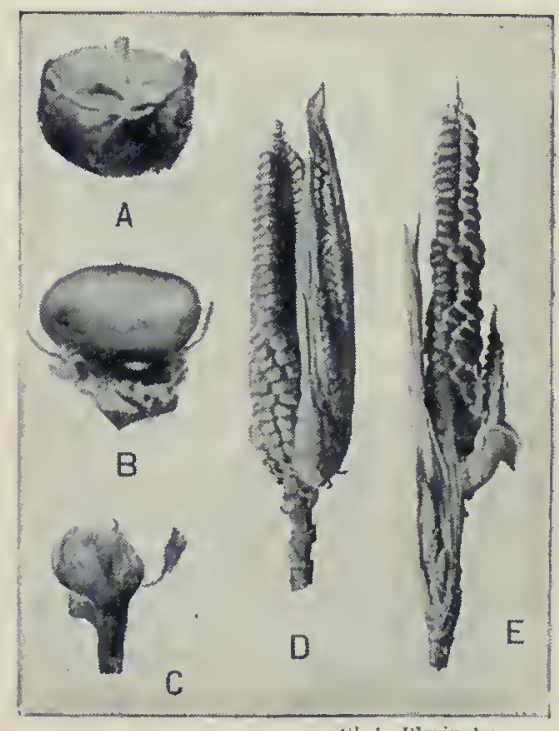

Fig. 124. - Variétés de Maìs obtenues par traumatismes.

A, B, Fruits de Mais pseudo-androgyne avec étamines: C, Ovalre avec étamines; D, E, Epillets hermaphrodites du Maïs à épis dissociés. 


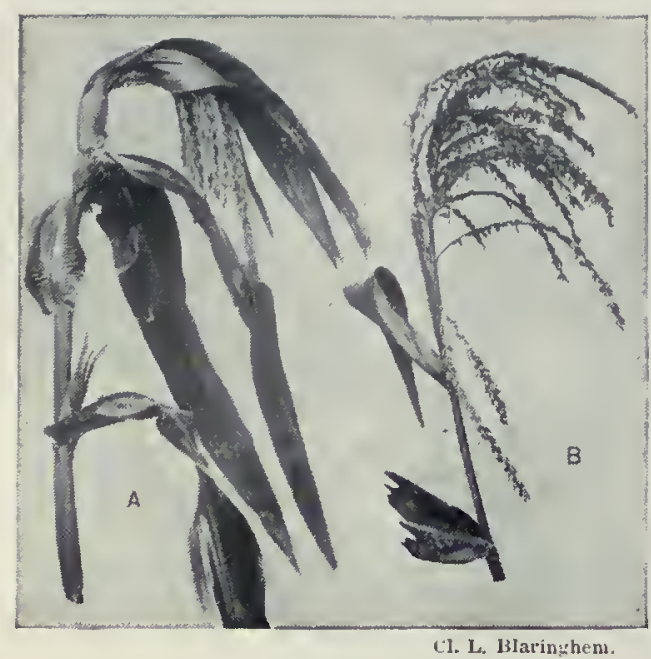

Fig. 125. - Mais à port pleureur.

A, Début de la floraison; B, Pleine floraison.

suite des sections de la tige, il a vu apparaître des fleurs femelles et les grains ainsi récoltés ont donné, à la génération suivante, des pieds reproduisant l'anomalie précédente dans une proportion extrêmement grande de 70 pour 100 . Ainsidonc il y a transmission héréditaire de l'anomalie. Mais il y a plus, car il a vu naitre ainsi une mutation et il a obtenu des races fixées et présentant un intérêt agricole: le Maïs précoce, le semi-précoce; il a vu naîtrc des Maïs à port pleureur (fig. 125), des Maïs chou-fleur (fig. 126), des Maïs à feuilles bullées, à épis dissociés (fig. 124), etc.

C'est là d'ailleurs une méthode générale qui mérite d'être approfondie. Les traumatismes font naître des monstruosités. Par des mutilations expérimentales, Blaringhem a obtenu des tiges fasciées, des feuilles à ascidies, des fleurs doublées, notamment des Pensées monstrueuses. Il y avait longtemps déjà que les zoologistes, et surtout les vétérinaires, avaient observé des phénomènes monstrueux à la suite d'actions brutales. A cet ordre d'idées il y a lieu de rattacher les modifications du Papayer, arbre dioïque qui, sur ses pieds femelles, donne normalement des fruits qui sont attachés près de la tige ; lorsqu’à la suite de blessures sur un pied mâle on y fait naitre des fleurs femelles, le port de la plante est tout à fait changé et on voit les fructifications se former loin du tronc. Les résultats de cette pratique ont été souvent observés à Madagascar, où $\mathrm{M}$. Fauchère, inspecteur de l'Agriculture dans cette île, nous a signalé le fait comme fréquent. On voit donc que les traumatismes ont non seulement de l'action sur la production de monstruosités, mais aussi sur la question si importante du changement de sexe. On sait d'ailleurs que, dans les oasis du nord de l'Afrique, les Arabes utilisent les mutilations pour obtenir le changement de sexe des Dattiers. Ajoutons à ces recherches sur l'origine de la mutation celles de Zeylistra, qui a montré le rôle d'une Bactérie qui intervient dans le cas de l'Onagre naine et qui est un facteur de son rabougrissement.

Le greffage et les variations. D'ailleurs, on peut produire des modifications profondes des plantes par d'autres méthodes que les traumatismes: le greffage notamment. C'est ainsi que l'on a expliqué autrefois, au XVt' siècle, l'apparition des Bigaradiers bizarrerie (fig. 128), dont le fruit présentait sur certaines tranches le caractère du citron et, sur certaines autres, le caractère de l'orange. Le Néfiier de Bronvaux est également célèbre; il a été greffé, il y a une centaine d'années, sur une Aubépine. A l'endroit $\mathrm{du}$ bourrelet, plusieurs branches anormales ont poussé, ayant des caractères intermédiaires entre ceux du Néflier et ceux de

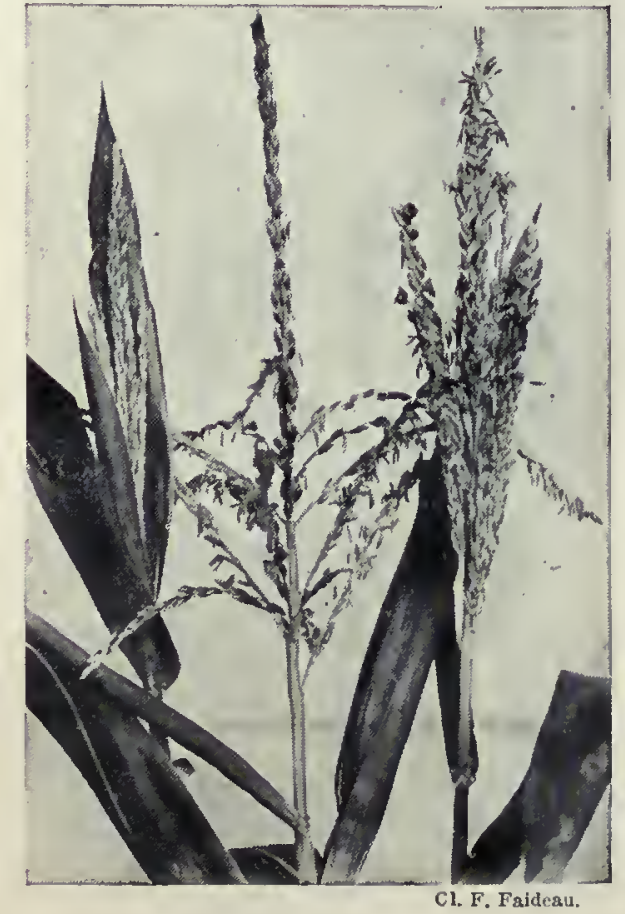

Maïs à épis normaux

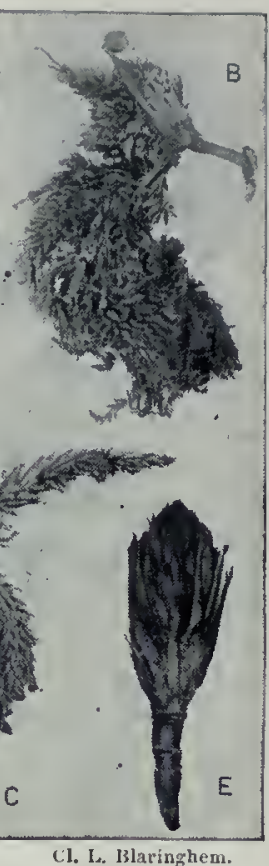

en "chou-fleur»

A Panicule à épillets mâles transformés en épis femelles ules déformées; D, E, Inflorescences latérales dant à la forme "chon-fleur".
l'Aubépine : les rameaux sont épineux comme ceux de l'Aubépine, veloutés comme dans le Néflier; les feuilles sont intermédiaires; l'inflorescence possède une douzaine de fleurs, c'est-à-dire plus que dans le Néflier et moins que dans l'Aubépine; enfin les fruits sont d'une grosseur intermédiaire, duveteux, comme dans le Néflier, à sépales dressés comme dans l'Aubépine. Daniel a entrepris l'étude expérimentale de cette question et, avec les Tomates, les Carottes, il a obtenu des changements qui paraissent se transmettre héréditairement, Certains auteurs tendent, il est vrai, à attribuer aux traumatismes le principal rôle dans la persistance de ces particularités héréditaires ou à expliquer certains de ces phénomènes par l'hybridation véritable, mais le cas du Néflier de Bronvaux paraît bien lié à la greffe.

Rôle de la culture dans les variations. - En somme, la cause primordiale des altérations transmissibles des plantes doit être cherchée dans des modifications profondes de la nutrition : aussi ne devons-nous pas être surpris d'apprendre que la culture est un agent très important de la métamorphose. Si les végétaux cultivés présentent des altérations si étranges, c'est à l'action du traitement que l'homme leur fait subir qu'il faut les attribuer. En cultivant des Pavots somnifères monstrueux, de Vries a mis nettement en lumière ce résultat. Il a choisi pour ses expériences la variété polycéphale (fig. 127), qui est caractérisée par l'existence au pourtour du pistil normal des fleurs de cette plante d'un certain nombre de carpelles surnuméraires formant autour de lui une sorte de couronne. Sous l'influence de diverses pratiques culturales, il a vu l'anomalie précédente évoluer de génération en génération, augmentant ou diminuant, suivant qu'on soumettait les plantes à des opérations diverses. De Vries a constaté ainsi que, par suite de la culture serrée, les anomalies s'accroissent, tandis qu elles s'atténuent en espaçant les plantules en germination : or on sait que l'horticulteur comme le pépiniériste cultivent les plantes en grand nombre les unes à côté des autres, soit en terrine, soit en planche de semis, et cette seule pratique, en apparence inoffensive, a les suites les plus profondes et les plus inattendues sur les phénomènes héréditaires. Une autre conséquence, découlant pour ainsi dire du résultat précédent, se trahit dans le repiquage, qui est une opération culturale journellement pratiquée; on voit que cette pratique contribue à entraver la multiplication des types très polycéphales. Enfin la culture sous verre, par opposition à la culture sans verre; la culture au soleil, par opposition à la culture à l'ombre, contribuent puissamment à multiplier les anomalies héréditaires.

L'influence de l'homme sur les végétaux est donc indéniable; elle se manifeste parfois d'ailleurs d'une manière saisissante. lorsque son intelligence se met, pour ainsi dire, à la torture pour soumettre les végétaux à un traitement extraordinaire. Tel est le cas des arbres rendus nains par les Japonais. On sait qu'ils sont passés maîtres dans l'art ćtrange de cultiver des arbres centenaires sur une étagère. Ils y parviennent, nous le verrons plus loin, en enlevant au végétal la plus grande partie de sa nourriture. Les plantes prennent alors un aspect inattendu. Il s'agit, il est vrai, dans ce cas d'une action directe et on ne sait pas jusqu ici si ces déformations sont susceptibles de passer 


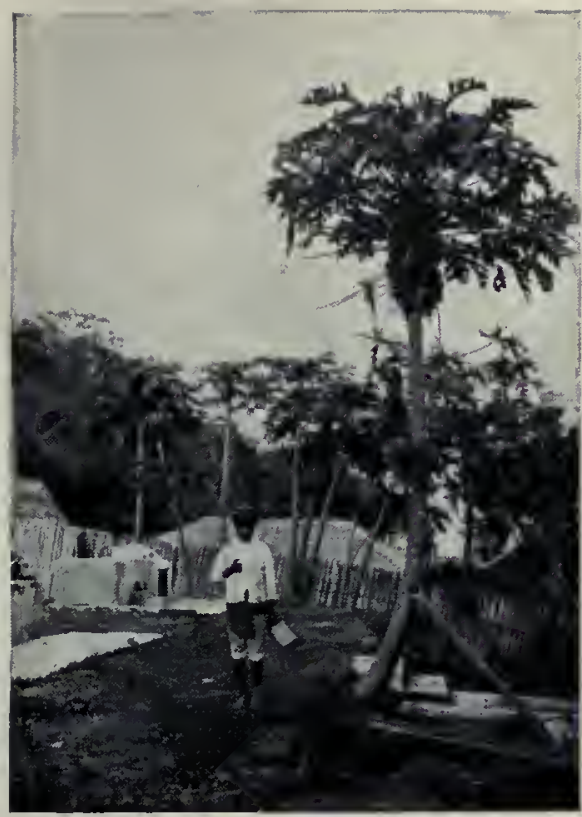

Papayer normal avec fruits (Sumatra).

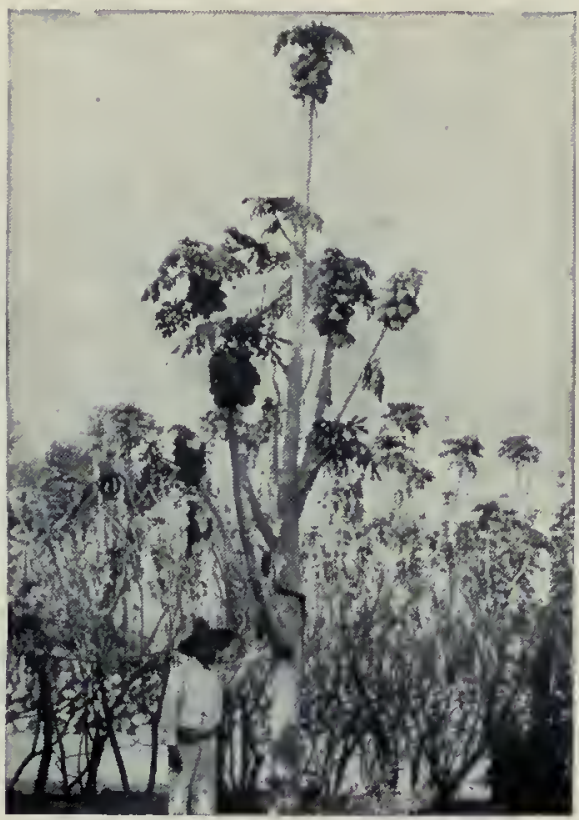

Papayer ramifiè avec fruits.

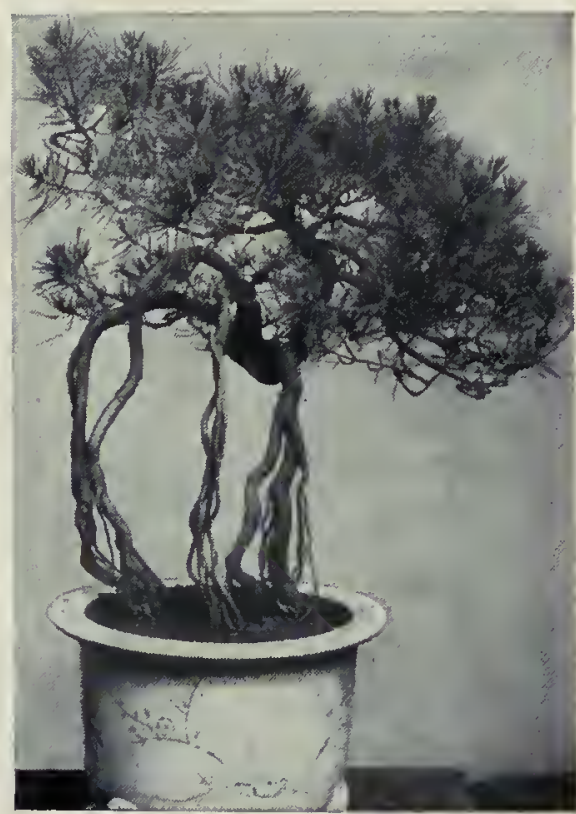

Conifère nain du Japon. à la descendance. La résistance des plantes aux traumatismes est parfois étonnante et on voit souvent, en forêt, des arbres dont la tige tordue indique qu ills ont victorieusement résisté à une action brutale subie pendant leur jeune âge.

Des déformations aussi bizarres, mais dont la cause est encore inconnue, peuvent s'observer dans la nature. Tel est le cas des "Faux " ou Hêtres tortillards de la forêt de Verzy, près de Reims ; ils sont certainement parmi les arbres les plus curieux que lon puisse voir. Leur énorme tronc, de 3 à 4 mètres de hauteur. est noueux, irrégulier ; il en part de nombreuses branches, contournées, sinueuses, dirigées dans tous les sens. Leur croissance est des plus lentes. Leurs racines, comme on s'en est assuré, ont une disposition analogue à celle des branches.

Les "Faux'", qui croissent au milieu d'autres arbres de même espèce absolument normaux, étaient autrefois fort nombreux ; il en reste aujourd'hui une dizaine de gros, situés à quelque cent mètres les uns des autres, mais on en trouve nombre de petits aux formes non moins bizarres. Leur tronc est spiralé; les extrémités de leur rameaux, tordus en tous sens, sont pendantes et s'enracinent facilement lorsqu' elles touchent à terre. Les Faux de Verzy croissent dans un sol calcaire, un peu argileux et ferrugineux; certains naturalistes les considèrent comme une variété non persistante du Hêtre ordinaire, due seulement à la nature du sol et à l'exposition. Le Hêtre tordu de Dain, près Metz, est aussi très connu. On en compte aussi quelques-uns dans les forêts d'Allemagne. Les variétés d'arbres d'ornement à branches tortillées ou pleureuses (Orme, Sophora, etc.) nous offrent un cas analogue.

Hybridation. - L'horticulture a d'ailleurs un autre procédé de déformer les plantes de manière que les caractères nouveaux se transmettent héréditairement: c'est le croisement. L'hybridation est une méthode d'une puissance extraordinaire qui permet, en effet, par la fusion du sang ou plutôt des sèves des deux plantes, d'obtenir des mélanges de caractères les plus inattendus et les plus intéressants.

Parmi les plantes pour lesquelles l'hybridation a été poussée le plus loin on peut citer en particulier les Sabots de Vénus, pour lesquels les orchidophiles sont arrivés à des résultats merveilleux. II y a environ soixante-dix espèces de Cypripedium connues, mais une cinquantaine seulement ont été croisées entre elles et, par leur combinaison, 1500 types nouveaux ont été obtenus, dont quelques-uns sont véritablement admirables. Au simple aspect de la fleur d'un de ces hybrides artificiels, on peut retrouver ses parents : un Cypripedium Helvetia, par exemple, présente un mélange net des caractères du Cypripedium Chambcrlainianum et du Cypripedium philippinense, qui sont ses père et mère.

Quand on se trouve en présence d'un pareil type, on a tout à fait l'impression qu'on éprouve en face d'un être nouveau, car c'est une création de l'homme qui peut se multiplier indéfiniment par division du rhizome et, par conséquent, ces hybrides peuvent indéfiniment persister; aussi certains hybrides, comme le Cypri- pedium Leeanum, sont aussi répandus dans les serres que leurs parents et, comme ils sont féconds, ils peuvent se croiser à nouveau entre eux; le nombre des hybrides peut se multiplier à l'infini.

Il est donc nécessaire, pour garder un type pur, d'empêcher les croisements qui peuvent se produire en dehors de la volonté de l'homme, par exemple sous l'influence des insectes, qui transportent le pollen d'une fleur à l'autre. On peut voir sur la photographie (p. 98) l'un des dispositifs employés pour empêcher la visite des insectes.

Mendélisme. Cas des monohybrides. - Les lois régissant la descendance des hybrides ont été découvertes par un prêtre -autrichien nommé Mendel; elles peuvent d'ailleurs être un guide précieux pour l'horticulteur dans la recherche de l'isolement de types nouveaux et héréditairement stables. Mendel a établi qu'en croisant deux races d'une même espèce qui ne diffèrent que par un seul caractère (monohybrides), par exemple deux variétés de Pois, l'une à grains ronds et gonflés, l'autre à grains ridés, on voit qu'à la première génération toutes les plantes ont des grains ronds. Ce caractère est dominateur, car l'autre caractère subsiste

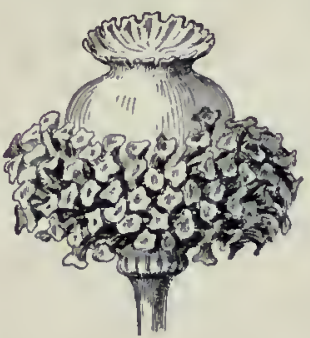

Fig. 127.

Pavot polycéphale.

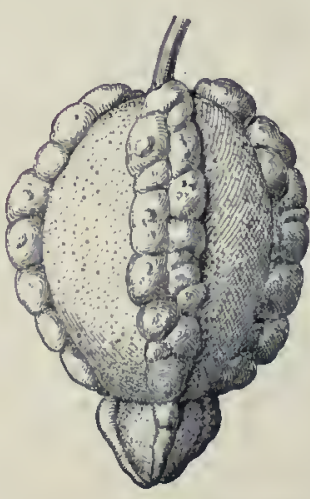

Fig. 128. - Bizarrerie du Bigaradier. au moins dans un certain nombre de grains, mais caché, non apparent : on dit que ce caractère des grains ridés est récessif. Si l'on sème ces graines de première récolte, on voit qu à la seconde génération, après autofécondation, les individus se divisent en deux lots : 25 pour 100 à grains ridés (race pure) et 75 pour 100 à grains ronds. Parmi ces derniers, on reconnaît, à la génération suivante, quil y en a de deux sortes : 25 pour 100 donnant toujours des grains ronds de race pure et 50 pour 100 de grains qui sont de nature hybride, susceptibles de donner des ronds ou des ridés. On peut donc dire que, dès la deuxième génération, ily avait 25 pour 100 de graines à caractère récessif; 50 pour 100 de graines hybrides (avec les deux caractères, le caractère rond seul visible) et 25 pour 100 de graines à caractère seulement dominateur.

Ainsi donc, dans le cas le plus simple de deux variétés qui ne diffèrent que par un caractère, la loi de Mendel se trahit par les chiffres 3 et I : 3 individus où le caractère dominateur existe, I où le caracière récessif est présent. On voit la chose nettement avec deux Mirabilis Jalapa ou Belles-de-Nuit, une blanche, l'autre rouge. L'hybride de première gé- 


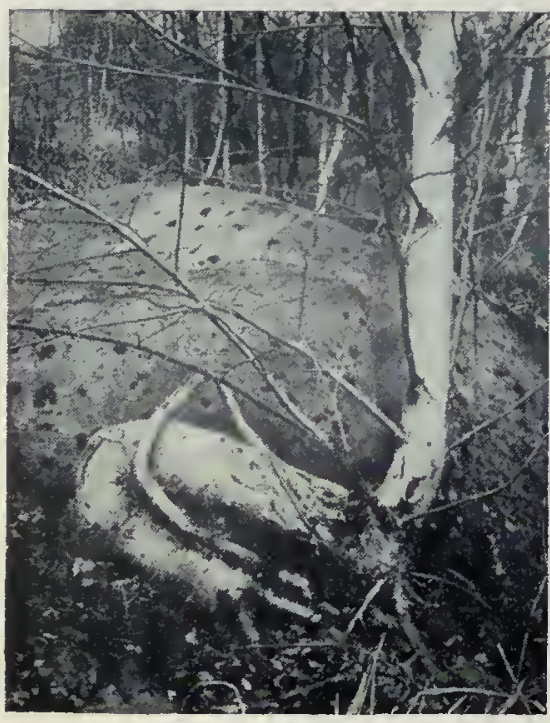

Traumatismes sur le Bouleau.

nération est rose. A la deuxième génération, il y a un blanc et trois roses ou rouges (fig. 129, A). Le schéma situé

sous les fleurs représente tous les individus des Mirabilis pendant trois générations. Il suffit de consulter le dessin pour comprendre. De même le croisement de deux Linaires, l'une blanche, l'autre rose (dihybride) $[$ fig. $129, \mathrm{~B}]$.

Cette loi de Mendel est une très grande loi biologique. Elle s'applique à une foule de caractères des plantes et à un nombre considérable d'espèces de genres et de familles, comme Pois nains et géants, Quarantaines à tige ramifiée et non ramifiée, Orties à feuilles très dentées (Urtica pilulifera) et peu dentées (Utica Dodartii) [fig. 131], Primevères à feuilles dont les découpures sont palmées et à teuilles dont les découpures sont pennées, plantes annuelles et bisannuclles, Pois de senteur à grand pétale droit ou plié (fig. 132), Orges ayant des avortements de fleurs femelles ou non. Céréales à paille creuse et pleine (ce qui est important pour le phénomène de la verse des Blés), plantes à fruits pourvus d'aiguillons ou à fruits lisses, Maïs à albumen amylacé ou dextrineux-sucré, etc. Cette loi s'applique aussi aux animaux et à l'homme.

On peut mettre en relief les phénomènes mendéliens par une autre méthode. Si l'on admet que chez le Pois chaque caractère qui produit les graines rondes ou les graines ridées est représenté

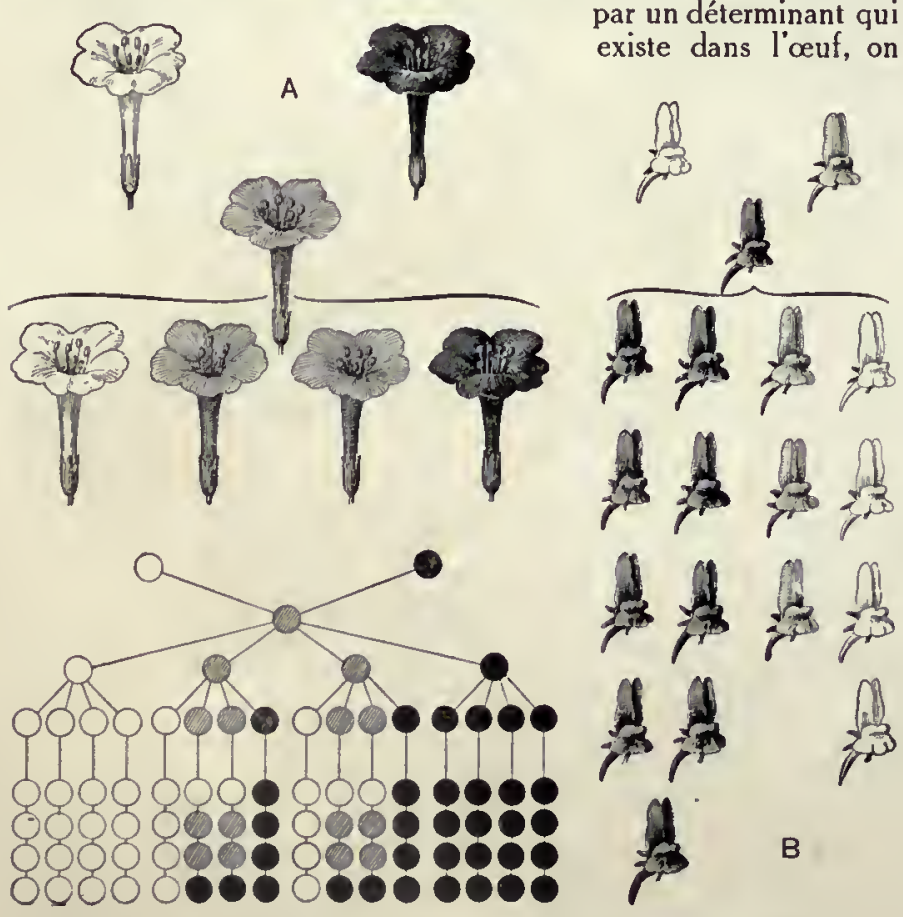

Fig. 129. - Effets de la loi de Mendel sur les hybrides. A, Sur les Belles-de-Nuit; B, Sur les Linaires.

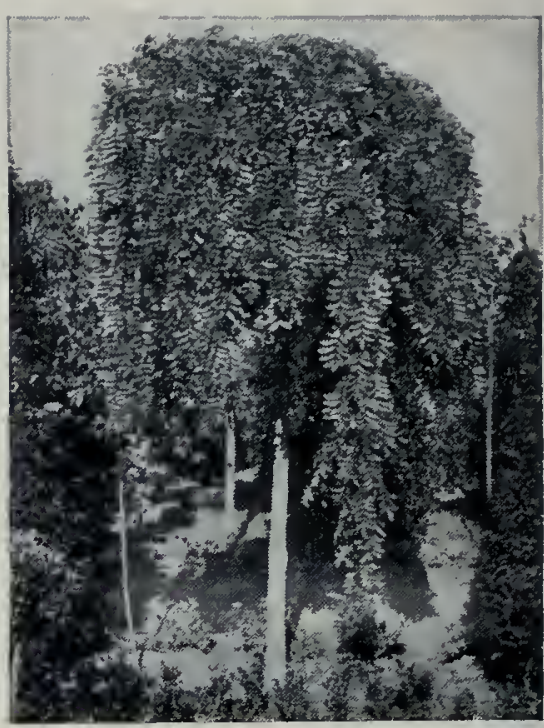

Sophora pleureur.

peut imaginer des symboles pour la représentation; soit $\mathrm{R}$ le caractère dominateur (rond), et $\mathrm{r}$ le caractère récessif (ridé). A la première génération, on a donc des graines résultant d'une plante hybride qui a des déterminants $\mathrm{Rr}$; mais le caractère dominateur masque le caractère dominé et le caractère $\mathrm{r} n$ 'apparaît pas ; l'hybride de première génération a donc des grains ronds. A la génération suivante, voici toutes les combinaisons des déterminants :

$$
\text { RR Rr } \mathrm{r} \text { rr ou encore } \mathrm{R}^{2}+2 \mathrm{Rr}+\mathrm{r}^{2}
$$

On peut encore représenter les phénomènes par des carrés. Une plante peut avoir quatre caractères dans son pollen et quatre caractères dans ses oosphères (fig. 130). En réunissant les caractères des grains de pollen et ceux des ovules comme des jetons rouges

\begin{tabular}{|c|c|}
\hline$R$ & $r$ \\
\hline$R$ & $r$ \\
\hline
\end{tabular}

\begin{tabular}{|c|c|}
\hline$R$ & $R$ \\
\hline$r$ & $r$ \\
\hline
\end{tabular}

\begin{tabular}{|l|l|}
\hline$R R$ & $r R$ \\
\hline$R r$ & $r r$ \\
\hline
\end{tabular}

Fig. 130, - A gauche, schéma de la division d'une cellule mère pollinique: deux grains de polten avec le caractère rond $(R)$, deux avec le caractère ridé (r). Au milieu, idem pour les cellules femelles. A droite, superposition des deux figures précédentes, symbolisant la fécondation.

et blancs, on a la combinaison des troisièmes carrés obtenus en superposant les deux premiers carrés l'un sur l'autre.

Quand il y a mélange de deux déterminants, le dominateur seu] apparaît; on a donc, sur quatre graines, trois avec le caractère dominateur ( $R R, r R, R r)$ et une avec le 'caractère récessif $(r r)$, soit 75 pour 100 des premiers et 25 pour 100 des seconds. Mais les types à caractère dominateur (ou à graines rondes) se décomposent en deux sortes $R^{2}+2 R r$; sur trois graines, il y en a une exclusivement à caractères dominateurs et deux avec mélange. A la génération suivante, la graine représentée par $\mathrm{R}^{2}$ est absolument ronde; elle est de race pure, tandis que les types hybrides $r R$ et $R r$ se comporteront comme le lot hybride de première génération, c'està-dire se diviseront en 25 pour 100 de graines rondes pures, 50 pour 100 de graines rondes hybrides et 25 pour 100 de graines ridées pures. Tout s'explique donc par la formule :

$$
R^{2}+2 R r+r^{2}=(R+r)^{2}
$$

Cas des dihybrides. - Supposons maintenant que l'on croise deux races de Pois différant par deux caractères : par exemple, une race a des graines rondes (R) et vertes ( $V)$ et l'autre des graines ridées $(\mathrm{r})$ et jaunes $(\mathrm{J})[$ fig. 133 et $\mathrm{I} 34]$; admettons de plus que le caractère jaune domine le caractère vert; Mendel a montré que les caractères de formes étaient indépendants des caractères de couleurs. Soit $\mathrm{J}$ et $\mathrm{V}$ les déterminants du jaune et du vert. En raisonnant comme tout à l'heure, en ne tenant compte 
que de la couleur, on pourrait représenter les choses par le système des carrés. On verrait à la deuxième génération trois lots représentés par les déterminants :

$$
\mathrm{J}^{2}+2 \mathrm{~J} \mathrm{~V}+\mathrm{V}^{2}=\left(\mathrm{J}+\mathrm{V}^{2}\right.
$$

Les quatre caractères précédents, pouvant s'associer, doivent donner les combinaisons qu on obtiendra en faisant les produits $\left(\mathrm{R}+\mathrm{r}^{2}\right) \quad\left(\mathrm{J}+\mathrm{V}^{2}\right)$. Ce produit peut s'écrire :

$R^{2} J^{2}+2 R^{2} J V+2 R r$ $\mathrm{J}^{2}+4 \mathrm{Rr}_{\mathrm{J}} \mathrm{JV}$ (9 9 yypes

$\mathrm{R}^{2} \mathrm{~V}^{2}+2 \mathrm{Rr} \mathrm{V}^{2}$ (3types de ce groupe)
$\mathrm{r}^{2} \mathrm{~J}^{2}+2 \mathrm{r}^{2} J \mathrm{~V}(3$ types $\mathrm{x}^{2} \mathrm{~V}^{2}$ (le groupede

Toutes les graines de la première catégorie (Ire ligne) sont rondes et jaunes, car les caractères ridé et vert sont dominés quand ils sont présents par le caractère correspondant rond et jaune. Or, les coefficients sont successivement :

$1+2+2+4=9$

Il y aura neuf graines de cette catégorie, tandis quil y en aura trois de la deuxième (2० ligne) à graines rondes et vertes, trois de la troisième ( $3^{\mathrm{e}}$ ligne) à graines ridées et jaunes et une de la quatrième $\left(4^{*} \mathrm{li}\right.$ gne) à graines ridées et vertes. Donc sur seize graines $(9+3+3+1=16)$ il y en a neuf rondes jaunes, plus trois rondes vertes. plus trois ridées jaunes et plus une ridée verte. $\mathrm{Or}$, l'expérience vérifie cette prévision. Mais si l'on examine, à la génération suivante, les graines du premier groupe ( ${ }^{\text {re }}$ ligne), on voit qu'elles sont de quatre catégories, avec les déterminants suivants :

$$
\mathrm{R}^{2} \mathrm{~J}^{2}, \mathrm{R}^{2} \mathrm{~J} \mathrm{~V}, \mathrm{Rr} \mathrm{J}^{2}, \mathrm{Rr} \mathrm{J} \mathrm{V} \text {. }
$$

Or, seules les premières graines (à déterminants $R^{2} J^{2}$ ) sont pures et se maintiennent indéfniment pures par autofécondation; les autres sont de natures hybrides et, à la génération suivante, on voit apparaître les caractères dominés qui étaient masqués. Parmi ces hybrides, il y en a de trois catégories avec les déterminants suivants: $1^{\circ} \mathrm{R}^{2} \mathrm{~J} \mathrm{~V}$, toutes les graines ainsi représentées sont de race pure pour la forme (toutes rondes), mais hybrides pour la couleur (jaunes et vertes); $2^{0} \mathrm{Rr} \mathrm{J}^{2}$, toutes les graines ainsi représentćes sont hybrides par la forme (rondes et ridées), de race pure par la couleur (jaune); $3^{\circ} \mathrm{Rr} \mathrm{J} \mathrm{V}$, toutes les graines ainsi représentées sont hybrides à la fois par la forme et la couleur (rondes et ridées, jaunes et vertes).

On ferait le même raisonnement avec les graines rondes vertes de la deuxième génération: $\mathrm{R}^{2} \mathrm{~V}^{2}+2 \mathrm{Rr} \mathrm{V}^{2}\left(2^{\mathrm{e}}\right.$ ligne). Le point essentiel à remarquer c'est que, à la génération suivante, on a tout de suite une race purc nouvelle $R^{2} V^{2}$ à graines rondes et vertes. Cette race est isolée sans sélection et c'est une création, car antérieurement on pouvait n'avoir jamais signalé l'association des caractères rond et vert. De même ( $3^{e}$ ligne) le déterminant $\mathbf{r}^{2} \mathrm{~J}^{2}$ indique des races pures à graines ridées jaunes. Il y a done, par la méthode de Mendel, le moyen d'isoler des ráces végétales nouvelles et complètement stables.

Ceci modifie la notion de race pure. On croyait qu un individu était de race pure lorsqu il descendait d'une longue suite d'ancêtres identiques à lui. Ceci ne sapplique pas aux races pures qui ont pour déterminants $R^{2} V^{2}, r^{2} J^{2}$, qui ne ressemblent à aucun de leurs parents immédiats et sont cependant le point de départ d'une race absolument stable et héréditaire.

La méthode de Mendel permet en outre, par culture pédigrée, c'est-à-dire en partant d'une seule graine et en suivant toute la descendance, d'arriver à isoler les races pures dès la deuxième génération. Avec la sélection simple, on n’arrive pas à des résultats aussi rapides et on voit toujours réapparaître des hybrides.

'En somme, la règle mathématique qui régit les monohybrides (dcux varićtés qui diffèrent par un caractère) cst cellc des nom- bres 3 et 1 ; celle qui régit les dihybrides (deux variétés qui diffèrent par deux caractères) est celle des nombres $9,3,3,1$; on la voit se manifester dans le cas de deux Linaires (fig. 129, B), dans le cas de deux Maìs, dans le cas de deux souris. La règle mathématique dans le cas des trihybrides (deux variétés qui diffèrent par trois caractères) se manifesterait de même par les chiffres de graines différentes correspondant aux nombres $27,9,9,9 ; 3,3,3,1$

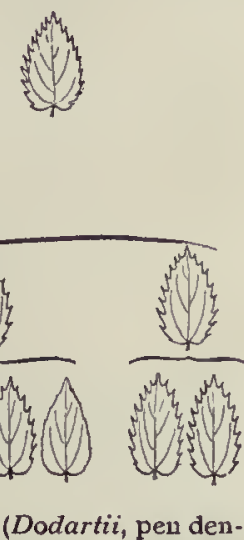
Fig. $131,-$ Croisement de deux Orties (Dodartii, pen den-
tée, et pilulifera, très dentée); $2^{\text {o }}$ ligne : hybride de première Fig. 133. - Pois à grains ronds et verts lhybride variete a grains jaunes et rides; des graines rondes et jaunes; les hybrides de deuxième génération (au-dessous de l'accolade) sont: neuf graines rondes et jaunes, e ridée et verte.

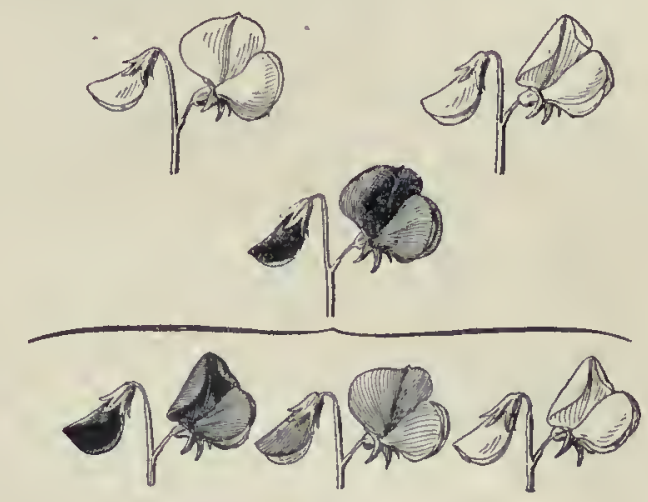

Fig. 132. - Croisement de deux Pois de senteur albinos (l'un á étendard plié et l'autre étalé) donnant un hybride de première génération (2e ligne) pourpre; $\dot{a}$ la deuxiéme génération ( $3^{\mathrm{e}}$ ligne), on a des pourpres, des roses, des blancs.

(en tout 64). Quand on s'est bien pénétré de ces principes, en somme, rien n'est plus facile que de comprendre la loi de Mendel, même dans des cas complexes.

Le mendélisme a été appliqué à l'explication d'une série de phénomènes singuliers. On a croisé deux Pois de senteur blancs (albinos) : la première génération a ćté pourpre (fig. 132). A la seconde zénération, sur 64 individus, on comptait 27 violets, 9 rouges et 28 blancs $(9+9+3+3+3+1)$. Cest la loi des trihybrides $(27+9+28=64)$.

Les caractères de la sexualité paraissent, dans certains cas, être mendéliens.

Enfin, et ce dernier résultat est le plus important, on cherche à appliquer la loi de Mendel à la question de la résistance des plantes aux maladies. Orton a déjà obtenu des résultats très nets dans le cas des races de Pastèques résistantes à la maladie de la flétrissure. Si l'on arrivait à appliquer ces données à la question de la Rouille des Céréales, ce serait un résultat très important.

Il suffit de jeter un coup d'ceil sur les carrés de la figure 134 pour comprendre; la superposition des déterminants de couleur jaune et verte donne, comme précédemment, les quatre combinaisons JJ. JV, VJ et JJ. En les associant aux combinaisons de forme, on obtient un premier carré. Le second (à droite) représente ce qu'on obtient par la superposition des caractères.

On peut arriver au même résultat par la méthode algébrique

\begin{tabular}{|c|c|c|c|}
\hline B R & $R r$ & RR & Ar \\
\hline \multicolumn{2}{|c|}{$\cdots$} & \multicolumn{2}{|c|}{$J \quad V$} \\
\hline$r R$ & $r r$ & r R & re \\
\hline RR & Rr & RR & Rr \\
\hline \multicolumn{2}{|c|}{$\ldots$} & \multicolumn{2}{|c|}{$\cdots \vee \cdots \vee \cdots$} \\
\hline$r R$ & $r e$ & $r R$ & $r e$ \\
\hline
\end{tabular}
qui a été indiquée au début dans le cas des monohybrides.

\begin{tabular}{|c|c|c|c|}
\hline$R R$ & $\mathrm{Rr}$ & R R & $\mathrm{Rr}_{r}$ \\
\hline $\mathrm{JJ}$ & $\mathrm{JJ}$ & JV & JV \\
\hline$r R$ & $r r$ & $r R$ & $r r$ \\
\hline $\mathrm{JJ}$ & $\mathrm{JJ}$ & JV & JV \\
\hline RR & $\mathrm{Rr}$ & RR & $\mathrm{Ar}$ \\
\hline VJ & $V J$ & VV & VV \\
\hline$r R$ & $r r$ & $r R$ & $r r$ \\
\hline$\vee J$ & VJ & VV & VV \\
\hline
\end{tabular}

Fig. 134, - Schéma expliquant les associations de deux couples de caracteres : grains ronds (R) ou ridés (r) et verts (V) ou jaunes (J). Daus chaque grain il $y$ a association d'une forme et d'une couleur. Le premier quadrillage correspond aux diverses combinaisons de formes; la combinaison avec les associations de couleurs est représentée sur le quadrillage de droite, ce qui donne toutes les combinaisons possi. bles (16) à la deuxième génération. 


\section{LA CLASSIFICATION BOTANIQUE}

\section{I. - LES VOYAGES ET LA BOTANIQUE}

$\mathrm{L}$ a recherche des plantes à épices. - La connaissance complète de la plante que possède le lecteur, grâce à tout ce qui précède, nous amène à aborder maintenant une nouvelle étude, celle de la classification. Il ne suffit pas de connaître la plante en général, il faut connaître toutes les plantes. Ce savoir a une immense importance, car les végétaux jouent, comme nous dirent en Europe et sur tout le globe : l'Ananas, le Maïs, la Pomme de terre, le Haricot, pour ne citer que les plus importantes, dont la propagation a amené des révolutions si profondes pour la civilisation humaine, puisque la Pomme de terre a fait disparaitre la famine de l'Europe.

Le but primordial visé par Colomb n'avait pas été atteint, mais il était réservé au Portugais Vasco de Gama de parvenir au pays des épices en doublant le cap de Bonne-Espérance et en gagnant ainsi l'Inde. C'est donc l'appât prodigieux de la découverte de plantes rarissimes qui a suscité les deux plus grands voyages des temps modernes et qui a orienté l'humanité sur les routes du progrès. D'ailleurs la possession de la terre aux épices a continué à faire l'objet des convoitises de toutes les nations de navigateurs. Après l'écroulement de Venise, la Hollande ne tarda pas à ravir au Portugal sa conquête et, pendant deux siècles, par des moyens étranges, garda le monopole de ces plantes à épices en concentrant leur culture et leur exploitation dans quelques îles et en organisant de véritables expéditions guerrières pour les détruire partout ailleurs. Celte situation ne pouvait durer et, au $\mathrm{XVIII}^{\circ}$ siècle, une expédition fut organisée par Poivre pour aller à la découverte des pays aux épices, dont les espèces furent alors propagées à la Réunion et ailleurs.

Les plantes à encens dans l'Egypte ancienne. - Un pareil récit éclaire suffisamment le lecteur sur l'importance des plantes pour la prospérité Seneçons arborescents au Kilimandjaro.

Cl. Alluaud

l'avons déjà montré, un rôle immense dans la vie des peuples. On ne peut mieux le prouver qu'en rappelant que l'Amérique a été découverte par Christophe Colomb parce qu'il voulait trouver un chemin plus court pour arriver aux pays producteurs d'épices: pendant tout le moyen âge, ces produits précieux de plantes rares de l'Inde et des archipels voisins arrivaient en Europe, après mille difficultés, par l'Ëgypte et l'isthme de Suez, et c'est à Alexandrie que les Vénitiens allaient les chercher. L'Italie a donc été, pendant tout le moyen âge, la pourvoyeuse de l'Europe pour tous les produits de I'Extrême-Orient. Marco Polo, dont les voyages en Chine ont été si célèbres, était Italien, comme devait l'être le Génois Christophe Colomb. Grâce à ce dernier, l'Amérique fut découverte, mais il ne devait pas y trouver les épices; dès son retour en Europe, l'illustre Génois rapporta des échantillons variés de la flore américaine; cette vue émerveilla les Espagnols et bientôt un certain nombre de plantes remarquables du Nouveau Monde se répan-

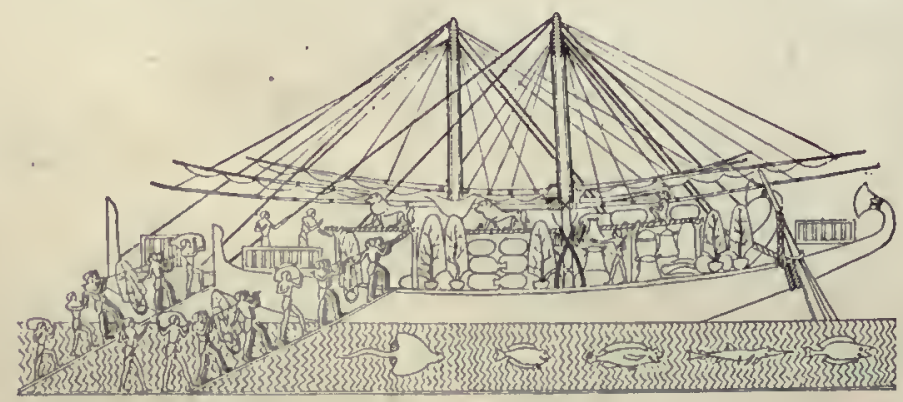

Fig. 135. - Expédition rapportant des plantes à encens.

(Inscriplions du temple de Deir-el-Bahari, en Ézypte.) commerciale des pemples et justifie les grandes explorations pour les découvrir. D'ailleurs déjà, dans l'ancienne Égypte, les Pharaons avaient organisé de grandes expéditions et frété des flottes qui, par la mer Rouge, ont été à la découverte des végétaux à encens. Les égyptologues ont déchiffré de précieux documents se rapportant notamment à un voyage qui a été fait par une flotte égyptienne, frétée par la reine Hatasou, de la XVIII ${ }^{\circ}$ dynastie, pour aller, en partant de la mer Rouge, au pays mystérieux de Pount. Les parois du temple de Deir-el-Bahari reproduisent les détails de cette expédition (fig. 135). On voit un bâtiment arrivé au port d'embarquement et les Égyptiens transportent les plantes précieuses dans une corbeille (analogue aux serres Ward actuellement employées pour le transport des plantes aux colonies), avec de l'or, de l'ivoire, des cynocéphales, des léopards. Les parois du temple mentionnent également l'arrivée des espèces sacrées en terre d'Égypte et les grandes fêtes religieuses qui scrvirent à célébrer cel événement important, quand les plantes furent installées autour du temple. L introduction d'une espèce rare ćtait donc à ces époques lointaines une grande date à la fois politique et religieuse.

Voyages modernes. - Dans les temps modernes, et encore à l'heure présente, les voyages d'exploration continuent. Les grands Etats européens et les jardins botaniques subventionnent des voyageurs qui, au péril de leur vie, s'en vont à la recherche de richesses qui importent tant à l'Europe. Il serait trop long d'énumérer tous les noms des voyageurs illustres qui ont enrichi nos connaissances botaniques, mais on peut rappeler les noms à jamais célèbres de Cook, de Dumont d'Urville, de Dombey, de Gaudichaud et, parmi les hommes qui, dans ces dernières années, ont le plus fait pour notre pays et pour le Muséum, MM. Diguet, Geay, Alluaud, Charcot, Gain, Chevalier. Ce dernier, depuis plus de vingt ans, 
explore fructueusement l'Afrique occidentale et a commencé à y organiser des jardins, germes d'établissements qui, dans un avenir lointain, seront peut-être les rivaux des grands jardins botaniques des régions tropicales. M. Caille, chef de service au Muséum, a été le compagnon et le lieutenant dévoué de $M$. Chevalier, et la photographie ci-contre donne une idée de l'installation rustique de l'Européen dans ces pays neufs où il a tout à faire : récolter les plantes et les sécher avec les plus grandes difficultés, faire des cultures, lutter contre les noirs, contre la fièvre et contre la mort.

Quand le voyageur, après avoir échappé à tous les périls qui le guettaient, revient en Europe, il rapporte dans nos serres des plantes rares et du plus grand intérêt économique qui peuvent être propagées partout dans les colonies.

Les classifications. - Mais il ne suffit pas d'aller à la recherche des richesses végétales, il faut les étudier, et c'est là le rôle du Muséum d'histoire naturelle et de tous les établissements similaires de l'étranger. C'est une tâche immense, car le nombre des plantes est prodigieux et, pour pouvoir s'y reconnaître au milieu de ce

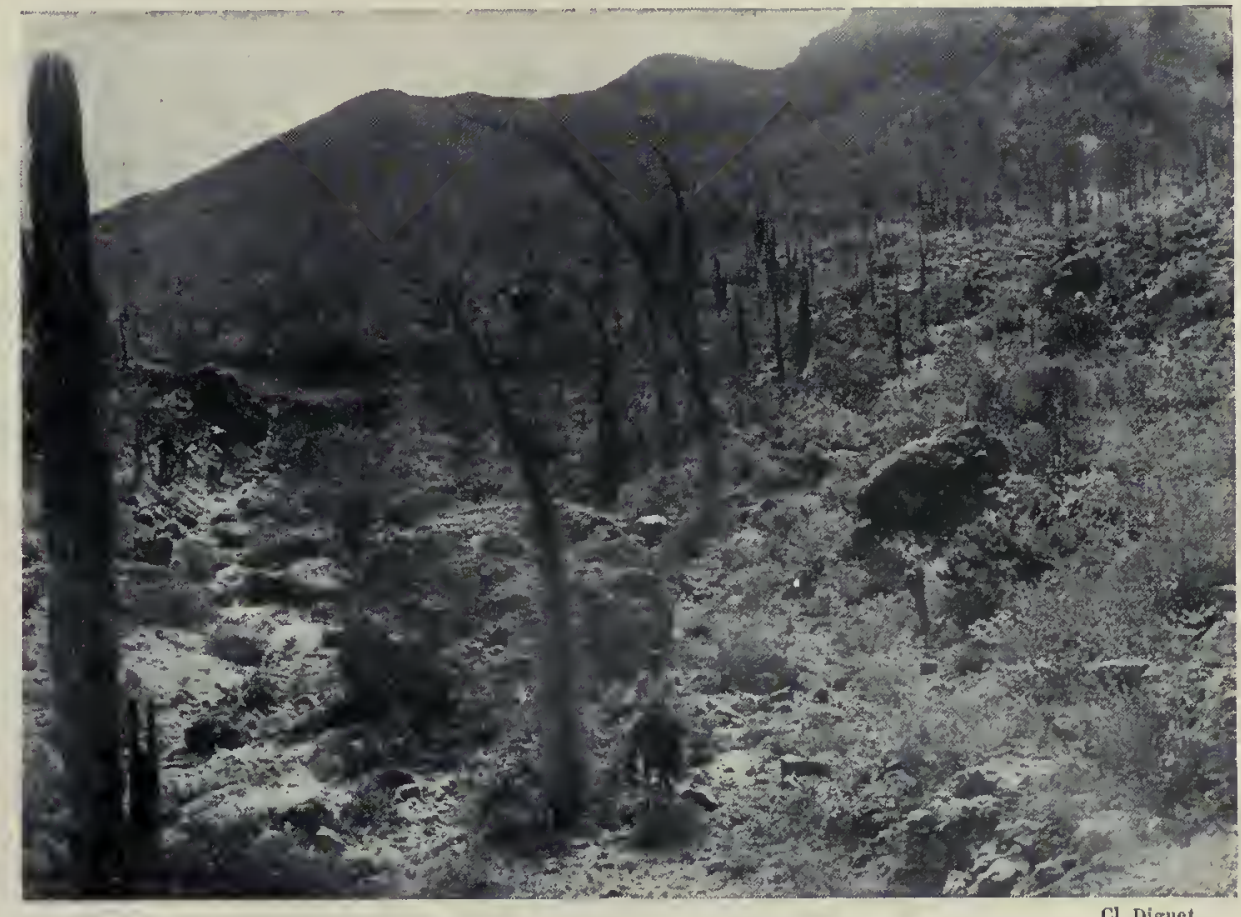

Idria columnaria dans un paysage du Mexique. gigantesque inventaire de la nature, il fallait créer les classifications. Les premiers essais sont dus à Césalpin, de Florence (1583), qui distribua 840 espèces végétales en quinze classes. Au cours du XVII ${ }^{\mathrm{e}}$ siècle, de nombreux essais de classification furent faits en Angleterre par Morison (1680) et Jean Rai (1682, I693), en France par Tournefort (1694). Mais, au XvitI ${ }^{\mathrm{e}}$ siècle, le nombre des plantes découvertes alla en se multipliant d'une manière inquiétante et la question de la nomenclature se posa à nouveau. Linné en fut le législateur et il imposa deux noms latins à chaque plante : un nom de genre et un nom d'espèce; ce dernier était un qualificatif. Cette simple réforme a eu une portée immense et elle a permis à l'illustre savant suédois d'apporter l'ordre et la simplicité dans une tâche extrêmement difficile. En 1735, il publia sa méthode sexuelle, fondée sur l'étude de la fleur et principalement sur l'examen de l'étamine. Il classait le règne végétal en vingt-quatre classes, suivant le nombre des étamines (1, monandrie; 2, diandrie, etc.), suivant leur taille (didynamie, tétradynamie), suivant leur soudure entre elles (monadelphie, diadelphie, etc.) ou au pisti] (gynandrie), et suivant l'existence de fleurs hermaphrodites ou unisexuées (monœecie, diøecie...); enfin la dernière classe comprenait les plantes nayant pas de fleurs (cryptogamie).

Le grand mérite de cette méthode artificielle de Linné était surtout d'être pratique, mais elle négligeait bien souvent les affinités naturelles des plantes. Il était réservé aux de Jussieu de fonder la méthode naturelle. En 1759, Louis XV, voulant faire planter le jardin botanique dans le parc de Trianon, près Versailles, chargea Bernard de Jussieu, démonstrateur au jardin du roi à Paris

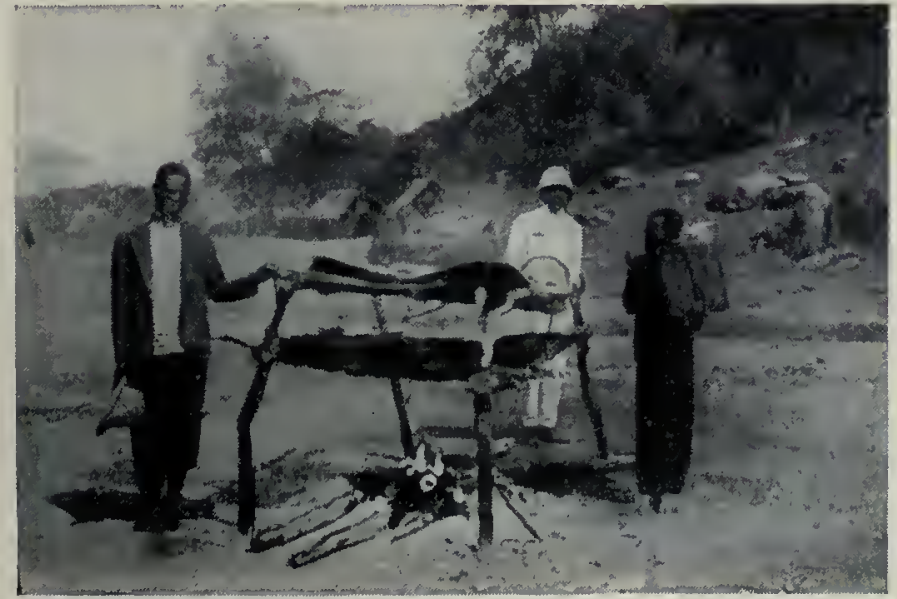

Séchage des plantes au cours d'une expédition.
(Muséum actuel), de diriger cette plantation. Celui-ci réalisa sur le terrain les conceptions qui avaient germé dans son esprit, à la suite d'une étude approfondie de la botanique. Malheureusement, i] ne publia jamais rien et les résultats extrêmement remarquables de ses études auraient pu être perdus, si son neveu, AntoineLaurent de Jussieu, n’avait continué et publié son cuvre. Il a été ainsi le fondateur de la méthode naturelle, œuvre qui est une des plus grandes gloires du Muséum: c'est ce savant qui a divisé les végétaux en Monocotylédones et Dicotylédones, ces derniers comprenant les apétales, les monopétales ou gamopétales et les poly. pétales, ou encore dialypétales. Cette classification a été remaniée depuis le début du XIX siècle; elle s'est enrichie; mais ce qu'il y a d'essentiel en elle subsiste encore à l'heure actuelle. Nous suivrons ici la classification de Van Tieghem, qui est la suivante :

EMBRANCHEMENTS

SOUS-EMBRA

-

1. THALLOPHYTES

Un thalle; ni feuilles, ni tige, ni $\mathrm{Pas}$ de matière verte.. Algues.

racines, ni feuiles, ni tige, ni De la chlorophylle. . . Champignons.

11. MUSCıNÉES $\quad$ Tige rampante ou thalle. Hépotiques.

Tige et feuilles, ni racines, nifleurs. Tige dressée . . . . Mousses.

111. cryptogames vasculaires / Ramificalion latérale. Filicinées.

Racines, tiges, feuilles, pas de Ramification verticillée. Equisétinées.

fleurs. . . . . . . . . . Ramification en fourche. Lycopodinées.

\section{PHANÉrogames (Gymnospermes}

Des fleurs, avec racines; tiges et Angiospermes(granies; Manocotylédones. feuilles............. Angiospermes(granies $\begin{gathered}\text { Manocotylédan } \\ \text { prolégées par l'ovaire). ( Dicotylédones. }\end{gathered}$

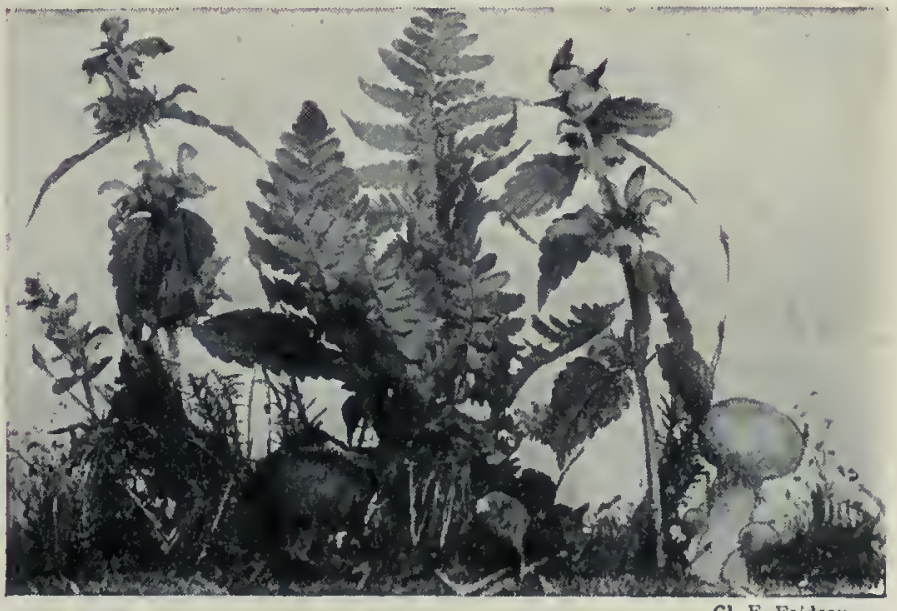

Plantes appartenant aux quatre embranchements. 


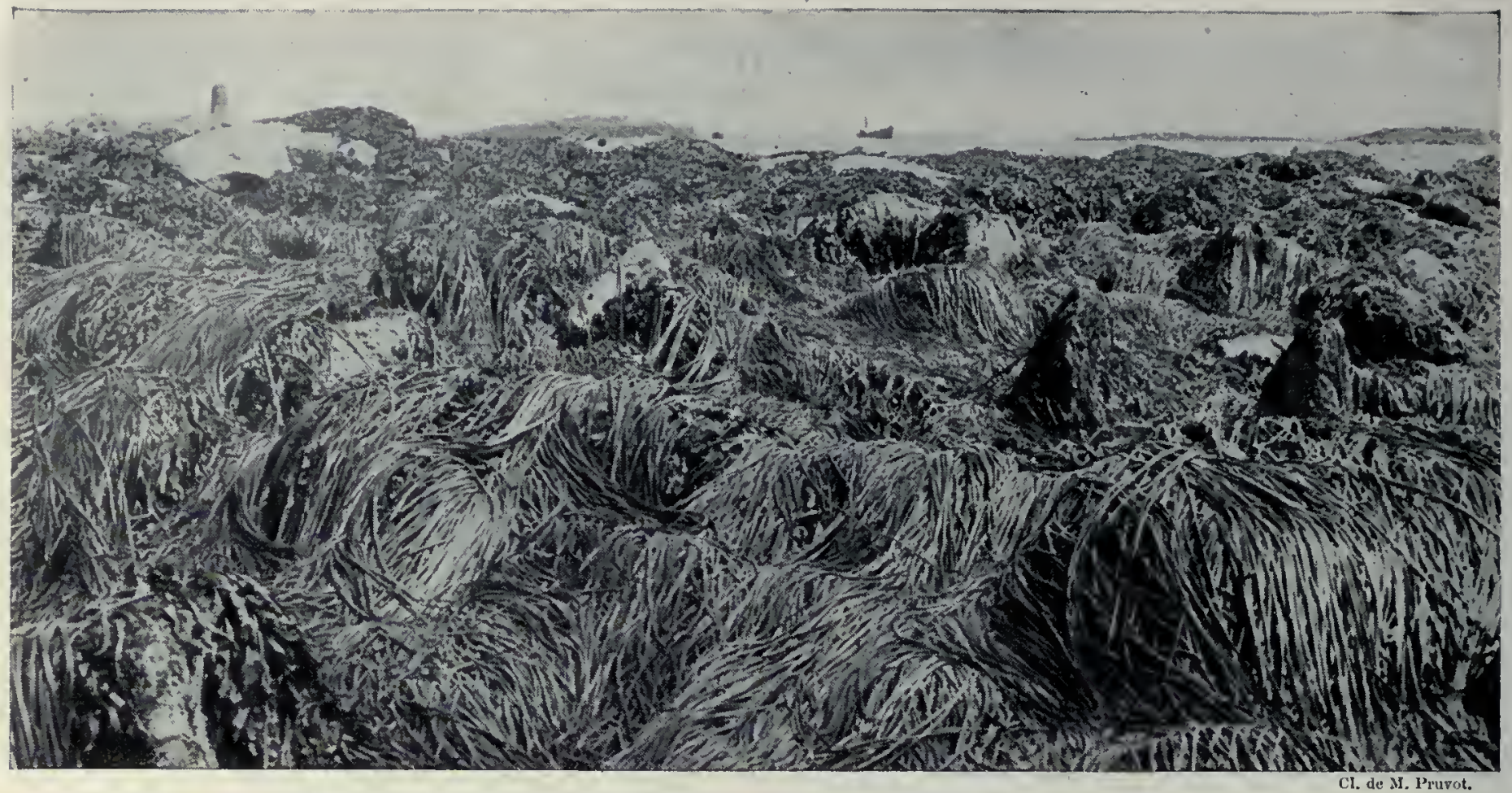

HIMANTHALIA EN FOUET, SUR LES ROCHERS, A MER BASSE, PRÉS ROSCOFF.

\section{II. - LES PLANTES SANS FLEURS}

\section{THALLOPHYTES}

Les Algues. - Les Algues sont des Thallophytes pourvues de matière verte. Dans les cellules de certaines d'entre elles, le pigment vert est seul : aussi les appelle-t-on Algues vertes; dans d'autres, il se complique de pigments de diverses couleurs: d'où les noms d'Algues bleues, brunes et rouges. Toutes ont besoin d'humidité; quelques-unes sont microscopiques; au contraire, certaines espèces marines ont des dimensions considérables. Leur unique organe, le thalle, plus ou moins différencié, consiste en un filament simple ou ramifié ou en une lame souvent compliquée; il sert à la fois à la nutrition et à la reproduction; cette dernière est tantôt sexuée et se fait par des aufs, tantôt asexuce et a lieu alors soit à l'aide de spores immobiles, soit par des spores mobiles ou zoospores. C'est surtout dans les milieux liquides (eaux douces ou salées) que se développent les Algues; quelques-unes sont terrestres.

Algues vertes.- Les Characées constituent le groupe supérieur, se rapprochant le plus des Muscinées; elles habitent les eaux douces ou saumâtres du monde entier. Un Chara atteint souvent une grande taille (parfois I mètre); il est formé de filaments constitués alternativement par de grandes cellules ou entre-nœuds, avec de très nombreux grains de chlorophylle, et des noeuds formés de cellules plus petites, qui se divisent en une cellule centrale et descellules superficielles. Ces dernières émettent des prolongements verticillés qui sappliquent étroitement par des appendices sur la cellule internodale et contribuent à la cortiquer. A l'endroit de ces noeuds, des branches en verticilles se séparent; elles ont la même constitution que la précédente, mais avec une croissance limitée : ce sont donc des sortes de feuilles. Il y a, en somme, des rudiments de tige et de feuilles; la tige est d'ailleurs fixée à l'aide de poils hyalins ou rhizoïdes à sa base; des branches semblables à la tige principale peuvent naître à l'aisselle des feuilles.

La reproduction est sexuée (fig. 136); elle a lieu par des organes mâles ou anthéridies, qui sont sphériques, rouges, et naissent à l'extrémité d'une foliole; ils portent à l'intérieur des fouets de longs filaments, dont chaque cellule produit un anthérozoïde spiralé, à deux cils vibratiles comme dans les Mousses. L'organe femelle ou oogone ćmane du noud

basilaire de la même foliole : sa cellule femelle est entourée par des cellules corticales rapprochées les unes des autres et tordues en spirale, se soudant à leur sommet pour former une couronne courte de cinq cellules petites. Au moment de la fécondation, cinq fentes latérales, provenant de l'écartement des cinq tubes, laissent pénétrer les anthérozoïdes qui, en se fusionnant avec l'oosphère, donnent un ouf.

Dans les Spirogyres, qui sont des Conjuguées, la chlorophylle a la forme d'un ruban spiralé composé de files de cellules. Au moment de la reproduction, deux filaments se placent parallèlement l'un à l'autre et les cellules qui se font face bourgeonnent l'une vers l'autre (fig. 137); les bourgeons s'accolent, les protoplasmas se fusionnent : tout le contenu d'une cellule passe dans l'autre, et un ceuf se forme, d'un vert intense, qui reproduira la plante en germant. Dans les Clostéries, qui appartiennent à un groupe voisin, celui des Desmidiées, consti-
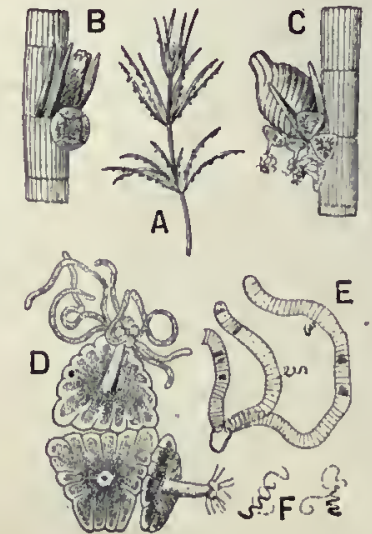

Fig. 136. - Reproduction des Characées

A, Tige de Chara fragilis; B, Portion de feuille a vec oosone et anthèridie; $\mathrm{C}, \mathrm{La}$ même avec loogone fécondé et l'anthíridie onverte: $D$ S Structure de l'anthéridie trois écussons désarticules; $E$, Trois files de cellules mères d'anthérozoildes; $\mathrm{F}, \mathrm{An}$ thérozoîdes isolés. tuées par des cellules isolées ayant la forme d'un croissant, quelque chose d'analogue se produit.

Jamais il n'y a de reproduction asexuée dans les deux plantes précédentes, tandis qu' elle

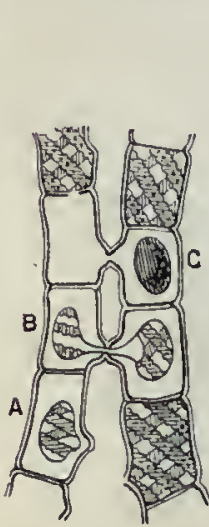

Fig. 137. Spirogyre.

Fusion de deux cellules semblables.

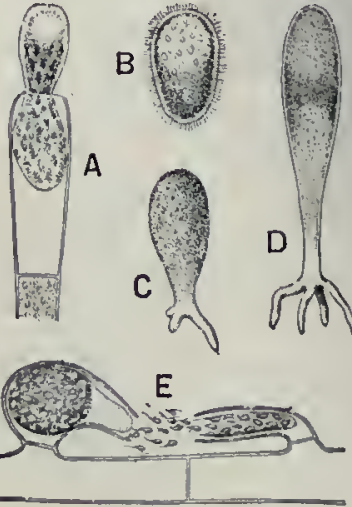

Fig. 138 - Reproduction de la Vaucherie.

A, Zoospores'échappant : B, Libre C, Hixée; D, Germanl: $K$. Ookone et anthéridie de Vauchérie 

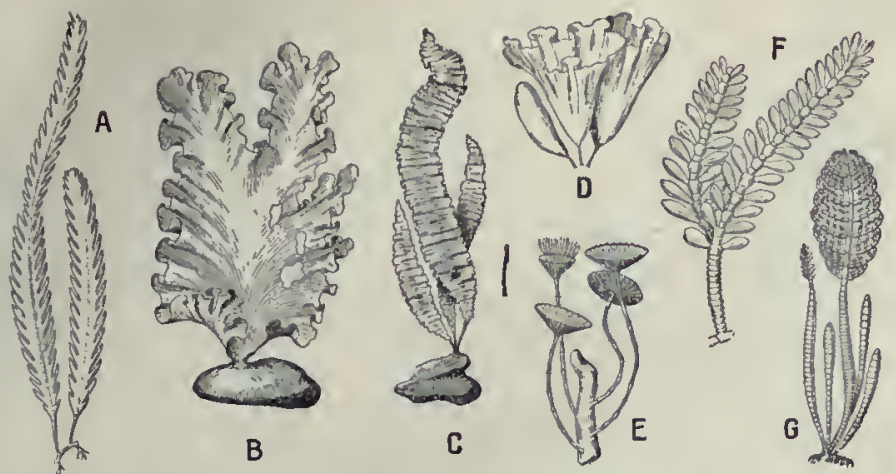

Fig. 139. - Algues vertes.

A, Caulerpa scalpelliformis; B, Ulva latissima; C, U. Linza; D, U. cornucopia; E, Acclabularia mediterranea; F, Caulerpa cacioiles; G, Struvea plumosa.

existe dans les Conferves, typęs de la famille des Confervacées. $\mathrm{Ce}$ sont des masses gluantes, filamenteuses, vertes, qui croissent abondamment dans les eaux stagnantes. Chez les E Edogones, genre de ce groupe, les anthérozoïdes ont une couronne de cils (comme les zoospores, qui sont plus grosses) et pénètrent sous l'ceil de l'observateur dans l'organe femelle ou oogone. Les Ulves ou Laitues de mer (fig. 139, B, C, D), grandes lames vertes translucides qui ondulent dans l'eau salée, se rattachent à ce groupe. Certaines Conferves, dans les eaux agitées, se rassemblent sous forme de boules, dites " pelotes marines ", formées de filaments brun clair, très ténus et dont la grosseur varie de celle d'un œuf à celle d'une tête humaine; on en trouve souvent sur les côtes de la Méditerranée, dans les lacs de Suède; on a, il est vrai, signalé dans la mer des agglomérations semblables, faites d'aiguilles de Pin.

Dans les Pleurocoques verts de Nægeli, le thalle est dissocié, pulvérulent : c'est la poussière qui recouvre l'écorce des arbres, surtout du côté nord, permettant de s'orienter quand on est perdu dans un bois. Parmi les Siphonées voisines, nous devons citer les $V$ aucheries (fig. 138), qui ont été dédiées au naturaliste Vaucher, vivant au XVIII ${ }^{\mathrm{C}}$ siècle; parfois ce sont des Algues filamenteuses ramifiées, poussant sur la terre, et contenant un très grand nombre de noyaux : les zoospores, qui sont les plus grosses connues, sortent de l'extrémité d'un filament par un orifice étroit, en s'étranglant; une fois libres, elles deviennent ovoïdes et leur surface est couverte diune multitude de cils vibratiles. Ces plantes peuvent d'ailleurs se reproduire sexuellement par des anthéridies en forme de cornes, donnant naissance à de petits anthérozoïdes à deux cils qui pénètrent dans des oogones ovoïdes, dissymétriques, terminées par un bec latéral où la membrane s'ouvre en se gélifiant.

Aux Siphonées à thalle continu, non cloisonné, se rattachent un certain nombre d'Algues marines très différenciées. Les Caulcrpa ( fig. 139, A et F) ont une sorte de rhizome rampant à la surface des roches et simulant une tige, des rhizoïdes fixateurs sur les rochers et des lames aplaties rappelant des racines et des feuilles; le thalle atteint ainsi de grandes dimensions. La membrane simprègne parfois de calcaire chez des Algues voisines: Acétabulaires (fig. 139, E), Cymopolies, qui ont étć confondues longtemps avec des Zoophytes.

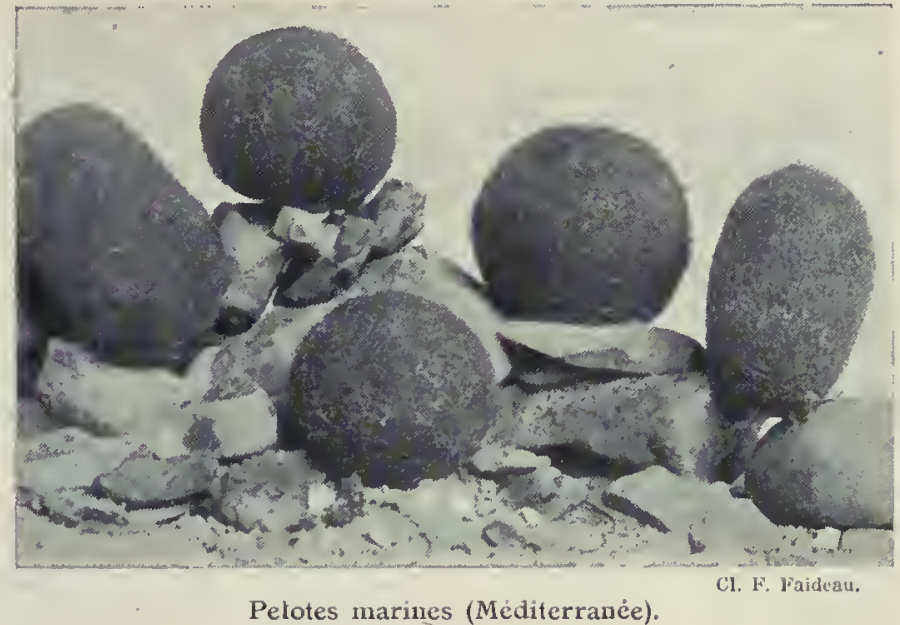

Mentionnons, en terminant cette étude des Algues vertes, le Réseau d'eau ou Hydrodictyon (fig. 140, C), qui a la forme d'un sac à grandes mailles hexagonales percées : au début, chacun de ses articles constitutifs résulte de la germination d'une zoospore à deux cils qui, après s'être déplacée dans une cellule mère, s'arrête, s'allonge et sajuste en un petit réseau avec une multitude d'articles semblables. Ces plantes sont les Cénobiées, c'est-à-dire vivant comme des cénobites ou en association ; elles sont représentées encore par les Volvox, formées de sphères mobiles couvertes de cellules analogues à des zoospores à deux cils (fig. 140, A et B).

Algues bleues. - Les Algues bleues ou Cyanophycées sont celles dont le pigment vert est additionné d'un pigment bleu appelé phycocyanine. Les Nostocs, qu'on appelle vulgairement " crachats de la lune ", font partie de ce groupe (fig. 141). Ce sont des masses gélatineuses d'un vert blewâtre, tremblotantes, que l'on rencontre parfois à la surface du sol; à l'intérieur de cette gelée se trouvent des chapelets de cellules dont les terminales se distinguent par des parois plus épaisses et un contenu hyalin jaune; les cellules du milieu d'un de ces filaments ondulés peuvent constituer des spores en grossissant. Dans les Oscillaires, la gelée n'existe pas: il y a seulement une membrane en forme de gaine: les filaments isolés sont formés de cellules aplaties tabulaires et ils ont la propriété curieuse d'osciller à leur extrémité en se déplaçant dans le champ du microscope.

La découverte des Bactéries (fig. 142 et 143), qui se rattachent aux Algues bleues, bien que généralement incolores, est intéressante à rappeler. Leuwenhoeck, au XVıt ${ }^{\mathrm{e}}$ siècle, construisit des lentilles plus puissantes que celles que l'on connaissait avant lui, et trouva une application capitale du microscope en étudiant à l'aide de cet instrument une foule de liquides, dans la bouche, dans l'intestin des animaux, et il y découvrit des organismes très petits qui étaient les Bactéries; à la fin du XVttt ${ }^{\mathrm{e}}$ siècle, on en connaissait un grand nombre et les dessins donnés par Otto Frédéric Müller permettent de reconnaître les Streptocoques, les Coques, les Spi-
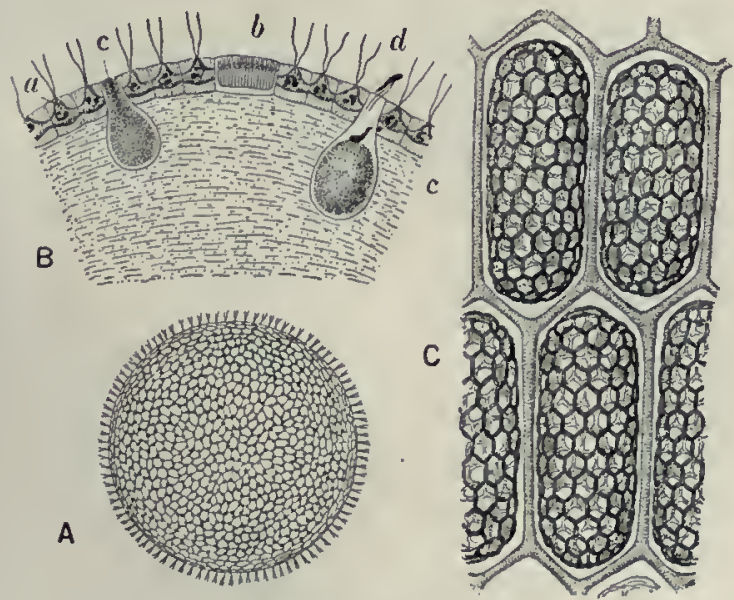

Fig. 140. - Algues vertes.

A et $\mathrm{B}$, Volvox globator: $a$, Cellules végétatives $b$, Antheridie; $c$, Oogone

d, Anthérozoïde pénétrant dans l'oosphère; C. Hydrodictyon.

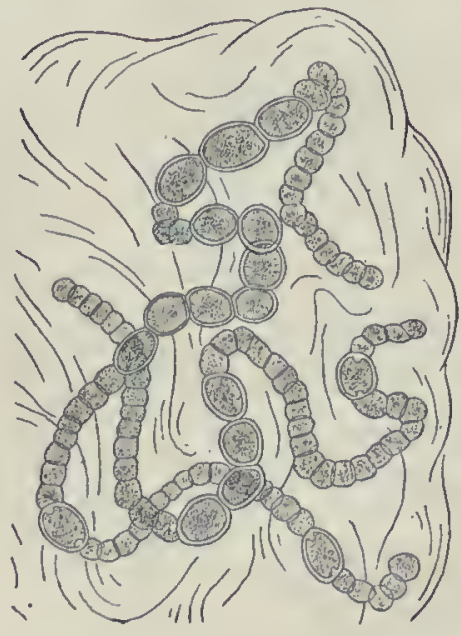

Fig. 141.

Nostocs ou Crachats de la Lune.
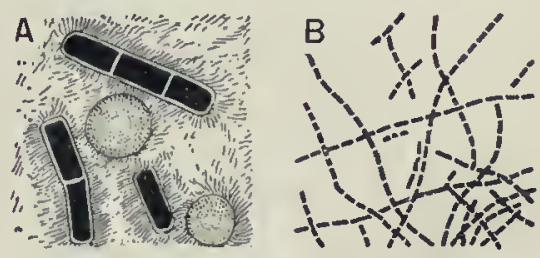

Fig. 142. - Bactéridie charbonneuse. A, Dans le sang; B, En culture.
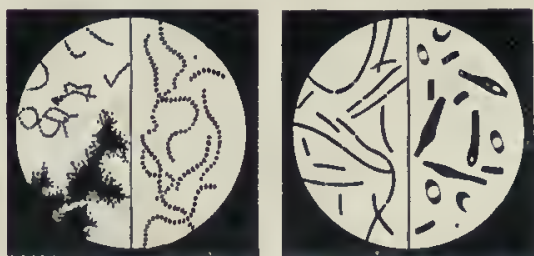

Fig. 143. - Streptocoque du puset de l'érysipéleet vibriou septique. 


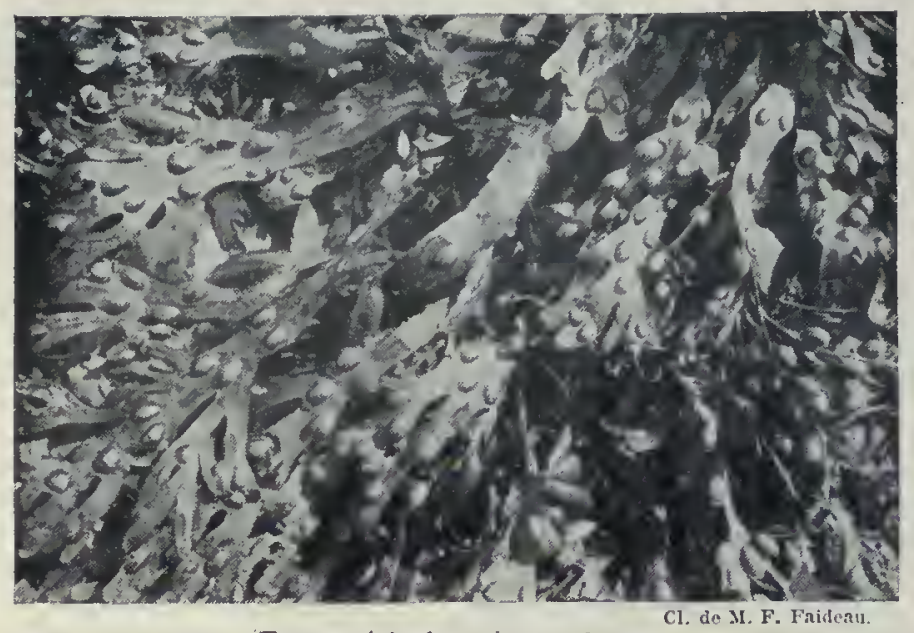

Fucus vésiculeux à mer basse.

rilles. Le plus gros des microbes pathogènes, la Bactéridie charbonneuse ( $f$ g. 142), a été anciennement entrevu, et son étude a été le fondement de la microbiologie médicale. En 1827, le vérérinaire français Barthélemy montra que la fièvre charbonneuse est inoculable par le sang des animaux morts. En 1845, le vétérinaire allemand Gerlach publia un mémoire célèbre où il démontrait la contagion. C'est à Rayer et Davaine, en 1852, que l'on doit la découverte, dans le sang des animaux morts, de la Bactéridie charbonneuse; mais, avec les idées régnantes, on n'attacha aucune importance à cette observation. En 1863, après les recherches de Pasteur sur les fermentations, Davaine revint sur cette question et présuma que la Bactéridie devait être la cause du mal ; i] l'inocula à des animaux de laboratoire (lapins, rats, souris); i] chercha à démontrer qu'elle agit seule : il ne put l'isoler. En 1876, Koch reprit les inoculations aux souris; il fit des cultures en petit de la Bactéridie dans du sérum ou dans l'humeur aqueuse du boeul; en goutte suspendue, il vit les Bactéridies s'allonger en quelques heures et donner un feutrage de filaments, puis, en douze à vingt-quatre heures, des spores. Pasteur avait déjà découvert, en 1868, les spores de la flacherie et Cobn celles du Bacille subtil. C'est en 1877 que Pasteur commença avec Joubert ses recherches sur le Charbon, qui devaient le conduire à la découverte du vaccin.

Les Bactéries se présentent sous des formes diverses : en bâtonnets, comme la précédente, pouvant s'allonger en longs filaments susceptibles de se désarticuler en zigzags et de donner des cellules isolées avec un seul article, à l'intérieur duquel une spore peut se produire. Dans d'autres types, on a des formes sphériques ou $\mathrm{Mi}$ crocoques, oblongues ou Bactéries, spiralées ou Spirilles. Les Streptocoques (fig. 143) sont des Microcoques qui ne se dissocient pas et qui sont en chapelet plus ou moins irrégulier. Dans la

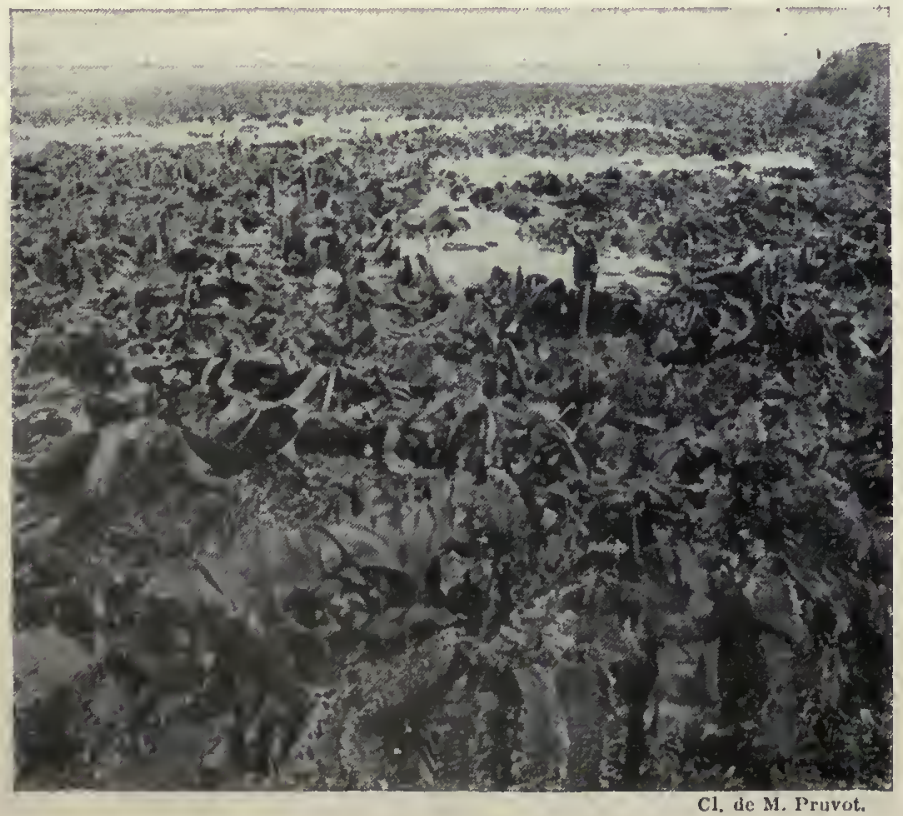

Lamiuaires à mer basse, près Roscoff.

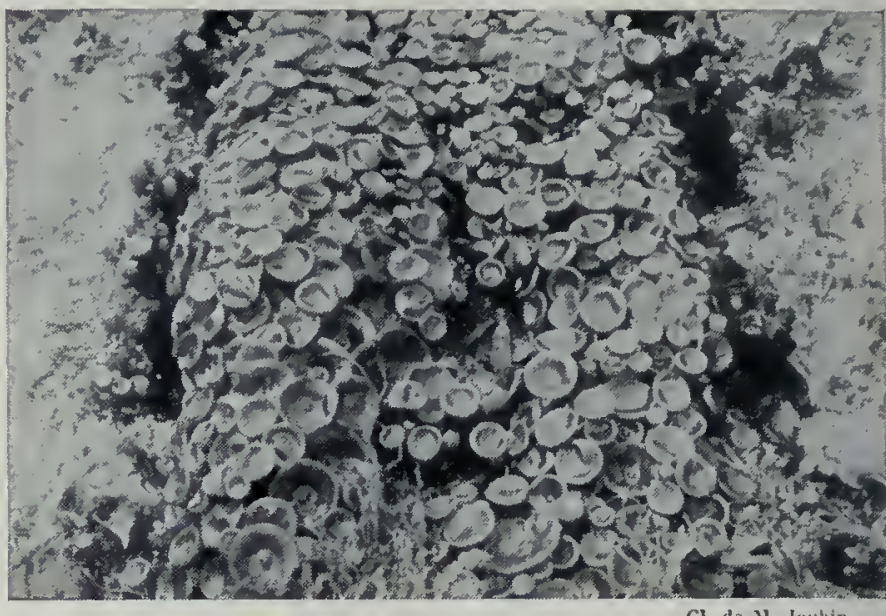

Cupules d'Himanthalia en fouet.

gomme des sucreries, qui se développe parfois dans les cuves, les chapelets précédents, en grand nombre, sont plongés dans une sorte de masse gélatineuse; ils ressemblent donc à un Nostoc, mais qui serait incolore ou blanc: d'où le nom de Leuconostoc qui lui a été donné par Van Tieghem. On comprend, par ce rapprochement, les affinités des Bactéries avec les Nostocacées : c'est pour cela que l'on place les Bactériacées dans le groupe des Cyanophycées, malgré l'absence de matière verte qui n'existe que chez un petit nombre de types. Il y a d'ailleurs beaucoup d'autres arguments qui justifient cette ressemblance.

$\mathrm{Au}$ lieu des formes arrondies, on peut avoir des espèces filamenteuses. Dans les Beggiatoa (fig. 144), qui vivent dans les eaux sulfureuses, les filaments sont longs et mobiles et, à cet égard, ils ressemblent un peu aux Oscillaires. Les Spirochètes, qui s'observent notamment dans la fièvre recurrente, ont un filament allongé pouvant se courber et présentent un enroulement en spirale.

En général, les Bactéries sont incolores; on a cependant trouvé de la chlorophylle chez quelques-unes d'entre elles. Dans certains types, le protoplasma est uniformément teinté par une matière rouge, la bactériopurpurine : on a affirmé que ces espèces avaient la propriété de décomposer l'anhydride carbonique et de produire un dégagement d'oxygène pur, mais cette propriété a été mise en doute par Molisch; ces Algues auraient cependant besoin de lumière pour leurs synthèses organiques. $D$ autres pigments peuvent exister dans plusieurs autres espèces : le Bacille pyocyanique ou du pus bleu, Bacille bleu qui se développe souvent dans le lait dit bleu; le Bacille prodigieux, qui produit des taches rouges et a servi à expliquer le phénomène singulier des hosties sanglantes, souvent observé au moyen âge. On connaît également des Bactéries phosphorescentes, et la phosphorescence de la mer est parfois due à plusieurs d'entre elles; elles exigent, pour se développer, un milieu salin. Les photobactéries ont été cultivées par Raphaël Dubois dans des ballons, qui laissent dégager une lumière pâle, d'une belle teinte vert bleuâtre.

Algues brunes. - Les Algues brunes (fig. 145) sont caractérisées par l'existence d'un pigment brun ou phycophylle qui se dédouble sous l'action de la chaleur ou dans l'eau douce en donnant une matière verte. Elles comprennent d'abord les Fucacées, dont les Fucus ou Varechs, qui abondent sur nos côtes, peuvent nous servir de type. Le thalle est plat, dichotome; il présente vers l'extrémité des parties vésiculeuses contenant de l'azote et, comme organes reproducteurs, des conceptacles apparaissant sur des parties terminales renflées, charnues, et dont la cavité arrondie s'ouvre par un faible orifice à l'extérieur; ils sont de deux types : les uns mâles,

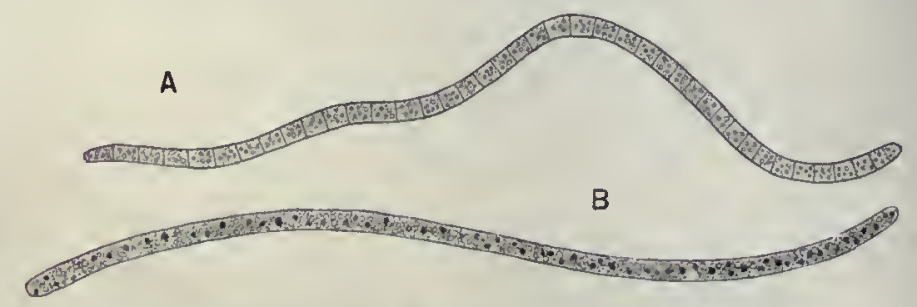

Fig. 144. - Beggiatoa, algue des eaux sulfureuses.

A, Filaments débarrassés des granules de soufre; $B$, Avec granuies. 


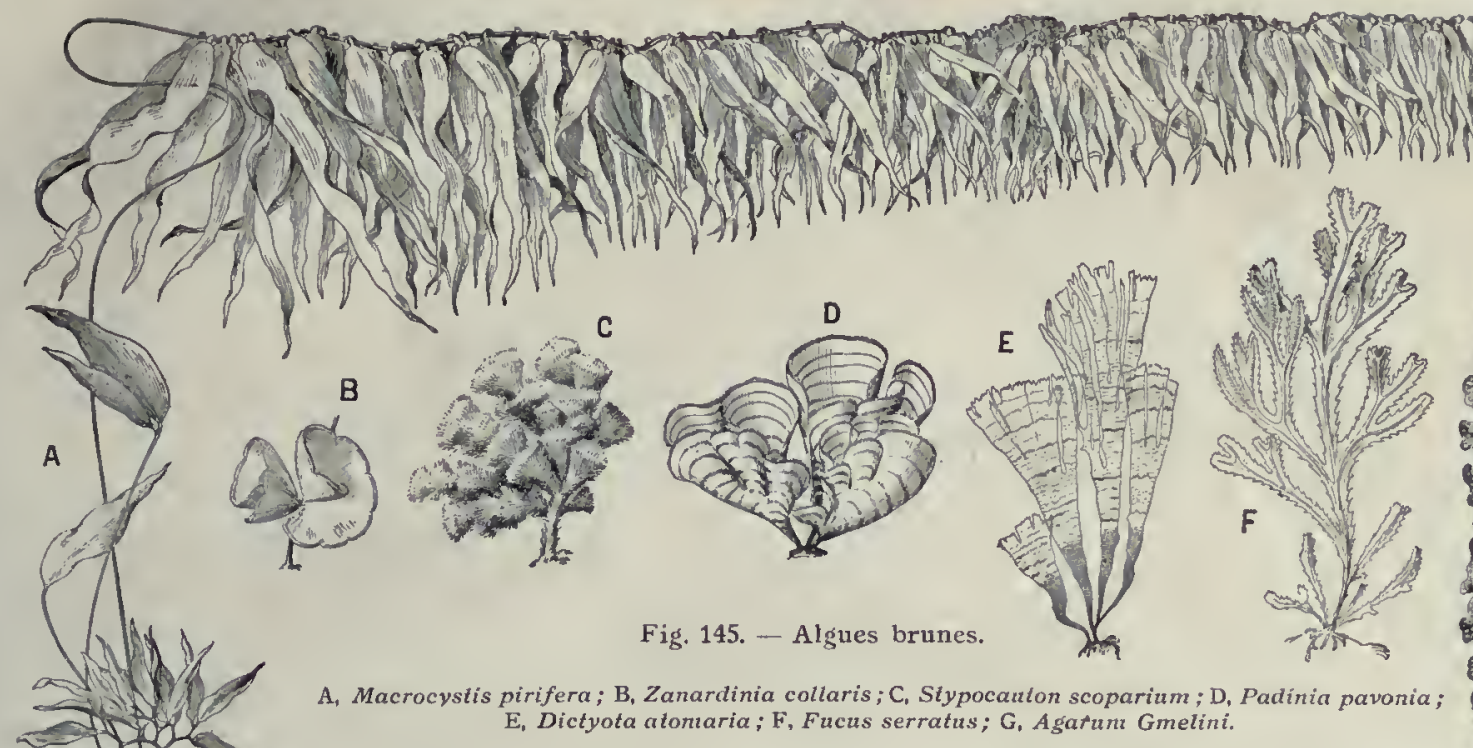

les autres femelles (fig. 7). Les anthéridies ou organes mâles sont des articles latéraux de poils ramifiés produisant un grand nombre d'anthérozoïdes pyriformes à deux cils vibratiles insérés latéralement. Les oogones sphériques ou organes femelles sont à huit oosphères arrondies, portées à l'extrémité de poils courts. Les oosphères et les anthérozoïdes sont mis en liberté; la fécondation a lieu; nous l'avons déjà décrite (p. 15). Dans les Pelvetia, qui sont voisins des Fucus, le thalle est régulièrement dichotome et cylindrique au lieu d'être plat. Dans l'Himanthalia, on remarque, à la base de la partie fertile, qui peut atteindre jusqu'à 3 mètres de long et qui est régulièrement dichotome, une partie stérile basilaire en forme de coupe et très petite, au milieu de laquelle la première est insérée. Dans les Ascophylles, on distingue dans le thalle un axe principal sur lequel sobservent de place en place des vésicules fotteurs et des courtes branches latérales pouvant se renfler à l'extrémité en parties ovoïdes, charnues, verruqueuses, correspondant à des conceptacles; il y a d'ailleurs seulement quatre oosphères au lieu de huit dans chaque oogone. Toutes ces Algues brunes de nos côtes résistent plus ou moins longtemps à la dessiccation et, de leurs exigences diverses sur ce point, résultent des zones bien tranchées: celle des Pelvetia est la plus proche du rivage, puis vient la zone des Fucus et des Ascophylles, enfin celle des Himanthalia, qui ne se découvre quaux grandes marées.

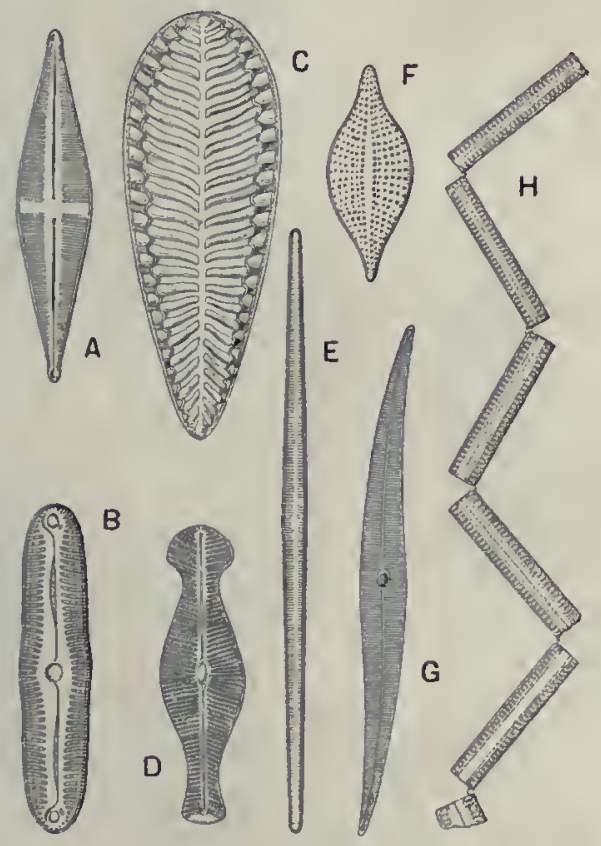

Fig. 146. -- Diatomées.

A, Navicula cuspialata; B, Pinnularia lata; C, Surirella splendida; D, Gomphonema geminatum; E, Svnedra radians; F, Fragilaria amphiceros: G, Pleurosigma deticatulum; H, Diatoma vulgare.
Dans les Sargasses, qui forment ces immenses prairies fottantes de 60000 -milles carrés que l'on rencontre au milieu de l'Océan Atlantique et qui avaient contribué à faire espérer à Christophe Colomb la découverte de la terre ferme, on observe des parties cylindriques simulant des tiges, sur lesquelles sinsèrent des organes aplatis qui peuvent rappeler des feuilles, et c'est sur des petits rameaux spécialisés que se flotteurs qui ressemblent à des fruits pédicellés. On a admis pendant longtemps que les végétaux étaient arrachés à la côte américaine et entraînés en pleine renlent les vésicules mer par les courants; ils végétaient un certain temps, puis finissaient par se détruire. Les travaux de Harvey, Sauvageau, Borgesen, ont montré que les deux espèces de la mer des Sargasses diffèrent de celles de la côte américaine, qu'elles n'ont aucunement l'aspect de débris, ne présentent jamais de crampons fixateurs, mais sont toujours en pleine vitalité et toujours stériles; il faut en conclure que ces espèces, probablement originaires de l'Amérique, se maintiennent, par bouturages naturels, à l'état flottant depuis des siècles. Enfin, dans les Durvillea, le thalle est puissamment développé et irrégulièrement ramifié. Le caractère essentiel et commun de toutes les plantes qui viennent d'être mentionnées est l'absence de zoospores.

II y a au contraire des zoospores dans les Phaosporées, comme les Ectocarpes, les Sphacélaries; celles qui nous intéressent surtout sont les Laminaires, dont le thalle a l'aspect d'une grande feuille rubanée, rétrécie à la partie inférieure en une sorte de pćtiole s'attachant sur les rochers par des crampons. On peut trouver au milieu du limbe une plage où se forment les organes qui sont des zoosporanges engendrant des zoospores, c'est-à-dire des organes asexués; Sauvageau a découvert deux petits thalles sexués. Certaines Laminaires peuvent découper leur limbe et le fenestrer. Dans les Macrocystes (fig. 145, A), Algues géantes des mers antarctiques, du Chili, des Falkland, il y a une partie courte inférieure, fixée aux rochers par des racines crampons, qui se continue en une tige cylindrique horizontale, sur laquelle sinsèrent des rameaux courts, renflés à la base en flotteurs et terminés en lames aplaties de 1 à 2 mètres de long; ces espèces de feuilles sont fixées en très grand nombre sur une sorte de tige pouvant avoir jusqu’à 200 mètres de longueur. Citons encore une jolie petite Algue de nos côtes, la Padinia Queue de Paon (fig. 145, D), dont l'aspect en éventail est des plus remarquables.

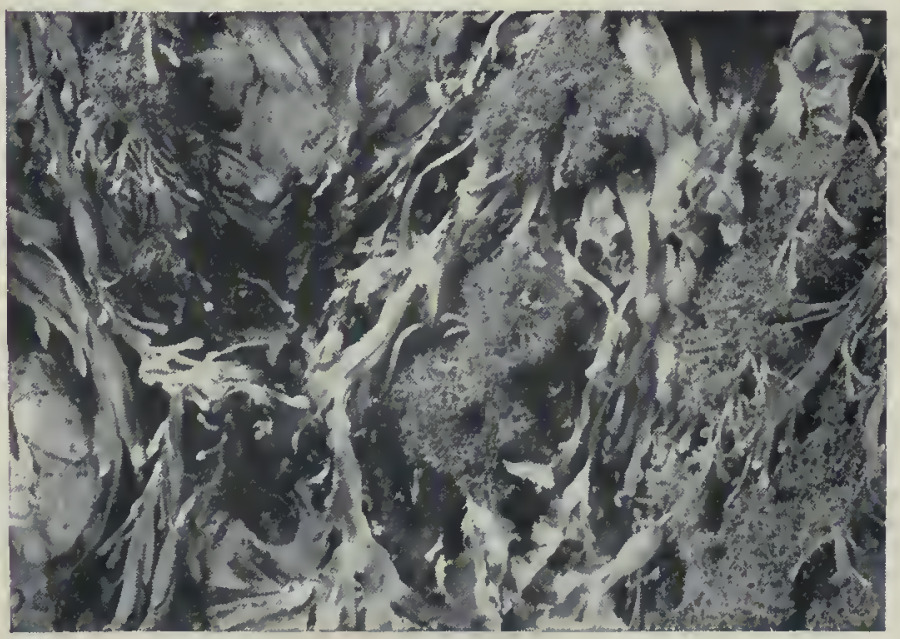

Polysiphonie, algue rouge parasite de l'Ascophylle noueux. 


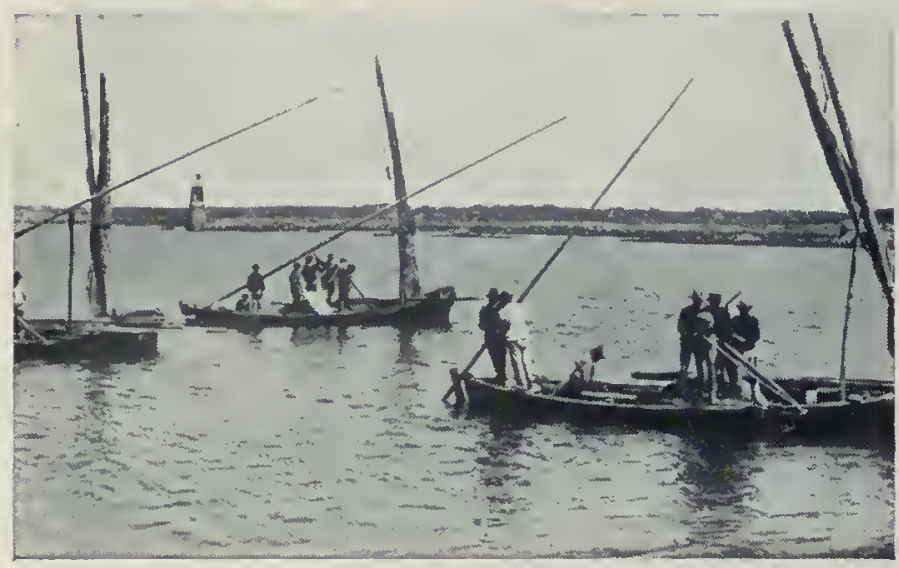

La pêche du maérl, à Tréguier.

Aux Algues brunes se rattachent des plantes curieuses, dont la membrane est silicifiée et dont les carapaces s'accumulent parfois en telle quantité qu'elles constituent des couches qui peuvent se former à l'heure actuelle, mais qui ont pu produire aussi dans les temps passés de véritables terrains. C'est ce que l'on appelle le tripoli, qui est exclusivement formé par les membranes de Diatomées (fig. 146). Ces plantes sont, en général, dissociées; les cellules, à mesure qu'elles se forment, se séparent les unes des autres: elles paraissent donc être des Algues unicellulaires. Leur membrane est formée de deux valves, comme celles d'une boîte et de son couvercle; elles sont ornées de sculptures variées surleur surface, souvent très fines, affectant des dispositions radiales on groupées de part et d'autre d'une ligne médiane; comme elles présentent des formes très variées, elles sont appréciées par des amateurs qui sont souvent passionnés pour cette étude. On peut signaler les Navicules qui, vues par-dessus, ont la forme d'une lentille biconvexe. La Navicule ostréaire ou Navicule bleue abonde en certains points des eaux marines; c'est elle, ainsi que l'ont démontré Bornet et Puységur, en 1877, qui provoque le verdissement des huîtres; elle se fixe sur les branchies par un phénomène de postdigestion. A côté des Naviculaires, citons encore les Pinnulaires, beaucoup plus allongées, les Pleurosigma, les Synèdres, etc.

Signalons, en terminant cette révision des Algues brunes, les Péridiniens, espèces pélagiques habitant la surface des eaux marines, plus rarement celle des eaux douces, et ayant des formes variées, unicellulaires avec deux cils, l'un en arrière dans un court sillon longitudinal, l'autre dans un sillon transversal. Avec les Diatomées pélagiques et diverses Algues bleues, les Péridiniens forment la partie végétale du plankton, c'est-à-dire de l'ensemble des êtres minuscules, animaux et végétaux, vivant en suspension dans les eaux, et nourrissant les invertébrés qui, eux-mêmes, sont la proie des poissons.

Algues rouges. - Les Algues rouges (fig. 147) ont mérité par leurs riches coloris le nom de fleurs de la mer ou de Floridées; ce sont elles qui s'enfoncent le plus profondément dans le milicu liquide et l'on peut rencontrer leurs représentants jusqu'à

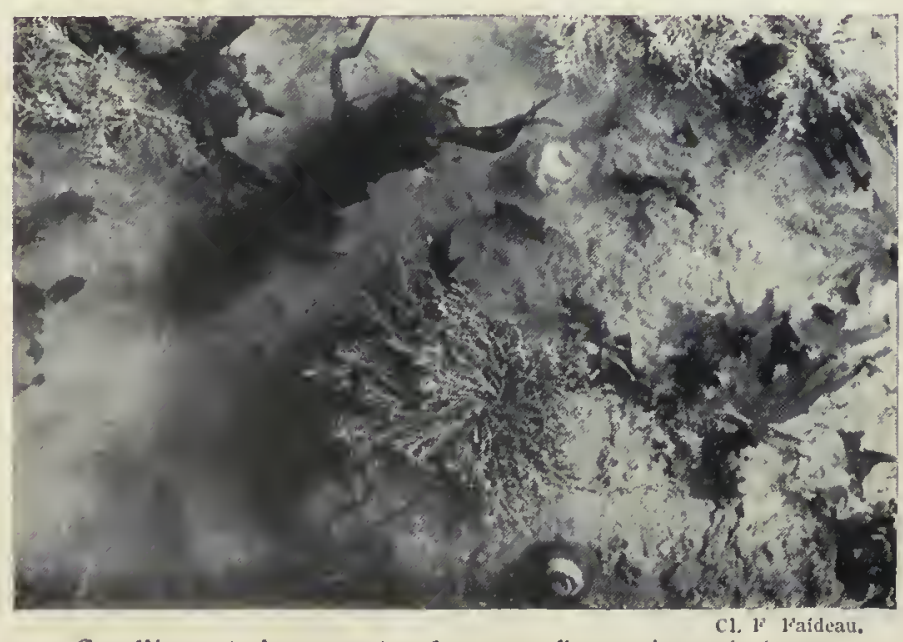

Corallines et algues vertes dans une flaque, à marée basse.
300 mètres. Au delà, les Algues font défaut. Leur thalle est d'ailleurs toujours fixé aux rochers ou sur celui d'autres Algues : ainsi la Polysiphonie fastigiée de nos côtes, sur une Algue brune, l'Ascophylle noueux; cest quelquefois un simple filament comme dans les Bangies, ou un filament rameux dans les Callithamnies, ou une lame mince, rouge, aplatie, translucide, qui ondule dans l'eau, comme chaz les Porphyres (fig. 147, H). Dans les Delesséries ( ig. 147, G), le thalle a la forme d'une feuille composée, palmée, à folioles; il est pourvu d'une grosse nervure médiane et de nombreuses nervures secondaires disposées suivant le mode penné. Dans les Chondrus, le thalle a la forme d'un cordon cylindrique ramifié en dichotomie ou suivant le mode penné dans les Gigartines. Dans ces deux types, et surtout dans les Gelidium corné et cartilagincux du Japon, le thalle se convertit dans l'eau bouillante en une gelée épaisse et nutritive, qui constitue ce que l'on appelle gélose ou agar agar, extrait surtout des espèces des mers de Chine. Le thalle peut s'incruster de calcaire : il est cylindrique, ramifié dichotomiquement et articulé dans les Corallines (fig. 147, E); il est en lames à tissu compact dans les Lithophylles, ou à tissu lâche dans les Lithothamnions, et, en brisant les excroissances obtuses, on trouve les conceptacles reproducteurs formés pendant les périodes végétatives antérieures. Les Algues calcaires sont dragućes et servent, sous le nom de maërl, à l'amendement des terres. Le Chondrus crispé est utilisé en médecine pour son mucilage.

La coloration des Floridées nest pas loujours rouge et, dans les Batrachospermes, qui habitent les eaux douces, la teinte est d'un vert sombre, presque vert olivâtre ou noirâtre; dans ce cas, ces plantes sont rattachées aux Floridées marines par lensemble de leurs caractères et de leur mode de reproduction; on les trouve dans les chutes d'eau douce naturelles, aux barrages des écluses on aux vannes des moulins. Les spores dans ce genre sont solitaires, mais en général l'appareil asexué des Floridées est formé de sporanges qui donnent naissance à quatre spores. L'appareil sexué est surmonté dans sa partie terminale d'un fin filament appelé trichogyne, sur lequel s appliquent des anthérozoïdes arrondis, sans cils, et qui se fusionnent avec le filament; le noyau mâle va vers la cellule femelle qui est dans le bas et un œuf se produit. Celui-ci bourgeonne presque aussitôt après la fécondation en un sporocarpe (spores spéciales ou tomies). Souvent, le sporocarpe ne procède pas directement de l'œuf; cet œuf déverse son contenu dans une cellule appelće auxiliaire et y détermine une sorte de fausse fécondation, car. en réalité, il n y a pas fusion des noyaux, et c'est elle qui produit soit directement, soit indirectement, les glomérules de spores.

Les Champignons. Organisation. - Les Champignons sont des Thallophytes incolores; l'absence de matière verte entraîne pour ces plantes des conséquences importantes au point de vue de la nutrition et, par cela même, relativement au mode de vie; un grand nombre d'entre eux sont parasites et vivent dans le corps soit de végétaux (maladies cryptogamiques), soit d'animaux (mycoses); les autres s attaquent aux matières en décomposition, comme les fumiers, ce qui arrive pour les Mucorinées, ou aux feuilles mortes, comme cela est le cas pour les Agaricinées et Hyménomycètes des bois.

Prenons comme type, pour notre étude, le Champignon de couche ou Agaric, on Psalliote champêtrc. La fructification nous est bien connue, car nous la voyons figurer dans un grand nombre de nos mets, qu elle contribue fortement à aromatiser; elle se compose d'un pied, pourvu vers la partie supérieure d'un anneau et d'un chapeau, à la face inférieure duquel sobservent des lames rayonnantes, d'abord rosées et devenant brun pourpre très foncé en vieillissant. Ce changement de teinte est dû à l'apparition et à la maturation des organes reproducteurs ou spores à la surface de ces lamelles. Elles naissent sur des cellules superficielles en forme de massues serrées les. unes contre les autres, qu'on appelle des basides (fig. 148), qui bourgeonnent à leur partie supérieure pour engendrer deux petites pointes appelées stérigmates, à l'extrémité desquelles se forment les spores qui, d'abord rosées, ne tardent pas à se teinter fortement de brun pourpre foncé. Ces semences, en germant, engendrent des filaments qui s'associent en cordons plus gros et constituent le mycélium ou blanc de champignon, que les champignonnistes lardent dans des meules de fumier pour produire des fructifications à la surface. On a pu faire germer ces spores en milieu stérilisé et obtenir du blanc de champignon stérilisé qui, étant pur et à l'abri de tous les parasites qui attaquent le Champignon de couche(môle, vert-de-gris, plâtre, etc.), est extrềmement vigoureux et très fécond.

La méthode de culture pure peut s'appliquer à la plupart des 

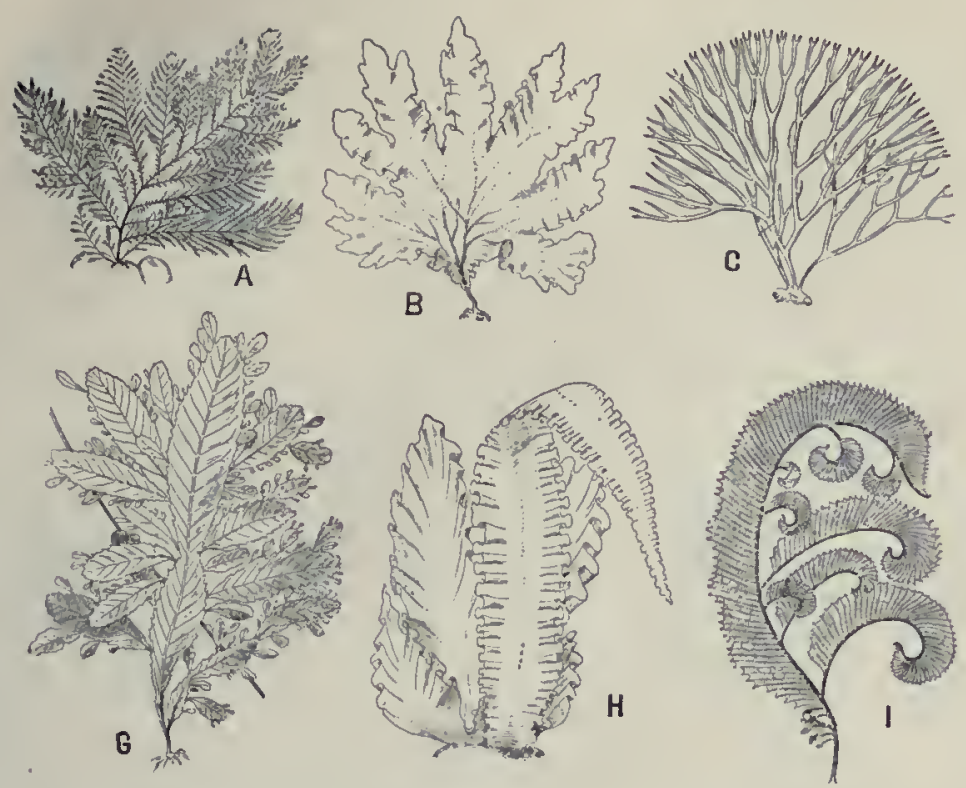

Champignons, notamment aux Moisissures, qui poussent partout, comme le Phycomyces brillant, qui est une Mucorinée poussant sur la laque; I'Isarie dense ou Botrytis du hanneton, qui attaque la larve ou ver blanc de cet animal et produit sur lui une maladie cryptogamique qu'il est intéressant de propager, etc. On peut ainsi constituer un Musée de Moisissures, dont lidée a été pour la première fois formulée par l'un de nous : on peut avoir alors dans une série de flacons qui sont, pour ainsi dire, autant de petites serres, des représentants bien isolés et cultivés seuls d'un grand nombre de spécimens de la flore mycologique. Il faut procéder avec grand soin à l'ensemencement des flacons, dont chacun contient un milieu stérilisé, approprié, où poussera une seule moisissure.

Champignons à lames ou Ágaricinées. - Si nous revenons aux Champignons comestibles munis de feuillets, comme le Psalliote champêtre, il en est un grand nombre que l'on ne sait pas cultiver, mais que l'on peut récolter dans les bois. Tel est le cas de l'Oronge, dont l'empereur romain Claude faisait une grande consommation. Cette passion lui fut néfaste, car ce fut, dit-on, par la substitution de la fausse Oronge à l'Oronge qu'on l'empoisonna. Ces deux Champignons sont des Amanites, caractérisées par une volve qui entoure complètement le Champignon jeune, lequel a l'aspect d'un ouf entouré d'une coquille (fig. 149) qui serait membraneuse et qui se déchire de deux manières différentes dans les deux espèces précédentes : restant à l'état de petites écailles blanches non adhérentes à l'épiderme rouge du chapeau dans l'A manite tue-

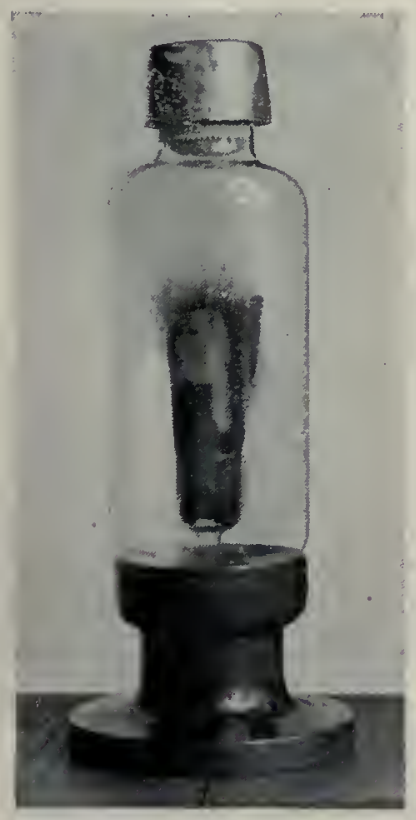

Phycomyces brillant. mouche, tandis que, dans l'Amanite des Césars ou Oronge, la volve forme un large étui membraneux persistant, entourant la base du pied.

Ce caractère de la volve est très important à connaître, car il permet de distinguer les Amanites les plus redoutables, dont un seul individu suffit dans un plat pour empoisonner une famille entière. Tous les ans, à l'automne, les journaux publient les récits, trop nombreux, de ces empoisonnements, qu on doit et peut ćviter.

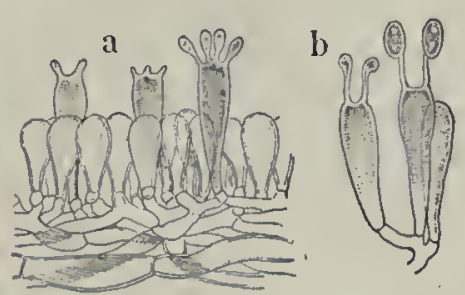

Fig. 148, - Basides. $a$, Hyménium produisant trois basides saillants; $b$, Champignon de couche.
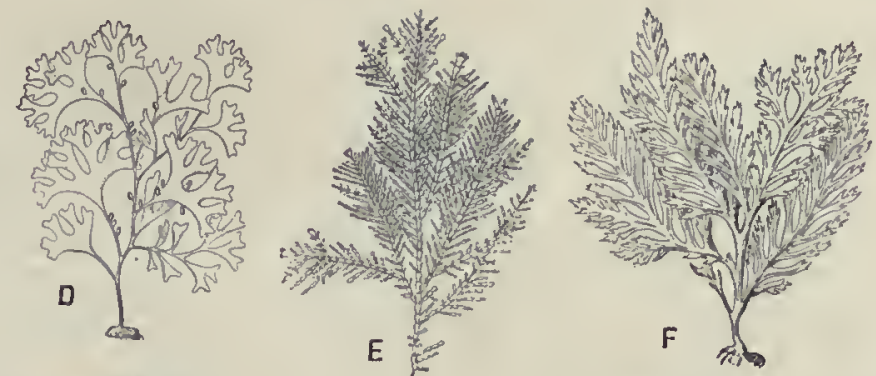

Fig. 147. - Algues rouges.

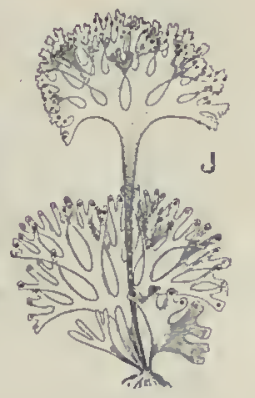

A Heterosiphonia parasitica, B, Nitophyllam Gmelini; C, Potyides rotundus; D, Phyllophora membranifolia ; E, Corallina officinalis; F, Odonthalia dentata; G, Delesseria sanguinea; H, Porphyra laciniata; I, Claudia elegans; J, Rhodynenia palmata.

Ces espèces sont cependant facilement reconnaissables : si l'on examine le pied, on y voit la volve qui l'entoure; on ne peut donc confondre l'Amanite citrine, qui devient souvent blanche dans la variété $M a p p a$, avec le Psalliote champêtre; la volve ici laisse, comme dans la fausse Oronge, des écailles sur le chapeau; ces écailles, il est vrai, peuvent être lavées par la pluie et disparaître, mais les feuillets sont toujours blancs, et non roses ou brun pourpre, même dans les exemplaires âgés.

En général, il faut se défier des représentants du genre Amanite, $c$ est-à-dire à volve; il y a cependant des espèces comestibles dans ce groupe : l'Amanite ovoïde, blanche, la Golmotte ou $A m a-$ nite rougeâtre, à volve réduite à des écailles sur le chapeau et à chair devenant rouge vineux et rougissant lentement.

Un genre tout différent est celui des Lépiotes, dépourvu de volve, qui a des écailles sur le chapeau parce que l'épiderme se déchire; le pied, tigré, est très allongé, à anneau.

Dans les Tricholomes, il ny a plus danneau, mais le pied est épais; ces Champignons sont trapus et charnus, et les feuillets présentent une petite échancrure au voisinage de leur point d'insertion sur le pied. C'est là que se placent les Mousserons de la Saint-Georges, qui sont des Champignons de printemps estimés, croissant en cercles et qui, par le développement du mycélium dans le sol, constituent des ronds de sorcières. On est parvenu à cultiver le Pied bleu ou Tricholome nu (Costantin et Matruchot), devant son nom à la coloration bleue du pied.

Dans les Pleurotes, le pied est excentrique ou nul, le chapeau est charnu; plusieurs espèces vivent sur les arbres.

Dans les Clitocybes, les pieds sont en général assez gros et soit charnus, soit fibreux; le chapez'd se retourne fréquemment vers le haut, de manière à prendre un aspect d'entonnoir, et les feuillets descendent longuement sur le pied. On peut citer le Clitocybe infundibuliforme et le Clitocybe nébuleux.

Les Lactaires sont encore des champignons bien caractérisés par le lait qui s'écoule de toutes leurs parties, quand on les blesse. Le Lactaire poivré a un lait d'une âcreté extrême et très poivré; il est blanc, gros, avec le chapeau retourné en entonnoir; malgré son goût, qui disparaît à la cuisson, cette espèce est comestible.

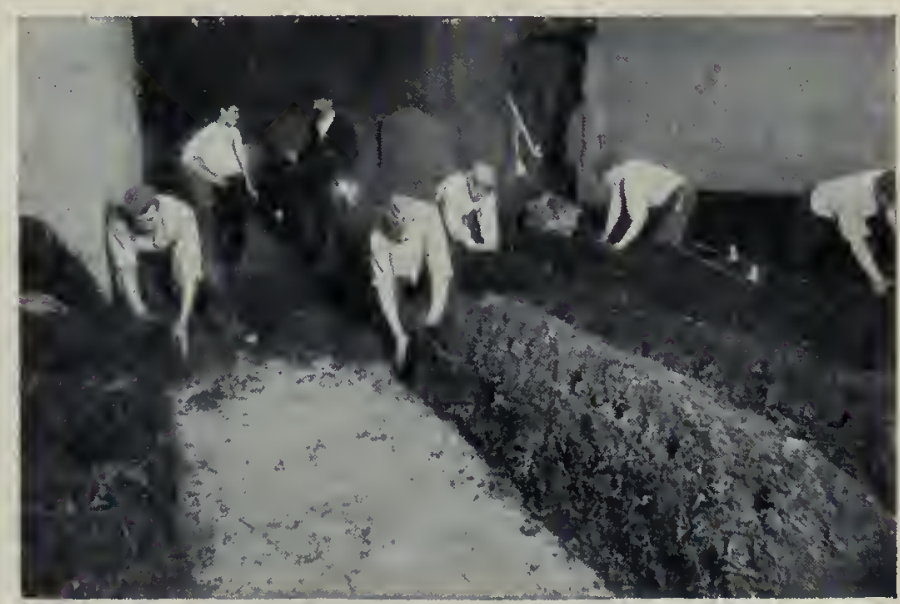

Culture du Champignon de couche; mise en meule du fumier. 


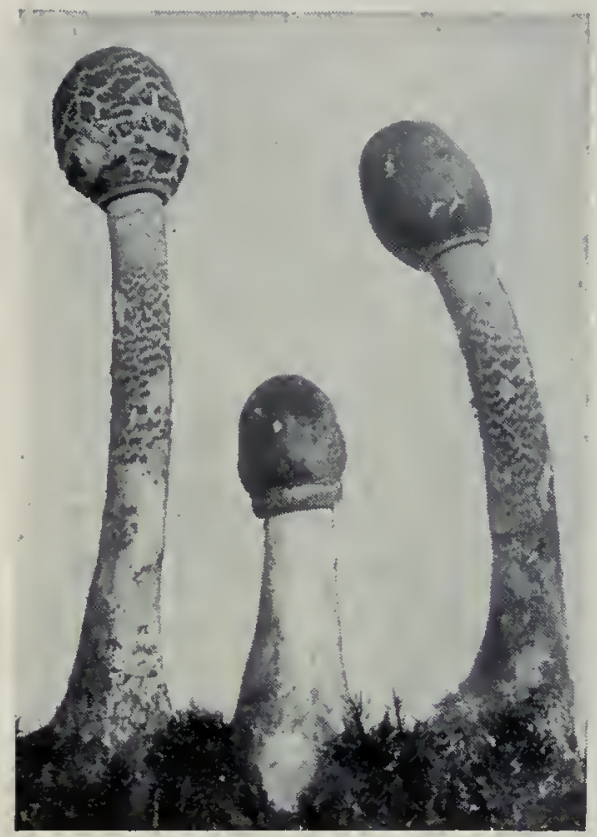

Jeune Lépiote élevée, non encore épanonie.

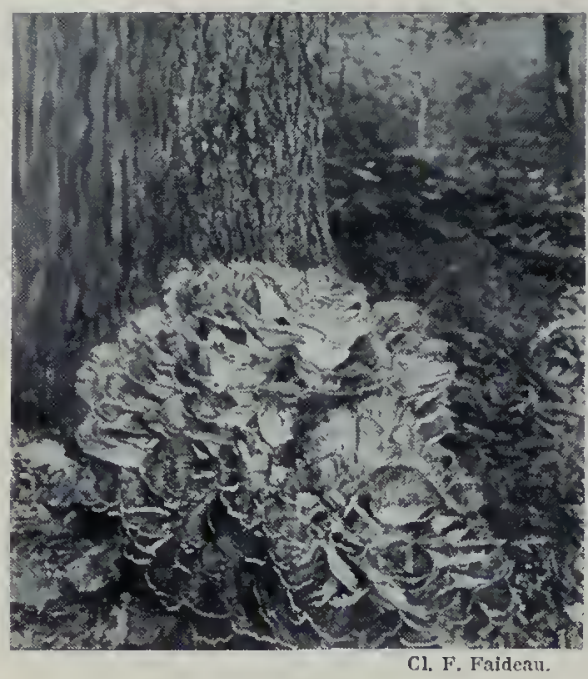

Polypore chicorée.

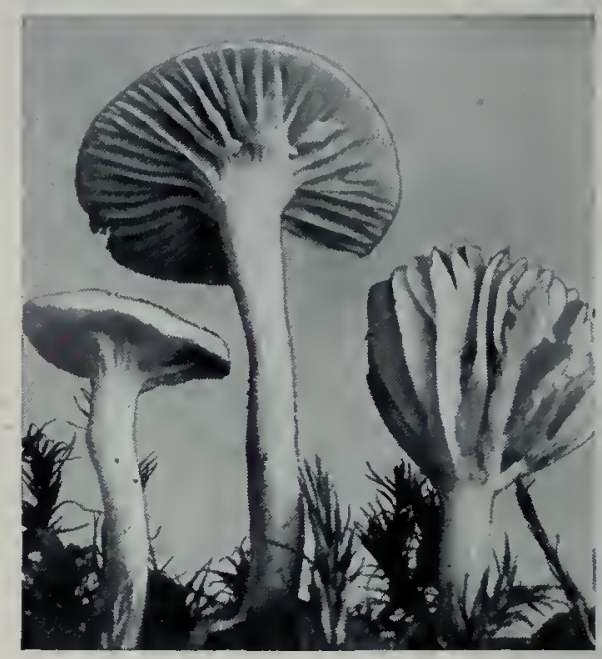

Hygrophore blanc.
Mais le Lactaire délicieux est surtout recommandable ; son lait est rouge orangé; les zones de son chapeau sont aussi rouge orangé, puis tachetées de vert; son lait est âcre, mais ce goût disparaît à la cuisson.

Les Russules ont, en général, l'épiderme du chapeau vivement coloré et facilement détachable; la Russule émétique est vénéneuse. Les Marasmes ne pourrissent pas en vieillissant : tel est le cas du Mousseron d'automne. Les Volvaires sont, pour ainsi dire, des Amanites, mais à spores ef feuillets roses et sans anneau. On voit la couleur de ces spores en mettant le champignon une nuit sur une feuille de papier: une poussière rose la couvre le lendemain. Les Volvaires sont des Champignons vénéneux.

Parmi les Champignons à lames ou Agaricinées, ayant des spores ocracées, on peut citer les Cortinaires, dont le pied est entouré d'un anneau filamenteux comme une toile d'araignée se colorant par les spores rouillées; les Hébélomes sont homologues des Tricholomes, mais à spores ocracées, etc.

Parmi les Agaricinées à spores brun pourpre, on doit citer les Strophaires, pourvus d'un anneau, et les Hypholomes, homologues des Cortinaires. Tels sont les principaux représentants de cette grande famille des Champignons à feuillets qui forment une armée compacte de plus d'un millier d'espèces.

Polyporées. - Les Polyporées sont un peu moins abondantes, mais leur importance est encore cependant considérable. Elles se distinguent par l'existence de pores à la face inférieure du chapeau, qui sont autant d'orifices de petits tubes tapissés par des basides portant les spores reproductrices.

La consistance de ces Champignons est parfois coriace, presque ligneuse, comme dans le Polypore de diverses couleurs ou versico-

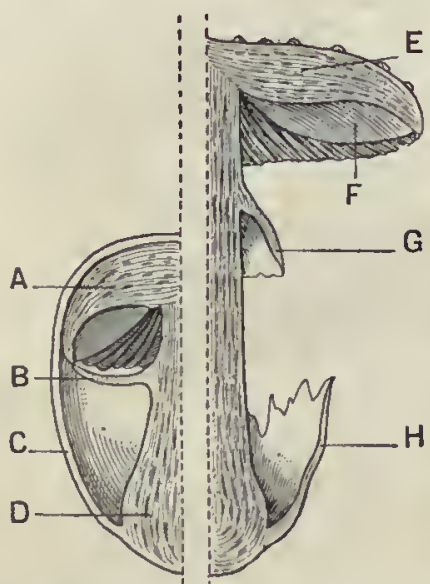

Fig. 149. - Structure du Cham pignon jeune et épanoui (droite).

A, Chapeau; B, Voile; $C, H$, Volve: D. Pied; E, Chair; F, Lames : G, Anneau provanant du voile.

lore. Il y a parfois absence de pied et le Champignon inséré sur

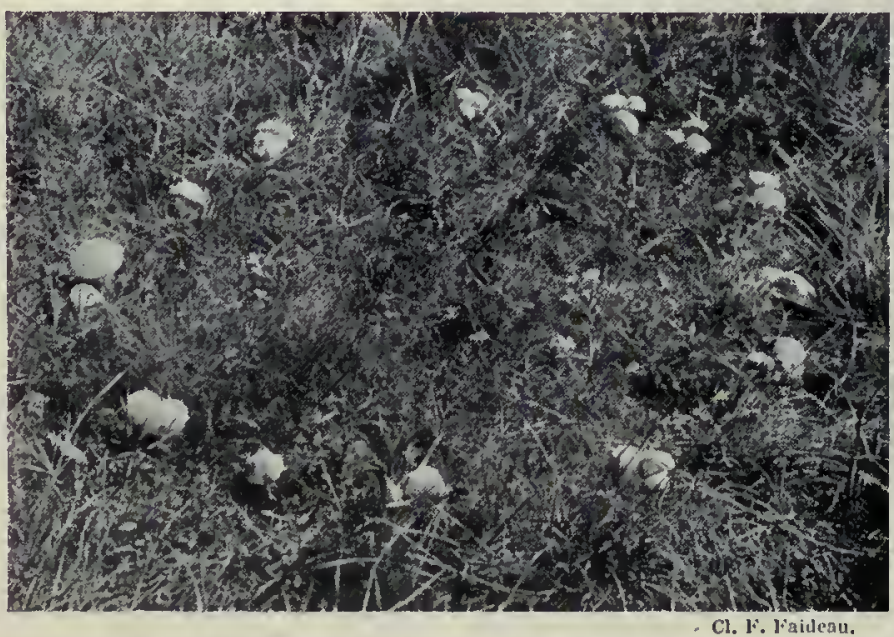

Cercle de sorcière formé par des Mousserons de la Saint-Georges. les arbres est en console ou cn sabot de cheval : tel est le cas du Polypore amadouvier, dont la chair fibreuse sert à la préparation de l'amadou. Parmi les Polypores pourvus de pied, il en est dont la chair est molle et comestible : tel est le cas du Polypore des brebis. Le Polypore lucide est un champignon très curieux, à peu près dur comme du bois, dont le pied est inséré de côté, à angle droit du chapeau, et dont toute la surface rouge brun est comme vernissée: c'est le type boréal de toute une armée de formes analogues qui se rencontrent en grand nombre dans les régions tropicales.

Les Bolets ont des pores réguliers, comme les Polypores, mais ils sont charnus, mous; ils ont toujours un pied et leurs tubes s'enlèvent avec la plus grande facilité, comme les feuillets chez les Paxilles; enfin c'est sur la terre qu'ils poussent. Dans le Cèpe ou Bolet comestible, le pied présente un réseau, et les pores, d'abord blancs, deviennent jaunes en vieillissant. C'est un des Champignons les plus estimés; on le récolte à l'automne, en grande abondance, et l'on en vend à Paris et dans les grandes villes, surtout à Bordeaux, des quantités considérables. Il y a d'autres espèces à recommander, comme le Bolet scabre, qui a le pied écailleux. Plusieurs Bolets présentent des changements de couleur très saisissants; lorsqu on les brise, ils virent au bleu avec une grande rapidité, sous l'influence d'une oxydase : tel est le cas du Bolet Satan, du Bolet pourpre ou du Bolet à pied rouge, qui sont regardés comme vénéneux. Le Bolet blafard, le Bolet bleuissant, bien que présentant le même caractère, ont été reconnus comme inoffensifs; on ne saurait cependant les recommander.

Hydnées, Clavariées, Lycoperdinées. - Une troisième famille est celle des Hydnées, qui, au lieu de tubes fructifères, présente à la surface inférieure du chapeau des aiguillons. L'Hydne bossclé ou Mouton est un excellent comestible.

Dans une quatrième famille, les Clavariées, la surface hyméniale portant les basides reste, au contraire, lisse : il n'y a ni lames, ni tubes, ni aiguillons. L'aspect de la fructification est alors très particulier ; c'est un petit arbuscule quelquefois fortement ramifié : tel est le cas de la Clavaire à pointes pourpres et de la $\mathrm{Cla}$ vaire jaune, qui sont comestibles. Jusqüici, nous n'avons envisagé que des fructifications dont les basides sont externes. Il peut arriver, au contraire, qu'elles se dissocient à lintérieur d'un conceptacle arrondi, parfois munid'un pied, dont la membrane parcheminée, superficielle et persistante, s'ouvre seulement par un pore à la partie supéreure. Telle est l'organisation des $L y$ coperdons, vulgairement appelés Vesses-de-loup. qui laissent dégager une poussière brune de spores par leur orifice, quand on les écrase. Ce groupe est celui des Lycoperdinées.

Tous les Champignons que nous venons de passer en revue ont 


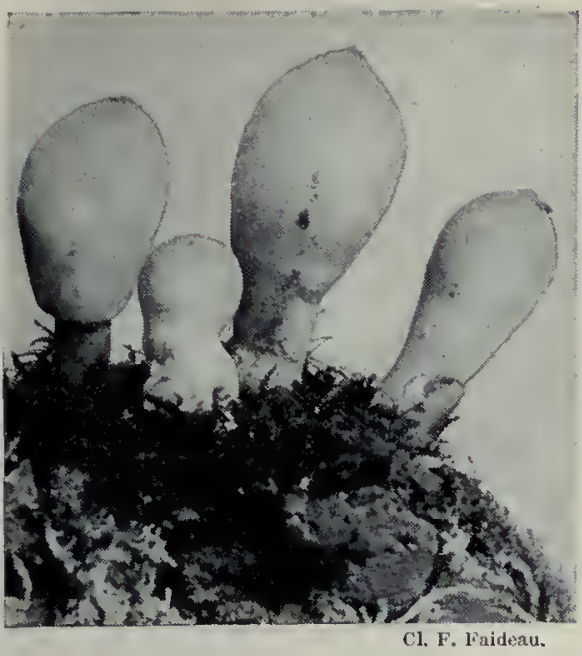

Lycoperdon en poire.

comme caractère commun d'avoir, pour organe reproducteur, des basides construites toujours de la même manière, c'est-à-dire en massue non cloisonnée, avec dés spores à la partie supérieure portées par des stérigmates : ce sont les Hyménomycètes. Dans deux groupes formés surtout de Champignons gélatineux, végétant sur le bois mort, les Trémellinées et les Auriculariées, les basides se cloisonnent, longitudinalement dans le premier cas, transversalement dans le second, et c'est l'ensemble de ces deux groupes et des Hyménomycètes qui constitue les Basidiomycètes ou Champignons à basides. L'Auriculaire oreille de Judas, de la famille des Auriculariées, possède une forme très curieuse rappelant l'oreille humaine.

Nous aurions pu passer ces deux petits groupes sous silence, sils ne nous servaient de transition vers les Urédinées et les Ustilaginées, deux groupes de parasites importants qui attaquent les plantes de grande culture, principalement les céréales.

Urédinées et Ustilaginées. - Les Urédinées présentent la très singulière particularité d'être hétéroïques, c'est-à-dire d'exiger deux hôtes pour leur développement complet. Les $P$ uccinics des Graminées vivent en été sur le Blé, où elles forment des pustules jaunes sur les feuilles, avec des spores unicellulaires : c'est ce qu'on appelle la Rouille des céréales. A l'automne, les mêmes taches deviennent noires et les spores sont bicellulaires; ce sont les spores d'hiver, qui, en germant sur le sol, donnent un filament qui se cloisonne transversalement en quatre cellules superposées et qui est tout à fait analogue aux basides des Auriculariées. Sur ces basides se développent quatre longs stérigmates, terminés à leur extrémité par quatre spores correspondantes qui, emportées par le vent, germent sur l'Épine-vinette et produisent des boursouflures à la face inférieure des feuilles. Les pustules, ouvertes comme des urnes, avec une membrane rabattue en dehors, constituent l'organe reproducteur; c'est ce que l'on a appelé les Acidies de l'Épinevinette. C'est seulement après ce stade d'évolution que les spores de l'Ecidie peuvent à nouveau se propager sur les céréales et reproduire la maladie de la rouille.

Avec les Ustilaginées, le développement est plus simple, en ce sens que le parasite reste sur un seul et même hôte, mais il doit l'attaquer dès le début de la germination. C'est lorsque la céréale sort de terre que les spores du Charbon germent et pénètrent dans son corps (fig. 150). Si, au contraire, la plantule a la bonne fortune de traverser sans encombre ce stade délicat de sa vie, elle n’aura plus rien à craindre
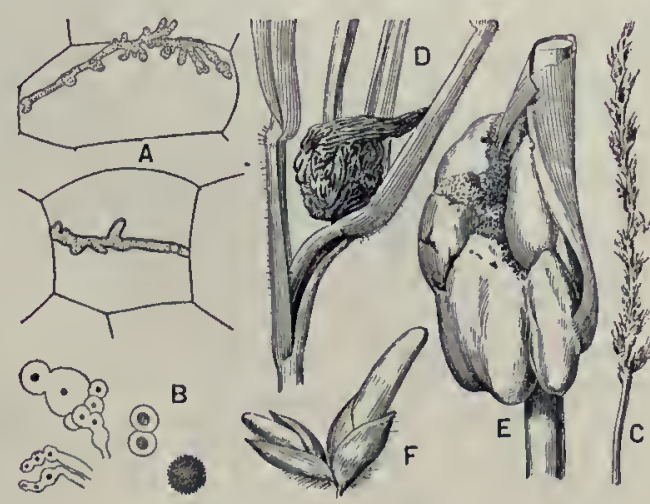

Fig. 150. - Charbon.

A, Du Mals : fraǵment de my célinm et cellules de la plante nourricière ; B, For mation des spores; C, Du Ble ; D, Du Millet :

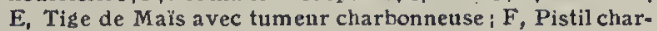
bonneux et hypertrophié du Sorgho. par la suite, car le parasite sera incapable d'y pénétrer. On concoit donc que si l'on parvient à immuniser la graine contre ce parasite redoutable, le fléau sera vaincu. C'est ce que l'on fait dans la pratique du sulfatage, qui consiste à immerger les graines dans une solution de sulfate de cuivre à 5 pour 100 ; les grains sont ensuite roulés dans la chaux. C'est là une opération entrée dans la pratique agricole et qüil ne faut jamais négliger, car une fois que le parasite a pénétré dans la plantule il s'y maintient jusqu'à sa mort ; ses filaments pénètrent dans la fleur, envahissent l'ovaire et donnent leurs spores formant une poussière noire qui crève le grain altéré, et le mal apparaît. Ces spores germent en donnant un tube court qui se cloisonne transversalement et forme comme une baside d'Auriculariée. Dans la Carie (fig. 15l), qui se distingue du Charbon par le fait que le grain de la céréale ne se déchire pas et qu'il faut l'écraser pour voir apparaître au dehors la poussière brune, les basides ne se cloisonnent pas et se terminent à leur partie supérieure par une couronne de spores, comme dans les Hyménomycètes. L'épi du Blé carié se distingue aisément par son port ébouriffé, c'est-à-dire que les balles sont étalées. En outre, à la maturité de l'épi, on remarque qu'il est rigide, dressé : il ne sinfléchit pas sous le poids des grains, qui sont remplis des spores du champignon, de moindre densité. II $\mathrm{y}$ a un autre caractère qui permet de distinguer facilement la Carie du Charbon, c'est celui qui est tiré de la germination des spores : dans la Carie, les conidies sont en couronne au sommet du tube germinatif; dans le Charbon, elles s'étagent sur les côtés.

Ascomycètes. - Il existe un autre groupe de Champignons presque aussi important que les Basidiomycètes par le nombre, les Ascomycètes (asquc, étui; mycètes, champignons), chez les-

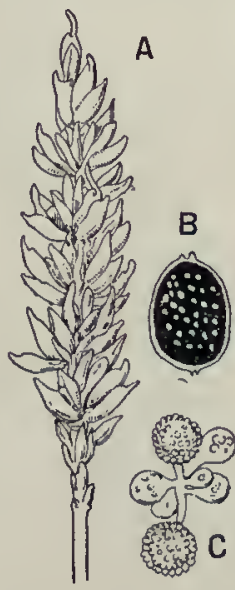

Fig. 151. - Carie. A, Aspect de l'épi ; $B$, Coupe du grain C, Mycélium avec spores ébauchées. quels les organes reproducteurs, au lieu d'être externes, comme dans le cas des basides, sont au contraire internes. L'asque est une cellule ordinairement allongée en forme de massue, rarement
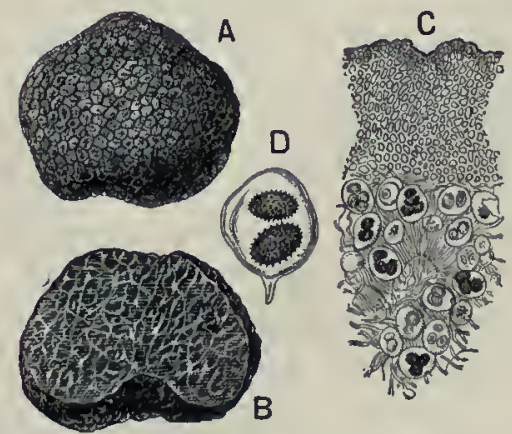

Fig. 152. - Truffe comęstible

$A$, Eutière ; $B$, La même en coupe : $C$, Grossissement montrant les asques : D, Asques à denx spores. 
sphérique, qui produit intérieurement, en général, huit spores qui y nagent librement ; à la maturité, l'asque crève ou s'ouvre par un couvercle à la partie supérieure, et les huit spores sont projetées au dehors.

Dans le premier groupe des Ascomycètes, les Discomycètes, les asques sont en contact avec le milieu extérieur directement et ils forment une membrane hyméniale. Le cas le plus simple d'organisation, dans ce groupe, est celui des Levures ou Saccharomyces, formées de cellules bourgeonnantes qui- sisolent.

Les Morilles sont d'excellents Champignons comestibles qui sont extrêmement appréciés des amateurs. On les récolte seulement au printemps. Le chapeau est développé et surmonte le pied; il est arrondi ou conique, mais sa surface est creusée d'un très grand nombre d'alvéoles qui sont toutes tapissées par un hyménium renfermant des asques ayant la constitution ordinaire. L'espèce la plus appréciée est la Morille comestible, à chapeau arrondi ou de forme peu régulière. Les Pézizes sont des Champignons voisins en forme de-coupe: telle la Pézize cochenille, qui pousse au premier printemps sur les petites brindilles de Noisetier.

Les Truffes (fig. 152) sont également des Ascomycètes (Tubéracées), mais vivant dans la terre. Lorsqu'on coupe une Truffe, on aperçoit sur la section une série de veines, et, au milieu de la masse charnue, une multitude de vésicules arrondies qui se touchent les unes les autres et qui ne sont pas autre chose que des asques renfermant en général quatre spores. L'histoire de ces Champignons est encore mal connue et cependant leur culture a pris une extension assez grande dans certains départements méridionaux, notamment dans le Périgord, où le commerce des Truffes représente une richesse importante du pays. En raison de son prix très élevé, la Truffe est parfois falsifiée, dans le but d'augmenter son poids, par l'introduction dans sa masse de grains de plomb, de clous, etc. La radiographie permet facilement de reconnaître cette fraude.

Pour avoir des Truffes, on plante des Chênes truffiers : c'est le Chêne Rouvre ordinaire. L'ensemencement du Champignon se tait spontanément; il est, semble-t-il, lié au développement des racines de l'arbre. Comment se fait la propagation des Champignons dans les truffières? c'est ce que l'on ignore. Il est très vraisemblable que certaines mouches truffières doivent contribuer à propager les spores; elles ont même une aptitude remarquable pour découvrir les places où se trouvent enterrées ces fructifications extrêmement odorantes. Aussi est-ce en suivant le vol de ces insectes que les trufficulteurs sont mis sur la voie pour la découverte des points où les tubercules sont enterrés. Il est vrai que tout chasseur de truffes qui peut avoir un porc, animal dont l'odorat est très fin, préfère s'en servir pour la recherche des truffes. Dès qu'il a trouvé un gîte de Champignons odoriférants, le porcin se met à fouiller le sol en le labourant profondément jusqu'au tubercule, que quelques coups de bâton sur le museau lui fon't abandonner.

Parmi les Ascomycètes, certaines espèces s'attaquent aux insectes: citons I'Isarie dense du hanneton ou le Cordiceps de la punaise; d'autres, comme l'Ergot de Seigle, l'Exoasque qui produit la cloque du Pêcher, sont nuisibles aux plantes de grande culture. Signalons à ce propos l'Ö̈dium de la Vigne, qui a commencé à sévir sur les Vignes au milieu du XIX siècle, importé $\mathrm{d}^{\mathrm{e}}$ Amérique dans les grappery, ou serres à Vigne, où l'on cultivait cette plante. Le Champignon se propagea dans tous les vignobles et produisit des dégâts incalculables qui furent heureusement arrêtés par l'emploi de la fleur de soufre que l'on projette sur les feuilles et qui amène sa destruction. L'Oidium forme une sorte de couverture grise à la surface des

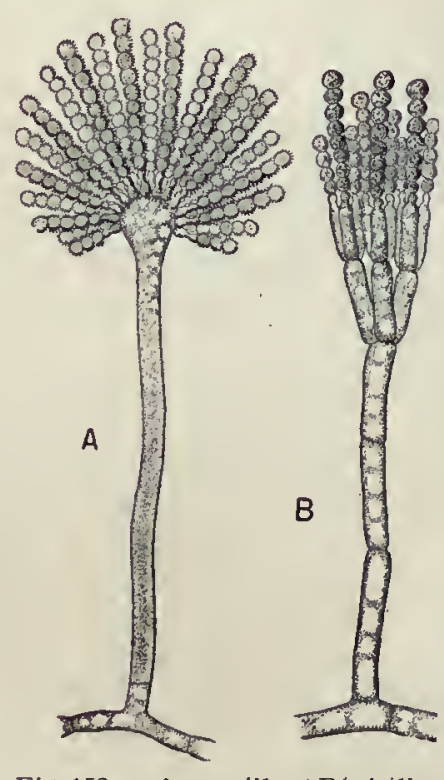

Fig. 153. - Aspergille et Pénicille. y avoir polymorphisme par la bouillie bor mais il faut faire des applications fróquentes. Certaines moisissures, commè les Aspergilles et le Pénicille glauque (fig. 153, A et B), se rapprochent des Tubéracées par leur mode de reproduction.

Oomycètes. - La maladie de la Vigne qui vient d'être mentionnée est traitée par un procédé qui a été découvert antérieurement pour une autreaffection parasitaire, laquelle est due à un Champignon d'un tout autre groupe, celui des Péronosporées; cette famille n'est formée que de parasites, et leur parasitisme est intense et nécessaire : nous voulons parler du Mildiou ou Mildew, mot anglais qui veut dire moisissure (Plasmopore viticole). C'est une affection très redoutable de la Vigne qui a commencé à se répandre en Europe, venant d'Amérique, en 1878; elle aurait causé des désastres immenses et irrémédiables si, par bonheur, le moyen de combattre ce fléau par les bouillies cupriques n'avait été découvert presque en même temps que l'invasion du mal. Une maladie analogue due au Phytophtore infestant, et plus anciennement connue, puisqu'elle avait commencé à devenir redoutable en 1845 , était la maladie de la Pomme de terre, qui a sévi partout en Europe, mais qui a eu en Irlande un effet épouvantable parce que la population de ce pays avait donné à la culture de la Pomme de terre une importance excessive. La famine, qui était bannie de l'Europe depuis plus de cinquante ans, fit à nouveau son apparition et, en quelques années, par suite de la mort ou de l'émigration, la population de l'Irlande diminua d'un million d'habitants. Ces Péronosporées se manifestent surtout sous la forme de petites pulvérulences à la face inférieure des feuilles, comme sil y avait de petits amas de sucre en poudre un peu grisâtre : ce sont les arbuscules fructifères qui sortent par les orifices des stomates et produisent leurs conidies dans l'air. En plus de ces appareils reproducteurs, au moins dans le Mildiou, il existe à l'automne, dans l'intérieur des feuilles, des appareils sexués ou cenfs qui résultent de la fusion de deux organes: l'un femelle ou oogone et l'autre mâle ou filament anthéridique; ce dernier sapplique sur les sphères femelles, les perfore et déverse à l'intérieur le protoplasma mâle; immédiatement après cette fécondation, l'œuf s'enkyste en une zygospore verruqueuse.

Les Péronosporées font partie du groupe des Oomycètes ou Champignons à œufs. Alors que tous les autres Champignons ne forment que des spores (on a découvert, il est vrai, dans ces dernières années, un phénomène de fusion de noyaux, précédant la formation des asques et des basides, que l'on rapproche de la reproduction, Dangeard), les Oomycètes peuvent, de plus, se reproduire par des oufs. A ce groupe appartient la famille des Mucorinées, dont les espèces sont connues sous le nom de moisissures des fumiers; certaines peuvent vivre à la façon des Levures et des Bactéries et produire des fermentations. Rappelons, en terminant, les Myxomycètes, dont nous avons signalé déjà les curieuses propriétés (p. 50). 


\section{PRINCIPAUX CHAMPIGNONS COMESTIBLES ET VÉNÉNEUX}

No 1. AMANITE PHALLOÏDE (Oronge ciguë). L’espèce la plus dangereuse. Bois; été, automne. Hauteur : 8 à 15 centimètres. Confusion possible avec les Russules vertes comestibles $\left(\mathrm{n}^{\circ} \mid 15\right)$, et les Psallioles $\left(\mathrm{n}^{\circ} \mid 2\right)$.

Amanite phalloide (Mortelle).

Chapeau vert olivâtre, plus foncé au centre (pariois décoloré par la pluie). Char blanche très âcre. - Un anneau.

Un étui à la base du pied.

Russule verdoyante (Comestible).

No 2. AMANITE CITRINE (Amanita mappa. Oronge ciguë jaunâtre). Espèce 'mortelle, très commune en forêt; été, automne,

Hauteur : 6 à 12 centimètres. Chapeau jaune paille, parfois presque blanc, et alors prête à confusion avec les Psalliotes $\left(n^{0} 12\right)$

Amanite citrine (Mortelle).

Chapeau jaunâtre ou blanc, parlois écailleux, mais les écailles sont plaquées sur l'épiderme et s'enlevent a vec l'ongle.

Feuillets toujours blancs. - Un anneau

Un ètui ou un bulbe à bord très saillant à la base du pied.

Psalliote champêtre (Comestible).

Chapeau blanc, blanc jaunâtre ou blanc brunâtre, mais les écailles proviennent de déchirures de l'épiderme et ne s'enlèvent pas avec l'ongle. Feuillets blancs, puis rosés, pourprẻs, noirătres. - Un anneau.

Pas d'étui à la base du pied, lequel est peu ou pas renflé.

No 3. AMANITE PRINTANIERE (Amanita verna. Oronge ciguë blanche). Espèce mortelle, assez rare. Ressemble beaucoup au $n^{\circ}$ l, s'il est décoloré; mais elle est plus petite, plus précoce et toute blanchc. Confusion possible avec les $\mathbf{n}^{0 \mathrm{~s}} 2,4,12$ et même 26 .

No 4. VOLVAIRE ÉLEGANTE. Espèce mortelle, ainsi que la Volvaire gluante. Prés, champs, jardins (printemps, automne). Hauteur : 8 à 15 centimètres. Confusion possible entre jeunes Volvaires et jeunes Psalliotes. Volvaires (Mortelles).

Pied long et mince.

Feuillets roses.- Pas d'anneau.

Large étui à la base du pied.

Psalliotes (Comestibles).

Pied court, trapu.

Feuillets blancs, puis rosés, pourprès, noirâtres. - Un arneau.

Pas d'étui à la base du pied.

Tout Chompignon à feuillets roses et à pied entouré d'un étui est à rejcter.

No 5. AMANITE A ÊTUI (Coucoumelle grise, Grisette). Espèce comestible des bois sablonneux; juillet-novembre. Hauteur: 5 à 15 centimètres. Se distingue de toutes les autres Amanites par l'absence d'anneau. Pied long, mince et creux avec étui allongé. Chapeau à bord toujours strié, blanchâtre, gris ou fauve, parfois avec plaques blanches. Feuillets blancs, chair blanche. La couleur blanche des feuillets évite la confusion avec les Volvaires $\left(n^{\circ} 4\right)$ et la présence de l'étui avec certaines Amanites tue-mouches $\left(\mathrm{n}^{\circ} 8\right)$ de teinte jaunâtre.

No 6. LÉPIOTE BRUNATRE (Lepiota helveola). Espèce très dangereuse. Jardins, pelouses de l'Ouest; juillet-novembre. Hauteur : 4 à 8 centimètres. Chapeau un peu bombé, gris rosé ou chocolat, a vec écailles rouge brique. Feuillets blancs, pied blanc rosé, puis brunâtre, anneau lugace. Chair blanche, de saveur acide, devenant rosée à lair.

No 7. AMANITE DES CÉSARS (Oronge vraie). Comestible; été-automne. Bois, surtout au sud de la Loire. Hauteur : 10 à 15 centimètres. Ne pas confondre avec l'Amanite tue-mouches $\left(n^{\circ} 8\right)$ dans les régions où leas deux espèces coexistent.

Amanite des Césars (Comestible).

Chapeau d'un jaune orangé plus ou moins jaune, sans plaques blanches.

Pied jaunâtre. - Un anneau bordé de jaune.

Amanite tue-mouches (Très dangereux).

Feuillets jaune dorè. - Un étui à la base du pied.

Chapeau rouge vermillon avec plaques blanches que la pluie peut enlever.

Pied blanc. - Un anneau très blanc.

Feuillets blancs ou blanc crème. - Pas d'ètui.

No 8. AMANITE TUE-MOUCHES (Fausse Oronge). Espèce très commune dans les bois; automne, Hauteur : 15 à 20 centimètres (voir $\mathbf{n}^{\circ} 7$ ).

No 9. AMANITE PANTHERE (Fausse Golmolte). Espèce très dangereuse. Bois et coteaux; été-automne. Hauteur : 10 à 12 centimètres. Ne pas confondre avec l'Amanite rougissante ou Golmotte $\left(n^{\circ} 10\right)$.

Amanite panthère (Très dangereux).

Chapeau brun fauve de teinte assez variable, striẻ au bord, avec plaques blanches, pouvant disparaitre.

Chair blanche, restant blanche au contact de l'air.

Feuillets blancs.

Pied blanc, portant à sa base un ou deux bourrelets écailleux.

Anneau blanc, pouvant disparaitre.
Amanite rougissante (Comestible).

Chapeau rouge vineux non striẻ au bord, avec plaques grisâtres, pouvant disparaitre.

Chair blanche, devenant rouge vineux à l'air quand on la brise. Feuillels blancs ou blanc rosé.

Pied blanc, taché de rose ou de rouge vineux, pas trace d'étui.

Anneau strié, rougeâtre, jaune en dessous.

No 10. AMANITE ROUGISSANTE (Amanita rubescens. Oronze vineuse, Golmotte). Espèce comestible, cammune dans les bois en juillet-novembre. Hauteur : 10 à 15 centimètres $\left(n^{\circ} 9\right)$

No 11. LÉPIOTE ÉLEVEEE (Coulemelle, Coimelle, Cluseau, Potrelle). Comestible. Bois et bruyères; été-automne. Hauteur : 20 à 30 centimètres; notre plus grand champignon. Chapeau charnu, mince, en parapluie ouvert, parfois 30 centimètres, écailleux, brunâtre avec mamelon central; pied tigré. rentlé à la base. Anneau mobile le long du pied (immobile chez les Amanites). Feuillets blanc crème serrés, n'arrivant pas au pied. Plusieurs Lépiotes plus petites sont comestibles. Aucune confusion dangereuse.

No 12. PSALLIOTE CHAMPETRE (Champignon rose, Boule-de-neige, Brunette, Potiron, Pratelle). Comestible. Prés, jardins; mai-octobre. Les jeunes peuvent être confondus avec les Amanites blanches ( $n^{\circ s} 2$ et 3$)$, les Volvaires $\left(n^{\circ} 4\right)$, l'Entolome livide ( $\mathrm{n}^{\circ}$ 13). Ne jamais cueillir un Champignon rose sans déterrer profondément le pied; on s'assure ainsi de l'absence d'étui.

N 13, ENTOLOME LIVIDE (Perfide). Espèce dangereuse, commune en été-automne, en cercles dans les bais secs, ou les prés, sous les arbres. Hauteur : 7 à 12 centimètres. Ne pas confondre avec les Psalliotes ( $n^{\circ \otimes} 2$ et 4 ) ou les Clitocybes $\left(n^{\circ} 27\right)$. Entolome livide (Dangereux).

Chapeau gris cendré pâle.

Feuillets espacés. ne descendant pas sur le pied, jaunes, puis rougeâtres, rosés, échancrés près du pied. - Pied ferme.

Glitocybe nébuleux (Comestible).

Spores roses. - Odeur lorte de larine.

Chapeau gris clair, à centre plus loncé.

Feuilets serrés,descendant sur le pied, blanchâtres, puis paille. Pied spongieux, puis creux.

Spores blanches. - Odeur laible de farine.

No 14. RUSSULE FOURCHUE. Mauvais champignon; assez commun dans les bois. Confusion possible avec la Russule verdoyante $\left(\mathrm{n}^{\circ \mathrm{s}}\right.$ l et 15$)$ et la Russuie bleu jaune ( $\mathrm{n}^{\circ \mathrm{s}} 16$ et $17 \%$, comestibles. Russule fourchue (Mauvais).

Chapeau vert, non craquelé, lisse, non strié. - Pied épais, blanc.

Fevillets blancs, - Chair amère et åcre.

Russule bleu jaune (Comestible).

Chapeau"gris de plomb, à fines rides rayonnant du centre, teinté de poupre nair, de violet fonzé, se décolorant parfois, alors jaune et paurpre clair.

nair, de violet lonzé, se décolorant parfois, alors jaune et pourpre
Feuillets blancs. - Pied blanc, ridé. - Chair douce, agréable.

Les espèces de Russules sont difficiles à distinguer entre elles, ta.t le chapeau change de couleur avec lâge. Le caractère le plus utile est : toute Russule à chair douce est comestible; à chair amère on piquante est mauvaise. 
No 15. RUSSULE VERDOYANTE (Russula virescens, Palomet, Cul-vert. Verdette). Espèce comestible. Bois sablonneux : étéautomne. Hauteur : 4 à 6 centimètres. Confusion possible avec l'Amanite phalloìde $\left(\mathrm{n}^{\circ} \mathrm{I}\right)$ et la Russule fourchue $\left(\mathrm{n}^{\circ} 14 j^{\circ}\right.$.

No 16. RUSSULE DE QUÉLET. Mauvaise espèce. Ressemble beaucoup à la Russule bleu jaune ( $n^{\circ}$ 17). Russule de Quelet (Mauvais).

Chapeau violet, parfois presque noir.

Pied blanc teinté de rose.

Fenillets crème on jaunâtre pâle. - Chair très poivrée.

Pousse dans les bois de Pins.

Chapeau (voir au $\mathrm{n}^{\circ} 14$ ).

Russule bleu jaune (Comestible).

Pied blanc, non teinté.

Fenillets blancs. - Chair douce, agrèable.

Pousse dans les bois, surtout de Hêtres.

No 17. RUSSULE BLEU JAUNE (Russula cyanoxantha. Charbonnier). Espèce comestible. Hauteur : 5 à 8 centimètres. Rejeter tout exemplaire un peu avancé. Eviter la confusion avec la Russule fourchue $\left(\mathbf{n}^{\circ}{ }^{14}\right)$ et la Russule de Quélet $\left(\mathbf{n}^{0} 16\right)$, mauvaises. No 18. RUSSULE JOLIE (Russula lepida, Cul rouge). Espèce comestible. Bois : été-automne. Peut être confondne avec le
No 19. RUSSULE EMÉTIQUE.

Russule jolie (Comestible) Chapeau rouge carmin, mat, non poli, farineux, se fendillant à la
sécheresse.

Chair douce, blanche, ferme, dure, d'un goût de noisette.
Russule émètique (Mauvais).

Chapeau rouge vif ou rose, poli, Juisant, se décolorant facilement par

Chair très poivrée, blanche, mais rougeâtre sous la peau du chapeau.

No 20. LACTAIRE VENEENEUX (Lactarius torminosus. L. aux tranchées, Mouton, Raffouet). Espèce mauvaise qui peut être confondue avec le Lactaire délicieux ( $\left.\pi^{\circ} 21\right)$.

Lactaire vénèneux (Mauvais).

Chapeau parfois un peu zoné, roussâtre, un peu velu et à bords laineux.

Fenillets blancs, un peu rosés. - Lait très âcre et très blanc.
Chair blanche et restant blanche

$$
\text { Tous bois et bruyères. }
$$

Lactaire dèlicieux (Comestible).

Chapeau ronge brique on orangé, glabre et à bords non laineux. Feuillets orangés. - Lait doux et orangé.

Chair jaunâtre, devient rouge, puis vert-de-gris.

Les Lactaires ressemblent beaucoup aux Russules, mais lenrs feuillets et leur chair laissent couler un lait de couleur variée ; pied court, sans étni ni anneau; d'une manière générale, toutes les espèces à lait ốcre ou poivré sont suspectes, et celles à lait doux, comestibles.

No 21. LACTAIRE DÉLICIEUX (L.deliciosus.'Polonais, Pignet. Roussillon, Sanguin, Vache rouge). Espèce comestible, pouvant être confondue avec le Lactaire vénéneux $\left(n^{\circ} 20\right)$ ou le Lactaire roux $\left(n^{\circ} 22\right)$.

No 22. LACTAIRE ROUX (Lactorius rufus, Raffouet). Mauvaise espèce qui peut être confondue avec le

No 23. LACTAIRE ORANGE.

Lactaire roux (Mauvais).

Chapeau non zoné, roux foncé, petit mamelon conique au centre.

Pied roussâtre, blanc en bas, poiln à la base.

Lait blanc, très âcre.

Sous les Pins et Sapins.

\section{Lactaire orangé (Comestible).}

Chapeau non zoné, orangé, brun rougeâtre ou chamois, parfois teinté de vert. Pied de teinte uniforme, plus clair que le chapean, non poilu à la base. Lait blanc abondant, doux.

Un peu partout dans les bois.

No 24. CHANTERELLE COMESTIBLE (Girolle, Jaunette). Espèce bien connue, comestible; peut se confondre avec le

№ 25. CHANTERELLE ORANGEE ou Fausse girolle, espèce comestible suivant les uns, suspecte suivant les autres, peu dangereuse en tout cas.

Chapean jaune d'œuf.

Chanterelle comestible.

Feuillets jaune d'ouf, épais, peu serrés, soudés souvent entre eux.

Pied janne d'ouf, èpais et court.

Odeur agréable.

Chanterelle orangèe.

Chapeau jaune påle.

Femillets orangès, fins, serrés, fourchus, non soudés entre eux. Pied orangé ou brinn foncé presque noir, long et grêle. Pas d'odeur.

NNo 26. MARASME D'OREADE (Mousseron d'automne, Petit Monsseron, Pied dur, etc.). Déliciense petite espèce ne prêtant à aucune confusion dangereuse.

No 27. CLITOCYBE NÉBULEUX (Petit gris, Mousseron gris). Espèce très commune, en cercles dans les bois en antomne. Eviter la confusion a vec l'Entolome livide ( $\mathbf{n}^{\circ}$ 13).

No 28. TRICHOLOME DE LA SAINT-GEORGES (Mousseron de printemps, Mousseron blanc, Blanquet). Comestible; en cercle dans les prés ; avril-mai. Chapeau charnu, lisse, sec, blanc jaunâtre. Pied épais, saus etui à la base. Pas d'anneau. Forte odeur de farine fraîche. La confusion a vec $\mathrm{l}^{1}$ Entolome livide $\left(\mathrm{n}^{\circ} 13\right)$ et l'Amanite printanière $\left(\mathrm{n}^{\circ} 2\right)$ serait impardonnable.

No 29. TRICHOLOME NU (Pied bleu). Espèce comcstible des bois (antomne). D'autres Pieds bleus voisins poussent dans les prés à la même époque et sont aussi comestibles. La confusion n’ est possible qu'avec les Cortinaires violettes, comestibles aussi.

No 30. COPRIN A CHEVELURE. Espèce comestible. Prés, automnè. Aucune confusion regrettable à craindre.

No 31. BOLET BRONZE (Boletus cercus. Cèpe noir, Tête de nègre, Gendarme noir). Espèce comestible, à chapean velouté, bronzé, presque noir, assez petit $\left(\mathrm{n}^{\circ} 32\right)$.

No 32. BOLET AMER (B. felleus. Cèpe chicotin). Mauvaise espèce dont les pores, d’abord blancs, deviennent roses et à chair très amère, ce qui évite une confusion possible avec le Bolet comestible $\left(\mathrm{n}^{\circ}\right.$ 33), qui a les pores blancs, puis jaune verdâtre et à chair douce. - On évitera toute confusion dangereuse, en matière de cèpes, en ne cueillant jamais les exemplaires trop jeunes et en suivant les indications ci-dessous :

Bolets comestibles.

Pores blanchâtres ou jaune verdâtre.

Pied blanc, jaune ou blanchâtre, jamais taché de rouge.

Chair restant blanche à l'air ou devenant à peine rose sous le chapean.

Chair douce, agréable.
Bolets dangereux.

Pores ronges ou roses.

Pied rouge ou taché de rouge.

Chair bleuissant oul verdissant à l'air.

Chair amère.

No 33. BOLET COMESTIBLE (B. edulis). Cèpe. Potiron (voir n 32 ).

No 34. BOLET RABOTEUX (B. scaber). Espèce comestible (voir $\mathrm{n}^{\circ} 32$ ).

N 35. BOLET SATAN ( B. Satanas). Mauvaise espèce des prés, pâturages, clairières (voir $\mathrm{n}^{\circ}$ 32).

Les espèces à fenillets et à pores (Agaricinées et Polyporées) sont les seules prêtant à confusion. La récolte des HYDNES (Mouton. Barbe de vache), des MORILLES, PÉZIZES, HELVELLES, CLAVAIRES (Barbe de chèvre), CRATERELLES (Trompette de la mort), noffre ancun danger, tant leurs caractères sont faciles à reconnaitre. 


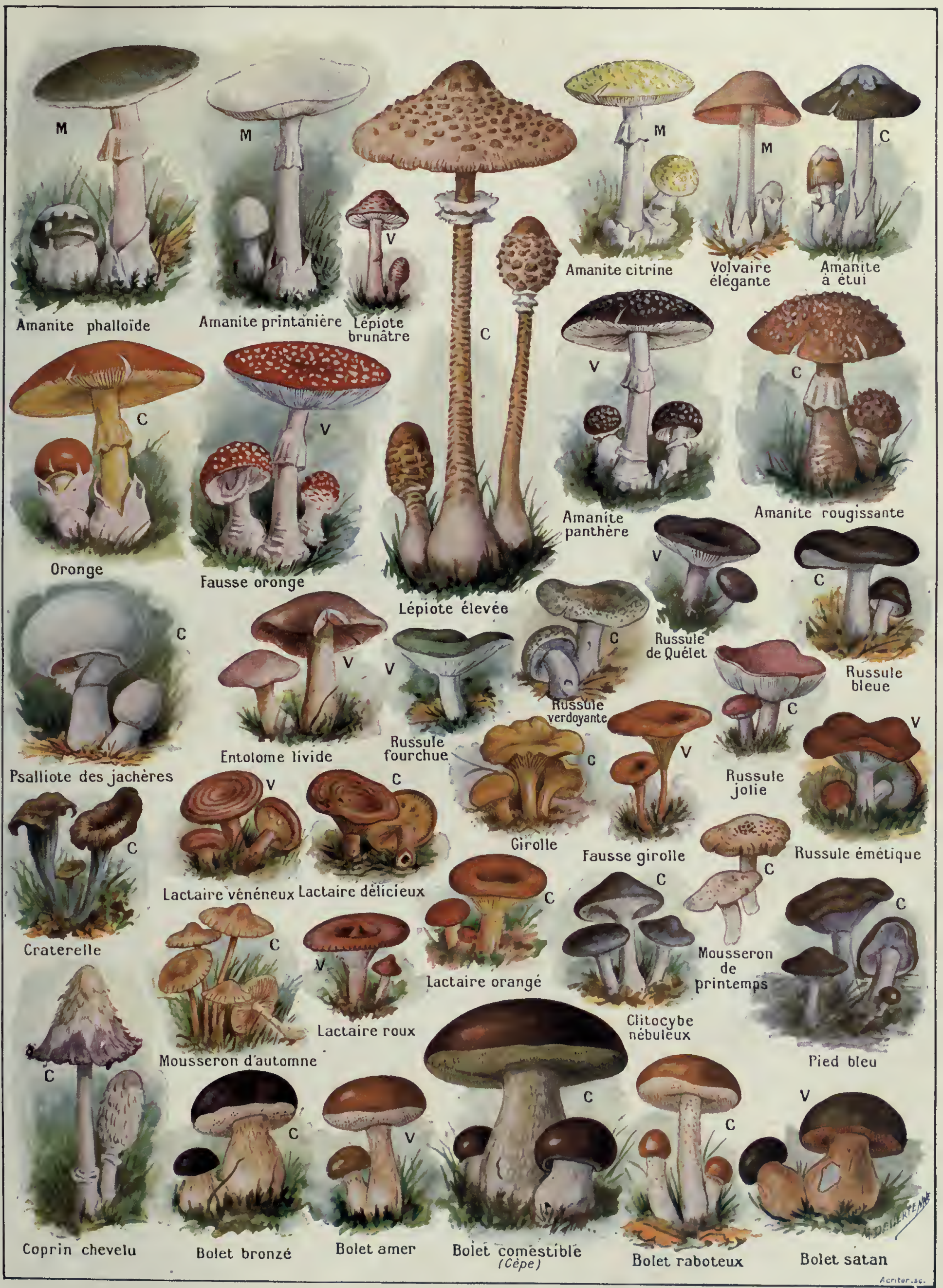





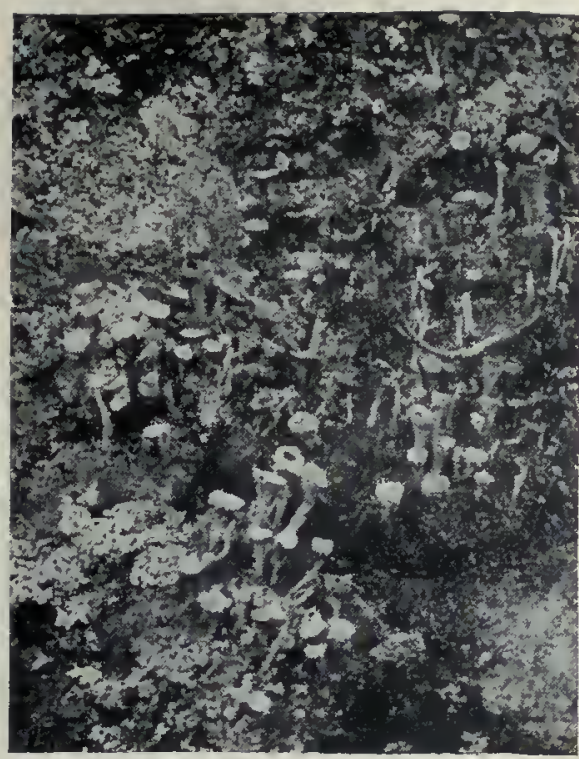

Cladonie en cornet, au bord d'un talus.

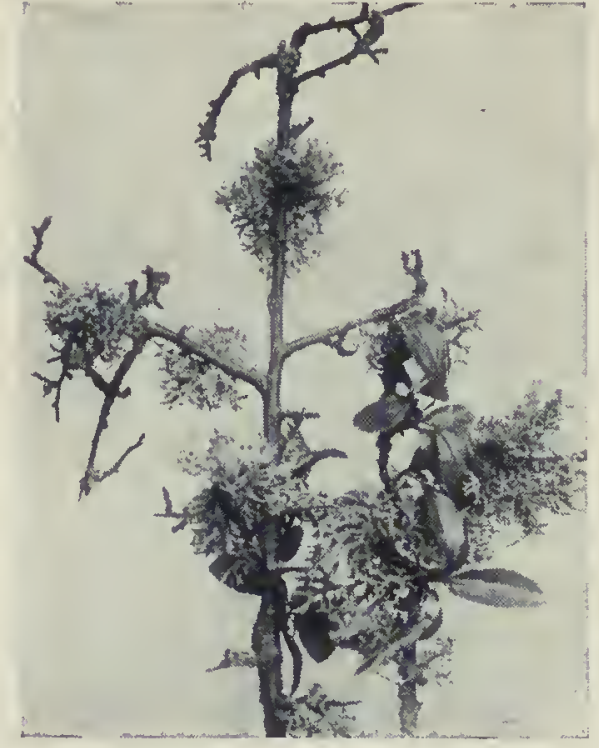

Évernie du Prunellier.

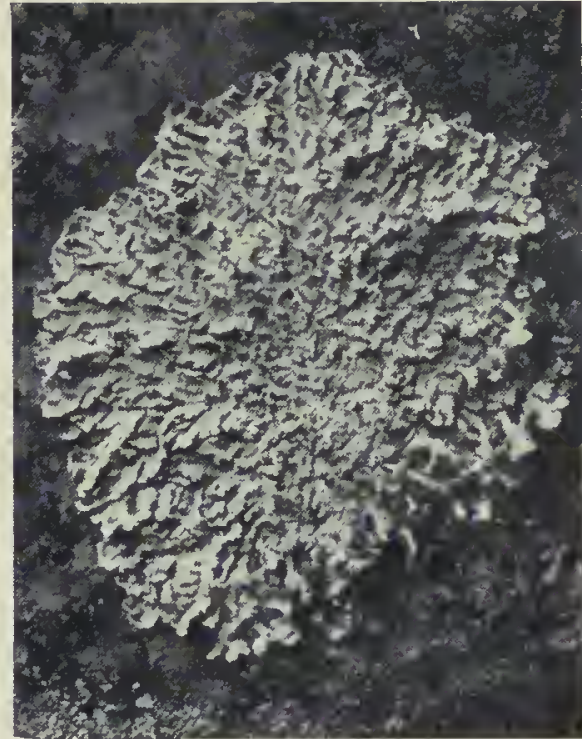

Parmélie froncée, sur un rocher.
Les Lichens. Organisation. - Les Lichens sont des Thallophytes poussant soit sur les arbres, et ce sont les rares épiphytes de nos pays froids ou tempérés, soit sur les rochers ou sur la terre. C'est ce dernier cas qui s'observe notamment pour le Lichen des rennes ou Cladonic rangifère, qui s'étend sur d'immenses espaces dans les plaines arctiques. Cette plante se rencontre d'ailleurs dans notre pays, dans les régions sèches; ce sont de petits arbuscules ramifiés, de consistance ferme, qui craquent sous les pieds lorsquion marche dessus. Si l'on vient à examiner la structure de ce Lichen, on y trouve, comme dans tous les autres représentants de ce groupe, des filaments incolores à membrane assez épaisse, que l'on a comparés à des tubes de macaroni à cause de l'épaisseur de la paroi ; en outre, il y a des cellules vertes. La première opinion qui est venue à l'esprit a été que ces deux sortes de cellules appartenaient à "un seul et même être, mais en réalité il s'agissait de deux êtres très différents associés ensemble : un Champignon et une Algue. Grâce à cette association, l'Algue est abritée contre la dessiccation et contre les autres causes de destruction qui la menacent parl'enchevêtrement du Champignon. Ce dernier bénéficie de la nutrition de l'Algue qui, contenant de la chlorophylle, peut décomposer l'anhydride carbonique de l'atmosphère et fixer le carbone, ce que le Champignon est incapable de faire.

Les Algues qui s'associent à un même genre de Champignon sont fréquemment différentes : dans les diverses espèces de $P a n-$ naria, on peut trouver des Scytonèmes, des Chroocoques et des Palmellaires; parfois dans une même espèce de Lichen, comme les Lichina, communs sur les rochers maritimes, on peut rencontrer à la fois une Rivulaire et un Glooocapse, ou même, chez d'autres espèces, une Algue bleue et une Algue verte; c'est d'ailleurs à ces deux groupes seulement qu'appartiennent les Algues des Lichens. Les Champignons peuvent être soit des Basidiomycètes, soit des Ascomycètes, mais ces derniers sont de beaucoup les plus fréquents, les premiers étant surtout représentés par le genre Cora. L'appareil reproducteur des Ascolichens se compose de cupules ou apothécies, qui peuvent être largement ouvertes en un disque dans lequel on trouve à la fois des asques et des paraphyses, cellules allongées qui, se gonflant par l'humidité, pressent sur les asques; ces dernières cellules éclatent et les spores en sortent. L'appareil reproducteur peut présenter des conceptacles en forme de bouteille renfermant simplement un bouquet ' d'asques à la base. En outre, le Champignon peut former des appareils conidiens, emprisonnés d'ordinaire dans des conceptacles souvrant par un orifice au sommet; ils sont enfoncés dans le thalle et émettent au dehors de fins bâtonnets ou des conidies. On appelle enfin sorédies des frag-

ments de thalle, sortes de boutures susceptibles de s"isoler et qui sont formées de cellules vertes d'Algues entourées de filaments incolores (hyphes) du Champignon.

Principaux Lichens. - Parmi les Ascolichens, le groupe le plus important est celui des Discomycètes-Lichens; leur thalle peut être en arbre, ou foliacé ou en croûte. Au premier rang de ceux qui ont des apothécies arrondies et un thalle en petit arbre figurent les Cladonics; leur thalle est au début écailleux et il ne forme que plus tard une partie dressée : c'est ce qui arrive pour les Cladonies pyxidées, à tige s'élargissant en coupe à sa partie supérieure, et ayant parfois plusieurs coupes superposées, et aussi pour la Cladonie rangifère, qui est un arbuscule plus grêle et plus élancé et ramifié qui constitue un pâturage excellent pour les rennes dans ies régions polaires; dans ces deux espèces, d'ailleurs, les apothécies sont convexes et rouges. Les apothécies sont planes, au contraire, dans plusieurs autres groupes qui ont un thalle en arbre dès le début. Ce thalle est cylindrique chez les Roccelles et les Usnées ; aplati, au contraire, chez les Ramalines, Evernies, Anaptychia. Les Roccelles fournissent une matière colorante d'un rouge violet, belle mais peu durable, connue sous le nom d'orseille; on rencontre ces plantes notamment à Madagascar. L'Usnée barbue, qui pend aux arbres dans les forêts de Conifères, a de larges apothécies en forme de bouclier. Dans les Ramalines des Frênes, le thalle glauque foncé est en bouquet crêpu comme dans les feuilles de Chicorée frisée, les spores sont incolores, bicellulaires, et le disque des apothécies installé sur la couche à cellules vertes, tandis que dans l'Evernic du Prunellier les spores sont unicellulaires et les apothécies sur la moelle; dans l'Anaptychic cilić, les spores sont brunes. Le Cétraire d'Islande, qui contient un principe amer employé en médecine, a un thalle aplati et des apothécies développées obliquement sur les bords.
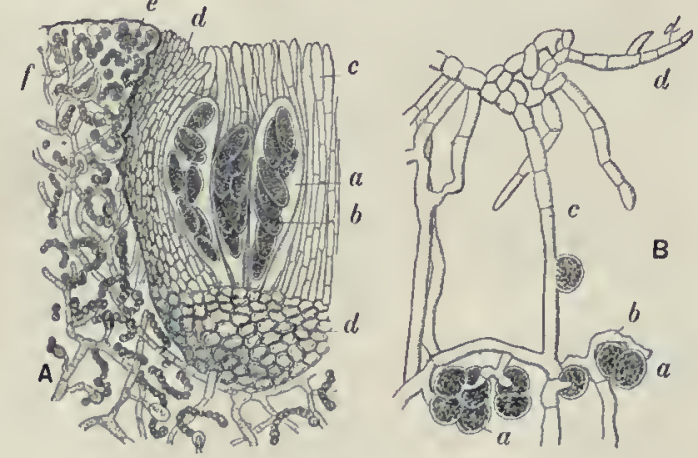

Fig. 154. - Organisation des Lichens.

A, Coupe d'un Lichen : $a$, Asque $; b$, Ascopores ; $c$, Paraphyses $d$, Tissus entourant l'apothécie; $e$, Cellules du Nostoc; $f$, Filaments du champignon plongés dans la gelée du Nostoc; B, Synthèse d'un Lichen : $a$, Cellules de l'algue: $b$, Filaments cram. pons : $c$, Filaments cherchenrs des cultures de Bonnier.
Parmi les Discomycètes-Lichens à thalle foliacé, on peut citer d'abord le Peltigère des chiens, à apothécies sur le bord et en général dressées, à thalle attaché au milieu. Dans la Sticte pulmonaire, le mode d'attache du thalle est le même, mais les apothécies y sont en saillie et non au bord. La lame foliacće est attachée au support par toutes sa face inférieure dans les Parmélies et les Physcies, mais les lobes de la périphérie sont larges dans les premiers, étroits dans les seconds.

Parmi les Discomycètes-Lichens en croûte, le Rhizocarpon géographique se détache en jaune sur le fond des rochers et a été comparé à une carte. Enfin, dans les Graphis et les Opegrapha, qui sont également crustacés, les apothćcies rappellent des hiéroglyphes. 


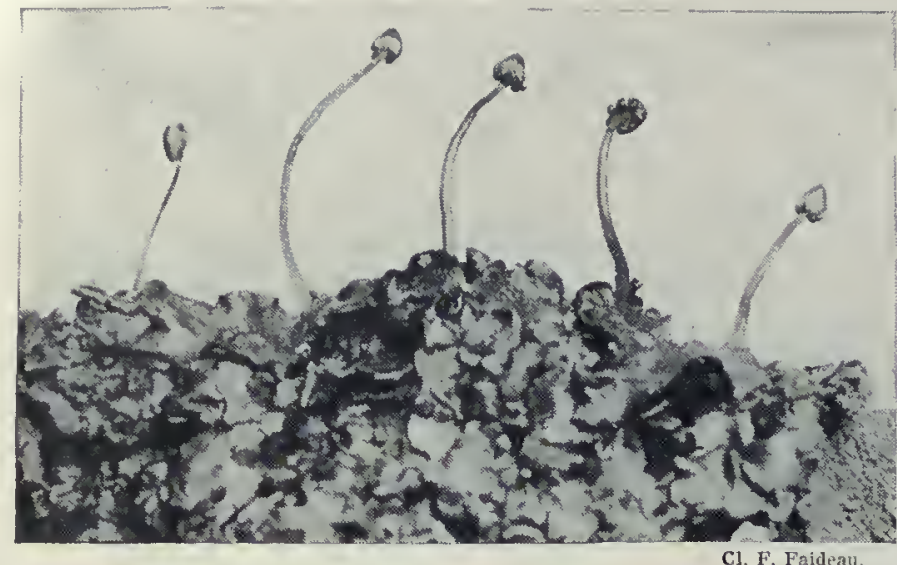

Fégatelle conique, portant des chapcaux femelles.

\section{LES MUSCINÉS}

Organisation. - Dans une Mousse (fig. 155), il y a une tige feuillée présentant à sa base des poils rhizoïdes, sans véritable racine, et se terminant par un filament ou soie, renflé en urne ou capsule à l'extrémité. Cette capsule renferme des spores; elle s'ouvre par des dents (péristome), de manière à mettre les spores en liberté; ces dernières germent. sur le sol et reproduisent des filaments verts (protoncma), puis la Mousse. Les organes mâles et les organes femelles se trouvent au sommet de la tige feuillée, soit sur le même pied, soit sur deux pieds différents. L'organe mâle ou anthéridie est en massue (fig. 156, C) et produit des authérozoïdes spiralés à deux cils vibratiles; l'organe femelle $(B)$ ou archégone a la forme d'une bouteille à long col. L'ouf résultant de la fécondation se forme dans la partie ventrue de l'archégone; il germe sur place, s'allonge en un filament qui se renfle en urne à l'extrémité et qui produit plus tard les spores; la capsule est couverte par un capuchon appelé coiffe, qui est l'archégone accru, distendu et déchiré.

Les Muscinées comprennent les Mousses, à tige dressée, et les Hépatiques, à tige rampante ou souvent à thalle aplati en lame.

Mousses. - Chez les Mousses (fig. 155), les feuilles sont disposées en général en spirale, sauf chez les $F$ issidens, plantes aquatiques où elles sont sur deux rangs. Dans les Polytrics, les dents du péristome sont réunies par une membrane, ou épiphragme, de façon à rappeler une peau de tambour; ce caractère s'allie avec une capsule anguleuse, tandis que dans les Pogonates la capsule est à section arrondie. Dans les Atrics ondulés, qui ont aussi la membrane en peau de tambour, la coiffe est de côté. D'ordinaire il n'y a pas d'épiphragme; alors la capsule est de forme variable, arrondie dans le Bartramic pomiforme, oblongue dans les Hypnes on-

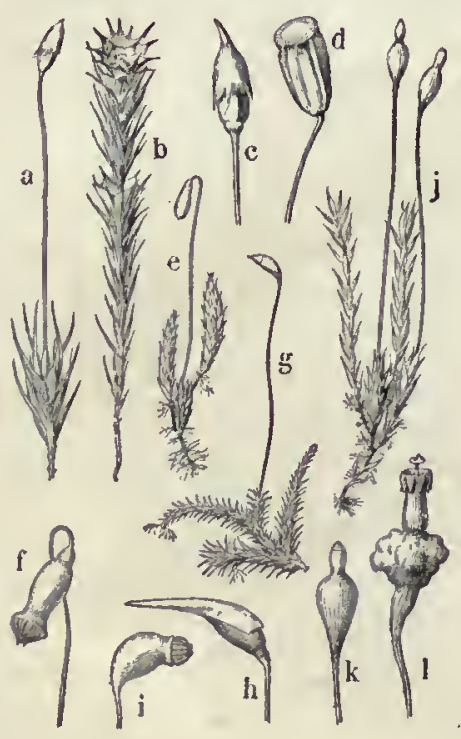

Fig. 155. - Mousses. Selıne; $d$, Urne mûre.- $e_{1} B r y u m ; f$, Urne mûre. - g, Hypnum; $h$, Urne jeune ; $i$, Urne mûre. $-j$, Splachnum; $k$, Urne jeune; $i$, Urne mûre. $a$, Polytric femelle; $b$, mâle; $c$, Urne dulés, mais dressée et à coiffe de côté. Si la capsule est allongée, pendante, par suite d'un brusque recourbement de la soie, on a les Bryes et les Mnics : les premiers ont des

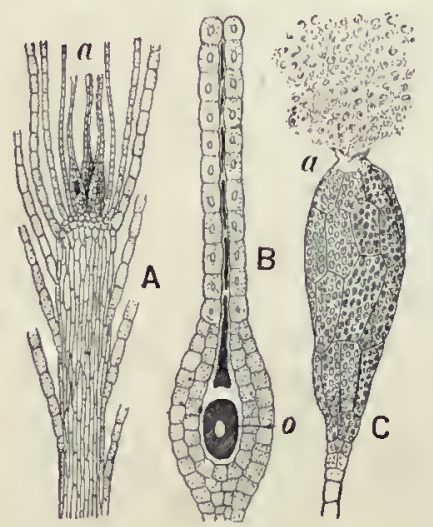

Fig. 156.

Fructification des Mousses.

A, Sommet d'une tife avec trois archégones $a ; \mathrm{B}$, Archégone grossi montrant l'oosphère o; $\mathrm{C}$. Anthéridie a vec anthérozoïdes $a$ s'échappant.

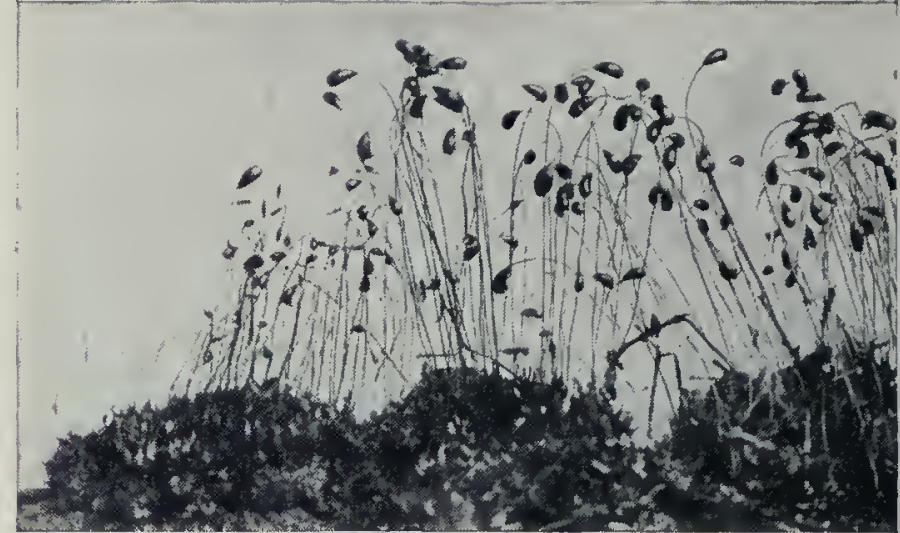

Funaire hygrométrique et ses capsules. tiges ramifićes, des feuilles à cellules longues; les seconds, des tiges peu ou pas ramifiées, des feuilles à cellules courtes. Dans la Funaire hygrométrique, qui pousse sur les vieux ronds de charbonnier, la soie est courbée, mais pas brusquement et non à l'extrémité; de plus la coiffe a l'aspect d'une vessie ovoïde. Dans l'Encalypte vulgaire, la soie et l'urne sont dressées, mais la coiffe, en forme de long éteignoir, dépasse beaucoup la capsule. Le péristome a des dents tordues en spirales dans la Barbule spirale; il est dépourvu de dents dans les Gymnostomes. Les touffes de Mousses ont parfois des aspects caractéristiques : elles forment des coussinets denses qui blanchissent par la sécheresse ou sont d'un vert glauque dans le Leucobrye glauque, qui pousse à terre; dans la Grimmia en coussinet, qui pousse sur les rochers, les feuilles se terminent par des poils et la soie recourbée s'enfonce dans le coussinet.

Le caractère de décoloration que nous venons de signaler dans les Leucobryes se retrouve à un plus haut degré dans les Sphaignes (Sphagnum), Mousses de marécages qui, par leur décomposition lente dans la partie inférieure, produisent la tourbe des tourbières. Leur décoloration tient, comme dans le Leucobrye, à ce que certaines cellules de leurs feuilles sont perforées et se remplissent d'air par la sécheresse. Ce caractère les fait employer par les horticulteurs pour la culture des Orchidées exotiques.

Hépatiques. - Les Hépatiques (fig. 157 et 158) ont une tige rampante et une capsule qui reste enfermée dans l'archégone. Les unes ont des feuilles, les autres ont un thalle en forme de lame. Dans le premier groupe se placent les Frullanies dilatées, qui forment des plaques vert noirâtre sur les écorces des arbres : les grandes feuilles, sur deux rangs, ont deux lobes inégaux, un grand et un petit, et au-dessous de la tige il y a des écailles foliacées, nommées amphigastres. Les amphigastres peuvent ressembler aux feuilles dans les Lépidozies (sans cils), dans les Trichocolées (ciliés), ou en différer, comme chez les Lophocolées. Dans les Hépatiques à thalle, la capsule est pédicellée; solitaire dans la Pellic épiphylle, dont la capsule est à quatre valves, le thalle large, opaque, sans nervures distinctes. Dans la Marchantic polymorphe (fig. 158), les organes mâles sont groupés sur des chapeaux arrondis, pédicellés, à dents peu profondes; les chapeau x femelles ont des lobes très profonds; le thalle est divisé superficiellement en petits losanges ayant au milieu un orifice stomatique, mais le stomate n'a pas la même constitution que dans les feuilles des Phanérogames. Ce dernier caractère se retrouve dans la $F$ egatella conique, maisle chapeau mâle est sans pédoncule et le chapeau femelle est conique.

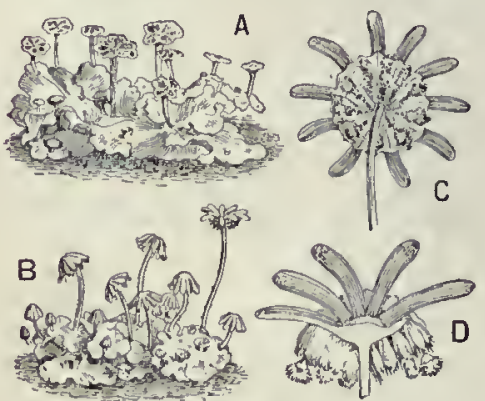

Fig. 157. - Hépatique (Marchantie). A, Pied mâle; B, Pied femelle: C, Chapeau femelle entier: $D$, Conpe longitudinale.

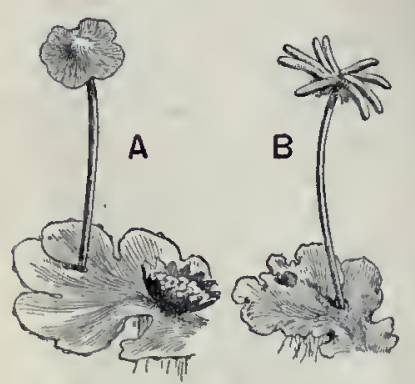

Fig. 158. - Marchantie.

A, Pied mâle: B, Pied femelle. 


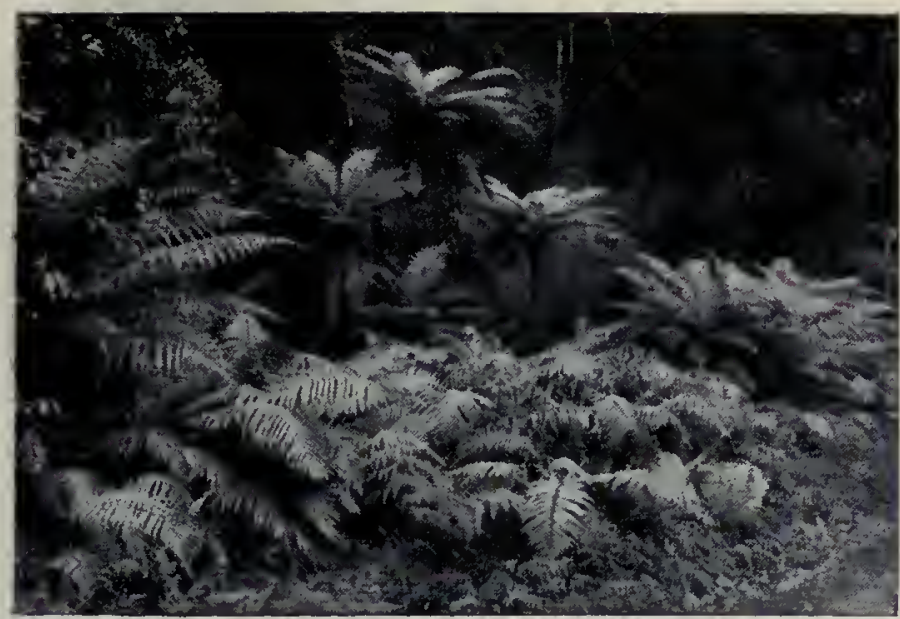

$7^{-} \quad$ Buisson de Fougères en Nouvelle-Zélande.

\section{LES CRYPTOGAMES A RACINES}

Les Thallophytes et les Muscinées n'ont ni vaisseaux, ni racines véritables; la sève y circule de proche en proche, à travers les cellules : ce sont des Cryptogames cellulaires. Les plantes dont nous allons parler leur sont supérieures par la division nette de leur corps en trois membres : tige, feuille, racine, et la présence de vaisseaux. On les divise en trois classes : les Filicinées, dont les Fougères forment le principal groupe, les Equisétinées et les Lycopodinées.

Organisation des Fougères. - Les Fougères jouent, au point de vue ornemental, un rôle important. Elles sont très cultivées comme plantes de garniture, parce que leur feuillage léger sert à faire ressortir les autres plantes qu' on leur mêle. Ainsi, par exemple, si l'on veut exposer des Orchidées, il sera très utile de les entourer de Capillaires, dont les frondes délicates s'harmonisent avec les couleurs vives et brillantes des fleurs. C'est ce même rôle que jouent les Fougères dans les jardins d'hiver et dans les appartements, où elles garnissent les jardinières. II $\mathrm{y}$ a d'ailleurs une autre catégorie de Fougères qui ont aussi de nombreux amateurs : ce sont les espèces de plein air qui réussissent sur les rocailles. Les modes d'existence et de culture de ces végétaux sont très particuliers; la plupart aiment les stations humides et peu éclairées. Dans les régions chaudes, au Mexique, par exemple, les parois des torrents, après la saison des pluies, se couvrent de gracieuses' Fougères herbacées.

Examinons une feuille ou fronde d'un Polypode; on remarquera à la face inférieure des taches brunes arrondies, comme granuleuses. L'examen à la loupe révélera que ces granules sont formés de boules ou sporanges (fig. 162) attachés à la feuille par de fins pédicelles; les têtes renferment les spores. Par un temps sec, la boule crève, les spores sont mises en liberté et tombent sur le sol; elles constituent une poussière véritablement microscopique, car chacune d'elles est formée d'une cellule. Cette ténuité des semences de Fougères est très remarquable; il n'en est pas de plus petites dans le règne végétal, d'aussi impalpables, donnant prise au vent qui les emporte au loin, les déposant partout, dans les anfractuosités

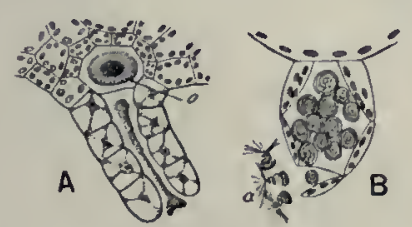

Fig, 159.

Fructification du Polypode.

A, Archégone (trés hrossi) conte. nant l'oosphère $0 ; \mathrm{B}$, Anthéridie (très grossie) dans laquelle se forment les anthérozoídes $a$.

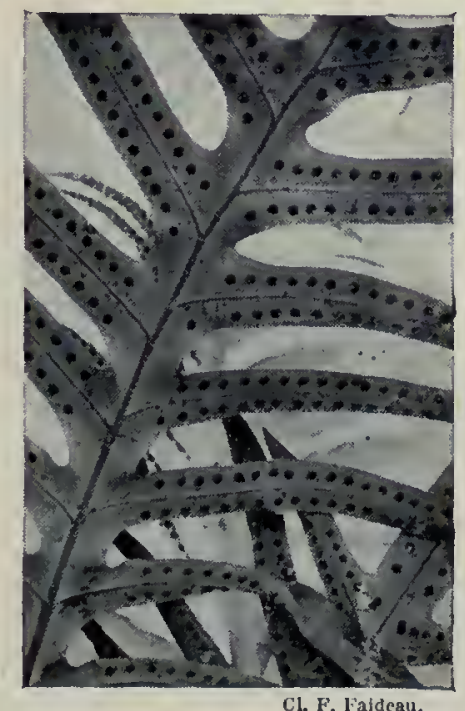

C1. F. Faideau,

Polypode glauque avec sporanges.

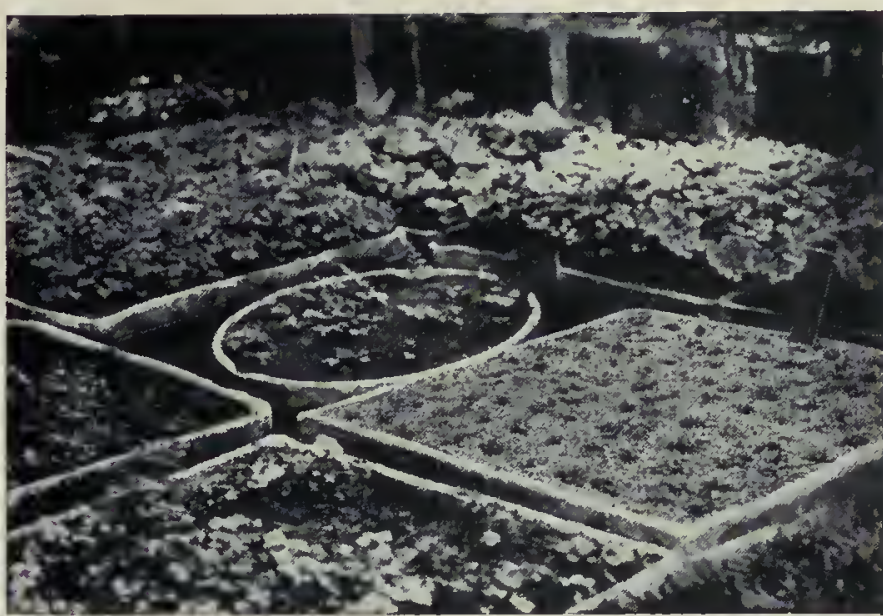

Semis de Fongères de différentes espèces.

des rochers, sur l'écorce des arbres; elles vont à travers les mers peupler les archipels les plus éloignés des continents.

La germination des spores de Fougères à la surface de la terre donne naissance à de petites lames vertes, translucides, à peine grandes comme l'ongle du petit doigt, qui s'étalent à la surface du substratum, fixées par de fins poils qui partent à la face inférieure de la lame très mince. Cette petite lame porte le nom de prothalle (fig. 160); elle produit des organes femelles ou archégones (fig. 159, A) qui affectent la forme d'une bouteille, dont la partie ventrale est enfoncée dans le tissu, tandis que les organes mâles ou anthéridies (fig. 159, B) ont la forme de boules plus superficielles. Quand, par l'action d'une goutte d'eau, les cellules mâles ou anthérozoïdes sont mises en liberté, on constate qu'elles sont formées d'un fin filament spiralé qui porte à son extrémité une touffe de cils vibratiles, et non pas deux cils seulement, comme nous l'avons signalé chez les Mousses. Grâce à la régulière trépidatión de ces cils, les anthérozoïdes se déplacent

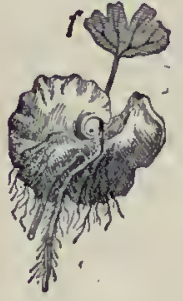

Fig. 160. Prothalle de Polypode sur lequel se developp feuillee $f$. et leur corps savance par un mouvement de tirebouchon. Attirés par les substances chimiques qui forment une gouttelette au sommet de la bouteille femelle, ils se diffusent en tous sens dans le milieu ambiant; les anthérozoïdes se précipitent vers l'orifice du col et l'un d'entre eux s'avance dans le canal jusqu'à venir se fusionner avec la cellule femelle ou oosphère, qui est contenue dans la partie ventrale de la bouteille. La fécondation a lieu; il en résulte un œuf qui germe sur place et ne tarde pas à engendrer une petite plantule qui se dresse au-dessus du petit prothalle (fig. 160). Chez les Fougères herbacées, comme les Polypodes, la tige reste souterraine : cest un rhizome; il en part les feuilles, seuls organes aćriens; clles sont toujours

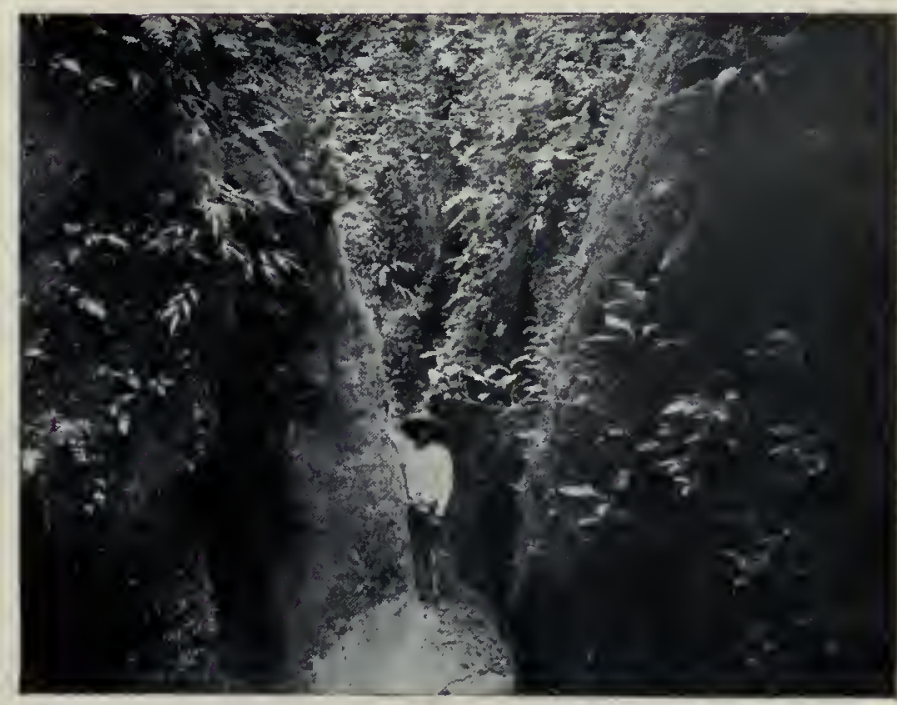

Fougères dans un ravin, au Mexique.
Cl. Diguet. 


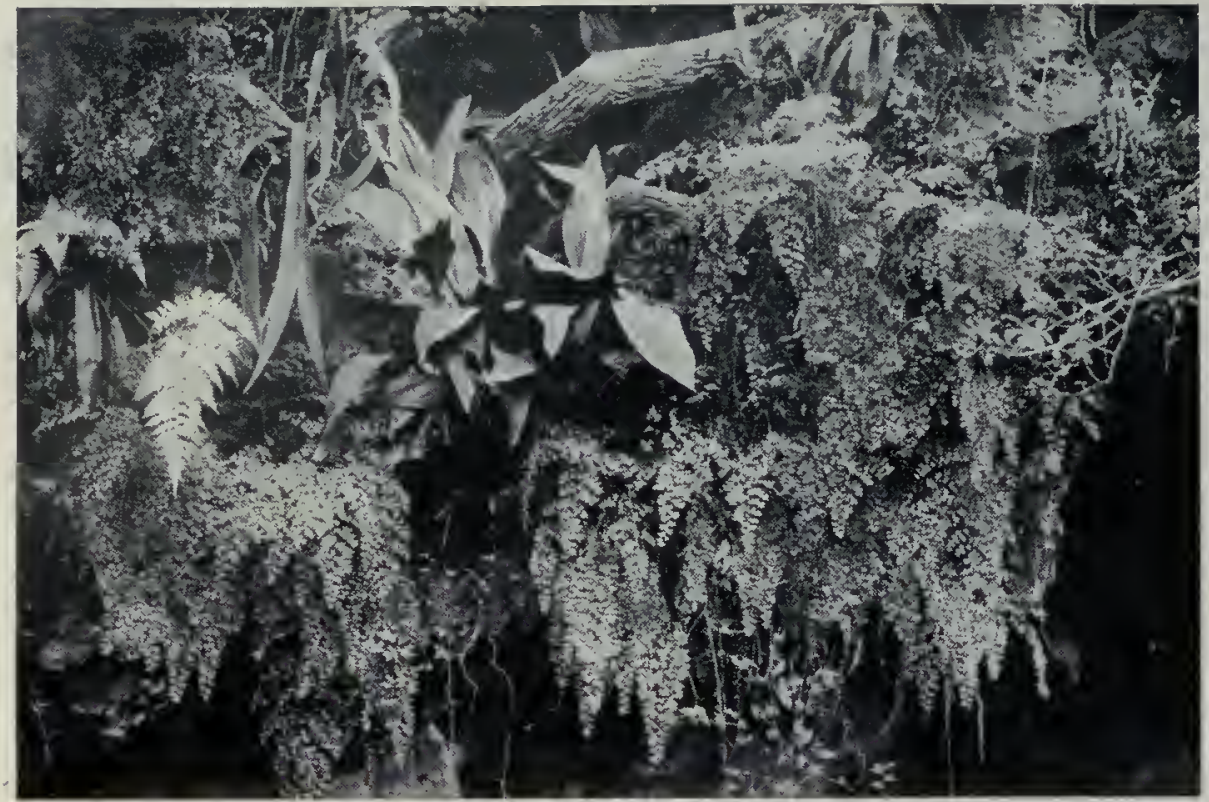

Capillaire en coin de l'Amérique tropicale.

enroulées en crosse dans leur jeunesse. Les Fougères arborescentes des pays chauds ont, au contraire, une tige aérienne qui peut atteindre jusqu’ à 15 mètres de hauteur.

Remarquons encore que la reproduction chez les Fougères se rapproche beaucoup de celle des Mousses, mais que les phénomènes s'y produisent en ordre inverse : chez les Mousses, la plante feuillée provient d'une spore et porte l'ouf ; chez les Fougères, elle provient d'un œuf et porte des spores.

Au point de vue de la culture, les phénomènes précédents sont indispensables à connaître. Puisqu'il n'y a pas de graine dans les Fougères, on ne peut les multiplier quà l'aide des spores, et on y parvient en les semant dans des coupelles plates contenant un mélange de terre de bruyère et de brique ou de sable siliceux et de poussière de charbon. Ces coupelles ayant été au préalable chauffées vers $100^{\circ}$, ou arrosées avec de l'eau bouillante, pour amener la destruction de tous les germes qu'elles peuvent contenir, on peut déposer les spores sur toute la surface du substratum. La coupelle reposant dans une assiette contenant de l'eau et le tout ayant été recouvert par un disque de verre, on abandonne l'ensemble dans une serre tempérée. Les prothalles apparaissent bientôt, puis les feuilles, les tiges et les racines après la fécondation.

En étudiant la multiplication végétative (p. 33), nous avons indiqué comment certaines Fougères se multiplient par des bulbilles. Chez la $W$ oodwardia radicante, c'est l'extrémité des feuilles qui s'enracine.

Fougères Polypodiacées. - Le Polypode vulgaire est une espèce très répandue dans nos forêts et poussant aussi sur les rochers et les vieux murs; il est le type d'une grande famille de Fougères, dont nous allons indiquer les principaux genres.

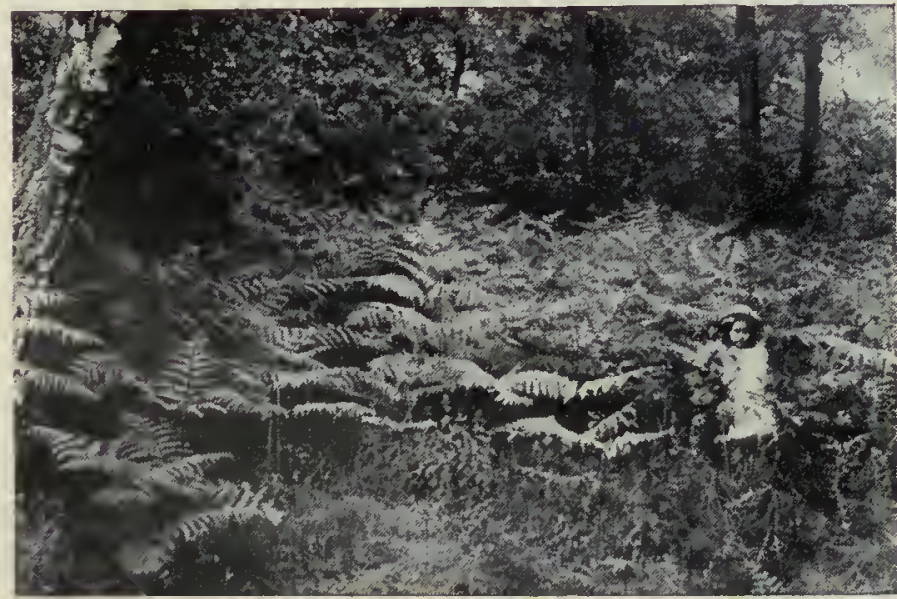

Fougère grand aigle en forêt de Meudon.
Les Capillaires ou Adiantum sont caractérisées par leurs pétioles noirs, leurs nombreuses folioles en forme de coin, pourvues de petits lobes arrondis, brunâtres, rabattus sur le limbe; c'est en dessous de ce petit volet que sont les sporanges. Les plus communes sont la Capillaire Cheveux de Vénus, la Capillaire en coin, à lobes très nombreux.

Les Ptérides ou Ptéris sont des Fougères beaucoup plus robustes, qui n'ont pas le pétiole noir, et dont les frondes sont en général très découpées et portent les sporanges insérés sur une nervure qui s'observe sur tout le bord de la feuille, ourlet étroit qui se rabat sur elle tout du long. En dehors du Ptéris ou Fougère grand aigle, qui est l'espèce indigène que l'on rencontre dans tous nos bois, qui peut se cultiver en plein air dans un terrain siliceux, on trouve, surtout très répandu dans la culture de serre et d'appartement le Pléris à crêtes et le Ptéris serrulé.

Les Gymnogrammes méritent une mention spéciale : c'est ce qu'on appelle les "Fougères dorées " ou "argentées "; elles présentent, en effet, à leur face inférieure des poils cireux qui apparaissent comme une poussière d'un beau jaune d'or ou d'un blanc d'argent bien remarquable. Ces plantes sont fort appréciées des amateurs et servent à la garniture des appartements; elles n'y vivent malheureusement pas longtemps.

Les Polypodes se reconnaissent aisément au caractère tiré de la nudité des sores ou groupes bruns de sporanges; ces petites taches sont arrondies, isolées à la face inférieure des feuilles et jamais elles n'ont aucune protection soit par le rebord de la feuille, comme dans les Capillaires et les Ptérides, soit par un autré appareil dont il sera question plus loin. En dehors du Polypode vulgaire, qui est une espèce rustique à cultiver en plein air, puisquelle habite notre pays, il y a un grand nombre d'espèces répandues dans les serres, comme le Polypode doré, avec ses gros rhizomes couverts d'écailles rousses, et un grand nombre de types de serre chaude qui ont, en général, des feuilles entières et assez épaisses. A côté se placent les Platycerium épiphytes (p. 58) et les Acrostiches.

Dans tous les exemples que nous venons de citer, les organes reproducteurs ou sporanges sont nus ou protégés simplement par le rebord de la feuille; il est des cas où un organe spécial, appelé indusie, se forme pour assurer leur protection. Ce peut être, par exemple, une petite lame insérée sur la nervure voisine, de manière à avoir l'aspect d'un volet à moitié ouvert, en dessous duquel on aperçoit les sporanges : c'est ce qui arrive dans tout le groupe des Aspléniées. Les Blechnum ont deux rangées de sporanges formant deux séries longitudinales à droite et à gauche de la nervure médiane; les Woodwardia offrent un caractère analogue. Dans les Scolopendres, que l'on observe sur les murs très humides, à l'orifice des puits, on a des feuilles simples, allongées, portées sur un pétiole relativement court. Le Cétérach des officines, rustique également, pousse sur les murs secs; ses feuilles ont deux rangées de lobes, de part et d'autre de la nervure médiane, lobes couver's

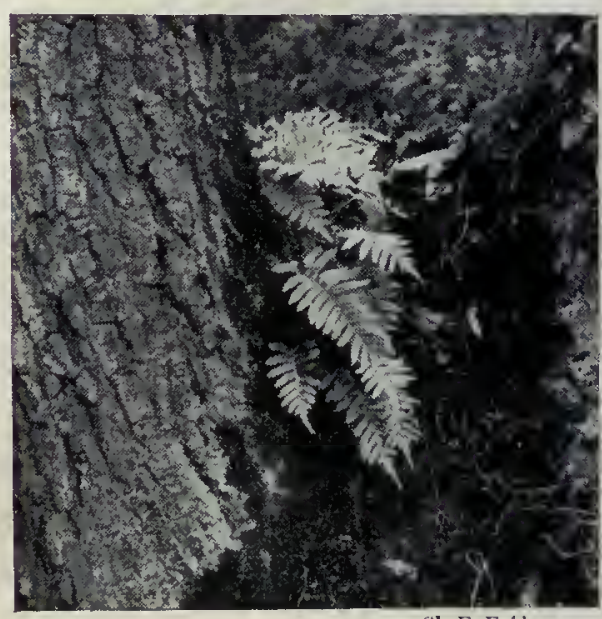

Polypode vulgaire, sur un tronc d'arbre.

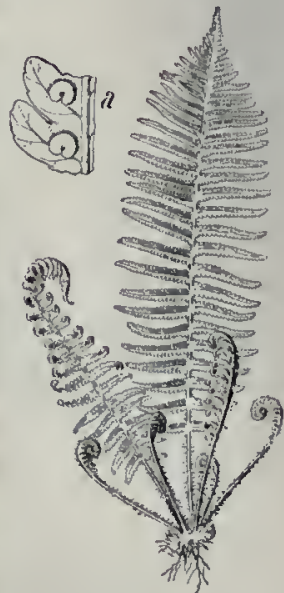

Fig. 161, - Aspidie. $a$, Fragment de feuille. 


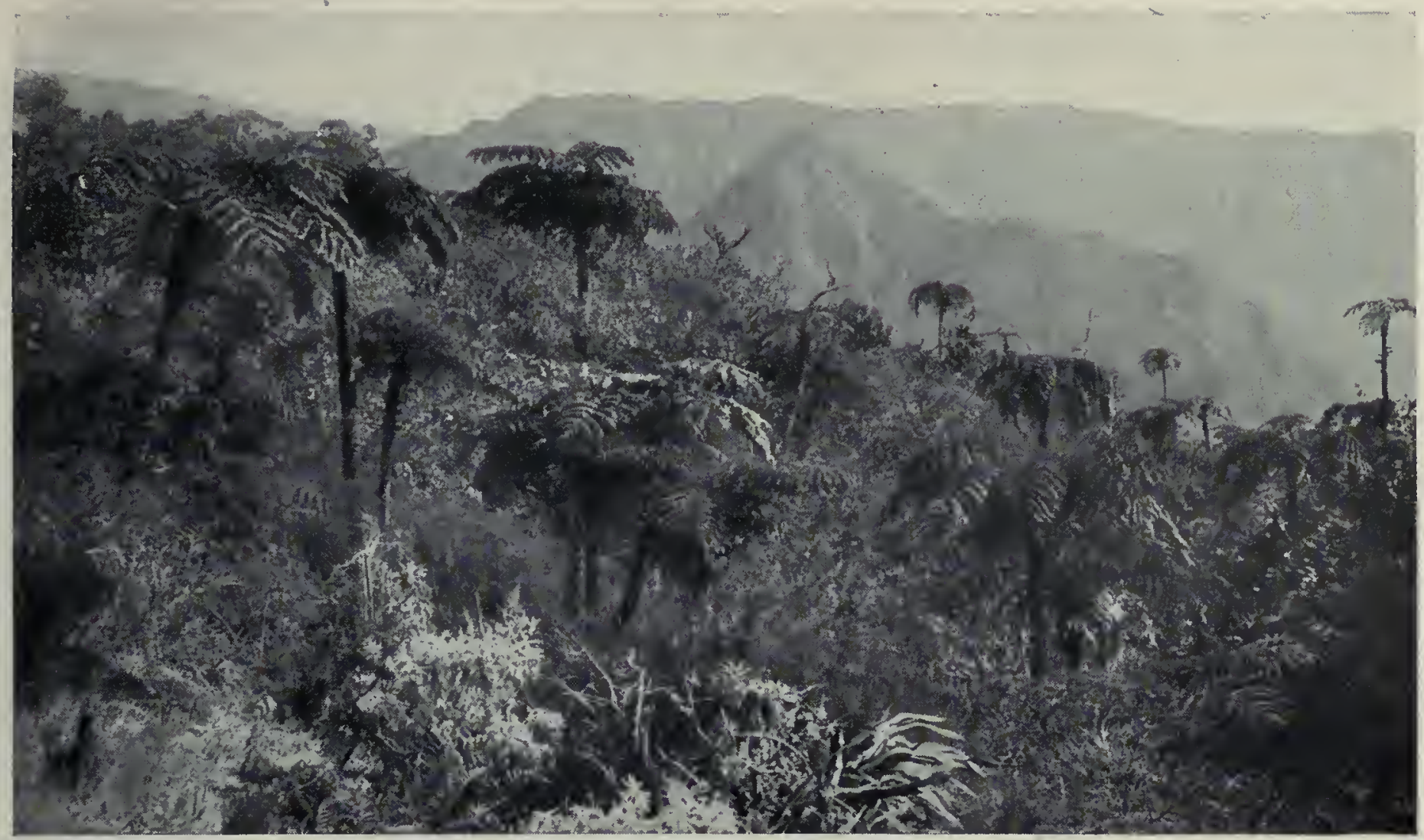

Ravin avec Fougères arborescentes (Cyathées); ile de la Réunion.

sur toute leur surface inférieure d'écailles brunes. Dans les Doradilles ou Asplénies, l'indusie a la forme d'un volet. Une espèce de serre chaude, la Doradille nid, dont nous avons déjà parlé (p. 58), est épiphyte. La Fougère femelle (Athyrium) doit prendre place' à côté; c'est une espèce indigène rustique qui, à cause de la délicatesse de ses frondes très finement divisées, mérite d'être souvent cultivće sur les rocailles des jardins.

L'indusie, au lieu d'avoir la forme d'un volet, peut être parfois en bouclier, en écusson ou en rein qui s'attache au milieu du sore qu'elle est destinée à recouvrir; c'est ce qui arrive chez les Aspidiées. Le genre Néphrodie, devant son nom à l'indusie en forme de rein, est très largement représenté dans les serres froides; ce sont des Fougères à feuilles assez amples. Les Aspidies (fig. 16l) ont, au contraire, l"indusie en bouclier. Les Didymochlènes sont de belles Fougères de jardins d'hiver, dont les folioles assez petites sont en forme de croissant et insérées en deux rangées alternantes.

Dans les Davallia, l'indusie forme une coupe placée sur le bord de la feuille et soudée presque complètement à elle. Ce sont de très belles Fougères dont quelques-unes à grand développement; par leur ample et majestueux feuillage elles font l'ornement des jardins d'hiver: telle est notamment la $D_{a}$ vallia majuscule, qui peut atteindre un mètre de haut; d'autres espèces sont de serre plus chaude et se cultivent seulement en panier suspendu comme plantes épiphytes: telle est la Fougère patte de lièvre (Davallia des Canaries), dont les feuilles sont très lćgères et finement découpées, dont le rhizome très ćcailleux a un peu l'aspect d'une patte poilue. La Davallia bulleuse est utilisée au Japon, son pays d'origine, pour la création de bizarreries végćtales. Sa tige souterraine, longue de 1 mètre à $]^{m}, 50$, est déterrée à l'automne. On fixe bout à bout plusieurs de
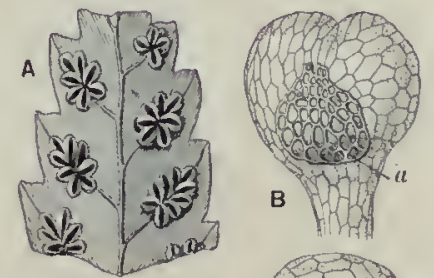

ces rhizomes sur une carcasse en fil de fer ou en bambou figurant un animal ou un objet quelconque, et on entoure le tout de mousse. Au printemps suivant, on bassine chaque jour la mousse; les bourgeons se développent et la carcasse verdoie. Des enseignes de commerçants sont parfois obtenues d'une façon pittoresque à l'aide de $\mathrm{Da}$ vallia suspendues au-dessus de la porte et assemblées de manière à former des lettres. Les Nephrolepis sont des Fougères de serre chaude, qui se cultivent aussi en paniers suspendus.

Toutes les plantes que nous venons de passer en revue sont herbacées. Lorsquion examine au microscope leurs sporanges (fig. l62), on voit que ces organes présentent une bande de cellules en forme de fer à cheval que l'on appelle l'anneau, et qui joue un rôle important dans la dissémination : c est grâce à la contraction de la membrane
Fig. 162. - Sporanges.

A, d'Angioptère; $B, C$, de Todea $\mathrm{D}$, de Lysodium : $\alpha$, Anneau.

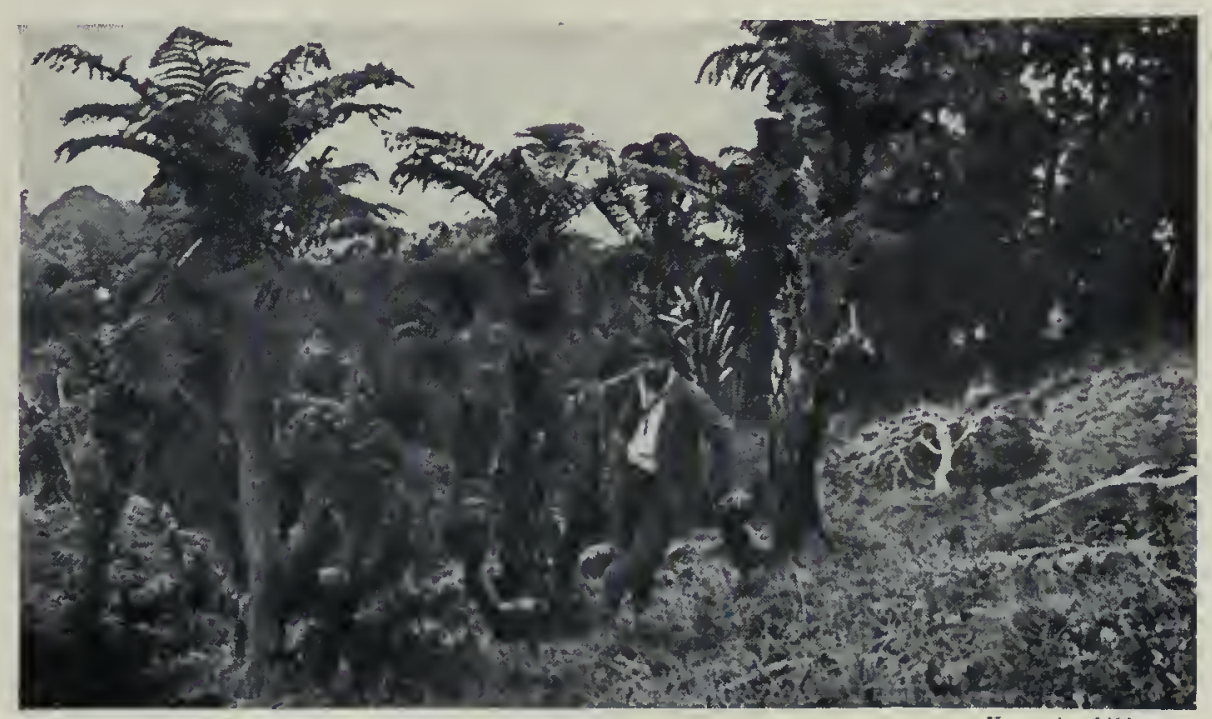

Dicksonia Berteroana (ite de Juan Fernandez).
Vegetationsbilder. 


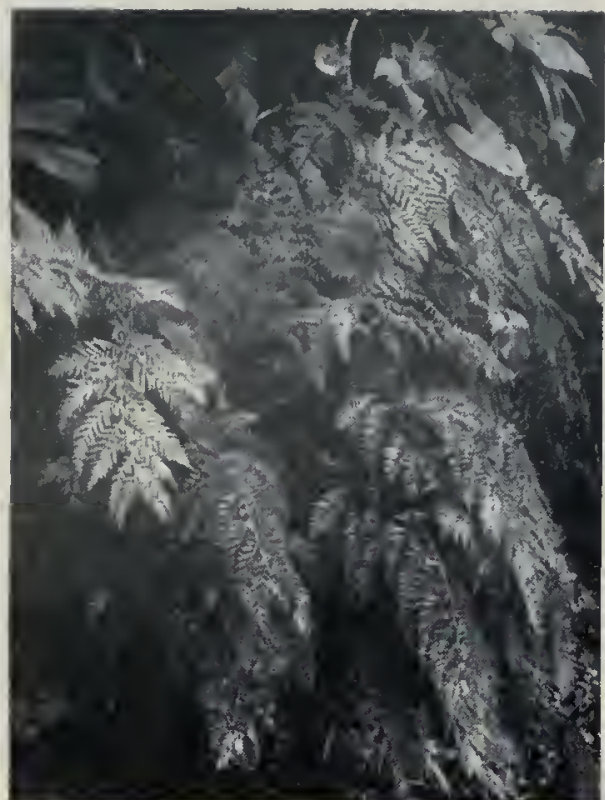

Todea barbare (Australie). mince qui réunit les extrémités du fer à cheval, contraction qui se produit par la dessiccation, que la membrane du sporange se déchire et que les spores sont mises en liberté. Dansle groupe des Polypodiacées, l'anneau est disposé suivant un méridien, mais i] est incomplet; le sore est alors nu.

Autres types de Fougères. - ll y a fréquemment dans les serres chaudes, et surtout dans les jardins d'hiver, des représentants d'une organisation différente: ce sont les Cyathéacées, qui constituent ce que l'on appelle les Fougères arborescentes; dans ce groupe, l'anneau est encore longitudinal, mais il forme un méridien complet. Le port de ces plantes est très élégant; les tiges, qui ne sont jamais d'une très grande hauteur, sont couronnées à leur partie supérieure par un cercle de grandes frondes très finement découpées; le tronc, qui reste toujours simple, est écailleux, couvert sur toute sa surface de cicatrices laissées par les feuilles anciennes tombées; ces bases de feuilles ont été décomposées plus ou moins complètement, ce qui donne à la surface une certaine irrégularité ; en outre très souvent, surtout dans les parties inférieures, il se développe une multitude de petits cordons brunâtres formés par les racines; ces organes apparaissent entre les cicatrices foliaires et descendent parallèlement à la tige, formant ainsi un enchevêtrement ayant cependant une même direction générale. L'aspect d'une de ces vieilles tiges de Fougères, lorsqu'elle a été arrachée, est un peu celui d'un balai (p. 19). C'est parmi les plantes de ce groupe que se placent les Cyathées, les Dicksonia, les Balantium, les Cibotium, les Alsophiles.

Dans les Schizéacées, ]'anneau est en calotte; cette particularité s'observe dans les Lygodium (fig. 162, D), qui sont des Fougères grimpantes, et les Ancimies, à fronde divisée en deux parties, dont l'une est stérile et l'autre fertile.

Les Hyménophyllées ont un anneau transversal et complet. Ce sont des Fougères intéressantes par la délicatesse de leurs tissus (Hyménophylles, Trichomanès); c'est parmi elles que s'observent les plus belles Fougères translucides, de culture souvent délicate.
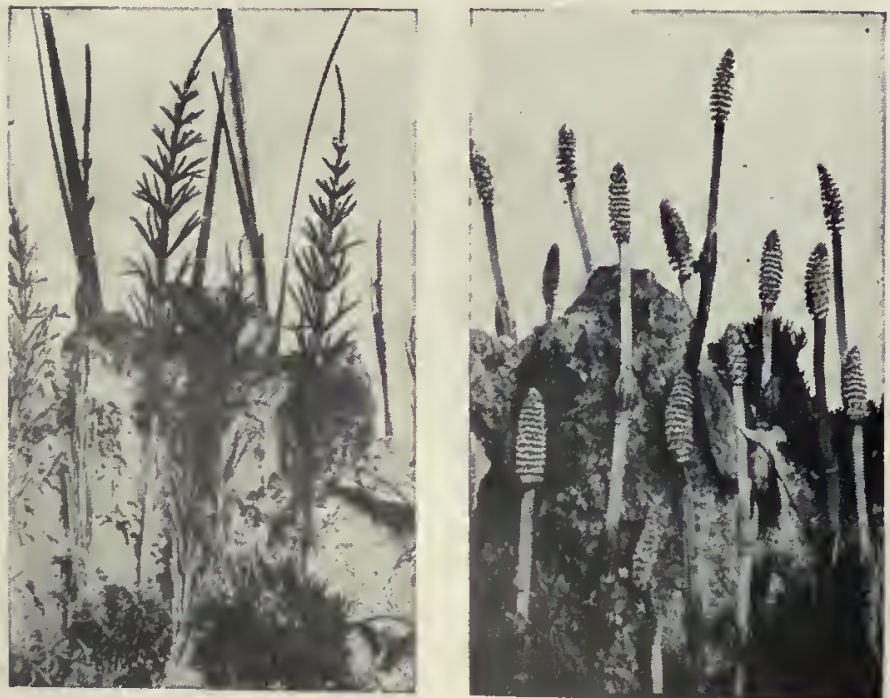

Prèle des champs; tiges stériles et tiges fertiles.

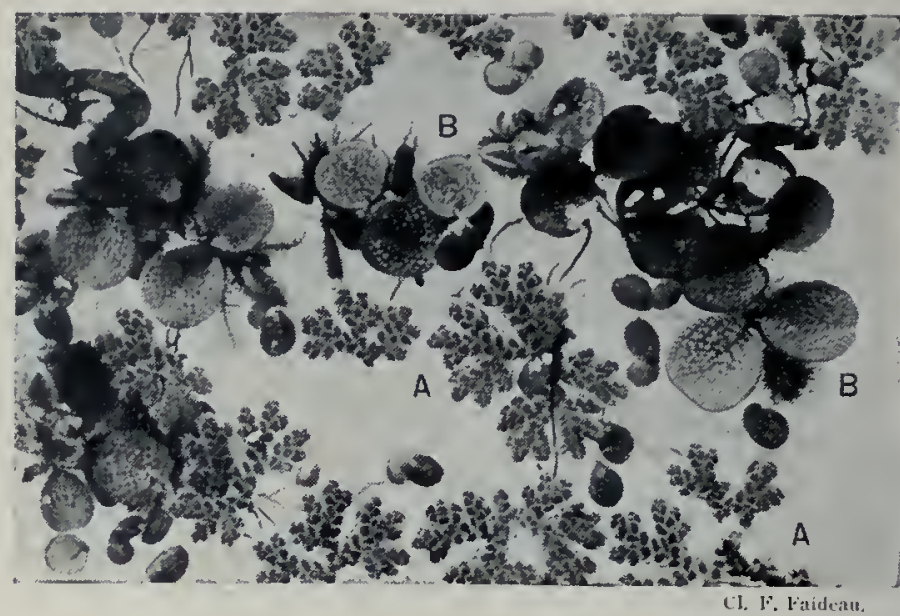

A, Azolla de la Caroline; B, Salvinie nageante.

Dans les Osmondées, l'anneau est transversal et incomplet (fig. 162, B, C). L'Osmonde royale est une belle Fougère indigène à partie fertile formant une panicule sans limbe. Parmi les Todea, certaines ont des feuilles translucides (Todea superbe), mais ce caractère ne s'observe pas dans le Todea barbare de l'Australie. Dans les Marattiacées, l'anneau fait défaut. Ce groupe est représenté dans les cultures par les Angioptères, qui sont des Fougères herbacées gigantesques. Les Ophioglosses ou Langues de serpent constituent un groupe plus aberrant encore, dans lequel la partie fertile est distincte, étroite, cylindrique, formant épi.

Filicinées aquatiques. - On distingue sous le nom de Rhizocarpées ou d'Hydroptéridées des espèces de Fougères aquatiques qui ont deux sortes de sporanges : des microsporanges à petites spores, qui engendrent des prothalles mâles en germant; des macrosporanges à grosse spore, qui engendre un prothalle femelle. La Salvinie nageante a des groupes de deux feuilles rapprochées à limbe arrondi ; elles sont aériennes, insérées au même point sur une tige horizontale; à chaque noud s'attache une troisième feuille laciniée aquatique; il ny a jamais de racines. L'Azolla de la Caroline est voisin, mais les feuilles sont petites, bilobées et alternent en deux rangs sur la face dorsale de la tige; la face ventrale porte deux rangs de racines. Les Marsilies sont des plantes non nageantes, de marécages, à quatre folioles.

Équisétinées. - Les Équisétinées, qui constituent la seconde classe des Cryptogames à racines, ont les feuilles verticillées. Les Prêles sont appelées ordinairement "Queues de cheval "; ies feuilles sont soudées entre elles autour de la tige, qui est imprégnée de silice et utilisée à cause de cela par les ménagères pour le nettoyage des casseroles. La fructification se compose d'un épi oblong qui se développe au sommet sur des tiges spéciales décolorées (Prêle des champs) ou sur des tiges vertes (Prêle des bois). L'épi est formé par des organes en forme de clous dont les têtes hexagonales sont rapprochées les unes des autres dans l'épi non mûr. Ces têtes de clous portent en dedans des sporanges sans anneau qui donnent des spores pourvues de quatre filaments enroulés autour d'elles en spirale et que l'on appelle élatères (fig. 163); ils sont hygroscopiques et contribuent à la dissémination.

Lycopodinées. - Dans les Lycopodinées, comprenant les Lycopodes, les Sélaginelles et les lsoetes, la tige, et surtout les racines, se ramifient en fourche ou dichotomie. Il y en a deux

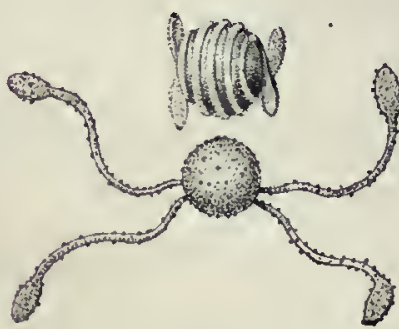

Fig. 163. - Spores de Prêle a vec élatères enroulés et déroulés. types: les isosporées et les hétérosporées. Les premiers sont à une seule sorte de sporange, comme les Lycopodes, dont les spores petites, impalpables, servent sous le nom de poudre de Lycopode en pharmacie. Dans les types hétérosporés (Sélaginelles et Isoetes), il y a deux sortes de sporanges. Les Sélaginelles servent à faire le gazon dans les serres. Les Isoetes, qui sont très voisins, ont l'aspect de Graminées bulbeuses qui ne donneraient jamais de fleurs. 


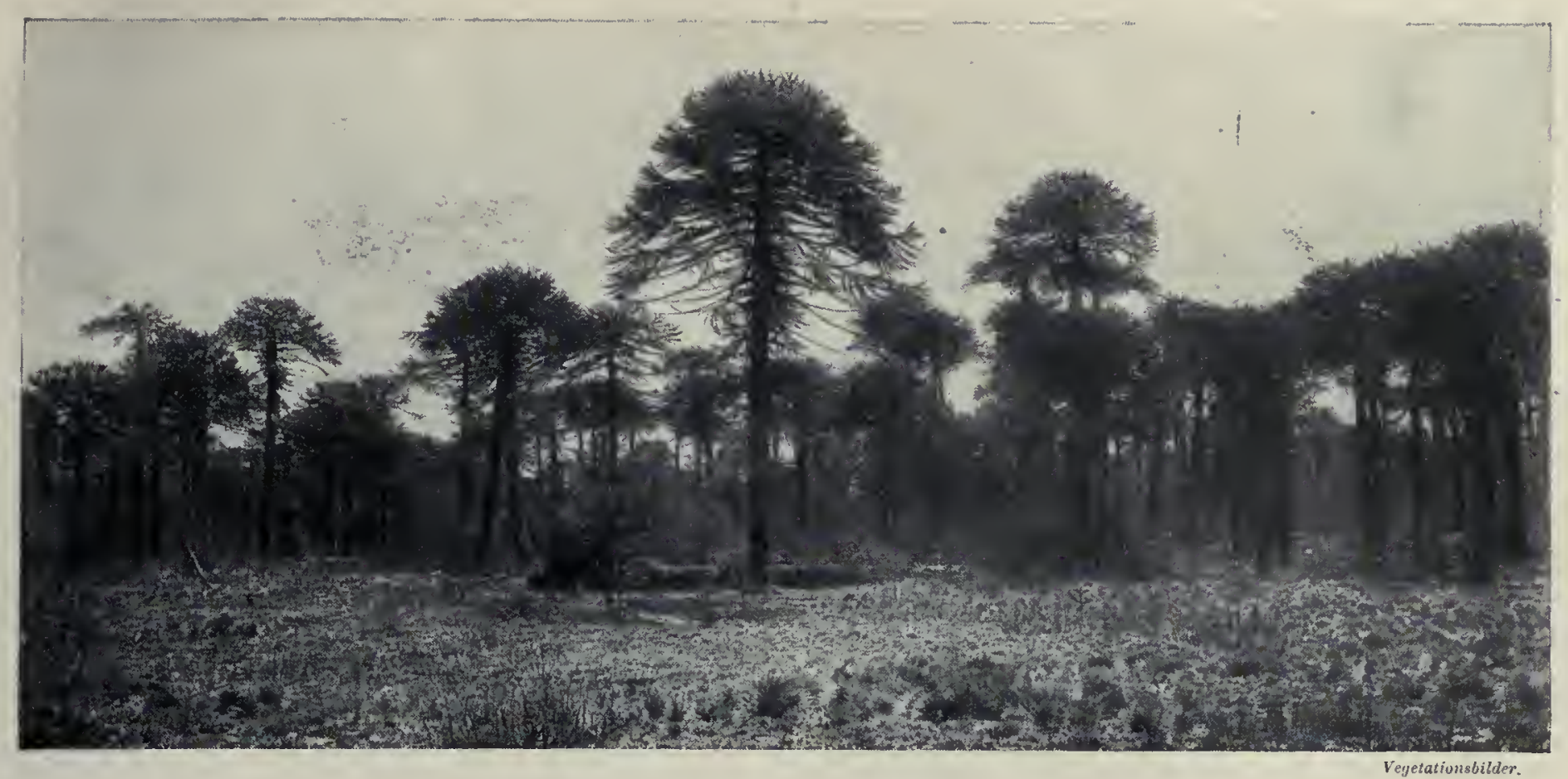

BOIS D'ARAUCARIA DANS LA CORDILLERE DU CHILI.

\section{III. - LES PLANTES A FLEURS : GYMNOSPERMES}

Caractères généraux. - Dans l'embranchement des plantes à fleurs ou Phanérogames, lc grand groupe des Gymnospermes. se distingue par l'existence habituelle des graines nues (fig. 164), c'est-à-dire non emprisonnées dans un ovaire, et surtout parl'absence de stigmates: d'où le nom d'Astigmatées qui leur est quelquefois donné. Pendant longtemps, ces plantes avaient embarrassé les classificateurs, car, d'une part, leurs tiges s'épaississent comme celles des Dicotylédones; d'autre part, elles ont un nombre variable de cotylédons dans leur graine. L'étude qui a été faite de leur ovule a permis d'y découvrir que les éléments femelles étaient des espèces de bouteilles ( $f \mathrm{gg}$. 165, A) avec une partie ventrue et un col qui était percé par une cellule canal: c'était donc une structure tout à fait analogue à celle des archégones ou bouteilles femelles des Fougères. L'analogie a pu être poursuivie plus loin lorsque, dans ces dernières années, des savants japonais, $\mathrm{Hi}$ rasć et lkèno, découvrirent que l'anthérozoïde ou organe mâle ( fig. $165, \mathrm{~B}, \mathrm{C}$ ) était pourvu de cils locomoteurs comme ceux des Fougères ou des Mousses. Mais, dans les Gymnospermes, l'élément mâle est un grain de pollen, et c'est seulement à sa germination que le corps mobile précédent se produit et réussit à devenir libre, de façon à pouvoir pénétrer, grâce au mouvement vibratile de ses cils, dans le col de l'archégone. Ces organes mâles ciliés ont ćté découverts chez les Cycadés et les Ginkgo; on les appelle, à cause de ces anthérozoïdes nageurs, des Natrices. Dans les autres Gymnospermes, le pollen est ordinaire avec un tube vecteur; on les nomme $V$ ectrices ou Conifères.

Il était nécessaire d'insister sur les analogies des Gymnospermes et des Cryptogames vasculaires pour faire comprendre

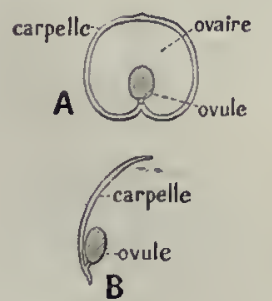

Fig. 164.

Feuille carpellaire A, d'une Andiosperme ; Bid'une Gyunosperme.
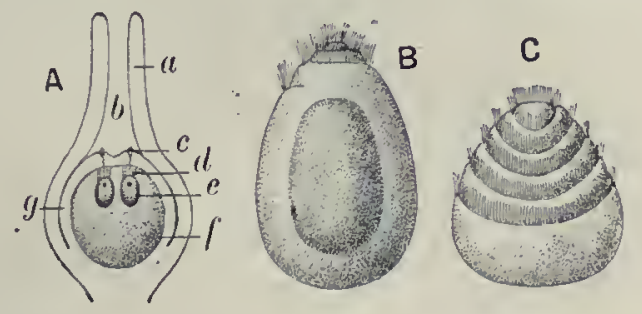

Fig. 165. - Reproduction des Gymnospermes.

A, Ovule : $a$. Tégument; $b$, Chambre pollinique; $c$. Pollen germant; $d$, Archégone; $e$, Oosphère i $f$, Sac émbryon naire; s, Nucelle; B, Anthérozoỉde de Gingko; C, de Cycas combien ces deux groupes, qui paraissent d'abord si éloignés, ont d'affinités véritables. Voici comment on classe les Gymnospermes:

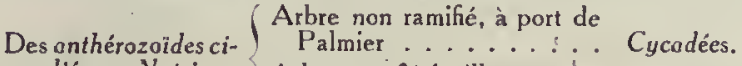

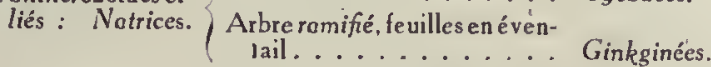

$$
\begin{aligned}
& \text { Un tube pollinique. }\left\{\begin{array}{c}
\text { Pas d'anthérozoïdes ciliés mo- } \\
\text { biles; ovule nu . . . Conifères ou Vectrices. } \\
\text { Ovule dans un ovaire } \ldots .
\end{array}\right.
\end{aligned}
$$

Famille des Conifères ou Vectrices ; organisation. - Nous commencerons l'étude des Gymnospermes par celle des Conifères, et nous examinerons d'abord comme premier type le $P$ in $(f g .166)$. Cette plante est désignée sous le nom d'arbre à aiguilles, à cause de l'étroitesse de ses feuilles effilées qui ne tombent pas chaque hiver; elles sont dites persistantes et durent de 2 à 7 ans. Elles sont attachées soit par deux, soit en plus grand nombre jusqu'à cinq, sur des rameaux extrêmement courts. Les branches longues sont au contraire dépourvues de feuilles aciculaires, et ne présentent que des écailles très réduites. Il y a donc, dans cette plante, deux sortes de branches (des longues et des courtes) et deux sortes de feuilles (des aiguilles et des écailles). Ces quatre types d'organes sont toujours associés de la même manière : rameaux courts et aiguilles, rameaux longs et écailles. Le nom de Conitères, que l'on donne au groupe dont le Pin fait partie, est tiré des caractères que prennent les chatons femelles en se développant après la pollinisation; ils sont composés d'une série d'écailles ligneuses persistantes, qui sont formées par les bractées épaissies, à l'aisselle desquelles se produisent des"rameaux courts femelles. Ceux-ci portent, à leur extrémité, deux carpelles ou feuilles soudées entre elles, sur lesquelles sont fixés deux ovules droits, mais pendants vers le bas (fig. 166, d). Ces feuilles carpel-

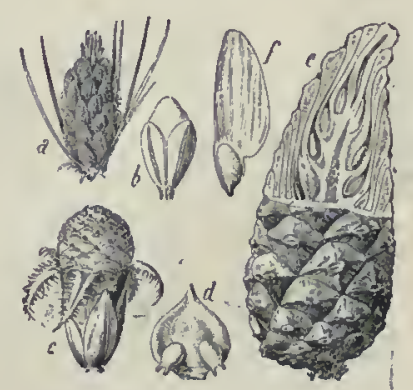

Fig. 166.

Fleurs et fruit du Pin. lée ; $c$, Chaton femelle; $d$, Une fleur deux ovules; $e$, Cônè mûr coupć en partie pour montrer les sraines; $f$, sraine. $a$, Chalon mâle; $b$, Etamine iso isolée montrant lée carpelle et les 


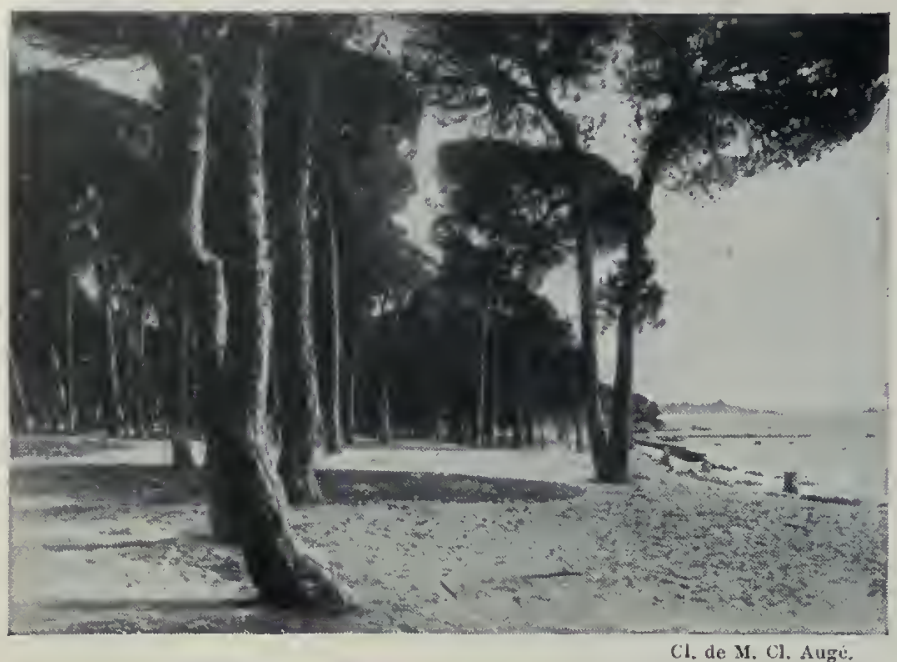

Pins parasols, au golfe Juan.

laires se sont étalées de manière à ne jamais se fermer : il n'y a donc pas d'ovaire. Les chatons mâles ( $f$ ig. $166, a)$ apparaissent sur le même pied que les parties femelles; le Pin est donc un arbre monoïque. Le pollen a deux petits ballonnets à air, grâce auxquels il tournoie dans l'atmosphère en grande quantité au printemps et est quelquefois entraîné par la pluie sur le sol ; les paysans disent qu'il y a pluie de soufre. Ce pollen est apporté par le vent à la partie antérieure de l'ovule dans une cavité, la chambre pollinique (fig. $165, \mathrm{~A})$, où il demeure en attendant la fécondation. Pendant ce temps, le cône se referme par l'agrandissement et l'épaississement de ses écailles et obvie ainsi d'une manière manifeste aux grands inconvénients de la gymnospermie, c'est-à-dire de l'exposition à l'air des ovules. La maturation des graines exige deux ans, rarement trois, ce qui tient à ce que le tube pollinique n arrive au sac embryonnaire que l'année suivante de la floraison. Les graines qui se constituent par la transformation de l'ovule sont pourvues d'une aile (fig. 166,f), formée aux dépens du carpelle voisin; elles contiennent un nombre de cotylédons qui peut varier de trois à quinze.

On subdivise les Conifères en trois tribus: Abiétinées, Cupressinées et Taxinées. Chez les deux premières, le fruit est un cône, lovule est au dos du carpelle et la graine est sans arille, mais, dans les Abiétinées, il y a des canaux sécréteurs dans la racine; ils manquent dans les Cupressinées; chez les Taxinées, il n'y a pas de cône, l'ovule est terminal, la graine est pourvue d'un arille dont la partie externe est charnue.

Abiétinées. - Dans ce groupe, les Pins ne se bouturent pas ou très difficilement; ils sont capables de drageonner et de repousser de la souche, mais on peut les multiplier par greffe en fente et demi-fente à l'état herbacé. Les espèces cultivées de ce genre sont nombreuses; parmi elles on peut mentionner le $P$ in sylvestre ou Pin d'Ecosse, ou Sapin rouge du Nord, qui est l'espèce indigène. Le Pin maritime est à aiguilles plus longues

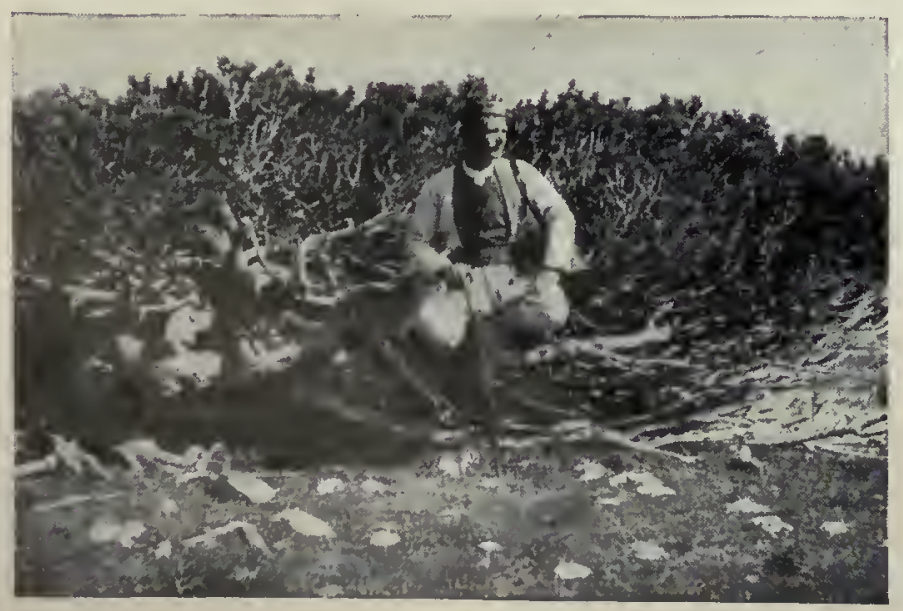

Pin Mughus, en Albanie.

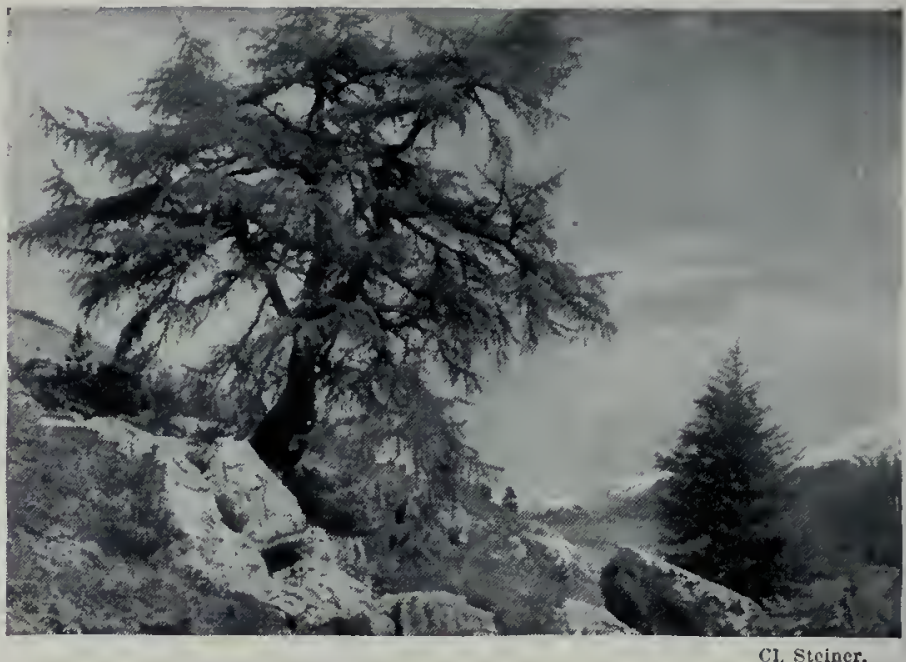

Métèzes, dans tes montagnes de l'Engadine.

et à cône plus gros. C'est le Pin de Bordeaux ou le Pin des Landes, qui dépérit sur les sols calcaires, mais se plaît tout particulièrement sur les dunes; aussi est-ce grâce à ces plantations, qui ont été préconisées par l'ingénieur Chambrelent, que presque tout un département, celui des Landes, est devenu exploitable. Le grand produit de cet arbre est le gemmage ou résinage, en vue d'obtenir la térébenthine et ses dérivés. La matière résineuse est produite par des canaux sécréteurs qui sont dans le bois, de sorte qu’il est nécessaire pour l'extraire de faire des entailles assez profondes.

Il y a encore d'autres espèces de Pins à deux aiguilles à mentionner; en particulier, le Pin Pignon, dont la tête forme une grosse boule arrondie très caractéristique: d'où le nom de $P$ in parasol, qu'on lui attribue quelquefois; il contribue à donner au paysage méditerranéen un facies assez spécial. Le $P$ in noir d'Autriche est une variété du Pin Laricio, habitant les montagnes calcaires de la Carinthie et de la Styrie, de la Moravie et de la Transylvanie. Citons encore le Pin de Norfolk et le Pin Mughus.

Le Mélèze a beaucoup de ressemblance avec les Pins, car ses aiguilles sont assez analogues, mais elles sont insérées aussi bien sur les rameaux courts que sur les rameaux longs; par conséquent sil y a encore deux sortes de rameaux, ici il ny a plus qu'une seule sorte de feuilles aciculaires, mais aplaties, à section losangique : les unes isolées, solitaires; les autres en bouquets ou fascicules; ces aiguilles sont caduques et l'arbre se dépouille complètement à l'automne. Les cônes de ces plantes sont petits, à maturation annuelle.

Les Cèdres ressemblent aux Mćlèzes par leurs deux sortes de rameaux courts et longs et par leurs feuilles d'une seule nature, mais ces feuilles sont persistantes. Chacun connaît le Cèdre du Liban par le bel exemplaire que l'on peut admirer au Labyrinthe du Muséum. Cet arbre est historique : il a été rapporté en 1735 d'Angleterre par Bernard de Jussieu; les puissantes branches

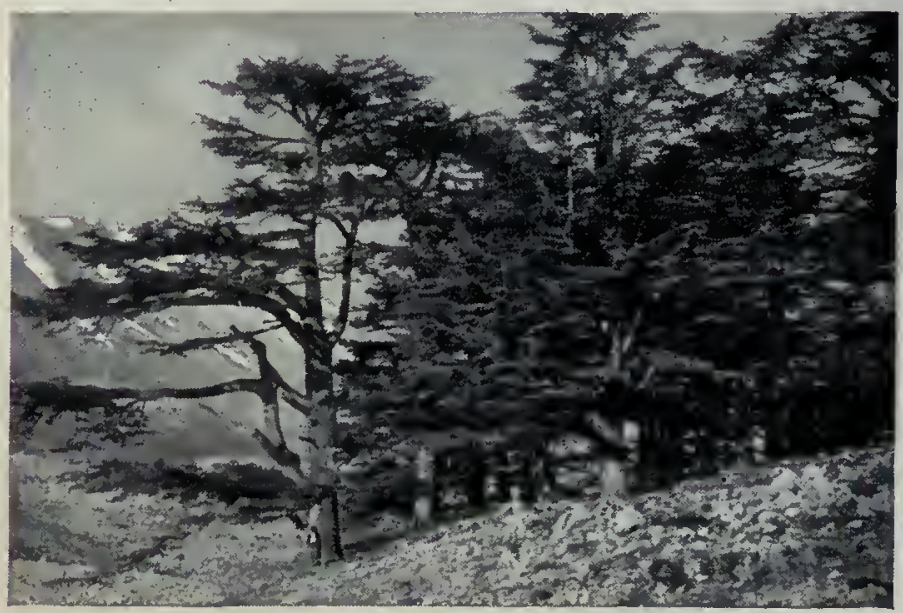

Groupe de Cèdres du Liban. 
horizontales situées à la partie supérieure, par suite de la perte de la flèche, lui donnent un aspect caractéristique. Le Cèdre argenté de l'Atlas, le Meddad des Arabes, est une variété de l'espèce du Liban, à feuilles courtes arquées. Le Deodora est le Cèdre de l'Himalaya : ses feuilles sont beaucoup plus grandes, de 3 à 5 centimètres, piquantes et glauques.

Le Sapin ou Abies, qui est voisin du Cèdre par ses caractères anatomiques, s'en distingue tout de suite par la disparition des rameaux courts: cette plante ne possède donc qu une seule sorte de branches allongées et une seule sorte de feuilles qui sont aplaties et ne présentent plus la disposition en aiguille. Les cônes sont dressés et leurs écailles tombent une à une. Le Sapin pectiné ou Sapin argenté, Sapin des Vosges, a un port pyramidal remarquable; son tronc est à écorce lisse, gris argenté, se gerçurant avec l'âge. C'est à 50 ans qu'il donne ses premières fleurs mâles, et un peu plus tard ses premières fleurs femelles; il peut être fécondé vers 70 ans. Citons encore le Sapin Baumier, qui forme le baume du Canada, et le Sapin Pinsapo.

Le Tsuga du Canada est un arbre très important de l'Amérique du Nord, où il constitue des forêts immenses. II est voisin des Sapins et il a comme ces arbres une seule sorte de rameaux (allongés) et des feuilles aplaties, mais les cônes sont pendants et à écailles persistantes. Le Ketelecria de Fortune, originaire du sud de la Chine, est un arbre magnifique à port du Cèdre du Liban, à cônes dressés dont les écailles sont persistantes; il a un très beau développement en Italie, sur les bords du lac Majeur.

L'Épicéa élevé ou Picéa (fig. 167) est confondu souvent avec le Sapin; il porte vulgairement le nom de Sapin blanc du Nord ou Pesse. II a, en effet, comme les Abies ou Sapins véritables, sculement des branches longues et une seule sorte de feuilles. Ces derniers organes sont moins aplatis, leur section est losangique et les cônes sont pendants, tombant d'un seul coup tout entiers. Dans les Abiétinées précédentes, les carpelles sont indépendants des bractées, les ovules sont renversés et la racine renferme des canaux sécréteurs (Rhizocèles).

Les Araucaria se rattachent aux Abiétinées parce qu'ils ont des canaux dans la racine, mais ils ont des bractées soudées aux carpelles, comme dans les Cupressinées, auxquelles on les a longtemps rattachés. Les Araucaria sont des arbres toujours verts à feuilles écailleuses, imbriquées, étalées, piquantes au sommet. L'Araucaria élcué, que l'on cultive dans les appartements, a une ramification régulièrement verticillée de rameaux, étalés puis redressés. Les cônes des arbres du Chili et du Brésil (Araucaria imbriqué) ou de l'Australie $(A$. élcvé) sont volu mineux, ovoïdes, à écailles ćpaisses. Cesont des plantes dioiques. A côté se placent les Dammara.

Cupressi nées. - Dans les Cupressinées, il y a soudure des carpelles et des bractćes mères, les ovules sont dressés

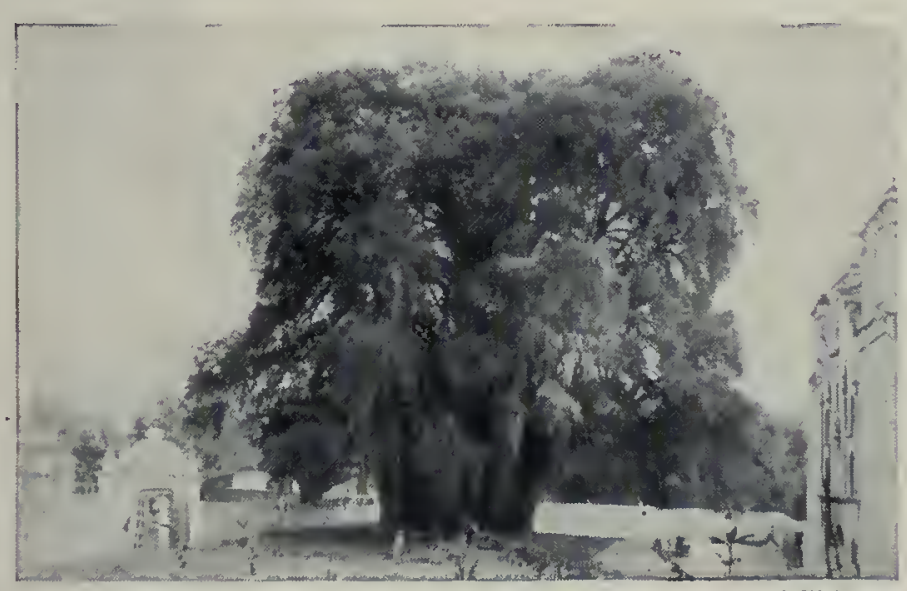

Cypres chauve du cimetiere de Santa-Maria (Mexique).
Mexique un arbre célèbre remontant à la période aztèque, avant l'arrivée des Espagnols, et qui a joué un rôle dans les lćgendes des anciennes populations de l'Amérique : c'est le Cyprès de Montézuma ou Taxode mexicain qui habite la Sierra Madre, de 1700 à 2000 mètres d'altitude. Le célèbre Taxode du cimetière de Santa-Maria del Tule (Oaxaca, Mexique) a 44 mètres de circonférence et 50 mètres de hauteur; on évalue son âge à 2000 ans.

Les Séquoia sont des arbres géants de la Californie ; ils attejgnent 100 mètres de haut avec un diamètre en proportion. Il y a d'ailleurs, parmi ces arbres géants, deux espèces qui ont été rattachées à des genres voisins : le Séquoia toujours vert, qui a un cône petit, pendant, mûrissant en un an et dont les graines ont deux cotylédons; le $W$ ellingtonia gigantesque ou arbre Mammouth des Américains, qui est plus grand encore, puisqu'il peut atteindre 138 mè-

tres de haut et une circonférence de 29 mètres; il

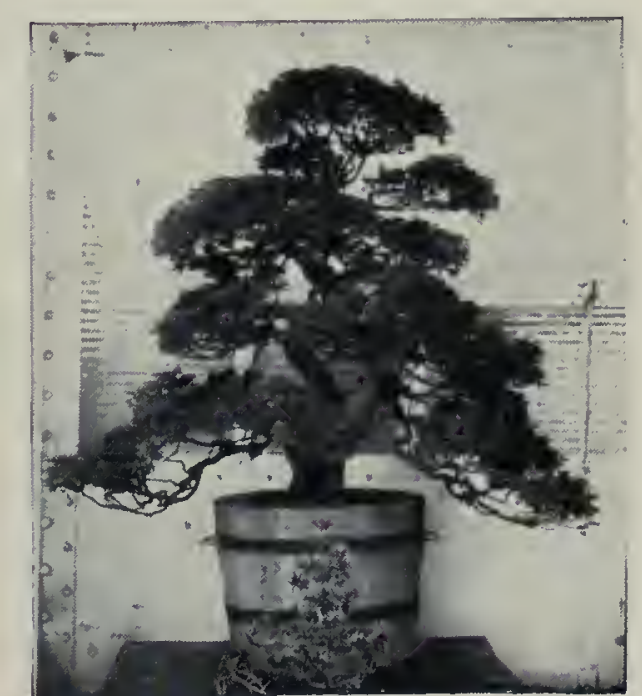

Thuya nain du Japou. 


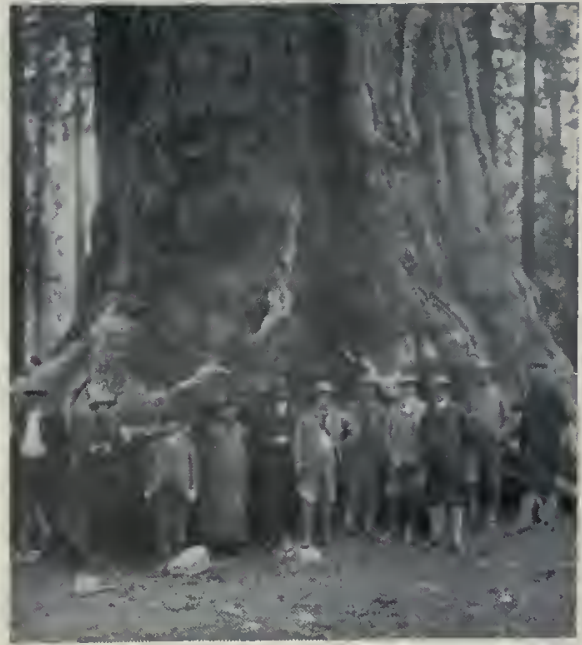

Un arbre condamné.

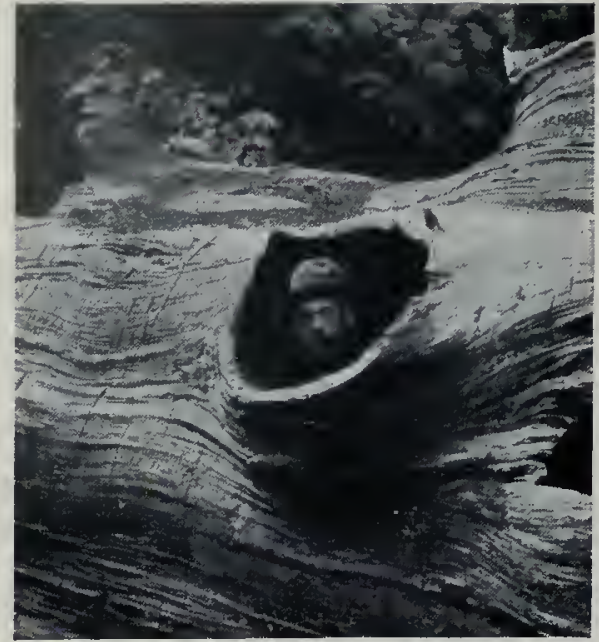

Bûcheron dans un tronc mort

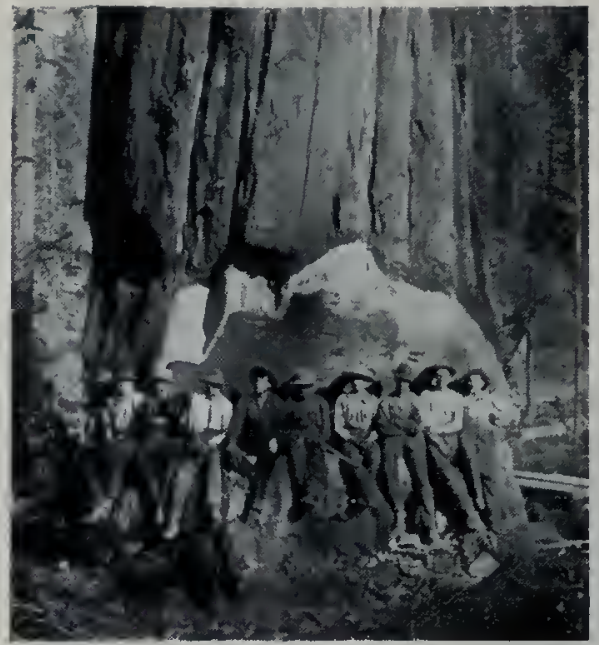

Préparatifs d'abatage.

Dans une forêt de Séquoia géants

s'élève de 1500 à 2200 mètres sur les pentes ouest de la Sierra Nevada; il a un cône plus grand, également pendant, mûrissant en deux ans et dont la graine présente trois à six cotylédons.

Dans un deuxième groupe de Cupressinées, les bractées mères sont verticillées et aussi les feuilles. Le cône est plus ou moins ligneux et formé, suivant les cas, d'un ou de plusieurs verticilles de feuilles fructifères: dans le premier type, qui se présente chez les Callitris à quatre valves, les quatre écailles du cône sont ligneuses, et leur ensemble forme un strobile tétragone. Les feuilles fructifères forment, au contraire, plus d'un verticille dans les Thuya, les Biota, dans les Cyprès et les Chamacyparis ou Faux Cyprès, les Libocèdres du Chili. Le cône du Cyprès ( $\mathrm{Cu}$ pressus) est globuleux; formé de six à douze écailles, dilatées au sommet en tête de clou ou en bouclier; une variété à rameaux fastigiés du Cyprès toujours vert sert à orner les cimetières et peut être employée pour couper le vent; les feuilles sont opposées par deux, petites, réduites à des écailles. Les Genévriers (Juniperus) tranchent nettement par leurs cônes charnüs, à écailles ayant des graines sans ailes. Leurs feuilles végétatives sont opposées par deux ou par trois, écailleuses, mais s'effilant en acicules.

Taxinées. - L'If ou Taxus est privé de canaux sécréteurs; la pousse forale est à une seule graine. C'est un bel arbre toujours vert, recherché pour l'ornementation des jardins. Ses feuilles sont aplaties, linéaires, acuminées, de consistance ferme, disposées en spirales. C'est un arbre pouvant atteindre une assez grande taille, jusqu'à 20 mètres, et dont l'écorce devient rougeâtre, fendillée, écailleuse; on peut en rencontrer des individus âgés : les pieds de 600 à 700 ans ne sont pas rares, notamment en Angleterre, où, dans le Derbyshire, un individu aurait près de 2000 ans. Ces

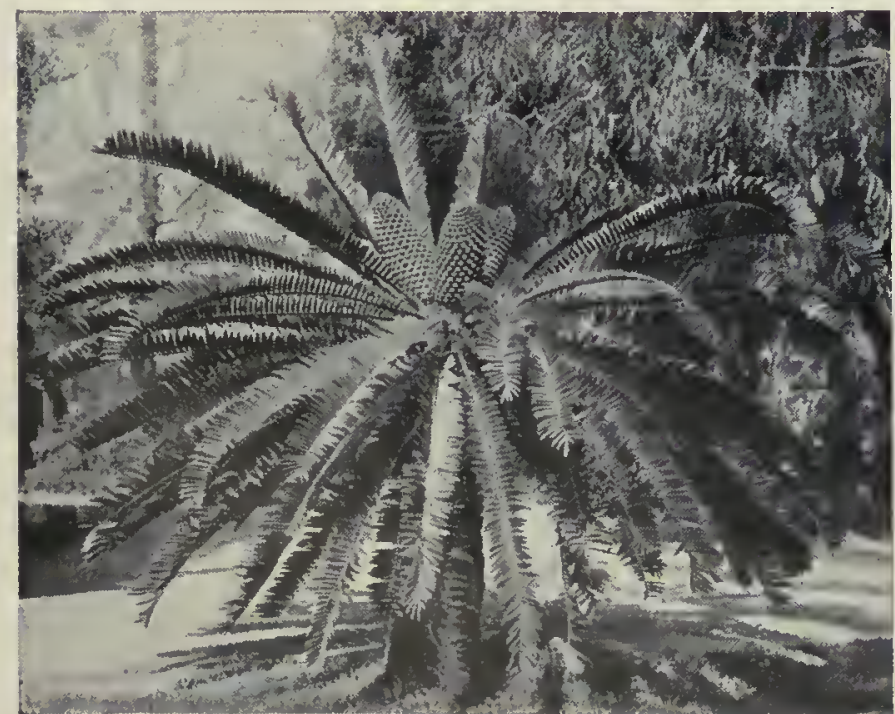

Encéphalartos d'Attenstein (Afrique mèridionate). plantes sont dioïques. Les fleurs femelles sont solitaires au sommet d'un petit axe; autour de la base de l'ovule se développe un disque membraneux, en forme d'arille, qui devient pulpeux, rouge.

Natrices. - Le Ginkgo bilobé, type de la famille des Ginkginées, a des feuilles pétiolées dont le limbe s'élargit en éventail, échancré au milieu; ces feuilles tombent chaque automne, mais deviennent, au préalable, d'un beau jaune d'or, et c'est à ce moment que cet arbre curieux du Japon mérite le nom qu'on lui a donné d'arbre aux quarante écus. Les deux sexes sont normalement séparés, mais Decaisne, ancien professeur de culture au Muséum, a fait greffer un sexe sur l'autre, de manière à avoir ainsi un pied monoïque : on peut le voir dans le Jardin des Plantes, à Paris. Grâce à cette opération, on peut récolter des graines qui ne se dćvelopperaient pas sans cela. La graine a une enveloppe charnue à sa partie périphérique, ligneuse intérieurement ; elle a donc tout à fait l'aspect d'une drupe: en réalité c'est une graine nue.

Les Cycadées constituent une seconde famille du groupe des Natrices. L'aspect d'un Cycas, d'un Encephalartos ou d'un Zamia rappelle celui du Palmier. Les feuilles ont 2 à 3 mètres de long et deux rangs de fermes folioles de part et d'autre du pétiole. Les fleurs sont de deux sexes et sur deux pieds différents. Dans les ovules, on trouve un sac embryonnaire qui, en se développant, produit un prothalle femelle dans lequel se développent deux ou trois archégones, mais le col est rudimentaire. Les étamines naissent de même au sommet des tiges et sont formées de feuilles dépourvues de folioles: leur pollen. en germant, donne naissance à deux gros anthérozoïdes couverts à leur surface de poils disposés en spirale; ces petits corps sont susceptibles de se mouvoir à l'intćrieur du boyau pollinique, puis d'en sortir et de pénétrer dans l'archégone, puis dans l'oosphère pour la féconder.

Famille des Gnétacées. - La famille des Gnétacées est caractérisée par l'existence d'un ovaire clos; ce caractère les rapproche des Angiospermes, mais il ne s'y forme jamais de style. Cette famille se réduit à trois genres : Welwitschie, Gnète et Ephèdre. Les Éphèdres sont des arbrisseaux d'Europe dépourvus de feuilles vertes, mais à bractées et dont le port rappelle celui des Prêles. Les Gnètes sont des plantes ligneuses volubiles d'Afrique et d'Amérique tropicale. Enfin la Welwitschic admirable (fig. 168) est caractéristique de l'Afrique australe, dans le désert de Kalahari et dans l'Angola; ses deux énormes feuilles alternent avec les cotylédons et sont étalées sur le sol; les inflorescences sont des épis rapprochés en grappes de 30 centimètres de haut, insérées sur la tige au-dessus des deux feuilles.

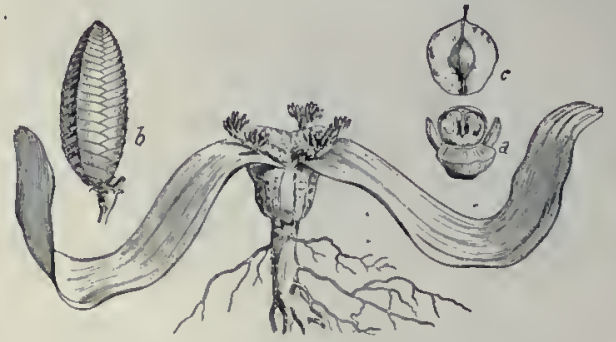

Fig. 168. - Welwitschie (réd. 62 fois). $a$, fleur; $b$, fruit ; $c$, sraine. 


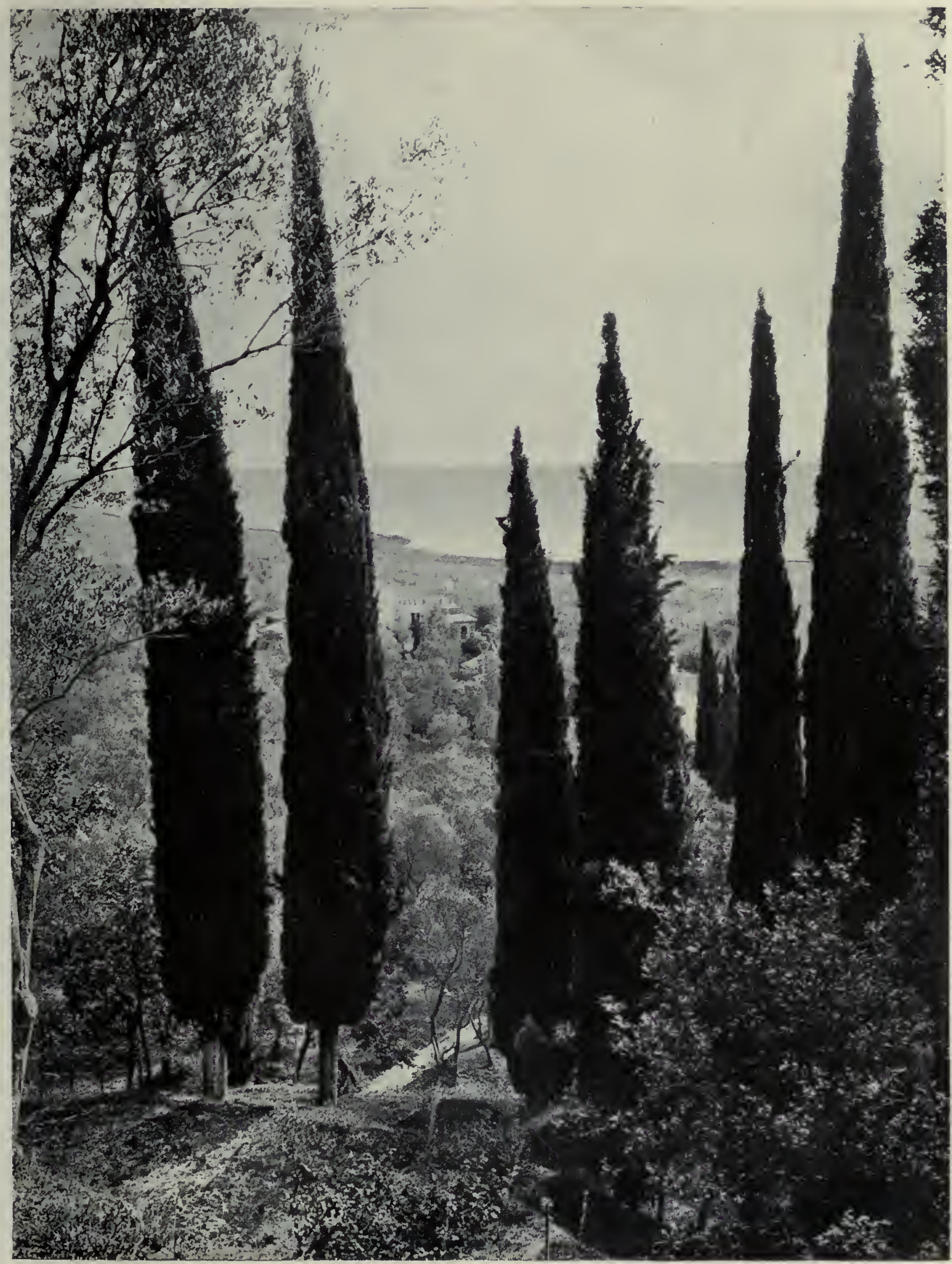

Vegesatiunsbilder.

CYPRES (CUPRESSUS SEMPERVIRENS), SUR LES BORDS DU LAC DE GARDE. 



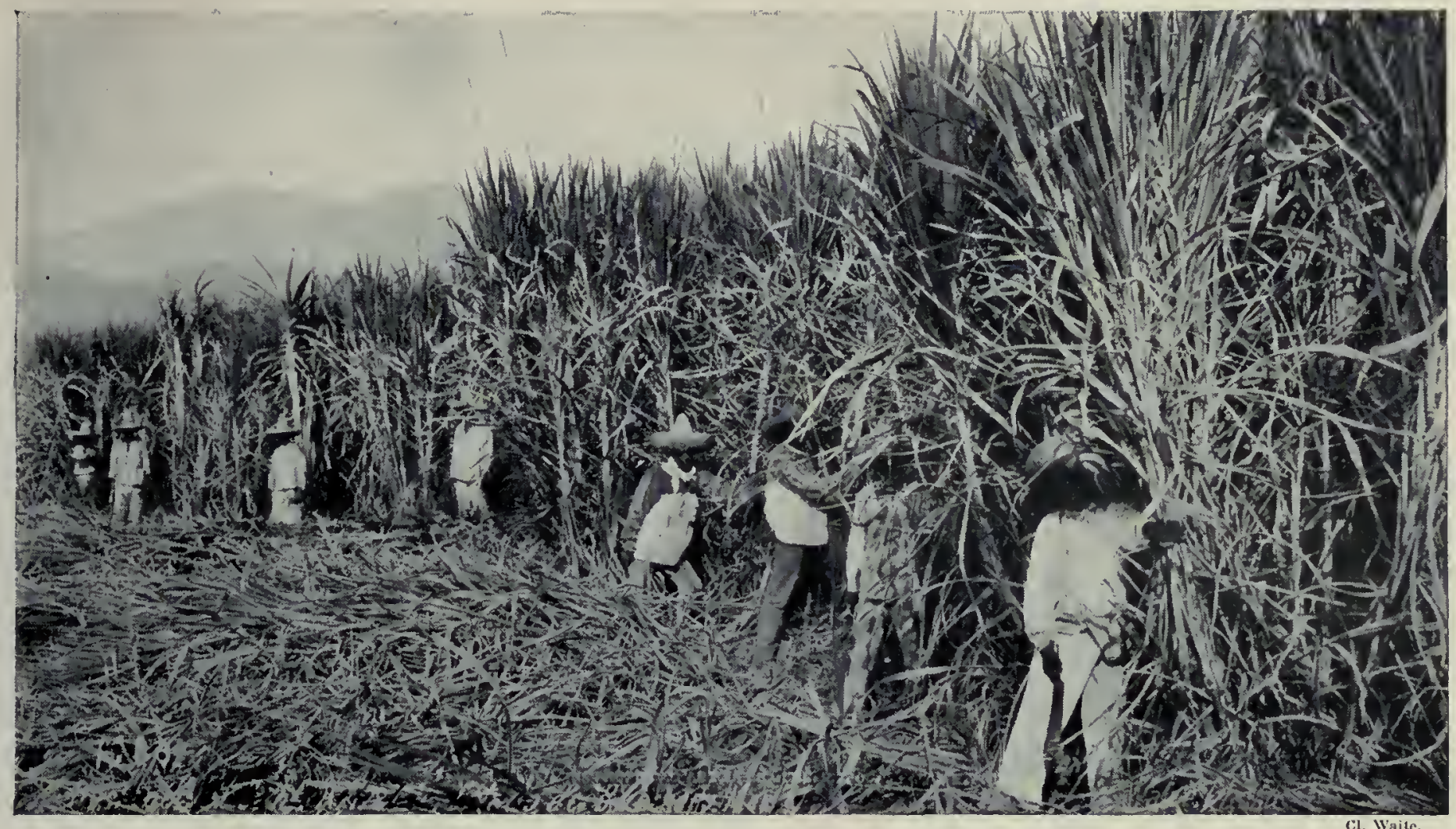

RECOLTE DE LA CANNE A SUCRE A ASLIXTAC (MEXIQUE).

\section{IV. - MONOCOTYLÉDONES}

Les Phanérogames Angiospermes se distinguent des Gymnospermes par l'existence d'un ovaire clos, surmonté d'un style et d'un stigmate: d'où le nom de Stigmatées. On les divise en deux classes: les Monocotylédones, dont l'embryon enfermé dans la graine porte un seul cotylédon, et les Dicotylédones, qui ont deux cotylédons. On divise les Monocotylédones en quatre ordres : $1^{\circ}$ les Graminidées, qui n'ont pas de corolle; leur ovaire est libre; $2^{\circ}$ les Joncinćes, qui ont ulie corolle verte et un ovaire libre; $3^{\circ}$ les Liliinées, à corolle colorée et ovaire libre; $4^{\circ}$ les Iridinées, à corolle colorée et ovaire adhérent. Chacun de ces ordres comprend plusieurs familles dont les principales sont les Graminées, les Palmiers, les Liliacées, les Iridacées et les Orchidées, autour desquelles nous en grouperons d'autres plus modestes.

\section{LES GRAMINIDÉES}

Caractères des Graminées. - Les Graminées constituent le principal groupe de l'ordre des Graminidées. C'est une famille d'une immense importance pour l'humanité, car les hommes peuvent être classés en mangeurs de pain, mangeurs de maïs, mangeurs de riz, mangeurs de millet, de sorgho, de tocusso, de teff, etc. Les dimensions des Graminées sont très variables: les Bambous atteignent 30 mètres et plus; la Mibora du printemps, qui croît sur nos murs et'sur le sol, n'a que quelques centimètres de hauteur.

Prenons le Blé (fig. 169, 170) comme exemple pour faire comprendre les caractères de cette grande famille dont les représentants sont surtout développés dans les pays septentrionaux. La tige forme ce que l'on appelle un chaume, c'est-à-dire qu'elle est creuse, sauf aux nouds, qui sont traversés par l'entre-croisement des faisceaux, ce qui leur donne une certaine solidité; cette tige, bien que très grêle, est renforcée par les matières minérales, surtout la silice qui se trouve dans ses tissus superficiels. A la suite des orages, ces chaumes sont fréquemment couchés sur le sol, mais, grâce à l'action de la pesanteur sur les nœuds, qui présentent une croissance tardive à la partie inférieure de la tige, la plante peut se redresser, ce qui est très important pour la culture des cćréales. La ra-

cine principale se détruit de bonne heure; mais les racines adventives se multiplient surtout sur la tige couchée, et l'opération du roulage sert à les faire naître; elle amène aussi le tollage et l'abondante ramification de la plante.

Les feuilles, très spéciales, sont sur deux rangs, alternativement à droite et à gauche de la tige ou distiques; elles présentent une longue gaine fendue qui entoure tout un entre-nœud de la tige; il n y a pas de pétiole et le limbe est étroit, à nervures parallèles; il présente à sa base, à l'endroit où il se sépare de la gaine, une petite lamelle souvent déchiquetée que l'on appelle la ligule. L'inflorescence est composée, formée d'un épi de petits épis appelés épillets; chaque épillet sattache sur la tige primaire du Blé à l'endroit où cette tige présente un cran; cet axe secondaire débute par deux bractées disposées transversalement à droite et à gauche, par rapport au pédoncule général de l'épi: on les appelle les glumes. Elles cachent à leur intérieur un certain nombre de

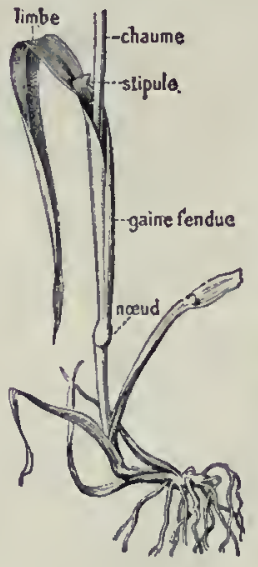

Fig. 169.

Chaume et feuille du Blé.

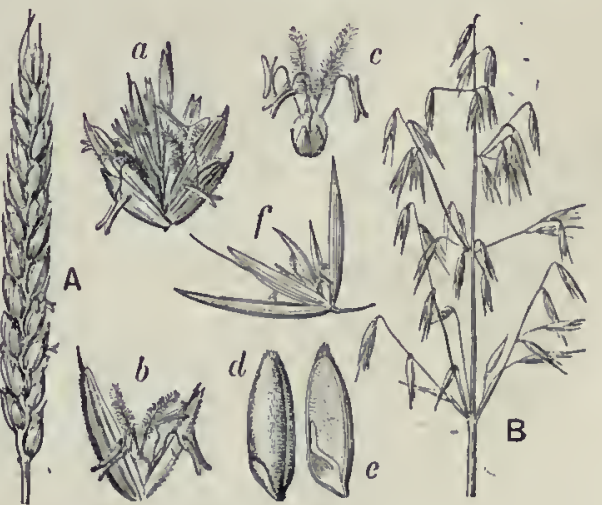

Fig. 170. - A. Bté (épi).

$a$ Épillet; $b$, Fleur isolée; $c$, Fleur dépouillée des glumelles; $d$. Graine; $e$, Coupe de la graine

$B$, Avoine (grappe d'épittets) : $f$. Épillet. 


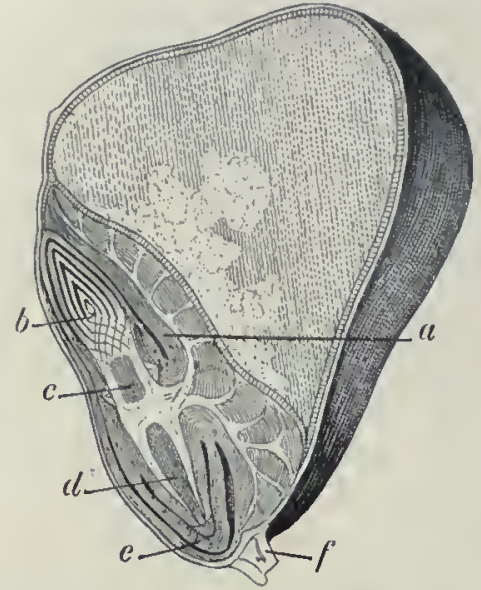

Fig. 171. - Section fongitudinale d'un grain de Mais.

$a$, Cotylédon; $b$, Gemmule; $c$, Tigelle ; $d$, Radicule; $e$, Gaine formée aux dépens de la tige: $f$, Funieule.

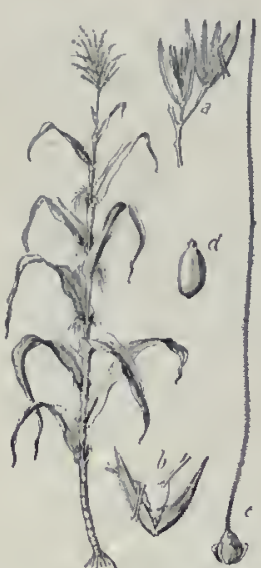

Fig. 172. - Téosintc.

$a$, Épillet mâle; $b$, Fleur màle; c, Fleur femelle; d, Graine.

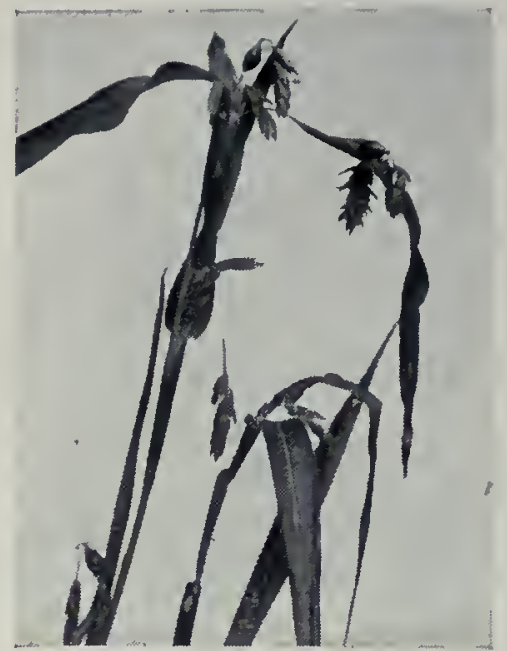

Larmes de Job (Coix laeryma).

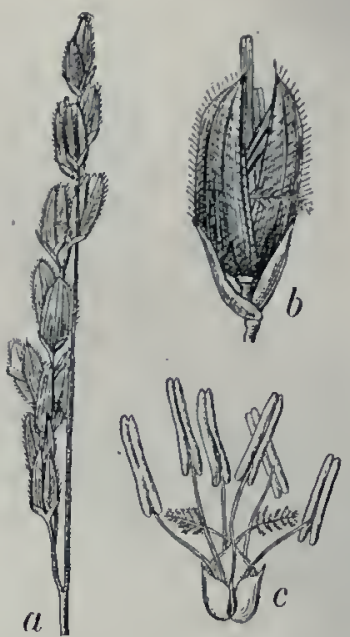

Fig. 173. - Riz ordinaire. $a$, Inflorescence; $b$, Èpillet ; bractées nouvelles (trois à cinq) appelées glumelles inférieures, à une carène, qui naissent toutes à la base d'axes tertiaires qui supportent chacun une fleur. C'est sur ces axes tertiaires que se rencontrent successivement, en s'éloignant de la base : la glumelle supérieure, bicarénée; deux très petites bractées, appelées glumellules, qui représentent le rudiment du périanthe; trois étamines à anthères oscillantes en $x$ et un pistil surmonté de deux longs stigmates plumeux qui servent à récolter le pollen comme des balais, car ces plantes sont fécondées par le vent; l'ovaire est à une seule loge; il contient un seul ovule. Ce que l'on appelle vulgairement le grain de Blé, c'est un caryopse, c'est-à-dire un fruit à une seule graine faisant corps avec lui par soudure; quand on le coupe longitudinalement, on voit qu'il contient une quantité considérable d'albumen amylacé qui est inséré de côté, et à la base se trouve l'embryon, relativement petit. Cet albumen si volumineux est l'origine de toutes les applications alimentaires de cette famille. L'embryon est très singulier; il présente une large feuille, appelée écusson, qui s'applique contre l'albumen et, à sa base, contourne et entoure la pointe de la partie axillaire; le petit corps de l'embryon présente deux singularités à ses deux extrémités : sa gemmule est entourée par une gaine membraneuse binervée qui, en s'épanouissant, devient incolore ou très légèrement verdâtre, parfois rouge, et que l'on appelle la pilćole; à sa base, il y a un étui que doit percer la radicule pour sortir, car elle se trouve emprisonnée au début dans la tigelle. A l'opposite de l'écusson se trouve une petite lame, qui manque parfois, par exemple, dans le Maïs (fig. $|7|$ ), et qui est un deuxième cotylédon rudimentaire: cette particularité fait placer les Graminées parmi les Dicotylédones dans certaines classifications.

La famille des Graminées comprend deux subdivisions principales, les Panicinées et les Poacinées : dans les premières,

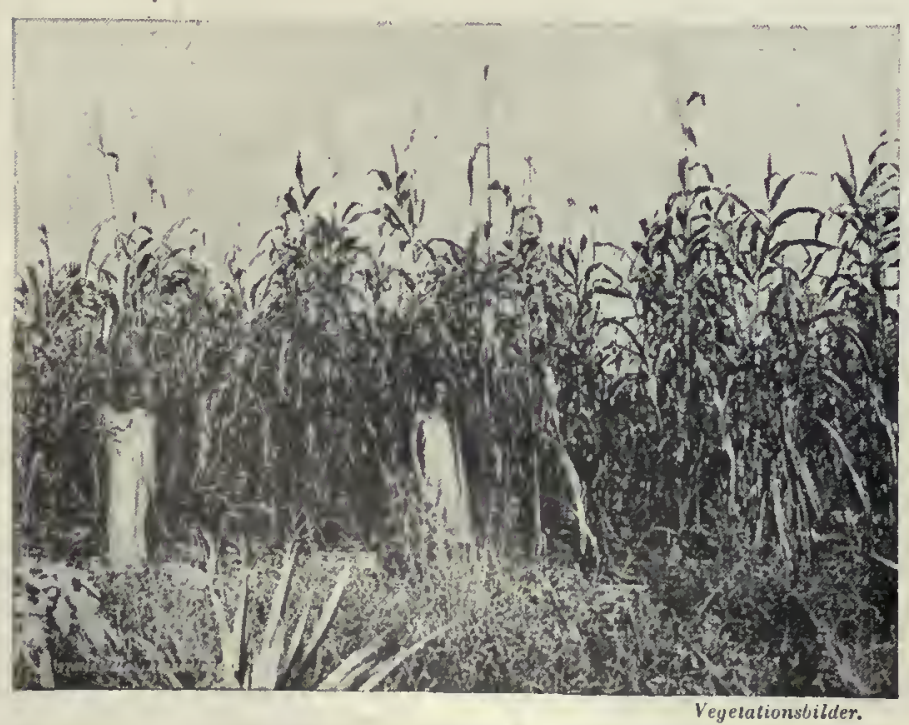

Culture du Sorgho en Afrique orientale. l'épillet est articulé au-dessous des glumes et les fleurs inféricures sont stériles; dans les secondes, l'épillet est articulé au-dessus des glumes et les fleurs supéricures sont stériles.

$$
\begin{aligned}
& \text { PANICINÉES } \\
& \text { Fleurs à sexes séporés. ............... Maydées. }
\end{aligned}
$$

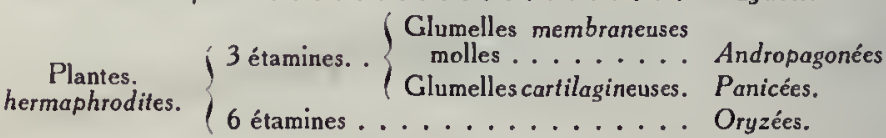

$$
\begin{aligned}
& \text { POACINÉES }
\end{aligned}
$$

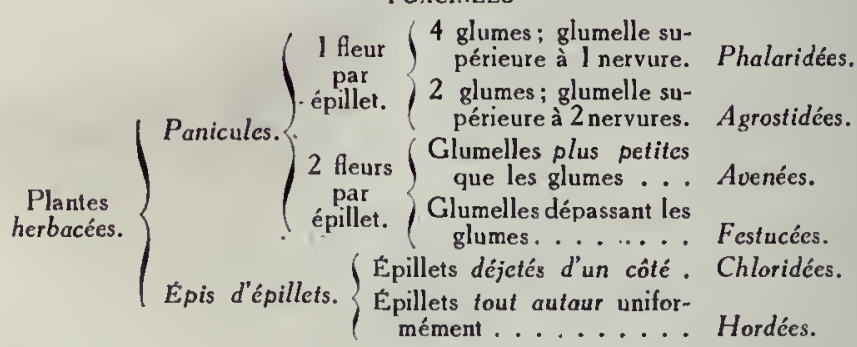$$
\text { Planles ligneuses .................. Bambusées. }
$$

Maydées. - Les Maydées sont caractérisées par le Maïs (Zea). Il y a, dans cette Graminée d'origine américaine, une panicule très ramifiée terminale de fleurs mâles et des épis latéraux de fleurs femelles, très serrés, sur lesquels les grains restent juxtaposés au moment de la maturité. Les variétés de cette plante sont très nombreuses; il y en a qui atteignent des tailles gigantesques : tel est, en particulier, le Maïs denl de cheval, cultivé au Pérou, et le Moîs de Jala, qui, au voisinage du village de ce nom au Mexique, au pied du volcan Ceboruco, atteint 6 mètres de haut. Comme de juste, cette plante s'est propagée en Europe et sur tout le globe; l'ltalie notamment l'utilise en quantité, en vue de la production d'une semoule qui donne la polenla, consommée par toutes les classes.

Le téosinte ou reana, Euchlène mexicoin (fig. 172), est une plante fourragère importante des pays chauds. Elle est très voisine du Maïs et certains natifs de l'Amérique centrale croient même que c'est la plante mère du Maïs, car cette dernière espèce cultivée n'est pas connue à l'état sauvage. Le téosinte se différencie du Maïs, parce qu'il a plusieurs épis femelles libres grêles, tombant en articles : le Maïs semble donc être un Euchlène avec fasciation de la partie femelle.

Les Lormes de Job ou Coix appartiennent au même groupe que le Maïs, mais l'épi mâle est simple et terminal; i] devient femelle à sa partie inférieure. C'est une plante de l'Asie, de la Nouvelle-Guinée et de la Po'ynésie, qui est cultivée par certaines tribus de l'Inde et de la Birmanie comme plante alimentairc.

Andropogonées. - Ce groupe se distingue du précédent par ses fleurs hermaphrodites, mais s'en approche par la consistance molle et membraneuse de ses glumelles. C'est là que se range la Canne à sucre (Saccharum officinarum,) originaire de l'Asie et de l'archipel de la Sonde. C'est dans la moelle de la 


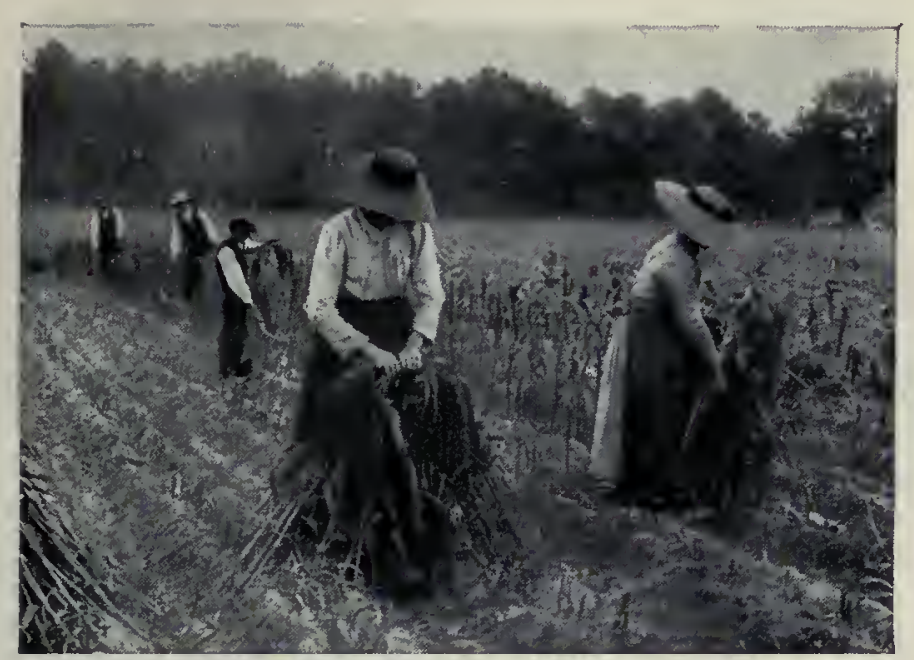

Confection des gerbes de Millet.

tige que se trouve cette matière sucrée qui est l'objet maintenant d'une si grande exploitation dans toutes les régions tropicales. La tige a une hauteur de I", 50 à 5 mètres et un diamètre de 4 centimètres; elle présente des articles nettement accusés quand elle est débarrassée de ses feuilles. Elle se termine par une grande panicule soyeuse, blanche, appelée flèche, en forme de pyramide de 30 à 90 centimètres. Les glumes sont entourées de poils persistants.

Une autre Andropogonée très importante est le Sorgho vulgaire, qui se distingue de la Canne à sucre par l'existence de panicules lâches, de 15 à 20 centimètres de long, plusieurs fois ramifiés, avec des verticilles de longs rameaux eux-mêmes ramifiés; les dernières ramifications portent des épillets trijumeaux uniflores. A la maturité, on voit les grains, isolés ou par deux, recouverts par les glumes diversement colorées sur les dernières ramifications de l'inflorescence, constituant ainsi ce que l'on appelle Blé de Cafrerie, gros mil, Millet indien, Doura. Le Sorgho est l'objet d'une très vaste culture dans toutes les contrées tropicales africaines et asiatiques; les graines sont converties en pain; elles servent à faire de la bouillie, de la semoule, du couscous et une bière appelée pouh.

Panicées. - Le groupe des Panicées se distingue du précédent par ses glumelles, qui sont de consistance cartilagineuse au lieu d'être molles. Dans la sous-tribu des Panicées entrent les Panics et les Paspalum. Dans les premiers, il y a trois glumes, une fleur hermaphrodite et aussi une fleur mâle; il n'y a que deux glumes et une fleur hermaphrodite dans les Paspalum. Le Panic miliacé est surtout connu sous le nom de Millet à grappe. On cultive cette plante dans le sud de l'Europe, dans le nord de l'Asie; les graines peuvent servir à la nourriture de l'homme; on les emploie aussi à l'alimentation de la volaille. Le Panic Burghu est une plante très importante de la région de Tombouctou. Les grains du Paspalum à longue fleur se mangent au Soudan et en haute Gambie, sous le nom de fonio.

Dans le genre précédent, les épillets n'étaient pas enveloppés; il y a, au contraire, une enveloppe dans le Pennisete typhoide sous forme de soies ou d'épines, qui sont des brac- tées stériles. Le nom vulgaire de cette plante est celui de Petit mil; ce qui le caractérise, c'est son inflorescence qui est très serrée, en forme d"épi cylindrique : d'où le nom de Mil à chandelle, qu'on lui donne quelquefois, ou de Pénicillaire en épi. Les grains sont utilisés dans l'alimentation.

Oryzées. - La sous-tribu des Oryzées est caractérisée par un hile allongé linéaire, tandis qüil est punctiforme dans toutes les graines qui viennent d'être énumérées. $\mathrm{Ce}$ quidistingue surtout le $R_{i z}$ (Oryza, fig. 173), c'est d'avoir des fleurs à six étamines, au lieu de trois que l'on observe dans presque toutes les Graminées. L'importance de cette plante est considérable ; on a pu direque 54 pour 100 des habitants du globe étaient des mangeurs

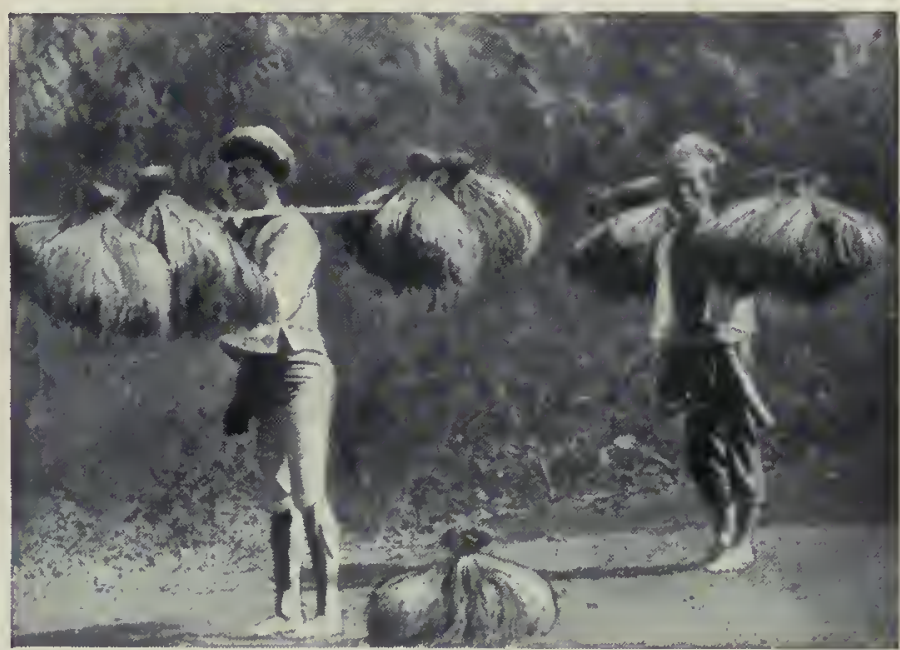

Porteurs de gerbes de Riz, à Java.

de riz. Sa culture se fait surtout dans les régions tropicales, mais elle peut réussir plus au nord, au Japon, au sud des États-Unis ; elle est également connue dans le midi de l'Europe et il y a dans la vallée du Pô des cultures importantes. Le Riz se trouve à l'état sauvage dans les marais de l'Indochine et de la Chine. C'est en rizières, c'est-à-dire en terrains inondés, que la culture a lieu. Le Riz de montagne, qui est cultivé dans les altitudes élevées et aussi au Japon et en diverses régions où la saison des pluies est longue, est au contraire un type qui est obtenu en terrain sec; il est particulièrement cultivé par les populations à demi sauvages du haut Tonkin. Une autre variété curieuse à mentionner est le Paddy flottant, cultivé notamment au Siam, en Indochine, dans la province de Chandoc; on l'utilise quand l'inondation atteint 2 mètres et plus de haut. II pousse avec une grande rapidité au moment de la montée des eaux, de 5 centimètres par jour, et prend ses éléments nutritifs non dans la terre, mais dans l'eau. La hauteur de sa tige peut être de 6 à 8 mètres.

Les feuilles de la Lygée spart, de la région méditerranéenne, servent en sparterie.

Phalaridées, Agrostidées. - Si nous passons maintenant à la tribu des Poacinées, nous rencontrons surtout les plantes vulgaires qui constituent les fourrages ou les herbes de nos prairies. Dans la première sous-tribu, celle des Phalaridées, nous signalerons le Phalaris arondinacé, qui croît dans les lieux humides, et dont les belles et grandes inflorescences servent pour les bouquets perpétuels. Une espèce voisine est le Phalaris des Canaries ou Alpiste, plante annuelle à panicule assez serrée, ovoïde, qui est cultivée dans les jardins pour la nourriture des oiseaux de volière.

L'Anthoxanthe ou Flouve odorante est une plante de ce groupe

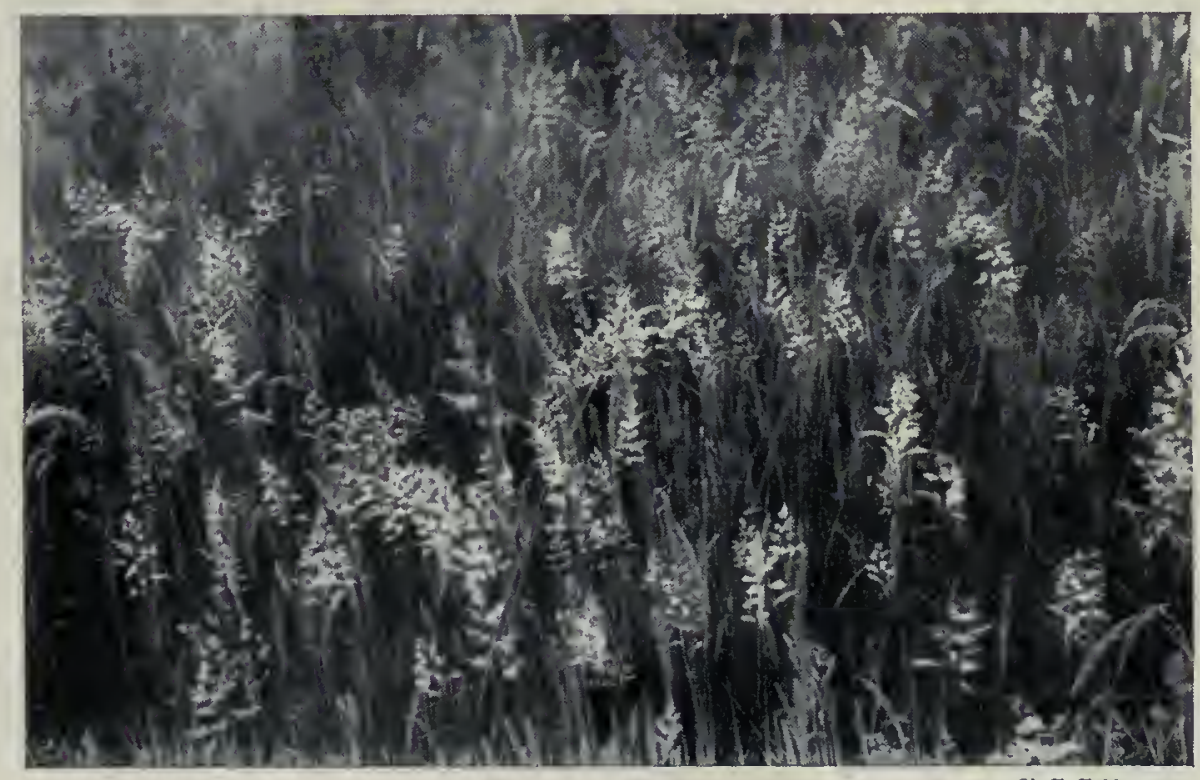

Panicules d'Agrostide dans un pré. 


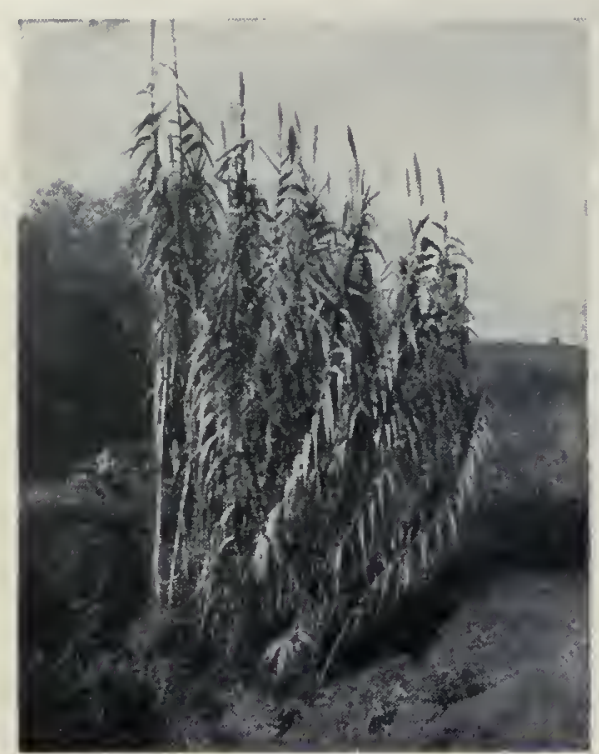

Arundo ou Caune de Provence.

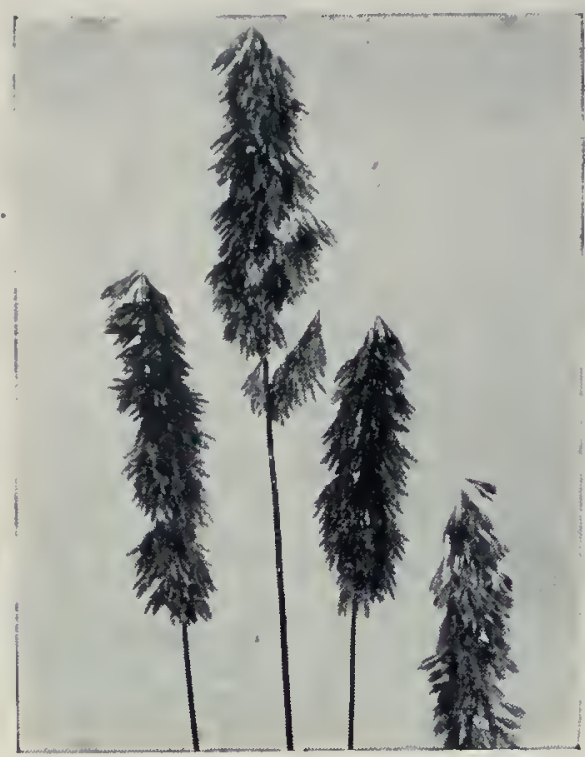

Lamarckie dorée.

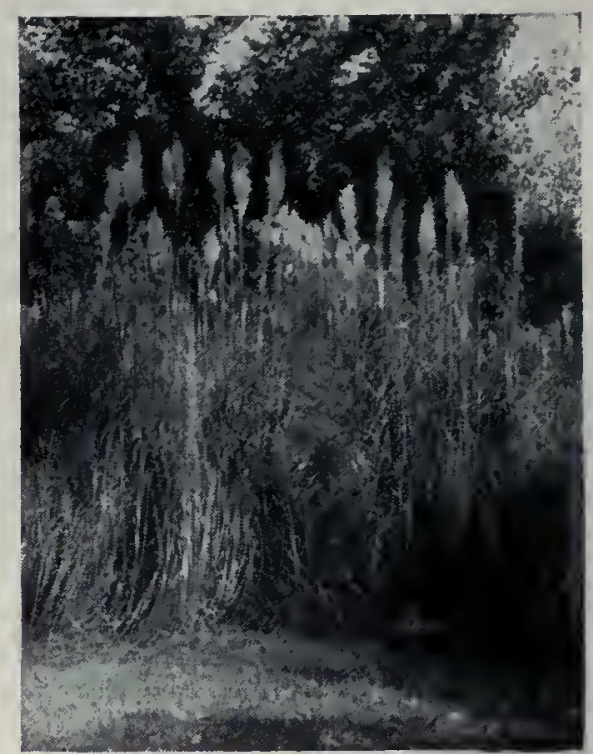

Gynérie ou Herbe des Pampas.

qui doit son nom à la forte odeur de pain d'épice de ses racines et qui se distingue aisément de toutes les Graminées par la présence de deux étamines seulement dans chaque fleur.

Dans les Agrostidées se classent les Agrostides, à panicule très lâche et très légère; les Phleum ou Fléoles et les $A$ lopecurus ou Vulpins, à panicule contraclée et serrée de façon à simuler une sorte d'épi terminal ; les Mibora, etc. Dans les Phleum, les glumes sont séparées; elles sont au contraire soudées dans les Alopecurus. C'est à ce même groupe quappartient le Stipa très tenace ou Alfa, espèce vivace spontanée de la région méditerranéenne, qui couvre en Algérie des surfaces considérables, de 5 à 6 millions d'hectares, constituant ce qu'on appelle la mer d'Alfa, notamment dans la province d'Oran; on exploite les feuilles de cette plante, qui est arrachée et exportée surtout en Angleterre pour l'industrie du papier. 11 y a en Tunisie une surface d'environ 1500000 hectares qui sont occupés par l'alfa, utilisé pour faire des cordages, des nattes, des paniers. Les Stipa se reconnaissent à l'allongement exagéré que présente l'extrémité plumeuse de la glumelle inférieure.

Une autre Agrostidée est le Lagure ovale, désigné vulgairement sous le nom de "gros minet ", dont l'inflorescence a l'aspect d'un épi ovoïde, garni de longs poils mous, blancs, soyeux, et qui est utilisé pour les bouquets secs.

Avenées, Festucées. - Les Avenées ont de grandes glumes dépassant les glumelles; les $F$ estucées ont des glumes petites dépassées par les glumelles.

Au premier groupe se rattache l'Avoine qui, parmi les Céréales de grande culture répandues partout dans les pays froids, se distingue tout de suite par son inflorescence formant une ample panicule très lầche, se terminant à son extrémité par des épillets légers, très nombreux et ainsi bien nettement séparés les uns des autres. C'est une culture appropriée pour les terrains pauvres et qui résiste mieux à un temps humide que les autres Céréales. A côté des Avoines se trouvent les Houques, molles et laineuses, à gaines poilues, et les Trisètes, qui sont des plantes de prairies.

Le groupe des Festucées est caractérisé par des épillets saillant nettement hors des glumes et formés de fleurs nombreuses, en général. Deux cas peuvent se présenter, suivant que les glumes sont plus petites que les fleurs ou au moins égales. Dans le premier cas rentrent les principales Graminées de prairies. D'abord les Bromes, dont les glumelles sont pourvues à leur extrémité d'une arête, ne s insérant pas au sommet, mais sur le dos et un peu au-dessous de la

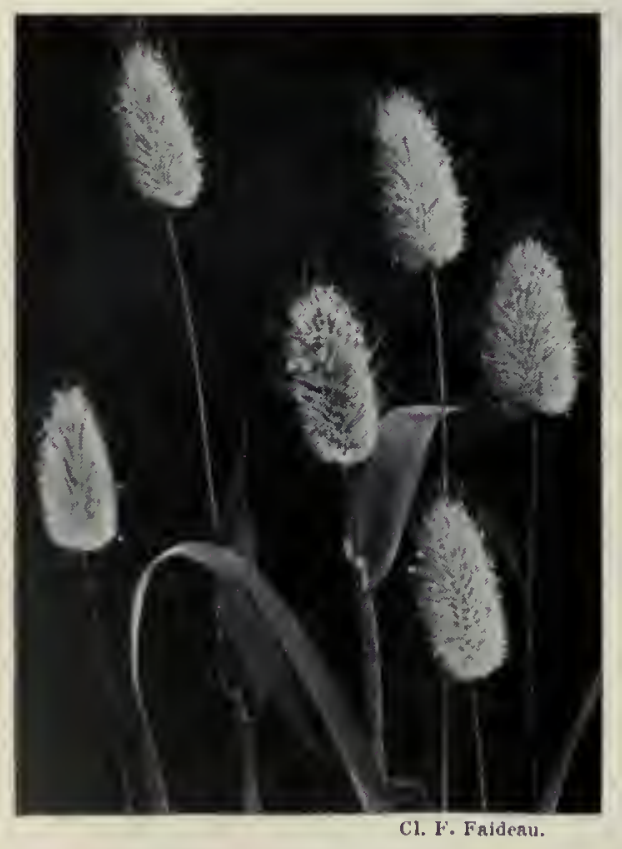

Inflorescences du Lagure ovale. pointe. Dans les Brizes et les Dactyles, l'arête de la glumelle fait défaut, mais l'épillet est très différent. Il est comprimé latéralement en forme de cœur chez les premières, et comme ces épillets, assez gros, sont portés sur une panicule lâche et délicate, il en résulte que les fleurs de ces plantes sont toujours en mouvement au moindre souffle de vent: d'ou le nom de langue de femme qu'on leur donne parfois. Les Dactyles agglomérés ont des épillets disposés, au contraire, en une masse compacte, mais sont d'ordinaire orientés d'un côté. Dans les trois genres: Poa ou Pâturin, Fétuque et Glycéric, les épillets sont groupés en panicule très lâche, mais ils sont étroits et allongés et non en forme de cœur. Dans les Pâturins, les glumelles sont carénées sur le dos et peu pointues ; dans les Fétuques, les glumelles sont arrondies dorsalement et pointues au sommet; dans les Glycéries, qui vivent souvent au bord des eaux, les glumelles sont aussi arrondies sur le dos; le sommet n'est pas aigu, mais obtus, arrondi. Signalons enfin, comme types voisins les Koleries ou Fausse Fléole, à épi lâche et à axe de la tige poilu, et la Lamarckic dorée, jolie Graminée de la région méditerranéenne.

Le second type de Festucées comprend des plantes qui ont toutes des glumes plus grandes ou au moins égales aux fleurs. C'est dans ce groupe que se place la Gynéric argentée ou Herbe des pampas, Herbe à plumet, qui est très répandue dans les jardins : cest une plante vivace, qui présente à sa base une touffe de feuilles étroites, très longues, retombant gracieusement au sommet, et c'est au milieu de cette touffe qu'apparaissent de longues hampes de 2 mètres de haut et plus, portant une grande panicule soyeuse argentée, très ornementale; c'est une plante dioïque, et les pieds mâles sont à plumets plus volumineux et plus légers.

Les Arundo sont également de très grandes Graminées; l"Arundo Donax de l'Europe méridionale peut atteindre 4 et 5 mètres de haut: c'est un Roseau utile pour fixer les terrains mouvants dans le Midi; les tiges sont utilisées pour faire des clôtures, des paniers, des treillages, des abris; c'est également une plante ornementale. Les Phragmites communs ou Roseaux à balais habitent le bord des cours d'eau. Le $P$ oa d'Abyssinic ou T ef est une Graminée annuelle, cultivée par les Abyssins et les Gallas, entre 1700 et 2800 mètres d'altitude, comme céréale, car elle constitue la principale partie de la nourriture de ces populations; elles s'en servent pour fabriquer un pain d'un goût agréable et acidulé.

Chloridées, Hordées. - La soustribu des Chloridées comprend le Cynodon Dactyle ou Chiendent, qui présente plusieurs épis d'épillets partant du même point ; 


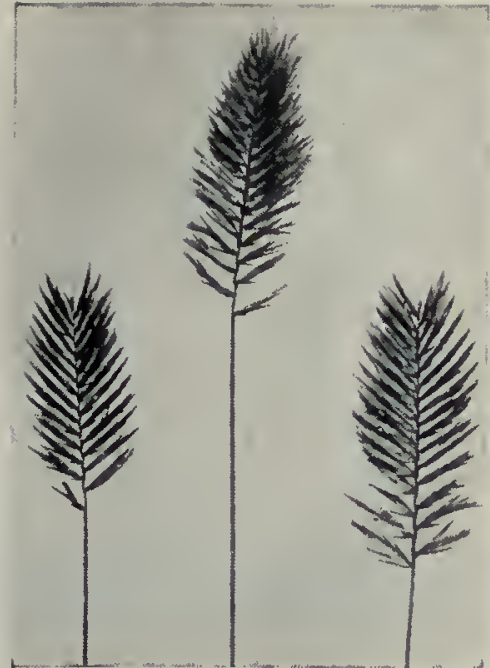

Agropyre à crète. le rhizome, qui a des renflements, est utilisé en herboristerie. Cette même tribu renferme l'Eleusine Coracona, ou Tocusso d'Abyssinie, dont les grains sont utilisés par les classes pauvres de l'Inde quand le Riz vient à manquer.

La sous-tribu des Hordées se distingue par l'existence d'un épi d'épillets serré, unique, terminant le chaume. C'est ce groupe qui renferme, avec quelques herbes de prairies: l'Agropyre rompant ou Chiendent, les céréales les plus importantes, le Blé(fig. 174) oú Froment (Trilicum), l'Orge (Hordeum), le Seigle (Secale). Les céréales sont sujettes à plusieurs redoutables maladies cryptogamiques : rouille, carie, charbon, piétin. La classification des Blés peut être résumée par le tableau ci-dessous:
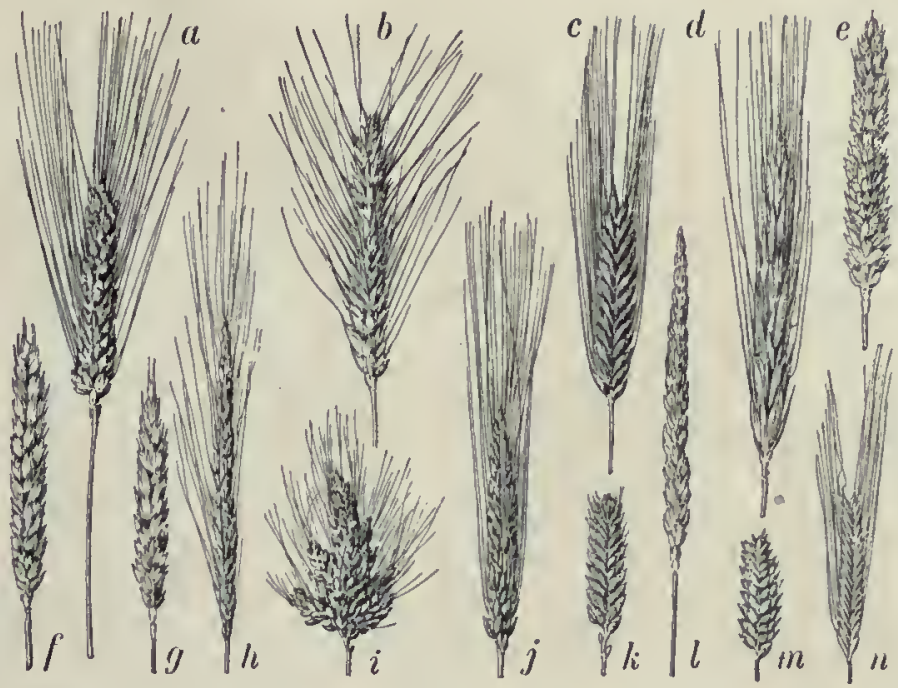

Fig. 174. - Espéces et races de Blé.

$a$ Nonnette de Lausanne; $b$, d'Automne rouge; $c$, Amidonnicr noir ; $d$ de Polosne; $e$, Victoria d'automne: $f$ Blanc de F tandre : Richelle de Naples: $h$, Épeautre blanc barbu; $i$, Blé de miracle; $i$. Poulard blanc lisse; $k$, Carré de Sicile; l, Epeautre blanc sans barbe; $m$, du Chili; $n$, Engrain.

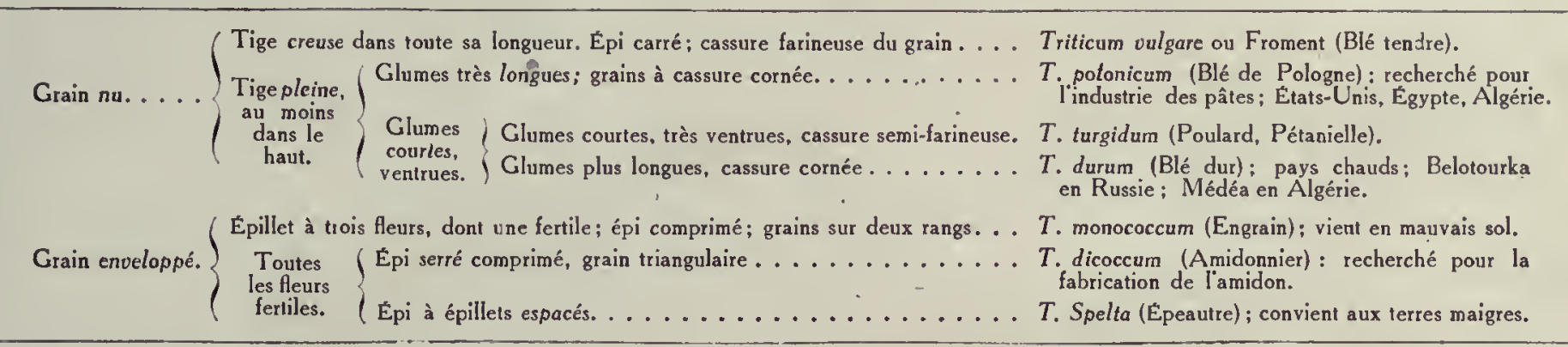

Le Seigle est une céréale qui se rapproche du Blé par ses glumes: elles sont aplaties, non ventrues; il y a, comme dans le Blé, un seul épillet inséré sur chaque cran de l'axe. La farine du Seigle contient peu de gluten; elle a une saveur particulière; le pain fabriqué avec elle est grisâtre, gluant, nourrissant, mais un peu laxatif. Le méteil est un mélange de Seigle et de Blé en proportions égales que l'on utilise dans les campagnes pour le pain de ménage.

L'Orge se distingue des deux céréales précédentes, Blé et Seigle, par la présence de trois épillets sur chaque cran de l'axe floral; les épillets médians sont seuls fertiles; ils sont flanqués, de part et d'autre. d'épillets stériles. On distingue l'Orge hexastique, à six rangs d'épillets ou Escourgeon, et l'Orge distique, à deux rangs d'épillets ou Paumelle.

Mentionnons enfin le genre IUraie (Lolium), qui est caractérisé par le fait que les épis sont grêles, ne se recouvrant qu incomplètement les uns les autres et qüil niy a qu une glume à la base. Une espèce de ce genre est importante, c'est l'Iuraie vivace, ou Ray-grass des Anglais, qui est un des types les plus répandus parmi les Graminées utiles au point de vue des pâturages. Un Champignon existe d'une manière normale dans la graine de l'luraie eniurante, espèce annuelle trop commune dans les moissons.

Bambusées. - Les Bombusées se distinguent tout de suite

par la tige ligneuse, qui peut devenir arborescente et atteindre 20 à 30 mètres, et par les feuilles pétiolées. Il y a deux types, suivant que la fleur a six étamines (Bambous, Gigantochloa) ou trois étamines (Phyllostachys, Arondinaires). Dans les Bambous, les étamines sont à filets libres, soudés dans les Gigantochloa. Citons le Gigonlochloo maxima de Java, qui peut atteindre 46 mètres de haut; il

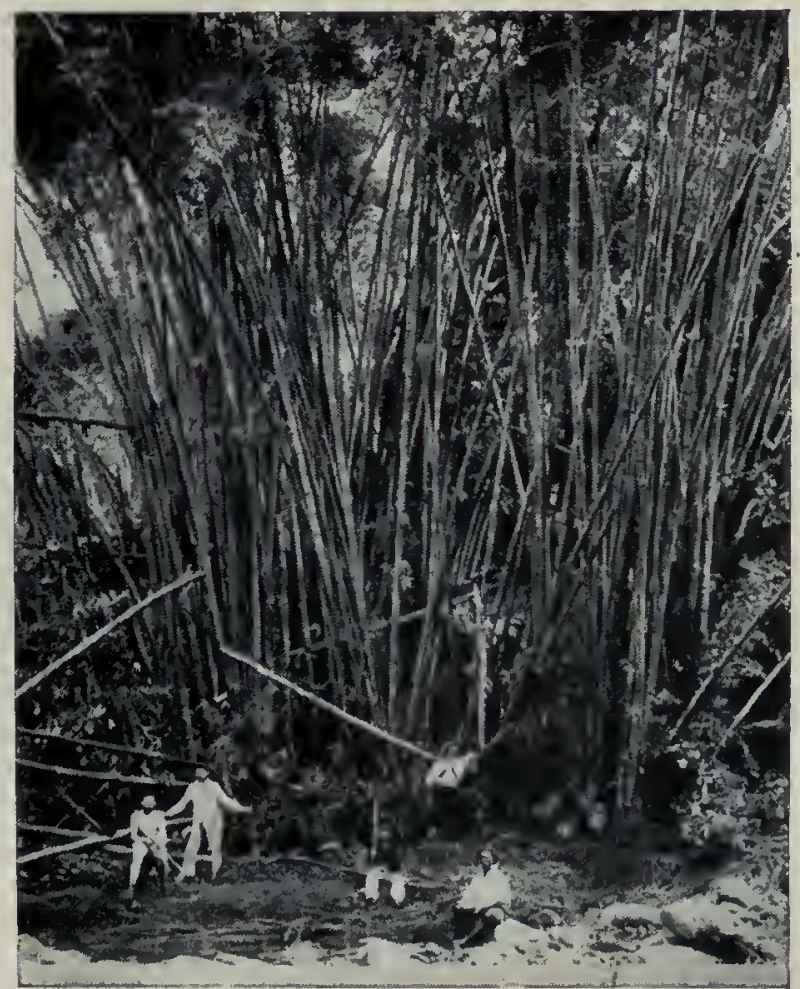

Taillis de Bambous (Guadeloupe). sélève dans les régions montagneuses et croît avec une étonnante rapidité de 12 mètres en trois mois : on sait que ces plantes peuvent sallonger de 50 centimètres en une nuit ; les jeunes pousses fournissent un légume. Parmi les autres espèces

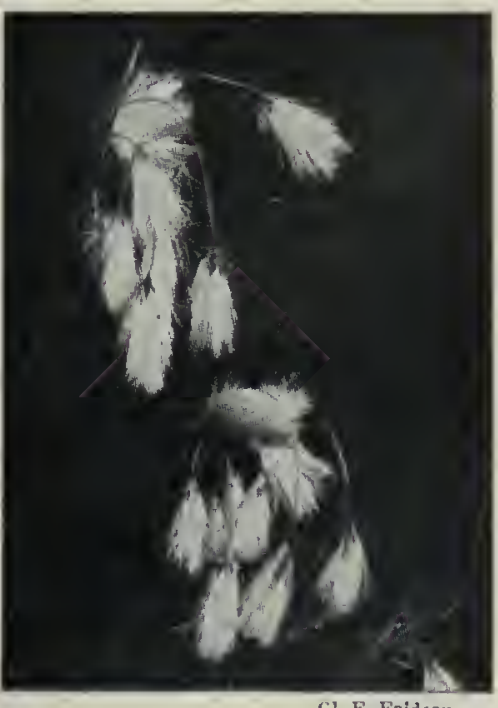

Épis de Linaigrette. 


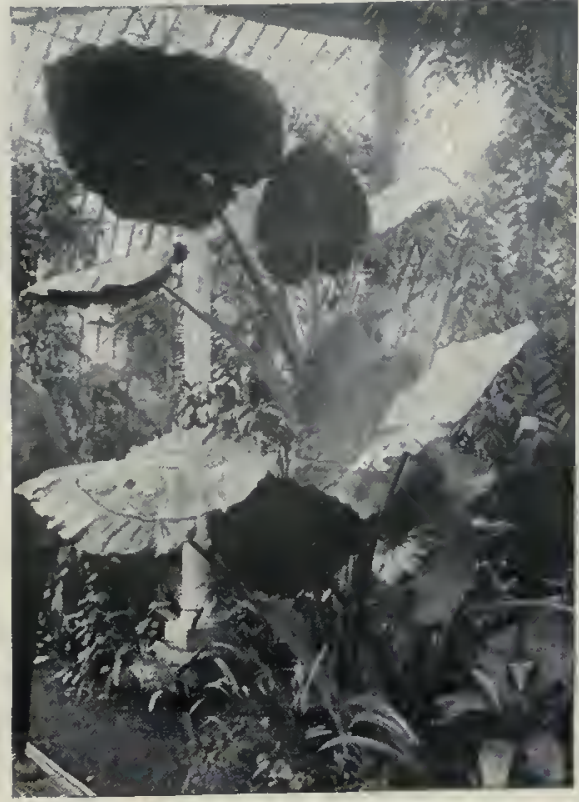

Alocase à gros rhizome, en serre.

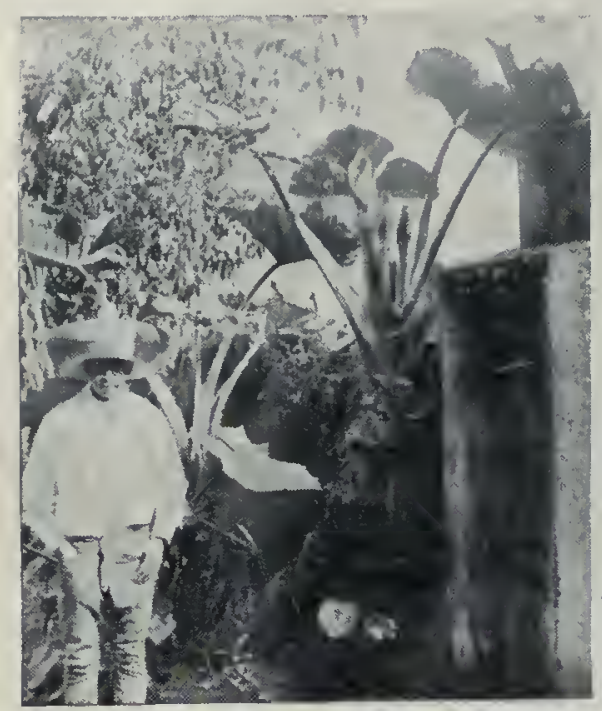

Cl. Diguet.

Caladium au Mexique.

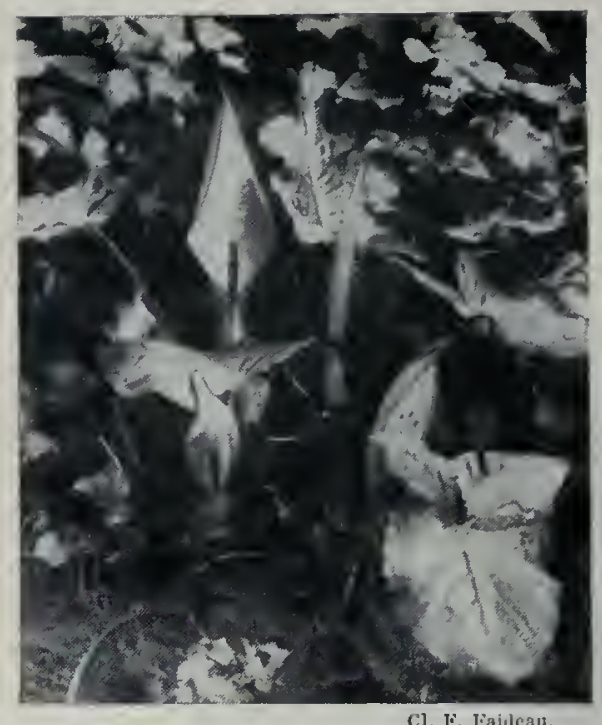

Arum tacheté, en fleurs. alimentaires, on peut citer le Bambou de Senam qui est consommé par toutes les classes au Japon, le Phyllostachys doré qui est cultivé en Chine, jusqu au nord de la grande muraille, et au Japon. L'Arondinaire doux est mangé quelquefois au Japon, mais est amer et inférieur; le Phyllostachys à grand chaume réussit en Algérie. Les Arondinaires forment de très belles plantes qui sont employées comme les Bambous pour faire des touffes sur les pelouses ou encore pour garnir les jardins d'hiver.

Cypéracées. - L'ordre des Graminidées comprend, en plus des Graminées, les familles suivantes : Cypéracées et Lemna cées (albumen amylacé), Naiiadacées (albumen nul), Aroïdées, Typhacées et Pandanées (albumen charnu).

Les Cypéracées sont terrestres, mais aiment cependant les stations marécageuses, et il est même des espèces tout à fait aquatiques comme les Scirpes lacustres. Tandis que dans les Graminées la tige est ronde et la gaine foliaire fendue, ici, la section de la tige est triangulaire et la gaine n'est pas fendue. Le fruit n'est plus un caryopse, comme dans les céréales, mais un akène.

Dans les Carex, les fleurs ont les sexes séparés, d'ordinaire réunis sur un seul pied avec un épi mâle vers le haut et les épis femelles sur les côtés; la fleur femelle présente une utricule qui est

une grande bractée bicarénée qui entoure l'ovaire en forme de sac et à la partie supérieure de laquelle sortent deux ou trois stigmates. La fleur mâle a d'ordinaire trois étamines.

Dans les autres Cypéracées, les fleurs sont hermaphrodites. Dans les Souchets (Cyperus), les écailles et les fleurs de l'épi sont sur deux rangs, et leur ensemble a été comparé à une natte. Le Souchet comestible a un rhizome de la grosseur d'une noisette, dont on consomme d'énormes quantités à Madrid (Chuffa). C'est avec les tiges du Souchet papyrus, découpées en tranches, que les anciens et particulièrement les Egyptiens fabriquaient le papier célèbre connu sous le nom de papyrus.

Dans les Scirpées, les écailles de l'épi sont en spirale. Parmi ce groupe, on peut citer les Eriophores ou Linaigrettes, qui abondent dans les régions marécageuses, notamment dans les toundras des régions polaires, où leurs épis à aigrettes blanches, dues à la subdivision du calice en une multitude de poils blancs, contribuent à égayer ces plaines un peu tristes. Une autre espèce curieuse est I Helecharis tabéreux ou le Pit'si des Chinois, plante qui ne fleurit jamais, dont les tubercules sont bons à manger et se cultivent dans l'eau comme le Riz.

Lemnacées. - Chez les Lemnacées, l’appareil végétatif est singulièrement réduit par suite de la vie nageante qui les caractérise. Ce sont les Lemna ou Lentilles d'eau qui se développent souvent si abondamment sur les étangs qu'elles forment un tapis vert cachant complètement la surface du liquide. Le thalle est une lame verte ovale se ramifiant dans son plan; il pend à la partie inférieure des racines à courte croissance qui servent de balanciers. Ces racines peuvent même manquer dans la $W_{\text {olt }}$ fia (p. 71). L'atrophie du système radiculaire, qui est si complet dans cette famille, est ébauchée dans les Lemna, car la radicule avorte; la Wolffia est presque une plante à thalle.

Naïadacées. - Les Nä̈adacées méritent une mention spéciale, parce qu'elles comprennent les quelques Phanérogames vivant dans les eaux de la mer. On rencontre très abondam. ment sur certaines côtes des Zostères, qui ont de longuss feuilles vertes rubanées; on les y observe avec les Posidonies, les Cymodoces et les Ruppies maritimes. Les fleurs sont unisexuées et d'ailleurs très réduites. Un autre type de Naïadacées est plus communément répandu dans les eaux douces courantes ou stagnantes, c'est le Potamot, dont les feuilles peuvent être toutes submergées (Potamot 


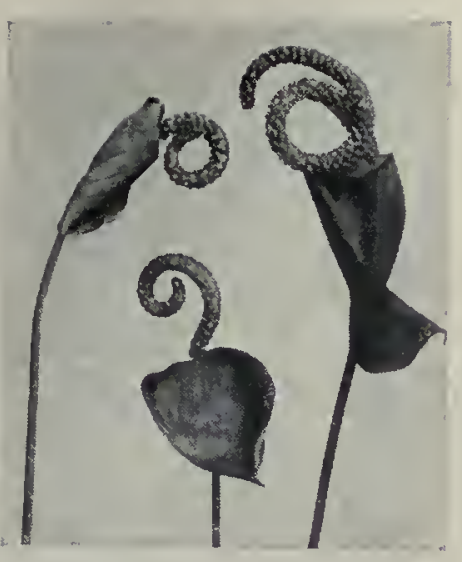

Anthurium de Scherzer.

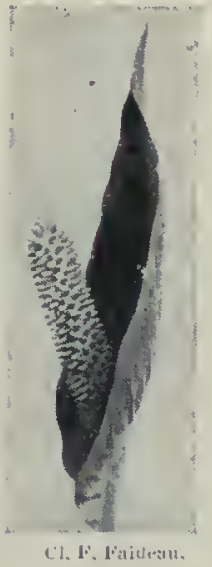

Spathiphylle.

crispé) ou dont les supérieures (Potamot nageant) viennent s'étaler à la surface du liquide. Les fleurs des Potamots sont hermaphrodites et présentent quatre étamines qui sont soudées à quatre appendices simulant des sépales ; il y a d'ailleurs quatre carpelles indépendants à un seul ovule chacun. Les Aponogeton sont de jolies plantes dont certaines sont cultivées dans les pièces d'eau des serres; d'autres en plein air.

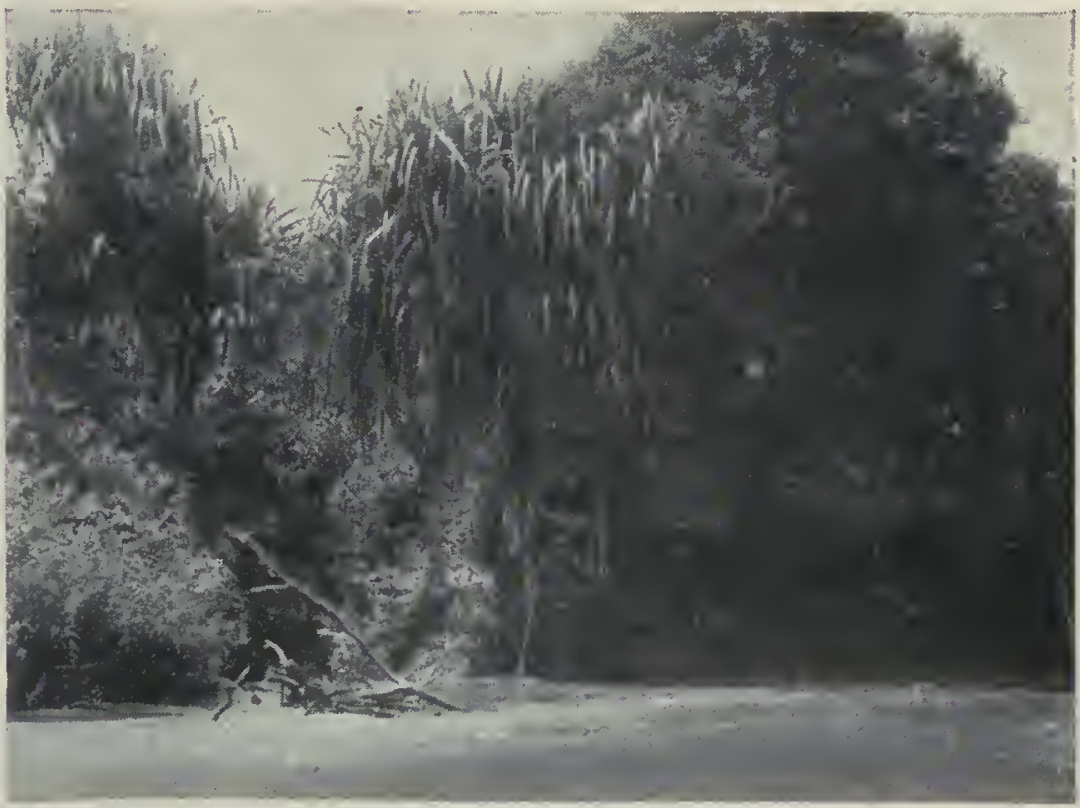

Vaquois ou Pandanus en Nouvelle-Catédonie.

L'Ouvirandra fenestré de Madagascar est une plante aquatique curieuse dont le limbe est réduit aux nervures qui forment un quadrillage de fenêtre.

Aroïdées. - Les Aroïdées constituent une famille qui a peu de représentants dans la flore des pays froids, car dans nos environs nous ne connaissons guère que l'Arum tacheté ou Gouet, Pied de veau, Manteau de la Vierge, rattaché à ce groupe, mais dans les régions tropicales elles deviennent beaucoup plus importantes et constituent un grand groupe de plantes surtout épiphytes. Le Gouet est une plante terrestre dont la tige est cachée dans le sol, et il se manifeste par la formation de la hampe florale qui est caractéristique dans cette plante; elle présente à sa partie supérieure une grande feuille vert jaunâtre pâle, en cornet, ou spathe; elle contient le spadice, qui est un axe renflé en massue à sa partie terminale, et portant à des étages successifs, à partir du haut, des fleurs mâles, puis des fleurs femelles, ces deux étages étant précédés au-dessus chacun d'un étage de fleurs analogues plus ou moins avortées; les étamines sont nues, le pistil monocarpellé; le fruit est une baie.

Les Caladium, remarquables par leurs grandes feuilles longuement pétiolées, à limbe délicat en forme de flèche, panaché et brillamment coloré, servent à l'ornement des serres froides. Une autre plante, à feuilles beaucoup plus amples, à pétiole plus vigoureux, à grandes feuilles sagittées, arrondies, élargies, est la Colocase, qui sert à faire pendant l'été, en plein air, des corbeilles du plus bel effet. C'est une plante de l'Inde et surtout de l'Océanie, où on la connaît sous le nom de taro; elle est l'objet d'une culture extrêmement importante dans les sols vaseux et imbibés d'eau et fournit une fécule de premier ordre, qui est la base de l'alimentation des populations océaniennes. L'Alocase, dont la placentation est basilaire, est très voisin, mais inférieur au point de vue alimentaire. Les Xanthosomes, à feuilles sagittées, sont les plantes à " taro " d'Amérique; on consomme non seulement les tubercules, mais les feuilles comme les choux : d'où le nom de Chou caraïbe. Le Sauromatum (plante magique) des Indes et de Java est un superbe Arum dont le spadice, vivement coloré, atteint 0 "', 60 de longueur.

Les Pistia sont des Arö̈dées aquatiques; les Philodendres, les Dieffenbachia et les Pothos sont des plantes grimpantes fréquemment cultivées dans les serres. Les Amorphophalles ont d'énormes tubercules de la grosseur d'une tête d'homme. L'Amorphophalle campanulé est consommé en Asie, dans l'Inde, en Malaisic et à Tahiti; sa chair a une grande âcreté qui disparaît à la cuisson; l'Amorphophalle de Rivière est utilisé par les Japonais sous forme de vermicelle (chira-také), de galette (konnyakou), de gâteau sec (chiro-ko). On utilise en Afrique des espèces tuberculeuses voisines : ainsi l'Anchomanes difformeet plusieurs espèces d'Hydrosome. Les feuilles des Amorphophalles sont à segments très divisés; elles apparaissent à d'autres moments que la hampe florale.

Ce même caractère se retrouve dans les Dracuntium, dont les feuilles atteignent des dimensions gigantesques; leur pétiole, qui est tigré ct dont la surface rappelle une pcau de sirpent ou de dragon

(et c'est de là que vient leur nom générique), se dresse verticalement dans l'air, à une grande hauteur, plusieurs fois celle d'un homme, et se termine par un limbe découpé de telle façon, qu'on croirait avoir affaire à une tige couverte de feuilles; d'autre part, on peut voir sortir de terre, à un autre moment, une hampe florale portant une grande spathe, le tout de 1 mètre à $]^{\mathrm{m}}, 50$.

Le Monstère délicicux est une espèce de Lierre géant à feuilles découpées et à limbe perforé d'une manière singulière; la spathe est verte, caduque; le spadice est comestible; il comprend, au milieu, des fleurs hermaphrodites, en haut des fleurs mâles, en bas des fleurs femelles. Dans la Richardie africaine ou Zantedeschia, il y a une grande spathe blanche en forme de cornet évasé à sa partie supérieure; on utilise beaucoup cette plante pour la fleur coupée, car elle est très ornementale. La Richardic d'Elliot, semblable, a ses spathes jaunes. Les Calla ont aussi un épi de fleurs hermaphrodites; plusieurs espèces sont indigènes.

L'Acore odorant est une herbe de marais, originaire de l'Inde, mais naturalisée en Europe. Les plantes surtout importantes de ce dernier groupe sont les Anthurium, qui sont des herbes vivaces à tige ligneuse, en général courte, à feuilles en flèche, à lobes basilaires arrondis, surmontant un long pétiole; ces végétaux sont caractérisés par leurs spathes et leurs spadices qui sont d'ordinaire de couleur très vive, presque toujours rouge vif; la spathe se rabat le plus souvent vers le bas en s'étalant, de manière à laisser bien voir le spadice qui est fortement coloré, en rouge notamment, cylindrique, couvert de fleurs hermaphrodites, toutes fertiles. Ce sont des plantes de serres chaudes qui peuvent servir à l'ornementation des appartements. Les Sfathiphylles sont voisins.

Typhacées. - Les Typhacécs sont des herbes aquatiques de notre pays, dont les fleurs mâles sont groupées sur des épis distincts, séparés des épis femelles. Dans les Massettes ou Typha, les épis mâles cylindriques sont à l'extrémité de la tige; ils sont jaunes et formés de fleurs à trois sépales et trois étamines; l'épi femelle, qui est au-dessous des précédents, et séparé d’eux par autant de bractées, est également cylindrique et de couleur brune. Chacune des fleurs femelles qui le composent est à trois sépales, et le pistil est à un seul carpelle, avec un seul ovule. Dans les $R u b a-$ niers ou Sparganiers, les épis, au lieu d'être cylindriques, sont sphériques.

Pandanées. - Les épis mâles et femelles étaient réunis sur la même plante dans la famille précédente; dans les Vaquois ou Pandanus, ils sont sur des pieds différents. La fleur mâle est formée d'un grand nombre d'étamines à filets grêles; la fleur femelle, d'un grand nombre de carpelles fermés; les fruits sont des drupes. Les Vaquois sont des arbres à tige cylindrique, se ramifiant en fourche à plusieurs reprises à leur sommet; vers le bas, le tronc porte plusieurs étages de racines adventives qui se dirigent vers le sol et qui servent à consolider la plante. On connaît un autre genre de cette famille, les Freycinéties, espèces grimpantes. 


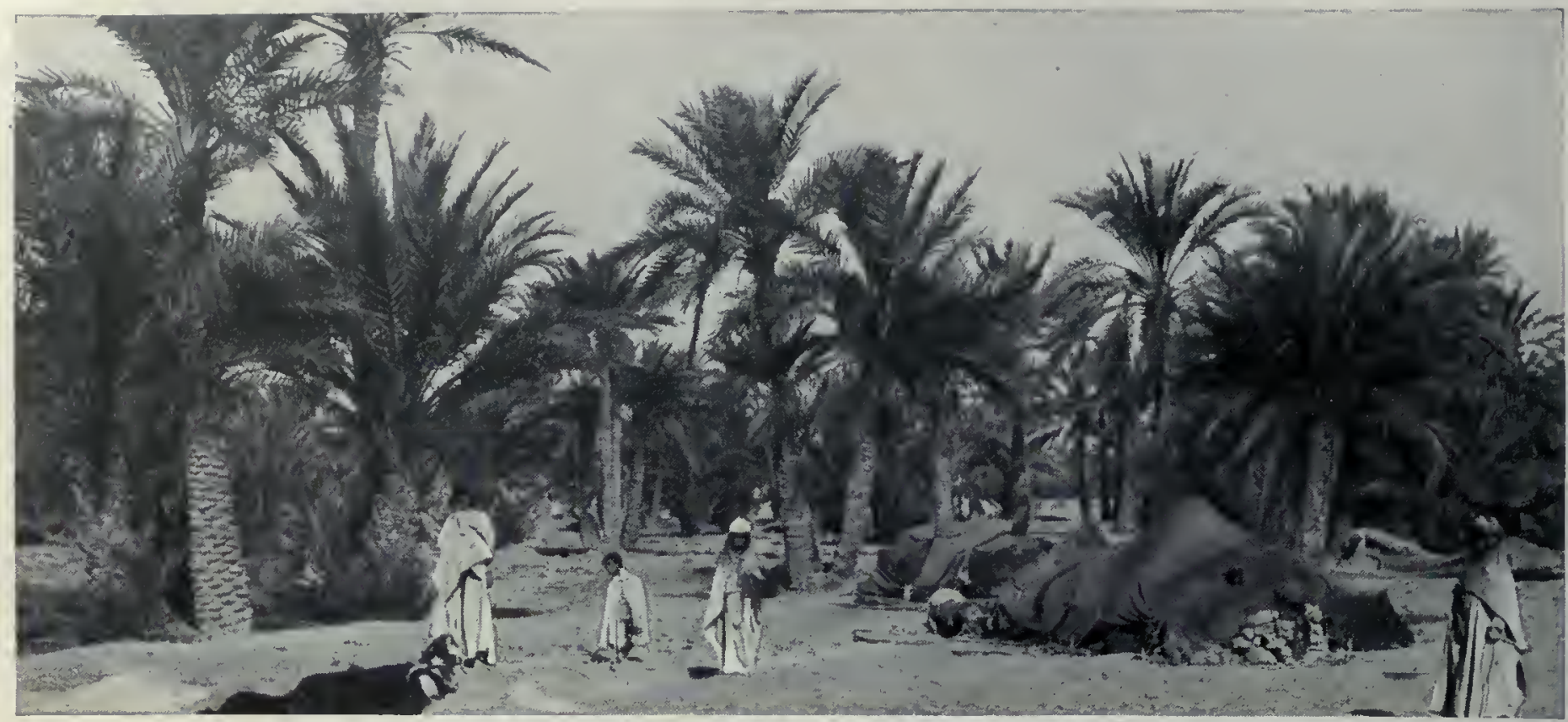

Un coin de l'oasis de Biskra (Algérie), avec Dattiers.

\section{LES JONCINEES}

L'ordre des Joncinées comprend trois familles : ${ }^{\circ}$ les Triglochinacées, plantes vivant sur le bord des eaux douces ou salées; la graine est sans albumen : tels sont les Triglochins ou Trocarts de nos marais; $2^{\circ}$ les Joncacées, herbes terrestres ou des lieux humides, à feuilles plates (Luzules) ou cylindriques (Joncs); l'albumen est charnu, le fruit est une capsule; $3^{\circ}$ enfin les Palmiers, plantes arborescentes que nous allons étudier en détail, et dont le fruit non capsulaire est le plus souvent charnu.

Utilité des Palmiers. - Les Palmiers constituent une des plus grandes familles du monde végétal tropical, méritant le premier rang par la beauté de leur port et par leurs nombreuses applications. Certaines espèces ont des usages si variés qu' un poème indien qui est consacré au Rondier ou Borassus énumère les huit cents façons dont cette plante peut être utile; les usages du Cocotier sont moins nombreux, car on prétend qu ils ne dépassent pas le nombre des jours de l'année. La tige fournit, comme de juste, du bois pour la charpente et des objets divers; les feuilles forment des toits; leurs fibres ou les lanières qu'on peut en extraire permettent de fabriquer des chapeaux, des paniers, des nattes. La sève fermentée, qui est sucrée, donne le vin de palme, et, pour l'extraire, on incise les inflorescences jeunes; naturellement, avant cette fermentation, on peut en retirer le sucre; en distillant ce vin, on obtient une eau-de-vie ou arack. Les fruits ont des usages variés; chacun connaît les dattes, les noix de coco, qui renferment le lait de coco, et l'albumen fournit une crème excellente pour la table. L'huile s'extrait des graines de diverses espèces, de l'Éléide de

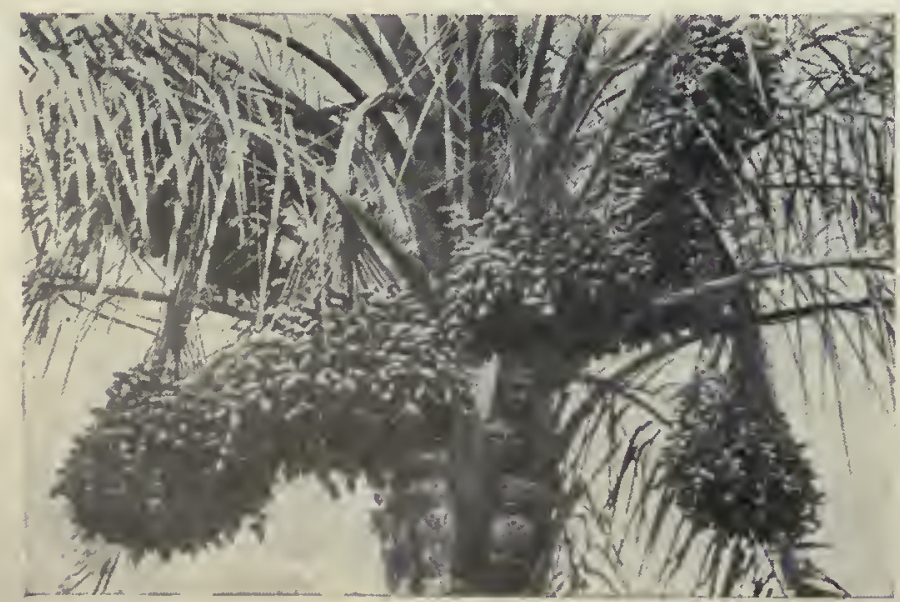

Dattier avec régimes de dattes.

Guinée notamment. Les fibres qui apparaissent sur la tige, après la chute des feuilles et la décomposition de leur base, servent à faire des balais, des tissus, etc. On comprend d'après cela que Linné ait pu qualifier les Palmiers de "princes " du règne végétal.

Organisation du Dattier. - Prenons comme exemple pour notre étude l'arbre le plus important pour notre colonie africaine l'Algérie, le Dattier. Son origine se perd dans la nuit des temps. Le nom grec du Palmier, qui est d'ailleurs conservé dans le nom latin et dans le nom employé par les botanistes, est celui de Phanix, et la Phénicie était le pays par excellence du Dattier.

Le Phonix dactylifère a un tronc élevé, restant simple, de 20 à 30 mètres dans sa patrie, souvent cespiteux (en groupe). Il est muni à sa base de racines adventives et il y présente également des rejets qui servent à multiplier les races qualifiées par leurs fruits délicats. Cet arbre vit 100 à 200 ans, continuant à produire chaque année sa récolte de dattes, bien qu'en avançant en âge la qualité devienne moins remarquable. Les feuilles, qui sont localisées à la partie supérieure en une magnifique couronne, sont composées pennées; les pinnules de 20 à 40 centimètres sont assez régulièrement distiques, souvent rćunies par deux ou trois; les bords de ces pinnules sont, surtout à la base, relevés vers le haut ; au début du développement, toutes ces parties maintenant distinctes étaient réunies entre elles; elles se sont fendues parallèlement, puis le pétiole a crû et elles ont été séparées; les pinnules inférieures sont en épines, fasciculées à la base. L'inforescence, de 30 à 60 centimètres de long, qui apparaît au milieu des feuilles et pend à la maturité, est ce qu'on appelle un régime (fig. 175, A); le pédoncule ou spadice est comprimé et ramifié; il est entouré à sa base par une grande bractée ligneuse, coriace, la spathe, emprison-

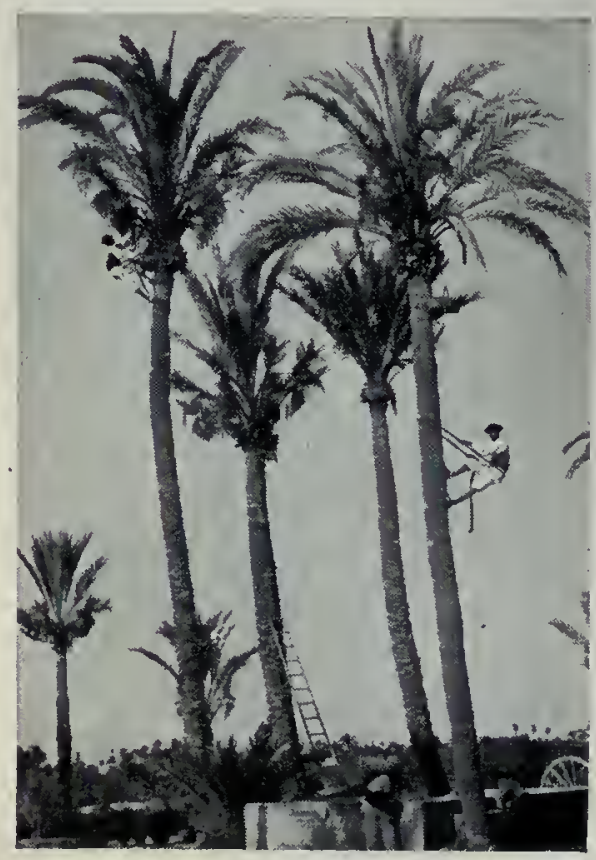

Récolte des dattes à Elche (Espagne). 
nant au début toute l'inflorescence et s'ouvrant plus tard. Les fleurs sont nombreuses, sessiles sur les divisions sinueuses de l'axe, relativement petites, unisexuées ( $f$ g. . 175, B et $C)$, et chaque sexe est sur un pied distinct ; la plante est dioïque : il y a des pieds mâles et des pieds femelles. Le nombre des pieds mâles dans une oasis est toujours restreint, puisquils ne sont cultivés que pour leur pollen, mais leur présence est indispensable. Les fleurs mâles ont un calice court, gamosćpale à trois dents, trois pétales beaucoup plus longs, épais, rigides, oblongs, lancéolés, à bords valvaires ou coupés en biseau, à l"intérieur six étamines en deux verticilles à filets courts, dont les anthères sont à déhiscence longitudinale; au centre se trouve un rudiment d'ovaire de forme variable, pouvant même manquer. La fleur femelle est presque sphérique, à trois sćpales soudés, à trois pétales larges, à six staminodes ou étamines avortées, parfois trois seulement, se développant alternativement avec

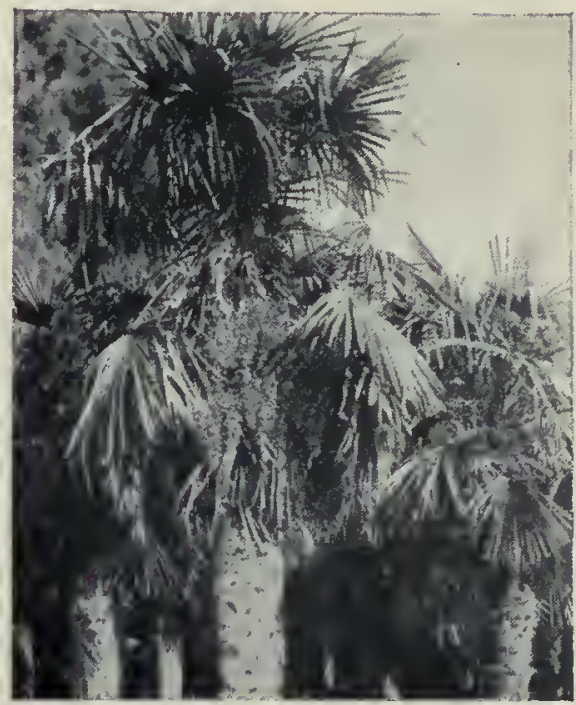

Un Trachycarpe avec fruits.

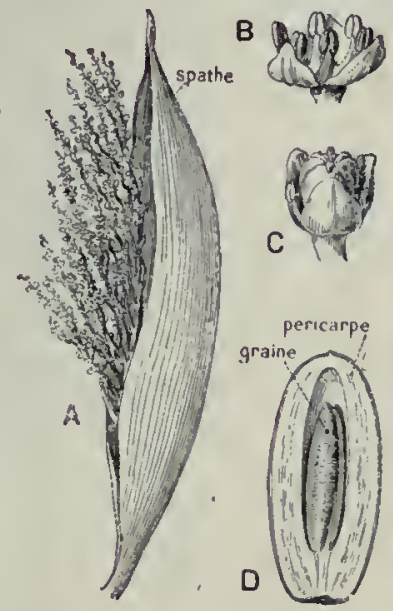

Fig. 175 .

A, Régime de fleurs femelles de Dattier; B, Fletur màle de Chamærops: C, Fleur femelle de Chamæ-

rops; $D$, Coupe d'une datte.

comprend trois carpelles alternan avec les pétales et présente trois ovaires indépendants, mais se touchant largement; le style est court, arqué en un bec crochu où se trouve la région stigmatique. Un seul carpelle se développe normalement, les deux autres sétant arrêtés dans leur croissance ou ayant disparu. Ce fruit charnu (fig. 175, D), brun jaunâtre ou brun rougeâtre à la maturité, est oblong, de 3 à 8 centimètres de long, à peau mince, à pulpe pâteuse, et sucrée surtout, délicieuse dans les variétés de premier ordre, comme dans le " deglet nour "): qui est le type sélectionné des oasis du sud de l'Algérie, et envié par tous les peuples qui veulent cultiver ce Palmier. Les variétés non sucrées servent de base à l'alimentation des Arabes; desséchées et aplaties, elles forment, placées dans des peaux de bouc, une sorte de pain utilisé par les caravanes pour traverser le désert. Une inflorescence peut donner deux cents dattes. La graine, qui est très dure, a un albumen corné contenant sa réserve sous la forme de membranes de cellulose épaisse. On extrait des Palmiers mâles (ou des Palmiers femelles à fruit médiocre) la sc̀ve pour faire un vin appelé lagmi.

Le Dattier est rustique dans tout le bassin méditerranéen, mais ses fruits ne mûrissent pas à Nice, pas plus que dans le nord de l'Algérie. Il faut à cette plante le soleil des tropiques et une grande humidité aux racines : "la tête dans le feu, les pieds dans l'eau ", dit le proverbe arabe. Les variétés fruitières sont innombrables, mais à peu près inconnues en France.

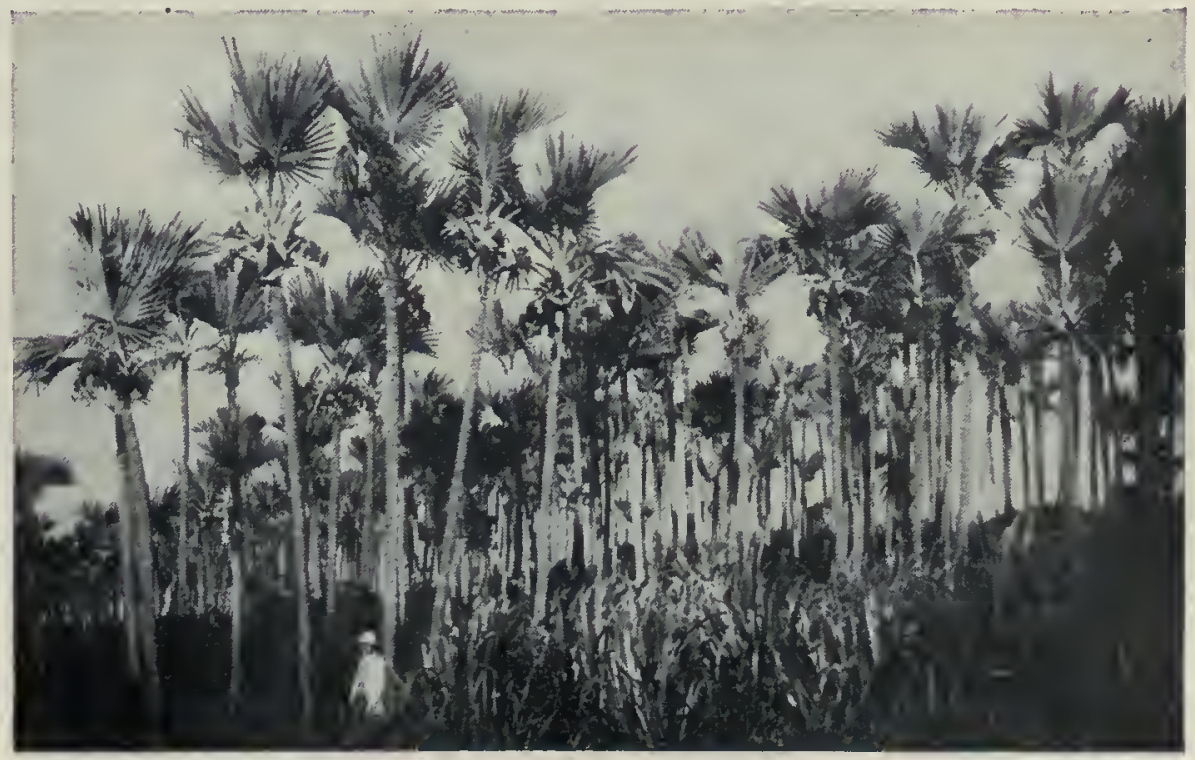

Livistona de Chine on Lataniers de Bourbon (ite de La Réunion). 


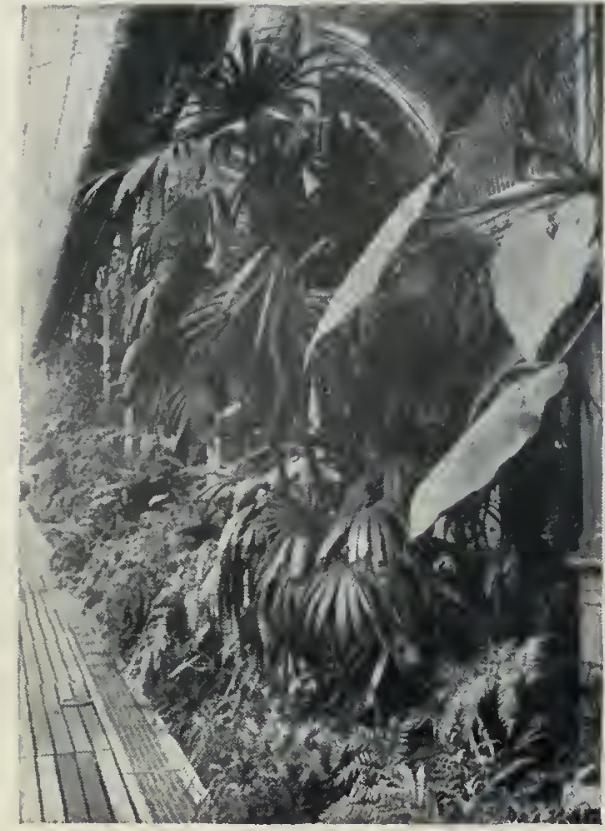

Rhapis flabelliforme de la Chine.

Coryphinées. - Le Dattier, caractérisé par ses carpelles lâchement soudés ou libres, se rattache par cette particularité aux Coryphinées, qui comprennent, en dehors des Dattiers dioíques précédents, un certain nombre de Palmiers polygames : ce sont les Sabalées, renfermant les genres Chamærops, Trachycarpus, Rhapis, Corypha, Livistona et Sabal, Washingtonia et Copernicia.

Les Chamarops, dont le nom veut dire buisson nain, sont de stature médiocre, à tige recouverte de débris filamenteux des gaines foliaires, à feuilles raides, semi-orbiculaires, à divisions palmées, et non pennées comme dans le Dattier, étroites, aiguës; le pétiole est biconvexe, à dents épineuses; les feuilles sont subdivisées en pinnules à une seule nervure. Ces plantes, bien qu'appartenant à un groupe crdinairement polygame, sont souvent dioïques; elles se distinguent des Dattiers, outre leurs feuilles, par des étamines soudées. Le Chamarops nain se développe en Espagne, aux Baléares, à Naples, en Grèce, dans le sud de la Corse; il ne dépasse pas Nice; c'est le représentant le plus septentrional de la famille des Palmiers dans l'Ancien Monde; en Europe il s'élève jusqu à $44^{\circ}$ de latitude nord. Le Chamærops nain, qui a 2 à 3 mètres (exceptionnellement 5 à 6), réclame l'orangerie à Paris; ses tiges sont par groupes divisés dès la base. C'est à ce type que se rattachent les deux fameux Palmiers de Louis XIV, offerts à ce souverain par le margrave de Hesse-Anhalt, et qui sont dans le pavillon froid (carré), serre près du labyrinthe, au Muséum; leur grande taille ( 12 mètres) empêche maintenant de les sortir l'été.

Les Trachycarpes élevés sont des plantes très voisines qui peuvent supporter $-12^{\circ}$ et que l'on peut laisser en plein air à Paris,

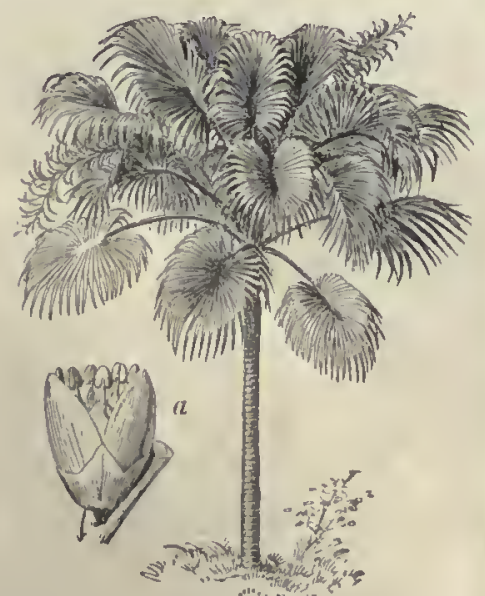

Fig. 176. - Sabal, $a$, Fleur,

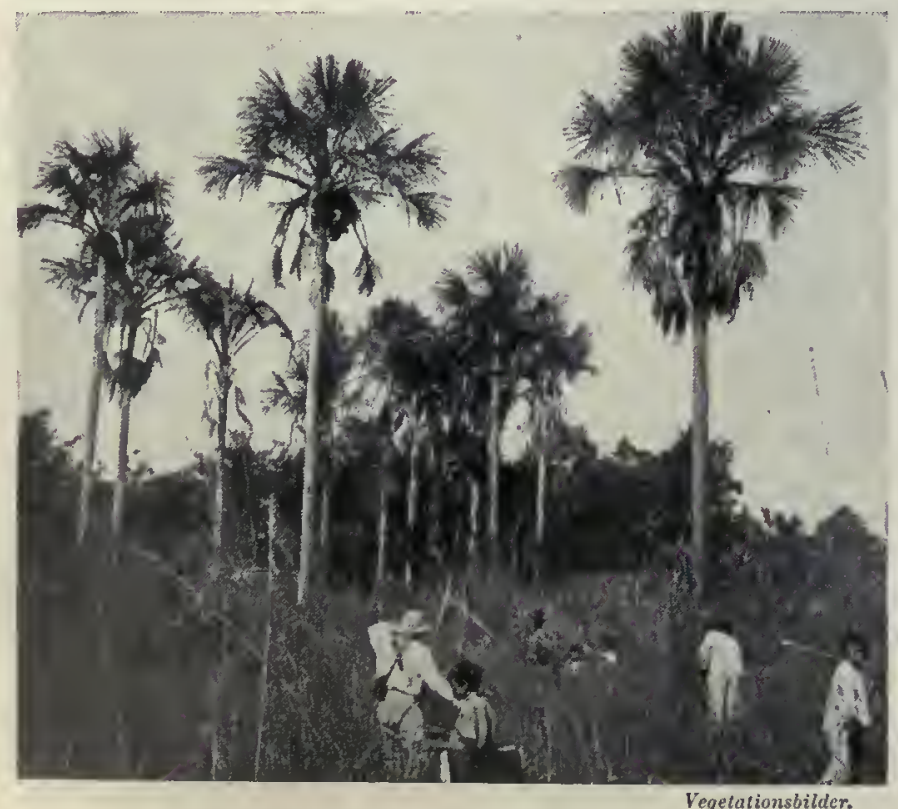

Mauritia vinifčre, cn Bolivic. même pendant l'hiver, à la condition d'abriter le cour du bourgeon terminal et les feuilles par des bâches disposées sur des cerceaux qui empêchent la neige de s'y accumuler. La tige de cette espèce de la Chine et du Japon atteint 8 à 10 mètres; elle est épaisse et fortement garnie de fibres brunes résultant de l'altération des bases des pétioles, ce qui lui donne un aspect poilu. Les feuilles sont palmées, à folioles bidentées ou courtement bifides au sommet; le pétiole est denté, serrulé sur les bords. Les spadices sont jaunes, pendants de 30 centimètres de long, entourés d'une spathe fauve, tubuleuse, bifide au sommet; les baies sont noir bleuâtre. Ces plantes sont monoïques ou accidentellement hermaphrodites.

Les Rhapis flabelliformes sont des Palmiers grêles, ressemblant à des roseaux, à tiges groupées, cespiteuses, qui ont des feuilles palmées, mais inégalement et irrégulièrement fendues. Les Corypha ont une couronne de grandes feuilles arrondies, dentées au bord; la tige se continue au-dessus des feuilles par un spadice très puissant et très spécial. Le Livistona de Chine figure fréquemment dans les serres sous le nom inexact de Latania de Bourbon. Le tronc est lisse, un peu renfé au bas, revêtu à sa partie supérieure par les vestiges des feuilles; ces dernières sont orbiculaires, en ćventail, fendues jusqu'au milieu et au delà en segments bifides; lepétiole est à bordsépineux, la gaine fibreuse; ces plantes, rustiques, sont cultivées depuis 1818 dans le midi de la France; elles sont précieuses comme garniture d'appartements.

Le genre Sabal (fig. 176) a un représentant dans le Sabal Palmetto ou Cabbage Palmetto du sud des Etats-Unis, qui est encore un des avantcoureurs de la grande armée des Palmiers dans les régions américaines : c'est là la limite septentrionale $\left(36^{\circ}\right.$ de latitude nord) de la famille dans cette région; les feuilles sont en éventail, à segments parfois filifères. La tigedu Washingtonia filitère est couverte à sa partie supérieure par les vestiges des feuilles, qui forment dans cette région une sorte de fourrure épaisse; les feuilles sont en éventail, étalées, orbiculaires ; les segments bifides sont fortement filifères sur la marge; $c$ 'est une espèce que l'on trouve dans les régions très sèches de la Californie; le fruit est ici pierreux, porté par un pédicelle cylindrique; c'est au contraire 


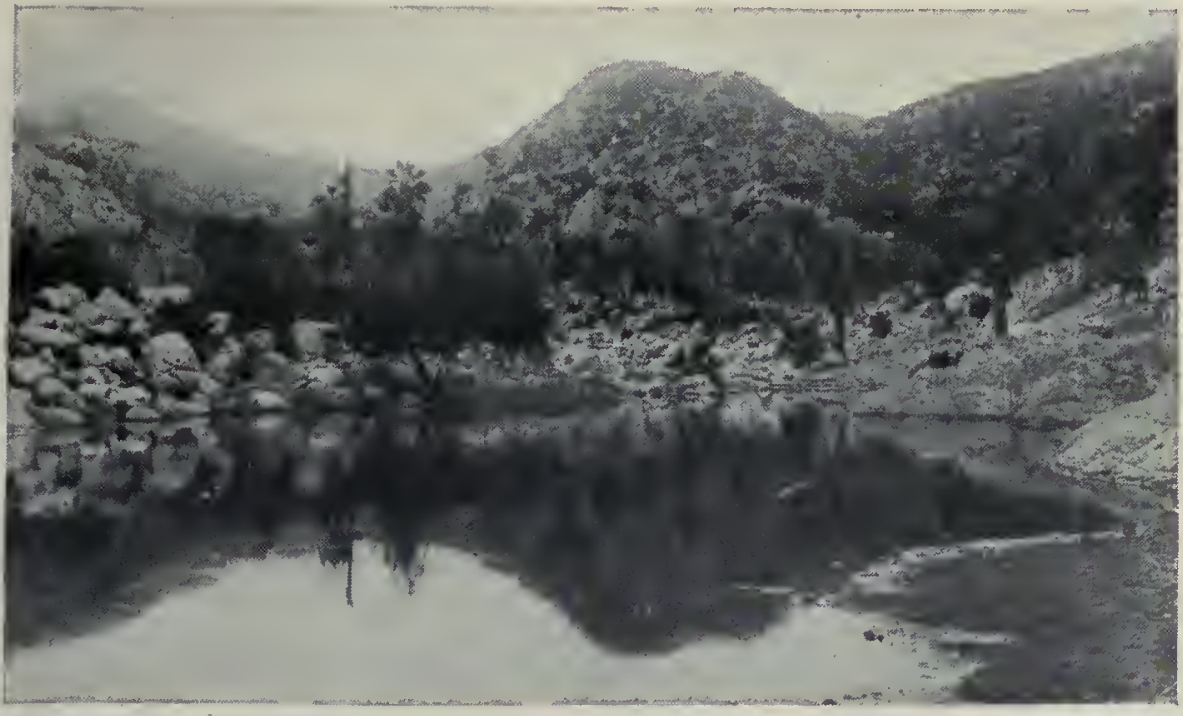

Paysage à Pritchardia (Washingtonia filifera), en Californie.

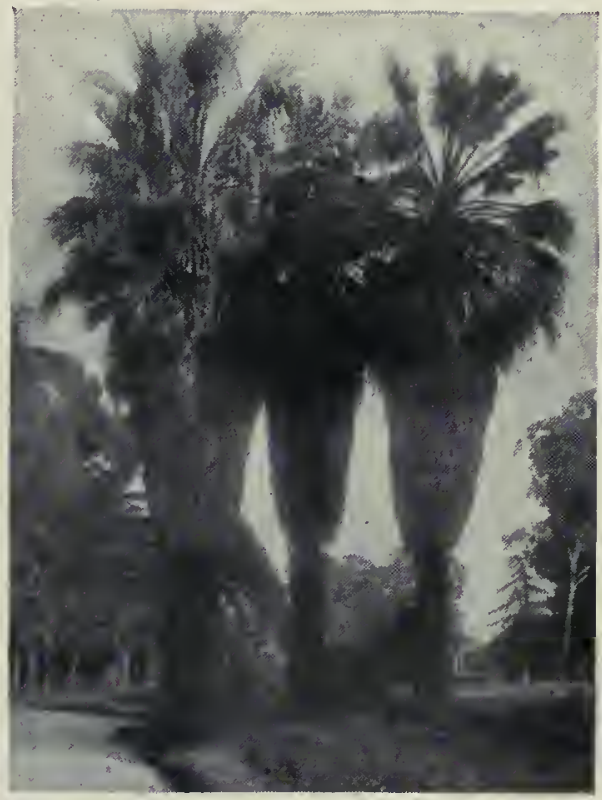

Pritchardia dans le parc d'Hyères. une baie dans les Sabal et les Copernicia. Ces derniers, qui se distinguent par un albumen ruminé, renferment une espèce importante, le Copernicia à cire, dont les noms vulgaires sont carnauba ou carnahyba. La tige est cylindrique, élevée de 10 à 15 mètres, d'un diamètre de 10 à 15 centimètres; sa surface est inerme, lisse, annelée surtout à la base; le tiers supérieur est garni des bases des pétioles; les feuilles sont palmées en éventail. Cette espèce vit au Brésil, dans la Bolivie orientale, la république Argentine, au Grand Chaco, au Paraguay. La récolte de la cire se fait en coupant les feuilles qui la produisent, à mesure qu'elles se développent, six mois de repos sulfisant au carnauba pour se regarnir. Les pétioles de cette espèce sont armés de deux rangées d'épines noires crochues; aussi servent-ils à faire des clôtures d'un caractère défensif marqué; le bourgeon terminal constitue un chou palmiste quand les feuilles sont jeunes et délicates.

Lépidocaryinées. - La tribu des Lépidocaryinées se distingue par ses carpelles écailleux; elle comprend des types à feuilles en éventail comme les Mauritia, des genres à feuilles pennées comme les Metroxylon, les Raphia et les Calamus.

Le Mauritia flexueux est un des Palmiers les plus utiles d'Amérique. 11 atteint 30 à 40 mètres; ses feuilles sont immenses, ses spadices souvent très grands. Ses fruits sont des baies écailleuses à pulpe épaisse. Ses feuilles fournissent une filasse; de sa moelle s'extrait un sagou. Une autre espèce, le Mauritia vinifère, doit son nom spécifique à la sève sucrée que l'on en extrait, fournissant un vin de palme.

Les Metroxylons sont les Sagoutiers vrais, des îles de la Sonde, etc. On en connaît deux espèces principales, le Sagoutier de Rumph et le Sagoutier lisse; les pétioles de ce dernier sont dépourvus de piquants; ils en sont au contraire armés dans le premier. Le sagou est la moelle remplie d'amidon que l'on extrait de l'arbre après l'avoir abattu. Les

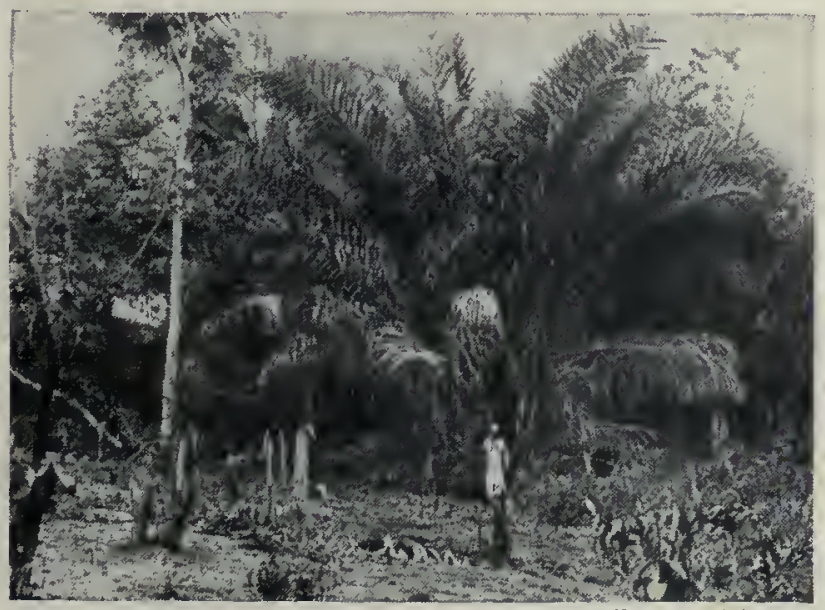

Raphia Monbuttorum en Afrique orientale. fruits durs, luisants, ligneux,

couverts d'écailles, sont à une seulc graine dont le sommet est tourné vers le point d'attache; l'ovaire n'est pas à trois loges comme cela a lieu chez les Raphia. Ces derniers ont une tige en général peu élevée, couverte de gaines persistantes; les feuilles sont très longues et pennées, garnies de filaments un peu épineux à la base et sur les bords; les gaines sont courtes, à bords pourvus de longues fibres; les inflorescences sont énormes, pesant 100 à 150 kilos, et pendantes presque jusqu'en bas de la tige, cylindriques, fortement et densément ramifiées, à branches imbriquées, fabelliformes, pectinées; la spathe générale est nulle, les spathes secondaires nombreuses; les bractées sont en cuiller à pot, comprimées et imbriquées. Les fruits sont ovoïdes ou oblongs, couverts d'écailles ligneuses, brunes, luisantes, avec une petite pointe au sommet. Le Raphia pédonculé ou Ruffia, de Madagascar et des Mascareignes, fournit avec les fibres des gaines le raphia du commerce et les rabannes; sa sève donne un vin ou harafa. Le Raphia vinifère, variété tadigère, des bords de l'Amazone, a une tige peu élevée, de 2 à 3 mètres, mais ses feuilles atteignent 15 mètres et s'élèvent verticalement, puis sont arquées; les fruits ont 6 centimètres, sont oblongs, à écailles dures; le tissu intérieur de sa tige sert à faire des flambeaux ou est utilisé comme du liège. Le Raphia vinifère de l'Afrique occidentale a une tige peu élevée, des feuilles de 2 mètres à folioles épineuses : la sève de cette plante fournit un liquide sucré susceptible de fermenter. Les fruits de cette espèce, mis à

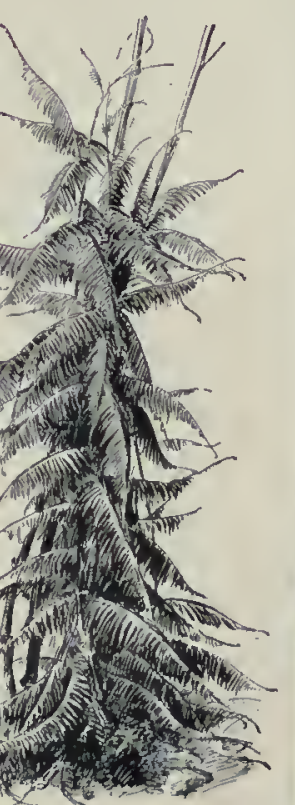

Fig. 177.

Rotang ou Calamus. fermenter après qu'ils ont été dépouillés de leur enveloppe écailleuse, peuvent donner une eau-de-vie. Signalons aussi le Raphia Monbuttorum de l'Afrique occidentale et du Congo.

Les Rotangs ou Calamus (fig. 177) se

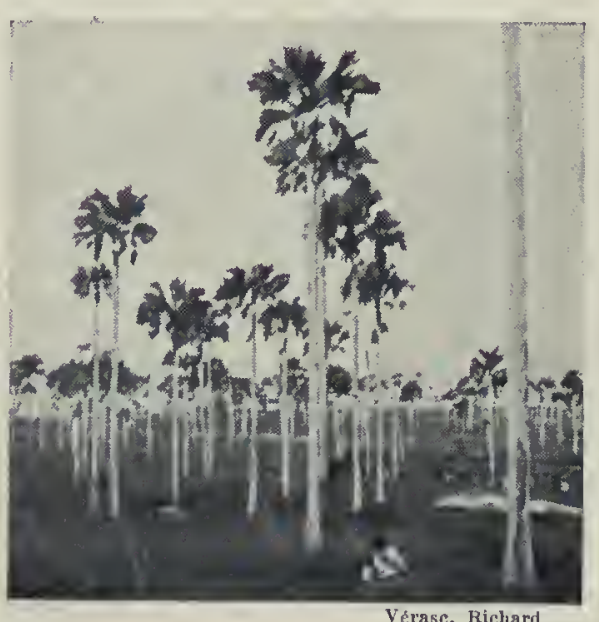

Groupe de Ròniers (Còte d'Ivoire). 


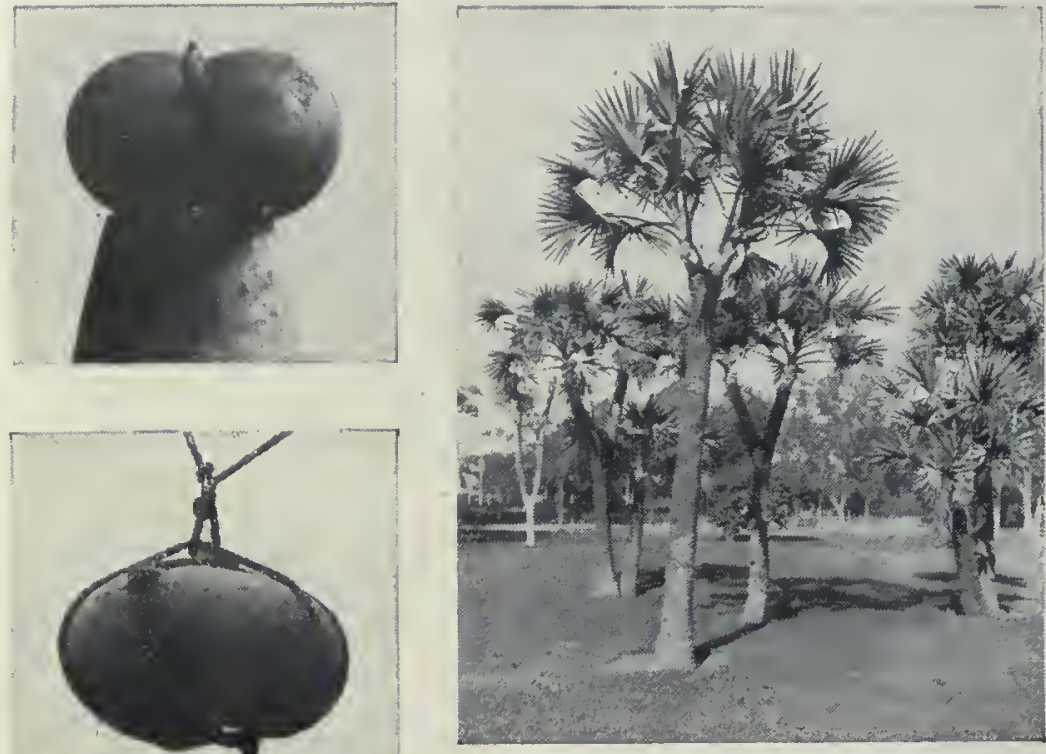

Le Palmier Doum.

placent à côté des Metroxylon; ce sont des Palmiers grimpants, qui atteignent parfois 200 mètres de long et plus. Ces Rotangs s'accrochent d'après deux types: dans les uns (Calamus extensus), c'est la tige qui est métamorphosée en fouet; dans les autres (Oncocalamus), qui habitent l'Ancien Monde (Gabon, Afrique occidentale), c'est le pétiole qui se prolonge au sommet en un long fouet portant de nombreux et fins crochets.

Borassinées. - Dans les Borassinées, les carpelles soudés sont nus, dépourvus de ces écailles qui caractérisaient le groupe précédent, et les feuilles sont palmées. Ce grand groupe contient des Palmiers célèbres, d'abord le Rondier ou Rônier ou Borassus flabelliforme. C'est un arbre de l'Afrique tropicale, fréquemment cultivé dans les Indes orientales, où il rivalise, comme utilité, avec le Dattier et le Cocotier. Sa tige est robuste, élevée; son sommet est parfois divisé en deux ou plusieurs ramifications; on en a signalé à Maduré, dans l'Inde, qui avaient une quinzaine de branches.

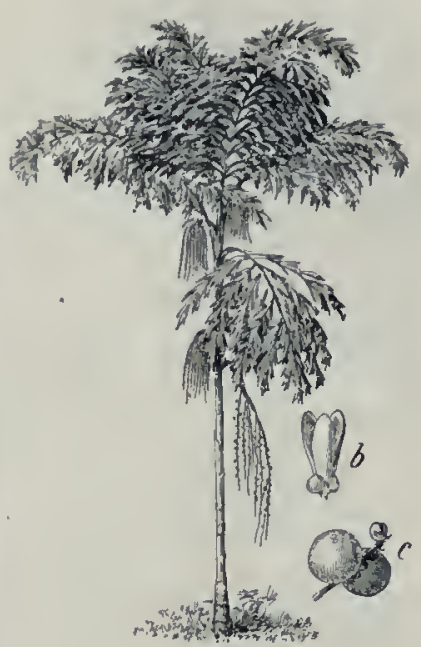

Fig. 178. - Caryote.

$$
\text { b. fleur; } c \text {, fruit. }
$$

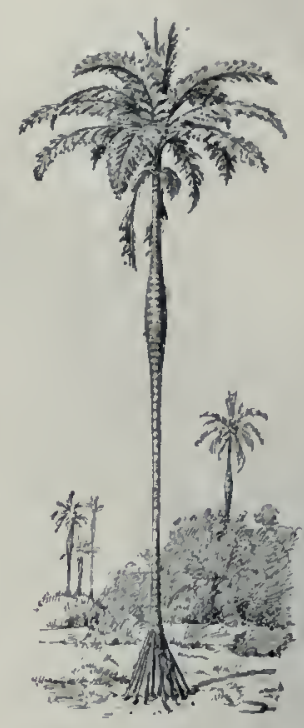

Fig. 179. - Iriartèe.

C'est une plante diö̈que. Les inflorescences sortent du milieu des feuilles : celles des pieds mâles sont plus volumineuses et ṛamifiées, avec de larges et épaisses bractées, de façon à donner à l'ensemble un aspect cylindrique; l'axe et les bractées forment de nombreuses fossettes où sont logés de petits groupes de fleurs mâles qui s'ouvrent successivement et viennent s'épanouir au dehors. Dans les inflorescences femelles, les fleurs sont peu nombreuses, volumineuses par rapport aux fleurs mâles, par une ou deux à l'aisselle de leurs bractées. Le fruit est gros, sphérique. Le bourgeon de cette plante donne un chou palmiste; une farine de gruau s extrait de la moelle de sa tige; le fruit, de la grosseur de la tête d'un enfant, sert à la nourriture de l'homme et des bestiaux; il est mangé cru ou cuit par des millions d'Indiens; il fournit dans l'Inde le quart de la nourriture, là où le prix du riz est trop élevé ; il fournit aussi la boisson appelée toddy à l'aide de sa sève. Cet arbre peut vivre deux cents ans.

Dans le fameux Palmier des Seychelles ou Lodoicea, ou Coco de mer, ou Cocotier des Maldives, les fleurs mâles sont, comme dans le Rondier, nombreuses dans des fossettes ou alvéoles du spadice, mais les étamines sont nombreuses. Le fruit est de dimensions considérables; il a une enveloppe ligneuse, divisée en deux lobes séparés nettement l'un de l'autre par un sillon profond, formant comme deux reins. Ce Palmier des Seychelles et de l'île Praslin a été signalé au milieu du XVII ${ }^{\circ}$ siècle par La Bourdonnais; il pousse au bord de la mer où ses fruits sont entraînés par les courants et transportés au loin. C'est ainsi quils sont connus depuis un

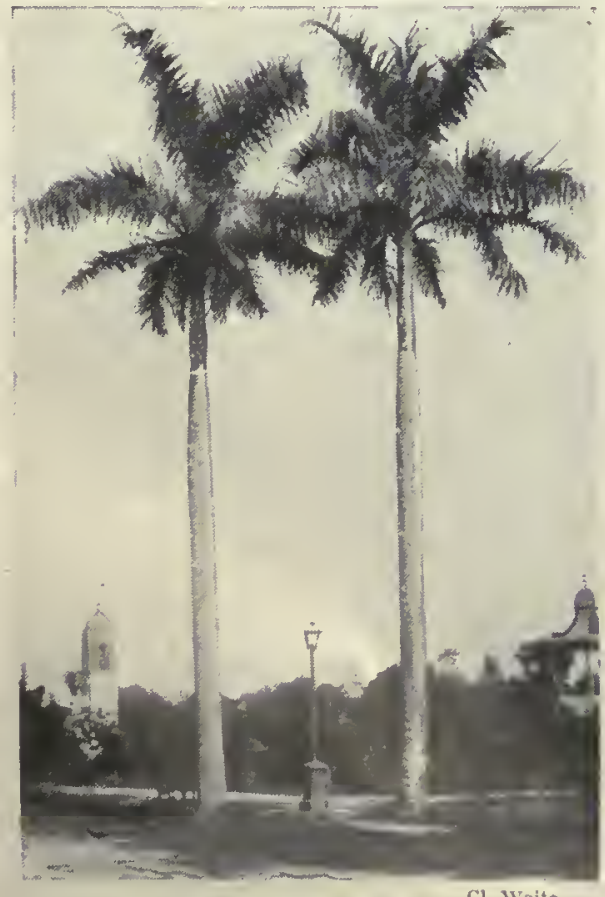

Palmiers royaux (Orendnxa), an Mexique.

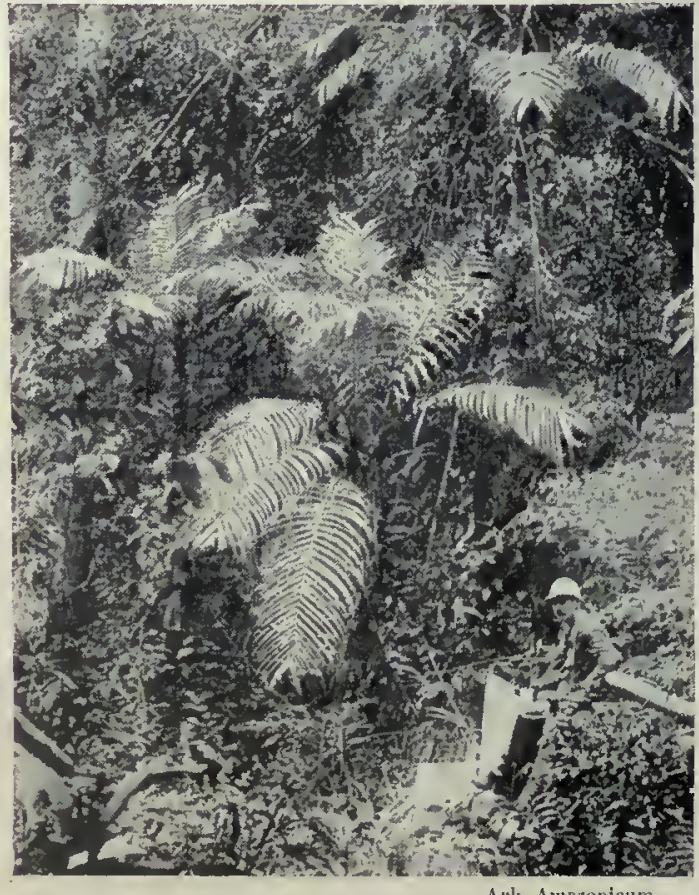

Palmier Manicaria saccifèrc temps immémorial aux Maldives, mais on ignorait quelle était leur origine véritable. On conçoit que des légendes extraordinaires aient couru se rapportant à ce singulier coco de mer qui semblait rejeté des profondeurs de l'Océan et dont on attribuait vraisemblablement la production à l'arbre mystérieux et divin qui vit au fond de la mer et dont on retrouve des traces dans tant de mythologies. Les souverains de l'Inde, qui achetaient ce produit singulier à un prix élevé, faisaient avec son enveloppe des coupes qu on enrichissait de métaux précieux et dans lesquelles ils buvaient, afin de se préserver des poisons qu'ils pouvaient craindre. Le tronc du Lodoicea a 35 mètres de haut, sur 40 à 50 centimètres de diamètre; il est marqué de cicatrices annulaires provenant de la chute des feuilles; ses feuilles en éventail ont 5 à 6 mètres de long sur 3 à 4 de large. Le bois se fend aisément, et sert à faire des conduites d'eau, des haies, des palissades; 


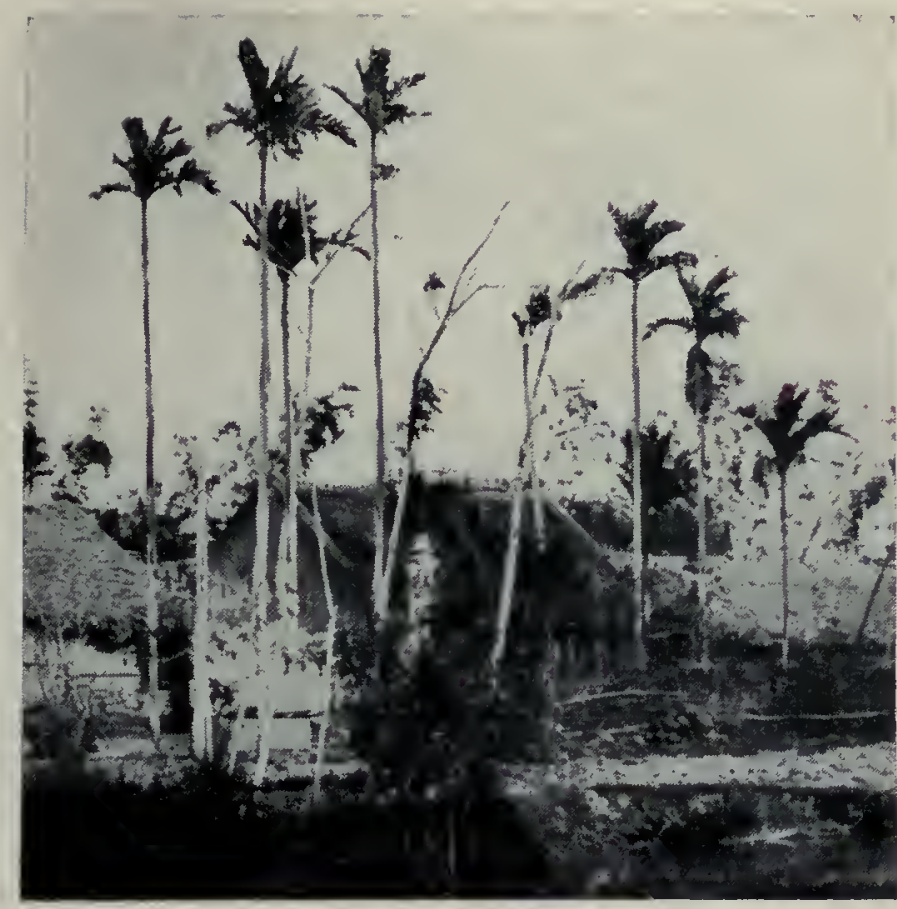

Palmiers Aréquiers aux environs d'Hanoï.

les jeunes feuilles sont entourées d'une sorte de bourre laineuse qui sert à rembourrer des oreillers, des coussins, des matelas. $\mathrm{On}$ fait avec les feuilles des chapeaux, des toitures, des balais. Le fruit est comestible; il renferme un liquide laiteux agréable à boire, mais qui rancit vite. 11 met sept ou huit ans à mûrir, mais, récolté à trois ou quatre ans, il est mou et comestible.

Le Doum ou Hyphène thébaïque est remarquable par sa tige bifurquée; il se distingue des types précédents dont il est voisin par ses fleurs dioïques: les mâles, solitaires, ont six étamines; ses fruits, qui ont été trouvés dans les tombes de l'ancienne Egypte, sont comestibles; on les vend au Caire; son bois dur est très utilisé; ses feuilles servent, à Tombouctou, à faire des paniers.

Arécinées. - Les Caryola se distinguent de tous les Palmiers par leurs feuilles composées deux fois. La moelle de la tige du Caryota urens ( $f$ g. 178) fournit dans l'Inde un sagou bâtard; ses feuilles donnent un crin végétal (Kittool fibres) servant pour les brosses et les engins de pêche; il fournit un toddy ou vin de palme. L'Arenga saccharifère a des feuilles une seule fois pennées, dressées, à segments linéaires; les fleurs mâles et femelles sont sur des inflorescences distinctes, mais réunies sur le même pied; la tige a 10 à 15 mètres de haut et est couverte d'écailles ou d'un réseau de fibrilles; c'est une plante sucrière importante de la Malaisie (Java, Sumatra, Philippines); sa sève sucrée, brune, fournit par fermentation un vin de palme par l'incision de ses spadices ; les fibres du tronc donnent de l'étoupe et des cordages. Les Chamadorea sont des Palmiers grêles qui rappellent un peu les Bambous.

Dans les Howea, le spadice est simple. Ces Palmiers sont peut-être les plus importants au point de vue de la culture de ces plantes en appartement et ils sont vendus par les horticulteurs sous

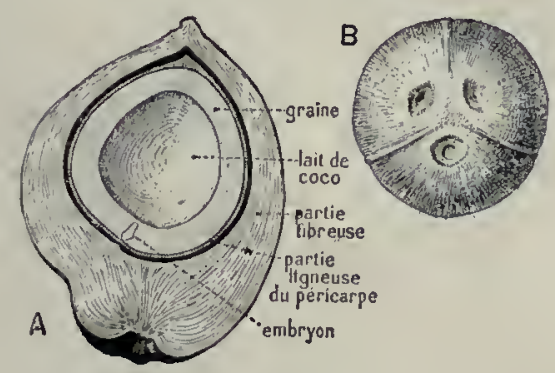

Fig. 180.

A, coupe d'une noix de coco: $B$, noix de coco vue en dessous et montrant les trois cavites correspondant aux cactées, divisions ovariennes primitives.

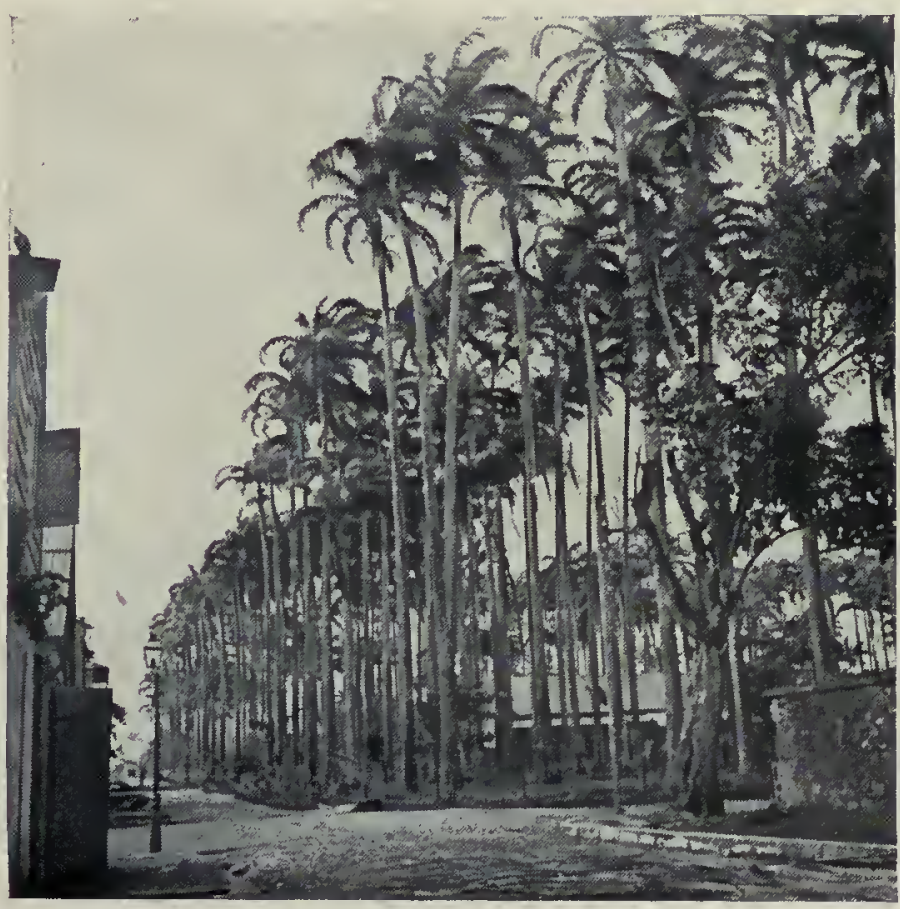

La place des Palmistes, à Cáyenne.

grand pétiole, et les folioles sont groupées vers le haut, de sorte qu'à un examen premier et rapide, on croirait avoir affaire à des feuilles palmées.

Le nom de Ceroxylon vient de deux mots grecs : keros, qui veut dire circ, et xylon, bois, parce que la tige élevée, grêle relativement à la hauteur, lisse, pourvue seulement de cicatrices annulaires, sécrète une substance cireuse blanche, se déposant sous forme de croûte ou d'écailles blanches, tranchant sur les anneaux bruns. Le Céroxylon des Andes atteint 30 ou 40 mètres de haut; il est couronné à sa partie supérieure d'un magnifique panache de feuilles de 7 à 8 mètres de longueur, argentées dessous. Les spadices sont allongés, rameux à rameaux grêles, avec cinq spathes coriaces, soyeuses, les baies rouges ou violacées. C'est dans l'Amérique du Sud, à une altitude comprise entre 2000 et 3000 mètres, que l'on rencontre ce bel arbre, où il forme de grandes forêts.

Dans les Aréquiers ou Areca, Palmiers dont le nom rappelle le mot arec, qui est le nom vulgaire de ces plantes au Malabar, le spadice apparaît au-dessous des feuilles. La tige est plus ou moins élevée, annelée, pouvant atteindre 10 à 16 mètres de haut, avec un panache de feuilles pennécs. Le spadice est monoïque paniculé ou simplement rameux, enveloppé dans deux spathes membraneuses, coriaces; les fleurs mâles sont très nombreuses, solitaires ou par deux; les fleurs femelles sont à la base des rameaux. Les

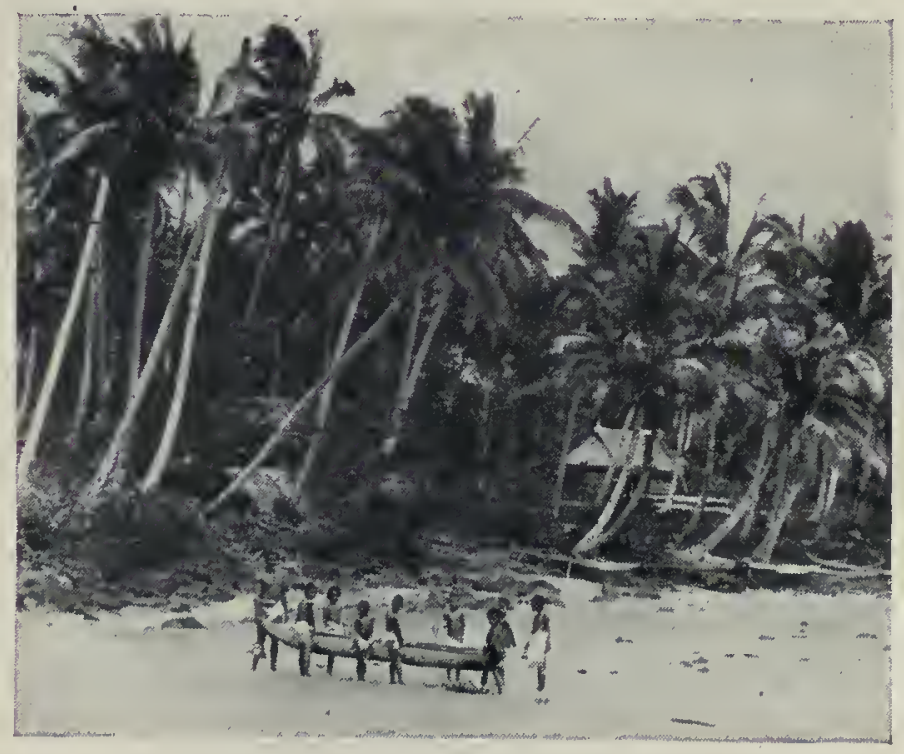

Cocotiers aux iles Gilbert (Polynésie). le nom impropre, mais universellement répandu, de Kentia. La tige est robuste, lisse, annelée, mais on ne connaît guère ces plantes qu' en individus jeunes, à tronc court. Dans l'Howea Balmoreana, la tige peut atteindre jusquà 12 mètres de haut. Cette espèce est très employée, ainsi que l'Howea Forsteriana. Les feuilles, dans les deux cas, sont pennatiséquées, mais avec un 


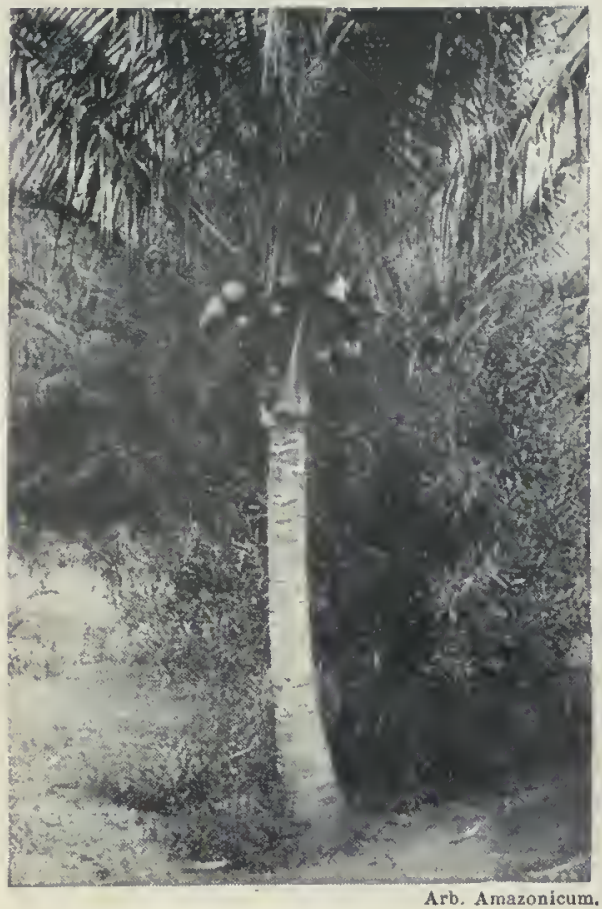

Cocotier avec fruits (Hanoï).

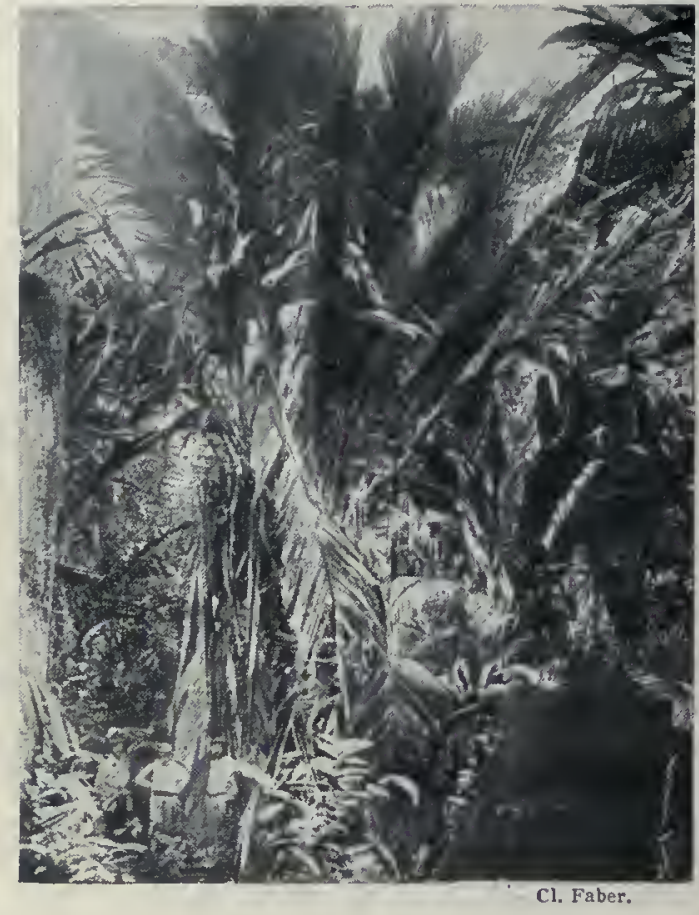

Palmier Astrocaryum mumbaca.

dit, ou Cocotier nucifère, est disséminé dans toutes les régions tropicales australes, probablement par les courants marins, car il pousse d'ordinaire au bord de la mer. C'est un arbre élevé, de 25 mètres de haut, à tronc en général énorme, mais à cicatrices foliaires pouvant servir d'appui pour grimper, portant au sommet un magnifque panache de feuilles pennées de 4 à 5 mètres. Les fleurs sont unisexućes. Le fruit (fig. 180) est une drupe ovoïde, couverte d'un épiderme mince, parcheminé, dont la partie charnue est remplie de fibres qui constituent le coir, utilisé pour la fabrication des cordages, des filets, des couvertures, des courroies, des brosses. Le noyau est très ligneux, avec trois trous à la base. Quand la graine n'est pas encore mûre, son albumen renferme un lait sucré, acide, utilisé comme boisson rafraîchissante. A la maturité, ce liquide disparaît, se transforme en albumen et il constitue le coprah du commerce, qui joue un rôle important dans l'alimentation de divers pays, surtout en Polynésie; on peut en extraire l'huile de coco. L'endocarpe dur et osseux du fruit

fruits sont des baies ovoïdes, de la grosseur d'un œuf, et jaune rouge; ils renferment un brou fibreux et une amande qui, débarrassée de son péricarpe, constitue la noix d'Arec, dure, cornéé, marbrée de blanc et de brun parce que l'albumen est ruminé. Ces noix forment la base d'un masticatoire très employé par les Asiatiques (Indochine, Malaisie, Inde, etc.), qui noircit les dents et rend les'gencives sanguinolentes; son abus produit à la longue l'aphasie.

Les Oréodoxa, voisins, ont un spadice ramifié; la tige est souvent renflée au milieu, en particulier dans l'Oréodoxa royal, d'Amérique. Les feuilles sont pennées; les spadices sont grands, pendants; il y a deux spathes : l'inférieure semi-cylindrique, la supérieure en sabre. L'Oréodoxa oléracé fournit par son bourgeon terminal un chou tendre et délicat. Signalons aussi les Iriartées de l'Amérique tropicale (fig. 179), remarquables par le renflement en fuseau de leur tige et par la présence fréquente de racines épigées à la base. Le Manicaria saccifère, du Brésil, porte d'immenses feuilles dont le limbe reste simple.

Cocoïnées. - Il nous reste à parler du dernier groupe, celui des Cocoïnées, à noyau perforé, à carpelles soudés et nus, à feuilles pennées. Les Eléides de Guinée ou Palmistes, qui se séparent de toutes les Cocoïnées par leurs fleurs situées dans des fossettes de l'axe, ont pour fruits des drupes grosses comme des prunes, de couleur jaune ou rouge, avec un noyau dur et un mésocarpe charnu, fibreux et riche en corps gras; la graine contient aussi une substance oléagineuse. L’Éléide a un tronc d'une vingtaine de mètres, inerme, avec une vingtaine de feuilles amples au sommet, ayant plusieurs mètres de long. Le spadice est ramifié, de forme ovoïde, gros comme une tête ; il est hérissé de bractées épineuses. En dehors des matières grasses, cet arbre fournit un vin de palme en Afrique occidentale; c'est une boisson rapidement enivrante; les indigènes se servent de la plante pour construire et couvrir leurs cabanes; les feuilles servent de fourrage pour les animaux domestiques.

Dans les Cocotiers, il y a six étamines; les fleurs ne sont plus dans des fossettes: elles sont superficielles. Ce genre renferme une trentaine d'espèces américaines. Le Cocotier proprement

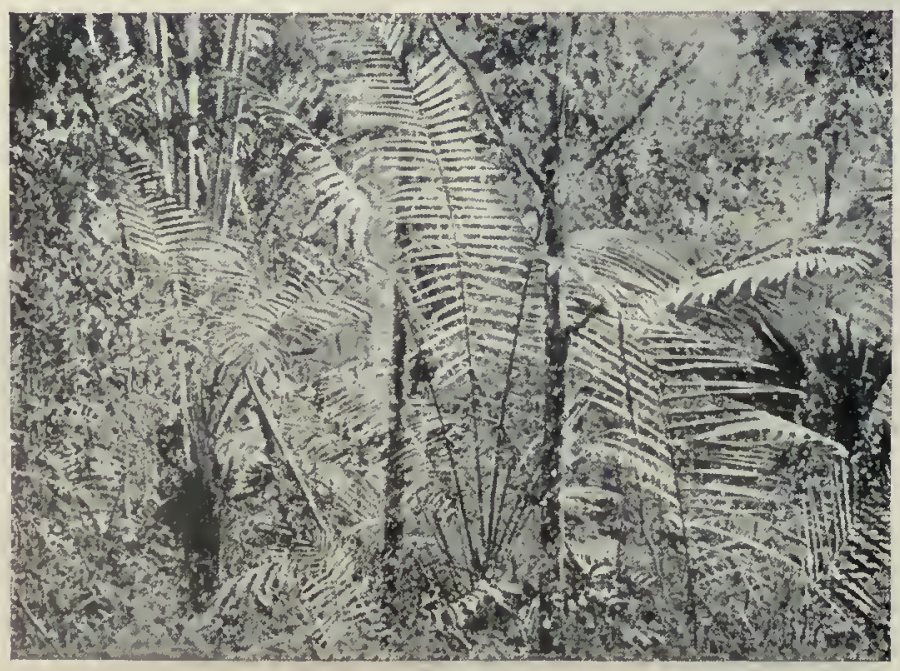

Patmier Phytetephas à petit fruit. peut fournir des vases grussiers aux indigènes. Le sectionnement de Iinflorescence donne un vin ou toddy; on peut extraire de celui-ci un arack ou alcool et, de la sève, du sucre ou jagre. Le bois sert par son tronc pour la charpente, bien que peu durable. Les feuilles sont utilisées pour couvrir les cases, pour la confection de corbeilles, etc.; jeunes elles donnent un chou palmiste. En dehors de cette espèce essentiellement utile, citons le Cocotier de Weddell, le plus délié, le plus élégant de tous les Palmiers, qui figure dans les salons.

Les. Jubcea se distinguent des Cocotiers par leurs étamines nombreuses; ils ont d'ailleurs comme eux les orifices de germination dans la graine à la partie inférieure. Parmi les représentants de ce genre, on peut citer le Jubrea remarquable ou Jubea du Chili, situé à l'avant-garde de l'armée des Palmiers dans les terres australes. Ce Palmier, connu au Chili sous le nom de Lila, a un fruit comestible par son albumen qui rappelle celui du Cocotier; malheureusement les enveloppes sont très dures; cependant les boeufs savent le décortiquer et se nourrissent de la partie externe, laissant intact le noyau d'où l'on extrait l'amande. Le bourgeon est un légume; la sève donne un vin de palme et on peut extraire du suc, avant la fermentation, le " miel de palma ", très estimé : les fibres de la tige sont textiles; avec les feuilles on fabrique des nattes, des chapeaux, des toiles, etc. Cet arbre peut atteindre 25 mètres de haut.

Les Astrocaryon Muru-Muru du Brésil ont le tronc extrêmement épineux, haut de 4 à 5 mètres. Les Bactris sont de petits Palmiers dont la tyge grêle sert à faire des cannes légères, dites de Tabago.

Les Phytéléphantinées forment ùn groupe caractérisé par ses fleurs mâles ou femelles sans périanthe et par le fruit qui est un syncarpe, c'est-à-dire résultant dela coalescence de plusieurs fruits distincts; ils fournissent l'ivoire végétal ou corozo. Les fruits ou cabeza de negro (tête de nègre) du Phytelephas macrocarpe sont de la grosseur de la tête, avec des drupes agrégées, à plusieurs loges ayant de trois à six graines. Il y a dans ces graines un lait, qui se solidifie en un albumen dur comme de l'ivoire, servant à fabriquer des objets finement ajourés; ces graines ont la taille de petites pommes. La patrie de cette plante est la Nouvelle-Grenade et les Andes du Pérou. 


\section{LES LILIINÉES}

L'ordre des Liliinées comprend quatre familles : 10 les Liliacées, à calice pétaloïde et albumen charnu; $2^{\circ}$ les Pontédériacées, à calice pétaloïde et albumen amylacé; 3" les Alismacées,

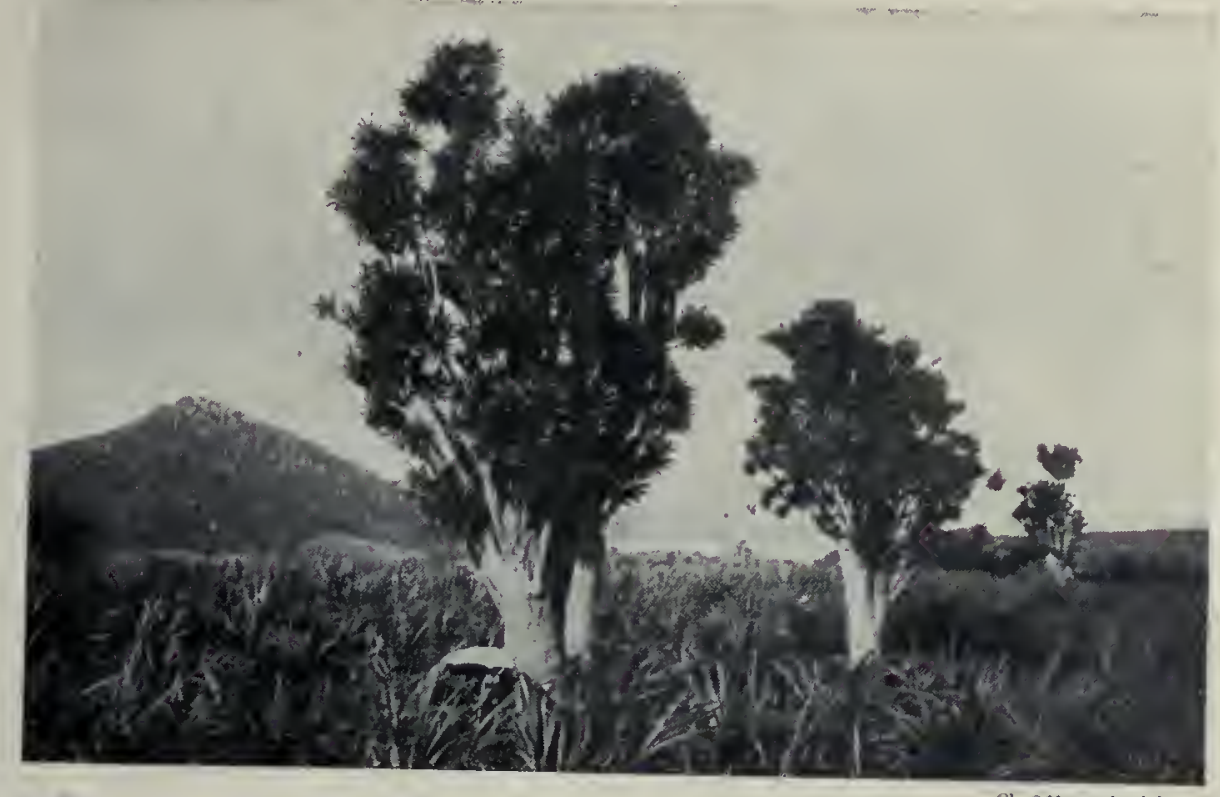

Paysage avec Dragonnier marginé, à La Rẻunion.

Cl. Oflice coloninl.

plantes d'eau à calice sépaloïde et à graine sans albumen; $4^{\circ}$ les Commélynacées terrestres, à calice sépaloïde et albumen amylacé.

Famille des Liliacées. Les Tulipes. - La famille des Liliacées renferme plusieurs types de fleurs qui ont eu leur temps de célébrité : parmi elles, il suffit de mentionner les Tulipes. C'est vers 1570 que Charles de l'Escluse, botaniste illustre, s'intéressa à ces plantes, mais ce furent les bourgeois d'Amsterdam qui, les faisant venir directement de l'Orient, les mirent à la mode. La passion pour les Tulipes se propagea avec rapidité au $X V t^{\mathrm{e}} \mathrm{t}^{\mathrm{s}}$ siècle, mais leur centre de culture se maintint en Hollande; cette maladie, car c'en était une, gagna la France, l'Angleterre. La tulipomanie provoqua des achats énormes, des jeux de hausse et de baisse; elle fut lorigine de fortunes colossales et de déconfitures célèbres; des lois furent faites, des fonctionnaires, les notaires de tulipes, furent créés pour réglementer ce négoce qui devint effréné. Les prix des Tulipes atteignirent des chiffres fantastiques : le Semper augustus fut vendu 5500 forins (1 l 660 fr.); à Lille, un seul oignon de la " Tulipe de brasserie ) trouva acquéreur pour 30000 francs. La Bruyère a célébré le fou Tulipier qui " a un jardin dans le faubourg, qui y court au lever du soleil et en revient à son coucher $"$. On a vu au XIX $\mathrm{X}^{\mathrm{e}}$ siècle disparaitre les derniers tulipomanes.

La Tulipe justifie cette histoire si fameuse qu'on vient de lire par l'ampleur et la richesse de coloris de ses fleurs. Son périanthe est formé de six pièces, trois sépales colorés et trois pétales semblables entourant six étamines en deux verticilles, l'ovaire supère à trois loges. La Tulipe duc de Thol et la Tulipe des jardins ou de Gesner sont les plus répandues, avec la Tulipe suave et la Tulipe sylvestre qui est indigène dans le Midi.

Autres Liliacées bulbeuses.-A côté de la Tulipe se place la Fritillaire qui, comme elle, a une fleur souvent solitaire, à grand périanthe en cloche, mais cette fleur est penchée vers le bas au lieu d'être droite et dressée comme précédemment. Dans la

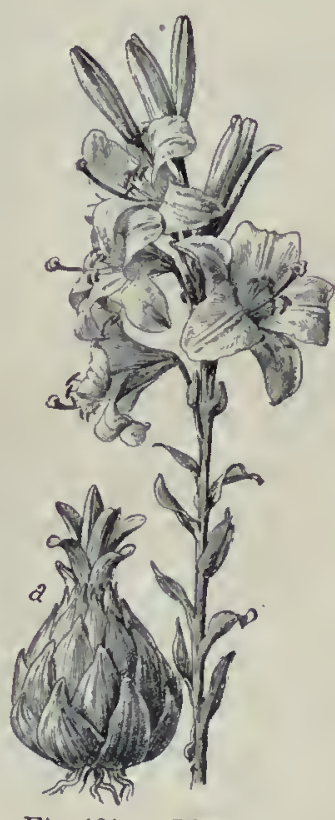

Fig. 181. - Lisoblanc. $a$, bulbe.
Fritillaire Cołronne impériale, à périanthe roux cuivré, les fleurs sont, au contraire, réunies en couronne surmontée d'un bouquet terminal de bractées.

La grande légion des Lis cst voisine; elle se distingue des deux genres précédents par les étamines à anthère oscillante, à filet inséré au milieu du connectif. Les bulbes sont d'ailleurs également différents : au lieu d'être tuniqués, ils sont écailleux (p. 24).

Le port majestueux, la grande taille des grappes de Lis, le parfum pénétrant du Lis candide (fig. 181), en ont fait la fleur de la royauté française, C'est une espèce de l'Europe méridionale, mais on a depuis le moyen âge cultivé beaucoup d'autres types : le Lis satrané, indigène; le Lis Martagon, portant trois à vingt fleurs pendantes en verticilles, d'un rouge violacé ponctué de brun; le Lis tigré, de la Chine et du Japon; le Lis doré, à fleur blanche avec une large bande jaune d'or au milieu des pièces du périanthe.

Dans toutes les plantes bulbeuses précédentes, la tige florale est feuillée; il est une autre catégorie de ces plantes à hampes dépourvues, au contraire, de feuilles : ce sont les Jacinthes des bois, ou Endymion penché; les Scilles, à sépales séparés; la Scille de Sibérie, à fleurs d'un bleu profond trèsremarquable; la Scille du Pérou, à grosse inflorescence pyramidale. Dans les Ornithogales, les sépales sont aussi séparés, mais le filet de l'étamine est élargi. Dans les Jacinthes d'Orient, les sépales sont soudés ainsi que dans les Muscari : les premières sont, à

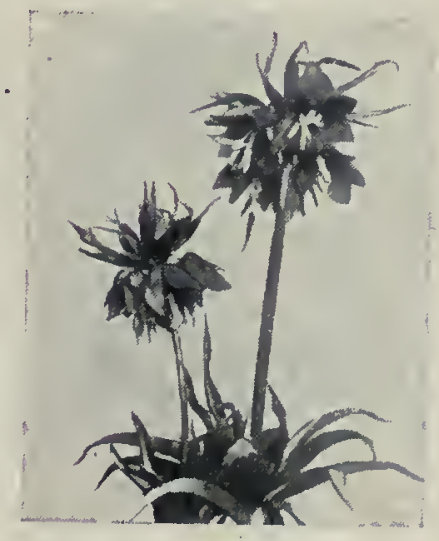

Fritittaire couronne impériale. l'heure actuelle, parmi les fleurs les plus cultivées pour l'ornementation des jardins au premier printemps; les secondes, à corolle en grelot, forment des toupets de fleurs souvent stériles à l'extrémité de l'inflorescence.

Dans toutes les plantes bulbeuses précédentes, l'inflorescence est en grappes; elle peut être en ombelle dans les représentants du genre $A i l$, qui a une si grande importance pour la culture potagère. $\mathrm{L} \mathrm{O} \mathrm{i}$ gnon (Allium Cepa), qui y est rangé, a sa feuille creuse, sa tige renflée au-dessus du milieu, tandis que dans la Ciboule, ou Ail fistuleux, c'est au milieu qu'est le renflement; l'Échalote ou Ail d'Ascalon a une tige non renflée, ainsi que la Civette ou Ciboulette (A. Schœenoprasum), l'Ail comestible ou Ail proprement dit, dont la feuille n'est pas creusée, mais a des petits bulbes à l'ombelle au lieu de fleurs, ce qui n'arrive pas dans le Poireau. Malgré la forte odeur alliacée qui se dégage des inflorescences de ce genre, plusieurs espèces sont cultivées, comme l'Ail de Naples, à fleurs blanches; l'Ail doré, ou Moly, à fleurs jaunes; l'Ail azuré, à fleurs bleues.

Liliacées à rhizome. - Dans les Agapanthes, parfois cultivées, comme l'Aga. panthe à ombelle du Cap, linflorescence est en grandes

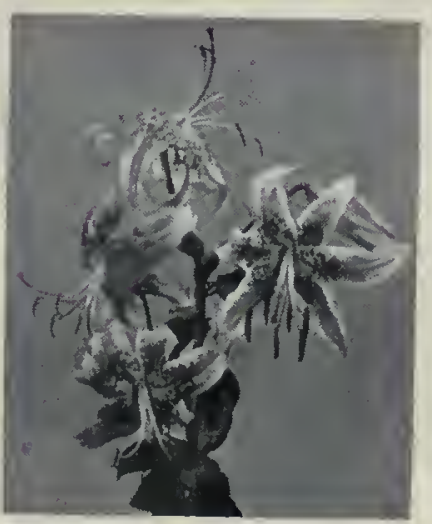

Fleurs de Lis Martagon.
Fig. 182.

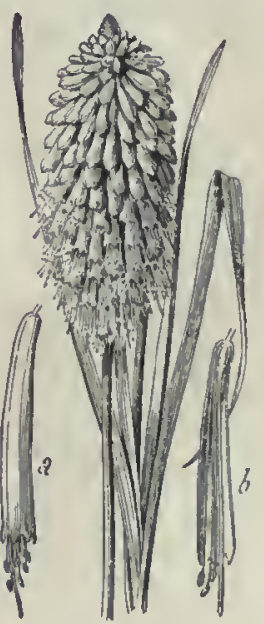

Tritome et fleur. 


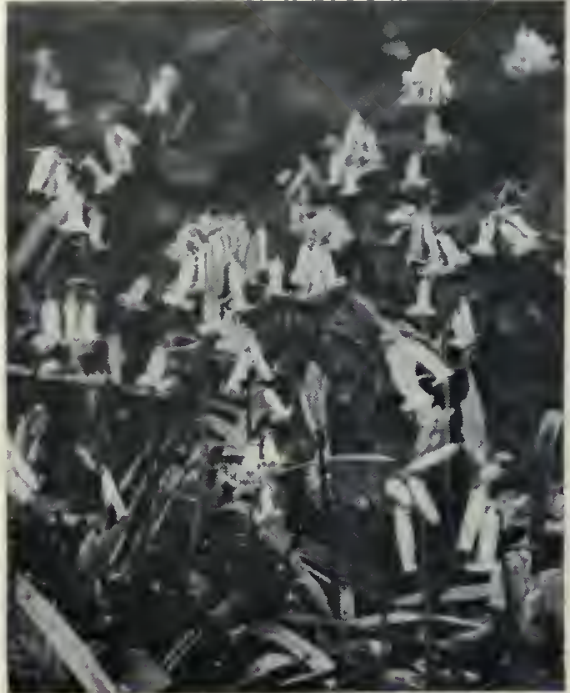

Endymion penché de nos bois.

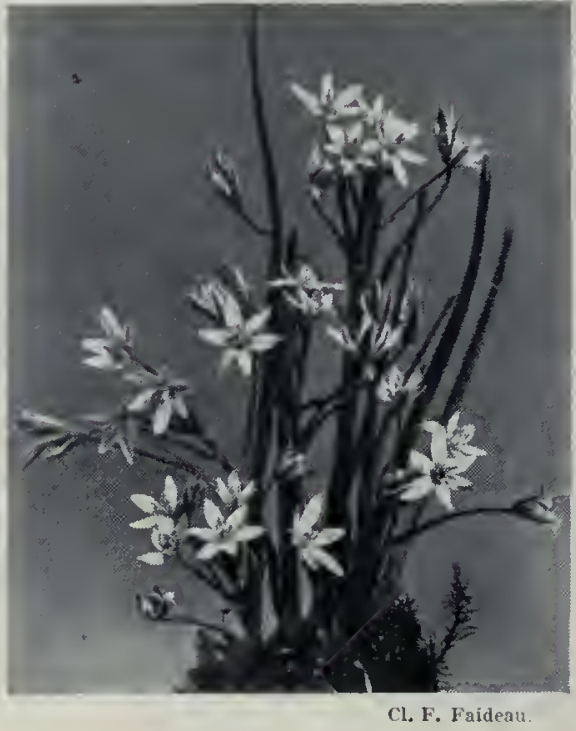

Ornithogale en ombelle.

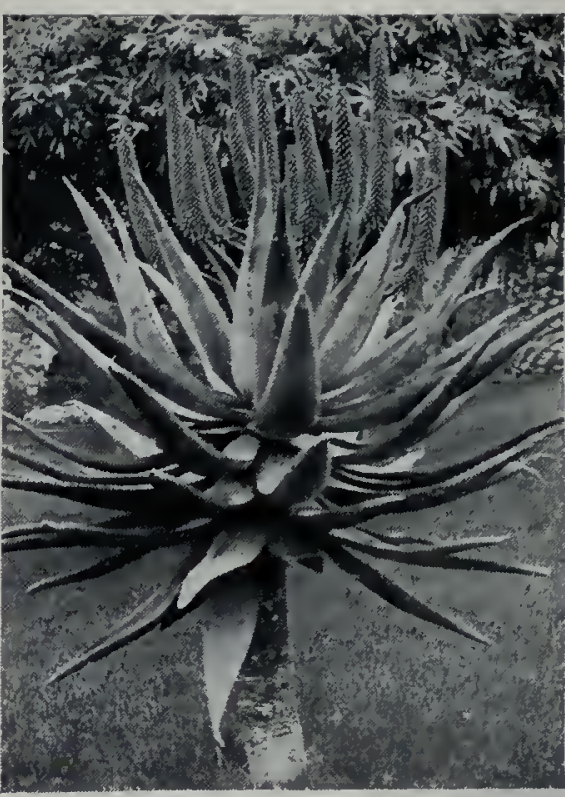

Aloès succotrin en fleurs.

ombelles de fleurs bleues, mais le bulbe n'existe plus et c'est un rhizome qu'on observe dans le sol.

Le groupe dont l'Asphodèle est le type voit définitivement le bulbe disparaitre et le rhizome dominer presque complètement, mais l'inflorescence est en grappe ou en épi. C'est à côté de ces plantes que se placent les Érémures, dont les grappes gigantesques font la gloire des expositions horticoles; ce sont des plantes admirables du Turkestan et parmi les plus belles, à fleurs à peine teintées de rose; on peut citer l'Érémure robuste, dont la hampe a jusqu’à 2 mètres et plus de haut.

Une plante de culture facile dans les jardins, et qui donne de belles fleurs rappelant celles des Lis safranés, est l'Hémérocalle qui se distingue des plantes précédentes, qui ont les sépales et pétales libres, par ses sépales et pétales soudés. L'Hémérocalle fauve et l'Hémérocalle jaune ou Lis jaune sont les plus communes. Les Funkia se rencontrent aussi fréquemment; elles se distinguent par leurs feuilles élargies, à nervures arquées, leur hampe simple portant une grappe de fleurs pendantes; plusieurs espèces sont cultivées : la Funkia ovale à fleurs bleues, la Funkia subcordée à grandes fleurs blanches. Nous ne pouvons omettre ici une plante utile très intéressante, le Lin de la Nouvelle-Zélande ou Phormium tenace, dont les feuilles, toutes à la base, distiques, en forme de sabre, sont très grandes et très belles; ces plantes fournissent des fibres textiles. Si le périanthe de la fleur est complètement soudé en un long tube courbé vers le bas, si l'inflorescence devient un épi dense de grandes fleurs passant du corail à l'orangé, avec des feuilles nombreuses étroites à la base, nous aurons le Kniphofia, parfois appelé Tritoma (fig. 182). Ces plantes du Cap font un très bel effet isolées sur les pelouses.

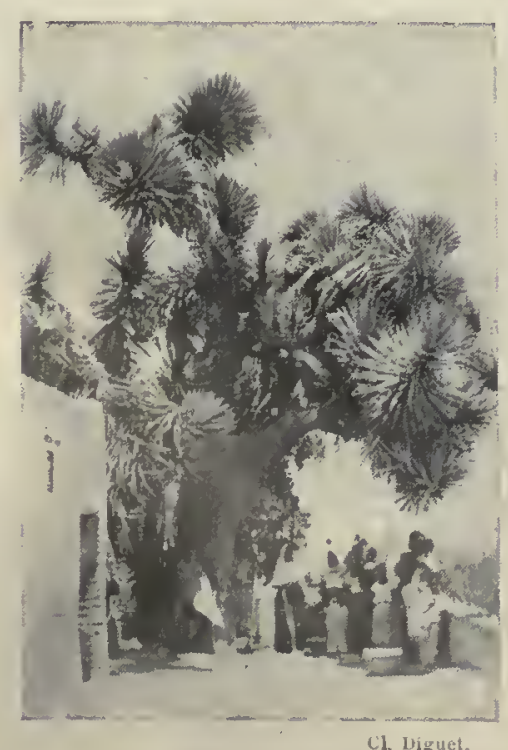

Yucca filifère (Mexique),

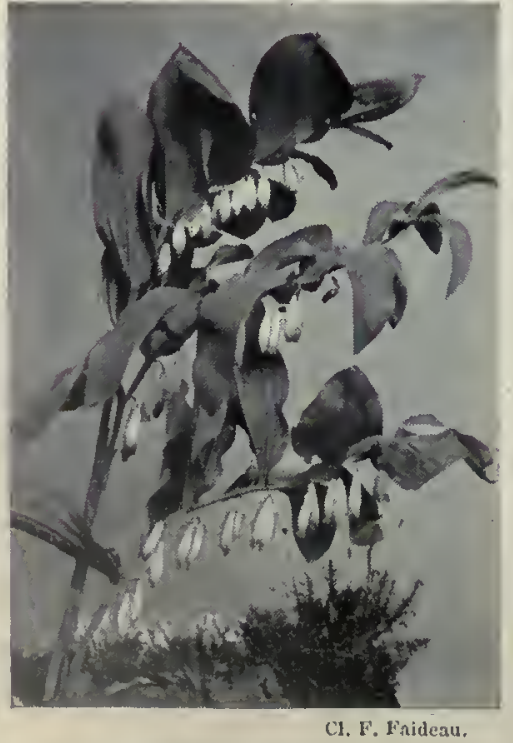

Sceau de Salomon fleuri.
Liliacées à tige ligneuse

ou Dracénées. - Les $A$ loès, qui sont voisins des plantes précédentes par leurs fleurs en tubes pendants et leurs étamines insérées sous l'ovaire, ont un port très différent : leurs feuilles charnues, épaisses, pointues, sont en rosette. C'est un genre africain qui est important par le suc résineux que contiennent surtout l'Aloès vrai et l'Aloès de Perry. Les Yucca, à capsule ou à baies, sont de superbes Liliacées qui figurent fréquemment dans les parcs pour leurs belles grappes de fleurs globuleuses, blanches, à sépales séparés; leurs feuilles raides, en rosette, surmontent en général une tige courte; ces feuilles ne sont pas charnues, comme dans les Aloès, mais elles sont susceptibles de résister cependant à la sécheresse, et c'est dans les contrées un peu désertiques du Mexique et du sud des États-Unis qu'on les rencontre.

Parmi les arbres les plus célèbres de la famille sont les Dragonniers ou Dracana, qui ont un fruit bacciforme, comme les $Y u c c a$ types, mais des sépales soudés. Leur nom vient de ce que leur suc rouge desséché fournit une poudre analogue au sang-dragon.

Asparaginacées, Colchicacées. - Dans les Asparaginacées, le fruit est une baie au lieu d'être une capsule, mais la tige reste basse ou souterraine. Ce groupe renferme l'Asperge officinale à fleurs unisexuées et hermaphrodites, dont les pousses, décolorées par la vie sous la terre, constituent un aliment très apprécié. 11 y a des espèces exotiques, commel'Asperge plumeuse ou celle de Sprenger, qui, à cause de la légèreté de leur appareil végétatif, sont utilisées pour orner les tables et les suspensions. Dans le même groupe se placent les Sceaux de Salomon ou Polygonatum, dont le rhizome à étranglements porte des cicatrices correspondant aux tiges aériennes successives (p. 24); le Muguet ou Convallaire de mai, à deux feuilles et à fleurs en grelot. Le Petit Houx ou Ruscus est un petit arbuste à cladodes piquants, c'est-à-dire à organes complexes, à la fois tige et feuille. Les Aspidistra, à feuillage résistant, servent à orner les appartements; leurs fleurs, en urne, sont au ras du sol.

Les Smilacées forment un groupe très voisin, toujours à baies, mais à port grimpant par des vrilles-stipules.

Ungroupe un peu aberrant est celui des Colchicacées, défini soit par le fruit, qui est une capsule septicide, soit par l'orientation extrorse des étamines, ces deux caractères étant réunis ou séparés. On doit mentionner la Colchique d'automne, dont les grandes fleurs violettes sortent solitaires du sol; ce n'est qu'au printemps, longtemps après la disparition des fleurs, que le feuillage sort de terre. Les Sansevièries, à ovaire demi-infère, sont des plantes textiles.

Les Pontédériacées comprennent de jolics plantes aquatiques, les Eichhornics. Les Alismacées sont aussi des plantes d'eau très répandues, comme la Sagittaire ou Fléchière. Les Flûteaux ou Alisma sont voisins, ainsi que les Butomes à ombelle dont les fleurs sont roses. Quant aux Commelynacées, elles renferment des types, tels que les Éphémérines ou Tradescanties; ce sont des herbes vivaces à fleurs en fausse ombelle. 


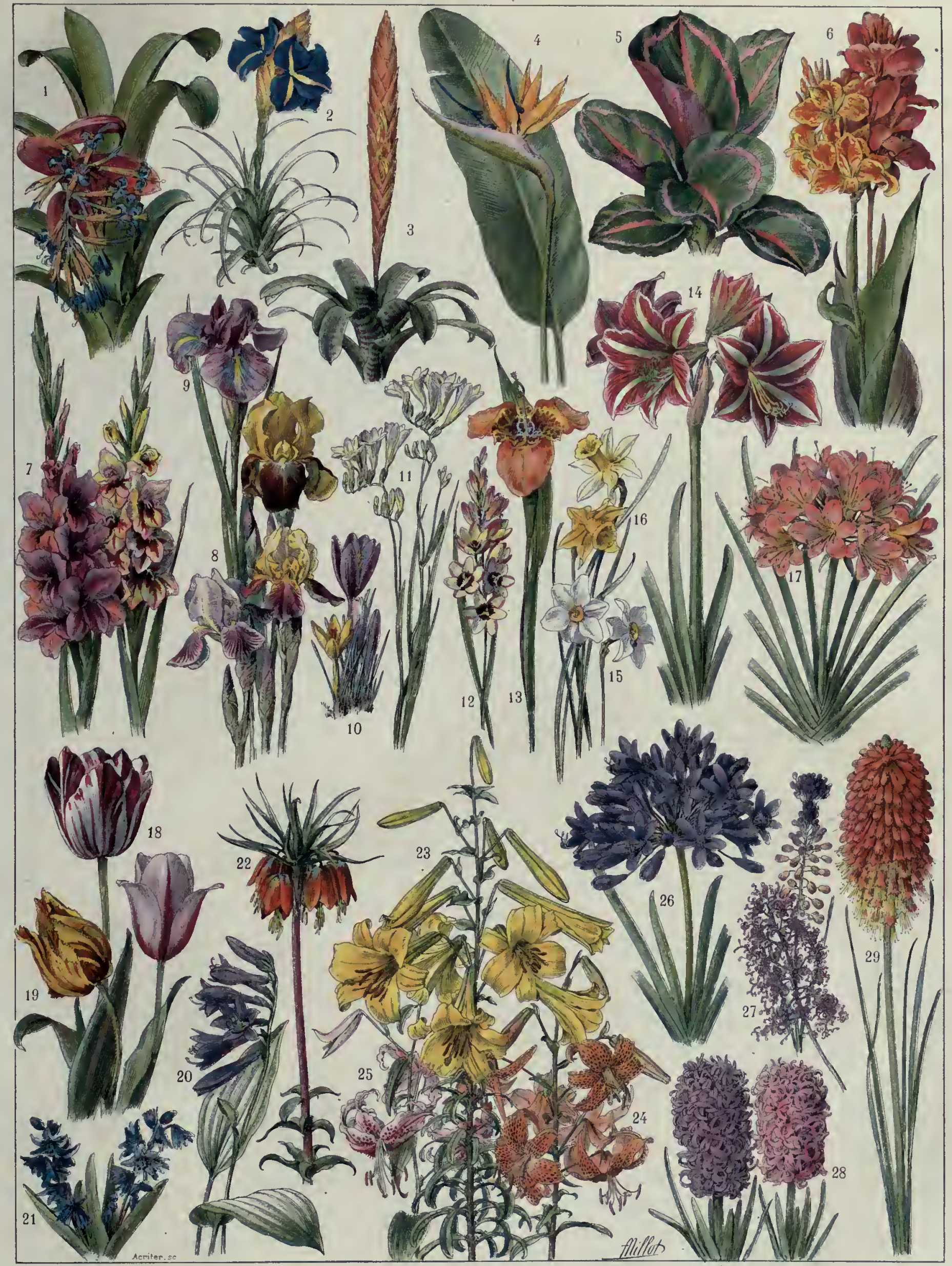

BROMÉLIACÉES, LILIACÉES, IRIDÉES, ETC.

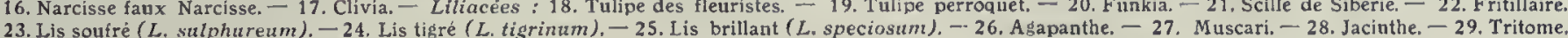





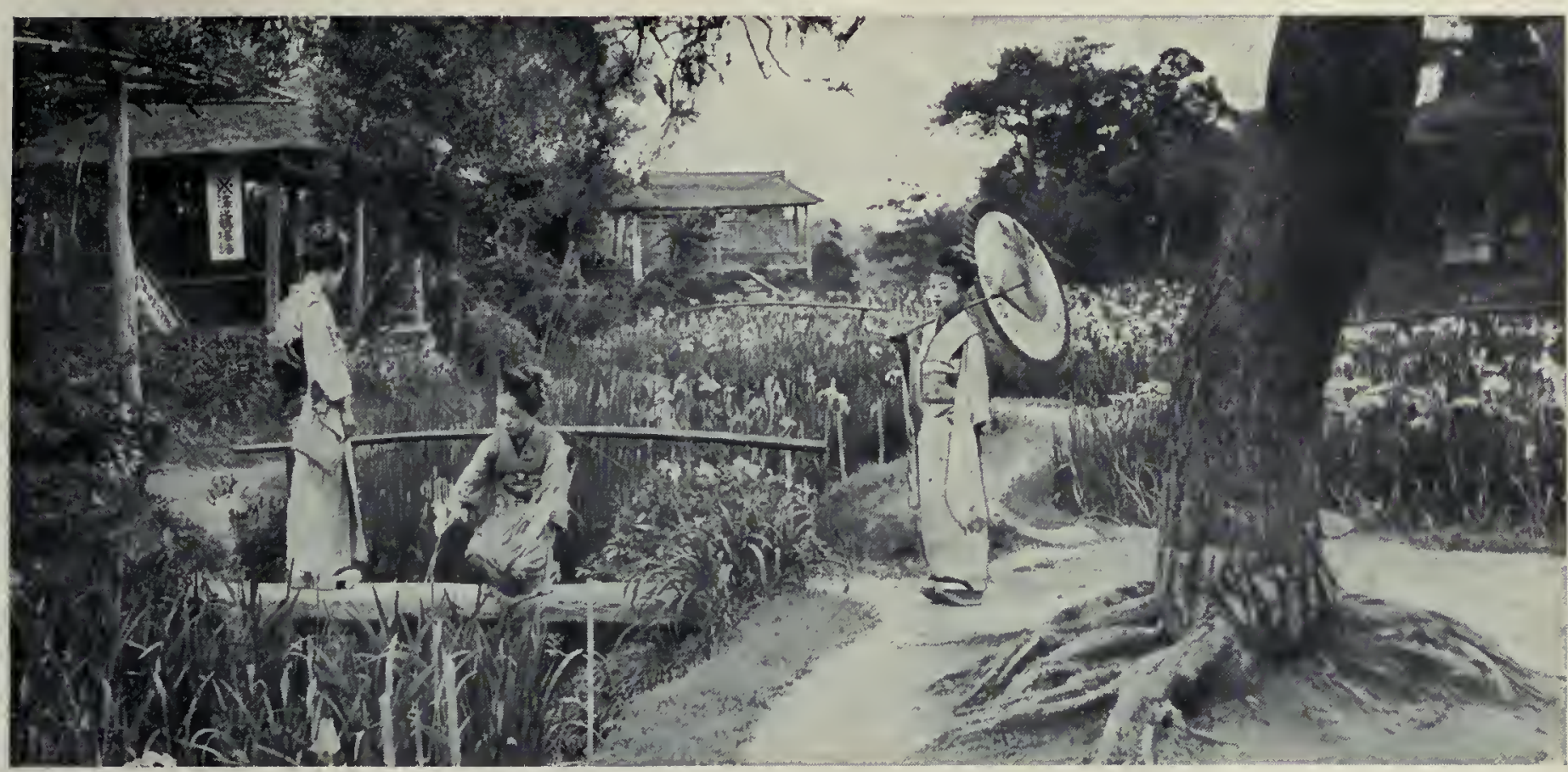

Jardin japonais avec Iris en fteurs anx environs de Tokio.

\section{LES IRIDINEES}

Les Iridinées sont des Monocotylédones à ovaire infère, comprenant les familles suivantes :

\begin{tabular}{|c|c|c|}
\hline & $\begin{array}{c}\text { Albumen } \\
\text { charnu. }\end{array}$ étamines $\begin{array}{l}\text { Hermaphrodites. } \\
\text { inlorses. Unisexuées.... }\end{array}$ & $\begin{array}{l}\text { Amaryllidacées. } \\
\text { Dioscoréacées. }\end{array}$ \\
\hline $\begin{array}{l}\text { Fleurs } \\
\text { régulières. }\end{array}$ & $\left\{\begin{array}{l}\text { Albumen amylacé . . } \ldots \ldots \ldots \\
\text { Graine sans albumen. . . . . . }\end{array}\right.$ & $\begin{array}{l}\text { Iridacées. } \\
\text { Brométiacées. } \\
\text { Hydrocharidées. }\end{array}$ \\
\hline $\begin{array}{l}\text { Fleurs } \\
\text { gomorphes }\end{array}$ & $\left\{\begin{array}{l}\text { Graine à albumen amylacé } \\
\text { Graine sans albumen ... }\end{array}\right.$ & $\begin{array}{l}\text { Scitaminacées. } \\
\text { Orchidées. }\end{array}$ \\
\hline
\end{tabular}

Amaryllidacées. - Cette famille présente de grandes homologies avec celle des Liliacées, dont elle diffère surtout par l'ovaire infère. Il y a un parallélisme complet entre les deux groupes, se manifestant aussi bien dans l'appareil végétatif que dans l'organisation forale; on y trouve des types à bulbes, à rhizome, à tiges ligneuses, ainsi que des plantes charnues rappelant, par leur port, tout à fait les Aloès, enfin quelques espèces grimpantes. Quant à la constitution florale, il y a un périanthe pétaloïde de deux verticilles de trois pièces, six étamines, un pistil à trois carpelles et un ovaire à trois loges à placentation axile; quant au fruit, il est presque toujours une capsule loculicide, rarement une baie charnue.

Les Amaryllidacées à bulbes peuvent nous servir à établir les ressemblances les plus accusées avec les Liliacées; la corolle cependant peut être pourvue de ce que l'on appelle une coronule; c'est ce qui arrive pour les Narcisses : cette coronule est une sorte de deuxième corolle qui double intérieurement la première, et qui est formée par un ensemble d'appendices des pétales, qui se soudent ensemble en un tube; ce tube èst très court, en coupe, dans le Narcisse Jonquille, à fleurs jaunes; il est au contraire très développé dans le Narcisse Faux-Narcisse ou Coucou; parmi les fleurs blanches, le Narcisse des poètes, à l-2 fleurs; le Narcisse Tazette, à 4-8 fleurs. Les Hippéastres, qui sont à tube court, présentent à la gorge une collerette d'écailles plus ou moins distinctes, correspondant à la coronule, et sur laquelle s'insèrent en dedans les étamines. La coronule est un tube faisant corps avec l'androcée chez les Hymenocallis (fig. 183), dont les grandes fleurs blanches sont en ombelle.

Les Crinum sont cultivés aussi pour la beauté de leurs fleurs odorantes.

La coronule fait au contraire défaut dans un certain nombre d'autres Amaryllidacées à bulbes. Dans les Hæmanthus, par exemple, les fleurs sont groupées en une grosse ombelle en forme de boule, où l'on aperçoit de nombreuses fleurs d'aspect filamenteux, d'abord à cause des six filets des étamines saillants, rapprochés et rouges, et ensuite à cause des six pièces du périanthe, très étroites et longues, surmontant un tube étroit et grêle. Les Clivia, connus souvent sous le nom d'Imanthophylles, très voisins des précédents, sont maintenant des plantes presque populaires; leurs feurs, au nombre de douze à vingt, sont encore en ombelle, mais leur périanthe est large, tubuleux à la base, puis s'élargissant en entonnoir à segments distincts; la tige aérienne est aplatic; elle surmonte un bulbe imparfait passant au rhizome.

Les Galanthes (Perce-neige) sont rustiques et justifient leur nom par leur floraison précoce; ils ont un tube du périanthe très court, des sépales et pétales dissemblables.

Les Agaves sont des plantes américaines des pays très secs, comme le Mexique, où elles ont joué do tout temps et où elles jouent encore à l'heure actuelle un rôle capital. Elles présentent à la base une rosette de très grosses feuilles charnues, en forme de triangles très pointus, dentées au bord; au milieu de cette rosette s'élève au bout d'un temps, variable de cinq à cent ans, une hampe florale qui peut atteindre 10 à 12 mètres dans certaines grandes espèces (A.américain, de Salman). Les Agaves fournissent le mezcal ou alcool d'Agave, dont on fait des eaux-de-vie supérieures (surtout avec l'A. de Salman). Il y a une autre espèce importante, c'est celle qui fournit le Chanvre de Sisal ( $A$. rigide, variété de Sisal), source de richesse du Yucatan. Signalons aussi le crin de Tampico, donné par différentes espèces ( $A$. hétéracanthe, etc.).

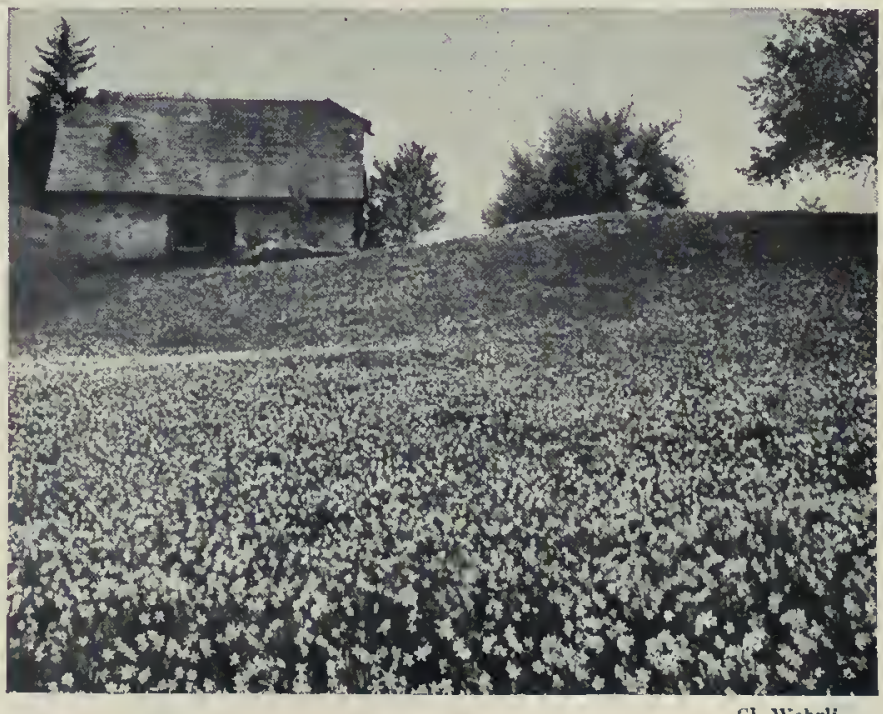

Floraison des Narcisses aux Avants (Vaud). 


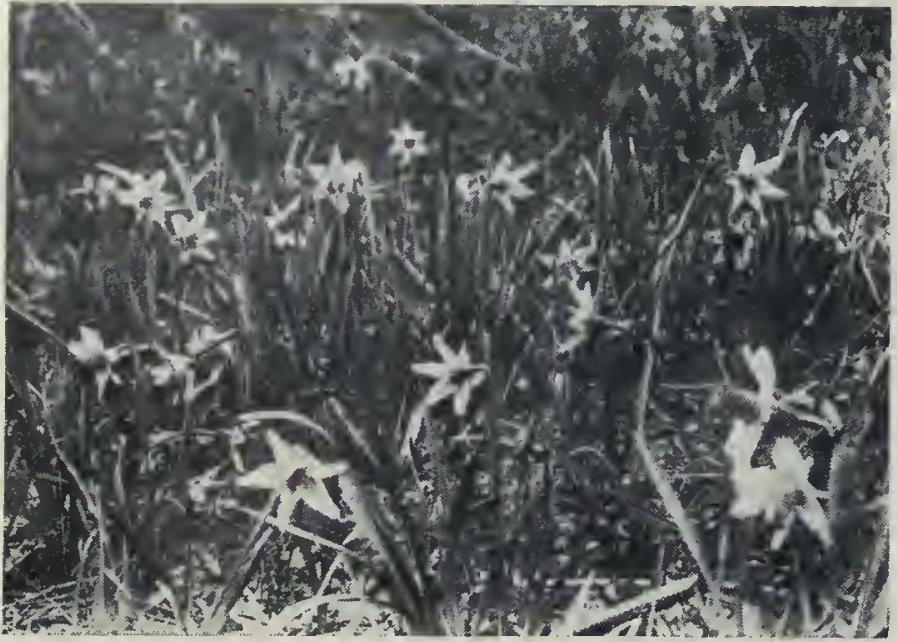

Narcisse Fanx-Narcisse (Forêt do Sénart).

Parmi les Amaryllidacées à rhizome, citons surtout la Polianthe tubéreuse ou Jasmin des Indes, plante du Mexique, à longue grappe sur un axe simple, à fleurs par deux à l'aisselle des bractées.

La petite famille des Dioscoréacées, très voisine, comprend des plantes volubiles, comme le Tamier de nos bois, les Dioscorea ou Ignames des régions chaudes. Le premier entre-nœud de la tige des Ignames se renfle en un tubercule pesant parfois 20 kilogrammes. Riches en fécule et en matière mucilagineuse, mais de saveur assez fade, ces tubercules font l'objet de cultures alimentaires en Chine et dans les régions tropicales.

Iridacées. - La famille -des Iridacées est très voisine des Amaryllidacées; elle est caractérisée par un ovaire infère et trois étamines extrorses. Nous prendrons comme type pour notre étude l'Iris germanique, ou Iris Armes de France, que l'on rencontre dans tous les jardins. L'appareil végétatif se compose d'abord d'un gros rhizome horizontal présentant une série d'étranglements plus ou moins accusés, les racines à la face inférieure; il se termine à son extrémité la plus jeune par un bourgeon redressé, recouvert de grandes feuilles vertes; ces feuilles sont sur deux rangs, distiques, et même équitantes, c'est-à-dire s'emboittant les unes dans les autres, se recouvrant par leurs gaines: elles sont en forme de sabre, aplaties sur le dos. La tige florale a quatre à cinq fleurs bleu ou lilas foncé ( $f$ ig. 184); les trois sépales bleu violet brillant sont réfléchis en dehors, à onglet veiné de brun, à barbes d'un jaune vif en dessus; les trois styles élargis ressemblent aux trois pétales, mais sont plus petits: le fruit est une capsule loculicide, les graines sont anguleuses. En dehors de l'Iris germanique, nous nous bornons à signaler l'Iris de Kampfer, qui est d'origine japonaise; $c$ 'est une espèce presque aquatique. Un troisième groupe d'Iris est formé par les bulbeux ou Xiphion, dont les sépales ont un onglet très long et divergent en coin, et un limbe divisé en apparence en trois parties, par suite de l'accolement des styles échancrés, dans l'Iris réticulé, de l'Asie Mineure et du Caucase.

Le style élargi en lame dans le genre Iris porte les stigmates sur sa face inférieure, à une distance notable de la pointe; il n'en est pas ainsi dans les Tigridia, pour lesquels : le stigmate est à la pointe. La fleur de tigre ou Tigridia oil de paon (fig. 185), du Mexique, a des sépales largement ovales,

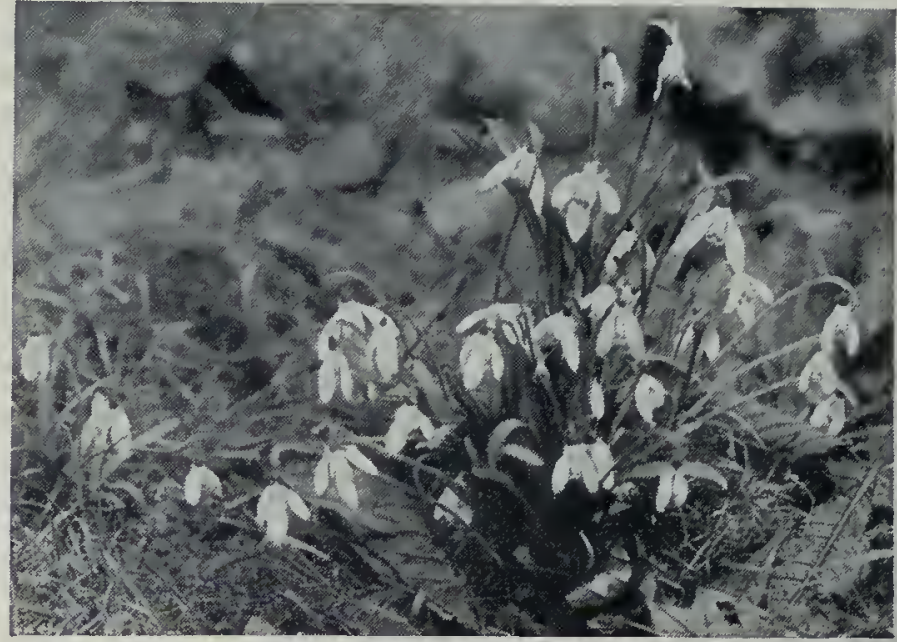

Perce-Neige dans le parc de Trianon.

étalés, non soudés à la base, maculés de pourpre; les pétales sont jaunes, tachetés de pourpre; les filets des étamines sont soudés en un tube au travers duquel passe le style.

Dans le genre Ixia, la spathe ne comprend plus

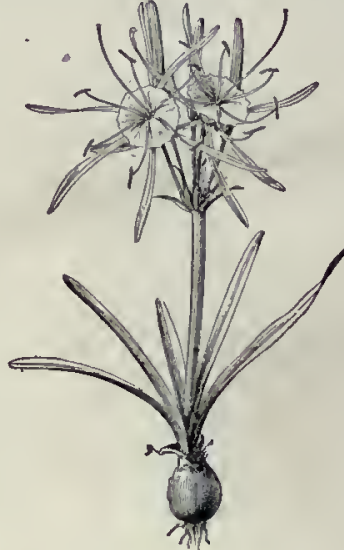

Fig. 183. - Hymenocallis. qu une fleur, l'épi est simple ou rameux, le périanthe étalé sans tube; la couleur des fleurs dans l'Ixia maculé est un mélange de jaune, de pourpre et de blanc.

Dans les Glaïeuls, les fleurs sont nettement irrégulières, à périanthe courbé. Ce sont des plantes à bulbes aplatis, solides, entourés de plusieurs tuniques fibreuses. Le périanthe est plus grêle, droit, bien que zygomorphe dans les Tritonia ou Montbretia, qui sont fréquemment employés dans l'ornementation des jardins. Ce sont des plantes bulbeuses susceptibles de prospérer magnifiquement en plein air pendant la belle saison.

Dans un dernier genre, celui des Freesia, qui nont toujours qu'une seule fleur par spathe, les branches du style sont deux fois divisées. Dans le Freesia réfracté, les grappes sont simples, à un petit nombre de fleurs d'un côté; le pédoncule floral présente la curieuse propriété de se courber brusquement à angle droit à l'endroit de l'insertion des premières fleurs. C'est une plante du Cap qu'on cultive en serre froide, qui est précieuse par sa floraison précoce et utilisée surtout pour la fleur coupée.

Les Crocus ou Safrans forment le type d'une dernière tribu caractérisée par l'absence de tige, par une fleur unique le plus ordinairement ou plusieurs, axillaires autour de la fleur terminale. Ce sont de très jolies plantes à bulbes solides, charnus; les feuilles sont étroites, linéaires, paraissant en même temps que les fleurs; le périanthe est en entonnoir et sort de terre; il est à tube très long et grêle, à six divisions dressées d'abord, puis étalées; les trois étamines sont insérées à la gorge du périanthe, souvent incluses, à filets courts ; le style est à trois branches, vivement colorées, et ce sont elles qui constituent la matière colorante que l'on en extrait et qui est connue sous le nom de safran. Il faut 140000 styles pour avoir I kilogramme de safran, d'une valeur de 70 francs. Les bulbes simportent de Hollande à l'automne en grande quantité; on les plante à 3 centimètres de profondeur. Ils fleurissent dès le mois de mars. Il y a aussi des espèces automnales, notamment le Crocus comestible, dont les fleurs sont violettes, la gorge barbue, les feuilles ciliées; le Crocus cancellatus est aussi mangé en Syrie. 


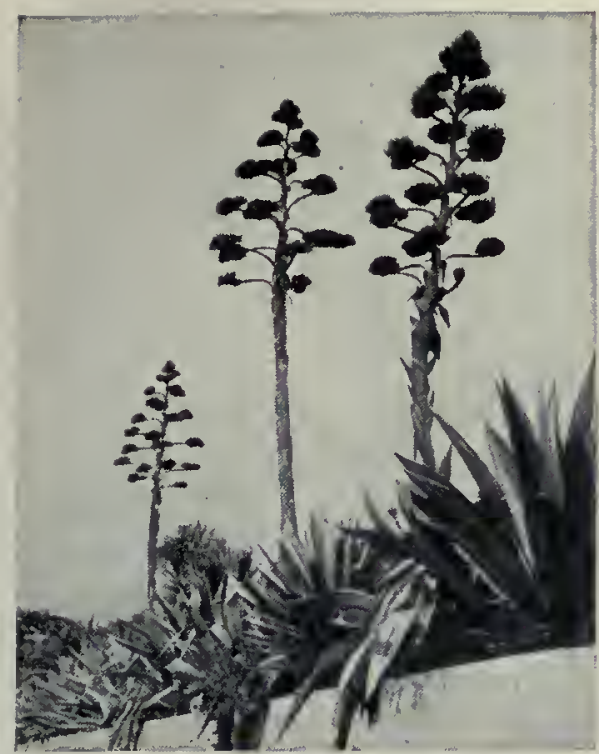

Agaves en fleurs (Côte d'Azur).

Broméliacées. - Les Broméliacées sont des herbes, en général épiphytes, de l'Amérique tropicale et subtropicale, qui jouent un rôle assez important dans les cultures de serre. Leur tige reste, en général, courte et épaisse; elle ne s'allonge quau moment de la production de l'inflorescence; les feuilles sont rassemblées en rosettes à la base de la tige; elles sont charnues, en gouttière, et l'eau de pluie est susceptible de s'y accumuler comme en de véritables réservoirs. Certaines esyèces sont destinées à vivre sur la couronne des arbres, comme les Tillandsies usnéoides, dont l'appareil végétatif se réduit à des feuilles qui jouent, pour ainsi dire, tous les rôles d'ordinaire dévolus aux racines et aux tiges.

Toutes les Broméliacées ne sont pas épiohytes : il y a un certain nombre de types terrestres comme les Ananas, les Pitcairniées, certains Karatas. Dans les Karatas, les feuilles du centre de la rosette se colorent souvent d'une manière vive et font ainsi passage aux bractées florales, pièces qui jouent dans cette famille un rôle important par leur taille et la beauté de leur coloris.

Les fleurs sont en général construites sur le type trois, c'està-dire à trois sépales en général courts; la corolle est formée de trois pétales soudés ou libres, six étamines et trois carpelles soudés en un ovaire infère (ou semi-infère dans les Pitcairniées), à trois loges, à placentation axile. Le fruit est une baie parfois comestible, souvent colorée d'une manière vive; ailleurs le fruit est une capsule septicide, comme dans la Dyckic, ou loculicide, comme dans les Puya. Dans les Ananas, toutes les baies se soudent à l'axe et aux bractées, et c'est l'ensemble qui constitue un fruit délicieux surmonté d'un toupet de feuilles stériles.

La variation du fruit permet de distinguer deux groupes dans les Broméliacées : celles à baies et celles à capsules, subdivisées en trois tribus : Broméliées, Pitcairniées et Tillandsiées.

Les Broméliées comprennent les Karatas et les Nidulaires dont les feuilles en rosette rappellent un nid, et dont les pétales sont soudés en tube. Les pétales sont au contraire libres dans tous les autres genres de Broméliées, notamment dans les Cryptanthes, qui ont, en outre, le calice gamosépale. C'est encore un genre curieux formé d'une rosette de feuilles s'étalant, dures, souvent épineuses, ondulées, écailleuses, rayées et ornées de panachures diverses qui leur donnent un aspect assez particulier.

Dans les Ananas, le calice est dialysépale, ce qui différencie tout de suite ce genre du précédent. II a d'ailleurs des caractères très spéciaux qui ne permettent pas de le confondre avec aucune autre Broméliacée. Ces plantes vivaces débutent par une rosette de feuilles étroites, coriaces, en sabre, épineuses le plus souvent, parfois panachées; la hampe florale apparaît au milieu et porte un épi serré

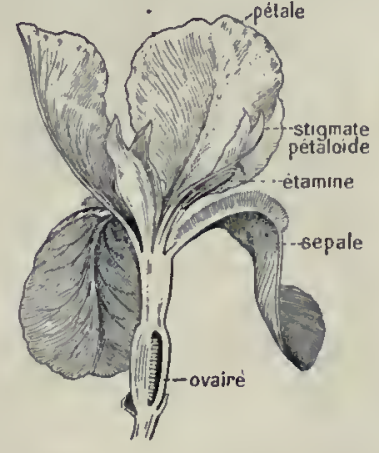

Fig. 184. - Coupe longitudinale de la fleur d'Iris. et les fruits mentionnés plus haut. La plante produit à sa base des drageons ou œilletons quand la fructification est prochaine; une fois le fruit coupé, les œeilletons se développent et on les laisse sur le pied mère jusqu à ce qu'ils aient de bonnes dimensions, puis on les détache alors et on les empote. On peut également multiplier la plante en enterrant la couronne qui surmonte le fruit. L'Ananas est une plante, originaire de l'Amérique du Sud, dont la culture s'est répandue partout dans les tropiques; c'est une espèce exclusivement tropicale.

Dans les Billbergia et les Echmea, qui ont le calice dialysépale comme dans les Ananas, l'inflorescence est lâche, en panicule, ou se condense en épi, mais sans jamais présenter la coalescence des fruits caractéristique du genre précédent.

La seconde tribu des Broméliacées est celle des Pitcairniées, dont le fruit est capsulaire et dont l'ovaire est seulement à moitié infère. Elle est surtout caractérisée par le grand genre Pitcairnia, qui renferme de très nombreuses espèces, les unes à fleurs en tête capituliformes, dites Cephalopitcairnia; les autres à grappes de fleurs ordinairement rouges, à graines avec des appendices à chaque extrémité. On en distingue des types nombreux, d'après les feuilles.

Enfin, dans les Tillandsiées, l'ovaire est entièrement supère, les feuilles sont entières. C'est là un groupe important qui renferme plusieurs genres dans les cultures, parmi lesquels on doit citer les Caraguata et Guzmannia, à corolle en tube, les premiers à inflorescence en tête ou pyramidale, les secondes à épis simples. Mais ce sont surtout les deux genres Vriesea et Tillandsia qui jouent un rôle important dans les serres par la multiplicité des types qu'on $\mathrm{y}$

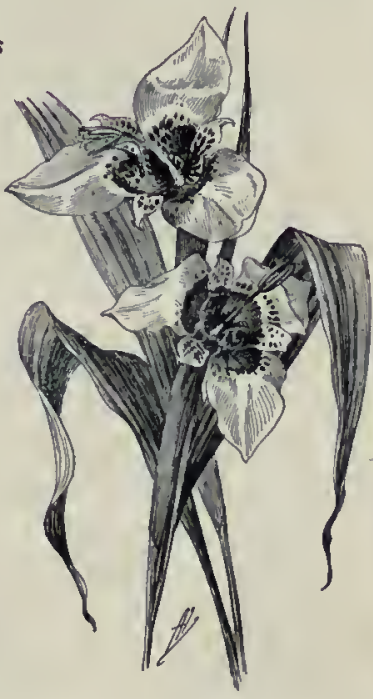

Fig. 185.
Tigridie en floraison.

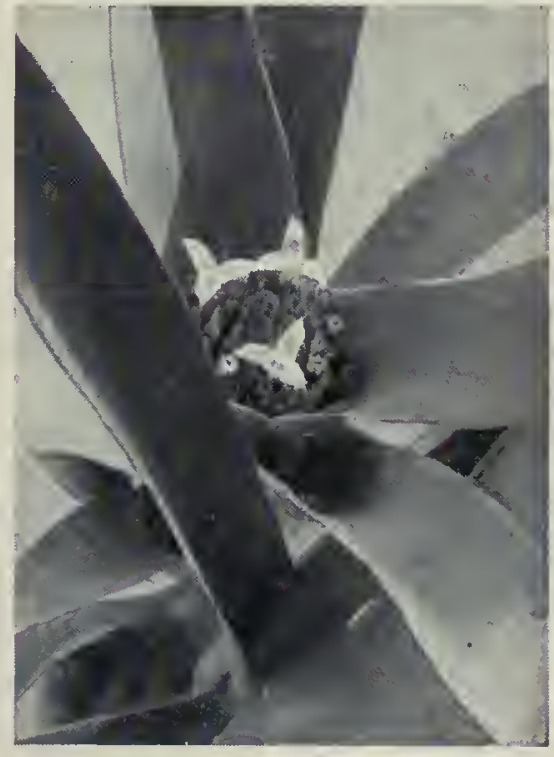

Nidulaire remarquable. 


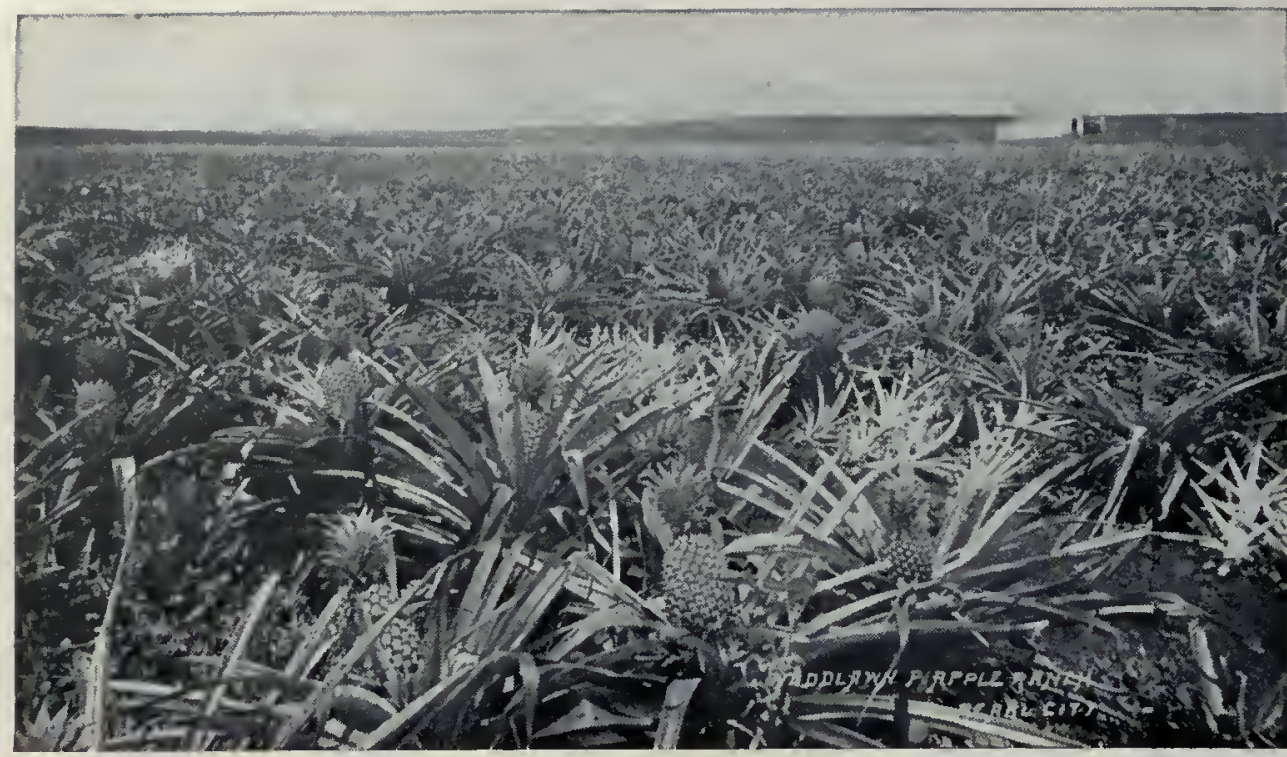

Une plantation d'Ananas aux iles Hawaï
Scitaminacées. - Musées. Prenons comme type das Scitaminacées le Bananier ou Musa. Nous connaissons ces plantes par le Bananier Ensete, que l'on voit figurer souvent dans les jardins; la tige, qui est surtout formée par la juxtaposition des gaines des feuilles, atteint I mètre de haut, mais dans les contrées tropicales cette plante peut avoir une hauteur de 6 à 7 mètres et la grosseur d'un homme; à la partie supérieure de la tige, il existe un certain nombre de grandes feuilles pouvant atteindre, dans les conditions les plus favorables, 4 à 6 mètres de long et I mètre de large; malheureusement, sous l'influence du vent, le limbe se déchire perpendiculairement à la grosse nervure et la feuille, primitivement simple, se fend en un certain nombre de lobes; on doit donc l'employer, dans les jardins paysagers, dans les positions abritées du vent. L'espèce la plus importante est le Bananier des sages ou du paradis. L inflorescence est un gros régime arqué, s infléchissant vers le bas;

rencontre. Dans les deux cas, le calice et la corolle sont formés de pièces libres; il y a deux écailles à la base de la corolle des Vriesea; elles manquent dans les Tillandsia. Parmi les plus beaux Tillandsia, on peut citer notamment le Tillandsia de Linden qui est une plante merveilleuse par l'opposition des fleurs bleues, grandes, qui apparaissent au milieu des bractées roses. Les Schlumbergeria, de l'Amérique du Sud, sont aussi de superbes plantes.

Hydrocharidées. - Les Hydrocharidées forment une petite famille de plantes aquatiques, qui sont, dans l'ordre des Iridinées, ce que sont les Alismacées dans celui des Lillinées, les Naïadacées dans celui des Graminidées. Les fleurs, régulières et du type trois, sont enveloppées par une spathe; l'ovaire est à une loze; le fruit est une baie. Cette famille renferme quelques plantes marines (Thalassia), mais la plupart sont d'eau douce, comme la fameuse Vallisneria spiralée (p. 71), la Morène ou Hydrocharis des grenouilles (H. Morsus rane), aux petites fleurs blanches, abondantes en été dans les fossés; le Stratiotès faux Aloès, dont les feuilles sont raides et à dents aiguës (Voir PLANCHE EN COULEURS). L'Elodea du Canada est arrivée, dit-on, d'Amérique en Irlande en 1836, attachée sans doute à la coque d'un navire. En 1846, elle est en Ecosse; en 1860, en Belgique; en 1867, elle remonte les eaux courantes de toute la France; en 1879 , elle atteint Cracovie, ayant ainsi conquis toute l'Europe. C'est une plante submergée, à feuilles très finement denticulées et à fleurs d'un blanc rosé. il est couvert de bractées disposées en spirale et portant à leur aisselle plusieurs fleurs hermaphrodites régulières. Chacune de ces fleurs présente un périanthe composé de cinq pièces soudées entre elles, soit trois sépales et deux pétales, réunis en un tube qui est fendu à sa partie supérieure; à l'opposite de ce tube se trouve le troisième pétale, qui est libre. L'androcée se compose de cinq étamines seulement, la sixième étant absente ou réduite à un staminode ; l'ovaire, qui est infère, est à trois loges, à placentation axile. A la maturité, le fruit est une grande baie oblongue, de section triangulaire, remplie d'une pulpe charnue où sont rangées, dans les plantes sauvages, les graines noires globuleuses. Normalement la plante cultivée est dépourvue de graines; elle ne peut donc pas être reproduite par des semis et c'est par les rejets qui se forment à la base du tronc que la plante se multiplie. Les fruits du Bananier des sages sont consommés crus : ce sont les bananes; ceux de la variété paradisea sont, au contraire, consommés cuits. L’importance de ces plantes est considérable pour l'alimentation des populations tropicales. La quantité d'aliment que peut produire une plante est énorme, un régime pouvant peser de 15 à 60 kilogrammes. Boussingault assure avoir vu un hectare de Bananiers rapporter 150000 kilogrammes de fruits; en général cependant la récolte ne dépasse pas 50000 à 70000 kilogrammes. Mangé cuit, le fruit du Musa paradisea est féculent; on peut en obtenir une farine qui est connue sous le nom de conquintay, aliment pour les enfants et les malades. Dans les Antilles, la culture du

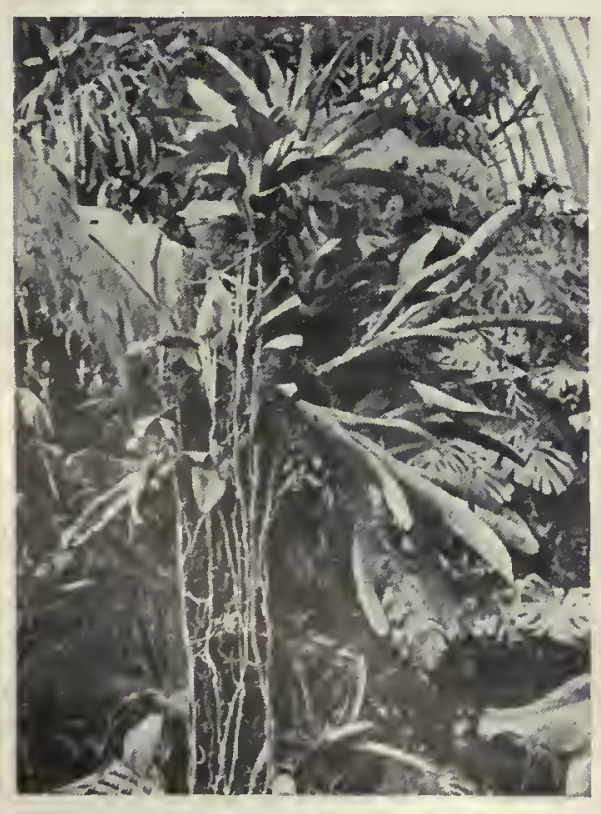

Echmées sur un tronc de fougère.

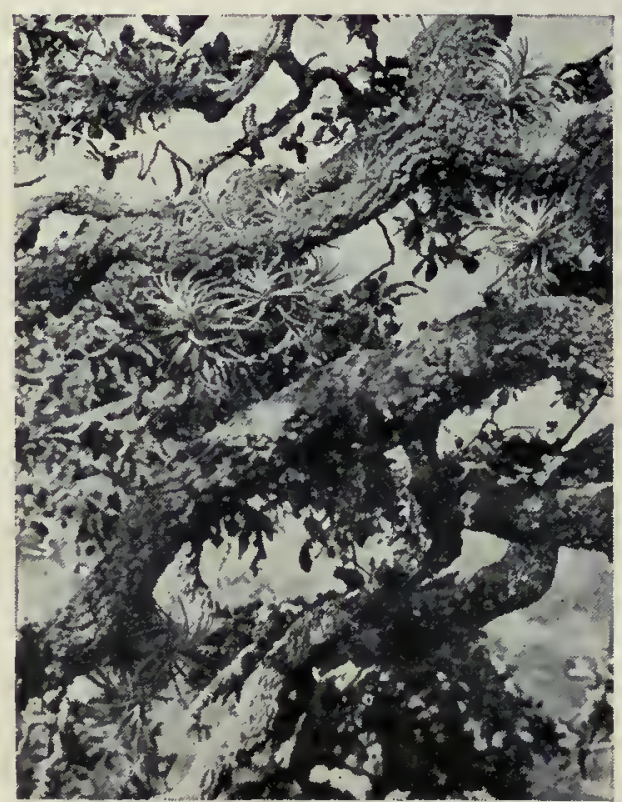

Tittandsia sur les branches d'un Chêne. Bananier se fait surtout pour les fruits et cette entreprise agricole a pris un énorme développement. Citons enfin le Musa textile, qui donne le chanvre de Manille.

Les Musa constituent dans la famille des Scitaminacées le type le plus perfectionné, caractérisé par l'existence de cinq étamines fertiles et par l'albumen amylacé de la graine. Dans le voisinage, on signale le Ravenala et l'Heliconia. Le Ravenala de Madagascar constitue ce que l'on appelle vulgairement l'Arbre du voyageur, parce quil offrirait, par l'eau qui s'accumule à la base de ses feuilles, une ressource aux gens altérés; mais il pousse généralement dans les endroits humides, ce qui diminue son utilité. Ses feuilles servent à faire des cuillers, des coupes, des nattes, etc.; elles sont distiques sur deux rangées, ce qui contribue à donner à cette plante un aspect très spécial. Cette disposition distique se retrouve dans les Strelitzia, qui sont cultivés dans les serres. Les Heliconia n'ont qu'une graine dans le fruit; les feuilles ont un long pétiole.

Zingibérées. Les Scitaminacées ont 


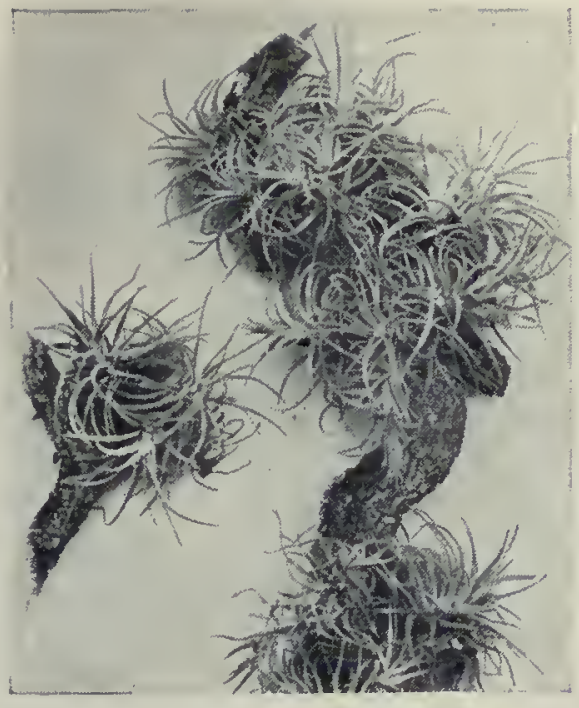

Tiltandsia de Bentham.

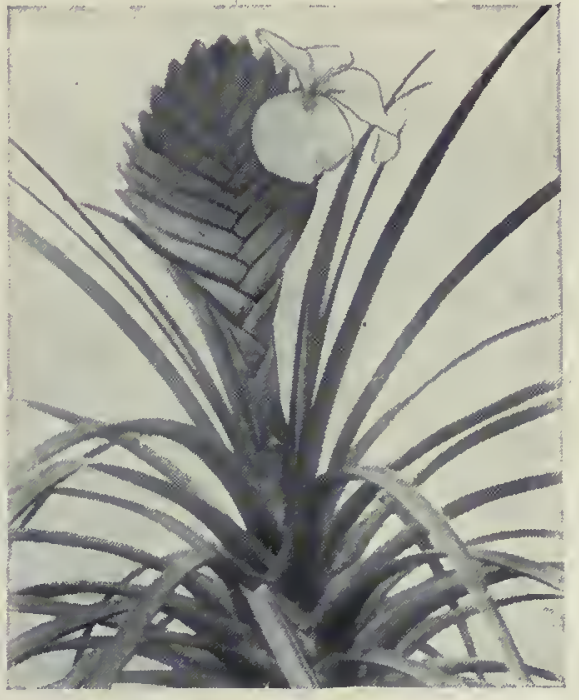

Tillandsia de Linden avec fleurs.

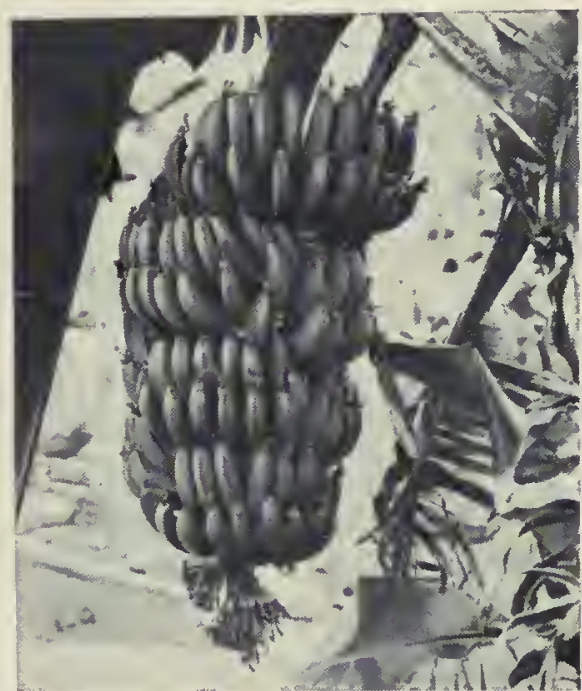

Régime de bananes sur la plante. été divisées en trois tribus : celle des Musées, dont nous venons de parler, puis celles des Zingibérées et des Marantées. Les Zingibérées, qui ont une seule étamine à leur fleur, renferment le Gingembre officinal, produit pharmaceutique et alimentaire bien connu. On distingue le gingembre blanc et le gris; le premier est le rhizome dépouillé de son écorce. Le Gingembre Mioga, originaire du Japon, est très utilisé dans ce pays : on y mange les jeunes tiges et les jeunes inflorescences; les fibres servent à faire des cordes. Les Cardamomes (Elettaric Cardamomes) sont voisines; les graines sont utilisées comme poivre ou girofle. Dans l'Amome Melegueta, les graines ont le même emploi; le connectif est aussi sans prolongement, mais il est élargi, ce qui n'est pas le cas dans les Cardamomes.

Une autre Zingibérée intéressante est le Curcuma long, dont le rhizome arrondi, ovoïde, avec de nombreuses racines, est plus épais et plus court que celui du Gingembre; ce rhizome est riche en amidon; il fournit l'arrow-root de l'Inde orientale, le tichir ou tikhur; on l'ajoute au chocolat et au cacao comme condiment. II donne également une matière colorante jaune qui sert à colorer le papier, le bois, le cuir, le tussah.

Chez les Kampferia, le connectif de l'étamine est à prolongement vers le haut, tandis que dans les Curcuma il se prolonge vers le bas. On cultive le Kampferia Galanga, que l'on emploic comme médicament et comme parfum.

Les Marantées ou Cannées constituent le troisième groupe de Scitaminacées, caractérisé par l'existence seulement d'une moitié d'étamine, le reste de l'organe étant pétalisé. La fleur du Canna ou Balisier est à trois sépales, trois pétales soudés en tube à la base à six pièces internes pétaloïdes, trois staminodes externes correspondant à trois étamines transformées; un labelle, grande lame correspondant au verticille interne, puis l'étamine à moitié pétalisée; enfin le stigmate lui-même se transforme en une lame colorée. Les plantes de ce genre ont été l'objet d'une culture très intense de la part des horticulteurs. Citons notamment le Canna d'Anné, hybride du C. de l'Inde et du C. du Népaul. En dehors des espèces ornementales, il y en a d'alimentaires : le Canna comestible ou capacho toloment (tous les mois, à cause de sa fécondité) est un aliment féculent; un rhizome peut peser jusquà 22 kilogrammes; le $C$. cocciné, le $C$. de l'Inde, sont utilisés en Afrique.

Il y a dans le groupe des Cannées une autre plante alimentaire plus importante encore. C'est celle qui fournit l'arrow-root du commerce, l'amylum Marante, le salep des Indes occidentales; c'est le Maranta arondinacé, espèce cultivée dans les régions tropicales pour son rhizome qui contient de la fécule blanche, de digestion facile, employée par les personnes délicates et dans les maladies des enfants notamment. Les rhizomes sont comprimés, charnus; la tige aérienne a 2 à 3 mètres de haut, les feuilles inférieures sont réduites à des gaines, les supérieures sont à long pétiole, à limbe ovale arrondi à la base, aigu au sommet; les fleurs sont blanches, en cyme terminale lâche, bipare; le fruit est à une seule loge; il n'y a pas cinq staminodes comme dans le Canna, mais deux staminodes latéraux. On cultive dans les serres un certain nombre d'espèces de ce genre, qui sont ornementales par leurs feuilles tachetées. On peut citer encore les Phrynium et les Calathea, et, parmi les espèces de serre chaude, les Thalia dealbata, qui sont de belles plantes aquatiques.

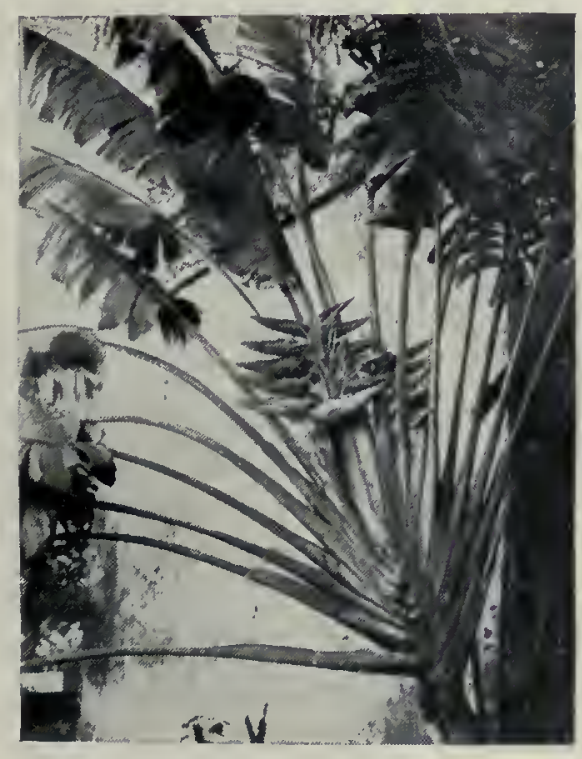

Ravenala et sa fleur.

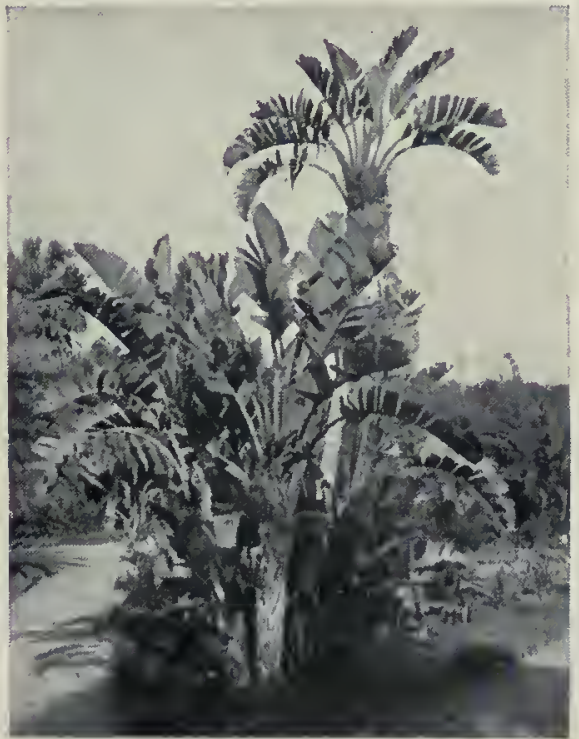

Stretitzia de la Reine,

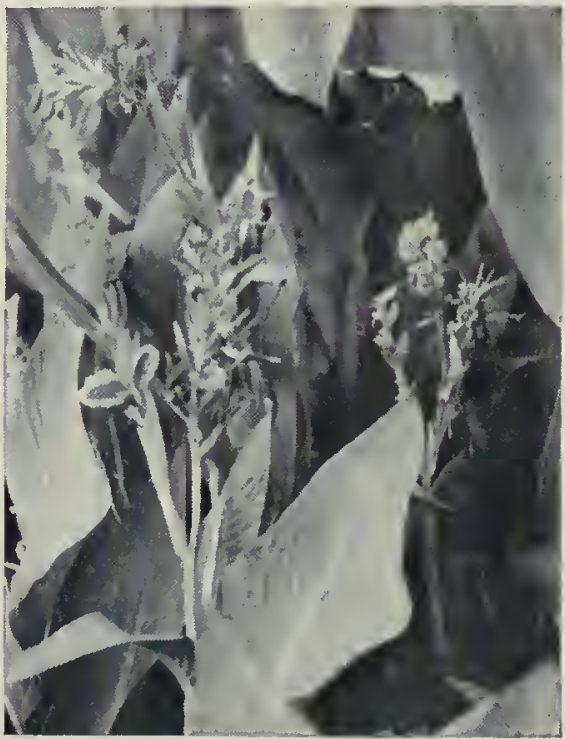

Batisier ou Canne d'Inde 


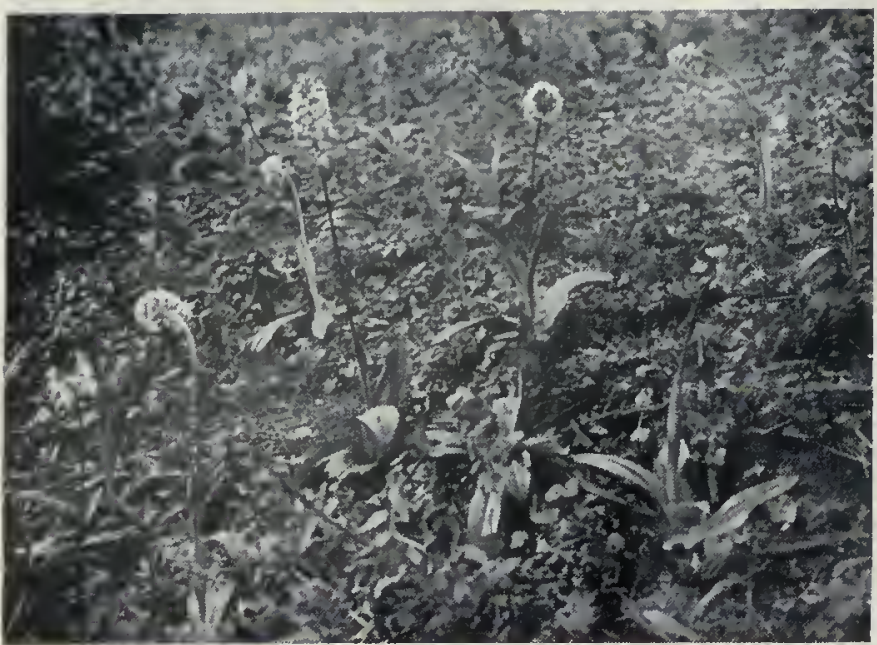

Colonie d'Orchis pourpres, en forêt de Carnelle.

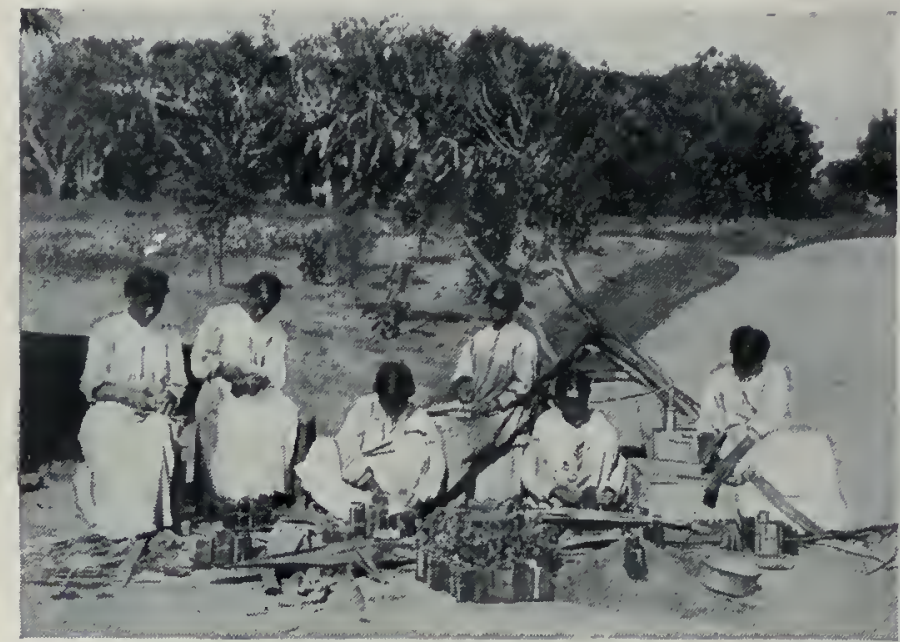

Fabrication des boites pour l'exportation des Orchidées, à Madagascar.

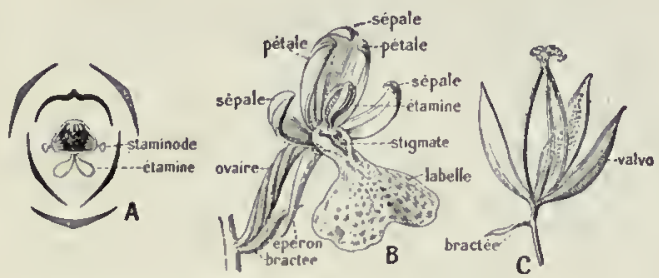

Fig. 186. - Fleur d'Orchidée.

A, Diagramme d'une fleur; B, Ensemble d'une fleur; C, Mode d'ouverture du fruit.

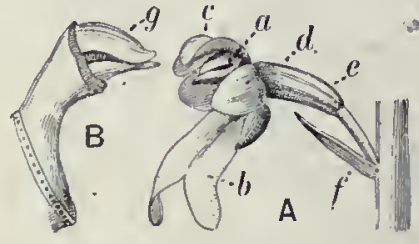

Fig. 187. - Néottie.

A, Fleur : $\alpha$, Gynosteme ; $b$, Labelle c, Sépale: $d$ Pétales latéranx: e, Ovaire; $f$, Bractée; B, $g$. Anthère.

\section{LES ORCHIDÉES}

Organisation. - Parmi les merveilles du règne végétal, les Orchidées tiennent le premier rang; la grandeur de leurs fleurs, leurs brillants coloris, leurs parfums enivrants, séduisent tous ceux qui les examinent; leur aspect étrange frappe tout d'abord, car ce sont des plantes de petite taille, malgré la grande dimension des organes foraux; leurs tiges, souvent bulbeuses, leurs feuilles épaisses et rigides, leurs racines aériennes argentées éveillent tout de suite notre attention et nous apprennent que nous n'avons pas affaire à des plantes ordinaires. Nous ne nous doutons pas de ces singularités quand nous étudions les Orchidées indigènes, beaucoup moins brillantes, que nous rencontrons d'ordinaire dans les prés humides et dans les bois sombres.

En déterrant ùn Orchis indigène, nous trouvons deux tubercules à sa base, souvent ovoïdes, parfois palmés; l'un d'eux est jeune, gonflé de matière nutritive; l'autre est ridé, brunâtre, en voie de résorption; ce dernier, en effet, a servi à nourrir la pousse florale qui sépanouit au moment où nous récoltons la plante en fleurs. Les palmures qui existent parfois dans les tubercules indiquent exactement son origine : c'est un faisceau de racines ou un cas de fasciation dans les organes radiculaires, mais il semble que cette anomalie des organes souterrains soit en relation avec la présence d'un Champignon dans les racines, bien que cependant les filaments de l'endophyte n'existent pas dans les tubercules. Lorsqu'à l'automne un seul tubercule subsiste à la suite de la décomposition du pluz ancien et que des racines ordinaires simples, non fasciées, sortent pour nourrir la plante, elles sont rapidement envahies dans leur écorce par un endophyte qui existe dans le sol. La présence de cet être étranger a des conséquences sur l'évolution du jeune bourgeon prêt à se développer; il est probable que le Champignon produit des toxines qui agissent à distance, car elles amènent la tuméfaction des bourgeons et la formation de cette tumeur qu'est le tubercule, constitué de racines fasciées (p. 59).

Ces quelques mots suffisent pour montrer que l'Orchis est une plante assez singulière; nous aurons une confirmation de cette opinion en examinant la fleur. La hampe florale est portée à l'extrémité de la tige feuillée, dont les feuilles élargies, dépourvues de pétiole, sont souvent maculées.

La fleur (fig. 186) naît à l'aisselle d'une bractée plus ou moins développée; elle a un ovaire infère, surmonté d'un périanthe formé de six pièces: trois sépales et trois pétales. Le sépale médian et les deux pétales latéraux sont rapprochés à la partie supérieure, de laçonà constituer un casque qui s'oppose à la partie inférieure, composée de deux sé-

pales latéraux et d'un pétale médian; ce dernier prend un grand développement et porte le nom de labelle. C'est ce labelle qui, par son amplitude, par la variété de ses formes, par la richesse de ses teintes, contribue à rendre les Orchidées si remarquables. Dans l'Orchis, il est découpé d'ordinaire en avant et présente en dessous un éperon où s'accumule du nectar, que viennent chercher les insectes, qui en sont friands (fig. 188). La partie mâle de la fleur se compose d'une seule étamine qui est sous le casque et qui se fend longitudinalement pour mettre en liberté deux masses polliniques

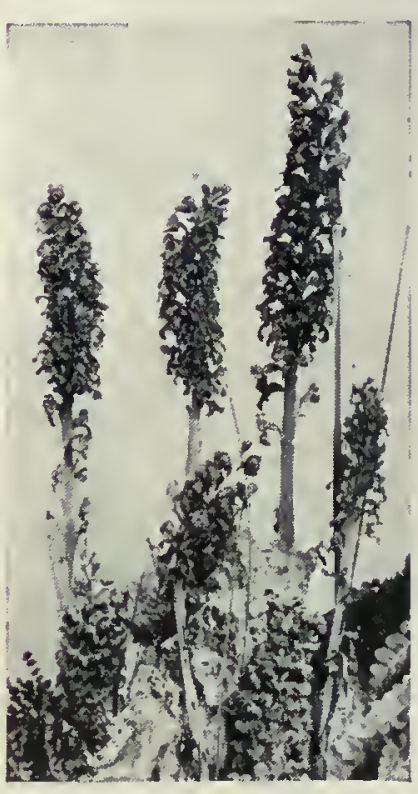

Néottie nid d'oiseau (fteur). liées, par une sorte d'appendice appelé caudicule, à une masse gélatineuse renfermée dans une petite bourse placée en avant. C'est cette pelote gélatineuse qui s'attache au corps de l'insecte et qui sert à la fécondation croisée (p. 61). Cette étamine est soudée au style, de façon à faire un organe hermaphrodite que l'on appelle un gynostème. L'ovaire est à une seule loge et pourvu de trois placentas pariétaux; il porte un très grand nombre dovules, tellement petits qu' on les a comparés à de la sciure de bois; les graines qui se développent après la fécondation, au bout d'un temps assez prolongé, de plusieurs semaines dans les Orchidées indigènes, mais de plusieurs mois pour les Orchidées exotiques cultivées dans nos serres, ne sont d'ailleurs guère plus grosses que les ovules eux-mêmes; elles renferment un embryon extrêmement 
petit, indifférencié, c’est-à-dire ne présentant ni radicule, ni tigelle, ni cotylédons; il est orné simplement de cellules semblables, toujours dépourvues de Champignons. Le fruit est une capsule qui s'ouvre par six fentes: trois valves restant réunies aux deux extrémités, les trois autres devenant libres à leur partie supérieure (fig. 186, C).

Nous avons insisté sur la présence du Champignon dans les racines et son absence dans la graine; c'est que la présence de cet endophyte, qui est d'ailleurs localisé dans les organes souterrains, joue un rôle capital dans la vie de l'Orchidée, et la germination de la graine ne peut avoir lieu sans que son invasion se produise.

A côté de l'Orchis que nous venons de décrire, il existe parmi les Orchidées indigènes un type très différent, c'est la Néottie nid d'oiseau. C'est une plante non colorée en vert, d'un blanc ocracé, qui ne donne jamais de feuilles

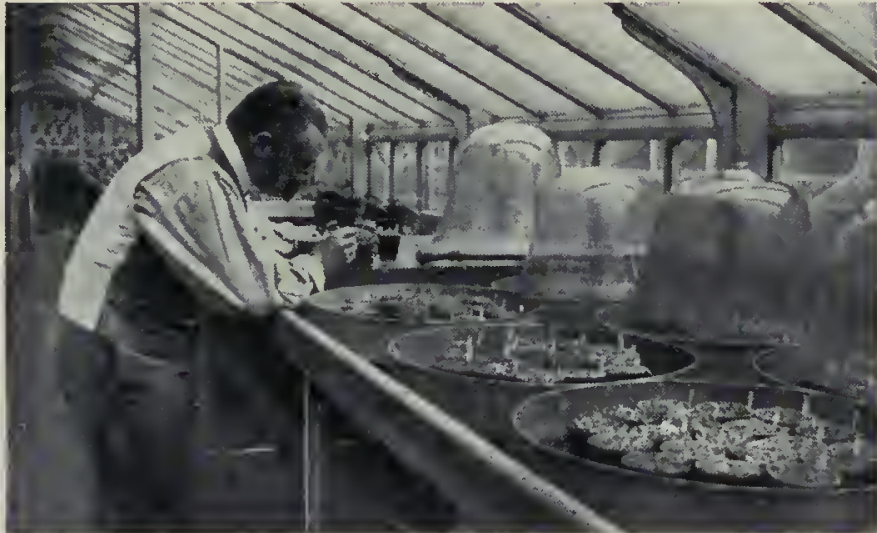

Repiquage des jeunes Orchidées exotiques. un peu de racines de Polypode fragmenté; les bûches ainsi constituées doivent être suspendues près du verre, de manière à donner à ces plantes le maximum de lumière. On peut encore les installer dans un panier à jour, dans le fond duquel on met de gros morceaux de charbon, audessus une couche de Sphagnum et, enfın, le compost destiné à entourer les racines; ces paniers doivent être encore suspendus à la charpente de la serre où l'on cultive la plante. Enfin, pour les espèces qui ont des exigences moins grandes au point de vue de la vie aérienne, on les place dans des pots dont on remplit à moitié le fond avec des tessons

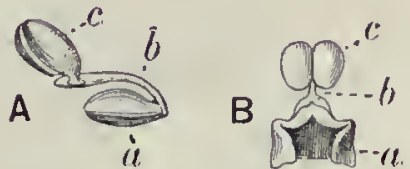

Fig.189. - Gynostèmede Vanda. A, Pollinaire vu de profil ; $B$, vu de face. - $a$, Masse adhésive; $b$, Stylet c, Pollinie. vertes, car ces organes sont réduits à des écailles blanchâtres; elle habite dans les régions sombres des forêts et ses parties souterraines sont formées de racines serrées les unes contre les autres, restant courtes, se ramifiant à leur extrémité en dichotomies répétées, de manière que l'ensemble a l'aspect d'un nid (p. 59).

Pour ces plantes, la vie en symbiose avec le Champignon est encore plus nécessaire, car la nutrition aux dépens de l'anhydride carbonique de l'air n'a pas lieu. Dans ce groupe, les pollinies sont formées de pollen pulvérulent : c'est ce qui arrive d'ailleurs aussi chez l'Orchis; la pollinie $n$ a pas ici de pédicelle et c'est par le sommet de l'anthère qu'elle s'attache aux corps étrangers ( $f$ ig. 187).

Culture des Orchidées épiphytes. - Dans la plupart des Orchidées des régions tropicales, le pollen reste agrégé en masses cireuses dont tous les grains sont fortement adhérents entre eux. Le mode d'existence est en outre différent; ce sont presque toujours des plantes épiphytes, vivant sur les arbres et qu'on doit cultiver d'une manière très particulière, en harmonie avec leurs conditions naturelles d'existence. Nos cultures sont approvisionnées de ces plantes par les introductions nouvelles des explorateurs, par les envois des grands établissements horticoles des régions chaudes, Java, Brésil, Madagascar, etc.; enfin par les plants obtenus de semis en serre. Les Orchidées épiphytes peuvent être suspendues à des morceaux de bois, à des troncs de Fougères en les attachant à l'aide d'un fil de laiton et en insinuant dans les anfractuosités qui existent entre la plante et le support du Sphagnum haché et de pots, cassés de manière à assurer le drainage; on recouvre d'une couche mince de Sphagnum, puis on met les plantes que l'on attache à un support et l'on entoure les racines du compost ordinaire, formé d'un mélange, haché à parties égales, de Sphagnum et de racines de Polypodes; la surface du pot est ensuite recouverte supérieurement par des têtes de Sphagnum, dont la décoloration indique la nécessité de l'arrosage. Les pots ainsi préparés sont placés sur des tablettes ou des étagères à claire-voie, de manière que toujours l'eau qui sort du pot, par le trou inférieur, puisse s'écouler; on met d'ailleurs souvent les récipients sur d'autres pots vides et renversés. On voit quelles précautions minutieuses on a été obligé de prendre pour simuler, dans nos serres, la vie épiphyte à laquelle les Orchidées sont habituées dans les régions chaudes.

Il y a lieu de distinguer deux groupes parmi ces plantes aériennes : les Vandées et les Épidendrées. Les premières ont des pollinies cireuses attachées sur un long stylet à une glande gélatineuse qui adhère d'une manière très forte au corps des insectes; en outre, leur inflorescence est toujours latérale ; dans les secondes, les masses polliniques cireuses sont dépourvues toujours de glandes, fréquemment le caudicule manque; enfin, leur inflorescence est presque toujours développée à l'extrémité de la tige.

Vandées. - Deux aspects très distincts de l'appareil végétatif peuvent sobserver dans les Vandées. La tige reste cylındrique, dressée, simple, avec deux rangées de feuilles insérées à droite et à gauche, et elle s'accroît par son extrémité d'une manière continue, portant de côté des pédoncules floraux, nés à l'aisselle des feuilles: c'est le cas des Sarcanthées; ailleurs, la tige se renfle en pseudobulbe formé $d$ 'un ou plusieurs entre-nœeuds et l'accroissement de la plante se fait par un sympode qui rampe à la surface du substratum nourricier : c'est le cas des Oncidićes, etc.

Le groupe des Sarcanthées (fig. 190) est illustré par une série de genres remarquables de serre chaude, tels que les Angracum, à fleurs en général grandes et surtout pourvues d'un très long éperon, qui peut atteindre, dans le fameux Angracum d'un pied et

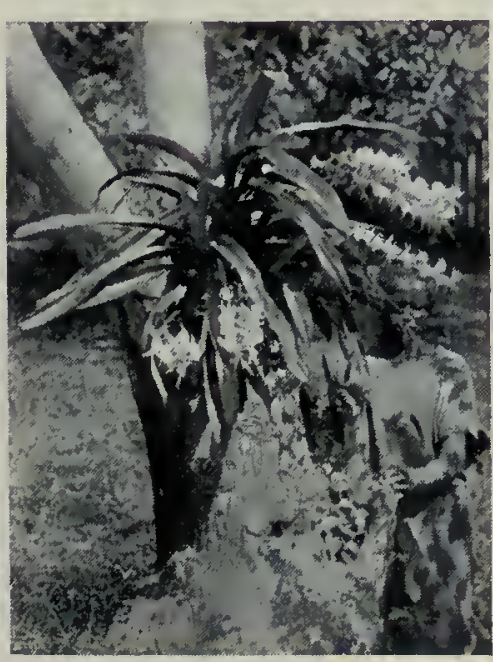

Orchidée épiphyte (Angraenm)

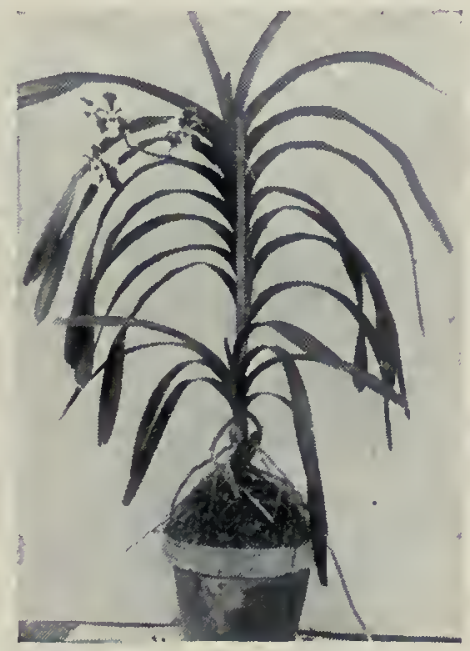

Vanda tricolore.

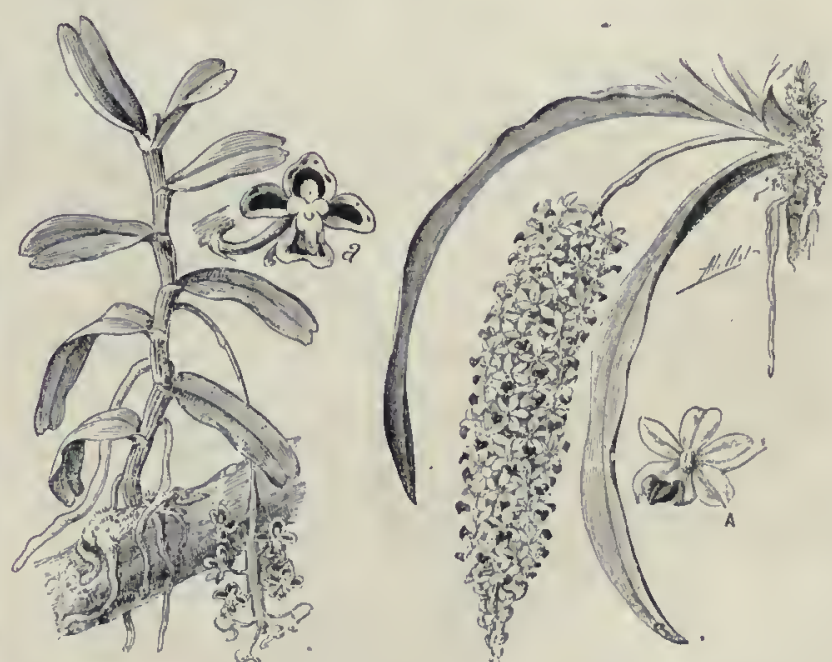

Fig. 190. - Sarcanthe, a,Fleur. Fig. 191. - Saccolabe. A, Fleur. 


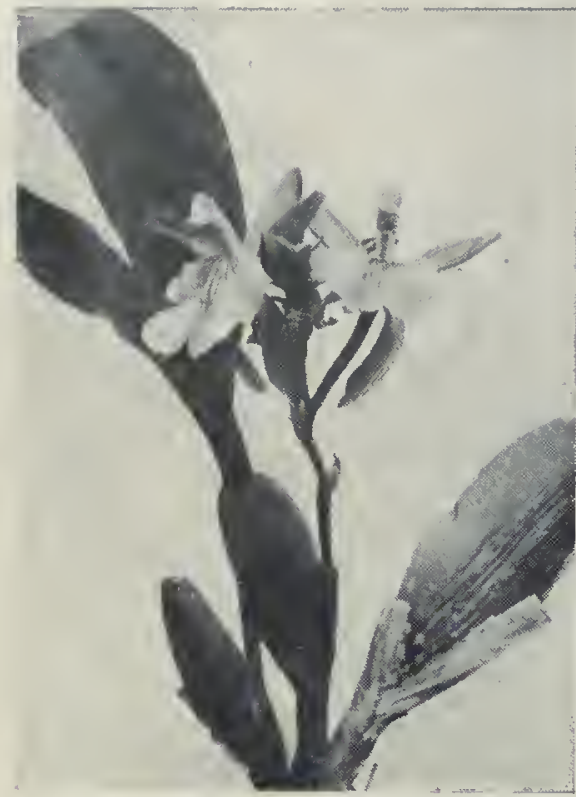

Aspasie panachée.

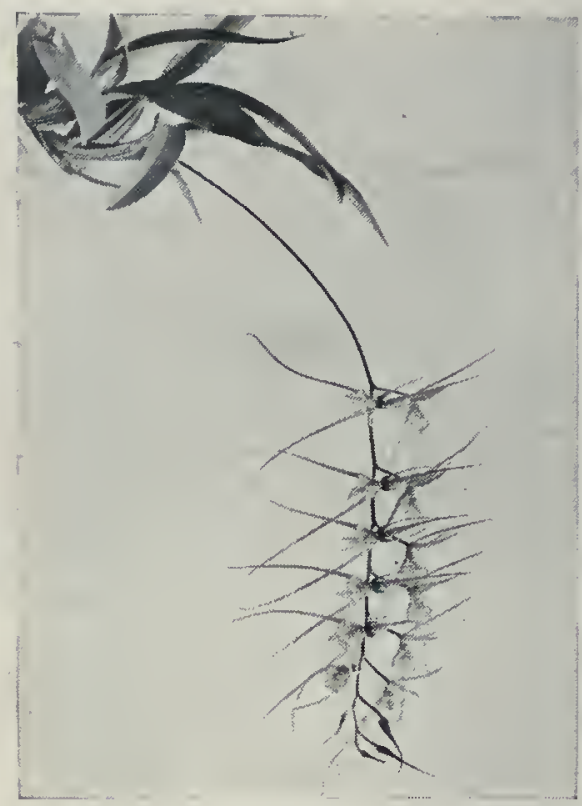

Brassia verruqueuse.

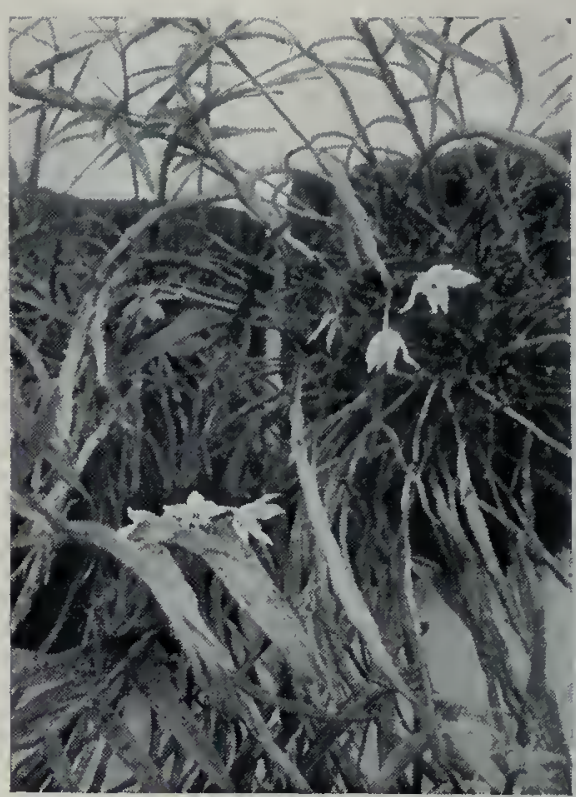

Dendrobe crochn. demi, de Madagascar, jusqu’à 45 centimètres; les $A$ érides, à éperon beaucoup plus court et courbé en avant, ont une grappe un peu plus serrée; la grappe devient tout à fait dense dans les $S a c-$ colabes (fig. 19l), mais les fleurs, par contre, deviennent plus petites et sont dépourvues d'éperon; il en est de même des $V$ anda, dont les fleurs sont en général plus grandes, plus espacées, formant une sorte de grappe assez lâche. Les Phalenopsis appartiennent au même groupe et leur corps floral a été comparé à un insecte; c'est le labelle qui est surtout de forme compliquée, avec des lobes latéraux, largement dilatés en palettes ovales, relevées sur les côtés; le lobe terminal est en forme d'ancre, avec deux cornes à sa base, se rétrécissant vers la pointe, qui se termine quelquefois par deux filaments tordus en spirale. Toutes ces plantes se développent dans les régions asiatiques et malaises et dans l'archipel de la Sonde.

Le groupe des Oncidiées est, au contraire, surtout américain. Il est rendu populaire par les Odontoglossum, qui sont des plantes merveilleuses; l'Odontoglosse crispée notamment est l'objet d'une grande culture pour la fleur coupée, et l'exploitation des forêts des environs de Pacho, à 30 milles de Bogota (Colombie), où se trouve cette espèce, est faite d'une manière tout à fait intense par les indigènes ou peons, en très grand nombre, qui se livrent à cette chasse fructucuse; cette exploitation abusive ne tardera pas à faire disparaître cette parure de la forêt vierge. Les Odontoglosses ont, au point de vue cultural, cet avantage d'être des espèces le plus sou-

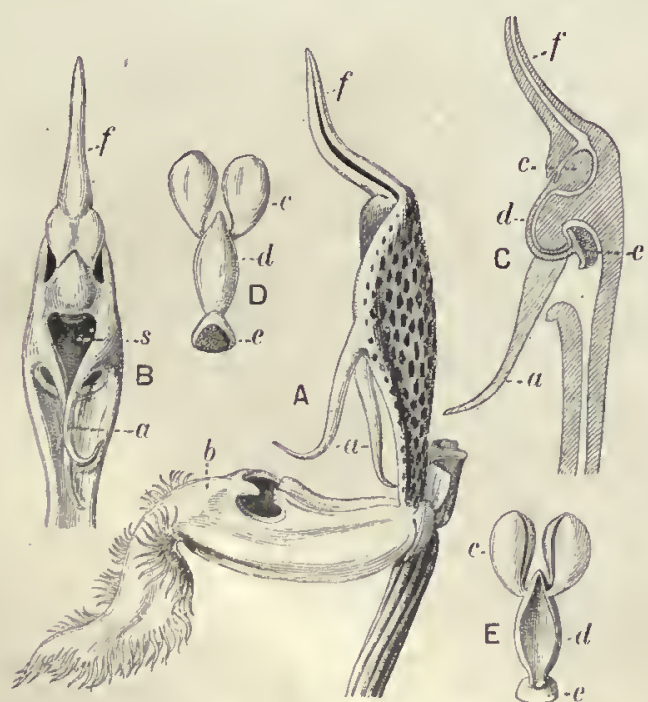

Fig. 192. - Gynostème du Catasetum.

$A$, Fleur débarrassée du périanthe, sauf le labelle; $B, C o-$ lonne vue de face; $\mathrm{C}, \mathrm{Sa}$ coupe longitudinale; $\mathrm{D}, \mathrm{E}$, Pollinaire, faces supérieure et inférieure. $-a$, Appendíces tactiles : $b$, Labelle; $c$. Pollinie; $d$. Son pédicule; $e$, Disque adhésif $f$ Pointe de l'anthére; $s$, Stigmate. vent montagnardesqui s'accommodent d'une faible quantité de chaleur et qui peuvent être placées dans la serre peu chauffée, même dans la serre froide. La forme de leur grand pétale est très caractéristique; leurs pétales et sépales sont étalés en étoile, mais leur labelle, qui est étalé dans sa partie terminale, présente une coudure à sa base; cette inflexion manque dans les Oncidies et les Miltonies, qui sont, au contraire, étalés dans un plan : les premiers ont un labelle contracté à la base; les seconds, au contraire, ayant ce grand pétale très élargi, échancré au sommet; la base ou disque du labelle est pourvue dans les Oncidies de crêtes, tubercules ou verrues qui manquent d'ordinaire dans les Miltonies. A côté se placent les Cochlioda, à pétales soudés à la colonne du gynostème à la base, et aussi les Brassia, ces derniers caractérisés par leurs sépales et pétales effilés, très étroits et très longs; les $A d a$, dont la fleur ne s'ouvre pas; les Trichopilia, dont le labelle est en forme de cornet. Dans tous ces types, les feuilles sont charnues, épaisses, solitaires ou par deux ou trois au sommet des pseudobulbes formés d'un seul entre-nœud.

Dans les autres Vandées, les feuilles deviennent plissées; elles sont moins épaisses que dans les genres précédents et parcourues par de nombreuses nervures presque parallèles. C'est là que se placent les Zygopétales à fleur étalée, à labelle élargi en éventail présentant à sa base un coussinet transversal; les Huntleya, superbes plantes de l'Amérique du Sud; les Lycastes, dont les trois sépales sont plus grands que les pétales et que le labelle; les Anguloa, dont la fleur globuleuse ne s'ouvre pas et rappelle celle d'une Tulipe. Dans les Cymbidies, le labelle a les lobes latéraux relevés en gouttière, le lobe terminal étant au contraire rabattu par le bas; ils ont d'ailleurs des pseudo-bulbes allongés, formés de plusieurs entre-nœeuds, tandis que dans tous les genres précédents le pseudo-bulbe est à un entre-nœud; les Eulophies et Lissochiles à labelle pourvu d'un éperon, ces derniers ayant les pétales plus grands que les sépales. $\mathrm{Ci}_{\mathrm{i}}$ tons, enfin, les Maxillaria à grandes feuilles solitaires, longuement pédonculées.

Un dernier type mérite d'être men tionné dans les Vandées à feuilles plissées: ce sont les Stanhopées, dont le labelle est charnu; ce sont certainement les plus étranges des Orchidées; cest là que se rangent les Stanhopes, dont l'inflorescence pendante est formée de fleurs qui rappellent un

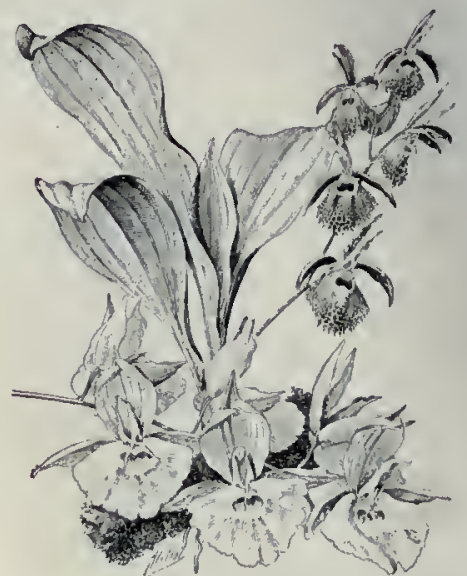

Fig. 194, - Catasète. 


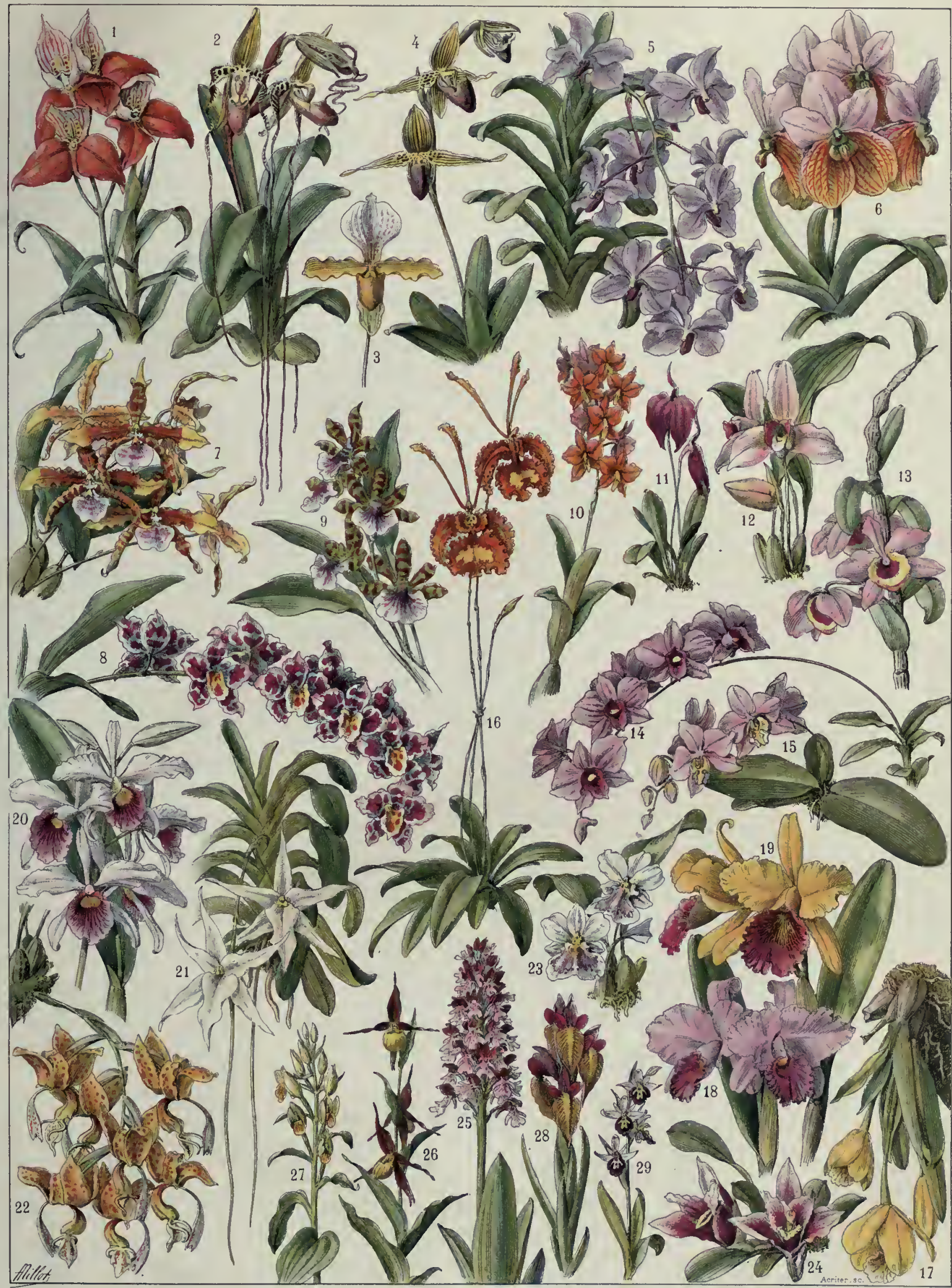

ORCHIDÉES

. Disa grandiflora. - 2. Cypripedium Sanderianum. - 3. Cypripedium Madame Engelhardt (C, insisne Maulei $\times$ Spicerianum $\Rightarrow C$. $\times$ Lecanum). crinitnm. - 10. Epidendrum vitellinum. - 11. Masdewallia Harriana. - 12. Lycaste Skinneri. - 13. Dendrobium nobile - 14 crispum. - 9. Zy 15. Phaloenopsis grandiflora. - 16. Oncidium Pa pilio - 17. Cattleya citrina - 18. Cattleya Trianx - 19. Cattleya Dowiana - 20. Llia purpurata - 21. Anfracum 



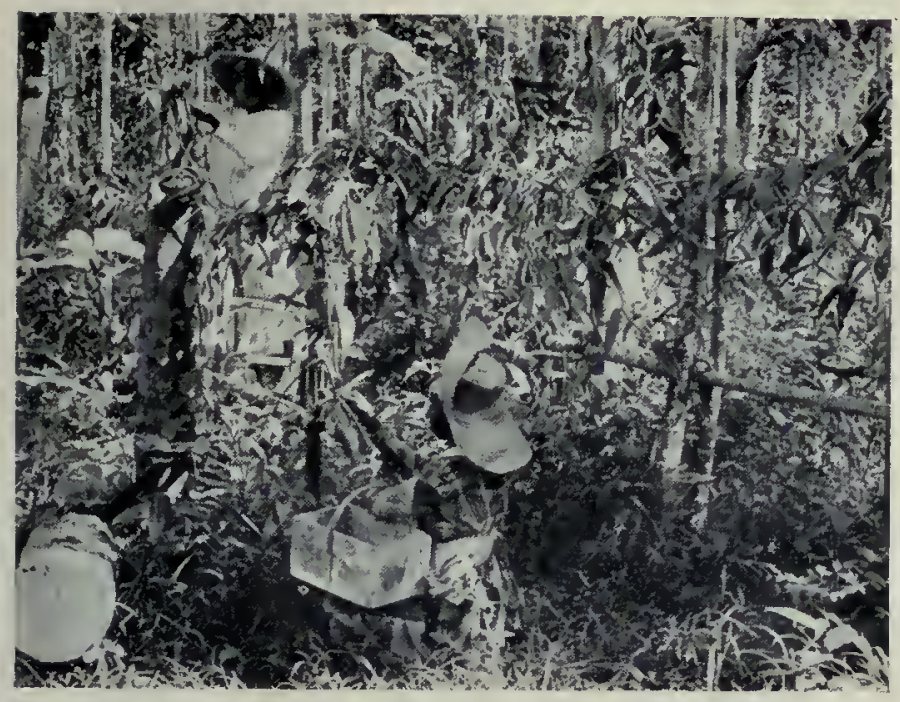

Récolte de la Vanitle, à la Guadeloupe.

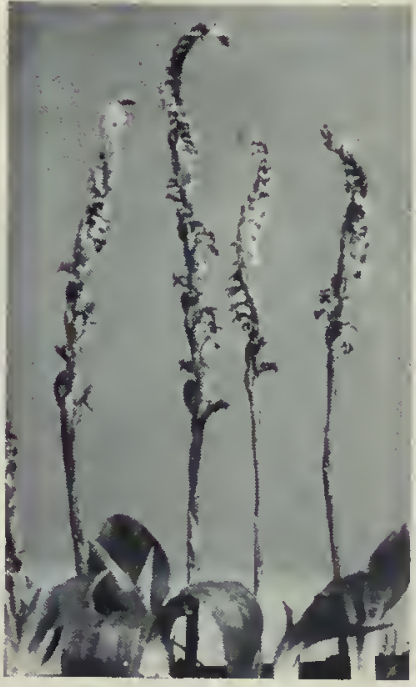

Spiranthe d'automne.

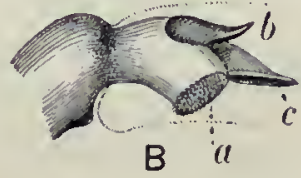

le système pollinique est lancé à la façon d'un projectile qui s'attache comme de la glu à l'animal. Les Acineta ou Fleurs du SaintEsprit sont de ce groupe : elles doivent ce nom à deux appendices du labelle qui ont été comparés aux deux ailes d'une colombe.

Épidendrées. - Dans les Épidendrées, les pollinies sont ou bien sessiles, sans caudicule ni glande adhésive, ou bien elles ont un caudicule, mais jamais de glande; l'inflorescence est d'ordinaire terminale. Parmi les plus remarquables représentants de ce groupe, on peut citer les Épidendres, qui sont les plus anciennement connus, et, du temps de Linné, presque toutes les Orchidées exotiques étaient appelées des Épidendres, parce qu'elles poussaient sur les arbres; mais les deux genres les plus remarquables du groupe sont surtout les Cattleya (fig. 193) et les Lalia; il n'y a pas de fleurs plus belles, et il ny en a pas maintenant dé plus connues, à cause de la splendeur du coloris et de leur grande taille. Dans ces deux genres, il y a des pétales particulièrement larges et un labelle en forme de cornet; ils peuvent, à cause de cette similitude d'aspect, être confondus l'un avec l'autre, mais ils se distinguent par la constitution de l'étamine : il n'y a que quatre pollinies dans les Cattleya, il y en a huit dans les Lælia. Ces plantes merveilleuses ont été croisées entre elles et les hybrides obtenus, que l'on appelle des Lalio-Cattleya, sont d'une grande beauté et se vendent parfois au poids de l'or. Dans les Sophronitis, qui sont très voisins, le cornet du labelle est plus accusé encore; mais tandis que les lobes latéraux étaient précédemment libres, ils deviennent ici connivents et masquent complètement le labelle.

Dans tous les types d'Épidendrées que nous venons de signaler, les inforescences sont terminales et les feuilles pliées dans le bouton, de manière que les bords ne se recouvrent pas; il en est encore de même dans les Thunia, qui ont un port élancé et à pseudo-bulbes très allongés; leurs belles feurs ont le labelle un peu en cornet, pourvu d'un éperon à la base. L'éperon manque chez les Calogyne, qui ont, au contraire, des pseudo-bulbes.

L'inforescence est latérale chez les Phajus, plantes terrestres ressemblant beaucoup aux Thunia, mais ici toutes les feuilles sont à la base et à nervures nombreuses, plissées; le labelle est libre, bien qu'entourant le gynostème. Dans les Calanthe, il est soudé à lui et l'éperon est assez allongé. Les Chysis sont, au contraire, dépourvus d'éperon, mais pourvus d'un menton, c'est-à-dire de deux sépales latéraux décurrents sur le pied de la colonne. Les Bletia, très voisins, sont dépourvus de menton.

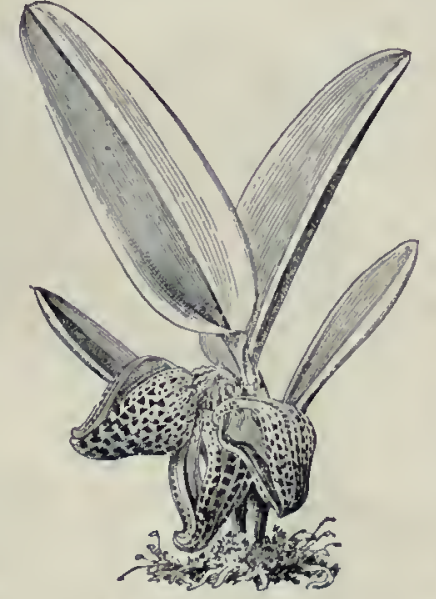

Fig. 196. - Cryptophoranthe.
Fig. 197. - Orchis tacheté.

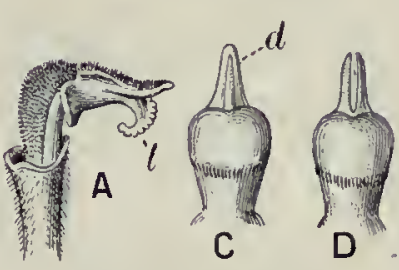

Fig. 195.

Gynostème d'un Spiranthe.

A, Gynostème; B, Vue latérale, périanthe enlevé el pointillè ; $C_{\text {, Stigmate }}$ et rostellum vus par-devant: $D$, Les mêmes, moins le disque visqueux. $a$, Stigmale; $b$, Anthere ; $c$, Rostellum; d. Disque visqueux. Bulbophyllinées comprennent des genres singuliers, comme les Megaclinium, à hampes florales aplaties sur le milieu desquelles apparaissent de petites fleurs; les Cirrhopitalum, dont l"inforescence est une ombelle, et les Bulbophyllum, dont la hampe est cylindrique et les fleurs en épis ou solitaires. Chez quelques-unes de ces espèces, la mobilité du labelle et l'excitabilité de cils tactiles est très remarquable.

Enfin, un dernier groupe d'Épidendrées est celui des Pleurothallidinées, qui ont des tiges filiformes, sans pseudo-bulbes et, dans la fleur, des sépales prédominants; c'est ce qui arrive, par exemple, dans les Masdevallia, où les trois sépales sont soudés en coupe à la base et s'effilent d'ordinaire en longs appendices, for-

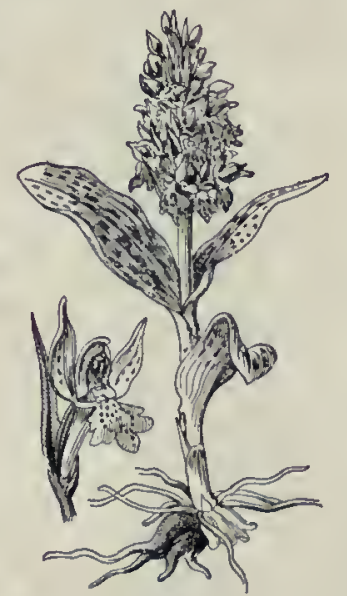
mant trois sortes de queues qui rendent ces fleurs très différentes de toutes les autres Orchidées; les pétales et le labelle sont petits et cachés dans le tube calycinal. Les Cryptophoranthes (fig. 196) ont trois sépales soudés à la pointe, laissant par conséquent sur les côtés deux fentes latérales.

Néottiées. - Les Néotliées et les Ophrydées, qui comprennent la plupart des Orchidées indigènes des pays froids, se distinguent des Vandées et des Epidendrées par leur pollen qui est pulvérulent, au lieu d'être formé de masses d'assez forte taille et de consistance cireuse. Ce groupe comprend surtout les Sobralia, qui ont l'aspect de Cattleya, avec une tige élevée, des feuilles plissées, mais qui 


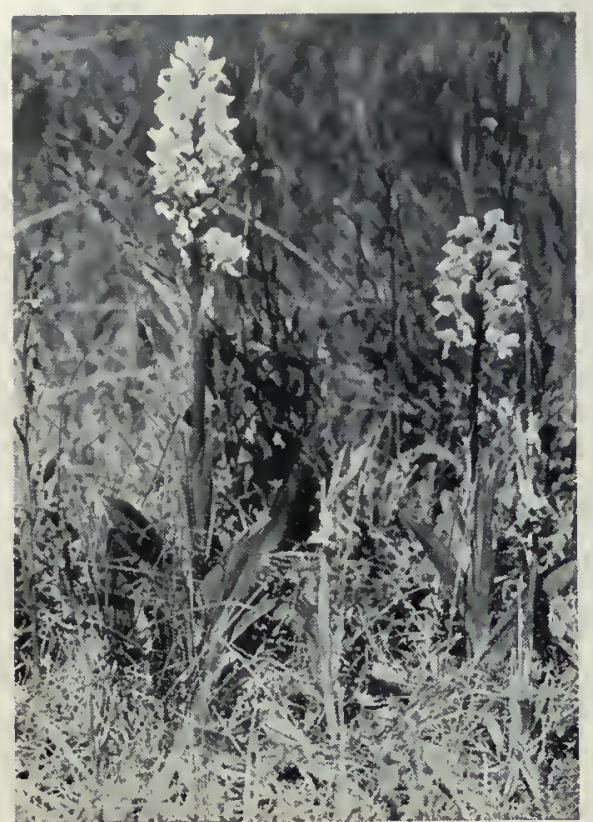

Orchis singe.

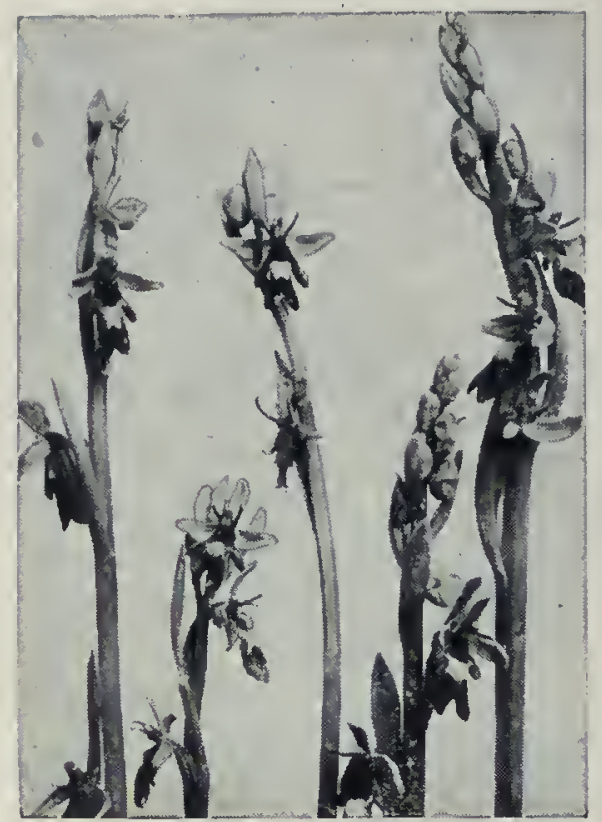

Ophrys mouche.

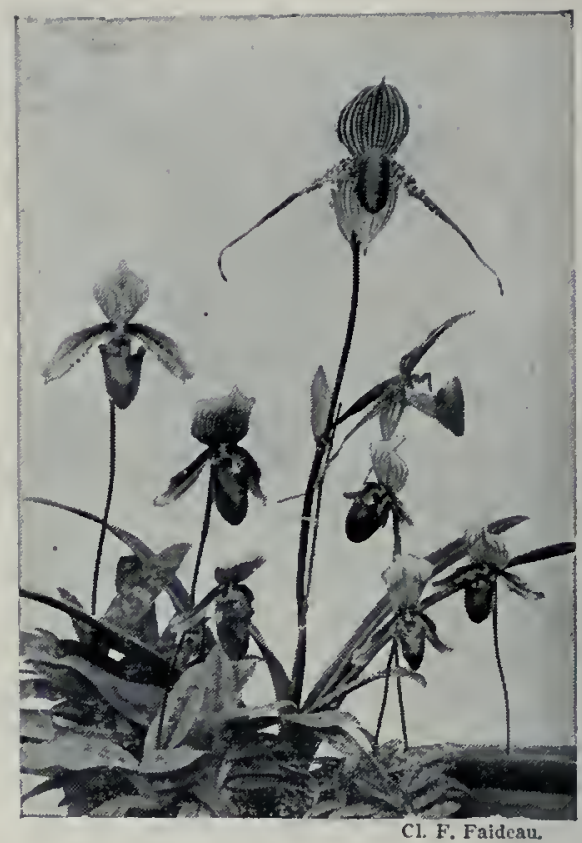

Groupe de Cypripèdes.

sont terrestres; les Vanilles, qui sont des plantes grimpantes, à labelle en cornet, que l'on cultive à la Réunion pour leurs fruits allongés. Enfin, c'est dans ce même groupe que se rangent ces jolies Orchidées délicates, exigeant en serre chaude la culture sous châssis, que l'on appelle les Anectochilus, les Dossinia, les Hamaria, les Macodes: leur feuillage est d'une singulière beauté, velouté et parcouru de nervures d'or ou d'argent.

Ophrydées. - Les Ophrydées comprennent les Orchidées indigènes à pollen pulvérulent et basitones, le pollen s'attachant par un caudicule à la basc de l'anthère; les unes ont des tubercules souterrains : tels sont les Ophrys et les Orchis, qui se distinguent l'un de l'autre par l'existence de deux bursicules pour contenir des glandes adhésives attachées à la masse pollinique dans le premier genre et d'une seule petite bourse dans le second. Il y a deux glandes adhésives dans les Orchis (fig. 197), tandis quil n'y en a plus qu'une, dans une seule bourse, chez les Serapias, les Aceras, les Loroglosses, les Anacamptis; les Serapias sont des Orchidées de la région méditerranéenne, à lobe médian du labelle large, non divisé et terminé en pointe. Chez les Spiranthes ( $f$ g. 195), les fleurs, petites et blanches, sont disposées sur la hampe suivant une ligne spirale. Les Céphalanthères ont un rostellum presque avorté, le labelle est éperonné; la Céphalanthère rouge est commune dans nos bois.

Le labelle est, au contraire, divisé en quatre parties, qui ont été comparées à deux bras et à deux jambes, dans l'Acéras homme pendu; la tête du pendu, étant orientée obliquement par rapport au labelle, est constituée par le casque du sépale dorsal et des sépales latéraux. Dans le Loroglosse, le labelle est démesurément long et enroulé en spirale dans le bouton, tordu sur lui-même quand il est épanoui. L'Anacamptis pyramidal a un labelle relativement petit, trilobé, avec deux bourrelets longitudinaux. Nos Ophrys indigènes se rencontrent sur les coteaux secs; ce sont de charmantes petites plantes, dont le labelle épais et velouté ressemble fréquemment à un insecte : d'où les noms d'Ophrys mouche; O. araignée, O. abeille, O. frelon.

Le rétinacle ou glande est nu dans la Gymnadénie et le Platanthère, qui se distinguent par leur éperon très long et parfois renflé vers l'extrémité. Dans tous les genres précédents, les stigmates sont en creux, tandis quils sont, au contraire, en saillie dans un grand genre exotique à grands éperons, appelé $\mathrm{Ha}$ benaria. Les Disa sont des Ophrydées du Cap que l'on rencontre dans les cul-

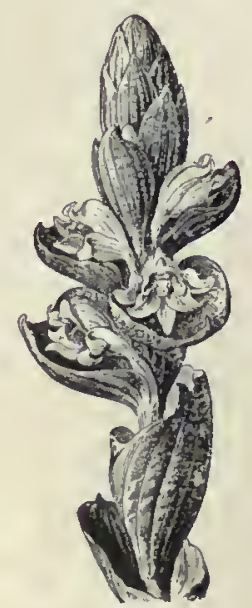

Fig. 198.- Satyrion.

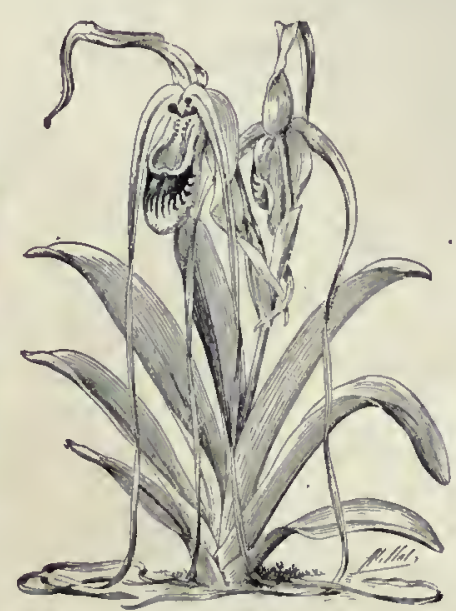

Fig. 199. - Sélénipède. tures; elles ont un sépale médian prolongé en casque et éperonné dans le dos; dans les Satyrions (fig. 198), qui sont voisins, le labelle présente deux éperons à la base.

Importance des Orchidées. - L'importance économique des Orchidées résulte de la beauté de leur fleur et de l'engouement des classes riches d'Angleterre, de Belgique, de France, etc., non seulemént pour les espèces rares, mais pour les variétés nouvellement signalées, et il n'est pas rare de voir une variété d'Odontoglossum atteindre un chifre fantastique dans les ventes qui se font à Londres. Il y a d'ailleurs un cas bien compréhensible où les prix doivent étre très élevés: c'est lorsqu il s'agit de créations faites de toutes pièces par l"art de l'horticulteur. Tel est le cas des hybrides: il y a, à ce point de vue, dans le domaine des Orchidées, des choses absolument merveilleuses dont le public n’a aucune idée. Depuis les expériences de Dominy, qui remontent à 1856 , on a fait des croisements extrêmement nombreux dans la famille des Orchidées; pour ne citer que le sous-genre de Cypripède, $\mathrm{Pa}$ phiopedilum ou Sabots de Vénus de l'ancien monde tropical, on en connaît à l'heure actuelle plus de 600 , en éliminant tous les synonymes et en passant au crible les types mal connus. On a croisé par exemple le Cypripède de Fairrie, qui est une espèce du Bhotan, des régions montagneuses de l'Inde, avec toutes les autres espèces des contrées tropicales asiatiques et océaniennes (barbatum, spicerianum, Curtisi, etc.), et on a obtenu des hybrides remarquables sur lesquels la parenté se lit à livre ouvert. Chacun de ces hybrides se multiplie par division du rhizome, ce qui permet de conserver indéfiniment chaque nouvelle création, de sorte quau lieu de 70 espèces de Sabots de Vénus, on en connaît maintenant plus de 1500, avec toutes les variations et les hybridations réciproques. D'ailleurs pour obtenir chacun d'eux il faut des années d'efforts et de patience, car souvent près d'une année est nécessaire pour avoir des graines, et plusieurs années (parfois une vingtaine) pour les élever. On conçoit donc qu'une de ces merveilles, quand elle apparaît, se paye 5000 à 10000 francs, et ce n'est pas trop payé. Citons aussi les Sélénipèdes ( $f$ g. 199), qui ont des fleurs en grappes avec un ovaire à trois loges, au lieu d'être isolées, avec ovaire à une loge. Les fruits aromatiques du Sélénipède chica ou Vanille en arbre sont employés comme succédané de la $\mathrm{Va}$ nille. Signalons aussi l'Angracum tragrans, dont les feuilles servent, à Madagascar, à préparer une sorte de thé. appelé faham. 


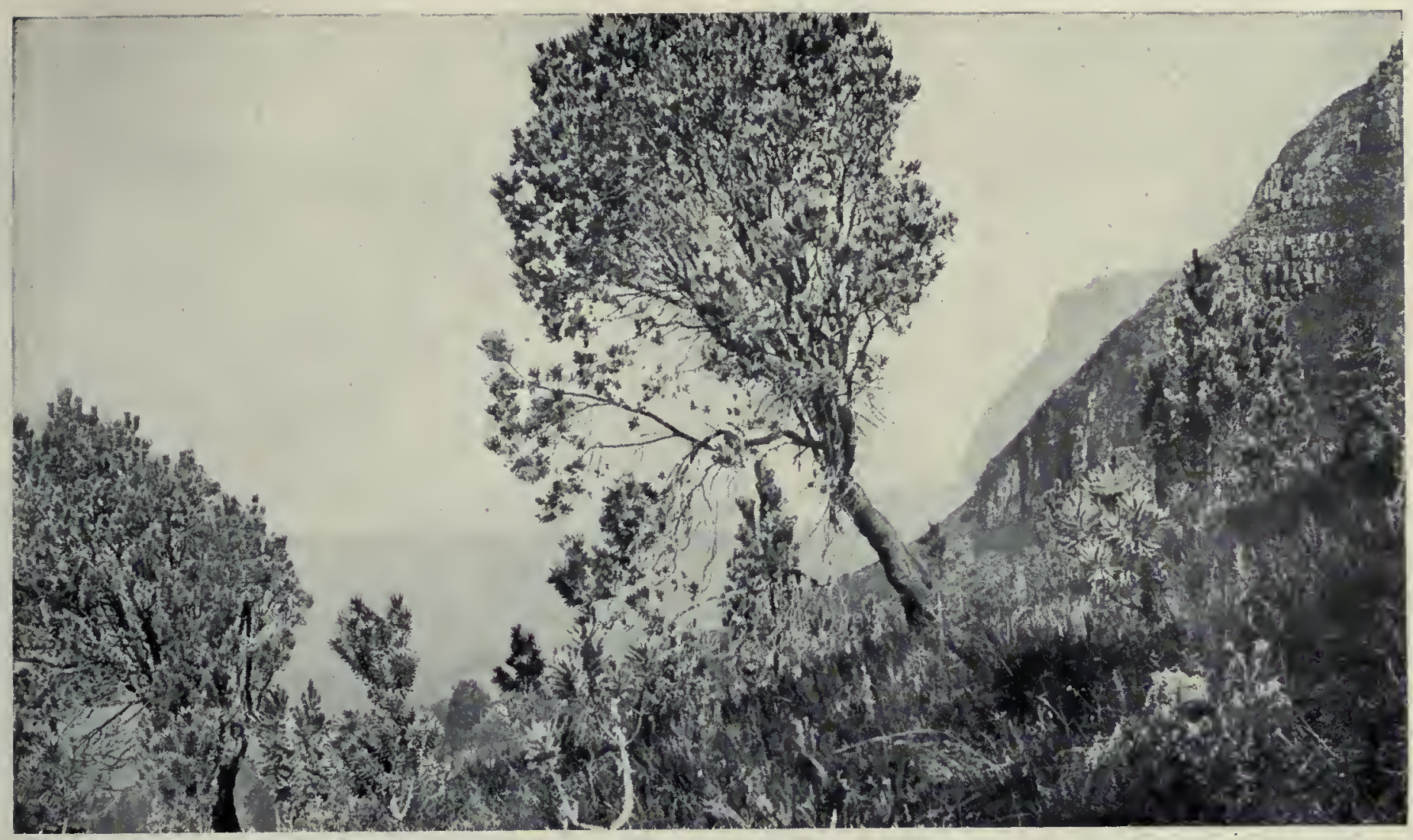

LE PROTEE ARGENTÉ (PROTEA ARGENTEA) OU ARBRE D'ARGENT DU CAP.

\section{V. - DICOTYLÉDONES APÉTALES}

Les Dicotylédones, plus nombreuses et moins homogènes que les Monocotylédones, sont divisées en trois groupes : celui des Apétales, qui n'ont qu'une seule enveloppe florale ou qui en sont dépourvues; celui des Gamopétales, à pétales soudés; enfin, celui des Dialypétales, à pétales libres entre eux (fig. 200). Chacun de ces groupes est ensuite divisé en familles.

Les Apétales sont les plantes Dicotylédones les moins élevées en organisation. Voici comment on les divise :

$$
\begin{aligned}
& \text { Ovaire }\left\{\begin{array}{c}
\begin{array}{c}
\text { Fleurs } \\
\text { à sexes séparés. }
\end{array}\left\{\begin{array}{l}
1 \text { calice. . . . . . . . . . . . U Uticacées. } \\
\text { Pas de calice. }
\end{array}\right. \text { Akène . . . . Ptatanacées. } \\
\text { Capsule. . . . Salicinacées. }
\end{array}\right. \\
& \text { supère. }\{\text { Fleurs } \quad \text { Pas de calice ....... Pipéracées. }
\end{aligned}
$$

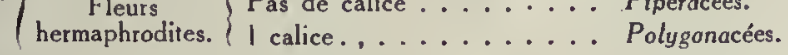

$$
\begin{aligned}
& \text { Ovaire }\{1 \text { ou } 2 \text { ovules dans chaque loge. . . . . . . . Amentacées. }
\end{aligned}
$$

infère. $\{$ Plus de 2 ovules dans chaque loge. . . . . . . Aristolochiacées.

Autour de plusieurs de ces familles sen groupent d'autres moins importantes que nous signalerons.

\section{LES. URTICACÉES}

Urticées, Morées. - Les Urticacées constituent un grand groupe renfermant des plantes assez disparates. On y rattache d'abord des herbes à feuilles opposées urticantes, comme les Orties (fig. 200 et 202), dont les poils raides se brisent en se détachant (fig. 201) et déversent dans la peau un suc qui produit une vive brûlure; la piqûre de certaines espèces exotiques est très redoutable. Les fleurs sont à quatre sépales et, dans les fleurs mâles, à quatre étamines dont les filets sont courbés dans les boutons et se détendent brusquement, sous l"influence de la sécheresse, quand la fleur s'ouvre, en projetant le pollen; dans les fleurs femelles, il y a quatre sépales, un pistil à ovaire à une seule loge contenant un ovule droit, et le fruit est un akène. La Boehmerie blanche est voisine, mais sans poils urticants; $c^{\prime}$ est une plante textile de la plus grande importance, connue sous le nom de Ramie blanche, China grass ou Chouma; la Ramie verte est la Bohmerie très tenace (ou utile).
Les Pariétaires qui croissent sur les murs et les Bleckroodea à caoutchouc appartiennent aussi aux Urticées.

Dans les Morées, les filets des étamines sont courbés, mais les ovules sont aussi courbés et non droits; il y a d'ailleurs du lait dans les tissus. C'est là que
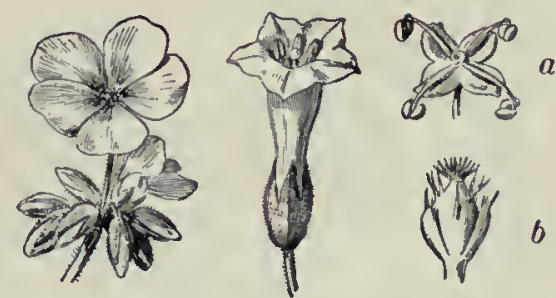

Fig. 200. - Dicotylédones à corolle : dialypétale; gamopétalc; apétale. Géranium. Tabac. Ortie. se rangent les Mûriers et les Broussoneties. Le $M \hat{u}-$ rier noir est indigène dans notre contrée; le Mûrier blanc est une espèce de la Chine; il est connu dans ce pays depuis les temps les plus anciens, où il sert par ses feuilles à la nourriture du ver à soie; cette plante s'est répandue vers le X $11^{\circ}$ siècle dans la région méditerranéenne; elle a été rapportée en France en 1494 , après la conquête de Naples par les armées françaises, sous Charles VIlI. Dans la mûre, les épis femelles présentent un épaississement des sépales après la fécondation et ils sunissent aux sépales des fleurs voisines : il ne faut pas confondre ce fruit avec celui de la Ronce (Rosacée). Le Broussonetia ou Mûrier à papier est utilisé au Japon et en Chine par son écorce qui sert à la fabrication de papier et de tissus; ses feuilles présentent un polymorphisme assez remarquable; elles ont parfois trois lobes, dont un médian plus grand et deux latéraux plus petits; ailleurs un lobe avorte; enfin, souvent les feuilles sont entières. L'Orange des Osages ou Maclura orangé est un arbre de l'Amérique du Nord qui servait aux Indiens à faire leurs arcs et ils tiraient une couleur jaune de son fruit.

Artocarpées. - Dans les Artocarpées, les filets des étamines sont droits, les ovules renversés; il y a d'ailleurs du latex dans les tissus. C'est à cette tribu que se rattache l'Arbre à pain ou Arto- 

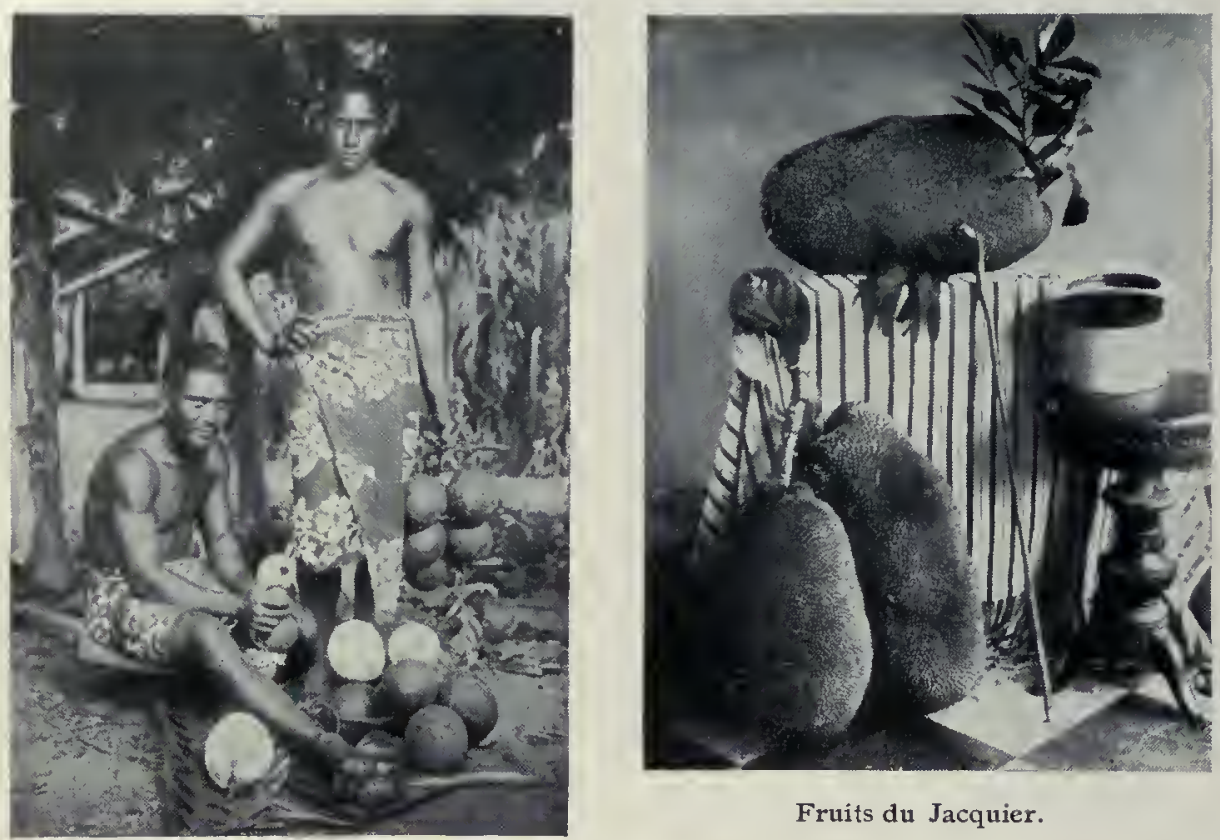

Fruits du Jacquier.

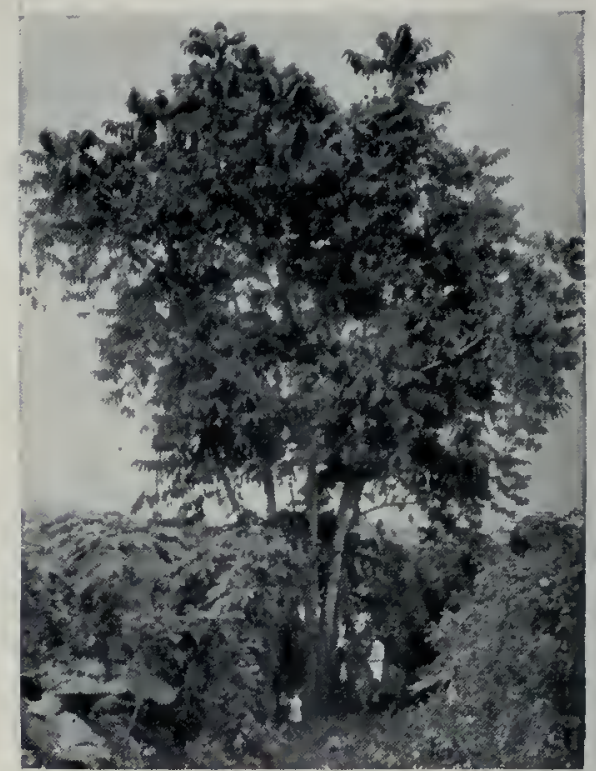

Castitloa étastique.
Fruits de l'Arbre à pain.

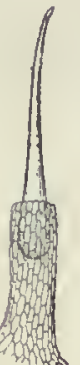

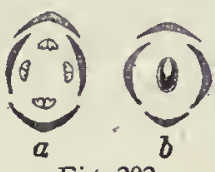

Fig. 202. delafteurd'Ortie. $a$, Fleur à étamines $b$, Fleur à pistil. carpe incisé. Les fleurs femelles sont une sphère et elles groupées en unent un fruit composé, hérissé de piquants et de la grosseur d'une tête d'homme. Coupé en tranches et légèrement grillé, il peut être consommé comme du pain; on peut en faire une pâte fermentée demeurant plusieurs années en terre. On conçoit qu'un pareil arbre soit précicux pour les populations qui le cultivent, car il suffit d'un petit nombre d'exemplaires pour nourrir une famille pendant toute l'année. L'Arbre Fig. 201. à pain est une plante alimentaire, surtout dans les archid'Ortie. pels de l'Océanie, notamment de la Société et des Très grossi. Marquises, etc. ; il y a une variété dépourvue de graines et une variété seminifère ayant soixante à quatrevingts graines grosses comme des châtaignes. Le Jacquier est l'Artocarpe à feuilles entières; son fruit, né sur le tronc, est plus volumineux, plus allongé : il pèse 15 kilogrammes et plus et contient des graines que l'on mange comme des châtaignas; la pulpe est crémeuse, mais d'odeur désagréable disparaissant à la cuisson ; on en fait des confitures.

Dans les Castilloa élastique et d'Ule, qui ont des réceptacles étalés en un disque plus ou moins plan, le latex de la tige est utilisé pour fournir du caoutchouc. L'Antiaris toxique Ipo, ou Upas, est employé par les indigènes, à Java et dans l'archipel de la

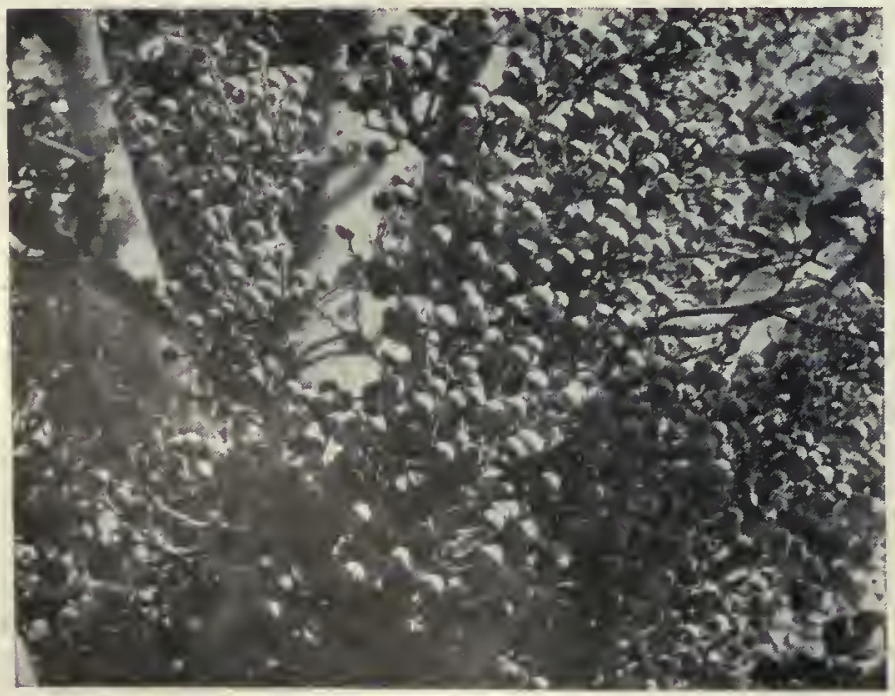

Fruits du Figuier sycomore.
Sonde, pour empoisonner les flèches, car son suc est vénéneux. Dans le Brosime arbre à lait ou Arbre à la vache, le latex a une constitution qui se rapproche de celle du lait; il est particulièrement caractéristique du Venezuela; il atteint 30 mètres de haut : ses réceptacles sont sphériques; on y trouve au centr z une fleur femalle et, sur toute la surface, des fleurs mâles.

Les fleurs des Figuiers sont portées sur un réceptacle en forme de coupe qui se rétrécit à la partie supćrieure et se termine par un étroit orifice. Les fleurs mâles sont vers la partie supérieure, les fleurs femelles vers la partie inférieure de la coupe. Le genre F : guier comprend 600 espèces qui sont répandues surtout dans les pays chauds. La culture du Figuier commun ou Figuier de Carie est répandue surtout dans le bassin méditerranéen, où elle est connue depuis la plus haute antiquité, grâce au rôle des Blastophaga qui habitent et éclosent dans les Caprifiguiers ou Figuiers sauvages (p. 64). Le Figuier Sycomore est un arbre d'Egypte qui a joué dans la civilisation ancienne de ce pays un grand rôle religieux; ses fruits sont comestibles.

Ce rôle religieux des Figuiers se retrouve dans l'Inde, où le Figuier religieux (Pipala), à feuilles linéairas lancéolées, à pointe terminale allongée, est sacré pour les bouddhistes à Ceylan. Le port gigantesque de cette plante, que l'on retrouve dans le Figuier du Bengale, dans le Figuier Benjaminea de Java avec ses mille racines adventives qui pendent comme des colonnes, est caractéristique; ces racines permettent l'accroissement indéfini des plantes. Une autre espèce intéressante appartenant à ce genre est le $F$ iguier élastique, connu vulgairement sous le nom de Caoutchouc, que l'on trouve dans les appartements; en réalité cette espèce indomalaise est l'objet de cultures en Assam, à Java, et on peut même au Tonkin la cultiver sur des terrains médiocres; elle fournit du caoutchouc qui est inférieur à celui de Para (Hevea), et ne peut rendre des services que là où les Hevea sont incultivables.

A côté des Artocarpées, et n'en différant que par leur ovule dressé et non pendant, se placent les Cécropiées, qui méritent d'être rappelées à cause du genre Cecropia dont nous avons déjà parlé comme plante à fourmis (p. 66).

Cannabinacées. - Les Cannabinacées sont également rattachées aux Urticacées; elles n'ont plus de latex, l'ovule est courbé et les sexes sont séparés. Dans le Houblon lupulin, dioïque, la tige est volubile, les feuilles opposées; dans les fleurs mâles, il y a cinq sépales et cinq étamines qui leur sont superposées; dans les fleurs femelles, l'ovaire est entouré complètement par le calice en cupule; il y a au-dessus deux stigmates; après la floraison, les bractées femelles se développent et forment une sorte de cône couvert de poils glanduleux qui sécrètent la lupuline, cette matière amère qui fait utiliser la plante dans la fabrication de la bière.

Le Chanure a des feuilles opposées, alternes au sommet, mais, au lieu d'être lobées, elles sont à cing ou sept segments étroits dentés; les pieds mâles sont très grêles; sur les pieds femellcs il y a des glomérules de fleurs avec un calice gamosépale à la base en sac tronqué; ses graines servent à la fabrication d'un savon noir et 


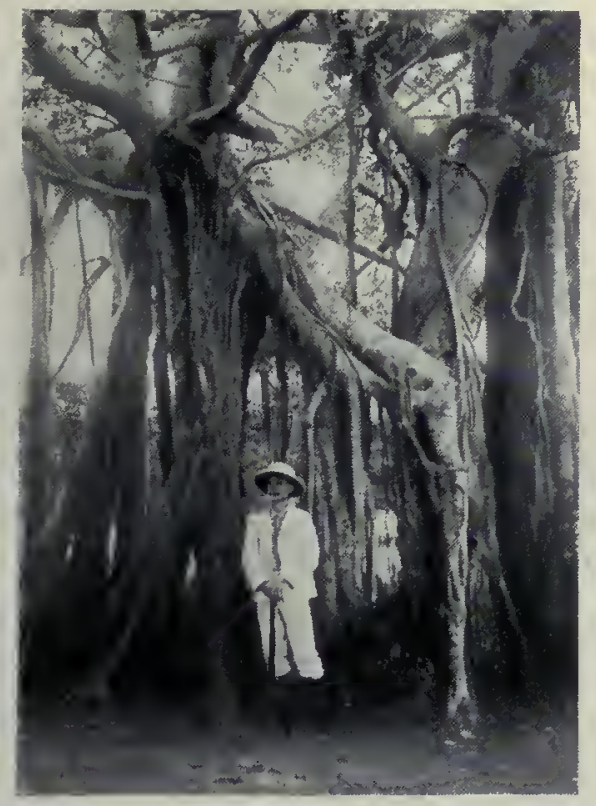

Figuier de Schlechler (Nive-Calédonie).

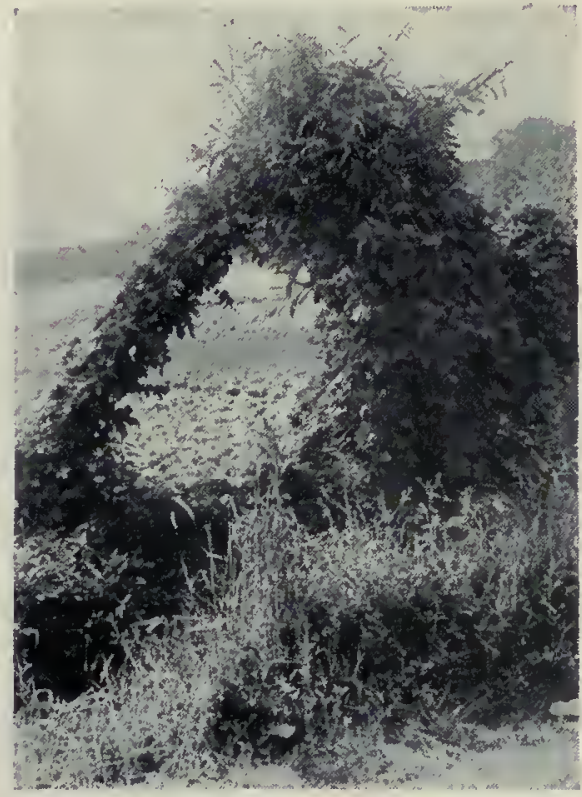

Houblon dans une haic.

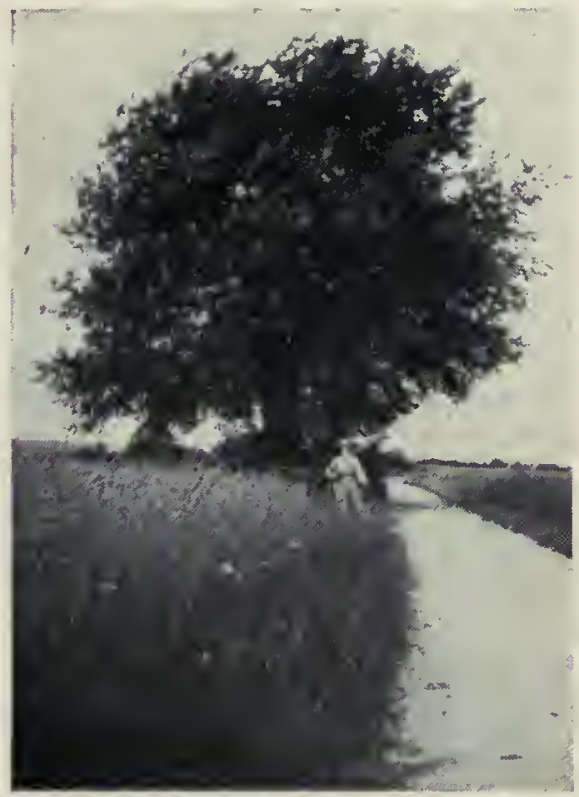

Vieit Orme dans les champs. donnent une huile pour l'éclairage; ses fibres libériennes sont textiles. Sur les feuilles se trouvent de petites glandes qui donnent une résine, base d'une substance produisant l'effet de l'opium : c'est avec le Chanvre indien, variété du Chanvre ordinaire, que le haschich est obtenu par des hommes à vêtements de cuir qui se promènent dans les plantations : on obtient ainsi les chururs. Le mot assassin qui est devenu français vient de haschichins, secte qui a semé la terreur en Perse au $1 t^{\circ}$ siècle de l'hégire par ses méfaits dus à l'ivresse et au délire produits par le haschich. En Perse, on utilise les sommités fleuries en infusion. Le bois du Chanvre, séparé de l'écorce, sert à la fabrication des allumettes et fournit du charbon utilisé pour la poudre.

Ulmacées, Celtidacées. - Les Ormes (Ulmus), qui sont des arbres à feuilles alternes dentées, appartiennent à une autre tribu, celle des Ulmacées, caractérisée par des fleurs hermaphrodites ou polygames et par l'absence de latex. Les fleurs de l'Orme champêtre sont petites, rougeâtres, et s'épanouissent dès février; les fruits sont bordés d'une aile tout autour et constituent des samares; l'écorce contient du tanin; après rouissage, elle sert à faire des cordes et des nattes. L'écorce de l'Orme américain et celle de l'Orme fauve sont employées aux États-Unis pour faire des cataplasmes et des gelées nourrissantes; le bois de tous ces arbres sert surtout au charronnage. Les Planères aquatiques sont des arbres de régions marécageuses aux Etats-Unis qui appartiennent à la même tribu des Ulmacées, mais leur fruit n'est pas une samare.

Les Celtidacées constituent un groupe voisin des Cannabinacées, dont elles se rapprochent par l'ovule unique pendant en haut de la cavité ovarienne, par les stipules dont sont munies les feuilles, par la présence de deux styles stigmatifères; ces deux tribus sont cependant très distinctes, parce que le Celtis austral ou Micocoulier est un arbre à feuilles alternes. La différence avec les Ormes tient à ce que le fruit est une drupe et non une samare; son noyau est orné de rugosités en réseau; les feuilles sont ovales, lancéolées, très longuement et finement acuminées, dentées, épaisses, vert grisâtre dessous. A côté des Micocouliers à style central, se placent les Zelkowa à style excentrique.

Casuarinées, Platanacées, Pipéracées. - Ces trois familles présentent des affinités variables avec le grand groupe des Urticacées dont il vient d'être question.

Les Casuarina sont des arbres ou arbustes à feuilles très petites, verticillées par quatre à vingt, concrescentes en une gaine qui enveloppe la base de l'entre-nœud, à rameaux verticillés; le port, par conséquent, rappelle un peu celui des Prêles. Ils habitent la Nouvelle-Calédonie et l'Australie. On utilise certaines espèces, notamment les Casuarina à quatre values et à feuilles de Prêle (filaos), à Madagascar, comme arbres supports pour la culture de la Vanille. Au point de vue anatomique, ces plantes présentent la singularité qui a été retrouvée d’ailleurs chez les Bétulées, Corylées et Juglandacées, que le tube pollinique pénètre, non par le micropyle ou petit orifice du sommet de l'ovule, mais par la chalaze ou extrémité opposée. Elles forment un groupe très spécial.

Les Platanacées comprennent de grands arbres, les Platanes vulgaires, dont on fait deux types: Platane d'Orient et Platane d'Occident. Leur tige s'exfolie par larges plaques minces; à la base du pétiole, il y a des stipules soudées entre elles, formant une collerette complète autour de la tige et tombant de bonne heure. Les fleurs sont à sexes séparés, monoïques, groupées en capitules sphériques dont les uns portent les ćtamines, les autres les pistils. Les fruits sont des akènes serrés les uns contre les autres, constituant ces boules qui, en automne, sont suspendues aux branches des Platanes.

Les Pipéracées ont des fleurs hermaphrodites, mais dépourvues de calice; elles forment des épis axillaires ou terminaux. Les Poivriers (Piper) sont d'ordinaire des plantes grimpantes à feuilles isolées, brièvement pétiolées, engainantes et munies de stipules concrescentes; leur limbe est entier, en forme de coeur. Le fruit est une baie rouge à péricarpe mince; la graine renferme un double albumen, un albumen proprement dit charnu et un périsperme amylacé. Les $\mathrm{Pe}$ peromia sont des plantes de serre communément cultivées qui appartiennent à cette même famille.

\section{LES POLYGONACÉES}

La famille des Polygonacées est représentée par la Renouée alimentaire ou Sarrasin ou Blé noir, dont l'akène. contient une graine amylacée fournissant un aliment important pour les pays pauvres; les abeilles sont friandes du nectar des fleurs et elles en font du miel, servant à la fabrication du pain d'épice. Dans la fleur des Renouées, qui est hermaphrodite, le périanthe est sur le type cinq, il y a cinq à huit étamines, l'ovule est droit.

Dans la Rhubarbe, les fleurs sont sur le type trois, à trois sépales externes et trois sépales internes; l'androcée a neuf étamines, 
trois fois deux étamines superposées aux sépales externes et trois étamines superposées aux sépales internes; le pistil est à ovaire à une loge, à trois stigmates, à un ovule. La Rhubarbe est mentionnée dans les anciens livres chinois, 2700 ans avant J.-C.; le colonel russe Przewalski a montré que la principale source de la Rhubarbe de Russie et de Turquie était la $R$ hubarbe palméc (variété de Tangut) poussant dans le nord-est de la Chine: la Rhubarbe de Canton était la $R$. officinale. On cultive beaucoup la $R h u-$ barbe rhapontique en Angleterre : on fabrique des confitures purgatives avec les pétioles.

Les fleurs des Oseilles (Rumex) sont parfoisà sexes séparés; elles ont six étamines externes seulement, superposées par deux aux trois sépales externes: les trois sépales internes n'ont pas d'étamines correspondantes dans les fleurs mâles. C'est à ce genre qu' appartient la Canaigre ou Rumex hymenosépale, plante à tanin importante de l'ouest du Texas, du Nouveau-Mexique.

Chénopodiacées. - Les Chénopodiacées ont beaucoup d'affinités avec la famille précédente : elles ont des fleurs hermaphrodites, mais l'ovule est courbé au lieu d'être droit. La Betterave vulgairc appartient à ce groupe; elle est à cinq sépales, cinq étamines, un ovaire à une loge à un ovule, surmonté de deux ou trois stigmates; la variété Poirée est utilisée comme légume à la manière des Cardons; la variété rapa est alimentaire par sa racine, que l'on emploie cuite à l'eau ou au four pour la salade; on peut en retirer une sorte de vin doux et en faire des confitures; cest aussi une racine fourragère, précieuse pour l'alimentation du bétail, et une plante sucrière de premier ordre.

L'Épinard potager se distingue par sa dioïcité, le périanthe des fleurs mâles à 4-5 divisions, quatre à cinq étamines; dans les fleurs femelles, le périanthe globuleux s’accroît en épines après la fécondation, mais il y a une variété non épineuse. L'Arroche des jardins (Atriplex) est cultivée comme épinard depuis longtemps sous le nom vulgaire de Bonne-Dame; elle a des feuilles un peu charnues. Le Quinoa (Chénopode Quinoa) est une espèce alimentaire de l'Amérique du Sud, dont les petitesgraines servaient déjà à l'alimentation des lncas, comme le montrent certains pains trouvés dans les tombeaux. Beaucoup de Chénopodiacées habitent les bords de la mer (Salsola à potasse et à soude. Salicorne) et les terrains salés; le Saxaoul ( $\mathrm{Ha}$ loxylon) est une plante caractéristique de l'Asie centrale ( $f$ g. I12, B).

Amarantacées, Nyctaginacées, Basellacées, Phytolaccacées. - Les Amarantacées sont tout à fait voisines, mais les fleurs ont trois bractées qui manquent à la famille précédente. C'est à cette famille qu'appartiennent les Célosies crête de $\operatorname{coq}$ ou Passe-velours, à tige rouge aplatie, fasciée; les Iresine, à joli feuillage rouge; les $A l$ ternanthères, utilisées en mosaicul. ture. L'Amarante à queue, cultivée dans les jardins, est une plante alimentaire de l'Himalaya, où elle abonde vers 2700 mètres.

Les $N$ yctaginacées comprennent

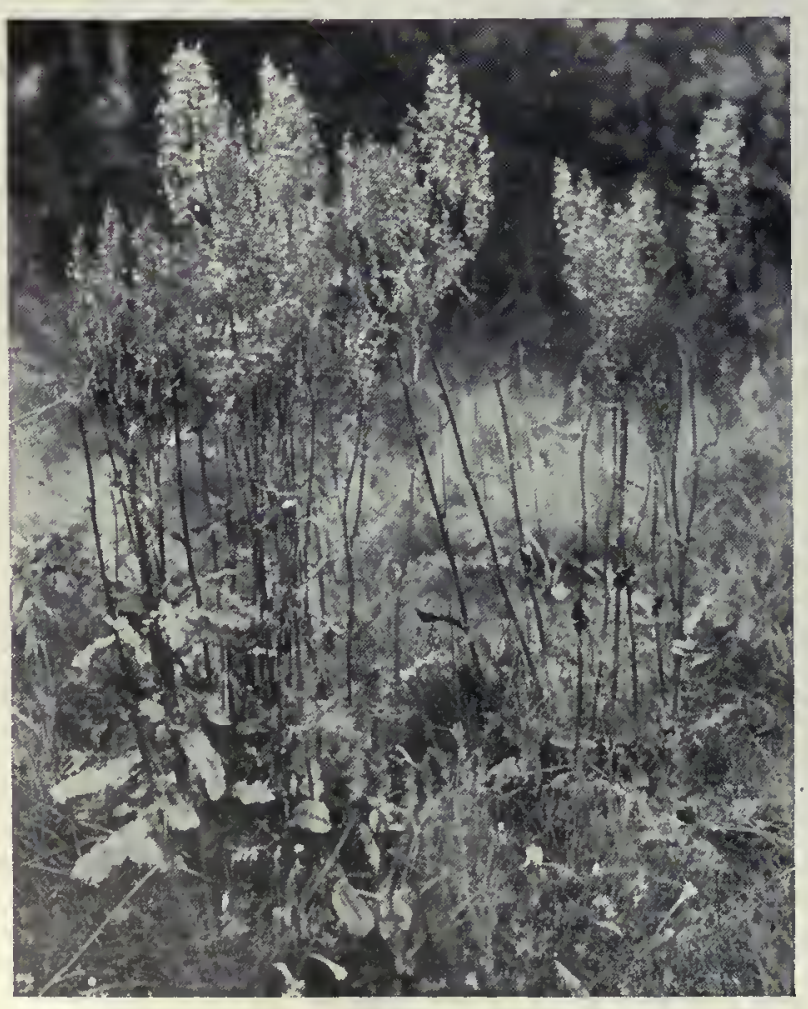

Oseilte sauvage et fruits. la Belle de nuit (Mirabilis Jalapa), dont le faux calice est un involucre et sa fausse corolle est un calice. Les Bougainvillées (fig. 203) sont des plantes grimpantes voisines, à grandes bractées colorées en rose ou en violet.

Dans les Bascllacées, les étamines sont longuement adbérentes au périanthe. Les Boussingaultia sont des plantes grimpantes, souvent cultivées dans le Midi pour garnir les tonnelles. L'Ulluque tubéreux du Pérou produit un tubercule comestible, utilisable au même titre que la pomme de terre. Enfin, la Basclle rouge a mérité le nom d'Épinard des Indes ou du Malabar.

Dans les Phytolaccacćes, les carpelles sont verticillés $(1-10)$ et portent chacun un ovule; les fleurs hermaphrodites présentent de nombreuses étamines. Les Phytolacca sont de petits arbustes à gros tronc que l'on sort l'été pour l'ornementation des parterres, après les avoir conservés à l'état de bûche au repos pendant l'hiver. Le fameux Ombu ou Belsombra (fig. 204). l'arbre des pampas de la république Argentine, qui atteint une tailleénorme. est le Phytolacca dioïque; son bois tendre est inutilisable, même pour le chauffage; il est recouvert d'une écorce épaisse et très friable. Dans les deux sexes, les fleurs sont disposées en grappes et ont chacune cinq sépales pétaloïdes et de douze à quinze étamines, ou de dix à quinze carpelles. Le feuillage est vert sombre.

Protéacées. - Les Protéacécs constituent une famille d'Apétales à fleurs hermaphrodites comme dans les Chénopodiacées, mais à ovule renversé ou droit. Elle est composée surtout d'arbres et arbustes exotiques comme les Protea, habitant les terres australes (Cap, Australie). Les quatre sépales pétaloïdes d'une Grévilléc sont soudées aux quatre étamines; le pistil est à un carpelle à deux ovules. On cultive souvent les Grévillées à feuilles d'Asplénium que l'on appelle Fougères en arbre. Les Banksia sont bien adaptés à la sécheresse. Il y a plusieurs espèces à fruit comestible par les graines, notamment le Nut-tree ou Arbre à noix, ou Macadamic ternitolié.

\section{LES AMENTACÉES}

La famille des Amentacées comprend la plupart des arbres de nos forêts septentrionales. Elle est caractérisée par ses épis de deux sortes, les uns mâles et les autres femelles, qui constituent ce que l'on appelle des chatons (en latin amentum). On divise les Amentacées en Quercées, Corylées, Bétulées, Juglandacées et Salicinacées. Les trois premiers groupes sont souvent réunis sous le nom de Cupulifères, à cause de la présence autour du fruit d'une cupule dont nous verrons l'origine.

Quercées : Le Chêne. Le Chêne Rouvre (Quercus Robur) ou Durclin, Drillard, a des feuilles à lobes accusés, arrondis et peu nombreux, d'un vert intense, assez longuement pétiolées; lécorce de la tige est crevassée longitudinalement, mais les crevasses ne sont pas très allongées. Les épis mâles sont allongés, pendants, pourvus 'd'un axe grêle, avec des fleurs solitaires ou réunies en glomérules; chacune 


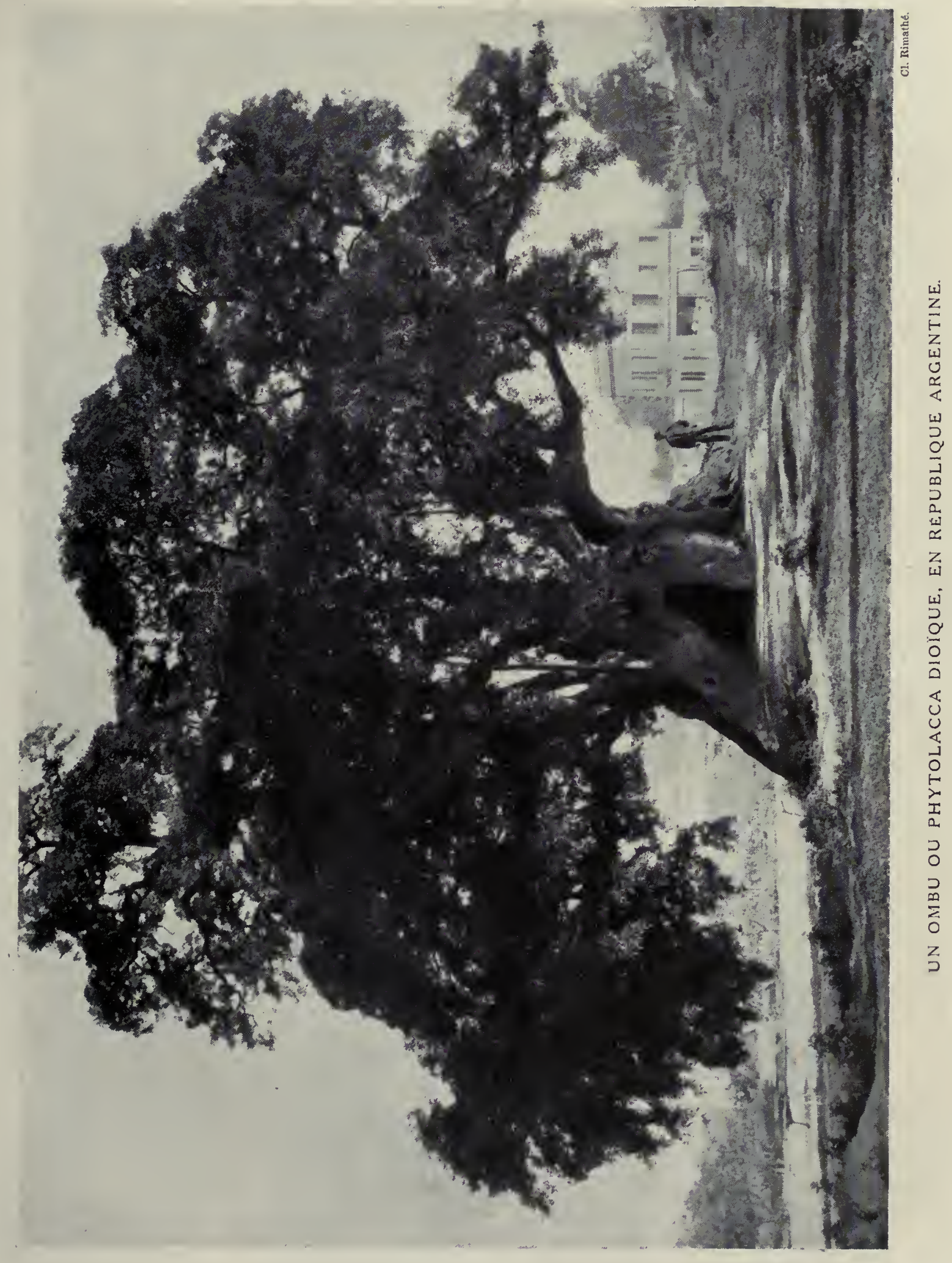





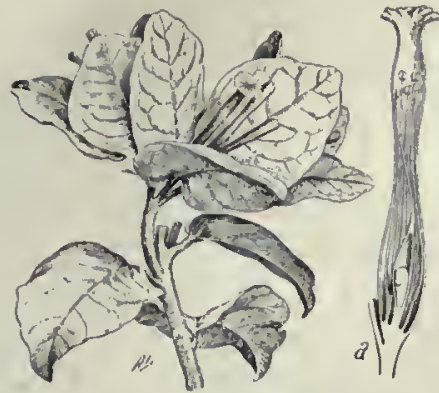

Fig. 203. - Bougainvillée. $a$, Coupe de la fleur.

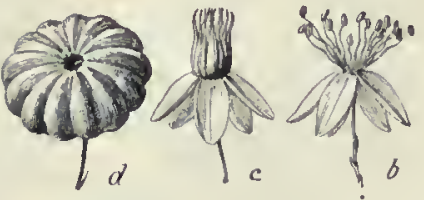

Fig. 204. - Ombu.

$b$, Fleur mâle; $c$, Fleur femelle; $d$, Fruit.

d'entre elles est formée de quatre à douze étamines insérées sur un disque et entourées d'un périanthe verdâtre à $3-8$ divisions inégales. Les épis femelles sont pauciflores; les fleurs y sont so-

litaires, entourées d'un involucre qui s'accroît après la fécondation et sur lequel s'aperçoivent les bractées soudées : il forme la cupule du gland de Chêne; l'ovaire infère est à trois loges, chacune contenant deux ovules, mais, sur ses six ovules, cinq avortent et le fruit est un akène; au-dessus de l'ovaire infère se remarque un périanthe à six petites dents en deux verticilles.

On connaît deux variétés de Chêne Rouvre : l'une à fruits sessiles, c'est le Chêne rouge ou le Chêne mâle; l'autre à fruits pédonculés, c'est le Chêne femelle ou Gravelin. Les glands renferment de l'amidon qui est mélangé à un principe âpre, difficile à séparer; aussi ne sont-ils consommés que par les porcs. 11 y a d'autres Chênes dont les glands sont doux et susceptibles d'être comestibles, comme le Chêne Houx et le Chêne Ballote, qui sert à préparer le racahout des Arabes. Le genre Chêne a d'autres applications intéressantes; deux espèces fournissent le liège : le Chêne-liège et le Chêne occidental, variété du précédent, qui se distinguent l'un de l'autre par le temps qu'ils mettent à mûrir leur fruit, le premier mûrissant dans l'année, l'autre n'arrivant à maturité quau bout de la seconde année. Le Chêne aux kermès (fig. 205) ou Chêne coccifère habite la région méditerranéenne; sa taille est très petite, $\mathrm{I}^{\mathrm{m}}, 50$ à 3 mètres; il héberge un animal, le Kermes ilicis, qui, desséché et pulvérisé, donnait une substance tinctoriale rouge ou carmin autrefois recherchée. Le Quercitron (fig. 206) est fourni par l'écorce du Chêne tinctorial (coccinea), espèce de Pensylvanie qui renferme un principe colorant jaune des soies et laines et qui sert aussi en Amérique pour le tannage des peaux. Le Chêne de Portugal est un arbre polymorphe qui habite la presqu'île Ibérique, le nord de l'Afrique et la Turquie d'Asie: sa variété infectoria est le Chêne à galles d'Alep, qui est commun en Asie Mineure, en Syrie, en Grèce et dans les îles de l'Archipel: il produit les noix de galle du Levant (p. 65). On obtient encore des noix de galle avec le Chêne Tauzin et avec le Chêne Velani ou Egilops; les

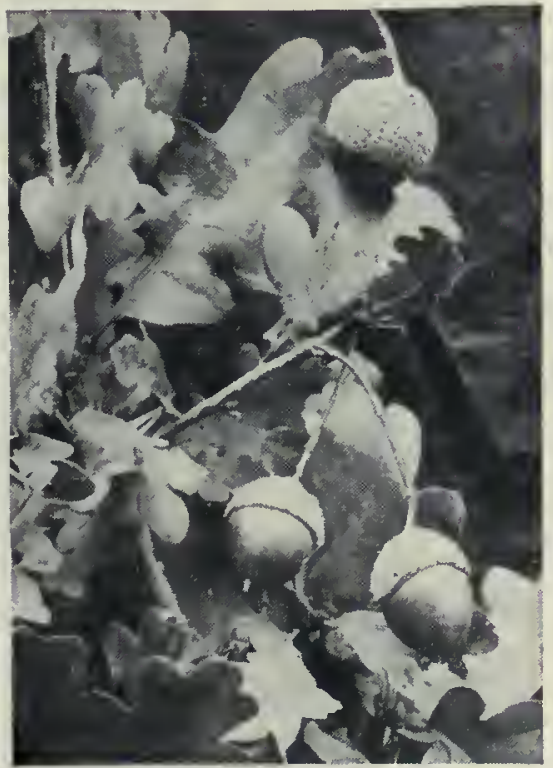

Glands du Chéne pédonculè.

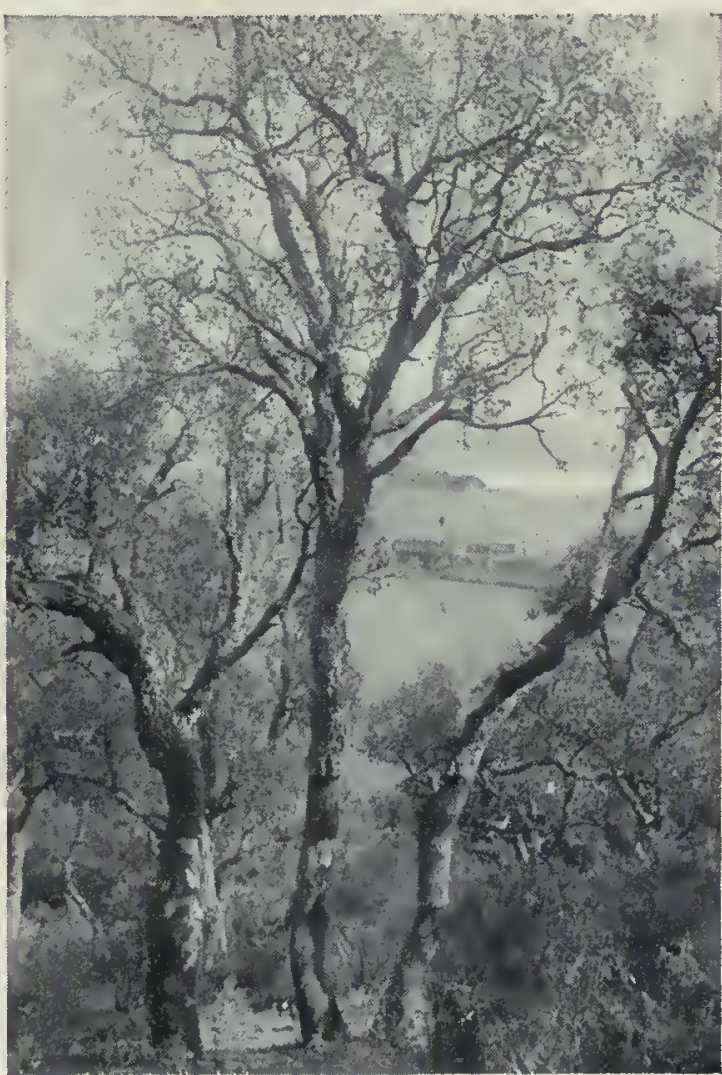

Chènes-liéges dans l'Esterel.

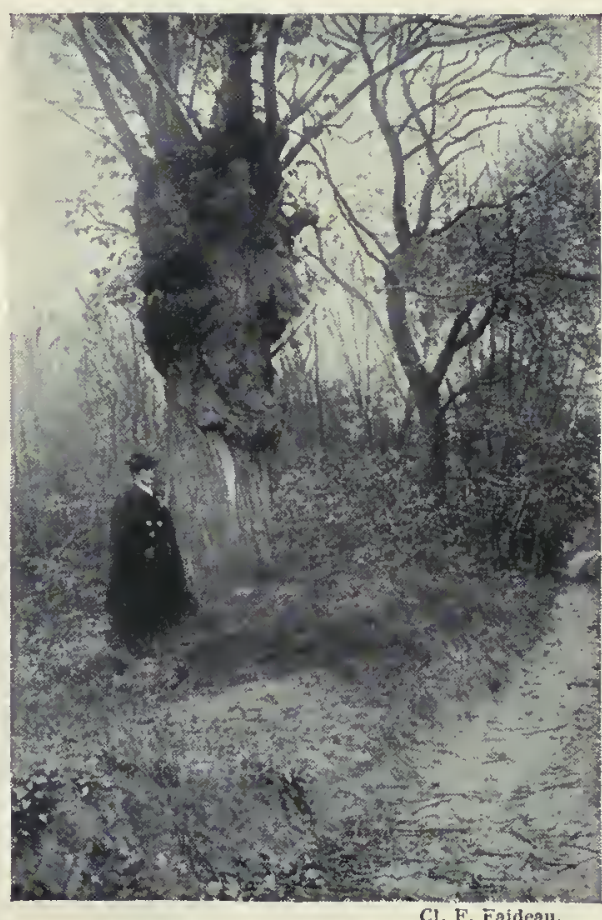

Châtaignier, en forêt de Marly. cision (p. 116); on

ne rencontre pas de Truffes, ou du moins de bonnes Truffes, dans les terrains dénudés, labourés ou gazonnés. Il est vraisemblable que le mycélium du Champignon se nourrit aux dépens du chevelu des arbres et des plantes couvrant superficiellement le sol, qu'il ferait mourir; si les arbres font peu de chevelu, la truffière se développe mal et toute cause agissant sur la multiplication des racines (élagage, recépage, façon culturale) agira sur la production. Matruchot est arrivé à obtenir le mycélium de la Truffe; en 1903. Boulanger avait même affirmé que sur une propriété de $30 \mathrm{hec}$ tares aux environs d'Etampes il avait produit cinq mille places truffières. Aucune autre donnée nouvelle sur les résultats de ses premiers essais n’a été jusqu ici publiée, et c'est la méthode empirique qui fonctionne encore et qui permet la prospérité d'une importante industrie agricole. Dans le Vaucluse, des truffières poussent sousle Chêne vert (Quercus llex).

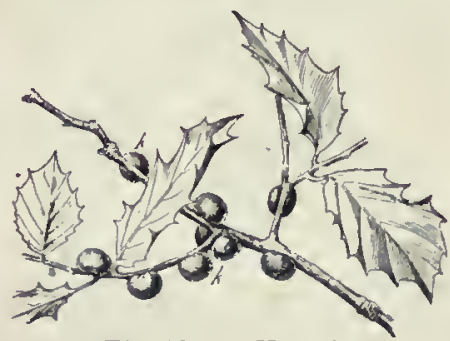

Fig. 205, - Kermès

sur une branche de Chêne kermès.

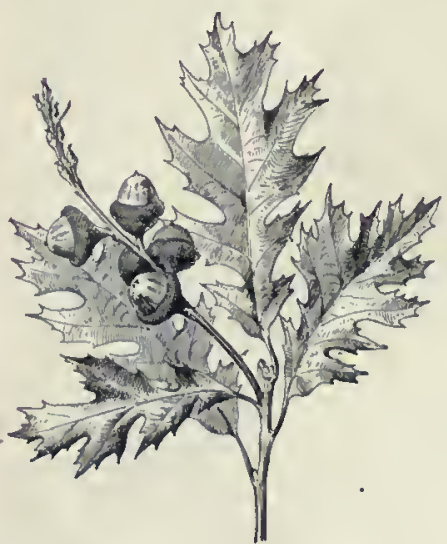

Fig. 206. - Chène tinctorial. 


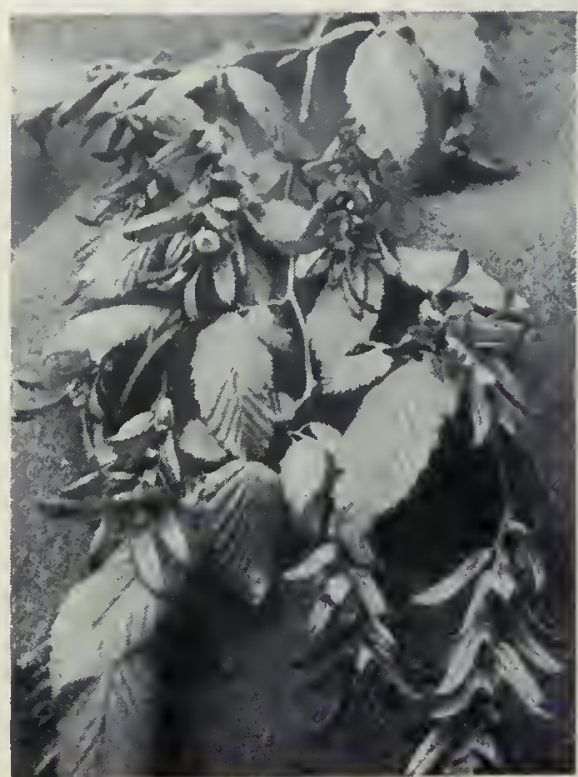

Branche de Charme, avec fruits.

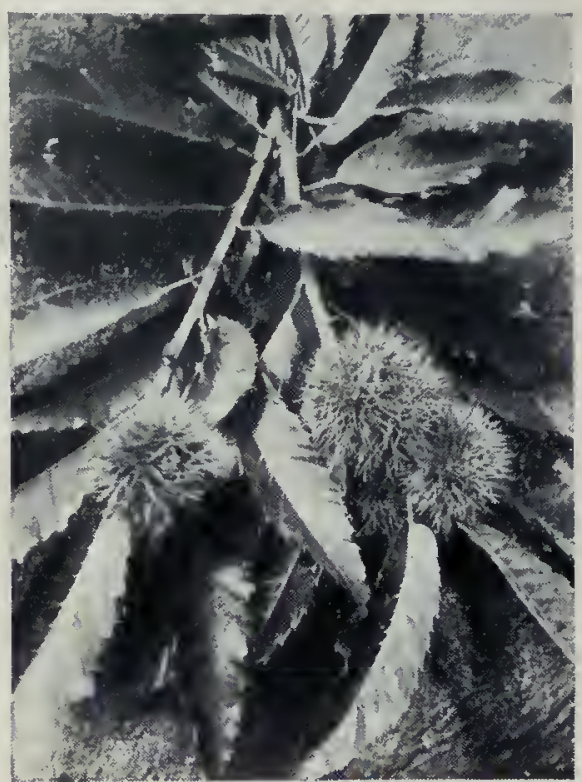

Branche de Châtaignicr, avec fruits.

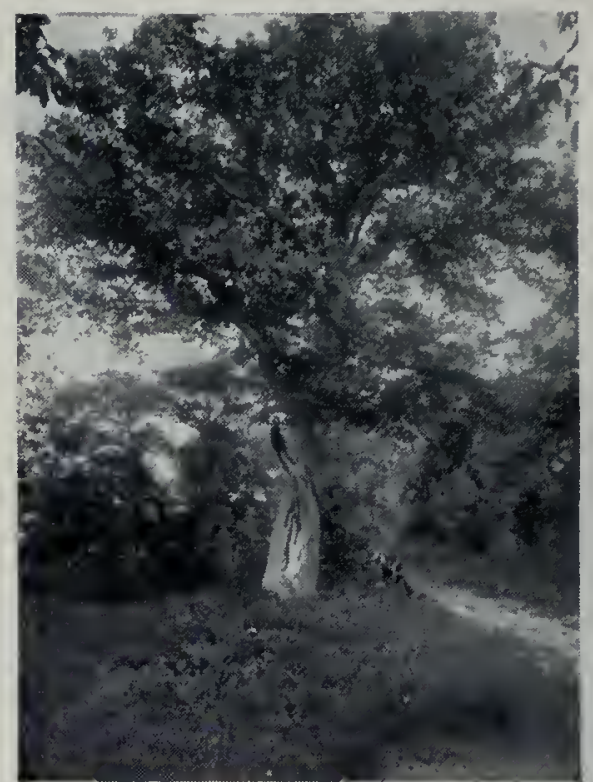

Un vieux Châtaignier, à Orsay.
Le Hêtre et le Châtaignier. - Un second type du groupe des Amentacées est le Hêtre (Fagus), à feuilles non dentées, poilues au bord, à écorce de la tige lisse. Les épis mâles sont globuleux, à fleurs pourvues d'un périanthe campanulé, à quatre à huit divisions, enfermant une dizaine d'étamines. Les inflorescences femelles sont pauciflores, globuleuses; elles consistent en des cupules se fendant en quatre valves hérissées d'écailles et renfermant des fleurs femelles qui ressemblent tout à fait à celles du Chêne. A la maturité, la faîne contient deux akènes résultant du développement des deux ovaires des deux fleurs. Le Hêtre des forêts est un des arbres les plus importants de l'Europe; il n'a pas de préférence pour le sol, mais cest sur les terrains calcaires qu'il acquiert les plus belles dimensions. Les faînes sont utilisées pour les fruits qu'elles contiennent; ceux-ci sont comestibles et ont une saveur de noisette; la graine renferme 20 à 22 pour 100 d'huile, qui rancit malheureusement assez vite. On voit souvent dans les forêts des femmes récolter ces faînes pour les envoyer à des usines voisines.

Le Châtaignier est caractérisé par les longues crevasses de l'écorce de sa tige, par ses feuilles très longues, fortement dentées et nọn poilues. Ses épis mâles sont dressés, à fleurs groupées par sept, les étamines d'une fleur variant de six à vingt, entourées de six pièces au périanthe. Dans les ćpis femelles, la cupule est formée de quatre pièces qui sont hérissẻes de piquants; elle renferme trois fleurs femelles et finalement, quand les quatre valves s'ouvrent, on y trouve de un à trois fruits monospermes ou akènes. C'est un arbre essentiellement silicicole ou mieux calcifuge, qui prospère dans les terrains granitiques, schisteux, feldspathiques. Son bois est utilisé pour la charpente, pour faire des planches de parquet, des clôtures; les jeunes tiges, surtout les rejets, servent à faire des cercles de tonneaux", des treillages, des tuteurs; pour le chauffage, il fournit un bois médiocre, car il éclate et donne des étincelles. C'est surtout pour la châtaigne que cette plante est cultivée et c'est la variété sativa, ou à gros fruit, qui constitue ce qu'on appelle vulgairement le marron.

Les Castanopsis sont intermédiaires entre les Chênes et les Châtaigniers. Il y a des espèces de l'Asie tropicale (C. argenté) à fruits comestibles comme les châtaignes et d'autres appréciées pour la construction des roues et des navires (C. à feuilles dorées).

Dans toutes les Amentacées qui viennent d’être examinées, les étamines étaient à filet simple; il est un second groupe où le filet est bifurqué en $Y$, chacune des branches se terminant par une anthère : tel est le cas du Coudrier et du Charme.

Corylées. - Dans le Coudrier ou Noisetier (Corylus), les feuilles sont poilues, les pétioles poilus glanduleux. Dans les chatons mâles, qui sont pendants et qui apparaissent de très bonne heure, au premier printemps, à l'aisselle de trois écailles, il y a six à huit étamines groupées deux par deux en $\mathrm{Y}$; le calice proprement dit est nul. Dans les chatons femelles, qui sont plutôt des bourgeons ćcailleux, les écailles du bas sont infertiles, celles du haut prćsentent à leur aisselle deux pistils à deux loges, chacune ayant un ovule; chaque pistil est entouré par un involucre tubuleux lacinié qui devient à la maturité la cupule, laquelle contient la noisette qui renferme une seule graine, car c'est encore un akène.

Le Charme (Carpinus) est très voisin du Coudrier, mais c'est un arbre au lieu d'être un arbuste; ses feuilles sont à nervures secondaires simples plissées et non ramifiées jusqu'au bord; l'écorce de la tige est lisse comme celle du Hêtre, mais l'arbre est moins gros et plus irrégulier, tortillé. Comme dans le Coudrier, les filets des étamines sont bifurqués, le périanthe nul et il y a de dix à vingt étamines à l'aisselle de chaque bractée. Les fleurs femelles, également pourvues de calice à quatre pièces, sont à deux loges avec un ovule dans chaque loge; elles sont entourées d'un involucre trilobé qui s'accroit après la fécondation et qui est largement ouvert : il y a deux de ces involucres à l'aisselle d'une bractée.

Dans nos forêts, il se produit souvent des greffes par approche entre branches voisines; habituellement elles ne se produisent qu'entre branches d'un même arbre ou d'arbres de même espèce, surtout entre Hêtres. Une curieuse exception est le Chêne-Charmé de la forêt de Fontainebleau.

Bétulées. - Dans les Bouleaux (Betula), les deux filets des étamines sont également bifurqués en $\mathrm{Y}$; celles-ci sont comprises entre deux ou quatre pièces inégales correspondant au calice. Dans les chatons femelles, les fleurs sont groupées par trois à l'aisselle de trois bractées; chaque ovaire est à deux loges; il n'y a plus de calice et c'est par analogie avec les fleurs précédentes que l'on considère l'ovaire comme infère. L'écorce du Bouleau est blanche par suite de la présence d'air dans les assises externes du liège; le feuillage est triangulaire et léger. Le bois est estimé pour le chauffage; on s'en sert comme allumes pour éclairer le four des boulangers; l'écorce contient un principe balsamique, la bétuline, qui est employée dans la préparation des cuirs, notamment des cuirs de Russie. On pense que c'est à ce même principe que le bois doit sa conservation dans l'eau. Enfin, la sève du Bouleau fournit un liquide sucré, susceptible de fermenter; on obtient du sucre ou un vin pétillant, ou du vinaigre; pour l'extraire, on fait dans l'arbre des trous de 5 à 6 centimètres, et un arbre un peu grand peut fournir plus de 200 litres par an.

Dans l'Aune, le filet des étamines reste simple, mais les fleurs femelles, à deux loges ovariennes, renfermant chacune un ovule, sont groupées par deux à l'aisselle de cinq bractées qui se soudent entre elles et se lignifient, de manière que leur ensemble, dans le chaton femelle, ressemble un peu à un cône de Pin. Les feuilles de l'Aune glutineux, petit arbre qui pousse dans les endroits humides, sont assez caractéristiques par leur élargissement vers le sommet, qui est arrondi, les bords étant un peu dentés.

Juglandacées. - Un autre groupe que l'on rattache aux Amentacées, mais dont on fait souvent une famille spéciale, est le groupe des Noyers (Juglans), qui se reconnaissent de suite par leurs feuilles composées alternes contenant un principe aromatique 


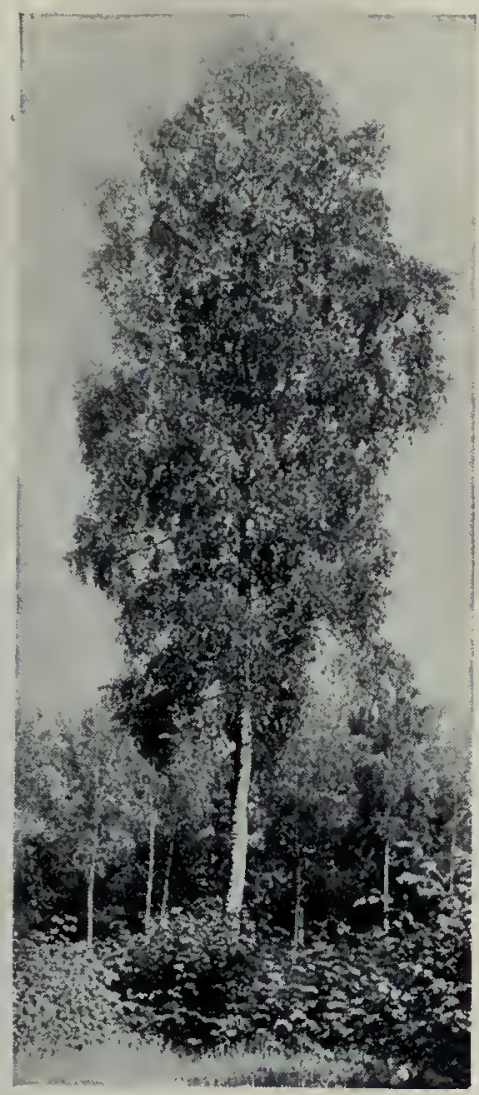

Bouleau blanc, à Chantilty.

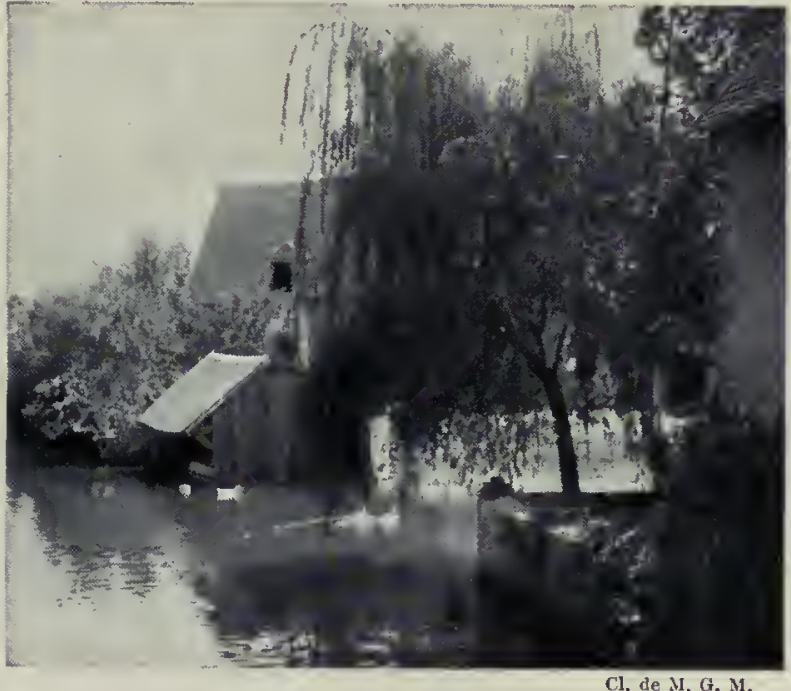

Paysage avec Saule pleureur.

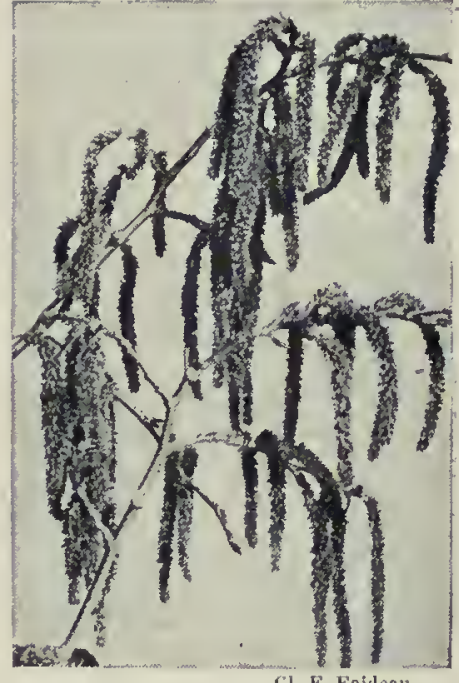

Chatons de Peuplier blanc. que l'on distingue aisément quand on les froisse entre les doigts; elles sont terminées par une foliole impaire. Les inflorescences sont encore en chatons : les fleurs mâles sont à quatre sépales et à huit ou quarante étamines; dans les fleurs femelles, l'ovaire est infère et surmonté de quatre sépales; cet organe à une loge contient un seul ovule droit qui donne naissance à un embryon subdivisé par deux à quatre fausses cloisons; l'embryon est gros, les cotylédons plissés cérébriformes; ils contiennent une huile utilisée pour la fabrication des couleurs fines. Le bois du Noyer royal (fig. 207) est très apprécié en ébénisterie, mais c'est surtout par ses fruits que le Noyer est un arbre important; à l'état frais, ils sont entourés par un péricarpe charnu ou brou.

A côté des Noyers se placent les Carya (Hickony en anglais), qui s'en distinguent par leurs fleurs mâles dépourvues de calice. Le fruit est entouré de trois bractées et d'une quatrième pièce supérieure correspondant à un rudiment de calice : toutes ces pièces apparaissent à la partie supérieure du fruit, dont le brou se fend en quatre valves; à l'intérieur se trouve une noix à deux valves, à 2-4 loges incomplètes. L'Hickory blanc fournit par son bois des instruments aratoires et, par son fruit, une amande agréable; mais c'est surtout le Carya Pacanier dont les noix sont délicieuses et font l'objet d'un commerce considérable dans le sud des États-Unis.

Salicinacées. - Les Salicinacées constituent une famille facilement distinguée des groupes précédents par le caractère de l'ovaire, qui est supère, et la placentation, pariétale au lieu d'être axile, comme dans tous les types mentionnés plus haut, sauf les Noyers. On y distingue deux genres : les Saules et les Peupliers. Dans les premiers, les étamines des fleurs des chatons mâles sont au nombre de deux, rarement de trois ou de cinq; elles apparaissent à l'aisselle d'une bractée solitaire; dans les chatons femelles, les ovaires sont également nus, sans calice et présentent deux carpelles; le fruit est une capsule à deux fentes, mettant en liberté des graines sans albumen, qui présentent au voisinage du hile une touffe de poils soyeux rappelant un peu ceux du Cotonnier. Les Saules (Salix) comprennent un groupe à feuilles étroites, à tige flexible, formant la section des Osiers, utilisés pour la vannerie. Les Saules à feuilles larges comprennent le Saule Marceau. Le Saule pleureur ou de Babylone n'est représenté en Europe que par les individus mâles; les femelles existent en Asie.

Les Peupliers ont des fleurs mâles, à étamines nombreuses, entourées d'une sorte de cupule parenchymateuse ; leurs fruits sont semblables à ceux des Saules. Le Peuplier noir ou Peuplier franc a des feuilles très finement dentées, terminées par une pointe sans dent; les bractées des fleurs sont dépourvues de poils; une de ses variétés les plus connues est le Peuplier d'ltalie ou Peuplier pyramidal, à branches courtes, fastigiées. Dans le Peuplier blanc ou Grisard, comme dans le Tremble, les bractées sont velues; mais dans le Peuplier blanc, les feuilles sont blanches dessous, les bourgeons secs; dans le Tremble, les feuilles ne sont pas blanches dessous et les bourgeons sont visqueux; elles ont un pétiole aplati au milieu, ce qui les rend très mobiles.

Aristolochiacées. - Les Aristolochiacées sont, pour la plupart, des plantes grimpantes volubiles, à larges feuilles en coeur. Au fond du périanthe tubuleux, il y a six étamines extrorses soudées au style en un gynostème; l'ovaire est infère à six carpelles. Beaucoup d'espèces sont cultivées : l'A ristoloche siphon de l'Amérique du Nord, $I^{\prime} A$. grandiflora du Guatemala (fig. 208), qui est une espèce de serre. Les Asarets (fig. 209) ont les anthères libres.

Comme familles parasites à ovaire infère, on peut citer : les Santalacées (Osyris, Thesium, Santal) [fig. 210], les Rafflésiacées, comprenant les Rafflesia; les Cytinus, vivant sur les Cistes; les Loranthacées, avec le Gui (fig. 2ll) et beaucoup de parasites tropicaux vivant sur les arbres; les Balanophoracées (p. 57).

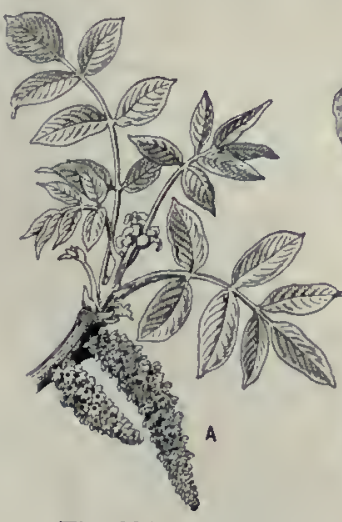

Fig. 207. - Noyer

A, Chaton mâle.

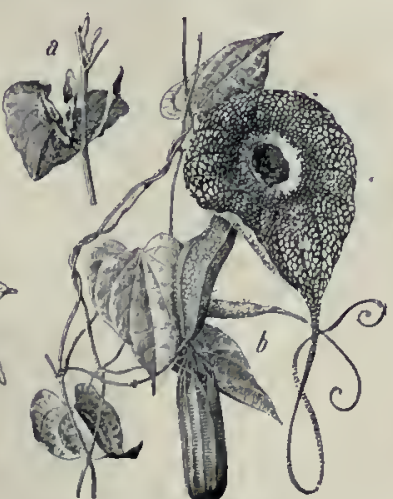

Fig. 208. - Aristoloche. $a$, A. Clématite; $b$, A. grandiflora.

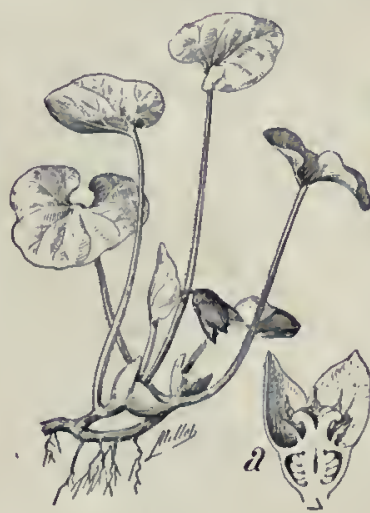

Fig. 209. - Asaret. $a$ Coupe de la fleur.

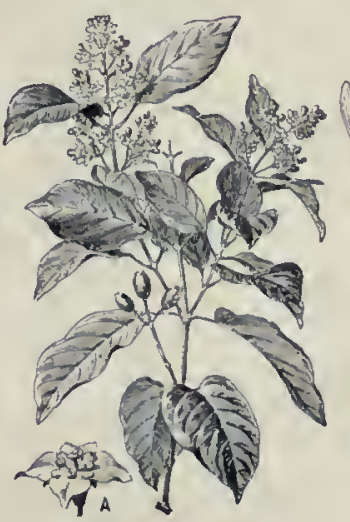

Fig. 210. - Santal. a. Fleur.

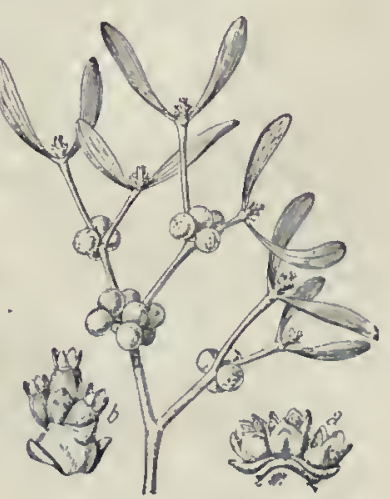

F1g. 211 - Gui. $a$, Fleurs måles ; $b$, Fleursfemelles. 


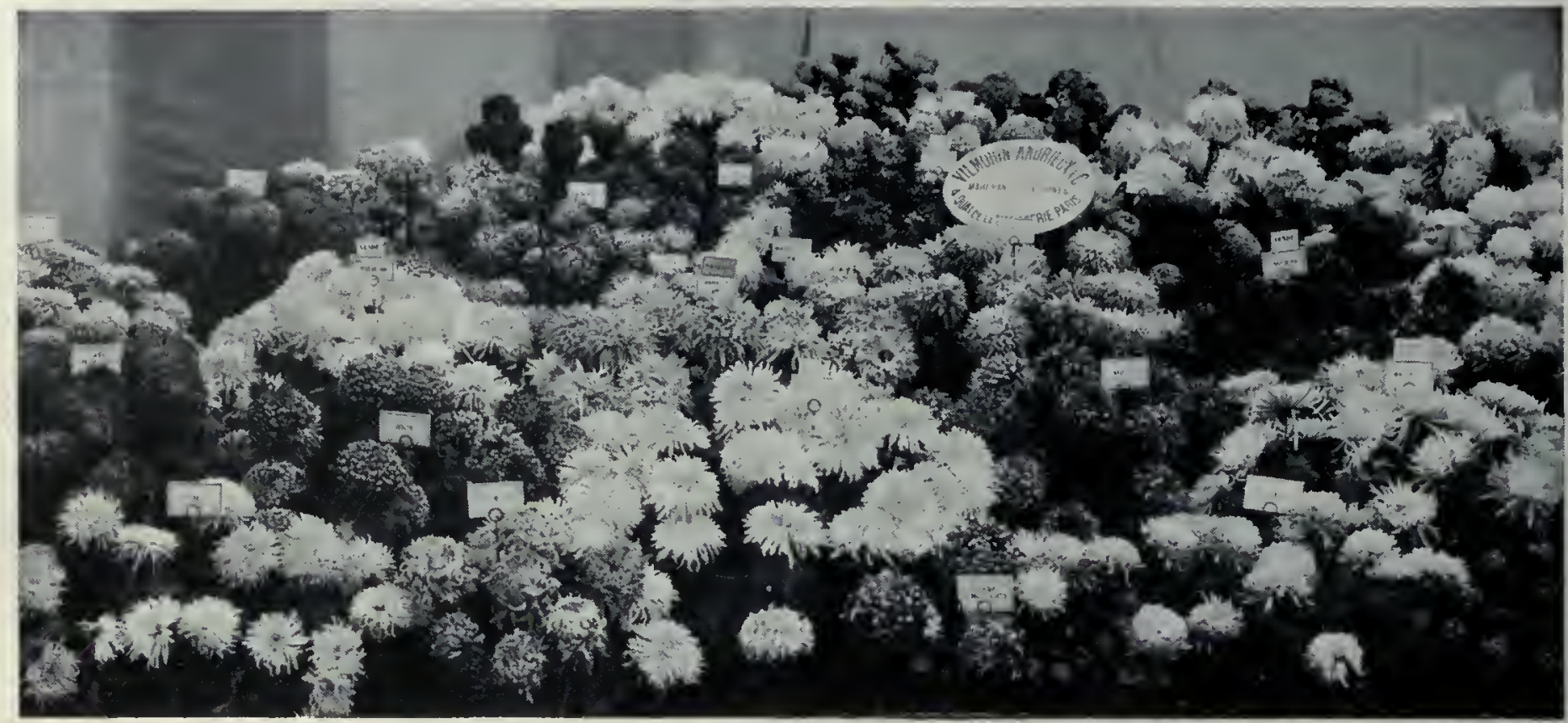

UNE EXPOSITION DES DIFFERENTES VARIETES DE CHRYSANTHEMES.

\section{VI. - GAMOPÉTALES INFÉROVARIÉES}

La fleur des Dicotylédones gamopétales est à deux enveloppes. Les pétales, soudés entre eux, portent d'ordinaire des étamines dont le nombre est habituellement égal à celui des pétales, c'està-dire qu'il y en a quatre ou cinq. Le pistil n'est jamais formé non plus de nombreux carpelles. Certaines plantes à pétales séparés sont rangées dans les familles de Gamopétales par leurs affinités naturelles. On peut établir deux grandes sections parmi les Gamopétales, d'après les rapports de leur ovaire qui est libre ou non d'adhérence avec les autres pièces florales.

Les Gamopétales à ovaire infère ou adhérent comprennent :

Fleurs hermaphrodites. $\left\{\begin{array}{r}\text { Pas de capitule, feuilles opposées. Caprifoliacées. } \\ \text { Capitules. Étamines à anthères rap- } \\ \text { prochées. . . C . Composées. }\end{array}\right.$

Autour de ces familles nous en grouperons quelques autres.

\section{LES CAPRIFOLIACÉES}

Le Chèvrefeuille des bois (Lonicera), dont les jolies fleurs parfumées égaient, en été, les haies et les taillis, est un arbrisseau volubile de droite à gauche. Les fleurs, groupées en tête, ont un calice à cinq petites dents, une corolle à cinq pétales d'un blanc jaunâtre, soudés en un long tube se terminant par deux lèvres, cing étamines insérées sur la corolle, enfin un ovaire adhérent à trois loges. Le fruit est une baie rouge. Beaucoup de Chèvrefeuilles sont des arbrisseaux à tige dressée, non enroulable; le plus ornemental est le Chèrefeuille des buissons ou Camerisier. Les Weigelia ou Diervilla (fig. 213), la Symphorine en grappes ou Symphoricarpus, dite Boule-de-cire, sont de jolis arbustes d'ornement à baie blanc laiteux.

Presque toutes les Caprifoliacées habitent les régions tempérées de l'hémisphère Nord et sont des arbrisseaux à feuilles opposées. On distingue deux tribus, dont nous venons d'étudier la première: celle des Lonicérées, qui a pour type le Chèvrefeuille; elle est caractérisée par la corolle tubuleuse à limbe irrégulier et le style unique. La seconde, celle des Sambucées, dont le type est le Sureau, possède une corolle régulière et plusieurs styles.

LeSureau commun ou Sureau noir (Sambucus) [fig. 212] est un petit arbre à feuilles composées, à feurs blanches, d'odeur forte, groupćes en larges corymbes; le fruit est une baie noire. Le Sureau à grappes a des fleurs en panicules ovoïdes et des fruits rouges. Enfin, le Sureau yèble est une plante vivace, à

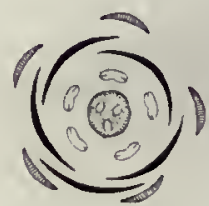

Fig. 212.

Diagramme de la fleur du Sureau. tiges annuelles herbacées, hautes d'un mètre; ses fleurs blanches ont l'odeur d'amande amère.

Les Viornes diffèrent principalement des Sureaux par leurs feuilles entières ou dentées. $\mathrm{La}$ Viorne cotonneuse (Viburnum Lantana) ou Mancienne a des feuilles dentées et velues en dessous, des fleurs blanches en corymbes plans terminaux; le fruit est une petite drupe noire. La Viorne obier a des feuilles trilobées et des fleurs en corymbes plans: celles du centre, petites, régulières et fertiles; celles du pourtour, stériles, rayonnantes et à grande corolle irrégulière; les fruits sont d'un rouge vif. Par la culture, cette plante a donné la Boule-deneige, à fleurs entièrement stériles et à inflorescences globuleuses. Dans la région méditerranéenne, ces deux Viornes sont remplacées par la Viorne-tin, dite à tort Laurier tin, à feuilles persistantes.

Valérianacées. - La Valériane officinale ou Herbe aux chats est commune dans les bois humides. Sa haute tige fistuleuse porte des feuilles opposées très découpées et se couronne en juin de fleurs rosées, groupées en corymbes de cymes et dont la composition est la suivante : calice à un ourlet; corolle tubuleuse, un peu bossue à la base et à cinq divisions presque égales; trois étamines insérées sur la corolle; ovaire adhérent à trois loges; pour fruit, un akène couronné d'une aigrette plumeuse, qui est l'ancien calice. De toute la plante se dégage une odeur spéciale qui semble très appréciée par les chats; ils se roulent, en effet, sur le sol autour de ces plantes avec une sorte de frénésie. La racine est em ployée en médecine. Le Centranthe rouge ou Valériane rouge, Lilas d'Espagne, est commun sur les vieux murs; c'est une jolie plante à étamine unique. La rosette foliaire de plusieurs Valérianelles, petites herbes annuelles, se mange en salade sous les noms de Mâche, Doucette, Boursette, etc.

Les Valérianacées se rattachent aux Caprifoliacées; elles en diffèrent notamment par leur fruit à une seule graine et par l'avortement d'un nombre variable d'étamines (1-2-4).

Rubiacées. - Les Rubiacées forment une grande famille naturelle voisine des Caprifoliacées, dont elles ne diffèrent que par les feuilles stipulées et l'ovaire à deux carpelles. Les feuilles, simples et entières, sont opposées; les fleurs, hermaphrodites et régulières, à calice peu visible; le fruit est variable. Cette famille tire son nom des matières colorantes rouges que renferment plusieurs de 


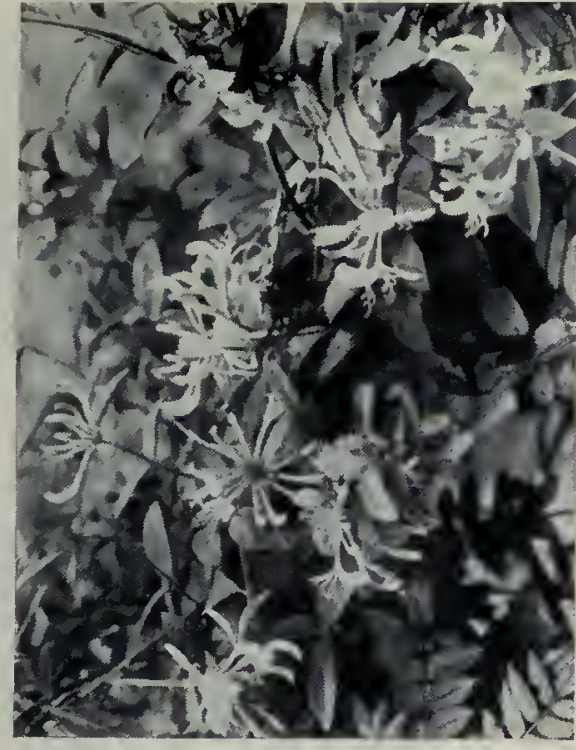

Chévrefeuille des bois,

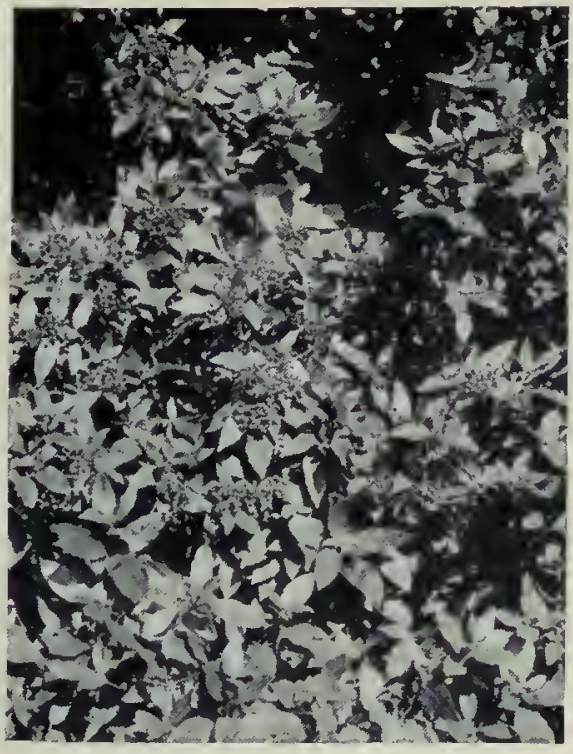

Viorne tin en fruits.

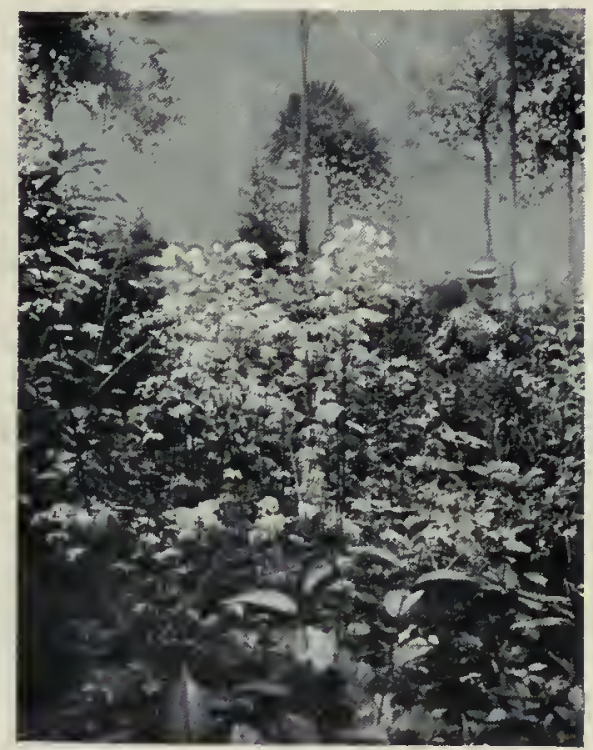

Vatériane officinale en fleurs. ses espèces et principalement la Garance (Rubia) [fig. 214]; on la divise en trois tribus: les Galiées, qui ont les carpelles à un seu] ovule et les stipules foliacées; les Coffées, qui en diffèrent par leurs stipules membraneuses; enfin, les Cinchonées, aux stipules membraneuses et aux carpelles renfermant plusieurs ovules.

Le Gaillet vrai (Golium) ou Caille-lait jaune, type des Goliées, est une herbe vivace de nos prés; ses feuilles sont, en apparence, verticillées par six à douze. Les fleurs, petites, d'un jaune franc, ont les pièces par quatre, à corolle étalée en roue. A côté du Gaillet jaune, on trouve le Gaillet croisette, à fleurs jaunâtres; le Goillet Mollugine, à fleurs blanches, et le Gaillet grateron, à tiges couvertes d'aiguillons.

Les Aspérules, comme la jolie Aspérule odorante de nos bois, ou Petit Muguet, diffèrent des Gaillets par leur corolle nettement tubuleuse. Les Garances ont leurs pièces Horales par cinq et leur fruit est une baie (au lieu d'akènes).

Les principales Cofféées sont les Caféiers et les Céphélides. Les Caféiers, originaires d'Afrique pour la plupart, sont des arbrisseaux à feuilles persistantes, à fleurs blanches odorantes, disposées en glomérules à l'aisselle des feuilles. L'ovaire est arrondi et surmonté d'un style simple, avec stigmate bifide. Le fruit ou " cerise " est une drupe rouge renfermant deux graines à albumen corné. Le Céphélide ipécacuanha, de l'Amérique du Sud, est un petit arbrisseau dont les racines constituent l'ipéco officinol, qui renferme un principe vomitif, l'émétine.

Les Quinquina, types de la tribu des Cinchonées, sont des arbrisseaux ou de grands arbres originaires des Andes de l'Amérique tropicale; leurs feuilles sont entières et pétiolées; les fleurs, odorantes, blanches ou purpurines, à corolle longuement tubuleuse, sont groupées en panicules terminales; le fruit est une capsule oblongue renfermant de nombreuses graines. Les propriétés fébrifuges de l'écorce de Quinquina sont bien connues. Enfin les Bouvardia et les Gardenia sont de jolies plantes ornementales.

Dipsacées. - Étudions la Cardère sauvage (Dipsacus), haute plante bisannuelle des lieux incultes. Des aiguillons couvrent sa tige ferme et cannelée, hérissent la nervure médiane et les bords de ses feuilles, garnissent le capitule ovoïde de ses fleurs. Ses feuilles opposées sont soudées à leur base en une sorte de réservoir dans lequel s'accumulent la rosée et l'eau des pluies, ce qui justifie les noms vulgaires de Cabaret des oiseaux et Baignoire de Vénus, tandis que les épines de son capitule lui ont fait donner le nom beaucoup moins poétique de Peigne-veau. Le capitule est entouré par un involucre de bractées raides, et chaque fleur par un involucelle, spécial à cette famille. La fleur comprend un calice à quatre angles, unè corolle tubuleuse bilabiée, à quatre pétales blancs ou lilas, quatre étamines saillantes; un ovaire adhérent, à une seule loge uniovulée; les fruits sont des akènes surmontés d'une aigrette.

La Cardère à foulons, dite aussi Chardon à foulons, est moins armée; elle sert encore à carder les draps minces. Non épineuses et différentes des Cardères par l'aspect, sont les Scabicuses de nos prés, aux gracieux capitules de fleurs violettes, blanches ou roses.
Les Dipsacées ont de grandes affinités avec les Valérianacées; elles s'en distinguent par leur inflorescence et leur ovaire à une loge; elles sont encore plus voisines des Composées.

\section{LES COMPOSEES}

Caractères généraux. - La famille des Composées constitue le plus grand groupe végétal; elle comprend près de 800 genres avec 10000 espèces, sur environ 100000 espèces de plantes à fleurs. Les Composées, plutôt rares dans les régions tropicales, sont fort communes dans les régions tempérées.

Pour en connaître les caractères, nous nous adresserons à la Pâquerette vivoce (Bellis perennis). De la rosette des feuilles de cette herbe partent des pédoncules dont chacun se termine par ce qu' on nomme vulgairement une fleur de Pâquerette, mais qui est, en réalité, un capitule, c'est-à-dire un ensemble composé de nombreuses fleurs de deux formes et de deux couleurs. Les très petites fleurs jaune d'or du centre sont régulières: on les nomme fleurons (fig. 2I7, c); elles comprennent un calice avorté adhérent à l'ovaire; une corolle à cinq pétales égaux soudés; cinq étamines insérées sur la corolle et soudées par leurs anthères (Synanthérées) en un tube au centre duquel passe le style, qui surmonte l'ovaire adhérent et se termine par un stigmate fourchu (fig. 2]8). L'ovaire, à une seule loge uniovulée, devient un petit akène velu. Les grandes fleurs du pourtour sont irrégulières et dépourvues d’étamines; on les nomme ligules ou semi-fleurons (fig. $217, b)$. La corolle, d'un blanc pur, souvent rosée en dessous, est rejetée d'un seul côté, en languette. Le capitule est entouré par deux rangs de petites écailles formant un involucre. Beaucoup d'autres Composées ont, comme

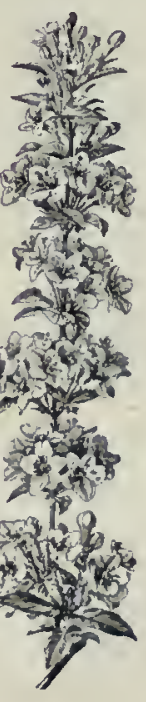

Fig. 213.

Fig. 213. la Pâquerette, un capitule formé de fleurons au centre et de ligules rayonnantes au pourtour; on en a constitué la tribu des Radiées. En examinant le capitule d'un Bleuet, on verrait qu il ne contient que des fleurs en tube : d'ou le nom de Tubuliflores, donné à toutes les plantes analogues. Enfin les Liguliflores, comme la Laitue, ont le capitule entièrement formé de fleurs en languette.

Tubuliflores. - La Centourée bleue ou Bleuet est une plante adventice des céréales. Les fleurons, dun si beau bleu, qui constituent le centre

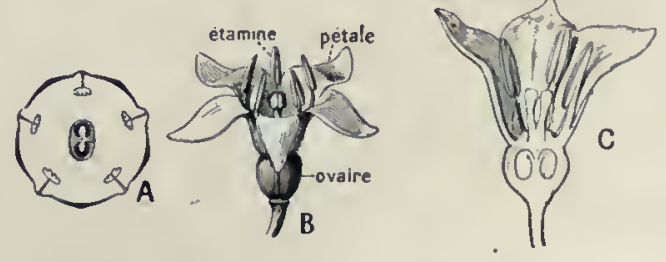

Fig. 214. - Garance.

A. Diagramme de la fleur; B, Fleur entière: C, Coupe. 


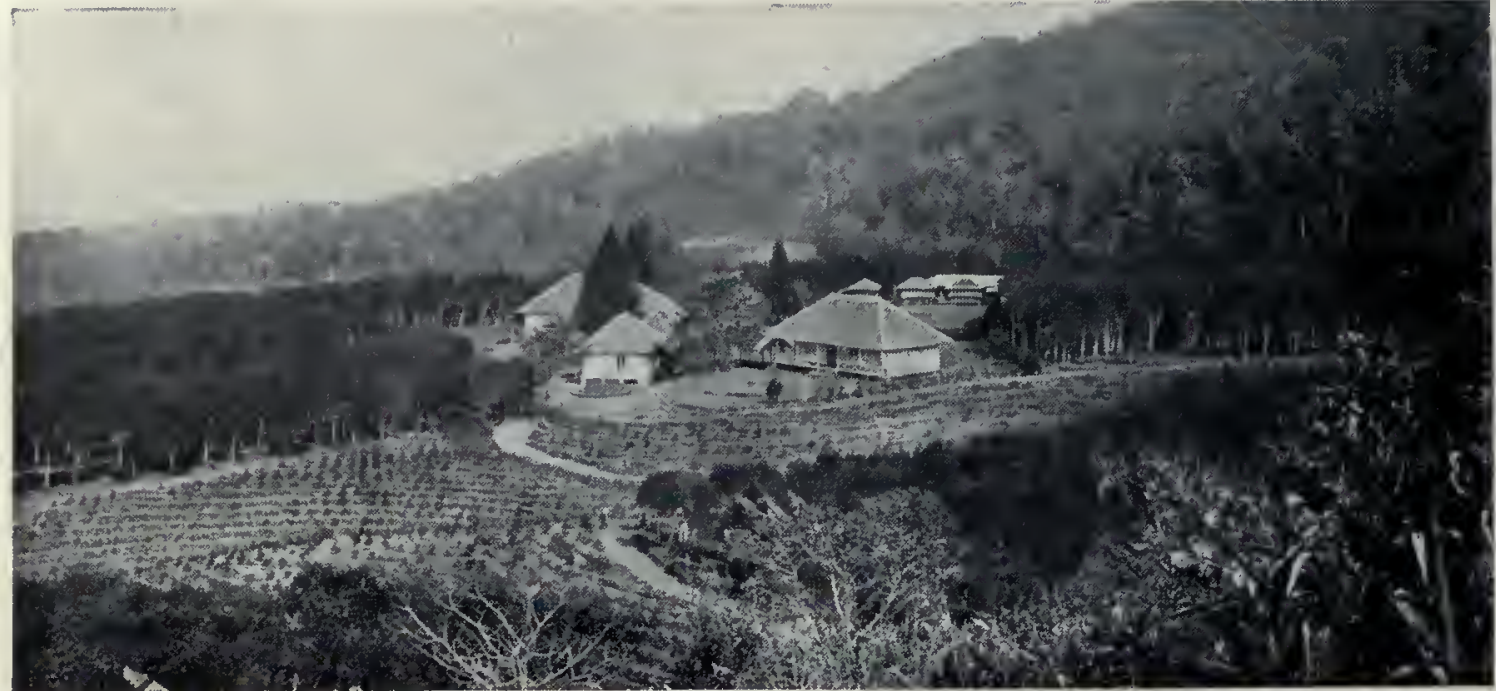

Une culture de Quinquina, à Java.

Cirses : cest la Cardonnette (Cynara Cardoncelle). Par sa culture, pratiquée depuis des siècles, l'homme a modifié les feuilles du $C y$ nara el obtenu le Cardon. En développant les fleurs, il a peut. être obtenu l'Artichaut (Cynara Scolyme) [fig. 215]. Dans l'Artichaut, on mange le fond ou réceptacle et la base des feuilles ou bractées de linvolucre; le foin est formé par les fleurs non encore épanouies. Le Cardon a des feuilles plus découpées que l'Artichaut, et à côtes très saillantes.

Parmi lesautres Composées tubuliflores, nous

du capitule, sont entourés par une rangée de fleuronis plus larges, irréguliers et stériles. Le genre Centaurée comprend bien d'autres espèces : la Jacée, herbe des prés, vivace, à fleurs violacées; la Centaurée Chausse-trape, petite plante épineuse, bisannuelle, à fleurs purpurines, etc.

Le nom de Chardon (fig. 216) est improprement donné à nombre de plantes épineuses et raides, portant des fleurs en tête arrondie : le Panicaut, qui est une Ombellifère, est le Chardon roland; la Cardère, qui est une Dipsacée, est le Chardon à foulons; la Centaurée chausse-trape est le Chardon étoilé. Les vrais Chardons forment un groupe de Composées tubuliflores épineuses; leurs tiges sont parfois aiguillonnées, leurs feuilles le sont toujours, ainsi que les bractées de l'involucre; entre les feurs s'insèrent des soies rigjdes; hes fruits sont surmontés d'une aigrette de filaments, simples chez les Chardons proprement dits et plumeux chez les Cirses. Les Chardons sont des plantes pittoresques, souvent reproduites et interprétées dans les arts. Très mauvaises herbes, envahissantes, leurs fruits soyeux, disséminés par le vent, se répandent avec une déplorable facilité; la loi en prescrit la destruction.

Le Cirse ou Chardon des champs est particulièrement abondant et nuisible; le Cirse laineux ou Chardon des ânes est très recherché des bestiaux; plusieurs autres espèces constituent d'ailleurs pour eux une excellente alimentation, à la condition d'être broyées ou légèrement Rétries. Le Chardon penché (Carduus nutans) est commun au bord des routes. Citons encore le Chardon bénit ou Cnicaut bénit $\left(C_{\text {nicus }}\right)$, auquel on attribuait jadis d'étonnantes propriétés médicales. LOnopordon acanthe, le Chardon Marie ou Silybe de Marie sont de grandes espèces décoratives, ainsj que les Échinopes, dits Chardons bleus, à capitules de capitules.

Les Carlines sont de petites herbes à feuilles épineuses et à port de Chardons.

LaBardane (Lappa) ou Teigne est une grande herbe, à larges feuilles molles; les enfants s amusent à lancer sur les vêtements, où ils s'accrochent, les capitules de fruits mûrs, à bractées crochues.

Dans tout le midi de l'Europe, on rencontre çà et là une sorte de Chardon à gros capitules de fleurs bleues longuement tubuleu ses, à feuilles doublement fendues et pen nées; le fruit est surmonté d'une courte aigrette de soies plumeuses commecelle des

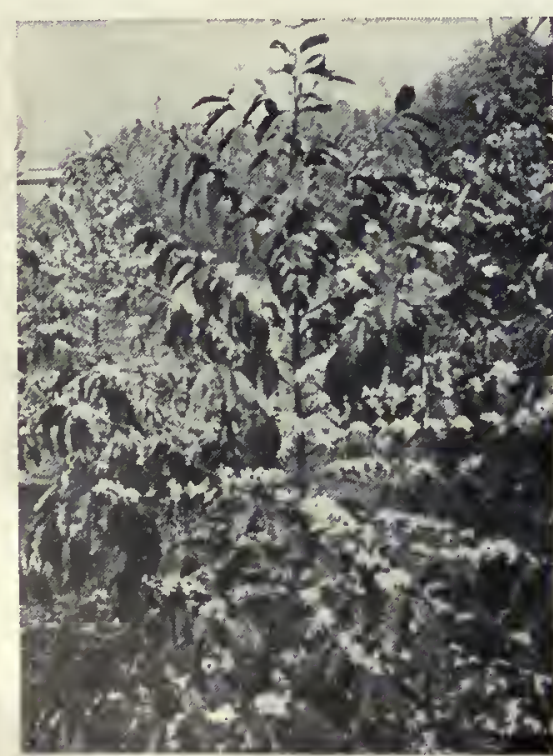

Caféier en fleurs. nous bornerons à citer l'Eupatoire chanurine des lieux humides; l'Agérate du Mexique, dite Eupatoire bleue, si répandue dans les jardins; le Carthame, jadis utilisé en teinture.

Radiées. - La tribu des Radiées a des fleurs tubuleuses centrales et des fleurs périphériques en languette tridentée. Tandis que les Tubuliflores sont riches en cellules résinifères qui les rendent astringentes et fébrifuges, les Radiées renferment des canaux oléifères sécrétant des huiles essentielles qui les rendent stimulantes el aromatiques. Des caractères secondaires ont permis d'établir des groupements dans la masse des genres que comprend cette tribu. Chez les Astérées, les Hélianthées, les Héléniées, les Anthémidées, les Senecionidées, les anthères sont normales, tandis que chez les Inulées et les Calendulées elles présentent à leur base des appendices en forme de queue.

Les Astérées ont un style à branches aplaties et non terminées par un anneau de poils; leurs fruits sont dépourvus d'arêtes. La $P \hat{a}$ querctte vivace, décrite plus haut, présente ces caractères. $\mathrm{Par}$ la culture, elle a donné des variétés à grands capitules garnis de fleurs doubles (toutes en languettes), blanches, roses ou rouges. La Mère de famille est une variété à fleurs prolifères, chaque capitule étant entouré de plusieurs autres très petits, nés dans les aisselles des écailles de l'involucre. Les Asters sont des herbes vivaces. La Reine-marguerite ou Callistephus de Chine, très voisine, est une superbe plante annuelle, introduite en Europe vers 1731. Les Érigérons ou Vergerettes sont de mauvaises herbes velues, propres aux régions tempérées. L'une des plus répandues aujourd'hui en France est l'Erigéron du Canada, qui a été introduite avec les emballages des peaux de castor. Les Solidages, plus

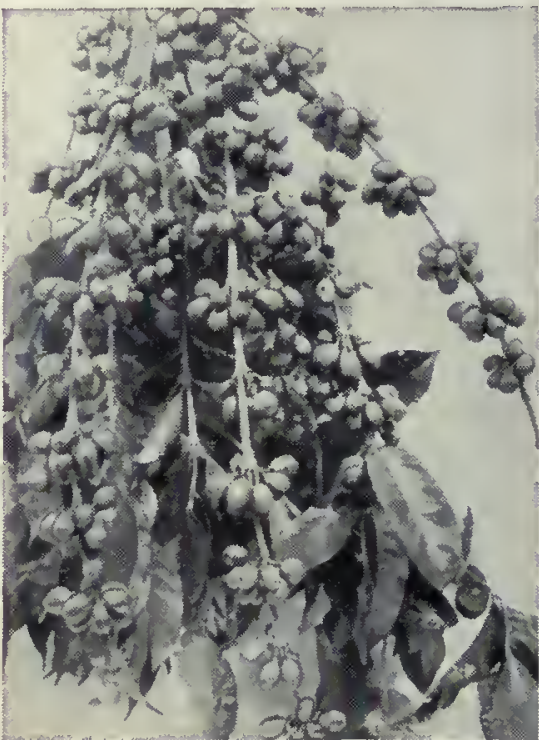

Fruits du Caféier grandes que les précédentes, sont représentées chez nous par la $V$ erge d'or, cultivée dans les jardins, ainsi que la Gerbe d'or ou Solidage du Canada.

Les Hélianthées, de même que les Héléniées, Anthémidées et Senecionidées qui suivent, ont lesdivisions du style terminées par un anneau de poils. Chez les Hélianthées, les fruits sont anguleux, nus ou surmontés de une à quatre arêtes, souvent caduques; le réceptacle est garni de paillettes séparant les fleurs, et les feuilles sont ordinairement opposées. Les Hélianthes cu Soleils sont de grandes herbes 


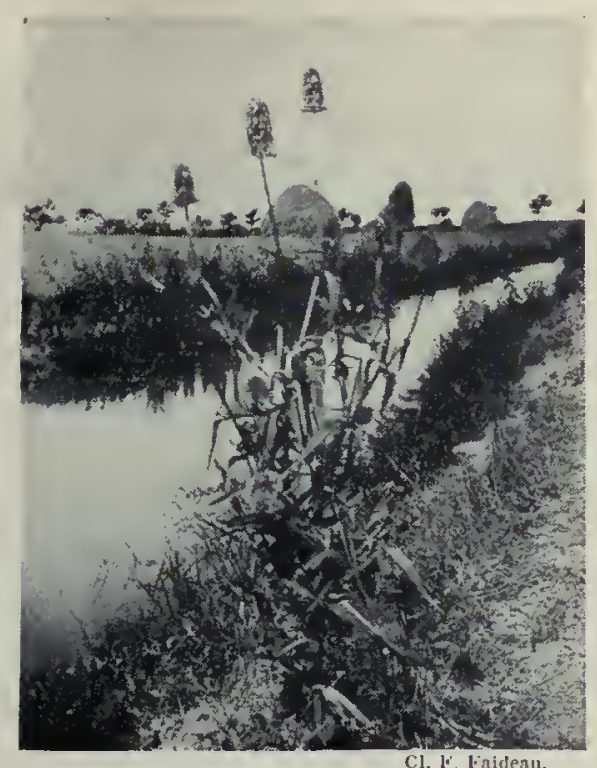

Cardére ou Cabaret des oiseanx.

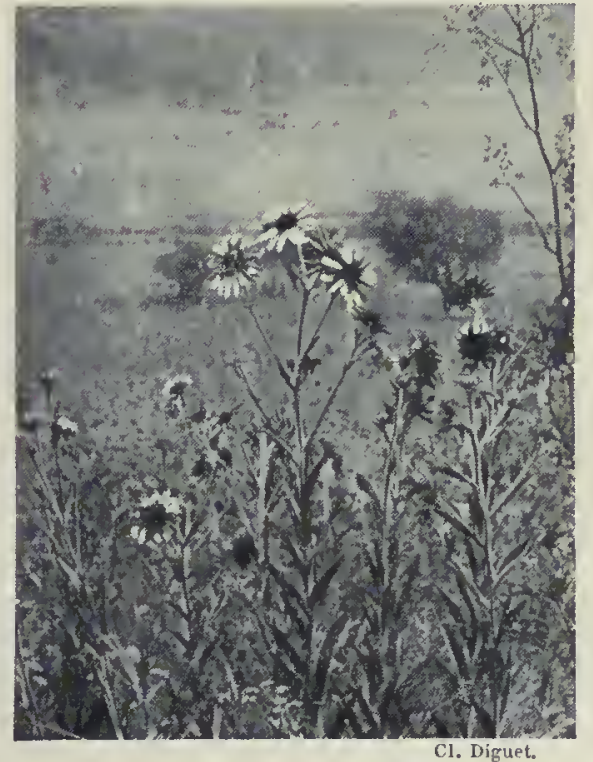

Helianthus, an Mexique.

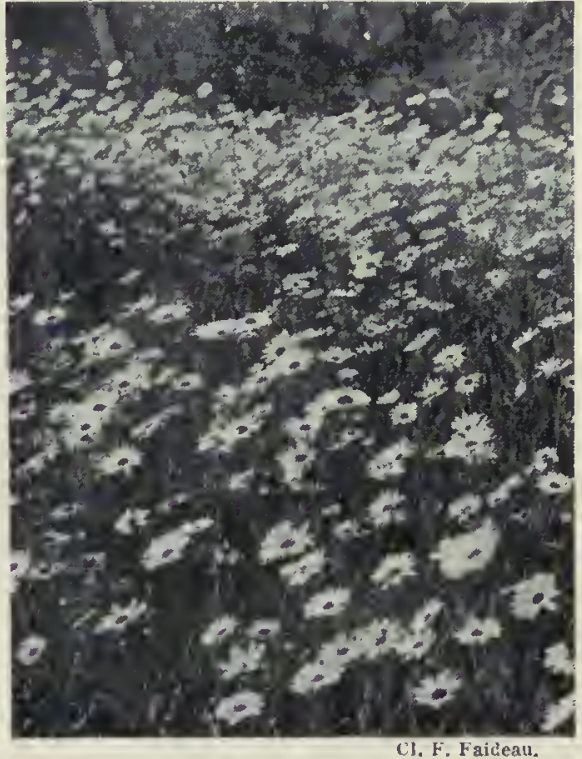

Leucanthémes dans un pré. américaines à larges capitules jaunes, communes dans les prairies. Deux espèces, introduites et cultivées en France depuis la fin du XVIt ${ }^{\mathrm{e}}$ siècle, sont à citer : l'Hélianthe tubéreux ou Topinambour et l'Hélianthe annucl, dit aussi Tournesol ou Grand Soleil. Le Topinambour, originaire du Brésil, est remarquable par ses rhizomes tubéreux, comparables à ceux de la Pomme de terre. Le Grand Solcil a des feuilles alternes, pétiolées; les fleurs sont rassemblées en un capitule géant pouvant avoir jusqu à 25 centimètres de diamètre; les ligules sont d'un jaune orange et les fleurons, d'un jaune pâle, sont entremêlés de paillettes noires.

Parmi les Hélianthées figurent de belles plantes d'ornement ayant aussi une origine américaine : les Corćopsis, les Zinnia et les Dahlia, ces "rois de l'automne ". Le Dahlia, vivace par scs faisceaux de racines tuberculeuses, ne fut importé en Angleterre, venant du Mexique, quen 1789.

Très voisins des Dahlias, sans écailles entre les fleurs, sont les Héléniées; ce groupe, d'origine américaine comme eux, comprend les Tagetes ou Eillets d'Inde, les Hélénies et les Gaillardes.

Les Anthémidées sont caractérisées par leur style à branches arrondies et tronquées au sommet, par leurs anthères non appendiculées à la base et par leur fruit sans aigrette ou à aigrette peu développée, par leurs bractées à rebord sec d'un côté.

Les $A n t h c ́ m i s$, ainsi que quelques plantes des genres voisins, sont désignés communément sous le nom de Marguerites. Dans l'Anthémis camomille, ou Camomille romaine, le réceptacle, très bombé, porte des fleurons jaunes et des ligules femelles d'un blanc pur. Ces capitules ont une odeur aromatique agréable et une saveur amère due à une huile essentielle. Les capitules de l'Anthémis cotule ou Camomille puante sont mélangés parfois fraudulensement à ceux de la Camomille romaine. II faut signaler aussi la Matricaire camomille des moissons, qui est la Camomille d'Allemagne ou Camomille ordinaire des officines, et le Leucanthème vulgaire ou Grande Marguerite de nos prés (fig. 217).

Le genre Chrysanthème comprend un nombre considérable d'espèces. Citons seule-

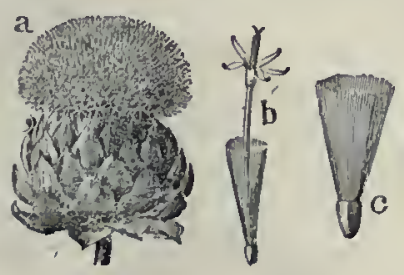

Fig. 215, - Artichaut.

$a$. Capitule; $b$, Fleuron ; $c$, Fruit. ment le Chrysanthème des moissons ou Marguerite dorée, dont les capitules d'un beau jaune d'or sont communs dans nos blés: le Chrysanthème des jardins, plante annuelle originaire de l'Europe méridionale; le Chrysanthème trutescent, dit encore Marguerite ou Anthémis en arbre; mais l'espèce la plus connue, celle que l'on désigne sous le nom de Chrysanthème, sans autre indication, est le Chrysanthème de l'Inde ou de Chine (Pyrèthre). Cette superbe plante vivace est sortie de plusieurs types distincts originaires de l'Inde, de la Chine et du Japon. Ses tiges annuelles sont raides, ramifiées, cassantes; les feuilles alternes, plus ou moins incisées et découpées, répandent une odeur forte quand on les froisse.

En 1764, les premiers pieds de Chrysanthèmes furent apportés en France par un voyageur revenant de Chine; ils n'y excitèrent qu'une faible curiosité. Ce n'est quà partir de l'année 1827 , grâce aux efforts de Bernet, officier en retraite à Toulon, et de Pertuzès, son jardinier, que la brillante destinée horticole du Chrysanthème commença à se dessiner, quand on s'avisa de le multiplier par semis au lieu de se contenter des boutures; de nouvelles variétés furent obtenues. Aujourd'hui elles sont innombrables.

Au Japon, le Chrysanthème joue le premier rôle dans les jardins; il est employé en médecine et on utilise pour l'alimentation les fleurs confites de certaines variétés.

Les Pyrèthres, rattachés aux Chrysanthèmes, sont ornementaux par leurs fleurs ou leur feuillage. Le Pyrèthre rigide et plusieurs autres espèces sont cultivés en vue de la préparation des poudres insecticides. Les Armoises ont de petits capitules groupés en grappes et comprenant autour des fleurons une seule rangée de fleurs femelles tertiles à fine corolle tubuleuse. Ce sont des herbes aromatiques, dont plusieurs atteignent une grande taille; on les emploie en médecine. L'Armoise commune est très répandue; l'Armoise absinthe ou Grande Absinthe est un peu plus rare; on la cultivait jadis dans l'est de la France. Les capitules desséchés de l'Armoise de Judée et ceux de l'Armoise pauciflore et maritime constituent le semen-contra, doué de propriétés vermifuges; l'Armoise estragon est cultivée comme condiment. On nomme

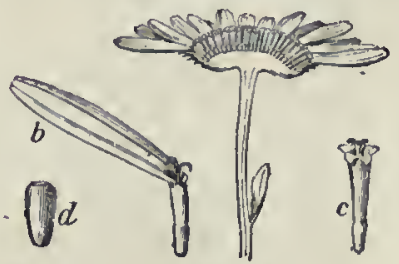

Fig. 217. - Grande Marguerite.

$\left(0^{\mathrm{m}}, 80\right.$; fleur blanche au pourtour et jaune au centre). $-a$, Coupe du capítule: $b$, Fleur ligulée; $c$, Fleuron; ¿, Fruit.

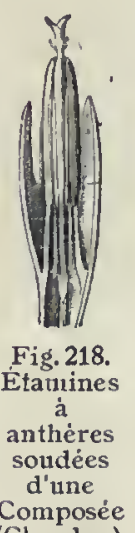

(Chardon)
(1 $\mathrm{m}, 60$, fleur rouse): $\mathrm{C}, \mathrm{C}$ icaut bénit $\left(0^{\mathrm{m}}, 50\right.$, fleur jaune); D. Cirse acaule ( $0^{m}, 05$ a $0^{n 1}, 20$, fleur rouge) ; $E$, Sily be de Marie ou Chardon Notre-Dame (1 metre, fleur pourpre ou blanche. 


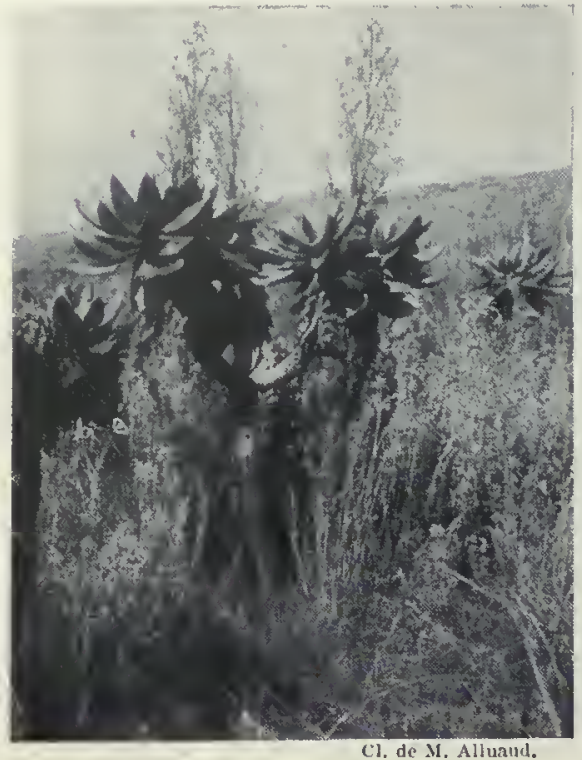

Séneçon arborescent (Kitimandjaro).

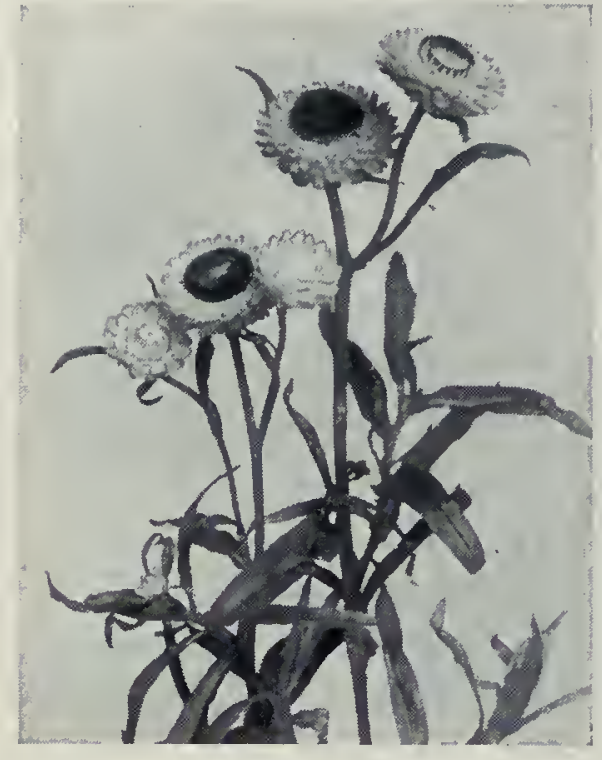

Immortelte à bractées.

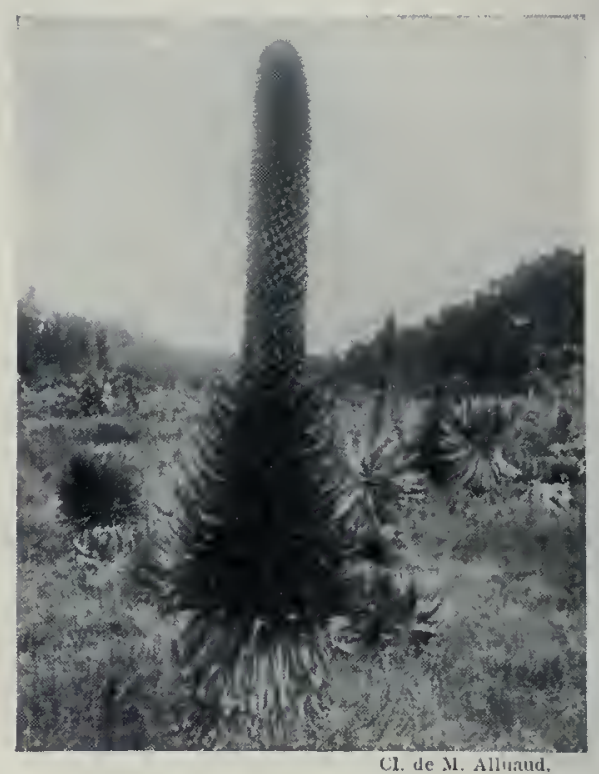

Lobélia arborescent (Kitimandjaro).
Génepi, dans les Alpes, diverses Armoises (glaciale) et Achillćes (musquée) vivaces et naines, duveteuses et aromatiques, entrant dans la confection de l'absinthe et de liqueurs analogues.

La Tanaisic vulgaire ou Herbe aux mites possède des propriétés voisines de celles de l'Absinthe. La Tanaisie balsamite ou Grand Baume est cultivée dans les jardins et employée comme vulnéraire. Il faut citer aussi l'Achillée millefeuille de nos prés.

Les Senecionidées se distinguent surtout des Anthémidées par la blanche aigrette qui surmonte leur fruit. On connaît un millier d'espèces de Seneçons répandues dans le monde entier. Plusieurs espèces des pays chauds sont des arbres ou des arbrisseaux, mais la plupart sont des herbes, comme le beau Seneçon Jacobée de nos prés ou l'humble Seneçon commun. Le Tussilage ou Pas-d'âne (fig. 219) est fort répandu dans les terrains argileux. Chez le Pétasitès odorant des jardins, la grappe des capitules rosés répand une douce odeur d'héliotrope: d'où son nom d'Héliotrope d'hiver. Le Pétasitès vulgaire, très voisin, porte des grappes de capitules violacés inodores. Toutes ces plantes sont pectorales. Signalons encore parmi les Senecionidées: les Cinéraires ( $f i g$ 220), superbes plantes ornementales; l'Arnica de montagne, à feuilles opposées.

Les Inulées diffèrent des groupes précédents par la présence d'appendices en forme de queues à la base de leurs anthères; les fleurs du bord du capitule sont peu développées, souvent filiformes et femelles. L.es Inules ou Aunées, vivaces, glanduleuses et velues, portent des feuilles entières ou dentées, des capitules jaunes comprenant des ligules femelles et des fleurons fertiles; le fruit est surmonté d'une aigrette. Beaucoup croissent en France, dans les lieux humides; la plus intéressante est l'Inule aunée ou Grande Aunée. C'est dans son rhizome qu'on a découvert une sorte d'amidon soluble, l'inuline, retrouvée depuis chez le Dahlia, le Topinambour, etc. ; on l'a appelée l'amidon de l'avenir.

Bien différentes des Inules, comme aspect, sont les Gnaphales, blançhes, cotonneuses, à feuilles entières et à petits capitules; deux espèces de notre flore sont à citer : le Gnaphale dioïque ou Piedde-chat et le Graphale pied-de-lion ou Étoile du glacier, qui est l'Edelweiss des Allemands. La première a pour inflorescence un corymbe terminal de petits capitules blancs ou roses, suivant le sexe, qui font partie des quatre fleurs pectorales. La seconde se rencontre dans les régions montagneuses du monde entier. La beauté de cette plante vient des bractées épaisses et larges de l'involucre, formant une étoile blanche et cotonneuse.

Les Hélichryses ou Immortelles ont des capitules jaunes composés surtout de fleurs en tube, avec un très petit nombre de fleurs en languette grêles; les fruits portent une aigrette; elles sont remarquables par leur involucre dont les bractées, imbriquées sur plusieurs rangs, sont scarieuses, souvent colorées et d'une conservation indéfnie: d'où le nom d'/mmortelles. Le genre Hélichryse est particulièrement bien représenté en Afrique par des arbrisseaux; en France, quelques petites espèces herbacées se rencontrent çà et là. On cultive, aux environs de Toulon, l'Immortelle ou Hélichryse d'Orient, duveteuse, à nombreux petits capitules entourés de bractées jaunes, et en Normandie, aux environs de Lisieux, l' $/ m$ mortelle à bractées, plante australienne aux larges capitules, dont les écailles sont blanches, roses, jaunes ou bronzées. Plusieurs autres espèces voisines ont un involucre satiné, brillant ou coloré, et méritent le nom d'Immortelle : l'Antennaire margaritacée ou Immortelle blanche, Bouton d'argent; I'Acroclinium rose ou Immortelle rose et la superbe Rhodanthe de Mangles, à capitule conique. On peut même en rapprocher le Xéranthème annuel, dit aussi Immortelle annuelle, ou de Belleville, qui est une Tubuliflore. Toutes ces plantes sont recherchées pour l'ornementation; leurs fleurs, coupées avant complète maturité et desséchées rapidement à l'abri du soleil, gardent longtemps leurs couleurs.

La longue série des Radiées se termine par les Calendulées, différant des Inulées par les fleurs périphériques bien développées. Le représentant principal est le Souci des champs (fig. 221), trop commun dans les terres cultivées. Ses capitules, d'un jaune orangé, ont des fleurs centrales tubuleuses, dont beaucoup sont stériles, et des ligules femelles fertiles au pourtour. Le réceptacle est nu, sans écailles, et les fruits sont de deux sortes : les externes, irréguliers et garnis d'épines; les centraux, lisses, contournés et d'apparence annelée comme de petites chenilles. On cultive dans les jardins le Souci officinal du midi de l'Europe et le Souci plavial du Cap, dont les fleurs se ferment quand le temps menace.

Liguliflores. - Les Ligulifores forment une tribu très nette; le capitule ne comprend que des corolles tontes ligulées à cing dents; les fruits sont souvent munis d'aigrettes; ces plantes ne produisent pas d'huiles essentielles comme les Radiées, mais un latex blanc qui les rend narcotiques et vénéneuses, ou simplement amères. Plusieurs sont comestibles dans le jeune âge, lorsque le latex est encore peu abondant.

Étudions d'abord l'une des Ligulifores les plus répandues, le Pissenlit dent-de-lion. C'est une petite herbe vivace, à tige très courte, presque nulle. Les feuilles, disposées en rosette, sont longues, profondément incisées en dents triangulaires. Les hampes florales, qui partent du pied, se terminent par un capitule dun

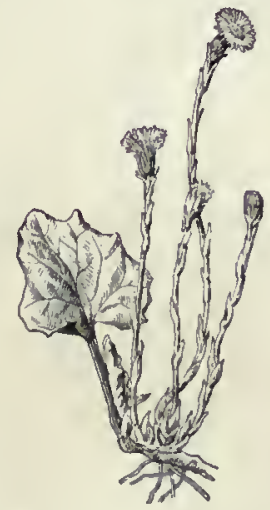

Fig. 219. - Pas-d'àne.

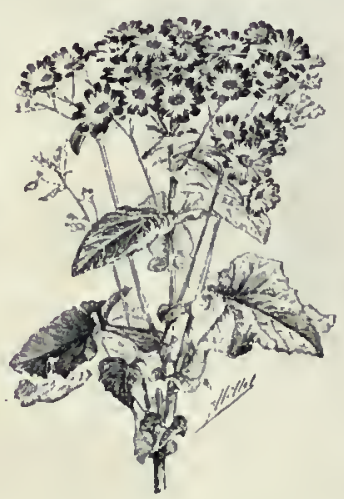

Fig. 220. - Cineraire.

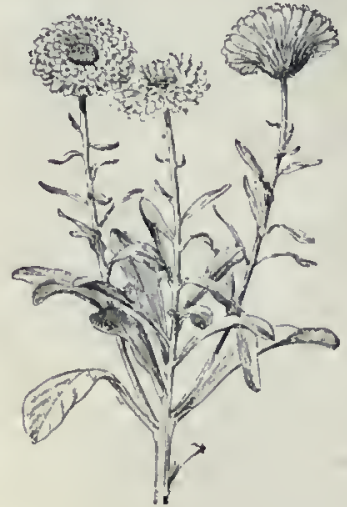

Fig. 221. - Souci. 


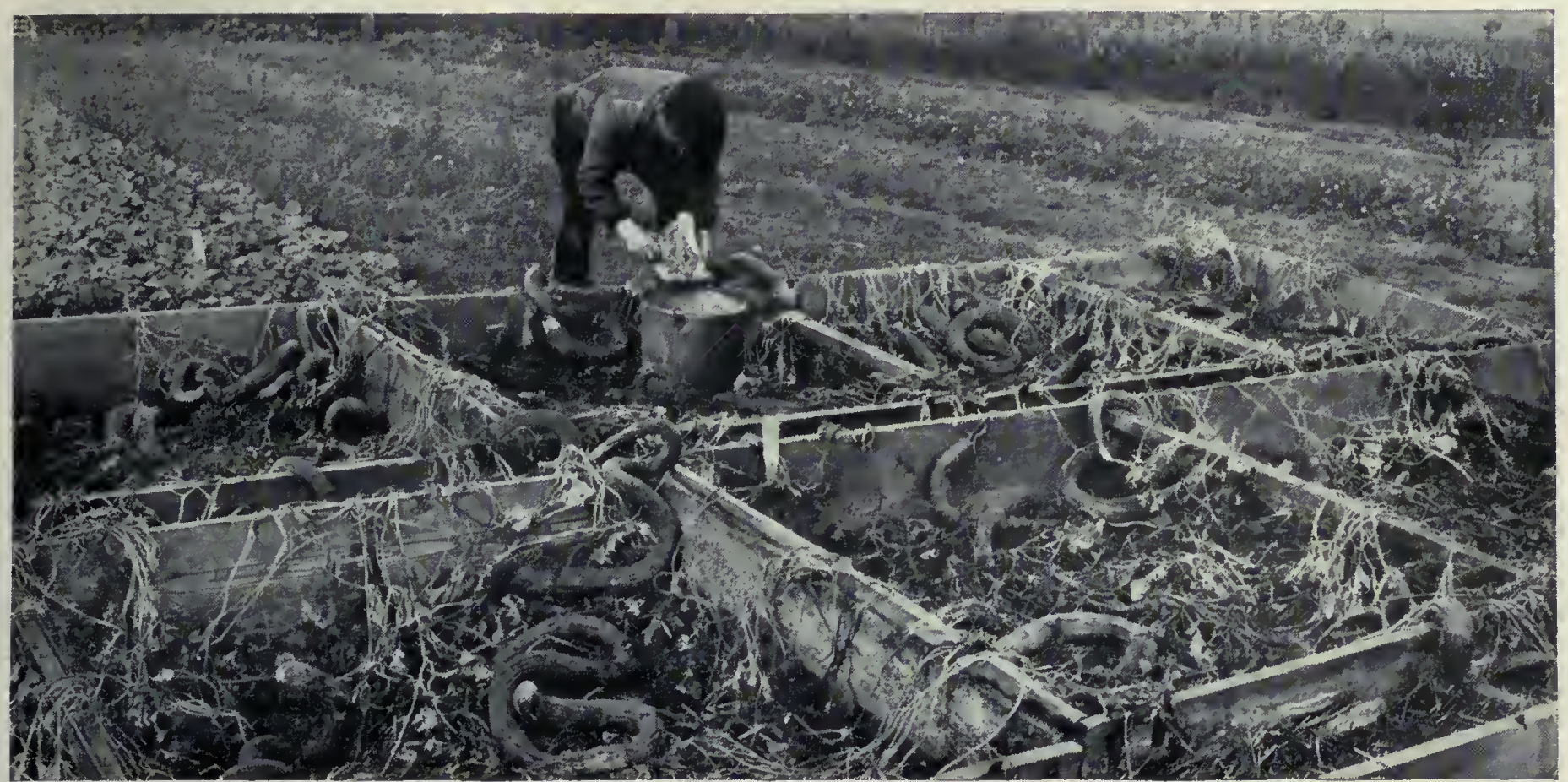

Concombres serpents.

jaune doré. Le fruit porte une aigrette de poils blancs soyeux au sommet d'une longue épine; les enfants les nomment des chandelles et samusent à souffler dessus pour les disperser. Avant la floraison, les feuilles du Pissenlit font une excellente salade.

La Chicorée sauvage, aux capitules d'un si beau bleu, possède une racine forte, pivotante. Les Laitues doivent leur nom au latex qui s'échappe de toutes leurs parties blessées. Plusieurs espèces sont indigènes en France; la plus répandue est la Laitue scariole, des lieux incultes; sa tige fistuleuse, aiguillonnée inférieurement, atteint parfois 2 mètres de haut. Les capitules, petits, très étroits et d'un jaune pâle, forment des grappes. La Laitue cultivée est une plante maraîchère de première importance.

Les Salsifis ont des feuilles entières, étroites et longues, des capitules terminaux se transformant en une grosse sphère d'akènes plumeux : le Salsifis cultivé a des fleurs violettes; il est bisannuel, et on mange, la première année, sa racine qui est blanche. La Scorsonère d'Espagne est vivace et à fleurs jaunes; sa racine est le salsifis noir. Enfin le Scolyme d'Espagne, également vivace, est à feuilles épineuses, à capitules jaunes et à port de chardon; sa racine se mange comme celle des salsifis. Parmi les autres plantes de cette tribu, citons les Laiterons, Porcelles, Epervières, Picrides, Lampsanes, Crépides et Catananches.

Campanulacées. - La famille des Campanulacées comprend surtout des herbes à feuilles alternes, à fleurs hermaphro-

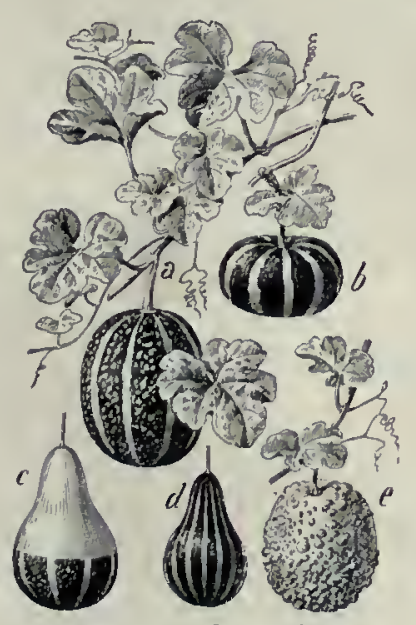

Fig. 222. - Coloquintes.

$a$. Du Malabar; $b$, Plate rayée $c$, Poire bicolore; $d$, Poire rayée; e, Galeuse. dites du type cinq; les étamines sont indépendantes de la corolle, disposition fort rare chez les Gamopétales ; l'ovaire est adhérent, formé de deux à cinq carpelles clos avec autant de loges multiovulées; la pla-

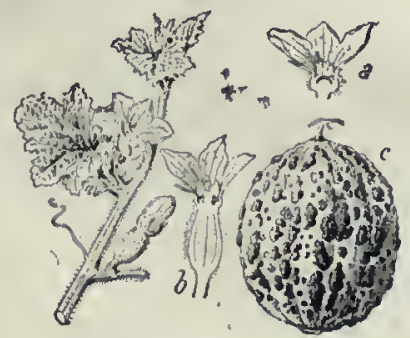

Fig. 223.

Melon Cantaloup d'Alger.

$a$, Coupe de la fleur mâle; $b$, Coupe de la fleur femelle; $c$, fruit. centation est axile; le fruit est une capsule. Tous ces végétaux contiennent un latex. On les divise en deux tribus : les Campanulées, dont la fleur ést régulière, et les Lobéliées, chez lesquelles elle est bilabiée. Les fleurs bleues, rarement blanches ou jaunes, des Campanules ont une corolle en forme de cloche (Campanula), dont le style serait le battant. Parmi les plus communes sont : la Campanule raiponce, qui élève tout son jeu de clochettes jusqu'à un mètre de hauteur. Les horticulteurs cultivent des Campanules à fleurs très grandes comme celles de la Campanule carillon. La Campanule pyramidale forme un cône de plúsieurs centaines de fleurs d'un bleu pâle; ses rameaux flexibles se laissent guider et prennent toutes les formes. Dans les moissons se plaît la Spéculaire miroir de Vénus.

Les Lobelia sont, pour la plupart, des plantes exotiques (Cap, Caroline), atteignant une assez grande taille et d'un port fort curieux avec leur long épi de fleurs, rigide comme une colonne. En France, deux petites espèces herbacées représentent le genre.

\section{LES CUCURBITACÉES}

Les Cucurbitacées sont des herbes annuelles ou vivaces qui rampent sur le sol ou grimpent à l'aide de vrilles disposées à l'opposé de la base du pétiole; elles présentent parfois ce caractère singulier que leur partie inférieure provient d'un rameau et leur extrémité est une feuille. Les feuilles sont larges, alternes, pétiolées;

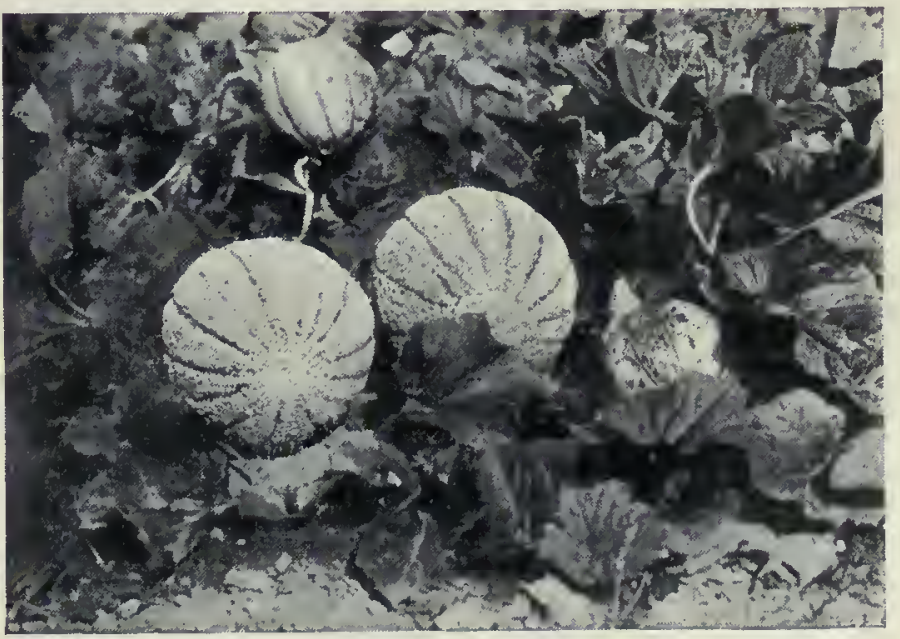

Melon Cantaloup brodé. 
les fleurs, isolées ou en grappes, sont le plus souvent jaunes ou blanches, et toujours (ou à peu près) unisexuées et régulières; les cinq sépales sont soudés à leur base en un tube doublé intérieurement par la base des cinq pétales; ces derniers sont, à leur sommet, libres chez certaines espèces, soudés chez d'autres.

Les fleurs mâles sont à trois étamines; deux de celles-ci se terminent par une grosse anthère à deux loges courbées en S; l'anthère de la troisième est plus petite el à une seule loge. En réalité, la fleur comprend primitivement cinq étamines, qui sedédoublent. Sur les dix demi-étamines ainsi formées, cinq avortent, quatre se soudent deux par deux, la cinquième reste libre. Les fleurs

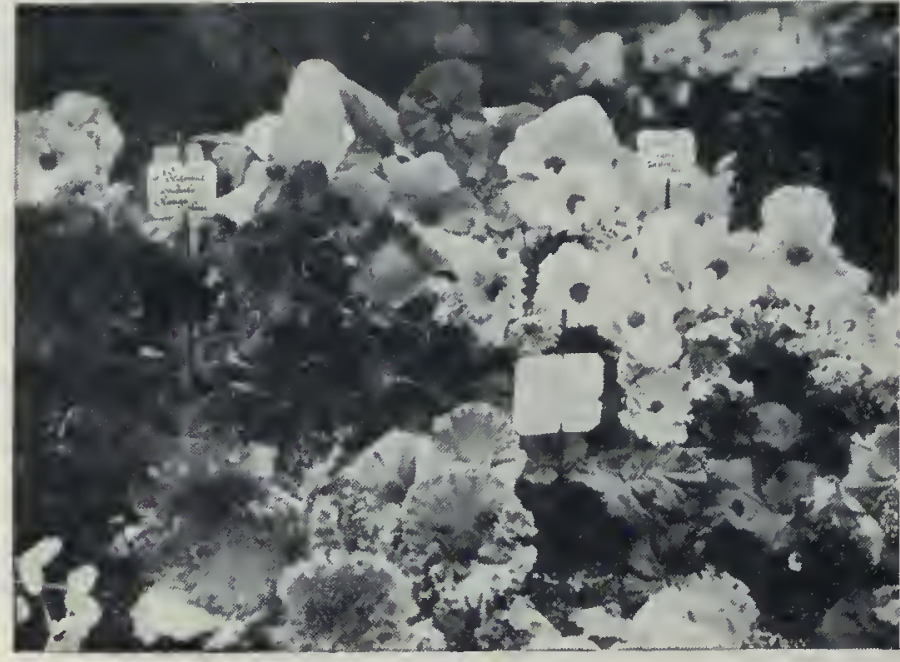

Bégonias ondulés à grandes fleurs.
La Courge Pepo ou Citrouille a le pédoncule fructifère prismatique, sillonné profondément et garni de côtes, tandis qu'il est cylindrique et à peine strié chez le Potiron. $C^{\prime}$ est une espèce très variable, à fruits allongés, de grossaur et de couleur très diverses. Citons la Citrouille de Touraine. la Coucouzelle ou Courge d'Italie, la Courge à la moelle dont les Anglais sont très friands.

La Courge musquée, aux feuil. les tachetées de blanc el aux truits cylindriques, est appréciée dans le midi de la France. Le Pâtisson ou Bonnet d'électeur, Artichaut de Jérusalem, se distingue des autres Courges par ses tiges dressées, sans vrilles, et la forme curieuse de ses fruits comestibles.

Les Gourdes (Logenaria) sont des plantes grimpantes, à fleurs emelles sont formées de trois carpelles soudés en un ovaire adhérent à trois loges. Le fruit, qu'on nomme péponide, est une sorte de baie à paroi coriace abritant une pulpe charnue qui, selon les espèces, est sucrée et alimentaire, ou très amère et plus ou moins toxique. On n'y retrouve plus la division en loges de l'ovaire; les cloisons et les placentas se sont détruits au cours du développement; au centre sont les graines plates et sans albumen. Les fruits des Cucurbitacées sont de véritables protées : chez une même espèce il en existe des variétés très nombreuses. Les Cucurbitacées sont des plantes des pays chauds; cependant la culture de plusieurs espèces réussit dans les climats tempérés, à l'aide de la chaleur des couches.

Le genre Concombre (Cucumis) comprend les Concombres proprement dits et les Melons, herbes annuelles, à feuilles entières, palmées, à vrilles simples, à fleurs jaunes dont les pétales sont presque libres. Le Concombre cultivé (C. sativus) est une plante couchée, à fruits longs, presque cylindriques, plus ou moins hérissés de petits tubercules; une variété rustique a des petits fruits ou cornichons qui sont cueillis avant maturité. Le Concombre serpent, qu'on fait ramper sur les pelouses, possède un fruit bizarre, long et flexueux.

Le Melon ( fig. 223) est cultivé depuis des siècles en Orient et en Grèce. Dans le midi de la France, il supporte la pleine terre; dans le Centre et le Nord, il lui faut la couche ou le châssis. Ses fruits sont agréables, rafraîchissants, mais peu nutritifs, d'une digestion difficile.

Les Pastèques (Citrullus) diffèrent peu des Concombres par leurs caractères floraux; leurs fleurs mâles sont solitaires comme les fleurs femelles, et leurs vrilles sont rameuses et non simples. On range dans ce genre la Pastèque commune et les Coloquintes. La Pastèque commune ou Melon d'eau a de gros fruits sphériques, lisses, d'un vert uniforme ou marbré. La Coloquinte (fig. 222) est une plante à tige charnue, cassante, couverte de poils rudes. Ses fleurs sont jaune orangé; le fruit est recouvert d'une écorce mince, mais dure et presque ligneuse. Sa pulpe, blanche et spongieuse, d'une amertume extrême, est un violent purgatif. Plusieurs espèces de Coloquintes sont ornementales par leurs fruits aux couleurs vives.

Les Courges (Cucurbita) sont des herbes à fleurs solitaires gamopétales, en cloche et non en étoile comme chez les Cucumis ou les Citrullus, et leurs fruits sont très gros. Trois espèces alimentaires sont cultivées depuis longtemps en Europe : le Potiron, la Citrouille et la Courge musquée. La Courge potiron porte un fruit géant qui atteint parfois 70 centimètres de diamètre et pèse plus de 100 kilogrammes! Il existe de nombreuses variétés de Potirons; les plus curieuses sont celles dites Turbans ou Bonnets turcs, dont la partie en calotte représente la saillie considérable de l'ovaire au-dessus du réceptacle.

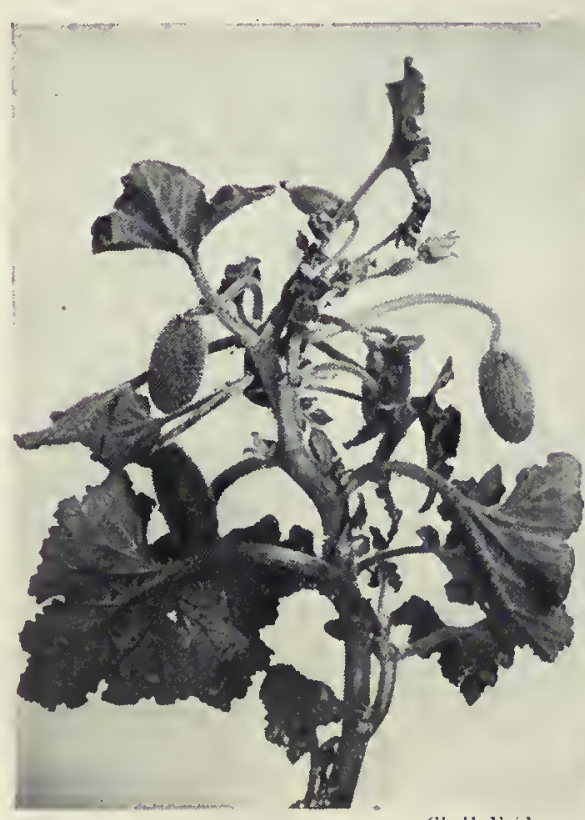

Ecballium èlastique, solitaires dialypétales. On cultive en France la Gourde calebasse: ses fleurs sont grandes, blanches, odorantes; le fruit est d'abord charnu, plein et d'un vert clair; on en peut, avant le développement complet, manger la pulpe, qui est sucrée; à la maturité, il est dur, ligneux et creux, ce qui permet, après l'avoir débarrassć des graines et de la pulpe sèche, de la transformer en un récipient.

Les Lofahs (Luffa) ou Pipengailles sont de belles plantes annuelles grimpantes, dont la culture réussit assez bien en France. Le fruit allongé est, dans sa jeunesse, comestible à la façon des cornichons; à la maturité il est fibreux et peut servir d'éponge : c'est la plante torchon ou éponge végétale.

L'Ecballium élastique ou Concombre sauvage est une petite plante dressée, sans vrilles, velue, remarquable par le mode d'ouverture de son fruit qui lance au loin ses graines. Le Momordique balsamine est une espèce grimpante cultivée depuis longtemps en France pour ses fruits, ou pommes de merveille, qui ont la taille d'une grosse prune. D'abord verts, puis jaune orange, ils s'ouvrent à la maturité et montrent alors leur pulpe d'un rouge vif.

La Bryone dioïque est une plante à énormes racines. Commune dans les haies, elle est élégante par ses feuilles lobées, ses vrilles spiralées et ses petits fruits $\mathrm{d}^{\prime} \mathrm{un}$ beall rouge vif. Citons encore la Chayottc (Sechium), du Mexique, plante grimpante cultivée dans beaucoup de pays chauds pour son fruit comestible, en forme de poire mamelonnée; sa racine est un légume.

Bégoniacées. - La petite famille des Bégoniacées comprend des herbes et.des sous-arbrisseaux à tige dressée ou grimpante, parfois réduite à un rhizome tubéreux. On connaît plus de 400 espèces de Begonia, habitant les conirées chaudes de l'Asie, de l'Afrique et surtout de l'Amérique. Leurs jolies fleurs sont unisexuées et irrégulières: les mâles, avec quatre sépales colorés et de nombreuses étamines; les femelles, avec quatre sépales ou plus, entourant un ovaire adhérent à trois loges. Le fruit est une capsule pourvue de trois ailes souvent inégales, et renfermant un nombre considérable de graines extrêmement petites. Les feuilles sont alternes, épaisses, inégalement partagées par la nervure médiane. Depuis un demi-siècle, le Bégonia a pris dans nos jardins une importance qui ne peut être comparée qu’à celle du Pélargonium. Le Bégonia à grandes fleurs oll hybride fournit du début de l'été à l'arrièresaison des fleurs énormes. Quelques espèces, comme le Begonia rex, ont un fenillage ornemental de premier ordre, à la fois très ample et richement teinté avec des reflets métalliques et parfois d'élégantes panachures. Les Bégoniacées forment une famille assez isolée; elles ont des analogies avec les Cucurbitacées; mais leur unique enveloppe florale les fait ranger quelquefois parmi les Apétales, à côté des Aristolochiacées. 


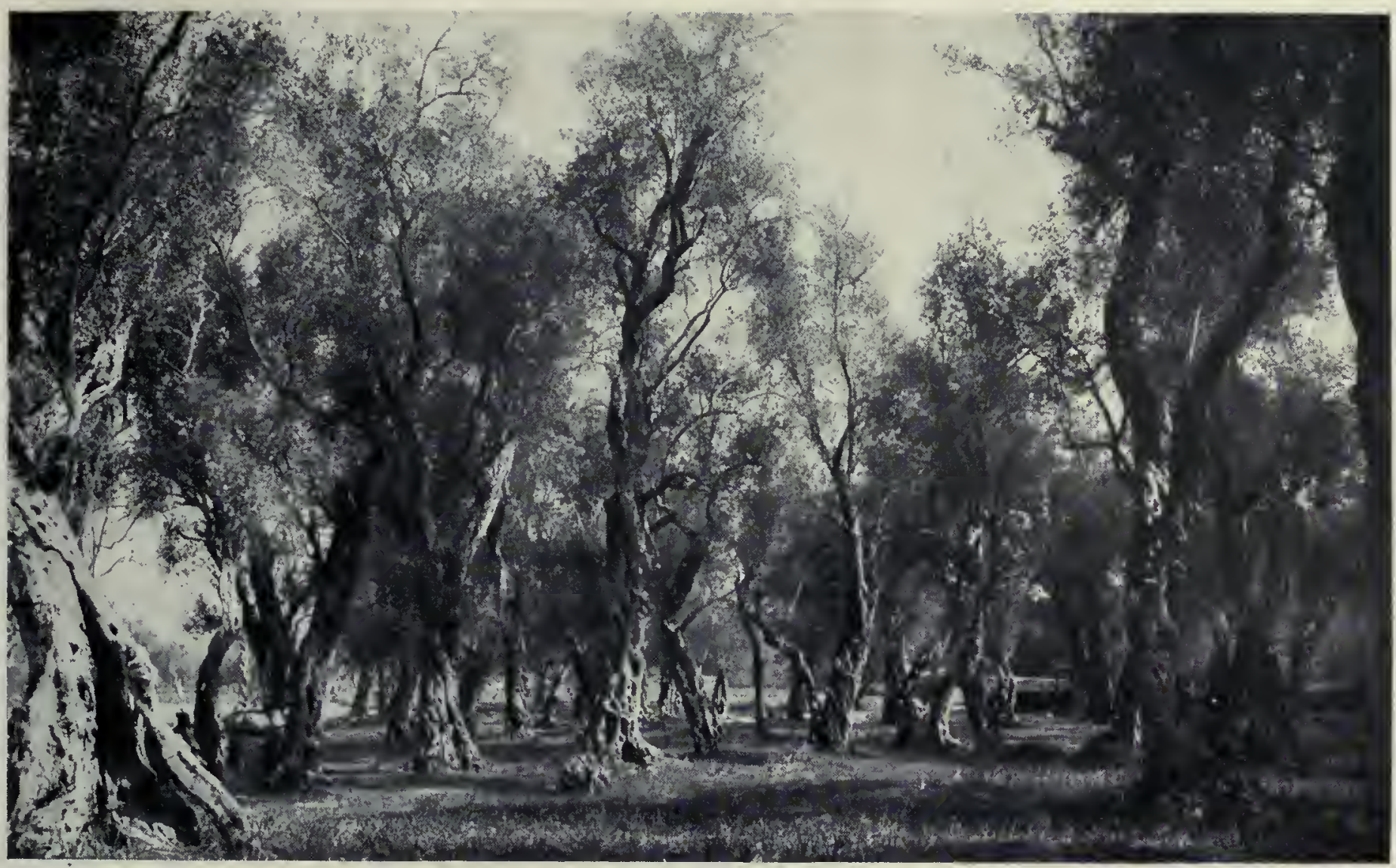

UN BOIS D'OLIVIERS DANS L'ILE DE CORFOU:

\section{VII. - GAMOPÉTALES SUPÉROVARIÉES}

Toutes les familles de Gamopétales étudiées jusqu ici ont l'ovaire adhérent; nous allons parler maintenant des familles, beaucoup plus nombreuses, chez lesquelles il est libre. Aux Gamopétales à ovaire libre ou supère se rattachent quatre types, autour desquels nous grouperons les autres familles :

2 verticilles d'étamines (en général 10) ou un verticille... Éricocées.

1 verticille à filets attachés au milieu des pétales (Primulacées).

1 verticille d'étamines $\left(5\right.$ en $\left\{\right.$ Corolle régulière. $\left\{\begin{array}{l}2 \text { étamines. Oléacées. } \\ 5 \text { élamines. Solanacées. }\end{array}\right.$ général ou moins) super-
posées aux sépoles... Corolle irrégulière, 4 ou 2 éta-

mines. .. Scrofulariacées.

\section{LES ÉRICACÉES}

Les Bruyères recouvrent d'un tapis vert et rose les landes granitiques et les terres sableuses des bois. Ces petits arbrisseaux à tige dure, sèche et buissonnante, à feuilles menues, étroites et coriaces, toujours vertes, ont un port particulier qui les fait immédiatement reconnaitre ; ils forment un groupe immense, particulièrement bien représenté au cap de Bonne-Espérånce. Notre Bruyère commune ou Calluna vulgaire (fig. 224) a de petites feuilles opposées, groupées sur quatre rangs en couronne, et des fleurs en longues grappes terminales. Le calice membraneux à quatre sépales d'un rose tendre est la partie la plus apparente de la fleur. La corolle comprend quatre pétales plus petits, soudés à la base seulement et cachés par le calice; en dedans sont huit étamines s'ouvrant chacune par deux trous; l'ovaire est libre, surmonté d'un style long et fin; pour fruit, une capsule à quatre loges. La Bruyère cendrée (Erica cinerea) ne doit pas être confondue avec l'espèce précédente, à côté de laquelle elle croît et fleurit; son calice est très petit et sa corolle beaucoup plus grande, rose, globuleuse, à pétales soudés presque complètement. La Bruyère à balai $(E$.scoparia), à petites corolles verdâtres, atteint $I$ mètre de hauteur, et la Bruyère arborescente, du midi de la France, haute parfois de
4 à 5 mètres, se garnit de fleurs blanches très odorantes. Beaucoup de Bruyères du Cap sont de superbes plantes d'ornement.

La grande famille des Éricacées, dont la Bruyère est le type, comprend des arbustes à feuilles alternes ou verticillées souvent persistantes, à fleurs régulières et complètes des types cing ou quatre, avec double verticille d'étamines dont les filets sont indépendants de la corolle; leurs anthères s'ouvrent par des pores qui mettent en liberté un pollen dont les grains sont toujours groupés par quatre. L'ovaire est à plusieurs loges, avec style unique ramifié en autant de stigmates qu'il y a de loges; le fruit est une capsule, parfois une baie ou une drupe. Ces plantes habitent les pays tempérés ou

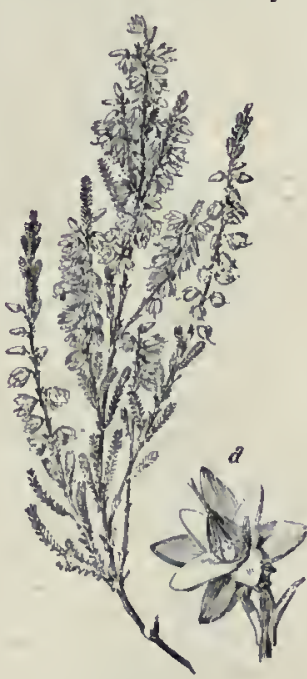

Fig. 224.

Calluna vulgaire.

a, Fleur. chauds; on peut les diviser en trois tribus : les Éricées, dont le fruit est une drupe, une baie ou une capsule; ces dernières s'ouvrent par des fentes situées au milieu des loges, tandis que, chez les Rhododendrées, elles s'ouvrent près des cloisons; enfin les Vacciniées qui ont l'ovaire infère et le fruit charnu.

Outre les Bruyères, la tribu des Ericées comprend les Arbousiers (Arbulus). L'Arbousier commun ou Arbre aux fraises croît dans la région méditerranéenne; ses feuilles sont dentelées, coriaces et persistantes; ses fleurs, petites, blanches ou légèrement rosées, sont en grappes pendantes; sa baie rouge rappelle la fraise par l'aspect. La Gaulthérie couchée est un arbrisseau de l'Amérique du Nord, dont les feuilles aromatiques sont employées en guise de thé; on les utilise en médécine sous le nom de Wintergreen.

Répartis sur tout le globe, les $R$ ho- 
dodendrons ou Rosages affectionnent les montagnes; leurs fleurs, grandes et belles, s'ćpanouissent au printemps : corolle à cinq lobes inégaux, dix étamines. Les Azalées sen distinguent par leurs feuilles caduques ct leurs fleurs à cinq étamines.

L'Airelle myrtille (Vaccinium), petit arbrisseau de nos bois, est le type des Vacciniées; il a des feuilles rappelant celles du Myrte; les fleurs sont solitaires, penchées, avec calice sans découpure, corolle à cinq pétales rosés, soudés en grelot, huit à dix étamines, ovaire devenant une baie d'un bleu noirâtre divisée en quatre loges. Ce fruit a une saveur acide, mais se mange avec plaisir. Parmi les Éricacées,

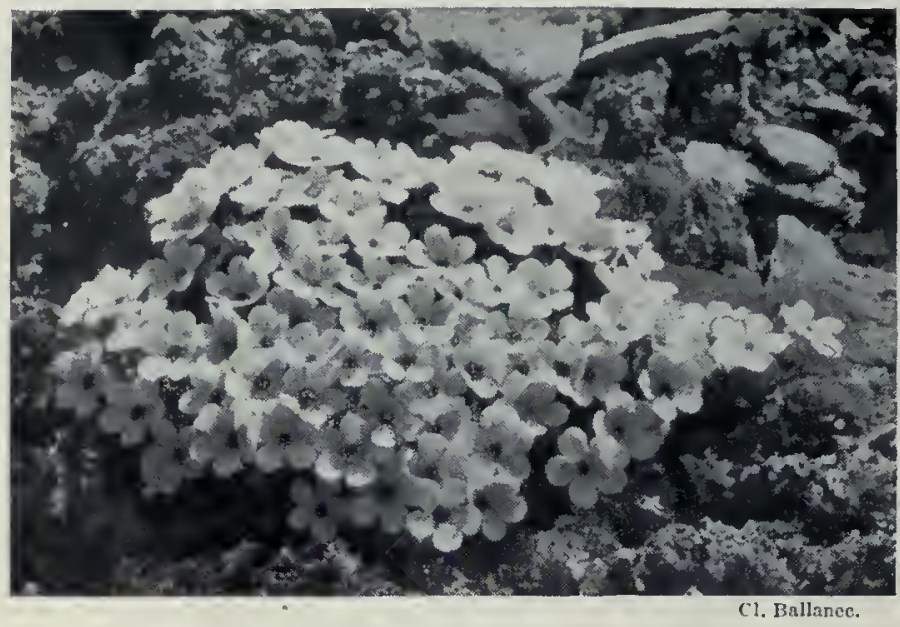

Androsace en fleurs, dans les Alpes. comme celle des nèfles. Les Sideroxylon, grands arbres à feuilles coriaces, ont de petites fleurs naissant en faisceaux à l'aisselle des feuilles; tous fournissent des bois durs, veinés, incorruptibles; ce sont les bois de fer des ébénistes.

L'Arganier bois de fer est inconnu en dehors du territoire marocain : il croît entre $29^{\circ}$ et $32^{\circ}$ de latitude Nord, sur une bande de 40 kilomètres de largeur parallèle au littoral. Épineux, le tronc noueux, haut de 6 à 8 mètres, il rappelle beaucoup l'Olivier; son fruit ou argan est une drupe vert jaunâtre ponctué de blanc, de la taille d'une grosse olive; ses feuilles sont broutées par les chèvres et les chameaux, ainsi que les fruits mûrs. Les on peut ranger encore les Pirolées, représentées dans nos bois par les Piroles, petites herbes à fleurs blanches, et les Monotropées, qui sont des plantes saprophytes blanc jaunâtre (p. 59).

Primulacées; Plombaginacées. - Les Primulacées sont des herbes habitant les régions tempérées de l'hémisphère boréal; elles sont nombreuses sur les montagnes. Leurs caractères sont les suivants : feuilles simples, entières; fleurs régulières du type cinq ; les étamines, insérées sur la corolle, sont placées vis-à-vis du milieu des pétales, exception remarquable à la règle de l'alternance des pièces florales d'un verticille à l'autre. L'ovaire est libre, à une loge renfermant en son centre une sorte de colonne renflée sur laquelle sont fixés de nombreux ovules; c'est la placentation centrale, caractéristique de la famille; le fruit est une capsule.

La Primevère officinale (Primula) ou Coucou de nos prés porte une ombelle de fleurs d'un jaune foncé; la Primevère élevée et la Primevère à grandes fleurs, fort communes aussi, sont cultivées dans les jardins, ainsi que la Primevère auricule ou Oreille d'ours des Alpes et plusieurs espèces d'Extrême-Orient : Primevère obconique, Primevère de Chine, etc. Les Cyclamens ont un rhizome tubéreux, des feuilles radicales à long pétiole, des fleurs pendantes, nombreuses, dont les ciny pétales, redressés vers le ciel, sont tordus sur eux-mêmes. La Soldanelle des Alpes, à corolle d'un bleu intense, et les Androsaces de nos montagnes, à corolle blanche ou rose, se cultivent sur les rocailles. Parmi nos Primulacées indigènes : les Lysimaques, dont une espèce à tiges couchées et à fleurs d'un jaune d'or est l'Herbe aux écus; le Mouron des champs (Anagallis) ou Mouron rouge, très petite herbe à fleurs rouges, bleues ou blanches; il ne faut pas, dans ce dernier cas, la confondre avec le Mouron des oiseaux (Stellaria), qui est une Caryophyllacée, car ses graines sont mortelles pour les petits hôtes des cages. Les Hottonies sont des herbes aquatiques nageantes à feuilles très découpées et à fleurs en grappes.

Les Plombaginacées diffèrent surtout des Primulacées par la pluralité de leurs stigmates, leur placentation basilaire; elles habitent principalement les terrains salés, comme les Statices ou Lilas des marais salants. L'Armérie maritime ou Gazon d'Olympe forme de jolies bordures dans les jardins.

Sapotacées. - Les Sapotacées sont des plantes ligneuses laticifères des régions tropicales; leurs feuilles sont alternes, simples, entières; les fleurs, régulières, hermaphrodites, à pièces presque toujours par cinq; les carpelles clos forment un ovairc à plusieurs loges uniovulées; le style est simple et le fruit charnu. Elles diffèrent surtout des Primulacées par leur placentation et leurs ovules.

Le Sapotillier comestible (fig. 225), originaire des Antilles, est un bel arbre à fleurs blanches isolées; le fruit ou sapotille est une baie grisâtre de la taille d'unc pomme; sa pulpe se mange presque blette,

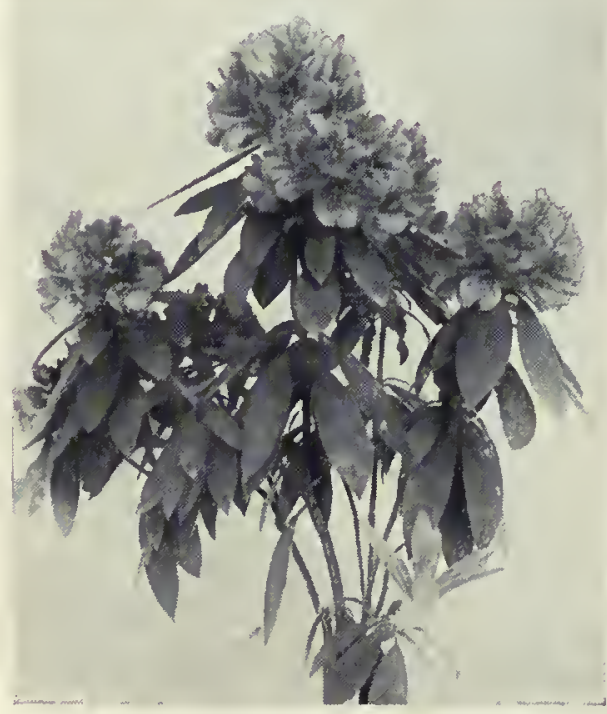

Fleurs de Rhodadendron. noyaux, rejetés par les animaux, sont recueillis, brisés, et les graines torréfées fournissent une huile de savcur forte, qui est très estimée des Marocains.

Le Butyrosperme de Mungo-Park, dit Arbre à beurre ou Karité, est un bel arbre de 20 mètres de haut, à port de Chêne, à feuilles oblongues, caduques, répandu dans les savanes du Soudan. Ses fruits, de la grosseur dune noix, renferment sous leur chair comestible, agréable, une coque dure abritant la graine: celle-ci contient une matière grasse qui est le beurre de Karité. Les Bassia voisins sont des arbres de l'Inde et d'Afrique; l'Illipe ou Bassia à longue feuille fournit le beurre d'Illipé.

Le latex desséché des Palaquium, grands arbres à feuilles coriaces, constitue la gutta-percha; celui des Mimusops ou balata a des propriétés analogues.

Ébénacées, Styracées. - Les Ébénacées peuvent être considérées comme des Sapotacées sans latex, à fleurs dioïques et à carpelles biovulés; elles habitent les régions chaudes du globe. Le genre Diospyros, seul intéressant, comprend les Ébéniers. dont le bois à cœur dur et noir est très recherché, et les Plaqueminiers, qui sont des arbres fruitiers dont les fruits se mangent blets. Le Plaqueminier lotus ou d'ltalie croît dans l'Europe et l'Asie méridionale; ses fruits jaunâtres sont gros comme des cerises ; le Plaqueminier de Virginic ou persimon, prune-datte, cultivé dans le midi de la France et en Algérie, a des fruits un peu plus gros. Lespèce la plus utile est le Plaqueminier du Japon ou Kaki, figue-caque, dont les fruits, d'un jaune brun particulier, rappellent agréable au goût (Voir planche en couleurs des FRUITS EXOTIQUES).

Les Styracées sont des Ébénacées à fleurs hermaphrodites. Les Aliboufiers ou Styrax produisent des baumes qui s'écoulent par des incisions pratiquées dans l'écorce : tels sont le Styrax benjoin, des íles de la Sonde, fournissant le benjoin, et le Styrax officinal, de la région méditerranéenne, donnant le storax.

\section{LES OLÉACÉES}

De toutes les Oléacées, la plus utile est l'Olivier, type de la famille, mais la plus répandue est le Lilas commun (Syringa), Bulgarie. C'est un arbuste à feuilles opposées, entières, d'un vert tendre. Ses fleurs odorantes, groupées en un thyrse terminal, sont d'une nuance charmante à laquelle la plante a donné son nom. Chaque fleur se compose d'un court calice à quatre divisions, d'une corolle à quatre pétales soudés en un tube étroit et long, puis s'étalant en quatre lobes en croix ; deux étamines insérées sur la corolle et un ovaire à deux loges biovulées sont enfermés dans le tube de la fleur; le fruit est une capsule s'ouvrant par deux valves. Le Lilas, splendeur des bosquets au printemps, a donné un grand nombre de variétés culturales. les tomates par l'aspect; leur pulpe, molle et sucrée, est assez originaire des montagnes de Serbie et de 


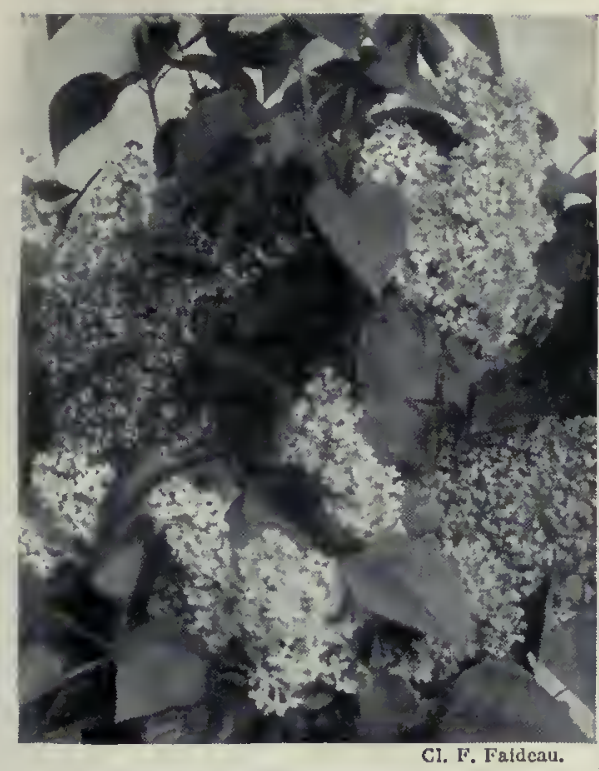

Branches de Lilas commun.
Le Troène vulgaire (Ligustrum) est un arbuste de $2 \grave{a}$ 3 mètres, commun dans nos bois; ses feuilles, entières, luisantes et lancéolées, sont presque persistantes: ses fleurs, blanches, en grappes, rappellent celles du Lilas, mais l'odeur en est peu agréable; le fruit est une baie noire. Les Forsythia sont des arbustes d'ornement aux fleurs jaunes très précoces.

L'Olivierd'Europe (Olea) qui. malgré son nom, est probablement originaire de l'Asie Mineure, a été introduit et cultivé dès la plus haute antiquité sur tout le pourtour méditerranéen. C'est un arbre à croissance très lente, mais pouvant cependant atteindre des dimensions colossales, jusqu'à 10 et 12 mètres de circonférence à la base du tronc, avec une hauteur de 15 à 20 mètres; alors il est noueux, à branches tortueuses et ramifićes, d'un aspect tourmenté remarquable. Ses feuilles, étroites et d'un vert grisâtre, à ourlet inférieur, sont persistantes. Les fleurs, petites et d'un blanc jaunâtre, en grappes courtes et serrées, ont une corolle à tube très court, laissant déborder deux étamines; le fruit ou olive est une drupe ovoïde, d'abord verte, puis d'un violet noirâtre à la maturité; son noyau très dur ne renferme qu'une graine. Les olives vertes sont servies comme hors d'œuvre, après un séjour dans la saumure. Pour l'extraction de l'huile, qui est leur usage le plus important, on cueille les olives à leur maturité complète. L'Olivier donne aux tourneurs et aux ébénistes un bois dur, richement nuancé et veiné.

Notre Frêne commun (Fraxinus) est un bel arbre atteignant jusqu à 35 mètres de haut. Écorce grisâtre, assez lisse, bourgeons d'un noir velouté, feuilles opposées à folioles denticulées en nombre impair, tels sont ses caractères les plus apparents. Ses fleurs polygames, d'un vert jaunâtre, naissent en panicules sur le vieux bois; les hermaphrodites n'ont ni calice ni corolle et se composent simplement de deux étamines et d'un pistil nu, auquel succède une samare étroite et longue. Le Frêne est un arbre d'alignement; son bois dur et tenace est excellent pour le charronnage et la menuiserie. Le Frêne orne ou Frêne à manne de la région méditerranéenne a des fleurs pétalées et blanches : c'est le Frêne à fleur. Il laisse écouler par incision de son écorce une substance sucrée, la manne, excellent purgatif doux.

Les Jasmins sont des arbrisseaux dressés ou grimpants à grandes fleurs, à cinq pétales et à fruits charnus (baies). Le Jasmin commun est une espèce grimpante à fleurs blanches, d'odeur suave.

\section{LES SOLANACÉES.}

En été, dans les haies, fleurit la Morelle douce-amère, arbrisseau à rameaux dressés ou volubiles, à feuilles alternes, entières ou lobées, suivant leur position sur la tige. Les fleurs ont un calice régulier à cinq sépales soudés persistants, une corolle à cinq pétales violets étoilés, en tube à la base et supportant cinq étamines à filets gros et courts, à anthères rapprochées; l'ovaire est libre, à deu x loges. La Douce-amère est un bon remède populaire comme dépuratif.

Les caractères que nous venons d'indiquer se rencontrent chez les autres Solanacćes. Ce sont des herbes ou des arbrisscaux, à feuilles alternes, découpées, d'un vert sombre et sans stipules; la fleur est régulière, du type cing; les anthères, très rapprochées les unes des autres, s'ouvrent non par deux fentes, mais par deux trous au sommet. Le pistil est formé de deux carpelles renfermant de nombreux ovules: le fruit est une baje ou une capsule : d'où la division en deux tribus. Les Solanacées renferment des principes vénéneux. Ces plantes abondent dans les régions chaudes du globe et principalement en Amérique.
Solanacées à baies. - Le genre Morelle ou Solanum est représenté en France par la Morelle douceamère et la Morelle noire ou Tue-chien, herbe vénéneuse, ou du moins narcotique, fort commune. La Morelle tubéreuse ou Pomme de terre (fig. 226) est une plante à feuilles composées, à fleurs blanches ou violacées. Ses rhizomes se renflent par place en tubercules gorgés d'amidon. Originaire du Chili, la Pomme de terre fut introduite en Espagne après la conquête du Pérou, de là en Italie, puis dans les Flandres; Clusius la cultivait en 1588 et John

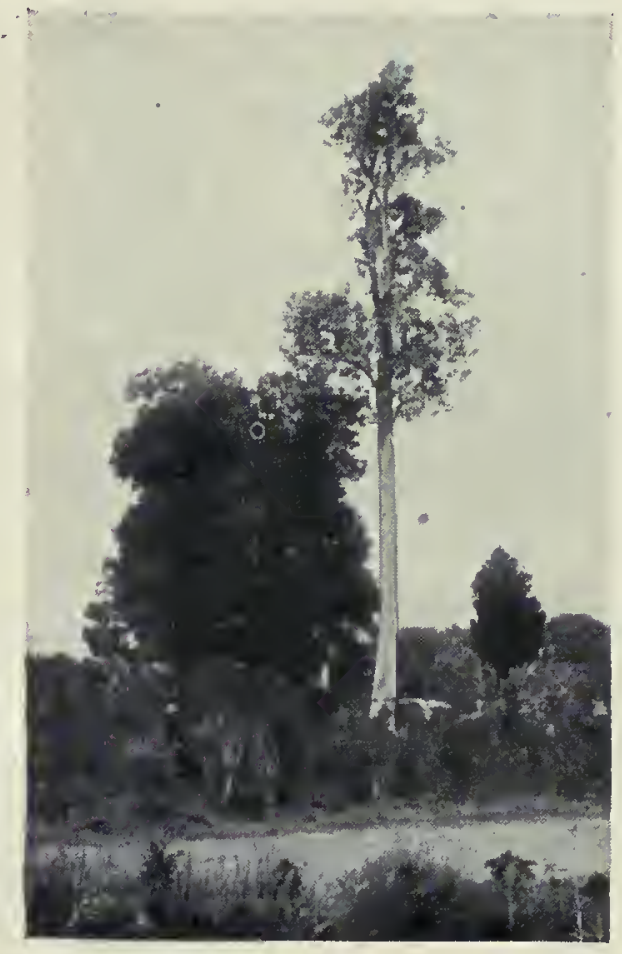

Sidéroxylon cendré (à droite)

et Eléodendron oriental, à La Réunion.
Gerarde, grâce à Walter Raleigh, l'obtint en 1596. Au début du $\mathrm{XVI} \mathrm{I}^{\circ}$ siècle, elle existait dans presque toutes les contrées d'Europe et était déjà beaucoup cultivée en lrlande. Dès 1650, la pomme de terre était utilisée pour l'alimentation en Angleterre, en FrancheComté, en Lorraine, mais dans la plus grande partie de la France on répugnait à son usage, même pour le bétail. Parmentier est célèbre par l'ardente campagne qu'il mena, sous Louis XVI, pour l'utilisation de la Pomme de terre; cependant la culture de cette plante ne devint générale dans notre pays que vers 1820, après plusieurs récoltes de blé déficitaires.

La Morelle mélongène est l'Aubergine; les grosses baies, oblonques et d'un violet spécial, de cette plante, de patrie inconnue, sont fort appréciées. Une variété curieuse est la Morelle à œufs ou Plante aux ceufs, dont les fruits non comestibles rappellent tout à fait des cufs de poule (p. 44); enfin la Morelle faux piment ou Ceriser d'amour est un petit arbuste décoratif par ses jolis fruits d'un rouge orangé. La Tomate (Solanum Lycopersicum), d'origine américaine, est une herbe d'odeur forte et à fleurs d'un jaune pâle. On la cultive pour ses fruits rouges ou jaunes de formes variées.

Les Coquerets ou Physalis sont remarquables par leur fruit, baie rouge emprisonnée dans un grand sac écarlate qui n'est autre chose que l'ancien calice de la fleur. A l'automne, ce sac se réduit à des nervures et devient une cage en dentelle à travers laquelle on aperçoit le fruit: Amour en cage, Cerise d'hiver, sont les noms vulgaires de notre espèce indigène. Plusieurs espèces américaines sont ornementales ; le fruit des Coquerets est comestible.

Les Piments (Capsicum) sont des herbes des pays chauds et principalement d'Amérique; les fleurs solitaires sont blanchâtres; lc fruit est une baie d'abord verte, puis d'un rouge vif à la maturité;

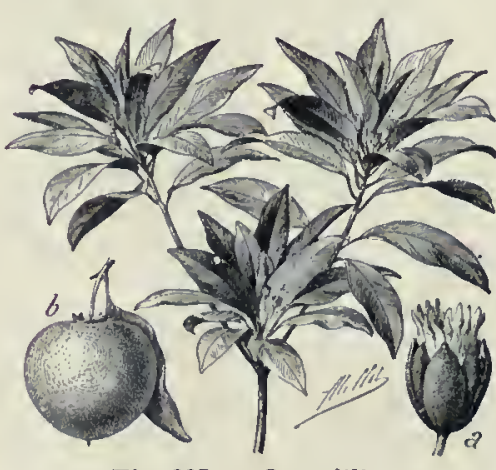

Fig. 225. - Sapotillier. $a$, Fleur: $b$, Fruit. il doit sa saveur âcre et forte à un principe rubéfiant, la capsicine.

Signalons encore les Lyciets, arbrisseaux souvent épineux, utilisés pour garnir les palissades, et deux plantes très vénéneuses, la Belladone et la Mandragore. La Belladone (Atropa) est une herbe à feuilles entières, à fleurs brunes en tube; son fruit est une petite baie noire entourée par le calice persistant; il renferme un alcaloïde, l'atropine, qui dilate la 


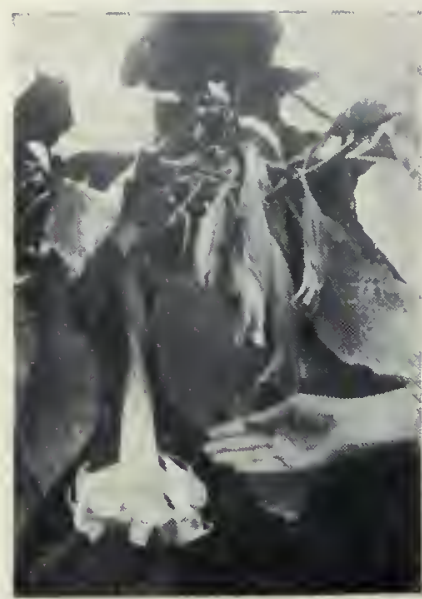

Datura en arbre.

pupille, diminue la sensibilité, réduit les sécrétions, agit sur les muscles. Les Mandragores habitent la région méditerranéenne; herbes à tige courte et à très grosse racine charnue, elles ont des propriétés narcotiques.

Solanacées à capsule, Le Datura Stramoine, que l'on rencontre au bord des routes, a des fleurs blanches en tube étroit plissé; son fruit, ou pomme épineuse, est une capsule hérissée d'aiguillons et s'ouvrant en quatre valves; ses propriétés toxi-

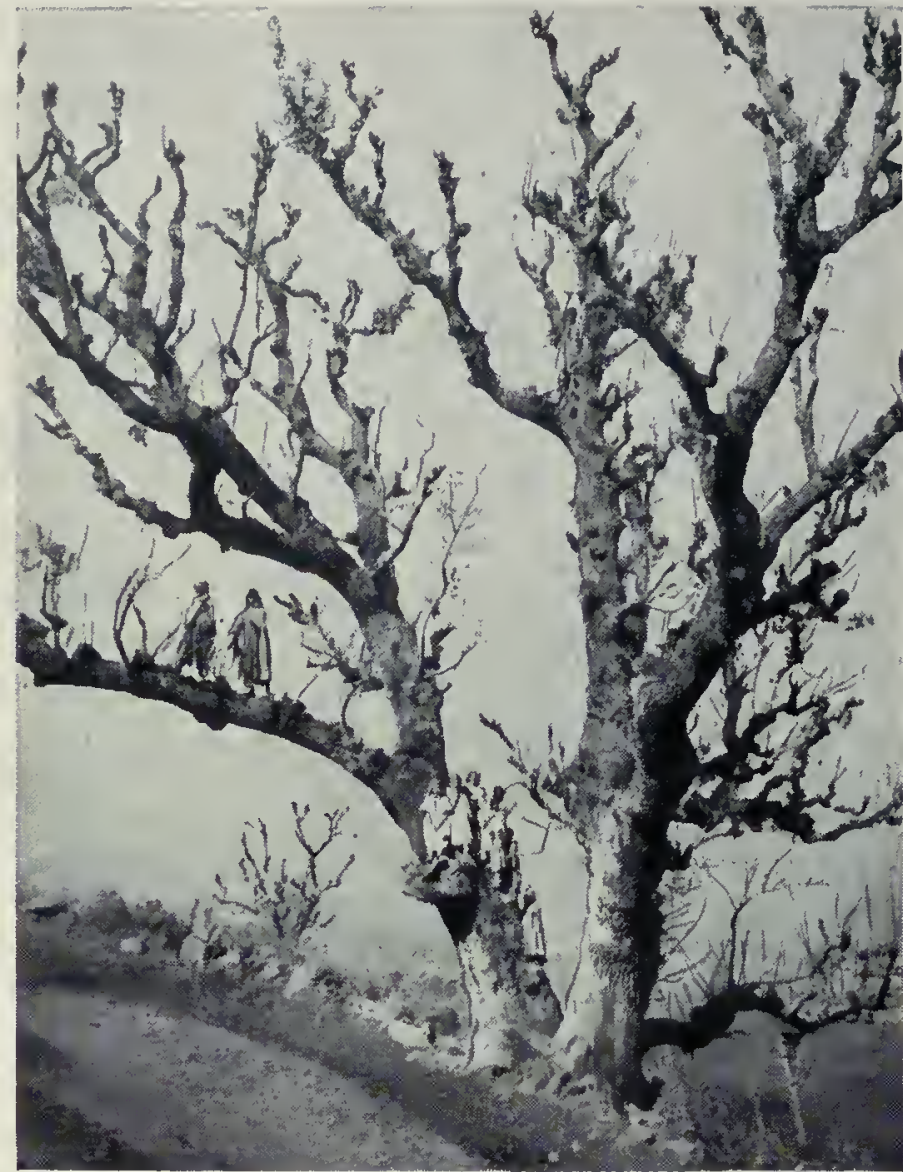

Un vieux Frène, en Kabylie.

Du Myosotis des marais on a fait le symbole du souvenir affectueux; les noms les plus doux ( $N e$ moubliez pas) lui ont été prodigués dans tous les pays $\mathrm{d}^{\prime} \mathrm{Eu}$ rope où il crốt et, de fait, rien n'est plus gracieux que sa mignonne corolle d'un si beau bleu.

Tandis que chez toutes les espèces précédentes le style part de la base de l'ovaire, il est terminal chez les Héliotropes; on cultive souvent l'Héliotrope du Pérou, aux fleurs violettes d'odeur suave. Les Cordia sont des plantes ligneuses des régions tropicales; elles fournissent des bois estimés.

Ilicacées. - Les llicacées forment une petite famille ayant certaines analogies avec les Rhamnacées et qui, pour cette raison, a été placée parfois dans les Dialypétales.

Le Houx commun (Ilex aquifolium), répandu dans les bois de l'Europe tempérée, a des branches flexibles, des feuilles alternes, coriaces, luisantes, souvent ondulées et dont les nervures se prolongent en épines. Les fleurs, menues et blanches, par petits bouquets à l'aisselle des feuilles, ont un calice à quatre dents, une corolle dont les quatre pétales sont soudés à leurs base, quatre étamines chez les fleurs mâles et, chez les fleurs femelles, un ovaire la Belladone. Nombre d'espèces de Datura, dont certaines sont des arbustes, se cultivent pour la beauté et le parfum de leurs fleurs; la culture natténue pas leurs propriétés toxiques.

Une autre Solanacée fort dangereuse est la Jusquiame noire, herbe molle et velue, assez commune dans les décombres.

Les Tabacs (Nicotiona) sont de hautes herbes à larges feuilles entières, à corolle longuement tubuleuse et dont le coloris varie. Le Tabac renferme comme on sait un alcaloïde très toxique, la nicotine. L'usage de fumer les feuilles de cette plante semble remonter fort loin chez les Indiens d'Amérique. Le Tabac fut introduit en Europe par les Espagnols et les Portugais (15/8); aujourd'hui il est universellement cultivé. Plusieurs Tabacs sont de très belles plantes d'ornement. Comme Solanacées de nos jardins, les Pétunia, les Nierembergio, les Salpiglossis, à corolle bilabiée; les Schizonthes, à deux étamines, sont très connus.

Borraginacées. - Les Borraginacées se distinguent des Solanacées par leur inflorescence et leur ovaire. Ce sont presque toujours des herbes à feuilles alternes, couvertes de poils rudes; leur cyme scorpiöde se redresse à mesure que les fleurs s'épanouissent. La fleur, rarement un peu irrégulière, est du type cinq. L'ovaire est libre, à deux carpelles et à deux loges, devenant plus tard, par formation d'une fausse cloison, à quatre logettes dont chacune abrite un ovule. Le fruit consiste le plus souvent en quatre akènes (fig. 227, a); le style est basal. La plupart de ces plantes contiennent dans leurs tissus une quantité assez notable de salpêtre qui explique leurs propriétés sudorifiques ou diurétiques.

La Bourrache officinale (fig. 227) [Borrago], type de la famille, est une herbe annuelle des lieux cultivés; l'infusion des feuilles et des fleurs est un remède populaire. Les Pulmonaires, les Grémils (Lithospermes), les Vipérines (Echium), les Cynoglosses, les Consoudes abondent dans les champs, les bois ou au bord des eaux. Les Buglosses (Anchusa) sont aussi fort communes; l'Alkanna tinctoriale ou Orcanette, de la région méditerranéenne, fournit une matière colorante rouge, réactif des chimistes.

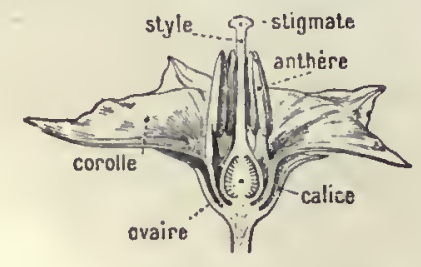

Fig. 226. - Coupe de la fteur de Pomme de terre. à quatre $\operatorname{loges}$ uniovulćes et à style court. Les pieds femelles se couvrent à l'automne de drupes d'un rouge vif, renfermant quatre petits noyaux très durs. Le bois du Houx, à grain fin et serré, est employé aux ouvrages de tour et de marqueterie.

Dans tout le bassin du Rio de la Plata croît un petit arbre, le Houx maté du Paraguay ou thé du Paraguay, cultivé aujourd'hui dans une grande partie de l'Amérique du Sud. Ses feuilles coriaces, dentées, renferment de la caféine et fournissent une infusion stimulante qui remplace le thé.

Convolvulacées, Polémoniacées. - Nos Liserons indigènes sont des représentants bien connus de cette famille qui se relie intimement aux Borraginacées, et qui comprend des herbes couchées ou volubiles à droite et parfois dressées; peu sont ligneuses. Les feuilles sont alternes, les fleurs du type cinq, à ovaire

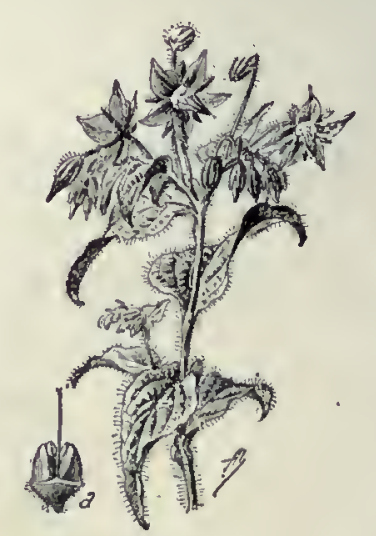
libre ayant deux loges; le fruit variable est le plus souvent une capsule. Ces plantes abondent surtout dans les pays chauds.

Le nom de Liserons est donné à plusieures plantes des genres Convolvulus ou Calystegia. Le Liseron des champs (Convolvulus) ou Petit Liseron, Vrillet, est une mauvaise herbe qui court sur le sol ou senroule autour des chaumes; ses jolies fleurs en entonnoir et d'un rose très pâle exhalent un délicat parfum d'amande amère. Le Liseron tricolore (Convolvulus) est une herbe annuelle non grimpante; ses fleurs, qui ne s'épanouissent que pendant le jour : d'où son nom de Bellede-jour, ont le tube jaune, la gorge blanche et le limbe bleu. Le Liseron scammonée d'Orient laisse écouler de sa grosse racine incisée un latex résineux purgatif. Le Grand Liseron ou Liseron des hates (Calystegia sepium) affectionne le bord des eaux et fait grimper autour des Roseaux ou 
des branches de Saule ses grandes feuilles en cour et ses larges fleurs blanches comme neige. Le Liseron soldanelle (Calystegia Soldanella) orne de ses fleurs roses les sables et les rochers du littoral maritime.

Les Ipomées diffèrent peu des Liserons : leur style est en bouton et non en fourche; elles habitent les pays chauds. L'Ipomée pourpre est le Volubilis, originaire de l'Amérique du Sud; transporté dans nos jardins, il y a fait merveille. L'Ipomée purgative est le Jalap du Mexique, dont la racine pulvérisée sert en médecine. L'Ipomée batate de l'Inde est la Patate, dont les racines tubéreuses à chair sucrée et tendre remplacent la pomme de terre sous les tropiques.

Les Cuscutes forment une tribu spéciale d'herbes parasites, sans chlorophylle et sans feuilles (p. 56). Leurs tiges filamenteuses si abondantes leur ont fait donner les noms de Tignasse, Perruque du diable, etc. Les fleurs, petites, campanulées, blanches ou roses, en glomérules compacts, ont leurs pièces par cinq; l'ovaire porte deux styles et le fruit est une capsule à deux loges renfermant en tout quatre graines. Les Cuscutes sont des plantes redoutables dont la destruction est obligatoire.

Les Polémoniacécs forment une petite famille différant des Convolvulacées, et surtout des Borraginacées, par l'ovaire à trois loges. Plusieurs sont appréciées dans les jardins comme la Polémoine bleue ou Valériane grecque, les Phlox, les Gilia et la Cobéa grimpante, qui atteint jusqu'à 8 mètres de hauteur.

Apocynacées. - La Pervenche (Vinca), une des jolies fleurs de nos printemps, a des corolles d'un bleu superbe. C'est une herbe vivace à feuilles opposées, luisantes et à fleurs solitaires. Le calice est à cing sépales courts; la corolle, à cinq pétales égaux, soudés en tube à la base et s'étalant ensuite en soucoupe; cing étamines à anthères rapprochées sont insérées sur le tube de la corolle; le pistil est libre, à deux ovaires fermés, non soudés; la soudure s'opère par le style.

La Pervenche est dans la flore trancaise le seul représentant de la famille des Apocynacées, qui comprend surtout des arbres et des arbustes tropicaux, à feuilles opposées ou verticillées, à fleurs régulic̀res et à fruit variable. Ces plantes contiennent un latex qui, selon les espèces, est sucré et alimentaire (Tabernomontana), ou fébrifuge, ou très vénéneux (Adenium); celui des Hancornia, Landolphia et du Mascarenhasia fournit un excellent caoutchouc. Les Frangipaniers ou Plumeria sont des arbustes de l'Amérique tropicale, cultivés dans les serres pour leurs jolies fleurs à odeur de frangipane. Les Pachypodes sont de très curieuses plantes ligneuses de Madagascar. Le Pachypode de Geay ( fig. 228) est un arbre de 8 à 10 mètres, à tige simple, charnue, épaisse, tellement molle qu'on peut presque l'abattre avec un sabre, et terminée par une rosette de feuilles. D'autres espèces sont des arbres gros et courts couverts de rameaux épineux, ou même sont réduites à un tronc difforme de 20 centimètres de haut poussant entre les rochers.

Le Laurier-rose ( $\mathrm{Ne}$ rium oleander) est un bel arbuste qui, en Perse et en

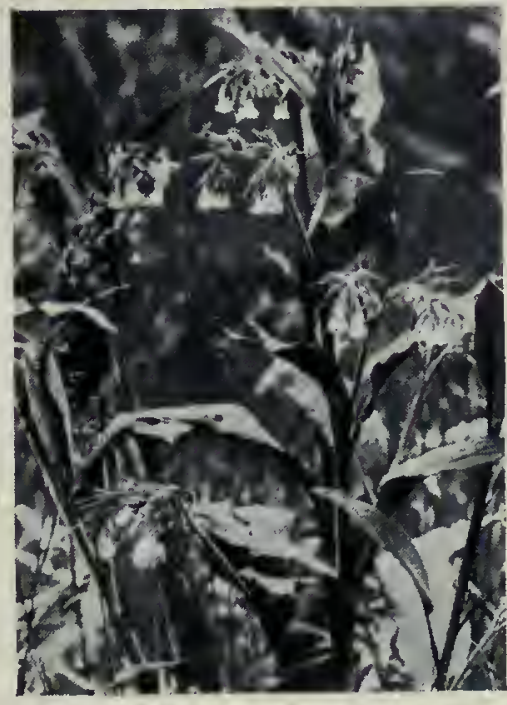

Consoude officinale.

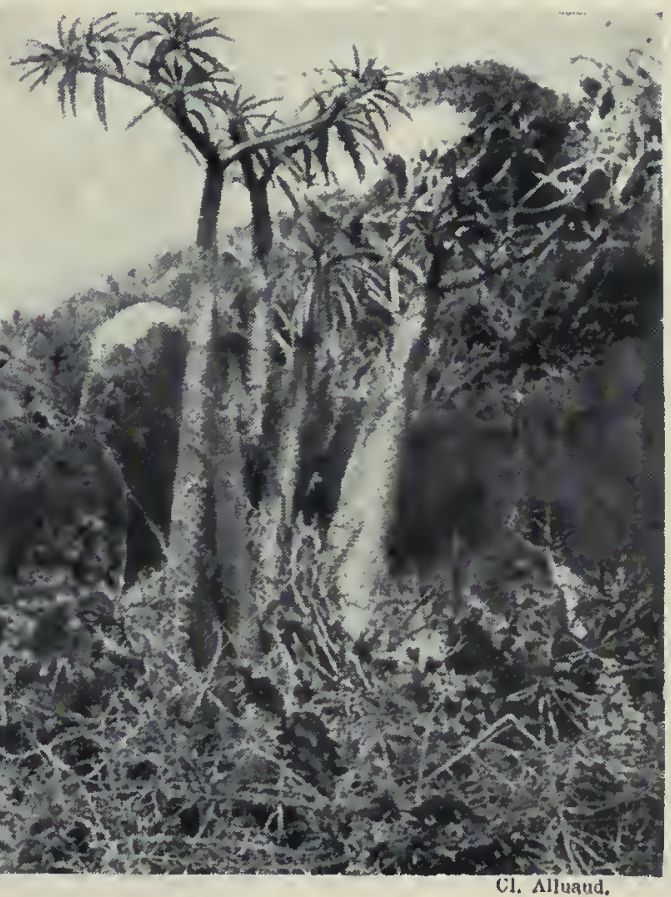

Pachypode de Lamere, à Madagascar.

Grèce, garnit le fond des ravins de ses charmantes fleurs roses ou blanches. Ses feuilles entières sont verticillées et persistantes; son latex blanc est un poison violent.

Les Strophanthes, lianes habitant les régions intertropicales de l'Ancien continent, ont les fleurs à pétales prolongés en une étroite lanière tordue sur elle-même et atteignant 15 centimètres de long; le fruit, cylindrique et de la grosseur du petit doigt, est un double follicule, long parfois de 50 centimètres et renfermant jusqu’à trois cents graines, dont chacune est surmontée d'une longue aigrette soyeuse. L'extrait aqueux des graines ou de la racine de ces plantes est employé par les peuplades d'Afrique pour empoisonner les flèches.

Asclépiadacées. - Les Asclépiadacées ne diffèrent des Apocynacées que par leurs étamines insérées au fond de la corolle et fortement adhérentes au pistil, et par leur pollen agglutiné en deux à quatre masses ou pollinies par anthère. Le fruit consiste en deux follicules parallèles; les graines sont pourvues d'une aigrette dont les filaments ou soie végétale ont des qualités textiles utilisées chez plusieurs espèces de l'Inde. Le latex des Asclépiadacées a les mêmes propriétés que celui des Apocynacées.

Le Dompte-venin officinal (Cynanchum Vincetoxicum) est une herbe commune dans nos bois; le Gomphocarpe à feuilles de saule ou Faux Cotonnier est très répandu en Corse; on le cultive dans les jardins ainsi que l'Asclépiade cornue ou Herbe

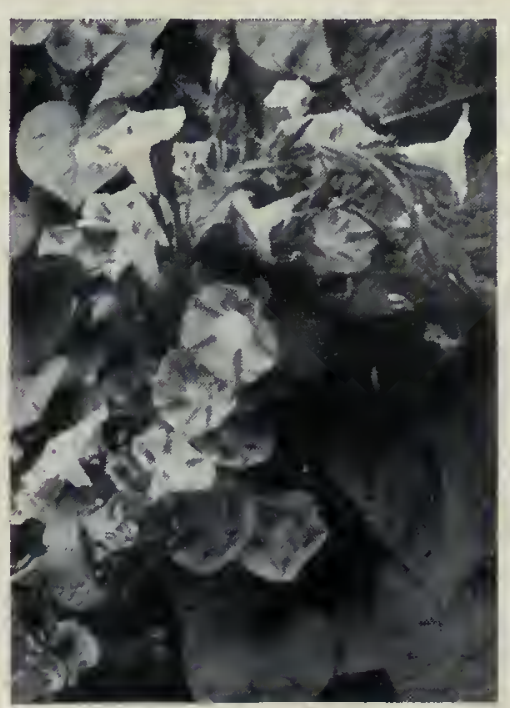

Fleurs du Volubitis. à la ouate, originaire d'Amérique, et les Stapelia, de l'Afrique du Sud, qui, sans feuilles et à tiges charnues dentelées, ont tout à fait l'aspect de Cactées.

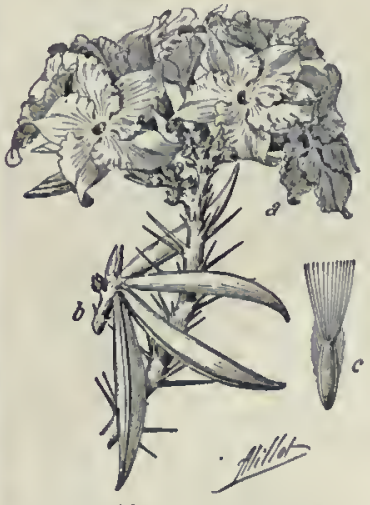

Fig. 228. - Pachypode.

$a$, Rameau fleuri: $b$, Fruil. 


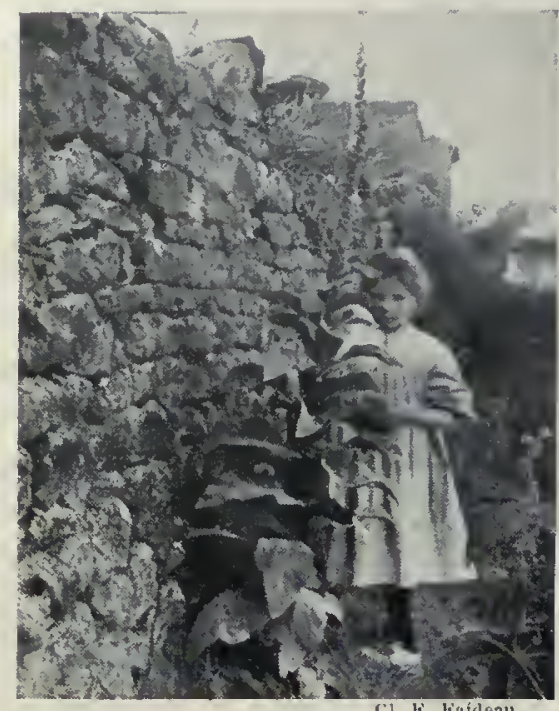

Pied de Bouilton blanc.
Gentianacées. Les Gentianacées sont des herbes amères et fébrifuges, propres aux régions tempérées et montagneuses. Les feuilles sont opposées, sauf pour le Trèfle d'eau; les fleurs, groupées en cymes, sont hermaphrodites, régulières, à pièces par cinq ou rarement par quatre; l'ovaire est à une loge; le fruit est une capsule.

L’Érythrée petite centauréc est une herbe à fleurs roses s'épanouissant en été dans les pâturages. Ses sommités fleuries, en infusion, constituent l'un des meilleurs fébrifuges indigènes.

Les Gentianes ont de belles fleurs vivement colorées; sur nos montagnes, elles abondent parfois au point de nuire à la qualité du fourrage. Leur racine renferme un principe amer et un sucre, la gentianose. D'autres Gentianacées indigènes sont aquatiques, tels le Ményanthe trèfle d'eau et le Limnanthème faux nénuphar.

Loganiacées. - Les Loganjacées, plantes des régions tropicales, ne diffèrent des Gentianacées que par leurs feuilles stipulées et leur ovaire à deux loges; le fruit est variable. Elles sont aussi très amères et, de plus, beaucoup sont très vénéneuses, notamment les Strychnos, arbres ou lianes à fleurs ordinairement blanches et dont le fruit est une grosse baie sphérique. Le Strychnos vomiquier, de'l'Inde, est un arbre dont le fruit jaune orange, gros comme une orange, renferme des graines ayant l'aspect de boutons déformés; connues sous le nom de noix vomique, elle sont très vénéneuses, en raison de la présence d'un alcaloïde, la strychnine; c'est un poison violent et rapide, un excitant du système musculaire qui, à dose massive, tue un homme en vingt minutes après de terribles convulsions. Le Struchnos ignatier est un arbre des Philippines; ses graines ou fèves de Saint Ignace ont des propriétés analogues. L'écorce et le bois de beaucoup de Strychnos ( $S$. de Castelnau) fournissent, après coction, le curare, célèbre poison de fièche, employé jadis par les Indiens de l'Amazone, de l'Orénoque et des Guyanes. C'est une matière noirâtre, soluble dans leau et qui doit son activité à un alcaloïde, la curarine. L'introduction du curare par la voie digestive n'est dangereuse que si les muqueuses sont excoriées, car l'absorption se fait assez lentement pour que le poison soit éliminé au fur et à mesure par les reins; c'est pourquoi la chair des animaux tués à l'aide de flèches plongées dans le curare peut être consommée; mais, inoculé dans le sang, ce poison tue en quelques minutes par paralysie des voies respiratoires. Claude Bernard a montré que le curare respecte l'appareil musculaire et le système nerveux sensitif, mais engourdit et paralyse le système nerveux moteur (mort par arrêt de respiration).

\section{LES SCROFULARIACÉES.}

Le Muflier (fig. 229) ou Gueule-de-loup (Antirrhinum majus) est commun au sommet des vieilles murailles; il orne aussi les jardins. C'est une herbe vivace, à feuilles allongées, étroites; les inférieures opposées, les supérieures alternes. Ses grandes fleurs en grappes terminales ont un calice persistant à cing lobes courts, une corolle irrégulière à cinq pétales soudés formant un tube bossu à la base et se terminant par deux lèvres; à l'état spontané, elle est rouge ou blanche, à gorge jaune, parfois entièrement jaune. A l"intérieur de cette corolle fermée sont insérées quatre étamines, dont deux plus petites; l'ovaire est libre, à deux loges, et surmonté d'un style simple. Le fruit est une capsule souvrant par trois trous au sommet ( $\mathrm{p}$.44). Le Mufier peut être pris pour type de la famille des Scrofulariacées, qui comprend des herbes et quelques arbres des régions tempérées et montagneuses. On peut les considérer comme des Solananées à fleurs irrégulières et n’ayant plus que quatre étamines dont deux petites. Nous rapprocherons les Verbascées et les Scrofulariacées proprement dites.
Les Verbascées se rapprochent le plus des Solanacées; leur fleur presque régulière comporte cinq étamines, inégales, il est vrai. LesMolènes (Verbascum) ou Bouillons blancs sont les représentants de cette tribu dans nos champs. Ce sont de grandes herbesà larges feuilles molles, cotonneuses, à hauts épis dressés de feurs d'un beau jaune (V.Thapsus); elles sont pectorales.

Parmi les Scrofalariacées proprement dites, il faut

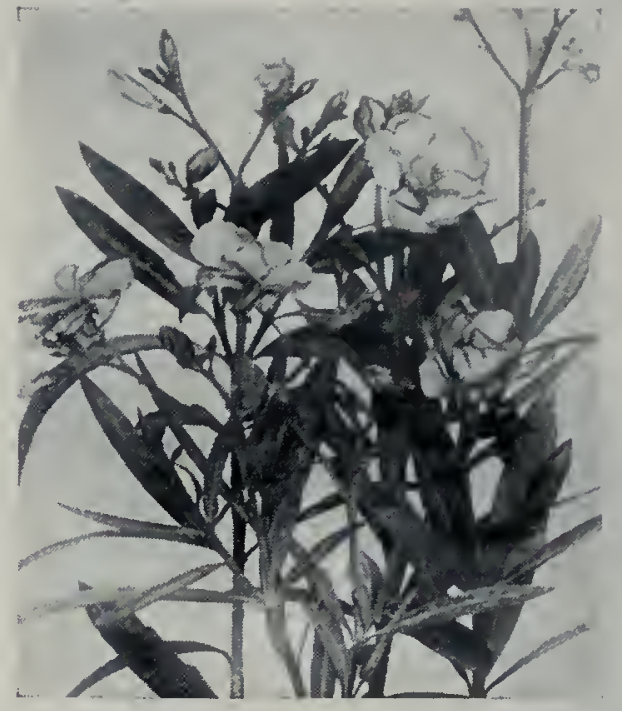

Laurier-rose en tleurs. ranger les Linaires,

dont les feurs, assez semb!ables à celles du Mufier, sornent d'un long éperon à la base de la corolle; l'une des plus jolies espèces est la Linaire cymbalaire, dite Ruine de Rome, qui garnit les vieilles murailles de ses fleurs violettes et de son feuillage lobé. La Scrofulaire de nos bois a donné son nom à la famille. La Digitalc pourpre, très vénéneuse, porte une longue grappe de grandes fleurs pourprées, presque régulières et en forme de dé à coudre : d'où son nom. Des feuilles, on retire un poison, la digitaline, employée contre les palpitations de cour. Très commune dans les bois siliceux, après la coupe des taillis, la Digitale pourpre est remplacée en terrain calcaire par la Digitale jaune.

Les $V$ éroniques forment un genre nombreux. Nos espèces européennes sont de charmantes petites herbes; plusieurs espèces étrangères cultivées dans les jardins sont des arbustes. Le calice et la corolle, presque réguliers, ont quatre divisions, et il n'y a que deux étamines. Les fleurs, petites mais fort élégantes, sont souvent d'un bleu admirable.

Parmi les Scrofulariacées étrangères, il faut citer le Paulownia impérial, bel arbre du Japon, qui a été introduit en France en 1834; ses garandes fleurs bleues très parfumées, en panicules dressées terminales, s'épanouissent en mai, en même temps que commencent à paraître ses larges feuilles en cœur. Les Calcéolaires, originaires de l'Amérique du Sud, sont des plantes d'ornement remarquables par la beauté et la bizarrerie de leurs fleurs qui ressemblent à de petits sabots; elles n'ont que deux étamines. Le Maurandia grimpant, du Mexique, garnit gracieusement les tonnelles; les Collinsia, les Mimules sont de jolies plantes de jardins.

Plusieurs espèces indigènes, bien que pourvues de chlorophylle, sont parasites: tels sont les Euphraises, les Pédiculaires, les Rhinanthes, les Odontites et les Mélampures; ces derniers se nourrissent par des suçoirs qui partent de leurs racines et s'enfoncent dans celles des Graminées (p. 56). On rencontre des Pédi-

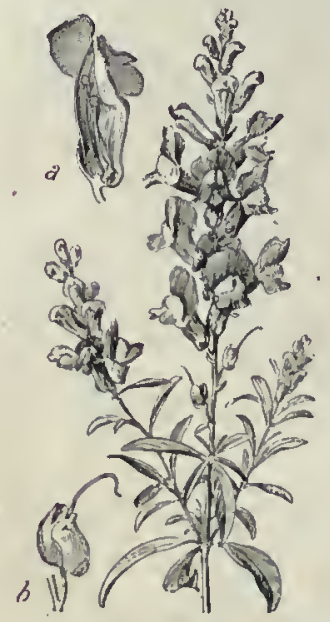

Fig. 229. - Muflier ou Gueule-de-Ioup. $a$, Coupe de la fleur; $b$, Fruit. culaires $(P$. laineuse, $P$. à fleurvelue) jusque dans les régions arctiques.

Utriculariacées.- Les plantes formant la petite famille des Utriculariacées diffèrent des précédentes par leur ovaire à une loge et leur placentation centrale. Les Utriculaires habitent les eaux stagnantes; leurs fleurs sont jaunes, irrégulières; leurs feuilles, très découpées, semblent réduites aux nervures; certaines cependant présentent de petites vésicules ovoïdes, dont l'ouverture, entourée de poils ramifiés, peut être fermée par une mince soupape s'ouvrant de dehors en dedans. Ce sont des flotteurs et aussi des pièges, où l'on trouve souvent des débris de petits crustacés ou de larves d'insectes.

La Grassette commune (Pinguicula) abonde dans les prairies tourbeuses, où elle épanouit en juillet ses mignonnes 


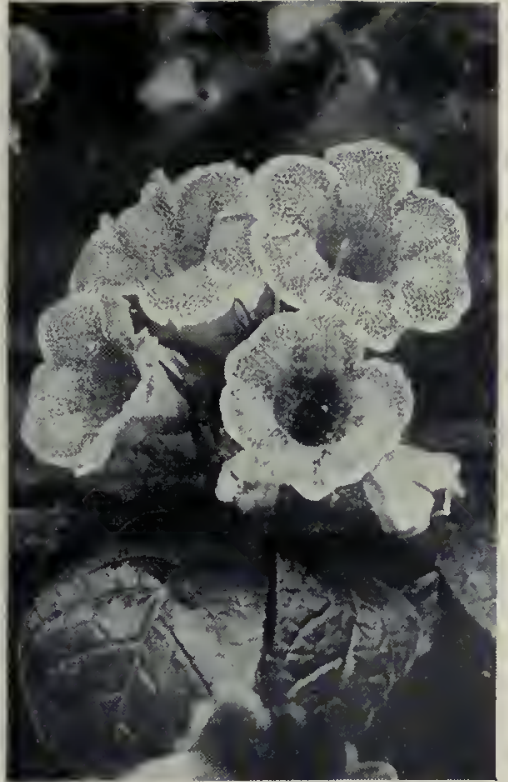

Fleurs de Gloxinia (Sinningia).

Aleurettes irrégulières. Ses feuilles charnues, disposées en rosette, ont leur face supérieure couverte de poils glanduleux dont la sécrétion digestive englue les insectes. Les Genlisea à feuille en cornet ramifié ont le même mode de vie : ce sont encore des plantes carnivores.

Orobanchacées. - On rattache les Orobanchacées soit aux Scrofulariacées, dont elles se rapprochent par la corolle et les étamines, soit plutôt à la famille suivante des Gesnéracées, dont elles ont l'ovaire à une loge avec placentas pariétaux. Elles se distinguent des unes et des autres par leur mode d'existence : ce sont des parasites dont les racines sont reliées par un gros tubercule suçoir aux racines d'autres plantes. C'est à ces organes souterrains que se réduisent les Orobanchacées pendant la plus grande partie de l'année. En été, elles laissent sortir deterre une hampe chargée de fleurs et portant des écailles tenant lieu de feuilles; le tout sans chlorophylle, de nuance pâle et d'aspect maladif. Telles sont les Orobanches, parasites du Caillet, du Trèfle, du Sainfoin, du Lierre, etc. ; la Lathrée, les Phélipées, qui vivent aux dépens des $\mathrm{Peu}$ pliers, du Tabac, du Chanvre (p. 56).

Gesnéracées, Bignonia cées, Acanthacées. - Ces trois tamilles, comprenant surtout des plantes des pays chauds, ont de grandes affinités avec les Scrofulariacées; la première s'en distingue par l'ovaire ordinairement à une loge et la placentation pariétale; la seconde, par les graines ailées et sans albumen; la troisième, par le mode d'ouverture de la capsule loculicide et les graines non ailées et dépourvues d'albumen.

Les Gesnéracées comprennent de superbes plantes de serres et principalement les Gloxinia (Sinningia), les Saint-paulia, les Achimènes. A une tribu de Gesnéracées, celle des Pédaliées, appartiennent les Martynia, aux fruits de forme curieuse, et le Sésame de l'Inde, plante oléagineuse d'une certaine importance.

Les Bignoniacécs sont ligneuses.

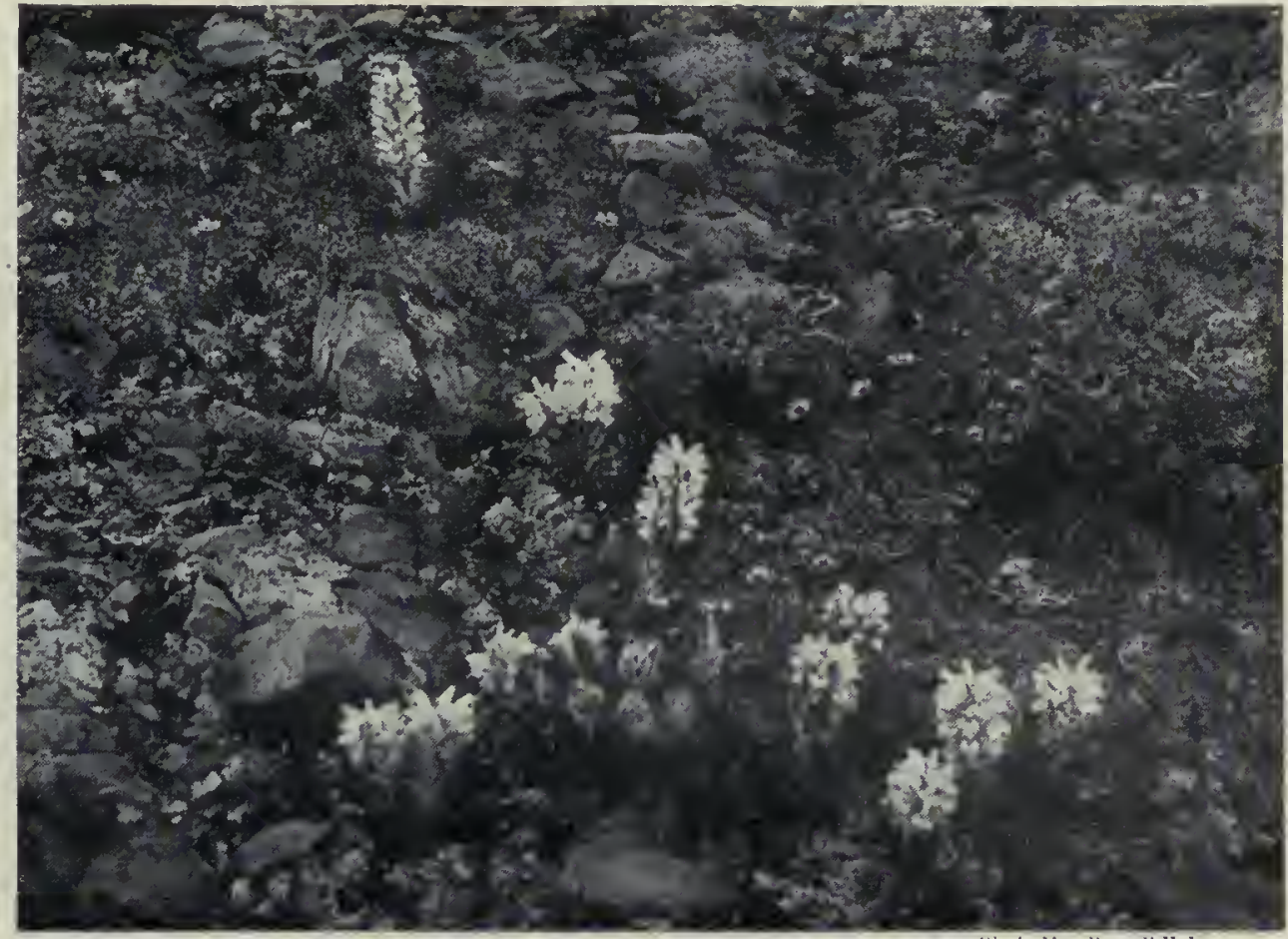

Pédiculaires des terrains pierreux du Spitzberg

Le Catalpa, bel arbre de l'Amérique du. Nord acclimaté en Europe, rappelle le Paulownia par ses larges feuilles; mais ses fleurs sont blanches et n apparaissent quaprès les feuilles. Le Tecoma, dit Jasmin trompette ou Jasmin de Virginie, est un arbrisseau grimpant. Le Crescentia ou Calebassier, de l'Amérique tropicale, fournit des fruits à paroi ligneuse, employés comme récipients. Les Kigelia ont de longs fruits cylindriques (p. 7 et 44).

Les $A$ canthacées, enfin, sont représentées par les $A$ canthes, herbes à vastes feuilles découpées et dentées, très ornementales: leurs fleurs blanches, roses ou pourpres, sont en longs épis terminaux.

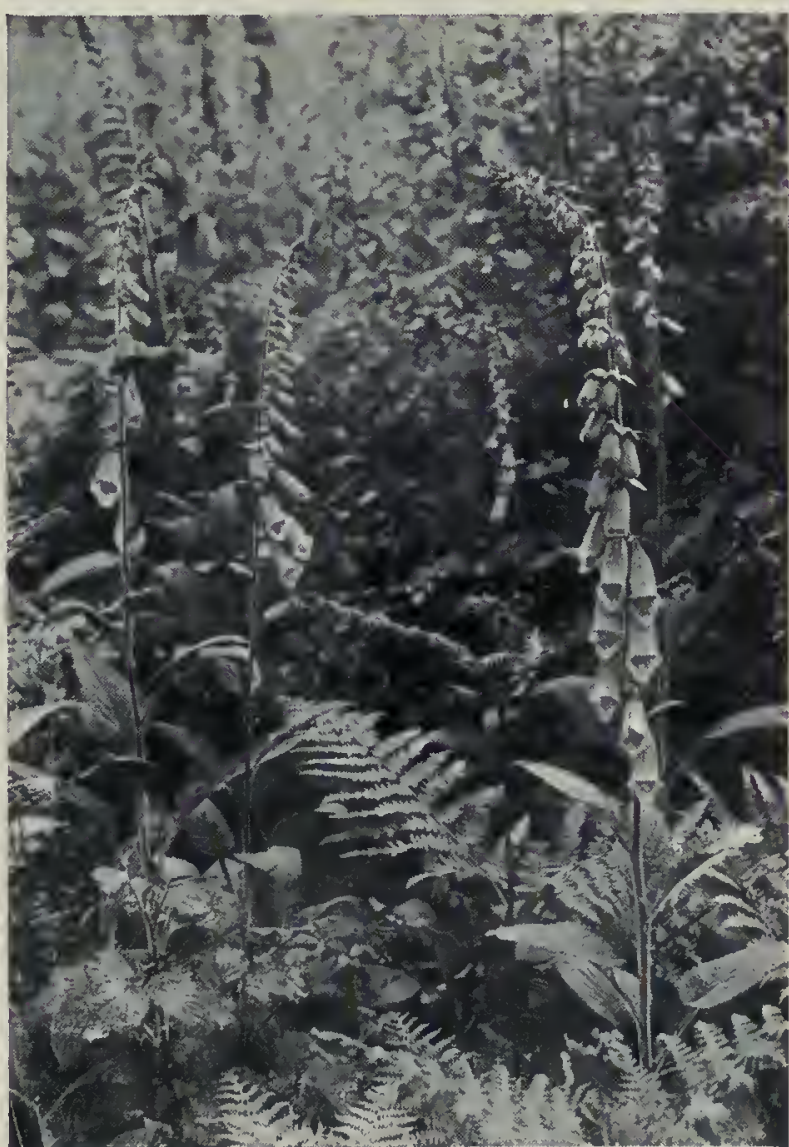

Digitale pourpre des bois siliceux.
Labiées. - L'immense famille des Labiées a des représentants sur tout le globe; ils sont particulièrement nombreux dans la région méditerranéenne. Ce sont des herbes, rarement de petits arbrisseaux, comme le Thym ou la Lavande. La tige quadrangulaire porte des feuilles opposées (fig. 23I , E). Le calice est à cinq sépales soudés; la corolle est bilabiée : la lèvre supérieure formée de deux pétales soudés et la lèvre inférieure de trois (fig. 230). 11 y a quatre étamines, dont deux plus petites. L'ovaire est libre, à deux loges partagées plus tard par une fausse cloison en quatre logettes et devenant quatre akènes; le style est basal (gynobasique). La plupart des Labiées sont couvertes de poils, renflésà leur extrémité en une petiteglande sécrétantdes essences aromatiques. Ce sont des plantes mellifères; elles ont des usages en parfumerie, confiserie, liquoristerie, médecine, horticulture; certaines sont condimentaires. On peut les considérer comme des Borraginacées irrégulières, de même que les Scrofulariacées sont des Solanacées irrégulières.

Les Lamiers (fig. 230 et 231, A) sont des herbes communes partout. Le Lamier blanc, dit Ortie blanche, vit dans les endroits incultes. Le $L a-$ mier pourpre et l'Agripaume car- 


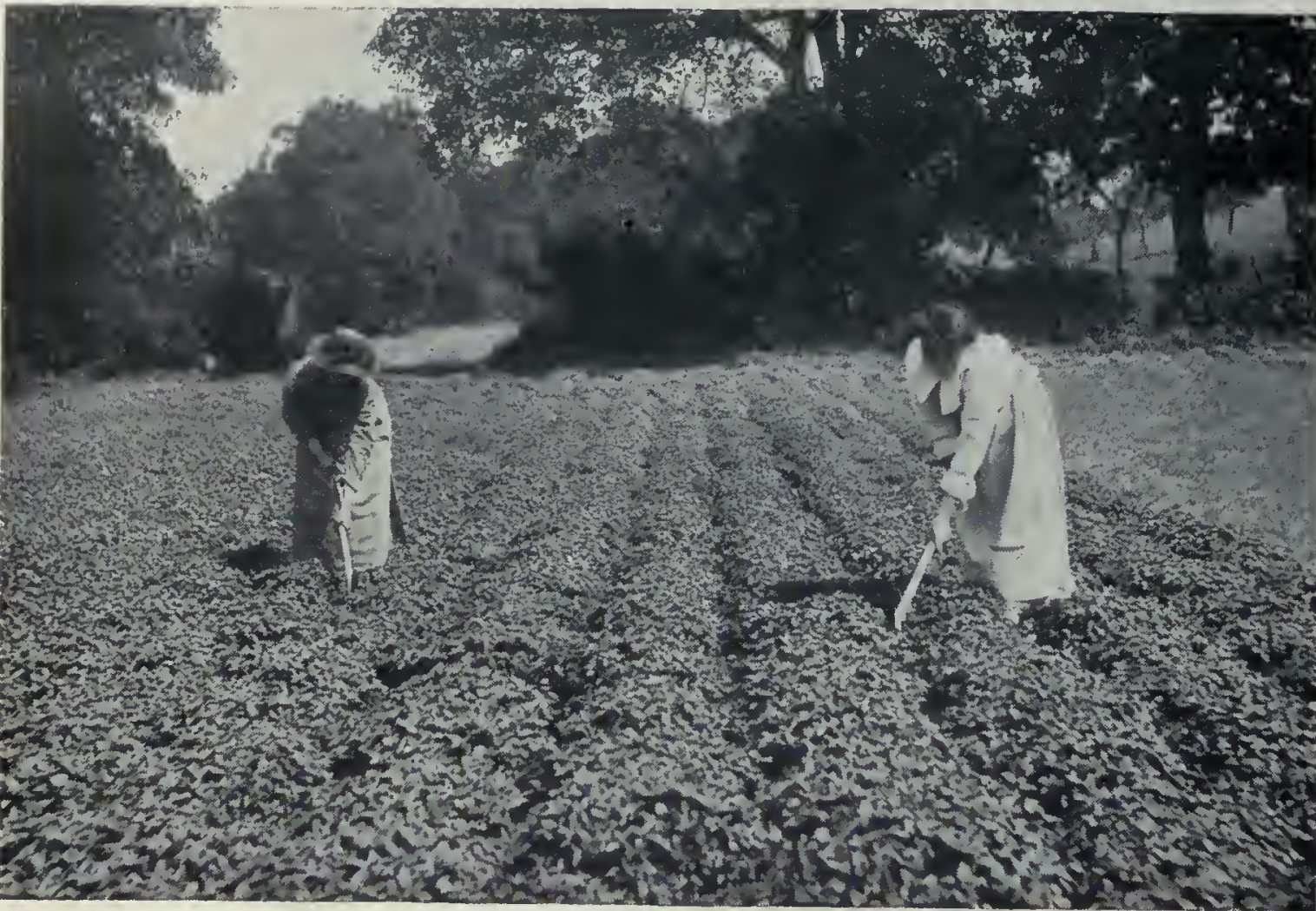

Binage d'ut champ de Mélisse:

de nos champs, est l'espèce la plus connue. Le Thym vulgaire, du midi do l'Europe, est cultivé dans tous les jardins potagers: le Thym serpolet croît dans toute la France. $\mathrm{Ci}$ tons encore : les Sarriettes (Satureia), condiments bien connus; l'Hysope officinale, les $\mathrm{Ca}$ laminthes et les $M e^{\prime}$ lisses. Enfin, les Bugles (Ajuga) et les Germandrées (Teucrium) sont des herbes dont la fleur est remarquable par sa corolle à une seule lèvre réunissant les pétales(fig. 231, B-D).

\section{Verbénacées} Plantaginacées. - Les Verbénacées se relient étroitement aux Labiées, mais leur style est terminal et non basal, et leur fruit est souvent charnu. La $V$ er -

diaque (Leonurus), la Ballote fétide, les Épiaires ou Stachys sont aussi fort répandus. Le Stachys affinis, originaire du Japon, a été introduit en France en 1885; ses rhizomes en chapelet sont vendus comme légumes sous le nom de crosnes, qui est celui du village de Seine-et-Oise, près Montgeron, où ils furent d'abord cultivés.

Les Toques ou Scutellaires, les Brunelles abondent dans les bois et les prés. Le Gléchome à feuille de Lierre ou Lierre terrestre est une petite plante aromatique à fleurs bleuâtres dont l'infusion est pectorale. La Népéta chataire ou Herbe aux chats croît dans les haies; son odeur attire les chats comme celle de la Valériane. Le Romarin officinal, arbrisseau à feuilles étroites, coriaces, couvre les collines arides du midi de la France. La Sauge des prés (Salvia) est une jolie plante dont les grappes de fleurs bleues égaient les prairies en été; la Sauge sclarée ou Toute bonne la Sauge officinale, du midi de la France, ont des propriétés stimulantes prononcées; certaines espèces, comme la Sauge splendide des parties chaudes de l'Amérique, sont de belles plantes. Les Sauges, comme le Romarin, n'ont que deux étamines.

Les Lavandes (Lavande spic, Lavande vraie) sont des arbrisseaux couvrant certaines parties de la région méditerranéenne : souche ligneuse très ramifiée, feuilles linéaires, étroites et blanchâtres, fleurs bleues ou violacées, par petits groupes disposés en épis cylindriques : tels sont leurs caractères. Le Basilic commun (Ocimum Basilic), de l'Inde, est cultivé dans les jardins pour son odeur agréable; les Coleus et les Perilla ont des fleurs insignifiantes, mais un superbe feuillage coloré; le Pogostemon patchouly, de l'Inde et de la Malaisie, possède un parfum pénétrant.

Les Menthes affectionnent les lieux humides; leurs fleurs sont presque régulières (fig. 231, C); aromatiques, stimulantes, toniques,

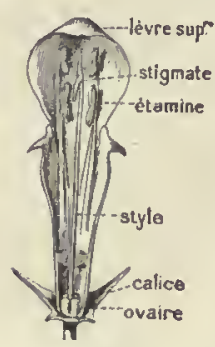

Fig. 230.

Coupe en long d'une fleur de Lamier blanc. ces plantes résument les propriétés des Labiées.

Les Origans sont des herbes ou des sous-arbrisseaux dont l'Origan vulgaire, ou Marjolaine

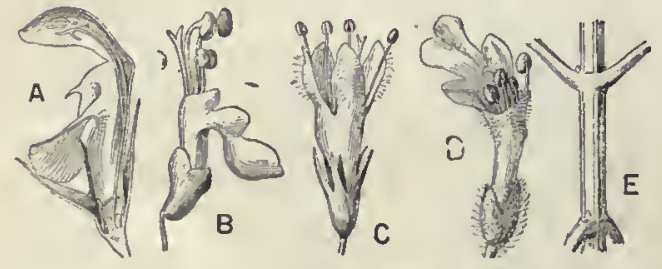

Fig. 231. - Corolles et tiges de Labiées.

A, Lamier (coupe de la fleur); B, Germandrée

C. Menthe; D, Bugle; E, Tige carré de Lamier. veine officinole est une herbe de nos champs; sa tige est quadrangulaire, ses feuilles sont opposées; ses fleurs, purpurines, très petites, en longs épis grêles, sont irrégulières; clles renferment quatre étamines, dont deux plus petites, et le fruit consiste en quatre akènes. La Verveine des jardins, hybride de plusieurs espèces étrangères, est une jolie plante à fleurs de coloris varié. Les feuilles de la Lippia à odeur de citron ou Citronnelle dégagent, lorsqu'on les

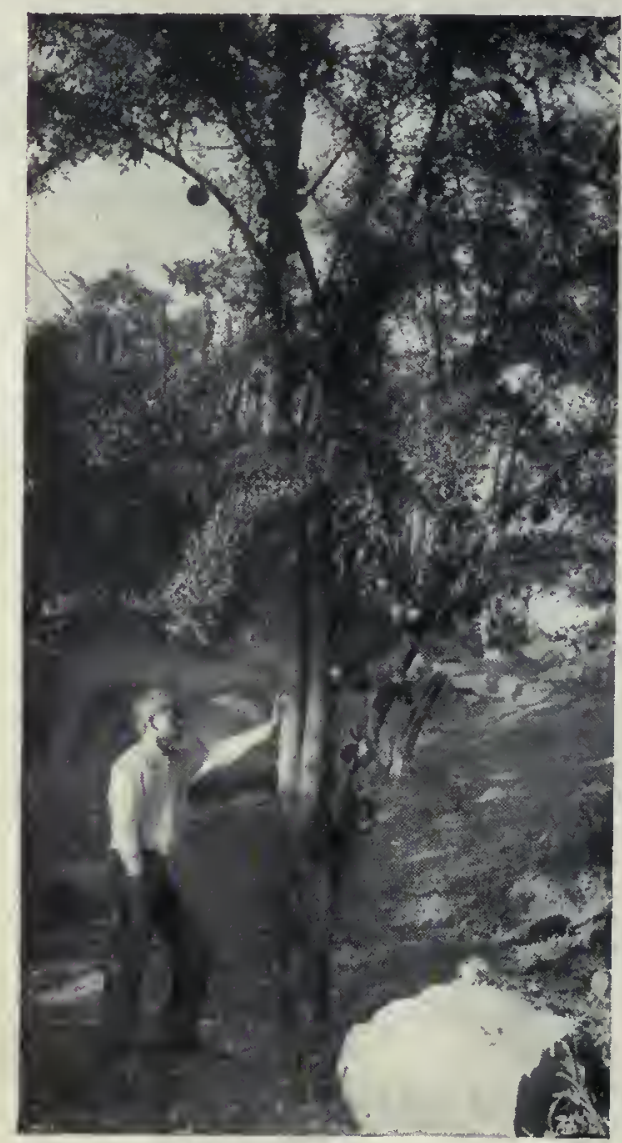

Calebassier, au Mexique. froisse, un agréable parfum de citron ; le Gattilier(Vitex) est un petit arbuste de Provence, à fruits drupacés, âcres et aromatiques. Les $T_{e c-}$ tona, grands arbres formant des forêts au Siam, en Birmanie et dans l'Inde, fournissent le bois de teck, à la fois léger, solide et incorruptible. Les Avicennes vivent au bord de la mer dans les régions tropicales; ils rappellent les Mangliers, mais leurs racinesasperges diffèrent de celles des Palétuviers.

Les Plantaginacées forment un petit groupe ayant des analogies avec les Labiées et les Verbénacées par la structure du pistil. Nos Plantains (Plantago) en sont les principaux représentants indigènes. 


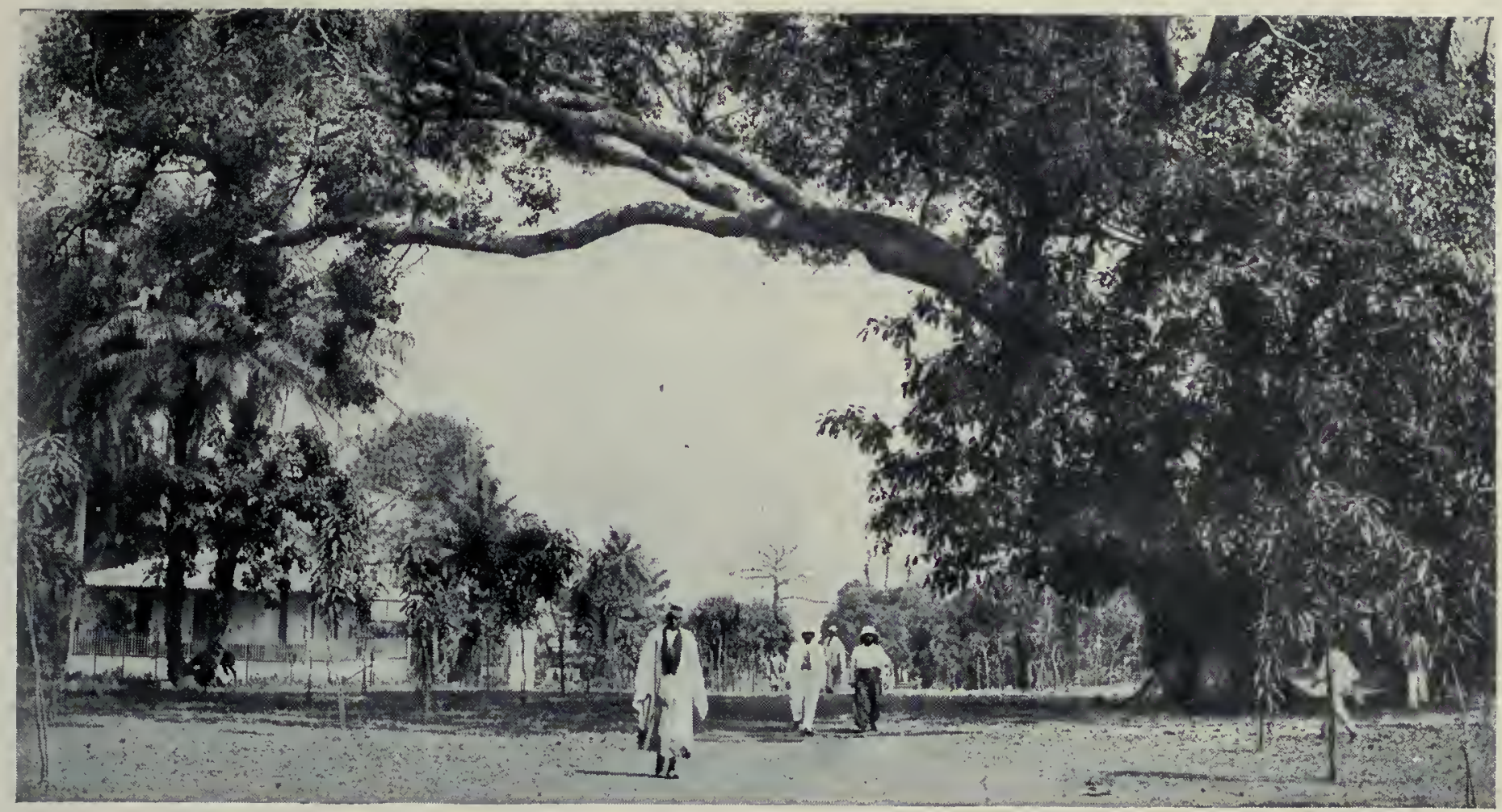

UN VIEUX FROMAGER, A KONAKRY (GUINEE FRANÇAISE)

\section{VIII. - DIALYPÉTALES SUPÉROVARIÉES}

Les Dicotylédones dialypétales forment un ordre extrêmement vaste comprenant environ soixante-dix familles. Nous les diviserons d'abord en deux grands groupes: celles dont l'ovaire est libre ou supère; celles dont l'ovaire est adhérent ou infère. Nous commencerons par les Dialypétales supérovariées, que nous ramènerons aux huit familles types énumérées dans le tableau ci-dessous, et autour desquelles nous grouperons toutes les autres familles:

\begin{tabular}{|c|c|c|}
\hline & Étamines nombreuses (polystémones). & Renoncutacées. \\
\hline & $\begin{array}{l}\text { Étamines nombreuses par :amification } \\
\text { (méristémones). }\end{array}$ & Motvocées. \\
\hline & Fleurs à placentalion pariétale. . . . & $\begin{array}{l}\text { Molvocées. } \\
\text { Cistocées. }\end{array}$ \\
\hline & $\begin{array}{l}\text { Etamines en } 2 \text { verticilles, de } 5 \text {, en géné- } \\
\text { ral (diplostémones). }\end{array}$ & \\
\hline $\begin{array}{l}\text { Étamines insérées sur } \\
\text { le réceptacle ou } \\
\text { thalamus (THALA- } \\
\text { MIFLORES). }\end{array}$ & $\begin{array}{c}4 \text { ou } 5 \text { étamines en } 1 \text { seul verticille (iso- } \\
\text { stémones) } \ldots \ldots \ldots \ldots \ldots\end{array}$ & Rham \\
\hline
\end{tabular}

Étamines insérées sur le calice (CALICifLores). Légumineuses et Rosacées.

\section{LES RENONCULACÉES}

Les Renoncules (fig. 232 et 233 ) sont des herbes à feuilles découpées, à fleurs régulières pourvues d'un calice à cinq sépales verts et d'une corolle à cinq pétales libres; les multiples étamines, libres, insérées sur le réceptacle, s'ouvrent vers la périphérie de la fleur (extrorses). Au centre est un pistil à nombreux carpelles, dont chacun renferme un seul ovule et donne à sa maturité un akène. Les Renoncules vivent de préférence dans les endroits frais, humides. La plupart des espèces terrestres ont les pétales d'un beau jaune qui leur a fait donner le nom de Boutons d'or. Quelques espèces aquatiques, à feuilles découpées en fines lanières, parent au printemps les fossés et les rivières de leurs innombrables fleurs blanches. Très voisine des Boutons d'or est la Ficaire fausse renoncule, abondante dans les bois humides.

Les $A$ némones sont caractérisées par un involucre ou collerette de trois feuilles découpées qui protège le bouton floral avant son épanouissement. Les fleurs sont isolées, régulières, mais à une seule enve-

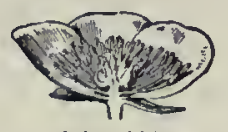

Fig. 232. Coupe de la fteur

Bouton d'or.

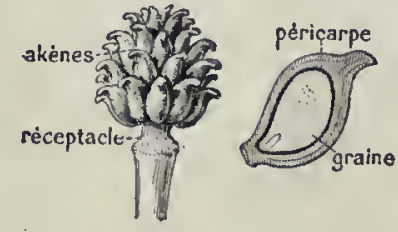

Fig. 233. - Fruit de Renoncule et coupe grossie d'un akène. loppe, blanche chez l'Anémone des bois ou Sylvie, violette chez la Pulsatille, jaune chez l'Anémone renoncule, de couleur variée, enfin, chez l'Anémone couronnée (Anémone de Caen) du midi de la France, qui est une plante horticole importante. Une mention spéciale doit être faite de l'Anémone du Japon, grande et belle plante d'ornement, fleurissant à l'arrière-saison.

L'Hépatique à trois lobes est proche parente des Anémones. Les Adonis, qui ornent les moissons de leurs fleurs écarlates, en diffèrent par la présence d'une double enveloppe florale.

Alors que toutes les autres Renonculacées ont des feuilles alternes, les Clématites ont des feuilles opposées et, chez la plupart des espèces, les fleurs n'ont qu' une seule enveloppe. Ce sont des arbustes à tige sarmenteuse, grimpant à l'aide du pétiole enroulable de leurs feuilles. La Clématite vigne blanche couvre les haies en été de ses fleurs blanches, et en automne de ses fruits plumeux à longue aigrette disséminatrice; en forêt elle parvient parfois jusguau sommet des arbres, et laisse pendre de tous côtés ses lianes flexibles. Pour orner les balcons et couvrir les murailles, on utilise les Clématites à grandes fleurs (patens), dont le périanthe, de nuances variées, atteint jusqu' à 15 centimètres de diamètre.

Toutes les espèces qui précèdent ont pour fruits de nombreux akènes et leurs fleurs sont régulières. Chez les Elléborées, le fruit consiste en un petit nombre de follicules et, suivant les genres, la fleur est régulière ou irrégulière. Les Ellébores ont de larges feuilles divisées, des fleurs régulières comprenant cinq grands sépales, verts chez l'Ellébore fétide ou Pied de griffon, d'un blanc rosé chez l'Ellébore noir ou Rose de Noël; l'Ellébore d'Orient, qu'on trouve en Grèce et en Turquie, passait autrefois pour guérir la folie. Dans ce genre, les pétales sont petits, peu apparents, yerts et en cornet. A côté des Ellébores se placent la Nigelle de Damas, du midi de la France, à la fleur somptueuse, entourée d'un involucre finement découpé, et la Nigelle des champs, aux fleurs d'un bleu clair; chez les Nigelles, la beauté de la fleur est due aux cinq sépales pétaloïdes, car les pétales sont très courts, Il en est de même chez le Caltha 


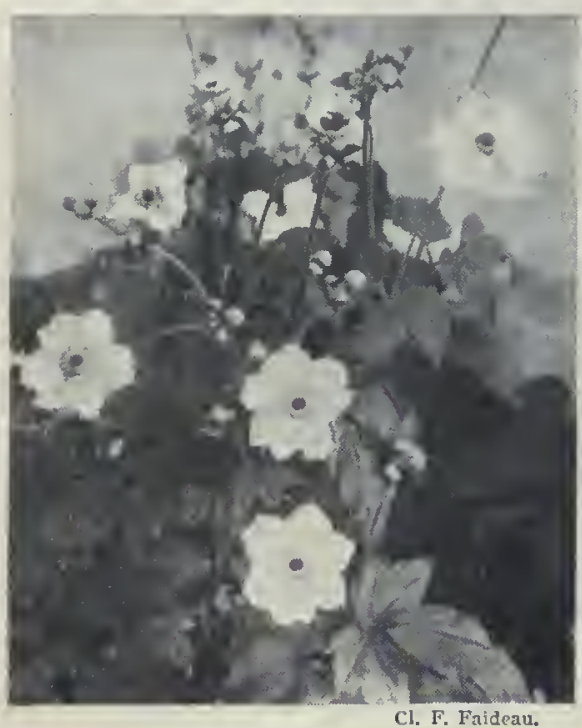

Anémone du Japon.

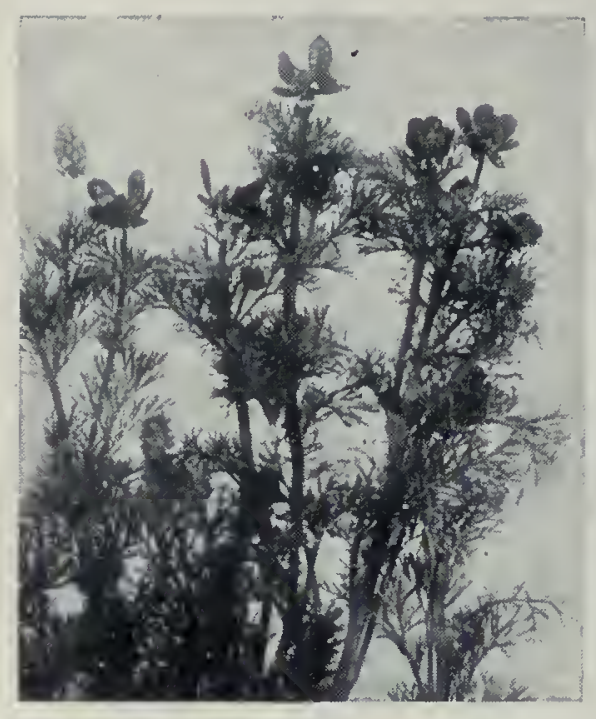

Adonis d'automne.

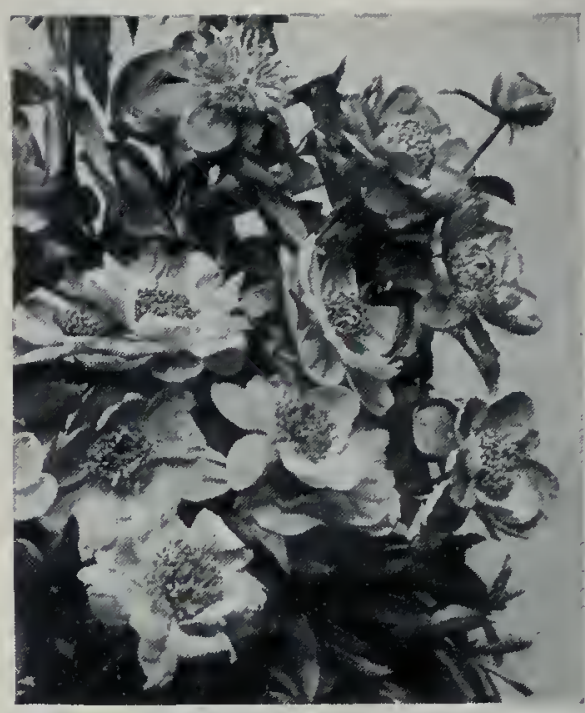

Gronpe de Pivoines. des marais ou Souci d'eau, Populage, aux larges sépales d'un jaune d'or. L'Ancolic vulgaire (Aquilegia) est une des plus belles plantes de nos bois; ses fleurs régulières ont cinq sépales bleus, cinq pétales bleus recourbés en corne d'abondance; les étamines nombreuses entourent le pistil à cinq carpelles.

Les Dauphinelles et les Aconits ont des fleurs irrégulières. La Dauphinelle consoude ou Pied-d'alouette présente cinq grands sépales, dont le supérieur se prolonge en un long éperon; il y a deux pétales postérieurs soudés en un seul, qui forme un éperon inclus dans celui du calice; par exception il n'y a qu'un carpelle. L'Aconit napel de nos régions montagneuses a cinq grands sépales bleus, dont le supérieur est en forme de casque. Chez les Pivoines, les anthères non extrorses s'ouvrent non vers le centre de la fleur, mais latéralement.

La famille des Renonculacées renferme des plantes très différentes par leurs organes végétatifs et floraux; elle est hétérogène. Les caractères communs sont en petit nombre : pétales séparés, étamines nombreuses, libres, insérées sur le réceptacle et à anthères s'ouvrant presque toujours vers la périphérie de la fleur, ovaire libre, fruit sec. Toutes renferment un suc âcre, vénéneux. Les Renonculacées n'ont d'importance que pour l'ornementation des jardins.

Magnoliacées; Anonacées. - Les Magnoliacées et les Anonacées sont voisines des Renonculacées, mais à pièces florales disposées par trois et non par cinq : calice à trois sépales, corolle à six pétales disposés suivant deux cercles concentriques; le fruit est variable; l'albumen de la graine est ruminé dans les secondes.

Les Magnoliacées sont des plantes ligneuses, souvent aromatiques, à feuilles alternes, coriaces, à grandes fleurs régulières. Les Magnolia, beaux arbres d'ornement, originaires de l'Asie et de l'Amérique, ont des fleurs abondantes blanches ou roses, agréablement parfumées. Le Tulipier de Virginie ou Liriodendron est un arbre superbe, qui peut atteindre jusqu'à 40 mètres de haut; ses feuilles, tronquées à leur extrémité libre, ont une forme curieuse ; ses grandes fleurs d'un jaune verdâtre rappellent un peu celles des Tulipes. Le Badianier de Chine ou Anis étoilé (Illicium vrai) est un arbrisseau commun en Extrême-Orient. Ses fruits, qu il ne faut pas confondre avec ceux de l'Anis vert, Ombellifère cultivée en France, sont formés par huit à douze capsules à une graine s'ouvrant vers le haut ef groupées en une étoile.

Les Anonacées sont des plantes ligneuses des pays tropicaux ; leur fruit est formé de baies, souvent comestibles, soudées ensemble. Diverses espèces d'Anones ou Corossoliers fournissent l'anone, la pomme-cannelle ou atte, le cherimolia, grosses baies composées, ovoïdes, dont la pulpe crémeuse et parfumée possède une saveur délicieuse (Voir planche en couleurs des FRUITS EXOTiques). Des fleurs du Canang odorant ou Arbre à ylang-ylang, cultivé dans tout le sud de l'Asie, on retire un parfum estimé.

Ménispermacées, Berbéridacées. - Ces deux familles se relient intimement aux deux précédentes par leurs pièces florales disposées par trois; mais ici le calice est à six pièces, comme la corolle. Chez les Ménispermacées, chaque carpelle ne contient qu'un ovule; il en renferme plusieurs chez les Brrbéridacées.
Les Ménispermacées ont de petites fleurs unisexuées; le fruit est formé de drupes multiples. Citons le Ménisperme du Canada, arbrisseau grimpant ornemental ; les Jatéorhizes, dont une espèce fournit une racine tonique et astringente nommée colombo, employée contre la dysenterie; enfin l'Anamirte cocculus, liane des Indes, dont les fruits ou coques du Levant, de la grosseur d'un pois, sont très toxiques.

Les Berbéridacées nous ramènent à la flore des pays tempérés. Cette famille renferme les Vinettiers ou Berberis, qui sont des arbrisseaux épineux à feuilles simples. Notre espèce indigène, le Vinettier commun ou Epine-vinette, a des fleurs petites, régulières, jaunes, à six sépales et six pétales, et groupées en grappes pendantes. Leurs anthères souvrent vers le centre de la fleur par de petits clapets se soulevant de bas en haut (fig. 57, C). L'Épinevinette forme des haies fleuries au printemps, garnies de fruits rouges à l'automne; on doit l'exclure du voisinage des terres à Blé, car le Champignon qui produit la rouille des céréales (p. 60) accomplit une de ses phases parasitaires sur ses feuilles. Des fruits de l'Epine-vinette on fait, à Chanceaux, près de Dijon, des confitures renommées. Dans les jardins, plusieurs Vinettiers jouent un rôle décoratif, ainsi que les Mahonia et les Épimèdes.

Myristicacées. Lauracées. - Les Myristicacées peuvent se rattacher aux Ménispermacées par la conformation de leurs fleurs, mais celles-ci sont dépourvues de corolle. Le genre Muscadier (Myristica), qui forme à lui tout seul cette famille, comprend des arbres des pays chauds, à fleurs unisexuées diöques, à feuilles alternes entières. Le plus utile est le Muscadier aromatique.

Les Lauracées se relient intimement aux Berbéridacées, mais leur corolle, semblable au calice, est formée d'un seul verticille de trois pièces (ou deux). Toutes, sauf le Laurier commun, sont des arbustes ou des arbres aromatiques des régions tropicales. Les feuilles sont coriaces et persistantes, le fruit est une baie, les anthères souvrent par des clapets, comme celles des Vinettiers. Le Laurier commun ou Laurier noble, consacré jadis à Apollon, est un arbre de la région méditerranéenne; ses fleurs sont petites, blanc jaunâtre; ses fruits sont des petites baies d'un bleu noirâtre; les feuilles, simples, servent en cuisine pour les assaisonnements.

Le Cannellier ou Cinnamome de Ceylan atteint 10 mètres: son écorce est utilisée comme épice; le Camphrier de Chine ou Cinnamome Camphrier est un grand arbre à petites feuilles dentées: on en retire le camphre par distillation; le Sassatras habite l'Amérique du Nord; enfin l'Avocatier ou Persea de l'Amérique du Sud est cultivé pour son fruit excellent, la poire-avocat, grosse baie pyriforme, verte ou violette (Voir PLANCHE EN COULEURS).

Nymphéacées. - Cette famille comprend des plantes aquatiques caractérisées par le grand nombre de leurs pièces florales disposées suivant une spirale régulière. Ce sont des plantes nagzantes, fixées au sol par un rhizome; il en part de grandes feuilles à long pétiole, à limbe arrondi, ferme, étalé à la surface de l'eau; plus tard apparaissent de grandes fleurs solitaires.

En été, nos étang et nos rivières sont égayés par le Nénuphar jaune (Nuphar luteum), dont les fleurs ont un calice formé de cinq 


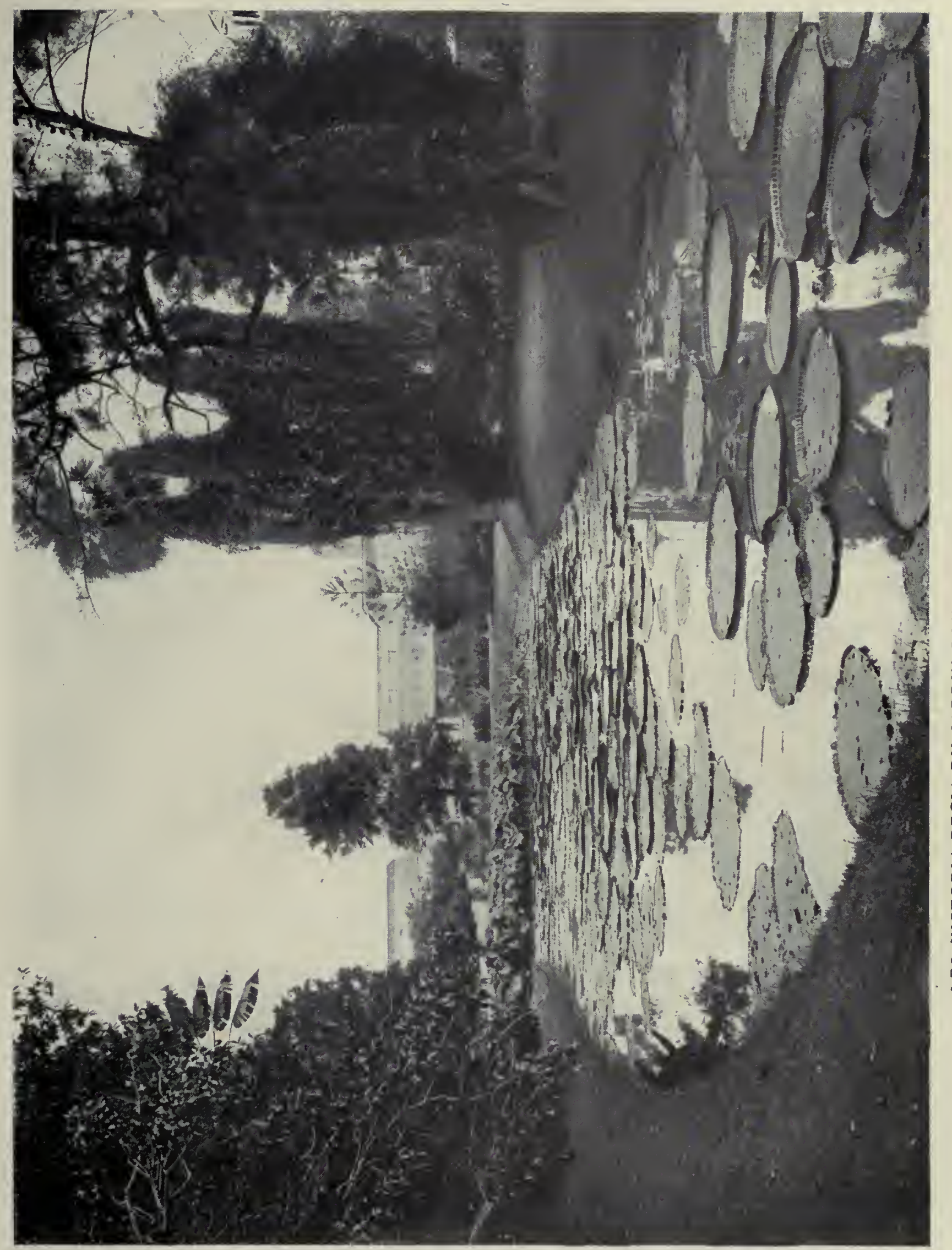

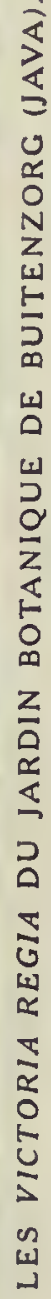



longs sépalesd'un jaune foncé, entourant dix petits pétales, et le $N$ énuphar blanc ( $N y m-$ phrea $a l b a$ ), dont les fleurs comptent quatre sépales verts à l'extérieur et blancs en dedans, un grand nombre de pétales blancs, puis d’étamines soudées par leur base à un ovaire à plusieurs loges. Le fruit, dans les deux genres (Nuphar et Nymphaa), est une capsule ventrue. On connaît une vingtaine d'espèces de Nymphra dont certaines sont de superbes plantes d'ornement, par exemple le Nymphaa rose de l'Inde orientale, le Numphaa

bleu d'Égypte et le Nymphea rouge de l'Inde.

Les plantes aquatiques connues sous le nom de Lotus étaient sacrées chez les Egyptiens de l'antiquité. Elles apparaissent, en effet, au moment de linondation périodique du Nil et annoncent la fécondité du sol; de plus, par l'immersion de leurs fleurs, chaque soir quand le soleil se couche, et par leur émersion matinale, elles semblent en relation mystérieuse avec l'astre du jour. Les graines et les rhizomes de ces plantes jouaient un rôle important dans l'alimentation. Ce nom de Lotus a été appliqué à des plantes de genres différents; ainsi le Lotus blanc et le Lotus bleu des anciens Egyptiens sont des Nymphaa: le premier est le Nymphaa lotus, le second le Nymphaa stellata ou Nénuphar bleu.

Le nom de Lotus s'applique aujourd'hui aux Nélombo, qui diffèrent des $N$ ymphæa par leurs feuilles en forme de coupe, dépassant de beaucoup la surface de l'eau. On en connaît deux espèces: le Nélombo d'Orient (Nelumbium speciosum) ou Lotus rose, de l'Inde et de l'Extrême-Orient, et le $N$ elombo jaune ( $N$. luteum), de l'Amérique du Sud (Voir PLANCHE EN COUlEURS).

La Victoria royale, de l'Amérique du Sud, est une merveille végétale. Ses feuilles ont leur face inférieure couverte de nervures saillantes, hérissées, ainsi que le pétiole, de puissantes épines défensives de 2 centimètres de largeur. A leur naissance, les feuilles ressemblent à un hérisson enroulé; peu à peu elles s'étalent, mais leurs bords restent relevés de quelques centimètres, formant une sorte de nacelle qui, grâce aux lacunes du pétiole et du limbe, peut supporter sans couler un poids considérable. Les feuilles ont jusqu'à 2 mètres de diamètre, et les fleurs 30 à 40 centimètres; ces dernières, blanches au moment de l'épanouissement, deviennent roses, tournent au rouge cramoisi. Ce sont des fleurs nocturnes; elles s'ouvrent le soir vers cinq heures, exhalent pendant la nuit une odeur pénétrante, se ferment le lendemain matin (dix heures) pour se rouvrir le soir suivant; elles sont flétries le matin du second jour. Les fleurs fécondées s'enfoncent au-dessous de l'eau pour y mûrir un fruit globuleux de $0^{\mathrm{m}}, 15$ de diamètre, rempli de graines farineuses.

\section{LES MALVACÉES}

La Mauve sylvestre (fig. 234) ou Grande Mauve (Malva), commune dans les champs, est une herbe vivace, velue, à feuilles alternes, dont le limbe, longuement pétiolé, présente de cinq à sept lobes. Ses grandes fleurs régulières, disposées à l'aisselle des feuilles, ont un

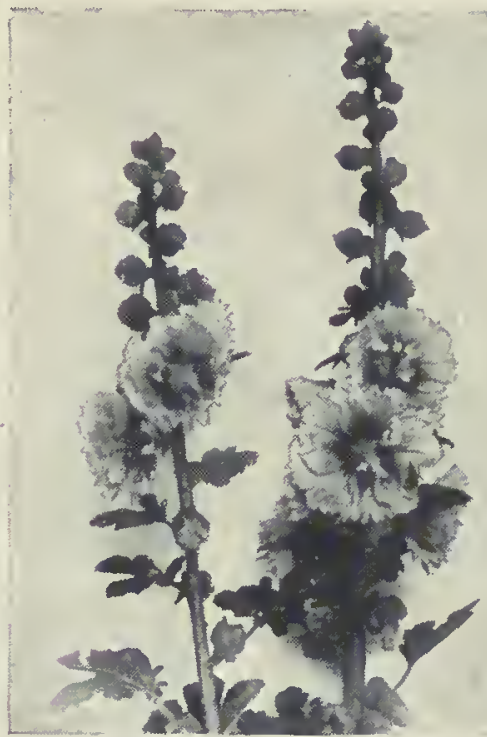

Rose trémière. calice à cinq sépales soudés, doublé en dessous d'un calicule, sorte de collerette formée par trois petites feuilles; la corolle comprend cinq grands pétales veinés d'un rose violacé. Les étamines nombreuses sont soudées entre elles par leurs filets; les anthères n'ont que deux sacs polliniques, au lieu de quatre, chiffie habituel. L'ovaire est libre, arrondi, à nombreuses loges et surmonté d'un stylequi passe au centre du tube formé par les étamines et se divise en autant de stigmates que l'ovaire a de loges. Le fruit est à loges distinctes, dont chacune renferme une seule graine

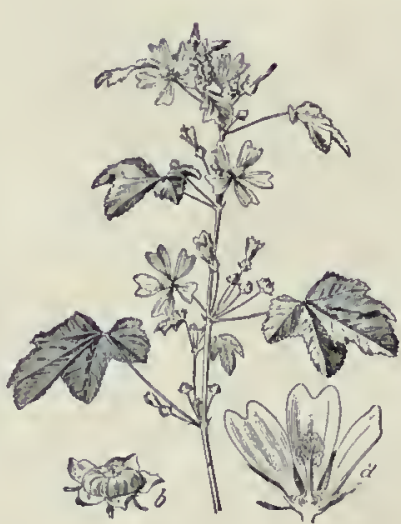

Fig. 234.

Mauve sylvestre.

Coupe de la fleur; $b$, Fruit. et se détache isolément : il se divise ainsi en akènes. Les Malvacées rappellent les Renonculacées par leurs nombreuses étamines. Ces plantes sont répandues sur la terre entière, sauf dans les régions arctiques; dans les pays chauds, beaucoup sont de grands arbres. Feuilles alternes à nervation palmée et munies de stipules; fleurs régulières du type cing, souvent de grande taille, étamines parfois partiellement soudées, ovaire libre à carpelles clos, placentation axile, tels sont leurs caractères. Le fruit est variable. Les Malvacées sont parfois divisées en trois tribus : les Malvées, dont les étamines soudées en tube ont des anthères à deux sacs; les Sterculiées, qui offrent le même caractère avec des anthères à quatre sacs; enfin les Tiliées, ayant les étamines à peine soudées à la base, avec des anthères à quatre sacs.

Les Malvées contiennent un mucilage, substance visqueuse qui les fait employer comme émollientes ou adoucissantes; beaucoup ont dans leurs tiges des fibres libériennes souples ou, autour de leurs graines, des filaments soyeux qui en font des plantes textiles.

La Guimauve officinale (Althaa), des prés du littoral maritime, est une grande herbe à feuilles blanchâtres, molles et velues, à fleurs d’un blanc rosé. Sa racine, écorcée et desséchée au four, est blanche, un peu sucrée ; c'est un excellent émollient.

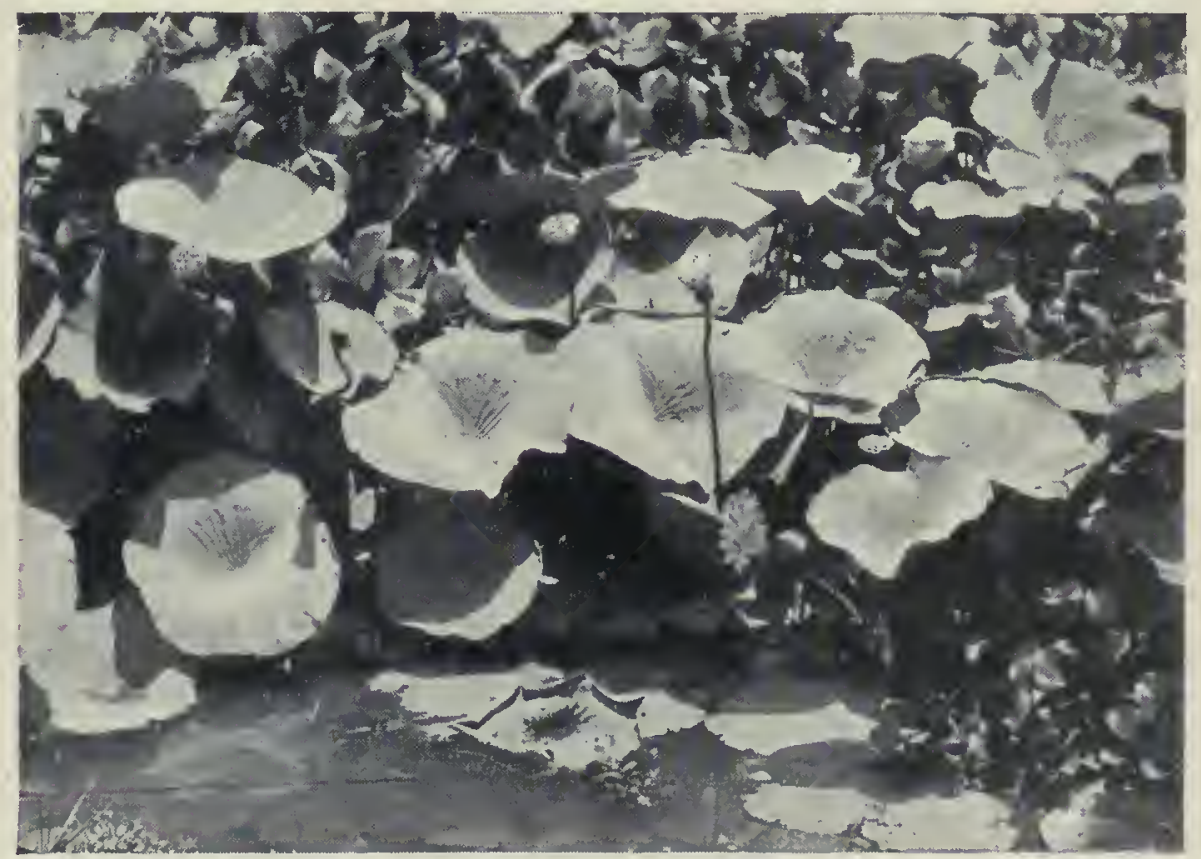

Touffes de Lotus ou Nélombo (réceptacles en pomme d'arrosoir). 


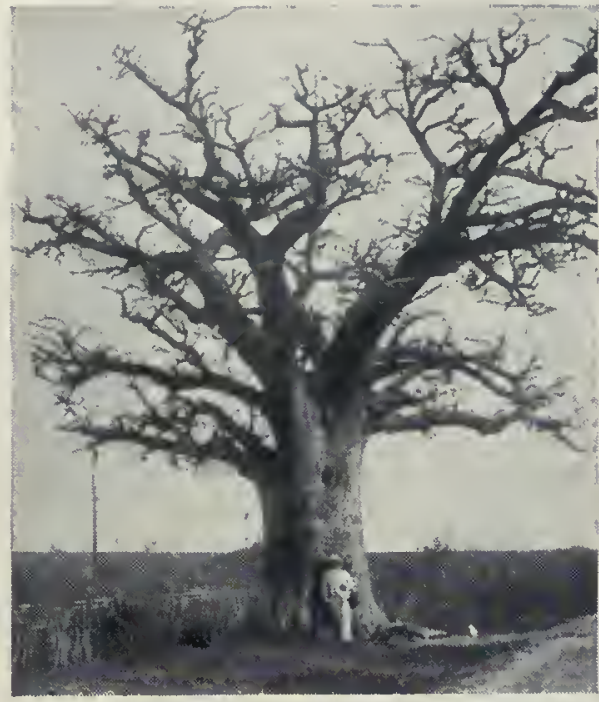

Baobab, au Sénégal.

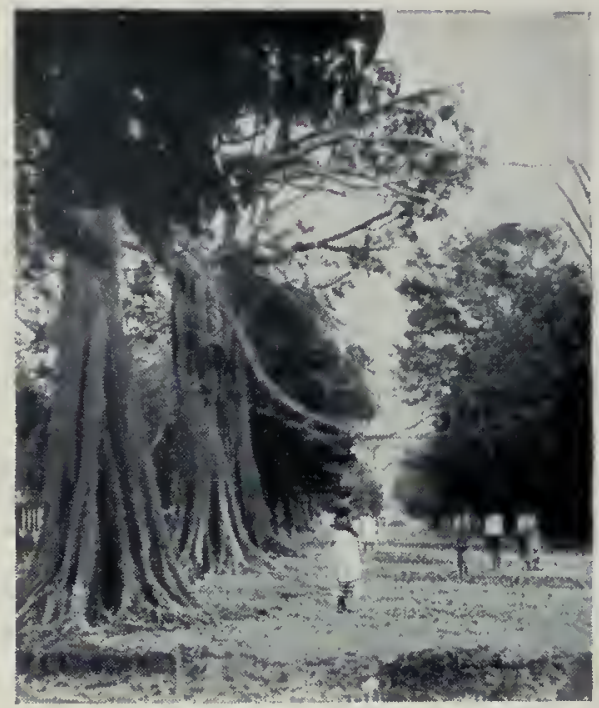

Fromagers, au Soudan.

port du Kolatier ou Kola acuminée, originaire de l'Afrique tropicale, rappelle celui du Châtaignier; il atteint 20 mètres de haut; les fleurs, mâles, femelles et monoïques, sont d'un jaune rougeâtre; la capsule. longue de 10 à 15 centimètres, abrite une douzaine de graines nommées noix de Kola; celles-ci renferment des alcaloödes excitateurs du systène musculaire.

Les Cacaoyers ou Theobroma sont des arbres d'Amérique; leurs fleurs sont complètes; leur fruit est une baie volumineuse. Le Cacaoyer commun, arbuste de 4 à 10 mètres de haut, a des fleurs petites et rougeâtres, se succédant toute l'année. Son fruit ou cabosse, en forme de concombre, contient dans une pulpe molle une trentaine de graines qui sont la base de l'industrie du chocolat.

Les Tilleuls, qui ont donné leur nom à la tribu des Tiliées, sont de grands arbres à feuilles alternes, simples; les fleurs, très odorantes, jaunâtres, forment un corymbe dont le pédoncule commun est soudé sur

Les Hibiscus ou Ketmies habitent les pays chauds; leurs fleurs, très belles, ont un ovaire à cinq loges. La Ketmic musquée, dite aussi Ambrette ou Herbe au musc, est un arbrisseau tropical; la Ketmie comestible, ou Gombo, tropicale, possède une capsule comestible après cuisson, quand elle est encore verte; la Ketmie à chanure de l'Inde est textile; la Ketmie de Syrie ou Guimauve en arbre est ornementale, ainsi d'ailleurs que beaucoup d'autres Malvées : les Calirrhoés, les Abutilons, les Lavatères, les Mauves et la superbe Rose trémière ou Passe-rose (Althaa rosea).

La Malvée la plus importante est le Cotonnier (Gossypium). Ce genre comprend des espèces ayant pour fruit une capsule coriace s'ouvrant par trois à cinq valves et contenant des graines anguleuses, revêtues de longs poils crépus, blancs ou jaunâtres, qui constituent le coton. Les Cotonniers sont des arbustes; l"espèce la plus répandue est le Cotonnier dit Sea Island (barbadense). On le cultive dans tous les pays chauds et humides comme plante annuelle; il atteint l à 2 mètres de haut; ses feuilles, alternes, pétiolées, ont cinq lobes arrondis; ses fleurs éphémères, jaunes, sont suivies de capsules de la grosseur d'une noix ; elles mûrissent et s'ouvrent en même temps que s'épanoujssent de nouvelles fleurs.

Plusieurs Malvées sont des arbres gigantesques des régions tropicales; on en forme le groupe des Bombacées. Les Baobabs ou Adansonia (fig. 235 ) sont parmi les géants du règne végétal. II en existe plusieurs espèces dont la plus connue est l'Adansonia digité du Sénégal, le plus gros des arbres; il dépasse rarement 20 mètres de hauteur, mais il a parfois 25 mètres de circonférence à la base, avec un sommet formant un dôme de verdure de 200 mètres de tour. Les feuilles, qui manquent pendant toute la saison sèche, c'est-à-dire pendant près des deux tiers de l'année, sont très brillantes et rappellent celles du Marronnier d'Inde; les fleurs sont grandes, blanches; le fruit ou pain de singe est une grosse capsule ligneuse, veloutée, indéhiscente; le bois, très léger, a de nombreux usages. 11 y a à Madagascar plusieurs Baobabs; l'un a le tronc étranglé vers le haut (rubrostipa). Les Bombax et les Eriodendrons se distinguent des Baobabs par leur capsule déhiscente, remplie de filaments cotonneux courts qui appartiennent aux parois de la capsule et non à la graine, comme chez les Cotonniers; ils constituent l'ouate végétale ou kapok employée pour le rembourrage. Ces arbres sont connus sous le nom vulgaire de Fromagers, dû à leur bois blanc et tendre, comparable à du fromage; leur tronc a des racines-palettes.

La tribu des Sterculiées com-

prend des plantes herbacées ou ligneuses, à feuilles alternes, simples, stipulées. Les Sterculiers sont des arbres à fleurs unisexuées groupées en grappes; plusieurs sont à fruits comestibles ou riches en principes astringents utilisés en médecine. Le Brachychiton à feuilles de Peuplier d'Australie est un bel arbre naturalisé dans le midi de la France, Le
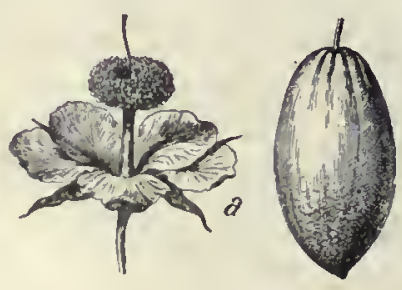

Fig. 235.

Fleur ef fruit du Baobab, une grande partie de sa longueur avec une longue et étroite bractée membraneuse; le fruit est un akène. Il existe une douzaine d'espèces de Tilleuls; elles habitent les régions tempérées de l'hémisphère nord. Les fleurs sont employées en infusions calmantes; le bois, blanc et léger, est recherché par les menuisiers, les sculpteurs. Certains vieux Tilleuls sont célèbres; tels sont : le fameux Tilleul de Morat, en Suisse; celui de Cadier en Keer, dans le Limbourg hollandais; celui de Schwartzenberg, en Saxe, qui a près de 8 mètres de tour à la base.

La Corrète capsulaire ou Jute est une herbe annuelle, haute de 2 à 3 mètres. Originaire de l'Inde, on la cultive pour ses fibres textiles donnant le chanvre du Bengale, propre à faire des sacs. Citons encore les Elœocarpus, donnant des bois d'œuvre estimés, les Sparmannia, cultivés pour leurs jolies fleurs et les fibres.

Ternstrémiacées. - Les Ternstrémiacées sont voisines des Malvacées et à feuilles à stipules caduques; elles se rapprochent surtout des Tiliées par l'organisation de leurs étamines soudées à la base. Ce sont des arbres et des arbrisseaux à feuilles simples, alternes et coriaces.

Les Camélia, originaires d'Extrême-Orient, sont des plantes ornementales fort appréciées pour leur feuillage persistant et la beauté de leur floraison précoce. Le calice est à cinq sépales, la corolle a cinq pétales; de nombreuses étamines sont soudées entre elles par la partie inférieure de leurs filets; l'ovaire libre devient une capsule s'ouvrant au milieu des loges.

Le Théier, très voisin, est un arbuste de Chine; il peut atteindre une dizaine de mètres lorsqu'on l'abandonne à luimême; ses feuilles sont luisantes et d'un vert foncé; ses fleurs, blanches, assez grandes, faiblement odorantes. Feuilles et fleurs renferment une assez forte proportion d'un alcalojde excitant, identique à la caféine. Les fleurs en boutons donnent une infusion d'arome agréable, mais on n'emploie que les feuilles.

Diptérocarpées, Clusiacées. - Les Diptérocarpées sont de grands arbres des régions tropicales, différant surtout des Ternstrémiacées par la présence de stipules, de canaux oléorésineux, et par la persistance des sépales longuement accrus qui entourent le fruit et facilitent sa dissémination. L'akène de certains Diptérocarpes, gros comme une petite noix, porte deux ailes puissantes, longues de 25 centimètres. Chez les Dryobalanops, les cinq sépales accrus forment cing ailes au fruit.

Le bois des Diptérocarpes est estimé pour la construction. Le Dryobalanops aromatique ou Camphrier de Bornéo fournit le bornéol, sorte de camphre très employé au Japon et en Océanie.

Les Clusiacées ou Guttifères sont aussi des plantes ligneuses tropicales, riches en canaux sécréteurs, mais leurs feuilles sont opposées et non alternes, comme celles des Diptérocarpées. Les Clusia d'Amérique sont, pour la plupart, épiphytes; ils enlacent si étroitement le tronc de l'arbre qui les supporte qu'ils l'étouffent ; aussj les nomme-t-on lianes meurtrières. Les Guttiers ou Garcinies sont surtout d'Asie; leur latex jaune, recueilli par incision, constitue la gomme-gutte (Garcinic de Hanbury), matière colorante employée pour la peinture à l'eau. La Garcinie mangoustan, 


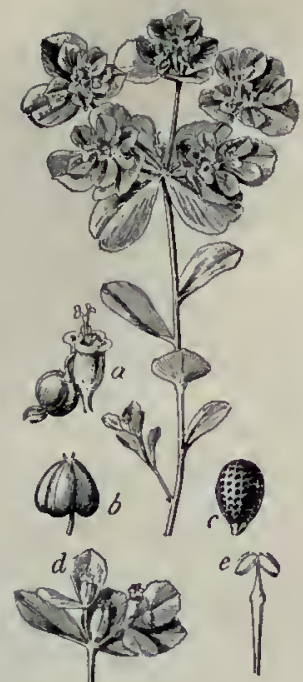

Fig.236. - Euphorbe réveitle-matin.

$a$, Fleur; $b$, Fruit rescence; $e_{1}$ Etamine. c, Graine grossie ; $d$, Inflo-

originaire des Indes, cultivée à Maurice et à La Réunion, a des fruits rouges volumineux d'une saveur exquise.

Hypéricacées. - Le Millepertuis perforé (Hypericum perforatum) est une herbe des lieux incultes. Sa tige porte des feuilles opposées et se termine par une cyme de fleurs jaunes. Si l'on interpose entre l'œil et la lumière une feuille de Millepertuis, elle semble percée de petits trous ronds; en réalité, ses tissus verts sont, en certains points, remplacés par des glandes remplies d'un liquide translucide. La fleur se compose de cinq sépales, de cinq pétales libres, de nombreuses étamines groupées en trois pinceaux saillants et d'un pistil libre comprenant un ovaire à trois loges surmonté de trois styles; le fruit est une capsule. Les Hypéricacées se relient directement aux Clusiacées par leurs feuilles opposćes et leurs canaux sécréteurs.

Euphorbiacées. - Les Euphorbiacées sont représentées dans notre pays par les Euphorbes (fig. 236), qui sont des plintes à latex blanc dont l'inflorescence est très particulière et l'on est tenté de la considérer comme représentant une fleur hermaphrodite; en réalité, il y a au centre une fleur femelle solitaire qui est pédonculée, et qui fait saillie en s'infléchissant au-dessus de l'inflorescence; elle est entourée d'un certain nombre d'inflorescences mâles, groupées en cinq faisceaux qui paraissent être la partie mâle de la fleur hermaphrodite; l'examen plus approfondi de la plante montre que la fleur mâle est formée d'une seule étamine qui est articulée à sa base sur un pédicelle. Autour des cinq faisceaux d'étamines on voít des organes glanduleux jaunes, souvent en forme de quatre croissants qui simulent des pétales et, autour, des pièces que l'on prendrait pour cinq sépales, mais' les premiers et les seconds sont des bractées. Cette inflorescence si singulière porte le nom de cyathium. Diverses Euphorbes sont utilisées dans la médecine populaire, notamment l'Épurge ou Euphorbe Lathyris; les feuilles et les fruits de l'Euphorbe piscatoire servent à endormir et à prendre le poisson; avec le suc de l'Euphorbe cotinifeuille, les Indiens empoisonnent leurs flèches; on cultive dans les serres l'Euphorbe splendide, à tige épineuse et à involucre rouge, et l'Euphorbe très belle (Poinsettia), dont les bractées rouges ont 30 à 40 centimètres. Le cyathium ne se retrouve pas dans les autres Euphorbiacées.

Les fleurs des deux sexes du Tournesol ou Chrozophore tinctorial sont nettement séparées et il y a un calice et une corolle, cinq sépales, cinq pétales; cinq étamines dans les fleurs - mâles; dans les fleurs femelles, un pistil à trois carpelles. Le suc de la tige de cette plante est employé dans les laboratoires pour obtenir le papier de tournesol qui sert à reconnaître les acides et les bases. La Mercuriale est voisine, mais le calice n'a que trois sépales et les étamines sont nombreuses; il y a dioïcité, rarement monoïcité. Le Ricin commun est une plante herbacée à végétation luxuriante, à larges feuilles palmilobées, qui est de grand effet en culture sur les pelouses; ses graines, qui sont à tégument moucheté et terminé par une excroissance charnue ou caroncule, contiennent l'huile de Ricin, purgatif très employé.

Dans la Jatropha Curcas ou Pignon d'Inde, Figue d'enfer, les graines fournissent une huile utilisée pour la fabrication des savons; cette huile est plus énergique encore que l'huile de Ricin. Le Bancoulier ou Aleurite des Moluques peut également, par ses graines,

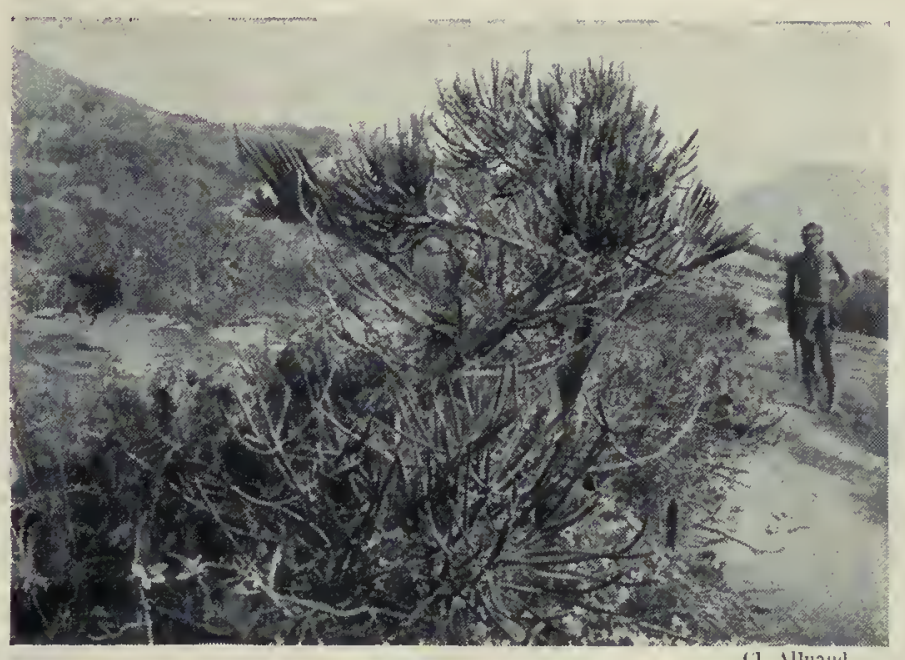

Buisson d'Enptiorbe Laro, à Madagascar.

fournir une huile. L'Hevea du Brésil appartient à la même tribu que le Jatropha, mais il est dépourvu de corolle; c'est un arbre extrêmement important, dont les forêts de l'Amazone contiennent un nombre immense, et qui est exploité pour le caoutchouc de première qualité qu'il fournit.

Dans le Manioc très utile (Manihot), les fleurs sont apétales, réunies en grappes terminales à l'aisselle des feuilles supérieures; c'est un arbrisseau de l'Amérique du Sud qui contient des réserves amylacées dans ses racines et des substances vénéneuses volatiles que la chaleur fait partir; ces racines servent à préparer le tapioca. Une autre espèce ou variété est le Manioc aïpi ou Cassave douce dont les racines ne contiennent pas ce suc dangereux et sont employées comme légume dans le pays natal. Le caoutchouc Ceara (nom d'un port du Brésil) est fourni par le Manioc de Glaziou.

Dans d'autres tribus d'Euphorbiacées, le calice est imbriqué au lieu d'être valvaire. C'est ce qui arrive dans les Codićes, vulgai rement mais inexactement connues sous le nom de Croton; ce sont des plantes à feuilles coriaces, découpées et présentant des colorations extrêmement vives qui les rendent très ornementales. Les Crotons véritables sont des plantes à étamines courbées par leur filet dont les graines fournissent l'huile de Croton (Croton de Tigli), révulsif énergique qui irrite la peau et dont deux gouttes suffisent à purger.

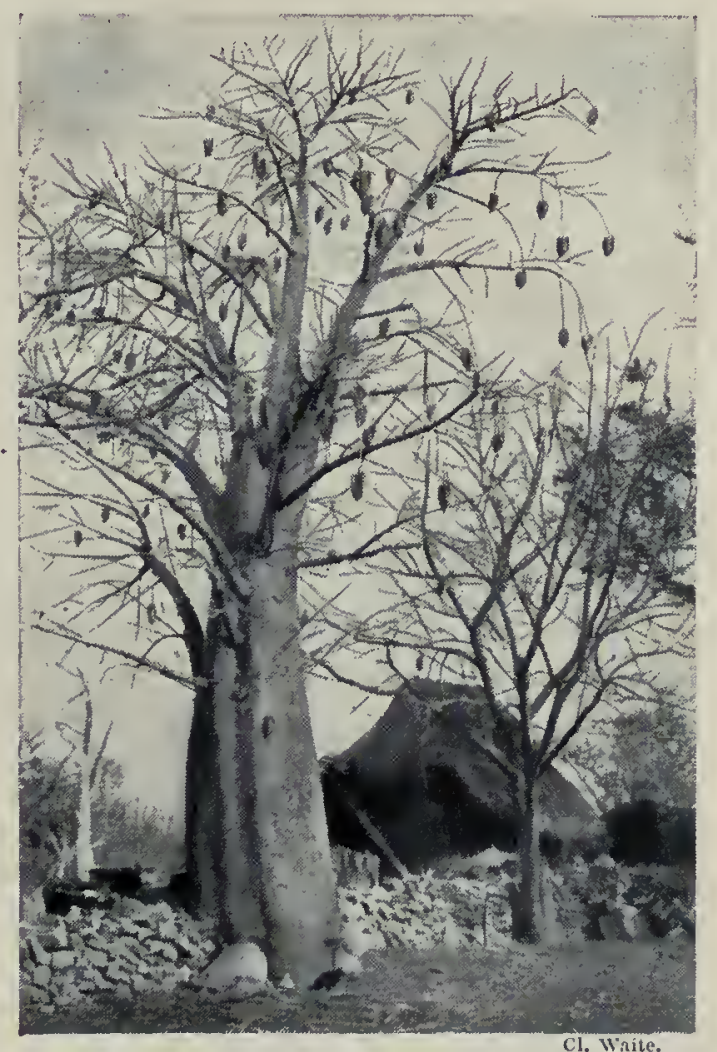

Papayer à sept feuilles ou "Bonete ", au Mexique.
Le Mancenillier (Hippomanée) appartient aussi à une tribu à calice valvaire; cest un petit arbre de la dimension du Poirier, sur lequel on a raconté beaucoup de fables : en s'endormant à son ombre, on risquait de ne pas se réveiller, et Meyerbeera rendu cette histoire célèbre dans L'Africaine, mais Scribe a commis une erreur géographique, car la plante est américaine; le suc de cette plante est extrêmement énergique ; quelques gouttes, injectées sous la peau, produisent des ulcères, et 3 à 4 grammes dans l'estomac produisent la mort. C'est à ce groupe des Hippomanées quappartient le Sablier crépitant (Hura); cette espèce présente à un haut degré une propriété qui est très répandue dans la famille des Euphorbiacées (chez l'Hevea, le Tcurnesol, etc.) où les capsules éclatent brusquement; le fruit du Sablier, qui est gros comme une petite orange et côtelé, éclate avec bruit en projetant ses graines; en faisant bouillir ces fruits dans l'huile, on en empêche la déhiscence; on peut l'utiliser comme sablier.

C'est au voisinage que doit se placer le Glutier à suif ou Arbre à suif de la Chine (Sapium sebiferum) : le suif existe dans les graines, et le Sapium à deux glandes, petit arbre de l'Equateur qui fournit un caoutchouc désigné sous le nom de "colombie ". Mentionnons 
également l'arbre aveuglant, l'Execarie agallochia, dont le latex est vénéneux et corrosif.

Les Buxées, dont le Buis est le type, sont pour certains auteurs une simple tribu des Euphorbiacées, four d'autres une petite famille voisine. Le Buis toujours vert de nos forêts est un arbuste à feuilles coriaces, d'odeur forte et de saveur amère, dont le bois, très dur et à grain fin, possède des qualités uniques pour la gravure. Les fleurs, petites, unisexuées, monoïques, sont privées de corolle; les mâles ont un calice à quatre pièces et quatre étamines; les fleurs femelles, placées au centre des bouquets de fleurs mâles, ont un calice qui est à cinq pièces et un ovaire à trois loges biovulées; le fruit est une capsule. Une variété naine du Buis est très employée dans les jardins pour faire des bordures.

\section{LES CISTACÉES}

Les $C$ istes sont des arbrisseaux de la région méditerranéenne; ils sont surtout communs en Espagne et affectionnent les collines sèches et ensoleillées. Leurs feuilles sont simples et opposées. Leurs fleurs, grandes et belles, sont régulières et formées d'un calice à cinq sépales persistants, d'une corolle à cinq pétales, de nombreuses étamines libres entre elles et d'un ovaire globuleux, comprenant de trois à cinq carpelles ouverts (puis fermés) et soudés bord à bord. La placentation est pariétale; le fruit est une capsule.

Ces plantes très mellifères sont cultivées pour la beauté de leurs

fleurs. Le Ciste de Crète et le Ciste ladanifère laissent exsuder abondamment une gomme-résine aromatique, le ladanum, utilisée en parfumerie. Les Hélianthèmes ressemblent beaucoup aux Cistes et ont deux sépales plus petits. Cette famille des Cistacées se rattache aux Malvacées, mais elle en diffère notamment par ses carpelles ouverts et sa placentation pariétale.

Bixacées. - Les Bixacées sont des arbres ou des arbustes des régions tropicales. Les feuilles sont alternes, entières ou dentées; les fleurs, régulières, hermaphrodites; certaines de ces plantes voisines sont polygames ou dioïques. Le plus souvent, chacune des enveloppes, calice ou corolle, est à cinq pièces libres ou partiellement soudées; les étamines sont nombreuses; le pistil comprend deux carpelles; le fruit est une capsule. Les Bixacées peuvent être considérées comme des Cistacées à feuilles alternes. Nous rapprocherons des Bixacées, qui ont les étamines libres et le nucelle persistant, les Flacourtiacées, souvent sans corolle, et les Papayées, quj ont les étamines concrescentes avec la corolle et le nucelle transitoire.

Le Rocouyer (Bixa orellana), type de la tribu des Bixées, est un arbuste répandu dans l'Amérique tropicale. Sa tige atteint 5 à 6 mètres de haut; ses feuilles sont grandes, luisantes; ses fleurs, larges, d'un rouge incarnat, se groupent en panicules terminales. Le fruit est une grosse capsule, qui se divise en deux loges renfermant de nombreuses graines dans une pulpe visqueuse, odorante et d'un rouge vif; on en retire une belle matière colorante, le rocou. Les Flacourtia, arbres ou arbustes épineux d'Asje et de Madagascar, sont à fleurs sans corolle et à fruit comestible.

Les Papayers, types des Papayées, sont originaires de l'Amérique tropicale; ils sont dioïques, à fleurs très petites. On en connaît une vingtaine d'espèces, dont certaines sont de grands arbres, comme le Papayer à sept feuilles (Carica heptaphylla). Le Papayer commun, répandu aujourd hui dans toutes les régions chaudes, a le port d'un Palmier; il peut atteindre 6 à 7 mètres. Sa tige, épaisse, charnue, non ramifiée, se couronne d'un bouquet de larges feuilles découpées, à long pétiole, et rappelant un peu celles de notre Figuier. Les pieds mâles ont des fleurs à cinq sépales, cinq pétales soudés (gamopétales) et dix étamines, avec un pistil rudimentaire; très odorantes, elles sont groupées en longues grappes. Chez les pieds femelles, les
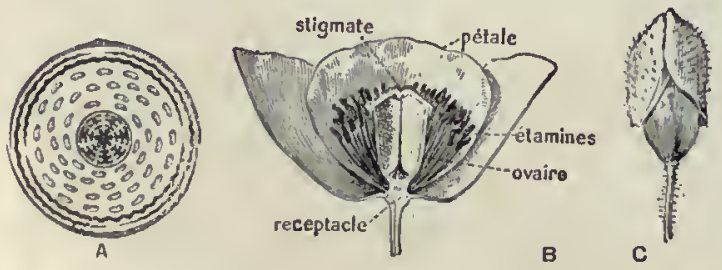

Fis. 237. - Coqueticot.

A, Dlagramme de la fleur, B, Coupe de la fleur; C, sépales. fleurs sont à cinq sépales, cinq pétales à tube court (dialypétales), et un ovaire libre à une loge. Il y a souvent, de plus, des étamines rudimentaires. Les fruits ou papayes, baies d'un jaune orange, ont une saveur sucrée agréable et pèsent jusqu à 6 kilogrammes dans certaines variétés; leur forme explique le nom vulgaire d'Arbre à melons donné au Papayer. Il renferme un latex âcre, riche en papaïne, ferment voisin de la pepsine du suc gastrique et pouvant, comme ce dernier, dissoudre les albuminoïdes; il coagule le lait ; on l'emploie en médecine pour faciliter la digestion.

Passifloracées. - Les Pas. sifloracées sont, pour la plupart, des arbustes grimpants de l'Amérique du Sud. Le genre Passiflore a des feuilles alternes, avec des vrilles latérales qui sont des tiges; dans les fleurs très grandes, les missionnaires espagnols ont voulu retrouver tous les instruments de la Passion. Le calice et la corolle sont ordinairement à cinq divisions; du fond de la fleur naît une couronne (d'épines) constituée par une ou deux rangées de filaments vivement colorés qui sont des appendices ligulaires; puis viennent cinq étamines soudées par leur base (en marteau); l'ovaire à une seule loge est surmonté de trois styles que terminent trois stigmates (en tête de clou); le fruit est charnu. Les Passifloracées ne diffèrent des Bixacées que par leur corolle munie d'une couronne et leurs étamines, au nombre de cinq.

Tamaricacées. - Les Tamaricacées ont des affinités avec les Droséracées, les Violacées et les Caryophyllacées (p. 185).

Les Tamarix sont des arbustes à très petites feuilles écailleuses isolées, à fleurs roses du type cinq; le fruit est une capsule. Le Tamarix à manne ou Turfah des Arabes du désert croît dans tout l'Orient et, sous l'action de la piqûre d'un insecte, laisse écouler de ses branches une substance visqueuse sucrée, qui est certainement la manne de la Bible.

$\mathrm{Au}$ Mexique vivent quelques espèces curieuses : les Fouquiera, arbustes épineux à fleurs rouges dressées en grappes, et l'Idria ou Cirio, qui est bien l'un des plus étranges représentants du monde végétal, avec sa tige charnue, dressée comme une colonne.

Papavéracées, Fumariacées. - Les Pavots sont les Papavéracées les plus connues. Notre espèce indigène est le Pavot coquelicot (Papaver Rhaas), à feuilles alternes très découpées. Ses fleurs, isolées et terminales, ont un calice à deux sépales (fig. 237); la corolle est à quatre pétales d'un rouge ponceau, caducs; les étamines sont nombreuses. L'ovaire libre, arrondi, à une loge, avec stigmate en disque, devient une capsule poricide. Le Coquelicot renferme un latex âcre, vénéneux, narcotique.

Le Pavot somnifère est une plante annuelle dont il existe deux variétés: celle à graines blanches, ou Pavot blanc, et celle à graines noires, ou Pavot noir. La première a une capsule ovoïde indéhiscente; on la cultive en Orient et en Extrême-Orient, pour en obtenir de l'opium; la seconde est plus petite et à fruits déhiscents. Par le nombre et la disposition des étamines, les Papavéracées ont des analogies avec les Renonculacées; certaines espèces, comme la Chélidoine, dont le fruit est une silique, se rapprochent des Crucifères.

La Chélidoine est une herbe indigène qui laisse écouler par incision un latex jaune, caustique, employé jadis pour brûler les verrues. La Glaucienne jaune ou Pavot cornu, des rivages maritimes, a des fleurs jaunes, puis de longues siliques arquées. La Sanguinaire du Canada renferme un latex rouge employé par les Indiens pour se tatouer.

Les Fumariacées sont voisines des Papavéracées, à deux étamines trifurquées extrorses et à fleurs irrégulières: tels sont les Fumeterres (Fumaria), les Corydales et le Dicentra, vulgairement Cocur de Jeannette, à cause de la forme de ses jolies fleurs roses pendantes. 


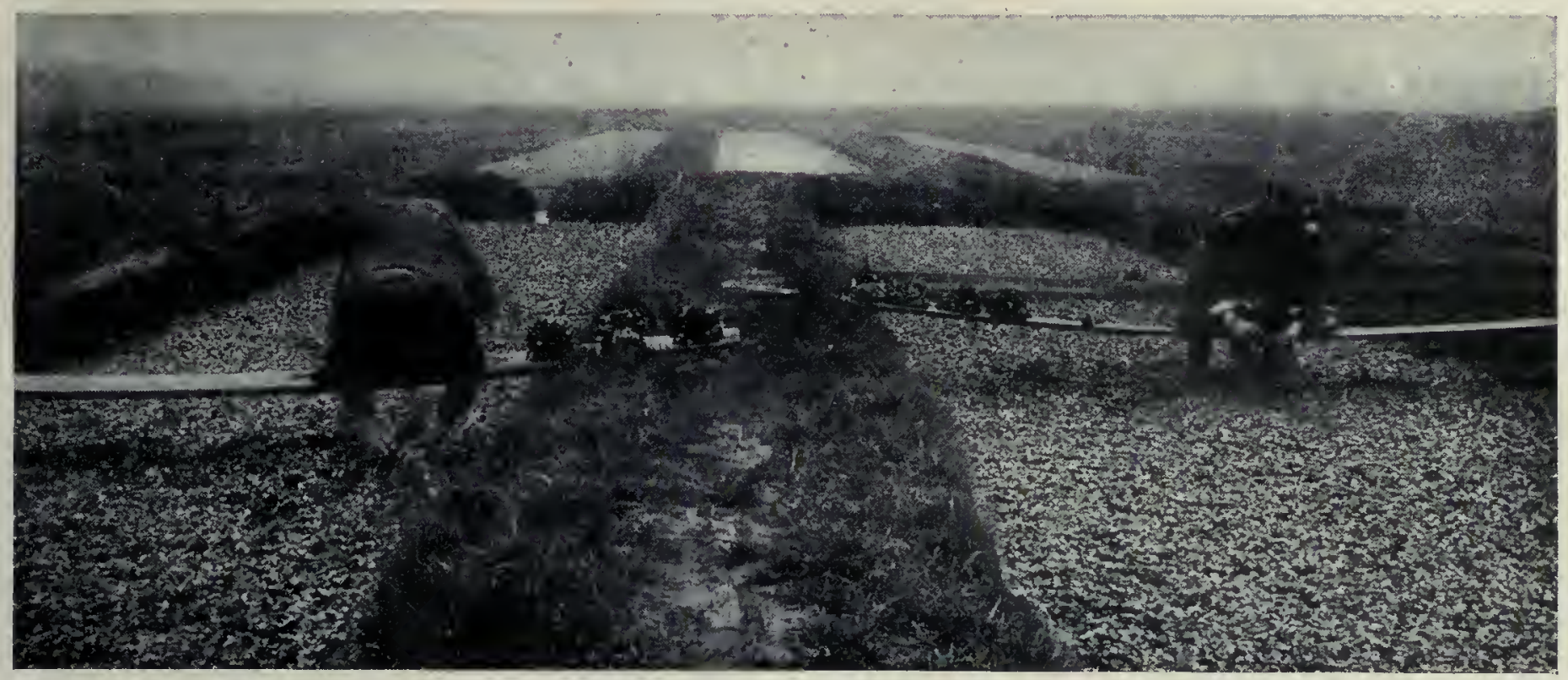

Récolte du Cresson et mise en bottes.

\section{LES CRUCIFÈRES}

Les Crucifères forment une famille nombreuse, mais très homogène. Herbes à racines pivotantes, à feuilles alternes, sans stipules, elles se rencontrent dans le monde entier. Pour connaître leur organisation, il nous suffira de décrire la Giroflée jaune (fig. 238), qui orne le sommet des vieux murs. C'est une herbe vivace dont les fleurs jaunes, d'odeur agréable, s'épanouissent au premier printemps. Groupées en grappes simples au sommet des rameaux, ces fleurs comprennent un calice à quatre sépales, une corolle à quatre pétales égaux et disposés en croix; six étamines, dont deux plus courtes; un ovaire libre, allongé, formé de deux carpelles ouverts soudés; le fruit est une silique, les graines formant quatre rangées, deux de chaque côté sur la fausse cloison médiane qui séparait le fruit en deux lages.

La forme du fruit a permis de diviser les Crucifères en deux groupes: celles à silique, c'est-à-dire à fruit beaucoup plus long que large ( $f i g .78, \mathrm{C})$, et celles à silicule, fruit presque aussi large que long.

Les Giroflées (Cheiranthus), qui appartiennent au premier groupe, sont les plus importantes des Crucifères ornementales; on cultive surtout la Girofée jaune, la Giroflée des jardins ou Giroflée d'hiver, puis les Matthioles ou Giroflées annuelles ou Quarantaines. La Cardamine des prés, amie des terrains frais, a des feuilles découpées et des fleurs d'un lilas clair. On la cultive dans les jardins, avec d'autres espèces voisines: Julienne, Malcomie ou Julienne de Mahon, Arabis alpin ou Corbeille d'argent.

On rencontre çà et là à l'état sauvage, sur les falaises du littoral, une grande plante bisannuelle à fleurs jaunes : c'est le Chou potager (Brassica). Cultivée dès la plus haute antiquité, cette plante a donné de nombreuses variétés d'une importance alimentaire considérable : Choux pommés, Choux de Bruxelles, Chouxfleurs, Choux verts non pommés, comme le Chou branchu, le Chou moellier, le Chou cavalier, etc. Citons encore le Chou-navet (B. napus) avec ses variétés: Navet, Colza, et Chou (B. rapa) Rutabaga, Navette. Le genre Chou fournit des plantes fourragères précieuses à la fin de l'hiver. Les graines de Colza et celles de la Navette sont oléagineuses; certaines variétés de Choux à feuilles frisées et panachées très élégantes servent à orner les pelouses.

Le fameux Pé-tsaï ou Chou de Chine (Brassica sinensis), qui joue un si grand rôle dans l'alimentation des Célestes, a l'aspect et la couleur claire d'une grosse romaine.

Le genre Moutarde (Sinapis), chez lequel la silique se prolonge par un bec plus ou moins développé, est voisin du genre Chou. Il comprend des herbes annuelles à fleurs jaunes. La Moutarde noire ou Sénevé contient dans des cellules distinctes une sorte de glucoside alcalin, le myronate de potassium, et un ferment, la myrosine, qui réagissent par broyage en présence de l'eau. La Moutarde blanche est une mauvaise herbe très envahissante. Les graines des Moutardes sont la base du condiment bien connu; réduites en farine, elles servent à préparer des sinapismes.
Le Radis sauvage ou Ravenelle (Raphanus), mauvaise herbe trop répandue, se distingue de toutes les autres Crucifères par sa silique cylindrique, étranglée et cloisonnée, divisée en articles à une seule graine (fig. 239); le Radis cultivé possède aussi une silique indéhiscente,' mais non divisée en articles.

Les Cressons (Nasturtium) aiment les lieux frais ou vivent dans leau; le plus connu est le Cressan de fontaine, à fleurs blanches, cultivé comme salade dans des fossés pleins d'eau. Les propriétés dépuratives et antiscorbutiques des Crucifères, déjà bien développées chez le Cresson, la Cardamine, la Passerage cultivée ou Cresson alénois, atteignent leur plus haut degré chez les Cochléaria.

Le fameux Chou de Kerguélen ou Pringlée antiscorbutique (fig. 110), cantonné sur cette terre australe, possède des propriétés antiscorbutiques marquées. La Rose de Jéricho (Anastatica hicrochuntica), dont nous avons signalé les mouvements hygroscopigues (p. 51), est une plante à fleurs blanches, haute d'environ 10 centimètres; elle croît dans les régions sablonneuses d'Orient.

Les Crucifères à silicule sont moins importantes que les précédentes. Les silicules ont des formes variées: globuleuses à deux articles, comme chez le Cakilier maritime; aplaties et ressemblant à une bourse, comme chez la Capselle baurse-á-pasteur; plates et d'un blanc d'argent, ainsi qu'on les admire chez la Lunaire annuelle ou Monnaie du pape; séparées, enfin, en deux parties semblables aux deux verres d'une paire de lunettes, comme chez les Lunetières (Biscutella).

Les Draves (Draba) sont de petites herbes dont beaucoup sont alpestres. Notre Drave printanière, commune sur les vieux murs, est remarquable par la précocité de sa floraison, qui a lieu dès la fin de janvier. Les Alyssons, les Thlaspi ou Tabourets, les Ibéris ont des applications ornementales, ainsi que l'Aubrietie deltoïde, aux jolies fleurs lilas. Le genre Cochlearia est représenté en France par deux espèces croissant au bord des rivières et sur les rivages de la mer : le Cochléaria officinal, plante bisannuelle à racine longue et mince, et le Cochléaria de Bretagne ou Cranson, Raifort sauvage, vivace et à très grosses racines charnues et rameuses. Le Crambé maritime ou Chou marin croit sur le littoral maritime du Nord et de l'Ouest; on cultive cette

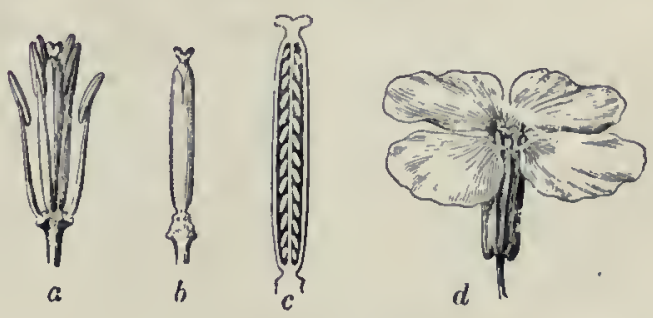

Fig. 238. - Fleur de Giroflée.

$a$, Androcée et pistil ; $b$, Pislil isole ; $c$, Coupe du pistil montrant les deux carpelles; $d$, Fleur entiére.

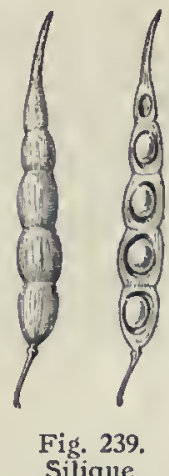

du Radisavec

coupe

du fruit. 
plante et on l'utilise comme lćgume. Terminons en citant la $\mathrm{Ca}$ méline, cultivée, dans le nord de la France, pour ses graines d’où l'on retire une huile industrielle, et le Pastel des teinturiers (Isatis), qu'on ne cultive plus aujourd'huj.

Capparidacées. Résédacées. - Les Capparidacées habitent la zone tropicale et les régions chaudes de la zone tempérée. Les fleurs ont un calice à quatre sépales, une corolleà quatre pétales, quatre ou six étamines libres ou un plus grand nombre; le pistil comprend, tantôt deux carpelles donnant pour fruit une silique, tantôt un plus grand nombre, et alors le fruit est une baie ou une drupe.

Le Câprier épineux (Capparis) est cultivé dans toute la région méditerranéenne. C’est un arbrisseau très rameux, à branches herbacées annuelles, sarmenteuses, à feuilles ovales, luisantes, présentant à leur base deux stipules épineuses en hameçon. De grandes fleurs blanches se succèdent pendant tout l'été; le bouton floral ou câpre est un condiment bien connu. L'ovaire est porté par un pied (gynophore).

Les Résédacées forment une petite famille d'herbes à feuilles alternes, découpées, se rattachant aux Capparidacées par leurs nombreuses étamines; d'autre part, la structure de leur pistil et leurs fleurs irrégulières les rapprochent des Violacées. Notre Réséda sauvage, herbe aux feuilles découpées, porte des grappes de fleurs petites, irrégulières, d'un jaune verdâtre et sans odeur : calice à six sépales, corolle à six pétales inégaux et très découpés, étamines nombreuses, ovaire libre à une loge devenant une capsule allongée; cette plante ressemble beaucoup au Réséda odorant d'Egypte, cultivé dans les jardins. Le Réséda jaunâtre ou Gaude peut atteindre la hauteur d'un homme; toutes ses parties renferment une matière colorante jaune; son calice ne porte que quatre sépales.

Violacées. - Les Violacées sont répandues par toute la terre; celles des contrées tempérées sont herbacées, celles de la zone tropicale sont ligneuses. Les feuilles sont simples et alternes: les fleurs, solitaires ou disposées en grappes, sont du type cing, avec trois carpelles ouverts; le fruit est une capsule. La plupart des Violacées renferment dans leurs parties souterraines une substance vomitive, analogue à l'émétine de l'Ipécacuanha.

La Violette odorante ( $V$ iola) fleurit dès février dans nos bois; elle est fort envahissante, se reproduit par ses graines et se multiplie abondamment par ses rejets. Ses fleurs violettes, parfois blanches, ont un calice à cinq sépales inégaux, une corolle à cinq pétales, dont l'inférieur, plus grand, est prolongé en éperon, cinq étamines à filet très court (deux à appendices); l'ovaire libre supporte un style tordu; le fruit est une capsule souvrant par trois valves qui projettent les graines. Dans les jardins, cette plante a donné de nombreuses variétés. La Violette tricolore ou Pensée sauvage est une herbe des champs à petites fleurs jaunes et violettes; la Pensée des jardins, aux grandes fleurs veloutées, en provient.

Droséracées. - Cette famille comprend seulement six genres d'herbes vivaces, à très petites racines, habitant les marécages. Leurs feuilles, réunies en une rosette radicale, sont des pièges à insectes couverts d'innombrables glandes sécrétant un liquide visqueux, acide, qui renferme de la pepsine, du moins chez cerlaines espèces. Les Droséracées sont, par excellence, les plantes carnivores (p. 68). Leurs fleurs, régulières et du type cinq, contiennent de cinq à vingt étamines et un ovaire libre ordinairement à une seule loge; le fruit est une capsule.

Les Drosera ou Rossolis, à cinq étamines extrorses, sont répandus sur presque toute la terre et principalement en Australie. Trois espèces sont indigènes en France; la plus connue est le Drosera à feuilles rondes, petite herbe à fleurs blanches insignifiantes. Les feuilles rougeâtres ont un long pétiole et un limbe arrondi couvert à sa face supérieure de poils glandulaires irritables. La Dionće attrape-mouche a été aussi décrite à propos des plantes carnivores. Le Drosophylle du Portugal, les Roridula de l'Afrique australe et les Byblis d'Australie ont également des poils glanduleux.

L'Aldrovandic à vessies est une plante flottante de l'Europe

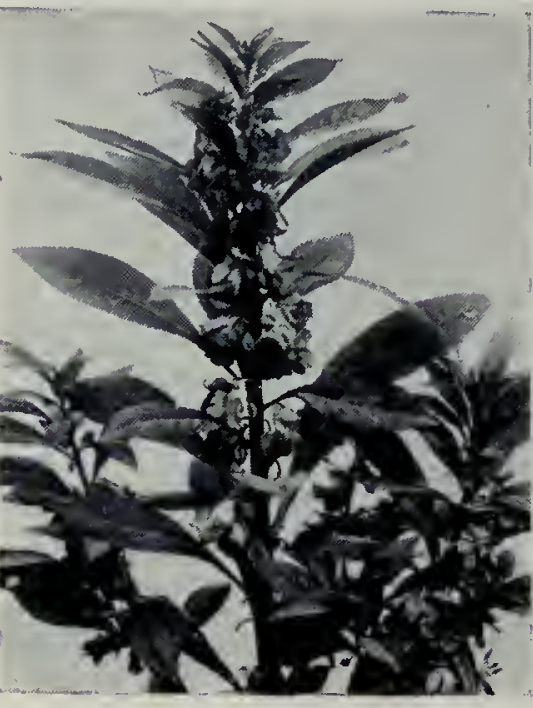

Balsamine des jardins. méridionale; ses feuilles, verticillées par six à huit, ont pour limbe deuxlobes arrondis rap. pelant les valves d'une coquille. Entre ces lobes, normalement un peu écartés, il pénètre parfois un petit animal aquatique; lorsqu il arrive en contact avec des poils irritables qui se dressent sur la tace interne, la charnière entre en action, les lobes se referment et l'emprisonnent. L'Aldrovan die absorbe les matières provenant de la décomposition des animaux capturés.

Les Droséracées ont des affinités avec les Violacées, mais leur fleur est régulière; on les rapproche aussi des Saxifragacées; mais, par leurs feuilles irritables, elles sont assez isolées dans la classification.

Sarracéniacées. Népenthacées. - Très différentes par la conformation de leur fleur, les Sarracéniacées doivent être rapprochées des Droséracées par leur mode de végétation; cependant elles ont une placentation axile, tandis que la placentation est pariétale chez les Droséracées. Ce sont des herbes vivaces des lieux marécageux; on n'en connaît que trois genres: Heliamphoro de la Guyane britannique, Sarracenia et Darlingtonia de l'Amérique du Nord (p. 69). Ces plantes sont remarquables par la conformation de leurs feuilles qui, disposées en rosette partant d'un rhizome, sont souvent considérées sans preuves comme des pièges à insectes. Les fleurs régulières ont cinq sépales, cing pétales, de nombreuses étamines, un ovaire globuleux à cinq loges.

Les Népenthacées, formées par le seul genre Nepenthes, des régions tropicales, se distinguent des Sarracéniacées parce qu elles sont dépourvues de corolle; leurs fleurs sont petites, dioïques, régulières. Les feuilles sont des ascidies, c'est-à-dire qu'elles ont la forme de vases. La face interne excrète un liquide considéré par certains auteurs à tort comme digestif; ce sont des réservoirs d'eau.

\section{LES GÉRANIACÉES}

Les Géraniacées ressemblent aux Malvacées par leurs feuilles alternes, leurs fleurs complètes du type cinq et ordinairement régulières, leurs larges pétales, leur ovaire libre à placentation axile et à cinq carpelles, mais leurs étamines sont beaucoup moins nombreuses; leur nombre normal est de dix, groupées en deux verticilles alternes. Chez quelques genres, il se produit un avortement, chez d'autres un dédoublement de plusieurs étamines; le fruit est presque toujours une capsule. Herbacées pour la plupart, ces plantes habitent les régions tempérées et subtropicales, et abondent dans l'Afrique australe. On les a divisées en quatre groupes ou familles secondaires :

Pas d'albumen. $\left\{\begin{array}{l}\text { Capsule . . . . . . . . . . Géraniées. } \\ \text { Trois akènes, } 8 \text { élamines. . . . . Tropéalées. }\end{array}\right.$

Albumen.... Fleur régulière, 10 élamincs ...... Oxalidées.

Pas d'albumen. . Fleur irrégulière, 5 étamines. . . . . . Balsaminées.

Les Géranicées sont caractérisées par leur capsule que prolonge le long bec des cinq styles soudés. A la maturité, chacun des anciens styles se détache de l'axe commun, entraîne la surface de son carpelle et lance au loin les semences (p. 5l).

Beaucoup de Géranium et d'Érodium sont indigènes en France; 
les plus répandus sont le Géranium herbe à Robert, à feuilles découpées et à fleurs roses, comme l'Erodium à feuilles de Ciguë des champs incultes. Plusieurs espèces sont cultivées dans les jardins; mais, sous le nom de Géranium, on désigne surtout communćment les Pélargonium, plantes ornementales de première importance dont la fleur est un peu irrégulière; le sépale postérieur se prolonge en un éperon soudé avec le pédicelle de la fleur à sept

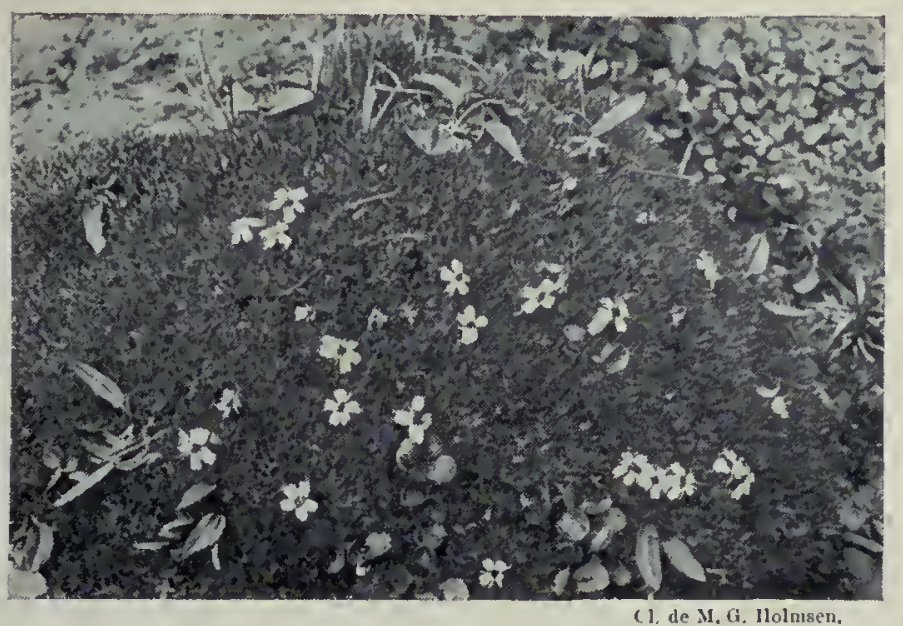

Touffe de Silène acaule (Spitzberǵ).

étamines. On cultive le Pélargonium à feuilles zonées du Cap, aux feuilles marquées vers le milieu d'une zone d'un vert noirâtre, et le Pelargonium inquinans; de leur croisement sont nées d'innombrables variétés. Les Pélargonium à grandes fleurs sont moins rustiques. Il faut signaler encore le Pélargonium à feuilles de Lierre, aux tiges retombantes, et le Pélargonium rosat, dont les feuilles molles et velues dégagent, quand on les froisse, une agréable odeur de rose et donnent une essence de rose de qualité inférieure.

Chez les Tropéolées, le sépale postérieur se prolonge en un éperon libre, et non soudé comme chez les Pélargonium; il n’y a que trois carpelles, non prolongés par un bec, et le fruit est un triple akène. 'Le genre le plus marquant est la Capucine (Tropaolum) dont les espèces, toutes américaines, ont des feuilles peltées, des fleurs grandes, d'un rouge orangé, et huit étamines. Il n'est pas de plante plus populaire que la Capucine grande; elle grimpe à l'aide du pétiole enroulable de ses feuilles; la Capucine tubéreuse possède un rhizome renflé, comestible. Malgré ses fleurs régulières, on peut ranger, près des Tropéolées et des Méliacées, la Corroyère à feuilles de Myrte ou Redoul, arbrisseau de l'Europe méridionale à feuilles riches en alcaloïde (Coriacées).

L'Oxalis petite oscille ou Surelle, Trèfle aigre, type des Oxalidées, habite les bois humides. Ses feuilles sont à trois folioles articulées, se pliant chacune par le milieu à l'obscurité (position de sommeil); leur saveur est acidulée, rafraîchissante. Les fleurs, régulières et isolées, ont cing pétales blancs ou rosés et dix étamines aux filets soudés par leur base; le fruit est une capsule à cinq loges. L'Oxalis crénelée ou Oca, du Pérou, possède un rhizome renflé en tubercules. Les Caramboliers ou Averrhoa, petits arbres de l'Inde, ont pour fruits des baies comestibles.

La Balsamine sauvage ou Impatiente ne-me-touchez-pas, type des Balsaminées, est une herbe annuelle à fleurs jaunes tachées de rouge que l'on rencontre çà et là dans les bois. Son calice n'a que trois sépales, dont le postérieur se prolonge en éperon; il y a cinq pétales, cinq étamines et un ovaire libre à cinq loges. Dès qu'on touche à une capsule mûre de Balsamine, elle se partage brusquement en cinq valves qui se tordent sur elles-mêmes en projetant leurs graines; on cultive la Balsamine des jardins ou lmpatiente Balsamine, originaire des Indes.

Linacées. - En juin, les campagnes du nord de la France sont égayées par les linières, couvertes de mignonnes fleurs d'un bleu pâle. Herbe annuelle à tige grêle, flexible, le $L$ in usuel a des feuilles alternes, étroites, entières; ses fleurs régulières sont formées de cinq sépales, de cinq pétales, de dix étamines alternativement stériles et fertiles, à filets soudés à la base, enfin d'un ovaire globuleux, libre, à cing, puis dix loges par l'apparition d'une fausse cloison. Les Linacées sont des Géraniacées à feuilles entières. L importance de la filasse de Lin est grande; celle de la graine n'est pas moindre.
L'Erythroxylon coca ou Cocaier, qu'on range souvent dans une famille spéciale, diffère du Lin par ses dix étamines fertiles et par son fruit qui est une drupe. C'est un arbrisseau de I à 3 mètres qui abonde dans les Andes; ses feuilles alternes sont molles, caduques et luisantes. Les Incas l'avaient divinisé, se servaient de ses feuilles en guise de monnaie et en faisaient grand usage comme masticatoire permettant de résister à la fatigue et au jeûne.

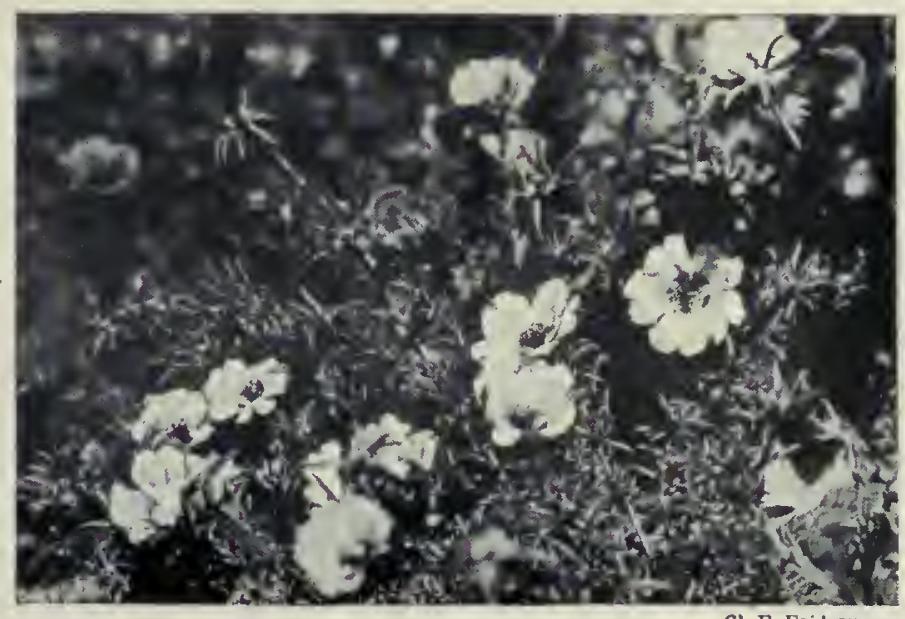

Pourpier à grandes fleurs.

Zygophyllacées. - Plantes des pays chauds, voisines des Géraniacées par leur structure florale, les Zygophyllacées se relient intimement à l'une des familles suivantes, celle des Rutacées, par leurs feuilles opposées composées pennées, stipulées, et par la présence d'un disque nectarifère sur le réceptacle. Les plus intéressantes sont les Gaïacs et la Zygophylle fabagelle ou Faux Câprier de Syrie, dont les boutons floraux servent de condiment.

Le Gäac officinal, des Antilles, peut atteindre 18 mètres de haut; son bois, dur et pesant, est recherché par les tourneurs.

Caryophyllacées, Portulacées. - L'Eillet des fleuristes croít à l'état sauvage sur les vieux murs du midi de la France. Vivace, à souche presque ligneuse ramifiée dès la base, ses feuilles sont opposées et ses tiges fortement renflées aux nœuds. La fleur, régulière et complète, a son calice formé de cing sépales soudés, doublés par deux paires d'écailles formant calicule; la corolle est à cinq pétales rouges à onglets, étalés en roue; l'androcée comprend dix étamines; l'ovaire est libre, à deux carpelles clos et deux styles; le fruit est une capsule à une loge à la fin ( $f i g .77, \mathrm{~B})$.

L'Eillet est le type de la famille des Caryophyllacées qui, par ses dix étamines en double verticille, se rapproche des Géraniacées, mais présente des caractères spéciaux, notamment les feuilles opposées et les cloisons de l'ovaire fugaces. On la divise en deux tribus : les Silénées, dont le calice est à sépales soudés; les sépales sont libres, au contraire, chez les Alsinées.

Aux Silénées appartiennent les Eillets, les Silènes, les Gypsophiles, les Lychnis, les Saponaires. L'Eillet des fleuristes (Dianthus caryophyllus) a fourni plus de 2000 variétés simples ou doubles, remontantes ou à floraison unique. La petite taille de l'Eillet mignardise ( $D$. plumarius) le fait surtout employer comme bordure; l'CEillet de poète ou CEillet barbu a des fleurs petites, de nuances vives, groupées en un large corymbe. Les Gypsophiles, à deux styles et sans calicule, sont remarquables par le nombre immense de leurs menues fleurs blanches. La Saponaire officinale, également à deux styles et sans calicule, est à grandes fleurs odorantes et d'un rose pâle. Les Silènes ont de jolies fleurs roses ou blanches; l'ovaire est à trois carpelles avec trois styles. Plusieurs espèces de Lychnis sont indigènes; l'une des plus répandues est la Nielle des blés (L. Githago).

Dans la tribu des Alsinées, citons les Arenaria ou Sablines, les Céraistes, la Stellaire intermédiaire ou Mouron des oiseaux.

Les Portulacées sont voisines des Caryophyllacées à feuilles charnues entières, pourvues de fleurs à deux sépales, cinq pétales et d'étamines (trois, cinq, dix et plus); l'ovaire est libre (parfois infère). Le Pourpier cultivé (Portulaca oleracea) a des fleurs jaunes; ses feuilles épaisses font une excellente salade; le Pourpier à grandes fleurs, transplanté du Brésil, orne nos jardins et les ćgaie de ses larges fleurs de couleurs varićes. 


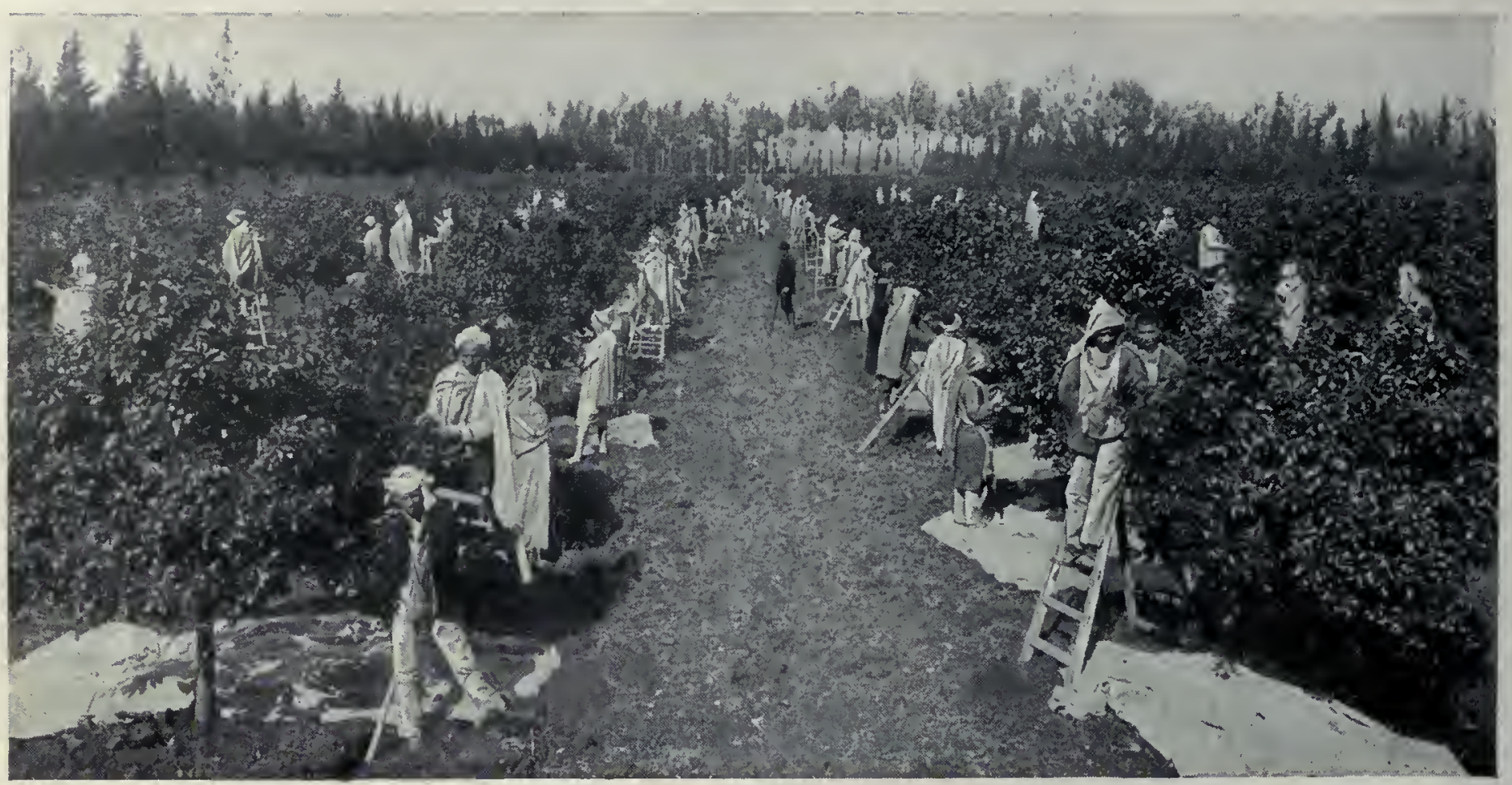

Cueillette des fleurs d'Oranger, en Algérie.

\section{LES RUTACÉES}

La Rue fétide est une herbe vivace, commune dans le midi de la France, sur les coteaux secs et pierreux. Ses tiges ramifiées partent d'une souche ligneuse, portent des feuilles alternes très découpées, puis des corymbes de fleurs jaunes régulières; celles-ci comprennent, sur une même inflorescence, quatre ou cinq sépales, autant de pétales, huit à dix étamines insérées en deux verticilles sur un disque glanduleux entourant la base du pistil; au moment de la fécondation, elles s'animent de mouvements curieux et viennent déposer elles-mêmes leur pollen sur le stigmate. L'ovaire est formé de quatre à cinq carpelles libres entre eux, sauf à la base, avec style court et stigmate lobé; le fruit est une capsule à quatre ou cinq loges. Toutes les parties de la Rue renferment de petites glandes remplies d'une huile essentielle à odeur forte et désagréable. Ses propriétés excitantes, astringentes et emménagogues, sont connues depuis la plus haute antiquité. C'est d'ailleurs une plante dangereuse dont l'emploi nécessite la plus grande prudence.

La Rue (fig. 240) a été prise pour type de la grande famille des Rutacées, qui comprend des plantes ligneuses pour la plupart et propres aux régions chaudes et tempérées. Elles sont glanduleuses; leurs feuilles sont alternes, rarement opposées; leurs fleurs, presque toujours hermaphrodites et du type cinq, ont un disque nectarifère; le fruit est une capsule ou une baie, parfois une samare ou une drupe. Elles se relient intimement, d'une part aux Géraniacées, d'autre part aux familles suivantes des Anacardiacées, des Simarubacées et des Méliacées. Nous les diviserons en trois tribus: les Rutées, les Zanthoxylées et les Aurantiées.

Les Rutées ont les carpelles libres ou à peine concrescents; leur fruit est une capsule. Elles comprennent, outre la Rue, la Fraxinelle ou Dictamne blanc, du midi de la France. Ses larges feuilles rappellent celles du Frêne; ses fleurs, blanches ou rosées, grandes, forment une longue grappe terminale; toutes ses parties renferment une essence volatile inflammable dont l'odeur agréable évoque celle du citron. On peut rapprocher des Rutées les Diosmées du Cap et les Boroniées d'Aus-

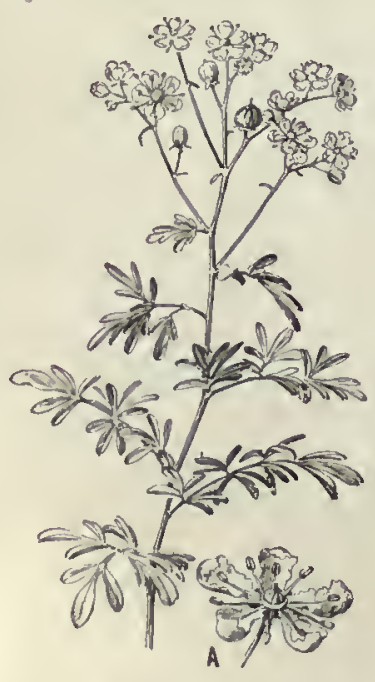

Fig. 240. - Rue. $a$, Fleur. tralie, plantes aromatiques à port de Bruyères, que l'on cultive dans les jardins.

Parmi les Zanthoxylées, que leurs fleurs polygames dioïques, à carpelles à deux ovules, distinguent des Rutées, citons le Pilocarpe à feuilles pennées ou Jaborandi, arbuste du Brésil, dont les feuilles et l'écorce contiennent un alcaloïde, la pilocarpine, qui excite d'une façon extraordinaire les sécrétions. Les Zanthoxylum ou Clavaliers ont aussi quelques applications : les fruits du Clavalier poivrier fournissent le poivre du Japon; le Clavalier frêne des États-Unis est l'Arbre au mal de dents des Américains; son écorce mâchée est réputée odontalgique. Le Ptelée trifolié de l'Amérique du Nord est un arbuste cultivé dans les parcs.

Les Aurantices ou Hespéridées sont, de toutes les Rutacées, les plus importantes et les plus connues. Elles se distinguent des deux tribus précédentes par leurs fruits et la concrescence de leur carpelles. Ce sont des espèces du seul genre citronnier.

L'Oranger doux (Citrus Aurantium) ou Oranger commun peut atteindre jusqu'à 12 mètres de hauteur. La tige, armée de fortes épines dans les variétés sauvages, porte des feuilles alternes; elles sont pourvues de poches glandulaires. Le pétiole, articulé avec le limbe et pouvant s'en séparer nettement, est bordé dé deux lames vertes comme deux ailes. Cette disposition fait considérer la feuille d'Oranger comme une feuille composée, unifoliolée, dont les folioles latérales ne se sont pas développées. Les fleurs, par petits groupes, apparaissent de mars en octobre, mais une seconde floraison, plus faible, a lieu en automne. Chaque fleur comprend un calice formé de cinq à sept sépales soudés, une corolle à cinq pétales (parfois quatre, six, sept ou huit) épais, d'un blanc pur et d'une odeur suave, puis vingt à trente étamines, à larges filets groupés par la base en faisceaux de quatre à six; enfin un ovaire globuleux. L'ovaire se transforme en un fruit d'abord vert et très amer, puis d'un jaune d'or, el à la fois sucré et acidulé; c'est une sorte de baie entourée d'un péricarpe on zeste très riche en glandes à essence. Au-dessous sont sept à douze quartiers, dont chacun représente un carpelle à poils charnus remplissant la cavité (fig. 67).

Le Bigaradier ou Oranger amer (variété amara) est un peu plus petit; ses feuilles sont à pétiole plus largement ailé; ses fleurs, plus grandes et plus parfumées. Très rustique, il se cultive dans les orangerjes du Nord; les fameux orangers de Versailles, plusieurs fois centenaires, sont des Bigaradiers. Le Bergamotier (var. Bergamia) est un arbre assez élevé, dont les fruits non comestibles sont ordinairement piriformes; le zeste fournit l'essence de bergamote. L'Oranger Kumquat (var. Suntara) a des fruits un peu ovoïdes, de la grosseur d'une belle cerise et qui se mangent entiers, tant la peau en est fine, sous le nom de chinois ou de bigarade 
chinoise. Le Pamplemousse ou Schaddock (var. sinensis ou decu mana) est surtout un arbre d'ornement; à ses fleurs blanches succèdent de gros fruits globuleux à saveur douce et fade. Citons aussi la variété Keonla ou fausse mandarine. Le Mandarinier(Citrus nobilis), originaire de Chine, est un arbrisseau dont les petits fruits à zeste mince sont doux et d'un goût très fin.

Le Limonier, dit aussi Citronnier ( $C$. medica), dépasse rarement 5 à 6 mètres de hauteur; c'est un arbrisseau épineux, surtout à l"état sauvage; ses feuilles à pétiole non ailé, ses fleurs grandes, blanches à l'intérieur et d'un rose violacé en dehors, son fruit jaune pâle, ovoïde, terminé par un mamelon, le distinguent aisément de l'Oranger. Le citron est un fruit très parfumé, mais toujours acide, servant de condiment. Il a des propriétés antiscorbutiques.

Le Cédratier (var. Bajoura) se rapproche beaucoup du Limonier. Son fruit ou cédrat, beaucoup plus gros que le citron, à zeste très rugueux, irrégulièrement bosselé, est très recherché par les confiseurs et les parfumeurs. Les bais de toutes les espèces du genre $\mathrm{Ci}_{\mathrm{i}}$ tronnier sont très denses, jaunes et veinés; on les emploie surtout en ébénisterie et en tabletterie.

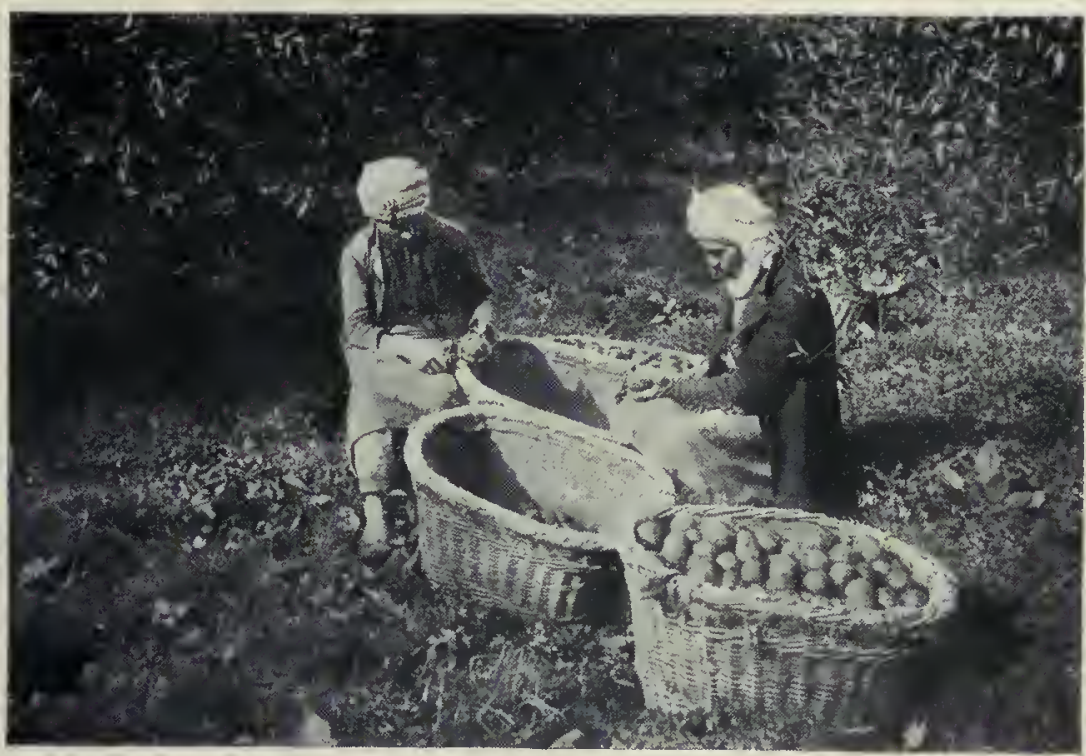

Anacardiacées, Burséracées. - Cultivé

Épluchage et triage des oranges.

dans nos parcs, le Sumac fustet (Rhus cotinus) est

un arbuste touffu, rameux, à feuilles simples, aux fleurs petites et verdâtres aux pièces par cinq, avec un ovaire réduit à un seul carpelle uniovulé, surmonté de trois styles. Parmi ces fleurs, quelques-unes sont hermaphrodites et donnent de petites drupes luisantes et brunes, portées à l'extrémité de longs pédicelles lisses; mais la plupart des fleurs sont mâles et tombent peu après la floraison; leurs minces pédicelles sallongent, se couvrent de poils rouges ou rosés qui les rendent plumeux et forment par leur groupement des houppes délicates dont on fait des bouquets et qui ont valu au Fustet le nom d'Arbre à perruque.

On connaît plus de cent espèces de Sumacs; toutes vivent dans des régions chaudes, en dehors des tropiques; ce sont des arbres ou des arbustes riches en tanin, à suc âcre, plus ou moins vénéneux et irritant la peau. Les feuilles du Sumac des Corroyeurs de la région méditerranéenne servent pour le tannage des peaux; une autre espèce donne du vinaigre (Vinaigrier). Le suc laiteux de certaines espèces d'Extrême-Orient renferme une oxydase, la laccase, et sert à la fabrication des fameuses laques de Chine et du Japon. Le latex du Sumac faux vernis ( $R$. succedanea, var. Dumortieri), du Japon et de l'Indochine, donne aussi une bonne laque; ses graines contiennent une matière grasse. L'emploi ornemental des Sumacs est considérable. Le Melanorrhaa laccitère fournit la laque du Cambodge.

Les Sumacs forment le genre le plus important de la famille des Anacardiacées ou Térébinthacées, qui comprend des plantes ligneuses à suc plus ou moins caustique, riche en produits balsamiques. Les feuilles sont alternes, simples ou composées pennées, sans stipules; les fleurs, petites, régulières, sont hermaphrodites ou polygames, avec un calice, une corolle et un nombre ordinairement double d'étamines; l'ovaire libre, avec une à cinq loges uniovulées, se transforme en une drupe.

Les principaux genres sont, outre les $\mathrm{Su}$ macs, les Pistachiers, les Manguiers, les Anacardiers, les Schinus et les Spondias.

Les Pistachiers sont des arbres résineux, à feuilles composées, à petites fleurs dioïques et sans corolle, groupées en grappes axillaires; les fleurs mâles ont cinq étamines, les fleurs femelles un ovaire devenant une drupe à peine charnue. Le Pistachier vrai est cultivé dans la région méditerranéenne pour son fruit de la grosseur d'une olive, et dont la chair, très mince, s'ouvre en deux valves à sa maturité, laissant paraître la graine, ou pistache, d'un vert clair; elle se mange crue ou sert en pâtisserie. Chez le Pistachicr lentisque, les feuilles sont persistantes et non caduques, comme celles du précédent; son fruit est petit et noir ;

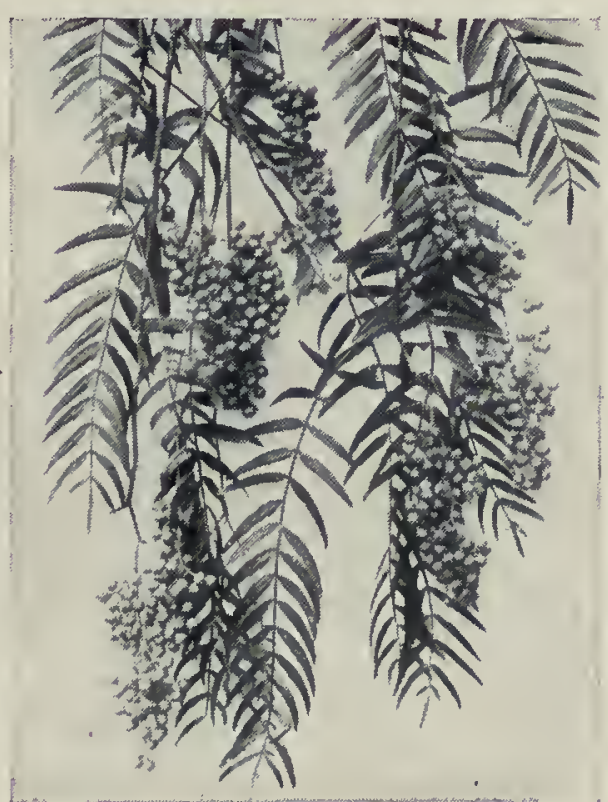

Schinus faux Poivrier en fruits. on le cultive en Orient pour une substance résineuse ou mastic, qui s'écoule d'incisions pratiquées sur son tronc, et qui est un masticatoire employé par les femmes en Grèce et en Turquie. Le Pistachier térébinthe est un arbre assez élevé, à feuilles caduques, et portant de petites drupes rouges, puis brunes. Par les fissures naturelles de son écorce, en été, ou par des incisions nombreuses pratiquées au printemps, s'écoule un liquide résineux, la térébenthine de Chio, qu'on utilise en la mélangeant à la térébenthine de Venise, extraite du Mélèze.

Les Manguiers (Mangifera), spontanés dans l'Asie tropicale, ont des feuilles simples; le Manguier de l'Inde ou Mango est cultivé en Asie et dans toute l'Amérique tropicale. C'est un grand et bel arbre à feuilles lancéolées, à fleurs blanc rosé; son fruit ou mangue est une grosse drupe oblongue, de la couleur d'un abricot, à chair à la fois succulente et filandreuse (Voir PLANCHE EN COULEURS).

Des arbres de l'Amérique tropicale, les Anacardiers, présentent une particularité curieuse : leur fruit, sorte de noix en forme de rein, est porté par un énorme pédoncule charnu, jaune ou rouge, de la forme et de la grosseur d'une poire moyenne. On cultive surtout l' $A$ nacardier occidental, appelé aussi Acajou à pommes, bien qu'il n'ait rien de commun avec les arbres fournissant le bois d'acajou. Le fruit, ou noix d'acajou, est un akène à péricarpe coriace, creusé d'alvéoles renfermant un suc caustique; la graine est blanche, oléagineuse, comestible; la masse charnue située au-dessus, ou pornme d'acajou, est juteuse, sucrée, acidulée; elle se mange fraîche ou en confiture.

Le Schinus faux Poivrier, dit encore Poivrier d'Amérique, est un arbre fort décoratif, avec ses rameaux pendants, toujours garnis de longues feuilles à étroites folioles pennées; en été, il se pare de jolies grappes de fleurs blanches, et durant tout l'hiver de petites drupes globuleuses d'un rose passant au rouge corail. Originaire de l'Amérique centrale, il est naturalisé sur le littoral méditerranéen; son fruit, sous un noyau dur, renferme une graine d'odeur poivrée.

Les Spondias, ou Monbins, Pruniers mirobolans, sont des arbres fruitiers à feuilles composées pennées, à fleurs polygames petites et nombreuses, dont les pièces sont par quatre et cing, avec un nombre double pour les étamines; les fruits du Spondias doux, de Tahiti, ou pommes de Cythère, sont les plus estimés.

Les Burséracées diffèrent des Anacardiacées par leurs carpelles biovulés; elles sont surtout remarquables par leurs produits gommo-résineux. Les Boswellia sont de petits arbres du pays des Somalis et de I'Arabic, à feuilles minces caduques comme celles de nos Bouleaux. L'encens véritable 


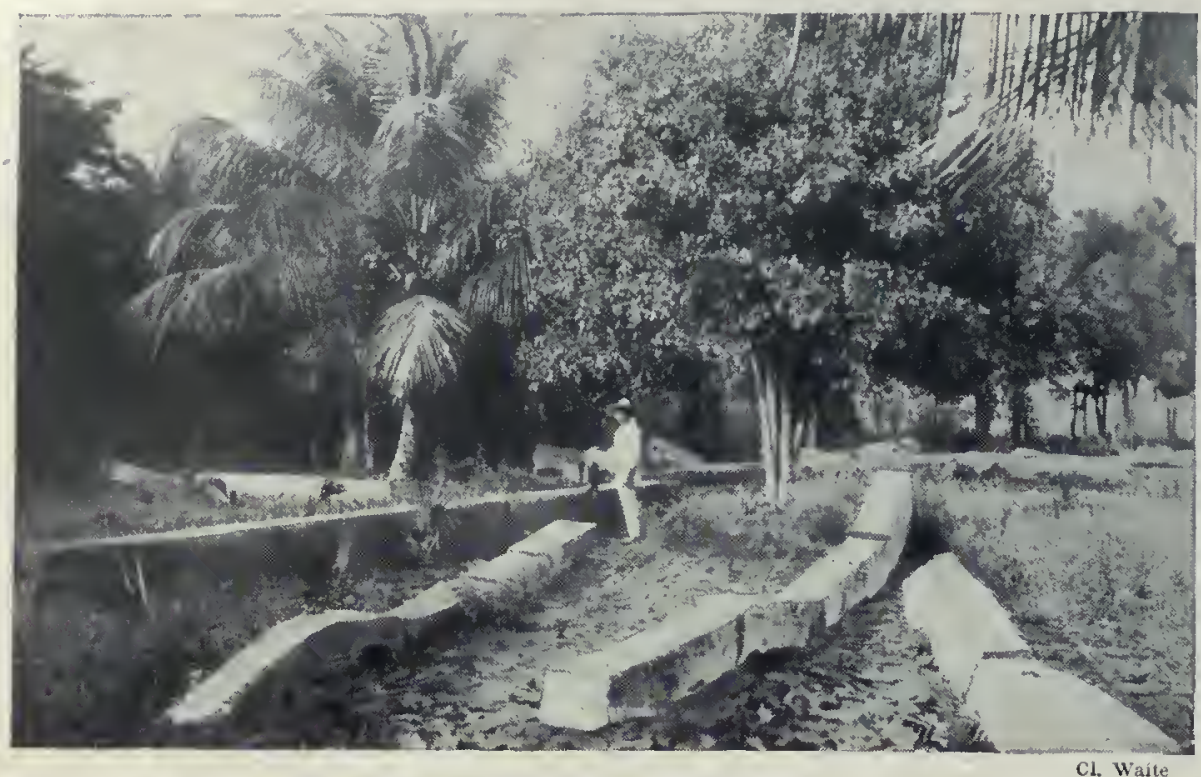

Bois d'Acajou prèt à ètre expédié (Mexique).
Sapindacées. - De tous les arbres de nos parcs, le Marronnier d'Inde (Asculus Hippocastanum) est peut-être le plus beau quand, en mai, sur son épais feuillage, se détachent les panicules dressées de ses fleurs blanches. Son profil régulier, la symétrie de ses feuilles opposées, dont le long pétiole se termine par cing à sept folioles gracieusement incurvées, la beauté de ses inflorescences et leur disposition à l'extrémité des rameaux, tout contribue à lui donner un aspect robuste et majestueux. Le nom qu'il porte est usurpé; l'Inde n'est pas sa patrie; il est originaire de la région montagneuse de la Thessalie et de l'Épire, donc européen.

Chaque fleur présente un calice, une corolle à cinq pétales inégaux, blancs avec taches pourprées, sept étamines à filets arqués, insérés à l'intéricur d'un disque annulaire. Lovaire est libre, à trois loges biovulées. Le fruit est une capsule verte à péricarpe coriace épineux; elle renferme de une à trois grosses graines ou marrons d'Inde, au tégument luisant, de couleur acajou. Les Pavia, plantes ligneuses de l'Amérique du Nord, sont des Marronniers pourvus d'étamines à filets dressés,

ou oliban (oleum Libani) est fourni par le Boswellia Carteri. La myrrhe est produite par des arbres de la même famille poussant dans les mêmes régions (Commiphora abyssinica et Schimperi).

Les Bursera sont américains; ils produisent des oléo-résines odorantes; le Bursera porte-gomme ou Gommart fournit la 'gomme chibou ou élémi des Antilles; plusieurs espèces du Mexique, connues sous les noms de bois de rose femelle, ont un bois parfumé d'où l'on retire par distillation l'essence de linaloé ( $B$. Delpechiana, etc.), qui est de qualité supérieure, richesse de la Guyane.

Simarubacées. - L'Ailante glanduleux, improprement nomimé Vernis du Japon, a été introduit en Europe en 1750. Ses feuilles alternes, composées, sont fort jolies. En juin apparaissent les fleurs, petites et verdâtres, groupées en panicules dressées et d'odeur désagréable. Certains Ailantes ne portent que des fleurs mâles, d'autres que des fleurs femelles ou hermaphrodites; les pièces en sont disposées par cinq; il y a dix étamines chez les fleurs mâles et deux ou trois seulement parfois chez les fleurs hermaphrodites; le pistil comprend de deux à cinq carpelles; le fruit, ailé et sec, est formé de cinq samares.

Les Ailantes sont les seules Simarubacées des pays tempérés; les autres appartiennent aux régions chaudes et tropicales. On trouve dans le bois et dans l'écorce de divers types une matière amère et fébrifuge, la quassine, par exemple dans la Quassia amèrc et la Picrénic élcućc. Les Simaruba de l'Amérique tropicale sont employés comme fébrifuges, toniques et apéritifs. L'Irvingic du Gabon ou Oba, voisin, fournit un fruit jaune, gros comme un ouf de cygne; on retire de sa graine le beurre de $O^{\prime}$ dika, comestible, rappelant le beurre de cacao.

Méliacées. - Les Méliacées ne diffèrent des Rutacées que par l'absence de ponctuations glanduleuses et de canaux sécréteurs et la soudure des étamines par leurs filets en un tube épais. Ce sont des arbres ou des arbustes des régions chaudes.

Le Mélier azedarach ou Margousier, Lilas de l'Inde, Patenôtre, aujourd'hui commun en Provence, est un petit arbre à feuilles composées pennées; il porte des grappes de fleurs violettes à odeur de lilas; le fruit est une drupe jaunâtre, grosse comme une cerise et dont le noyau, à cing côtes saillantes, sert à faire des chapelets. Plusieurs Méliacées donnent de beaux bois d'ébénisterie. Le Chloroxylon swie tina fournit le bois satiné de l'Inde; le Flindersia ambainensis des îles Moluques donne le bois d'Amboine, le plus cher de tous les bois. L'acajou provient du Swictina mahogani, grand arbre des Antilles, et de plusieurs arbres voisins d'Amérique et d'Afrique.

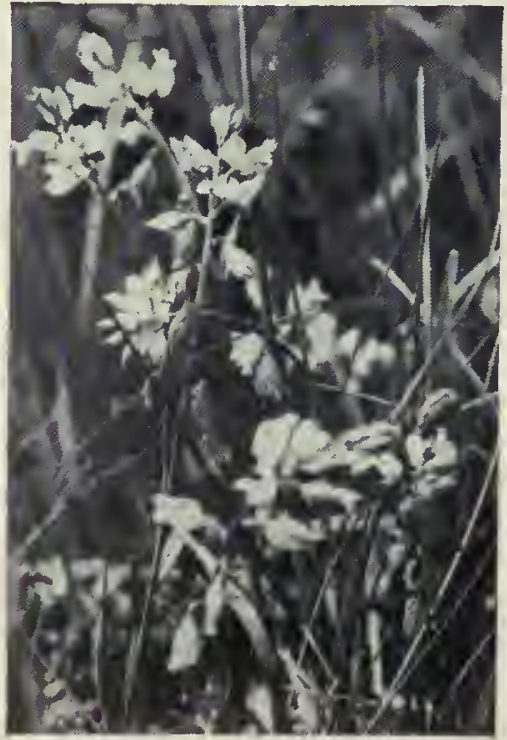

Potygale communu. et non arqués, et de fruits non épineux.

Dans les Savonniers (Sapindus) des régions tropicales, les feuilles sont alternes, ordinairement composées ; les fleurs régulières, en grappes, avec quatre à cinq sépales, autant de pétales, huit à dix étamines et un ovaire à trois loges devenant trois drupes. Le Savonnier saponaire, des Antilles, porte des fruits semblables à de grosses cerises amères; sa racine et ses fruits surtout sont imprégnés de saponine; on écrase les fruits et on fait bouillir la pulpe pour le dégraissage des étoffes.

Les Li-tchi (Nephelium), petits arbres fruitiers de l'Inde et de la Chine, cultivés aujourd'hui dans toutes les régions chaudes, ont des feuilles alternes composées paripennées, des fleurs petites, régulières, sans corolle, à deux carpelles dont un seul se développe pour donner un fruit gros comme une prune; il renferme une seule graine, de la grosseur d'une fève, entourée par un arille comestible, charnu et très épais, de saveur délicieuse (Voir PLANCHE EN COULEURS).

Marronnier d'Inde, Savonnier et Li-tchi ont été groupés dans la grande famille des Sapindacées, caractérisée par la présence constante d'un disque floral arrondi. Les fleurs, régulières ou irrégulières, en grappes, ont un calice et une corolle à cing pièces ou quatre parfois, dix étamines en deux verticilles alternes et dont le nombre peut se réduire par avortement, enfin un ovaire libre ordinairement à trois carpelles; le fruit est variable. Les Sapindacées se relient surtont aux Anacardiacées; elles en diffèrent par l'absence de canaux sćcréteurs, leurs fleurs souvent irrégulières et la position divise en trois tribus:

( 3 carpelles à 1 ovule;

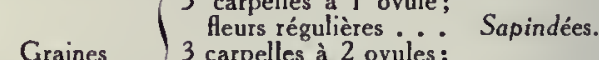
Graines
sans albumen. $\begin{gathered}3 \text { carpelles à } 2 \text { ovules; } \\ \text { fleurs irrégulières. }\end{gathered}$ 2 carpelles; fleurs régu-

Graines Fleurs régulières; feuil-

à albumen. $\quad \begin{array}{r}\text { les opposées...... Staphylécs } \\ \text { lon }\end{array}$

La tribu des Sapindées comprend les Savonniers et les Li-tchi; celle des $\mathbb{E}$ sculées, dont on fait parfois la petite famille des Hippocastanées, comprend le Marronnier, les Pavia. Ajoutons quelques lianes, comme les Serjania et les Paullinia, qui sont des plantes vénéneuses des forêts d'Amérique.

Dans la tribu des Acérinées se rangent les Érables (Acer) de nos forêts. Ces arbres ont des feuilles caduques, opposées, simples et lobées; les fleurs, apparaissant avant les feuilles, sont verdâtres, régulières, polygames, en grappes ou en corymbes; l'ovaire, à deux loges, se transforme en une samare double (p. 43). Deux de nos espèces indigènes, l'Érable sycomore et l'Erable Platane ou Plane, sont de beaux arbres donnant un couvert très épais. du disque fréquemment situé en dehors des étamines. On les 
De l'Érable de Montpellier et de l'Érable champêtre, on fait des haies vives; l'Érable à sucre et l'Erable rouge, de l'Amérique du Nord, sont exploités pour le sucre que fournit leur sève. Le bois des Érables, dense et veiné, est recherché par les ébénistes et les tourneurs.

Les Négondo se distinguent des Érables proprement dits par leurs fleurs dioïques apćtales et leurs feuilles composées pennées.

Les Staphyliers sont des arbustes des régions tempérées; ils ont des feuilles composées pennées; on les utilise pour orner les jardins; le Staphylier penné ou Faux Pistachier est le plus répandu; sa graine donne une huile douce comestible.

Polygalées. - Les Polygalées se relient aux Sapindacées à fleurs irrégulières, dont elles diffèrent surtout par leurs feuilles simples. Ce sont des plantes à feuilles alternes, à fleurs irrégulières; le calice est à deux ailes colorées, la corolle à trois pétales, avec huit étamines : deux (sur dix) avortent habituellement; il n'y a que deux carpelles; le fruit est une capsule. Les Polygales de nos pays sont de charmantes petites herbes des prairies, à fleurs bleues, blanches ou roses. Le Polygala Senega (Snake root) est employé en médecine comme expectorant et stimulant.

\section{LES RHAMNACÉES}

Dans tous bois humides de l'Europe tempérée, jusqu'en Laponie, on rencontre abondamment le Nerprun bourdaine (Rhamnus Frangula). C'est un arbrisseau de 3 à 5 mètres, à tiges rameuses, flexibles et sans épines, à feuilles simples et alternes, caduques, ovales ; ses fleurs, petites et verdâtres, forment des groupes peu compacts à l'aisselle des feuilles. Leur calice est à cinq sépales, la corolle à cinq pétales, l'androcée à cinq étamines opposées aux pétales et soudées par leur base, ainsi que ces derniers, avec le tube du calice; l'ovaire globuleux renferme trois loges et le fruit, petite drupe d'abord rougeâtre, puis noire, contient d'ordinaire une graine enfermée dans un noyau. Le Nerprun purgatif ( $R$. cathartica) est épineux, à feuilles denticulées; ses fleurs jaunâtres sont souvent polygames; son fruit est vert, puis noir, à quatre noyaux. L'écorce et les fruits des Nerpruns sont des purgatifs très actifs; le suc violet de leurs fruits verdit par les bases, et cette couleur verte, enfermée habituellement dans des vessies de porc (vert-de-vessie) est employée, après addition d'alun, par les peintres. Le vert de Chine est une sorte de laque obtenue avec l'écorce et le fruit de Nerpruns d'Extrême-Orient $(R$. chlorophorus et $R$. utilis). Le bois de Bourdaine fournit un charbon léger pour la fabrication de la poudre de chasse.

Les Rhamnacées se distinguent des Géraniacées et des Rutacées par leur unique verticille d'étamines.

Les Paliures sont de petits arbrisseaux aux stipules transformées en deux fortes épines; le Paliure épineux ou Argalou du midi de la France aurait, d'après la tradition, fourni les éléments de la couronne d'épines : d'où son nom vulgaire d'Épine du Christ; on le nomme encore Arbre au chapeau, Porte-chapeau, à cause de l'aspect de ses fruits secs et plats, pourvus d'un large rebord membraneux (p. 44). Le Jujubier commun (Zizyphus Jujuba) de Syrie est cultivé depuiş longtemps en Provence comme arbre fruitier. Le fruit ou jujube est une drupe rougeâtre; la pulpe en est sucrée et pectorale, un peu fade. L'Hovénia doux est une Rhamnacée arborescente du Japon; ses fruits sont de la grosseur d'un pois; à la maturité, ils restent secs, mais leur pédoncule ramifié devient charnu et succulent, comme chez l'Anacardier. Les Céanothes sont appréciés dans les jardins.

Ampélidées. - La Vigne vinifère ( $V$ itis vinifera) est un arbrisseau dont la tige noueuse, tortueuse, porte des rameaux flexibles ou sarments, munis de vrilles ( $f g .241)$. Les feuilles, alternes, sont à nervation palmée, et présentent cinq lobes aigus et dentés; dans certaines variétés, elles sont très

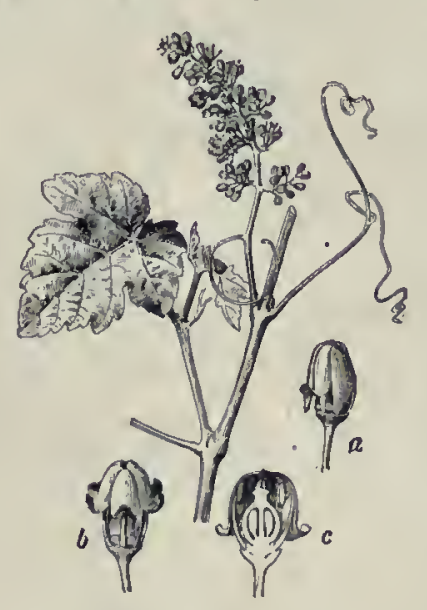

Fig. 241

Rameau fleuri de Vigne.

$a$, Bouton s'entrouvrant; $b$, Fleur ouverte; $c$, Coupe de la fleur. découpées. Les vrilles, bien qu'opposées aux feuilles et non situées à leur aisselle, proviennent de rameaux transformés. En mai apparaissent des grappes composées de petites fleurs verdâtres, odorantes. La fleur se compose d'un calice cupuliforme à cing dents, d'une corolle à cing pétales soudés par le haut en un capuchon se fendant en bas, et que les cinq étamines et le pistil, par leur croissance, soulèvent et font tomber comme un bonnet; les étamines sont opposées aux pétales ; l'ovaire libre, ovoïde, à deux loges biovulées, est inséré sur un disque annulaire et surmonté d'un court style, avec stigmate bilobé; le fruit ou raisin est une baie à jus sucré, ovoïde ou globuleuse, de couleur variable, contenant de un à quatre pépins. On voit combien les Ampélidées ou Vitées se rapprochent des Rhamnacées; elles en diffèrent surtout par leurs vrilles et l'absence de soudure entre les trois verticilles floraux externes. La Vigne atteint parfois des proportions considérables. En Amérique, certaines vieilles Vignes, de la variété dite de la Mission, ont un cep plus gros que le corps d'un homme.

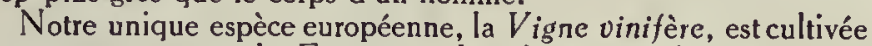
dans presque toute la France et dans beaucoup de contrées du globe; aux Etats-Unis, on trouve, de plus, quelques espèces indigènes: Vitis estivalis, $V$.riparia, $V$. rupestris.

Les Ampelopsis, dont le plus connu est l'Ampelopsis à cinq feuilles (folioles) ou $V$ igne vierge, ne se distinguent des Vignes que par leurs pétales libres et non soudés en un capuchon. Leurs vrilles, à la fois enroulables ou adhésives, au moins dans certaines espèces ( $A$. muralis), se dirigent toujours vers les parties les moins éclairées du support, sy collent par un suc résineux. La Vigne vierge, originaire des Etats-Unis, est une plante grimpante dont les feuilles très décoratives se relèvent à l'automne de tons rouges fort remar-
quables. Les Cissus voisins ont les parties de la fleur par quatre, au lieu de cinq.

Célastracées. - Le Fusain d'Europe (Evonymus), arbuste de nos forêts, a des feuilles caduques opposées, lancéolces. Ses petites fleurs régulières, d'un jaune verdâtre, ont les pièces par quatre ou cinq ; les étamines, insérées, ainsi que la corolle, sur le bord d'un disque annulaire épais, alternent avec les pétales; l'ovaire, uni à sa base avec le disque, est formé de quatre (trois, cing) carpelles à loges biovulées, et devient une capsule à quatre angles saillants à forme de bonnet de prêtre. Son enveloppe rose, entr'ouverte à la maturité, laisse voir les graines, entourées d'un arille charnu rouge orangé.

Le Fusain est le type de la famille; comme les Rhamnacées, les Célastracées n'ont qu'une seule rangée d'étamines, qui alternent avec les pétales. En dehors des Fusains, citons le Célastre grimpant (Bourreau des arbres) du Canada, vigoureuse liane qui enlace les arbres et les fait périr, et le Catha comestible ou Khât, arbrisseau d'Arabie et d'Abyssinie, qui jouit de propriétés analogues à celles du café. 


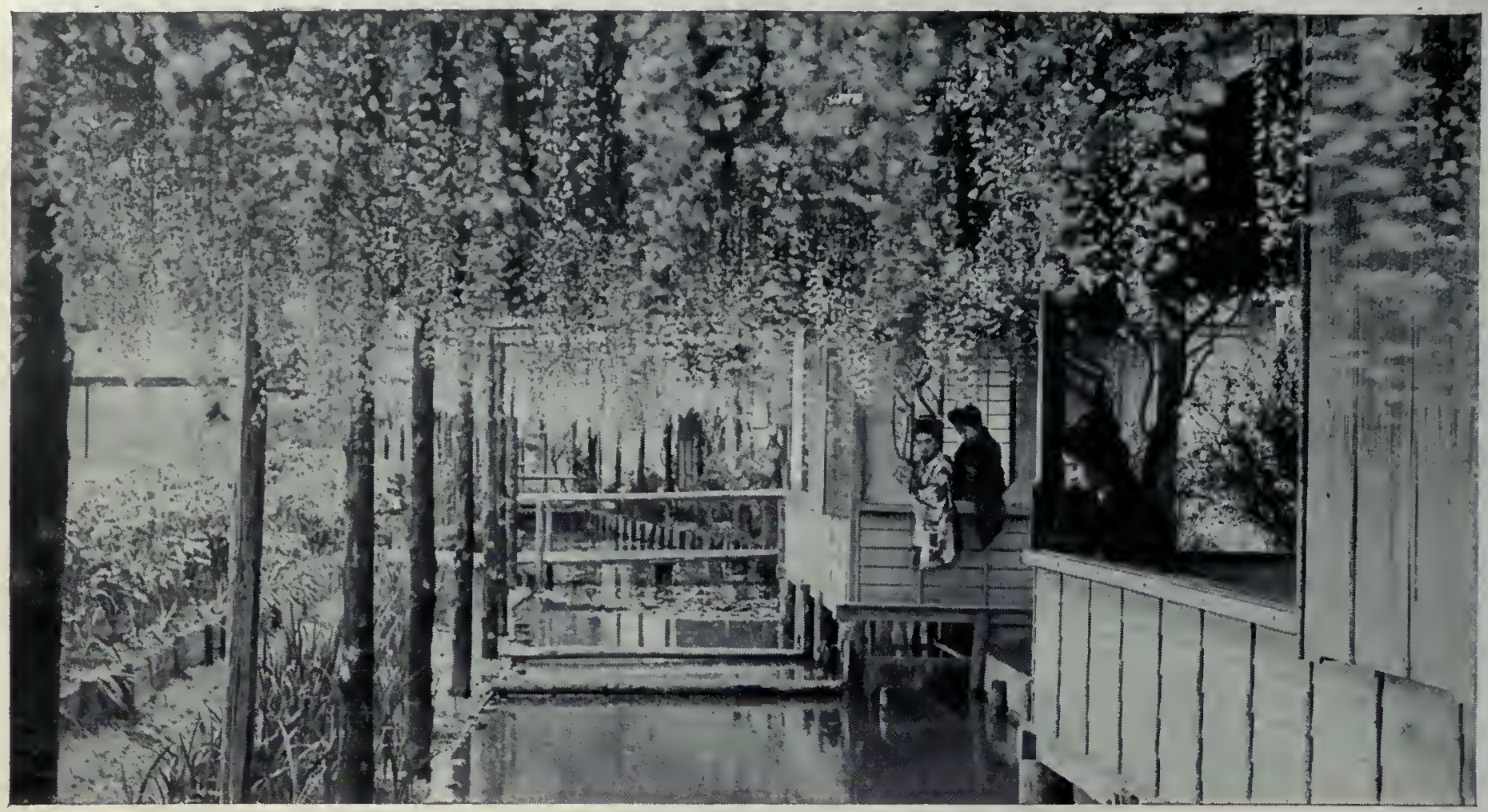

Glycine dans un jardin de Tabata (Japon).

\section{LES LÉGUMINEUSES}

Les Légumineuses forment une des plus vastes familles de la classification botanique; on y range 430 genres, avec plus de 7000 espèces répandues par tout le globe, et dont beaucoup sont utiles à l'homme. Ce sont des plantes de ports très divers; certaines sont de grands arbres, d'autres des arbrisseaux ou des herbes. Les Légumineuses, bien que formant une famille très naturelle, n'ont entre elles qu'un petit nombre de caractères communs : feuilles alternes, ordinairement composées et munies de stipules, fleurs généralement du type cing, avec dix étamines en deux verticilles, pistil formé d'un seul carpelle clos se transformant en une gousse ou légume: d'où le nom de la famille. Ce fruit sec, à une seule loge, souvre ordinairement par deux valves dont chacune porte un rang de graines.

Cet immense groupe a été divisé en trois sous-familles : 10 les Papilionacées, à fleurs irrégulières dont le calice est gamosépale ; dans le bouton, le pétale supérieur est externe, les étamines sont ordinairement soudées en un seul groupe (monadelphes), ou en deux (diadelphes), une étamine étant séparée des neuf autres; l'embryon est courbé; $2^{\circ}$ les Césalpiniées, à fleurs irrégulières dont le calice est à peine soudé à la base; dans le bouton, le pétale supérieur est interne, les étamines sont ordinairement libres, l'embryon est droit; $3^{\circ}$ enfin, les Mimosées, à fleurs régulières, dont les pétales libres sont soudés à la base ; les étamines sont libres, l'embryon est droit.

Les Légumineuses ont des affinités assez complexes; elles se rapprochent des Rosacées, de la tribu des Prunées; par les Mimosées, elles se relient aux Géraniacées et aux Anacardiacées; les types à fleurs irrégulières rappellent aussi les Polygalées.

Papilionacées. - Les Papilionacées doivent leur nom à la forme de leurs fleurs qui évoguent, avec plus ou

moins de ressemblance, un papillon aux ailes étendues. C'est la section la plus nombreuse : 300 genres, avec près de 5000 espèces; c'est aussi la plus importante par ses applications et, enfin, la seule qui soit bien représentée en France.

Pour en connaître les caractères, nous examinerons l'Ajonc d'Europe (Ulex europaus). C'est un arbrisseau des terres stériles, très commun dans les landes bretonnes, que, de janvier en avril, il pare de ses fleurs d'or. De haut en bas, il est couvert d'épines, dont les unes sont des rameaux fortement vulnérants, les autres des feuilles réduites à leur pétiole. Les fleurs, abondantes et grandes, sont par une ou deux à l'aisselle des feuilles; le calice jaunâtrc très velu est divisé en deux parties séparées jusquà la base; la corolle est à cing pétales libres, inégaux: l'un dressé, supérieur, l'étendard (fig. 242), recouvre en partie deux pétales latéraux symétriques, ou ailes, qui, eux-mêmes, cachent les deux pétales inférieurs soudés formant la carène. Viennent ensuite dix étamines soudées par leurs filets en un seul groupe formant un tube fermé qui entoure l'ovaire libre. Celui-ci se transforme en une gousse courte, renflée, velue, renfermant peu de graines.

On divise les Papilionacées en neuf tribus principales :

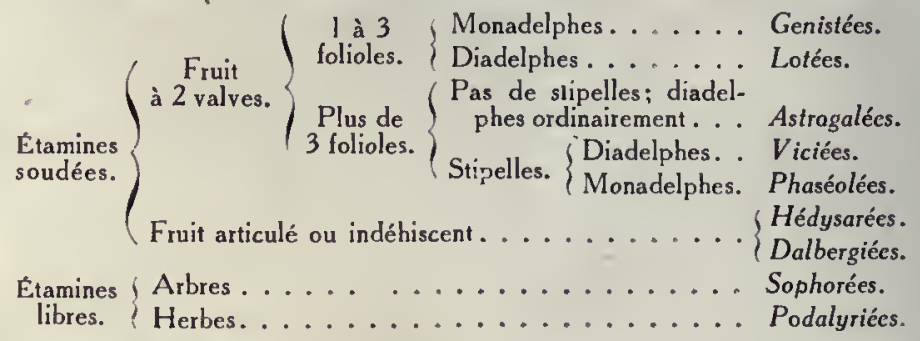

Genistées. - Aux Genislées appartient l'Ajonc, avec les Genêts, les Cytises et lès Lupins.

Sous le nom de Genêt, on réunit des plantes appartenant à

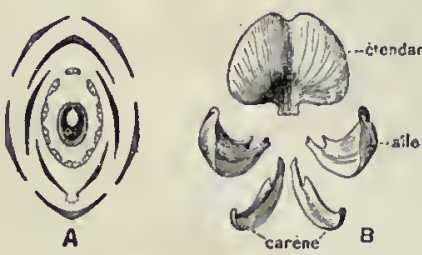

Fig. 242. - Fleur du Pois. A, Diagramme; $B$, Pétales séparés. plusieurs genres voisins. Ce sont des arbrisseaux épineux ou inermes, à petites feuilles simples ou trifoliées, à grandes fleurs ordinairement jaunes et dont la carène abaissée ne cache pas complètement les étamines. Amers et toxiques à dose un peu ćlevée, les Genêts peuvent fournir une filasse résistante propre à fairc des cordes et des toiles gros- 


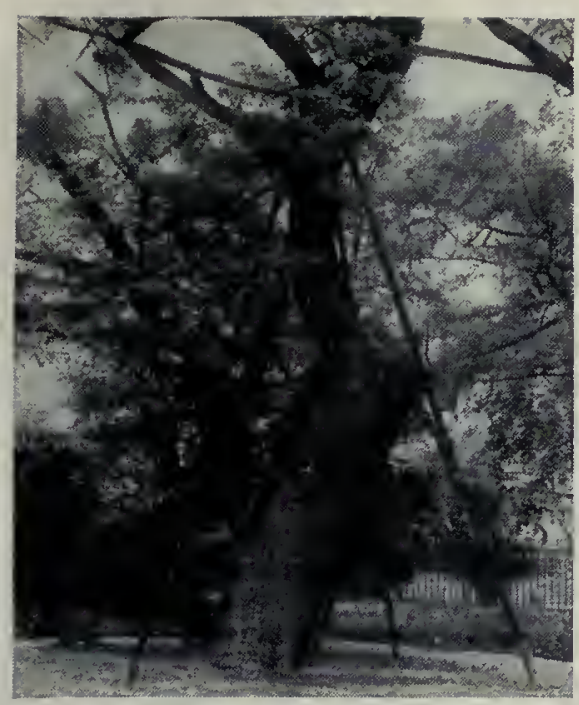

Vicux Robinier, au Muséum.

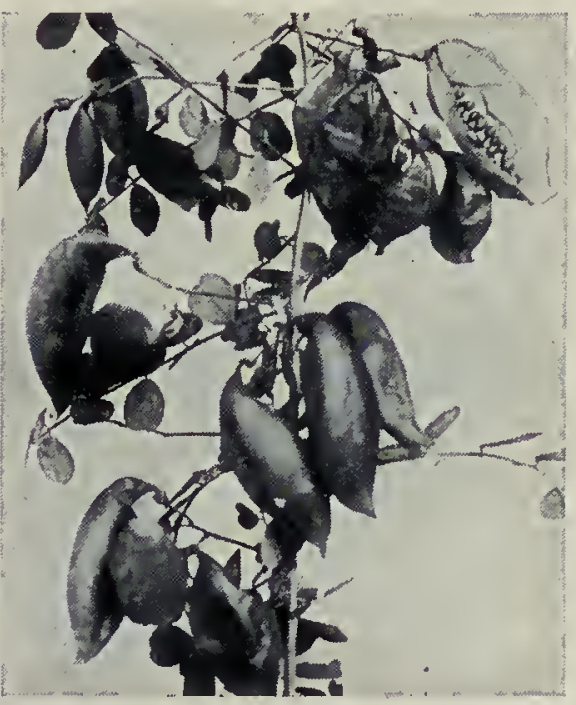

Baguenaudier en fruits.

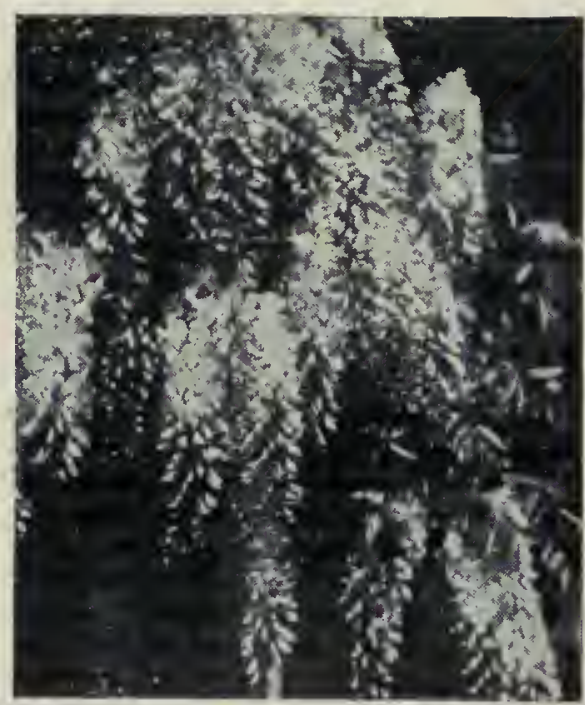

Wistaria ou Glycine. sières. Les principales es’èces sont le Genêt des teinturiers ou Genestrolle (Genista tinctoria), à feuilles simples; le Sarothamne ou Genêt à balai, à feuilles inférieures trifoliées; le Spartier à branches de jonc ou Genêt d'Espagne.

Le Cytise faux ébénier ou Aubour, dit aussi Acacia jaune, est un petit arbre aux rameaux grêles et aux feuilles trifoliées portées par un long pétiole; ses fleurs, d'un jaune clair, pendent en longues grappes. Les Lupins, herbes à feuilles entières ou digitées, portent des fleurs de couleurs variables, réunies en grappes dressées. On en compte une centaine d'espèces originaires de l'Amérique du Sud. Beaucoup ont un port élégant, un feuillage superbe et des fleurs grandes, qui en font des plantes de jardin; d'autres espèces sont cultivées comme fourrage.

Lotées. - Chez les Lotées, l'étamine supérieure est libre. Le Lotier corniculé est une petite herbe, à fleurs jaunes, groupées par quatre à huit au sommet d'un long pédicule, donnant des gousses allongées, dont la disposition rappelle les doigts d'une patte d'oiseau. La Trigonelle fenugrec est cultivée sur les rives méditerranéennes comme fourragère et médicinale.

Les Trèfles et les Luzernes sont, avec le Sainfoin, les Lotées les plus importantes; elles constituent les prairies artificielles. Les Trèfles, ainsi que l'indique l'étymologie (tres, trois; folium, feuille), ont des feuilles à trois folioles. Les fleurs, petites, purpurines, rouges, blanches ou jaunes, sont groupées en épis ou en grappes, souvent presques globuleuses; les pétales en sont soudés en tube à la base; leur corolle est persistante. La gousse, petite et indéhiscente, à une ou quatre semences, est incluse dans le calice et la corolle qui saccroissent et deviennent membraneux. après la floraison. Les Luzernes (Medicago) s'en distinguent par leur corolle non persistante et par leur curieuse gousse indéhiscente, monosperme, souvent contournée en une hélice ( $f$ ig. 243), parfois garnie d'épines ou de tubercules. Le Mélilot officinal a des feuilles trifoliées; ses fleurs jaunes, à corolle non persistante, possèdent une agréable odeur, qui s'accentue par la dessiccation; elle est due à la coumarine.

Astragalées. - Les Astragalées comprennent des plantes dont les feuilles composées pennées portent ordinairement plus de trois folioles.

Le Robinier faux Acacia, plus connu sous le nom inexact d'Acacia, est originaire de l'Amérique du Nord. Ses fleurs blanches, en grappes pendantes, égaient et parfument, au début de l'été, les parcs, les jardins et les routes. Tous les Robiniers européens sont les descendants de celui qui fut planté par Vespasien Robin en 1636, et qui existe encore au Jardin des Plantes. C'est le doyen de ces arbres. Le Robinier peut atteindre 25 mètres de haut; ses feuilles, composées de onze à vingt-trois folioles pennées, portent à leur base des stipules transformées en épines très fortes, surtout quand l'arbre est jeune. Le bois du Robinier est dur, pesant, propre au chauffage et recherché par les ébénistes; ses fleurs sont comestibles : beaucoup de personnes apprécient fort les beignets d'acacia.

Le Baguenaudier commun ou Arbre aux vessies (Colutea ar- borescens) cst un arbrisseau à fleurs d'un jaune foncé, donnant à la maturité de grosses gousses à parois translucides, renflées, vésiculeuses, qui éclatent avec bruit quand on les presse entre les doigts.

Les Indigotiers sont des herbes ou des arbrisseaux répartis dans les régions chaudes. On en retire l"indigo, bèlle matière colorante.

La Réglisse glabre (Glycyrrhiza), de la région méditerranéenne, de l'Asie Mineure et de la Perse, atteint presque la taille d'un homme et porte des feuilles composées de neuf à quinze folioles allongées et des fleurs bleuâtres ou violacées en. grappes axillaires. La tige souterraine ou bois de réglisse est très développée et chargée d'un principe sucré, la glycyrrhizine. Les Astragales forment un genre très nombreux. Ses caractères essenticls sont des feuilles à folioles imparipennées et surtout le fruit séparé en deux loges par une fausse cloison longitudinale ( $f$ g. $244, a$ ). Quelques espèces. habitent la France, mais beaucoup sont des plantes épineuses adaptées aux climats chauds et secs, et abondantes dans tout l'Orient; elles fournissent la gomme adragante.

Viciées. - Les Viciées fournissent à l'homme des graines alimentaires importantes : la lentille, le pois, la fève, le pois chiche. Tandis que la plupart des Lotées ont des feuilles à nombre impair de folioles dépourvues de stipelles, petites stipules accompagnant les folioles, les feuilles des Viciées en ont, avec un nombre pair de folioles, la dernière étant transformée en un simple filet, comme chez la Fève ou le Chiche, ou en un système de vrilles qui rendent la plante grimpante, tels les Vesces, Gesses et Pois.

Les $V$ esces ( $V$ icia) sont communes dans les champs; la $V$ esce cultivée est une herbe annuelle à fleurs isolées ou groupées par deux. On l'utilise comme fourrage; ses graines sont données aux

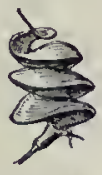

Fig. 243. Gousse contournée de Luzerne.

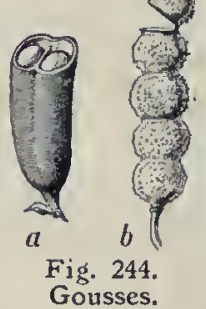

$a$, d'Astragale, coupée

transversalement $b$, Articulee, d'un Sainfoin exotique. bestiaux et aux volailles.

La Lentille comestible (Vicia Lens) est cultivée depuis la plus haute antiquité, comme en témoigne l'histoire d'Ésaü. C'est une herbe annuelle dont les feuilles sont toutes terminées par une vrille. Aux fleurs, petites et blanches, succèdent de courtes gousses bosselées, pendantes, ren fermant deux graines qui constituent un aliment végétal de premier ordre.

La Fève ( $F a b a)$ est universellement connue; ses feuilles, à une ou deux paires de folioles, terminent leur pétiole par une pointe effilée; les fleurs, blanches avec une tache noire sur chaque aile, donnent de grosses gousses renfermant des graines volumineuses. Cette plante, inconnue à l'état sauvage, est cultivée depuis les temps préhistoriques.

Les Gesses (Lathyrus), grimpantes pour la plupart, ont des feuilles paripennées, pourvues à leur base de larges stipules et transformant au sommet leurs folioles en vrilles; leurs fleurs, solitaires ou en grappes, sont souvent grandes et de coulcurs vives. On rencontre en France une vingtaine d'espèces sauvages. L'une des plus curieuses est la Gesse aphaca des moissons; sa feuille, réduite à 
l'état de vrille, porte à sa base deux grandes stipules, qu'on prendrait volontiers pour deux feuilles simples opposées. Plusieurs Gesses font l'objet d'une culture comme fourrage, notamment la Gesse cultivée et la Gesse chiche ou Jarosse, Gérousse. La Gesse odorante ou Pois de senteur est cultivée dans tous les jardins pour ses jolies fleurs, qui garnissent agréablement les berceaux, les tonnelles (Voir PLANCHE EN COULEURS).

Les Chiches sont aussi des plantes d'Asie et de la région méditerranéenne. On connaît surtout en France le Chiche de bélier $\left(C_{i-}\right.$ cer arietinum), dit Pois chiche, plante annuelle à feuilles imparipennées et, par suite, dépourvues de vrilles et non grimpantes. Ses fleurs blanches isolées donnent des gousses renflées et courtes, renfermant chacune deux graines très riches en principes nutritifs, mais de digestion un peu pénible.

Le Pais cultivé (Pisum sativum) est une plante annuelle qui, comme la Fève, la Lentille et le Chiche, nous vient des pays d'Orient. Les feuilles comprennent deux ou irois paires de folioles et des vrilles; ses fleurs sont entièrement blanches ou partiellement violacées. Une espèce voisine, le Pois des champs ou Bisaille, Pois de pigeon, croît spontanément dans les moissons (Europe méridionale); on la cultive parfois comme plante fourragère. Signalons enfin l'Abrus precatorius ou Liane réglisse, qui croît dans l'Inde; sa pousse allongée renferme quatre à cinq jolies graines sphériques d'un rouge brillant, avec une petite tache noire; la racine a la propriété de la réglisse, mais atténuée.

Phaséolées. - La tribu des Phaséolées, dont le Haricot est le type, comprend surtout des herbes grimpantes à feuilles trifoliées, munies de stipelles; les fleurs sont isolées, géminées ou en grappes; les étamines en un groupe et la gousse à une loge déhiscente; la carène est contournée.

Le Haricot commun (Phaseolus vulgaris) a des tiges volubiles, des fleurs en courtes grappes; la couleur des graines varie avec les races. Notre Haricot est inconnu à l'état sauvage; son origine a été longtemps discutée; on sait aujourd'hui qu'il est de provenance américaine; les Haricots utilisés jadis dans l'Ancien Monde étaient les graines de Doliques, plantes très voisines, cultivées dans les pays chauds. Le Haricot de Lima (lunatus) a donné lieu parfois à des empoisonnements chez les bestiaux et aussi chez les hommes, ce qui tient à la présence de doses variables d'acide cyanhydrique; le Haricot d'Espagne ou multiflore est une espèce ornementale originaire de l'Amérique du Sud.

Le Soja hispide (fig. 245), ou Soya, Pois chinois, est une des espèces les plus utiles d'Extrême-Orient. Annuelle, dressée, velue, rameuse, haute d'un mètre, à fleurs verdâtres ou lilacées, cette plante forme des gousses contenant deux ou trois graines, arrondies comme celles du Pois, et jaunes dans la variété usuelle. Ces graines constituent un aliment des plus précieux; assez pauvres en amidon, elles renferment une forte proportion d'huile et surtout de léguminé, matière azotée qui est une sorte de caséine végétale. Les Japonais utilisent le Soja comme légume; ils en obtiennent des gâteaux blancs en écrasant les graines cuites et salées, mélangées avec du riz, et en les faisant fermenter pendant un mois; ils en retirent aussi de l'huile. Le haricol de Soja sert surtout à la fabrication d'un condiment, le sho-you. En filtrant à travers un linge la pâte formée par les graines ramollies dans l'eau et écrasées, on obtient un lait végétal employé par les Chinois à l'exclusion du lait de vache; on le conserve en boîtes comme le lait condensé. Ce liquide, légèrement salé, puis chauffé, se caille et donne un fromage. Des essais ont été tentés en France, pour acclimater cette Légumineuse à tout faire.
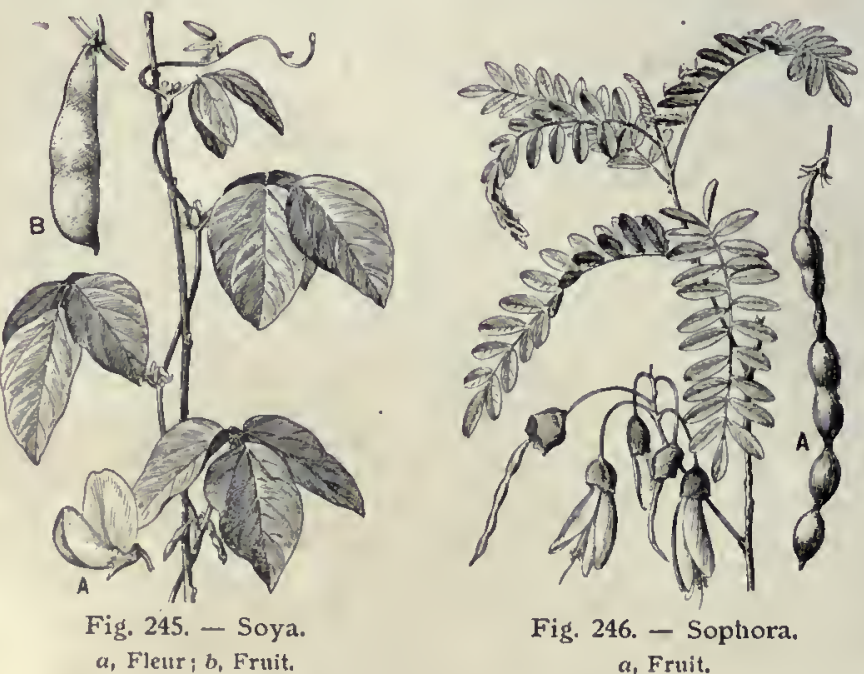

Fig. 246. - Sophora. a, Fruit.

Un autre type, le Soya bean ou Fève de Mandchourie, beaucoup plus rustique, prospère fort bien" sous nos climats. Ses graines ont l'aspect de haricots nains blancs; avec leur farine, additionnée de beurre et d'eau, on fait pour les diabétiques un pain dix fois plus pauvre en amidon que le pair. de froment.

Le Voandzeia souterrain ou Haricotpistache, de l'Afrique tropicale, est voisin des Sojas et sa culture est très répandue; comme l'Arachide, cette plante enterre sa gousse à une seule graine, qui mûrit dans le sol et a la saveur de la châtaigne.

La Wistaria de Chine, connue sous le nom impropre de Glycine, est une superbe liane à rameaux volubiles. En avril, ses branches, encore dénudées, se couvrent d'admirables grappes pendantes de grandes feurs odorantes, aux corolles d'un lilas pâle. La Glycine est le tsuji des Japonais; c'est une de leurs plantes favorites : ils la cultivent en vase, sous forme d'arbre nain; dans leurs jardins, des sujets de grandes dimensions sont étalés sur des charpentes en bambou formant des berceaux ou sur des pergolas établies au bord d'un étang; au moment de la floraison, une profusion de grappes, atteignant parfois jusqu’à 1 mètre de longueur, pendent du toit et se réfléchissent dans le calme miroir de l'eau : c'est une véritable féerie.

Les Mucuna ou Pois pouilleux, Lianes à gratter, son des plantes grimpantes des régions chaudes; leurs gousses sont couvertes de poils dont le simple contact avec la peau produit de vives démangeaisons. L'Apios tubéreux de l'Amérique du Nord est une jolie plante ornementale.

Signalons encore l'Erythrine corail des Antilles (Voir PLANCHE EN COULEURS), arbre fournissant un bois très résistant aux agents de destruction, le bois immortel des ébénistes; de ses graines luisantes, rouges avec tache noire, on fait des colliers, des bracelets.

La Physostigma vénéneuse ou Fève de Calabar, de Guinée, est volubile; sa tige atteint 16 mètres et plus de longueur; ses gousses brunes, longues de 20 centimètres, renferment deux à trois grosses graines de couleur chocolat et qui sont fort toxiques, à cause de la présence d'un alcaloïde, l'ésérine, qui paralyse les muscles à la façon du curare.

Le Cajanus indien ou Ambrevade, Pois d'Angole, n'a plus les étamines toutes soudées. On le rattache cependant aux Phaséolées. C'est un arbrisseau de 2 à 3 mètres, cultivé dans les pays chauds pour la nourriture des indigènes.

Hédysarées, Dalbergiées. - La tribu des Hédysarées comprend des plantes dont la gousse est ordinairement divisée, par des cloisons transversales, en articles à une seule graine qui se détachent isolément à la maturité $(f i g: 244, b)$. Ce groupe est représenté en France par plusieurs herbes des prairies : les Coronilles, les Ornithopes, etc. Chez les Ornithopes, la disposition des gousses articulées rappelle les doigts d'un pied d'oiseau; les Hippocrepis doivent leur nom vulgaire de ferà cheval à la forme deséchancrures qui découpent leur fruit ; celui des Scorpiures, contourné et velu, rappelle une chenille.

Le Sainfoin cultivé (Onobrychis) ou Esparcette est une jolie plante vivace à feuilles composées imparipennées et dont les fleurs roses, en épis dressés, très visitées par les abeilles, fournissent un miel de qualité supérieure. Le Sainfoin est, comme l'indique son nom, un excellent fourrage.

La Desmodie oscillante du Bengale est remarquable par les mouvements, déjà signalés (p. 53), de ses feuilles à trois folioles inégales. La tige du Sola de l'Inde ( Eschynomena paludosa), arbuste de 2 à 3 mètres, commun au bord des eaux, est formće d'un tissu léger 


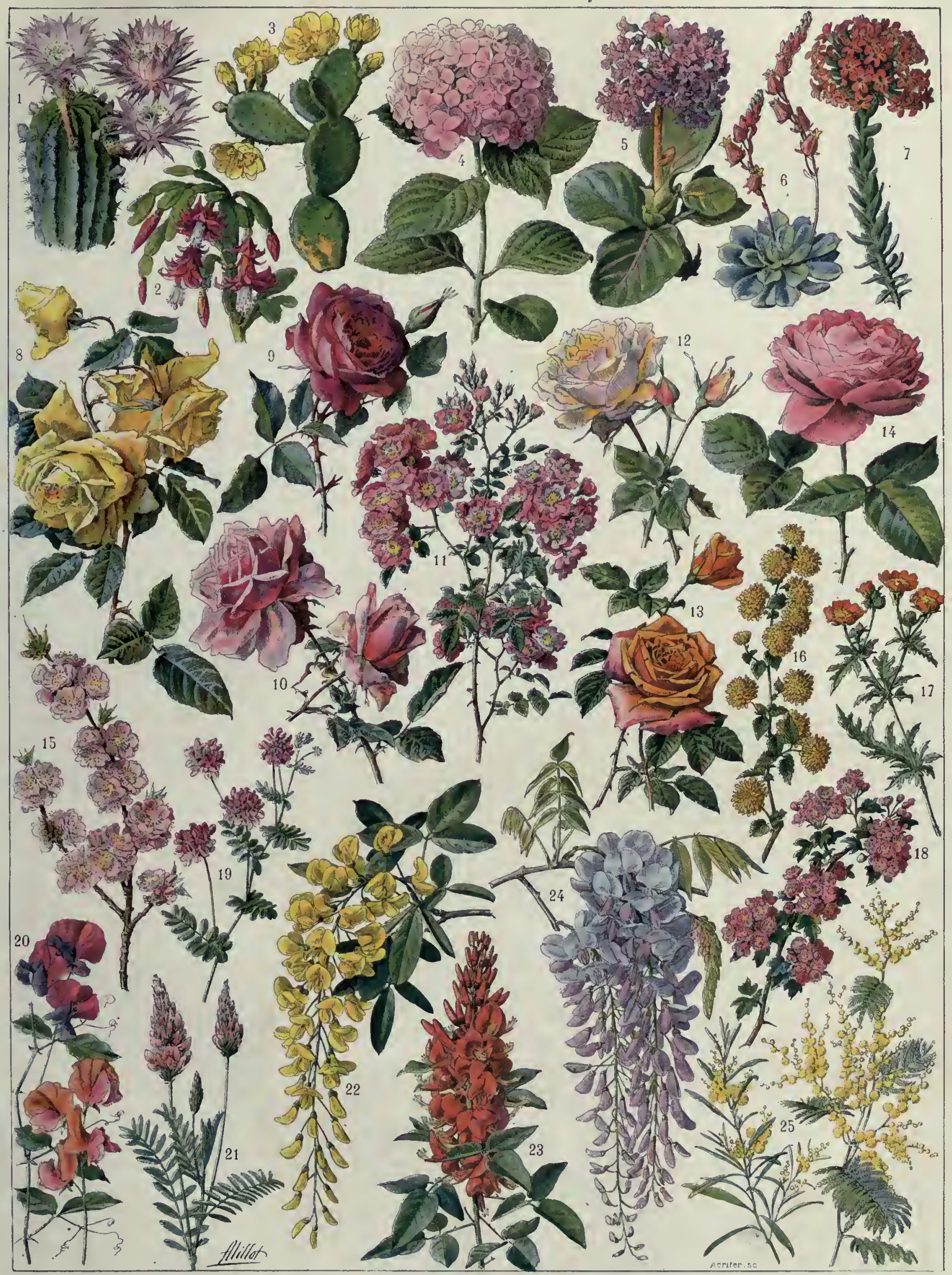

ROSACÉES, LÉGUMINEUSES, CRASSULACÉES, ETC.

Cactées: 1. Échinopsis de Rholand (hybride). - 2. Épiphylium tronqué- - Opuntia. - Saxifragées: 4. Hortensia. - 5. Saxifrage de Sibérie. - Crassulacées: 6. Echeveria, - 7. Crassula écarlate (Rochea coccinea), - Rosacécs: 8. Rose Maréchal Niel. - 9. Rose Gẻnéral Mac-Arthur. - 10. Rose Duchesse 17. Benoite du Chili. - 18. Aubépine rose - Lésunineuses: 19 Coronille. - 20. Gesse odorante. - 21. Sainfoin d'Espą̧ne, - 22. Cytise, - 23, Erythrine, 



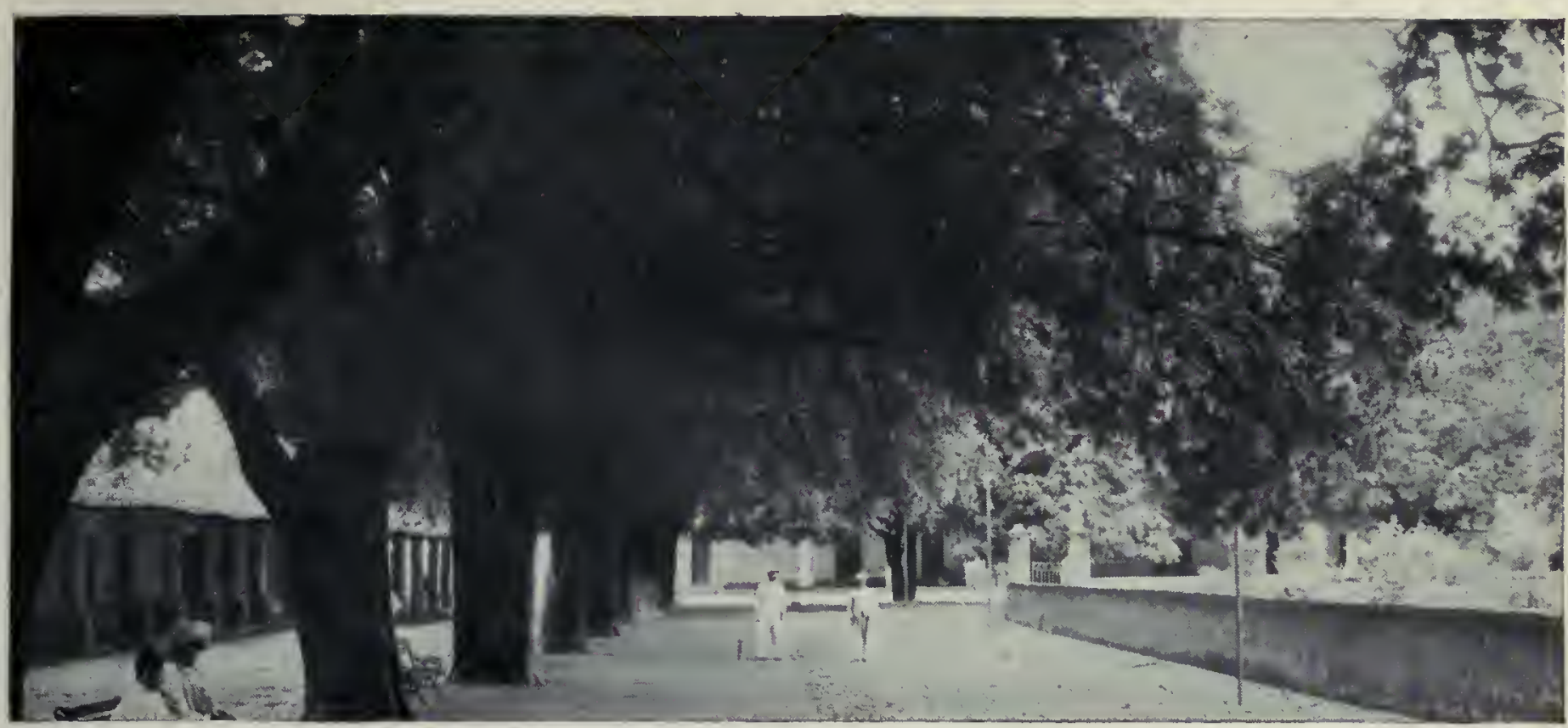

Sous les Tamariniers des Indes, à Iguala (Mexique).

(bois d'Ambatsch), spongieux, propre à remplacer le liège. Enfin, l'Arachide souterraine ou Pistachier de terre est une herbe à tige velue, à feuilles composées de deux paires de folioles, avec stipules. Les fleurs, menues et jaunâtres, sont par petits groupes à laisselle des feuilles: les supérieures mâles avec les étamines en un faisceau, et les inférieures femelles ou polygames. Après la fécondation, le pédoncule des fleurs femelles sallonge, se recourbe et fait pénétrer dans le sol la jeune gousse qui y mûrit ses graines. Cette gousse (cacahouète), coriace et parcheminée, présente des étranglements entre ses graines, au nombre de deux à trois, et de la grosseur d'une noisette. L'Arachide est cultivée dans tous les pays chauds, pour ses graines oléagineuses.

Les Dalbergiées sont des Papilionacées ligneuses des régions tropicales; beaucoup sont grimpantes, d'autres sont de grands arbres. Leurs feuilles comprennent de nombreuses folioles pennées; les fleurs, souvent grandes et belles, réunies en grappes, présentent des étamines en un ou deux faisceaux; la gousse, ligneuse ou drupacée, a des parois coriaces et ne souvre pas; chez plusieurs espèces, elle a l'aspect d'une noix, d'une amande ou d'une samare ne renfermant qu une seule graine.

Les Dalbergiées fournissent des bois durs, colorés, veinés, souvent odorants et d'un prix très élevé : tels sont les Ptérocarpes, Angelins ou Andira, et surtout les Palissandres ou Dalbergia, qui croissent au Brésil, dans l'Inde ou en Afrique. De plusieurs Ptérocarpes, on retire du kino, suc rouge, astringent, voisin du cachou; d'autres, du sang-dragon, sorte de résine. Le fruit du Dipteryx odorant ou Coumarouna, de la Cuyane, ressemble à une grosse amande dont la graine parfumée est d'un noir brillant (drupe); c'est la fève Tonka, employée à parfumer le tabac.

Sophorées, Podalyriées. - Avec ces tribus, nous terminons l'immense groupe des Papilionacées. Les Sophorées sont des arbres à feuilles pennées; la corolle est parfois presque régulière ; les dix étamines sont libres; la gousse est indéhiscente ou bivalve.

Du Sophora du Japon (fig. 246), introduit en Europe en 1763. on apprécie le feuillage touffu et gracieux plutôt que les petites fleurs blanchâtres. Les Myroxylon, arbres atteignant 5 mètres de haut, qui vivent dans l'Amérique centrale, sécrètent et fournissent par incision des produits résineux odorants : les baumes du Pérou et de Tolu, utilisés en parfumerie et en médecine.

Les Podalyrićes comprennent des plantes de jardin, comme les Baptisia à fleurs bleues et les Thermopsis à fleurs jaunes.

Césalpiniées. - Le Gainier siliquastre (Cercis) ou Arbre de Judée, originaire de l'Asie occidentale, croît en pleine terre dans nos jardins. Au printemps, avant l'apparition des feuilles, son tronc noueux, ses branches irrégulières se couvrent de fleurs d'un rose foncé qui semblent sortir du vieux bois. La corolle comprend cinq pétales libres; les dix étamines, disposées en deux verticilles, sont libres jusqu’à leur base; le pistil ressemble à celui du Pois; la gousse, aplatie ef mince, renferme de nombreuses petites graines. Les feuilles, déjà presque complètement formées à la fin de la floraison, sont alternes, simples, cas très rare chez les Légumineuses, et en forme de cœur.

Les autres Césalpiniées ont une organisation analogue; cependant la plupart ont des feuilles composées pennées; les fleurs sont grandes, belles et papilionacées, rarement petites et presque régulières; jamais les deux pétales inférieurs ne sont soudés en une carène; la gousse, déhiscente ou non, est souvent divisée en loges par des cloisons. Les Césalpiniées sont, sauf de rares exceptions, des plantes ligneuses des régions chaudes.

Le Caroubier commun (Ceratonia siliqua) des rives méditerranéennes a des feuilles persistantes comprenant six à dix folioles coriaces paripennées; les fleurs, pourprées et très petites, disposées en épis, n'ont pas de corolle et n'offrent qu'un calice à cinq dents, cinq étamines et un ovaire un peu arqué; certaines fleurs sont unisexuées. La caroube est une gousse coriace, longue de 15 à 20 centimètres, et divisée par des cloisons transversales en loges remplies d'une pulpe sucrée qui emprisonne les graines. Ces fruits sont excellents pour nourrir les bestiaux; l'homme les mange aussi avec plaisir; l'écorce sert en tannerie.

Le Févier ou Gleditschia à trois épines (fig. 247) est un arbre de 15 à 20 mètres, originaire du Canada et cultivé dans nos parcs. Ses feuilles sont, les unes composées de dix à quatorze paires de

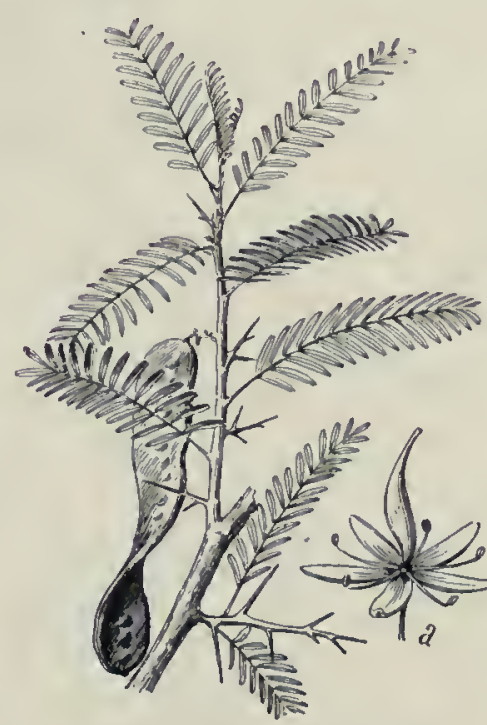

Fig. 247. - Févier. $a_{1}$ Fleur. folioles pennées, les autres bipennées; il est garni de piquants groupés à l'aisselle des feuilles et qui sont des rameaux avortés; les fleurs, petites et blanchâtres, polygames, presque régulières, donnent de longues gousses brunes, plates, arquées et remplies d'un tissu pulpeux qui abrite les graines. Le Gymnoclade ou Chicot du Canada est un arbre ornemental très voisin du Févier.

Toutes les Césalpiniées dont il nous reste à parler habitent les régions chaudes. Les Brésillets ou Casalpinia fournissent des bois tinctoriaux dont le plus répandu est le bois de Fernambouc ou du Brésil, qui sert à teindre en rouge. Lé Brésillet des corroyeurs ou Libi-dibi, 
Divi-divi, a des gousses indéhiscentes, curieusement contournées en $C$ ou en $S$, et qui servent en tannerie. Le bois de Campêche est fourni par un arbre épineux de 6 à 15 mètres de haut, l'Hématoxylon de Campêche. Le cour de ce bois tinctorial, d'un rouge brun pâle, est lourd, à grain fin et à odeur d'Iris.

Les Casses sont riches en principes purgatifs : la Casse fistuleuse ou Canéficier officinal est un grand arbre à port de Noyer; ses feuilles sont parjpennées, ses fleurs jaunes en longues grappes pendantes; le fruit est une gousse cylindrique ligneuse, d'un brun noirâtre, longue de 30 à 40 centimètres, indéhiscente, divisée par des cloisons en loges à une graine; la pulpe qui entoure les graines est la casse. La Casse à feuilles aiguës, arbrisseau d'Egypte, fournit le séné.

Un des plus beaux arbres des régions tropicales est le Tamarinier des Indes (Tamarindus); ses grandes leuilles alternes sont formées de dix à quinze paires de folioles opposées, paripennées; les fleurs, d'un jaune rougeâtre, 'n'ont que quatre sépales, trois pétales grands et deux inférieurs en forme de soie ou d'écaille et trois étamines fertiles, les autres stériles ou avortées; l'ovaire est étroit, courbé en faux; le fruit est une épaisse gousse comestible de 10 à 15 centimètres de longueur, avec quelques graines anguleuses dans une pulpe douceâtre acidulée, rougeâtre; elle sert à préparer le tamar.

Les Copaïers (Copaifera), grands arbres à feuilles très élégantes, sont presque tous américains; leur fleur apétale est presque régulière, avec un calice à cinq lobes et dix étamines; la gousse ne contient qu une seule graine. Ils sécrètent une oléorésine, le baume de copahu. Citons encore les Bauhinia, dont certains sont d'étranges lianes à tige aplatie et rubanée, serpentant et grimpant dans les forêts tropicales (p. 92), et le Courbaril (Hymenca) du Brésil et de Madagascar, dont le bois dur, ressemblant au Santal, sert en ébénisterie; on en retire la résine animée ou copal.

Mimosées. - En hiver, à Paris, sur les voitures des marchandes de fleurs, les petits pompons jaunes du Mimosa accompagnent la violette et les autres productions parfumées des horticulteurs du Midi. Ce Mimosa des lleuristes est, en réalité, l'Acacia dealbata d'Australie, acclimaté depuis longtemps déjà sur le littoral méditerranéen. C'est un arbre de 8 à 10 mètres, à rameaux blanchâtres, garnis de feuilles bipennées d'une délicatesse infinie; de janvier en mars, il se couvre de grappes odorantes de petits capitules globuleux, dont chacun est la réunion de plusieurs minuscules fleurs régulières, à nombreuses étamines multiples.

Plusieurs Acacia d'ornement, originaires d'Australie et acclimatés en Provence, fournissent encore des branches fleuries qui, dans le commerce, portent aussi le nom de Mimosa, mais qui sont beaucoup moins gracieuses, car leur feuillage est réduit à des phyllodes: tels sont l'A cacia retinodes, garni toute l'année de fleurs parfumées d'un jaune citron; l'A cacia à longues feuilles, dont les épissont cylindriques; l'Acacia en coutre ( $A$. cultriformis), etc. (Voir Planche EN COULEURS).

Les Acacia forment le groupe le plus important de la tribu des $\mathrm{Mi}$ mosées; on en compte près de
500 espèces, arbres ou arbrisseaux, souvent épineux, habitant les régions chaudes, et particulièrement l"Afrique et l'Australie. Leurs feuilles alternes sont bipennées, mais,

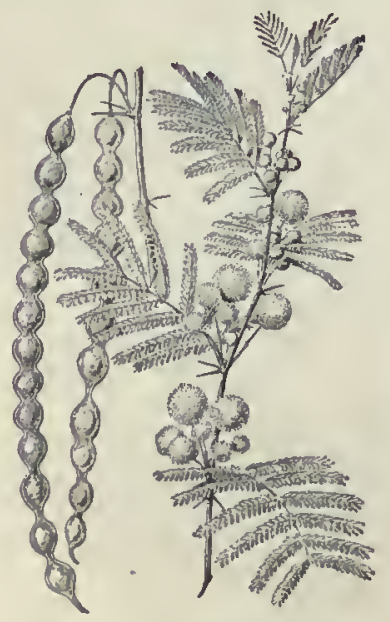

Fig. 248. - Acacia arabique. Branche en fleurs et branche en fruits. chez beaucoup d'espèces australiennes, les folioles se métamorphosent peu à peu, le pétiole s'élargit et reste seul, sous forme d'une lame verte dressée ou phyllode. Cctte disposition a pour effet de sopposer à une transpiration trop active. Chez l'Acacia à feuilles diverses (heterophylla), on observe, en même temps, des leuilles à tous les degrés de transformation. Les fleurs, petites, régulières, hermaphrodites ou polygames, et du type quatre ou cinq, avec un grand nombre d'étamines, sont groupées en capitules globuleux ou en épis cylindriques; le fruit est une gousse articulée de forme variable.

On cultive, en Provence et aux environs d'Alger, en vue de la parfumerie, la Cassie ou Acacia de Farnèse, arbrisseau des tropiques. Beaucoup d'Acacia produisent des gommes, liquides épais lormés par les membranes cellulaires qui se gonflent et se ramollissent. Le plus important des Acacia gommilères est l'Acacia arabique (fig. 248), arbrisseau de 2 à 6 mètres de haut, qui croôt non seulement en Arabie, mais dans une grande partie de
l'Alrique et de l'Inde; il est épineux, à fleurs jaunes en pompons. La gomme arabique se présente
en larmes arrondies, transparentes. La gomme du Sénégal, utilisée surtout en France, provient d'une espèce voisine. Le bois de l'Acacia cachou ou Cachoutier de l'Inde, épuisé par l'eau bouillante, fournit du cachou, principe amer et astringent, renfermant un tanin particulier, employé en médecine, en teinturerie (couleur kaki) et en tannerie. Le fameux tsofar ou Arbre siffleur des nègres d'Afrique est l'Acacia fistula, dont les épines stipulaires attaquées par un insecte se renflent en galles sphériques évidées. Le vent pénètre en sifflant par l'unique orifice de ces boules cieuses et produit des sons variables avec leur grosseur. Signalons aussi l'A cacia à girafe d'Alrique, dont le feuillage est le lourrage préféré de ces grands ruminants.

Les Mimosa proprement dits ne possèdent ni les nombreuses étamines (ils ont seulement quatre étamines), ni le pollen aggloméré des Acacia; ce sont des herbes ou des plantes ligneuses dont il existe près de 300 espèces habitant les régions chaudes. Comme la plupart des Légumineuses, mais à un plus haut degré, les $\mathrm{Mi}$ mosa ont des mouvements périodiques, dits de veille et de sommeil, de leurs gracieuses feuilles bipennées. Mais quelques espèces ont, de plus, des mouvements provoqués fort curieux (p. 53) qui leur ont valu le nom de Sensitives (fig. 249). La plus connue est le Mimosa pudique, qui croît spontanément au Brésil, mais s'est aujourd'hui répandu en Asie et en Afrique. C'est une herbe de 60 centimètres de hauteur; sa tige est armée de

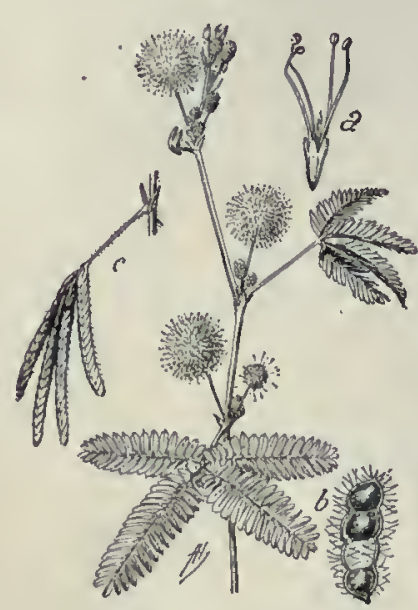

Fig. 249. - Sensitive. $a$, Fleur ; $b$, Fruit ; c, Fenilles en position de sommeil. quelques épines; ses fleurs, très petites, sont groupées en gracieux capitules roses.

La Houlle des Ouoloffs est un arbre de 12 à 15 mètres, le Parkia africana, dont les fleurs forment de gros pompons d'un rouge écarlate. Ses gousses, longues de 30 centimètres, renlerment une pulpe sucrée qui se consomme en nature ou en boisson lermentée. Quant aux graines, elles donnent une inlusion theiforme nommée improprement calé du Soudan.

L'Albizzia julibrissin ou Acacia de Constantinople, Arbre de soie, est, en réalité, originaire de Perse. On le cultive dans le midi de la France pour ses jolies fleurs d'un blanc rosé, groupées en capitules, et qui portent des aigrettes soyenses de longues étamines. 


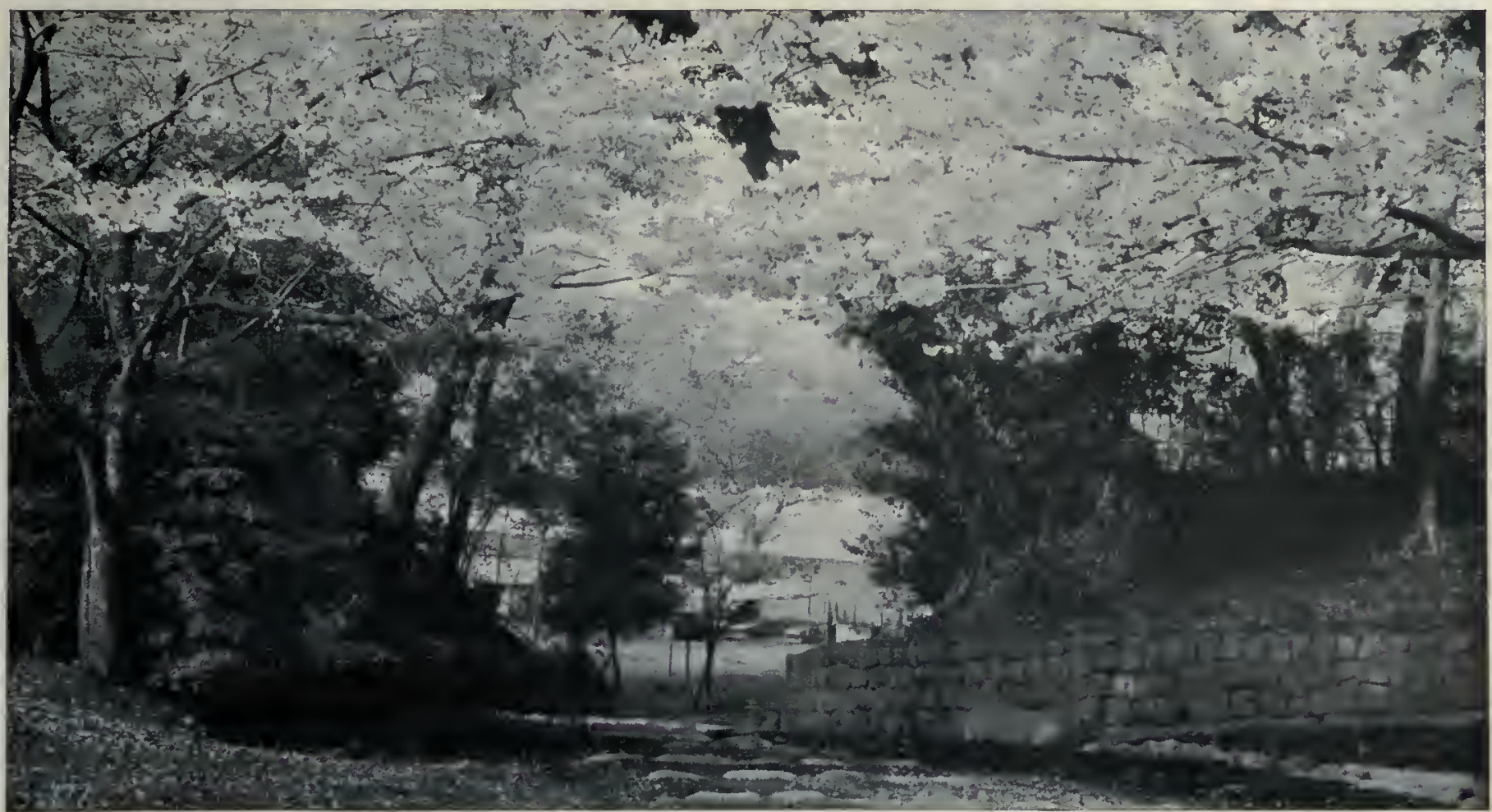

Cerisiers en fleurs dans an parc de Tokio (Japon).

\section{LES ROSACÉES}

Prunées. - Au premier printemps, dans les haies, les rameaux épineux et sombres des Prunelliers se couvrent de fleurs blanches à la douce senteur d'amande amère. Ces fleurs sont régulières et comprennent un calice à cinq sépales, une corolle à cinq pétales; vingt étamines, dont dix plus courtes, sont insérées sur le calice; les anthères s'ouvrent vers le centre de la fleur; toutes ces pièces sont fixées sur le bord d'une sorte de godet dont le fond est occupé par le pistil. Celui-ci, formé d'un seul carpelle libre d'adhérence avec les parties voisines, se compose d'un ovaire arrondi renfermant deux ovules, visibles seulement à la loupe dans la section; il est surmonté d'un style allongé, avec stigmate terminal.

Aux fleurs succèdent à l'automne des fruits arrondis, d'un violet bleuâtre, les prunelles, recouvertes d'une brillante pruine. Ce sont des drupes à noyau un peu aplati, n'entourant ordinairement qu'une seule graine, car l'un des deux ovules avorte au cours du développement. Le Prunellier, dit aussi Prunier épincux (Prunus spinosa) ou Epine noire, est une Rosacée.

Dans nos bois, en avril, fleurit une autre Rosacée, le Merisier ou Cerisier sauvage (Cerasus avium). C'est un arbre à l'écorce lisse et comme satinée, senlevant par bandes transversales; ses fleurs blanches, qui apparaissent en même temps que les feuilles, ont une structure identique à celle du Prunellier, mais, au lieu d'être isolées et sessiles, elles sont groupées en ombelles à l'extrémité de longs pédoncules; le pétiole de la fcuille porte deux petits nectaires rougeâtres, très visibles et caractéristiques. Le fruit du Merisier

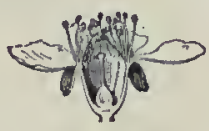

Fig. 250. Coupe de lafleur d'Âbricotier. est arrondi, noir, à noyau lisse et presque glo-

buleux, sans côtes saillantes; amère et presque immangeable, la merise fermentée donne un kirsch excellent. Deux autres espèces de Cerisiers croissent encore dans nos bois : le Cerisier Mahaleb et le Cerisier à grappes (Cerasus padus); le premier se distingue du Merisier par sa taille plus petite et l'absence de nectaires au pétiole; le second se reconnaît aux grappes allongées de ses fleurs.

Pour faire plus ample connaissance avec les Rosacées à drupes, c'est dans les vergers et les jardins qu'il faut aller. Là, nous rencontrerons des espèces utiles: Prunier, Cerisier, Abricotier, Pêcher, Amandier, originaires de l'Asie tempérée, mais acclimatés chez nous depuis des siècles; elles fournissent à nos tables des fruits savoureux, elles donnent à nos paysages printaniers une splendeur sans pareille, lorsque, dans les vallécs qu'elles garnissent, sur les flancs des collines quelles escaladent en files serrées, elles offrent à l'œil émerveillé le prodigieux épanouissement de leurs fleurs blanches, rosées ou presque rouges. Puis c'est l'éparpillement des pétales, que le vent emporte comme des papillons et dont il poudre le sol; c'est plus tard, enfin, la lourde parure des fruits dont les nuances vives tranchent sur les feuillages touffus.

Le Prunier cultivé (Prunus domestica) s'échappe parfois des jardins et on le rencontre à l'état sauvage dans nos bois; sa floraison précoce l'expose aux gelées blanches. L'Abricotier (Armeniaca) a des fleurs d'un blanc rosé (fig. 250) apparaissant en février-mars, avant les feuilles; celles-ci sont luisantes, coriaces, ovales et presque en cœur; le fruit est une grosse drupe à peau veloutée, à chair jaune, ferme, succulente et à noyau lisse. Le Pêcher (Persica) a des fleurs d'un rose rouge caractéristique, apparaissant en mars, avant les feuilles lancéolées, doublement dentées et à pétiole court. La pêche est une drupe à épiderme velouté, à noyau ridé.

De tous nos arbres fruitiers à noyau, l'Amandier (Amygdalus) est le plus précoce; il est aussi le plus sensible aux gelées. Dès février, il se couvre de fleurs blanches ou blanc rosé, groupées par deux; ses feuilles allongées, d'un vert clair, ont un long pétiole; ses fruits sont des drupes à chair coriace, verte, non comestible. Le noyau ou coque est mince, rugueux; la graine, douce dans les variétés à longs styles dépassant de beaucoup les étami-

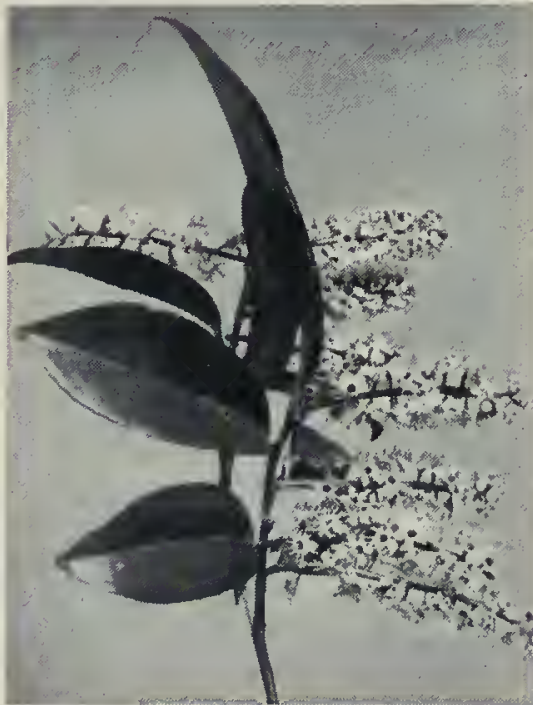

Prunier Laurier-cerise en fleurs. nes, est amère chez les autres. Les amandes amères renferment un glucoside, l'amygdaline, et un ferment, l'émulsine, localisés dans des tissus différents de la plantule; une réaction se produit entre ces substances quand on broie la graine en présence de l'eau; il se forme alors du glucose, de l'essence d'amande amère et de l'acide cyanhydrique ou prussique, le plus redoutable des poisons. Cette propriété, à laquelle on a donné le nom de cyanogénèse. est fort répandue dans le monde végétal, surtout chez les Rosacées. 
Toutes les Rosacées à drupēs, dites aussi Prunées ou Amygdalées, sont utiles encore pour leurs bois, recherchés par les ébénistes; leur rôle décoratif est de premier ordre. En Chine, on admire pardessus tout la splendide floraison des Pruniers et des Pêchers. Au Japon, la fleur nationale est celle du Sakura ou Cerisier du Japon. Nos jardins sont égayés au printemps par les fleurs des Pêchers de Chine, des Pruniers et Merisiers à fleurs doubles: le Lauriercerisier (Prunus Laurocerasus) est précieux pour son beau teuillage persistant et ses longues grappes de fleurs blanches.

De nos Prunées, il faut rapprocher les Chrysobalanées des pays chauds; la plus estimée est I'Icaquier commun, arbrisseau de l'Amérique tropicale : son fruit ou prune-coton est comestible à la fois par la pulpe et par l'amande.

Caractères et division des Rosacées. - Les Rosacées n'ont qu'un petit nombre de caractères communs : feuilles alternes et pourvues de deux stipules, fleurs régulières et du type 5 presque toujours, réceptacle en godet sur lequel s"insèrent les pièces; étamines nombreuses et en cercles, à anthères s'ouvrant vers' le centre de la fleur. Le pistil et le fruit, très variables, ont permis la division en tribus :

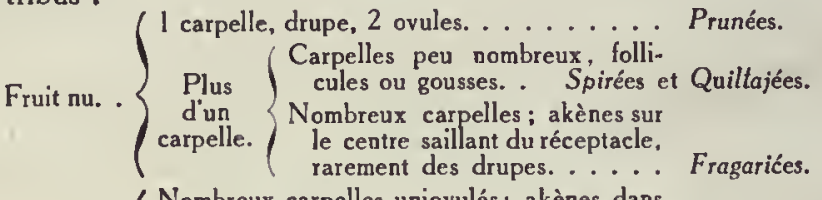

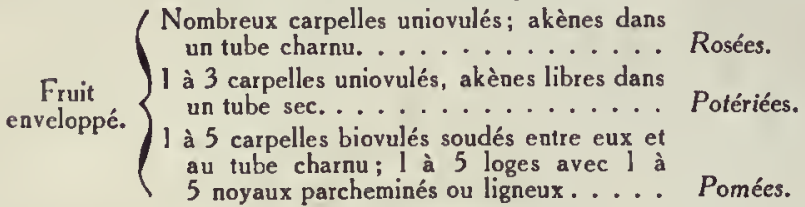

Les Rosacées ont une grande ressemblance extérieure avec les Renonculacées à fleurs régulières, mais elles en diffèrent par la forme du réceptacle et le mode d'insertion des étamines; par les Prunées, qui sont monocarpellaires, elles se relient aux Légumineuses. Ces plantes sont réparties dans le monde entier, mais communes surtout dans les régions tempérées de l'hémisphère boréal; elles nous fournissent presque tous nos fruits de dessert, plusieurs boissons usuelles, des bois utiles et des fleurs superbes.

Spirées, Quillajées. - En été, dans les prés humides, on rencontre une herbe, haute d'un mètre, aux feuilles gracieusement découpées; ses fleurs blanches, d'une incomparable légèreté, sont groupées en corymbes d'où s'exhale un parfum d'amande amère. C'est la Spirée ulmaire ou Reine des prés (fig. 25l). Sa fleur ressemble beaucoup à celle du Prunellier : cinq sépales, cinq pétales et trente étamines fixées sur le bord d'un réceptacle en godet, mais le pistil qui se dresse au fond de celui-ci, au lieu de comprendre un seul carpelle, en comporte cinq d'ordinaire qui deviendront autant de follicules tordus en spire. Les Spirées sont de belles plantes d'ornement aux fleurs blanches, roses ou rouges, souvent odorantes.

Les Quillaies, qui sont des arbres de l'Amérique du Sud, peuvent être rattachées aux Spirées; la Quillaic savonncuse (Quillaja saponaria), du Chili, a une écorce très riche en saponine, qui est vendue,

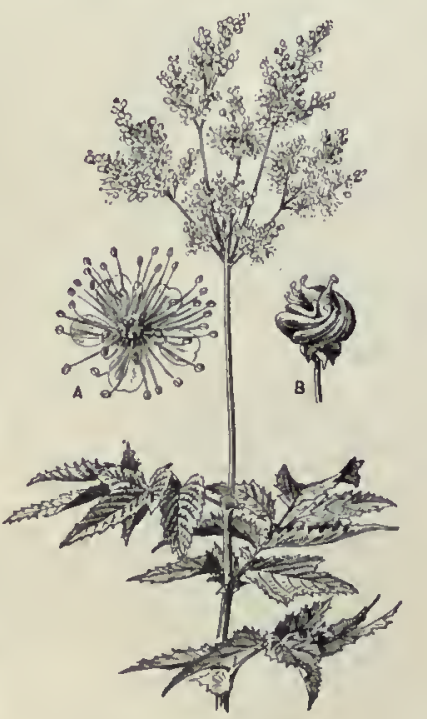

Fig. 251. - Spirée. A, Fleur; B, Fruit. comme le Savonnier, de la famille des Sapindacées (p. 188), sous le nom de bois de Panama; le fruit est une gousse.

Fragariées.-Portons maintenant notre attention sur la fleur du Fraisier (Fragaria) [fig. 252, A]. Blanche, régulière, elle possède encore la même structure que celles des Prunées et des Spirées : cinq sépales souvent doublés d'un calicule, cinq pétales, vingt étamines disposées au pourtour d'un godet, ici peu profond; mais du fond de celui-ci s'élère une éminence conique, portant un nombre considérable de petits carpelles à style basal contenant chacun un seul ovule. Ce mame-

lon central du réceptacle creux
i est chargé caractérisent une troiet les multiples carpelles dont il est chargé caracté
sième tribu de Rosacées : celle des Fragariées.

Le Fraisier est une herbe vivace munie d'un rhizome d'où partent de grandes feuilles alternes composées de trois folioles dentées et portées au sommet d'un long pétiole. Du rhizome naissent aussi des tiges grêles ou coulants, qui rampent en senracinant par un marcottage naturel, multipliant ainsi la plante; enfin, à la belle saison, apparaissent des rameaux dressés, garnis de petites feuilles et terminés par des fleurs; celles-ci ont leur calice doublé d'un calicule, l'un et l'autre persistants. A la maturité, les carpelles se transforment en akènes, tandis que le mamelon du réceptacle sur lequel ils sont fixés grossit, devient charnu, rouge et comestible; on le nomme fraise et c'est lui qu'on prend ordinairement pour le fruit (fig. 72, B). Les Potentilles, herbes à fleurs blanches ou jaunes, communes partout, peuvent être considérées comme des sortes de Fraisiers dont le réceptacle reste sec.

Partout où l'homme cesse momentanément d'imposer des lois à la végétation, la Ronce (Rubus) triomphe, escalade les arbustes, étouffe les herbes sous ses arceaux inextricables armés de pointes aiguës. Ses sarments arqués sont de longs bras dont toutes les parties en contact avec le sol prennent racine, propageant ainsi la plante avec une étonnante rapidité. Les Ronces ont des feuilles alternes, composées de trois à cinq folioles; les pétioles et les nervures sont, ainsi que la tige, garnis de forts aiguillons crochus, élargis à leur base, non caducs comme dans le Rosier; leurs fleurs, blanches ou roses, en grappes terminales nombreuses, sont grandes et belles. Elles ne diffèrent de celle du Fraisier que par l'absence de calicule et par la nature du fruit; chaque carpelle devient un petit fruit à noyau; l'ensemble est une drupe multiple, luisante, noire ou bleuâtre à sa maturité : ćest la mûre sauvage, qui ña rien de commun, qu'une certaine analogie dans l'aspect, avec la vraie mûre, fruit du Mûrier. Le Framboisier sauvage (Rubus Idaus), commun dans les bois, est une Ronce moins férocement armée que les autres; ses tiges sont dressées, ses feuilles sont blanches en dessous et son fruit est rouge à la maturité (fig. 70). La Kerrie du Japon est un arbuste aux fleurs jaunes d'or, souvent doubles, formant des inflorescences globuleuses qui, de loin, rappellent des roses. Les Fragariées, sans avoir l'importance des Prunées, nous fournissent deux fruits parfumés et savoureux, la fraise et la framboise. Comme Fragariées ornementales: quelques espèces de Ronces à fleurs odorantes, des Potentilles, des Benoites (Geum), des Dryades et le curieux Fraisier des Indes, décoratif par ses rameaux retombants, ses fleurs jaunes et ses fruits rouges.

Rosées. - Nous connaissons maintenant quatre tribus de Rosacées : les Prunées, Spirées, Quillajées et Fragarićes; chez toutes, la base de la fleur se profile en un godet assez peu profond pour laisser le fruit parfaitement visible; ce sont des Rosacées à fruit nu. Les autres plantes de cette famille dont nous allons parler ont, au contraire, le fruit enveloppé dans un tube variable.

Dans les bois et dans les haies fleurit l'Eglantier ou Rosier des chiens (fig. 253, A), arbrisseau de 2 à 3 mètres, aux feuilles alternes, composćes de trois à sept folioles dentées et portant à la base du pétiole deux longues stipules vertes; tiges, pétioles, pédoncule floraux sont armés d'aiguillons caducs, forts et arqués comme des crocs de chien. La fleur, assez grande, odorante, a pour calice cing sépales verts offrant une disposition quinconciale : deux des sépales nont 


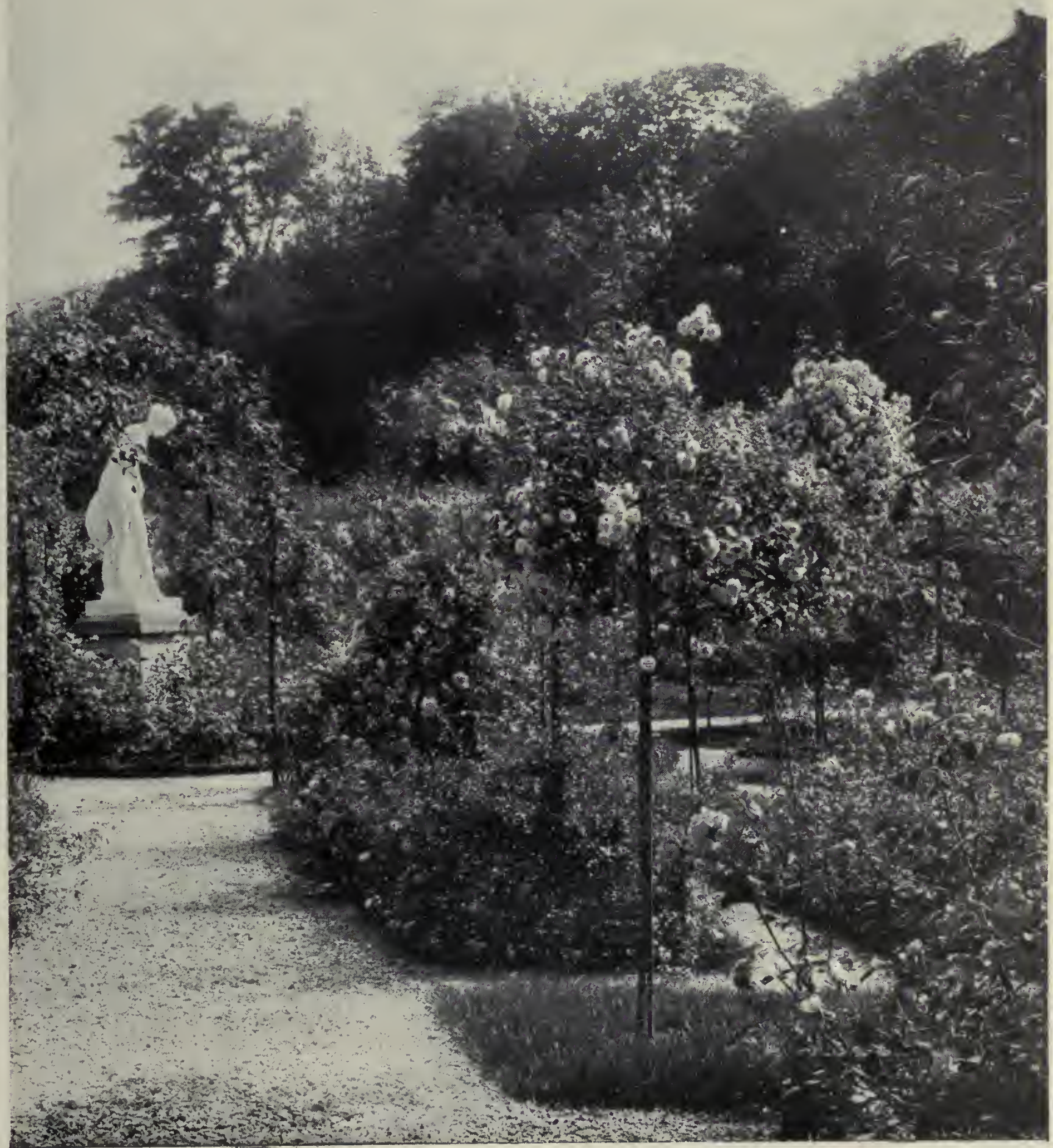

UN DETAIL DE LA ROSERAIE DE L'HAY (SEINE). 



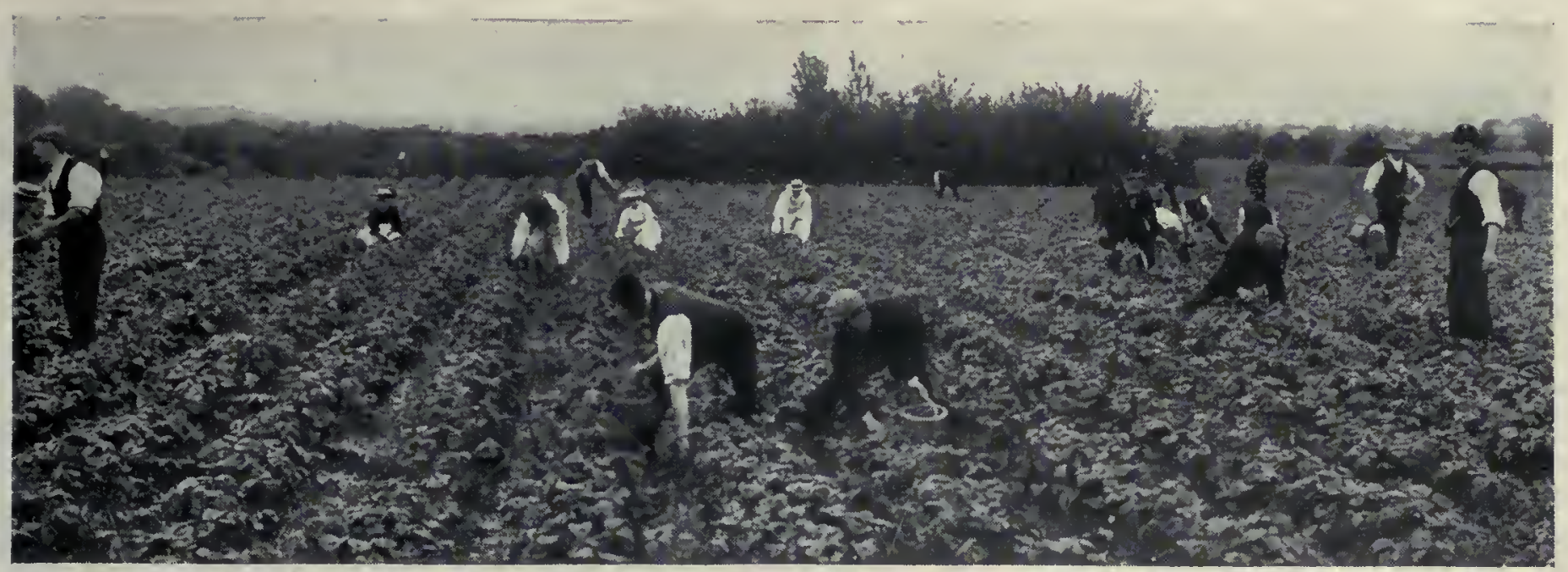

La cueiltette des fraises, en Angleterre.

aucune dentelure, deux autres portent de chaque côté deux petits lobes, tandis que le cinquième sépale n'offre deux lobes que d'un seul côté. A l'intérieur de ce curieux calice s'abritent une corolle à cing pétales et de nombreuses étamines. Toutes ces pièces sont fixées sur le goulot d'une sorte de bouteille, réceptacle à panse globuleuse et à col assez étroit dont le fond et les flancs portent de nombreux carpelles libres, uniovulés, à long style. A la maturité, chaque carpelle se transforme en akène; le réceptacle devient rouge et charnu: il constitue un faux fruit nommé cynorrhodon (fig. 253, B).

Le Rosier est le seul type de la tribu des Rosées : la forme de son réceptacle et ses nombreux carpelles la caractérisent. Le Rosier des chiens ( $R$. canina) se rencontre dans toute l'Europe et dans le nord de l'Asie; ses fleurs, roses ou d'un blanc rosé, sont très odorantes; le Rosier rouillé ( $R$. rubiginosa), presque aussi commun, a des fleurs d'un rose vif et peu parfumées, tandis que ses feuilles, garnies de petites glandes à leur face inférieure, laissent dégager, quand on les froisse, une agréable odeur de pomme rainette.

Depuis la plus haute antiquité, on cultive les Rosiers. Par la transformation de ses étamines en pétales, l'églantine, humble fleur sauvage, est devenue l'orgueil des jardins, la rose superbe, la reine des fleurs, dont les poètes de tous les temps ont célébré les louanges. Par les semis et les croisements, les horticulteurs ont obtenu d'innombrables variétés de roses (Voir PLANCHE EN COULEURS).

Les Rosiers font l'objet d'un commerce considérable, soit pour l'ornementation des jardins, soit en fleurs coupées. Tous sont de pleine terre; beaucoup de variétés sont rustiques et résistent très bien au froid; d'autres, au contraire, sont délicates (Thé, Bengale, Noisette, Banks, etc.) et doivent être protégées pendant l'hiver. Au point de vue de la durée de leur floraison, on distingue les non

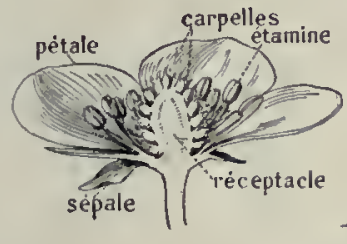

A

Fig. 252. - Fraisier.

A, Coupe de la fleur; B, Coupe d'une fraise.

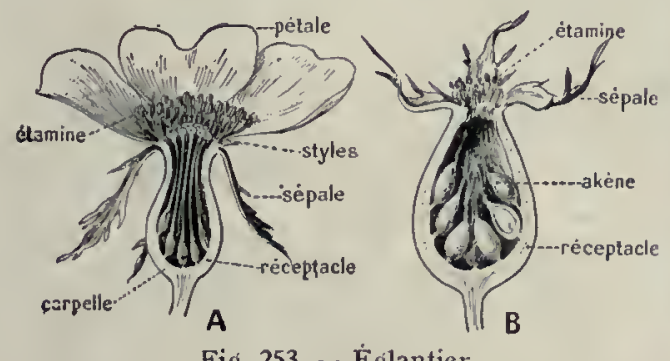

Fig. 253, - Églantier

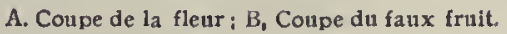

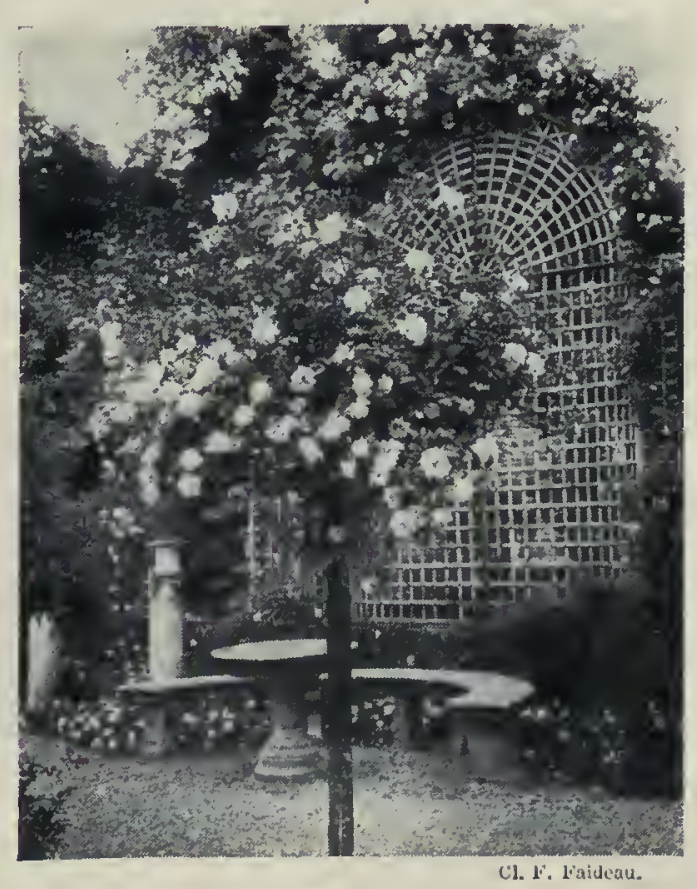

A la roseraie de l'Haý. remontants, c'est-à-dire ne fleurissant que pendant une courte période (Banks, Pompon, Toujours vert, Cent-feuilles, Multiflores, etc.) et les remontants ou perpétuels, qui donnent des fleurs pendant toute la végétation (Thé, Bourbon, Noisette, Bengale, etc.).

Voir rassemblées dans un jardin toutes les variétés de Rosiers, lequel de nous n'a fait ce rêve? Il existe, cependant, le paradis des roses; il est près de Paris, touchant à Bourg-la-Reine : c'est la Roseraie de l'Haÿ. Par une belle journée de juin, quel enchantement pour le visiteur qui en franchit pour la première fois la porte! Il vit dans une atmosphère de parfums; il a sous les yeux un décor de féerie qui se transforme au détour de chaque allée.

Potériées. - La tribu des Potériées est caractérisée par le petit nombre des carpelles et la consistance sèche du tube réceptaculaire. L'Aigremoine eupatoire, commune au bord des chemins, porte des feuilles alternes, à nombreuses folioles, des fleurs régulières en longue grappe, comprenant cinq sépales verts, cinq pétales jaunes, huit à douze ou vingt étamines insérées au pourtour d'un tube réceptaculaire très étroit, lequel abrite deux carpelles, qui, plus tard, deviendront deux akènes entourés par le tube devenu sec.

La Pimprenelle commune (Poterium Sanguisorba) a de petites fleurs groupées en une tête globuleuse : celles du sommet, femelles à deux petits stigmates rouges dressés; celles du pourtour, mâles ou parfois hermaphrodites avec des étamines pendantes. Le Coussotier d'Abyssinie ou Brayère anthelminthique (Hagenia) est un grand arbre à feuilles persistantes rappelant celles du Sorbier; ses fleurs, petites et nombreuses, constituent le cousso employé contre les vers intestinaux.

Pomées. - Nos forêts renferment plusieurs Rosacées ligneuses se distinguant par quelques caractères importants des formes qui précèdent : ce sont les Pommiers, Poiriers, Sorbiers, Néfliers, Aubépines, formant la tribu des Pomées à laquelle appartiennent nos arbres fruitiers à pépins.

Cueillons au printemps un corymbe des jolies fleurs rosées du Pommier; nous y retrouvons la symétrie de forme et de disposition observée jusqu'ici ; mais, pour la première fois dans la famille des Rosacées, nous remarquons que l'ovaire est adhérent: les cinq carpelles inclus dans l'intérieur du godet réceptaculaire se sont soudés à sa paroi et forment corps avec lui; seuls cinq styles, soudés, terminés par cinq stigmates, apparaissent au centre de la fleur. 
Si nous coupons celle-ci suivant son axe, nous voyons, à l'aide d'une loupe, que les cing styles nous conduisent en bas à cing loges, dont chacune renferme deux ovules. Après la fécondation, l'ovaire et le réceptacle qui l'entoure se développent énormément, deviennent charnus et constituent la pomme dont la structure a déjà été étudiée (p. 42). Le Pommier commun (Malus communis) se ren-

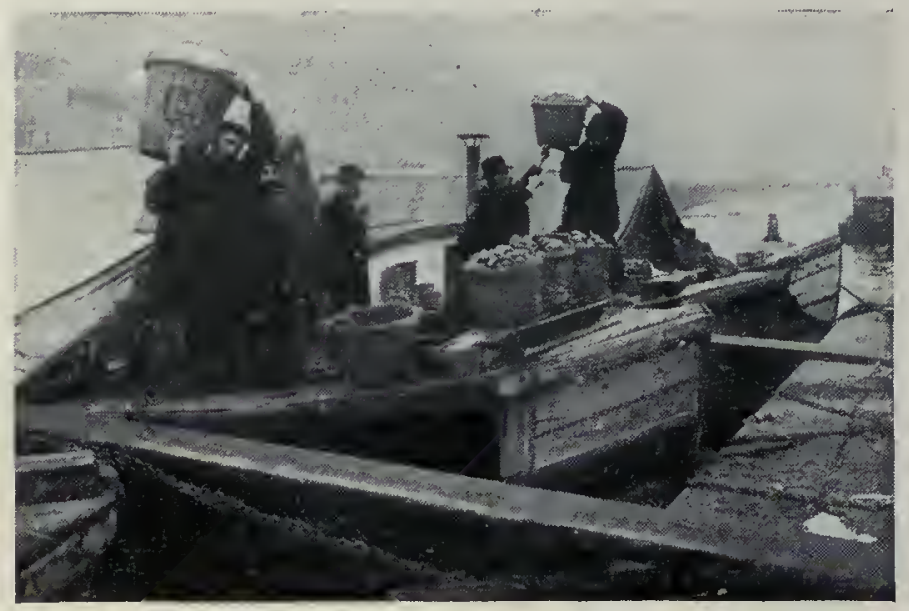

Le marché aux pommes, à Paris.

contre à l'état sauvage dans nos forêts. C'est un arbre atteignant 10 à 12 mètres de haut; ses rameaux stériles sont épineux; ses styles sont soudés; ses fruits sont petits, immangeables; sa culture a permis d'obtenir un nombre considérable de variétés.

Le Poirier commun (Pirus), épineux à l'état sauvage, inerme dans les cultures, atteint jusquà 15 mètres; ses fleurs, aux blancs pétales bordés de rose extérieurement, sont groupées en corymbes; sęs styles'sont libres; ses feuilles, alternes et oblongues comme celles du Pommier, sont plus longuement pétiolées. La poire diffère de la pomme par sa forme allongée, presque conique, mais même, lorsqu'elle est sphérique, la distinction est facile : la pomme est toujours ombiliquée au point d'attache de son pédoncule; la poire ne présente jamais cette particularité (fig. 69).

Le Cognassier commun (Cydonia), petit arbre de 4 à 8 mètres, a des fleurs, grandes, solitaires, blanches ou rosées, apparaissant en mai, après les feuilles; le fruit, ou coing, très gros, parfumé, duveteux et d'une belle couleur jaune, a la même structure que la poire, mais chacune de ses loges renferme plus de deux pépins; il est acerbe, astringent et n'est mangeable que cuit. On cultive en France une variété, dite mâle, à fruit rond (coing-pomme) et une autre, dite femelle, à fruit allongé (coing-poire).

Alisiers et Sorbiers sont des arbres très voisins dont les petits fruits n'ont ordinairement que trois carpelles. L'Alisier (Sorbus latifolia) est un arbre de 10 à 15 mètres de haut; on le cultive pour ses fruits rouge orange ou alises, de la grosseur d'une petite cerise, que l'on mange blets comme les nèfles. L'Alisier allouchier ( $S$. nivea) a des fruits rouges, acides, comestibles aussi après blettissement. Les Alisiers ont des feuilles simples, plus ou moins lobées et découpées; chez les Sorbiers elles sont composées; les fruits sont petits, rouges, arrondis, chez le Sorbier des oiseleurs (S. aucuparia), rouge jaunâtre et pyriformes chez le Cormier (S. domestica). Le. Néflier germánique (Mespilus) est un arbuste indigène, présentant à l'état sauvage des rameaux épineux. Ses fleurs isolées, blanches ou légèrement rosées, ont un calice à cing longs sépales. Le fruit ou nèfle, assez agréable lorsqüil est blet, est presque sphérique, avec un oeil très large et cing noyaux durs entourant les pépins (fig. 42). Le Biwa des Japonais ou Bibassier (Eriobotrya japonica), improprement nommé Néflier du Japon, a des fruits dont l'aspect rappelle celui de petits abricots; leurs pépins sont enfermés dans de gros noyaux. Les feuilles sont grandes, coriaces, persistantes; de ses grappes de fleurs blanches, se dégage une odeur d'amande amère; ses fruits mûrissent dès le mois d'avril en Provence, où il est naturalisé; leur pulpe est sucrée, acidulée et rafraîchissante.
Fig. 254.

Orpin brůlant. $a$, Fleur.
L'Aubépine ou Epine blanche (Crategus oxyacantha) offre en mai une floraison superbe : ses fleurs embaumées, groupées en corymbes, dissimulent son feuillage d'un vert tendre et son armure de rameaux épineux. A l'automne, ses branches sont chargées de cenelles, petits fruits rouges qui, au milieu d'une pulpe insipide, renferment de un à trois pépins, entourés de forts noyaux.

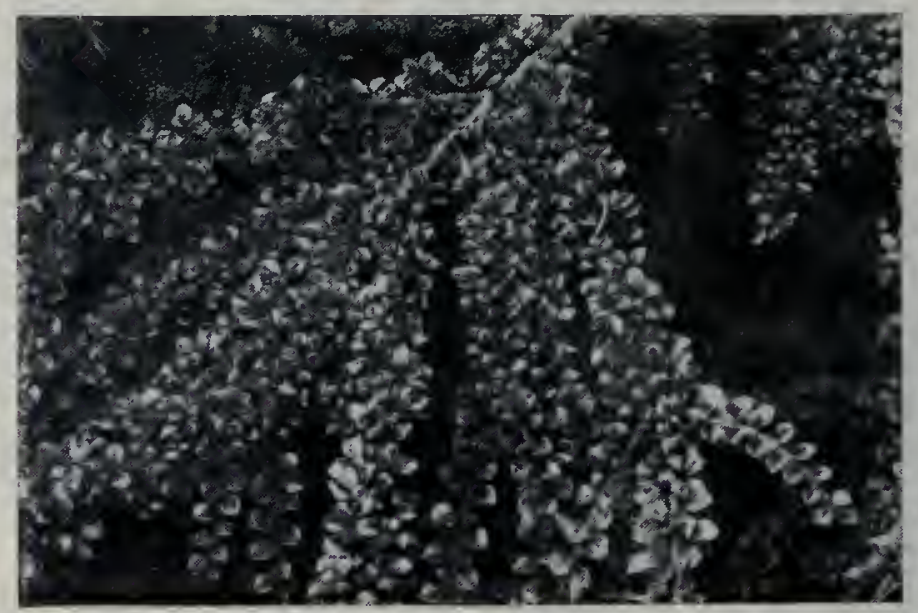

Branche, avec fruits, du Cotonéaster à petites feuilles.

Les Pomées nous fournissent des fruits de dessert; leur bois est recherché par les ébénistes; leur rôle décoratif est important. Citons pour cet usage les Pommiers d'ornement de Chine (Malus spectabilis), de Sibérie et du Japon, aux petits fruits rappelant des cerises ou des prunes; le Sorbier des oiseleurs, les Photinies, les Cotoneasters, les variétés de l'Aubépine commune, de l'Aubépinẹ buisson ardent (Cratagus pyracantha) et del'Azerolier (Cratagus azarolus).

Crassulacées, Céphalotacées. - Au cour de l’été, sur les rochers arides, sur le versant des toits orientés au midi, sur les vieux murs, fleurissent les Joubarbes (Sempervivum), dont les feuilles charnues sont groupées en rosettes persistantes : c'est l'Artichaut des toits. Au centre de ces rosaces se dressent, en été, des hampes terminées par des cymes de fleurs roses régulières, groupées en panicules; chacun des verticilles floraux comporte douze à quinze pièces, avec un nombre double pour les étamines. Les carpelles, libres ou rarement soudés entre eux, deviennent des follicules.

Les Crassulacées (du latin crassus, épais), famille à laquelle appartient la Joubarbe, ont des feuilles charnues, épaisses; elles affectionnent les endroits secs et peuvent résister longtemps à la sécheresse, grâce aux réserves d'eau de leurs feuilles; ce sont des plantes grasses. Elles se rattachent aux Géraniacées et aux Rutacées par leur double verticille d'étamines, mais surtout aux Saxifragacées par tous leurs caractères floraux; ce sont des caliciflores à pistil libre, voisines des Légumineuses et des Rosacées.

Les Sédum ou Orpins (fig. 254) sont fort répandus en France, dans les mêmes stations que les Joubarbes. Ce sont des herbes vivaces qui, selon les espèces, ont des feuilles plates, cylindriques ou même globuleuses; les fleurs, délicates, élégantes, jaunes, blanches ou roses, ont leurs pièces ordinairement par 5 . Les principales espèces sont le Sédum réfléchi et le Sédum âcre ou Poivre de muraille, à fleurs jaunes, le Sédum blanc ou Raisin de rats, le Sédum reprise $(S$. Telephium), grande et belle plante à fleurs roses qui, contrairement à ses congénères, se plaît dans les bois humides. On trouve encore en France, surtout dans le Midi, l'Ombilic à feuilles pendantes ou Nombril de Vénus, qui doit son nom à la cavité centrale de ses feuilles charnues; sa corolle est gamopétale.

Les Crassulacées ont des racines ténues, nombreuses, s'insinuant dans les plus petites fissures; elles se multiplient abondamment par des tiges rampantes ou des filets issus des rosettes de feuilles. Elles servent pour orner les rochers artificiels, les suspensions. Citons les Cotylédons, l'Échevéria glauque du Mexique, les Rochéa et les Crassules du Cap, les Kalanchoe à corolle soudée.

Le Céphalote folliculaire, unique représentant de la famille des Céphalotacées, vit dans les marais du sud-ouest de l'Australie. Rapprochée des Saxifragacées par son port et sa structure florale, cette petite herbe rappelle les Népenthès par ses feuilles en urne qui la font ranger dans les plantes dites carnivores. Ses pièces florales sont disposées par six, sans corolle, et l'ovaire est supère. 


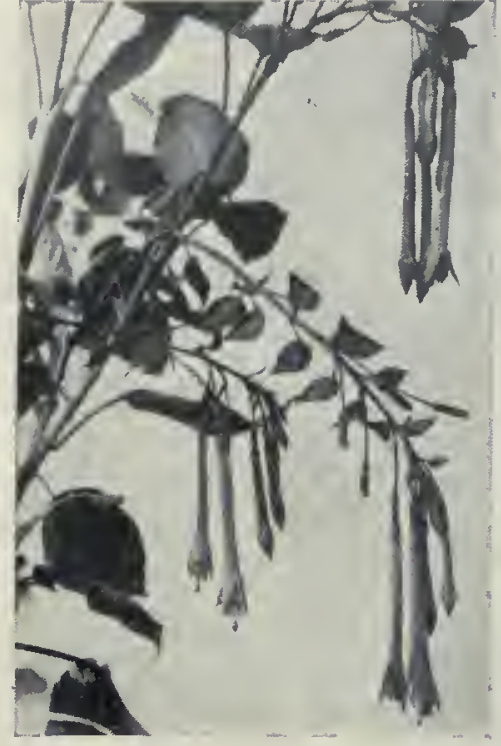

Fucbsia britlant (fulgens).

feuilles alternes, simples, à fleurs régulières, solitaires ou en grappes, dont le calice tubuleux à quatre ou cing lobes est souvent coloré; les quatre ou cinq pétales sont petits; les étamines, insérées au sommet du tube du calice, sont en nombre égal; l'ovaire est infère, à une loge, et formé de deux carpelles ouverts soudés; le fruit est une baie. Trois espèces fruitières indigènes sont cultivées en Europe : le Groseillier rouge ou à grappes (fig. 256) [Ribes rubrum], non épineux, à fleurs petites et verdâtres, en grappes pendantes; le Groscillier noir ( $R$. nigrum) ou Cassis, non épineux, au calice glanduleux, au fruit noir; enfin, le Groscillier épineux ( $R$. Uva crispa), dont le fruit lisse ou velu est la groseille à maquereau ( fig. 66, A). En dehors des espèces fruitières, plusieurs Groseilliers à jolies fleurs ornent les jardins (R. aurcum, palmatum, sanguineum).

Hamamélidacées. - Les Hamamélidacécs sont des plantes ligneuses à feuilles stipulées: Leurs fleurs, très petites, régulières ou non, unisexuées ou hermaphrodites, sont ordinairement réunies en glomérules; l'ovaire est plus ou moins adhérent; le fruit est une capsule ligneuse. L'Hamamélis de Virginie, de l'Amérique du Nord, a le port d'un Noisetier; ses fleurs sont jaunes et du type 4; l'extrait alcoolique de l'écorce et des feuilles est employé contre les affections du système veineux : varices, hémorroïdes, phlébites.

Les Liquidambars forment une famille voisine à canaux; ce sont de beaux arbres à suc balsamique, à feuilles caduques, alternes, lobées, à port de Platane, à fleurs sans périanthe; les fleurs mâles sont en capitules, groupés en épis ou en grappes; les capitules femelles, solitaires et longuement pédonculés, se transforment en capsules globuleuses enchâssées dans le capitule devenu ligneux et hérissé de pointes qui sont des styles durcis. Le Liquidambar oriental, haut de 12 à 15 mètres, forme des forêts dans l'Asie Mineure; de son écorce interne, bouillie dans l'eau, se dégage une résine, le styrax liquide, employé en médecine et en parfumerie. Le Liquidambar d'Amérique (L. styraciflua) ou Copalme atteint 40 mètres; son bois sert en ébénisterie; par incision de l'écorce, il laisse écouler le baume copalme ou ambre liquide, qui a les propriétés excitantes des autres résines aromatiques.

Onagracées. - Le Fuchsia est une plante populaire; il n'est pas de bonne fête sans lui; on le cultive dans tous les jardinets; il orne les fenêtres des plus humbles demeures de ses jolies fleurs rouges qui pendent comme des sonnettes, et qui se succèdent jusqu'à l'arrière-saison. Feuilles simples, le plus souvent opposées ; fleurs longuement pédonculées, formées d'un calice tubuleux coloré à quatre lanières, de quatre larges pétales, de huit étamines saillantes, d'un ovaire adhérent à quatre loges, avec un long style que couronnent quatre stigmates; le fruit est une baie : tels sont les caractères des Fuchsia et ceux de la plupart des Onagracées. Les Onagracées ou Enothéracées ont de grandes affinités avec les Saxifragacées par leur double rangée d'étamines, mais leur ovaire est plus complètement adhérent et leurs graines nont pas d'albumen.

L'Onagre bisannuelle (Enothera), des lieux sablonneux, est venue de l'Amé rique du Nord vers 1614; c'est une grande herbe à larges fleurs jaunes disposées en un épi terminal; son fruit est une capsule. Les Épilobes sont des herbes à fleurs roses, d'un port élégant; leurs graines sont entourées de filaments soyeux. Dans les jardins, on utilise aussi les Clarkies, les Gaura et les Godetia.

Plusieurs Onagracées sont aquatiques. Les Jussiées vivent dans les rivières des pays chauds; elles ont une souche d'où partent, en plus des racines ordinaires, des organes dressés qu'on a qualifiés de racines natatoires et qui sont, en réalité, des réservoirs d'air pour les parties submergées. La Mâcre ou Châtaigne d'eau (Trapa natans) est une plante annuelle flottante; elle naît dans la vase et sy fixe par un rhizome; plus tard, elle se détache du sol, flotte entre deux eaux et ne s'élève à la surface que pour y porter ses fleurs. Ses feuilles flottantes forment une rosette au sommet de la tige; leur pétiole, d'abord cylindrique, se renfle en son milieu en une vésicule qui maintient la plante au-dessus de l'eau. Aux fleurs petites et blanches, du type 4 , succèdent des fruits à coque épaisse, pourvus de quatre cornes épi-
neuses très dures qui représentent les sépales accrus et lignifiés; chaque fruit renferme une graine volumineuse, que l'on mange crue, ou cuite sous la cendre. En Chine, au Japon, on cultive la Mâcre à deux cornes, pour son fruit comestible, qui ressemble, en petit, à une tête de bœuf.

Haloragacées, Lythracées. - Des Onagracées aquatiques on rapproche les $P$ esses ou Hippuris, les Myriophylles, qui forment la famille des Haloragacécs. Les Cornifles ou Cératophylles, les Callitriques appartiennent à des familles aquatiques voisines. $\mathrm{Ce}$ sont des plantes submergées dont le sommet apparaît ordinairement à la surface de l'eau pour la floraison. Avec leurs fleurs minuscules, leurs feuilles souvent découpées en lanières filiformes, elles rappellent les Charaignes et les autres Algues qui les accompagnent dans les eaux douces (Voir planche en couleurs des PLANTES D'EAU).

Les Lythracées sont des Onagracées à ovaire libre. Il y en a une trentaine de genres propres aux régions tropicales; en France, nous possédons le genre Lythrum ou Salicaire, qui affectionne les lieux humides. La Salicaire commune porte des feuilles opposées et se termine par de longs épis de glomérules de fleurs d'un beau rouge pourpre. Chaque fleur comprend un calice à six dents (et un calicule), une corolle à six pétales, douze étamines; l'ovaire libre, à deux loges, devient une capsule (fig. 101, C, D, E).

Dans les jardins on cultive les Cuphéa, qui sont de jolies plantes américaines à fleurs irrégulières. Le Lawisonia inerme ou Henné

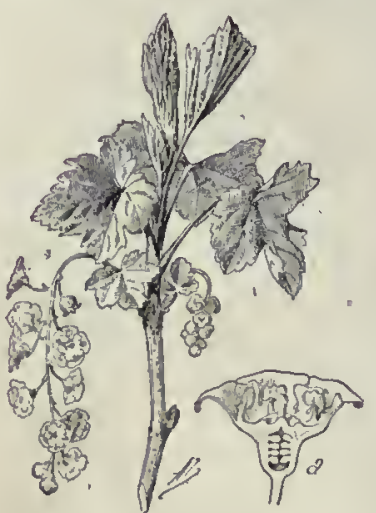

Fig. 256.

Groseitlier à grappes. $a$, Coupe de la fleur. est un arbrisseau de 3 à 4 mètres, à feuilles opposées; ses fleurs sont petites, blanches, odorantes, dutype 4, groupées en panicules.

Myrtacées. - Le Myrtc croît sur les collines du littoral méditerranéen; c'est un arbrisseau aromatique, rameux, à feuilles opposées, persistantes, coriaces, parsemées de poches glanduleuses. Les fleurs, blanches, odorantes et solitaires, présentent un calice en tube ovoïde terminé par cinq dents, une corolle à cinq pétales égaux, un grand nombre d'étamines à filets libres qui sont disposées sur plusieurs rangs, un ovaire adhérent à trois loges; le fruit est une baie d'un bleu noirâtre. 


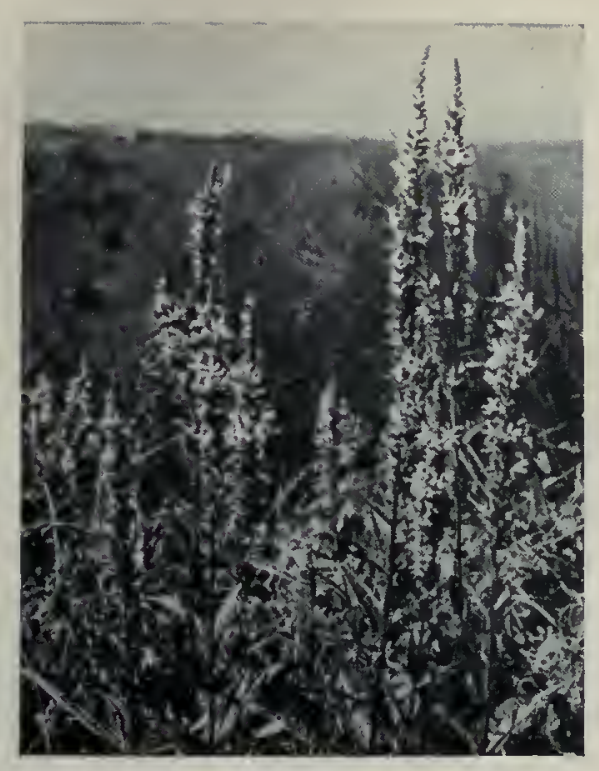

Salicaire commune.

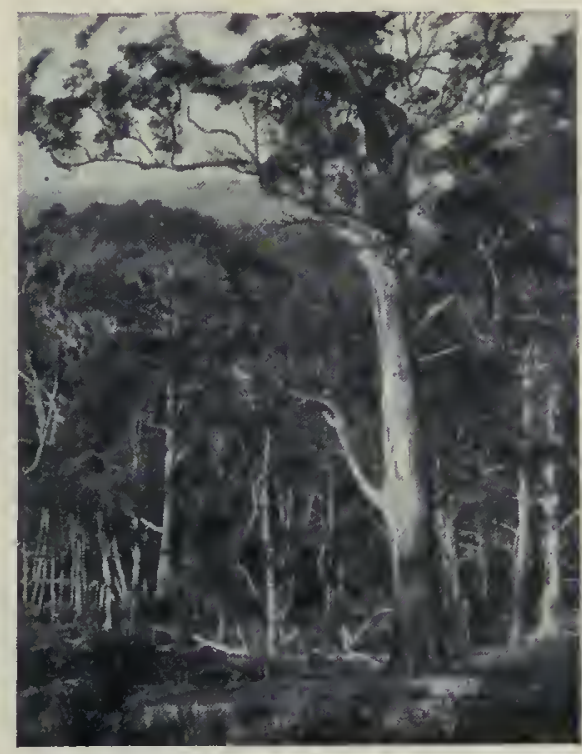

Forêt d'Eucalyptus (Australie).

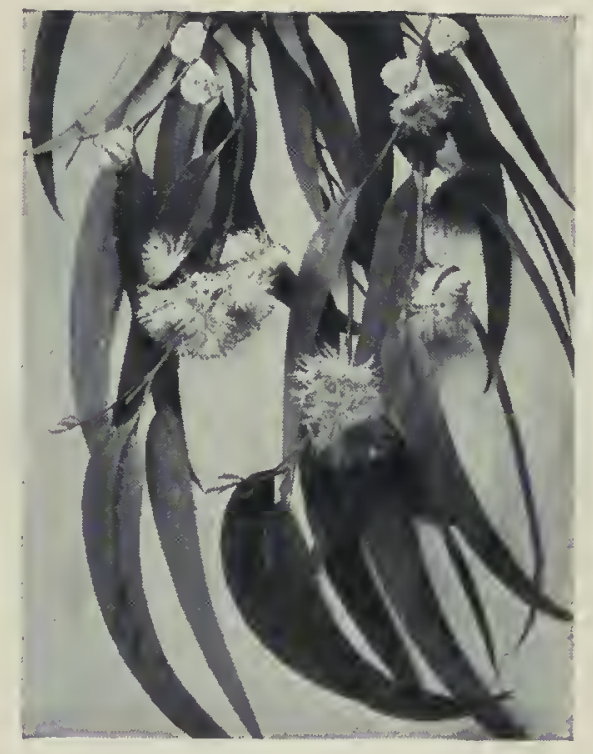

Eucalyptus en fleurs.
Les Myrtacées forment une grande famille d'arbres ou d'arbustes presque tous tropicaux, à feuilles généralement opposécs, simples, à fleurs hermaphrodites régulières dont les pièces sont par quatre ou par cinq; les étamines, très nombreuses, sont, le plus souvent, ramifiées en groupes dans lesguels elles sont plus ou moins soudées; l'ovaire adhérent donne un fruit variable. Ces plantes fournissent des bois durs et incorruptibles, des essences médicinales, du tanin, des fruits ou graines comestibles. Voisines des Rutacées par leurs canaux sécréteurs, des Hypéricacées par leurs nombreuses étamines, les Myrtacées se rapprochent par leur structure florale des Saxifragacées et surtout des Lythracées, mais les sécrétions aromatiques de l'ćcorce et des poches sécrétrices les distinguent nettement de toutes les familles du groupe ćtudić en ce moment.

Le Caryophylle aromatique ou Giroflier, originaire des Moluques, est un arbre de 8 à 15 mètres, à feuilles persistantes; le fruit est une drupe sèche, ovoïde; les fleurs non épanouies sont les clous de girofle. Beaucoup d'Eugéniers voisins ont des fruits comestibles: l'Eugénier de Michel ou Cerisier de Cayenne, Cerise carrée; l'Eugénier jambos ou Jambosier de l'Inde, etc. Les fruits de l'Eugénier piment (Pimenta officinalis et acris) des Antilles servent de condiment.

Les Goyaviers sont de petits arbres fruitiers des régions chaudes de l'Amérique et de l'Asie; leurs fruits ou goyaves sont des baies à quatre ou cinq loges. Le Goyavier blanc ou Goyavier poire (Psidium Goyava, var. pyriferum) fournit les fruits les plus estimćs: puis viennent le Goyavier rouge ou Goyavier pomme (var. pomiferum); le Goyavier fraise ( $P$. Cattleyanum), plus rustique, qui mûrit en Provence ses fruits dont on fait des confitures.

L'Eucalyptus globuleux ou Gommier bleu de Tasmanie est acclimaté sur le littoral de la Provence et en Algérie; il orne les avenues, les jardins, les parcs; on admire sa forme robuste, l'aspect singulier de son feuillage. A Paris, pendant l'hiver, on vend ses branches chargées de fleurs étranges et de feuilles glauques recourbées en faux. Lorsque l'Eucalyptus est tout jeune, il porte des feuilles opposées, sans pétiole et à limbe horizontal, comme celles de nos arbres; mais les feuilles qui apparaissent à l'âge adulte sont alternes, plus longues, plus étroites, et pourvues d'un pétiole qui subit une demi-torsion; elles pendent verticalement et $n$ arrêtent guère les rayons solaires; les forêts d'Eucalyptus de l'Australie sont des forêts sans ombre. Les boutons floraux, dont l'épanouissement exige une année, sont solitaires à l'aisselle des feuilles; le calice est épais, coriace; les sépales en sont soudés en un tube court et presque quadrangulaire que surmontc la corolle, sous la forme d'un capuchon renflé en son milieu; le tout est d'un vert foncé, avec des reflets bleuâtres. Plus tard, l'opercule se détache circulairement et laisse jaillir une couronne d'étamines jaune pâle, fixées en grand nombre à la paroi interne du calice; elles entourent l'ovaire arrondi, à quatre loges multiovulées; le fruit est une toute petite capsule.

L'Eucalyptus globuleux, qui atteint jusqu'à 100 mètres de hauteur dans son pays d'origine, est très aromatique; il sécrète une huile essentielle, l'eucalyptol, qui a des propriétés tébrifuges, stimulantes et aromatiques. On connait, en Australie, plus de cent espèces d'Eucalyptus ou Gommiers, formant d'immenses forêts dont l'exploitation est très active: certaines espèces atteignent jusqu'à 165 mètres de hauteur. Plusieurs fournissent un kino utilisé pour le tannage et la teinture: d'autres, une manne analogue à celle des Frênes; la plupart sont importantes par leur bois. Le Jarrah ou Acajou australien (Eucalyptus marginata) ne dépasse pas 30 mètres; son bois rouge et très dur résiste d'une façon merveilleuse à l'eau, aux tarets et aux termites; on en fait des pilotis, des pavés, des meubles; le Karri ou Gommier blanc ( $E$. diversicolor) atteint 100 mètres; il fournit un bois un peu moins dur.

Les forêts d'Australie sont aussi riches en Mélaleuques, arbres odorants, à feuilles rigides, dont les fleurs sont du type 5. Le Mélaleuque arbre blanc des Moluques (Niaouli cajeput) donne l'huile de cajeput, essence d'odeur forte employée en frictions contre les rhumatismes; les Mélaleuques à fleurs vertes et arbre blanc fournissent l'essence de niaouli, utilisée en parfumerie; on en a extrait le goménol, très utile dans les affections des voies respiratoires.

Les Myrtacées, dont il nous reste à parler, ne sont pas aromatiques. Le Grenadier (Punica Granatum) est cultivé autour du bassin méditerranéen (fig. 257). C'est un petit arbre un peu épineux, à feuilles entières, luisantes, non ponctućes; les fleurs, fort jolies, ont un calice coriace à cinq lobes, une corolle à cinq pétales un peu chiffonnés et d'un rouge éclatant insérés au sommet du calice, de nombreuses étamines, un ovaire adhérent à plusieurs loges et comprenant deux verticilles de carpelles, parmi lesquels cinq sont extérieurs et trois intérieurs; au cours du développement, les carpelles externes se trouvent portés au-dessus des autres. Le fruit ou grenade est une capsule globuleuse couronnée par les dents du calice, entourée par une enveloppe coriace et renfermant dans ses loges de nombreuses graines dures, dont le tégument rouge, transparent, à saveur aigrelette et sucrée, constitue la partie comestible. L'écorce de la tige et le péricarpe du fruit sont astringents; ['écorce

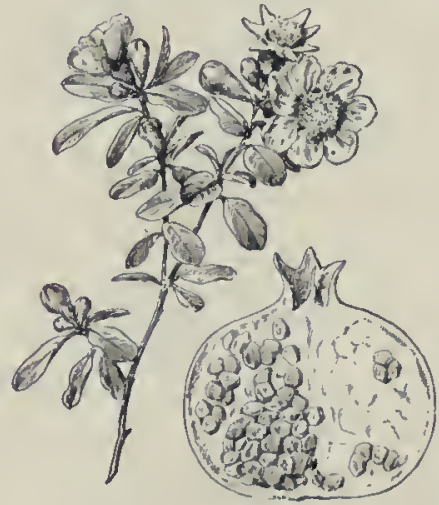

Fig. 257. - Grenadier et Grenade ouverte. fraíche de la racine renferme un alcaloïde, la pelletiérine, douć de propriétés téniafuges énergiques. Le Bertholletia élevé ou Châtaignier du Brésil est un grand arbre à gros fruits quadrangulaires et dont les graines comestibles ou noix de Para sont oléagineuses (Lécythidée).

Les Mélastomacécs forment une famille de plantes tropicales se distinguant des Myrtacées par leurs étamines en nombre défini; leur corolle est à préfloraison tordue ou valvaire. Beaucoup d'espèces ont un feuillage ornemental et sont cultivées dans les serres. 


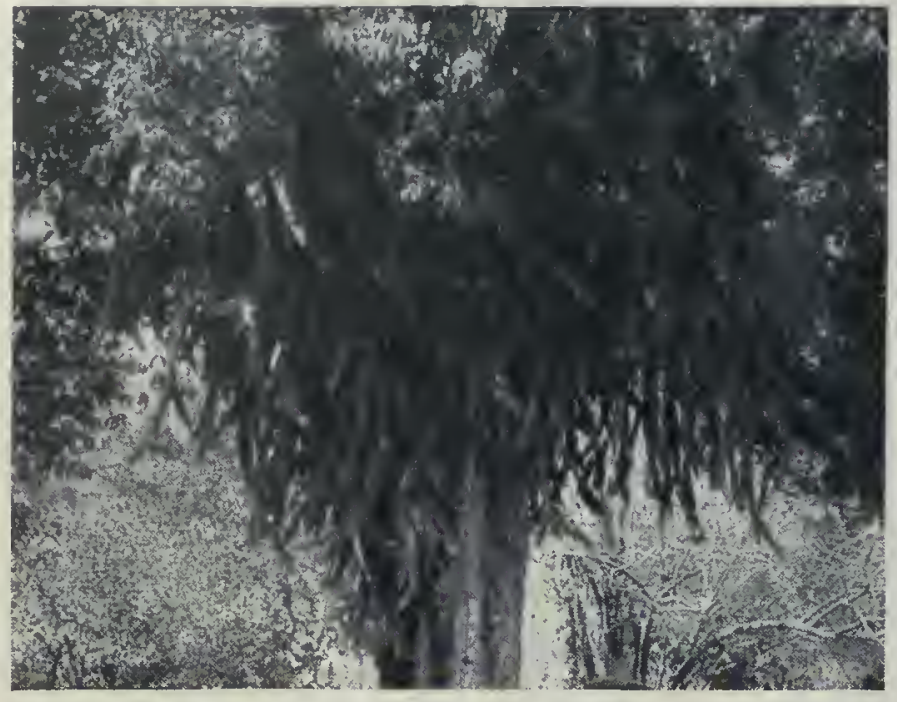

Cierge (Cereus ocamponis) [Mexique].

Rhizophoracées. - Le famille des Rhizophoracécs se relie aux Onagracées par ses genres à pistil adhérent, aux Lythracées par ses genres à pistil libre; elle diffère de ces deux familles par ses feuilles pourvues de stipules caduques.

Les Mangliers ou Rhizophora (fig. 114) font partie de la mangrove, c'est-à-dire de cette forêt singulière du littoral dans les pays chauds, et dont toutes les plantes, bien qu'appartenant à des familles diverses, présentent une certaine ressemblance due aux conditions d'existence analogues, et ont reçu le nom général de Palétuviers. Nous avons déjà décrit (p. 18) les curjeuses racines en échasse des Palétuviers, qui forment un fouillis inextricable fréquenté par des légions de crabes et servant de support à une foule de mollusques. Hauts de 10 mètres, les Mangliers portent des feuilles opposées, entières et coriaces; les fleurs, d'un jaune verdâtre, sont du type 4 , avec huit étamines à court filet, insćrées sur les pétales; l'ovaire adhérent est à deux loges; le fruit est indéhiscent, à une loge, à une seule graine qui présente la propriété déjà signalée d'être vivipare.

\section{LES CACTACEES}

Les Cactacées forment une famille très homogène et très isolćc; elles comprennent un millier d'espèces vivaces, localisées à peu près complètement dans les régions chaudes et sèches de l'Amćrique, ef principalement du Mexique. Ce sont des plantes grasses aux formes étranges, adaptées d'une façon merveilleuse à la vie sur les plateaux rocailleux, où quelquefois une année s'écoule sans une goutte de pluie. Leurs tiges simples ou ramifiées sont en colonnes cannelées, en boules, en rubans ou en raquettes articulées; elles sont revêtues d'une écorce épaisse, verte et charnue, constituant une abondante réserve d'eau. Pour diminuer la surface évaporante et économiser l'eau, les feuilles ont disparu; à leur place on trouve des coussinets hérissés de faisceaux d'épines souvent redoutables, défense nécessaire contre la dent des animaux herbivores. De plus, les racines courent à la surface du sol et envoient, entre les interstices des pierres, de longs filets qui plongent et aspirent l'humidité dans la profondeur. Les fleurs des Cactacées sont souvent grandes et belles, mais très éphémères. Régulières, hermaphrodites, solitaires, elles se composent de nombreuses pièces florales, disposées suivant une spirale continue, et sont plus ou moins longuement soudées entre elles; l'ovaire est adhérent, à une seule loge, à style unique divisé en segments radiés dont le nombre égale celui des carpelles; le fruit est une baie. En somme, les Cactacées correspondent aux Nyma phéacées, chez les Dialypétales à ovaire libre, par la disposition spiralée de leurs pièces florales.

On divise les Cactacées en trois tribus : les Opuntioïdées, chez lesquelles la tige est en raqueties aplaties; les Céréoidées, à tige cylindrique ou sphérique; enfin les Péreskioïdées, qui ont des feuilles.

L'Opuntia figuier d'Inde, du pre-

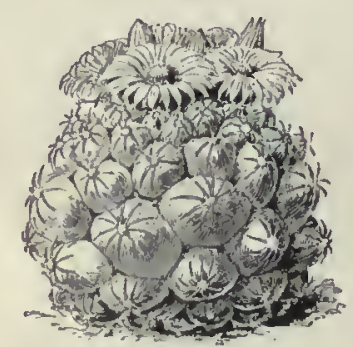

Fig.258. - Mamillaire

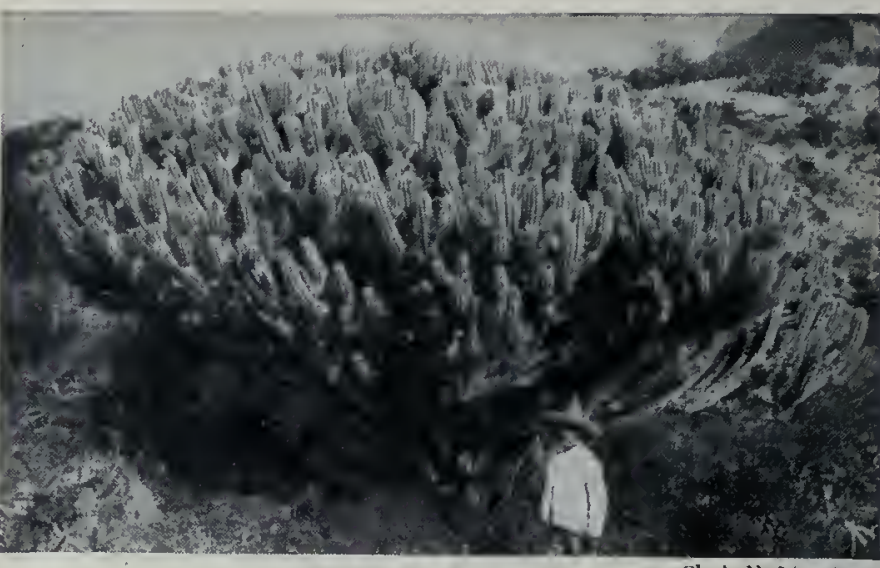

Cierge (Cercus chichipe) [Mexique].

mier groupe, dit aussi Cactus raquette, Nopal, Figuier de Barbarie, est naturalisé aujourd'hui sur tout le pourtour du bassin méditerranéen. Lorsqu'il est jeune, il est herbacé; ses tiges sont formées d'articles plats en raquettes; les vieux exemplaires ont un tronc ligneux presque circulaire, et atteignent 2 à 3 mètres de hauteur. Les fleurs sont grandes et rougeâtres; le fruit, ou figue de Barbarie, gros comme un ouf de poule, présente à sa surface de petits tubercules munis de piquants; la pulpe en est farineuse, sucrée, assez délicate. L'Opuntia a pris une certaine importance culturale en Algérie, en Tunisie, et surtout en Sicile.

A la tribu des Céréoïdées appartiennent de nombreux genres. Dans la Basse-Californie et les autres régions arides du Mexique, le Cierge géant (Cereus giganteus) se dresse isolé ou par petits groupes au milieu d'autres plantes grasses de taille plus réduite. C'est une sorte de colonne verte, charnue, hérissée, atteignant parfois 15 à 18 mètres de hauteur, avec un diamc̀tre de 80 centimètres à la base; quelquefois elle se ramifie, porte trois à quatre branches, six à huit au plus, et prend l'apparence d'un gigantesque candélabre. Globuleux quand il est jeune, le Cierge gćant devient cylindrique, sillonné de côtes longitudinales que surmontent des faisceaux d'épines très aiguës. Le Cierge géant, le Cierge de Pringle sont désignés au Mexique sous le nom de Cardon; ils sont très utiles dans ces régions dénućes de ressource; leur tronc ligneux sert de bois de construction ou de combustible; leurs fruits, nommés pitayas (C. pruinosus, queretarensis, Dyckii, Thurberi, etc.), sont excellents; on en retire par fermentation une boisson enivrante. Le Cierge du Pérou est aussi une très grande espèce atteignani jusqu'à 20 mètres de hauteur. Sous le nom de Cierge rocher, on cultive en serre froide une variété monstrueuse à port épaissi, devenant une grosse masse charnue, mamelonnée et presque informe.

Tous les Cierges ont des fleurs superbes de 10 à 15 centimètres de largeur; chez certaines espèces, elles ne s'ouvrent que la nuit et leur durée est très courte. Le Cierge à grandes fleurs et le

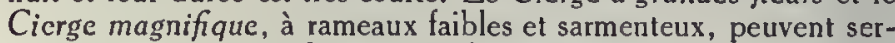
vir à tapisser un mur de serre et fleurissent abondamment; d'autres ont des tiges cylindriques traînantes ou grimpantes, se pliant facilement sur les supports et prenant les formes les plus curieuses : tels sont le Cierge serpent et le Cierge fouet. Les Échinopsis, les Pilocereus sont parmi les Cierges les plus cultivés dans les serres.

Tandis que chez les Cierges les fleurs naissent latéralement, elles se développent sur les aréoles chez les Échinocactus, plantes dont la tige globuleuse, oblongue ou cylindrique, porte plusieurs rangs de côtes saillantes armées de faisceaux d'épines. Les Visnaga des Mexicains sont de volumineux Échinocactus semblables à des grosses bornes de 3 mètres de hauteur; leur tronc ne se lignifie pas comme celui des grands Cierges. Quand le fourrage

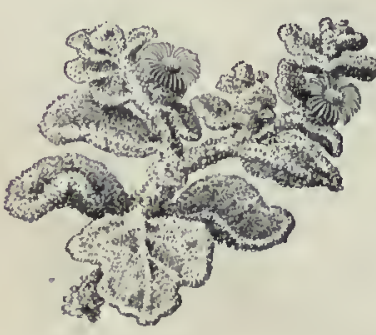

Fig. 259. - Ficoide. manque, les habitants enlèvent toutes les épines du Visnaga, le débitent en tranches charnues dont les chevaux sont très friands.

Les Mamillaires (fig. 258) sont de petites Cactacées à tige courte, couverte de tubercules mamelonnćs, à épines ; les fleurs, assez menues, naissent à l'aisselle des mamelons.

Les Phyllocactus et les Epiphyllum diffèrent des plantes précédentes par leurs tiges plates donnant l'idée 
de feuilles épaisses et charnues; chez les seconds, elles sont, de plus, articulées (Voir PLANCHE EN COULEURS).

Les Péreskioïdées sont les seules Cactacées pourvues de feuilles bien développées, un peu charnues, avec des aiguillons à la base; elles ont une tige cylindrique ramifiée qui leur donne l'aspect ordinaire des arbrisseaux. L'espèce la plus intéressante est la Péreskia principales, des côtes secondaires. On y range, à côté de la Carotte, plusieurs plantes utiles. La Coriandre cultivée est annuelle, à feuilles très découpées et à fleurs blanches; ses fruits verts sentent la punaise, mais la dessiccation leur fait acquérir une agréable odeur; ils sont digestifs comme l'anis. Les fruits du Cumin ont les mêmes usages. Les Thapsia sont de grandes herbes vivaces de la région

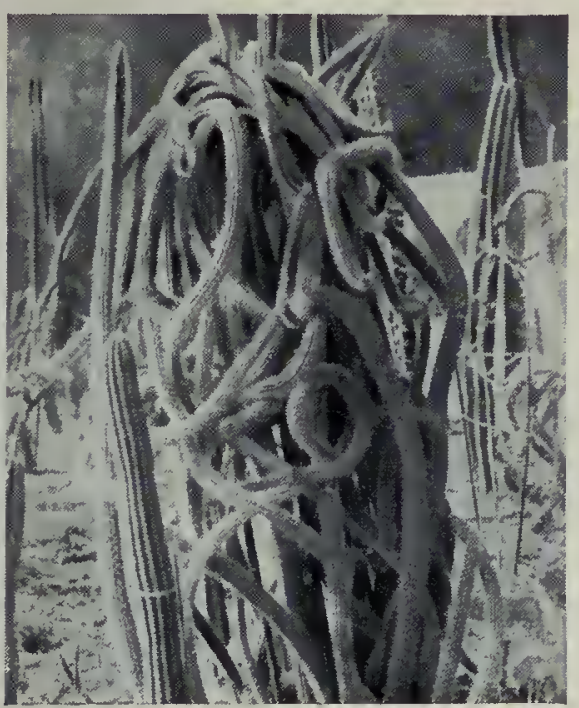

Cierge serpent.

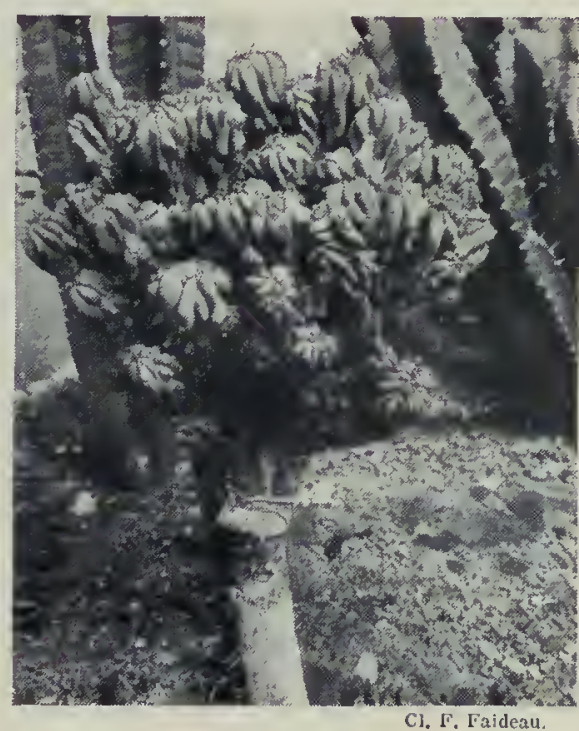

Cierge rocher (C. du Pérou).

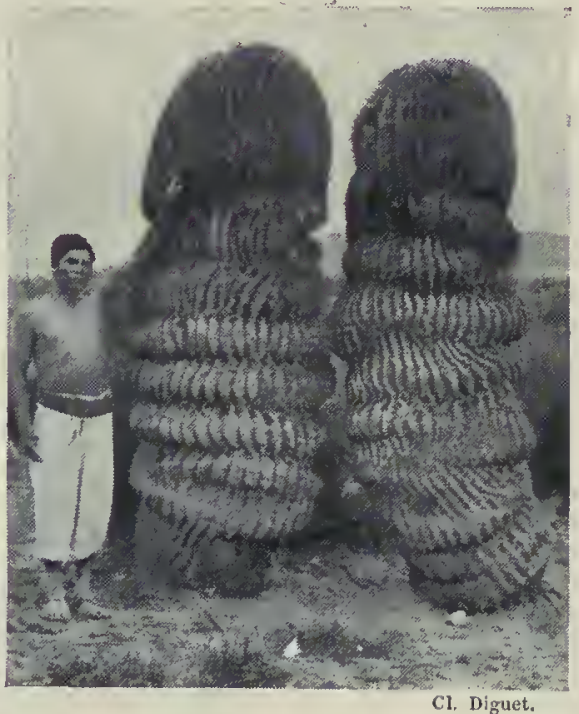

Echinocactus ingens. épineuse ou Groseillier d'Amérique (des Barbades), dont les fruits rappellent la groseille à maquereau par l'aspect et par la saveur.

Les Cactacées sont très recherchées pour l'ornementation des serres et de l'appartement. Elles tiennent peu de place, sont d'une extraordinaire résistance, se bouturent et se greffent avec facilité.

Ficoïdées. - La famille des Ficoïdées ou Mésembryanthémacées, qui a des affinités avec celle des Caryophyllacées, en présente aussi avec les Cactacées par ses fleurs et par le tissu charnu des feuilles qui font de beaucoup d'entre elles des plantes grasses. II nous suffira de citer les Ficoïdes (fig. 259), herbes ornementales par leurs feuilles charnues de formes bizarres. Leurs fleurs, régulières, assez grandes, formées de nombreuses pièces, souvrent chaque jour vers midi et se referment dans la soirée.

\section{LES OMBELLIFÈRES}

Dans les prairies sèches, calcaires, se dressent, au cœur de l'été, les blanches ombelles de la Carotte sauvage (Daucus Carota). Cette herbe bisannuelle porte des feuilles alternes, à divisions étroites et très multipliées. Les fleurs, petites et nombreuses, sont groupées en ombelles composées ayant jusqu'à quarante rayons ; l'involucre est très découpé; l'involucelle ou collerette de chaque ombellule est divisée en trois parties. Les fleurs ont un calice à cinq sépales très petits, une corolle à cing pétales libres ( $f$ g. 260$)$, recourbés, cinq étamines, un ovaire adhérent surmonté de deux styles et de deux stigmates; formé de deux carpelles, il donne à la maturité deux akènes qui, attachés à un support en $Y$, s'écartent l'un de l'autre et sont couverts de pointes raides.

La famille des Ombellifères, très homogène, comprend des herbes possédant une tige cannelée et creuse, à cause de la prompte disparition de la moelle; les feuilles sont alternes, à pétiole élargi en gaine et à limbe découpé; les fleurs, petites et régulières, se groupent en ombelles composées, rarement en ombelles simples. Chacun des deux akènes formant le fruit est marqué de côtes longitudinales plus ou moins saillantes, que séparent des sillons dont le fond est occupé par des canaux pleins d'une huile volatile; la racine, la tige et les feuilles sont traversées par des canaux sécréteurs fournissant des principes oléorésineux odorants. On peut diviser les Ombellifères en trois sections, en s'appuyant sur l'inflorescence et les sillons du fruit.

Dans une première section (Diplozygiées), les fruits portent, en plus des saillies méditerranéenne; leurs fleurs jaunes forment de larges ombelles; leur racine contient un suc âcre, irritant, d'où l'on extrait une résine révulsive. Les Laserpitium sont voisins.

La deuxième section (Haplozygiées), de beaucoup la plus nombreuse, est caractérisée par ses fruits dépourvus de côtes secondaires. On peut la diviser en trois groupes : les Sésélinées, dont le fruit est presque cylindrique (rarement ailé); les Peucédanées, au fruit comprimé dans la région dorsale, et les Amminées, chez lesquelles il est comprimé latéralement.

L'Angélique officinale est la plante la plus utile du groupe des Sésélinées (fruit ailé); ses feuilles très grandes, doublement composées, ont un pétiole engainant; les fleurs blanches ou verdâtres forment de grandes ombelles sphériques; [ involucre est presque nul et chaque involucelle porte huit folioles. On utilise les tiges et les pétioles de cette plante aromatique en confiserie et pour la fabrication des liqueurs. Le $F_{\text {enouil vulgaire }}\left(F_{\text {ceniculum officinale) de }}\right.$ nos champs est une grande herbe parfumée, dont les ombelles de fleurs jaunâtres sont dépourvues d'involucres et d'involucelles; ses feuilles extrêmement découpées sont presque réduites aux nervures (p. 27). On cultive dans le midi de l'Europe le Fenouil officinal et le Fenouil doux; les tiges et les côtes de cétte dernière espèce, blanchies à l'abri de la lumière, se mangent comme légumes. L'Ethuse ache des chiens, répandue dans les champs et les jardins, ressemble assez au Persil : c'est la Petite ciguë ou Faux Persil, herbe très toxique; son involucelle est à trois bractées renversées (involucre nul). Les (Enanthes sont aussi des plantes vénéneuses, dont les plus redoutables sont l'Enanthe phellandre, ou Ciguë aquatique, et l'Enanthe safranée. Enfin le Crithme maritime ou Perce-pierre croît sur les falaises de nos côtes de l'Ouest.

Le groupe des Peucédanées a tiré son nom des Peucédans, herbes de nos prairies, réputées jadis en médecine. On en rapproche l'Ancth odorant (A. graveolens), originaire d'Orient, cultivé dans le Midi comme condiment. Les Férules, dont le nom évoque les antiques corrections scolaires, sont de grandes herbes vivaces du pourtour méditerranéen; leur tige fistuleuse est assez forte pour servir d'appui, mais trop légère pour blesser ccux qu elle frappe. Plusieurs Peucédanées fournissent des gommes-résines d'odeur désagréable, employées en médecine contre les troubles nerveux. Ce sont: l'assa-fatida, provenant d'une Férule de Perse; le sagapenum ou gomme séraphique et le galbanum, de plusieurs Férules d'Orient; la gomme-ammoniaque ou Dor rème ammoniac de Perse. Enfin l'Opopanax, dit à tort opoponax, provient $\mathrm{d}^{\circ} \mathrm{Om}$ - 
bellifères de ce nom propres à la région méditerranéenne. L'opoponax des parfumeurs provient d'une Burséracée (Commiphora pobalsamum) n'ayant aucune analogie avec les Ombellifères.

Il convient ensuite de citer : le Panais (Pastinaca), cultivé dans le jardin potager ; les Berces (Heraclum), qui sont de grandes herbes des prés humides.

La tribu des Amminées renferme de nombreuses espèces indigènes : l'Ammi élevé, les Berles (Sium), les Buplèvres, etc. L'Anis vert (Pimpinella anisum) est cultivé en Ita-

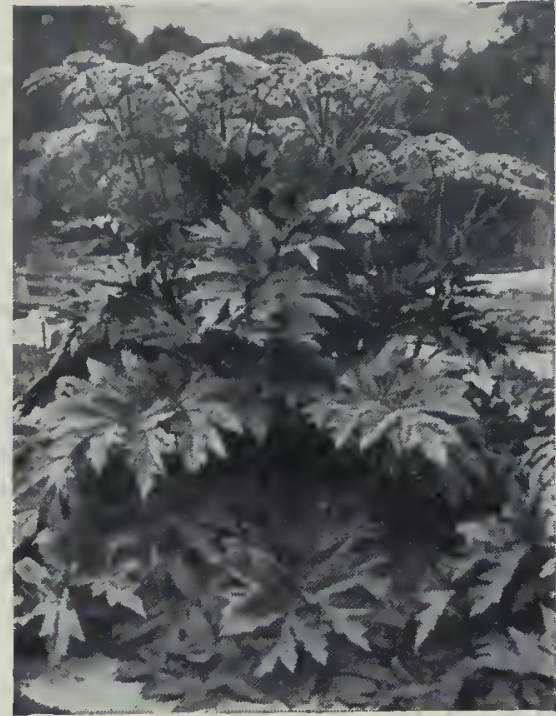

Berce spondyle.

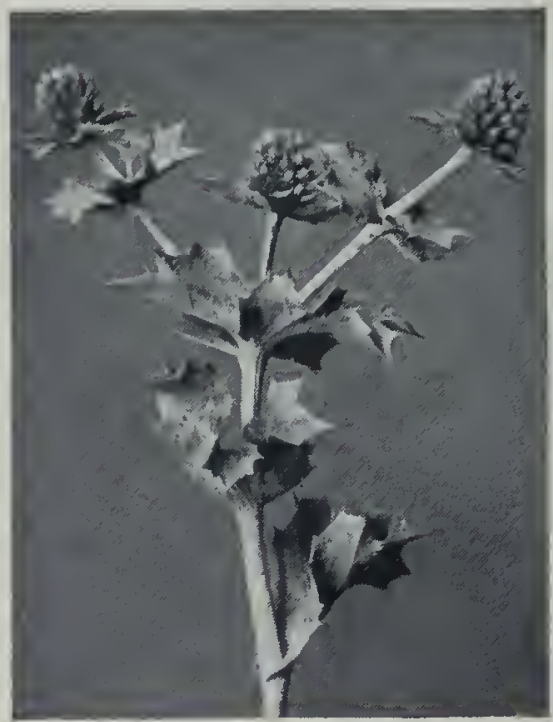

Panicaut maritime.

excellent légume par ses racines renflées. Sigualons encore une plante des moissons, le Scandix peigne de Vénus ou Aiguille de berger (fig. 26l), remarquable par la forme curieuse de ses fruits, surmontés d'un bec linéaire très allongé.

Les Ombellifères dont il nous reste à parler forment une troisième section (Hete. rosciadiées), peu nombreuse, se distinguant nettement des précédentes par la nature de l'inflorescence qui est une ombelle simple ou un capitule. Le Panicaut des champs(Eryngium campestre) est commun dans les lieux

Touraine et le Bordelais; cest une plante annuelle à fleurs blanches, et dont les ombelles sont privées d'involucre et d'involucelles; ses fruits sont verdâtres, striés, ovoïdes, très aromatiques; on en fait de petites dragées, des liqueurs. Le Chervis (Sium Sisarum) était très cultivé jadis pour ses racines alimentaires. Le Smyrnium maceron était aussi jadis très réputé comme légume.

L'Ache odorante (Apium graveolens) est une belle plante célèbre, en médecine populaire, comme apéritive, fébrifuge et diurétique. Cette herbe bisannuelle, répandue dans les lieux frais, a des feuilles luisantes, découpées en folioles triangulaires; il n’y a pas d'involucre ni d'involucelles sous ses ombelles d'un blanc verdâtre. L'Ache doit ses propriétés à une huile essentielle, voisine de l'apiol contenu dans le Persil; par la culture, l'Ache a développé ses feuilles ou ses racines; il est devenu le Céleri ou le Céleri-rave. Le Carum carvi est bisannuel; l'involucre de son ombelle blanche est nul ou n'est formé que d'une seule bractée; l'involucelle manque. Cette plante, très aromatique, est cultivée en Allemagne, en Hollande et en Russie; ses fruits ont des propriétés analogues à celles de l'Anis, du Fenouil, etc. Le Persil (Petroselinum sativum) est cultivé depuis longtemps comme condiment; une variété a des feuilles frisées.

La Ciguë vireuse (Cicuta) est une plante vivace, commune dans les lieux humides; son odeur est désagréable ; sa racine pivotante rappelle celle du Navet. La Ciguë tachetée (Conium), dite aussi Grande Ciguë, est une plante bisannuelle qui croît dans les lieux incultes, en Europe, en Asie et même en Amérique, où elle est naturalisée. Sa tige fistuleuse est de la grosseur du poignet. Toutes les Ciguës doivent leurs propriétés toxiques à la conicine, ou cicutine, poison stupéfiant (Voir pl. en coul. des PLANTES VÉNÉNEUSES).

Le Cerfeuil commun (Anthriscus cerefolium), à fleurs blanches et à fruits lisses allongés, est cultivé comme plante d'assaisonnement; le Cerfeuil bulbeux (Chorophyllum bulbosum) est un

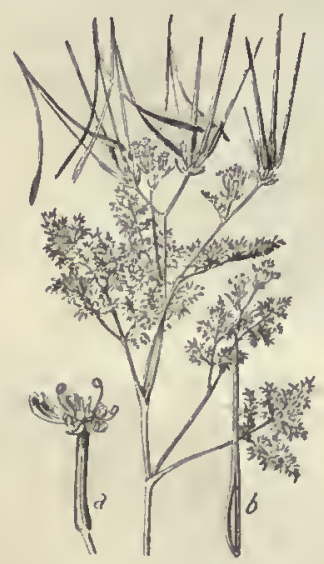

Fig. 261. - Scandix. a. Flepur; $b$, Fruit,

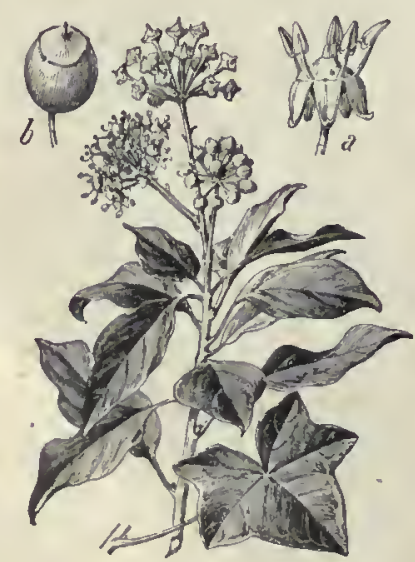

Fig. 262. - Lierre. a. Fleur; $b$, Fruit.

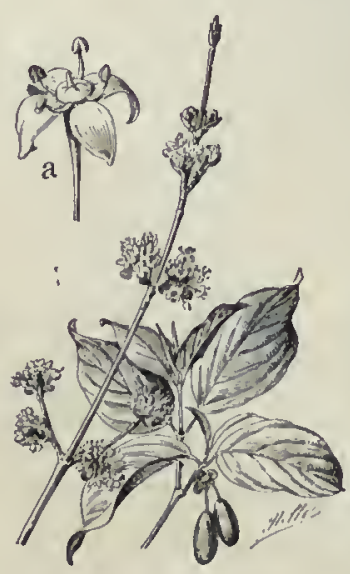

Fig. 263. - Cornoniller. $a$, Fleur. arides; c'est une plante vivace, ramifiée et presque globuleuse, à feuilles alternes, coriaces, à nervures saillantes : c'est le Chardon roland ou mieux roulant, parce qu'à l'automne sa tige se dessèche, le vent la casse et fait rouler la plante; les fleurs, d'un blanc verdâtre, forment de nombreux capitules arrondis groupés en corymbes. Dans les Alpes on trouve une plante admirable, le Chardon bleu (Panicaut alpin).

Araliacées, Pittosporées, Cornacées. - Ces familles se relient intimement aux plantes précédentes.

Les Araliacées, dont la plupart habitent les régions chaudes, sont des arbres ou des arbustes aromatiques, à fleurs groupées en grappes d'ombelles ou de capitules; le fruit est, le plus souvent, une drupe. Le Lierre grimpant (Hedera Helix) est notre seule Araliacée indigène (fig. 262). Il rampe sur le sol tant qu'il ne rencontre pas de support et y puise sa nourriture par de nombreuses racines; mais arrive-t-il au contact d'un rocher, d'un mur ou d'un tronc d'arbre, il y grimpe, s'y fixe solidement à l'aide de milliers de racines-crampons. Les tiges appliquées contre le support portent des feuilles lobées; les tiges ramifiées du sommet libre sont garnies de feuilles ovales sans découpures: les fleurs, qui napparaissent qu'en septembre, sont petites, verdâtres, groupées en grappes d'ombelles simples; de petites drupes noirâtres succèdent à ces fleurs. Le Panax ginseng est une panacée qui se paie au poids de l'or en Chine et en Corée; les Asiatiques ont dans ses propriétés une foi inébranlable. Ses feuilles sont à cinq folioles; à ses fleurs pourprées succèdent en été des fruits rouges; la racine, seule partie utilisée, possède un goût douceâtre rappelant, avec un peu d'amertume, celui du bois de réglisse.

Sous le nom d'Aralia on désigne de beaux arbustes d'ornement, remarquables surtout par leur feuillage. Quelques-uns sont bien véritablement des Aralia; d'autres appartiennent à des genres voisins, comme l'Aralia ou Fatsia du Japon, le Fatsia papyrifère, etc.

Les Pittosporées ont comme les deux familles précédentes des canaux secréteurs, mais l'ovaire est libre à deux carpelles ne formant qu'une seule loge; ce sont des arbustes, australiens pour la plupart; les plus employés dans les jardins sont les Pittosporum, aux jolies fleurs odorantes.

Les. Cornacées n'ont pas de canaux sécréteurs; leurs fleurs sont du type 4 et le fruit est une drupe. Deux espèces de Cornouillers (Cornus) habitent nos forêts: le Cornouiller mâle (fig. 263), arbuste dont les fleurs jaunes en ombelle apparaissent avant les feuilles (ses petites drupes rouges ou cornouilles sont comestibles), et le Cornouiller sanguin, aux fleurs blanches sépanouissant après les feuilles et aux fruits noirs très amers.

L'Aucuba du Japon est un arbuste diö̈que cultivé pour la beauté de son feuillage perpétuel; les pieds femelles sont garnis en hiver de jolies baies rouges, 


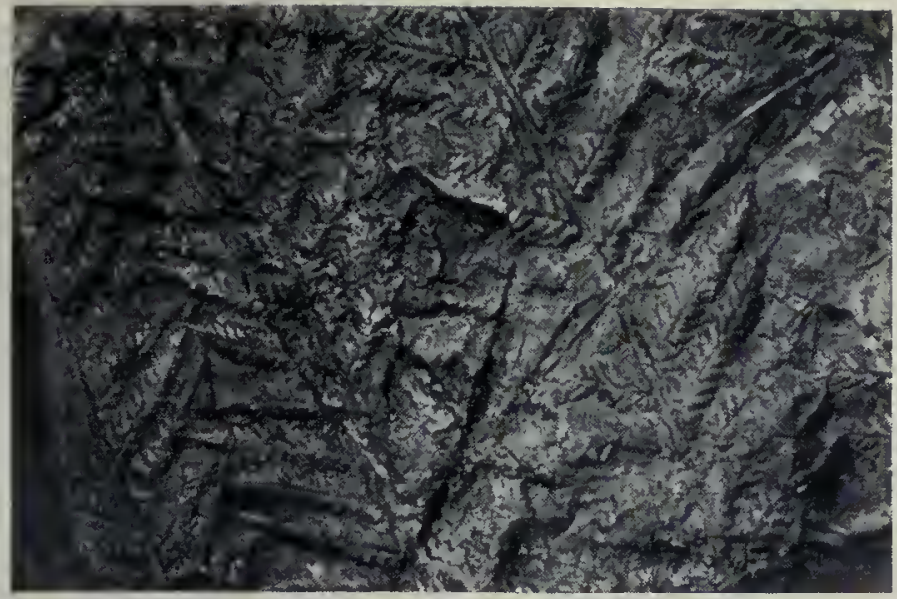

FOUGËRE FOSSILE : ODONTOPTERIS SUR SCHISTE.

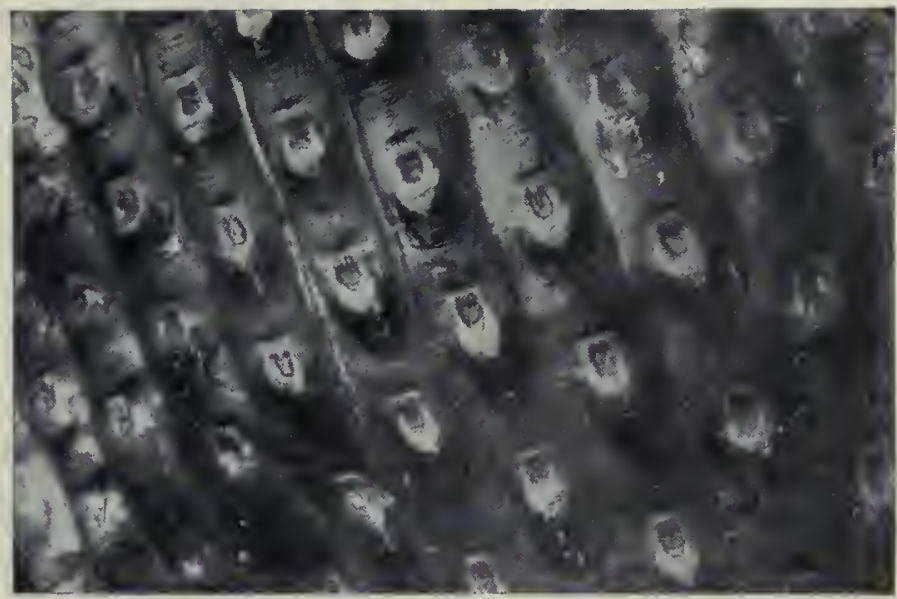

EMPREINTE DE SIGILLARIA SUR SCHISTE HOUILLER

\section{X. - LES PLANTES FOSSILES}

L'étude des végétaux fossiles est du plus grand intérêt; elle nous montre, en effet, d'une manière aussi éclatante que par l'examen des animaux disparus, et également très saisissante, que les plantes qui vivent aujourd'hui à la surface du globe n'y ont pas toujours existé, que la répartition des flores fut très différente de ce qu'elle est à l'heure présente, que les climats ont été autres et que les flores se sont perfectionnées au cours des siècles, permettant d'assister ainsi à la marche de l'évolution.

Ere primaire. - Le premier grand fait que nous ayons à mentionner est ce que l'on a appelé le phénomène paléothermal. La flore des terrains anciens, surtout à la fin des temps primaires, a présenté une magnifique végétation de caractère tropical, qui était uniformément répandue sur tous les continents existant alors. On a retrouvé, en effet, cette même flore splendide en Europe, au Spitzberg, dans l'Amérique du Nord, dans l'Inde.

Cette végétation admirable était formée de plantes très élevées, pouvant se ramifier dichotomiquement; ce sont notamment des Lepidodendron, qui sont des Lycopodinées à deux sortes de sporanges et dont la surface est divisée en losanges, traces des coussinets foliaires des feuilles tombées. Dans les Sigillaires, se rattachant au même groupe, la ramification est plus rare et les cicatrices quadrangulaires sont disposées, en général, suivant les génératrices longitudinales du cylindre; $c$ 'est surtout à l'époque carbonifère que ces plantes s'épanouissent puissamment. Elles sont accompagnées d’Équisétinées, comme les Calamites et les Annulariées. Citons, parmi ces dernières, les Astérophyllites, à tiges élancées, à feuilles verticillées égales grêles, et des Annulaires (fig. 264), à feuilles inégales et à deux sortes de sporanges.

A l'ombre de ces arbres et des Fougères arborescentes puissantes, dont les troncs avaient jusqu' à ${ }^{\text {ma }}, 50$ de diamètre et dont la taille était de 20 mètres et plus, se développaient les formes les plus diverses de Fougères herbacées et de Ptéridospermées : les unes à rhizomes allongés, existant déjà dans le dévonien (Hyménophyllite, etc.); les autres à souches renflées bulbiformes (Aulacoptéride, $M$ yeloptéride, etc.). La plupart de ces plantes ont l'aspect de Fougères; beaucoup d'entre elles appartiennent surtout au groupe des Marattinées. On a cru, jusque dans ces dernières années, que toutes étaient des Filicinées, mais les découvertes de Scott, Oliver, etc., ont établi qu'un certain nombre ont de véritables graines et de véritables étamines: ce sont donc des Angiospermes.

Le groupe des Ptéridospermées, depuis longtemps éteint, apparaît dans le dévonien, atteint son maximum de développement dans le houiller, et disparaît à la fin du permien. On ne connaît pas les graines mûres; comme cela arrive souvent chez les Cycadées, la fécondation était très tardive : ce sont des graines dépourvues d'embryon. On y distingue deux groupes: 10 les Néuroptéridacées, où l'ovule est au sommet d'une foliole composée et remplace la foliole terminale; $2^{\circ}$ les Lyginodendrées, dont l'ovule est une foliole latérale entourée d'un involucre de six à huit pièces libres. C'est la présence sur les divisions des pièces de cet involucre de sortes de glandes qui a permis d'identifier avec certitude le Lyginodendron avec le Sphenopteris Honinghausii, qui a été longtemps regardé comme une Fougère. Les organes mâles ont été autrefois désignés sous le nom de Crossotheca; on les a confondus d'abord avec des sporanges composés de Marattinées.

Les Conifères apparaissent au dévonien, mais se développent surtout pendant le houiller : on peut citer les Cordaitées (fig. 265), magnifiques plantes à tiges élevées de 30 à 40 mètres, à feuilles en bouquet sur les branches terminales de 1 mètre de long, de 15 à 20 centimètres de large, à plusieurs nervures, dont on connaît la structure comme celle des graines et des étamines; le rameau femelle a des bractées et un ovule droit d'apparence terminal, comme dans les Taxinées, et il n'y a pas de cône; on connaît la

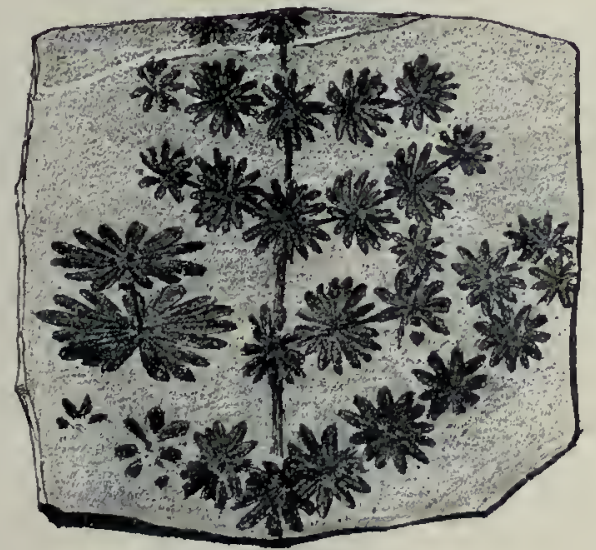

Fig. 264. - Annularia.

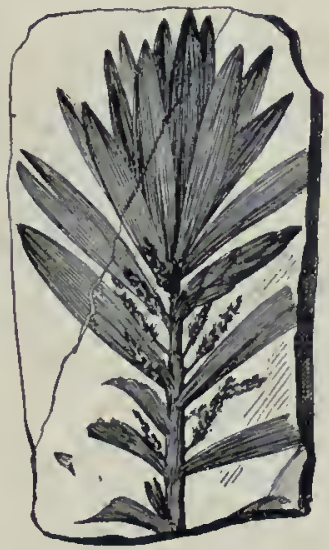

Fig. $265,-$ Cordaite.

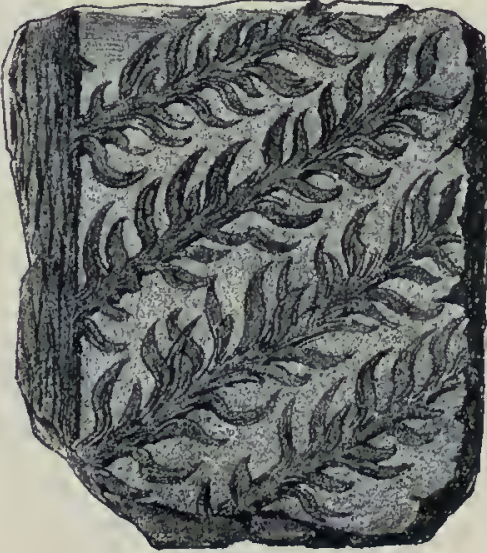

Fig. 266, - Walchia,

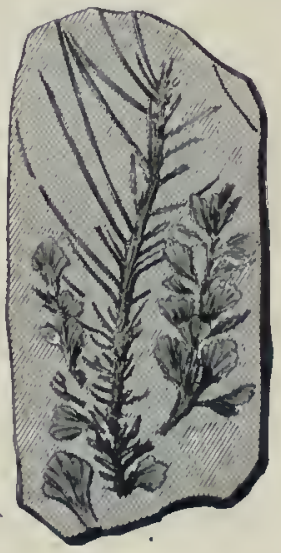

Fig. 267. - Voltz1a.

LES PLANTES. 
structure de la tige et celle de la feuille, de sorte que ces végétaux sont aussi bien connus que des végétaux actuellement vivants. Dans la flore permocarbonifère, on doit signaler, à côté des Cycadinées (Pterophyllum), des plantes voisines du Ginkgo (Baiera), enfin les Walchia (fig. 266), voisins des Araucaria.

C'est l'accumulation de ces forêts qui, à la période carbonifère, a produit les dépôts de houille, par fermentation des couches ligneuses des forêts enfouies dans le sol, sous l'influence de microorganismes, dont la première découverte est due à $\mathrm{Van}$ Tieghem, découverte confirmée par Renault. Ces accumulations d'arbres résultent soit du transport par les courants et les torrents, soit d'un affaissement du sol sur place qui a amené l'enfouissement des forêts. La houille ainsi produite n'a étć utilisće qu'à partir des temps modernes.

Ėre secondaire. - Tandis que les temps primaires ont vu le magnifique développement des Cryptogames vasculaires, l'extension de quelques Gymnospermes et surtout des Ptéridospermées, les temps secondaires, depuis le trias jusquau néocomien supérieur, voient prédominer les Gymnospermes. Parmi les Cycadées, les Bennettitées ont pris une énorme importance avec leurs tiges à port de Cycas; leurs fleurs étaient compliquées et hermaphrodites, tandis que les Cycadées sont actuellement dioïques. Ils annoncent les Homoxylées de Van Tieghem, placées autrefois dans les Magnoliacées, ce qui ouvre des horizons nouveaux sur l'origine des plantes à fleurs. Mentionnons également les Cycadospadix de l'infralias, qui sont manifestement des feuilles femelles de Cycas très voisines de celles des espèces vivantes. Parmi les Conifères, on remarque les Voltzia (fig. 267) du trias, les Taxées du crétacé; dans le jurassique, on voit les Araucaria et des $P$ ins se rapprochant des types actuels. Dans les dépôts arctiques se rapportant au néocomien, on trouve des vestiges rappelant les Sequoia de la Californie. Les Fougères sont encore très nombreuses se rapprochant des formes actuelles; on trouve des Cyathéacées, des Polypodiacées, et un grand nombre de Fougères herbacées anciennes (Lygodium, Marattia, etc.).

Les Algues calcaires ont eu d'ailleurs à cette époque un énorme développement; c'est surtout la famille des Siphonées, représentée aujourd'hui par les Acétabulaires, Algues qui ont un pied et un chapeau comme des Champignons. Munier-Chalmas s'est illustré dans l'étude de ces plantes : il a démontré que d'anciens débris, pris autrefois pour des Foraminifères, étaient soit des Siphonées verticillées, soit des Siphonées dichotomes, et il a trouvé de nombreux genres dans le trias, le jurassique, le crétacé (et même dans le tertiaire), se rattachant aux Cymopolidées, Acétabularićes, Thyrsoporellidées, etc.

A la fin des temps secondaires, on doit signaler l'apparition des Angiospermes. Dans l'infracrétacé, on a des Fougères (Osmonde, Thrysopteris, Gleichenia), des Cycadées (Otozamites, Anomozamites, Nilssonia, Zamia), des Conifères (Frenclopsis, Sequoia, Torreya), et cette fore est constante et indépendante de la latitude. Mais dans quelques-uns de ces gisements on a vu apparaître quelques Angiospermes : Peupliers, Saules, Lauriers, Sassafras, Sterculia. C'est en réalité dans le crétacé que les plantes à fleurs prennent une grande importance. Un fait digne de remarque est la présence dans l'hémisphère nord (Europe, Etats-Unis) de plantes de l'Australie comme les Eucalyptus; elles se sont maintenues en Europe jusqu à l'éocène. On trouve aussi bien au Groenland qu'en Provence une flore remarquable. Au Groenland, on voit associés des Bananiers et des Bambous à des Peupliers, des Ginkgo et des Sequoia.

Il semble bien que les climats aient commencé à se dessiner à la fin de l’époque crétacée. Dans la région occidentale de l'Amérique du Nord, dans le système de Laramie (passage entre le crétacé et le tertiaire), on remarque qu'aux mêmes niveaux, où l'on observe des types comme les Palmiers, Figuiers, Cannelliers, se rencontrant sous des latitudes basses, certaines espèces, se rattachant aux Peupliers, Noiseticrs, sont cantonnées dans des gisements plus septentrionaux.

Ère tertiaire. - L'époque tertiaire, qui débute par l'éocène inférieur, a vu sépanouir, aux environs de Reims, de Sézanne, de Soissons, de Liége, etc., une flore extrêmement intéressante qui se rapproche de beaucoup de genres du crétacé supérieur et rappelle celle de la région méditerranéenne actuelle et de l'Asie centrale : il y a des Châtaigniers à feuilles persistantes, voisins des Castanopses, puis des Noyers, des Chênes, des Viornes, des Lauracées, des Araliacées; il y a des Bambous, des Palmiers. Signalons les Sezannella, étudiés par Viguier, et des Vignes dont on a vu les fleurs s'épanouir, grâce aux injections de mastic dans les cavités de roches poreuses.

Dans les terrains oligocènes, on doit signaler les dépôts d'ambre jaune ou succin, résine fossile de plusieurs espèces de Conifères, principalement de $P$ in succinifère ( $P$ ityoxylon), qui formait à cette époque des forêts couvrant la Prusse orientale aux environs de Kœnigsberg, dans le Samland, la Scandinavie et la Finlande; cette résine, sédiments marins où la transformation en succin s'est opérée au cours des siècles. L'ambre renferme des diptères (mouches, taons), des hyménoptères (abeilles, bourdons), des coléoptères; on évalue à 2000 le nombre des espèces qu'on y a trouvées; on y a observé aussi des fleurs, et les Palmiers notamment y sont nombreux et très variés; les types des régions chaudes sont prédominants.

Lorsqu'on étudie la flore d'époques plus rapprochées de la nôtre, miocène, pliocène, quaternaire, on voit peu à peu les ressemblances devenir de plus en plus grandes avec la végétation qui peuple aujourd'hui la terre. A l'époque pliocène, le mouvement vers le sud des types tropicaux s'accentue; Heer et Saporta admettent le refroidissement progressif de nos régions dont la température moyenne a passé, de $25^{\circ}$ à l'éocène, à 20 à $22^{\circ}$ au miocène, et 17 à $18^{\circ}$ au pliocène.

Ère quaternaire. - L'extension des glaces à la période quaternaire a été contrôlée par l'étude des tufs ou des tourbes. Sur un grand nombre de points, on a retrouvé des restes de la flore des régions arctiques: Dryas à huit pétales, accompagnés de Saules polaires (Norvège, Suède, Saxe). Après le retrait des glaces, il y a eu un réchauffement de la température, et la flore a pris dans l'Allemagne du Nord un caractère plus méridional (Noisetier, Tilleul platyphylle, Nymphea). Aux environs de Paris, à la même époque, il y avait des Figuiers de Carie, des Arbres de Judéc, des Buis toujours verts.

Les tourbières signalent le début du régime actuel de la terre; elles contiennent des plantes intéressantes. Blytt, Nathorst et Steenstrup en ont étudié la végétation; ils ont démontré plusieurs alternances de climat séc et de climat humide. En Danemark, au début, l'arbre caractéristique des tourbières est le Tremble, puis est venu le Pin sylvestre, auquel ont succédé le Chêne, le Hêtre et l'Aune. Fliche est arrivé à des conclusions analogues en France, et on doit attribuer ces variations à une élévation graduelle de la température. Les Sphaignes (p. 120) forment l'élément principal des tourbières. On sait qu' on emploie les mottes de tourbe pour le chauffage. 


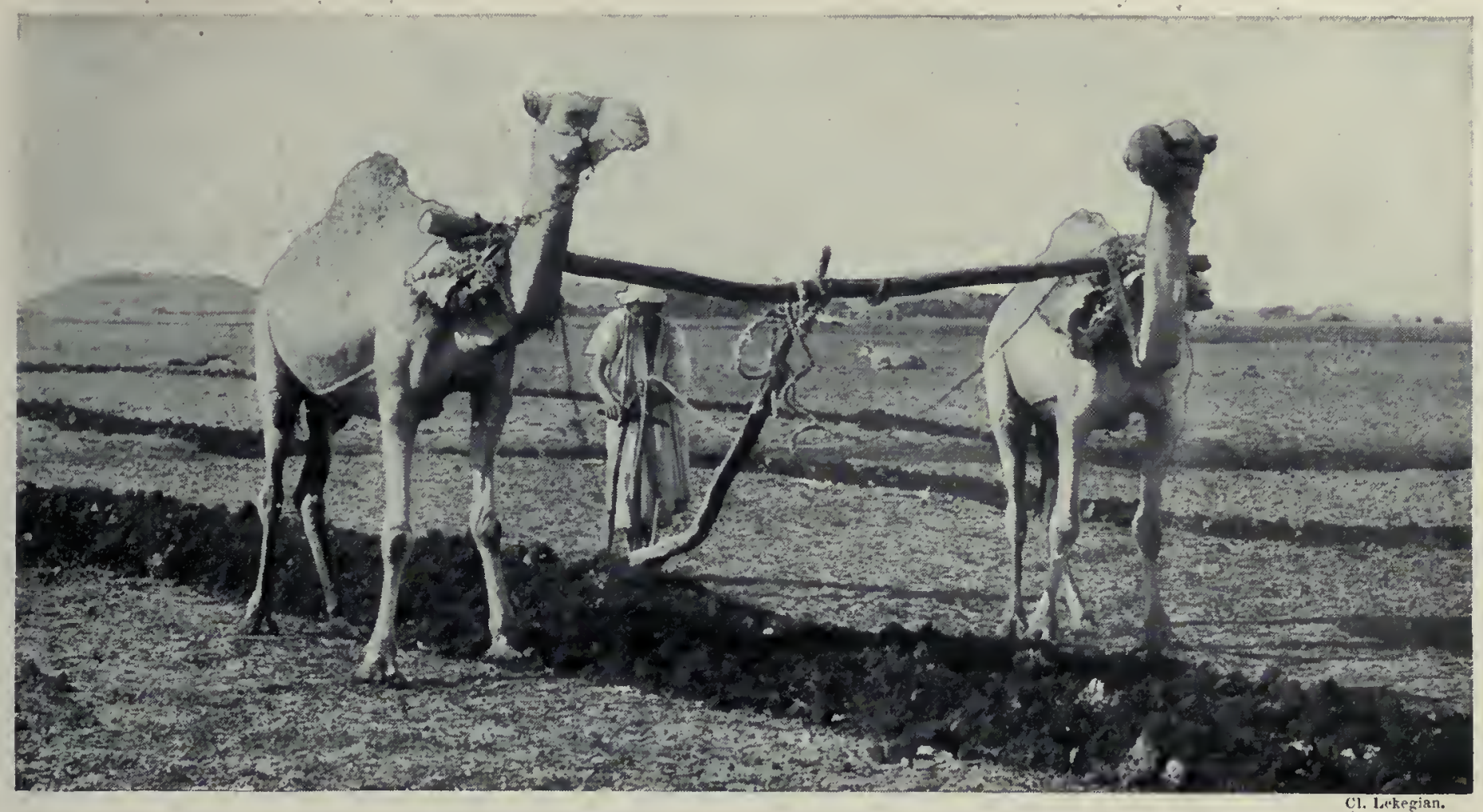

LABOURAGE A L'AIDE DE CHAMEAUX, EN TUNISIE.

\section{UTILITÉ DES VÉGÉTAUX}

\section{I. - LA CULTURE DU SOL}

$\mathrm{L}$ 'âge des cueillettes. - L'Homme vécut d'abord en troupes peu nombreuses, toujours en lutte avec la faim, les bêtes sauvages et les intempéries. Il est probable que sa première nourriture consista en fruits et en racines : l'expérience lui fit vite acquérir la connaissance des propriétés alimentaires, indifférentes ou nuisibles, des plantes qui croissaient autour de lui.

I - nlante fournit aussi à l'homme sa première arme et son premier outil, le bâton; l'âge du bois, qui n'a pas laissé de traces, précéda certainement l'âge de pierre. En saisissant une branche d'arbre, l'homme a étendu le rayon de son énergie musculaire de la longueur de ce bâton. C'est encore le bois qui permit de réaliser l'arc, la première arme de jet; il constitua aussi la hampe de la lance, terminée par une pointe de silex. Crâce au bois et à la pierre, la chasse devint fructueuse et l'homme put varier son alimentation. La dćcouverte du feu lui donna la possibilité d'employer la nourriture animale et d'utiliser certains produits végétaux qui, sans cuisson, n'ont aucune valeur.

A la plante, l'homme doit aussi son premier vêtement, que remplacèrent plus tard les peaux des bêtes tuées à la chasse. Enfin, le tronc d'un gros arbre abattu par le vent et creusé au silex et au feu devint le premier canot.

Pendant bien des siècles, l'humanité dut exclusivement ses repas à la chasse, à la pêche et aux cueillettes. Notre lointain ancêtre, l'homme paléolithique, qui, au début de l'ère quaternaire, taillait grossièrement la pierre, n’a jamais cultivé les plantes.

Début des cultures. - L'âge néolithique amène des progrès immenses : l'homme polit la pierre et invente la hache, arme terrible pour attaquer ou se défendre, outil sans pareil pour abattre les arbres et tirer du bois de précieuses ressources. Quelques animaux sont domestiqués, ce qui permet la vie pastorale et, par elle, une nourriture abondante et assurée : le lait et la chair des animaux domestiques. Enfin, un dernier progrès est accompli : l'homme commence à cultiver les plantes; la vie nomade à la recherche de nouveaux territoires de chasse ou de nouveaux pâturages fait place à la vie sédentaire d'où sont nés les arts et la civilisation.

Dans les assises de la grotte du Mas-d'Azil (Ariège), datant d'une époque que l'on considère comme formant la transition entre le paléolithique et le néolithique, Piette a trouvé, à côté de vestiges se rapportant à des plantes sauvages (noyaux de prunelles, de merises, etc.), des restes incontestables d'espèces cultivées : du blé,
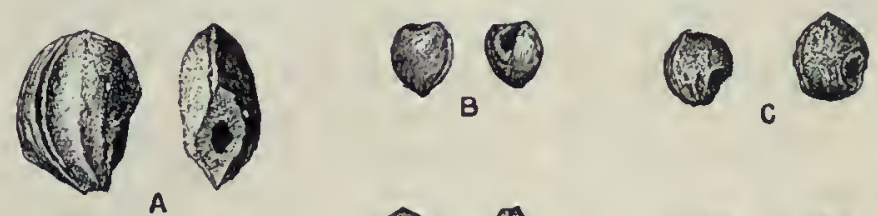

A
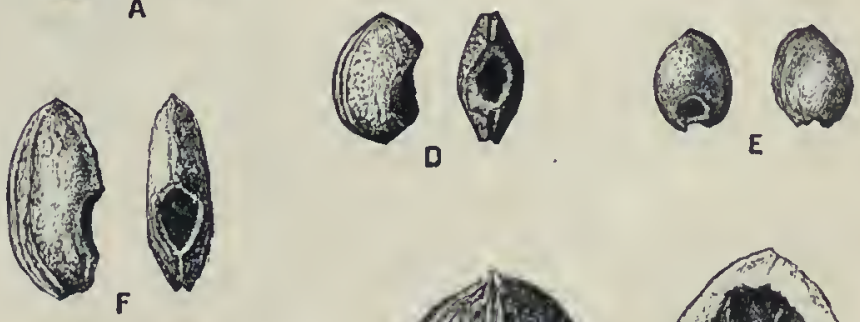

E
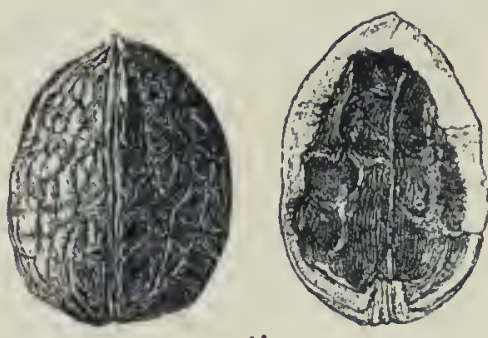

$H$

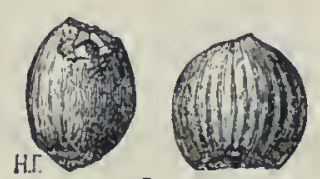

G

Fig. 268. - Fruits cultivés par l'homme préhistorique au Mas-d'Azil

A, D, F, Noyaux de Prunes; B, de Cerises: C, de Prunelles; E, de Merises G, Noiselles; II, Noix. - (Extrail de l'Anthropolugie, Masson, édit.). 
des noix petites et à coque dure, des noyaux de prunes et de cerises, de plusieurs variétés tranchées.

Vers la fin de la période néolithique et même pendant la période du bronze, beaucoup de peuplades habitaient des huttes bâties sur pilotis dans les eaux peu prolondes des lacs de la Lombardie, de la Bavière et de la Suisse. Ces habitations, nommées palafittes ou stations lacustres, ont été détruites par le feu. Des fouilles pratiquées dans la vase ont mis au jour des restes indiquant une agriculture en progrès et un degré de civilisation déjà avancé. L'homme cultivait les céréales et les arbres fruitiers. Le Froment et ses variétés, l'Amidonnier, l'Engrain et le Poulard sont représentés par des graines beaucoup moins grosses que les nôtres, mais très reconnaissables. L'Orge à deux rangs, l'Orge à six rangs, le Millet commun ou Panic miliacié et le Millet d'Italie sont abondants, ainsi que le Lin à feuilles étroites, espèce vivace, distincte de notre Lin usuel. On trouve aussi des graines de Pavot qui devaient lournir de l'huile; de petites pommes, toujours lendues en long, sans doute pour la dessiccation; des noyaux de cerises, de prunelles et de prunes. Les stations plus récentes, datant de l'âge du bronze, ont fourni, en outre, de l'avoine, des pois, des fèves minuscules et des pépins de raisins. L’homme travaillait le bois, tissait le lin, broyait son grain à l'aide de meules primitives et cuisait un pain grossier dont on a retrouvé un fragment. l] élevait des animaux domestiques pour l'agriculture, comme le montre la découverte de jougs.

Dans l'Égypte ancienne, les industries exploitant le règne végétal étaient très prospères. Les tisserands façonnaient de beaux tissus de lin qu'on retrouve aujourd'hui autour des momies; le Henné, le Carthame étaient exploités pour la teinture ; la fabrication des parlums, la préparation des aromates étaient en honneur; le Papyrus fournissait un excellent papier qui est parvenu jusquà nous, avec les hiéroglyphes dont il était couvert; de l'Orge, on tirait une sorte de bière sans houblon; on cultivait le Blé, le Dattier, l'Olivier, le Figuier sycomore, l'Oignon, l'Ail, la Fève, la Lentille, etc.

Dans l'Inde, le Riz, la Canne à sucre, le Sésame, le Citronnier, le Manguier, le Bananier sont cultivés depuis des millénaires, de même qu'en Chine, le Thé, l'Oranger, l'Abricotier, le Pêcher, le Mûrier blanc, le Riz, la Pastèque, le Canellier.

Ces anciennes civilisations nous ont transmis, par l'intermédiaire de la Grèce et de Rome, la plupart des plantes de première utilité cultivées encore de nos jours. Il serait injuste d'oublier ce que nous devons au Nouveau Monde et, en particulier, à la civilisation des Incas. Les nombreuses graines et plantes trouvées dans les tombeaux de l'ancien Pérou et datant du $X^{\prime} I^{\theta}$ au $X^{\circ}$ siècle de notre ère nous renseignent sur ce sujet. Costantin et Bois ont étudié des restes végétaux recueillis pár le capitaine Berthon dans plusieurs anciens cimetières des environs de Lima. Ce sont des tubercules de Ma-

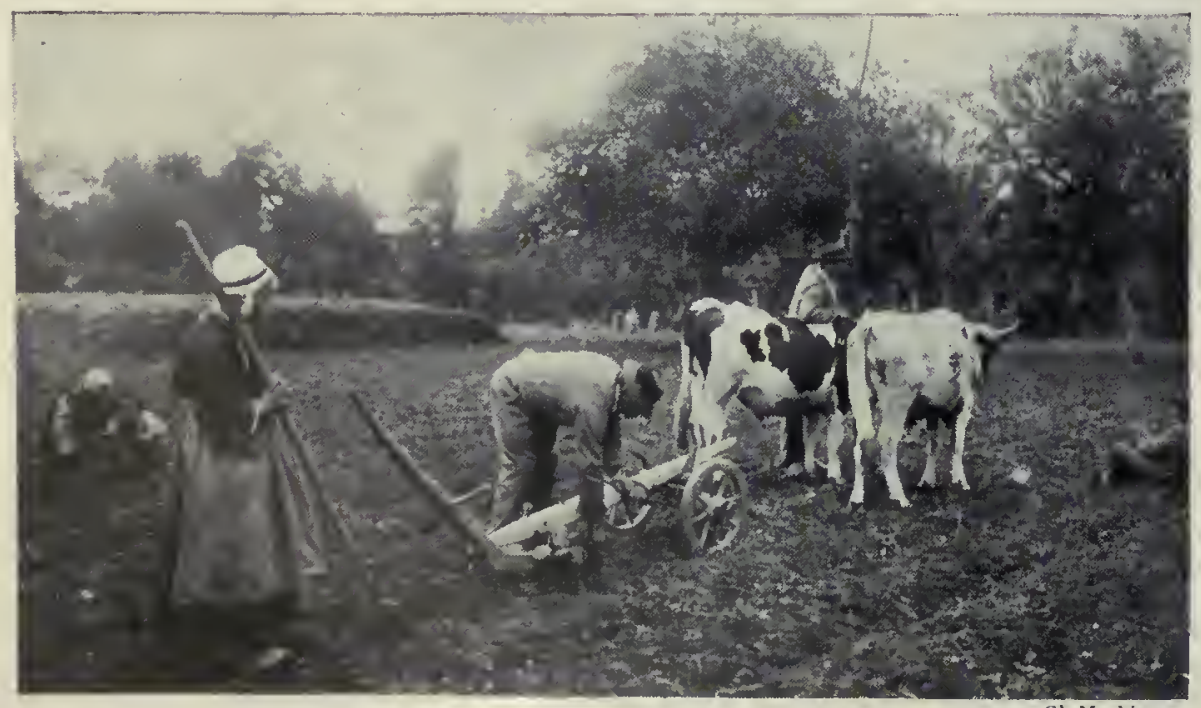

Labourage à l'araire, en Bretague. nioc, des graines de Cotonnier, d'Anone chérimolier, de nombreux épis de Maîs appartenant à plusieurs races et montrant que la plante était parvenue à un remarquable degré de perfectionnement cultural, puis des Iruits d'Arachide et des haricots, plantes dont l'origine américaine ne fait plus aujourd'hui aucun doute; enfin, des Gourdes calebasses dont la présence témoigne peutêtre de relations précolombiennes entre l'Asie et l'Amérique, car la plante à gourdes de pèlerin existe dans l'Inde.

Partout où se sont étendues les cultures, la flore naturelle a été prolondément modifiée. La Gaule était une immense lorêt de Chênes, de Hêtres et de Bouleaux, mais la forêt des régions tempérées ne peut nourrir l'homme; à mesure que notre pays se peuplait, les arbres étaient abattus et le sol qu ils occupaient livréaux cultures. Il en a été de même en bien des points du globe.

Le délrichement, le débroussaillement sont des opérations longues et pénibles. Dans les pays neufs où les moyens de transport manquent et où le bois n'a aucune valeur, le leu prépare la besogne.

Le labourage. - Toute culture exige une préparation du sol. Le première houe avec laquelle l'homme remua la terre fut peut-être un de ces bois de cerl réduits à un seul andouiller, comme ceux qu'on a trouvés dans les tourbières de Suède et dans les cités lacustres. Des instruments tout aussi primitils sont encore en usage : les Fidgiens ont pour bêches des côtes de baleine, et certaines peuplades d'Afrique utilisent des rondins de bois laçonnés en lorme de cure-dent. Quant à la première charrue, ce fut, sans doute, une grosse branche recourbée, sorte de crochet en bois dont une extrémité servait de soc et l'autre de manche. De pareilles charrues se rencontrent encore, sans grands perfectionnements, dans l'Afrique du Nord. Les Egyptiens y attellent des bouls, les Arabes des dromadaires ou des ânes, ou même leur lemme. Plus tard, la découverte des métaux fit adapter à la charrue un soc en fer. L'allongement de la flèche à laquelle on attelle les animaux, l'addition du coutre, qui fend d'abord la terre que le soc doit soulever, et celle d'un manche simple ou bifurqué pour la direction, transformèrent la charrue primitive en un araire.

L'araire fut la charrue des Grecs et des Romains de l'antiquité, celle du moyen âge; on le retrouve au Japon pour la culture du Riz, en Égypte, en Algérie. L'araire, compliqué du versoir, pièce l-ıérale renversant sur le côté la terre soulevée par le soc, est encore très employé dans certaines régions de la France. Ceper dant, on y trouve surtout une charrue plus perfectionnée dont le corps ou age portant coutre, soc et versoir, se guide avec des mancherons. Un avant-train à deux roues la supporte et un régulateur, fixé sur l'age, permet de modifier la prolondeur du labour. On emploie beaucoup aussi la charrue Brabant double, comprenant deux corps de charrue superposés qu'on retourne autour de leur age commun à chaque extrémité du sillon, ce qui permet de renverser la terre toujours du même côté.

De toutes les opérations agricoles, le labourage est la plus importante : il retourne, ac̀re, divise la couche superficielle du sol, active les fermentations utiles, détruit les mauvaises herbes, enfouit les engrais, facilite la germination et la pénétration des racines des plantes. Les labours sont complétés par le hersage qui ameublit le sol, et par le roulage qui le tasse, couche les jeunes tiges des céréales et provoque le tallage, c'est-à-dire la formation de nouvelles tiges. Herse et rouleau sont actionnés le plus souvent par les animaux domestiques; mais dans la très petite culture, le moteur humain - et pour cause - se substitue parfois au moteur animal. La culture mécanique, ou motoculture, née en France, utilisée d'abord dans les immenses domaines de l'Amérique du Nord, a pris un développement important; elle pare, en effet, à la rareté de la maind'œuvre et permet la préparation de grandes surfaces de terrain en un court espace de temps favorable. Elle utilise des moteurs à vapcur 


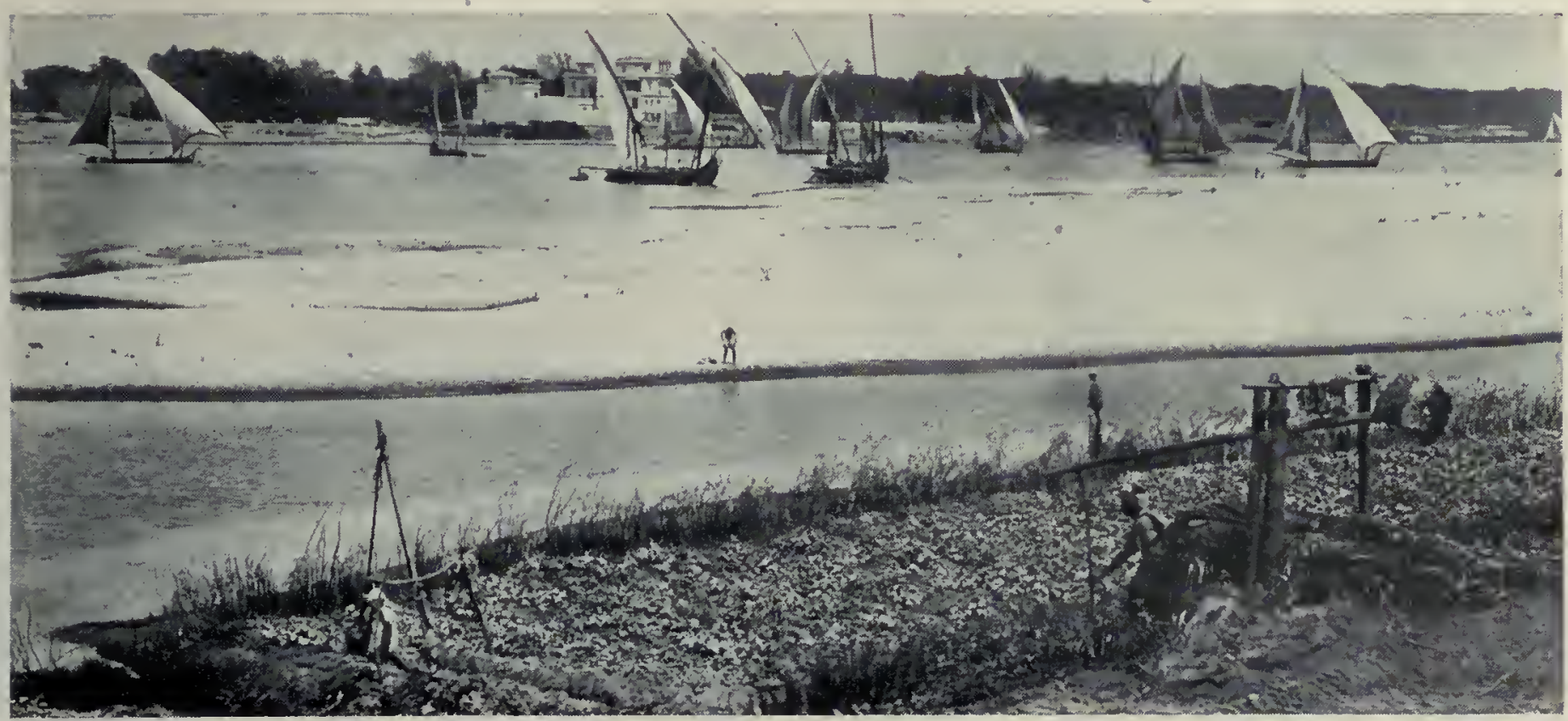

Ctradoufs elı étage, sur les bords du Nit.

ou à explosions, ou même le courant électrique. On distingue trois types: les treuils-tracteurs, dans lesquels le moteur agit sur l'instrument de culture par l'intermédiaire d'un câble; les tracteurs proprement dits qui le remorquent directement, enfin les instruments automobiles (charrue, herse, rouleau, faucheuse, etc.), dans lesquels le moteur et les pièces travaillantes sont réunis dans un même châssis.

Amendements, irrigation. - La pratique des amendements consiste à fournir au sol les éléments qui lui manquent : chaux ou marne aux terrains granitiques, sable aux terrains argileux, etc. Le drainage assainit les terres trop humides: l'eau en excès est recueillie par une série de fossés ou de drains en poterie.

L'eau, en proportion convenable, est le facteur le plus puissant de la fécondité des terres. L'humidité apportée par les pluies est, en beaucoup de régions du globe, suffisante pour le développement des plantes. Dans le jardinage, on l'augmente par l'arrosage; dans la grande culture, par l'irrigation. Pour arroser ou irriguer une petite surface, on se contente ordinairement de l'eau d'un puits tirée à laide de seaux, ou mieux d'une pompe actionnée à bras ou par un moulin à vent, Dans l'Afrique du Nord, on emploie beaucoup le chadouf, solide balancier pouvant osciller autour d'un axe et portant un seau à l'une de ses extrémités et à l'autre une grosse pierre. On 'fait basculer la perche de façon que le récipient plonge dans l'eau, et, grâce au contrepoids, il suffit d'un faible effort pour relever celle-ci. Le même appareil, sous le nom de cigogne, est utilisé dans diverses parties de la France. Dans le puits à charpente, commun en Tunisie, le récipient est une peau de bouc attachée à deux cordes glissant sur deux poulies superposées, et les deux autres extrémités de ces cordes se fixent au bât d'un chameau ou d'un âne. Les allées et venues continuelles de l'animal sur une rampe ayant pour longueur la profondeur du puits font monter et descendre alternativement le seau qui se déverse automatiquement dans un bassin.

La noria est une machine élévatoire fort ancienne; un animal domestique, attelé à un manège, met en mouvement une corde portant des vases en terre qui plongent dans un puits ou dans une rivière pour déverser ensuite leur eau dans une rigole. Dans le Sahara et le Sud algérien existent des eaux souterraines qui permettent le forage de puits artésiens.
Lirrigation, telle qu'on la pratique dans la grande culture, exige souvent des travaux considérables; elle peut rendre prospères les pays les plus arides. Les Hollandais à Java, les Anglais en Égypte, ont fait, à ce point de vue, des choses merveilleuses.

Engrais. - Les récoltes enlèvent à la terre des éléments indispensables qüil faut lui restituer par les engrais. Le fumier est le plus complet des engrais organiques. Au moment de l'emploi, on l'épand sur le sol, puis on l'enterre à la charrue.

L'engrais humain est employé dans nos pays sous forme de poudrette ou bien, au voisinage des grandes villes, il est véhiculé par les eaux d'égont qui, par épandage, apportent la fertilité aux cultures maraî́chères. En Extrême-Orient, par suite de la pénurie d'animaux de ferme, il est tenu en haute estime et, au grand détriment de l'hygiène, on l'utilise en nature. En bordure des routes, il est bien peu de champs qui ne soient " agrémentés ") d'un édicule où tout passant est invité à pénétrer. Les paysans laissent fermenter les matières pendant six à huit jours, puis les étendent de dix volumes d'eau. Pour l'emploi, une équipe de trois hommes se partage la besogne : l'un porte sur son épaule, suspendus aux deux extrémités d'un bambou, deux vastes seaux contenant l'engrais; les deux autres y puisent à l'aide de grandes cuillers de bois et, d'un geste auguste, arrosent les plantes.

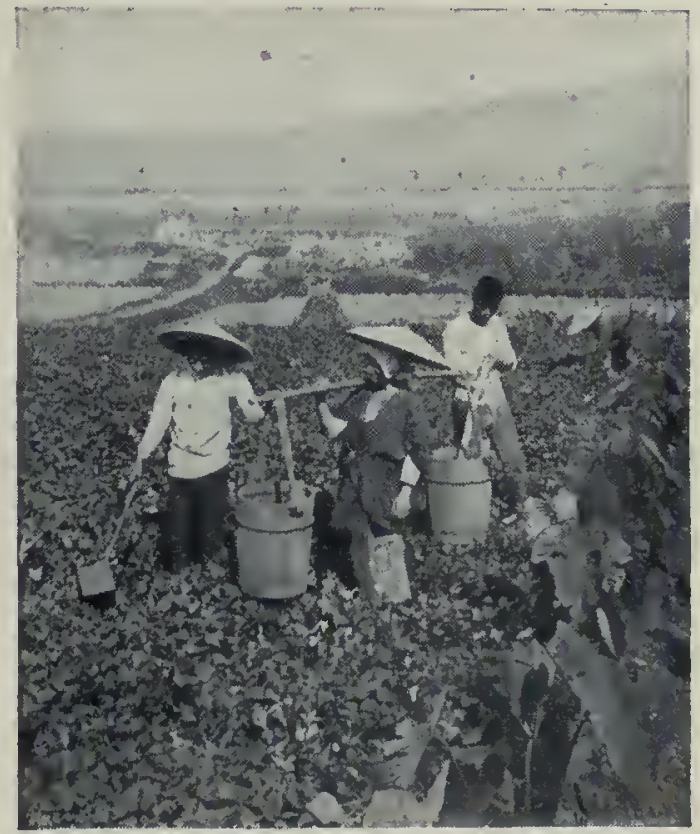

Epandage de l'engrais humain, au Japon.
Les débris animaux, comme l'engrais de hareng, au Japon, les goémons, les engrais verts sont aussi très employés. Les progrès de la chimie agricole ont fait de nos jours accorder une grande place aux engrais minéraux, qui sont d'une utilisation presque immédiate : engrais azotés, comme les nitrates de soudde et le sulfate d'ammoniaque, engrais phosphatés, etc.

L'emploi des engrais catalyseurs est rempli d'avenir. Depuis les travaux de Gabriel Bertrand, on sait que de très petites quantités de sels de manganèse, de cuivre, de zinc, de magnésium, incorporés au sol, favorisent les synthèses de la vie végétale et augmentent le rendement de certaines récoltes. La fertilisation à l'aide de ces stimulants, répandus par arrosage, est facile et peu coûteuse.

Enfin, ajoutons qu'on ne peut cultiver indéfiniment certaines plantes dans le même sol: malgré les fumures, les récoltes s'amoindrissent. L'assolement consiste à diviser la terre d'une ferme en plusieurs portions ou soles, sur. chacune desquelles on fait se succéder régulièrement des plantes d'espèces différentes. 


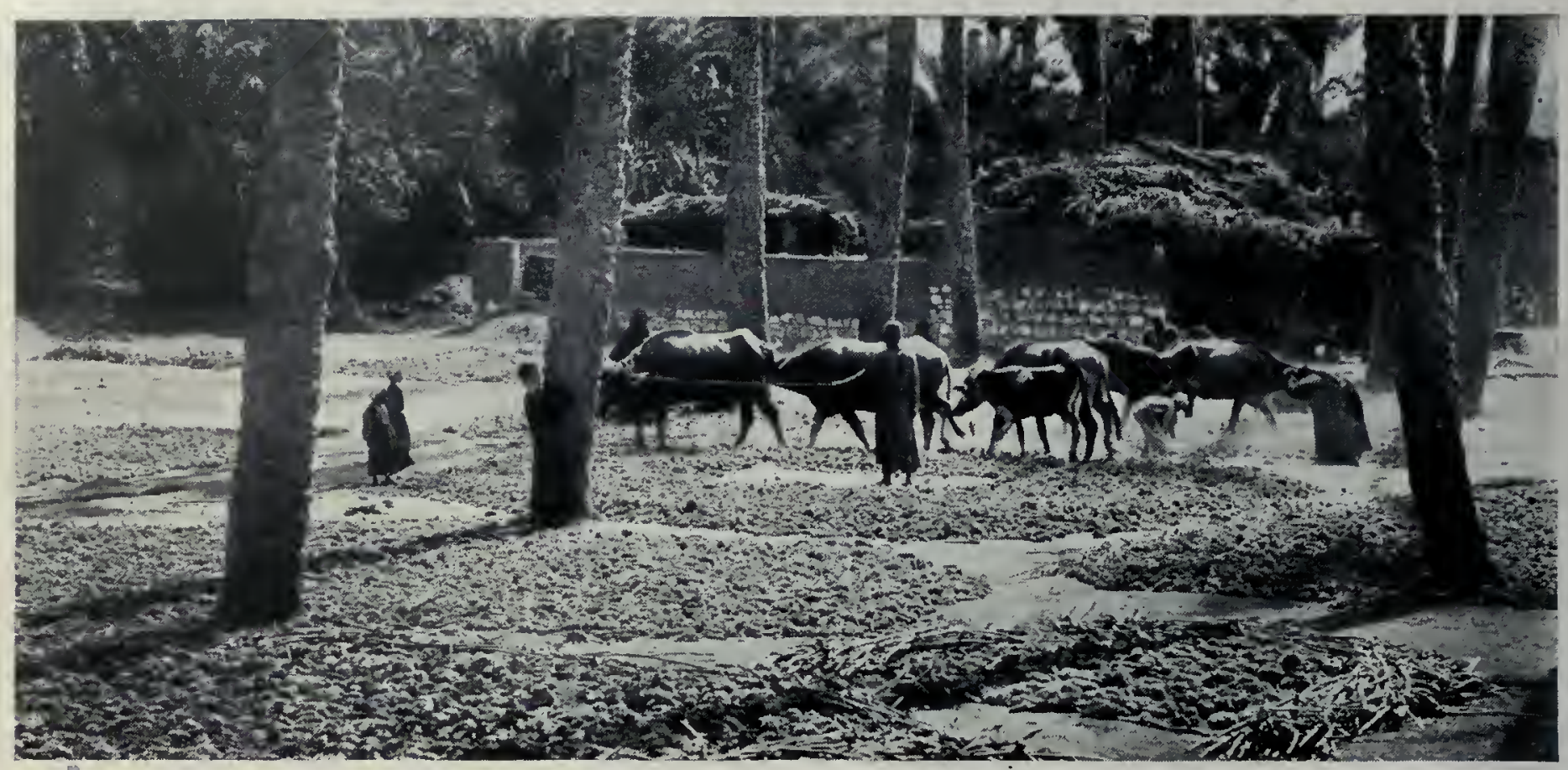

DÉPIQUAGE DU SORGHO, PAR LES BUFFLES, EN EGYPTE.

\section{II. - LES PLANTES ALIMENTAIRES}

\section{LES CÉREALES}

Les céréales sont les plantes dont les graines, réduites en farine, forment la base de la nourriture de l'humanité presque entière. Ce sont des herbes annuelles appartenant toutes à la famille des Graminćes, sauf le Sarrasin ou Blé noir, qui est une Polygonacée. Leur développement est rapide; leurs graines peuvent se conserver longtemps et renferment, sous un très petit volume, un riche aliment complet. Lagriculture n'a vraiment pris naissance qu'avec la culture des céréales. Le Blé dans les régions tempérées, le Riz dans les pays chauds, sont actuellement les plus importantes; les autres sont : l'Orge, le Seigle, l'Avoine, le Maïs, le Millet et le Sorgho.

Froment. - Le Blé ou Froment est cultivé depuis les temps les plus reculés. De Chaldée, il parvint aux pays baignés par la Méditerranée, puis dans presque toute l'Europe, où il remplaça peu à peu l'Orge et le Seigle pour la confection du pain.

Dans le sol préparé par un labour et affermi par le roulage, on sème le Blé à l'automne, soit à la volée, soit au semoir mécanique. On le herse et on le roule en mars, on le sarcle en avril s'jl est

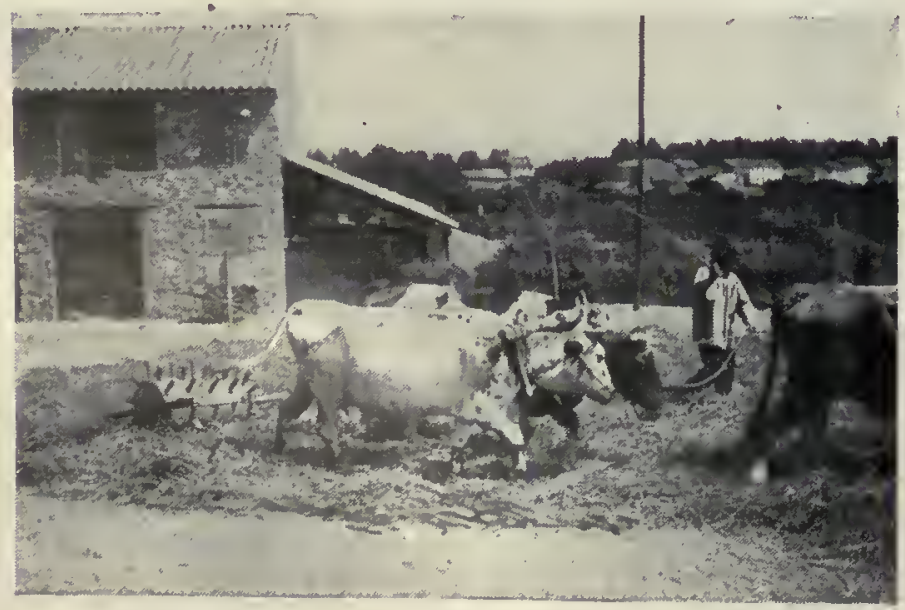

Dépiquage du Blé, en Provence, avec l'ancien tabulum latin. envahi par les mauvaises herbes, on moissonne en juillet. II existe des variétés de Blé moins productives, à semis printanier.

Dans la classification des Graminées, nous avons indiqué qu il existe plusieurs espèces: Blés poulard, épeautre, engrain, avec de nombreuses variétés (p. 133). On les divise aussi pratiquement en Blés d'automne et Blés de printemps; en Blés tendres, à grain farineux, qui, en France, forment les trois quarts de la récolte, et en Blés durs, à grain plus corné, à paille fine et à épis barbus résistant mieux aux attaques des oiseaux.

Le Blé craint l'humidité stagnante en hiver, les gelées quand le sol n'est pas recouvert de neige; il est sujet aux maladies cryptogamiques : rouille, charbon, etc. ; la nielle est due à des anguillules, vers microscopiques qui attaquent la graine; plusieurs insectes ou leurs larves : cécidomyes, chlorops, chinch-bug (Blissus leucoptère) ou punaise des blés d'Ámérique, etc., causent parfois de grands dégâts; il faut compter aussi avec la coulure, l'échaudage, dû à des vents chauds et secs après la floraison; la verse, par laquelle les épis se couchent et mûrissent mal.

Le Blé est mûr et bon à couper quand le grain, devenu jaune, ne s'écrase plus sous la pression du doigt, mais se laisse encore fendre avec l'ongle et ne se détache que difficilement de l'épi. Une maturité trop avancée diminue beaucoup le rendement, les grains tombant à terre au moindre choc.

La récolte du Blé. - D'un bout à l'autre de l'année, on moissonne le Blé en un point ou l'autre du globe. En janvier, on coupe le Blé en Nouvelle-Zélande, au Chili; en février et mars, en Égypte et aux Indes; en avril, dans la Perse et l'Asie Mineure; en mai, dans l'Asie centrale, en Chine, en Algérie; en juin, dans les régions du sud de l'Europe et des Etats-Unis; en juillet, dans la plus grande partie de l'Europe centrale et de l'Amérique du Nord; en août, en Belgique, Hollande, Danemark; en septembre, dansla Suède; en octobre, en Écosse; en novembre, dans l'Áfrique du Sud, le Pérou, le nord de l'Australie; enfin, en décembre, dans l'Argentine et l'Australie méridjonale.

Depuis les temps les plus lointains, la coupe du Blé se fait à la faucille ou à l'aide de la faux à ployon dont le manche porte, près de la lame, une sorte de support sur lequel tombent les tiges de Blé qu'on peut ensuite coucher en ordre sur le sol. Les javelles sont assemblées, puis redressées en gerbes liées avec des pailles de Seigle. Les gerbes, engrangées ou mises en moyettes, puis en meules, achèvent leur maturation en attendant le battage. La petite 


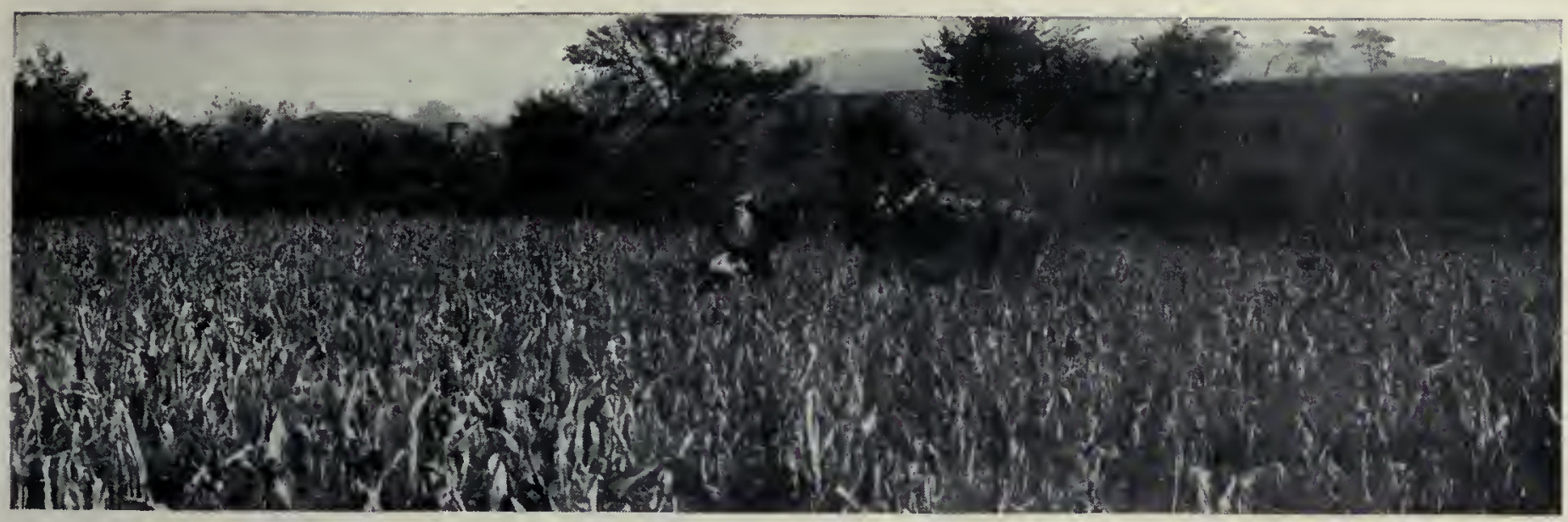

La récolte du Maïs, dans le midi de la France.

culture, en certaines régions, utilise encore la faucille ou la faux des ancêtres, mais l'emploi des moissonneuses-lieuses se généra-. lise de plus en plus.

Le plus antique instrument employé pour le battage du Blé est le fléau, composé d'un manche et d'une batte qui, tournoyant dans l'air, vient frapper les gerbes à égrener, préalablement étalées sur une aire durcie. Le fléau se retrouve encore, dans la petite culture, pour le battage des Fèves. On emploie aussi l'échaubage ou battage des épis sur le bord supérieur d'un tonneau défoncé, ou encore le dépiquage, dans lequel l'aire, garnie d'épis, est piétinée par des chevaux ou foulée par un rouleau pesant. La paille est ensuite enlevée à la fourche et le grain est vanné, c'est-à-dire secoué sur un plateau d'osier pour que le vent enlève les impuretés.

Ces méthodes disparaissent devant l'emploi des batteuses mécaniques. Il en existe de petits modèles mus à la main; d'autres dont le moteur est un bœuf ou un cheval piétinant sur un plan incliné; d'autres, enfin, pourvus d'un moteur à pétrole ou actionnées par une locomobile. Le grain est séparć, nettoyé, ensaché et pesé; la paille, montée sur le pailler.

$C^{\prime}$ est au Canada ou aux Etats-Unis, dans les immenses plaines de l'Ouest, qu'on peut admirer la puissance du machinisme agricole employé pour la culture et la récolte du Blé. Le grain, empilé à nu dans les wagons, est conduit aux grands centres commerciaux: Chicago, Buffalo, New-York, etc., et déchargé mécaniquement dans de gigantesques entrepôts ou elevators, constructions en acier avec manouvre électrique. Certains elevators peuvent contenir jusqu'à 700000 hectolitres de grains; le chargement et le déchargement s'effectuent à l'aide de chaînes à godets ou par aspiration.

Meunerie et boulangerie. - La transformation du blé en farine se fit d'abord en écrasant les grains entre deux pierres, puis à l'aide de pilons et de mortiers. Dans les premières civilisations, on trouve déjà un moulin à bras pourvu de deux meules superposées en pierre dure. A cet instrument primitif succédèrent les moulins à vent et les moulins à eau, dont la pittoresque silhouette disparait peu à peu de nos paysages. Les grands moulins à vapeur, vastes usines où le grain est broyé sous des cylindres d'acier, se répandent de plus en plus.

Sous la meule, le grain de Blé écrasé donne la boulange. C'est un mélange de farine, de fragments nommés gruaux qu un nouveau broyage plus serré transforme en farine, et enfin de son, ce dernier provenant du péricarpe et du tégument du grain ou fruit du Blé. Des tamis ou blutoirs en gaze de soie séparent ces éléments.

Une farine de froment de bonne qualité renferme 10 pour 100 d'eau, 60 pour 100 d'amidon, 14 de gluten (partic azotée), 1,5 de principes gras, des matières sucrées, des phosphates et d'autres sels.

La fabrication du pain est extrêmement ancienne; le millet, l'orge en ont d'abord fourni les éléments; puis, plustard, le froment mélangé au millet et à la fève. La cuisson s'en fit primitivement à l'aide de pierres plates fortement chauffées, sur lesquelles on disposait la pâte qui devenait une galette compacte. Ce sont les Juifs et les Egyptiens qui ont d'abord fait le pain levé, mode de fabrication qui se répandit ensuite en Grèce, puis à Rome. Au $\mathrm{Vi}^{\mathrm{e}}$ siècle de notre ère, le peuple, en Gaule, ne mangeait encore que du pain sans levain.

La panification comprend le pétrissage, la fermentation et la cuisson. Au pétrissage à bras d'homme se substitue peu à peu le pétrissage mécanique, plus économique et plus propre. La fermentation saccomplit sous l'action du levain, fragment de pâte aigrie provenant d'une opération précédente et renfermant des cellules de Levure et d'autres ferments. Pour les pains de fantaisie, on emploie de la Levure pure. Ces ferments engendrent du sucre après le pétrissage, lequel donne de l'alcool en petite quantité et des bulles de gaz carbonique; ces dernières font lever la pâte, se dilatent pendant la cuisson, ne peuvent se dégager à cause de la formation rapide de la croûte, et rendent le pain léger et digestif. Seules, les farines à gluten extensible, comme celles de blé, d'orge, de seigle, d'avoine, lèvent sous l'action du gaz carbonique et sont panifiables; celles du riz, du maïs, du sarrasin ont un gluten pulvérulent ou trop peu abondant; elles sont propres seulement à faire des bouillies ou des galettes. La cuisson a lieu dans des fours chauffés directement au bois. On utilise dans les grandes villes des fours continus et à foyer distinct.

Pâtes alimentaires. - En dehors de son application principale qui est la fabrication du pain, la farine est consommée parfois sous forme de bouillie; les gruaux moyens des Blés durs constituent la semoule, dont on fait des potages; en amidonnerie, on isole de la farine l'amidon et le gluten; enfin, la farine, mélangée au gluten et additionnée parfois de safran, de beurre et d'oeufs, est la base de l'importante industrie des pâtes alimentaires: nouilles, vermicelle, macaroni, etc., si prospère en Italie et en France même, à Clermont-Ferrand, Paris, Lyon, etc.

Pour cette fabrication, on emploie surtout les gruaux fins provenant des Blés durs. Le mélange de toutes les matières employées, additionnées d'un quart d'eau bouillante, est pétri au pétrin mécanique, puis broyé sous une meule verticale. La pâte des nouilles est soumise à un laminage; celle qui est destinée à la fabrication d'autres sortes de pâtes alimentaires est portée à la presse, sorte de cylindre en bronze chauffé à la vapeur, et dont le fond est percé de trous, ronds pour le vermicelle, elliptiques pour le macaroni,

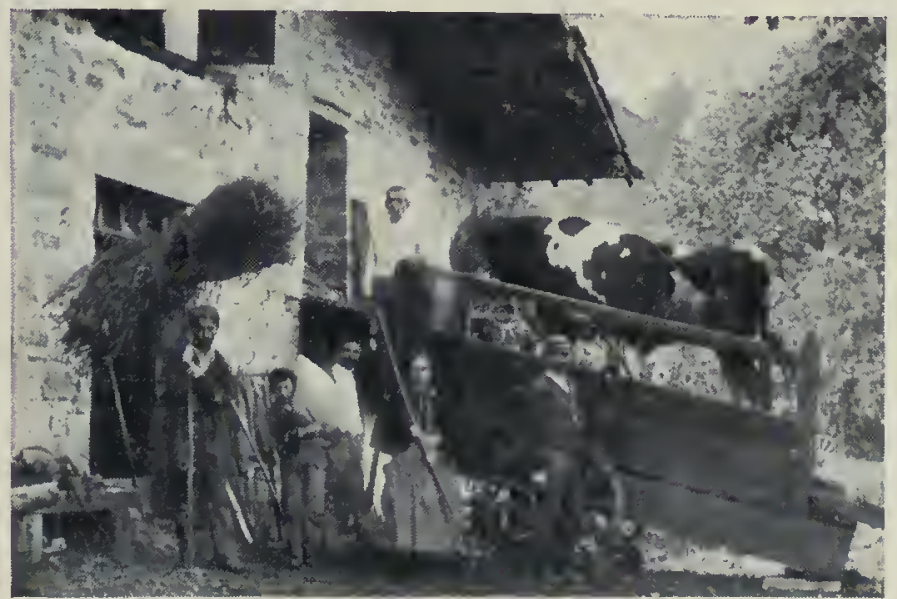

Batteuse actionnée par un bouf (Jura). 
ou en forme d'étoiles, de lettres, de chiffres, etc. Un piston pousse la pâte vers le fond, d'où elle sort en filaments ou en tubes continus. Les lettres et chiffres sont coupés en tranches minces, à mesure que sort la pâte, par un couteau tournant, centré sur le milieu du fond.

Orge, Seigle, Avoine. - L'Orge semble être, avec le Millet, la céréale le plus anciennement cultivée. Elle est rustique et
Aux Etats-Unis, le Maïs est, après le Cotonnier, la plante la plus importante. Nébraska, lowa, Kansas, Missouri, lllinois, Indiana et Ohio forment le corn belt des Américains, la région du Maïs. La farine de maïs est la base de l'alimentation chez les nègres des États du Sud; les graines engraissent les volailles et surtout les porcs; c'est sous la forme condensée de viande de porc que les Américains exportent leur maïs. Du maïs on fait de

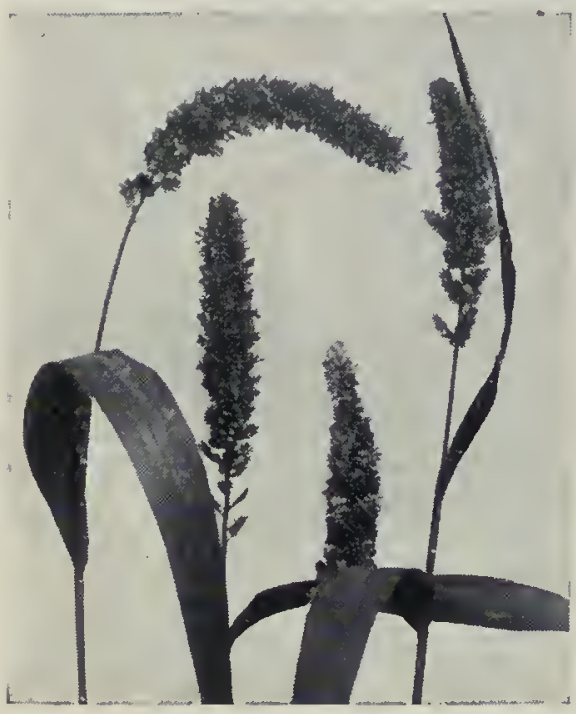

Épis du Millet d'Italie.

résistante; sa croissance est si rapide qu'elle mûrit durant le court été des régions septentrionales, aux îles Orcades, à Shetland et en Suède, jusqu' au cercle polaire; elle supporte d'ailleurs aussi bien les climats chauds de la région méditerranéenne. Son rendement est presque le double de celui du Froment, mais, à superficie égale, sa valeur alimentaire est plus faible, car le gluten est peu abondant. L'Orge a joné autrefois un rôle considérable dans l'alimentation de l'homme, mais le pain d'orge, lourd 'et indigeste, a disparu peu à peu, sauf en pays du Nord, devant le pain de froment. Parmi ses nombreux usages, les plus importants sont : l'alimentation des chevaux, dans la région méditerranéenne, et surtout la fabrication de la bière.

Le Seigle est, comme on l'a dit, le Blé des pays pauvres; c'est la céréale des pays du Nord et des régions montagneuses. Il résiste à des froids rigoureux, ne craint pas la neige, et se cultive dans les Alpes jusqu'à près de 1600 mètres d'altitude. En France, comme en beaucoup de pays tempérés, il a été remplacé par le Froment dans les bonnes terres; on le cultive encore dans le Morvan, les Cévennes, les hautes vallées alpines et pyrénéennes, et surtout en Russie et en Suède, au nord du Blé. Du grain de cette céréale, on fait un pain bis moins riche en gluten et, par suite, moins nourrissant que le pain de froment. La farine de seigle est la base du pain d'épice. Le grain est utilisé pour nourrir les animaux, fabriquer de l'alcool et, en Russie, une bière spéciale.

La culture de l'Avoine est moins ancienne que celle des céréales précédentes; les climats assez froids et humides lui conviennent seuls. La farine d'avoine est très riche en matière azotée (1) pour 100) et en matières grasses ( 5 pour 100$)$; elle donne un pain noir, compact et visqueux, encore utilisé de nos jours dans certaines parties de l'Écosse, de l'Irlande, de la Suède; avec le gruau d'avoine, on prépare d'excellents potages. Nous retrouverons l'Avoine comme plante à alcool et surtout comme plante fourragère.

Maĩs. - Le Maïs est une plante américaine, cultivée au Péroui, même àvant la période incasique. Introduite en Espagne au $\mathrm{XVI}^{\mathrm{e}}$ siècle, puis en Italie et en Orient, elle nous en revint sous le nom de Blé de Turquie. On la récolte aujourd'hui dans tous les pays tempérés, et elle a donné nombre de variétés culturales. En France, sa limite septentrionale est une ligne sinueuse partant de La Rochelle, contournant au Sud le Plateau Central, pour remonter en Bourgogne et en Franche-Comté. Le Maïs contient un peu moins de matières minérales que le blé, le double de matières grasses et presque autant d'amidon et de gluten. La farine de Mais est consommée sous forme de bouillies : gaudc, polenta, etc.

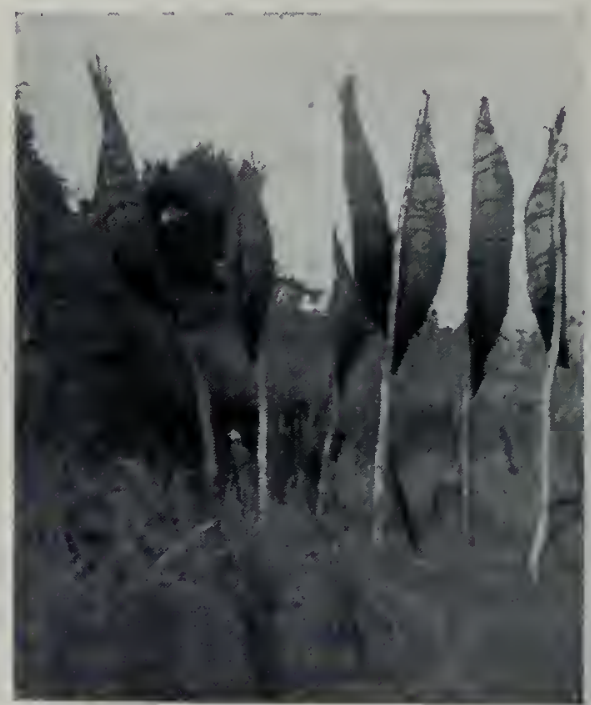

Conservation du grain, au Congo.

la bière, de l'alcool, comme le pulqué de Maïs et le chicha de l'Amérique du Sud; l'embryon du grain fournit une huile alimentaire et industrielle; les feuilles servent de fourrage ou sont employées à fabriquer du papier; les épis ćgrenćs sont un excellent combustible et la moelle de la tige un bon cofferdam pour les navires de guerre; des inflorescences mâles, on fait des cigarettes.

Le Maïs est cultivé aussi dans l'Amérique du Sud (surtout dans la République Argentine), en Egypte, en Roumanie, au Dahomey, en Abyssinie, en Indo-Chine, etc.; en France, surtout dans les Landes, les Basses-Pyrénées, la Haute-Garonne. Ses graines nourrissent les animaux domestiques et les oiseaux de basse-cour.

Millet. - Le Millet appartient à la région du Maïs; il supporte aisément la sécheresse et les fortes chaleurs; plusieurs espèces sont utilisées. Le Millet commun (Panicum miliaceum), originaire d'Egypte et d'Arabie, est à grappes lâches et retombantes; ses grains blancs, rouges ou noirs, assez gros, ont alimenté les peuplades préhistoriques; en Crimée, les Tartares les emploient encore pour fabriquer leur pain. On le cultive en France, en Hongrie, en Allemagne, en Russie, aux lndes (blé du Dekkan), au Sénégal. Sa farine, dont la composition chimique se rapproche de celle du maïs, entre dans l'alimentation des peuples méridionaux.

Le Millet d'ltalie (Setaria italica) est originaire de Chine. Ses épillets se groupent en un épi compact; ses minuscules graines jaunes sont le millet des oiseaux. On le cultive dans les mêmes régions que le précédent, mais il s'étend plus loin en Asie et en Afrique. En France, ce Millet se cultive surtout dans le Midi.

Le Pennisete typhoïde ou Millet à chandelle, Petit mil, présente des épis serrés, de couleurs variées. On ne le cultive pas en Europe, mais il est très répandu aux Antilles, en Asie, et surtout en Afrique, où il forme la base de l'alimentation des nègres, sous forme de bouillies d'un goût délicat, de gâteaux et de couscous.

Dans les pays chauds, où pullulent les insectes, les graines des céréales sont conservées parfois dans des greniers spéciaux, ou placées dans de sortes de bourriches en paille fortement serrées et affectant la forme de longs cigares.

Riz. - Le Riz, " ce Blé des races jaunes », est, par excellence, la céréale des pays tropicaux; sa graine est beaucoup moins. nourrissante que le blé; elle est très riche en amidon (75 à 80 pour 100$)$, mais pauvre en gluten ( 7 pour 100 ).

Le Riz a besoin de terres riches, inondées pendant une partie de 


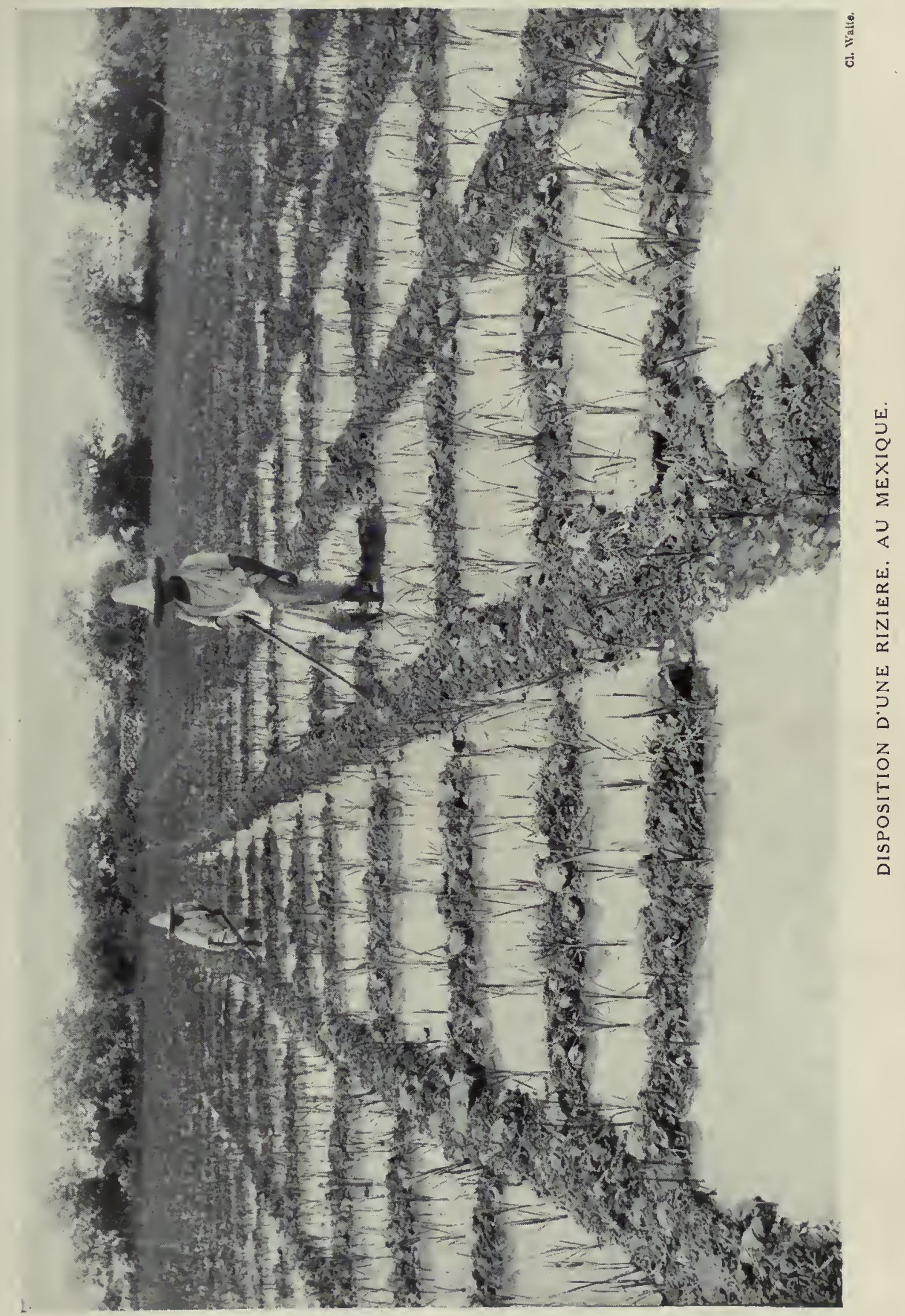





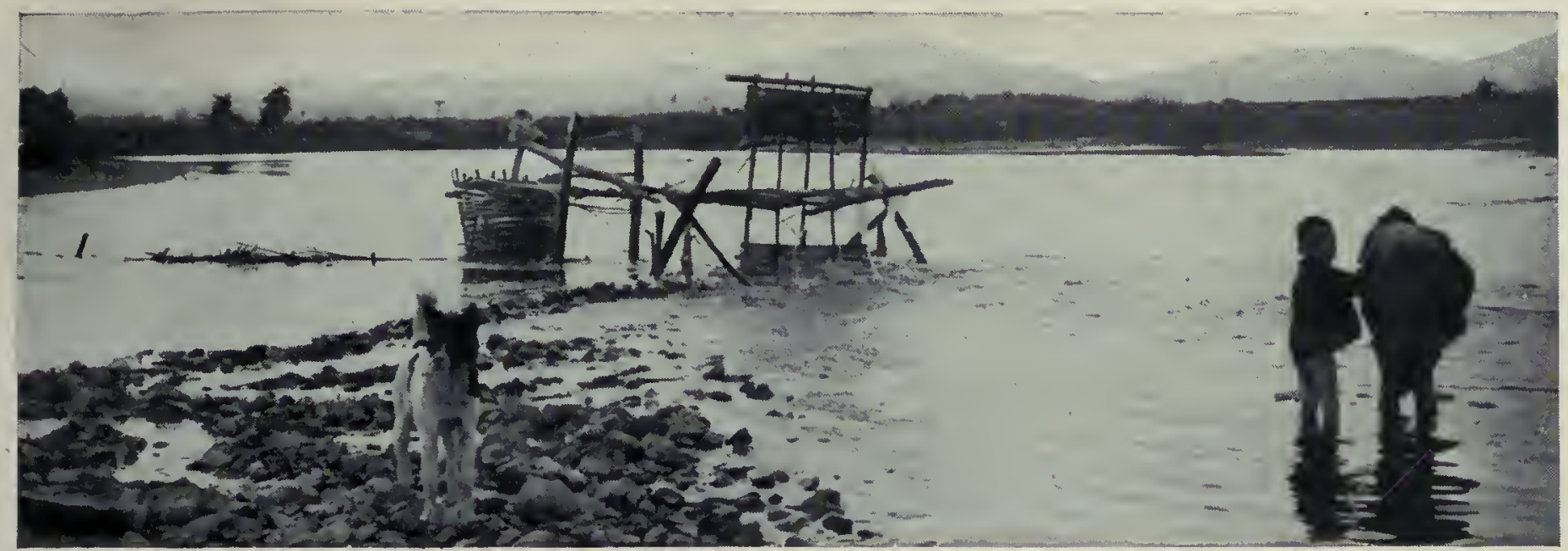

Un moulin à eau pour piler te riz, à Cao-Binh (Tonkin).

son développement; les régions deltaïques, arrosées par des crues régulières, sont celles qui lui conviennent le mieux. On cultive de nombreuses variétés de Riz : barbues ou sans arêtes, hâtives et pouvant donner deux récoltes la même année, si le climat s̀y prête, ou tardives et ne donnant jamais qu'une seule récolte.

Les grandes régions de Riz sont l'Inde et toute l'Asie méridionale, l'Extrême-Orient, la Malaisie. Des rizières importantes se rencontrent encore en Afrique, dans les vallées du Nil et du Niger, à Madagascar; en Amérique, dans le sud des États-Unis, au Mexique; en Europe, enfin, dans le Portugal, l'Italie (vallée du Pô) et l'Espagne. Depuis quelques années, en Camargue, sont des rizières prospères qui paraissent appelées à prendre de l'extension.

Les procédés de culture, de récolte et de battage du Riz sont fort variés, depuis les méthodes les plus primitives, implantées en Extrême-Orient et au Soudan, jusquà l'emploi du machinisme agricole le plus perfectionné en Louisiane et au Texas.

Les rizières peuvent être irriguées naturellement par les pluies ou des crues normales, comme en Cochinchine ou au Siam; elles sont alors en terrain plat; ou bien, comme en Chine, à Java, à Madagascar, l'irrigation est artificielle, et on établit des rizières en gradins. L'eau y est amenée, et souvent de fort loin, par des pompes, des norias, des moulins, des machines hydrauliques de toutes constructions, même les plus imprévues et les plus baroques. Conduite au point le plus hant, l'eau arrose successivement tous les étages de la rizière; des petits talus en terre, qu'il faut réparer chaque année, la maintiennent et servent de chaussée.

Les travaux commencent avec la pluie. L'eau est répandue jusquà 10 centimètres d'épaisseur; le sol est piétiné par les animaux ou par l'homme, labouré deux fois à la charrue, puis hersé pour égaliser le fond. Le cultivateur monte ordinairement sur la herse pour la faire entrer davantage dans le limon. Le sol ainsi préparé est apte à recevoir les jeunes plants de Riz, semés d'abord en pépinières dans un autre endroit. Ces jeunes plants (mâs), par touffes de douze, sont repiqués en lignes à 30 centimètres de distance les uns

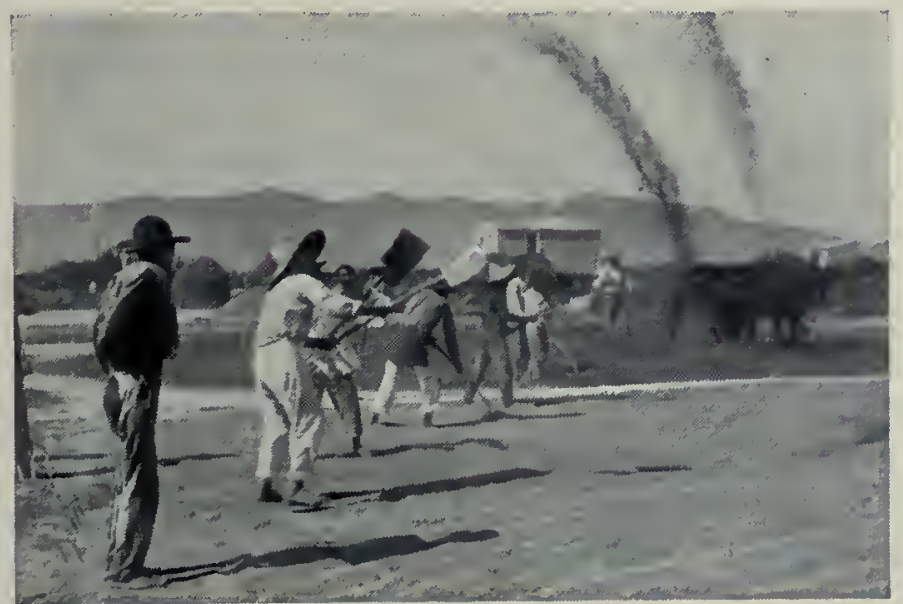

Le vannage du riz, en Espagne. des autres. Il n'y a plus ensuite qu'à surveiller la rizière, réparer les talus et maintenir le niveau de l'eau à 30 centimètres au maximum. Quand l'épi est formé, on assèche la rizière et il mûrit sans eau.

La moisson se fait à la faucille et les gerbes sont rassemblées en meules sur un terre-plein ou sous un hangar. L'égrenage se fait à la main, au pied ou à la batteuse. Le riz est décortiqué dans un mortier de bois avec un grand pilon ou à l'aide de machines primitives à moteur humain; dans les grands centres, comme à Saïgon, existent des moulins perfectionnés. Le riz, décortiqué, ou riz cargo, passe ensuite dans une machine qui, à l'aide de brosses, lui le donne poli : c'est le riz blanc, que nous recevons en Europe. Les usages secondaires du riz sont l'extraction de l'amidon et la préparation de boissons enivrantes, comme le saké des Japonais.

Sorgho. - Le Sorgho est une céréale des pays tropicaux; il cn existe plusieurs types; certains peuvent vivre sur le pourtour méditerranéen, où on les utilise comme fourrage. Le Sorgho est le doura des Arabes, le gaolian des Chinois, le blé de Cafrerie et de Guinće, gros mil, etc. Sa graine joue un grand rôle alimentaire en ces pays, ainsi que dans certaines parties de l'lnde.

Les graines de plusieurs autres Graminées sont encore utilisées pour l'alimentation. Tels sont: l'Elcusine, cultivée dans l'Inde, au Japon, en Afrique; le Paspaie, dans l'Inde et en Guinée (fonio), le Tef d'Abyssinie (Eragrostis) [p. 131 et 133].

Sarrasin. - Le Sarrasin ou Blé noir n'est pas une Graminée; on le range cependant parmi les Céréales, en raison de ses usages et de la composition de son grain. C'est une ressource précieuse pour les pays où le Blé ne peut croître. Originaire de la Mandchourie, puis introduit en Chine et en Russie, le Sarrasin est cultivé en France depuis le $X V^{\mathrm{B}}$ siècle. Il aime les climats tempérés, assez humides, jusqu' à 1000 mètres d'altitude; les sols granitiques et sablonneux lui conviennent, surtout la Bretagne, le Limousin, le Morvan. On utilise sa farine en bouillies ou en galettes cuites à la poêle.

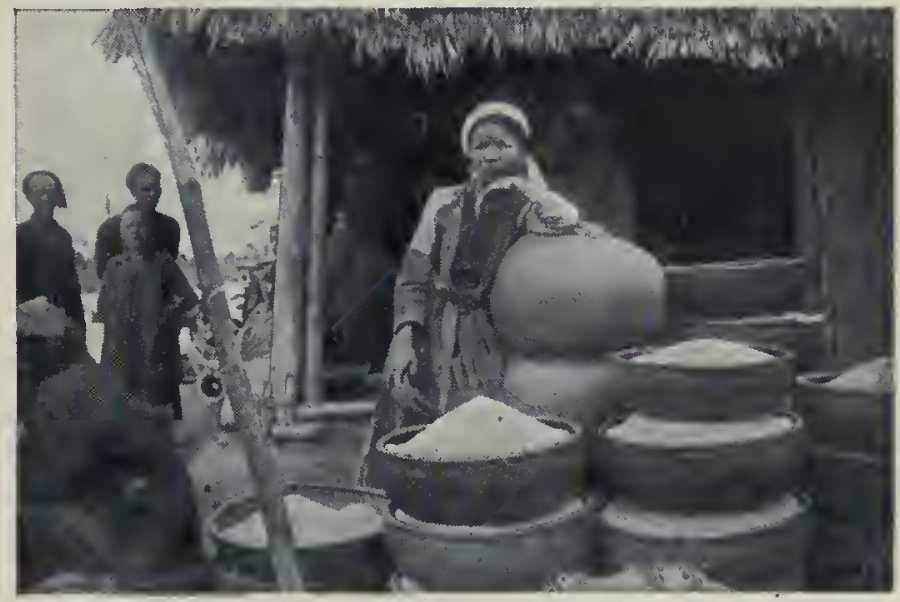

Une marchande de riz, à Hanö̈. 


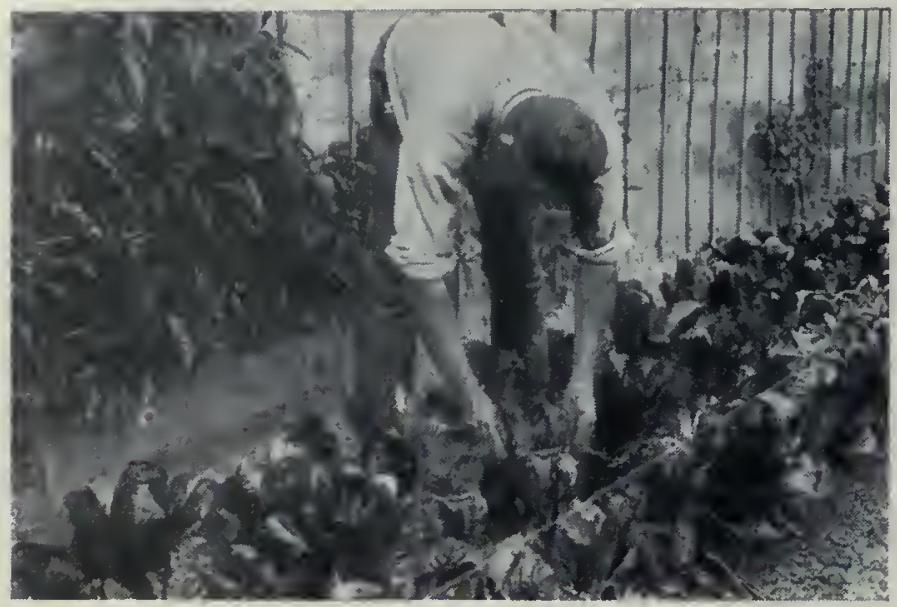

Le liage des Romaines.

\section{LES LÉGUMES}

La cuilture maraîchère. - Les légumes sont des plantes alimentaires dont la culture est fort ancienne; elle n'a pu prendre naissance qu'au sein d'une civilisation déjà avancée. La Fève, la Lentille, le Pois, le Chou, le Navet, la Laitue, l'Ail, l'Oignon sont cultivés de toute antiquité en Egypte, en Grèce, en Italie et dans l'Europe occidentale. Les découvertes géographiques, le développement des relations entre les peuples ont successivement introduit en nos pays d'autres légumes, comme la Pomme de terre, la Tomate, etc.; enfin les progrès de la culture maraîchère ont amené la création de nombreuses races, relativement récentes, comme le Chou de Bruxelles, le Chou-fleur, etc. Un jardin potager renferme, de nos jours, nombre de légumes qui étaient inconnus au moyen âge; mais, en revanche, certains autres qui y figuraient à la place d'honneur sont fort délaissés, ou même disparus. Qui cultive encore le Laiteron, le Chervis, le Maceron?

Partout où la place n'est pas mesurée, le jardin potager est le complément obligé de la demeure. On le retrouve sous toutes les latitudes; c'est une joie pour nos coloniaux de cultiver autour de leur habitation quelques-unes des plantes potagères de la mère patrie, et, même dans l'oasis, croissent des légumes à l'ombre des Dattiers. La culture maraîchère, c'est-à-dire celle qui s'applique à produire des légumes pour la vente, a pris une énorme extension aux environs des grandes villes. A Paris, l'industrie de la culture maraîchère est aussi ancienne que la ville même. Etablis primitivement dans les marais qui entouraient la ville naissante, puis, de siècle en siècle, chassés de plus en plus loin par l'élévation du prix des terrains, les maraîchers occupent aujourd'hui une grande partic de la banlieue parisienne.

La qualité du sol dans cette culture intensive, où pas un pouce

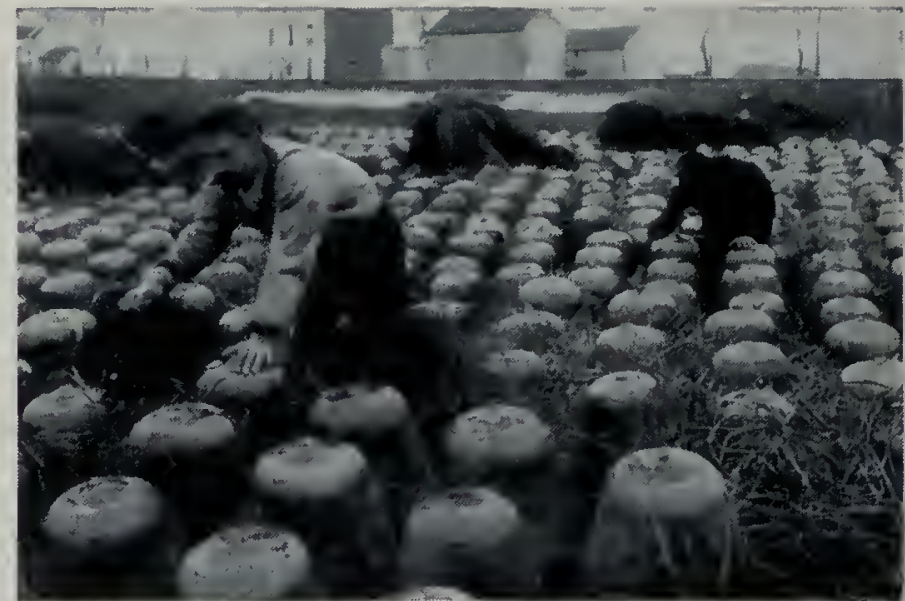

Cloches pour les salades.

de terrain n'est perdu, a peu d'importance, car il se borne à supporter les couches de fumier et de terreau que le maraîcher renouvelle d'un bout de l'année à l'autre. Avec le fumier, l'eau est l'élément le plus indispensable de la culture maraíchère. Un manège, mû par un cheval et actionnant une pompe, est le dispositif le plus employé pour retirer l'eau du puits; quelques installations utilisent un moteur à pétrole. L'eau coule ensuite par des tuyaux dans des bassins espacés où elle séjourne et prend la température de l'air; on y remplit les arrosoirs, on y lave les légumes.

L'irrigation des cultures maraîchères par l'eau d'égout est pratiquée à Gennevilliers, Achères, etc. ; en ouvrant une vanne, l'eau jaillit, coule dans des rigoles, sert d'engrais et arrose. Dans ces champs d'épandage, on récolte surtout le Chou et l'Artichaut.

La production des légumes, quels quils soient, est à peu près ininterrompue d'un bout à l'autre de l'année. A l'aide de cloches, de châssis vitrés recouvrant les couches, le maraîcher parisien force Laitues, Carottes, Radis, Navets et les produit avant leur époque naturelle ou, au contraire, longtemps après, par des semis tardifs. La rapidité des moyens de transport permet aux produits des cultures très éloignées d’aborder avantageusement les marchés parisiens. L'Algérie, la Provence, le Roussillon, la vallée de la Caronne, le littoral breton expédient les primeurs de toutes sortes.

Parmi nos maraîchers français, une mention spéciale doit être faite des hortillons $\mathrm{d}^{\prime} \mathrm{Amiens}$, dont la réputation date $\mathrm{du} \mathrm{XV}^{\theta}$ siècle; ils cultivent les terrains marécageux des bords de la Somme et apportent leurs produits en ville dans de grandes barques en forme de pirogues. C'est dans une charrette que le maraîcher parisien conduit ses légumes aux Halles; il y arrive vers minuit; les marchandises sont déchargées par les "forts " et la vente commence au " carreau " à quatre heures du matin. $C$ "est là que viennent s'approvisionner les fruitiers, les restaurateurs, les marchandes au panier et les marchands des quatre-saisons qui vont rouler leurs petites voitures dans tous les quartiers de la ville immense où se fondra rapidement le stock formidable d'aliments végétaux amené chaque nuit.

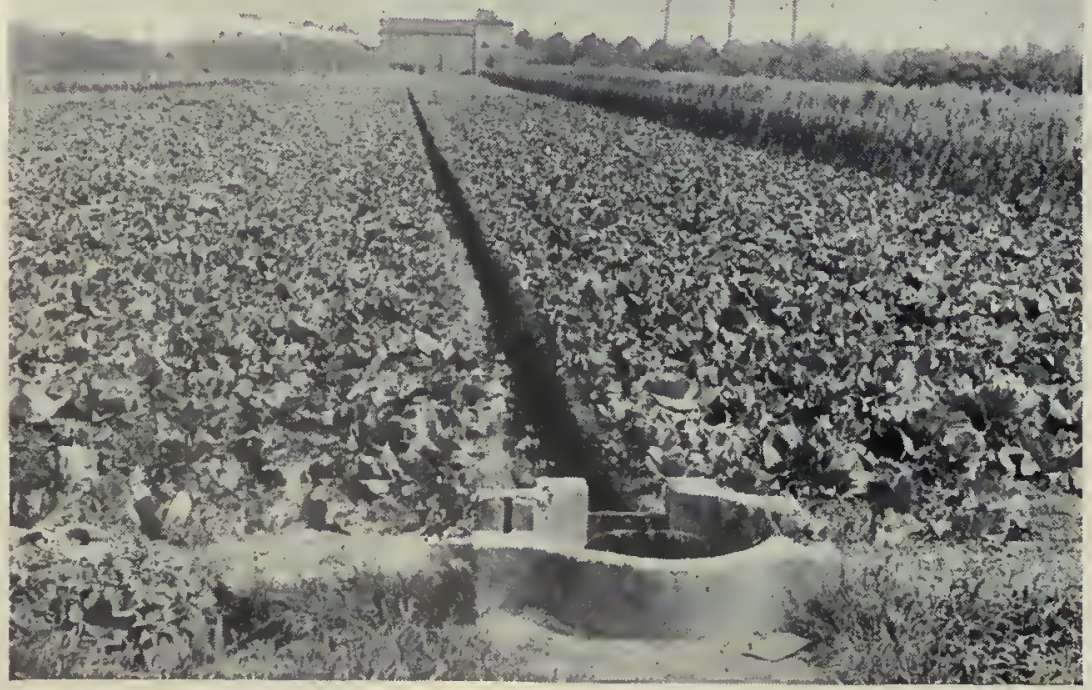

Épandage des eaux d'égout, d̀ Gennevilliers.
Légumes cultivés pour leurs tiges, leurs bourgeons ou leurs feuilles. - Le Chou potager, très estimé par les Anciens, qui en faisaient une panacée, tenait une grande place dans l'alimentation des Celtes et des Germains; il est encore l'élément le plus important de la culture maraîchère en Europe; il est rafraîchissant et sain.

Dans le pot-au-feu on utilise surtout les choux cabus ou pommés, chez lesquels le bourgeon terminal est devenu énorme (cœur de bœuf, York, quintal ou d'Alsace, choux de Milan à feuilles cloquées, etc.); les feuilles du chou rouge se mangent crues, en salade. On mange aussi les feuilles de certaines variétés de choux-verts, ne pommant jamais, comme le chou cavalier et le chou branchu du Poitou. Dans le chou de Bruxelles, les bourgeons axillaires sont développés en " pctites pommes "; chez le chou-rave, c'est un renflement charnu et moelleux de la tige qui est comestible. Le chou-fleur est une variété curieuse dont l'inflorescence, blanche et volumineuse, à gros pédoncules charnus, se mange avant l'ćpanouissement ; 


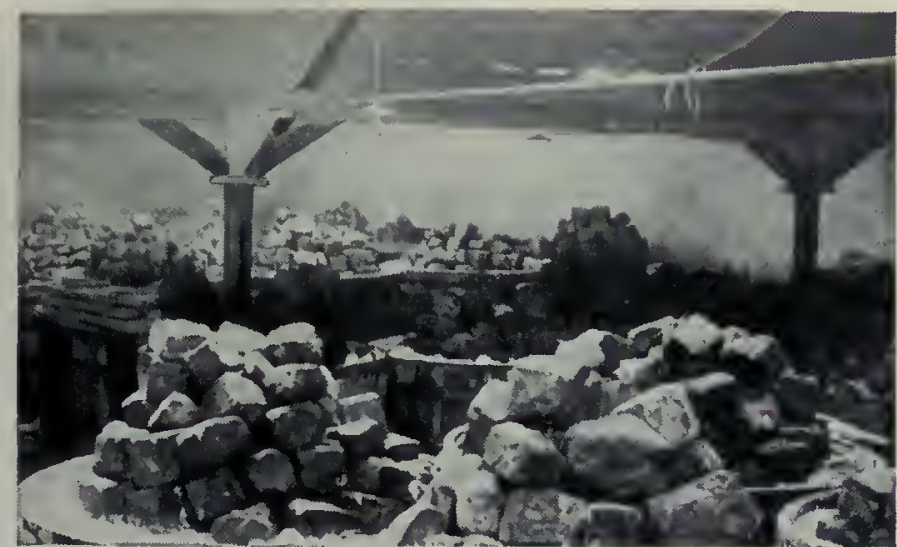

Cuves pour la fermentation de la choncroute.

venu d'Orient et introduit en ltalie vers le $X V t^{e}$ siècle, il a pris de nos jours, dans toute l'Europe, une imoortance considérable; le Brocolis ou Chou-fleur d'hiver est bisannuel ; son. port est plus élevé, ses feuilles plus étroites. Les environs de Copenhague sont très renommés pour la production des graines sélectionnées de Chou-fleur.

La choucroute, mets de prédilection dés races germaniques, résulte d'une fermentation du chou, principalement du chou quintal, dont certaines têtes peuvent peser jusqu'à 20 kilogrammes. Les choux, débarrassés des feuilles vertes ou fanées, blanchissent quelques jours sous un hangar, au bout desquels on enlève leur trognon. On porte au hachoir, qui coupe les choux en lanières. Celles-ci sont empilées dans une futaille défoncée par un bout; les couches de 15 à 20 centimètres d'épaisseur sont séparées par du sel. Quand le tonneau est plein, on recouvre d'un linge, puis d'un fond mobile qu'on charge de pavés. Bientôt s'établit une fermentation acide; le liquide des choux pressés est évacué par le bas.

A côté du Chou, se rangent le Crambe maritime ou Chou marin, utilisé surtout en Angleterre, et le fameux Pé-tsaï ou Chou de Chine, qu'on cultive avec succès en France.

L'Oscille est un légume rafraíchissant dont les feuilles cuites et hachées se mangent en garniture; il renferme du bioxalate de potasse en quantité notable, ainsi d'ailleurs que l'Épinard et la Patience ou Oseille-épinard, et ne convient pas aux goutteux. La Poirée ou Bette a les mêmes usages et n'offre pas les mêmes inconvénients: une variété, la Poirée à carde, possède des nervures principales très développées qu'on mange comme le cardon; la Tétragone ou Épinard néo-zélandais est un légume à saveur légèrement acide, qui réussit fort bien dans nos régions. L'Ansérine amarante (Chenopodium amaranticolor) est cultivée pour ses jeunes feuilles, revêtues d'une pulvérulence pourpre, qui se mangent comme épinards.

Le Poircau fait partie des légumes à pot-au-feu; il entre dans la confection de sauces et de potages. La Rhubarbe est d'une culture moins générale; cependant elle a une certaine importance aux environs de Paris et surtout en Angleterre pour les pétioles de ses larges feuilles, dont on fait des tartes et des confitures.

Le Céleri et le Céleri-rave sont deux variétés de notre Ache indigène, dont l'une a des feuilles très développées et l'autre la racine;

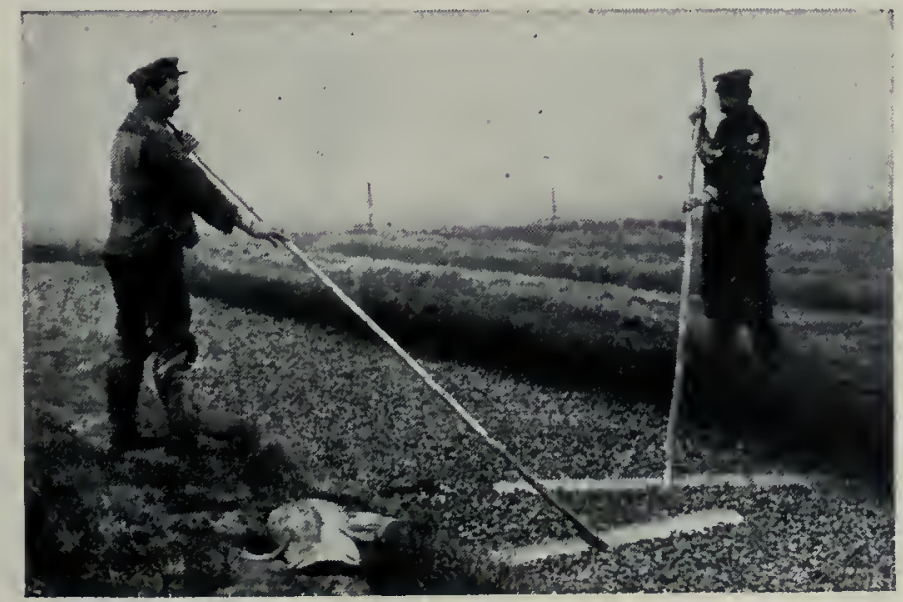

Schuellage ou tassement du Cresson. on les mange en salade ou cuits au jus. C'est dans la Californie du Sud que l'on trouve les plus grands champs de Céleri; la récolte s'en fait pendant l'hiver, très doux en cette région.

Le groupedessalades comprend des herbes à feuilles tendres qui peuvent être utilisées cuites, comme les légumes précédents, mais qui sont, le plus souvent, assaisonnées et mangées crues : beaucoup de nos plantes indigènes fournissent avant la floraison des salades agréables : Cresson,

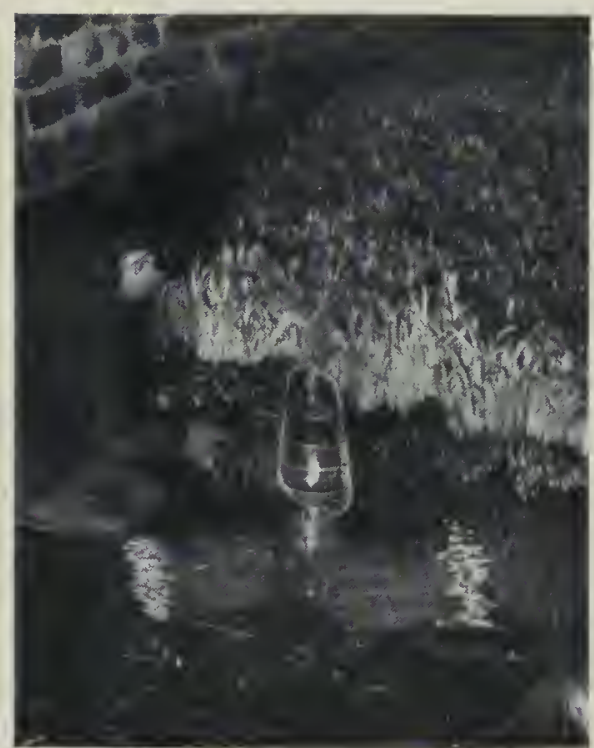

Plantation des bottes de Chicorée. Cardamine, Laitue

vivace, Raiponce, Bourrache, etc.; certaines, comme le Pissenlit et la Mâche, ont été très améliorées par la culture.

La Laitue cultivée est connue fort anciennement dans l'Inde, en Egypte; elle était hautement appréciée des Grecs et des Romains; c'est une plante maraîchère de première importance dont on connaît plus de cent variétés qu'on peut répartir en trois groupes : les Laitues pommées, à feuilles arrondies et molles; les romaines ou chicons, à feuilles plus allongées, à nervures droites et fermes; les batavia, pommées et à larges feuilles. En liant les Laitues, on fait blanchir les feuilles centrales qui deviennent plus tendres.

Notre Chicorée sauvage est une plante vivace extrêmement amère, mais qui sadoucit beaucoup par la culture et l'étiolement ; la variété à grosse racine de Bruxelles, étiolée et forcée en cave par les maraîchers belges ou parisiens, est la barbe-de-capucin. On sème au printemps les graines de la variété à forcer; à la fin de l'automne, on arrache à la fourche les jeunes chicorées; on sectionne les feuilles à 2 centimètres au-dessus du collet, puis on entasse les racines sous un hangar en les recouvrant pour empêcher la dessiccation, enfin on les met en jauge. Au fur et à mesure des besoins, les Chicorées sont déplantées, nettoyées, débarrassées des feuilles, sauf le bourgeon terminal, et mises en grosses bottes, qui sont portées au souterrain et posées simplement sur une couche de fumier dégageant une température de 18 à $22^{\circ}$. Quelques arrosages et, au bout de deux à trois semaines, la barbede-capucin est assez développée pour la vente. Lorsqu elle est pommée, on la vend à Paris sous le nom impropre d'endive (Witloof, en Belgique). La vraie Chicorée endive est une plante annuelle, originaire d'Orient; elle a fourni deux races intéressantes : la Scarole ou Escarole, à feuilles amples, presque entières, et la Chicorée frisée, à feuilles très découpées.

Le Cresson de fontaine, la "santé du corps " des marchands

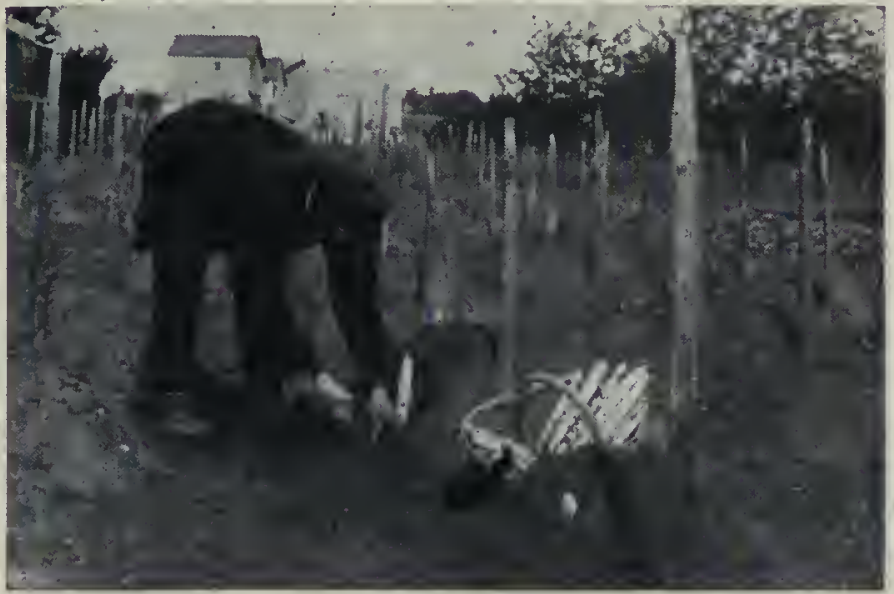

La récolte des Asperges, à Argenteuil, 


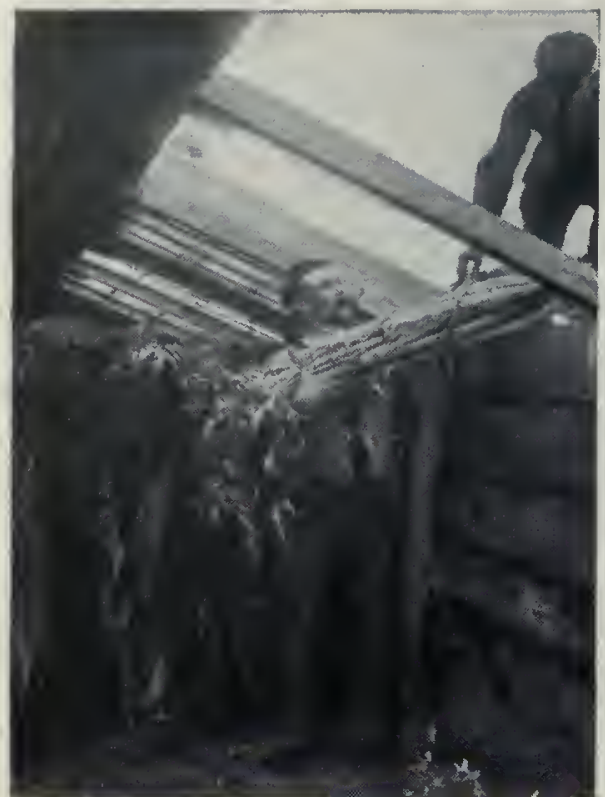

Mise en serre des Cardons.

dans un sol fumé copieusement. Quand les semis sont levés ou les boutures reprises, on met l'eau dans les cressonnières, en sujvant le développement du plant et sans le submerger. La récolte se fait en suivant la direction du courant; l'ouvrier se met à genoux sur une planche formant pont, coupe le cresson tige par tige, sans tirer, et le met en bottes, dont il peut faire jusqu'à cent vingt à l'heure, en coupe de printemps. Après la coupe, chaque fosse subit le roulage qui refoule dans l'eau les tiges du cresson, puis un fumage, et enfin le schuellage, qui consiste à frapper la plante avec un "schuel ", grande planche fixée à un long manche. Enghien, Luzarches, Gonesse, Provins, alimentent Paris en Cresson.

Le Cresson alénois (Lepidium sativum) ou Cressonnette, dont la croissance est très rapide, est utilisé plutôt comme condiment. Une autre salade donnant lieu à une culture assez importante est le Pourpier.

L'Asperge est un délicieux légume cultivé très anciennement; il est apéritif et diurétique. Les Romains en faisaient grand cas et estimaient surtout celles de Ravenne. Dès le Xvit $\mathrm{t}^{\mathrm{e}}$ siècle, la culture de l'Asperge avait acquis une certaine importance dans les environs d'Argenteuil; elle sy faisait alors en plein champ; depuis 1818, elle est associée à celle de la Vigne ; les Asperges de Besançon, Vendôme, Gravelines, Lauris sont aussi très estimées. Aux Etats-Unis, cette culture a pris une grande extension dans le New-Jersey, le Colorado et la vallée du Mississipi. Les griffes, c'est-à-dire le rhizome et les racines venant des semis, sont plantées, dans le courant d'avril, en fosses isolées ou en lignes, dont le fond est garni de fumier. On recouvre ensuite de terre formant monticule. Chaque année, on bine en mars, on coupe les tiges en octobre et on recharge de quelques centimètres de fumier et de bonne terre. La récolte commence seulement la quatrième année; la période de production dure quinze ans et plus.

On force les asperges, de manière à en avoir en toutes saisons. Pour obtenir les asperges blanches, on force sur place dans les premiers jours de novembre, avec du fumier neuf autour des planches d'asperge et sur elles. On recouvre ensuite d'un coffre. On n'aère jamais et on ajoute de temps à autre du fumier neuf. Le forçage en vue de l'obtention d'asperges vertes se fait danș de

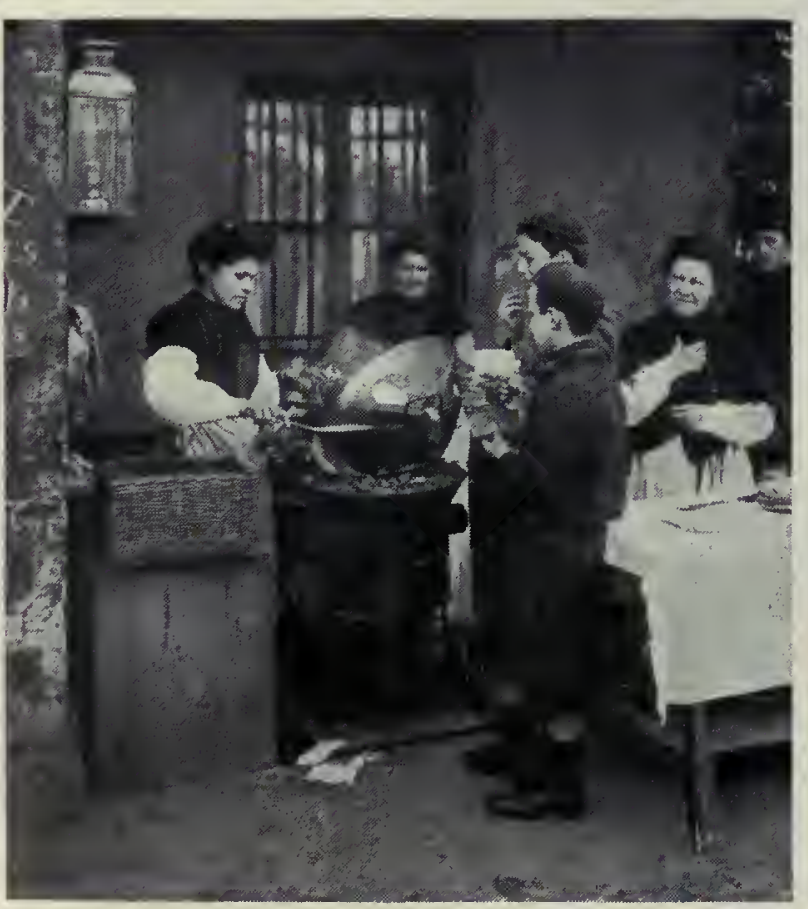

Marçhande de Pommes de terre frites,

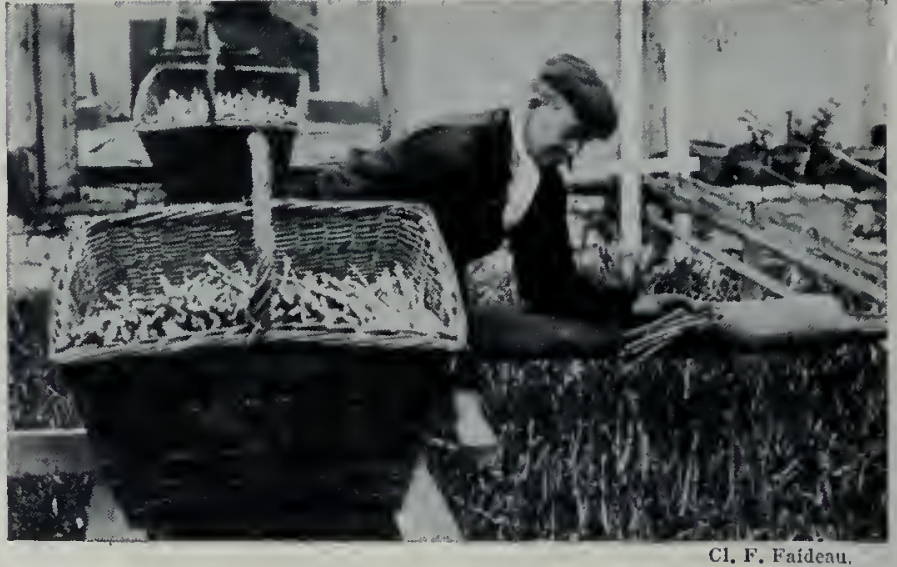

La cueillette des Asperges forcées.

grandes serres, principalement à Saint-Ouen, près de Paris. On y plante des griffes de trois à quatre ans, qu'on arrache des champs. La terre est chauffée en dessous à l'aide de thermosiphons jusqu'à une température qui, au début du forçage, peut atteindre $70^{\circ}$. Quand les asperges commencent à pousser, on aère pendant le jour, si le temps le permet. Au bout de quinze jours, une griffe commence à produire; elle donne pendant trois mois environ; elle est ensuite épuisée et bonne à jeter.

L'Artichaut et le Cardon sont deux légumes estimés. Cultivé d'abord en Italie, l'Artichaut ne passa en France qu'au début du $\mathrm{XVI}^{\sharp}$ siècle. Il en existe de nombreuses races : camus de Bretagne, vert de Laon, etc. On force l'Artichaut sur place, comme l'Asperge blanche. Le Cardon est un légume de luxe dont on mange les grosses nervures des feuilles et les racines. En septembre, on empaille les pieds bien développés pour les faire blanchir, ce qui exige trois semaines, Avant les fortes gelées, on arrache les pieds restants et l'étiolage se fait, durant tout l'hiver, sous serre couverte.

Les légumes herbacés consommés dans les diverses régions du globe sont innombrables. Citons les bourgeons de certains Bambous (plante qui joue un rôle capital en Chine) et de diverses Fougères qui sont en grand honneur au Japon, les jeunes tiges de Maïs sucré qui, aux Etats-Unis, se mangent au sel et au vinaigre. Le chou caraïbe, utilisé aux Antilles, se retire du Xanthosome à feuilles en flèche et de diverses autres Aroïdées. Le bourgeon terminal de plusieurs Palmiers: Arec oléracé, Oreodoxa oléracé, Cocotier, Sagoutier, etc., est le chou-palmiste.

Légumes cultivés pour leurs parties souterraines. - La Pomme de terre est plus qu'une plante maraîchère : c'est une plante de grande culture, à la fois alimentaire, fourragère et industrielle. On en connaît aujourd'hui plus de mille variétés; elle figure sur toutes les tables; la marchande de pommes de terre frites est, dans les grandes villes, un des types populaires de la rue.

La Pomme de terre est un aliment très sain, riche en amidon (22 pour 100) avec seulement 2 pour 100 de matières azotées.

Les maraîchers de Paris ont longtemps cultivé la Pomme de terre en primeurs, mais ils ont dû y renoncer, les Pommes de terre nouvelles d'Algérie arrivant sur nos marchés à prix réduit, pendant l'hiver et le printemps. Un procédé, très curieux, permettant d'obtenir en toute saison des Pommes de terre nouvelles, est le suivant : On pose des tubercules sur une couche de terreau humide dans une cave obscure, à la température à peu près constante d'environ $15^{\circ}$. Au bout de quelque temps, on coupe les germes formés à 2 ou 3 centimètres au-dessus des tuber- 


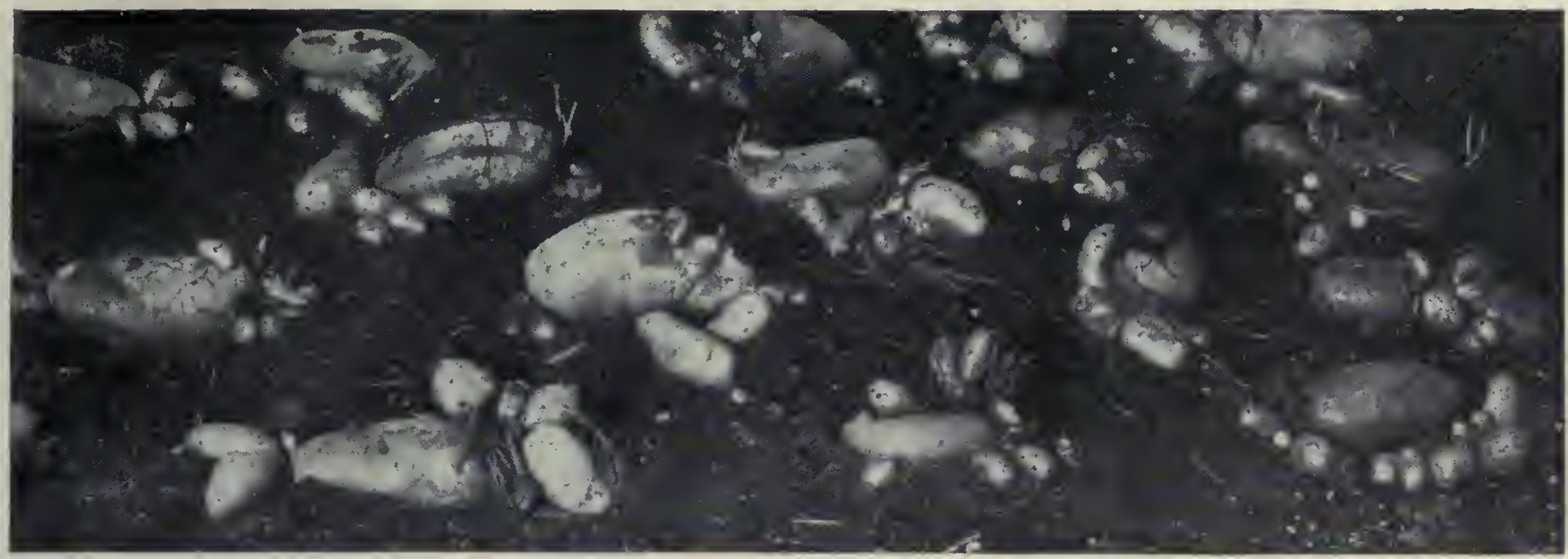

Petites pommes de terre développées autour des tubercules mères.

cules; il se développe de petites pommes de terre dont la récolte totale représente environ la moitié du poids des tubercules mères.

La Pomme de terre est sujette à de nombreuses maladies, dont la plus redoutable, le mildiou, est due à un champignon, le Phytopthora infestans (p. 116).

L'Allemagne tient le premier rang pour la culture de ce tubercule; on y emploie des procédés perfectionnés. La France expédie en Angleterre une grande partie de l'importante production bretonne.

Les tubercules du Topinambour (Helianthus tuberosus), malgré leur saveur un peu forte, sont utilisés frits ou dans les ragoîts; l'Hélianti $(H$. decapetalus), acclimaté en France, est une sorte de Topinambour à saveur délicate; sa vente est courante à Paris. Les racines sucrées de la Betterave potagère sont cuites au four et coupées en tranches dans les salades d'hiver.

Le Navet a tenu jadis dans l'alimentation une place considérable; c'est un légume à pot-au-feu et à ragoîts; on nomme raves les navets à racine aplatie et circulaire. La Carotte est une plante indigène transformée par la culture; on utilise surtout pour l'alimentation les variétés à racines rouges. La racine du Panais, à chair blanche et sucrée, mélange souvent dans le pot-au-feu son arome à ceux de la carotte et du navet.

Le Radis est cultivé depuis la plus haute antiquité; sa racine est tendre et savoureuse ; on rapporte ses innombrables variétés à deux groupes : les radis de petite race, ordinairement rouges, et les radis de grosse race, à saveur plus piquante et qui sont surtout noirs, gris ou violets. Les Daikons sont d'énormes radis blancs japonais, pesant jusqu'à 30 livres; on les mange crus ou cuits. Le Salsifis, la Scorsonère ou Salsifis noir, le Scolyme d'Espagne, sont, par leurs racines, des légumes très nourrissants; leur goût est délicat et ils s'apprêtent de bien des façons.

Les rhizomes en chapelet du Stachys du Japon ou Crosnes ( fig. 269), les racines du Cerfeuil bulbeux sont utilisés aussi comme légumes, de même que quelques plantes exotiques: racines de la

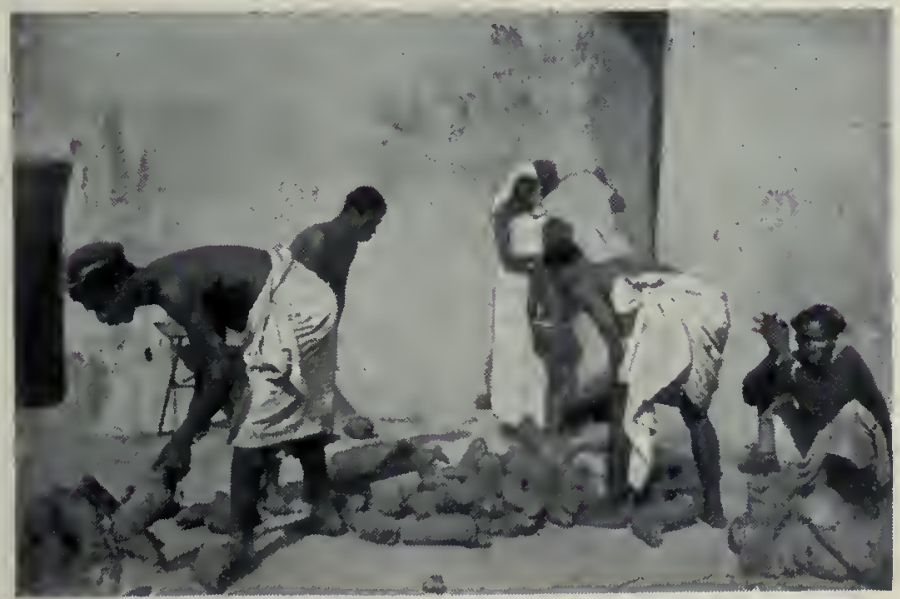

Triage des Ignames, au Pays de Kong (Afrique occidentale).
Poire de terre ou Polymnia edulis d'Amérique, tubercules de la Capucine tubéreuse, de l'Oca (Oxalis), de l'Ulluque de Colombie. La Patate (Ipomea Batatas); qu'on cultive parfois en France sous châssis, est une des plantes importantes des pays chauds; ses racines renflées, à chair tendre et sucrée, un peu aqueuse, se mangent comme la pomme de terre. Il en est de même des Ignames (Dioscorea) et des rhizomes de la Colocase comestible ou taro, ainsi que de divers Canna et Maranta.

Légumes cultivés pour leurs graines. - A la famille des Légumineuses se rapportent plusieurs plantes: Pois, Fèves, Lentilles, etc., cultivées dès la plus haute antiquité pour leurs graines farineuses, qui sont des aliments de premier ordre. Riches en sels minéraux $(2$ à 3 pour 100$)$ et en hydrates de carbone $(55$ à 60 pour 100), elles contiennent, sous forme de gluten pulvérulent ou légumine, plus de matière azotée que la viande (jusqu'à 26 pour 100 dans la lentille). Notons cependant que cette matière azotée

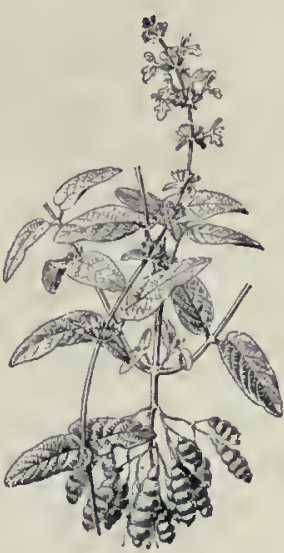

Fig. 269. Stachys du Japon.

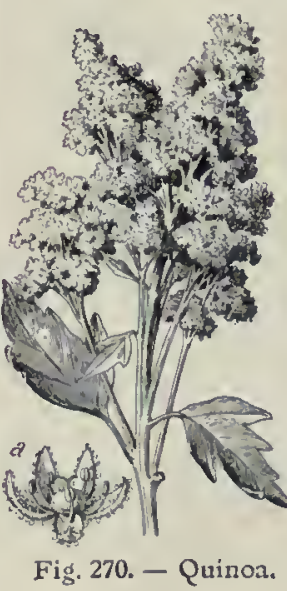

a, Fleur. n'est pas entièrement utilisable par l'organisme.

On mange crues les graines de la $F$ ève, avec un peu de sel, ou cuites, en purées, en potages; on estime surtout deux variétés: la Fève des marais, à grosses graines, et la Féverole, à petites graines. On cultive la Lentille grosse blonde, la Lentille du Puy, de teinte verte, avec points noirs, et le lentillon, ou Lentille rouge d'Égypte.

Le Pois est une plante maraîchère de première importance; les petits pois ou pois verts sont tendres, de saveur agréable, sucrée, et de digestion facile; les pois secs sont plus lourds; on les consomme surtout après décortication; ce sont alors les pois cassés, utilisés pour la confection de purées et de potages. On connaît des races naines et à ramer, des variétés à écosser, dont on ne mange que les graines et d'autres, dites mange-touf, à cosse tendre. Un insecte, la bruche, pond ses œufs dans les jeunes gousses, et les larves ou vers des pois dévorent les graines. Le Haricot offre des variétés naines ou grimpantes, à ramer, des races à écosser et d'autres

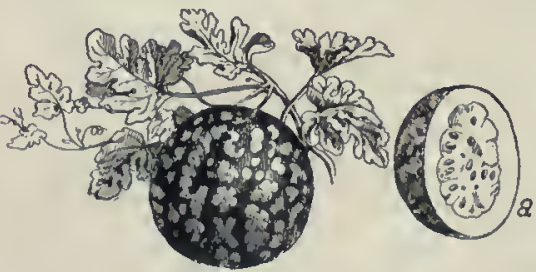

Fig. 271. - Pastéque. a, Coupe. 


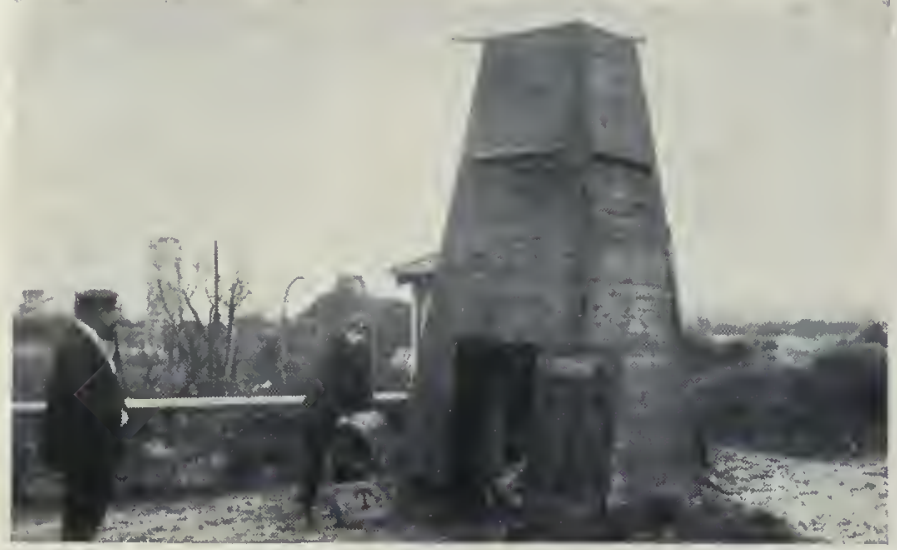

Cheminée d'aération d'une champignonnière.

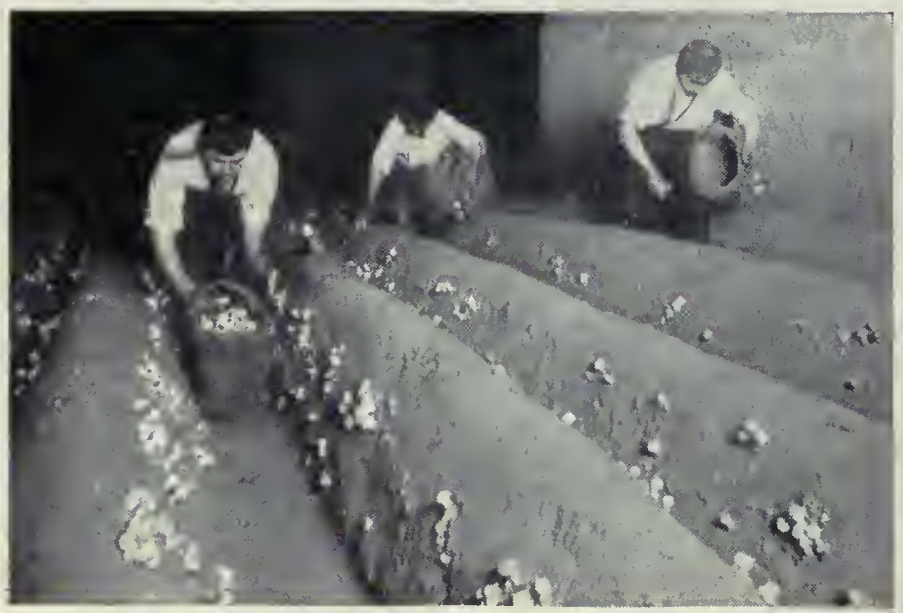

Cueillette des Champignons de conche.

mange-tout. La gousse, cueillie longtemps avant sa maturité, ou haricot vert, est un légume herbacé, sain et agréable.

Parmi les autres graines alimentaires des Légumineuses, citons le Pois chiche, du midi de l'Europe, et la Gesse cultivée ou Lentille d'Espagne. Rappelons l'importance des graines du Soja dans l'alimentation des Chinois et des Japonais. Dans l'Amérique du Sud, on utilise sous le nom de petit riz les graines alimentaires du Chénopode quinoa (fig. 270).

Fruits légumiers. - La famille des Cucurbitacées fournit tous les fruits légumiers, sauf la Tomate et l Aubergine, qui sont produites par des Solanacées.

La Tomate n'est cultivée en France que depuis le début du $\mathrm{XV} 1 \mathrm{t}^{\circ}$ siècle ; elle compte cependant un grand nombre de variétés. C'est un joli fruit, de saveur acide, dont le Midi fait une énorme consommation, cru en salade, ou cuit en sauce, farci, en conserve ou en confiture. L'Algérie nous en approvisionne pendant tout l'hiver, puis au début de l'été. L'Aubergine est cultivée en Europe depuis le XVII siècle; son fruit se mange cuit et fortement assaisonné, car il est fade.

Les Melons, forcés ou de plein champ, fontl'objetd'un commerce considérable. Cavaillon nous expédie ces fruits dès juillet. On distingue les Melons communs ou brodés, à surface couverte d'un réseau saillant; les cantaloups, verruqueux et à côtes; les melons lisses, ovoïdes, peu odorants, mais à chair très fondante. Les Pastèques (fig. 27I) ou Melons d'eau, peu cultivés en France, sauf dans le Midi, sont abondants et très appréciés dans

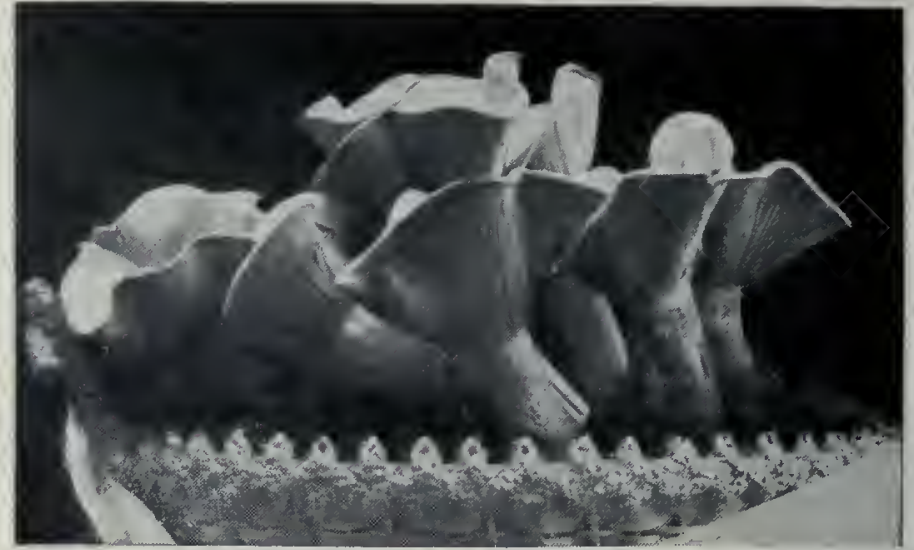

Pieds-bleus (Tricholome nn) cultivés par Costantin et Matruchot.

tous les pays chauds. Potirons, Citrouilles et Courges sont des fruits volumineux, se conservant longtemps pendant l'hiver, et pouvant se couper par tranches, au fur et à mesure des besoins. Des potirons et des citrouilles, on fait des potages. La Courge musquée, la Courge d'Italie et plusieurs autres Cucurbitacées, comme la Chayotte du Mexique, sapprêtent comme le Cardon.

Le Concombre est une plante de culture très ancienne, dont le fruit mûr est très apprécié dans le midi de la France, en Angleterre et en Russie; on le mange farci ou cru, salé ou en salade. Les fruits verts du Bananier du paradis sont, dans les payschauds, consommés cuits comme légumes et fournissent pour potages une excellente farine, dont la composition se rapproche de celle de la pomme de terre.

Champignons. - Les Champignons sauvages se vendent dans les marchés: beaucoup d'entre cux ont une saveur exquise. Les bons champignons constituent un aliment sain; malheureusement, à côté des espèces comestibles, il en croít d'autres fort vénéneuses qui provoquent chaque année des accidents.

La culture des Champignons, qui amènerait une sécurité absolue, est encore dans l'enfance. On sait obtenir plusieurs espèces, notamment le Tricholome nu ou Pied-bleu, mais une seule espèce, la Psalliote champêtre, qui est le Champignon de couche, est cultivée en grand. On le cultivait autrefois en plein air; depuis la fin du XVIIt ${ }^{\circ}$ siècle, sa culture a lieu en cave. Aux environs de Paris, il existe trois cents champignonnièresétablics dans les anciennes carrières de calcaire grossier et dont la présence s'annonce par des tours carrées en bois, qui sont des cheminées d'aération et souvent des orifices pour l'entrée et la sortic des matériaux et des ouvriers. Aux environs de Berlin, on cultive dans de grandes fosses qu'on recouvre de planches; à New-York, dans des bâtiments spéciaux, dits " maisons à champignons ". Cette culture exige de l"eau, une température de 16 à $18^{\circ}$ fournie par la fermentation du fumier de cheval. Ce fumier est disposé en longues bandes ou meules, hautes de 40 centimètres. On " ensemence " ou "larde " avec des plaquettes de fumier déjà envahi par du blanc de champignon. On gopte ensuite, opération qui consiste à recouvrir les meules ensemencées d'une mince

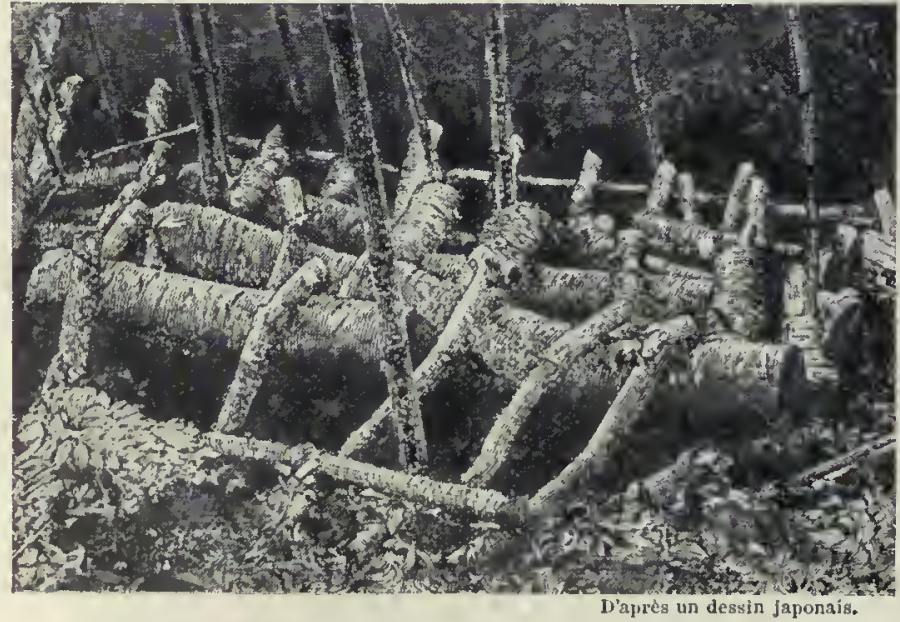

Troncs d'arbres portant te mycélium du Cortinellus. couche de terre calcaire. On arrose souvent; deux mois après l'ensemencement apparaissent les premiers champignons; la production dure parfois plusieurs mois.

La culture des champignons comestibles est pratiquée au Japon suivant une méthode tout autre : c'est sur des morceaux de bois de divers arbres : le Nara ou Chêne glandulifère, le Shii ou Chêne cupsidé, le Kounougi ou Chêne serrule, le Kuri ou Châtaignier, le Buna ou Hêtre sylvatique, que sc développent le mycélium, puis les fructifications du Shii-laké (ce qui veut dire Champignon de l'arbre Shii), qui est le Cortinellus Shii-také. Il faut environ trois ans de séjour 


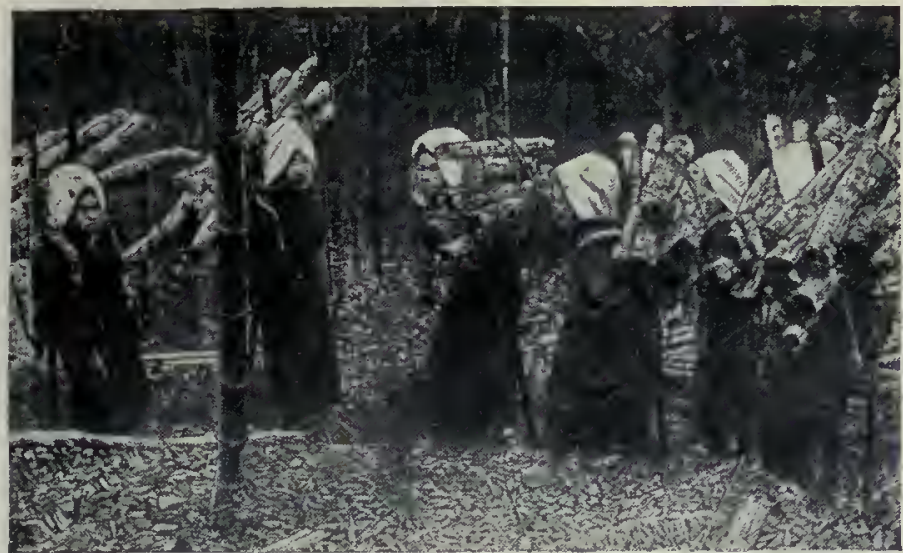

Japonaises transportant les bois producteurs de Cortinellus.

sur des neseba (nésé, coucher; ba, place) pour que le Champignon puisse effectuer son évolution. Au bout de ce temps, dans la dernière quinzaine, quand les fructifications vont être à point, on les transporte après les avoir imbibées d'eau dans des réservoirs où on les laisse séjourner un nombre déterminé d'heures; parfois on les bat et on transporte les morceaux de bois au "tatekomi " (taté, mettre droit; homi, arrangement), où sont des chevalets qui permettront la maturation des fructifications. Les Champignons sont consommés frais, et ils portent alors le nom de $N a m a-k o$, ou desséchés, et on les appelle alors Hanagata. Le Japon exporte en Extrême-Orient, surtout en Chine, une quantité considérable de ces Champignons secs.

Légumes condiments. - Certains légumes ne sont cultivés que pour relever le goût des préparations culinaires : ce sont les condiments, dont la plupart sont originaires des régions chaudes du globe.

L'Oignon a joué un rôle considérable dans l'alimentation des peuples de l'antiquité et notamment des Égyptiens. On consomme encore comme légumes proprement dits certains gros oignons à saveur douce; les autres races sont des condiments figurant dans toutes les sauces. L'oignon est apéritif, diurétique, riche en glucose et en une essénce sulfurée qui irrite la conjonctive; on le cultive en grand aux environs de Roscoff, d'où il s'exporte en Angleterre. L'Ail, plus caustique et de saveur plus forte que l'oignon, a ses fervents et ses détracteurs; il en est fait grand usage, ainsi que de I'Echalote, de la Ciboulc et de la Ciboulette. Cette dernière, sous le nom d'appétits, parfume agréablement la salade et triomphe dans les omelettes. Nombre de plantes aromatiques sont condimentaires : Persil, Cerfeuil, Thym, Laurier, Sarriette, Fenouil.

Le Piment (Capsicum annuel) est le fruit d'une Solanacée; vert d'abord, il est, à la maturité, d'un rouge éclatant. Les piménts doux sont mangés en salade; les piments forts ou enragés sont employés à petite dose comme condiment. Les Cornichons sont les jeunes fruits verts du Concombre cultivé; confits dans le vinaigre, ils accompagnent agréablement les viandes froides.

La Moutarde fait l'objet d'importantes cultures, notamment aux environs de Dijon et de Bordeaux, pour ses graines condimentaires qu'on broie dans du vinaigre ou dans du verjus. Le Raifort possède une grosse racine à saveur forte, rappelant celle de la moutarde; en Alsace et aussi en Allemagne, où sa culture est très développée, elle figure sur les tables presque à chaque repas comme hors-d'œuvre ou comme condiment, soit après cuisson, soit, le plus souvent, crue et rapće.

Les Olives vertes et les $C \hat{a}-$ pres, bourgeons floraux du Câprier, après un séjour dans le vinaigre, servent, les unes de hors-d'œuvre et les autres de condiments. Le Safran est l'accompagnement obligé de la bouillabaisse; il colore et relève cer-

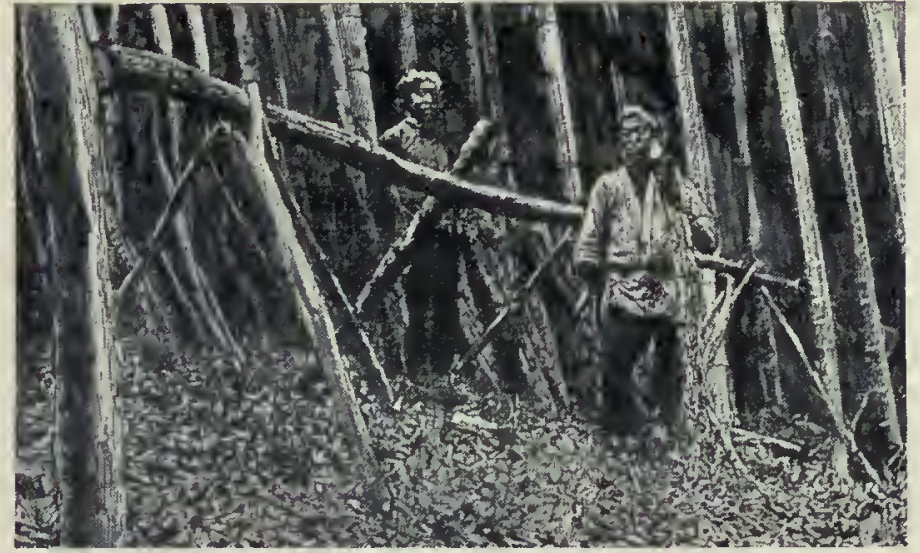

Chevalet permettant ta fructification du Cortinellus.

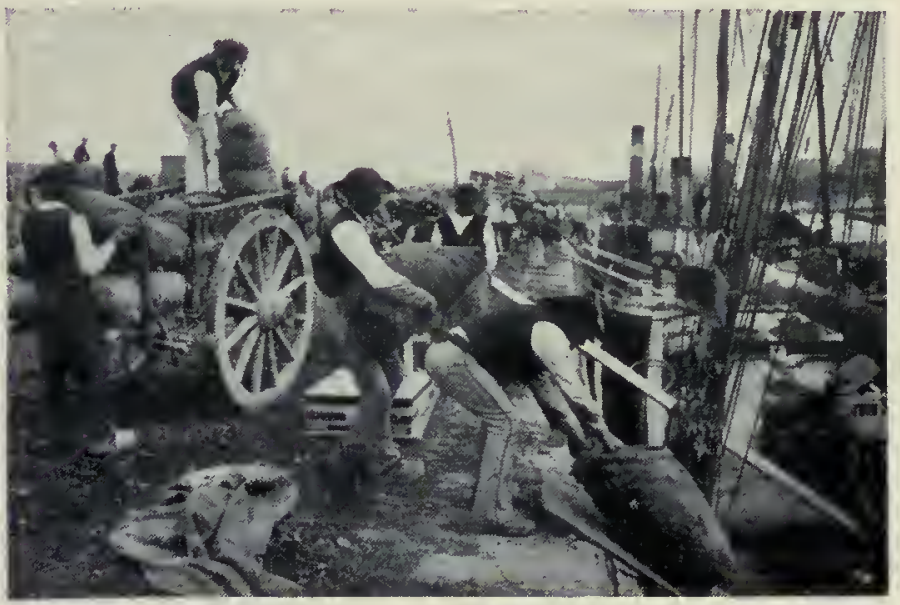

Expédition des Oignons bretons en Angleterre.

tains mets. Rappelons le rôle condimentaire du jus de citron, et noublions pas la Truffe, condiment de luxe dont la France produit annuellement 500000 kilogrammes.

La graine du Soja, outre son rôle comme légume, sert au Japon à préparer un condiment, le sho-you, nécessaire pour masquer la fadeur de la cuisine japonaise. Dans la seule ville de Nangasaki, dix usines produisent ensemble près de 15000 tonnes de cette sauce, qui est un liquide brun, d'odeur et de saveur spéciales, obtenu par la fermentation de l'orge et de la graine de Soja, en présence d'un grand excès de sel marin et sous l'action de divers Champignons : Aspergillus du riz et Levures. Cette fermentation, très lente, dure environ deux ans, puis la pâte est mise sous presse; le jus qui s'ćcoule est le sho-you.

Conserves de légumes. - Cette industrie, très importante, comprend la préparation de légumes desséchés et de conserves proprement dites; le pre-

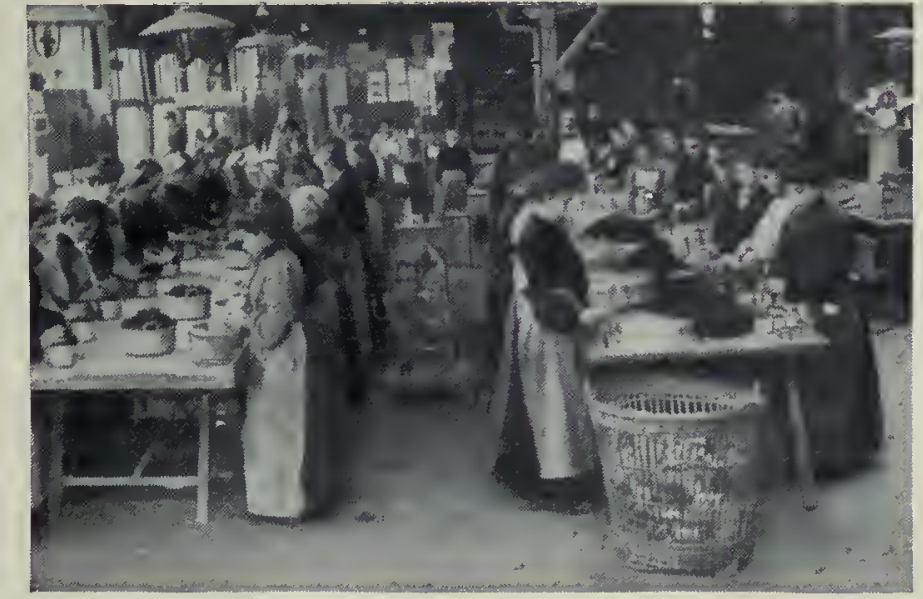

Nettoyage et mise en flacons des Truffes. mier mode s'applique à un petit nombre de plantes qui sont coupées en tranches, desséchées et racornies, mais qui reprennent à peu près leurs propriétés alimentaires au contact de l'eau bouillante; on en fait des potages. La conservation en récipients clos, après chauffage, est le procédé général. On prépare ainsi les petits pois, les flageolets, les asperges, les fonds d'artichaut, les champignons, etc

Signalons aussi l'industrie des conserves de condiments macérés dans le vinaigre, et surtout celle des achards ou pickles, si développée en Angleterre; ce sont des mélanges de légumes additionnés de piment. 


\section{LES ÉPICES ET AROMATES}

Nous avons vu plus haut combien ces plantes ont eu de l'importance au point de vue commercial pendant tout le moyen âge, et que c'étaient elles qui avaient fait découvrir le Nouveau Monde.

Les épices se vendaient d'abord chez les apothicaires à un prix élevé. C'est au XIV siècle que s'établirent les boutiques d'épiciers à Paris, et le prix de ces denrées devint un peu moins élevé. Les buste tout à fail différent de l’arbre précédent : c'est une Solanacée du genre Capsicum; ses fruits sont des baies légèrement pulpeuses, blanches, jaunes ou rouges, de formes et de dimensions très variables. Dans le Piment fastigié elles sont conico-cylindriques et atteignent 2 à 4 centimètres de long, mais cette espèce présente des variétés sphériques plus petites qu un grain de poivre, ou aussi petites, mais de forme conique; il s'emploie pulvérisé sous le nom de Poivre de Cayenne. Le Piment enragé, que l'on dé-

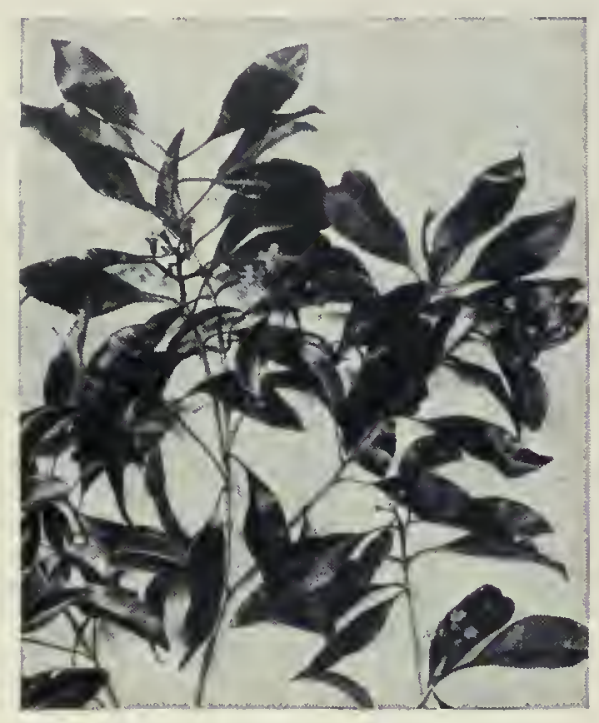

Branche de Giroftier.

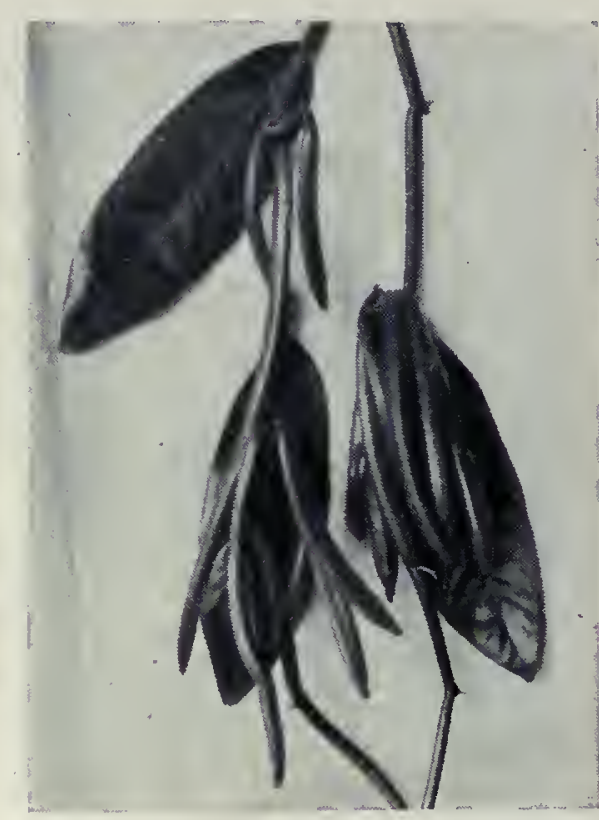

Vanille en fruits.

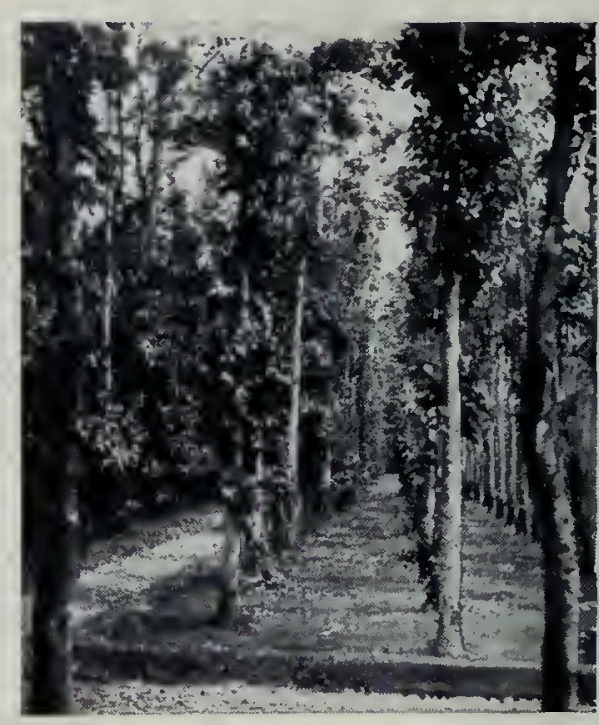

Culture du Poivrier, à Java. principales épices étaient le Poivrier, le Cannelier et le Muscadier. Ces plantes doivent leurs propriétés stimulantes à des huiles cssentielles ou grasses; à des alcaloïdes, à des résines à saveur brûlante, etc. Ces principes sont localisés dans divers organes: $1^{\circ}$ les boutons floraux; $2^{\circ}$ les fruits et les graines; $3^{\circ}$ les écorces; $4^{\circ}$ les rhizomes.

Épices provenant de boutons floraux. - Le Giroflier vient des Moluques ou îles à épices. C'est d'Amboine que Poivre le rapporta à la Réunion en 1770 , malgré les efforts des Hollandais, qui voulaient garder le monopole de cette culture. Dans une deuxième expédition, Poivre fut assez heureux pour découvrir de nouveaux pieds de cette plante précieuse à Guéby, port inconnu des Hollandais. En 1772, il donnait à un créole de la Réunion cing pieds de Giroflier : quatre périrent et c'est le cinquième qui devint la souche de tous les Girofliers qui se sont propagés dans les régions chaudes du globe. C'est un arbre dont les fleurs ont quatre lobes calicinaux épais, persistants, rouges. Les clous de girofle sont les fleurs encore en bouton qui sont cueillies au moment où le calice prend sa coloration rosée. On les emploie comme condiment et leur goût très fort et très caractérisé est dû à une huile essentielle, l'essence de girofle, qui est employée dans les préparations microscopiques. Par fraude, on mélange souvent aux clous les griffes de girofle, qui sont les pédicelles floraux, et les mères de girofle ou anthofles, qui sont ses fruits, mais ces parties sont beaucoup moins riches en essence que les boutons ou clous. C'est vers la septième année que le Giroflier est susceptible de donner une récolte; à dix ans il est en plein rapport et peut produire jusquà soixante-dix ans. Les clous, après la récolte, sont desséchés au soleil, étendus sur des nattes et rentrés le soir; au bout de cinq jours de ce traitement, la dessiccation est suffisante. Un arbre produit de 5 à 10 kilogrammès.

Épices provenant de fruits et de graines. - Les fruits d'une autre Myrtacée, le Piment officinal ou tout-épice, ou quatre-épices, se trouvaient il y a quelques années chez les épiciers en France : ce sont des baies rondes rugueuses, de la grosseur d'un pois; elles renferment l'essence de piment. On les cueille avant la maturité et on les sèche au soleil en six à dix jours; elles sont brun rougeâtre, d'une saveur chaude et poivrée, et le nom de quatreépices rappelle que leur goût évoque celui de la cannelle, de la girofle, du poivre et de la muscade. Chaque arbre peut fournir 10 à 15 kilogrammes; à partir de sept ans la récolte commence.

Le Piment proprement dit ou Poivre de Cayenne est un arChillee (Chili pepper) des colonies an-

signe ainsi dans nos diverses colonies, est une autre forme (Piment frutescent); c'est le glaises; ses fruits sont coniques. Dans le midi de l'Europe et dans les pays tempérés, c'est le Piment annuel, sous la forme de piment doux, qui est ordinairement cultivé.

Le Poivre proprement dit est produit par une liane, le Poivrier noir, de port tout à fait différent; elle atteint une dizaine de mètres de long avec des tiges souples; les inflorescences sont des épis et les fruits des baies presque sphériques, serrées les unes contre les autres, d'abord vertes, puis rouges, de vingt à quarante par épi. Ce fruit est cueilli un peu avant la maturité et simplement desséché, et il donne ainsi le poivre noir du commerce; il renferme 2 à 3 pour 100 d'un alcaloïde, la pipérine, une huile essentielle très odorante et des résines à saveur brûlante. Pour obtenir le poivre blanc, on cueille le fruit mûr, puis on le laisse tremper quelque temps dans une eau de chaux ou dans de l'eau de mer, et le péricarpe ainsi gonflé est ensuite enlevé par frottement entre les mains : le produit obtenu n'est que la graine et non plus le fruit. C'est à partir de trois ans, quand la plante vient de bouture, que la récolte commence, et elle peut atteindre de l kg. 750 à 3 kilogrammes, de six à quinze ans, pour diminuer à un âge plus avancé, et à partir de trente-cinq ans la plante doit être remplacée, car elle ne produit plus suffisamment. On peut faire, en général, deux récoltes par an.

Le Poivre long entre dans l'Inde dans la composition de divers médicaments. On connaît enfin d'autres Poivriers donnant le poivre long de Java (Poivrier des officines) et le poivre des Achantis (Poivrier de Guinée). Le Poivre de Kissy a été adopté pour la consommation des troupes au Soudan. On désigne souvent encore, sous le nom de Poivrier de Guinée, une Anonacće, le Xylopia d'Ethiopic, dont les fruits allongés sont en bouquets de huit à dix baies, avec une série d'étranglements.

Une autre plante à épices utilisée pour ses graines est le Muscadier, longtemps cultivé exclusivement aux Moluques, surtout aux îles de Banda. Poivre, avec Provost et d'Etcheverry, l'introduisit à Maurice et à la Réunion. C'est un petit arbre ressemblant à nos Poiriers, à feuilles entières, à fleurs jaunâtres, à fruit constitué par une capsule charnue jaunâtre en forme de prune, qui s'ouvre en deux valves et laisse apercevoir de jolies graines recouvertes d'une arillode charnue se détachant par sa couleur rouge sur la graine brune: cette partie superficielle constitue le macis du commerce, utilisé surtout dans la fabrication de liqueurs et médicaments, et comme condiment. En cassant le tégument dur de la 
graine, on retire l'amande, qui est la noix de muscade, formée surtout par l'albumen ruminé; elle est de saveur âcre, d'odeur aromatique; par pression à chaud, on en extrait les corps gras, surtout la trimyristine, qui entraînent les hydrocarbures de composition complexe formant l'essence, et l'ensemble est le beurre de muscade. La Muscade de calebasse est fournie par le Monodora muscadier (Anonacée), dont les graines donnent une essence rappelant celle du macis de la muscade; on l'emploie surtout en Afrique : c'est le poussa des Gabonais.

Les graines de Cardamome (Elettaria Cardamomum) sont également utilisées à cause de leur essence aromatique, poivrée, qui les fait employer comme le poivre et la girofle. C'est surtout dans l'Inde et à Ceylan qu'on les récolte; on expose au soleil le fruit pour le faire sécher. C'est un produit important exploité à l'état sauvage dansle Haut Tonkin. Les graines de paradis, ou maniguette ou meliguette, sont très consommées en Angleterre; elles ont la saveur du poivre ou des Cardamomes; elles sont dues aux Amomes Meleguettes du Sierra-Leone et du Congo (fig. 274). Le maniguette bâtard est dû à l'Amomum Clusii,

à saveur moins forte, qui vient également de l'Afrique occidentale, ainsi que le dadi-gogo du Congo (Ceratanthera Beaumetzi).

La Vanille peut être rattachée aux aromates employés par leurs fruits. C'est une Orchidée dont le fruit allongé se fend en deux valves, aux tissus fortement chargés de vanilline que l'on a pu reproduire par synthèse. C'est une plante d'origine mexicaine, et qui a été introduite dans les régions africaines et à la Réunion par Marchand en 1822, de boutures venant du Muséum de Paris, mais l'insecte qui la féconde dans son pays natal manquant, l'opération de la fécondation artificielle est nécessaire; cette pollinisation, qui peut s'étendre à plus d'un million de fleurs dans une seule exploitation de la Réunion, par exemple, est une opération agricole de la plus haute importance. Le fruit n'est mûr que six à sept mois après la fécondation. Les gousses coupées sont soumises à une série de manipulations en vue de développer leur parfum et de permettre leur conservation; elles consistent en des immersions courtes dans l'eau bouillante, puis fermentation et séchage : les fruits récoltés ne dégagent l'odeur recherchée de la Vanille que sous l'influence d'une oxydase; de verts et durs qu ils étaient au moment de la cueillette, ils deviennent bruns et bien souples. On emploie, depuis 1897, une nouvelle méthode de préparation dite " par le chlorure de calcium "). Signalons une autre Orchidée, le Sélénipède chica, qui fournit une vanille de qualité inféricure.
Épices provenant d'écorces.- Le Cannellier(Cinnamome, fig. 273) de Ceylan est une autre plante à épice. Les écorces de cette Laurinée sont enlevées, à Ceylan, par des indigènes appartenant à une caste spéciale, celle des Chaliyas; ils pratiquent, sur les jeunes tiges coupées, des incisions circulaires et longitudinales, et, avec un morceau de bois renflé à une extrémité, ils tapotent l'écorce de manière à la détacher à l'aide d'un couteau serpette en cuivre, métal ne s'altérant pas, car le fer noircit au contact du tanin de l'écorce. Ces écorces sont mises à sécher, débarrassées du liège par grattage. Elles se présentent dans le commerce sous forme de cylindres fendus en long. La culture de cette plante est surtout importante à Ceylan .

La cannelle blanche est fournie par une plante voisine des Magnoliacées; elle est surtout employée en médecine. A ce groupe nous pourrons également rattacher la cannelle de Winter (Drimys Winteri) $[$ fig. 276].

Épices provenant des rhizomes. - Il est enfin plusieurs plantes dont les rhizomes fournissent également des épices ou des aromates, en particulier le Gingembre officinal (fig. 275), à port de roseau, à rhizome tubéreux, qui renferme une huile essentielle, jaune pâle, à odeur vive, à saveur douce, aromatique, puis amère, légèrement brûlante. Cette plante, probablement originaire de l'Asie, n'a pas été trouvée à l'état sauvage. On l'emploie surtout en Angleterre comme condiment; elle sert également dans la fabrication d'une bière spéciale dite gingerbeer ou ginger-ale; elle a le même emploi en Afrique, notamment au Fouta-Djallon, où on l'utilise pour assaisonner le couscous et, au Sierra-Leone, pour faire une bière; en Chine, les rhizomes sont râpés et vendus en poudre; en Amérique, l'essence de gingembre est utilisée comme médicament énergique dans les remèdes calmants qui portent le nom de "pain expeller ". Une autre espèce, le Gingembre Zerumbet, employé de la même manière, est surtout commun dans l'Inde et en Nouvelle-Calédonie. Le Gingembre a une odeur un peu poivrée, agréable; sa saveur aromatique et brûlante est très forte.

Le Curcuma long ( fig. 272) ou Safran des Indes, Safran bâtard ou Souchet des Indes, est également importé en Angleterre, parce que son rhizome est un condiment apprécié; il est utilisé dans l'Inde pour la préparation du carry ou curry; il sert à la Guadeloupe à la préparation du mets créole appclé colombo. La poudre de curcuma ou Turmeric des Anglais est formée d'amidon, lequel est associé à une matière colorante jaune orangé, la curcumine, et à une huile essentielle volatile, aromatique, de saveur brûlante.

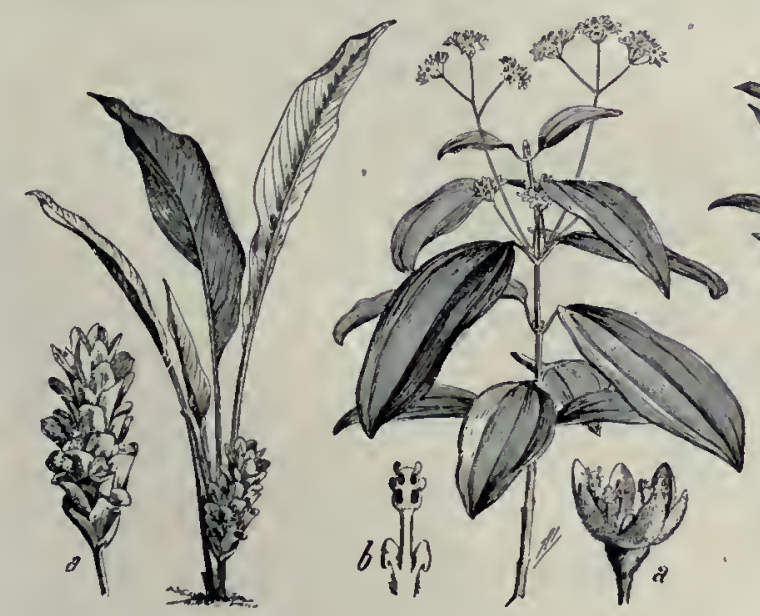

Fig. 272. - Curcuma. $a$, Épi de fleurs. LES PLANTES.

g. 273. - Cinnamome
$a$, Fleur ; $b$, Etamine.

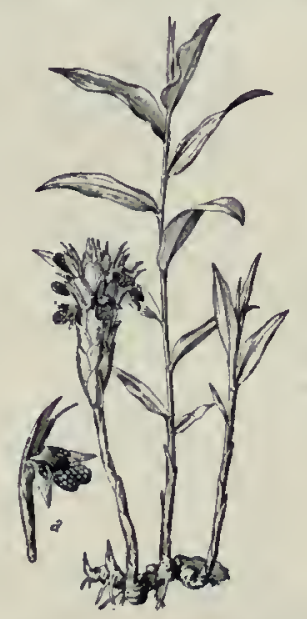

Fig. 275. - Gingembre.

Fig. 274. - Amome.

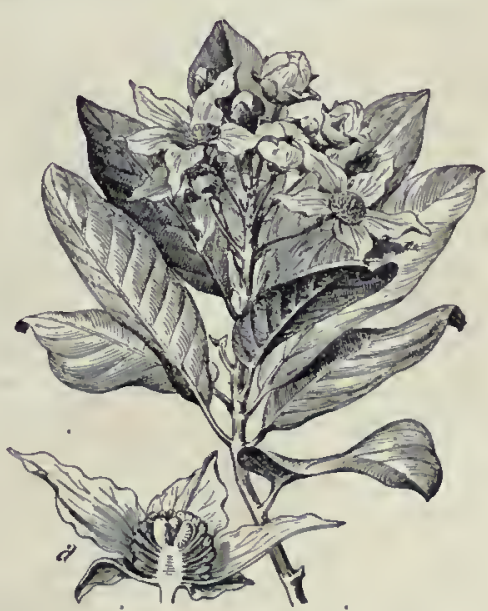

Fig. 276. - Drymide.

$a$, Coupe de la fleur. 


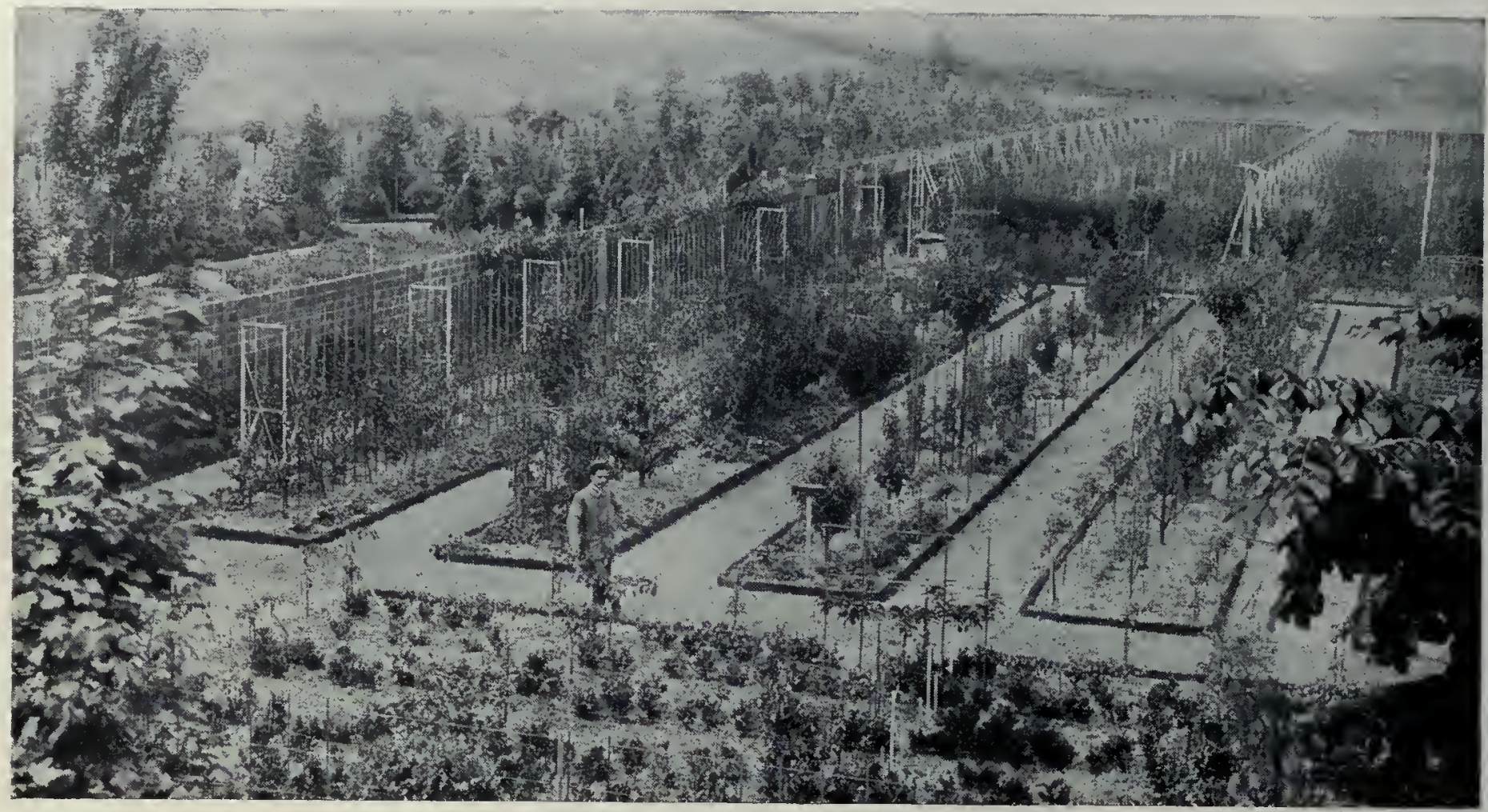

Un grand jardin fruitier, à Villejuif.

\section{LES FRUITS}

La culture fruitière. - Suivant leur origine, les fruits peuvent être divisés en fruits des régions tempérées, des régions tempérées chaudes et des pays chauds. Nous cultivons en France tous ceux du premier groupe : cerises, pommes, poires, raisins, etc., et sur notre littoral méditerranéen la plus grande partie de ceux du second: figues, grenades, oranges, etc. Les pays chauds sont riches en fruits comestibles, mais dont la plupart se récoltent à l'état sauvage; un petit nombre seulement, comme la banane, l'ananas, etc., sont soumis à la culture et améliorés.

Résumons en quelques lignes les principes de l'arboriculture fruitière en nos pays. Les arbres obtenus de semis sont les sujets francs ou sauvageons, dont les fruits sont de qualité inférieure, mais ces arbres servent de porte-greffe. La plantation des arbres fruitiers se fait à l'automne ou en mars. On laisse souvent crốtre librement les arbres : cerisiers, pommiers, amandiers, qui sont dits alors à haute tige; mais fréquemment aussi on taille en févriermars, cest-à-dire qu'on sacrifie un certain nombre de branches ou de bourgeons pour obtenir des fruits plus beaux, une forme plus régulière. Si les arbres sont en plein air, on leur donne une forme arrondie, ou en pyramide, en gobelet, etc.; les fruits recevront ainsi plus d'air, de lumière et de chaleur. S'ils sont en espalier, c'est-à-dire à branches appliquées le long d'un mur, ou en contre-

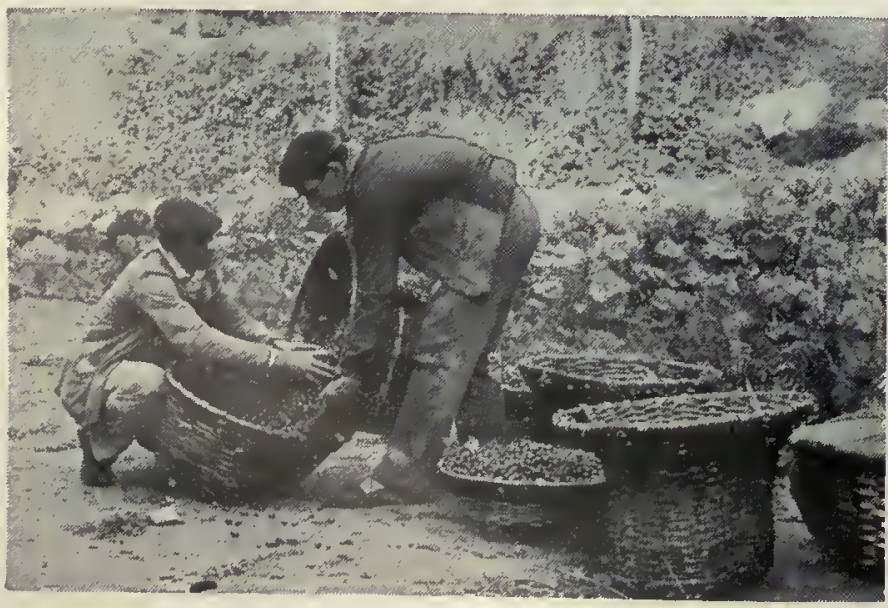

Mise en panier des cerises. espalier, suivant des fils de fer, on les taille en formes plates, palmettes, cordons, etc.

En France, les principaux centres fruitiers sont les environs de Paris, la Limagne, l'Anjou, et, pour les primeurs, les vallées du Rhône, d'Orange à Lyon, et de la Durance, la Provence, les Pyrénées-Orientales, le Gard (Aramon), la vallée de la Garonne. L'Algérie el la Tunisie nous envoient aussi beaucoup de fruits; le Tyrol méridional, la Crimée, la Hongrie, sont des pays d'abondante production; en Californie et en Floride, au Canada, au Cap, en Australie s'étendent d'immenses vergers.

On peut dire que jusquau milieu du XIX" siècle la consommation de chaque fruit dans les différents pays a été limitée à la période de sa maturité. La création de variétés précoces ou tardives a d'abord largement élargi cette période. La grande extension des moyens de transport, le perfectionnement des procédés de conservation et d'emballage, enfin le développement de l'industrie du forçage ont supprimé les saisons, au point de vue de la consommation des fruits.

Dès le mois d'avril, le Midi nous envoie des fraises, en mai des cerises, en juin des pêches, en juillet des prunes, en août du raisin. Dans des fruitiers perfectionnés, on conserve les pommes et les raisins cueillis en octobre jusqu au mois de juin de l'année suivante. La réfrigération a permis les transports lointains : les fruits de la Californie alimentent tous les marchés des États-Unis; les pêches et les raisins d'Australie, les abricots du Cap sont vendus à Londres et à Paris pour les fêtes de Noël ; les fruits d'Amérique viennent concurrencer les nôtres en Europe.

L’industrie du forçage des arbres fruitiers sous verre s'est développée dans les pays froids et brumeux où le charbon est à pied d'œuvre : Angleterre, Belgique, Allemagne, nord de la France; elle donne lieu à un commerce extraordinaire. C'est dans les forceries anglaises qu'a pris naissance la culture en pots des arbres fruitiers, qui permet, dans un repas, de placer à côté des convives des pêchers, des abricotiers, des cerisiers, des vignes etc., portant quelques fruits dont la cueillette se fera au dessert.

Le région parisienne compte nombre d'arboriculteurs se consacrant à la production des fruits de luxe. Ils ne doivent leur baauté et leur saveur qu'à l'intelligent emploi des abris et à des soins culturaux incessants. Les jeunes fruits en excès sont éliminés dès le début de leur formation; plus tard on ensache les spécimens qui restent pour les préserver de la piqûre des insectes; on leur rend ensuite peu à peu la lumière qui leur donnera de si jolies teintes. Le commerce des fruits a pris dans le monde entier une extension extraordinaire.

Les fruits, lorsquills sont mûrs, sont agréables et sains, à la 


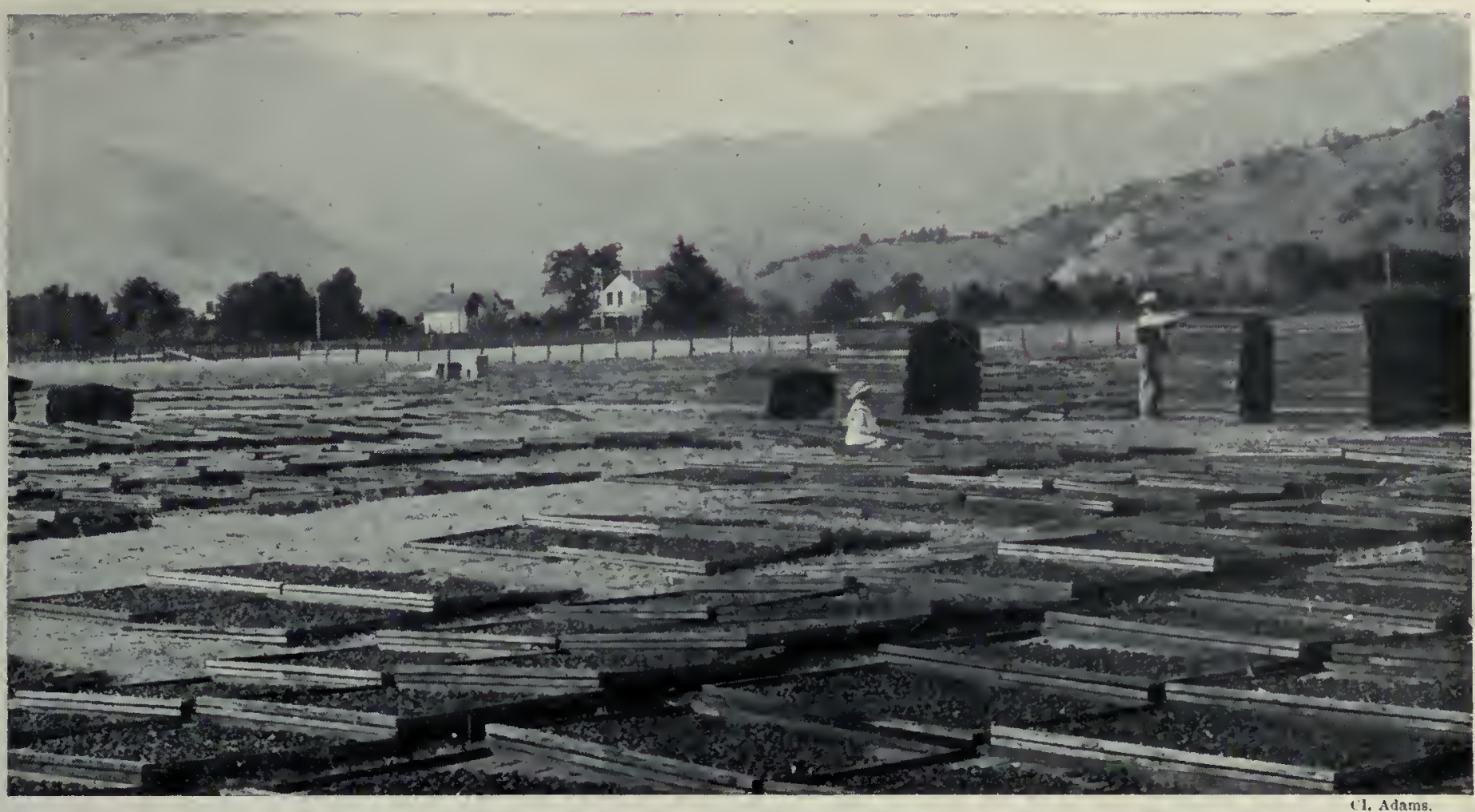

Le séchage des prunes, en Californie.

condition qu'on n'en abuse pas, mais la valeur nutritive de la plupart des fruits pulpeux est faible; l'amidon et le sucre qu'ils renferment en proportion parfois assez grande ont seuls un rôle alimentaire de quelque valeur. Les fruits-graines, comme la châtaigne, l'amande, sont beaucoup plus nourrissants.

Fruits à noyau. - Le Cerisier sauvage ou Merisier de nos bois porte de petits fruits noirs, amers, propres seulement à faire du kirsch. Par la culture il a donné deux races principales portant des fruits à saveur douce et à jus coloré : les guignes, à chair molle, et les bigarreaux, à chair ferme et dont la peau est noire, rouge ou blanc jaunâtre suivant les variétés. Le Cerisier vrai ou Grioltier n'est probablement qu'une forme dérivée très anciennement du Merisier. Ses nombreuses variétés se groupent en cerises proprement dites, à fruits doux légèrement acidulés: Montmorency à courte queue, anglaise hâtive, reine Hortense, etc., et en griottes ou cerises acides, à maturation tardive se prolongeant jusqu à la fin d'août. Les Cerisiers aiment la pleine lumière ; ce sont, par excellence, des arbres de coteaux. La vallée du Gapau, avec Solliès-Pont (Var) pour 'centre, envoie à Paris, du 20 avril au 15 mai, des trains entiers de cerises. Les cerises douces ont deux ennemis redoutables : le moineau et une petite mouche, l'ortalide des cerises, qui y pond ses œufs; la larve vit dans le fruit.

Le Prunier prospère dans tous les sols. Bien que le semis reproduise fidèlement la plupart de ses variétés, on le multiplie surtout par drageons et par greffage. La prune est un fruit très sucré; la maturité de ses diverses variétés cultivées en plein air en France s'échelonne de fin juillet à la mi-octobre; on en compte plus de 300 , donnant des fruits bleuâtres, violets, roses, verts, jaunes ou de teinte orange, et de forme assez variable, tantôt presque sphériques, tantốt ovoïdes. Les plus remarquables sont : reine-Claude, Kirke, mirabelle, Monsieur, Damas, perdrigeon, Quetsch, Sainte-Catherine, etc. La Champagne et la Lorraine cultivent surtout la mirabelle, pour les confitures.

La culture des Pruniers en vue de la préparation des pruneaux se pratique dans plusieurs de nos départements; celui de Lot-etGaronne est, de beaucoup, le plus fort producteur français. Sur toute la rive droite de la Garonne, de Montauban à Bordeaux, on cultive la prune d'ente, oblongue et violette, qui mûrit à la miseptembre. Les fruits sont cueillis en parfait état, placés sur des claies et exposés au soleil pendant quelques jours. Ils passent ensuite dans une étuve dont la température s'élève progressivement de 40 à $70^{\circ}$. Ils y restent un jour ou deux suivant leur grosseur. La cuisson se termine dans un four à feu doux; les pruneaux y séjournent de deux à six heures, puis sont triés et portés au mar- ché ; c'est là que viennent s'approvisionner les maisons de gros. Nos pruneaux français, jadis sans rivaux, doivent lutter aujourd'hui contre ceux de la Hongrie, de la Serbie et surtout de la Californie.

L'Abricotier aime les sols frais et redoute les gelées printanières, en raison de sa floraison précoce; on le greffe sur Pêcher ou sur Amandier. Ses fruits, très délicats, se gâtent facilement. Les environs de Clermont-Ferrand fournissent les abricots gros blancs pour la faobrication des confitures, pâtes et fruits confits. Le Cap, les îles Baléares sont aussi des producteurs importants; en Californie, l'Abricotier occupe d'immenses surfaces; la production presque entière est séchée au soleil.

Originaire de Chine, où sa culture est très ancienne, le $P$ êcher fut connu et cultivé par les Romains de l'antiquité, qui le transmirent aux pays voisins. Comme l'Abricotier, cet arbuste ne peut être cultivé en plein air et franc de pied que dans la région de la Vigne; dans le Nord, il lui faut l'espalier et on le greffe sur Amandier ou sur Prunier. Il subit facilement le forçage sous verre. Le Pêcher est attaqué par de nombreux insectes et sujet à la cloque, maladie causée par un Champignon.

Les nombreuses variétés de pêches sont divisées en deux groupes : les pêches proprement dites, à peau duveteuse, et les brugnons, à peau lisse. Les pêches à noyau adhérent sont des pavies, si la chair est rouge ou blanche; des persèques, si elle est jaune. Les nectarines sont les brugnons à noyau libre. Les variétés d'espalier

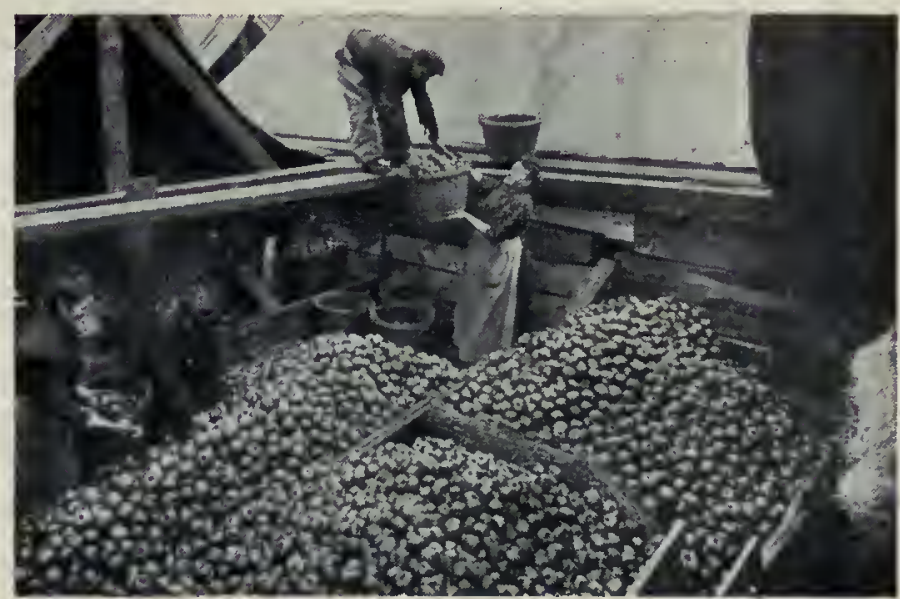

Bateau apportant des pommes, à Paris. 


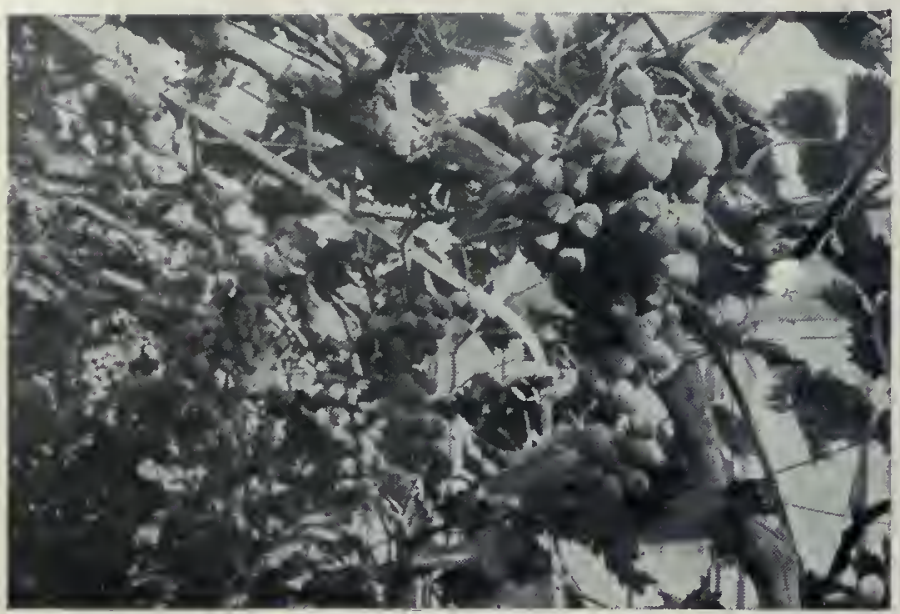

Culture du Muscat Canuou-halt.

les plus renommées sont : amsden, alexander, mignonne hâtive, mûrissant de la fin de juin au milieu d'août; grosse mignonne, téton de Vénus, de la mi-août à la mi-septembre; reine des vergers, bon ouvrier, etc., jusqu'au milieu d'octobre, La pêche est un fruit délicieux, très aqueux et sucré; elle se conserve peu.

Les célèbres cultures de Pêchers de Montreuil, près Paris, établies en 1695 par Girardot, ont fait la fortune de cette localité. 300 hectares y sont consacrés, portant 600 kilomètres de murs où le Pêcher est cultivé en espalier; les bandes de terrain entre les murs sont occupées par des Pommiers et des Poiriers en cordons ou en contre-espalier. Dans certains jardins fruitiers modèles, des toiles peuvent être tendues au-dessus des murs contre les gelées printanières; les espaliers sont protégés par un auvent de verre qu'un grillage en fil de fer préserve de la grêle. Les vergers $\mathrm{d}^{2}$ Écully, près de Lyon, la Provence, les Pyrénées-Orientales, l'Auvergne, produisent aussi des pêches estimées. En Californie, les pêches sont, pour la plupart, préparées sous forme de conserves.

Fruits à pépins. - Les fruits du Pommier ont servi à la nourriture des habitants des cités lacustres; il en est parlé dans la Bible; Pline en cite plusieurs variétés; La Quintinie, sous Louis XIV, en indique vingt-cing; sans compter les pommes à cidre, nous en avons aujourd'hui des centaines qui sont des fruits de table superbes et délicieux. La maturation des pommes de dessert s'échelonne de juillet à décembre. Les pommes d'été sont peu agréables et ne se conservent pas; parmi les pommes d'automne; mûrissant en septembre et octobre, sont : le doux d'argent, les calville rouge et Saint-Sauveur, et, parmi les pommes d'hiver : les reinettes, la calville blanche, l'api, la court-pendu qui, longtemps après la cueillette, achèvent de mûrir dans le fruitier.

Le Pommier est peu exigeant sur la nature du terrain. Le semis de pépins ne reproduisant pas fidèlement les variétés, on greffe sur franc ou sur sauvageon. Cet arbre fruitier est attaqué par nombre d'insectes : puceron lanigère, yponomeute, etc. II est cultivé dans tous les pays tempérés; au Nord, il dépasse $60^{\circ}$ de latitude en Finlande et en Norvège. La pomme de luxe : reinette de Canada, calville blanche, grand Alexandre, est produite abondamment dans la région parisienne, à Montreuil, Montmorency, Groslay, Chambourcy, et aussi dans la Normandie et la Basse Auvergne. Ces jolis fruits sont parfois vendus illustrés : lorsque la pomme est encore sur l'arbre, on colle sur sa face éclairée un dessin découpé, ou une pellicule négative qui y reste de vingt à vingt-cinq jours; le fruit se colore sur toute sa surface, sauf dans la région protégée.

A Paris, il y a deux principaux marchés aux pommes : les Halles et le quai de l'Hôtel-de-Ville, le long duquel séjournent, de novembre à la fin d'avril, des bateaux chargés de pommes, et dont les clients sont principalement les petits marchands des rues. $\mathrm{Ce}$ marché pittoresque perd de son importance.

Le Canada et les États-Unis, notamment dans la région des Grands Lacs, produisent des pormmes en quantité phénoménale. La plus grande partie est desséchée. Des machines pèlent les fruits, en enlèvent le cœur et les découpent en rondelles qu'on blanchit à l'acide sulfureux et qu'on place dans des fours à $90^{\circ}$ pendant six à sept heures. Ces pommes sont utilisées pour la pâtisserie, les compotes, les marmelades; on les accommode au beurre, au riz, en beignets, etc., comme les pommes fraîches.

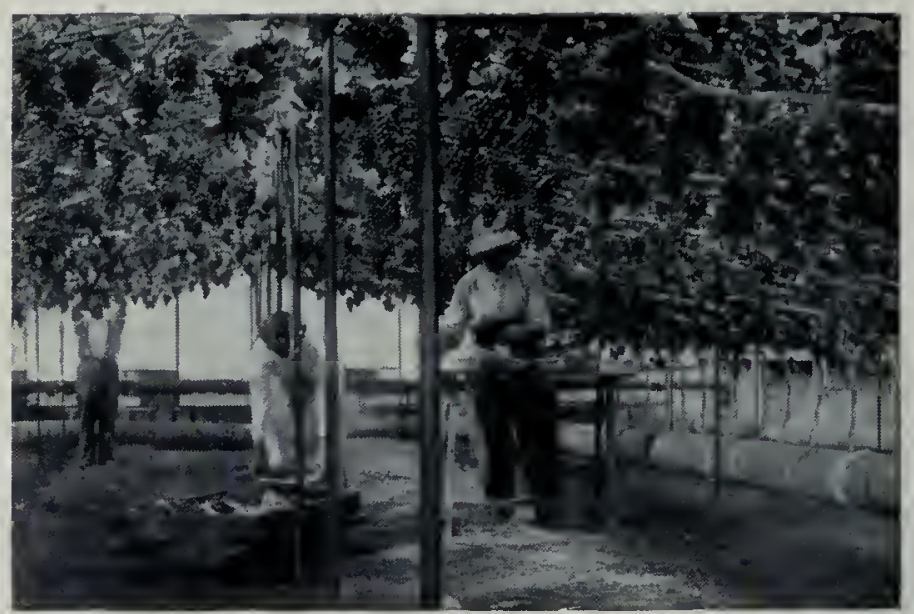

Culture du raisin noir en serre.

Le Poirier réclame un sol riche; on le greffe sur Cognassier ou sur franc. La tavelure, due à un Champignon qui envahit lefruit, est une maladie fréquente. Les Grecs et les Romains ont cultivé le Poirier, dont ils connaissaient six variétés. On en compte aujourd'hui des centaines donnant des fruits qui ont l'avantage de mûrir à des époques successives: poires d'été, bonnes à cueillir de juillet à septembre, comme beurré Giffard, Williams, etc.; poires d'automne, mûrissant d'octobre à décembre, telles que beurré d'Angleterre, doycnné du comice, crassane, bergamote, etc. ; poires d'hiver, de décembre en mai : passe-colmar, passe-crassane, doyenné d'hiver, belle angevine, beurré Bretonneau, Charles Cognée, etc. Les environs de Paris, la Normandie, l'Anjou, Corbigny (Nièvre) produisent des poires de premier choix.

Le Cognassier a peu varié, bien que cultivé depuis longtemps. Son gros fruit cotonneux, parfumé, mais acerbe et astringent, n'est bon que cuit, en compote; il donne d'excellentes gelées. Le Néflier porte de petits fruits à gros noyaux, assez agréables quand ils blettissent, de même que les cormes et les alises dont il se fait une certaine consommation dans le midi de la France.

Fruits pulpeux divers. - Le Framboisier de nos bois n'est cultivé que depuis la fin du moyen âge. Son fruit parfumé, d'une saveur exquise, se conserve mal et se transporte difficilement. On le consomme en nature ou sous forme de gelées, confitures, sirops On en connaît des variétés à fruits rouges, jaunes ou noirs. Burbank, en Amérique, a obtenu une jolie variété à fruits blancs, si transparents qu'on voit les graines à la maturité. En Angleterre, où l'on cultive beaucoup le Framboisier, on apprécie le logan-berry, fruit d'un hybride de la Ronce sauvage et du Framboisier.

Le Fraisier n'est cultivé que depuis la fin du XVI ${ }^{\theta}$ siècle. On compte aujourd'hui plus de six cents variétés, issues d'une demidouzaine d'espèces sauvages, et que l'on peut répartir en trois groupes : $1^{\circ}$ les Fraisiers des quatre-saisons qui, pendant la plus grande partie de l'année, donnent des fruits d'assez petite taille, mais délicieux de goût et de parfum; $2^{\circ}$ les fraisiers hybrides à gros fruits, cultivés en grand pour l'approvisionnement des marchés, et dont l'ancêtre est le Fraisier du Chili; les variétés les plus renommées sont : docteur Morère, Joseph Paxton, général Chanzy, etc., et, dans la région parisienne, vicomtesse Héricart de Thury, dite vulgairement la Ricart; $3^{\circ}$ les Fraisiers remontants à gros fruits, qui fleurissent et fructifient du printemps aux gelées. La Saint-Joseph, l'ancêtre de cette séric, a été obtenue en 1891; Jeanne d'Arc, Saint-Antoine, Merveille de France, la Perle, etc., sont d'obtention plus récente. On produit la fraise en grand en Hollande, en Angleterre, aux Etats-Unis, en Algérie; en France, aux environs des grandes villes, dans le Finistère, en Provence, dans les vallées de la Durance (Carpentras), et de la Garonne (Mautauban, Moissac).

Les Groseilliers sont des arbrisseaux indigènes cultivés en Europe depuis le moyen âge. Le Groseillier à grappes, à fruits rouges ou blancs, acides, est très cultivé dans les régions parisienne et bordelaise et aux environs de Bar-le-Duc pour la préparation de confitures; le Groseillier noir ou Cassissier l'est surtout aux environs de Dijon, de Paris, en Hollande et aux États-Unis pour la confection de la liqueur de cassis. Le Groseillier épineux fournit les groseilles vertes ou à maquereau, appréciées en Angle- 


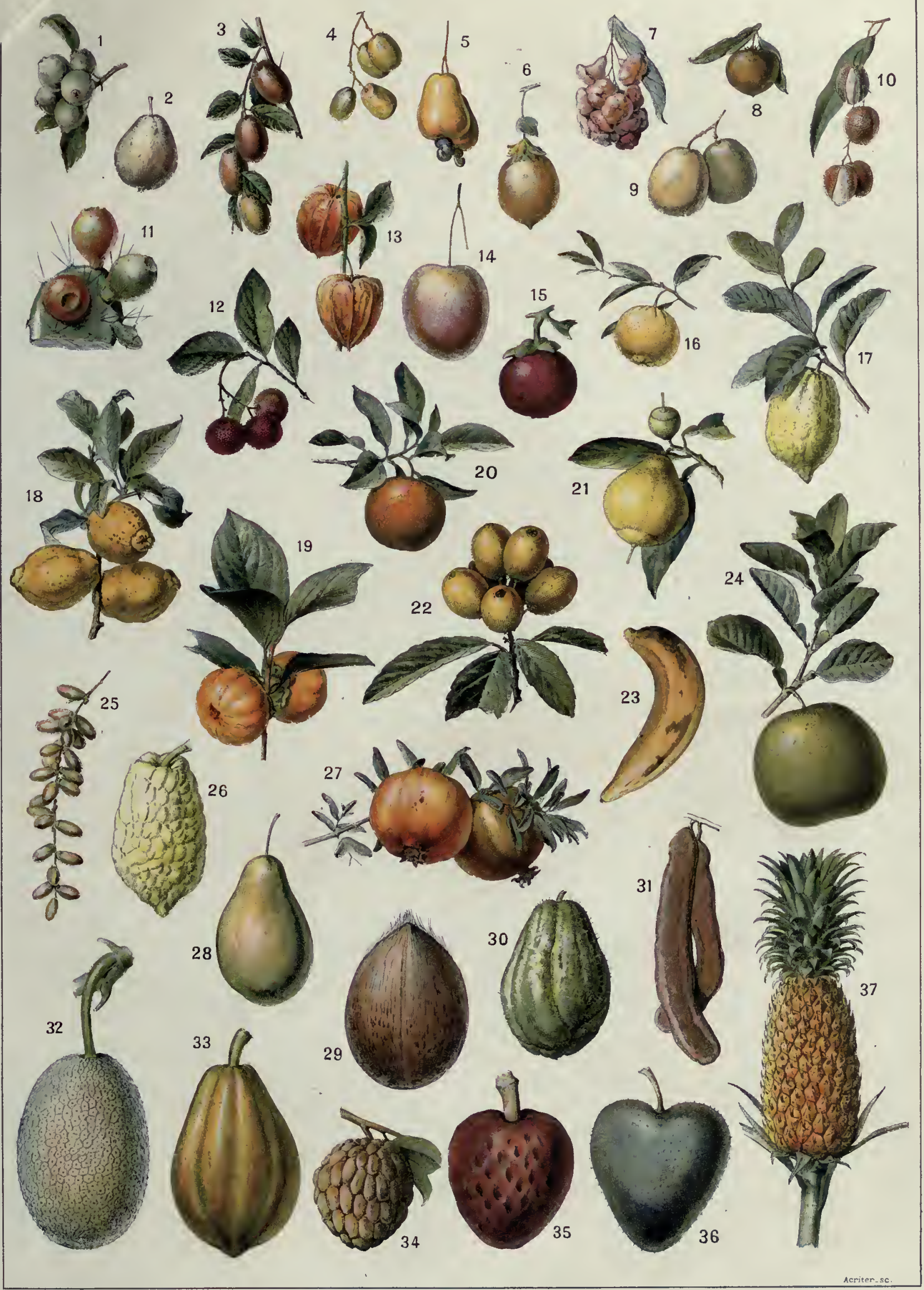

FRUITS EXOTIQUES

1. Goyave pomme. - 2. Goyave poire. - 3. Jujube. - 4, Mombin. - 5. Noix d'Acajon ou de Cajou, - 6. Grenadille (Passiflore) - 7. Jambosa (Pomme rose) 8. Sapotille - 9. Pomme Cythère - 10. Litchi - 11. Firue de Barbarie ou d'Inde - 12. Arbouse - 13. Coqueret de Chine - 14. Mangue blanche - 15. Mangoustan. 16. Bigarade - 17. Citron - 18. Coing du Japon - 19. Kaki de Mazel - 20. Orande - 21.Berdamote - 22. Néfles du Japon ou bibaces - 23, Banane blanche 24. Pamplemonsse. - 25. Dattes, - 26. Cédrat. - 27. Grenade. 28. Poire d'avocat. - 29. Noix de coco. - 30. Chayote. - 31. Caroube, - 32. Fruit de 1'Arbre a pain. - 33. Papaye. - 34. Anone Pomme Cannelle. - 35. Anone Coeur de bouf. - 36. Anone Corossol. - 37. Ananas. 

terre et surtout aux Etats-Unıs, où elles servent de condiments et même à la préparation de gâteaux, tartes et compotes.

Les fruits de la Vigne sont surtout destinés à la vinification, mais le commerce des raisins de table est fort important. Les variétés les plus estimées pour ce dernier usage sont, comme raisins blancs : chasselas, madeleine, clairette, muscat blanc, panse nomme figues-fleurs. Nous avons déjà parlé du rôle de la caprification pour réaliser la fécondation et hâter la maturation (Figuier de Smyrne et de Californie) [p.64]. La figue, mûre à point, est délicieuse, onctueuse et sucrée; il en existe de nombrcuses variétés blanches ou violettes. Fraîche ou séchée au soleil, elle joue un rôle alimentaire important dans l'Afrique du Nord, en Grèce, en Espagne.

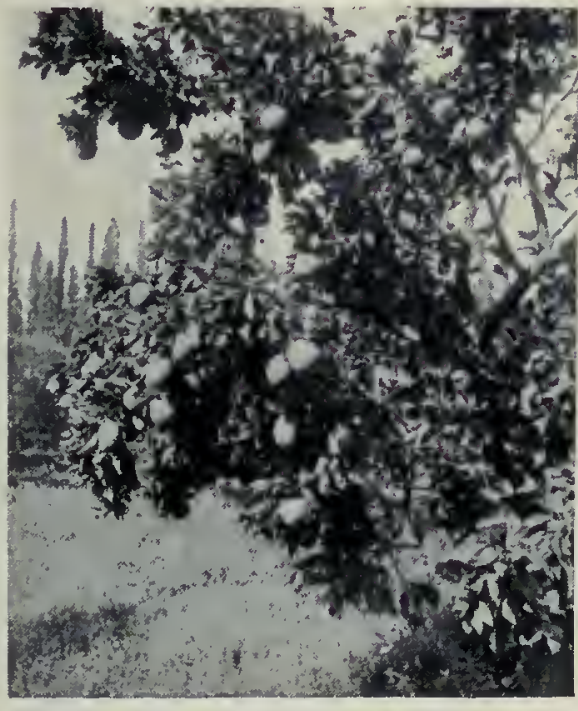

Oranger en fruits, à Jaffa.

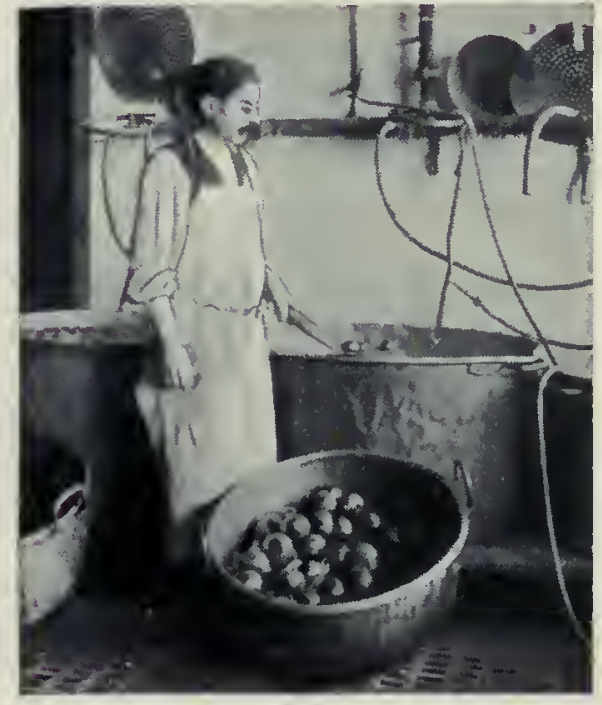

Blanchiment des oranges.

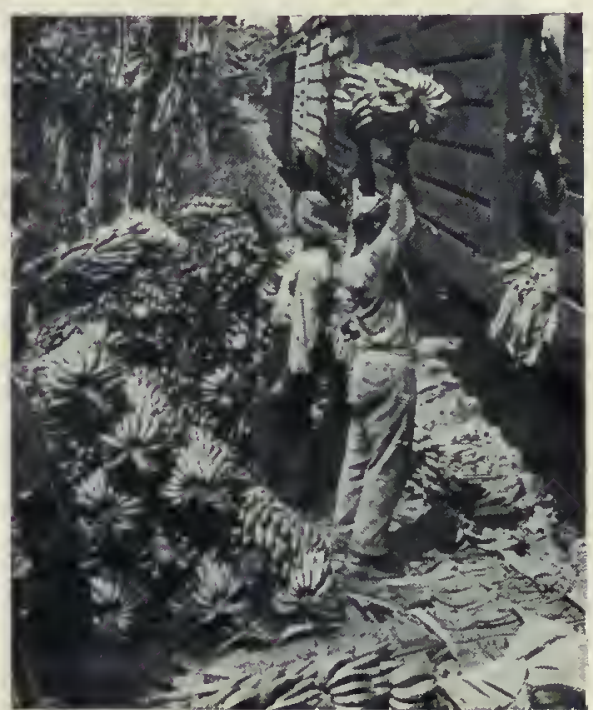

Expédition des bananes. musquée, muscat gris; comme raisins noirs : madeleine noire, muscat noir, Frankenthal, gros Colman, black Alicante.

Les raisins de table proviennent surtout de treilles. Thomery, près Fontainebleau, est aussi célèbre pour ses chasselas que Montreuil pour ses pêches. Le long de murs sont fixées les treilles en cordons horizontaux régulièrement étagés. Un peu après la floraison, on éclaircit si la Vigne est trop chargée de grappes, puis on cisèle les grappes conservées, c'est-à-dire qu'on supprime environ la moitié des grains. A la véraison, on coupe les feuilles en excès : les grains se dorent et mûrissent mieux; on bassine de temps à autre par temps sec et on ensache les grappes pour les préserver de l'attaque des insectes. Le raisin à conserver est coupé du 25 septembre jusquau 10 novembre et porté dans des fruitiers dont certains peuvent contenir jusqu'à 100000 grappes. On conserve à rafle sèche dans des tiroirs ou à rafle fraîche, avec un brin de sarment plongeant dans une petite bouteille ou dans des ampoules (procédé Béchard frères) où l'on maintient toujours de l'eau. Andrésy, Conflans-Sainte-Honorine et plusieurs autres localités se livrent à la viticulture de table. La culture du raisin de table de primeur est très importante en Algérie, aux environs de Montpellier et dans le Lot-et-Garonne.

En 1860, Méredith créa près de Liverpool la première forcerie de Vigne pour la production du raisin de table. Il eut de nombreux imitateurs dans son propre pays, puis en Allemagne, en Belgique, Plusieurs forceries importantes existent à Roubaix, Bailleul, Tourcoing, Rueil, etc. Les meilleures variétés de forçage sont le Frankenthal, le white Nice, gros Guillaume, gros Colman, Cannon hall muscat. Les grappes, après cisellement, atteignent un poids invraisemblable; celles de 4 à 5 kilogrammes sont communes; on en a vu de II kilogrammes.

L'industrie des raisins secs est aussi fort importante, soit pour le dessert, soit pour la fabrication du vin. On dessèche au soleil, en Grèce, en Turquic, en Asic Mineure, le raisin de Corinthe et le saltanina; en Espagne, le moscatel : l'opération dure environ quinze jours; en Calabre, le séchage est précédé d'un ramollissement pendant deux secondes dans une lessive alcaline bouillante. En Californie, la dessiccation se fait en deux jours dans des séchoirs monstres, chauffés à $45^{\circ}$ par courant de vapeur.

Le Figuier, spontané dans l'Asie occidentale et sur le pourtour méditerranéen, est très anciennement cultivé. Il vient bien dans tous les terrains et préfère l'exposition au midi; en France, il ne mûrit bien ses fruits qu'au sud de la Loire et sur les côtes bretonnes. On le multiplie par rejetons, marcottes ou boutures. Sur chaque branche, les figues mûrissent en automne, de la base vers le sommet : quand viennent les froids, les figues du sommet cessent leur développement pendant tout l'hiver, et mûrissent en juillet : on les
En hiver, les grenades nous arrivent d'Algérie et d'Espagne; on apprécie la pulpe sucrée et rafraîchissante qui entoure les graines.

L'Oranger doux, originaire de Chine et de l'Asie orientale, n'a été introduit en Europe qu'au XV $\mathrm{XV}^{\mathrm{e}}$ siècle. Il est répandu aujourd'hui dans tous les pays où la température moyenne est supérieure à $14^{\circ}$ et où les petites gelées sont rares. On le multiplie par bouture, marcotte ou greffe sur Bigaradier. L'orange est un fruit rafraîchissant, sucré et légèrement acide, qu on mange en nature ou auquel on fait subir nombre de préparations : salades, beignets, compotes, gelées, sirops, etc. L'Oranger est cultivé dans les Alpes-Maritimes, les Pyrénées-Orientales et la Corse. L'Espagne, l'Algérie, l'Italie, la Palestine, sont des producteurs importants. Hors d'Europe, les principaux centres sont la Californie, puis le Brésil, l'Australie, etc.

Le Bigaradier ou Oranger amer, originaire de l'Inde, a été connu en Europe avant l'Oranger doux; il a été rapporté de $\mathrm{Pa}$ lestine par les croisés; ses fruits ne sont mangeables qu'en confiture; ceux du Bigaradier de Chine, amers et acides, cueillis verts, pelés et confits, sont les petits chinois. Le Mandarinier, originaire de Chine, a bien réussi en Algérie; il donne de petites oranges très estimées; les pamplemousses ou shadok sont de grosses oranges à saveur fade; on en fait des conserves, ainsi d'ailleurs que de la bergamote. Les zestes d'orange sont l'objet d'un commerce notable pour la préparation des liqueurs : curaçao, kummel, amers, etc.

Citons encore les fruits du Mûrier noir, assez agréables crus ou en confitures.

Fruits confits, confitures. - Parmi les industries auxquelles donnent lieu les fruits pulpeux, l'une des plus importantes est celle de la conservation par le sucre, comprenant, d'une part, les fruits confits, et, d'autre part, les confitures, marmelades et gelées; Nice, Clermont-Ferrand, Paris, Niort sont des centres importants pour la préparation des fruits confits. Les fruits, choisis sains et de belle grosseur, sont cueillis un peu avant leur maturité, puis blanchis, c'est-à-dire pelés, piqués avec une épingle, et chauffés à la vapeur, de manière à les' amollir pour leur permettre de mieux recevoir le sucre. On les plonge ensuite, à différentes reprises, séparées par un jour d'intervalle, dans un sirop faible que l'on concentre peu à peu, de sorte que le sucre y pénètre graduellement. Ensuite, on les glace dans un sirop très épais.

La fabrication des confitures, jadis exclusivement familiale, tend à devenir le monopole de grandes usines. Rappelons aussi la préparation des fruits à l'eau-de-vie.

Fruits pulpeux exotiques. - Parmi les fruits pulpeux des pays chauds, trois sont devenus de consommation courante en Europe : la datte, la banane et l'ananas. 


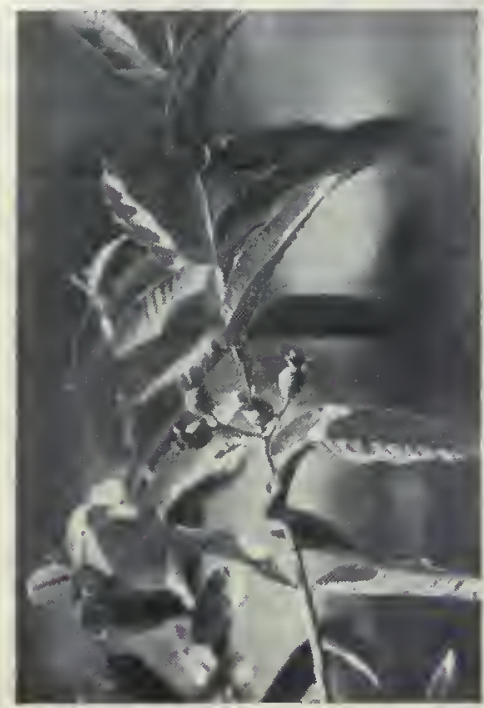

Branche de Goyavier.

Le Dattier est l'arbre des oasis dans le Sud algérien; on le cultive en Égypte, en Tunisie, au Maroc, sur les rives du golfe Persique;

Elche, en Espagne, possède une forêt de 60000 Dattiers. Ce Palmier se propage par rejets pris au pied d'un Dattier femelle, porte des fruits vers quinze ans et peut en fournir annuellement 200 kilogrammes. La datte est un fruit très nourrissant $(72$ pour 100 d'hydrates de carbone); il en existe plus de deux cents variétés, réparties en dattes sèches (remplaçant le pain), petites et peu sucrées, qui forment la base de la nourriture dans les pays producteurs, et en dattes molles, grosses, onctueuses, qui paraissent sur nos tables.

- Le Bananier, comme le Cocotier et le Dattier, appartient à la catégoric des végétaux providentiels. Il n'est pas de plante qui, à surface cultivée égale, fournisse, à beaucoup près, une masse aussi considérable de substance nourrissante. Le Bananier exige un climat chaud et humide; ses fruits ont une pulpe fondante et parfumée. La Jamaïque se place en tête des pays exportateurs. Viennent ensuite Costa-Rica, puis les Canaries, Honduras, Cuba, etc.

L'Ananas est un fruit délicieux, dont la culture en serre a été longtemps florissante en Angleterre. La grande culture en plein air se fait aux Antilles, aux Hawaï, dans l'Inde, à la Réunion, etc. Le prix des fruits frais est encore assez élevé en Europe; mais les fruits conservés, qui fournissent d'excellents desserts, sont plus abordables. Les Ananas consommés en Europe proviennent des Açores et des Canaries, où la plante est cultivée sous abris.

Quelques autres fruits des pays chauds se rencontrent en Europe dans le commerce : anones de Madère, goyave et mangue de la Martinique, figue de Barbaric et kaki d'Algérie, bibace ou nèfle du Japon, li-tchi, arbouses, jujubes, etc., provenant des régions méditerranéennes.

Fruits-graines. - Le Châtaignier forme des forêts dans les régions siliceuses de la zone tempérée. Certaines variétés cultivées qu'on propage par greffe ne contiennent qu'un seul gros fruit sous la coque épineuse, et non deux ou trois, comme chez le châtaignier sauvage. La châtaigne est une graine farineuse et sucrée, qui, bouillie ou rôtie, constitue dans nos pays un dessert agréable. Dans certaines parties de l'ltalie, en Corse et dans quelques communes du Limousin, elle forme la base de la nourriture : réduite en farine, on la mélange au pain, on en confectionne des bouillies ou polenta. La maladie de l'encre sévit gravement sur. l'arbre, peut-être un Endothia.

Limportante industrie des marrons glacés utilise les plus beaux fruits :

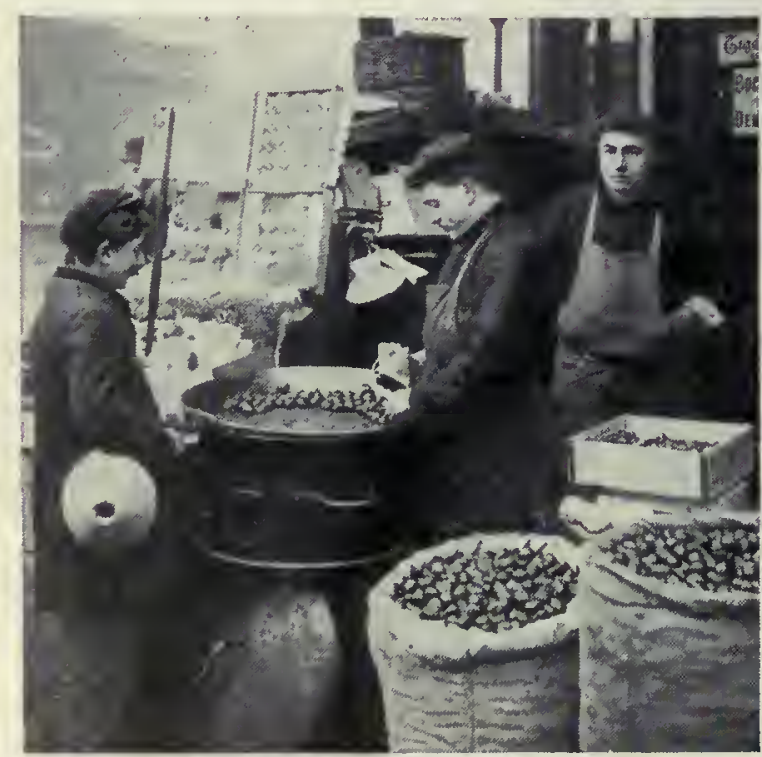

Marchand de marrons à Paris. marrons dits de Lyon, venant de l'Ardèche; marrons de Luc, cultivés en Basse-Provence; marrons de Turin, de Florence et de Naples. Les fruits sont pelés, nettoyés à l'eau bouillante, puis cuits dans un sirop de sucre; on les retire du feu et on les laisse dans le liquide pendant douze heures, au bout desquelles on les passe dans un autre sirop très concentré.

Le Noyer, originaire d'Orient, redoute les gelées printanières. Ses variétés culturales, au nombre d'une vingtaine, se greffent sur le Noyer commun, obtenu de semis. Un arbre de bon rapport peut donner de 80 à 100 kilogrammes de fruits. La noix sèche renferme une forte proportion de matières hydrocarbonées et de corps gras. La culture de la noix de table est très dévelopée dans la région de Grenoble; le port des arbres est maintenu modeste pour permettre la taille d'hiver. Presque toute la production de cette contrée est exportée en Amérique. La Dordogne et le Poitou ont aussi d'importantes plantations dont la production est utilisée pour la table, la confiserie ou l'huilerie. La noix verte est le cerneau, utilisé par les confiseurs et les liquoristes. On prépare aussi la noix blanche sucrée et glacée.

L'Amandier provient de l'Asie Mineure. Il aime les terrains secs, calcaires; on le multiplie de graines stratifiées pendant l'hiver ou de greffes sur Prunier. Il existe une dizaine de variétés d'amandes douces, les unes à coque tendre ou fine (Princesse) se cassant à la main, ou à coque demi-dure (à la dame) se cassant à la dent; les autres, à coque dure se cassant au marteau. En France, l'Amandier ne prospère que dans le Midi; il est cultivé en Espagne, en Italie, et surtout en Sardaigne, au Maroc, en Turquie d'Asie, en Californie. On mange les amandes vertes ou sèches; elles servent en pâtisserie, en chocolaterie, à la fabrication du sirop d'orgeat, du nougat, des pralines et des dragées. Aix a le monopole du triage des amandes destinées à la confiserie et livre les meilleures sortes. L'Amandier est en plein rapport à quinze ou vingt ans : il peut alors produire environ 15 kilogrammes de fruits.

Le Noisetier sauvage ou Coudrier, si commun dans nos bois, présente plusieurs variétés culturales ou Aveliniers, à fruits gros et ronds. Le Noisctier franc, de l'Europe méridionale, a un fruit plus allongé. Comme la noix et l'amande, la noisette est très riche en corps gras. En France, il n'existe qu'un seul centre vraiment important de culture du Noisetier, dans la vallée du Tech; une grande partie des noisettes utilisées pour la fabrication des dragées vient de la province de Trébizonde, en Turquie d'Asie ; elles sont expédiées " toutes cassées", c'est-à-dire dépouillées de leur coque: les belles noisettes d'Italie, d'Espagne, de Provence et du Roussillon sont, au contraire, vendues en coque.

Le Pistachier vrai est cultivé dans toute la région méditerranéenne pour sa graine ou pistache, qui se mange crue et sert en confiserie. Tous les autres fruitsgraines ont, en France, une importance moindre. Les amandes du Pin Pignon d'ltalie se mangent crues ou cuites et entrent dans la confection des gâteaux. La graine de l'Arachide, qui joue un rôle considérable dans l'alimentation des Sénégalais, est le cacahouète des marchands de nos rues; en Amérique, on en prépare une imitation de chocolat, contenant un tiers de cacao pour deux tiers d'arachide. On trouve couramment dans les grandes villes d'Europe la noix pacane, les noix du Brésil et d'Hickory et surtout la noix de coco. L'amande fraîche de coco est très employée en pâtisserie et en confiserie. 


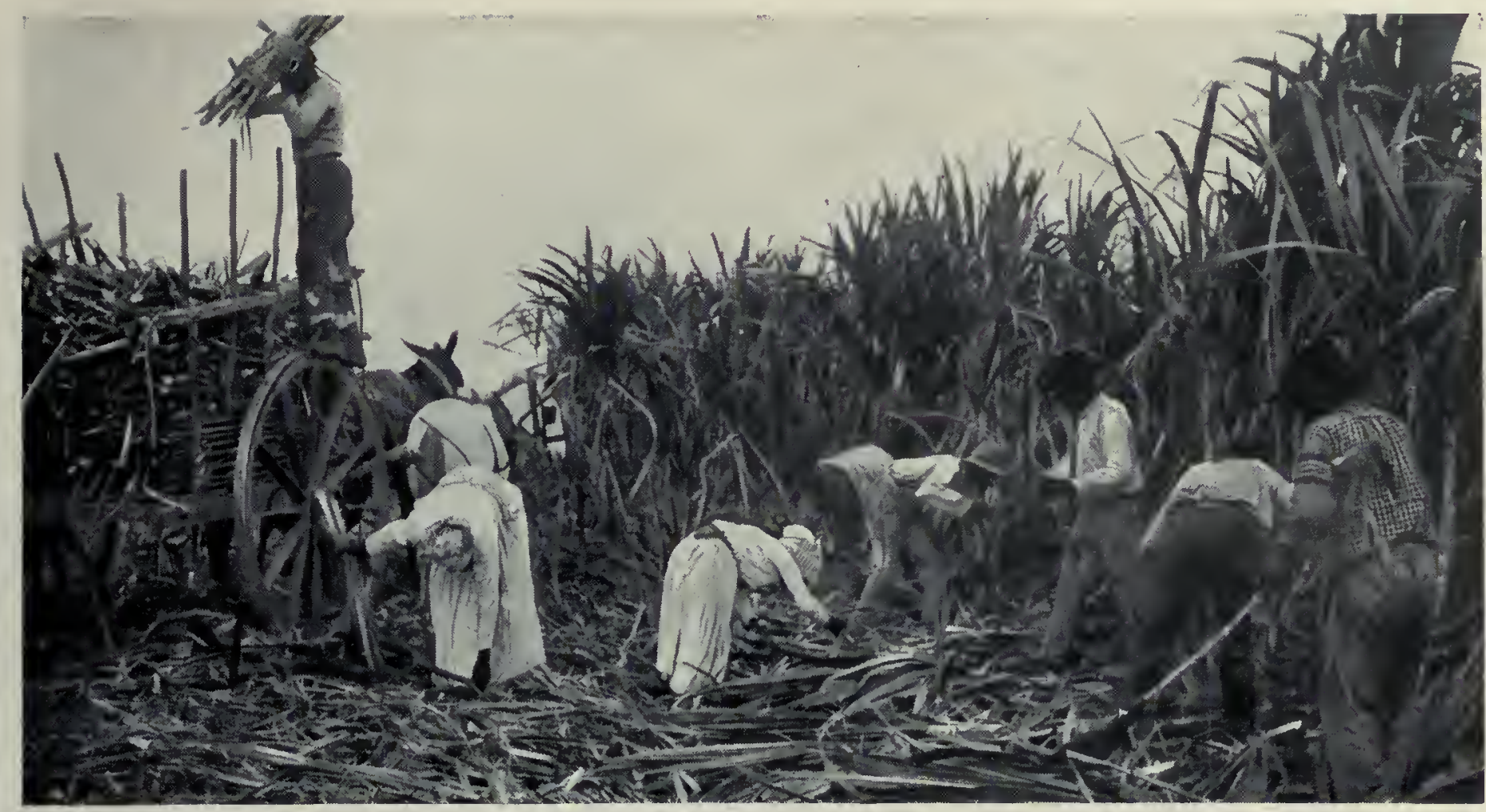

Récolte de la Canne à sucre, aux Antitles.

\section{LES PLANTES SUCRIÈRES}

Dans les plantes abondent les principes sucrés que les chimistes répartissent en trois groupes : glucoses, saccharoses et mannites. Les glucoses se rencontrent dans les fruits mûrs; les saccharoses suintent des nectaires, imprègnent les racines de Carotte, de Betterave, les tiges de Canne à sucre, d'Érable, les graines de Châtaignier; les mannites sont retirées du Frêne, de l'Olivier, des Tamarix, des Laminaires, des Champignons. Ces principes sucrés résultent surtout des transformations que subissent les matières féculentes élaborées dans les feuilles sous l'action de la lumière solaire. L’industrie sait produire des modifications analogues et former du glucose en partant des féculents et même des celluloses.

Le sucre est le plus parfait des aliments; il est entièrement utilisé par l'organisme et communique au système musculaire une grande résistance à la fatigue. Jadis c'était un remède d'un prix élevé; aujourd'hui c'est un aliment dont il se fait une consommation considérable sous forms de boissons, compotes, confitures, confiserie, gâteaux, biscuits.

Il n'y a que deux plantes sucrières véritablement importantes : la Canne à sucre, dans les pays chauds, et la Betterave, dans les régions tempérées.

Canne à sucre. - La Canne à sucre semble avoir été cultivée en Chine dès la plus haute antiquité. Son produit fut connu des Anciens; ils l'appelaient " miel de roseau ". Au moyen âge les Arabes introduisirent la Canne en Sicile, puis dans le midi de l'Espagne. Après la découverte de l'Amérique, elle fut importée aux Antilles, puis dans toutes les régions chaudes du Nouveau Continent. La limite de sa culture coïncide avec les isothermes de 200; elle ne dépasse guère $30^{\circ}$ de latitude dans chaque hémisphère; cependant, dans l'Amérique du Nord, sa limite est, sur la côte Est, $35^{\circ}$ lat, ; exceptionnellement, on la cultive en Sicile $\left(37^{\circ}\right.$ lat. $\mathrm{N}$.), dans le sud de l'Espagne $\left(37^{\circ}\right.$ lat. N.) et en Transcaucasie $\left(41^{\circ}\right.$ lat. N.). Les principaux centres producteurs sont en Asie : les régions deltaïques et la vallée du Gange, dans l'Inde, l'Indochine, les vallées et les régions côtières de Chine, le sud du Japon; en Océanie : les Philippines, Java, les îles Hawaï; en Amérique : les Antilles, le Mexique, la côte sud des États-Unis; en Afrique : l'Égypte, Natal, Madagascar. Végétant toute l'année, la Canne à sucre ne peut supporter le froid; il lui faut une température de $20^{\circ}$ à $25^{\circ}$ et jamais moins de $10^{\circ}$. Des pluies abondantes (au moins $1^{\mathrm{m}}, 20$ de hauteur d'eau par an) sont nécessaires, surtout pendant sa croissance.
Aucune plante cultivée ne comporte plus de variétés que la Canne à sucre. La multiplication a lieu par bouturage du sommet des Cannes coupées sur deux ou trois noeuds. On enlève les feuilles, et ces boutures sont plantées à $I^{\mathrm{m}}, 50$ les unes dès autres, par rangées écartées de 2 mètres. La Canne est mûre au bout de douze à dix-huit mois, suivant les pays. On la coupe au ras du sol et elle donne l'année suivante une seconde récolte. L'expérience a montré que sa teneur en sucre diminue beaucoup à partir de la troisième année; aussi renouvelle-t-on les plants par bouturage dès qu'ils ont fourni deux récoltes.

Les rats causent d'incalculables dégâts; toute tige blessée par eux fermente, rougit et se dessèche. Dans ces dernières années, la Canne a eu beaucoup à souffrir par suite de l'invasion de diverses maladies, notamment les borers, qui sont des insectes perceurs de la canne (Shot borer, Xyleborus perforans; Moth borer, Diatrea saccharalis) et c'est à la suite de ces blessures produites que les maladies parasitaires, dues à des Champignons, se sont introduites. Pour échapper à toutes ces affections si redoutables, on a trouvé, notamment par des croisements heureux, le moyen d'obtenir des graines, chose oubliée depuis longtemps, car, en se multipliant indéfniment par bouture, la plante avait fini par ne plus jamais se reproduire par la méthode normale; ces graines ont donné des germinations. On a pu faire des croisements de va-

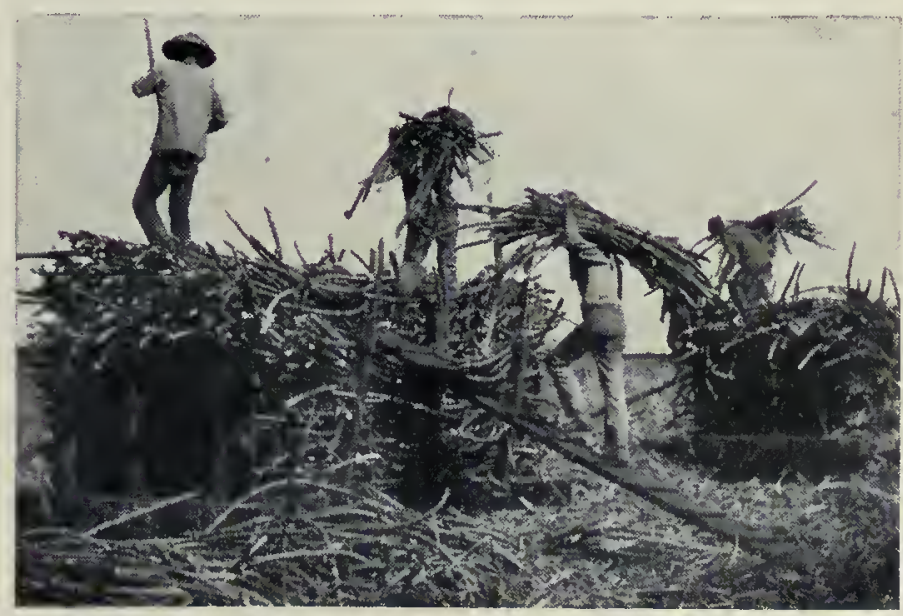

Chargement de la Canne en wagonnets. 


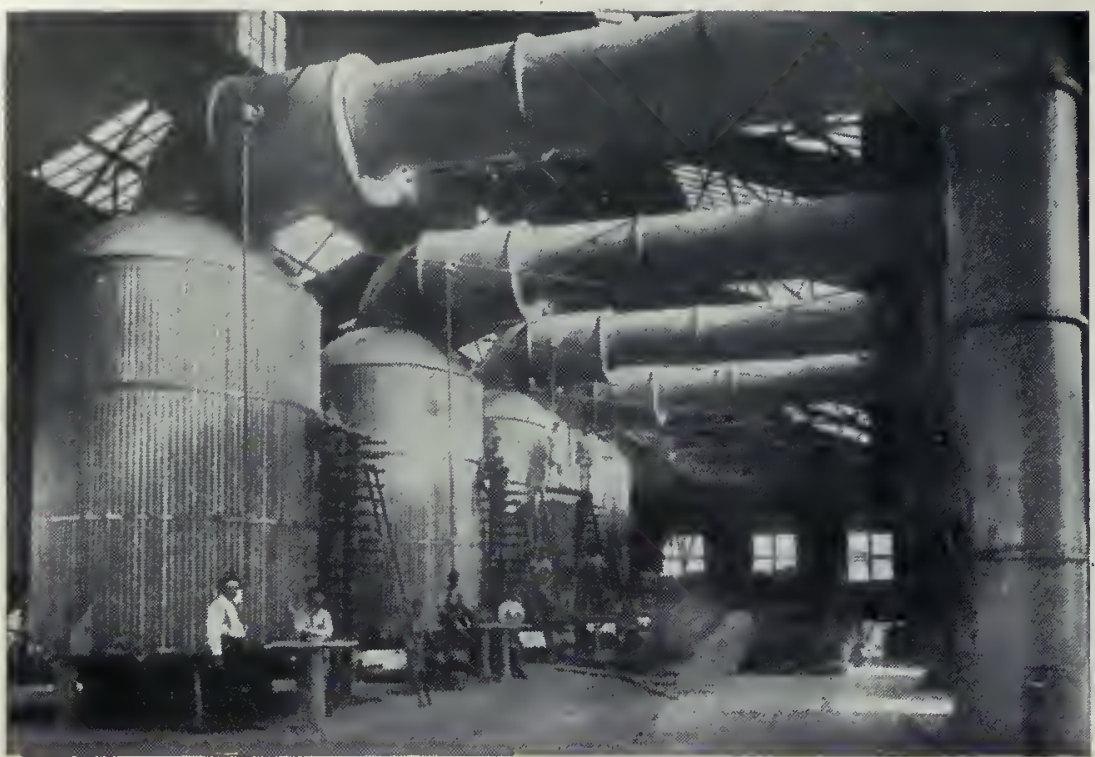

Fabrication du sucre de canne, à Hawaï.

riétés et, au milieu d'un grand nombre d'hybrides ainsi obtenus, découvrir les types les plus résistants.

Les champs de Cannes sont mis en coupe quand la plante est entièrement mûre, ce qu'on reconnaît à la chute des feuilles des entre-nouds inférieurs. Les tiges sont coupées aussi près que possible de terre, avec un couteau à lame très large ; la partie inférieure est, en effet, beaucoup plus riche en sucre que la partie supérieure, car cette dernière utilise pour sa croissance la sève sucrée au fur et à mesure qu'elle lui parvient. Le sommet de la tige et les feuilles, enlevés aussitôt, sont utilisés comme engrais vert ou comme fourrage.

Dans les grandes exploitations, les champs sont réunis à l'usine par des voies ferrées. La partie utilisable des Cannes est bottelée, puis chargée dans des wagonnets qu'une locomotive conduit à la sucrerie. Les tiges, déchargées sur une toile sans fin, sont broyées entre des cylindres de fer et il en sort un liquide visqueux ou vesou, recueilli dans des bassins. Les tiges épuisées, que l'on nomme bagasse, sont brûlées aussitôt dans des fours spéciaux, et suffisent pour la production totale de la vapeur nécessaire au fonctionnement de l'usine.

Le vesou, additionné d'un peu de chaux, est porté à l'ébullition dans une chaudière à double fond chauffée à la vapeur; les matières azotées sont coagulées, les acides saturés de chaux (puis $\mathrm{CO}^{3}$ ): toutes les impuretés remontent à la surface sous forme d'écume et sont enlevées (défécation). Le sirop purifié est alors soutiré, puis concentré, décoloré par le noir animal, cuit enfin dans le vide et mis à cristalliser dans des bacs. Le sucre s'y dépose en cristaux blancs que l'on débarrasse du liquide qu ils retiennent à l'aide de turbines. Ce sucre cristallisé est ensuite raffiné pour la mise en pains. Les résidus incristallisables ou mélasses, mis à fermenter en présence de la Levure de bière, donnent le rhum par distillation. En bon terrain, un pied de Canne à sucre fournit 10 kilogrammes de jus produisant environ 2 kilogrammes de sucre brut.

Betterave. - La présence du sucre dans la Betterave fut signalée en 1605 par Olivier de Serres, mais les premières recherches entreprises dans un but pratique datent de 1747 et sont dues à un chimiste allemand, Margraff. En 1785, un de ses élèves français, Achard, fonda près de Berlin la première sucrerie européenne.

Les circonstances forcèrent bientôt Napoléon I ${ }^{\text {er }}$ à s'occuper de cette question. En 1806, il décréta le blocus continental pour ruiner la marine anglaise; mais celle-ci donnait à nos navires marchands une chasse continuelle : le sucre des colonies, ne pouvant arriver jusqu'à nos ports en quantité suffisante, atteignit bientôt 6 francs la livre. L'empereur encouragea alors les savants et les industriels à reprendre les travaux d'Achard. Chaptal put bientôt annoncer à Napoléon qu'un riche industriel, Benjamin Delessert, venait de fonder à Passy une usine pour l'extraction du sucre de Betterave. Ce fut là un événement considérable. Des gens de trop d'esprit se moquèrent de cette transformation de la Betterave en sucre : une gravure de l'époque représente le roi de Rome mordant à belles dents dans une Betterave gigantesque, et, au-dessous, cette légende : "Papa dit que c'est du sucre." C'en était, en effet, et le 2 janvier 1812 le premier échantillon français de sucre de Betterave sortit de l'usine de Passy.

Par la culture, la Betterave est devenue une plante bisannuelle, formant son pivot la première année, et portant, la seconde, des tiges et des feuilles florifères.

Pendant longtemps. en France, on a cultivé des Betteraves d'un rendement cultural énorme, jus quà̀ 100000 kilogrammes à l'hectare, mais peu riches en sucre. La loi de 1884, en taxant les usiniers sur la betterave et non plus sur le sucre brut, et en les obligeant par suite à $n$ acheter que des racines très saccharines, modifia heureusement la situation. Par une soigneuse sélection des semences, le rendement moyen de nos Betteraves françaises, qui était de 5,55 pour 100 en 1884 , atteint aujourd'hui 12 pour 100 . La Betterave blanche à collet rose rend 12 à 14 pour 100 de sucre, et la Betterave améliorée jusquà 18 pour 100 .

La Betterave aime les climats tempérés; ['irrigation est indispensable dans les région trop sèches. Les terres franches, profondes et fraîches sans humidité, lui conviennent surtout. Les semailles ont lieu en avril, puis suivent deux ou trois binages pour extirper les mauvaises herbes; on arrache les plantes en excès en ne laissant à intervalles réguliers que les pieds les plus vigoureux, au nombre de dix environ au mètre carré. La floraison prématurée, se produisant dès la première année, cause de grands dommages aux cultures, car elle diminue fortement le rendement en sucre. Les maladies sont nombreuses : un minuscule nématode s'introduit à l'intérieur des radicelles, dont les larves du hanneton et celles du taupin rongent la pointe; le ver gris dévcre le collet; pucerons et sylphes sattaquent aux feuilles. Aux dégâts causés par toute cette vermine s'ajoutent ceux des Champignons et des $\mathrm{Ba}$ cilles produisant la rouille, la pourriture du coeur, la gommose, le mildiou (Peronospore de Schacht), la jaunisse, le brunissement, etc.

Larrachage des betteraves commence vers la fin de septembre, soit au moyen d'une bêche ou d'une fourche, soit à l'aide d'un arracheur à traction animale.

La transformation d'une racine de Betterave en un beau prisme blanc de sucre prêt à servir sur la table exige une longue série d'opérations. Les racines sont d'abord lavées mécaniquement et découpées en lanières minces ou cossettes qui passent dans des diffuseurs à eau chaude, où elles sont épuisées méthodiquement. Les jus sucrés sont traités par un lait de chaux qui les purifie (défécation), mais transforme le sucre en saccharate de chaux. Un courant de gaz carbonique passant dans le jus chauffé remet le sucre en liberté (carbonatation). Après un passage au filtre-presse, suivi d'une deuxième défécation et d'une nouvelle carbonatation, le jus est concentré dans des chaudières par ébullition à basse température. Le sirop obtenu est filtré, puis concentré dans la chaudière à cuire. Il en sort un sirop brun dans lequel nagent de petits cristaux ou sucre de premier $j e t$, qu'on sépare du liquide par turbinage. Ce liquide est repris de nouveau, concentré, turbiné, et donne successivement des sucres de deuxième et de troisième jet ou cassonades, de couleur plus ou moins foncée, avec de la mélasse comme résidu. 


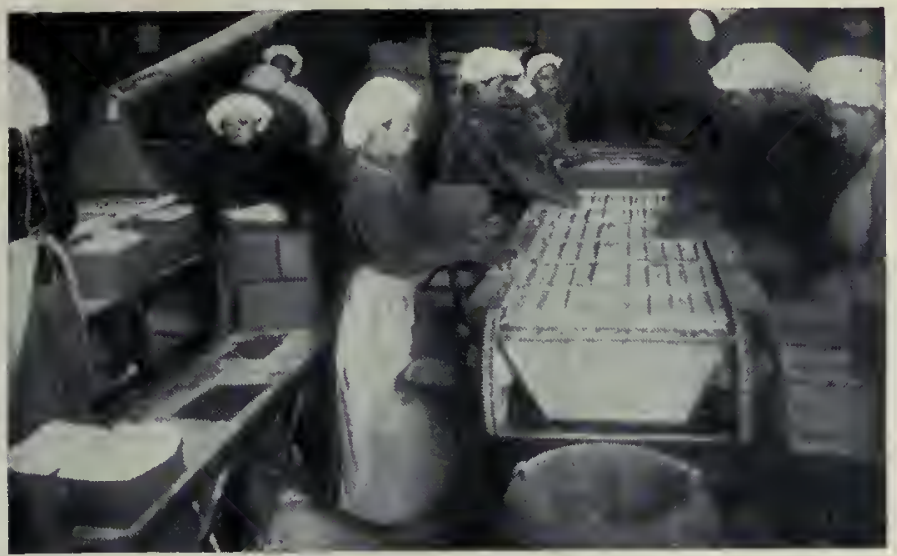

Cassage et mise en boites du sucre.

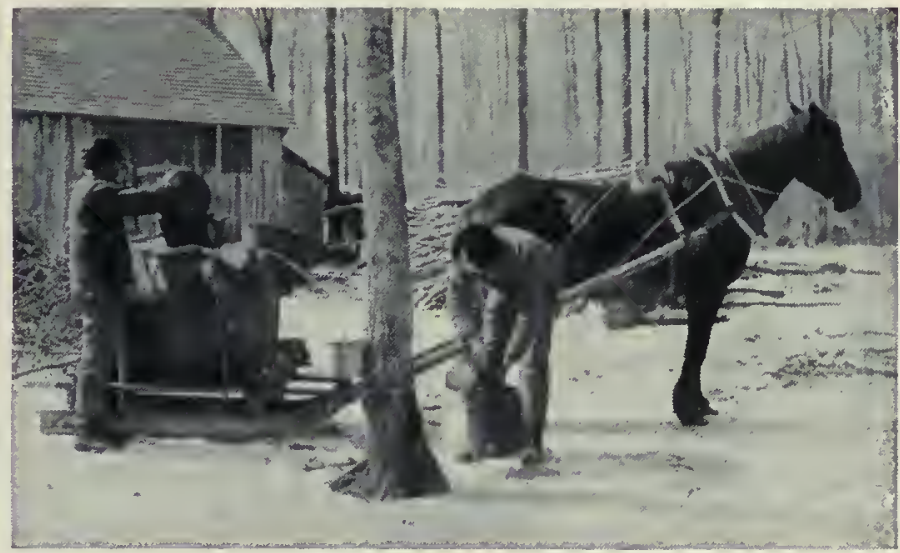

Récolte de la sève d'Érable.
Il faut ensuite procéder au raffinage. Les cassonades sont dissoutes dans l'eau chaude. Le sirop, mélangé de noir animal qui le décolore et de sang de bouf quile clarifie, est porté à l'ébullition, puis filtré sur du noir animal en grains, cuit de nouveau, mis en moules, débarrassé par clairçage du sirop impur qu il retient encore, enfin séché à l'étuve.

Comme on l'a dit avec raison, la sucrerie de Betteraves est, en France, la reine des industries agricoles. Elle a, par ses sousproduits, d'étonnantes répercussions sur les diverses branches de l'agriculture. La pulpe provenant des cossettes épuisées, débarrassée par la pression de l'excès d'eau qu'elle contient, sert à nourrir les bestiaux, dont elle amène l'engraissement rapide. Les mélasses sont vendues aux distilleries ou encore sont utilisées dans l'alimentation du cheval et des bovidés; une petite partie est employée à la fabrication du pain d'épice, de bonbons communs, de cirage, etc.

La Betterave est cultivée aujourd'hui dans la plus grande partie de l'Europe, aux Etats-Unis et au Canada, en Egypte, au Japon et en Corée.

Depuis 1840, la Betterave a gagné constamment du terrain sur la Canne à sucre. Le développement de cette dernière a été contrarié par l'abolition de l'esclavage, par les progrès incessants survenus dans la culture betteravière. Depuis quelques années, cependant, les progrès de la Canne à sucre sont notables, grâce aux perfectionnements apportés à l'outillage et aux méthodes de culture, et grâce aussi au prix plus bas de la main-d' œuvre dans les colonies.

Plantes sucrières diverses. Dans le nord des États-Unis et au Canada croissent plusieurs Erables dont la sève est très sucrée, et notamment l'Erable à sucre, l'un des plus beaux arbres des forêts américaines. Ces arbres ne donnent pas lieu à une grande industrie. Chaque fermier exploite les siens, fabrique du sucre pour sa consommation et vend le surplus de sa production. Du moins, les choses se passaient ainsi il y a quelques années, mais, d'une part, le bon marché des sucres de Canne et de Betterave et, d'autre part, la déforestation de ces régions, font disparaítre peu à peu cette industrie.

$C^{\prime}$ est seulement entre le 10 mars et le 20 avril que les Érables peuvent sup-

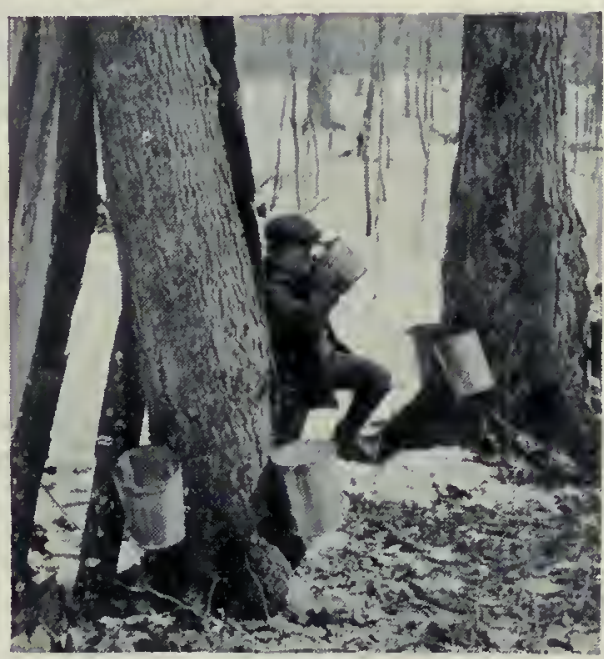

Enfant buvant la sève d'Érable.

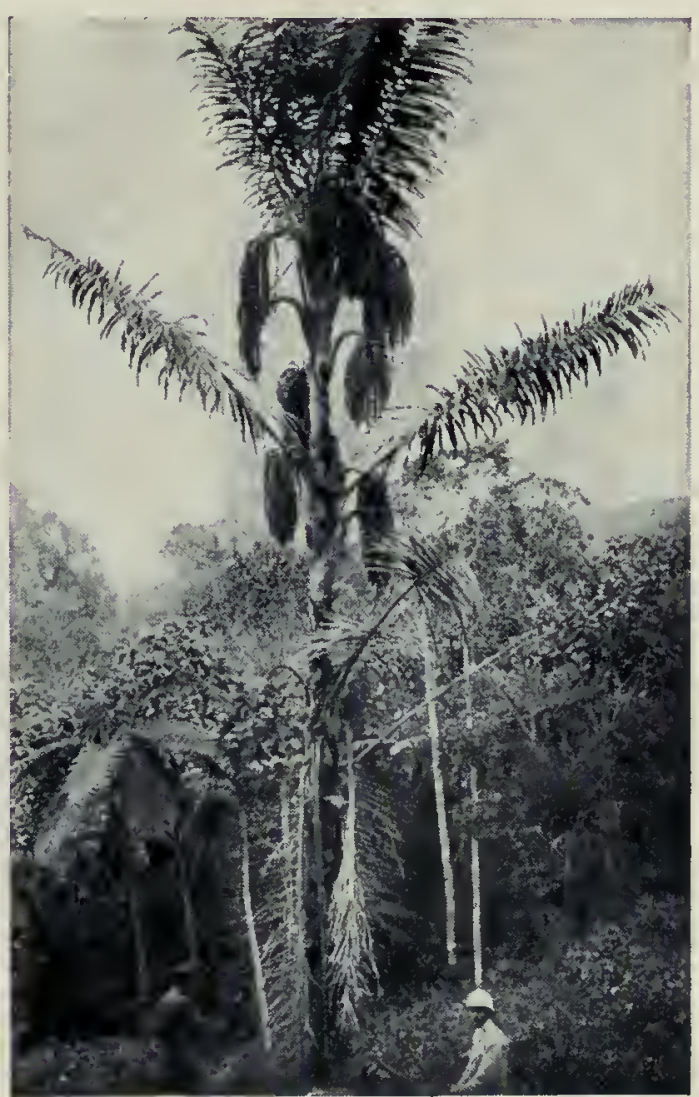

Arenga saccharifére on Palmier à sucre. porter sans dommage les saignées de sève : on traverse l'écorce et une partie de l'aubier d'un ou deux trous de tarière. Par un petit tuyau en Sureau enfoncé dans l'orifice, le liquide s'écoule dans des vases qui, deux fois par jour, sont vidés dans des barils. Le contenu de ces derniers va remplir un grand récipient où la sève est chauffée, brassée, écumée et transformée en un sirop dont une partie est consommée en nature. Le reste est concentré de nouveau au feu, versé dans des moules en terre; il en sort sous forme d'une masse granuleuse, d'un goût très agréable, rappelant à la fois le miel et la cassonade. Chaque arbre donne en moyenne pendant la durée du traitement, c'est-à-dire environ un mois, 30 kilogrammes de sève, fournissant plus d'un kilogramme de sucre.

En incisant le spadice de plusieurs espèces de Palmiers avant l'épanouissement de linflorescence, on recueille une sève sucrée qui, le plus souvent, est soumise à la fermentation. Cependant la sève du Palmier à sucre ou Arenga saccharifère des Moluques, des Philippines et de l'Asic tropicale, celle du Ronier de I'Inde, sont concentrées par les indigènes qui en retirent un sucre brunâtre. II n'est pas sans intérêt de signaler aussi les essais qui ont été tentés à diverses reprises pour extraire industriellement le sucre contenu dans les tiges de diverses Graminées, comme le Maïs, le Sorgho à sucre (Sorghum saccharatum), de la Chine; le Bourgou (Panicum Burgu), du Soudan.

Glucose. - Le glucose ne se retire pas des fruits mûrs où il est abondant; il se prépare industriellement en grand par la saccharification de la fécule de pomme de terre. Dans des cuves en bois, chauffées à la vapeur, on fait agir sur de la fécule de l"acide sulfurique dilué. Quand la saccharification est achevée, on sature l'acide sulfurique en excès par du carbonate de chaux; on décante, on filtre et on fait évaporer dans des chaudières, Le glucose est employé dans la fabrication de la bière, de l'alcool, pour remplacer le sucre dans les conserves de fruits, liqueurs, confitures; il est souvent impur et peut contenir des traces d'arsenic provenant de l'acide sulfurique employé. On obtient un glucose pur et sans danger en saccharifiant la fécule par la diastase du malt d'orge. 


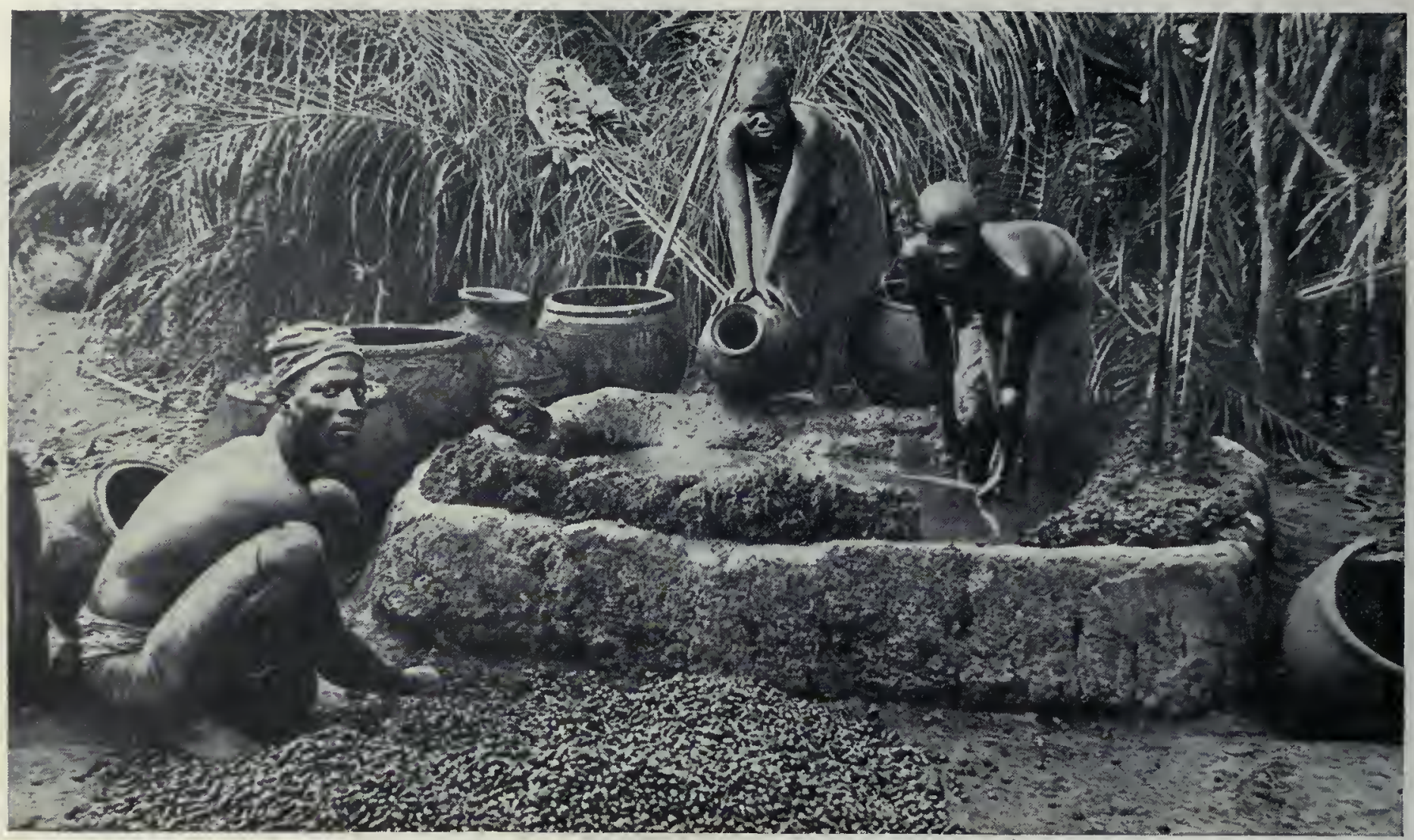

Préparation de l'huile de palme, au Dahomey.

\section{LES CORPS GRAS}

Nous rangeons parmi les plantes alimentaires celles qui renferment des corps gras, à cause des huiles de table et des beurres comestibles quelles fournissent; nous ferons remarquer cependant qu'elles appartiennent aussi à la catégorie des plantes industriclles, qui sera étudiée plus loin, par les matières premières que la plupart d'entre elles fournissent à la savonnerie, à la peinture, etc.

Les corps gras sont abondamment répandus chez les végétaux, principalement dans les graines, où ils constituent des matières de réserve qui seront utilisées au cours de la germination; on les rencontre aussi dans la pulpe de certains fruits, et même parfois dans la racine ou dans la tige (Souchet comestible). Les corps gras végétaux ont une composition analogue à celle des graisses animales; ce sont des combinaisons de la glycérine et des acides gras. Insolubles dans l'eau, plus légers qu elle, onctueux au toucher, ils brûlent facilement; à l'air, ils s'oxydent et rancissent; certaines huiles finissent même par s'y solidifier, surtout lorsquelles sont étalées en couches minces : elles sont dites siccatives; on les utilise en peinture.

L'extraction des huiles végétales est une industrie extrêmement

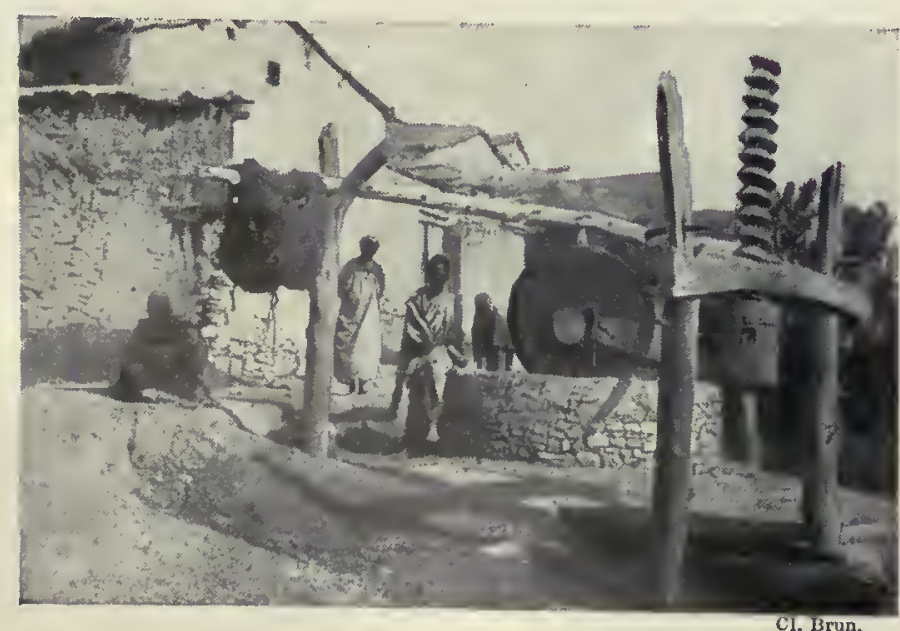

Moulin à huile, en Kabylie. ancienne et dont l'importance a toujours été considérable. Les huiles servent dans l'alimentation, pour l'assaisonnement, les conserves; elles remplacent parfois le beurre ou la graisse; leur rôle est grand en médecine, en pharmacie, en parfumerie, en savonnerie, pour la préparation des peintures, des vernis, le graissage des machines, etc. Leur emploi dans l'éclairage, qui fut, pendant des siècles, d'importance primordiale, est peu considérable aujourd'hui : le pétrole les a remplacées. Les matières azotées et cellulosiques qui forment le résidu des huileries constituent les tourteaux, employés comme engrais ou pour la nourriture du bétail.

Huiles de fruits. - L'Olivier croît à l'état sauvage sur le pourtour du bassin méditerranéen et possède des rameaux à extrémité épineuse dont le type cultivé est dépourvu. Sa culture remonte à la plus haute antiquité; il a été introduit depuis longtemps au Mexique et au Pérou; de vastes oliveraies existent en Californie. Parmi ses variétés, les unes (verdale, picholine) fournissent des fruits de table, et les autres (plant de Salon, olivière) des fruits à huile, contenant jusqu à 20 à 28 pour 100 de matières grasses. L'Olivier croît dans les sols les plus arides. On greffe au bout de quatre ans les pieds venus de semis de noyaux; on taille en février. Parmi les ennemis de cet arbre sont la mouche (Dacus olea) et la teigne de l'Olivier, dont les larves attaquent le truit; une cochenille, dite pou de l'Olivier, qui envahit les feuilles et favorise le développement d'une maladie cryptogamique, le noir ou fumagine.

La cueillette des olives se pratique en automne à la maturité complète; la cueillette à la main est préférable au gaulage, qui blesse branches et fruits. Ceux-ci doivent être traités peu de jours après la récolte; sans quoi ils fermentent, rancissent et donnent une huile à saveur âcre. Les olives sont d'abord broyées sous des meules verticales tournant dans une auge; la pâte obtenue est mise en sacs et portée au pressoir ; ce dernier, dans les petites exploitations, est une simple presse à vis en bois dur, façonnée plus ou moins grossièrement; dans les usines, on utilise des presses hydrauliques. L'huile ainsi obtenue à froid est l'huile vierge, la plus estimée; le marc, mis dans l'eau bouillante et pressé de nouveau, donne l'huile ordinaire. Le tourteau ou grignon, résidu de ce second pressage, est broyé, chaufé avec de l'eau et pressé une troisième fois; il donne l'huile de ressence ou huile d'enfer, propre à la savonnerie. La petite quantité d'huile retenue dans les tourteaux peut en être extraite par macération dans le sulfure de carbone; les tourteaux servent ensuite de combustible. 


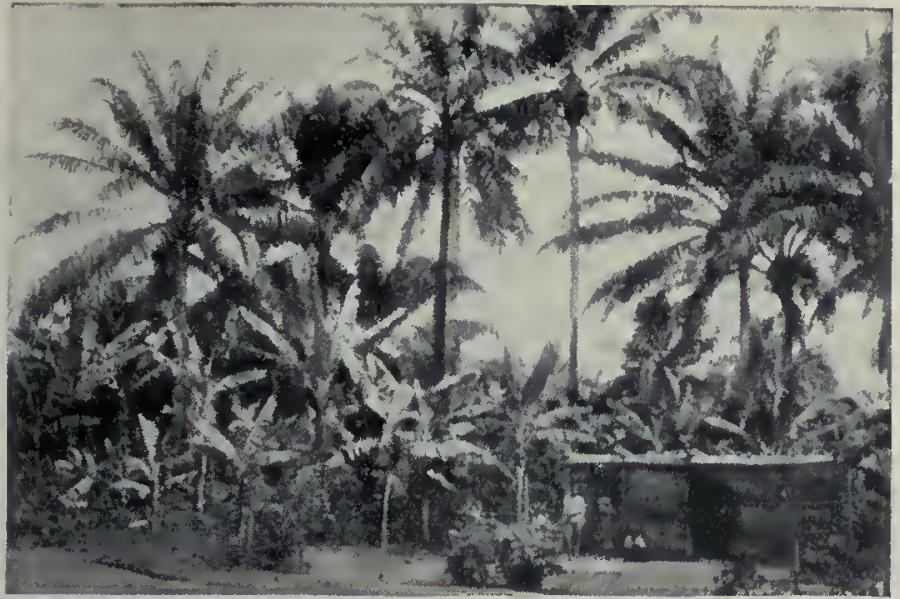

Culture de Palmiers à huile, au Canneroun.

L'Italie produit des huiles d'olive estimées; celles d'Espagne, détestables jadis, sont aujourd'hui plus soignées; l'Algérie, la Tunisie, la Grèce, sont aussi de forts producteurs; notre Provence livre des huiles d'une grande finesse et très réputées.

L'Elcis de Guinée ou Palmier à huile est une des richesses de l'Afrique; il abonde dans nos colonies: Guinée, Côte d'lvoire, Congo, Dahomey et sur toute la côte orientale entre $13^{\circ}$ de latitude Nord et $6^{\circ}$ de latitude Sud; il pénètre dans le continent jusqu'aux Grands Lacs. Ce bel arbre porte six à dix régimes composés chacun d'un millier de fruits qui sont des drupes. La pulpe jaunâtre fournit l'huile de palme, retirée sur place; de l'amande blanche ou noix de palme, enfermée dans un noyau très dur, on retire en Europe l'huile de palmiste. Un palmier adulte porte annuellement de 60 à 100 kilogrammes de fruits, fournissant 7 kilogrammes d'huile de palme et 14 kilogrammes d'huile de palmiste.

Il y a deux récoltes: l'une en mars, l'autre en novembre. Un nègre escalade le stipe du Palmier et coupe les régimes; on les débite en morceaux et les fruits fermentent durant quelques jours dans une fosse entourée d'un petit mur tapissé de feuilles. Ils sont ensuite égrenés, puis brassés avec de l'eau dans de grandes marmites en terre chauffées à feu doux. Amollis par cette cuisson, ils sont piétinés dans une fosse, afin de séparer les noyaux de la pulpe, qui est mise à bouillir dans des vases; l'huile se sépare, monte à la surface, où on la recueille; elle est jaune orangé, à odeur d'iris, se fige à $40^{\circ}$ et prend la consistance de la cire. La pulpe, tordue et pressée dans un tissu grossier, donne une nouvelle quantité d'huile. L'huile de palme fraîche est utilisée en cuisine indigène; sa saveur est douce. Tout ce qui n'est pas consommé est expédié en tonneaux sur Marseille, Hambourg ou Liverpool, pour servir en stéarinerie, savonnerie et même, mélangé avec le suif, au graissage des machines.

Les amandes, extraites des noyaux, sont traitées en Europe et fournissent une huile d'un blanc jaunâtre, inodore, solideà $25^{\circ}$ : elle est employée à la fabrication des savons de toilette.

Huiles indigènes de graines. Le Noyer est une plante oléifère assez importante. C'est au début de l'hiver, lorsque les noix sont sèches, qu'on en extrait l'huile : les coquilles sont brisées avec un maillet, puis enlevées, ainsi que les cloisons; on fait sécher les amandes, qui subissent le même traitement que les olives. La première expression à froid donne l'huile vierge ou huile blanche, alimentaire et de saveur agréable, mais qui rancit facilement; le deuxième traitement, qui a lieu à chaud, fournit l'huile noire, bonne seulement pour la savonnerie, l'éclairage et la peinture, car elle est très siccative.

Les graines du Noisetier fournissent une huile alimentaire; celles de l'Amandier donnent l'huile d'amandes douces pour la médecine et la parfumerie; les amandes du Prunier de Briançon ou Marmottier, celles

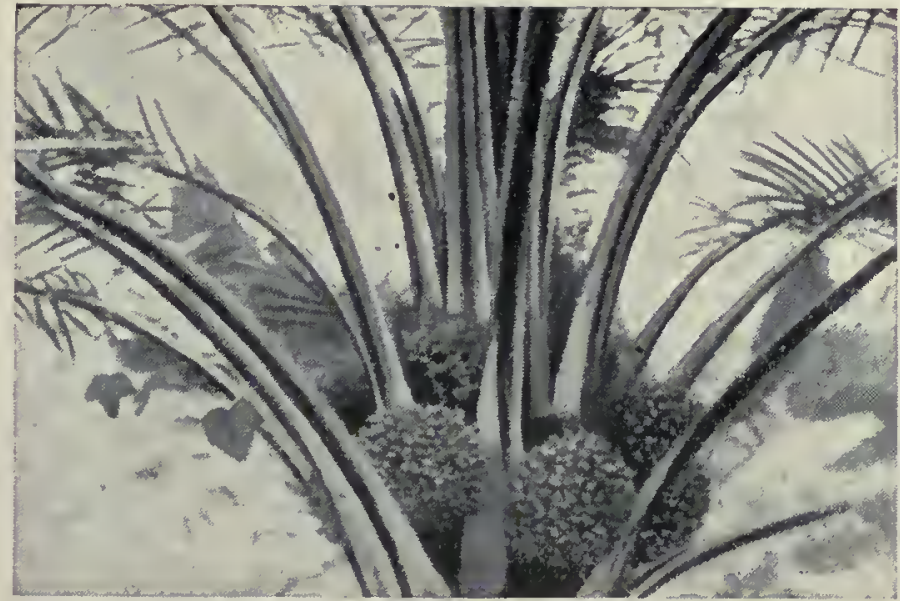

Régimes de fruits d'un Palmier à huile.

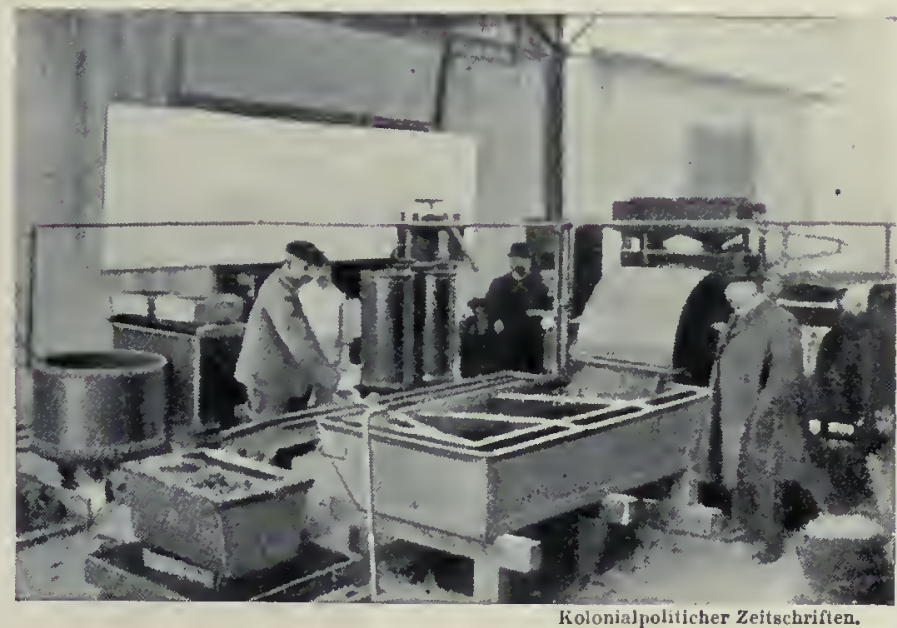

Préparation industrietle de l'huile de palme.

de l'Abricotier donnent l'huile dite de marmotte, qui est alimentaire, malgré sa forte odeur de noyau.

Un grand nombre d'herbes annuelles ont des graines oléagineuses. Pour en extraire l'huile, on commence par les broyer dans une sorte de laminoir en fonte ou concasseur; la matière pulvérulente passe sous les meules du moulin, puis au pressoir; elle fournit, à froid et par première expression, l'huile vierge; à chaud, par deuxième pressée, l'huile de rebat.

Le Colza, qui est une espèce de Chou, faisait jadis l'objet d'une culture étendue dans le nord de la France et dans une grande partie de l'Europe. Sa graine fournit l'huile végétale, douée du plus grand pouvoir éclairant; après la récolte, ses racines fibreuses servent pour le chauffage. Cette culture est, comme l'éclairage à l'huile, en pleine décroissance. La culture des deux autres Crucifères oléagineuses, la Navette et la Cameline, a aussi beaucoup perdu de son importance. Marseille reçoit, pour ses huileries, des Ravisons, qui sont les graines de diverses moutardes asiatiques: l'Inde lui envoie en abondance des graines de Colza et de Pavot.

Le Pavot somnifère à graines noires, dit Pavot œillette, occupait autrefois de grandes surfaces dans le nord de la France. Le fruit est mûr en août; on arrache les plantes; on bat en frappant les capsules les unes contre les autres au-dessus diune toile tendue. L'huile d'œillette, d'un blanc jaunâtre, est alimentaire. Très siccative, elle est aussi employée en peinture. Le $L$ in est cultivé surtout comme plante textile; sa graine renferme 30 pour 100 d'une huile très siccative, utilisée en peinture, pour la fabrication de l'encre d'imprimerie, des vernis gras, du
Récotte des amandes de patme (Guinée). 


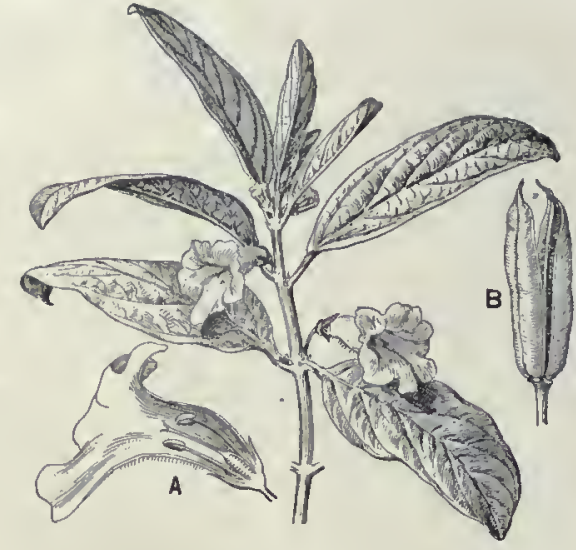

Fig. 277. - Sésame. A, Fleur ; B, Fruit.

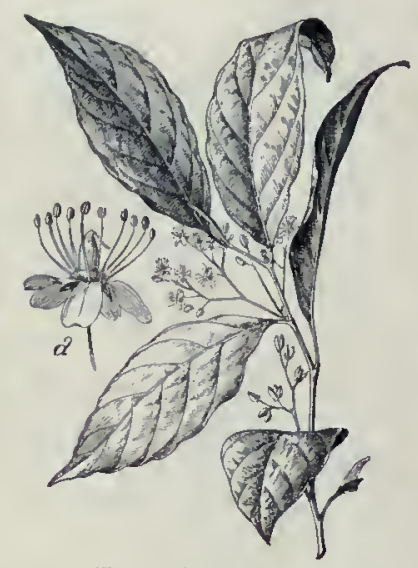

Fig. 278. - Irvingie. $a$, Fleur.

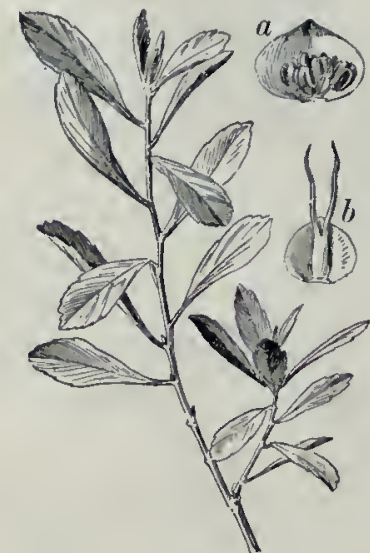

Fig. 279. - Myrica ou Cirier. Fleurs : $a$, mâle ; $b$, femelle.

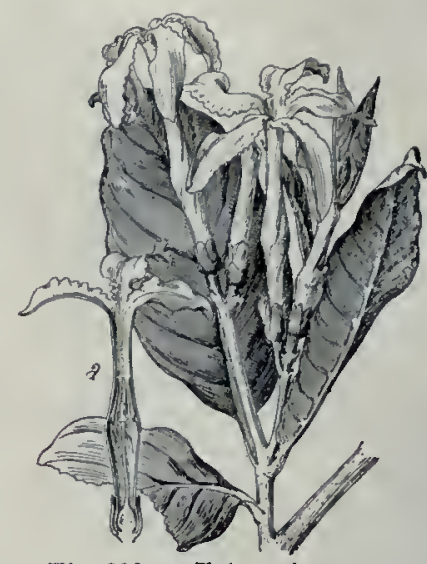

Fig. 280. - Tabernémontane. $a$, Fleur. linoléum, pour enduire les vêtements cirés imperméables; elle forme, en séchant, un enduit transparent. Souvent on la fait cuire avec de la litharge pour obtenir un enduit coloré. L'huile fournie par le chènevis ou graine de Chanure a des propriétés analogues.

Huiles exotiques de graines. - Les graines oléagineuses des pays chauds sont aujourd'hui beaucoup plus importantes en huilerie que nos graines indigènes. Le Cocotier donne lieu à une grande culture dans les pays tropicaux; les semis se font en pépinières, à faible profondeur; pour la mise en place, on taille les racines et les feuilles. Le Cocotier fleurit vers six ans, fructifie à huit et, plus tard, porte annuellement de dix à cent fruits. A la maturité, l'albumen de la graine se concrète presque entièrement en un tissu blanc, solide, lamande de coco, de saveur agréable, et très riche en corps gras. Les " doigts " de noix de coco, employés encore par des millions d'Asiatiques et de Polynésiens pour s'éclairer, sont des tranches d'amande desséchée que l'on allume par les deux bouts. L'extraction de l'huile se fait parfois sur place; le plus souvent, l'amande est retirée de la coque, fragmentée, séchée au soleil, puis exportée sous le nom de coprah. Dans beaucoup de pays, on emploie un moulin comprenant meules, presses et chaudières. A Ceylan, aux Indes, comme à Marseille, d'importantes usines disposent d'un matériel perfectionné : le coprah, réduit en poudre fine, est soumis trois fois, à chaud, à l'action des presses hydrauliques; on retire 65 à 70 pour 100 d'une huile se solidifrant à $25^{\circ}$ en une masse blanche qui rancit rapidement.

Jusqu'en 1895, elle n'était utilisée qu’en savonnerie et stéarinerie; on lui enlève aujourd'hui ses acides gras libres et ses éthers volatilisés et on la transforme en un beurre végétal (végétaline, cocose, etc.), très sain, agréable au goût, d'une digestion facile et d’un bon marché relatif. Les Philippines, Ceylan, Java, l'Inde sont les grands producteurs de coprah.

L'Arachide est une herbe annuelle d'origine américaine, mais

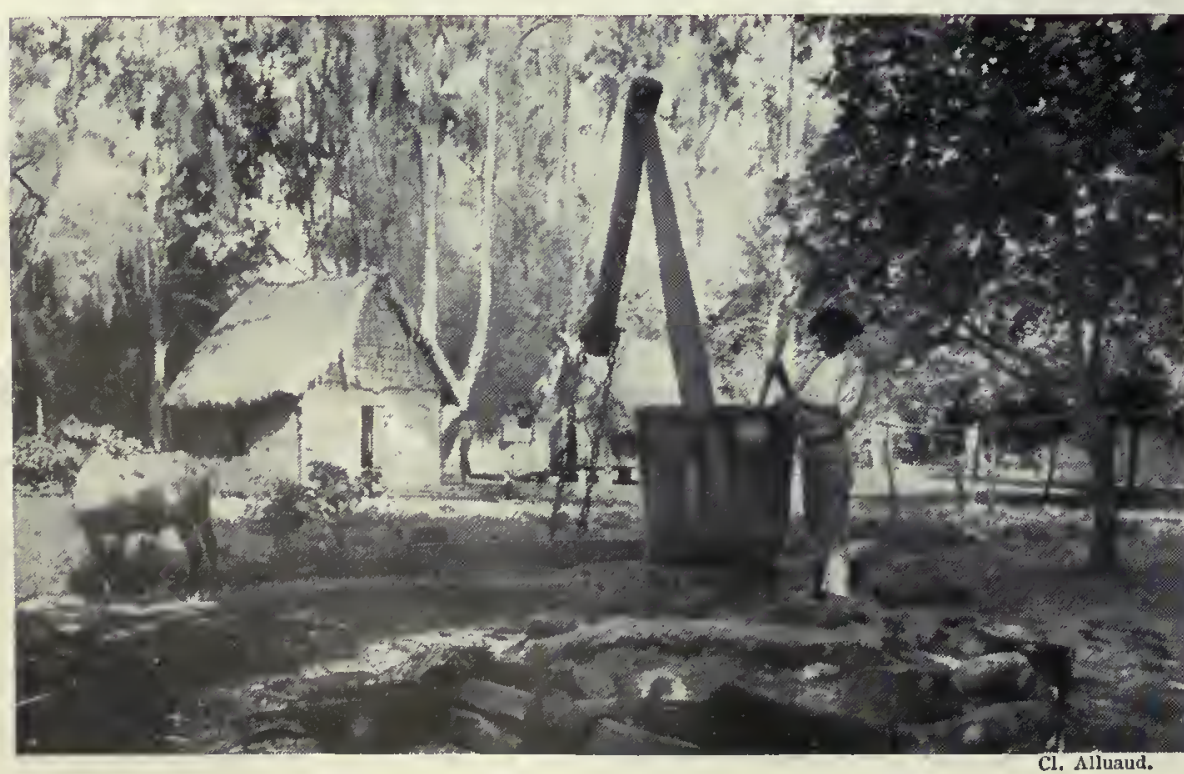

Moulin à huite de coco, aux îles Seychelles. cultivée aujourd'hui dans tous les pays chauds, entre $40^{\circ}$ de latitude Nord et $35^{\circ}$ de latitude Sud; elle réussit cependant quelquefois au delà, à bonne exposition: par exemple, dans la province de Turin, en Italie. Les principaux centres de production en vue de l'exportation sont l'Inde, le Sénégal, l'Afrique occidentale française et le Mozambique. Tout le cycle de la végétation de cette Légumineuse s'accomplit dans les limites de la saison des pluies, entre juillet et novembre.

Les graines contiennent 27 pour 100 de substances azotées, 11 pour 100 de sucre et 45 pour 100 d'huile. Une première pression donne une excellente huile de table, la meilleure après l'huile d'olive, qu'elle falsifie souvent; on l'utilise pour les conserves de sardines, la fabrication des fromages hollandais dits de pâte grasse, et des margarines ou beurres artificiels; deux autres pressions donnent des huiles de savonnerie.

Le Sésame ( $f g .277$ ) est une herbe de l'Inde, cultivée de toute antiquité en ce pays, ainsi qu'en Malaisie, en Chine, en Orient. Elle prospère dans la zone tropicale, en Afrique, en Amérique, mais peut croître dans les parties chaudes de la zone tempérée, en Grèce, à Malte, etc. Les graines, de la grosseur de celles du Lin, contiennent jusqu'à 46 pour 100 d'huile. L'amande décortiquée par un battage donne, à froid, en deux pressées successives, une huile de bouche d'un jaune citron, presque inodore et d'une longue conservation; une troisième pression, à chaud, fournit une huile industrielle.

Les graines du Cotonnier étaient autrefois jetées comme inutiles ou servaient de combustible; on en extrait aujourd'hui 18 à 20 pour 100 d'une huile blanche utilisée comme huile de table et aussi dans l'industrie des conserves et des margarines.

Des graines du Ricin, on retire une huile qui, exprimée à froid, est employée en Chine comme huile de table, mais qui, obtenue à chaud, est purgative. Les emplois industriels de l'huile de Ricin sont beaucoup plus intéressants que son usage médicinal; elle sert, en effet, pour l'éclairage, le graissage des machines (avions), la savonnerie et, en teinture, comme mordant, sous forme d'acide sulforicinique; cette graine contient un ferment diastasique employé dans, plusieurs usines, en Angleterre et en France, pour saponifier en grand les matières grasses à la température ordinaire.

Les graines de diverses Composées sont oléagineuses : dans le Caucase, où le Grand Soleil ou Hélianthe annuel est cultivé en grand, on retire de ses graines une huile comestible et industrielle; elle prend une certaine importance pour la fabrication des vernis injaunissables et résistants aux agents atmosphériques. Les graines de la Guizotie d'Abyssinic ou Niger, Composée annuelle de l'Afrique, fournissent aussi une huile alimentaire et industrielle.

Le fameux Arbre à huile ou Abrasin de Chine et du Japon est une Euphorbiacée, l'Aleurites cordata. Ses grosses graines, rôties, puis écrasées sous une meule et pressées, donnent une huile très siccative ayant l'aspect de l'huile de lin. L'huile blanche, de première pressée, est employée à préparer des pein- 
tures, des vernis, des laques grasses, à rendre imperméables le papier et les étoffes sans leur faire perdre leur souplesse. Des quantités assez grandes de cette huile sont importées en Europe. Lihuile obtenue par deuxième pression, à chaud, est employée pour badigeonner les jonques, de façon à boucher les fentes entre les planches. Le Bancoulier ou Noyer des Moluques (Aleurites moluccana) fournit une huile purgative, qui est utilisće aussi pour l'éclairage.

Citons encore l'huile de Pistache, utilisée en Orient ; celle de Mä̈s, aux Etats-Unis; d'Arganier, au Maroc; de graines de Camellia drupitera et de Soja, au Japon; de graines de Croton, de Jatropha, en diverses régions chaudes, etc. ; cette dernière est employée en Europe par la savonnerie. L'huile de ben, très appréciée en horlogerie, parce qu elle rancit difficilement, est extraite des graines d'une Moringée, le Moringa plerygosperme de l'Inde. L'huile tirée des graines de l'Ériodendron anfractueux ou Kapoquier est consommée en Chine et à Java; elle vaut l'huile d'arachide.

\section{Beurres et suifs vé-} gétaux. - On désigne plus particulièrement sous le nom de beurres végétaux les corps gras solides à la température ordinaire; les huiles de palme, celle de coco, sont plutôt des beurres; le beurre de cacao et le beurre de muscade sont des éléments très importants de ces graines. Le Butyrosperme de Mungo-Park est l'arbre à beurre ou Karité de l'Afrique occidentale française. Ses graines contiennent de 40 à 50 pour 100 d'une matière grasse, blanche, solide à la température des régions tropicales $\left(37^{\circ}\right)$, et qui paraît appelée à un bel avenir quand les moyens de transport auront acquis un développement suffisant en Afrique. Il est importé en Angleterre quelques milliers de tonnes dece beurre qui est épuré par des procédés analogues à ceux employés pour le coprah et sert aux mêmes usages que la végétaline. Dautres arbres, comme les Bassia de l'Inde et de l'Afrique, fournissent des matières grasses analogues.

Le suif végétal de Bornéo, importé de Singapore en Angleterre, provient des graines de certaines Diptérocarpées, notamment les Hopea. La forme cylindrique du produit commercial est due à ce que le corps gras est, après expression à chaud, coulé dans des bambous. On retire un corps analogue des graines d'une Euphorbiacée, l'Arbre à suif (Sapium sebiferum), qui est le Cay-soi de l'Indochine; on en fait des bougies très employées en ExtrêmeOrient. Introduites dans le commerce européen, ces graines servent dans la fabrication des bougies et des savons.

L'Arbre à chandelle ou Cay-Cay $\left(f_{i g} .278\right)$ est une Simarubacée (Irvingia Olivieri) formant des peuplements en Cochinchine et au Cambodge. L'Irvingie du Gabon ou Oba, dont nous avons déjà parlé (p. 188), fournit le beurre de O’Dika.

Cires végétales. - Les cérosies ou cires végétales, localisées dans la membrane externe des cellules épidermiques de la tige, des feuilles et des fruits, sont très répandues; elles rendent plus complète l'imperméabilité de l'épiderme. Chez quelques plantes, cette cire est assez abondante pour donner lieu à une exploitation qui devient chaque année plus importante.

Le Céroxylon des Andes est un superbe Palmier de Colombie et du Pérou. La récolte de la cire se fait par de légers raclages périodiques de l'écorce, en commençant par le sommet de la tige qui atteint 60 mètres de haut et qui ressemble, ainsi qu'on l'a dit élégamment, "à une colonne d'ivoire cerclée d'anneaux bruns". Chaque arbre fournit, par récolte, 8 à 12 kilogrammes d'une cire, dite cera de Palma, qui, mélangée au suif, sert à fabriquer des bougies. Les jeunes feuilles d'un autre Palmier, le Copernicia à cire (cerifera), des forêts du Brésil, présentent, à la partie inférieure de leur limbe, de petites houppes de cire longues d'un demi-centimètre. Une dessiccation des feuilles au soleil, suivie d'un frottement énergique, permet de recueillir la cire dite de Carnauba, qui est sèche et cassante et qu'on emploie en mélange avec la cire d'abeille.

L'écorce de la Canne à sucre, traitée par l'eau bouillante, donne 


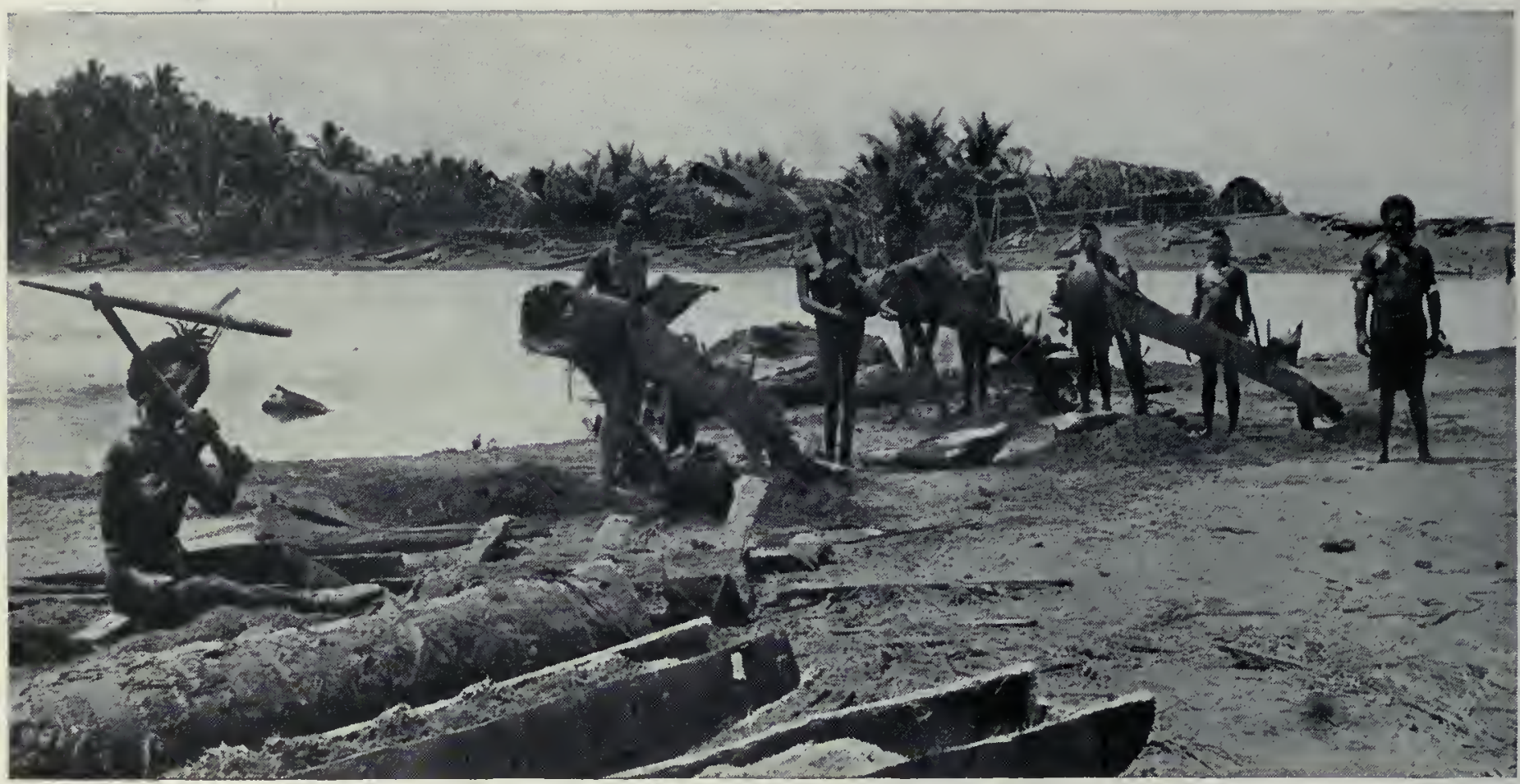

Préparation du sagou, aux Nouvelles-Hébrides.

\section{LES PLANTES FÉCULENTES}

L'amidon est une des matières les plus abondamment produites par les végétaux. Formé dans la feuille, il s'accumule dans les organes souterrains, les fruits, les graines ou même les tiges. Les graines des céréales, les légumes farineux doivent une grande partie de leur pouvoir nutritif à l'abondance de cet hydrate de carbone. Deux importantes industries, l'amidonnerie et la féculerie, s'occupent d'extraire les matières amylacées des plantes. Amidon et fécule sont des produits identiques; cependant le nom d'amidon est plus particulièrement réservé aux substances amylacées provenant des graines; le nom de fécule, à celles qui sont retirées des organes souterrains.

Amidonnerie. - L'amidonnerie a pour matières premières les farines des céréales et principalement du blé, et se propose d'en isoler deux matières utiles : l'amidon ( $f i g .282$ ) et le gluten. La farine est soumise à un malaxage énergique sous un courant d'eau, dans une amidonnière, double caisse allongée à fonds demi-cylindriques en fine toile métallique; un cylindre cannelé en bois tourne dans chaque caisse et malaxe la farine réduite en pâte. L'eau entraîne les grains d'amidon dans une auge à travers la toile métallique et le gluten reste dans les caisses. L'amidon est lavé, égoutté, séché à l'étuve; il servira à préparer l'empois des blanchisseuses; on l'utilise aussi en confiserie, en pharmacic. Quant au gluten, après avoir été mélangé à de la farine de blés durs, il formera des pâtes alimentaires: nouilles, vermicelle, etc.

On utilise aussi en amidonnerie les farines avariées; le gluten peut avoir été décomposé par la fermentation; l'amidon est intact. Dans ce cas, on achève de détruire le gluten restant : on ajoute à la farine de l'eau et un peu de levure ou d'eau sûre provenant d'une opération précédente. La fermentation dure de quinze jours à un mois; elle dégage des produits malodorants et très insalubres; la matière est alors jetée sur un tamis dans lequel des palettes l'écrasent; un filet d'eau entraîne les grains d'amidon.

On extrait aussi l'amidon du maîs et du riz. La poudre de riz employée pour la toilette est l'amidon très fin de cette graine.
Féculerie. - La pomme de terre est la base de l"industrie féculière, qui a pris naissance vers le milieu du XVIIt siècle, et qui est très importante en Allemagne, en Hollande, aux ÉtatsUnis, au Japon. En France, cette industrie est peu développée; elle est localisée surtout dans l'Oise, les Vosges et la Haute-Saône. On connaît aujourd'hui des variétés de pommes de terre, à la fois très riches en fécule et à grand rendement : Richter's imperator, Géante bleue, Farineuse rouge, etc. Dans notre pays, les tubercules sont vendus au poids et le cultivateur recherche surtout les grands rendements; les féculiers allemands, au contraire, les achètent d'après leur richesse en fécule, ce qui amène la création et la culture de variétés de plus en plus riches.

Les pommes de terre subissent d'abord un lavage très soigné, comprenant débourbage, nettoyage et finissage, qui se font dans trois appareils semblables, composés chacun d'une auge semi-cylindrique en tôle perforée, dans laquelle tournent des tiges garnies de boules et où circule un courant d'eau; des chaînes à godets prennent les pommes de terre pour les conduire dans les laveurs successifs.

Vient ensuite le râpage, qui a lieu dans des tambours métalliques garnis sur leur pourtour de minces lames de scie en acier qui réduisent les tubercules en une bouillie très fine. Ce broyage doit être assez parfait pour rompre les membranes cellulaires et rendre libres les grains de fécule. Une pompe amène la râpure dans de longs tamis en toile métallique tournant dans des auges; un courant d'eau sous pression chasse la fécule à travers les mailles de la toile, la séparant ainsi des matières cellulosiques. Cette eau féculente parcourt divers tamis successifs et vient s'arrêter sur des plans inclinés ou tables de dépôt. On l'épure par divers procédés, puis on l'égoutte et on la sèche à l'étuve; quant au résidu cellulosique mélangé de fécule, il sert de fourrage ou est transformé en glucose.

La fécule a des usages en cuisine et en pâtisserie, dans l'industrie textile pour les apprêts, en pharmacie, en parfumerie, dans la fabrication des cirages. Par des transformations chimiques, on en retire des produits importants : dextrines et combinaisons avec des radicaux acideś, à l'état de nitrates, acétates, formiates, pour les apprêts; on en fabrique du glucose et de l'alcool 


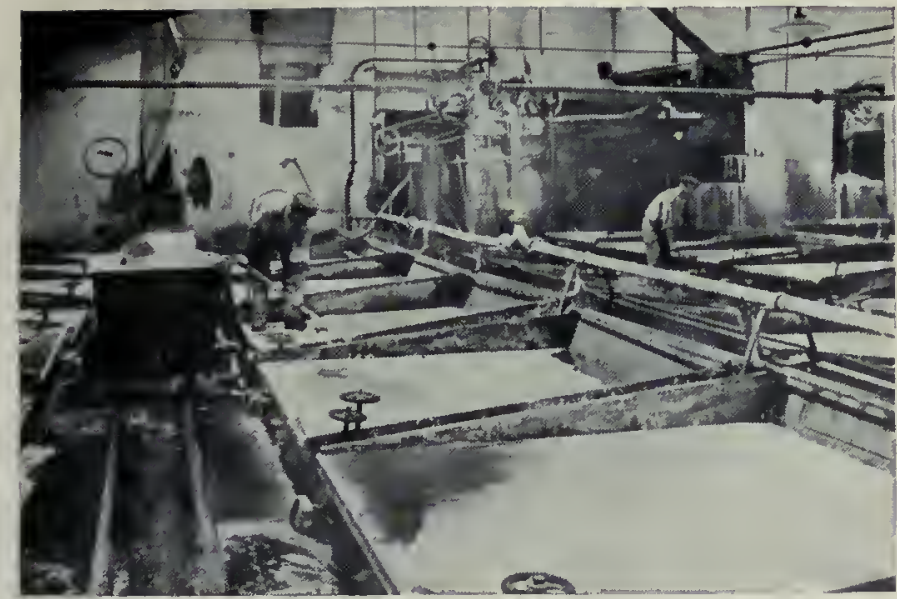

Tables de dépôt de la fécule de pomme de terre.

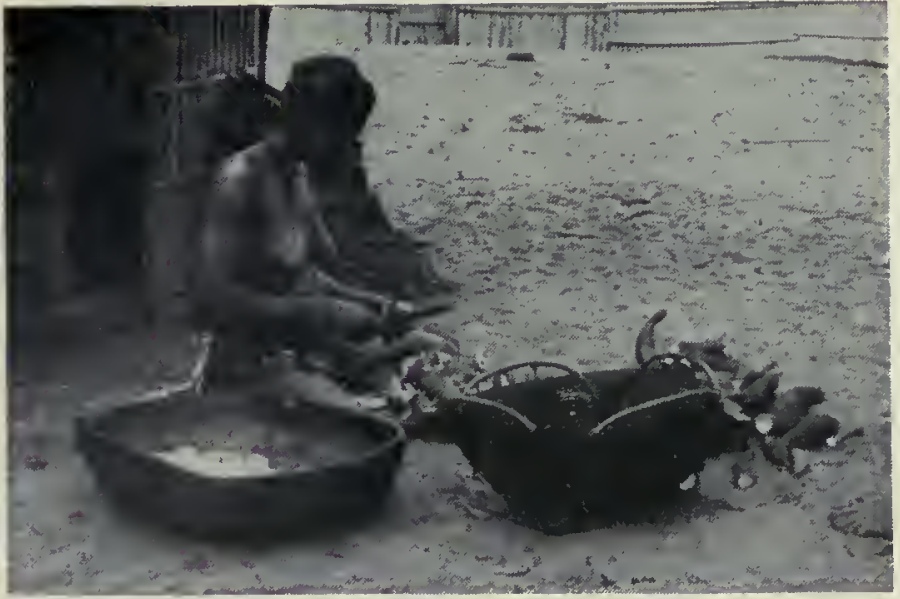

Préparation du manioc (Còte d'Ivoire).
Fécules exotiques. - Le Manioc est un arbrisseau du Brésil, cultivé aujourd'hui dans tous les pays tropicaux. Quelques-unes de ses racines deviennent tubéreuses, allongées, charnues, riches en fécule et en latex. Certains types ou variétés ( $M a-$ nihot aipi) fournissent des racines directement comestibles, après cuisson dans l'eau. D'autres, comme le Manihot utilissima, contiennent des produits isolés dans des cellules distinctes et qui réagissent au moment du râpage en donnant un poison, la manihotoxine, qui agit comme l'acide cyanhydrique; aussi leurs racines doivent-elles subir, après le râpage, une compression avec de l'eau qui leur fait perdre leur toxicité.

Dans les pays d'origine, pour l'alimentation journalière, les tubercules, écorcés et lavés, sont râpés sur une planche en bois garnie de pointes de fer. On laisse la pulpe fermenter pendant vingt-quatre heures pour détruire une partie des principes toxigues, puis on l'égoutte; on la presse énergiquement et on la fait sécher au soleil. Cette farine grossière est la moussache; par légère torréfaction, elle donne des grains durs, pareils à de la semoule : ils constituent le couac, qui sert de pain; la cassave est du couac finement broyé, mis en pâte, et transformé en galettes minces et dures sur des tôles chauffées.

Au Brésil, à Singapour, au Mozambique, à la Réunion, au Tonkin, les racines sont traitées mécaniquement, comme la pomme de terre en Europe, pour en extraire une fécule fine et blanche, presque entièrement transformée en topioca. La fécule, délayée en pâte épaisse, passe dans un granulateur, sorte de bassin à fond percé de trous, et tombe en gouttes sur une plaque de tôle chauffée aux environs de $100^{\circ}$; elle s'y solidifie en grumeaux. Le tapioca est souvent falsifié avec de la fécule de pomme de terre,

Les Sagoutiers ou Metroxylon (fig. 281) sont des Palmiers qui croissent dans les terrains recouverts d'eau saumâtre, en Polynésie, Malaisie, dans la presqu'île de Malacca et au Siam. Leur tige, qui a atteint 8 à 10 mètres de haut et 1 mètre et plus de diamètre, renferme, dans sa partie centrale médullaire, 300 à 400 kilogrammes d'une matière féculente qui est le sagou; il est contenu dans des cellules adhérentes à des fibres lignifiées très' fines. Lorsque la base des feuilles se recouvre d'une poussière jaunâtre, l'arbre est rempli de farine; on l'abat; on le fend longitudinalement en copeaux et on pilonne la matière; les fibres lignifiées sont enlevées à la main; on passe la farine sur des tamis en fibres de feuilles de Sagoutier; elle est délayée dans l'eau, décantée et agglo-

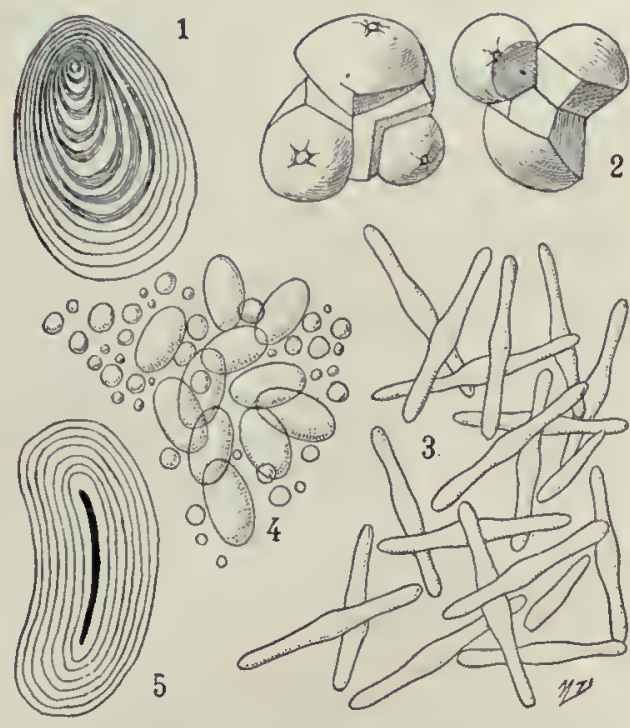

Fig. 282. - Amidon de différentes plantes. 1. Grain d'amidon de la pomme de terre. - 2. Fécule de sagou. - 3. Amidon d'euphorbe en bâtonnets. 4. Amidon de blé. - 5. Grain d'amidon du haricot. mérée en gros rouleaux d'une longue conservation qui forment la base de l'alimentation. Le sagou perlé s'obtient comme le tapioca. II constitue un très riche aliment, avec ses 63 pour 100 de matières hydrocarbonées et ses 6,5 pour 100 de matières azotées. Singapour exporte annuellement de grandes quantités de farine de sagou, dont on fait des potages. La tige du Raphia Ruffiade Madagascar, celle des Mauritia en Amérique, celles du Corypha, des Arenga, celle des Cycadées (Asie et Océanie) et leurs graines renferment aussi du sagou

L'arrow-root est une fécule plus riche encore que la précédente en principes hydrocarbonés, mais plus pauvre en azote; elle est de digestion facile et employée de plus en plus pour l'alimentation des malades et des enfants. On la retire des parties souterraines de diverses plantes et surtout du $\mathrm{Ma}$ ranto arundinocea, cultivé aux Antilles, au Brésil, en Afrique, en Australie. Les Bermudes sont un centre très important de cette culture. Les rhizomes d'un an sont arrachés, lavés, râpés; on tamise la pulpe, qu'on malaxe dans l'eau; après repos, on décante et on sèche à la turbine. Les rhizomes du Balisier comestible (Canna edulis), ceux du Balisier à deux couleurs (C. discolor), cultivés en Perse, aux Antilles, en Australie, fournissent un arrow-rot, dit toulema canna-root.

Le solep, extrait des tubercules de divers Orchis de Perse et d'Asie Mineure, est une fécule associée à un principe gommeux spécial; il a les mêmes usages que l'arrow-root, mais est moins répandu. Le Tavolo de Madagascar est le tubercule riche en amidon d'une Amaryllidacée (Tacca pinnatifido).

Le taro, qui assure presque exclusivement en Océanie la nourriture des indigènes, est une Aroidée, la Colocase comestible. Son rhizome, qui pèse 1 à 2 kilogrammes, est lavé, puis cuit dans l'eau bouillante, et enfin écrasé sous une meule à main. La farine est pétrie dans l'eau, transformée en pâte et mise à fermenter. Cuisson et fermentation font ici, comme pour le Manioc, disparaître un principe âcre et vénéneux. Après la fermentation, la farine est mangée sous forme de bouillie plus ou moins épaisse. Depuis l'occupation des Hawaï par les Américains, les rhizomes sont traités mécaniquement, et la fécule de taro se vend couramment aux Etats-Unis. Plusieurs autres Aroidées (p. 135) fournissent aussi du taro ou d'autres fécules alimentaires.

La coquintay ou Stanley meal est une farine extraite de la banane (farine de quinta) qui a rendu les plus grands services à l'expédition de Stanley au centre de la grande sylve atricaine. 


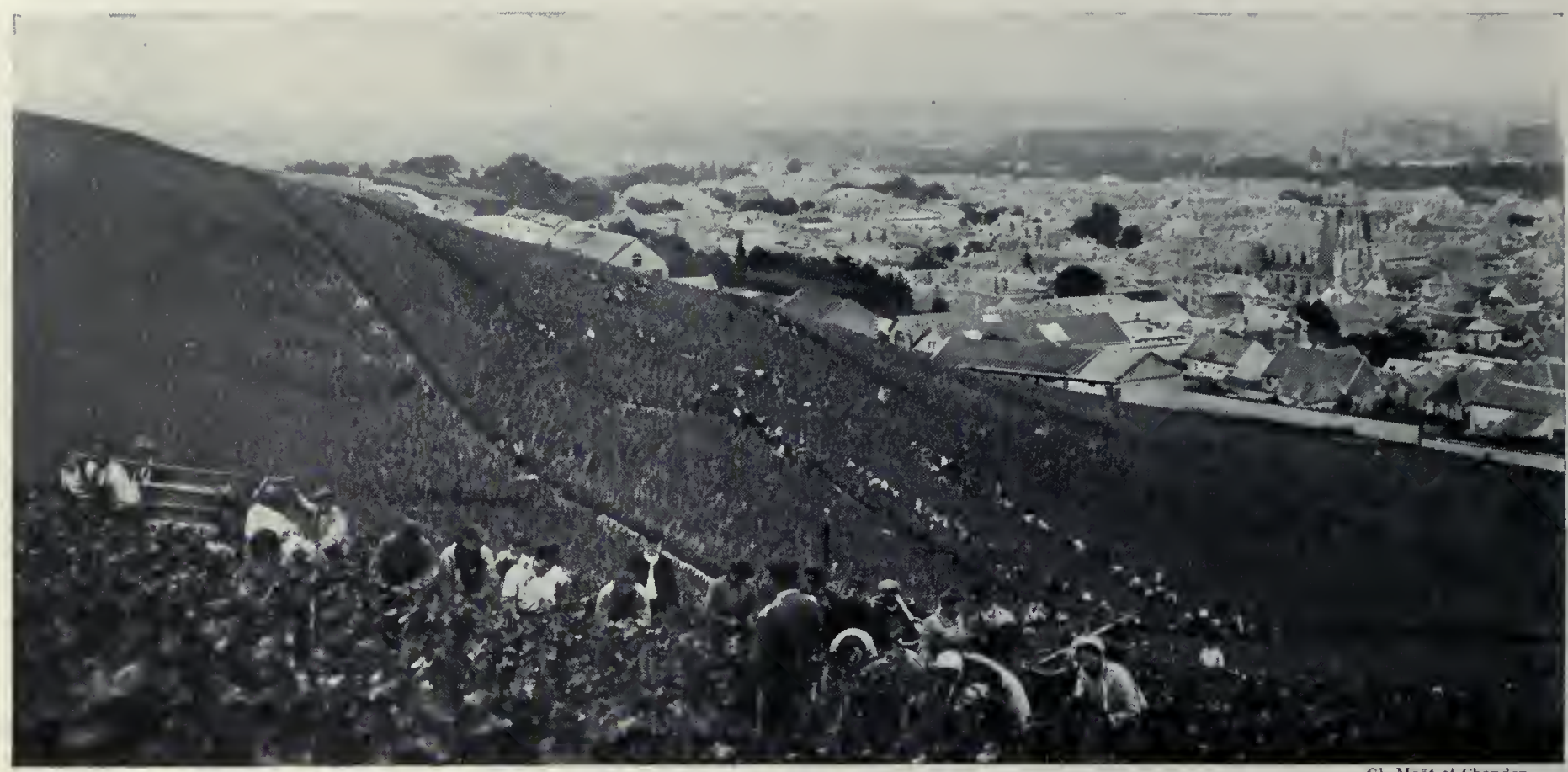

CUEILLETTE DU RAISIN DANS UN VIGNOBLE CHAMPENOIS.

Cl. Moẻt et Chandon.

\section{III. - PLANTES POUR BOISSONS}

L'eau pure est la boisson naturelle; c'est la seule qui soit indispensable, mais la civilisation a répandu l'usage de boissons artificielles innombrables, dont les éléments sont fournis par les végétaux et dont quelques-unes donnent lieu à des industries de premier ordre. On peut diviser les boissons artificielles en trois catégories : les boissons alcooliques, pour lesquelles l'humanité possède une prédilection marquée; les boissons alcaloïdiques, comme les infusions excitantes de café, thé, maté ; enfin les boissons sucrées, renfermant peu ou pas d'alcool. mais du sucre, des acides organiques et des principes aromatiques.

\section{LES BOISSONS ALCOOLTQUES}

Fermentation alcoolique. - Les boissons alcooliques sont dues à des Champignons microscopiques, les Levures ( $f$ g. 284), qui, plongées au sein d'un liquide sucré, le décomposent pour vivre en alcool et en acide carbonique. Les liquides qu on peut soumettre à la fermentation alcoolique sont : $1^{\circ}$ le jus des fruits mûrs, riche en glucose : raisin, poire, pomme, cerise, etc.; $2^{\circ}$ les sucs de la racine de Betterave, de la Canne à sucre, la sève sucrée des Erables, Bambous, Palmiers, etc.; mais le saccharose ou sucre ordi-

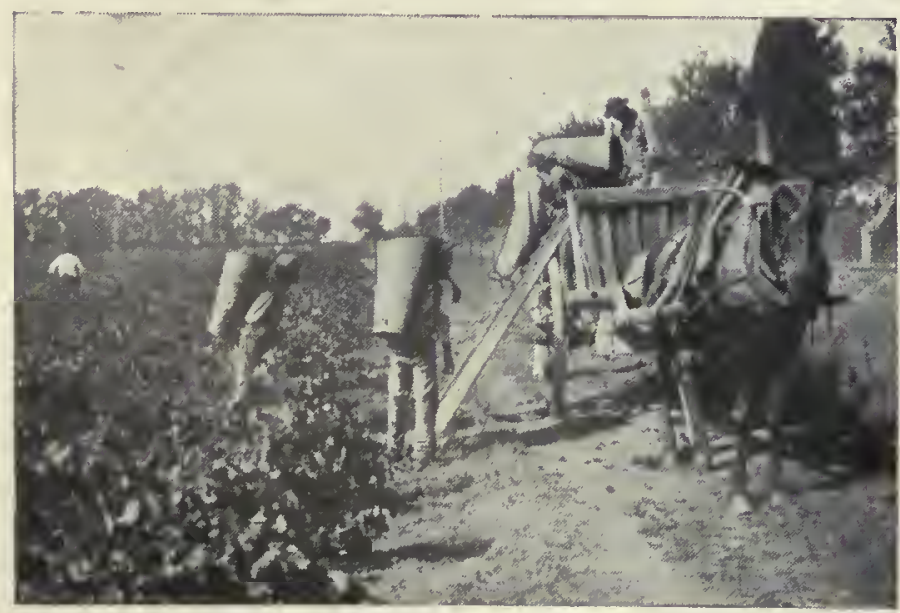

Vendanges dans le département du Var. naire que renferment ces liquides doit, avant de fermenter, être transformé en glucose par une diastase, l'invertine, que sécrètent certaines Levures; $3^{\circ}$ enfin, on peut, par les acides ou la diastase du malt d'orge, transformer en glucose l'amidon des céréales, de la pomme de terre ou de toute plante féculente, puis provoquer par la Levure la fermentation alcoolique du jus sucré obtenu. On utilise aujourd'hui en distillerie des Champignons inférieurs de la famille des Mucorinées, l'Amylomyces de Roux (fig. 283), découvert par le $D^{r}$ Calmette en Indochine, et divers Mucors qui possèdent la propriété de saccharifier l'amidon et de le transformer directement en alcool. En résumé, toute plante contenant du sucre ou de l'amidon peut fournir une boisson fermentée, et il existe de par le monde un choix varié de ces dernières. Légèrement excitantes, saines et agréables à dose modérée, ces boissons sont très nuisibles à dose plus forte, surtout quand leur teneur en alcool a été rendue considérable par la distillation.

Culture de la Vigne. - La Vigne, a-t-on dit, a été choisie et cultivée par l'homme dès les temps les plus reculés, comme lui apportant le principal soulagement de ses misères. A qui boit modérément le jus fermenté de son fruit, elle donne la joie et la force, mais elle rend faible et stupide celui qui en abuse. II n'est pas paradoxal d'attribuer à l'usage séculaire du bon vin certains des caractères de notre race, comme la gaieté, la vivacité de l'esprit.

Il y a encore peu d'années, l'opinion générale faisait venir d'Asie la Vigne, d'où les Phéniciens l'auraient introduite en Grèce, en Sicile, en Italie et sur le territoire de Marseille. Les récentes découvertes géologiques ont modifié cette opinion : la Vigne existait en France bien avant l'apparition de

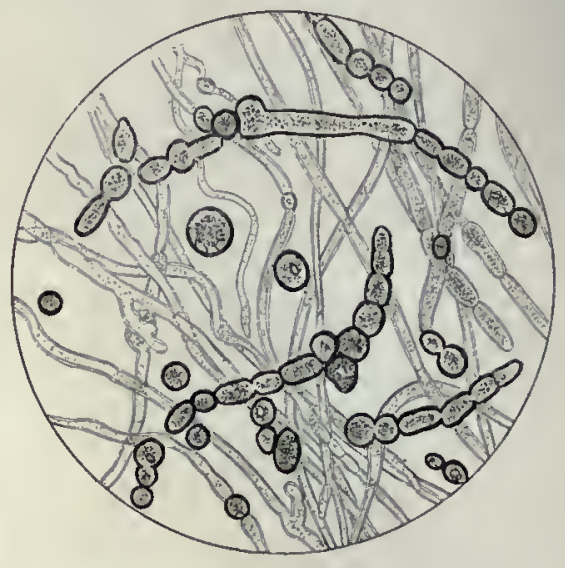

Fig. 283. - Mycétium d'Amytomyces. 


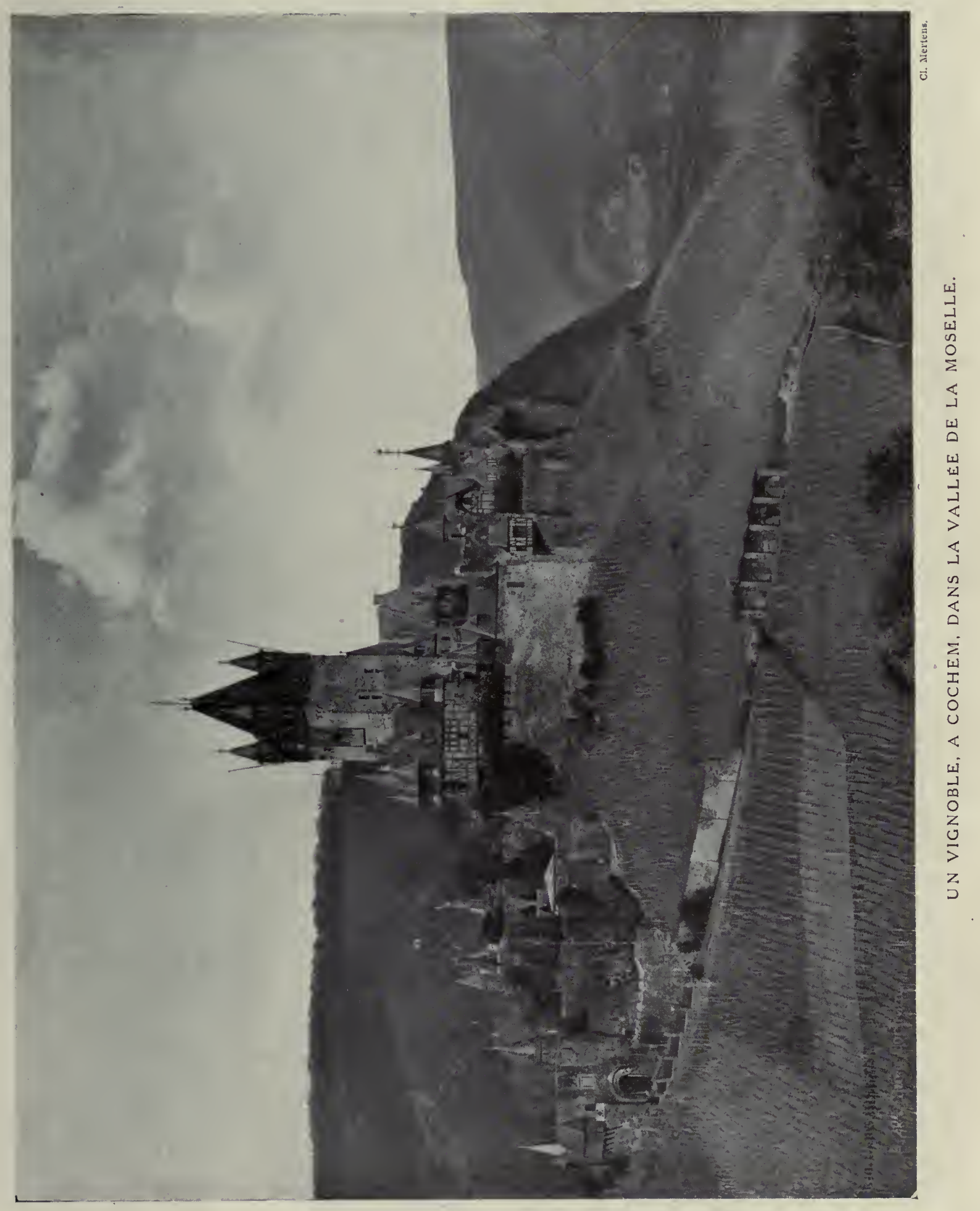





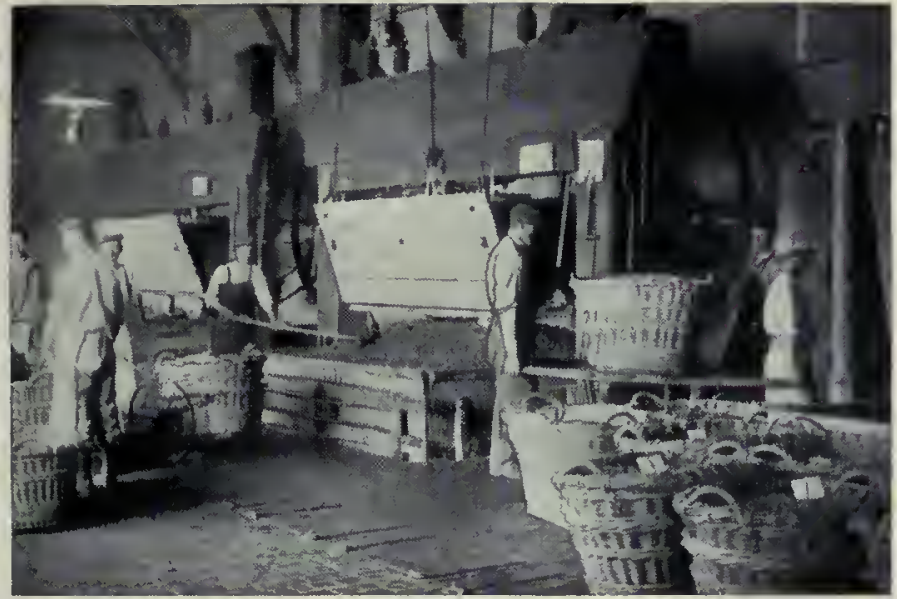

Le pressurage en Champagne.

l'homme. Dans les formations éocènes de Sézanne, en Champagne, on a trouvé les débris d'une Vigne qui se rapproche beaucoup des Vignes américaines, et notamment de l'espèce riparia; le miocène supérieur fournit en différents points une Vigne très voisine de la Vigne vinitère, c'est-à-dire notre Vigne cultivée; enfin, il est impossible de révoquer en doute l'existence, au quaternaire, sur le sol français, de cette dernière, puisquion en a trouvé des pépins dans les restes des habitations lacustres.

Par le semis et l'hybridation, notre espèce européenne a donné une foule de variétés ou cépages. Citons, parmi les admirables cépages Irançais, comme Vignes rouges : aramon, cabernet, corbeau, grenache, merlot, picpoul, pinot, teinturier; comme Vignes blanches : chasselas, colombar, folle blanche, jurançon, etc.

La Vigne est certainement la plante cultivée qui a le plus d’ennemis. Bornons-nous à citer, parmi les altérations provenant des conditions climatériques: la gelée, le grillage des feuilles,

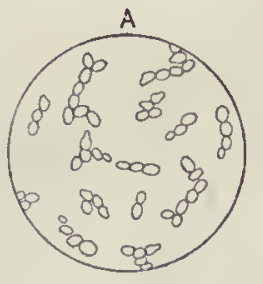

$A$, de bière $\left(0^{\mathrm{mm}}, 008\right) ; B_{\mathrm{r}}$ de vin $\left(0^{\mathrm{mm}}, 006\right)$.

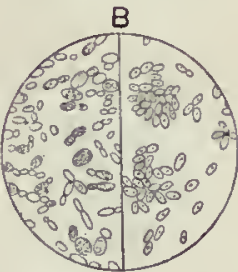

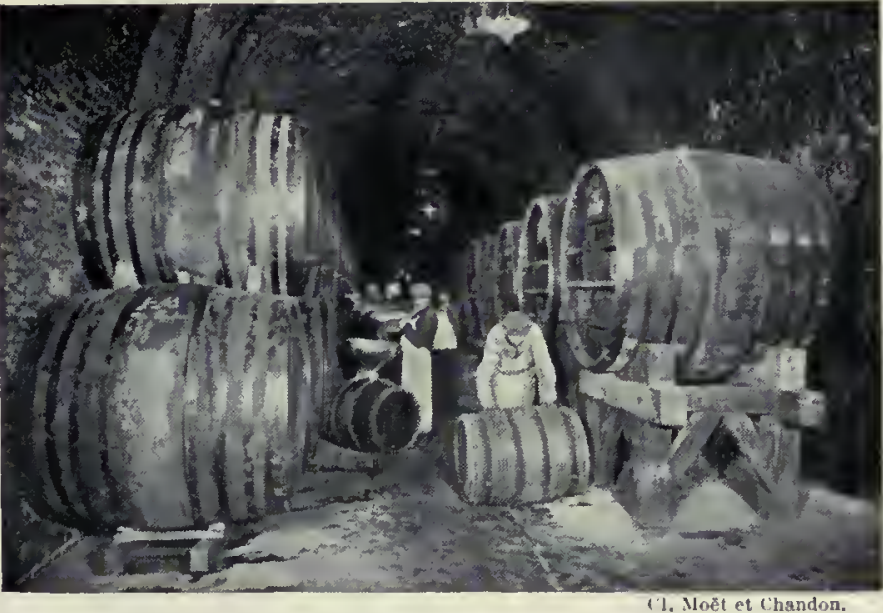

Le soutirage en Champagne.

Vinification. - Le vin rouge est obtenu par la fermentation du grain complet de raisin rouge avec sa peau et ses pépins. Il est foulé ou jeté tout entier dans de grandes cuves de bois ou de béton; l'alcool, au fur et à mesure de sa formation, dissout les matières colorantes. Le vin blanc se prépare indifféremment, soit avec du raisin blanc, soit avec du raisin ronge. Le fruit est écrasé, puis soumis à l'action du pressoir; c'est le jus seul qui fermente. Les rai-

Fig. 284. - Levures.

sins rouges très colorés, traités ainsi, donnent parfois cependant un vin légèrement rosé que lon décolore par le gaz sulfureux.

La fermentation du raisin est due à la Levure elliptique (fig. 284, B), qui existe dans l'air et sur la peau des raisins, à l'état de germes. Si la température est élevée au moment de la vendange, la fermentation du jus s'établit vite et devient très active au bout d'un jour et demi; elle reste tumultueuse de trois à dix jours, suivant la température extérieure: on dit que le vin bout. La masse du moût s'échauffe jusquà $30^{\circ}$ à $35^{\circ}$; puis le dégagement la chlorose, la coulure, le millerandage, la pourriture du raisin; parmi les maladies cryptogamiques : looidium, le mildiou, l'anthracnose, le black-rot, la fumagine, la brunissure, le pourridié; on combat la plupart dentre elles par le soufrage préventif (oïdium) ou l'application de bouillies cupriques; parmi les insectes: l'eumolpe, dit aussi écrivain ou gribouri (Adoxus), la cochylis, l'altise, les guêpes, la pyrale, et surtout le phylloxéra, sorte de puceron originaire de l'Ámérique du Nord, qui, de 1865 à 1880 , a ravagé et presque anéanti tout le vignoble français, quiil a fallu depuis reconstituer à grands frais. On y est parvenu en greffant nos cépages sur des Vignes américaines, dont les fines racines ont une écorce assez épaisse pour résister aux attaques du phylloxéra, notamment les Vitis riparia, rupestris, cordifolia, etc.

Les limites septentrionales de végétation de la Vigne en Europe sont $\mathrm{du} 47^{\circ}$ degré de latitude nord en France jusquau $52^{\circ}$ degré en Allemagne, en des points privilégiés. Une température estivale moyenne d'environ $20^{\circ}$ est nécessaire à la maturation de son fruit; elle supporte aisément au repos des froids de - $15^{\circ}$, mais au début de sa végétation elle est très sensible aux gelées. Les climats du type méditerranéen conviennent à sa culture, mais c'est dans les régions un peu humides et moins chaudes, comme le Bordelais, la Bourgogne, la Champagne, que ses produits arrivent à la perfection, par l'heureuse combinaison du climat, du sol, du cépage et des bons soins du viticulteur.

Les sols calcaires et perméables, en pente, avec exposition ensoleillée, lui conviennent surtout. La Vigne, dit-on, n'aime que l'ombre du vigneron. La Vigne est plantée en ligne dans un sol profondément défoncé. On la taille au printemps; on la pince, on l'ébourgeonne et on l'épampre en été; on la bine au moins deux fois par an.

La vendange a lieu du commencement du mois d'août à la fin d'octobre, selon la latitude, l'exposition, les conditions climatériques. Le raisin, coupé à la serpette, au sécateur ou aux ciseaux, est recueilli dans des paniers ou des baquets dont le contenu est versé dans une hotte. Celle-ci est vidée dans des récipients plus grands où l'on commence à écraser le raisin avec un grand pilon. Le moût est alors porté au cellier pour y subir la vinification. d'acide carbonique cesse peu à peu et le sucre disparaít presque entièrement; il est remplacé par de l'alcool. Une seconde fermentation, très lente, se continue pendant six mois environ; le sucre restant se transforme en alcool. Mais, plus tard, une partie de l'alcool s'oxyde, une autre se combine avec les acides pour former vin s'affirment; il devient, selon l'expression d'Armand Gautier, "l'un des produits les plus parfaits et les plus délicats de l"industrie humaine $n$, puis son développement continuant, comme tous les liquides vivants, il subit la décrépitude et ses qualités disparaissent.

Le vin est sujet à des altérations profondes, dites maladies : pousse, amertume, graisse, etc. Pasteur a montré qu'elles sont

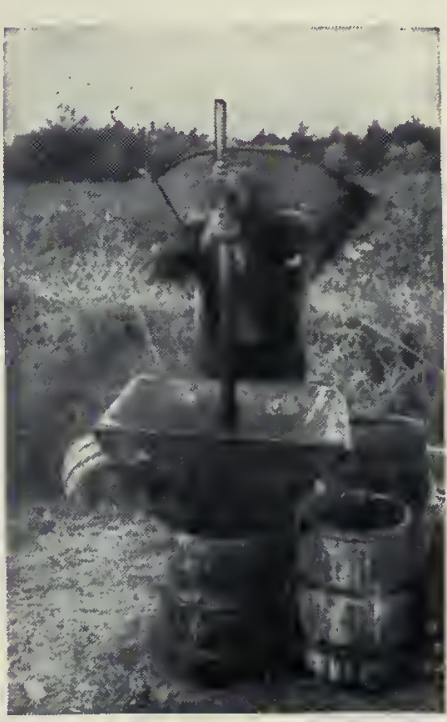

Foulage dans les Charentes. dues à des ferments parasites qu'on détruit, avant qu ils puissent nuire, en chauffant les vins pendant quelques minutes à une température de $55^{\circ}$ à $65^{\circ}$ : c'est la pasteurisation, trop peu employée encore. La vinification a peu profité jusqu ici des travaux de Pasteur sur les ferments; on fait encore le vin aujourd'hui comme au temps de Noé. Cependant, on sait qu'il existe de nombreuses races de Levures dont les unes accomplissent un bon travail, tandis que d'autres donnent des produits de saveur désagréable. Or, le vigneron ne choisit pas : il introduit en masse dans sa cuve, avec le moût, toutes les Levures et les Microbes qu il contient. Des essais intéressants de vinification rationnelle ont été tentés, notamment par Rodes éthers qui donnent le bouquet. Avec le temps, les qualités du 


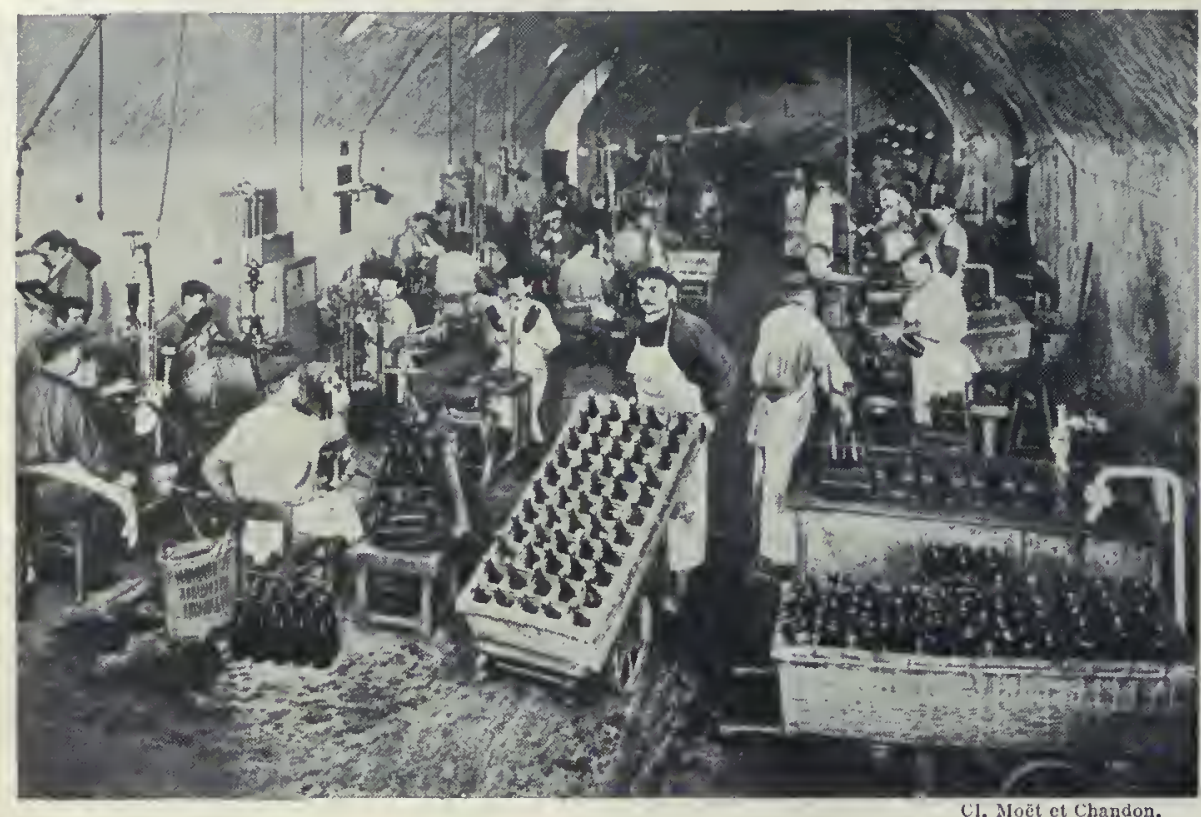

Manipulations diverses du vin de Champagne.

senstiehl, en Tunisie. Il stérilise le moût à $50^{\circ}$, en présence de l'acide carbonique, puis il l'ensemence de Levures pures sélectionnées provenant de crus renommés; il obtient des vins plus alcooliques, se conservant mieux, et dont le bouquet se rapproche de celui du vin d'où proviennent les Levures employées.

Les vins liquoreux, à la fois doux et alcooliques, des pays chauds, comme Madère, Malaga, Porto, etc., sont obtenus par la fermentation de raisins très sucrés; on y ajoute ensuite une dose d'alcool qui porte leur titre à $20^{\circ}$. Le midi de la France produit en quantité des vins d'imitation, reproduisant à peu près les caractères appréciés dans ces vins célèbres.

Vins mousseux. - La préparation des vins mousseux, telle qu'elle se pratique en Champagne, date seulement de la fin du $\mathrm{XVIt}^{\mathrm{e}}$ siècle. Les excellents vins blancs de cette région, obtenus avec des raisins rouges, subissent des recoupages de crus, spéciaux à chaque maison. Chacun de ces mélanges ou " cuvées ", réunissant le maximum de qualités, est mis en bouteilles au printemps, avec addition, sil est nécessaire, d'une petite quantité de sucre candi. Soigneusement bouchées et ficelées, les bouteilles sont couchées dans des caves immenses, comprenant des kilomètres de galeries creusées à même la craie et dont la température se maintient uniformément à $10^{\circ}$. Le sucre se transforme en alcool et le gaz carbonique ne peut s'échapper.

Pendant les trois années que dure cette fermentation, un dépôt très adhérent se forme sur les parois des bouteilles; on le fait disparaître par l'électrisation, opération qui consiste à tapoter le verre avec de petits marteaux mus électriquement. Les bouteilles sont mises sur pointe, goulot en bas, dans des casiers où chaque jour, pendant deux à trois mois, un ouvrier vient les remuer; le

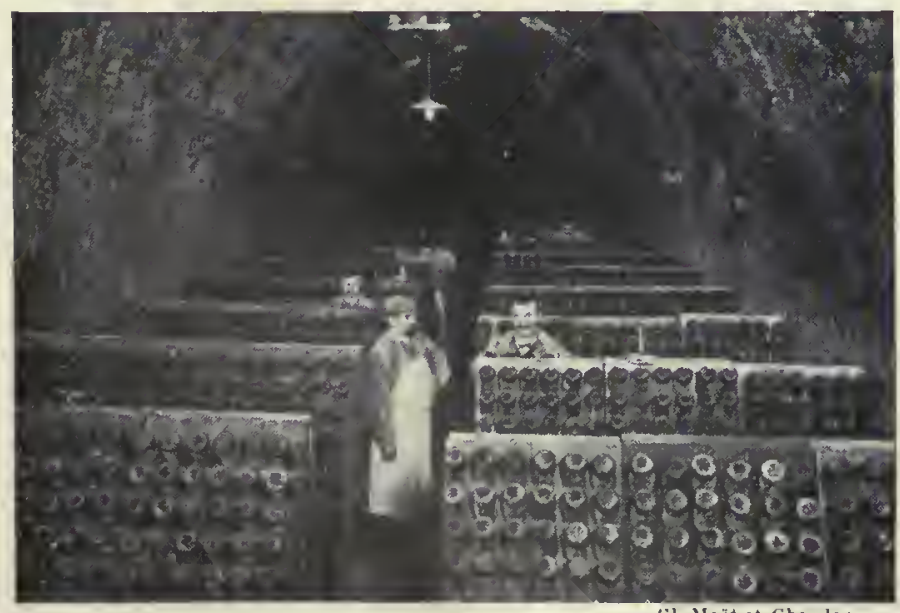

Bouteilles sur pupitres pour le remuage. dépôt descend sur le bouchon, d'où le chasse un dégorgeage rapide. $\mathrm{Ce}$ vin dégorgé est le champagne brut, qui ne contient plus de sucre. On y ajoute une liqueur sucrée, dite liqueur d'expédition, dont la composition est variable: les Anglais et les Américains aiment le champagne très peu sucré (très sec); les Français, beaucoup plus doux (demi-sec). Les vins dits champanisés subissent des traitements analogues, mais très simplifiés; ils sont gazéifiés à la façon des eaux gazeuses artificielles.

Cidre; poiré. - En Normandie, en Bretagne, en Picardie, le raisin ne mûrit pas : on boit du cidre. La " boisson d'or " est originaire de la basse Normandie, où l'on signale son emploi dès le $\mathrm{XtI}^{\mathrm{e}}$ siècle, en remplacement de la cervoise. Pour faire de bon cidre, il est nécessaire d'employer trois sortes de pommes : acides ou de première saison, donnant du piquant; douces, riches en sucre ou de deuxième saison; amères, plus tardives ou de troisième saison, qui assurent la conservation du cidre, conservation toute relative d'ailleurs, ne dépassant jamais trois à quatre ans.

Dans nos vergers normands, les meilleures variétés de pommes appartenant à ces trois groupes sont toujours mélangées. Récoltés de septembre à novembre, les fruits achèvent de mûrir sous des hangars. Après triage et essuyage, on les broie dans un moulin analogue au hachepaille ( $f$ ig. 285) et on laisse brunir la pulpe à l'air en la pelletant plusieurs fois; le lendemain, on la presse, et la fermentation du liquide obtenu donnera le cidre pur jus, qui peut titrer jusqu'à $7^{\circ}$ à $8^{\circ}$ d'alcool. Le marc, qui contient encore de 20 à 60 pour 100 de jus après cette première expression, est additionné d'eau pure et pressé de nouveau. La fermentation a lieu en tonneaux dans des caves à $14^{\circ}$. Au bout de deux mois, le cidre est fait; on le soutire, il est encore très sucré. Si on le met alors en bouteilles, ce sucre fermente et donne du gaz carbonique qui rend le cidre mousseux. En tonneau, la disparition du sucre résiduel exige environ trois mois; le cidre est alors paré.

Le cidre est une boisson agréable, riche en acides organiques, en tanin, en sels minéraux et en matières sucrées. Il existe aujourd'hui en France des cidreries industrielles où des méthodes perfectionnées sont employées.

Le poiré ou cidre de poires, plus alcoolique que le cidre de pommes et d'une conservation encore plus difficile, est fabriqué dans les mêmes régions et par les mêmes procédés.

Boissons de fruits. - Tous les fruits sont susceptibles de donner des boissons fermentées; c'est ainsi qu'en France on utilise en plusieurs contrées le cidre de cormes et la piquette de prunelles. Les pays méridionaux connaissent les vins de figues, de dattes, de caroubes, etc. La fabrication des boissons de fruits, purement ménagère en France, est devenue industrielle en Saxe, en Thuringe, en Silésie; on y prépare des vins de fraise, framboise, cerise, myrtille, groseille, mûre des haies, qui sont vendus au naturel ou après avoir été rendus mousseux. Ces liquides sont très sains, d'un bel aspect et d'un goût délicat.

Vins de sève. - Beaucoup de végétaux renferment, à une certaine phase de leur développement, une sève sucrée fermentescible capable de fournir des boissons enivrantes. Dans une grande partie de l'Asie, on connait le vin de Bambou, obtenu en faisant fermenter de jeunes feuilles de cette plante, écrasées avec un peu de riz cuit. Le lagmi, vin de Dattier des Arabes du Sud, sobtient en pratiquant une incision au-dessous des feuilles et en laissant fermenter la sève; la sangara des nègres du Soudan est la sève fermentée du Palmier à vin ou Borassus. Le Palmier à huile, le Cocotier, etc., fournissent des vins de palme, pétillants, sucrés, alcooliques, se conservant peu. Les noms de toddy (en anglais), callou (en tamoul), harafa à Madagascar, koundou-hari à Tombonctou, etc., sont attribués à des liqueurs fermentées diverses, provenant de fruits ou de sève.

Le fameux pulqué des Mexicains se retire de plusieurs espèces d'Agaves, et surtout de l'Agave Salmania, croissant à l'état sauvage ou cultivés. Au premier symptôme annonçant sa floraison, chaque plante est marquée, puis surveillée avec soin. On pratique le pince- 
ment du tronc, ce qui détruit les bractées et empêche la floraison; la sève sucrée s'accumule dans le tronc et le gonfle; on y creuse alors un trou cylindrique, dans lequel on recueille la sève deux fois par jour avec une sorte de pipette ou ococote, composée d'une courge dont l'extrémité effilée plonge dans le liquide ou agua de miel, tandis qu'un orifice percé à l'extrémité opposée sert à l'aspirer. Quand la courge est pleine, on la bouche avec une coiffe de corne et on vide son contenu dans un sac en peau de porc. On avive la plaie de temps à autre. L'exploitation dure de cing à douze mois, puis la plante meurt. La fermentation se fait dans des récipients de 500 litres ou tinas, constitués par des peaux cousues que soutiennent des cadres de bois. Elle est provoquée par l'addition de sève déjà en fermentation ou par l'ensemencement d'un ferment spécial, ou semilla, conservé sous forme de granules ayant l'aspect du tapioca; elle dure de trente à quarante heures. Le pulqué est un liquide blanc opaque, comme l'orgeat, d'odeur désagréable; il contient 3 à 6 pour 100 d'alcool: sa saveur rappelle celle du cidre mousseux. On débite cette boisson enivrante, par quantités énormes, dans des établissements spéciaux, les pulquérias.

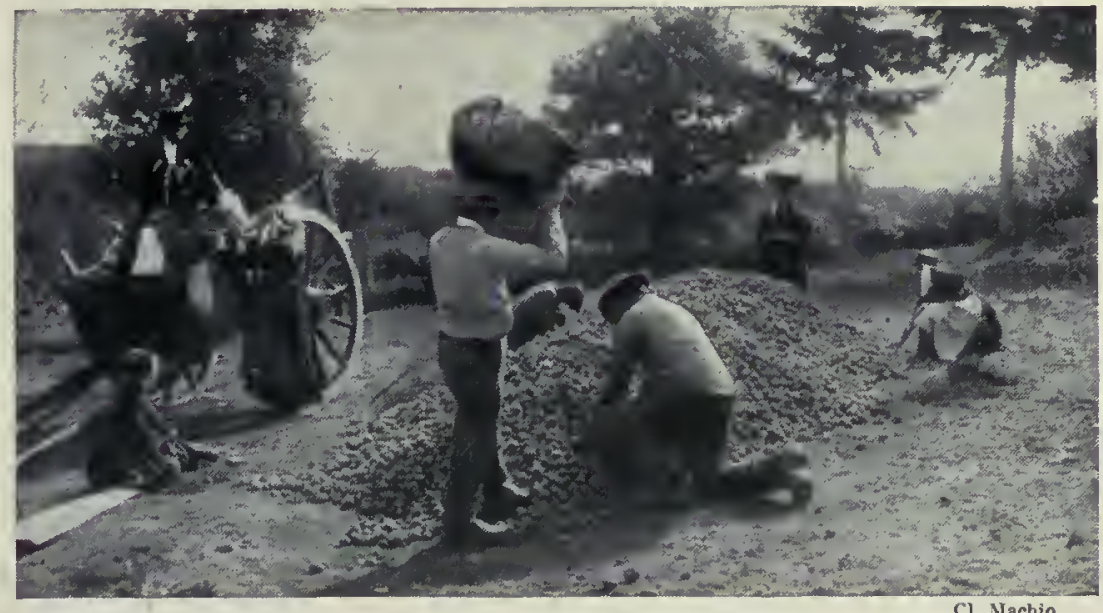

La récolte des pommes, en Bretagne.

Bières. - Les bières sont des liqueurs de grains saccharifiés et fermentés. Les Egyptiens, les Grecs, les Germains, les Gaulois ont connu des bières ou cervoises non houblonnées, mais aromatisćes avec du genièvre, du serpolet ou de la sauge. Le houblon fut employé en France et en Allemagne dès le IX ${ }^{*}$ siècle; en Angleterre, au $X^{e}$ siècle seulement.

L'Orge est la céréale la plus usitée en brasserie. Cette industrie, aujourd'hui très perfectionnée, comprend : maltage, brassage ou saccharification, cuisson avec houblonnage et, enfin, fermentation. Nous avons déjà longuement parlé du maltage à propos de la graine (p. 49). Le malt est préparé de plus en plus dans des établissements spéciaux, les malteries, où les brasseurs s approvisionnent.

Le malt concassé est introduit dans

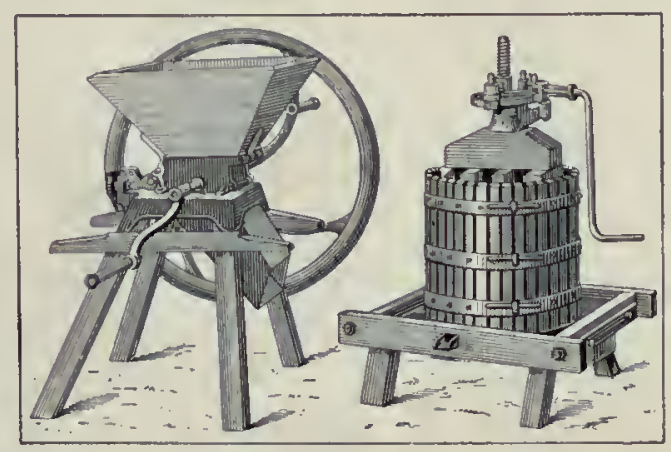

Fig. 285. - Broyeur à pommes et pressoir pour la fabrication du cidre.

refroidies entre $5^{\circ}$ et $8^{\circ}$ par circulation de solutions salines réfrigérées; la fermentation, calme et lente, dure de dix à douze jours. Dans la fermentation haute, usitée dans le nord de la France et en Angleterre, le moût, refroidi à $12^{\circ}$, passe dans les cuves guilloires contenant plusieurs centaines d'hectolitres et maintenues à la température de $12^{\circ}$ à $18^{\circ}$; la fermentation est alors tumultueuse; elle dure de quatre à dix jours; la bière ainsi fabriquée se conserve moins bien.

La bière est une boisson de premier ordre, à dose modérée. Elle est facilement digérable, tonique par le houblon, excitante par l'alcool; elle est plus nourrissante, mais moins stimulante que le vin.

L'orge n'est pas la seule céréale qui soit employée en brasserie; on utilise encore fréquemment le seigle, le maïs et le riz aux États-Unis, le froment en Angleterre, l'avoine en Russie, le seigle et le froment en Belgique : le faro et le lambick sont des bières fromentacées, très appréciées à Bruxelles. Depuis quelques années, la farine de Manioc est aussi très où il est brassé par un agitateur à palettes, en présence de l'eau à environ $70^{\circ}$. L'amidon se transforme en glucose; le moût est soutiré et le malt épuisé est séché à l'étuve; il constitue la drêche, utilisée pour nourrir le bétail. Le moût est très altérable en raison des matières azotées qu'il renferme; on le fait bouillir dans une chaudière et on y ajoute des cônes femelles de Houblon. La cuisson dure cinq heures environ; elle tue les germes de fermentations variées, coagule les matières albuminoïdes, donne au moût une saveur amère et aromatique, et prévient les fermentations secondaires.

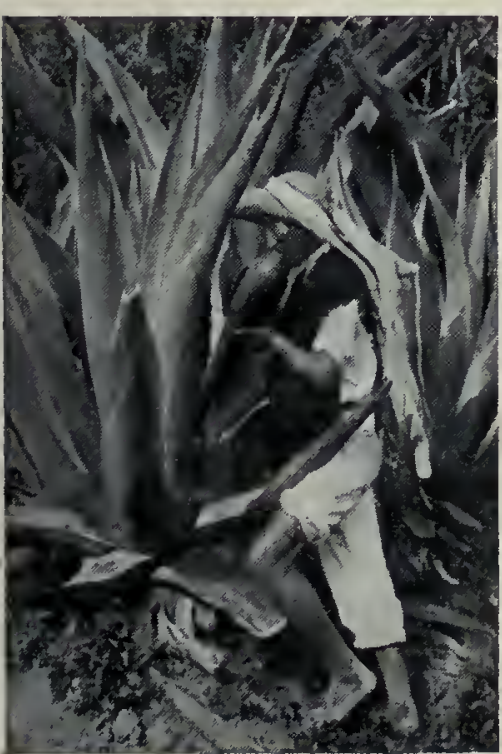

Récolte du suc de l'Agave.
Le moût houblonné passe dans des refroidisseurs, puis est conduit dans les grandes cuves à fermentation. La bière obtenue varie beaucoup, suivant que la fermentation a lieu à température basse ou élevée, ou sous l'action de telle ou telle race de Levure. Beaucoup de brasseries ont pour annexe un laboratoire de sélection des Levures, où l'on cultive, suivant les méthodes indiquées par Pasteur, des races pures qui serviront à ensemencer le moût dans les cuves.

Dans la fermentation bosse, employée pour les bières allemandes, le moût, refroidi à $5^{\circ}$, est conduit dans des cuves contenues dans des caves qui sont souvent employée par les brasseurs en mélange avec l'orge.

Boissons distillées. - L'art d'extraire l'alcool des boissons fermentées nous vient des Arabes. On ne connut longtemps que l'alcool de vin, qui était considéré comme un remède précieux (eau-de-vie); aujourd'hui, on retire l'alcool de toute substance capable de se transformer en un sucre fermentescible; on l'utilise dans la préparation d'une foule de corps : vinaigre, éther, chloroforme, vernis, collodion, etc.; pour le chauffage, l'éclairage, la force motrice; une quantité trop considérable est absorbée comme boisson, sous des formes diverses. On peut distinguer les alcools naturels et les alcools artificiels.

En tête des premiers est l'eau-de-vie de vin, mélange d'eau et

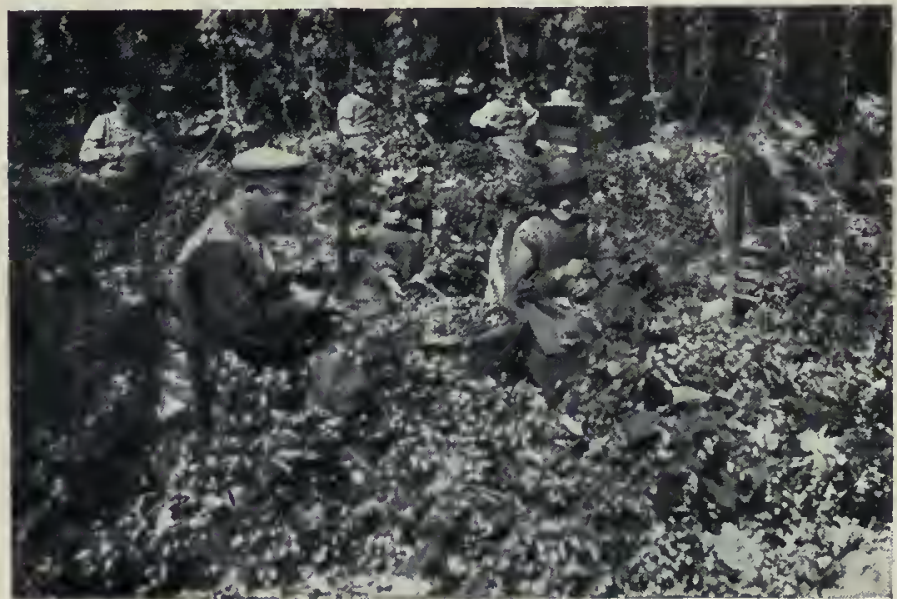

Cueitlette du houblon après l'abatage. 


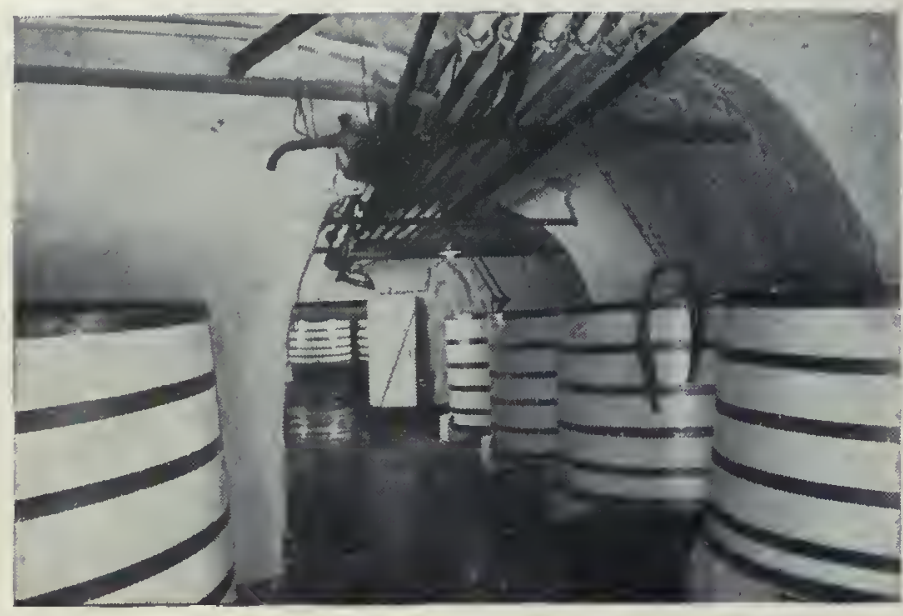

Cuves pour la fermentation de la bière, à Issy (Seine).

d'alcool éthylique presque pur; les cognacs et les armagnacs, provenant de la distillation des vins blancs de ces régions, ont, à juste titre, une réputation universelle. Les eaux-de-vie de marc, extraites des marcs de raisins fermentés, les eaux-de-vie de cidre ou calvados sont beaucoup moins recommandables au point de vue hygiénique.

Les eaux-de-vie de fruits obtenues en France sont le kirsch, le quetsch, la prunelle, résultant de la distillation des" merises, prunes ou prunelles fermentées. Les fraises, framboises, mûres, groseilles et baies du Sureau, auxquelles on peut joindre la racine de Gentiane utilisée dans les Alpes, fournissent aussi des eaux-de-vie. Toute cette fabrication est faite par des distillateurs de profession et surtout par le récoltant ou bouilleur de cru. La plupart des petits propriétaires, ne possédant pas d'alambic, font distiller les produits fermentés de leur récolte par des distillateurs ambulants ou brandeviniers.

La distillation du jus fermenté de Canne à sucre produit le rhum, et celle des mélasses fermentées, le tafia. Le mezcal, ou eau-de-vie d'Agave, se fait avec toutes les variétés de cette plante; il comprend la torréfaction du tronc qui provoque leur saccharification, leur broyage avec l'eau, la fermentation du moût sucré, puis

la distillation. Sous le nom d'arack on désigne diverses liqueurs fermentées ou distillées, obtenues dans les pays chauds, avec de la sève de Palmiers, des fruits, des graines, etc. Le bili de la Guinée française s'obtient par macération dans l'eau du rhizome du Dissotis à grandes fleurs, puis fermentation et distillation. Les alcools de grains, connus depuis la fin du XVI" siècle, ne sont pas moins nombreux et variés que les alcools de fruits : squidam en Hollande, wiskey en Écosse et aux États-Unis, saké au Japon, et tant d'autres, proviennent du seigle, de l'avoine, du riz, etc. On retire même de l'alcool des haricots, pois, lentilles et glands verts.

Les alcools industriels proviennent des pommes de terre, des topinambours, des résidus de féculerie. La distillation des jus et mélasses fermentés de Betteraves est, de beaucoup, la source la plus importante. Ces alcools, très impurs, doivent être rectifiés par plusieurs distillations fractionnées. Une portion énorme des alcools d'industrie entre dans le commerce des spiritueux; additionnés d'essences et de bouquets divers, ils imitent - très mal les cognacs, rhums, kirschs, etc., ou bien entrent dans la préparation des liqueurs à essences ou des vins aromatiques (vermouts, bitters, etc.).

Liqueurs. - Les liqueurs sont des boissons alcooliques aromatisées et souvent sucrées; le nombre en est immense : beaucoup de fruits, de graines odorantes et de

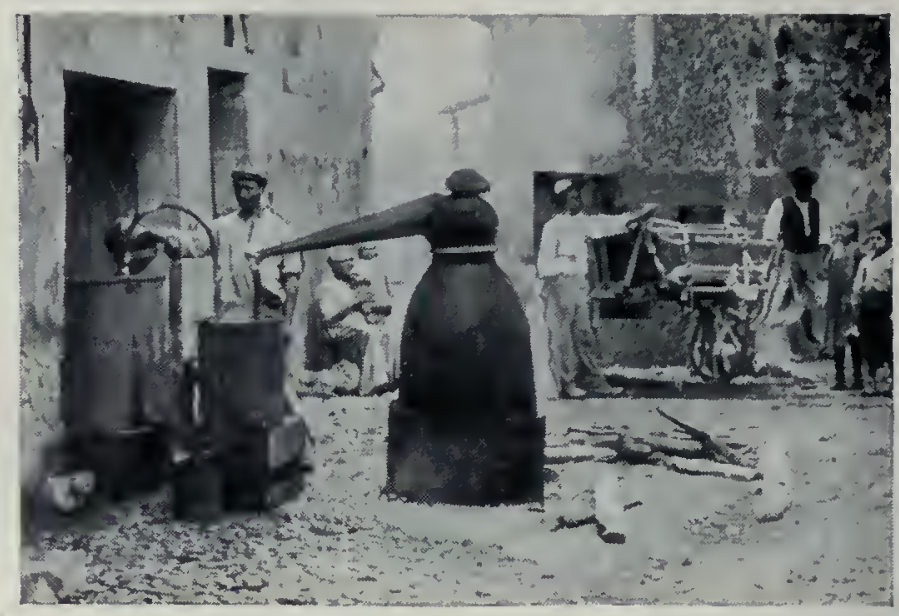

Un bouilleur de cru, dans le Var.

plantes aromatiques entrent dans leur composition. Les ratafias de cerises, cassis, angélique, noyaux, etc., s'obtiennent en faisant macérer les substances dans l'alcool, puis sucrant el décantant. D'autres liqueurs sont préparées par distillation : les plantes aromatiques macèrent dans une partie de l'alcool, on ajoute de l'eau et on distille: ainsi se préparent le kummel, à base de graines de Cumin et de Coriandre; le curaçao, avec les zestes d'oranges; la chartreuse, la bénédictine, etc., avec des Labiées, Composées et Ombellifères aromatiques.

\section{LES BOISSONS ALCALOÏDIOUES ET DIVERSES}

Café. - $M^{\text {me }}$ de Sévigné disait que l'engouement pour Racine passerait comme celui qui se manifestait à son époque pour le café. Cette boisson était nouvelle à cette date de l'his-

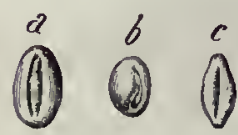

Fig. 287. - Café. , Martinique : $b$, Moka ; c, Bourbon. toire; en 1652 un marchand nommé Edward amena à Londres un Grec qui savait préparer le café et qui en fit adopter l'usage en Angleterre; dès 1644, un Vénitien, Pietro del Valle, avait apporté du café à Marseille; c'est seulement en 1672 que l'Arménien Pascal établit à la foire de Saint-Germain un café qu'il transporta ensuite quai de l'École, vis-à-vis du PontNeuf, mais son établissement périclita et c'est le Sicilien Procope qui a fondé le premier " café " durable en face de la Comédie française; il a été célèbre comme lieu de rendez. vous des littérateurs. Tous les introducteurs de ce produit nouveau venaient de l'Orient : ce sont, en effet, les Arabes qui ont été les

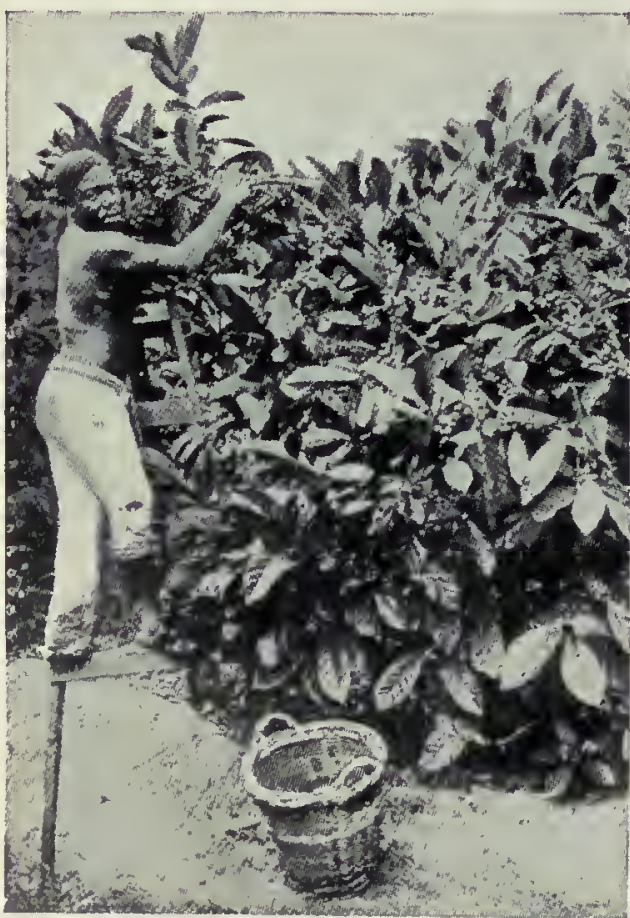

Une plantation de Caféiers en fruits. propagateurs du café, connu depuis un temps immémorial en Abyssinie, notam. ment dans la province de Kaffa, où il était employé par les Gallas à l'état de boisson et d'aliment; cest en effet dans cette contrée que l'arbrisseau de 3 à 6 mètres qui le produit vit à l'état sauvage. Cette liqueur est restée longtemps inconnue : les Croisés n'en eurent pas connaissance et un célèbre médecin, Ebn Baithar, qui parcourut le nord de l'Afrique et de la Syrie au $X 11^{\circ}$ siècle, ne la mentionne pas dans ses écrits. C'est au $\mathrm{XV}^{\mathrm{e}}$ siècle de l'ère chrétienne qu une légende le fait découvrir en Arabie, où le Caféier n’a jamais été spontané, par le Cheik Omar, dévot personnage de l'Yémen qui s'était réfugié dans les montagnes. En réalité, c'est seulement au $\mathrm{XV}^{\theta}$ siècle que les cultures de Caféier commencèrent à se propager en Arabie. Pendant longtemps, les Arabes de Moka fournirent seuls à l'Europe le café qui y était consommé, et le transport des pieds de la plante était interdit. Cependant des graines germèrent à Batavia, où elles avaient été transportées par $\mathrm{Ni}_{\mathrm{i}}$ colas Witsen, et un pied fut envoyé à Amsterdam, par le gouverneur de Java, en 1690. En 1712, un exemplaire fut apporté en France par de Ressons, lieute- 
nant général d'artillerie. Ce pied fut ensuite présenté à Louis XIV à Marly, ensuite confié au Jardin du roi (aujourd'hui le Jardin des Plantes) et c'est de là qu'en 1723 le chevalier de Clieu, qui se rendait à la Martinique, l'introduisit dans cette colonie : la traversée fut longue et dangereuse, l'eau manquait sur le bâtiment; de Clieu, qui sentait l'importance de sa mission, se rationna et put conserver vivantes ses précieuses plantes. Ce sont elles qui furent le point de départ des cultures de cette colonie qui se développèrent d'une manière prodigieuse.

Depuis ces temps lointains, la culture du café s'est répandue partout sous les tropiques. Le fruit, appelé " cerise ", de cette Rubiacée ( fig. 286 et 287 ) est une drupe ovoïde, rouge à la maturité, qui contient deux noyaux très minces, non lignifiés, seulement parcheminés et renfermant chacun une graine qui est le grain de café. Bien que la culture se fasse à l'heure actuelle sous les tropiques, la plante ne recherche pas les plus hautes températures; partout l'arbre réussit dans les régions un peu élevées et les plaines ne lui conviennent pas. Dans la province de São Paulo, au Brésil, où existent d'admirables cultures, c'est entre les altitudes de $600 \mathrm{et}$ de 1000 mètres que les meilleurs résultats sont obtenus. Les graines sont semées en pépinières un peu avant la saison des pluies et transplantées, un peu plus d'un an après, à des distances de 2 à 4 mètres en moyenne. Aux hautes altitudes, en Arabie, au Brésil, les arbustes ainsi plantés peuvent croître en plein soleil et seuls, mais ailleurs on les abrite par des plantes d'ombrage : des Pois doux (Inga laurina), des Acajous de pays (Cedrela odorata), des Albizzia, etc. Le Caféier d'Arabie fleurit la première fois à trois ans et est en plein rapport à six et huit ans; il continue à être fertile jusqu'à vingt ou trente ans. 11 faut huit mois pour la maturation du fruit : la floraison coïncide, en général, avec la fin de la saison sèche et la récolte des fruits a lieu d'ordinaire à la fin de la saison des pluies suivante. Le rendement d'un arbre varic de 300 à 1000 grammes; il est en moyenne de 500 grammes.

Les manipulations auxquelles le fruit du Caféier est soumis avant d'être livré au commerce sont assez compliquées et accomplies par une machinerie très perfectionnée. On traite par la voie sèche ou par la voie humide; la seconde est plus employée, bien que la première donne un produit plus fin. Les diverses phases de la méthode par voie humide sont les suivantes: dépulpage dans des cylindres à surface râpeuse en cuivre où les grains sont pressés, soit par une lame de caoutchouc, soit par des disques en acier tournant devant un disque immobile en caoutchouc; fermentation dans des citernes en maçonnerie; lavage dans des bassines où les graines sont remuées avec des râteaux à main ou des palettes automatiques; dessiccation, soit à l'air libre sur des terrasses, soit dans des séchoirs à air chaud. Le café ainsi desséché est encore enveloppé de son noyau ou parche; il est envoyé, en général, ainsi en Europe où se font les dernières manipulations : décortication ou enlèvement de la parche à l'aide de decascadores (en portugais), polissage ou enlèvement de la pellicule argentée qui est le tégument de la graine, enfin triage.

Les principaux types commerciaux de café sont le Moka, le Bourbon, le Martinique, qui se distinguent par la forme, la grosseur, la couleur et la saveur.

La graine de café contient un alcaloïde appelé la caféine $(0,70$ à 2,05 pour 100) auquel elle doit ses propriétés stimulantes; elle contient, en outre, des matières azotées et des matières grasses.

Le Caféier a été envahi, vers 1870 , par une maladie extrêmement redou-

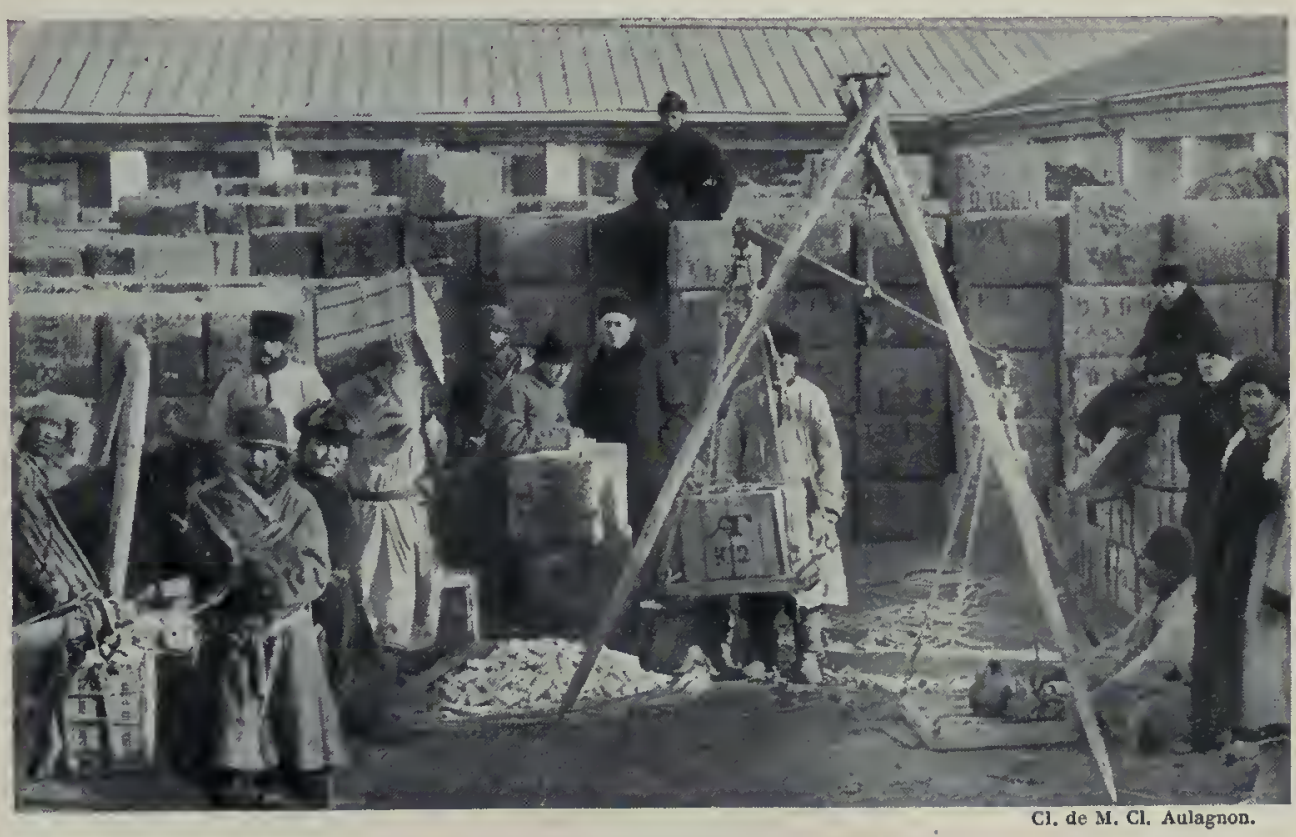

Un entrepòt de thé, à Kiakhta (Transbaikkalie). table, due à une Urédinée, l'Hemileia, qui a fait complètement péricliter les cultures de Ceylan, auxquelles les Anglais

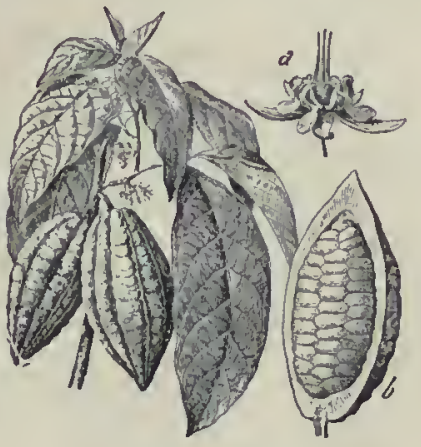

Fig. 288. - Cacaoyer. $a$, Fleur : $b$, Fruit.

ont dû renoncer. Depuis cette époque, le mal s'est propagé dans l’Ancien Monde, mais le Nouveau Monde est encore indemne. On a préconisé à Java un autre Caféier, celui de Libéria, qui a malheureusement un arome moins fin et une saveur plus âpre. On a entrepris l'hybridation entre le Caféier d'Arabie et de Libéria.

Succédanés du café. - L infusion de café est excitante par la caféine; aussi beaucoup de personnes nerveuses sont-elles forcées de s'en priver. Il existe bien à Madagascar et dans les îles voisines des Caféiers sauvages dont les graines sont dépourvues de caféine (Coffea Humblotiana et Perrieri), mais elles possèdent une extrême amertume dont aucune manipulation n'a encore pu les débarrasser; peut-être y parviendrait-on par la culture. On vend des cafés décaféinés par des procédés chimiques, dits cafés sanka.

Sous le nom impropre de succédanés du café, on désigne certaines substances qui sont rarement employées seules, mais en mélange avec le café pour en modifier le goût. La Chicorée à café, cultivée dans le nord de la France, en Belgique et en Allemagne, est employée depuis la seconde moitié du XVIII ${ }^{\circ}$ siècle; on la sème en avril et on l'arrache à l'automne. Les racines nettoyées, lavées, coupées en fragments, puis desséchées par un courant d'air chaud, sont livrées aux usiniers qui les torréfient et les broient.

Le malt d'orge, qui a le parfum du café, est très employé en mélange avec le lait; on emploie de même des cafés de pois chiche, de châtaigne, de seigle, de carotte, de betterave. Le café de glands doux torréfiés, et surtout celui de figues, font l'objet d'un commerce assez important. En Hongrie et dans les Balkans, de grandes quantités de figues sont, chaque année, séchées au soleil, puis torréfiées et réduites en farine pour cet usage très apprécié. En Bretagne, les graines du Lupin à feuilles étroites sont utilisées 


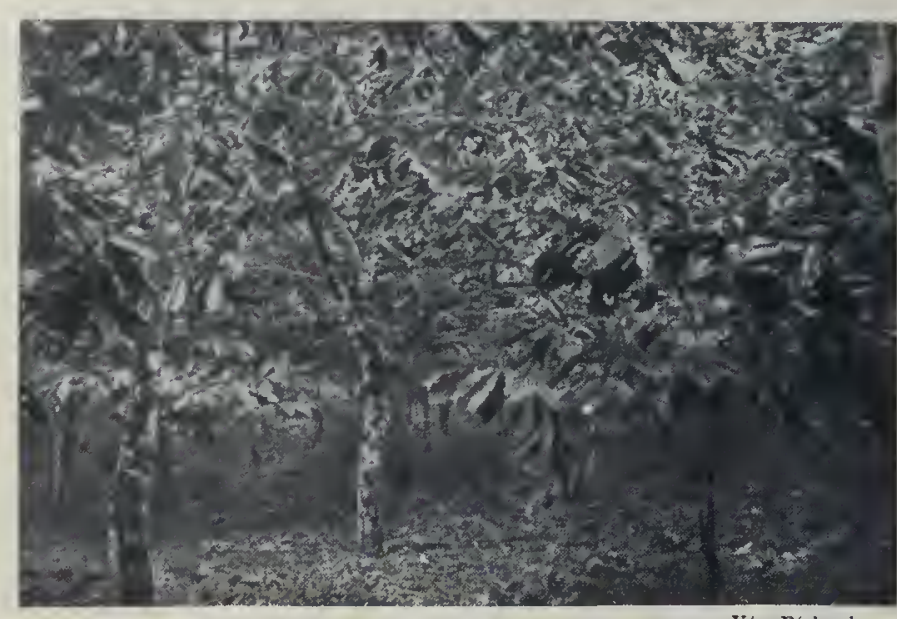

Une cacaoyère, à la Trinitad.

sous le nom de "café de jardin "; les graines de l'Astragale d'Espagne furent en honneur en France pendant le blocus continental; on utilise aussi au Sénégal celles du Cassier occidental, en Algérie celles des caroubes.

Thé. - Le thé nous vient, non de l'Orient comme le café, mais de l'Extrême-Orient. L'arbuste qui le produit est très voisin des Camellia, genre dans lequel il est incorporé par certains auteurs; il a 2 mètres à $2^{\mathrm{m}}, 50$ et pousse dans les provinces méridionales de la Chine; aussi la boisson connue sous le nom de thé est-elle d'un usage presque immémorial dans ce pays. D'après un vieil ouvrage chinois, le Pen-t'sao, qui a été composé au $X V t^{\circ}$ siècle, l'emploi des feuilles du Théier pour en faire une infusion remonterait à 2700 ans avant l'ère chrétienne. C'est seulement au

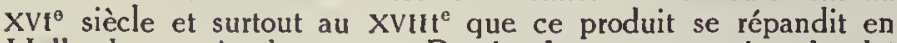
Hollande, en Angleterre, en Russie. La consommation du thé en Angleterre est considérable: c'est véritablement la boisson nationale; aussi les Anglais ont-ils cherché à ne plus être tributaires de la Chine et ils ont établi des cultures à Ceylan et dans l'Assam qui ont rapidement pris une énorme extension. Nous avons rappelé plus haut que, vers 1870 , les cultures de Caféier ont commencé à péricliter dans l'Inde par suite de l'extension de l'Hemileia, et comme aucun remède n'avait été trouvé à cette maladie; comme, d'autre part, les cultures du Caféier au Brésil prenaient un essor considérable, il en résulta vers 1878 pour Ceylan, qui était le principal exportateur de café, des troubles économiques considérables qui amenèrent de véritables catastrophes financières. En présence de ces désastres, avec l'énergie et le sang-froid qui caractérisent la race anglo-saxonne, les planteurs de Ceylan renoncèrent brusquement au Caféier et entreprirent sur une vaste échelle la culture de l'arbuste à thé. En quelques années cette transformation radicale fut opérée et, vers 1894, Ceylan devint un des principaux exportateurs. C'est là un des phénomènes écono-

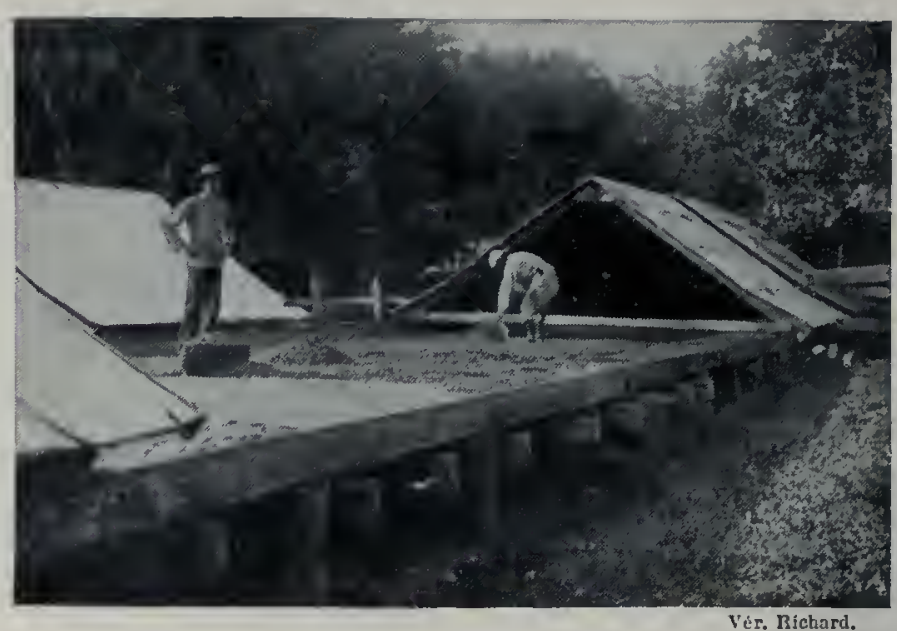

Le séchage du cacao, à la Trinitad.

miques les plus remarquables quait pu enregistrer l'histoire du $\mathrm{XIX}$ siècle.

Le Théier est aussi cultivé dans l'Assam, mais c'est une variété distincte qui existe dans ce pays; elle a 5 à 6 mètres de haut et se ramifie à quelque distance au-dessus du sol, au lieu de se ramifier au ras de terre comme le Théier de Chine; la croissance de la plante de l'Assam est plus rapide : elle bourgeonne plus tôt et plus abondamment; sa feuille est plus longue et durcit plus lentement; elle semblerait, d'après cela, devoir être préférée au Théier de Chine; malheureusement sa culture est beaucoup plus difficile: aussi cultive-t-on surtout les hybrides entre ces deux variétés.

Il ne faudrait pas attribuer aux deux variétés précédentes les deux thés connus sous le nom de thé noir et de thé vert : il n'y a entre ces deux produits qu une différence de préparation. La cueillette du thé se fait au Japon et à Ceylan par les mêmes méthodes: on détache l'extrémité des jeunes pousses, le bourgeon terminal et trois ou quatre feuilles voisines, on les accumule dans des paniers portés par les cueilleuses. La première feuille du bourgeon donne le thé supérieur ou pekoe, la deuxième le souchong, la troisième le congou, qui serait rejetée à Ceylan; le pekoe orange ou broken pekoe est obtenu avec le bourgeon terminal; on distingue encore le pekoe fleuri et le pekoe souchong. En fait, c'est là une classification assez artificielle qui na rien de rigoureux; toutes les feuilles sont traitées simultanément et ce n'est qu'après la torréfaction que le triage est opéré. Mais avant ces opérations finales, il y en a une série d'autres : flétrissage, par lequel les feuilles sont étalées en couches minces sur des toiles dans des greniers éclairés et aérés; enroulage, qui se fait en Chine par frottement des deux mains l'une sur l'autre circulairement, de façon à faire une boule, tandis quà Ceylan et à Java ce travail se fait mécaniquement; fermentation légère qui débarrasse les feuilles de leurs principes âcres et vireux : à basse température, elle dure de vingt minutes à trois heures; puis nouvel enroulage, séchage; enfin l'on procède à la torréfaction et au triage qui isole les sortes commerciales, dont la plus estimće est l'orange pekoe.

En Chine, on prépare les thés verts par une autre méthode sans fermentations; ils sont plus pauvres en théine, principe huileux identique à la caféine du café : ils n'en renferment que 2 à 5 pour 100 , mais ils sont plus riches en tanin (jusqu'à 18 pour 100 ). Lethé est parfumé en Chine et au Japon par diverses fleurs comme le Jasmin Sambac, le Camellia Sesanqua, l'Angræe odorant, l'Olivier odorant (Osmanthus fragrans).

Cacao, chocolat. - Le chocolat dérive de la graine du Cacaoyer et il peut être employé comme aliment solide ou liquide. Quand Fernand Cortez, en 1519, arriva au Mexique, il fut très étonné de voir que la monnaie était remplacée par les graines de Cacaoyer et que Montézuma accumulait dans certaines salles de son palais des quantités immenses de cette denrée qui représentait ses trésors. L'arbre qui la produisait est spontané dans l'Amérique du Sud, dans les bassins de l'Orénoque et de ['Amazone; i] avait été introduit au Mexique à une époque très ancienne et servait à préparer un breuvage national 


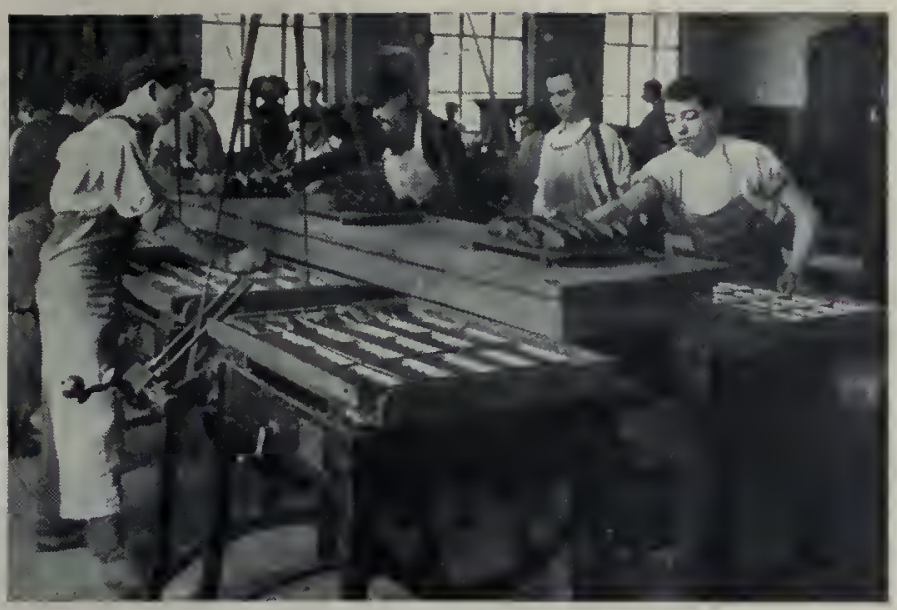

Transformation en tablettes, du chocolat.

qui était beaucoup trop épicé pour plaire au palais des Européens. Les Espagnols, en l'aromatisant avec la vanille, firent le chocolat, qui fut rapidement apprécié dans toute l'Europe. Pendant longtemps, l'Espagne garda le monopole de la culture du Cacaoyer et encore à l'heure actuelle elle fabrique des chocolats à la cannelle qui sont, pour ainsi dire, sa spécialité, mais la diffusion de la plante est maintenant complète et elle est répandue dans toutes les régions très chaudes et très humides où la température moyenne est de $24^{\circ}$ et ne descend jamais au-dessous de $10^{\circ}$, avec des pluies réparties sur toute l'année et un minimum de ] "m,60 d'eau. L'altitude doit être faible et rarement dépasser 200 mètres. L'ombrage est pour le Cacaoyer absolument nécessaire à tout âge. On se sert d'abris provisoires comme les Bananiers et on les coupe quand les arbres permanents, analogues à ceux qui abritent le Caféier (Bois noir ou Albizzia Lebbeck, Manguier, Acajou, Arbre à pain), sont poussés.

La première récolte de cabosses n'a lieu que vers la sixième année. Ces fruits sont des sortes de baies bosselées, sillonnées, à forme de concombre allongé, à péricarpe dur, coriace, à pulpe molle dans laquelle sont plongées les graines ou lèves de cacao.

Les cabosses cueillies sont écossées et les graines séparées. On soumet le tout à une fermentation dans des bassins en ciment recouverts d'un toit en tôle galvanisée; la pulpe se détruit et l'amande transforme ses matières astringentes. La duréc de l'opération dépend des conditions climatériques et des variétés traitées. Après la fermentation, à Ceylan, au Cameroun, on lave les graines, puis on les sèche au soleil pendant quelques jours sur des nattes ou de grands parquets de bois disposés de manière à pouvoir être abrités de la pluie. Au Venezuela, le cacao est en outre terré, c'est-à-dire roulé sur des toiles avec de la terre rouge ou de la brique pilée pour lui donner une belle couleur. Les lèves sont ensuite triées et emballées.

L'amande de la graine contient un alcaloïde voisin de la caléine, la théobromine ( 1.5 à 2 pour 100$)$, et une grande quantité de beurre de cacao ( 50 pour 100). Le cacao en poudre est le produit des amandes débarrassé de 60 à 80 pour 100 du beurre et additionné de sels alcalins. La fabrication du chocolat nécessite une longue suite d'opérations. Le nettoyage et le triage du cacao se font à l'aide de tamiseurs mécaniques; la torréfaction a lieu par circulation d'air chauffé entre $180^{\circ}$ et $225^{\circ}$, puis il est décortiqué, cassé et ventilé, enfin broyé en pâte fine sous plusieurs paires de meules. Mélangée à du sucre, de la vanille et divers aromates, la pâte est conduite dans des malaxeurs chauffés à la vapeur, puis subit plusieurs broyages sous des cylindres en granit formant laminoirs. Après un passage à l'étuve, la pâte est mise dans des moules reposant sur des machines dites " tapoteurs $n$; un refroidissement brusque permet le démoulage.

Le chocolat est à la fois un stimulant et un riche aliment par le beurre de cacao, les matières azotées, les sels et le sucre qu'il renferme. La consommation du chocolat est considérable en confiserie sous forme de bonbons trempés, consistant en un "intérieur y de sucre mou, de crème, de nougat, etc., plongé dans du chocolat liquide, ou de bonbons moulés, comme les ouls de Pâques, les poissons d'avril, etc.

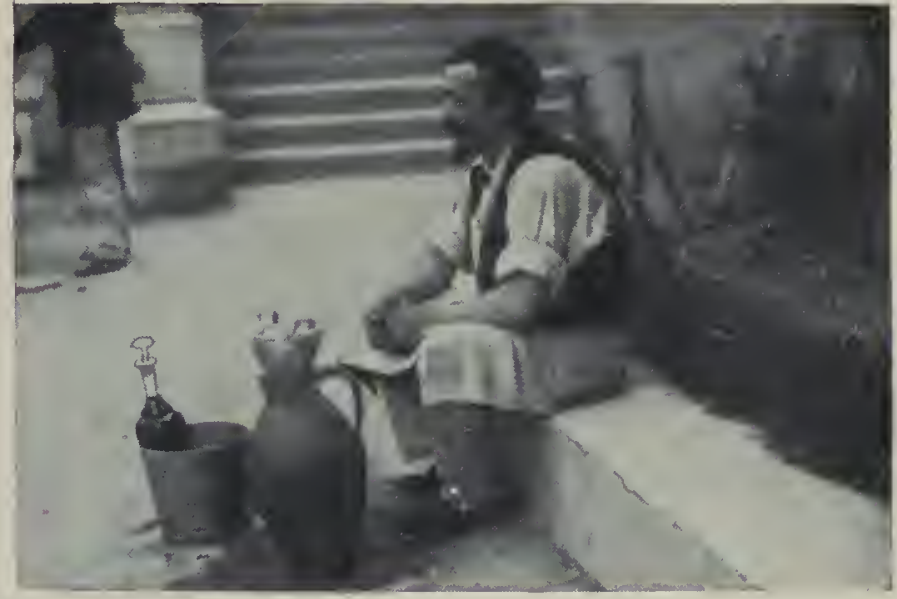

Un marchand de * coco », sur les quais.

Boissons diverses. - La caféine existe encore dans la noix de kola, dont nous parlerons à propos des plantes médicinales, dans le maté, le guarana, le Cat comestible d'Abyssinie. Le Houx maté ou thé du Paraguay est un petit arbre qui croit dans tout le bassin du Rio de la Plata; ses feuilles coriaces, dentées en scie, se trouvent dans le commerce séchées et concassées. Elles fournissent une infusion agréable, consommée dans toute l'Amérique du Sud, principalement dans l'Argentine. La dose est de 30 à 40 grammes de poudre de feuilles pour un litre d'eau très chaude. Des efforts sont tentés pour introduire en Europe l'usage de cette boisson, mais jusqu'ici sans grand succès, sauf en Allemagne et en Angleterre. En raison de la dilficulté d'obtenir le maté par semis, la récolte se fait en forêt et se dessèche sur place à l'aide d'un feu de branches sèches produisant peu de fumée. Il est ensuite pulvérisé et trié selon les diverses sortes commerciales : poudre, feuilles menues, pédoncules. Les graines du guarana (Paullinia sorbilis), qui est une liane du Brésil de la famille des Sapindacées, sont broyées sur une pierre chauffée, puis translormées en une pâte qu'on fait sécher et qui est vendue en cylindres ressemblant à des saucissons. L infusion est excitante et antifébrile.

Boissons sucrées. - Cette catégorie de boissons comprend les sirops, qui se boivent étendus d'eau : orgeat, groseille, grenadine, etc. Nous ne pouvons nous dispenser de citer le populaire coco, à base de jus de réglisse, et la limonade, préparée avec du jus de limon ou citron, de l'eau et du sucre. Souvent, le jus de citron est remplacé par un autre acide organique. En Sicile, on exprime le suc du citron ou du cédrat, on le mélange à un sirop et on obtient l'agrocotto (aigre cuit), sorte de limon qui se boit mélangé à l'eau, comme chez nous le sirop de groseille. En Espagne, et surtout à Madrid, on fait une énorme consommation des rhizomes de Chuffa ou Souchet comestible pour la fabrication d'une boisson rafraîchissante rappelant l'orgeat et se prêtant aussi à la confection des glaces. Les Arabes préparent aussi une sorte de limonade avec la pulpe sucrée des caroubes.

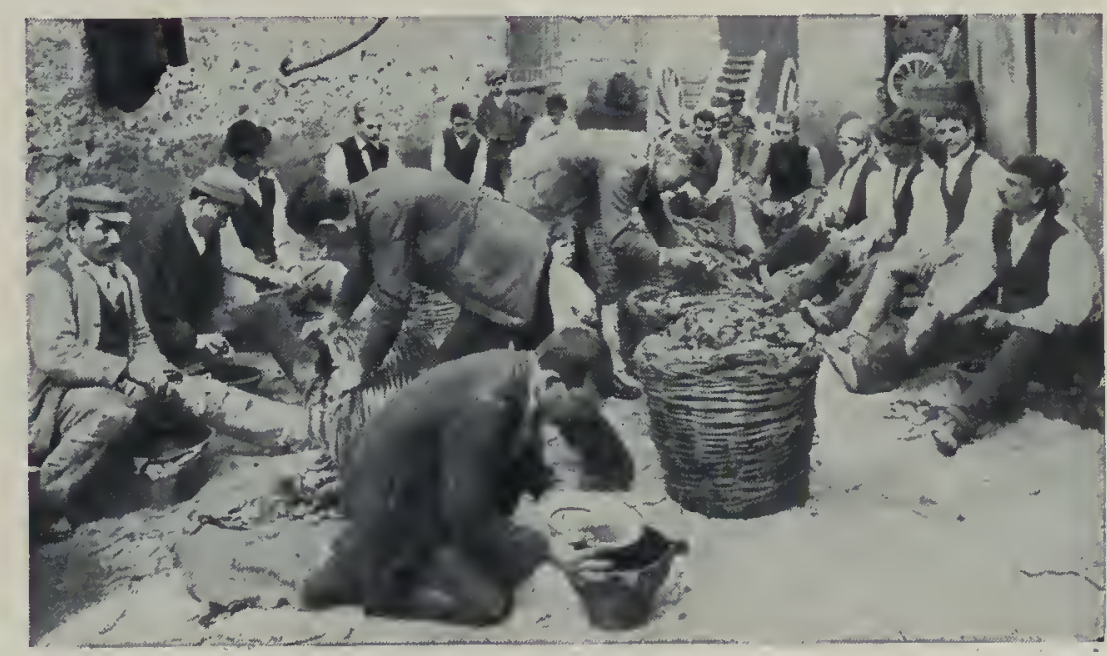

Fabrication de l'agrocotto, en Sicile. 


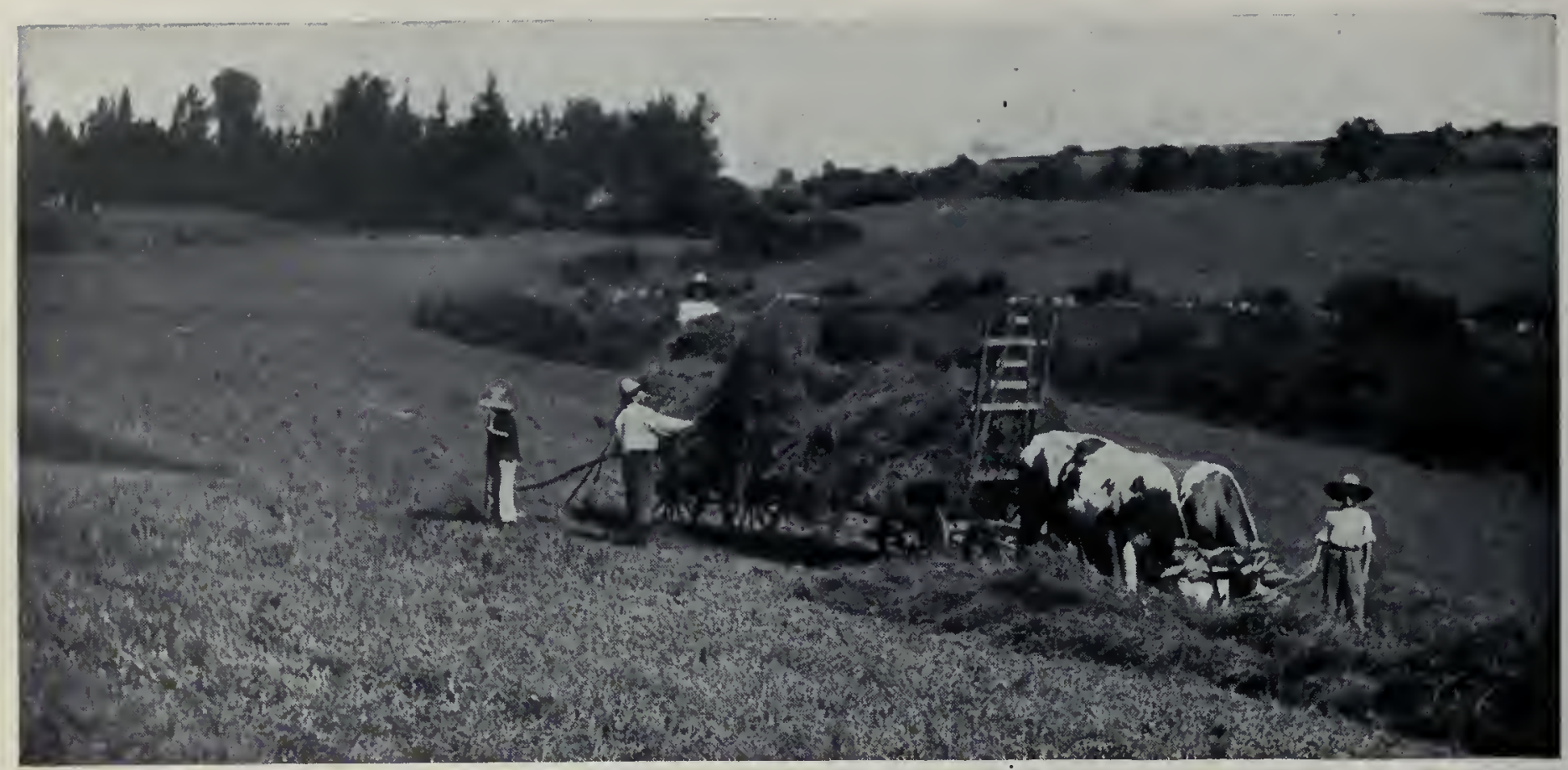

L A FENAISON EN FRANCHE-COMTÉ.

\section{IV. - LES PLANTES FOURRAĠ̀RES}

A l'état de nature, deux principaux types de végétation se disputent la surface du globe : la prairie et la forêt. Suivant le climat et la composition du terrain, l'une ou l'autre de ces formations végétales domine; elles peuvent même, dans les contrées où l'humidité s'allie à une température douce, se pénétrer plus ou moins et former un parc, dans lequel des bouquets de bois parsèment l'étendue herbeuse.

Lorsque l'Homme, aux temps néolithiques, commença la domestication des animaux et se fit pasteur, son bétail trouva d'abord d'abondants herbages. Quand ceux-ci devinrent insuffisants pour son troupeau accru, il abattit la. forêt pour étendre le pâturage. La création des cultures nécessita une extension considérable du bétail pour le labour et les travaux des champs et, par suite, un accroissement de la surface et du rendement des terrains produisant les fourrages. Ainsi naquit la praticulture, par laquelle sont créées, entretenues et exploitées les prairies. L'élevage du bétail est, de nos jours, une industrie des plus florissantes, et les

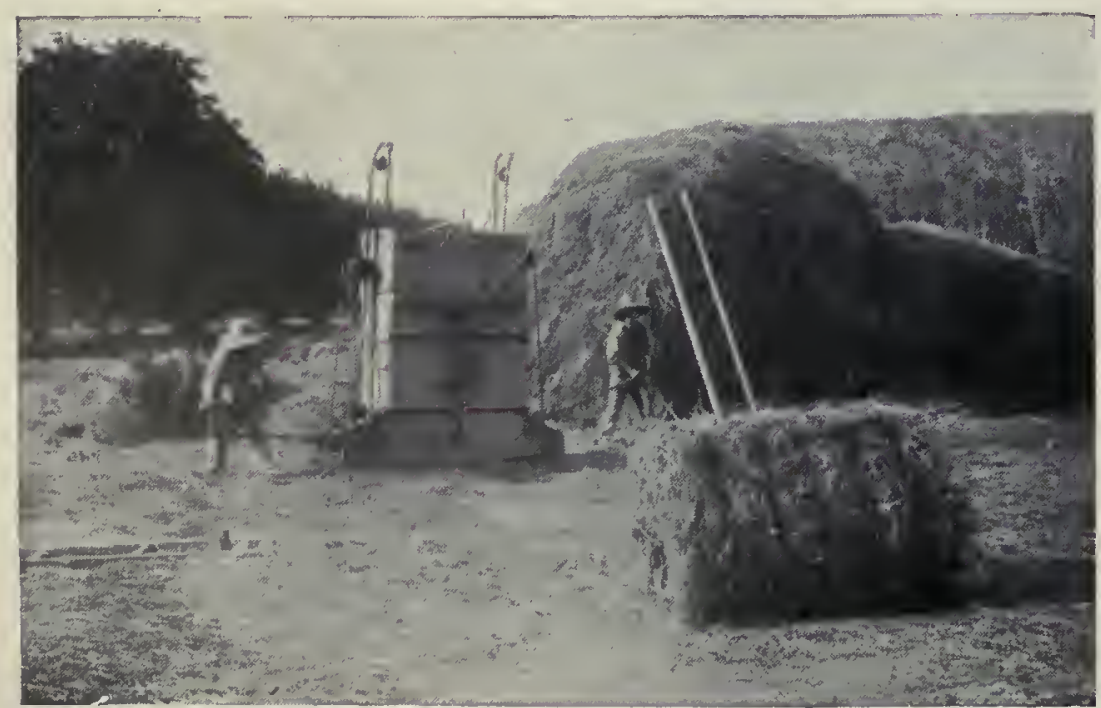

Une presse à fourrage. surfaces consacrées aux plantes fourragères sont en sensible augmentation. Les steppes de Russie, les pampas de l'Amérique du Sud, les plateaux australiens, les plaines des Etats-Unis, etc., sont d'immenses régions à pâturages.

Prairies naturelles. - Dans tout terrain abandonné à luimême se développent une foule de plantes, parmi lesquelles dominent bientôt les Graminées et les Légumineuses. Ainsi se forment des prairies par engazonnement naturel, mais on peut aussi les créer par ensemencement. La création de prairies est tout indiquée dans les sols qui ne pourraient porter d'autres cultures, dans ceux qui sont périodiquement inondés par les cours d'eau, dans les terrains en pente où l'herbe maintient la terre arable.

On peut diviser les prairies naturelles en prairies de fauche, dont l'herbe est coupée pour être convertie en foin, et en prairies de pâture, dont les plantes sont entièrement pâturées sur place. A cette dernière catégorie appartiennent les herbages de la Normandie, du Nivernais, du Charolais, de la Vendée, dont la végétation vigoureuse mène à bien l'engraissement des bovidés, et les pâturages ou pacages des terrains de montagne ou des terres maigres des Causses, du Berry, de la Sologne, parcourus par les moutons ou les vaches laitières. La composition du mélange des graines à semer est variable suivant qu'il s'agit d'une prairie de fauche ou d'un herbage. Dans le premier cas, il ne faut associer que des plantes hautes, fleurissant à la même époque et repoussant rapidement pour permettre une deuxième coupe; dans le second cas, au contraire, on mélange des espèces à végétation précoce, moyenne ou tardive, pour que les animaux aient toujours de l'herbe tendre. Quels que soient les soins donnés à une prairie, son rendement diminue au bout de quelques années; les mauvaises herbes l'envahissent; on la défriche à l'automne par un labour et on peut y obtenir pendant plusieurs années de bonnes récoltes d'avoine ou de plantes sarclées, puis on l'ensemence à nouveau de plantes fourragères.

Dans tous les pays du monde, les principales plantes de prairies sont les Craminées et les Légumineuses, herbes rustiques à graines nombreuses, dont la croissance n'est arrêtée ni par la faux, ni par la dent des 


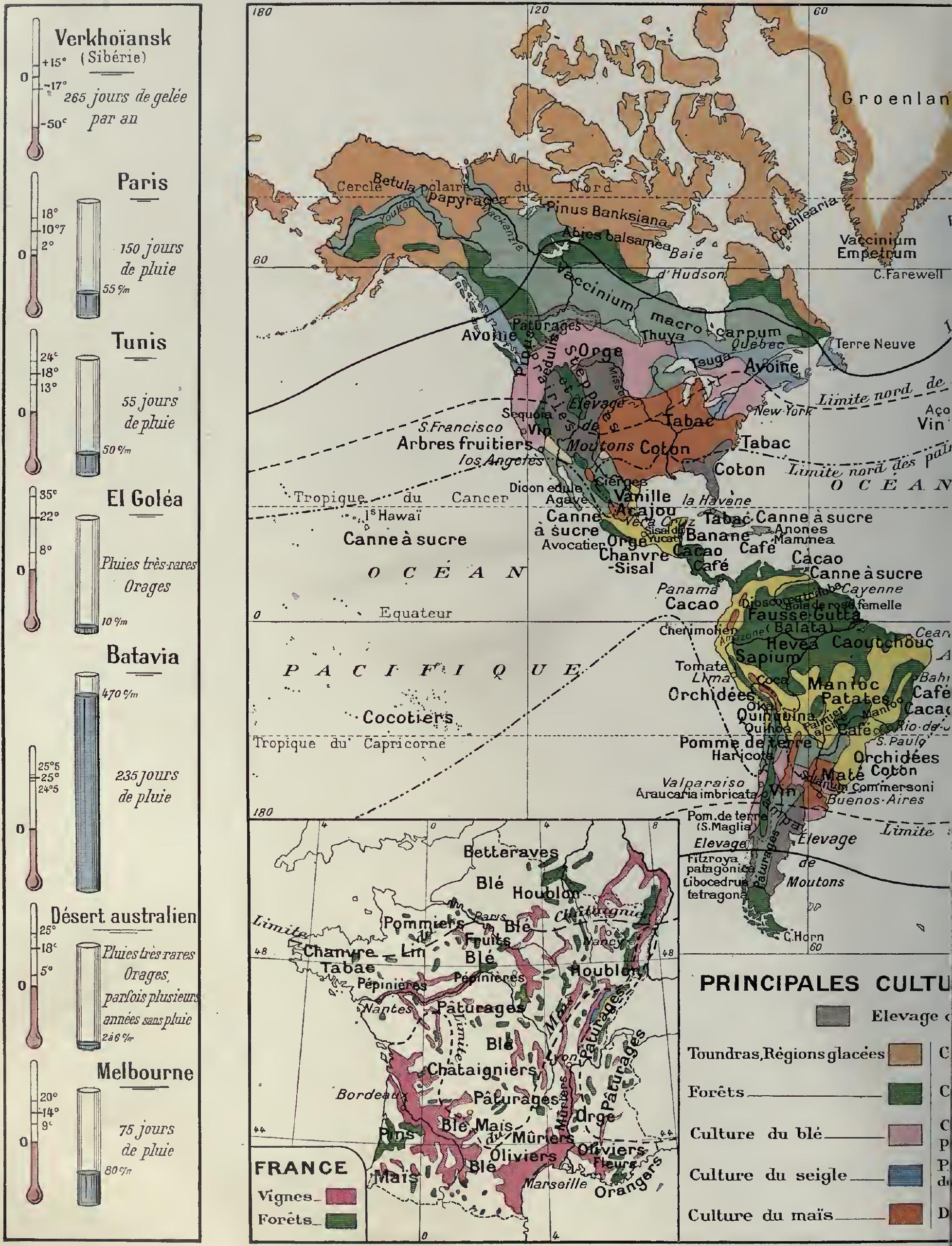


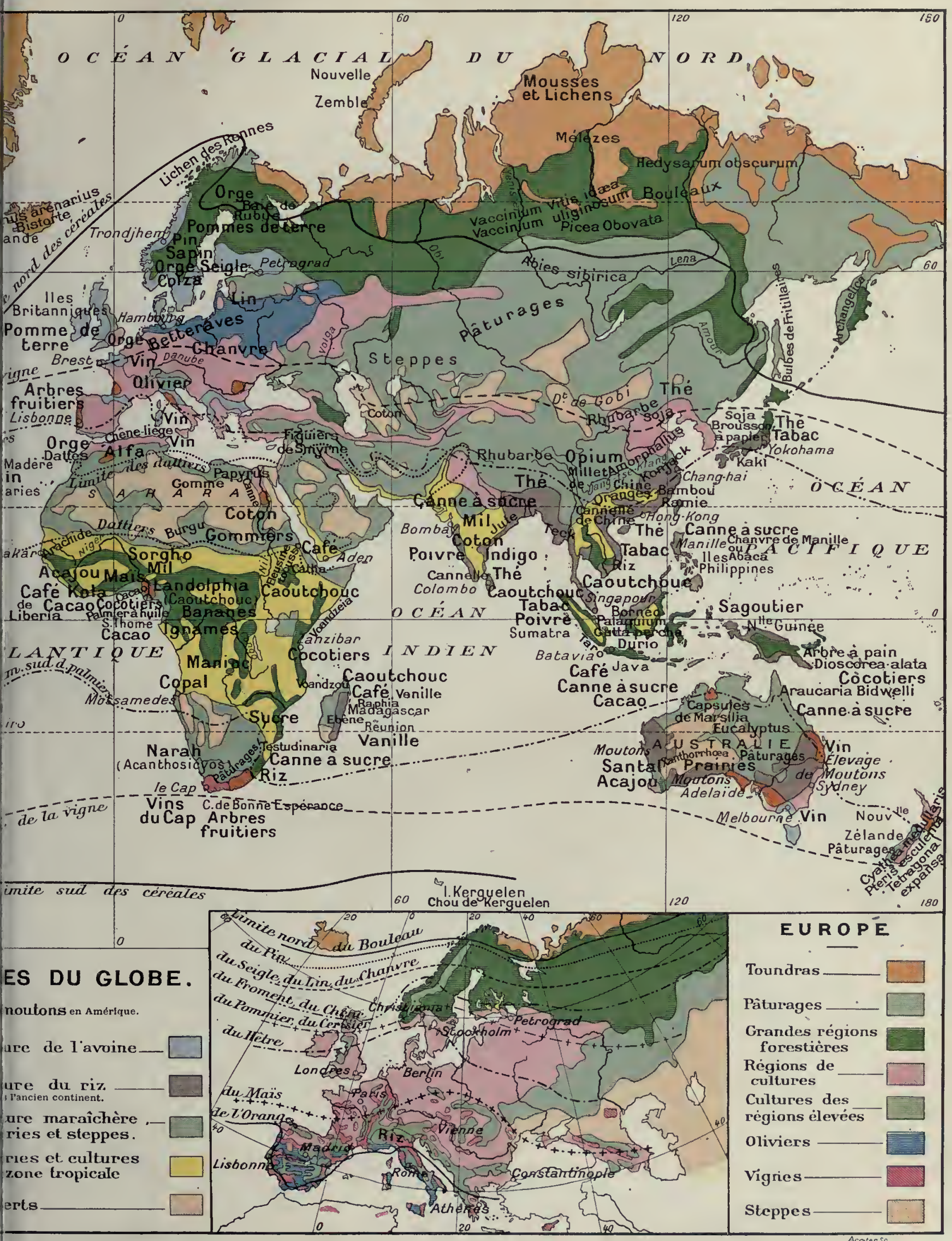

ILTURES DU GLOBE.

celui du milieu, la température moyenne annuelle; celui du haus, la température moyenne du mois le plus chaud el, celui du bas, celle du mois le plus froid. ntent la hauteur moyenne annuelle de pluie tombée. 



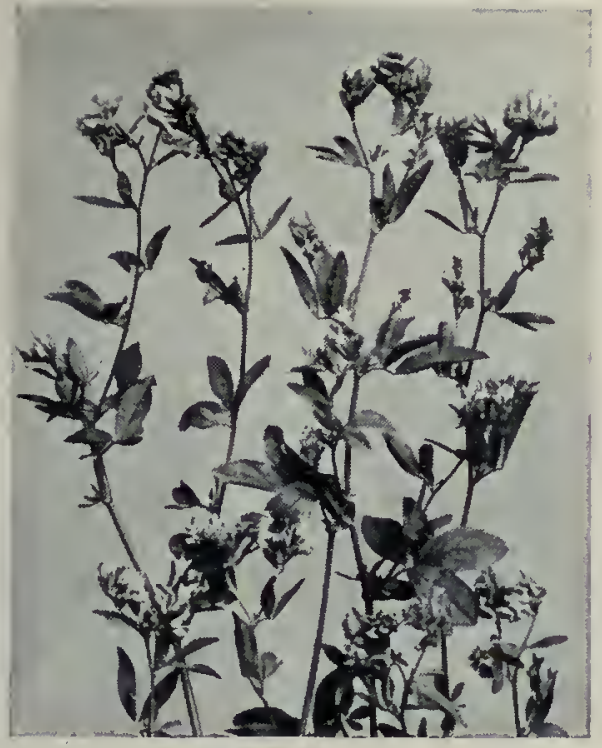

Luzerne cultivée.

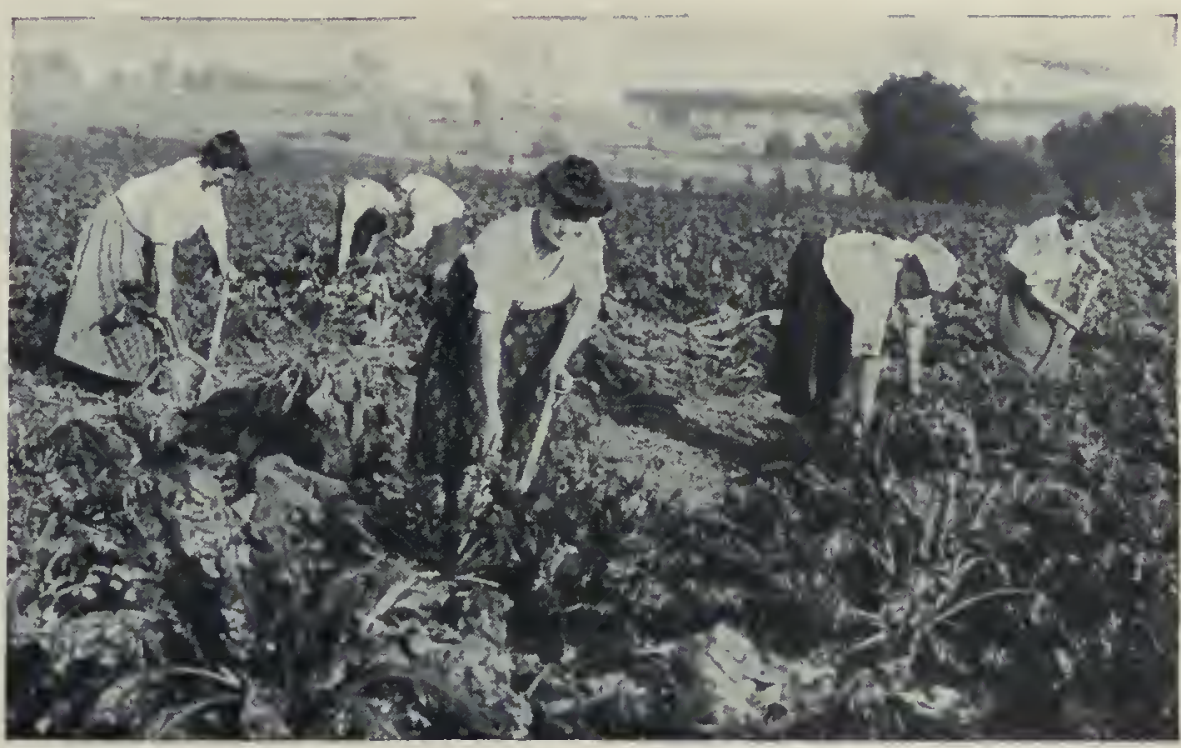

Femmes arrachant des betteraves. animaux qui les mutilent constamment. A ces plantes se joignent spontanément, dans nos pays, des végétaux qui, par leur arome, servent en quelque sorte de condiment, comme l'Achillée millefeuille, la Bugle rampante, les Centaurées, la Cardamine des prés, la Pimprenelle, etc., et aussi des plantes nuisibles : Aulx, Colchiques, Anémones, Renoncules, etc.

Passons en revue les principales Graminées des prairies. Les Pâturins, très répandus en Europe et en Amérique, ont une panicule dressée et étalée; le Pâturin des prés et le Pâturin commun sont d'excellents fourrages. Le Vulpin des prés et la Fléole des prés (fig. 289 et 290), au long épi cylindrique, sont aussi de bonnes plantes, amies des terrains frais. L'Ivraie vivace (Lolium perenne) [fig. 291] ou Ray-grass anglais vient bien dans les sols gras et sous les climats humides; elle abonde en Angleterre. Le Ray-grass d'Italie (Lolium multiflorum) est commun dans les prairies de la Haute Italie. La Fétuque des prés (fig. 292), à la panicule dressée, étalée et longue, est une des meilleures Graminées de nos prairies, et la $F$ étuque ovine, beaucoup plus petite, forme la base des pâturages à moutons dans les terrains secs. La Brize intermédiaire (fig. 293), la Cretelle des prés ont aussi de grandes qualités nutritives. La Flouve odorante, très répandue, surtout en Bretagne, est fort précoce et toujours trop mûre à la fauchaison ; cest un bon fourrage, un peu amer, mais très aromatique; il communique au foin son parfum de coumarine. Le Dactyle aggloméré (fig. 294), l'Orge des prés, la Houlque laineuse forment le fond des excellents herbages normands. On rencontre encore souvent les Agrostides (fig. 295), qui croissent dans les terrains les plus humides. L'Avoine élevée ou Fromental, l'Avoine jaunâtre et le Brome des prés aiment, au contraire, les coteaux secs.

Les Légumineuses sont presque indispensables dans les prairies naturelles; elles donnent un abondant fourrage, très recherché des animaux et plus riche en principes azotés ( 27 pour $100 \mathrm{du}$ fourrage sec) que les Graminées (12 pour 100). Une bonne composisition dherbage comporte la moitié en Graminées, les quatre cinquièmes restant sur la deuxième moitié en Légumineuses, le reste en plantes diverses.

Les principales Légumineuses des prairies naturelles sont : le Trèfle blanc ou Trèfle rampant, plante vivace, basse, abondante dans les herbages de Normandie et du Nivernais, qui résiste à la sécheresse d'une manière étonnante, repousse très bien sous la dent des animaux, mais n'est guère fauchable; le Trèfle des prés, qui est un excellent fourrage; la Luzerne tachée, des prés humides, et la Luzerne lupuline ou mignonnette, des prés secs; enfin le Lotier corniculé, commun partout, la Gesse des prés et, dans les terrains calcaires, l'Anthyllide vulnéraire.

La fauchaison des prés se fait au moment de la pleine floraison de la plupart des plantes; on emploie la faux ou la faucheuse mécanique, qui couchent l'herbe en andains. Pour le fanage, on l'éparpille, on la retourne plusieurs fois pendant deux à trois jours, à l'aide de la fourche à foin ou de la faneuse; on la dispose ensuite en meulons. Une fermentation favorable s'y produit, qui transforme en sucre une partie de la cellulose. Au bout d'un mois environ, on rentre le foin, on le porte dans des greniers ou bien on le dresse en plein air en une meule bien montée. 11 peut alors s y conserver. pendant trois ou quatre ans sans se détériorer. L'ensilage est employé au cours des années humides ou pour les regains fauchés tardivement; il est bon d'y surveiller les progrès de la fermentation, à l'aide d'un thermomètre placé au fond d'un long tube de fer.

Lorsque le foin est destiné à être transporté au loin, il est indispensable de le comprimer fortement. Les presses à bras, très usi-

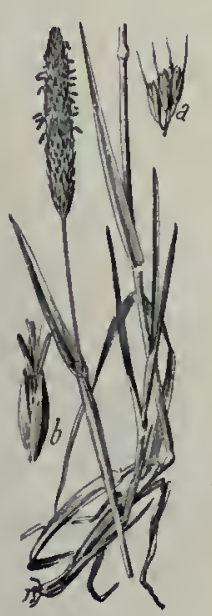

Fig. 289.

Vulpin.

$a$, Epillet; $b$, Fleur.

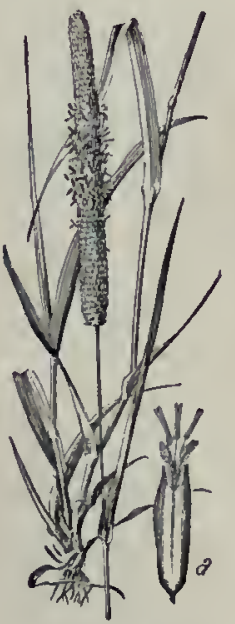

Fig. 290.

Flèole des prés. $\alpha$, Fleur.

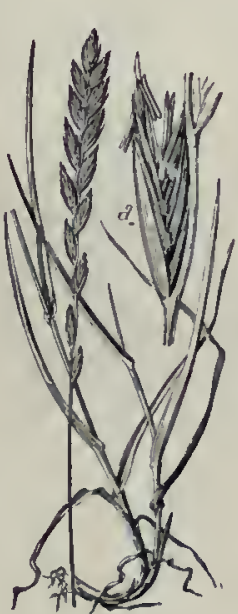

Fig. 291.

Ivraie vivace. $a$, Epillet grossi.

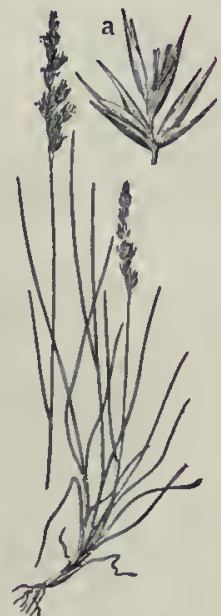

Fig. 292. Fétuque ovine. $a$, Epillet grossl.

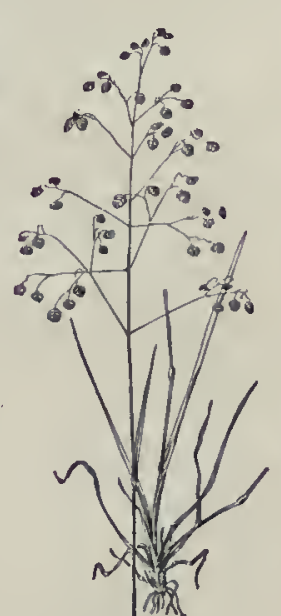

Fig. 293.

Brize intermédiaire.

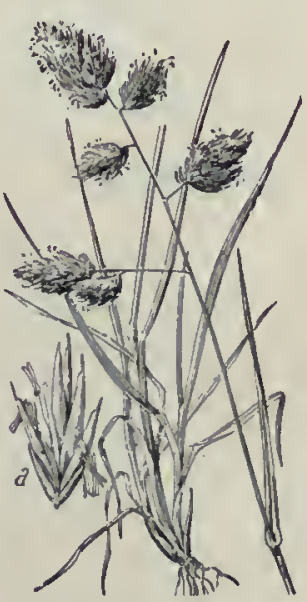

Fig. 294.

Dactyle.

$a$, Epillet.

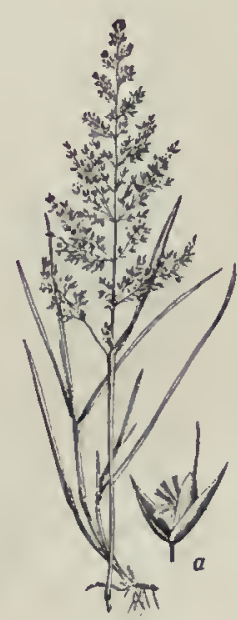

Fig. 295.

Agrostide. $a$, Épillet fleuri. 
tées, se composent de caisses en bois, fortement armées de fer, dont les deux fonds jouent le rôle de piston et compriment le foin en se rapprochant sous l'action de leviers.

Prairies artificielles. - L'introduction des prairies artifcielles dans les cultures a constitué un grand progrès agricole, en

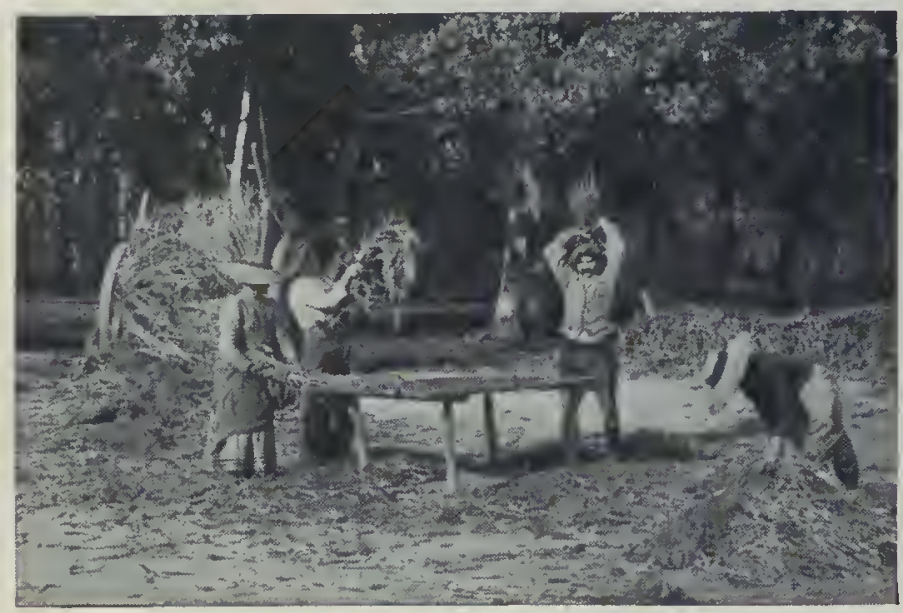

Le battage du millet.

raison de leur énorme rendement. On y cultive parfois des mélanges de Graminées, notamment le Ray-grass anglais et la Fléole des prés, ou des mélanges de Légumineuses associées parfois à des Graminées, mais le plus souvent une seule Légumineuse: Luzerne, Trèfle ou Sainfoin.

La Luzerne cultivée, dont la valeur fourragère était déjà reconnue par les Anciens, vient bien en terrain fertile et suffisamment calcaire ; ses racines s'enfoncent profondément dans le sol, ce qui lui permet de résister à la sécheresse ; elle redoute l'humidité ; elle dure environ dix ans, en fournissant deux à trois coupes par an. C'est le meilleur des fourrages. Il offre l'inconvénient, comme le Trèfle d'ailleurs, quand il est consommé vert en trop grande quantité, de fermenter dans la panse des ruminants, provoquant un gonflement ou météorisation, parfois mortel. Les luzernières sont souvent envahies par la Cuscute, qui est un parasite redoutable.

La culture du Trèfle comme plante fourragère n'est pas très ancienne; elle date à peine du XV! ${ }^{\circ}$ siècle et commença dans les Flandres. C'est une plante des pays tempérés, craignant la sécheresse. On cultive surtout le Trèfle commun ou violet, dit encore Trèfle des prés, dont les feuilles sont maculées par une tache blanche en fer à cheval.

Le Sainfoin cultivé ou Esparcette, inconnu des Anciens, est originaire du midi de l'Europe et cultivé en France depuis le $\mathrm{XV}^{\mathrm{C}}$ siècle. Il ne redoute pas les terrains secs et calcaires; il dure quatre à cinq ans et donne une à deux coupes par an. 11 ne provoque jamais la météorisation, et son foin est de qualité supérieure. On cultive aussi, dans le Midi, le Sainfoin couronné ou Sulla.

Fourrages tropicaux. - Parmi les fourrages des pays tropicaux, on peut d'abord citer le téosinte ou reanna, originaire du Guatemala et du Mexique, qui est une Graminée voisine du Maìs, l'Euchlène mexicain. Le climat, pour la réussite de cette plante, doit être chaud et humide: elle vient bien à la Réunion, même en Egypte, mais la sécheresse est trop grande en Algérie. C'est un fourrage très apprécié des bœufs, des chevaux, des mules; il faut d'ailleurs, avant de leur donner, le hacher.

Une autre Graminée très commune dans les pays chauds est l' " herbe de Guinée " ou Panic élcué. Le long des rivières et autour des eaux stagnantes, on emploie le Panic crête de coq, connu sous le nom de Barnyard grass ou Coksin grass. Il serait, d'après Stapl, identique au Panic Burgu, plante fourragère et saccharifère $(p, 131)$ du Soudan, que l'on cultive notamment sur les bords du Niger; la paille coupée en vert sert à l'alimentation des vaches et des moutons, mais non des chameaux; le foin coupé à l'état jaune et séché peut servir à nourrir les chevaux; les feuilles pourries servent en outre à calfater les navires; on peut en extraire un savon; on en fait des couvertures autour des villages; les graines peuvent être mangées crues, cuites et préparées en couscous.

Le Paspale scrobicule est connu et utilisé dans l'Inde sous le nom tamoul de "varagou "; il y a deux glumes et une fleur hermaphrodite. Une Graminée aquatique, qui appartient au même groupe que le Riz et qui s'en distingue par l'absence de glumes, est la Leersic hexandre; elle est donnée au bétail en Australie orientale, aux Philippines, en Amérique; sa culture se pratique dans l'eau, comme celle du Riz. Dans le Tocusso ou Dagussa,

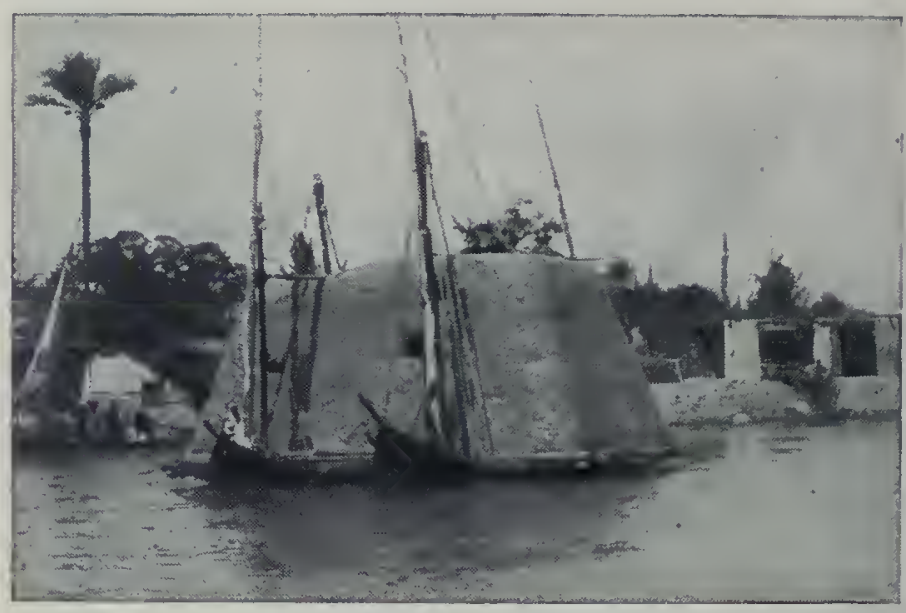

Transport de la paille en Égypte.

variété de l'Eleusine coracana, les inflorescences sont formées de cinq à six épis allongés, rapprochés les uns à côté des autres comme les doigts d'une main; ses tiges et ses feuilles constituent un bon fourrage à l'état sec.

En outre des Graminées qui viennent d'être mentionnées, on cultive encore des Papilionacées alimentaires pour les animaux, notamment le Pois patate ou Pois-cochon, Pois manioc, Manioccochon: c'est le Pachyrhize anguleux, recherché pour ses tubercules qui sont consommés par le bétail. Les tiges sont volubiles ou rampantes; les feuilles sont longuement pétiolées et composées de trois folioles triangulaires avec stipelles. Mentionnons également le Dolic biflore, le Cyamopsis psoraloides, qui constituent une grande ressource pour les pays pauvres, car le rendement est considérable.

Fourrages verts annuels. - Sans avoir, à beaucoup près, l'importance des fourrages précédents, les fourrages verts annuels ont pour rôle de varier l'alimentation du bétail. Ce sont des Légumineuses, des Crucifères ou des Graminées.

Le Trèfle incarnat ou Farouche, spontané en Catalogne et cultivé seulement depuis le $\mathrm{XVtII^{ \textrm {e } }}$ siècle, est plus précoce que la Luzerne et le Trèfle des prés; il croît très bien dans le nord de la France; ses fleurs rouges forment des épis oblongs.

La Vesce cultivée, le Pois des champs ou Pisaille, la Gesse chiche, dite aussi Pois cornu, Pois carré, jarosse ou gérousse, la Lentille sont parfois cultivées comme fourrage, de même que la Navette et le Colza. Quelques-unes de ces plantes, semées aussitôt après la moisson, donnent au premier printemps d'excellents fourrages.

Quelques céréales sont aussi cultivées comme fourragères : le Sarrasin, le Seigle, l'Avoine, les Millets, le Maïs. Le Maïsfourrage fournit une nourriture abondante; il est consommé en vert dans le courant du mois d'août, et coupé dès la fin de septembre sous le climat de Paris, car il gèle facilement. Débité en fragments de 15 à 20 centimètres, il est ensilé au fond d'une grange et utilisé jusquau printemps. La paille des Céréales, entière ou hachée, parfois désincrustée par une faible lessive de soude, comme en Allemagne, seule ou mélangée, joue un rôle assez important comme fourrage.

Plantes fourragères sarclées. - La culture de ces végétaux entre dans les combinaisons régulières d'assolement; ils se plantent en lignes assez écartées pour permettre le sarclage et fournissent une nourriture d'hiver abondante et fraîche.

Les Betteraves fourragères se sèment en avril, en terre fraîche et bien fumée; on arrache en octobre et on conserve en silo, après sectionnement du collet. Les variétés cultivées comme fourrage : corne de bouf, disette mammouth, jaune géante, etc., ont des racines blanches, jaunes ou rouges, contournées, cylindriques ou globuleuses, de grande taille et croissant presque entièrement 
hors du sol. La betterave, riche en eau, mais pauvre en azote, se mélange toujours au foin ou aux tourteaux oléagineux.

Les variétés de Pommes de terre à grand rendement : magnum bonum, institut de Beauvais, chardon, etc., conviennent à tous les animaux et sont précieuses pour l'engraissement des porcs.

Les tubercules du Topinambour, crus ou cuits, et arrachés au fur et à mesure des besoins, sont, comme la pomme de terre, un fourrage très nutritif. Les racines de la Carotte et ses feuilles conservées en silo sont surtout données aux chevaux pendant l'hiver, mais sont recherchées avidement par tous les animaux. Les variétés à racines volumineuses : blanche à collet vert, blanche des Vosges, rouge à collet vert des Flandres, sont les plus recommandables.

Le Navet fourrager est une culture du nord de l'Europe; certaines variétés tendres se délitent à la cuisson; les variétés dures, moins appréciées des animaux, se conservent mieux. Au point de vue de la forme, on distingue les navets longs et les navets globuleux ou turneps. Enfin les Choux fourragers constituent une précieuse ressource : les uns sont utiles par leur tige renflée, les autres par leurs feuilles. Au premier groupe appartiennent le Chou-navet ou Rutabaga, dont le tubercule souterrain est formé à la fois par la partie inférieure de la tige et la partie supérieure des racines, et le Chou-rave

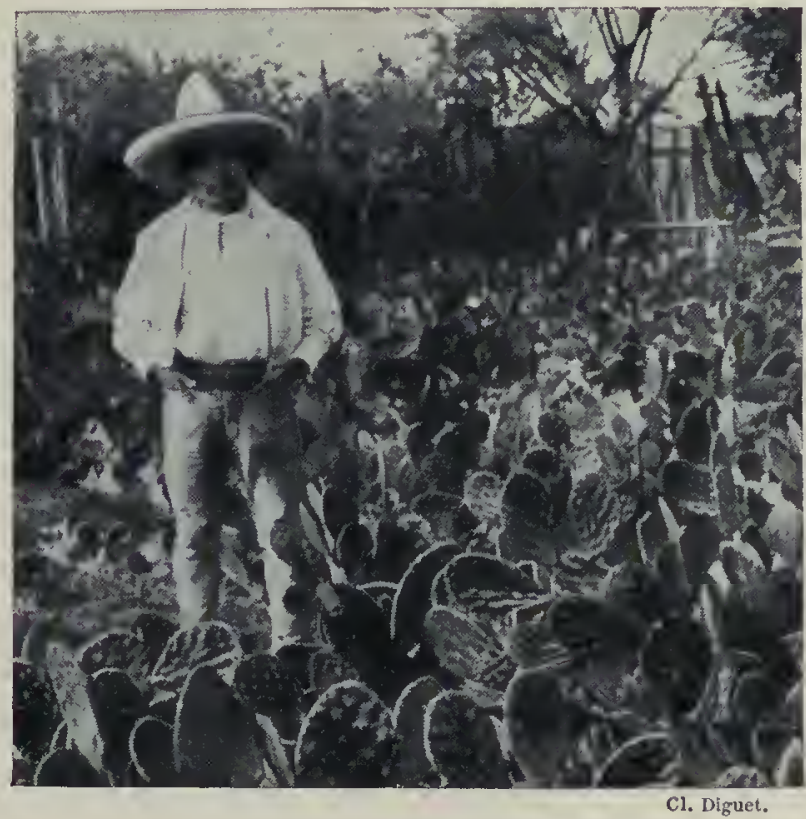

Plantation de Nopals, au Mexique.
La mélasse de betteraves, à la dose d'environ 2 kilogrammes par jour et par 1000 kilogrammes de poids vif, est excellente pour l alimentation du bétail. On l'utilise à l'état grenu ou on la liquéfie dans de grands bacs chauffés à $80^{\circ}$, et on lui incorpore 40 à 70 pour 100 de petit blé écrasé, de farine grossière de coprah ou d'arachide, de paille hachée, et même de tourbe, non digérable. On chauffe et on dessèche ces agglomérés qui sont facilement transportables.

Graines fourragères. L'avoine est, en Europe, la principale graine fourragère; elle est non seulement un aliment, mais un stimulant; elle entre dans la ration du cheval, des moutons et, au $\mathrm{Da}$ nemark, des vaches laitières; l'orge remplace l'avoine, dans la ration des chevaux, en Espagne et dans l'Afrique du Nord. Le maïs, aux EtatsUnis, nourrit les porcs. La téverole. la vesce, certaines variétés de haricots sont aussi données aux bestiaux. On utilise encore la caroube, fruit du Caroubier, et le son provenant de la mouture des céréales.

Le seigle, l'orge, le petit blé, le maïs, le sarrasin, la vesce nourrissent les volailles. L'alimentation des petits oiseaux de volière donne lieu à un commerce assez important. Les graines les plus employées sont le chènevis, le riz écrasé, l'alpiste, qui est la graine d'une Graminée; le Phalaris des Canaries, et surtout la graine du Millet commun, battue ou fixée encore à l'épi. Cette dernière plante, cultivée dans le midi de la France, se coupe à la faucille lors de sa pleine maturité; les épis sont mis en gerbes et sèchent sous des hangars lorsqu iils doivent être expédiés entiers aux oiseleurs; sinon, on les bat simplement en les frappant sur une table établie dans le champ même, ou encore, à la ferme, à l'aide de fléaux. A cette vente de graines s ajoute, dans les grandes villes, la vente du Mouron, cette "santé du corps" pour les petits oiseaux. Cette herbe est récoltée un peu partout dans la banlieue parisienne, sur les terrains vagues; elle est cultivée à Puteaux et dans plusieurs autres localités. Au marché aux oiseaux, qui a lieu le dimanche près de Notre-Dame de Paris, les camelots offrent, suivant la saison, le Séneçon, le Plantain, les fruits de l'Aubépine ou du Sorbier, etc.

Plantes fourragères pour insectes utiles. - A ces plantes, il faut ajouter celles qui remplissent un rôle analogue visà-vis d'insectes utiles.

Le Mûrier blanc, du nord de la Chine, a été introduit successivement dans l'Inde, en Perse, en Espagne, dans l'Italie méridionale, puis en France, sous Charles VIII. Il est cultivé dans le midi de la France pour les besoins de la sériciculture.

Le Chêne kermès, de la région méditerranéenne, nourrit une cochenille globuleuse, le kermès des teinturiers. Traité par l'acide acétique, l'insecte desséché donne une belle matière rouge, utilisée jadis pour teindre les laines et les soies, et qui n'est plus guère employée qu'en Orient; l'emploi de la cochenille parasite des Nopals fit péricliter cette industrie. Au Mexique, le Nopal (Opuntia Hernandsi et $O$. Ficus indica, var. inerme) est cultivé depuis l'époque précolombienne pour l'élevage de la cochenille, insecte qui, desséché et broyé, fournit le carmin. Cette culture a presque disparu, comme celle de la Garance, par suite de la concurrence de l'alizarine artificielle. Il n'existe plus au Mexique que quelques nopaleries à cochenille. On y cultive des variétés presque inermes : les Nopals de Castilla et de San Gabriel, qui se multiplient par boutures et, au bout de trois ans, on les ensemence dé cochenilles qui sont recueillies dans des étuis en feuille de Palmier qu'on pique sur les Nopals. L'insecte en sort bientôt, se fixe sur la plante et en suce la sève. Sa croissance dure de trois à quatre mois.

Quelquéfois, ce n'est pas l insecte lui-même qu'on utilise, mais un des produits de son activité : noix de galle (p. 65), galle de Chine de différents Rhus, manne de certains Tamaris, gommelaque de l'Ambrevade (Cajanus indicus) et du Combretum de Bovet, qui sont des arbustes de l'Inde et l'Indochine.
Les tourteaux de ravison, riches en essence de moutarde, ne doivent pas être employés; ils peuvent tuer le bétail, ou tout au moins rendre dangereux le lait des vaches laitières. 


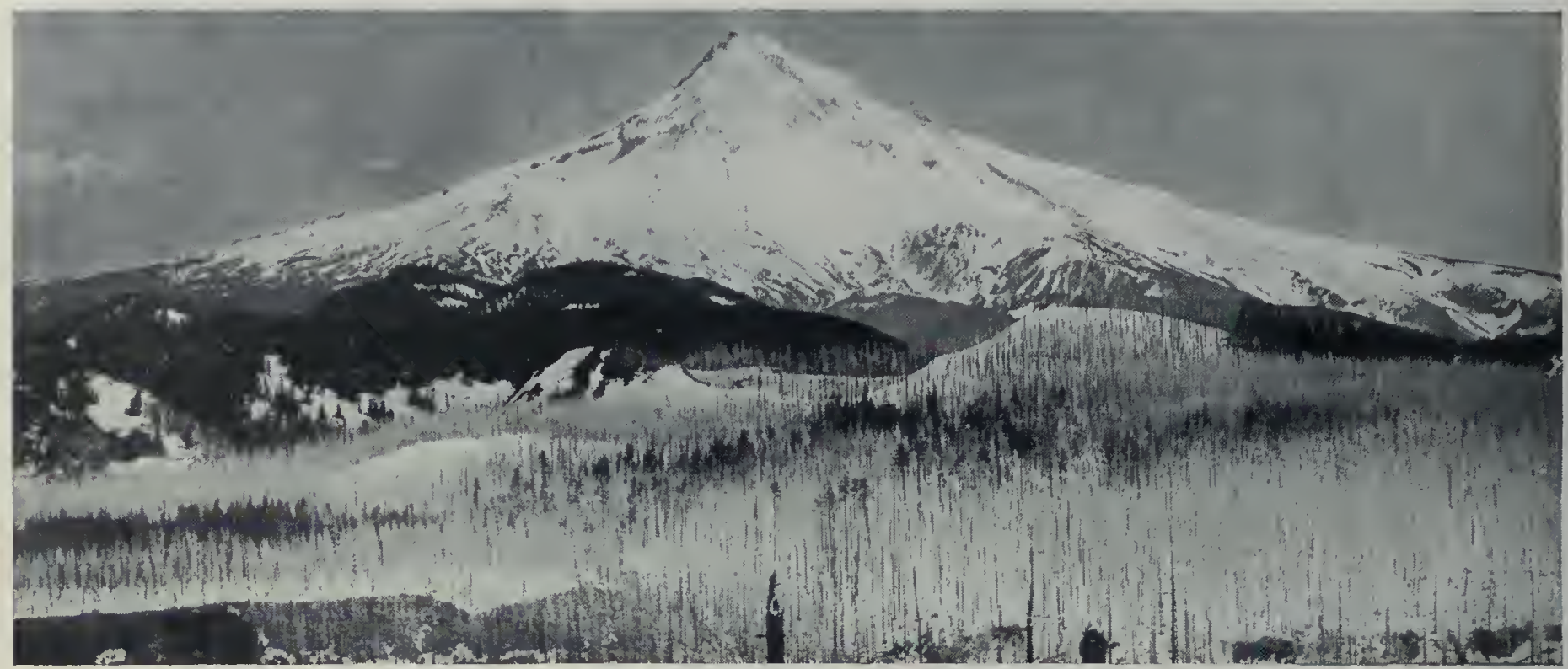

FORET RENAISSANTE, APRES UN INCENDIE, EN AMERIQUE DU NORD.

\section{V. - LES PLANTES INDUSTRIELLES}

\section{LE BOIS}

" J'ai voulu quelquefois, écrivait au $\mathrm{XVI}^{\mathrm{e}}$ siècle Bernard $\mathrm{Pa}$ lissy, mettre par estat les arts qui cesseraient alors qu il n'y aurait plus de bois, mais quand jen eus escript un grand nombre, je n'en sus trouver la fin à mon esprit et, ayant tout considéré, je trouvay quil n'y en avait pas un seul qui se peust excercer sans bois. "Malgré l'emploi de plus en plus grand des métaux, le bois est aujourd'hui, comme au temps du génial potier, une des substances les plus précieuses pour l'homme. Les découvertes modernes n'ont pas restreint les usages du bois : elles les ont seulement modifiés. Sans doute, le bois est moins employé qu'autrefois pour le chauffage; dans l'habitation, le fer et le ciment armé limitent son emploi; il a presque disparu de la grosse construction navale, mais dans nombre d'industries : tonnellerie, carrosserie, menuiserie, ébénisterie, il a conservé ses positions; le $\mathrm{XtX}^{\mathrm{e}}$ siècle lui a créé des débouchés de premier ordre : traverses de chemins de fer, poteaux télégraphiques, pavage, fabrication du papier, de la poudre, etc. La consommation de matières ligneuses est sj grande que le monde, dans son ensemble, s'appauvrit en bois; la pousse des forêts ne ccmpense pas la destruction quion en fait.

Il existe cependant encore, de par le mondé, quelques belles forêts. Celle qui s'étend au Canada sur les provinces de Québec

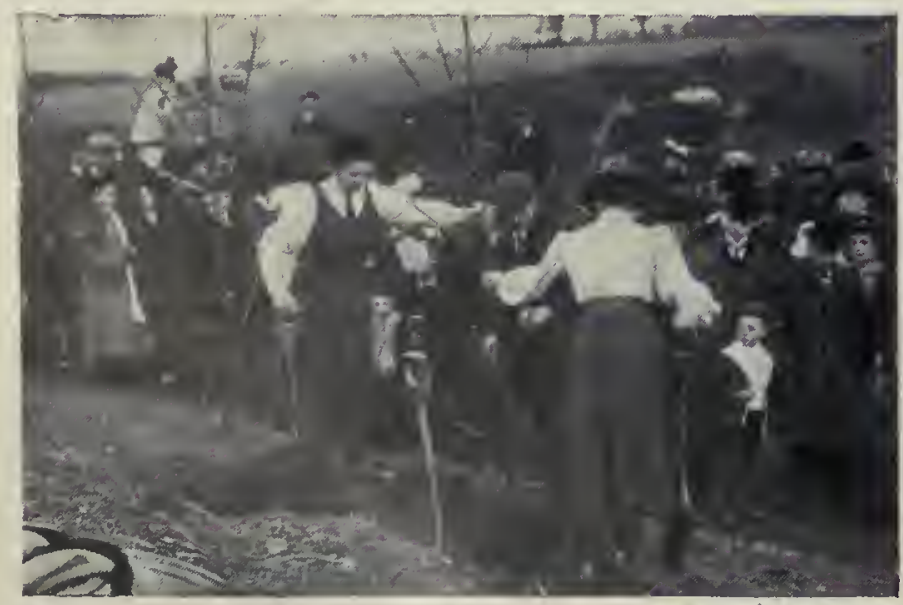

Une Féle de l'Arbre, en Angleterre. et d'Ontario, se prolonge au nord jusqu'à l'Hudson et au Labrador, mesure 2700 kilomètres de long sur 1500 de large. La forêt amazonienne dans l'Amérique du Sud recouvre au Brésil 3000 kilomètres sur 2000. Citons encore l'immense forêt équatoriale africaine et les vastes régions boisées de la Sibérie.

Bienfaits des forêts. - Par ses produits, la forêt met en valeur les terrains pauvres, comme le montre l'exemple de la Champagne pouilleuse, couverte aujourd'hui de pineraies. La forêt n'est pas seulement une " usine à bois "; par elle, on assainit les régions marécageuses, comme la Sologne et les Landes de Gascogne; dans les plaines, elle brise la violence des vents, régularise la température et le régime des pluies. Dans les montagnes, elle empêche le ravinement et prévient la formation des torrents temporaires, si dévastateurs. "L'arbre sur la montagne, a-t-on dit justement, c'est l'eau dans la rivière. ")

Pour une superficie totale de 54 millions d'hectares, la France possède près de 10 millions d'hectares de forêts; son taux de boisement est de 18,2 pour 100. Il est, pour l'Angleterre, de 4 pour 100 , l'Allemagne 16, la Russie 32, la Suède 40, la Finlande 60 . Notre taux de boisement n'est donc pas absolument réduit, mais c'est la montagne surtout qui a souffert par l'extension exagérée des pâturages, par l'exploitation abusive de la forêt. En Amérique, en Italie, en Angleterre, en France, des sociétés scolaires de reboisement ont été créées et des Fêtes de l'Arbre instituées. Chaque élève plante un arbre sur un terrain concédé par les communes; l'année suivante, on va voir en groupe les progrès de la plantation et en commencer une autre. Excellente leçon de choses, dont la généralisation en France est à souhaiter. Nos écoljers répareront ainsi l'imprévoyance de leurs ancêtres et empêcheront la réalisation de la fameuse prophétie de Colbert : "La France périra faute de bois. "

Les ennemis des arbres. - L'homme est le principal ennemi des arbres : chaque jour, la cognée du bûcheron en jette à terre une superbe armée; mais il n'est pas le seul ennemi. Le ver blanc attaque les racines; tout un peuple de larves: Sirex, Capricornes, Bostriches, Lucanes, creuse des galeries dans le bois. Parmi les Champignons, l'Armillaire, plusieurs Polypores et une foule d'espèces microscopiques causent des ravages incalculables. Le chancre est parfois une maladie à Nectria due à une blessure initiale.

Les arbres souffrent aussi des gelées, qui attaquent l'aubier, l'empêchent de se transformer en duramen et déterminent plus tard l'altération nommée lunure. Les tempêtes causent souvent dans les forêts de véritables désastres; les incendies détruisent en quelques 


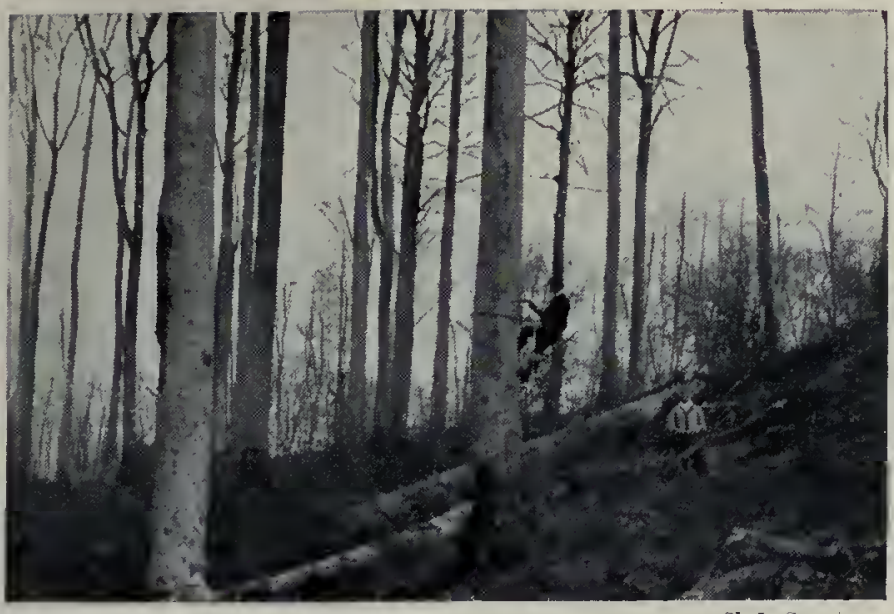

Un bûcheron en forêt de Compiègne.

heures des hectares de boisement. En France, les incendies sont fréquents, en été, dans la forêt de Fontainebleau, dans celles des Landes et de l'Estérel, où dominent les résineux.

Au Canada et aux Etats-Unis, après de longues périodes de sécheresse, de terribles incendies se produisent qui détruisent des surfaces boisées plus grandes que la France. Au printemps suivant, autour des troncs noircis, apparaît toute une végétation qu'on ne soupçonnait pas : herbes, Groseilliers, Framboisiers sauvages, puis, au bout de quelques années, pointent des Peupliers, des Merisiers, des Saules, des Hêtres, aux tiges élancées, couvertes d'une végétation d'un vert tendre. Sous leurs branches se dresse bientôt une pépinière de jeunes Conifères qui, au bout de cinquante ans, dépassent et étouffent les arbres à feuilles caduques; après cent ans, les Conifères restent maîtres du terrain.

Exploitation des forêts. - La sylviculture est l'art d'aménager et d'exploiter les forêts au mieux des intérêts présents et à venir.

On distingue trois modes principaux d'aménagement : le taillis, la futaie et le taillis sous futaie. Dans le taillis, la régénération repose sur les rejets que fournissent les souches ou les racines des arbres abattus; ce régime ne s'applique qu'aux essences feuillues, les Conifères ne produisant pas de rejets; le taillis ne fournit guère que du bois de feu. Dans l'aménagement en futaie, la régénération repose sur les jeunes plants venus naturellement de graines tombées ou provenant de semis. Les arbres sont exploités tous les cent ans, par exemple. On éclaircit de temps à autre pour favoriser les essences précieuses, enlever les bois blancs, nettoyer les morts-bois : Épines, Ronces, Troènes, etc. A ce régime, la forêt s'améliore, fournit régulièrement du bois d'cuvre et assure les besoins des générations futures. Enfin, le taillis sous futaie est un régime bâtard qui réunit en partie les avantages des deux modes précédents.

Abatage du bois. - Tout domaine boisé est divisé en triages exploités successivement par périodes de dix, vingt ans ou plus. Lorsque la coupe d'un triage est vendue, les bûcherons viennent y construire leur hutte, composée d'une charpente sommaire qui soutient des murs en épaisses mottes de terre et un toit en carton goudronné. La maison bâtie, le travail commence. Il a lieu surtout de novembre en avril, alors que les tissus végétaux contiennent moins de sève et sont, par suite, moins sujets à l'altération.

D'un seul coup de sa cognée, le bûcheron abat des tiges plus grosses que le bras; sa femme taille; ébranche, met en tas le menu bois. Les "vieilles écorces " demandent plus de préparatifs et exigent plus d'effort; on scie parfois, au préalable, leurs maîtresses branches que la

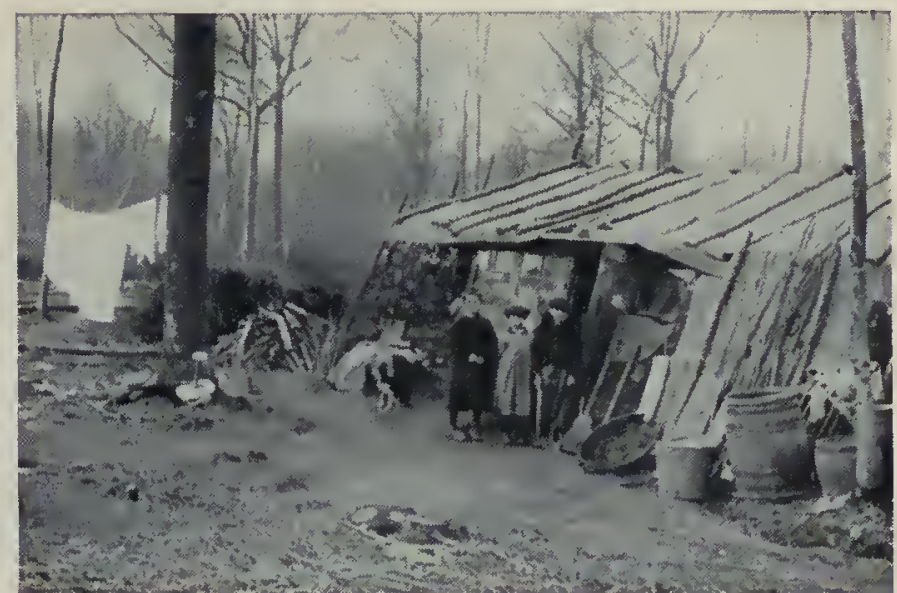

Cabane de bùcherons, dans les bois.

chute fracasserait; on attache de forts cordages dans la couronne; on les sape au pied à la hache, ou on les tronçonne à la scie à main dite passe-partout; quand l'entaille est assez profonde, on provoque la chute et on la dirige en tirant sur les câbles. Dans les grandes exploitations forestières, l'abatage est mécanique. Une chaudière verticale montée sur un chariot, et dont le foyer s'alimente avec les déchets de bois, fournit la vapeur au moteur de la scie par l'intermédiaire d'un long tuyau métallique flexible.

Quand la coupe est avancée, de nouveaux ouvriers scient les bois de feu, font des fagots, écorcent, façonnent des pieux, etc. Quant au gros bois d'ouvre, il est conduit à la scierie où il sera débité.

Transport du bois. - Les modes de transport du bois à la scierie, à l'usine où il sera mis en cuvre ou simplement à la gare la plus proche, sont variables avec les régions, les distances à parcourir et les dimensions des billots. En pays de montagne on utilise le lançage dans des rigoles semi-cylindriques revêtues de bois, ou "bien le schlittage, comme dans les Vosges et la Forêt Noire. La schlitte est un traîneau allongé dont les patins relevés en avant forment deux brancards entre lesquels se place le schlitteur pour diriger et modérer l'allure. Ce traîneau chargé de bois glisse sur une voie spéciale, le chemin de schlitte, établie sur des chevalets en bois et formée de troncs parallèles dans lesquels sont encastrés des rondins de bois qui fournissent un appui au traîneau et contre lesquels sarc-boute le schlitteur poussé par l'énorme fardeau. En Transylvanie, d'importantes exploitations ont établi des chemins de fer funiculaires ou un système de câbles porteurs.

Dans les forêts à sol plat, à défaut d'un petit chemin de fer menant les billots à la scierie, on pratique le traînage à bras d'homme sur chemin de rondins, comme en Afrique, ou par des bêtes de trait jusquaux chemins forestiers; on charge ensuite les grosses pièces sur de gigantesques fardiers.

Partout où des cours d'eau sont à proximité, comme en France, dans le Morvan, on utilise, de préférence, le flottage, très économique. Dans les petites rivières torrentueuses, c'est le flottage à

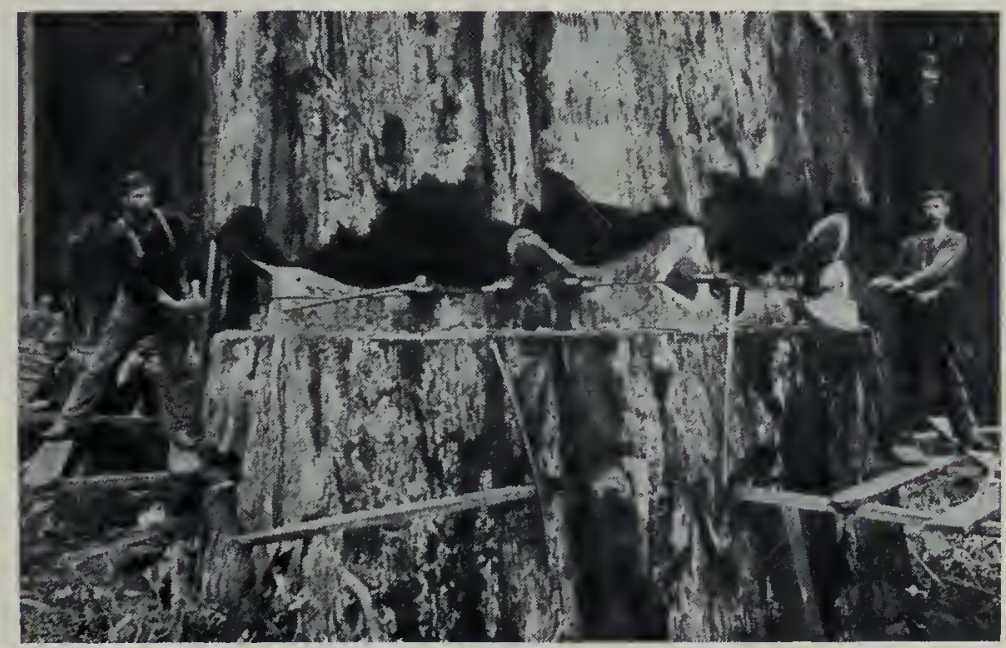

Abatage d'un Sequoia, en Californie. bûches perdues, lancées isolément, suivies et surveillées dans leur parcours par des hommesqui longent les bords, enfin recueillies dans un endroit calme ou port. Dans les rivières navigables, c'est le flottage en trains: les morceaux de bois, reliés solidement, constituent des sortes de radeaux que guident des hommes armés de longues perches. Sur les rivières des Etats-Unis et du Canada flottent des trains de bois d'un volume extraordinaire. Le train gigantesque que montre l'une de nos gravures a été photographié près de Minnéapolis; il occupe presque toute la largeur du Mississipi, a une épaisseur de 10 à 12 mè- 
tres et représente 5 à 6 millions de mètres cubes; beaucoup de bûches sont soulevées en l'air par la pression. Des lettres et marques permettent à chaque propriétaire de reconnaître son bien. Aux États-Unis, on pratique aussi parfois le flottage par mer, en trains énormes, tirés par deux remorqueurs quiles conduisent diun point forestier de la côte du Pacifique jusqu'à San-Francisco.

Débitage du bois. - Avant d'être débité, le bois est desséché en plein air ou sous un hangar par simple empilage. La dessiccation exige plu-

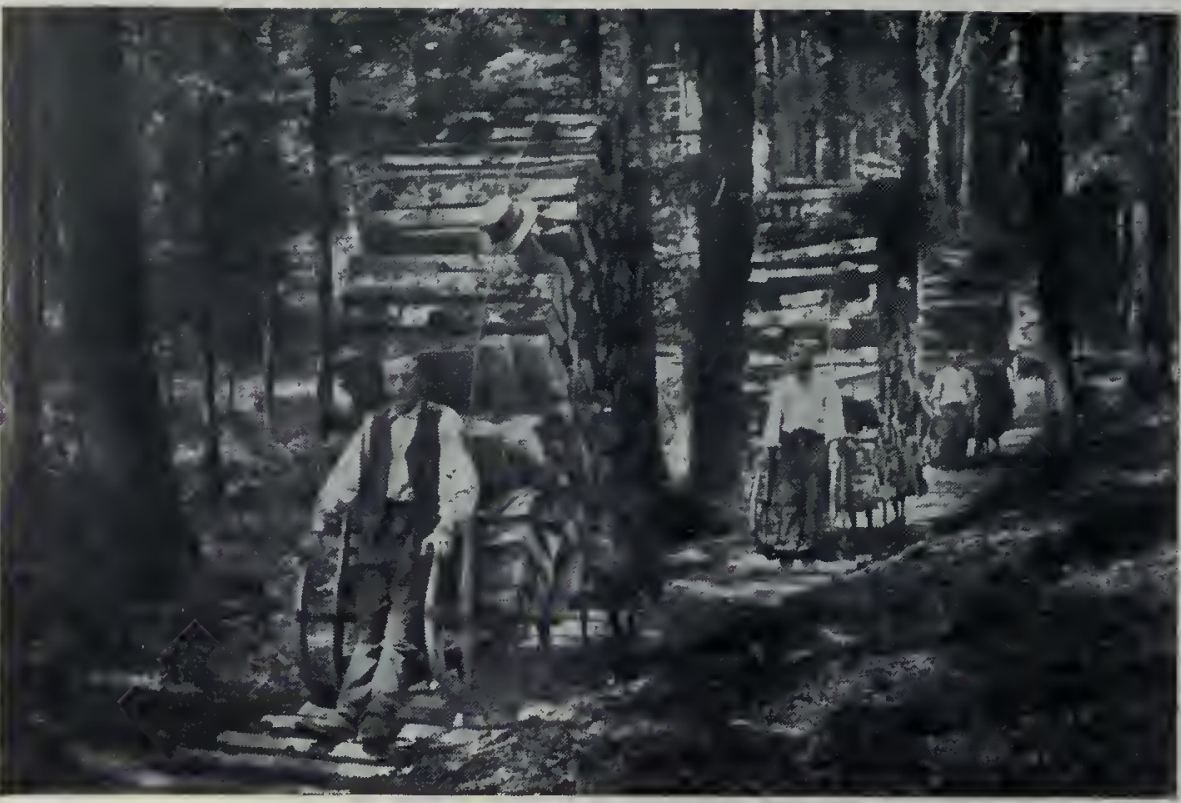

Schlitteurs dans une forêt des Vosges.

sons; les industrieschimiques l'utilisent pour la fabrication de l'acide oxalique. On en retire de l'alcool : dans un digesteur, sous l'action d'une solution d'acide sulfureux, la cellulose est transformée partiellement en sucre qu'on fait fermenter. Les rognures de bois, surtout celles de Pin, traitées par des machines spéciales, donnent des copeaux fins et menus qui, sous le nom de laine de bois, sont très employés pour les emballages, la literie, la bourrellerie, la tapisserie, la filtration.

Bois de chauffage. - Les bûches marchandes pour le chauffage sont fournies sieurs années; on opère plus rapidement à l'étuve, mais le résultat n'est pas toujours aussi bon. Une fois sec, le bois, suivant l'usage auquel on le destine, est équarri à la hache en supprimant l'aubier, ou bien débité en madriers, poutrelles, chevrons ou planches. L'emploi de la scie à main manouvrée par des scieurs de long est rare aujourd'hui en Europe; les scieries possèdent un matériel perfectionné qui opère plus vite et à meilleur compte. Des scies à mouvement alternatif, comprenant plusieurs lames montées sur un châssis, découpent dans un tronc d'arbre, en une seule opération, autant de planches qu'on le désire. Les scies circulaires, composées d'un disque d'acier denté, et les scies à ruban sont d'un usage courant. Des raboteuses mécaniques, des machines à percer, à moulurer, à mortaiser, à tourner complètent parfois le travail du sciage et permettent de fournir à l'industrie des bois déjà presque façonnés.

Déchets de scierie. - Dans les usines façonnant le bois, les copeaux et la sciure s'entassent en monticules énormes. En France, on n'en tire généralement que peu de parti; il n'en est pas de même en Suède, en Allemagne, aux États-Unis. Grâce à des grilles spéciales, on les utilise pour le chauffage des chaudières à vapeur et des étuves à dessiccation du bois. On les distille dans des cornues pour en obtenir un gaz propre à l'éclairage ou générateur de force motrice; par mélange avec du goudron ou de la résine, puis compression, on en fait des briquettes ou des allume-feu. La sciure est utilisée pour le filtrage des huiles épurées, pour l'épuration chimique du gaz d'éclairage comme corps divisant du mélange du sulfate ferreux et de chaux hydratée, comme substance absorbante sur les planchers, ou comme litière dans les écuries, comme matière d'emballage, comme substance isolante pour conserver les oignons à fleurs, pour empêcher la fusion de la glace. Pétrie avec du ciment, du sable, elle entre dans la confection des agglomérés pour cloi-

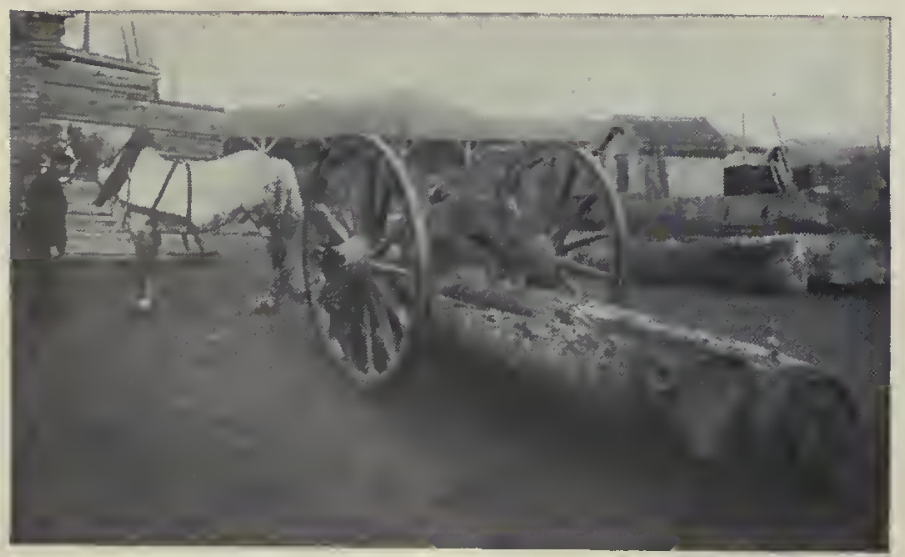

par des arbres âgés d'environ trente ans; les branches trop courtes ou trop minces sont groupées en fagots ou débitées en margotins. Une grande partie du bois brûlé à Paris vient des forêts du Morvan. Au printemps qui suit la coupe, les rondins, après un marquage spécial à chaque négociant, sont lancés dans les ruisseaux de la région, grossis par une masse d'eau envoyée à dessein du lac des Settons; la " courrée " les entraîne jusqu à Clamecy, sur l'Yonne, ou à Vermenton, sur la Cure. Les bûches sont triées d'après leurs marques et chargées sur des chalands.

Les bois de chauffage se divisent en bois durs ayant une densité supérieure à 0,7 , comme Hêtre, Chêne, Erable, Frêne, Orme, Charme; en bois tendres : Bouleau, Aune, Tilleul, etc., et en bois résineux, comme Pin et Sapin. A volume égal, les bois durs donnent plus de chaleur que les boistendres; à poids égal, il n'en est plus ainsi : le Tilleul tient la tête pour le pouvoir calorique, suivi de près parl'Orme, le Pin, l'Erable et de plus loin par le Chêne et le Hêtre.

Charbon de bois. - Deux procédés principaux sont employés pour la carbonisation du bois : celui des meules, sur place en forêt, et celui des cylindres ou de distillation en vase clos dans des usines spéciales.

Au centre de l'emplacement choisi pour construire la meule, les charbonniers enfoncent quatre perches verticales qui limitent une cheminée de 30 centimètres de diamètre ; puis, autour, ils dressent quatre à cing étages de rondins hauts de 60 centimètres; des canaux horizontaux communiquant avec la cheminée sont ménagés entre les couches. La meule est ensuite recouverte de mousse, de terre ou de gazon, sauf l'orifice central, par lequel on lance du bois enflammé. Quand au bout de quelques heures la fumée, d'abord noire, devient bleuâtre et transparente, le charbonnier bouche la

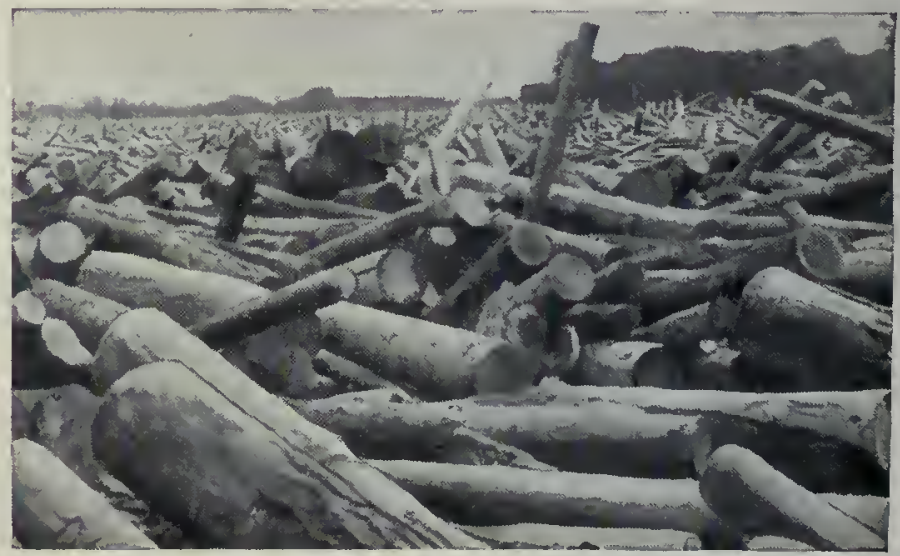

Flottage du bois par un fleuve, aux États-Unis. 


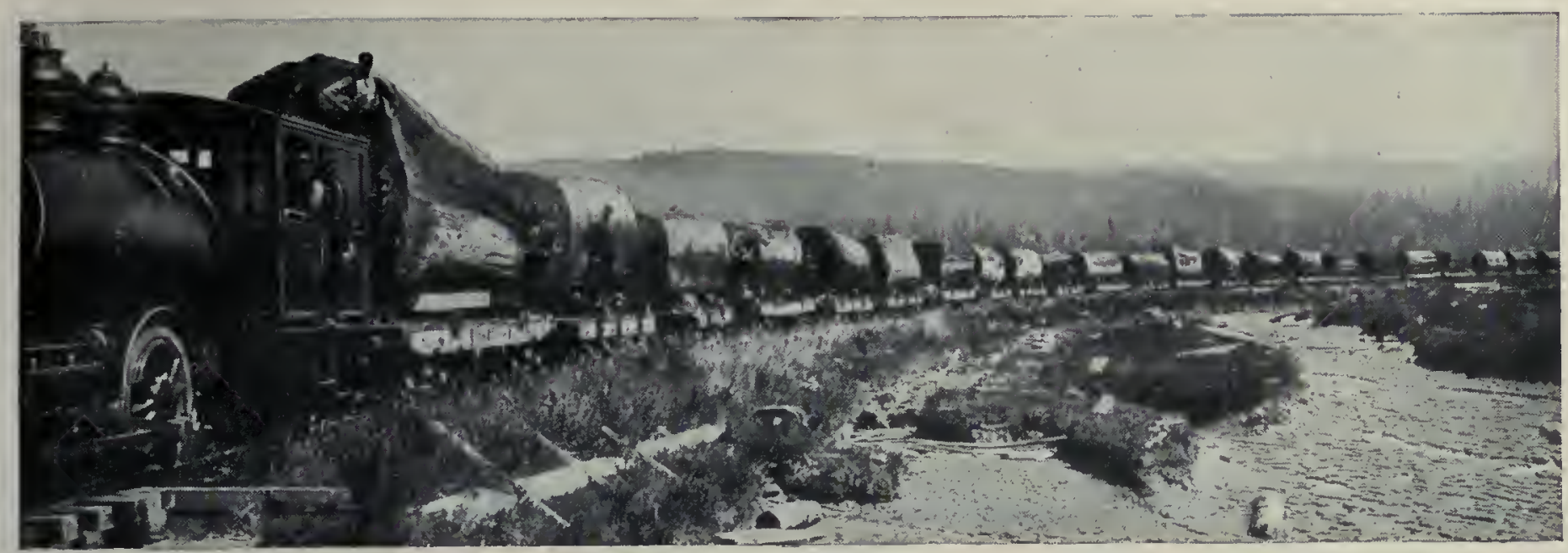

Transport de grosses sections de troncs d'arbres par chemin de fer, aux Etats-Unis.

cheminée et creuse avec un bâton des évents pour l'arrivée de l'air; il les bouche quand la fumée devient transparente, puis ouvre des évents au-dessous des premiers, et ainsi de suite. La carbonisation des 150 stères de bois d'une meule dure de douze à quinze jours; le rendement en charbon est de 21 à 24 pour 100.

Après refroidissement, la meule est démolie, le charbon criblé grossièrement et mis en sacs; il est utilisé pour les besoins du ménage ou en métallurgie pour la production du fer de première qualité.

La carbonisation en cylindres, par distillation, donne comme rendement 27 pour 100 d'un charbon léger, homogène, recherché pour la fabrication des poudres explosives, pour le filtrage, la réduction des métaux, comme désinfectant et absorbant des gaz en médecine, mais il brûle trop vite dans les fourneaux. La distillation des rondins a lieu dans des cylindres de tôle; les gaz se condensent dans des serpentins réfrigérants en donnant du goudron et un liquide, l'acide pyroligneux. Le goudron est employé à injecter les bois ou bien on en retire des produits pharmaceutiques. L'acide pyroligneux, saturé par la chaux et distillé, donne, d'une part, des produits volatils, l'alcool méthylique ou esprit de bois et l'acétone qui se condensent et, d'autre part, de l'acétate de chaux qui reste dans la chaudière. L'esprit de bois est employé pour le chauffage et dans l'industrie chimique; traité de façons spéciales, il donne le chloroforme, l"iodoforme, le chlorure de méthyle. L'acétone est utilisé comme dissolvant dans la fabrication des couleurs d'aniline et des poudres sans fumée.

Quant à l'acétate de chaux resté dans la chaudière, on le traite par l'acide sulfurique et on obtient de l'acide acétique, propre à fabriquer les acétates de fer, d’alumine et de chrome employés comme mordants en teinture, ou bien on lui ajoute la moitié de son volume d'eau et il constitue l'essence de vinaigre; celle-ci, diluée, peut servir de vinaigre de ménage.

Notons encore que de la distillation des souches et racines de

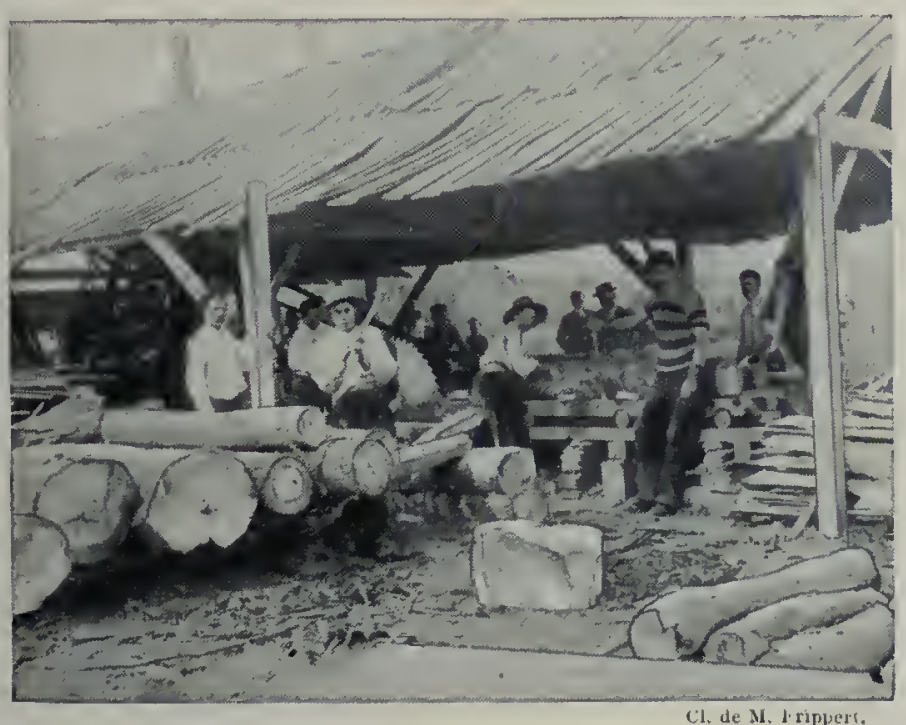

Une scierie mécanique dans le département de l'Yonne.
Sapin on retire, en Suède, l'huile de bois, utilisée pour l'éclairage, et que la distillation du goudron de Bouleau fournit une huile renfermant un principe employé pour aromatiser le cuir de Russie.

Bois de construction. - Sous ce nom, on réunit les bois de marine pour les constructions navales et les bois de charpente pour les constructions terrestres. Depuis la première pirogue, le bois fut d'abord uniquement employé pour la construction navale. Vers 1860, apparurent dans les grands navires les armatures en fer, avec bordage en bois et doublage en cuivre. Le fer et l'acier ont aujourd'hui complètement suṕplanté le bois dans la construction navale, sauf pour les navires d'un faible tonnage. Le Chêne est, par excellence, le bois de membrurc, c'est-à-dire celui qui forme le squelette de la coque; il sert aussi pour le bordé, concurremment avec le Pin, le Sapin ou le Hêtre. Les Pins et les Sapins du Nord, à croissance lente, bien droits, résistants, élastiques, forment la mâture. Le bois de Teck, du Siam, de Birmanie, de Cochinchine et de Java est très apprécié pour la construction des navires de plaisance; il est à la fois léger, dur et très résistant, assez facile à travailler; il ne se laisse pas attaquer par les tarets; il est presque incorruptible dans l'eau.

Le bois forme presque entièrement de nos jours, et non parfois sans élégance, le chalet suisse ou norvégien, l'isba russe, la maison canadienne, chinoise ou japonaise. Dans nos demeures modernes, sa part est considérable : planchers, escaliers, cadres des portes, etc. Le Chêne est, par excellence, le bois de charpente; on utilise aussi le Châtaignier, le Hêtre et, de plus en plus, le Sapin.

Traverses, poteaux, pilotis. - On a pu dire avec raison que les chemins de fer sont, avant tout, des chemins de bois; il faut, en effet, pour soutenir et fixer les rails, une traverse de mètre en mètre. Les traverses en Chêne et surtout en Hêtre créo-

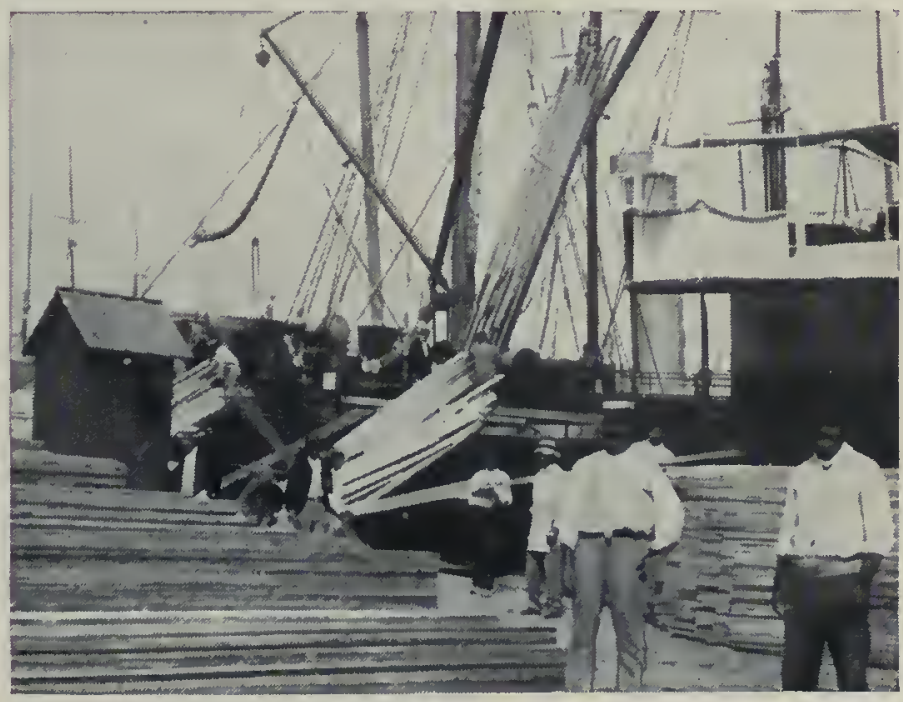

Déchargement du bois de Norvège dans un port français. 

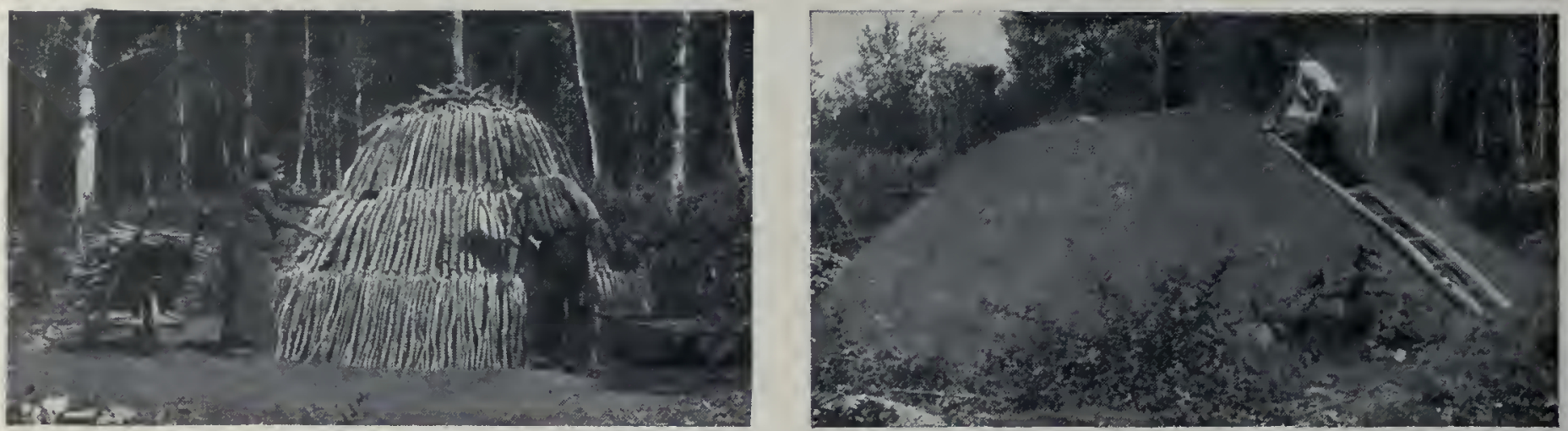

Fabrication du charbon de bois : Construction d'une meule et ouverture des évents dans une meule terminée.

soté sont les plus employées. Heureusement pour nos forêts, les traverses en acier commencent à devenir d'un usage courant.

Les forêts des Landes de Gascogne fournissent les poteaux télégraphiques en Pin maritime. Il faut encore citer les étais de mine en Pin, Chêne ou Aune, dont la consommation est formidable, et les grands pieux pour pilotis.

Les bois s'altérant rapidement à l'air humide, on leur assure une plus longue durée soit par simple revêtement de goudron ou de créosote ou par carbonisation superficielle, soit surtout par pénétration de ces corps antiseptiques en vase clos et sous pression. Le procédé Boucherie, employé pour l'injection des poteaux télégraphiques, se pratique sur des arbres récemment abattus et encore en sève; le tronc est couché, le pied un peu plus haut que la cime. Une solution de sulfate de cuivre contenue dans un réservoir élevé descend sous pression dans un manchon imperméable, chasse la sève et la remplace.

Pavage en bois. - Depuis l'année 1883, le pavage en bois a pris un grand développement en Angleterre et en France. A Paris, une usine municipale fabrique 25 millions de pavés par an. Les trois quarts de sa production sont alimentés par le Pin des Landes, puis viennent le Sapin du Nord, le Mélèze, le Pin sylvestre et, pour une part beaucoup moins grande, le Teck, le Chêne, le Hêtre et aussi le Karri et le Jarrah, qui sont des Eucalyptus d'Australie.

Tous ces bois arrivent à l'usine en madriers de 2 mètres de long sur une section de $0^{\mathrm{m}}, 22 \times 0^{\mathrm{m}}, 08$. Ces madriers sont placés sur une chaîne sans fin, munie de galets de guidage et de râteaux fixateurs, qui les conduit vers une tronçonneuse à dix-sept scies circulaires disposées en trois groupes. Les pavés arrivent au culbuteur, formé de plans inclinés, et tombent sur des tables, $d$ 'où des wagonnets les portent à la salle de créosotage. Une autre machine intéressante est l'ébarbeuse, qui rectifie les arêtes détériorées des pavés de bois usagés avant de les remettre en service.

Bois de fente. - Les bois de fente sont ceux qui sont fendus dans le sens du fil. L'ouvrier travaille en forêt, abrite son chevalet et lui-même sous une butte faite de quelques perches et recouverte de lanières d'écorce; ses outils sont la serpe et la plane; ses matières premières, le Chêne et le Châtaignier. Les pieux pour clôtures sont coupés à la longueur voulue, écorcés et appointis; si le diamètre est trop grand, le morceau est fendu en deux ou trois fragments; en le fendant encore à plusieurs reprises, on le transforme en échalas. Les lattes pour treillages, clôtures, toitures, etc., exigent, de plus, un dressage des faces à la plane.

Le cercle pour tonneau se fait avec le Châtaignier garni de son écorce; les plus grands ont 7 mètres de long, c'est-à-dire environ
2 mètres de diamètre, car les extrémités se recouvrent pour le ligaturage à l'osier. L’industrie du cercle est prospère en Seine-etOise, dans le Limousin et le midi de la France. Les merrains sont des planches de Châtaignier ou de Chêne débitées sur du bois encore vert, sans nouds et ne pouvant communiquer de mauvais goût aux liquides. Le Saule, le Mûrier blanc, le Frêne et plusieurs sortes de bois tendres servent à confectionner les tonneaux d'emballage pour matières sèches. La tonnellerie mécanique a aujourd'hui une grande importance.

Menuiserie, carrosserie. - La menuiserie utilise les bois de sciage les plus divers : durs, tendres ou résineux. La menuiserie en bâtiment consomme la plus forte quantité de bois, tant pour les ouvrages appliqués aux parois : panneaux, plinthes, moulures, montants, portants, etc., que pour les ouvrages mobiles : portes, fenêtres, volets. Les meubles de cuisine se font en Hêtre, Chêne ou Sapin ; les caisses d'emballage, en Peuplier ou Sapin. La menuiserie des jardins confectionne les coffres et châssis, caisses à fleurs, treillages pour berceaux et tonnelles. La menuiserie de voiture comprend la charronnerie et la carrosserie. La charronnerie veut des bois élastiques, tenaces, se fendant difficilement : Orme pour le moyeu et les jantes, Frêne pour les rais, le timon, les brancards. Le Charme, le Micocoulier sont aussi très employés; puis, à un rang éloigné, le Chêne, l'Érable et le Hêtre. La carrosseric, à laquelle le développement des moyens de transport, wagons, tramways, autobus, automobiles, a donné un grand essor, emploie surtout le Frêne, le Pitchpin et le Teck. Les fuselages d'avions se font en bois légers, élastiques et résistants; en Amérique, on emploie pour les longerons la Sapinette noire des Etats-Unis (Picea nigra); en France, on utilise le Frêne pour les longerons, le Peuplier pour les montants, le Frêne, le Noyer et l'Acajou laqués pour l'hélice.

Ébénisterie. - La menuiserie en meubles ou ébénisterie utilise nos plus beaux bois indigènes : Chêne, Noyer, Cerisier, Erable, Poirier; quelques bois américains comme l'Hickory ou Noyer blanc, Carya blanc, le Pitchpin (Pinus australis), solide, assez̨ dense, jaune et zébré de fortes veines résineuses rougeâtres, et aussi nombre de bois exotiques, remarquables par leurs colorations uniformes ou nuancées, veinées ou tachetées. On apprécie beaucoup les loupes, excroissances du tissu ligneux qui ont pour origine une blessure ou une irritation répétée. Le bois en est dur, veiné, avec des fibres à directions flexueuses, ondulées, souvent très bizarres. Cellesdel'Orme, du Thuya de Barbarie (Callitris quadrivalvis), du Frêne, de l'Érable, du Buis, du Noyer, du Noisetier du Levant (Corylus Colurna) sont les plus estimées.

A l'ćbénisterie se rattache l'industrie des bois courbés, qui a pris naissance à Vienne, en $\mathrm{Au}$ - 


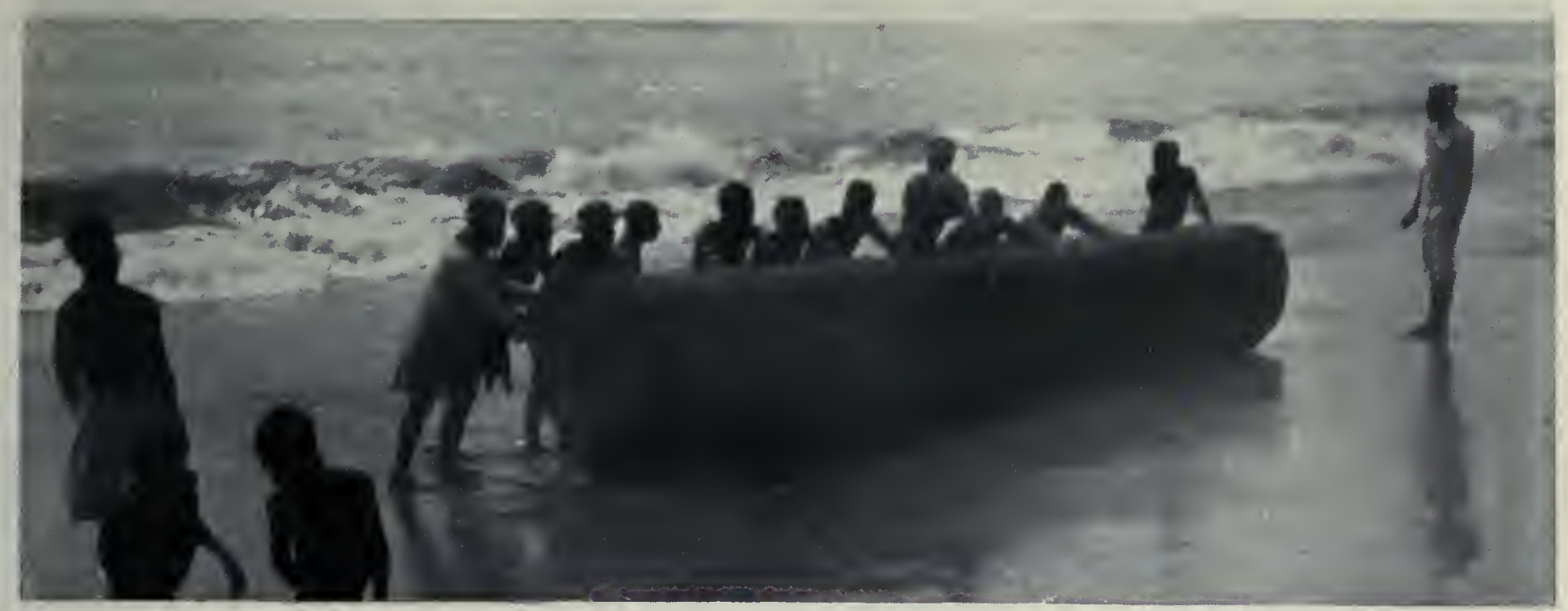

Réception du bois d'acajou, sur la còte du Congo.

triche. Elle utilise des bois durs arrondis au tour : Charme, Orme, Chêne et surtout Hêtre, qui sont soumis pendant quinze minutes à l'action de la vapeur surchauffée en récipients clos. On fait suivre au bois, devenu maniable, les contours d'un modèle en fer auquel on l'assujettit par des pinces et on laisse sécher de deux à huit jours à l'étuve.

Les bois de luxe exotiques sont utilisés pour le placage sous forme de bois tranchés. Des machines découpent les billots de la circonférence au centre en une lame mince spiralée, dont l'épaisseur varie de I millimètre à un cinquième de millimètre. Réservé jadis à la marqueterie, le placage est aujourd'hui d'un usage presque général en ébénisterie.

L'Ébène est fournie par l'Ebénier ou Plaqueminier de l'Inde et de la Malaisie (Diospyros Ebenum), et par plusieurs grands arbres de Cochinchine, de Maurice, de Madagascar et du Congo, appartenant à des espèces voisines. Ce bois n'acquiert toutes ses qualités que chez les exemplaires très âgés; le coeur en est alors noir, compact et d'un grain extrêmement fin. Sa densité est de 1,12 à 1,21 , celle du Hêtre étant de 0,66 à 0,82 .

L'Acajou est probablement, à l'heure actuelle, le bois de luxe le plus employé en ébénisterie. L'Acajou vrai (Swietina Mahagoni) est un grand arbre d'Amérique, formant de vastes forêts à Cuba et à Saint-Domingue, commun au Mexique, au Nicaragua ; son bois compact est d'une teinte rouge fonçant à l'air. Les arbres du genre Khaya, voisin des Swietina, fournissent aussi de l'acajou, principalement le Khaya senegalensis ou Caîlcedrat, au bois agréablement veiné et d'odeur aromatique, et le Khaya ivorensis de l'Afrique occidentale.

Le Palissandre provient d'arbres de la famille des Légumineuses qui croissent au Brésil (Dalbergic nigra), dans l'Inde (D. latifolia) et à Madagascar (D. Perrieri); il est violacé, fonce

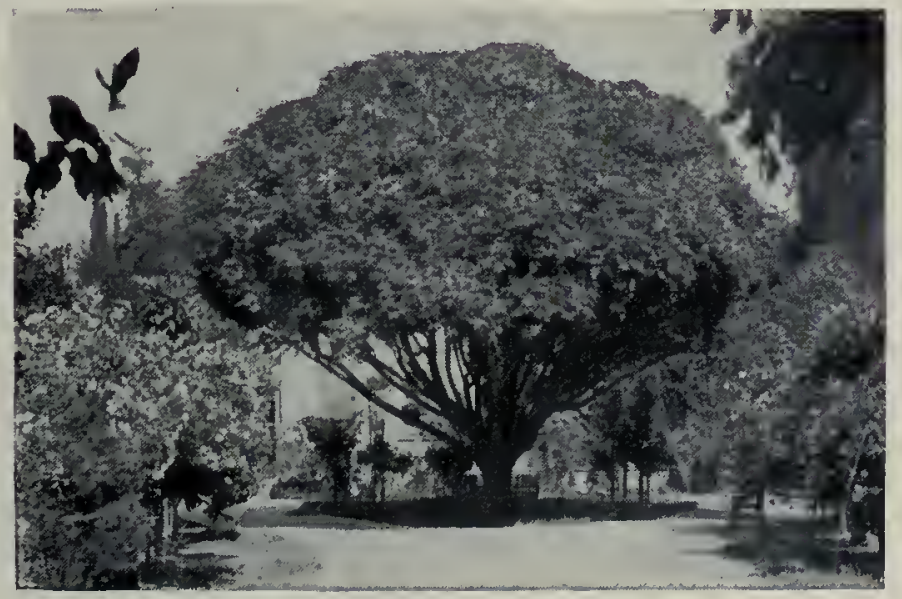

Bois de rose (Thespesia populnea), Californie. à l'air et répand une odeur douce. On utilise encore, pour la grande ébénisterie, la marqueterie, la tabletterie, un grand nombre d'autres essences. Citons, parmi nos bois indigènes, l'Alisier, le Buis, le Cerisier, le Cormier, l'Érable, le Fusain, le Houx, le Prunier, le Citronnier; parmi les bois exotiques, le Cèdre, le Thuya de Barbarie, le bois d'Amboine (Flindersia amboinensis) des Moluques, extrêmement nuancé; les bois de rose, plus ou moins odorants, fournis par des espèces très différentes: celui du Brésil par une Lythracée (Physocalymma scaberrinum), celui d'Océanie par une Malvacée (Thespesia populnea), celui de Guyane par une Lauracée (Licario guyanensis), celui de la Jamaïque par une Rutacée: les bois de Santal (Santalum album), les bois de fer, provenant également d'espèces diverses. Nous avons déjà parlé, en étudiant les familles, du bois d'amarante (Copaifera bracteata), du bois de lettres moucheté (Piratinera guyanensis), du satiné (Ferolia guyanensis), etc. Nos colonies tropicales sont extrêmement riches en bois d'ébénisterie.

Saboterie, boissellerie, allumettes. - Les sabotiers sont les artistes de la forêt; leur travail, assez compliqué, utilise le Tilleul, le Hêtre, l'Érable, l'Aune, le Bouleau, le Noyer. Un ouvrier habile tire d'un mètre cube de bois cent cinquante paires de sabots. Le "tailleur " donne à la bûche la forme du sabot, le "creuseur " l'évide, le "pareur " la termine. La saboterie mécanique fait disparaître peu à peu le façonnage à la main.

Les bois à employer dans la boissellerie sont fixés par la loi ; ce sont : Chêne, Hêtre, Noyer, Châtaignier, Sapin du Nord, Frêne, Orme rouge et Orme blanc.

Les bois pour allumettes employés en France sont débités à la manufacture de Saintine, en bordure de la forêt de Compiègne. On y utilise le Peuplier, le Tilleul, le Sapin, le Tremble, en tout

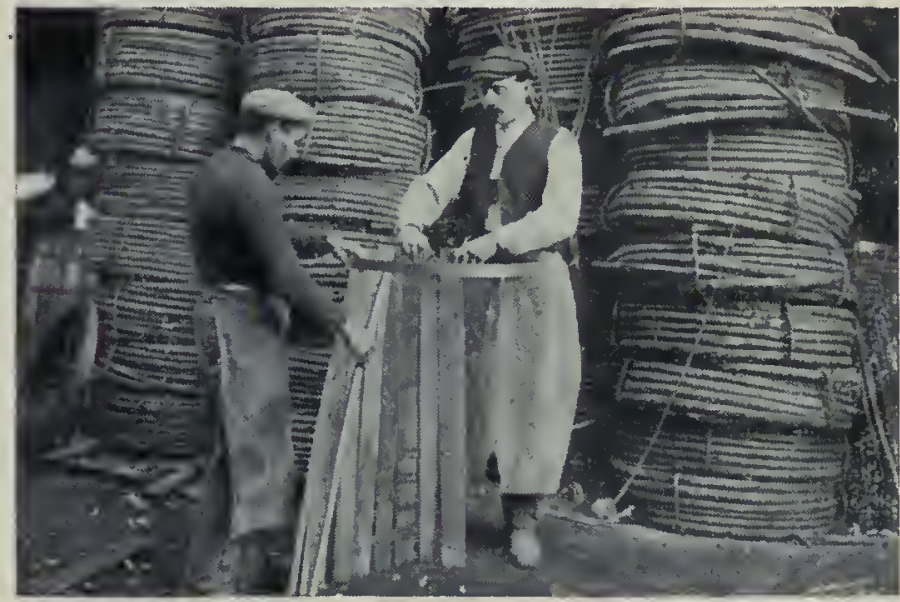

Encerclage des douves d'un tonneau. 


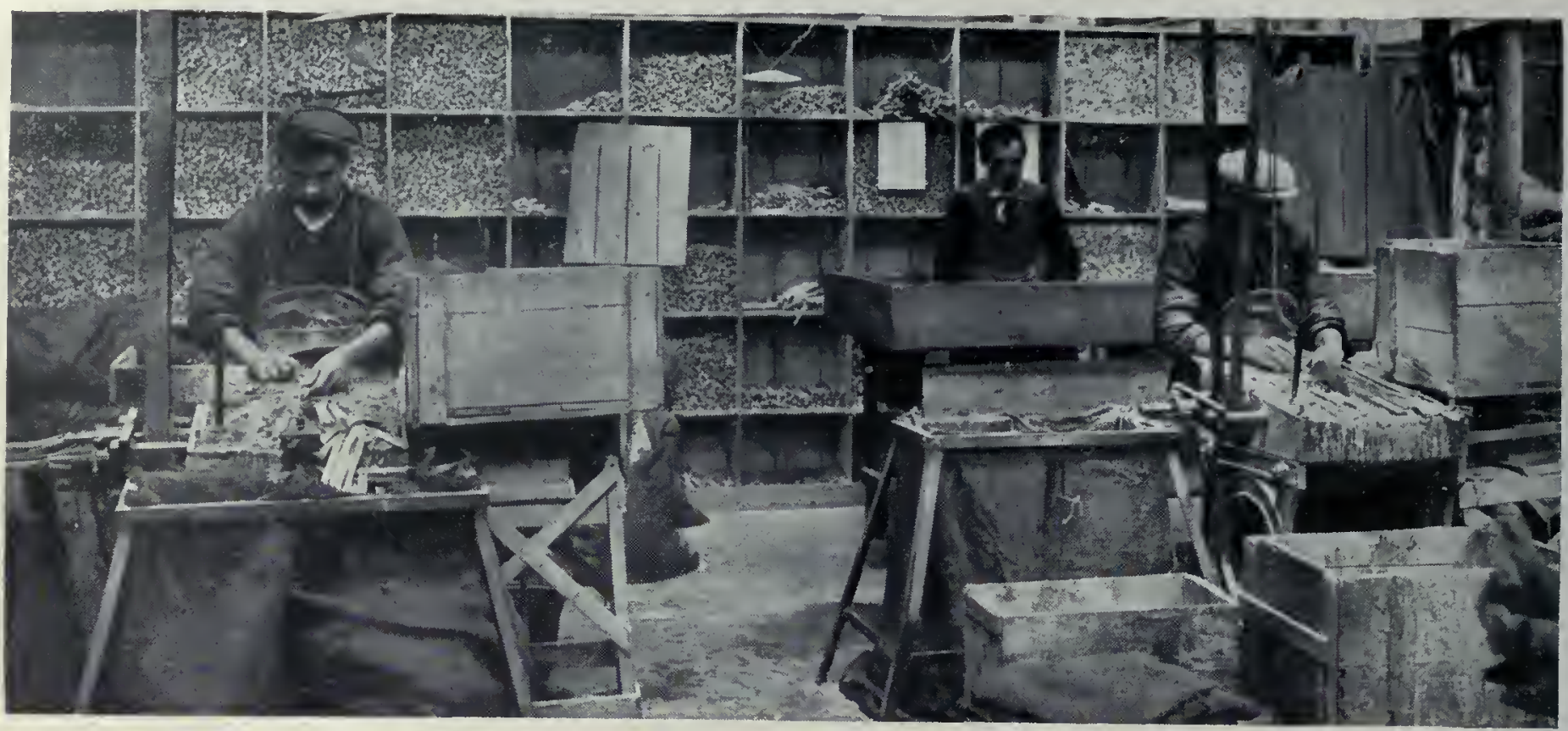

Atelier de sciage pour la monture des brosses.

5000 mètres cubes de bois, chaque année. La partie centrale de chaque tronc ou membrure y est coupée en tranches de la hauteur des futures allumettes. Chaque tranche passe sous une machine qui découpe, 300 bois d'allumettes à la minute; les bois sont triés et rangés mécaniquement, puis expédiés aux diverses manufactures nationales. La production totale française est chaque année de 30 milliards d'allumettes.

Les bois d'allumettes coupés à grande longueur servent, en Bavière, en Autriche, à fabriquer des stores, des tentes de jardin, etc. Les chevilles pour chaussures, en Erable ou en Bouleau, sont façonnées en Amérique et en Allemagne; les cure-dents en Saule blanc viennent du Portugal.

Crayons, pipes, manches d'outils. - Les bois utilisés pour enveloppes de crayons sont le Tilleul et surtout le Cèdre rouge d'Amérique ou Cèdre à crayons, qui est, en réalité, fourni par des Genévriers (Juniperus virginiana et barbadensis), dont le bois est d'odeur agréable. La maison Faber, de Nuremberg, a créé en Allemagne une forêt uniquement composée de Cèdres rouges. Régny, dans le département de la Loire, et Keswick, en Angleterre, sont des centres importants de fabrication des crayons.

La pipe en bois est la base d'une industrie intéressante, particulièrement développée à Saint-Claude (Jura). Le Buis, le Poirier, le Palissandre, et surtout le Merisier et la racine de Bruyère arborescente, provenant de Corse, sont les bois les plus

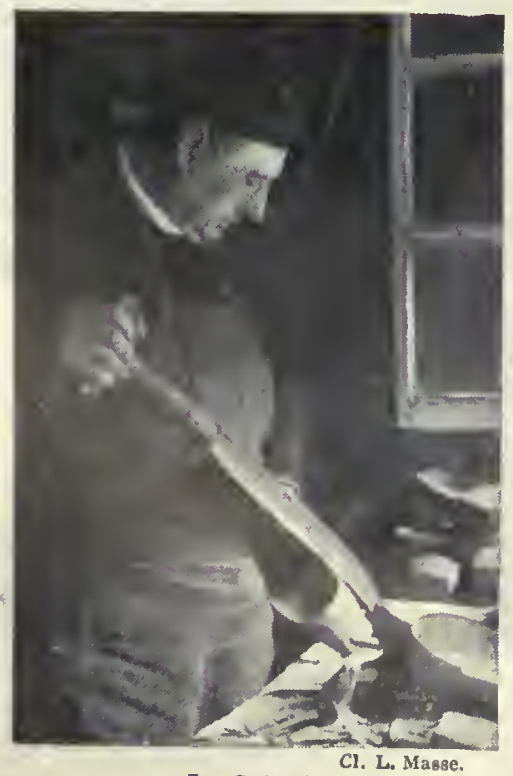

Le Sabotier. employés pour la confection du fourneau ; en Allemagne, on préfère la racine d'Orme. Le tuyau est de Merisier en France, de Bambou dans les pays chauds; en Orient, on fait des tuyaux en Jasmin; on introduit les jeunes tiges dans des tubes opaques où elles poussent sans produire de feuilles sur une longueur qui atteint parfois 3 mètres.

Les manches d'outils exigent des qualités spéciales: le Frêne est utilisé pour les gros outils; le Cornouiller, qui est notre bois indigène le plus dur et le plus tenace, pour les outils de forgeron: le Saule, à cause de sa légèreté, pour les pelles; l'Éra-

manches d'outils. Les Landes et le Lot-et-Garonne fabriquent par millions les manches à balai en Pin maritime; le Micocoulier, bois dur, compact, élastique, est cultivé spécialement dans le Gard pour la fabrication des fourches à foin. Dans l'Aude, on le recèpe au collet et les jeunes branches donnent des manches de fouets : c'est le bois de Perpignan, employé par presque tous les cochers d'Europe. Les maillets de tonnelier sont en Buis, Alisier, Cormier ou Charme; le manche est toujours en Micocoulier.

Des bois durs et tenaces du Charme et de l'Orme, on fait des dents d'engrenage, des vis de pressoirs, des formes de chaussures, des rabots, des poulies, des bobines de filature, des queues de billard, des quilles, des boules, etc.; le Sorbier cst transformé en règles et en équerres; l'Érable en robinets; le Hêtre fournit des battoirs de blanchisseuses, des rames; le Saule, des dents de râteau, des barreaux d'échelles et de râtelier, des perches à Houblon, des bondes; des brindilles du Bouleau, du Genêt, de la Bruyère. on fait des balais grossiers.

Une industrie importante est celle des bois pour brosses, forés ou non, suivant qu'ils forment la planchette où l'on fixera la matière flamenteuse ou le placage. La brosserie emploie tous les bois les plus communs : Bouleau, Peuplier, Hêtre, etc., et les plus luxueux : Acajou, Palissandre, etc. Signalons encore l'industrie des baguettes pour cadres, en Sapin du Nord, Tilleul et Cyprès. Saint-Dié est le centre important de cette fabrication qui emploie un outillage mécanique perfectionné.

Les conduites d'eau en bois sont très employées en Amérique pour les réseaux d'irrigation. Le Sapin jaune du Texas, l'Orme. l'Aune, le Mélèze, noyés dans la terre, résistent plus de cinquante ans et ne sincrustent pas comme les tuyaux métalliques. On les utilise sous forme de madriers, cintrés comme des douves de tonneaux et assemblés au moyen de cercles en fer.

Tour, gravure, sculpture, bois de résonance.- Les ouvrages de tour exigent des bois durs, résistants, à grain fin. $\mathrm{On}$ recherche pour cet usage, parmi nos bois indigènes, le Poirier, le Cormier, l'Alisier, l'Aubépine, le Buis, le Houx, le Lilas, le Troène, le Frêne, le Tillcul. Les bois propres à la gravure sont le Cerisier, le Poirier et surtout le Buis, provenant presque entièrement des forêts du Caucase. La sculpture demande des bois faciles à travailler, homogènes, à grain fin et se fendant difficilement: le Tilleul, le Poirier et le Noyer sont particulièrement appréciés.

La fabrication des jouets en bois à bon marché est très dévem loppée dans le Tyrol, dans le Cercle de la Forêt-Noire, en Allemagne, et aux environs de Marvejols (Lozère); elle utilise le Sapin, le Platane et le Tilleul. Les ouvriers travaillant aux pièces dans leurs villages reçoivent des usiniers des couronnes en bois. tournées suivant un profil déterminé : personnage, cheval, chien: cerf. etc.; ils les débitent en tranches, dégrossissent et finissent le sujet. Dans chaque famille, on ne fait généralement qu'un seul animal; d'autres façonnent les mobiliers de poupées, de petites 


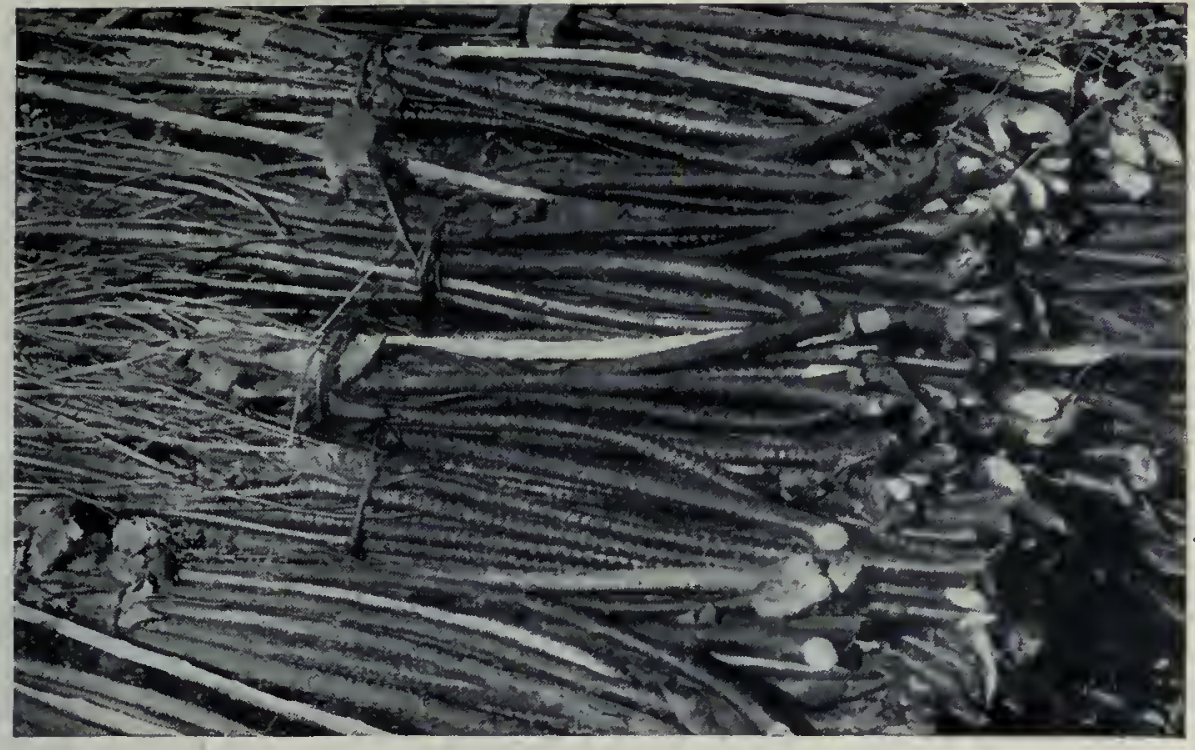

Bois incisés sur pied el qui vont subir l'écorçage.

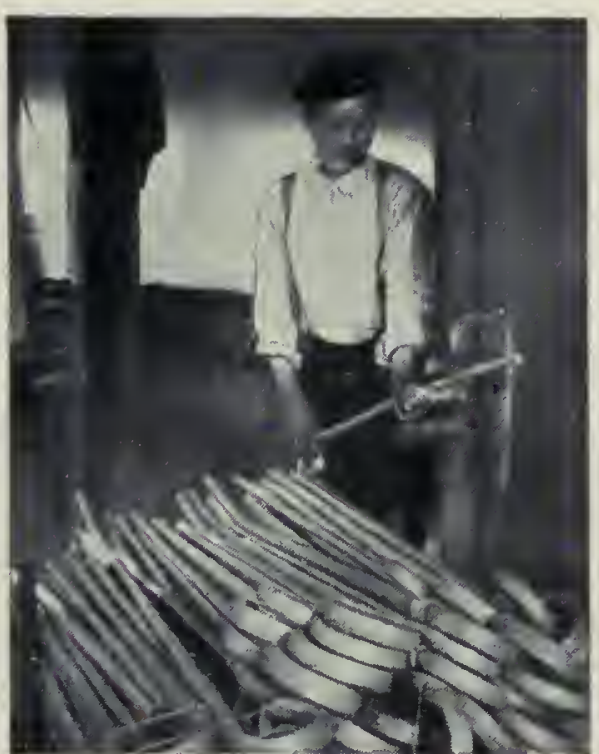

Redressage des bois pour cannes. charrettes. On peut rapprocher de ce genre de travail la fabrication des couverts en bois, coquetiers, salières, etc.

Les bois de résonance pour instruments de musique sont sonores et ne doivent plus travailler une fois secs; ils exigent dix à quinze ans d'empilage sous les hangars avant leur utilisation. Le Merisier, le Tilleul et surtout l'Épicea de la Forêt-Noire, de Bohême, du Tyrol ou de Hongrie, sont recherchés pour la confection des tables d'harmonie et des caisses d'instrument, qui n'emploie que des planches absolument sans défaut. Dans un violon, le manche, la tête, les éclisses et le chevalet se font toujours en Érable; la table et l'âme, en Épicea; la touche, le cordier et le bouton, en Ebène; les chevilles, en Ebène ou en Palissandre. La confection d'un piano exige un grand nombre d'essences : Épicea pour la table de résonance, Hêtre pour les sommiers de chevilles, Tilleul pour les touches de clavier. Le Charme, le Cèdre, l'Hickory, le Cormier, le Tulipier, le Chêne y trouvent aussi leur place, sans parler des bois de placage qui recouvrent l'instrument.

Nous parlerons dans d'autres chapitres des bois de râpage pour la papeterie, des bois tinctoriaux et des bois odorants.

Cannes, manches de parapluies et manches d'ombrelles. - Il existe, dans le monde entier, deux exploitations où l'on cultive spécialement les arbustes pour la production des cannes: l'une est à Maule (Seine-et-Oise), l'autre près de Vienne, en Autriche. Dans les pépinières de Maule on cultive le Frêne, le Sorbier des oiseleurs, le Staphylier ou Faux pistachier, le Cornouiller, les Érables plane et sycomore, le Chêne et le Châtaignier. Un an après la plantation d'un jeune arbuste, on le coupe au pied pour que la souche donne de nombreuses branches. Tous les quinze jours, on enlève les bourgeons latéraux, de manière à éviter la formation de nœuds; la jeune tige se développe droite et sans branches inférieures, terminée simplement par un panache de feuilles.

Au début du printemps, certaines tiges choisies sont incisées sur pied à l'aide d'appareils spéciaux, molettes et fers dentés de modèles variés qui entament les tissus superficiels et forment des dessins : grecs, perlés, torsades, etc. ; des bourrelets inflammatoires se développent qui, plus tard, formeront des saillies régulières sur le bois : ils donnent aux arbustes ainsi travaillés une apparence singulière quand on les voit sur pied.

Lorsque la tige est âgée de trois à cinq ans, suivant son essence et sa destination : canne d'enfant ou d'homme, manche d'ombrelle ou de parapluie, alpenstock, crosse de hockey, etc., on l'abat à la hache. L'opération a lieu d'octobre en avril; la première coupe ne fournit que quatre à cinq brins par pied. Aux coupes suivantes, le nombre des brins augmente; on a vu de vieilles souches de Châtaignier donner, d'un seul coup, cent cinquante cannes.

Les cannes abattues, mises en fagots, sont émondées en arrivant à l'usine. Certaines, à écorce luisante, agréablement colorées : Erable, Frêne, Merisier, Châtaignier, Noisetier, sont livrées telles quelles aux fabricants; les autres sont pelurées à la vapeur, brossées sous un courant d'eau, séchées à l'ombre, puis coupées par des scies mécaniques aux dimensions de $0^{\mathrm{m}}, 90$ à $\mathrm{I}^{\mathrm{m}}, 30$, suivant les besoins. Les tombis seront transformés en manches d'ombrelles ou de parapluies.

Certaines cannes subissent ensuite le courbage de la poignée après un séjour de quelques minutes dans une étuve à vapeur. $\mathrm{Ce}$ courbage a lieu autour d'une masse cylindrique en plomb servant de calibre; un double fil de fer maintient la courbure. Les cannes un peu tordues sont redressées après un nouveau passage à l'étuve, puis le tout va s'entasser sous les hangars, qui en renferment parfois près de 2 millions. Elles sont ensuite vendues aux fabricants qui les finissent, vernissent et ornementent au goût du jour.

Le sylviculteur pour cannes est forcé, lui aussi, de suivre la mode. Quand elle exige des manches d'ombrelles à poignées de fantaisie, les branches sont travaillées sur le vif, incisées, ligaturées, greffées par approche. Parfois même, un anneau d'ivoire est passé dans le cercle formé par deux branches quon ligature et qui finissent par se souder. Vers 1895, où cette décoration faisait fureur, on pouvait voir, dans les pépinières de Maule, des arbustes, futurs manches d'ombrelles, ayant des branches contournées bizarrement et portant pour fruits des anneaux d'ivoire.

En plus des bois dont nous venons de parler, le commerce des cannes en utilise un grand nombre d'autres: l'Ajonc vient de Bretagne; le Prunellier ou Epine noire, du Cher; le Houx, des forêts du Centre; le Saule Marsault ou Chevrin, de Sologne; la région méditerranéenne fournit l'Olivier, la Bruyère arborescente, le Laurier-rose, le Mûrier, le Citronnier, le Chêne-liège. Le Micocoulier est cultivé spécialement pour cannes dans l'Hérault, l'Olivier sauvage en Algérie et le Myrte en Sicile. Beau-

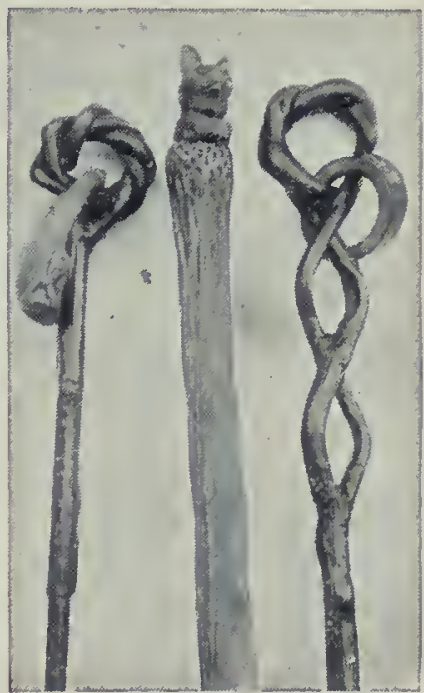

Manches d'ombrelles. coup de ces bois doivent présenter un morceau de racine assez gros pour qu'on puisse $y$ sculpter un sujet. La racine de Buis du Caucase, attaquée ou non à l'acide sulfurique dilué, fournit des manches de parapluies estimés; la racine de la Cardère à foulons, creuse et curieusement contournée, vernie et ornée, renforcée intérieurement de pâte à papier, donne des manches d'ombrelles ultra-légers, appréciés des Américaines; il en est de même de la racine de Molène ou Bouillon blanc. Il faudrait joindre à cette longue liste les essences exotiques : Rotin ou Rotang, donnant les cannes dites de jonc; Piment vrai (Myrtus pimenta), Ébène, Goyavier, Amourette (Mimosa tenuifolia), etc. Le Copernicia ou Palmier à cire fournit les 
manches de parapluies dits manches de Laurier.

Vannerie. - Tous les peuples du monde, même les plus arriérés, pratiquent la vannerie. On a trouvé des produits de cet art sur l'emplacement des villages lacustres et - dans les tombeaux de la vieille Egypte. L'osier, sa matière essentielle, est fourni par les branches flexibles de plusieurs espèces de Saules cultivés spécialement : Saule des vanniers, Saule blanc, Saule rouge, etc. On établit les oseraies par bouturage dans des terres humides, inutilisables autrement; les coupes ont lieu tous les ans à l'automne. Tout travail de vannerie exige une carcasse en branches un peu fortes, reliées entre elles par des brins moins épais; on la recouvre de brins refendus formant un tissu natté. Une école nationale de vannerie existe à Fays-Billot (HauteMarne).

Le Roseau de Provence (Arundo donax), dont on fait des cannes à pêche, des clôtures, des tuteurs pour plantes, est aussi utilisé en vannerie; on en fabrique des claies pour le séchage des fruits et surtout des paniers pour l'expédition des fleurs et des primeurs. Les tiges d'un an, bien sèches, sont raclées pour les débarrasser des gaines foliaires, puis fendues en trois à quatre lanières qu'on met tremper dans l'eau pour les assouplir avant de les tresser autour d'une carcasse d'osier. Certaines écorces sont employées dans l'Inde à des usages analogues. Le Rotang, privé de sa pellicule silicifiée externe, et le Bambou, entier ou refendu, courbé par la chaleur, sont les matières de vannerie les plus employées en ExtrêmeOrient. Parmi les applications des tiges flexibles, noublions pas

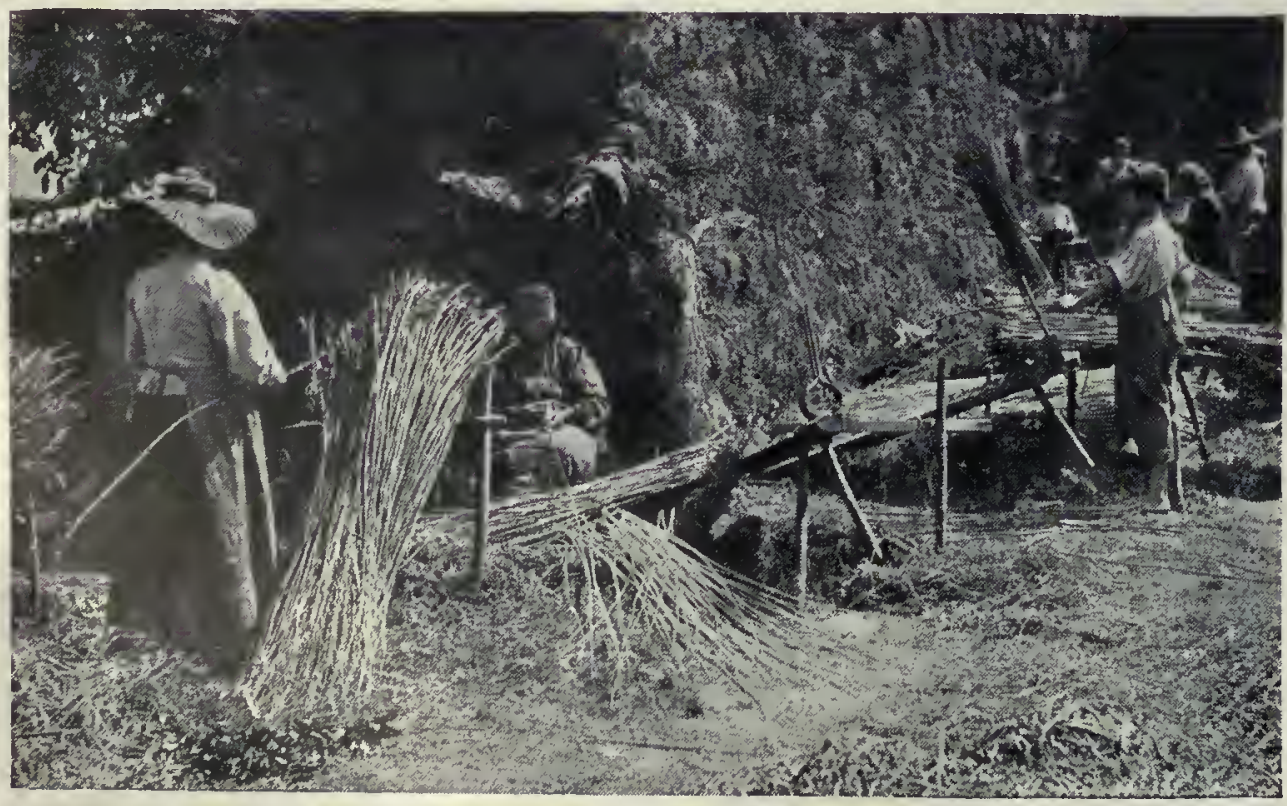

Blanchiment de l'osier à l'aide du petoir.

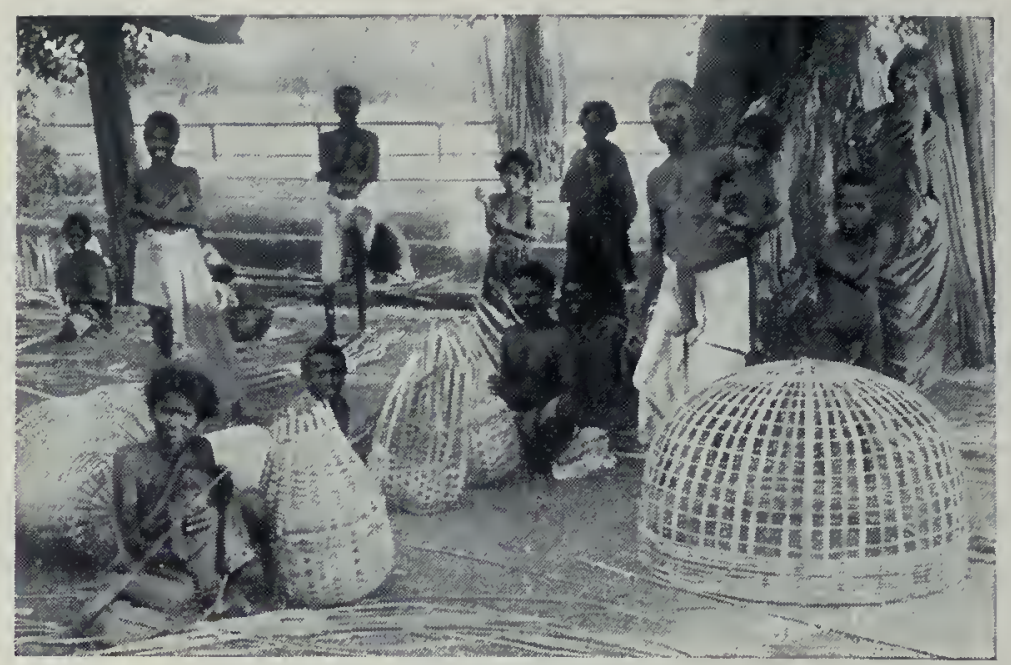

Le travail du bambou, aux Indes.

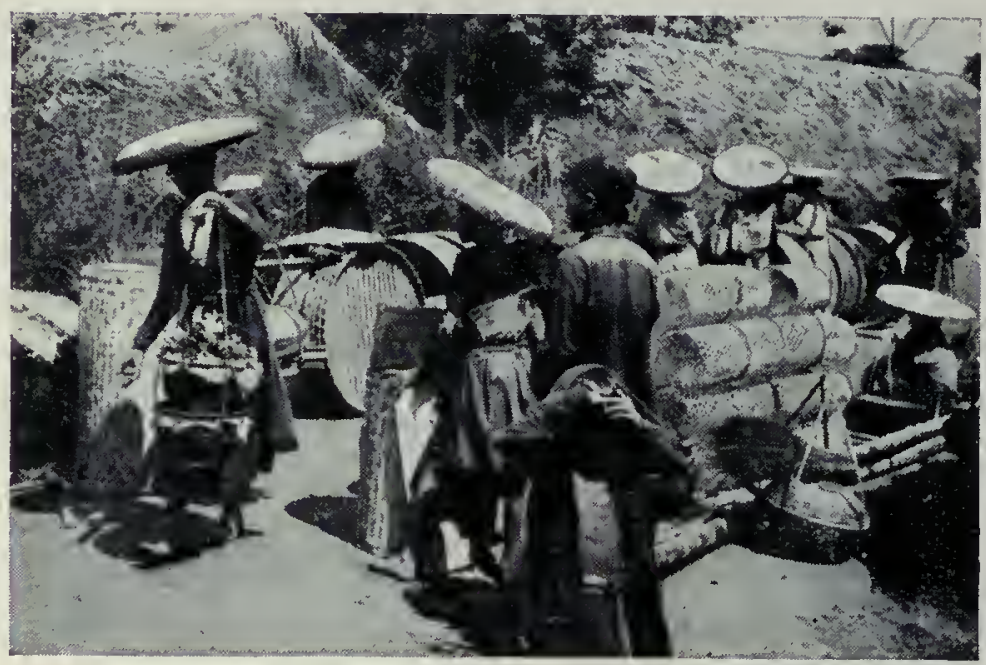

Marché d'objets en bambou, au Tonkin. designaler les ponts de lianes, qui rendent de grands services dans les pays tropicaux.

Bambou. - Où croît le Bambou (Bambusa arundinacea et autres), le bois des autres plantes ligneuses est à peu près inutile. Ses tiges creuses, légères, élastiques, incorruptibles et d'une résistance extraordinaire, sont propres à tous les usages. Dans toute l'Asie tropicale, les maisons sont en Bambou; on en fait des cloisons, des barrières; on en construit des ponts, des charpentes. A Java, cest avec des Bambous que les portefaix transportent sur leurs épaules les plus lourds fardeaux. Une grosse tige coupée entre deux nœuds et munie d'un trou de bonde fait un tonneau, ou deux grands vases, si on la coupe au milieu. Les meubles, les échelles, les mâts de barques, les conduites d'eau, les manches d'outils, les vases à fleurs, la plupart des objets usuels, tout est en Bambou. Dans les parcs à huîtres, au Japon, des rangées de Bambous garnis de leurs feuilles et piqués dans la vase servent de collecteur au naissain. Les artistes japonais sculptent et fouillent le bois poli et brillant du Bambou et en font de merveilleuses boîtes sculptées, des tabatières, des étuis à cigarettes, etc.

Écorces. - Le tanin est une substance fort répandue chez les plantes; on le "rencontre surtout dans l'écorce, dans le bois, les feuilles et même dans certains fruits. Dès la plus haute antiquité, les végétaux riches en tanin ont été utilisés pour rendre les peaux imputrescibles et les transformer en cuir.

L'écorce de Chêne, qui contient 5 à 6 pour 100 de tanin, est enlevée en forêt sur les arbres abattus âgés de quinze à trente ans. Elle est ensuite broyée et constitue le tan, qui est la matière tannante la plus usitée dans notre pays, avec les écorces de Châtaignier, de Sapin et de Pin. La tannée, ou tan usé sortant des fosses à cuir, sert aux jardiniers pour former le fond des couches et produire une chaleur douce par fermentation.

Il se fait aussi une forte consommation des extraits tannants retirés du bois des Chênes ou des Châtaigniers âgés d'au moins cinquante ans. On fait macérer les bois dans l'eau et le jus est évaporé dans le vide. Secs ou liquides, ces extraits sont utilisés en tannerie, et en teinture comme mordant.

Le wattle bark des Anglais est l'écorce des Acacia d'Australie qu'on abat vers l'âge de dix ans. On commence à cultiver les Acacia à tanin en Malaisic et dans l'Afrique méridionale. Un grand nombre d'autres produits exotiques sont aussi employés en nature ou sous forme d'extraits : les écorces des Palétuviers, dans les régions trọicales; du Pêcher, à Madagascar, où cet arbre est très commun; de Quebracho colorado (Que- 


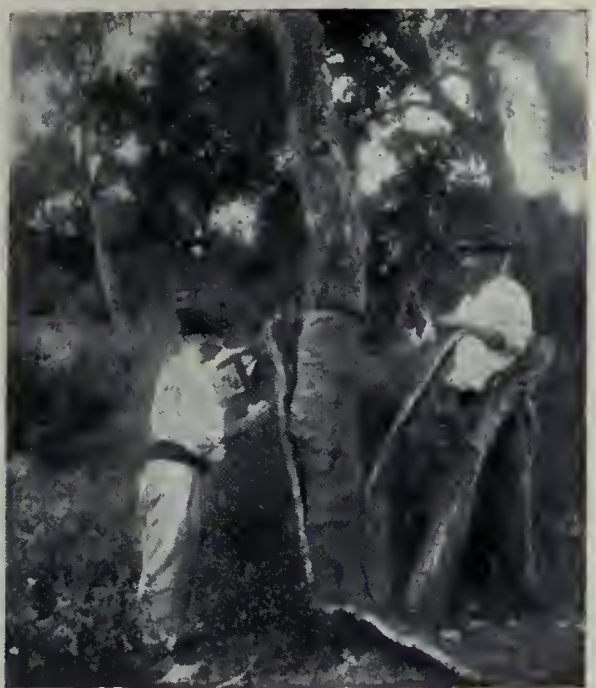

Écorçage du Chène-liège. brachia Lorentzii), qui est une Anacardiacée de l'Argentine; les racines de Canaigre du Texas (Rumex hymenosepale). Le sumac des corroyeurs est obtenu par le broyage des jeunes pousses de cet arbusteméditerranéen (Rhus coriara); le divi-divi est la gousse d'une Légu. mineuse de l'Amérique centrale ( $C \propto$ salpinia coriaria). Il ne faut pas oublier de mentionner la vallonée ou vélanède, qui fait l'objet de transactions considérables : c'est la volumineuse cupule du Chêne Velani. Le seul port de Smyrne expédie chaque année 60000 tonnes de vallonée.

Les cachous sont des substances astringentes provenant de l'Asie tropicale; on les extrait du bois et des gousses de l'Acacia cachou, de la Butée monosperme et des fruits de l'Arec cachou; elles tannent le cuir en quelques jours. Les cachous servent aussi en teinture et en pharmacie.

Liège. - Les forêts de Chêne-liège (Quercus suber) ne se rencontrent qu'en Portugal $(600000 \mathrm{hec}-$ tares), Espagne ( 300000 hectares), I talie $(80000$ hectares) et sur la côte barbaresque. La France possède 153000 hectares de forêts (Var, Pyrénées-Orientales, Landes, Lot-et-Garonne) à peuplement de Chênes-lièges mélangés de Pins et de Chênes verts l'Algérie, 426000 hectares, et la Tunisie 82000 hectares de massifs de Chêne-liège pur en Khroumirie.

Dans son jeune âge, l'arbre est couvert d'une écorce épaisse, dure, grossière, crevassée, qui constitue le liège mâle et qu'on enlève vers l'âge de douze à quinze ans: c'est le démasclage à l'aide d'incisions espacées faites à la hachette et sur une hauteur de 2 à 3 mètres à partir du sol. Il faut éviter de blesser la couche vivante, profonde, dite couche à tan, qui protège la couche génératrice. Le tissu fraîchement démasclé est rouge, mais il brunit bientôt. Une couche nouvelle se produit : c'est le liège femelle, qu'on exploite au printemps, tous les six à dix ans, lorsque son épaisseur atteint au moins $2^{\mathrm{cm}}, 5$. De cent dix à cent cinquante ans, l'arbre est abattu et on enlève l'écorce profonde pour le tannage.

Le liège est de plus en plus demandé; il possède un ensemble de qualités qui le rendent irremplaçable : légèreté (densité : 0.24 ), imperméabilité, mauvaise conductibilité pour la chaleur et lè son; d'où ses nombreux usages : bouchons, qui consomment plus des neuf dixièmes de la production; engins de sauvetage, flotteurs pour filets, casques, semelles, descentes de bain, agglomérés, linoléum, etc. La fabrication mécanique des bouchons est importante en Catalogne et en France (Var. Lot-et-Garonne). Les plaques de liège sont plongées dans une solution chaude d'acide oxalique avec un peu d'eau de Javel; elles blanchissent, se gonflent et s'assouplissent; elles sont ensuite raclées, sciées en bandes et découpées en prismes qu'un rabot mécanique arrondit. Les bouchons sont plongés dans l'eau bouillante, puis sèchent sur des claies; des machines les trient et les comptent.

La taille des bouchons laisse des déchets qui représentent 60 pour $100 \mathrm{du}$ liège employé

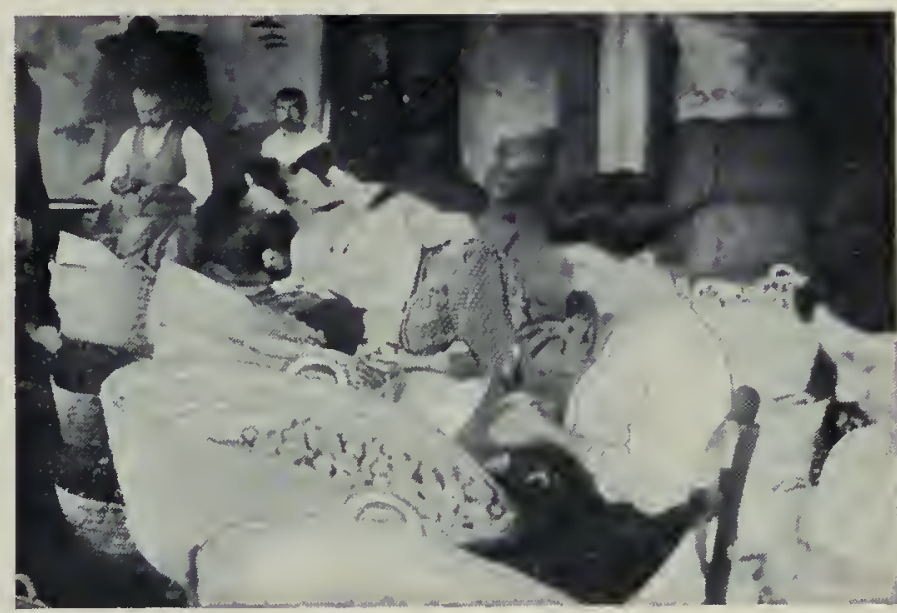

Atelier pour le triage des bouchons.

et qu'on réduit en une poudre excellente pour conserver les fruits. Mélangée à de l'huile de lin rendue siccative, elle donne une pâte qu'on étend sur une étoffe et qu'on dessèche entre deux cylindres chauflés à la vapeur: c'est le linoléum, dans lequel entre du caoutchouc. Additionnée de produits divers : lait de chaux, gomme, etc., soumise à la presse hydraulique, puis comprimée dans un moule chauffé, la poudre de liège se transforme en agglomérés, dont les propriétés varient fortement avec la nature de la substance agglomérante. On en fait des briques, carreaux et panneaux, des ruches, des poignées, des rondelles, des revêtements calorifuges pour tuyaux de vapeur, même des bouchons de champagne. Carbonisé en vase clos, le liège donne le noir d'Espagne, employé à la confection de diverses encres; enfin, sa distillation donne un gaz très éclairant.

Un petit nombre de produits végétaux peuvent remplacer le liège. La moelle des tiges de l'Agave du Mexique est transformée en bouchons, en plaques pour piquer les insectes de collections. La tige d'une Légumineuse, le Sola (Eschynomene aspera). de l'Inde, petit arbre de 2 à 3 mètres de haut vivant au bord des eaux; celle de certains Fromagers, ont des propriétés analogues; le bois en est extrêmement mou et léger. L'Herminiera elaphroxylon ou Marea est un arbuste de la famille des Légumineuses, qui croît sur les rives du Tchad. Son bois est beaucoup plus léger que le liège; les indigènes l'utilisent comme flotteur pour traverser les canaux séparant les îles du lac; ils en font aussi des boucliers très efficaces contre les fers de sagaie.

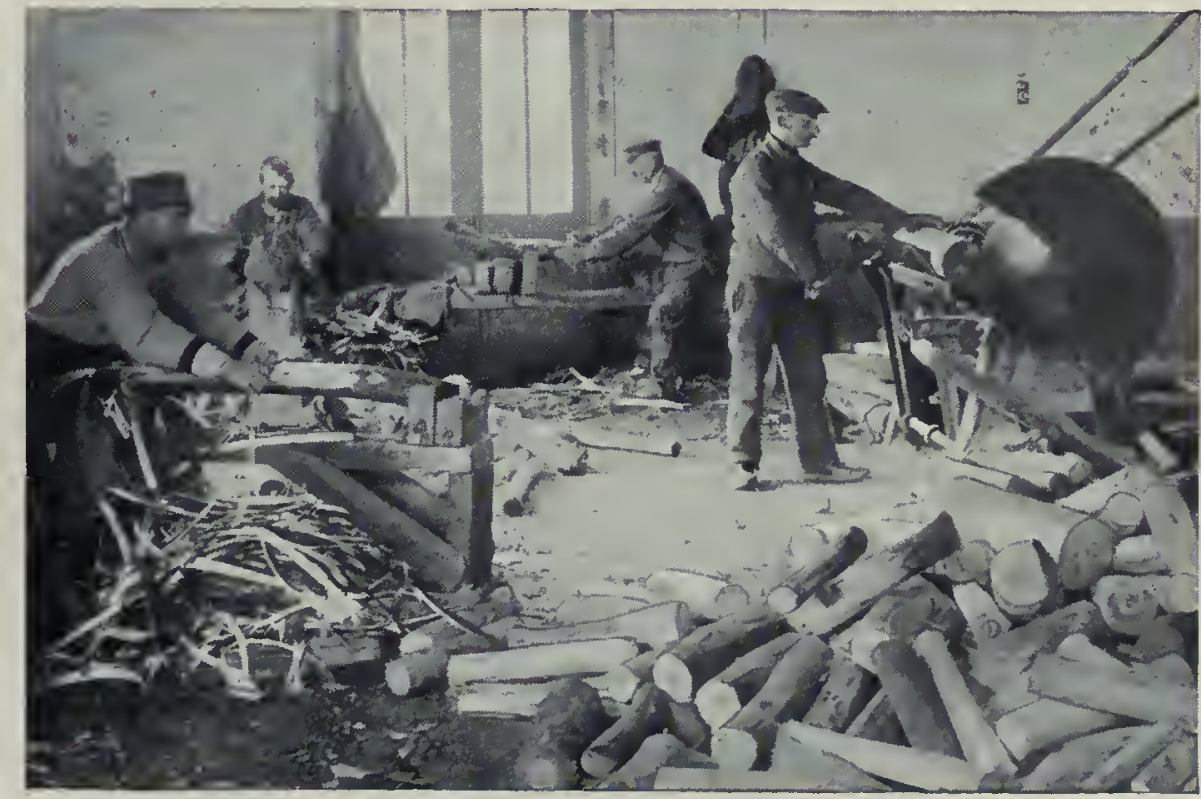

Ecorçage et sciage du bois pour la fabrication du papier. 


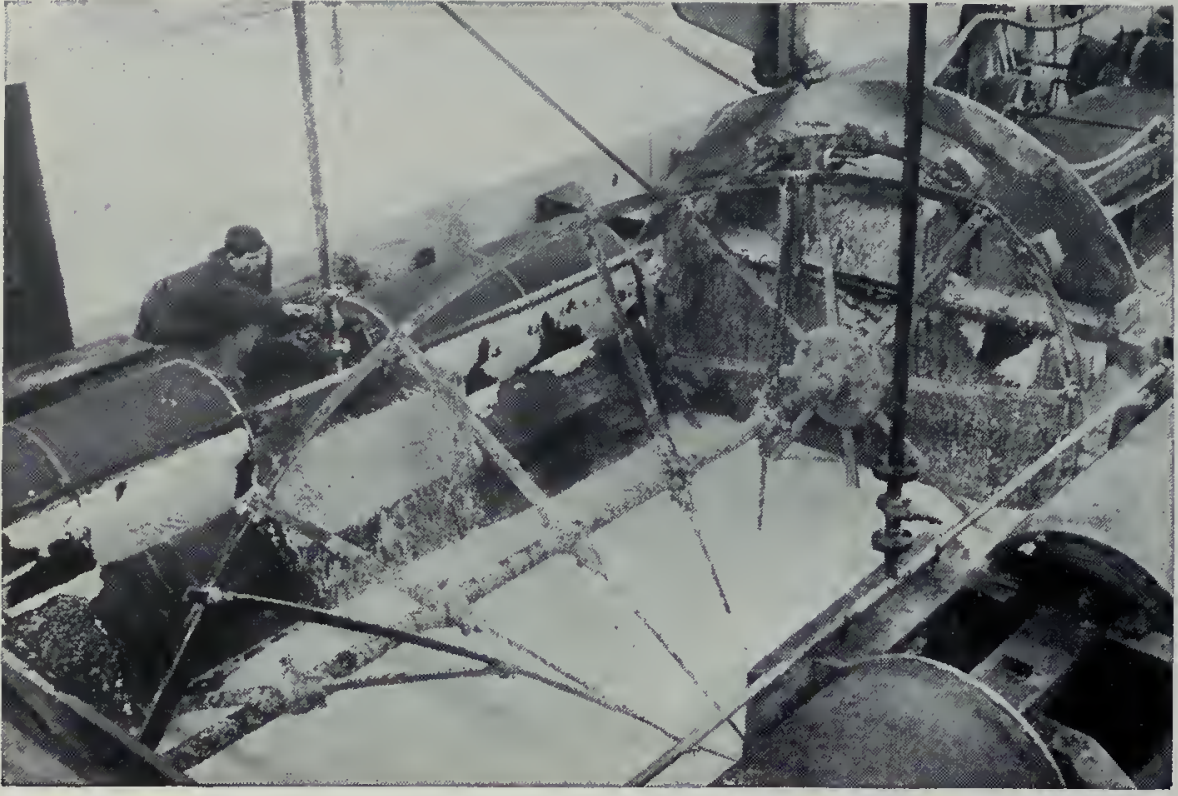

Cuvier récepteur de la pâte à papier.

\section{LE PAPIER}

Les matic̀res végétales, tablettes de bois, écorces, feuilles, ont été utilisées de temps immémorial comme support de l'écriture et le sont encore actuellement dans certaines parties de l'Asie. L'emploi d'une feuille mince de cellulose constitua un progrès, qui fut réalisé par les Egyptiens de l'antiquité. Elle était faite de la tige d'une plante des bords du Nil, le Souchet à papier (Cyperus papyrus). Les ouvriers la fendaient en longues bandes minces, qui, réunies côte à côte sur une table, puis humectées, collées, formaient un ruban au-dessus duquel on disposait une nouvelle couche de bandelettes croisant les premières. On comprimait à l'aide d'une presse et on laissait sécher au soleil.

La cellulose est abondante dans les végétaux, car elle forme les parois des cellules; mais elle est, le plus souvent, incrustée de matières dures dont il faut la débarrasser par divers procédés pour en obtenir le papier. Dès l'an 123 avant J.-C., les Chinois utilisaient les écorces du Bambou, du Mûrier à papier, de la Ramie. Au vitı ${ }^{e}$ siècle de notre ère, la fabrication du papier fut connue des Arabes; au $\mathrm{XI}^{\circ}$ siècle, des Espagnols; plus tard elle passe en Italie et en France : on utilisait alors uniquement les chiffons de Lin et de Chanvre. Les chiffons, encore employés pour obtenir les papiers de première qualité, sont triés, lessivés, effilochés, réduits en une pâte qui est égouttée, blanchie, étalée en feuille sur la forme, sorte de tamis rectangulaire agité à la main, ou bien est apprêtée à la mécanique. Dès le Xvltt ${ }^{\circ}$ siècle, les chiffons commençaient déjà à manquer aux papetaries, et des succédanés étaient cherchés et trouvés. La fabrication du papier de paille prit naissance en Angleterre en 1801 et se développa sans cesse jusqu'en 1862, époque de l'avènement de la pâte de bois.

Les substances végétales dont on a tenté l'emploi en papeterie sont innombrables : Guimauve, Genêt, Canne à sucre, Chardon, sarments de Vigne, etc. Quelques-unes d'entre elles, douées de qualités supérieures, donnent, seules ou mélangées, d'excellents papiers. $\mathrm{Ce}$ sont, outre les fibres libériennes du Lin, du Chanvre, de la Broussonétie ou Mûrier à papier (fig. 296) et de la Ramie, déjà citées, celles du Jute, du Lin de la Nouvelle-Zélande (Phormium). du Yucca brevifolia du Mexique, le Genêt ou Sarothamne à balais. La Ramie fournit un papier excellent; la Banque de France utilise cette fibre pour la fabrication de ses billets. L'Edgeworthia Gardneri ou mitsumata est la base du célèbre papier du Japon. Le Coton pur sert à préparer les meilleurs papiers à filtrer.

Les papiers à base de paille sont obtenus avec les pailles de Seigle, de Blé, de Riz, les bractées du Maïs ou l'Alfa (fig. 298). Cent cinquante mille tonnes de ces dernières feuilles sont exportées chaque année en Angleterre et transformées en un bon papier. Les pailles sont hachées, nettoyées, lessivées, défibrées et blanchies.

Les bois de râpage proviennent d'arbres feuillus: Peuplier, Tremble, Hêtre, ou de résineux : Pin, Sapin, Épicea. En Amérique on utilise surtout les Sapinettes blanche et noire (Picea alba, Picea nigra). Les bois, qui doivent avoir au moins quarante ans, sont écorcés et sciés en bûches; ils passent dans un défibreur qui les réduit en poudre fine. C'est la pulpe de bois ou pâte mécanique, employée parfois telle quelle en mélange avec de la pâte de paille ou d'Alfa. Le plus souvent, elle est transformée en pâte chimique par contact avec une solution d'un bisulfite alcalin à $130^{\circ}$, qui la décolore et détruit le ligneux. Beaucoup de nos papeteries reçoivent de Suède, de Norvège ou du Canada leur pâte de bois toute préparée.

Cette pâte, mélangée à une petite quantité de pâte de chiffon, qui lui donne du liant, et à des matières chargeantes et encollantes, est conduite aux machines à papier. Celles-ci comprennent une grande cuve, dans laquelle des agitateurs toujours en mouvement maintiennent l'homogénéité de la pâte, puis des épurateurs, qui sont des plaques de bronze finement perforées pour retenir toutes les impuretés. Ensuite, la pâte s'étale et s'égoutte sur une toile métallique sans fin de plusieurs mètres de long, animée mécaniquement de secousses transversales; elle passe entre plusieurs paires de cylindres, sortes de laminoirs qui la compriment en chassant l'eau qu'elle contient encore ; les derniers sont chauffés intérieurement à la vapeur: la pâte s'égalise, prend corps, sèche, se satine et s'enroule sur un cylindre à l'état d'une large bande continue de papier.

Les arbres des forêts se transforment en papier avec une rapidité inquiétante. Chaque année, des espaces immenses sont dénudés afin de nous donner notre pâture quotidienne de journaux. Un de nos grands journaux parisiens "dévore " à lui seul, annuellement, 125000 arbres. La production mondiale du papier peut s'évaluer à 60 millions de quintaux, dont 5 millions pour la France. C'est que le papier n'est plus seulement le support des caractères écrits ou imprimés. Il se consomme des quantités énormes de papier pour le pliage, l'emballage, les tentures, etc. La pâte de bois sert à préparer le carton. Lorsqu'elle est comprimée et additionnée de diverses substances, elle a les emplois les plus imprévus : vêtements, bouteilles, roues, meubles, cuvettes, chapeaux, jouets, allumettes, tuyaux, briques, etc.; enfin elle est la base de la soic artificielle. 


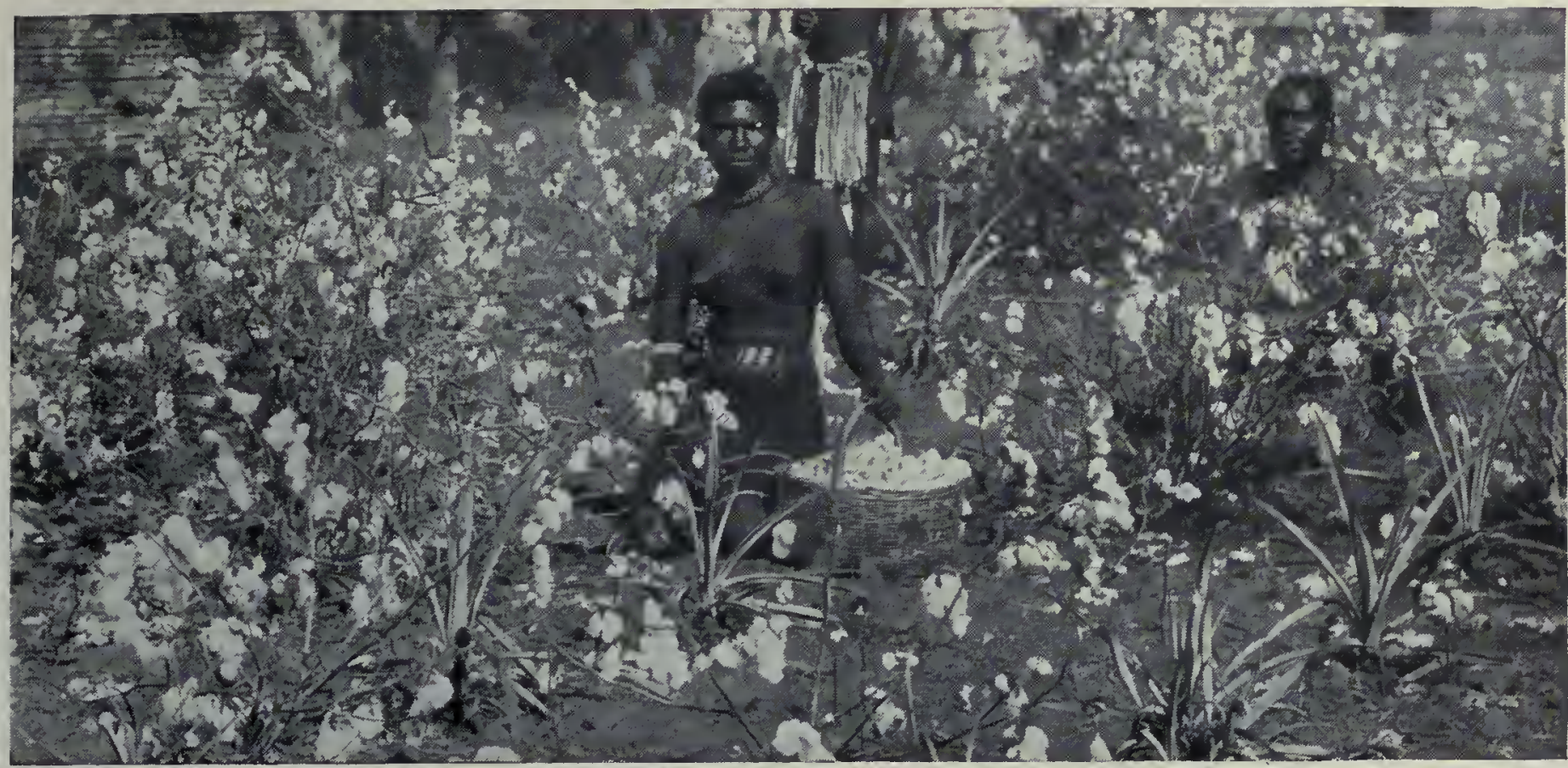

Cueiltette du coton au Natal (Afrique méridionale).

\section{LES PLANTES TEXTILES}

Les matières filamenteuses sont communes chez les végétaux : les uns, comme le Cotonnier, ont leurs graines entourées d'un duvet fin et soyeux, assez court, il est vrai; d'autres, plus nombreux, possèdent des fibres libériennes longues et souples, quand elles sont isolées de la matière pectique qui les réunissait. L'utilisation par l'homme des fibres végétales est fort ancienne, puisque dans les stations lacustres on a découvert des débris de tissus, des fragments de filets. Un petit nombre de plantes textiles sont aujourd'hui cultivées : Lin, Chanvre, Coton et quelques autres; elles possèdent des qualités supérieures qui ont imposé leur emploi. Le fil quion en retire est la base des importantes industries du tissage et de la corderie; il deviendra, suivant sa grosseur et la matière qui le forme, toile d'emballage ou fine batiste, filet de pêcheur ou délicate mousseline, câble de navire ou artistique dentelle.

Lin. - Le Lin, originaire d'Orient, vient en plaine, aussi bien dans les pays tempérés occidentaux que dans l'est de l'Europe; dans les premiers il donne d'excellentes fibres et peu de graines; c'est l'inverse dans les seconds.

On cultive en France diverses variétés de Lin de printemps, à fleurs bleues ou blanches, qu'on sème de février en avril, suivant le climat, et qu'on récolte en juin-juillet; la filasse est alors d'excellente qualité, mais les graines ne sont pas mûres; bonnes pour l'extraction de l'huile, elles n'ont qu'une faible valeur pour l'ensemencement. Les meilleures graines de semence viennent de Lithuanie et d'Esthonie, en tonneaux plombés; elles sont dites graines de Riga ou graines de tonnc. La première année, elles donnent le Lin de tonne, à baute tige, à filasse abondante et souple. Des semis obtenus en France avec la graine de ce Lin de tonne, provient le $L i n$ après tonne, plus petit, à filasse plus fine et moins abondante. Il faut alors renouveler les semences, sans quoi on n'obtiendrait plus que des lins sans valeur. Les Lins d'hiver ne se cultivent que dans les régions à hiver doux; on les sème à l'automne et on les recherche surtout pour leurs graines.

On cultive le Lin en Europe, aux Indes, dans le nord de la Chine, en Égypte, en Algérie, aux États-Unis et dans l'Argentine. En France, cette culture en décroissance se fait surtout en Bretagne, en Normandie et dans le Nord.

La moisson du Lin se fait à la faucille ou par arrachage à la main ou mécaniquement par l'arracheuse Crawford; les tiges coupćes, réunies en javelles, puis en meules, sèchent pendant quelque temps et sont ensuite égrenées au peigne ou bien battues pour $\mathrm{cn}$ retirer les graines. Pour obtenir les fibres, on procède au rouissage, soit par exposition sur un pré pendant un mois, soit par immersion dans l'eau pendant quinze jours. Il se produit une fermentation sous l'action'du Bacille Amylobacter, qui détruit la pectose englobant les fibres. Le rouissage en eau courante est préférable. Les eaux de la Loire, en France, mais surtout celles de la Lys, en Belgique, sur une longueur de 75 kilomètres, de Warneton à Deynze, ont des qualités spéciales qui donnent aux filassses une finesse et une ténacité extraordinaires. Du 15 avril au 15 octobre, on y rouit chaque année 100000 tonnes de lins belges, français ou hollandais. Courtrai est le grand centre de cette préparation qui occupe 12000 ouvriers. Cependant, d'autres méthodes de rouissage sont aujourd'hui courantes et donnent d'excellents résultats: $\left.\right|^{\circ}$ le rouissage chimique (procédé Peufaillit), par lequel on traite les textiles à une température déterminée, en autoclave sous pression, en présence d'eau et de pétrole lourd; 20 le rouissage bactériologique (procédé Feuillette), qui s'accomplit dans une cuve ou routoir dont l'eau est toujours maintenue à $25^{\circ}$ par un courant tiède : c'est la température favorable au développement des microbes du rouissage existant naturellement sur les tiges de lin; on peut rouir ainsi d'une façon continue toute l'année.

Après séchage, on opère le broyage, qui brise la partie ligneuse entre des mâchoires en bois, en laissant la fibre intacte, puis on procède au teillage, qui la sépare de la fibre. La filasse est alors peignée entre des aiguilles d'acier qui enlèvent les débris ligneux, isolent et parallélisent les fibres. 11 reste entre les dents des peignes un déchet formé de fibres courtes, irrégulières, dures : c'est l'étoupe, employée surtout en corderie et pour le nettoyage.

Les fibres peignées sont mises en cordons égaux et transformées en fil. Jadis les femmes filaient le lin à la quenouille et au rouet, et les tisserands en faisaient des toiles d'une solidité remarquable.

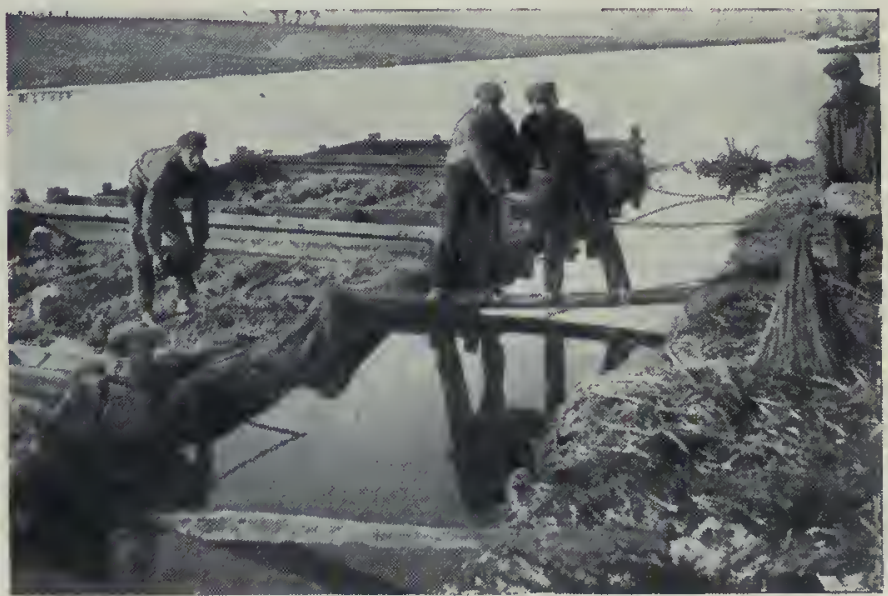

Installation pour le rouissage du lin. 
La filature et le tissage mécaniques ont fait disparaitre à peu près partout ces pittoresques industries rurales. Le lin fournit le linge fin de table et de corps, la batiste, le linon; il est souvent, comme tous les autres textiles, mélangé au coton. Ses fils sont employés pour la broderie et la dentelle.

Chanvre. - Le Chanvre (Cannabis sativa) est cultivé de temps immémorial. Les pays producteurs sont la Russie, l'Italie, l'Espagne, la Belgique. En France, notre plus importante région à Chanvre est l'Anjou. Les paysans donnent ordinairement le nom de chanure mâle aux pieds qui portent les graines, parce que leur taille est plus élevée que celle des pieds à étamines. L'espèce commune, haute de I' 50 à 2 mètres, présente plusieurs variétés: celle du Piémont atteint 3 à 5 mètres de haut, et produit une flasse fine et tenace. On récolte d'abord les pieds mâles après la lécondation, puis, vingt à vingt-cinq jours après, les pieds femelles. Le travail se fait à la main ou à la faucille; les tiges sont liées en bottes et dressées contre des perches pour les faire sécher; les pieds femelles sont battus plus tard pour en retirer les graines. Puis, lorsque les feuillés son tombées, on coupe les racines et l'on fait rouir en bottes dans l'eau courante ou dans des fosses. Les autres opérations sont identiques à celles que subit le lin. La filasse de Chanvre est moins fine et moins souple que celle du Lin, mais plus résistante; on en fait des toiles, du fil, des ficelles et des cordes.

Le cordier enroule autour de lui une provision de filasse; il en fixe une poignée au rouet qu'un aide tourne d'un mouvement uniforme, et recule peu à peu en abandonnant chaque fois une petite quantité de filasse avec la main droite, tandis que la gauche régularise les fibres : il obtient ainsi le fil de caret. Plusieurs de ces fils tordus ensemble forment les torons, et plusieurs torons tordus donnent des cordes plus ou moins grosses. La corderie est aujourd'hui presque entièrement mécanique; elle utilise les filasses de plantes diverses : Chanvre surtout, Lin, Jute, Sisal, etc. En Chine, on fabrique avec le Rotang des câbles imputrescibles et d'une grande solidité

Ramie. - La Bohmerie blanche, dite encore Ramie, Ortie de Chine, etc., est une plante rhizomateuse, haute de 2 à 4 mètres, et dont les tiges ont 1 à 2 centimètres de diamètre à la base. Elle est cultivée en Chine, son pays d'origine, en Indochine, à Java, à Sumatra; sa culture a réussi dans la plupart des pays chauds où on l'a essayée, mais elle n'est avantageuse que sous les climats où la plante peut donner trois à quatre coupes annuelles. En fait. toute la Ramie utilisée en Europe vient de Chine. La fabrication des tissus de Ramie est importante non seulement en Chine, mais au Japon, en Angleterre, en Allemagne, en France.

La filasse ne peut être obtenue par rouissage. Deux opérations sont nécessaires : l'une, mécanique ou décorticage, pratiquée à la main par les Chinois, isole l'écorce du bois sous forme de lanières ; l'autre, chimique, le dégommage, détruit la matière pectique unissant les fibres, par macération dans l'eau bouillante, puis séjour dans un autoclave contenant une lessive alcaline. Les fibres, blanchies et peignées, sont d'une finesse extrême, d'un blanc de neige, et, de plus, très résistantes et brillantes comme la soie. On en fait des pajiers de luxe, des cordes, des voiles de navires, des chapeaux de femme en simili-paille, des manchons pour becs à incandescence; seule ou mélangée à la soie, à la laine ou au coton, elle sert à la confection de linges, de peluches, de velours, des tissus les plus variés; mais elle est rarement vendue sous son nom.

Jute, sisal. - Le Jute ou Chanure du Bengale est tiré de plusieurs Tiliacées (Corchorus olitorius, C. capsularis), plantes annuelles des climats chauds et humides et notamment de l'Inde, où elle est utilisée depuis des millénaires. A la foraison, soit trois mois après le semis, on récolte ses tiges, hautes de 3 mètres et de la grosseur du doigt; on les effeuille et on les rouit en eau courante.
Les fibres, inférieures à celles du Lin et du Chanvre, servent à fabriquer des toiles d'emballage, des sacs, des cordages, des tapis, des lacets, des peluches, passementeries et tentures à bon marché, des vclours dont la trame est de coton et le poil de jute. Cette fibre occupe une place importante dans notre industrie textile, notamment dans les manulactures de Picardie.

Les Agaves fournissent aussi des fibres textiles; on en cultive quatre espèces ou variétés : le Tampico, le Henequen, le Sisal, puis le Maguey, dont les fibres sont souvent confondues sous le nom de Sisal. Le Henequen ou Sisal blanc (Agave rigida), originaire du Yucatan, se cultive au Mexique et à Cuba. Ses feuilles, de I à 2 mètres de longueur, très épineuses, ont une couleur vert clair, avec rẹflet argenté. Le Sisal proprement dit ou Henequen vert est une fibre extraite de l'Agave rigida, variété Sisalana, plante qui prospère dans le sol ingrat du Yucatan, au sud du Mexique. Ses feuilles, moins rigides et moins ćpineuses que celles du Henequen, sont d'un vert foncé, parfois bleuâtre. La filasse, très résistante, sert à faire des sacs, des toiles d'emballage, des sangles pour bêtes de trait et des cordages dont les moissonneuses-lieuses consomment une énorme quantité. Cette plante, dont on retire non seulement des fibres, mais de l'alcool et de la pâte à papier, est cultivée aujourd'hui au Cameroun, dans l'Inde, à Java et aux îles Hawaï. La récolte des feuilles se fait à raison de trente par plante dans le cours d'une année; on les défibre sous une roue à lames de bronze, alliage non attaqué par leur suc acide, et on porte les fibres au séchoir, où elles sont étalées sur des fils de fer. Mises en ballots, elles sont expédiées aux usines.

Le Maguey ( $A$. vivipara), originaire du Mexique, supporte mieux l'humidité que le Henequen et le Sisal; ses feuilles sont moins raides que celles du Henequen, à épine terminale plus courte et d'un vert clair ou foncé ne tirant jamais sur le bleu. Sa fibre est fine et on peut en faire de la toile.

L'Ixtle ou chanure de Tampico est une fibre analogue, fournie par l'Agave heteracantha, qui croît à l'ćtat sauvage dans une grande partie du Mexique.

Textiles divers. - L'Abaca ou Chanvre de Manille est extrait du pétiole des feuilles géantes d'un Bananier (Musa textilis), cultivé dans les îles Philippines, au point de vue textile, depuis 1840. Les Américains, depuis leur conquête de ces îles, ont donné une grande impulsion à cette culture. La récolte des feuilles commence trois ou quatre ans après la plantation; sur chaque pied, elle n'est jamais que partielle, se renouvelle tous les six à huit mois, à n"importe quelle époque, sauf quand la plante est en fruit. Après deux jours d'exposition au soleil, on défibre à la main, à l'aide d'un couteau mû par un grossier mécanisme à pédale; le séchage a lieu en plein air. Une partie des fibres est transformée, dans le pays même, en une fort belle toile, fine et résistante.

Les feuilles du Fourcroya gigantea ou Agave fétide, Aloès pitte, abondant au Brésil et cultivé à l'île Maurice, fournissent une fibre très résistante, dite Chanvre de Maurice ou fibre d'Aloès.

Citons encore le Lin de la Nouvelle-Zélande (Phormium tenax), dont les feuilles, longues de 1 à 2 mètres, fournissent des fibres utilisées pour le tissage et la corderie; les feuilles de la Sansevierie de Ceylan et de la $S$. cylindrique ont les mêmes usages; les fibres du liber de Tilleul enlevé avec l'écorce servent en corderie dans plusieurs parties de la Russie. Avec l'enveloppe externe fibreuse de la noix de coco ou coir, on fabrique des cordes et des toiles grossières. On fait à Madagascar, à l'aide de Raphia $R u f f i a$, des étoffes de tissu grossier couleur nankin appelées rabannes; en mêlant à de la soie, on a des rabannes de soie. On utilise encore comme textiles les fibres de la Ketmie à chanvre, des Sparmannia et de nombreux Palmiers.

Coton. - Le Cotonnier est une Malvacée qui croît à l'état sauvage dans beaucoup de régions ttopicales; ses fruits, qui 


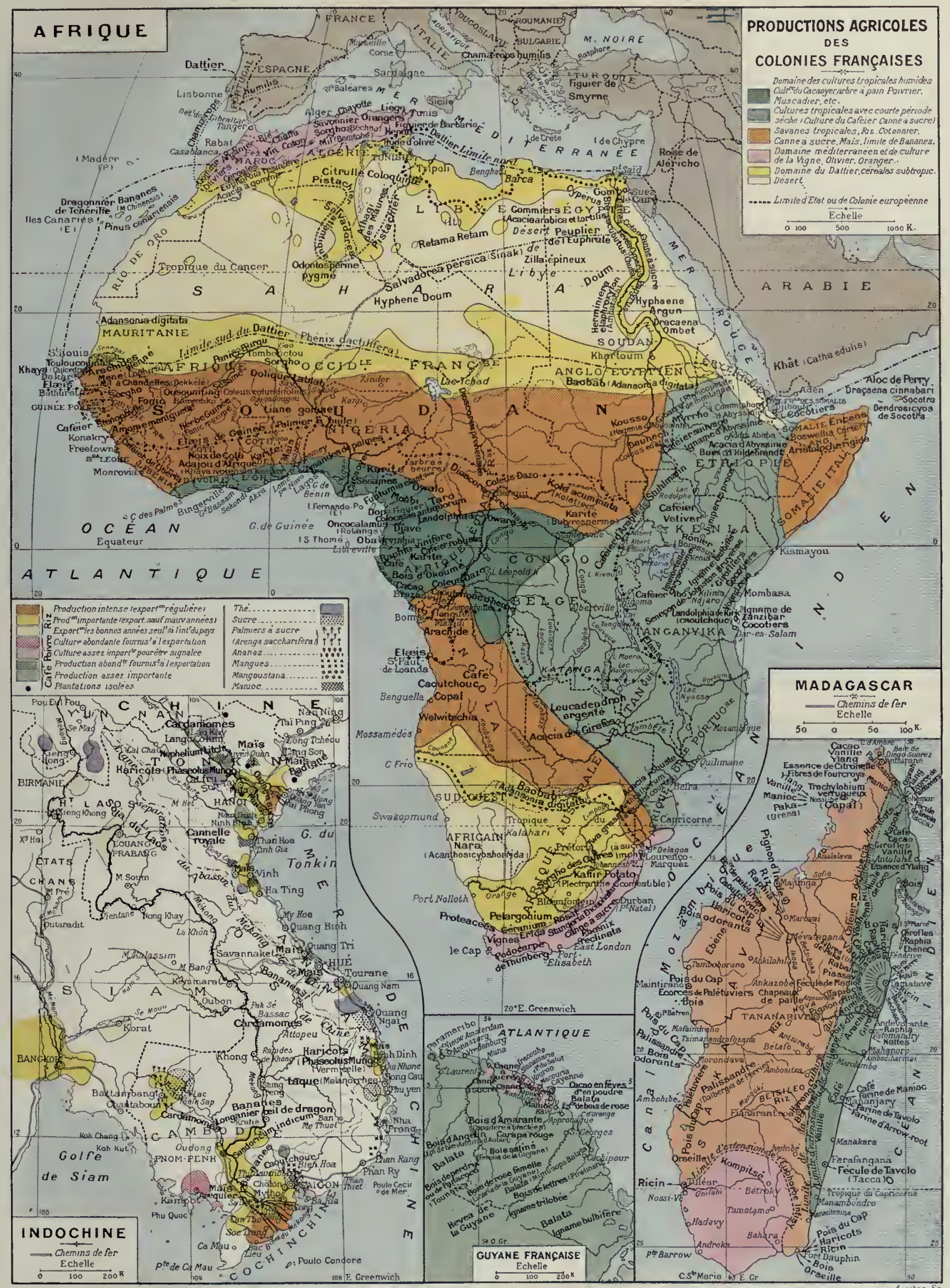

CARTE DES CULTURES ET DES PRODUCTIONS DANS LES COLONIES FRANÇAISES. 

s ouvrent par des valves, renferment des graines entourées par des filaments crépus ou coton, garnis de dentelures qui les font adhérer les unes aux autres et permettent leur transtormation en fil. Le Cotonnier est cultivé dans l'Inde et en Egypte depuis un temps immémorial; les indigènes d'Amérique, au moment de la découverte, étaient vêtus d'étoffes de coton.

Le Cotonnier exige un climat chaud, beaucoup d'eau pendant sa croissance, une grande sécheresse pendant la maturation du fruit

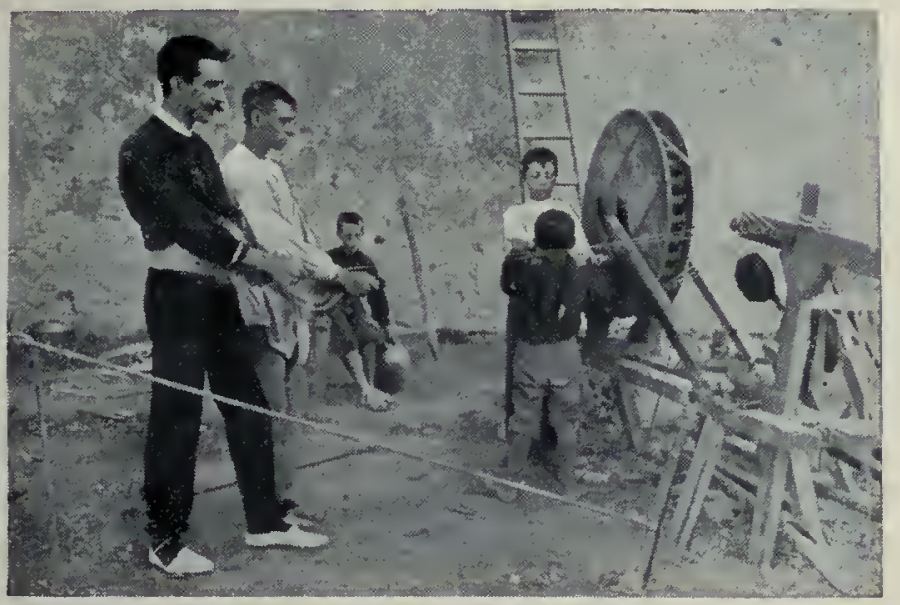

Une petite corderie de chanvre.

et la cueillette. Si les pluies printanières ne sont pas assez abondantes, l’irrigation est nécessaire. De toutes les nombreuses espèces et variétés du Cotonnier, la plus répandue est le Cotonnier herbacé (Gossypium herbaceum), originaire de l'Inde et seul susceptible d'être cultivé dans le midi de l'Europe, où il est alors arnuel, tandis que sous les climats chauds il vit plusieurs années; il donne lcs filaments dits courte soie ayant de 15 à 30 millimètres. Le Cotonnier des Barbades, cultivé en Géorgie, à la Réunion; la variété Sea Island, cultivée au Brésil, en Egypte, exigent plus de chaleur; ils fournissent des cotons longue soic, atteignant 30 à 60 et parlois même jusqu'à 75 millimètres de longueur. Il y a des poils longs et du duvet dans trois espèces (herbaceum, hirsutum et arboreum), tandis que les poils des graines sont tous de même longueur dans deux espèces (barbadense et pervvianum).

Aux États-Unis, on sème en mars diverses variétés du Cotonnier herbacé; il y a une variété à coton jaune, le Nankin. Les fleurs, qui sont très éphémères, apparaissent en juin ; deux mois après, les capsules mûrissent, atteignent la grosseur de châtaignes et, lorsquelles sont en pleine maturité, éclatent avec un léger bruit, en laissant apparaître le blanc duvet.

La cueillette se fait en plusieurs fois, en suivant la maturité ; on opère à la main ou aux ciseaux. On commence à employer aux Etats-Unis la cueilleuse de coton imaginée par Angus Campbell. Actionnée par un moteur à pétrole, elle savance à travers les rangées de Cotonniers à la vitesse d'un homme au pas et presse légèrement les plantes en leur milieu : des centaines de doigts d'acier finement barbelés saisissent et arrachent le coton mûr, mais ne font tomber ni les fleurs, ni les feuilles, ni les capsules encore fermées. Les capsules recueillies sèchent pendant quelques jours, puis la machine à égrener sépare le duvet des graines et des débris de capsules. Le coton nettoyé est pressé fortement. Lorsque les balles arrivent à la filature, leur coton comprimé est livré à des machines qui écartent et battent les flocons, puis les cardent, les étirent en un long ruban continu, enfin les transforment en fils.

Le coton est, de beaucoup, le textile végétal le plus important ; on l'emploie seul ou mélangé à la laine, au lin, à la soie. Les États-Unis fournissent près des deux tiers du coton récolté dans le monde; viennent ensuite l'Inde anglaise, la Chine, l'Égypte. Des essais de culture semblent appelés à réussir au Soudan, à Madagascar et dans l'Indochine.

En dehors de ses usages textiles, le coton est employé en médecine; il est la base du coton-poudre, du collodion, du celluloïde et de la soie artificielle; dans certaines de ces préparations, il peut être remplacé par la cellulose, obtenue en partant des bois de râpage dont nous avons parlé précédemment.

Coton-poudre, collodion, celluloïde. - En traitant le coton par l'acide nitrique, on obtient des nitrocelluloses, dont les propriétés varient avec la proportion d'acide nitrique employé : les nitrates à haut degré, comme le coton-poudre ou fulmicoton, sont de violents explosifs peu solubles dans le mélange d'alcool et d'éther les nitrates inférieurs sont, au contraire, solubles et fournissent des matières plastiques importantes, comme le collodion et le celluloïde.

Le collodion, dont on se sert en médecine et en photographie, est une matière sirupeuse obtenue en dissolvant une nitrocellulose dans un mélange d'alcool et d'éther. Le celluloïde s'obtient en

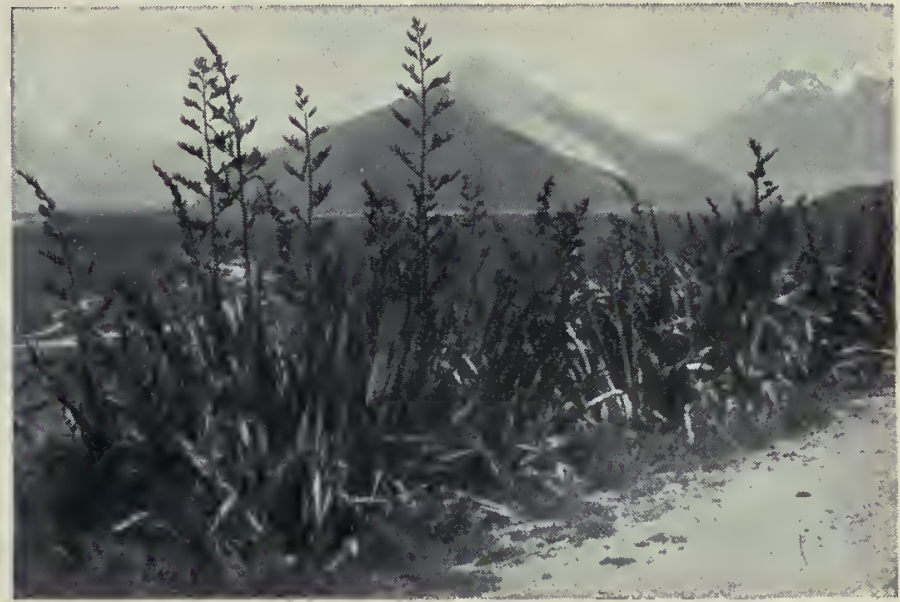

Phormium tenax ou Lin de la Nouvelle-Zétande.

broyant sous des meules métalliques la nitrocellulose avec du camphre et diverses substances qui lui donnent de l'opacité; une presse hydraulique réduit ce mélange en plaques qu'on broie et dont les fragments sont mis à macérer dans un mélange d'alcool et de toluène. Le produit, laminé à $50^{\circ}$, se met en feuilles qu'une presse réunit en blocs. Le celluloïde se ramollit par la chaleur, se travaille comme l'ivoire, se tourne, se scie, se colle et se moule facilement; il est, malheureusement, très inflammable. On en fait des peignes, des fleurs artificielles, l'article de Paris. Le linge américain est confectionné avec du celluloïde riciné.

Le pégamoïde est une sorte de celluloïde auquel ont été incorporées diverses matières augmentant son imperméabilité et supprimani son inflammabilité ; on l'applique sur les tissus, les papiers, et l'on obtient des imitations de cuir. La cellite est encore un succédané incombustible du celluloïde; cest une acétylcellulose et non une nitrocellulose. Les acétylcelluloses sont très employées pour la labrication des pellicules ininflammables pour films cinématographiques.

Soies artificielles. - La soie artificielle a été découverte en 1887 par le comte de Chardonnet. En partant du coton, on prépare un collodion qu'on soumet à une forte pression dans un récipient ; il passe à travers des tubes capillaires refroidis par un courant deau, et donne des filaments qu'on réunit par quatre à huit sur des bobines et qui deviennent des fils. Les écheveaux sont ensuite dénitrés dans une dissolution d'un sulfure alcalin, puis lavés et teints. Cette soie est moins résistante et plus brillante que la soie naturelle, mais aussi plus inflammable. On l'utilise à la fabrication des rubans, de la passementerie ; on en fait des tissus en la mélangeant à de la soie naturelle ou à d'autres textiles. Par filage à travers des tubes plus forts, on obtient du crin artificiel et, par moulage de la pâte cellulosique sur un cylindre gravé de lignes entre-croisées, fines et rapprochées, on fabrique le tulle et la gaze artificiels, qui n'ont que les apparences de tissus. Les procédés d'obtention des soies artificielles sont aujourd'hui fort nombreux ; l'un d'eux, donnant la soie dite viscose, utilise la pâte de bois. Besancon est le grand centre Irançais de cette fabrication.

Bien avant l'invention de la soie artificielle, on était parvenu à donner au coton l'éclat et le toucher de la soie. Le procédé a été découvert en 1852 par Mercer, chimiste anglais, en soumettant la fibre du coton à l'action des alcalis concentrés: c'est le coton mercerisé, vendu sous les noms de soie végétale, simili, etc.; les écheveaux, gazés dans une flamme et fortement tendus, sont plongés pendant cinq minutes dans une solution de soude caustique, puis rincés; il se forme une hydro-cellulose d'un très bel aspect. Le brillantage du coton consiste à recouvrir les fils d'un enduit de nitrocelluloses identiques à celles qu'on emploie pour fabriquer les soies artificielles. A l'aide du lin, modifié par des actions chimiques et mécaniques, on labrique de très beaux tissus dits soie de lin. 


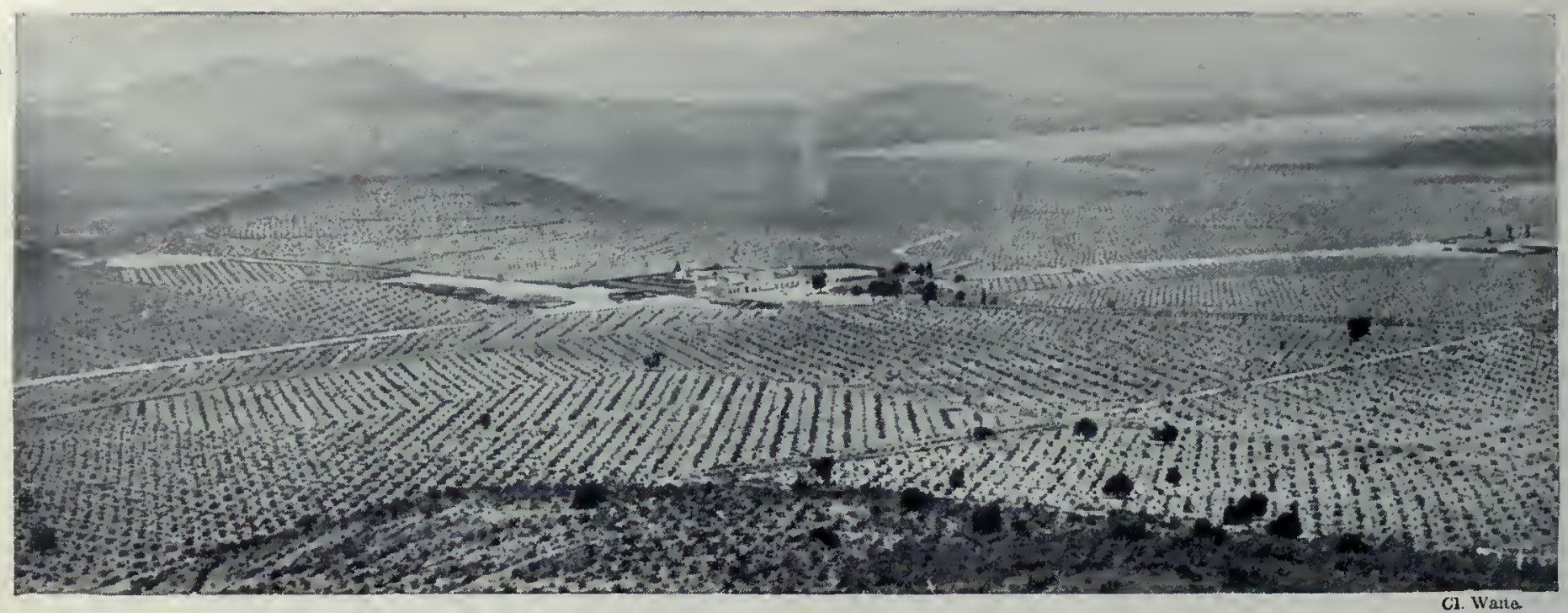

Plantation de Henequen (Agave rigida), au Mexique.

\section{LES MATIÈRES FILAMENTEUSES}

L'industrie met en ouvre, pour des usages variés, un grand nombre de substances filamenteuses végétales : tiges flexibles comme les pailles, feuilles fines en lanières résistantes, fibres trop grossières ou, au contraire, trop délicates pour être transformées en tissus. Ces substances ont des applications pour l'emballage, le rembourrage, la brosserie, la sparterie, la chapellerie, etc.

Emballage, rembourrage. - Les emballages utilisent le foin, la paille, la laine de bois, la tourbe. Les paillasses, que l'on' trouve encore dans les campagnes, sont garnies de paille de bractées de Maiis, des longues tiges de la Guinche ou Molinie bleue, Graminée commune en France, des feuilles de certains Carex. On utilise aussi les glumes ou bales d'Avoine, les fruits de Massette et de grandes herbes marines, les Zostères. Ces substances rendent de grands services pour le couchage des jeunes enfants.

Le crin végétal d'Algérie est tiré de la feuille du Palmier nain (Chamarops humble), qui croît spontanément dans les départements d'Alger et d'Oran sur une bande de 200 kilomètres de large, depuis le rivage maritime. Les feuilles sont portées aux usines, où on en extrait les fibres à l'aide de peigneuses à vapeur; elles sont ensuite filées et cordées à la main, puis, souvent, teintes en noir. Les pétioles des feuilles de beaucoup d'autres Palmiers : Areng, Palmier chanvre de Chine et du Japon (Trachycarpus), etc., fournissent le crin végétal dit du Japon. Le crin végétal le plus estimé est celui du Mexique, connu sous le nom de Tampico; il est extrait des feuilles de l'Agave heteracantha. Le crin végétal est d'un prix très inférieur au crin animal, dont il est loin d'ailleurs d'avoir les qualités d'élasticité; il offre l'avantage de n'être jamais attaqué par les mites, et il est très demandé par les tapissiers, matelassiers, bourreliers, carrossiers pour les articles à bon marché.

Le kapok ou ouale végétale provient de grands arbres des

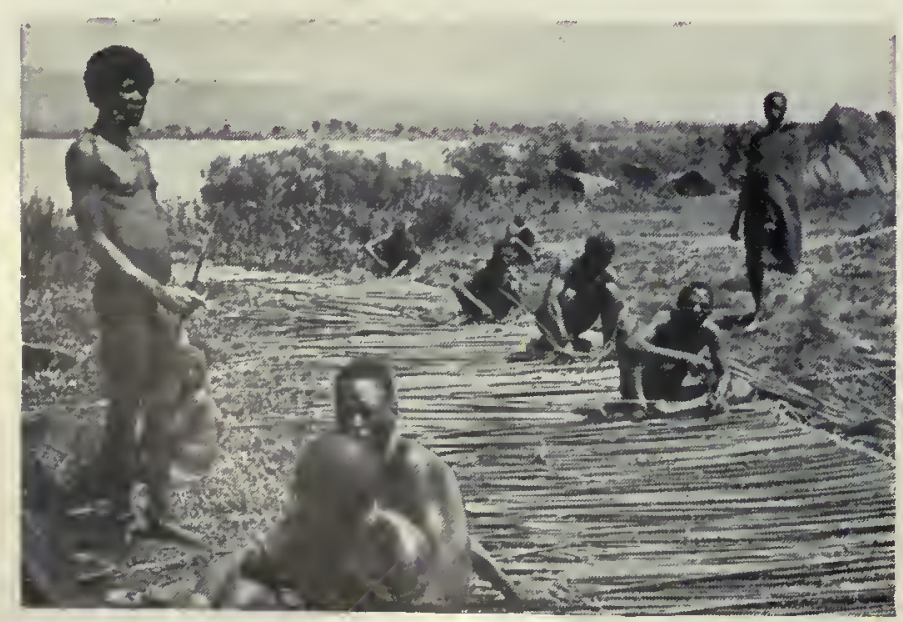

Confection d'un tramail en Papyrus (Lac Victoria-Nyanza). pays chauds, les Ériodendrons et les Bombax, connus sous les noms de Fromagers, Ouatiers, Faux cotonniers. Il est formé de poils courts, gris ou brunâtres, qui garnissent les parois du fruit; ces poils sont trop peu résistants et trop lisses pour être filés et tissés, mais leur élasticité et leur légèreté en font une matière de premier ordre pour le couchage, le rembourrage et le sauvetage; ils supportent dans l'eau dix-neuf fois leur propre poids, le liège quatre fois seulement.

Le kapok de Java, le meilleur et le plus employé, provient de l'Eriodendron antractueux. La bourre, extraite à la main des capsules, passe dans des petits moulins en fer mus à bras, qui enlèvent les graines, puis elle est pressée en balles, mais non trop fortement. Des plantations d'Ouatiers ont été faites au Cambodge, en Cochinchine et à Madagascar.

On extrait du mésocarpe fibreux de la noix de coco le coir ou husk; il faut pour cela recueillir la noix au début de la maturation, afin que les fibres ne soient pas trop dures. On le soumet au rouissage (eau courante, eau chaude ou vapeur), puis au cardage et au triage. On l'utilise pour la fabrication de câbles, cordages, vêtements grossiers, balais, brosses, tapis-brosses.

Brosserie. - En brosserie, les fibres végétales ont une place importante à côté des poils animaux; on peut les ramener à deux types principaux : le chiendent et le piassaba.

Sous le nom de chiendent, on désigne plusieurs mauvaises herbes de la famille des Graminées. Celle dont on fait de la tisane (Cynodon dactyle) a des racines cassantes, dures, noueuses, inutilisables en brosserie. On utilise, au contraire, les racines souples et solides de l'Andropogon Ischème ou Chiendent à balais, qui croît en France, mais qui abonde surtout dans les terrains sablonneux des bords de l'Adriatique, entre Ancône et Venise. On récolte tous les trois à quatre ans, en hiver; les racines sont peignées, triées par longueur et grosssur et blanchies au gaz sulfureux. Nous utilisons le chiendent d'ltalie, mais surtout celui du Mexique, qui est excellent; il est connu sous le nom de Zacaton, et abonde dans les zones élevées de l'État de la Vera-Cruz.

Le piassaba ou pissava est la fibre de l'inflorescence de divers Palmiers: Attalée funifère de Bahia, Borasse éventail de l'Asie tropicale, Raphia vinifère de l'Afrique tropicale, Palmier chanvre de Chine, etc. On utilise encore en brosserie le coir et le kittool, qui est fourni par un Palmier d'Asie, le Caryote brûlant. En arrivant aux usines, les fibres sont triées, peignées entre les dents d'un peigne en fer jusqu'à ce qu'elles perdent de leur raideur, puis lessivées, blanchies, séchées, sectionnées en fragments de longueur convenable. Le piassaba sert de garniture aux balais, aux rouleaux de balayeuses mécaniques, aux décrottoirs, etc.; le chiendent, aux brosses de cuisine, brosses à tapis, etc.

Balais, éponges. - Comme les brosses, les balais sont garnis de crin ou de matières végétales très diverses. Les tiges du Genêt à balais, de la Bruyère à balais, les brindilles de Bouleau, sont utilisées pour les balais grossiers. Le balai commun ou balai de paille est fabriqué avec les tiges de la panicule d'uno Graminée, le Sorgho à balais (variété technicum du Sorgho commun), cul- 


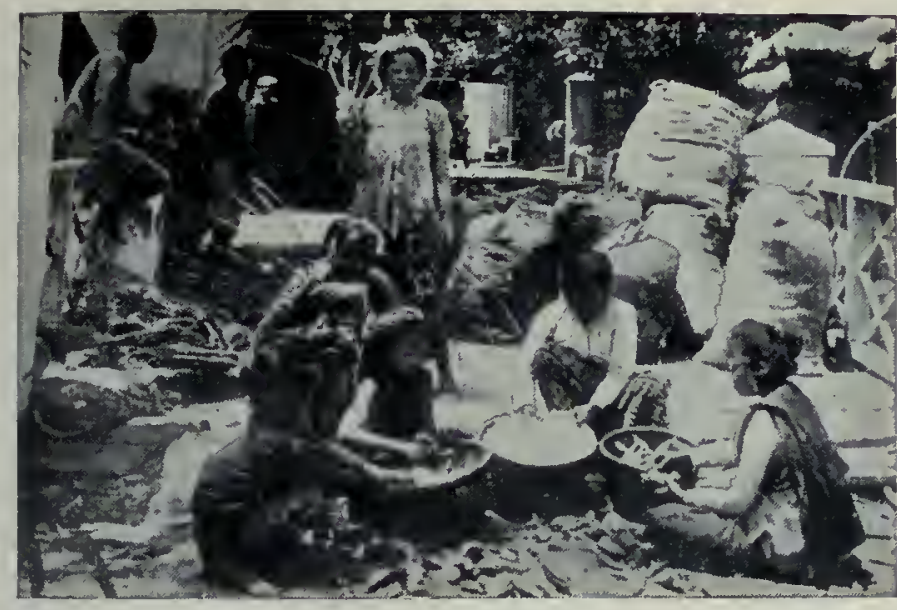

Extraction du kapok des capsules, à Java.

tivé en Espagne, en Italie, en Tunisie et dans nos départements du Sud-Ouest, principalement le Lot-et-Garonne. Cette plante atteint $2^{\mathrm{m}}, 50$ de haut.

L'éponge végétale, que l'on trouve dans les bazars, est le fruit d'une Cucurbitacée, le Lofah, dit aussi plante-torchon ou gourdeserviette (Luffa). C'est une plante annuelle grimpante des pays chauds; son fruit allongé est sec et fibreux à la maturité et souvre par un opercule. En le faisant rouir, on en tire un paquet de fibres qui prennent l'eau comme l'éponge animale, mais la conservent moins bien; on en fait aussi des gants de massage, des pantoufles pour salles de bain, etc. Le Japon en expédie d'énormes quantités. La moelle du Rotin sert aux mêmes usages.

Sparterie. - La sparterie utilise les fibres brutes ou décortiquées, qu elle transforme en paniers flexibles, nattes, paillassons, clisses pour bouteilles, etc.; ses procédés se rapprochent tantôt de ceux de la vannerie, tantôt de ceux du tissage. Cette industrie a pris naissance en Espagne, où l'on utilisait les feuilles étroites, longues et fortes de deux Graminées : la Lygée part (fig. 297) ou Spart et la Stipa très tenace ou Alfa (fig. 298), qui se rencontrent sur tout le pourtour méditerranéen, mais surtout dans l'Afrique du Nord. Les fibres de sparterie sont innombrables : Ramie, Rotin, paille, Jonc, Genêt d'Espagne, Roseaux, Scirpes, Carex, Cypérus, fibres de Palmiers, coïr, etc. Dans plusieurs régions de la France, on fabrique des paniers, des fauteuils, des nattes avec le Scirpe des lacs.

La sparterie d'Alfa est toujours très développée en Espagne, dans la région d'Alicante; elle n'utilise que la qualité inférieure venant.d'Algérie; les plus belles feuilles servent à fabriquer du papier et des tissus; par rouissage, on transforme l'Alfa en filasse dont on fait des cordes, des filets et aussi des espadrilles ou spartelles, chaussures dont l'empeigne est en toile et la semelle de corde ou de Spart, ou d'Alfa tressés.

Les Arabes confectionnent des nattes et des mannes d'emballage avec les Graminées des sables: Alfa, Spart, Drinn (Stipo barbue), Diss (Festuca patula), avec les feuilles du Palmier nain et du Dattier. La paille filée, c'est-à-dire réduite en fils à l'aide d'une machine, sert en Italie à faire des éventails, des bourses, des étuis, des cadres. A Madagascar, des longues feuilles du Raphia Ruffia on tisse de jolies nattes ou rabannes; l'épiderme de ces feuilles, qui est le Raphia des jardiniers, est utilisé à la confection de rideaux et d'une foule de menus objets.

La natterie fut jadis une industrie prospère dans nos pays, les nattes servant de tentures dans les habitations aisées; on ne les utilise plus guère que comme tapis. Canton est le centre de la fabrication des nattes chinoises, qui met en ouvre diverses espèces de Roseaux (Arundo mitis, etc.). Les Japonais cultivent les Roseaux à nattes dans les îles méridionales de la mer Intérieure. En Annam et au Tonkin, on cultive en vue de la natterie le coi, sorte de

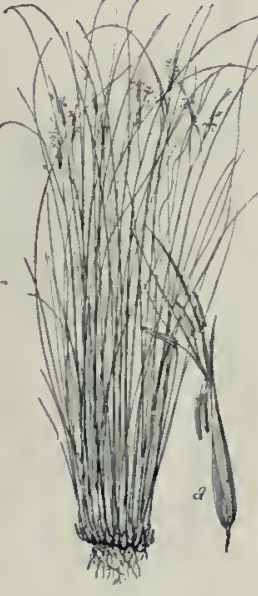

Fig. 297. - Lygée. $\alpha$, Fleur.

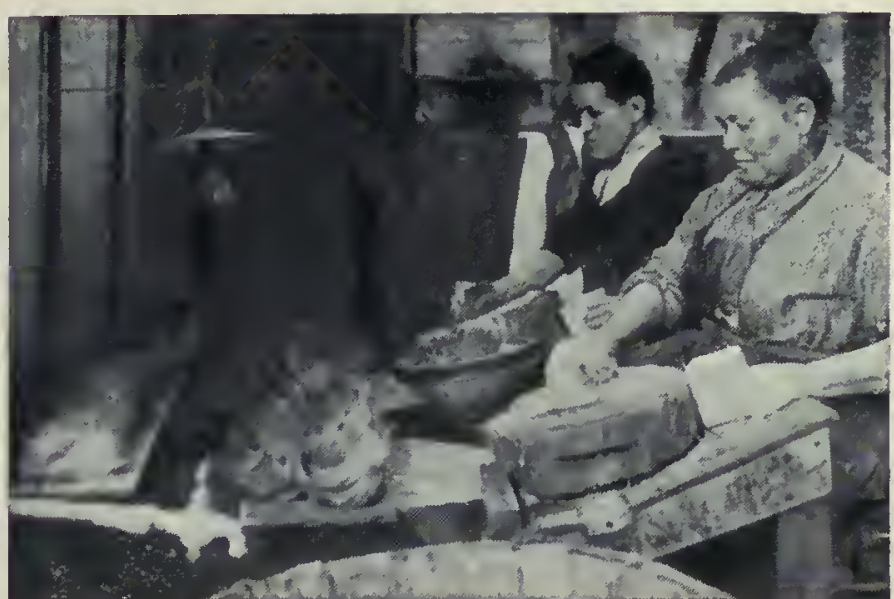

Lavage des fibres de chiendent pour la brosserie.

Cyperus haut de 2 mètres. Les tiges, coupées à la faucille, sont séchées, fendues en deux ou trois lanières qu on fait blanchir au soleil; elles forment la trame, la chaîne étant composée de ficelles de jute. Dans la région des Grands Lacs, en Afrique, les tiges de Cyperus sont utilisées pour fabriquer des filets de pêche; dans certaines parties de la Chine et du Japon, de grandes A! gues marines servent au même usage. Les Fuégiens emploient les longs stipes des Macrocystes pour la pêche à la ligne.

Chapellerie. - La chapellerie de paille est une branche importante de la sparterie; elle a pour matières premières les pailles de Graminées, les fibres de Palmiers, le Bambou, la Ramie, le Rotin, le crin végétal et même de minces lanières de bois de Saule et de Peuplier, préparées à Carpi, en Italie, et vendues sous le nom de paille de riz.

Lindustrie de la paille tressée, née aux environs de Florence dès le $X I V^{e}$ siècle, se répandit peu à peu dans toute l'Italie, pays qui en garda longtemps le monopole. Depuis, on s'est mis à tresser la paille en Suisse, dans le canton d'Argovie, en Saxe, en Amérique, à Madagascar, au Japon.

En Italie, on utilisait jadis la paille de Seigle : on cultive maintenant des Blés de printemps à paille longue et fine; on sème très serré et on récolte sans s inquiéter de la maturité des graines. Les pailles subissent un premier blanchiment à l'air pendant huit à dix jours; après leur transport à l'usine, elles sont humectées et blanchies au gaz sulfureux, puis triées par grosseurs; enfin, les épis sonit coupés à la machine.

Les principaux centres français d'utilisation des tresses de pailles pour la chapellerie sont Nancy, Sept-Fonds (Tarn-et-Garonne) et Paris. Les tresses, enroulées sur un dévidoir, sont cousues à la machine en commençant par le milieu du fond. Le chapeau est apprêté dans un bain de gélatine, séché, puis passe au bain de vapeur et sous la presse à pédale.

De tous les chapeaux en fibres de Palmiers, les plus célèbres sont ceux dits de Panama, qui se fabriquent en Colombie, au Pérou et surtout dans la république de l'Équateur. La matière première provient des feuilles du Carludo-

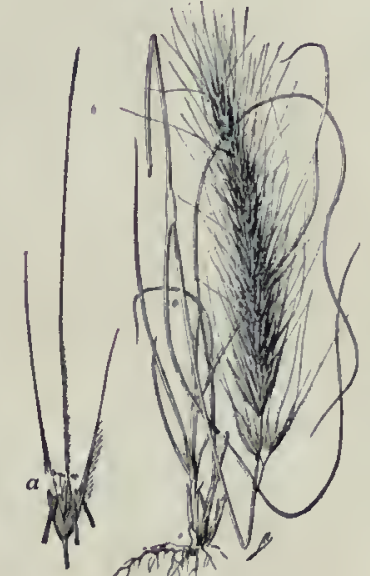

Fig. 298. - Alfa. $a$, Epillet fleuri. vica palmé, arbuste de 2 à 3 mètres de hauteur, appartenant à une famille voisine de celle des Palmiers et qui croît à l'état sauvage dans les régions tropicales des côtes du Pacifique. On récolte les feuilles au moment où, sur le point de s'ouvrir, elles ont la forme d'un long éventail fermé; on coupe les plis extérieurs et on obtient un fragment de pétiole terminé par une trentaine de lanières. Ces feuilles sont plongées dans l'eau bouillante additionnée de jus de citron qui les blanchit, puis sont séchées à l'ombre et enfin au soleil. La dessiccation transforme les lanières en brins larges de J à 2 millimètres et longs de 55 à 60 centimètres. Ces brins adhérant encore au pétiole constituent la " paille tonquilla ». La fabrication se fáit à la main; on mouille la paille pour les chapeaux ordinaires, tandis que les chapeaux 

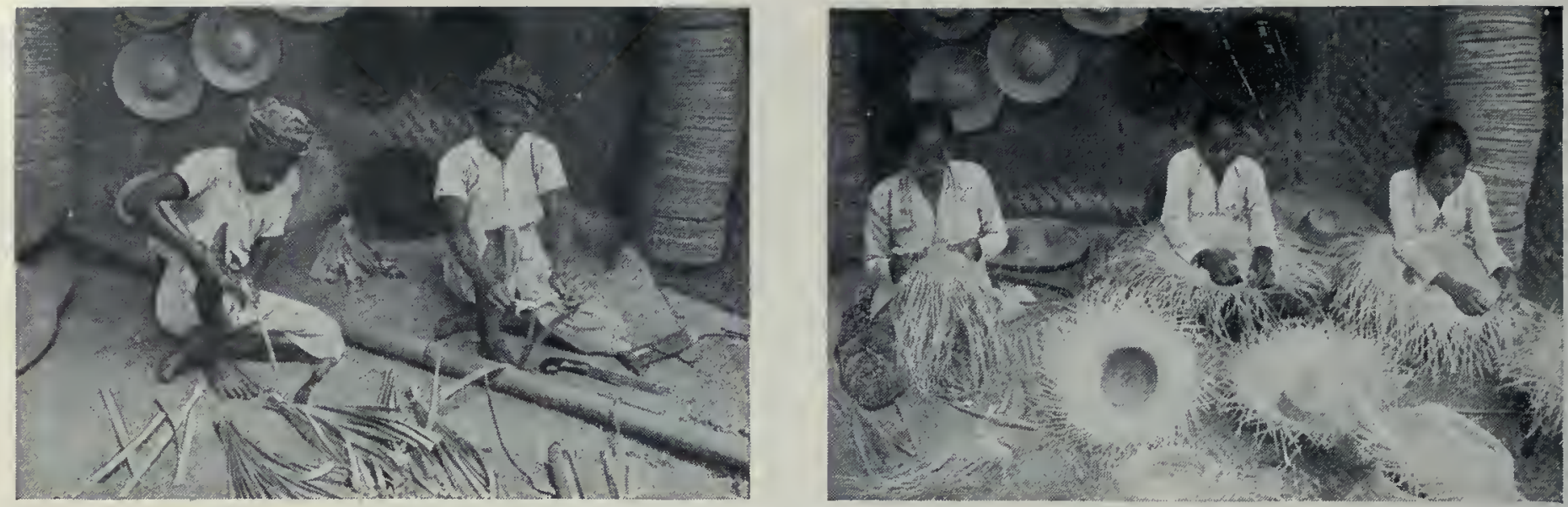

Fendage des lames de bambou et tressage des chapeaux de bambou, à Java.

fins se travaillent à sec, seulement de grand matin ou le soir quand l'air est très humide.

Le "manille ", rival du " panama ", se confectionne aux Philippines avec les fibres du Palmier buri (Corypha élevé) extraites de ses énormes feuilles en éventail, longues de 6 à 8 mètres. Les tiges d'un Rotang (Calamus mou) et celles d'une Fougère grimpante (Lygodium circiné) entrent dans la fabrication des chapeaux de luxe; les tiges du Bambou épineux, les feuilles d'un Vaquois (Pandanus Sabotan) et même les fibres du fruit du Luffa sont mises en ouvre pour les chapeaux communs. Les Philippins ont même introduit dans leur pays le Cardulovica palmé, afin de pouvoir fabriquer chez eux d'authentiques panamas.

En Chine et à Java, comme aux Philippines, l'industrie des chapeaux de Bambou est extrêmement florissante. Les tiges, coupées vertes, sont écorcées, sciées, fendues, bouillies, puis séchées, et enfin divisées en lanières minces qui sont tressées.

L'Espagne exporte des chapeaux fabriqués avec les feuilles du Palmier nain ou Chamoerops humble. La chapellerie utilise encore la fibre de Buntal, provenant de l'Australie, et produite par les feuilles de diverses espèces de Livistona (L. chinensis notamment). Les chapeaux sombreros sont faits avec le Sabal mexicain; les chapeaux nattés dits de Latanier, avec la Latania Loddigesii, qui est un Palmier très commun dans l'île de Cuba.

Madagascar fabrique et exporte une grande quantité de chapeaux en pailles diverses et en fibres tirées du Raphia Ruffia et d'un autre Palmier. Ces sortes, vendues en France sous le nom de " panamas malgaches ", sont souples, légères, peuvent de plus se mettre en poche sans se déchirer aux plis, et sont infiniment supérieures aux pseudo-panamas que l'industrie allemande obtient avec des pailles de jonc refendues.

Empaillage et cannage. Le siège des chaises est ordinairement formé de belle paille de Seigle, mais, en raison de son prix élevé, on ne l'emploie que pour recouvrir d'autres pailles d'un prix moindre, comme le Scirpe des lacs ou Jonc des chaisiers, le Carex raide ou les feuilles de Maïs, qui forment la paillasse. En Suisse, ces succédanés de la paille font l'objet d'une culture; dans l'arrondissement de Villefranche-deRouergue, on utilise des plantes de marais (Jonc, Carex, Massettes, Rubaniers). Rabastens (Tarn), Rancy, près Louhans (Saône-et-Loire) sont des centres importants pour le paillage des chaises. Cette industrie est alimentée par les plantes de la $\mathrm{Ca}$ margue, des étangs de la Bresse, de la Loire-Inférieure, du Nord, et même par des importations de Belgique et d'Espagne. Le cannage des sièges ou dossiers se fait en roseau tressé ou en pellicule de Rotin très dure et résistante. A Java, de nombreux ouvriers travaillent le Rotin, enlèvent les pellicules pour cannages et fendent en lanières les tiges dénudées pour la vannerie.

Usages divers. - La paille est utilisée surtout comme litière et comme fourrage ; on en fait du papier, des ruches, des paillons pour bouteilles, des chapeaux, etc. Elle sert pour la couverture d'habitations (chaumières), d'abris, de glacières; en Chine, en Afrique, en Malaisie, elle forme les parois des paillotes et des cases. Dans le Nord, on la remplace par les Roseaux ou les Carex, dans les pays chauds par des feuilles de Palmier, des tiges de Cyperus, etc: Sur le littoral de la Charente-Inférieure et de la Vendée, les sauniers recouvrent de Roseaux à balais (Phragmites commun) leur récolte de sel quand elle doit demeurer pendant tout l'hiver sur le talus du marais.

Les jardiniers utilisent la paille sous forme de paillassons ou en nature pour protéger contre le froid les plantes délicates; ils la répandent sur le sol pour en conserver l'humidité, l'empêcher de se fendiller au soleil ou pour préserver les fraises, les melons du contact du sol. Sur les pots de fleurs, dans les jardinières, la paille est remplacée par de la mousse (Hypnum triquetre) teintée ou naturelle. Dans les Sphaignes, on cultive les Orchidées. En Angleterre, les jardiniers emploient beaucoup l'étoupe, résidu du peignage de

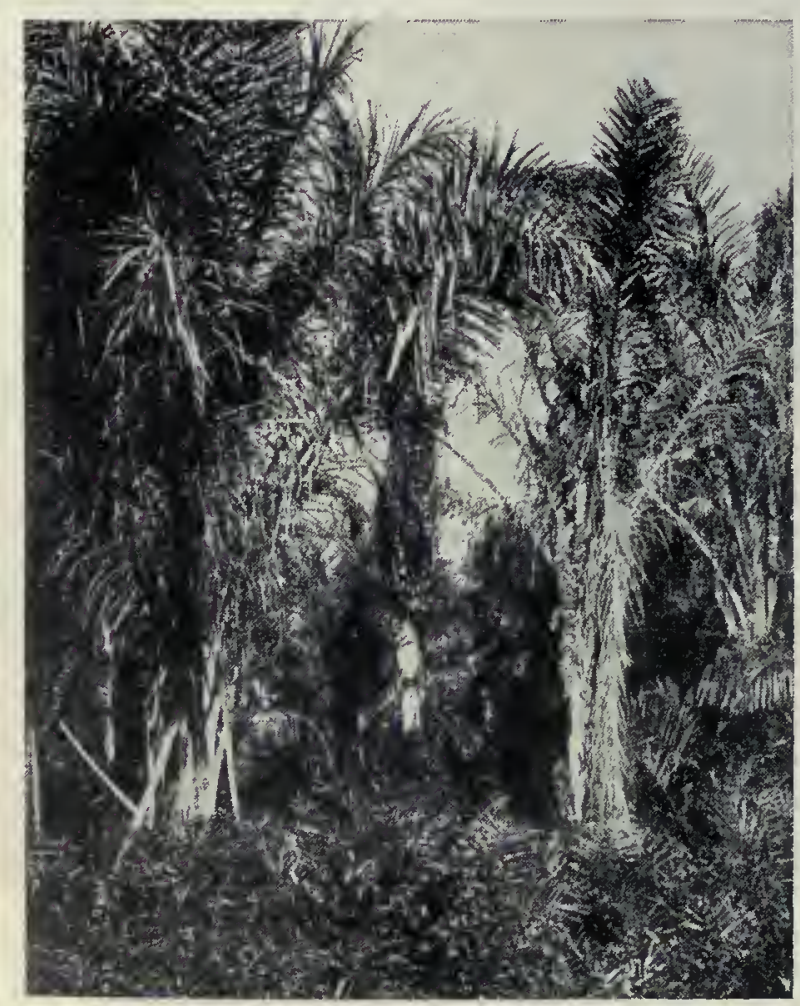

Le Raphia sur les còtes de Madagascar. la fibre de noix de coco. Comme liens pour fixer les plantes aux tuteurs, palisser les arbres fruitiers, maintenir les greffes, monter les bouquets, on utilise les tiges flexibles du Jonc glauque et aussi l'épiderme des feuilles de Raphia dont Madagascar exporte chaque année d'énormes quantités.

Fibres ornementales. - Les feuilles.détachées des arbres à l'automne subissent l'attaque des microbes; leur parenchyme se détruit et il ne reste bientôt plus que la dentelle des nervures, admirable, mais fragile. Si, an lien de s'adresser à des feuilles d'arbres, on fait pourrir en terre des raquettes d'Opuntia, leur tissu vert disparaît, et il reste un squelette très élégant et assez résistant que l'on blanchit à l'eau de Javel étendue. Ces fibres sont connues sous le nom de semelles de pape, qui sert à désigner vulgairement les Opuntia ; on les utilise dans l'industrie de l"éventail pour en faire des applications sur bois, ou encore pour orner les cannes on les manches d'ombrelles, mais auparavant on les recouvre, par la galvanoplastie, d'une mince couche d'or ou d'argent. 


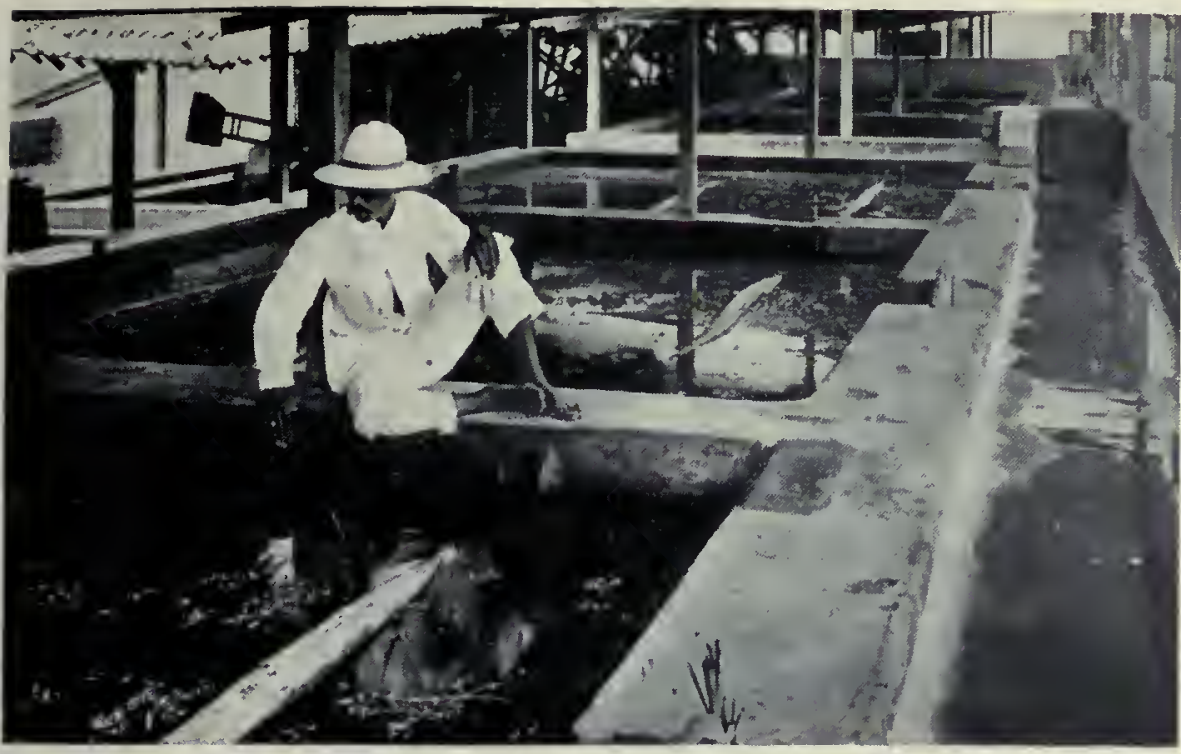

Cuves pour ta fabrication de l'indigo.

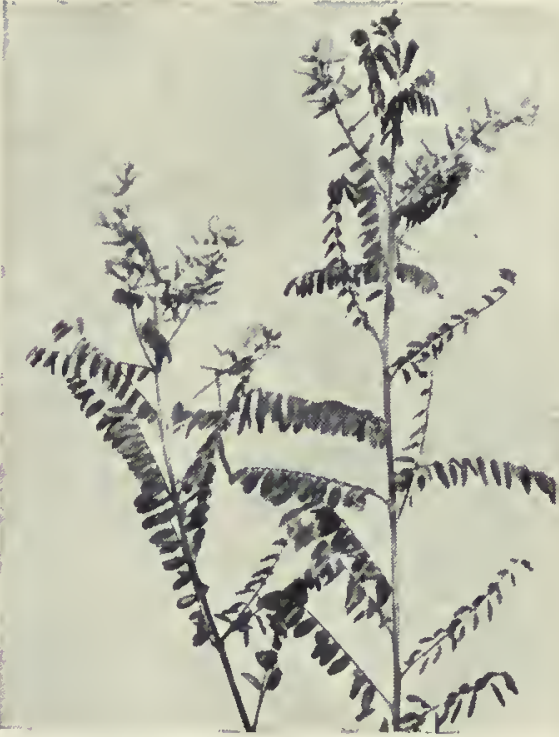

Indigotier (Indigofera dosua).

\section{LES PLANTES TINCTORIALES}

Les matières colorantes existent parfois toutes formées dans les plantes; souvent, elles n'apparajssent que par exposition à l'air, à la lumière ou par contact avec certains agents chimiques. Lutilisation des colorants végétaux est extrêmement ancienne; avant de teindre les tissus, l'homme s'est teint la peau, comme le font encore tant de peuplades dans le but de déterminer la tribu ou le rang, ou bien il a introduit la matière colorante dans la piqûre d'un tatouage servant d'emblème ou d'ornementation. Avec la civiljsation, la teinture est devenue un art important et compliqué, destiné à embellir les étoffes et les cuirs; l'emploi des mordants a constitué un progrès considérable, en permettant de fixer le colorant sur les fibres qui ne le retiennent pas directement et de modifier, pour ainsi dire à volonté, les teintes quil peut fournir.

La culture des plantes tinctoriales est, depuis I868, bien menacée par l'émploi des couleurs artificielles dérivées du goudron de houille. Un peu moins solides que les colorants végétaux, elles offrent une variété extrême, une grande fraîcheur de tons, une parfaite constance dans les résultats et une économie notable.

Garance. - La Garance (fig. 300), herbe très anciennement cultivée, fournissait une couleur rouge d'un éclat remarquable et d'une grande solidité. Les parties souterraines, récoltées sur les plantes âgées de deux à trois ans, étaient desséchées, puis broyées sur des meules. Le principe colorant de la Garance est l'alizarine. En France, d'immenses champs de Garance s'étendaient dans la région d'Avignon, en Provence, en Languedoc, en Alsace, en Auvergne. La récolte francaise, en 1862, fut évaluée à 54000 tonnes, d'une valeur de 50 millions de francs : notre pays fournissait de garance le moñde entjer.

En 1868, deux chimistes allemands, Graebe et Liebermann, obtinrent l'alizarine par voie chimique, en partant de l'anthracène. La lutte entre le colorant naturel et le colorant artificiel se poursuivit très ardente jusqu'en 1878; l'écrasement du premier fut définitif à partir de 1882; la Garance n'est plus cultivée depuis cette époque et les usines fabriquent l'alizarine.

Pastel, indigo. - Le Pastel des teinturiers (fig. 299) est une Crucifère qui, comme plusieurs autres plantes, produit de l"indigo. Elle est cultivée depuis longtemps. Les environs de Toulouse s'enrichissaient, au $\mathrm{XVt}^{\sharp}$ siècle, de la culture et de la préparation du pastel, dont le port de Bordeaux exportait annuellement 20000 tonnes. La pulpe, obtenue en hachant les tiges et les feuilles, puis en les broyant à la meule, était entassée et fermentait pendant quinze jours; la matière bleue formée était pétrie et moulée

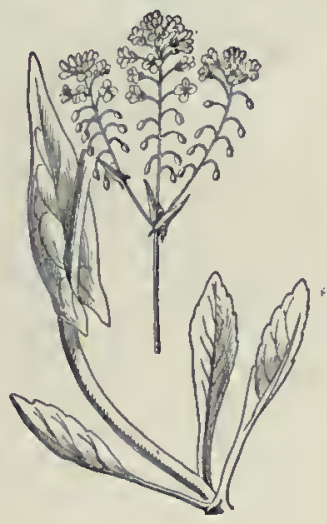

Fig. 299. - Pastel. en coques dans de petits cônes ou en pains ou boules, dits pastilli, d'où le nom de la plante.

L'indigo; d'origine hindoue, était connu des Romains. Dès le XIV siècle, de petites quantités d'indigo des Indes sont importées en Europe; au $\mathrm{XVI}^{\circ}$ siècle, les Hollandais en reçoivent des envois importants et cherchent à les écouler; la lutte commence entre l'indigo exotique et notre pastel. Malgré les ordonnances royales punissant de mort l'introduction et l'emploi de l'indigo en France, l'usage de ce magnifique colorant se généralise et, en 1730. sa victoire est complète. Son règne allait durer jusqu à nos jours.

On cultive surtout deux espèces: I'Indigotier argenté, qui fournit la plus belle qualité, et l'Indigotier franc ou des teinturiers, qui offre le meilleur rendement. Des Indes, leur culture s'est étendue en Chine, à Java, au Tonkin, au Mexique et dans l'Afrique équatoriale. On sème tous les ans et on fait deux à trois coupes; chaque récolte est mise dans un vaste bassin plein d'eau : elle y fermente pendant dix à douze heures. Un glucoside, l'indican, contenu dans les feuilles, se dissout; sa fermentation donne l'indigotine. Le liquide, soutiré dans une autre cuve, est additionné d'ammoniaque, qui transforme l'indigotine en indigo blanc; une roue à palette le bat, introduisant de l'air qui oxyde l'indigo blanc et le transforme en indigo bleu. Celui-ci précipite au fond de la cuve ou reposoir; on le recueille et on le fait sécher sur des claies ou dans des jarres; la pâte est égouttée sur des toiles, puis découpée en cubes ou gâteaux qu'on livre au commerce.

Dès 1878, von Bæyer, de Munich, avait réussi la synthèse de l'indigotine, mais le prix de revient en était très élevé. Ce n'est qu'en 1890 que l'indigo artificiel, préparé en Allemagne en partant de la naphtaline, a pu commencer à supplanter l'indigo naturel. Vers 1908 , l'emploi de ce dernier était à peu près abandonné en

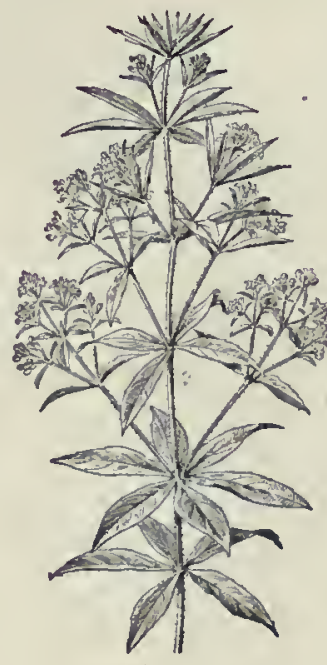

Fig. 300. - Garance. Allemagne, en Autriche, en France et en Angleterre et les usines allemandes exportaient de l'jndigo de synthèse à destination des Indes! La guerre de 1914 1918 et le blocus de l'Allemagne qu'elle entraîna amenèrent une reprise importante de la culture de l"indigo et des autres colorants naturels. Les producteurs de l'Inde poursuivent énergiquement la lutte; les conditions ne sont plus les mêmes que dan's le combat entre la garance et l'alizarine; la garance est très pauvre en alizarine, tandis que l'indigo naturel est très riche en indigotine.

Bois tinctoriaux. - Plusieurs bois exotiques ont leurs tissus imprégnés de matières colorantes ou pouvant le devenir par oxydation. Le bois de Campêche est produit par un arbre des Antilles et de l'Amérique centrale, l'Hématoxylon de Campêche; jl est 


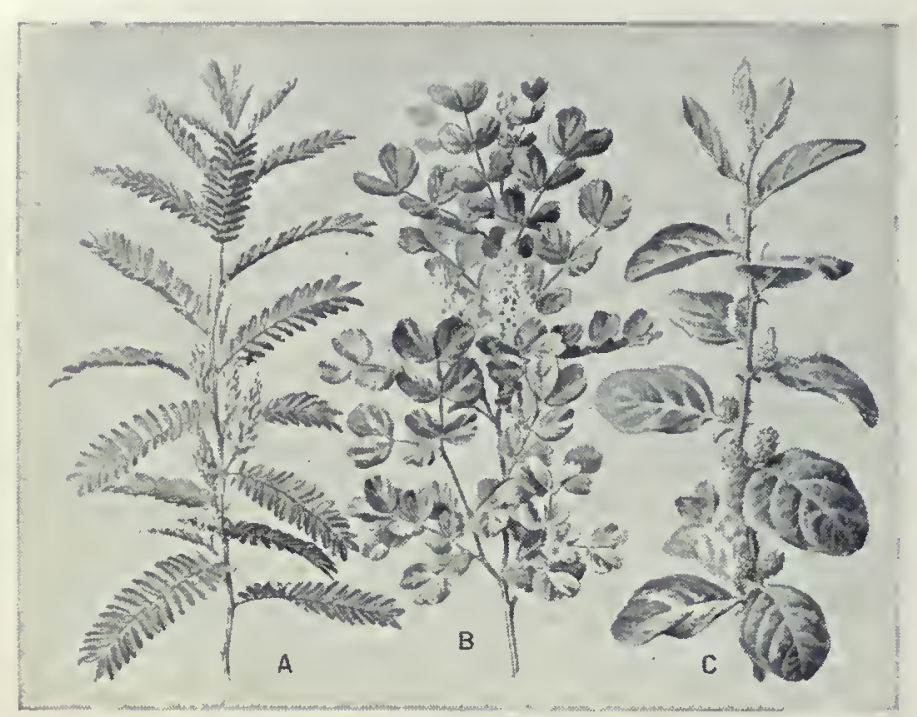

A, Indigotier (Indıgofera tinctoria). - B, Campèche (Hamatoxylon Campechianum). - C, Mûrier des teinturiers (Morus tinctoria).

d'un rouge brun pâle; son colorant est l'hématéine; isolé par Chevreul, il sert en teinturerie, où il entre dans la préparation de nombre de couleurs composées. Sa réputation est détestable à cause des fraudes sur les vins auxquelles, avec le jus des fruits de Sureau ou d'Yèble, il a souvent participé.

Les Brésillets ou Casalpinia fournissent les bois de Pernambouc, de Sainte-Marthe, des Antilles, de la Jamaïque, qui servent à teindre en rouge. Le fustet ou bois jaune est extrait du Mûrier des teinturiers (Morus tinctoria) croissant à Cuba, au Mexique, au Brésil, aux Indes. Son principe colorant jaune ou fustine change de teinte avec les mordants. Les bois de Santal sont usités aussi en teinturerie. Le bois de Châtaignier est souvent employé dans la teinture en noir, au même titre que les noix de galles et d'autres substances tannifères. Le cachou, fourni par une Légumineuse de l'Inde, l'A cacia Catechu, par un palmier (Areca $\mathrm{Ca}$ techu) et une Rubiacée de Malaisie, le gambir (Uncaria Gambir), est employé à teindre en. brun, en olive ou en noir, suivant les sels auxquels on l'associe. Enfin le quercitron est un colorant jaune fourni par l'écorce du. Chêne tinctorial (Quercus coccinea, fig. 206) de l'Amérique du Nord.

Matières colorantes diverses. - Le Rocoayer (fig. 302) [Bixa orellana] est un arbuste de l'Amérique méridionale cultivé jadis aux Antilles et dans la Guyane française. Le rocou renferme deux colorants, la bixine et l'orelline; cette dernière existe en granulations dans l'enveloppe externe des graines. Celles-ci sont broyées, délayées dans l'eau chaude; J'eau qui s'écoule au tamisage entraîne la matière colorante qu'on laisse déposer, puis qu'on sèche à l'ombre après décantation et qu'on divise en pains. Le rocon, qui n'est plus guère employé, permettait de teindre les tissus en toutes nuances et de colorer en jaune le bois, les cuirs et surtout le beurre et les fromages de Hollande. Le tournesol provient de la Maurelle, ou Croton des teinturiers (Chrozophore tinctorial), cultivée dans le Gard. Le suc de la plante, additionnéd'urine, de cendres et de chaux, est mis à

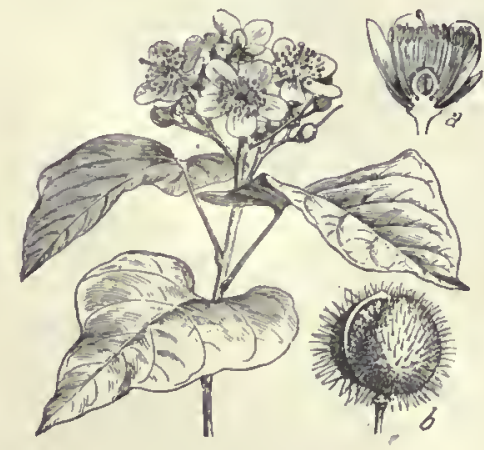

Fig. 3J2. - Rosouyzr.

$a$, Coupe de la fleur ; $b$, Fruit.

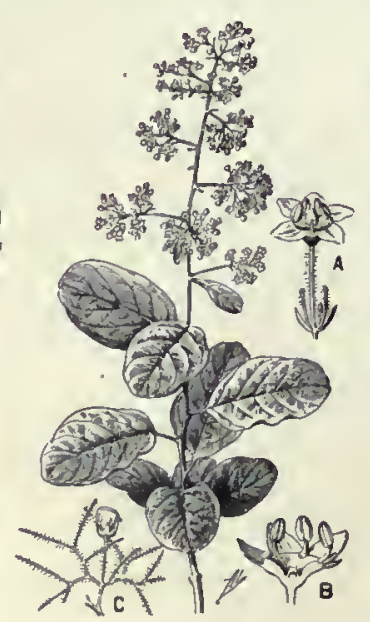

Fig. 303. - Sumac. $a$, Fleur.

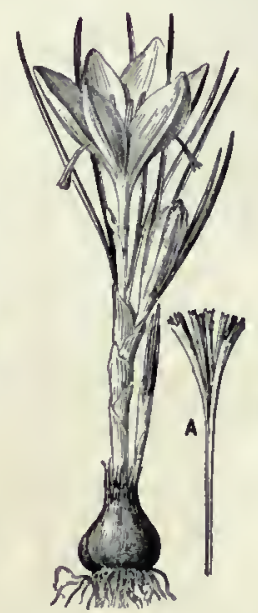

Fig 304. - Safran. a. Stigmate.
Fig. 301. - Gaude. $a$, Fleur; $b$, Fruit.

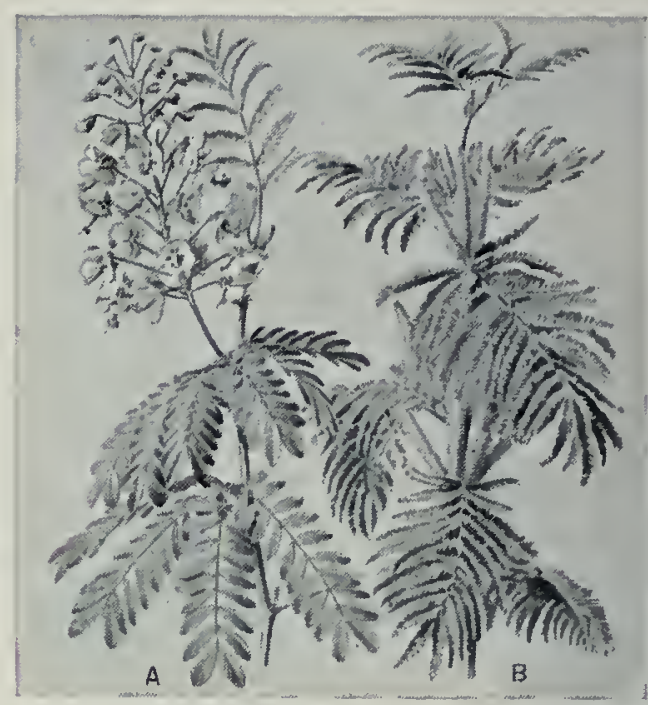

A, Bois de Pernambouc (Ciesalpinia echinala). B, Cachou (Acacia Catechu).

fermenter. On l'obtient en drapeaux (sur des linges quil imprègne), en pains ou en papier de tournesol.

L'orseille est une belle matière colorante d'un rouge violacé, qu'on retire de divers Lichens (Roccella, etc.). La Gaude ( $f$ ig. 30l) est un Réséda indigène cultivé jadis dans l'Hérault et dans l'Eure pour teindre en jaune. Le Sumac (fig. 303) représente les feuilles plus ou moins finement broyées d'arbustes du genre Rhus (Sumac des corroyeurs, S. fustet) et du Redoul; on le récolte en Sicile, en Espagne, en France, où les principaux marchés sont Montélimar et Montauban. Il sert en tannerie, à la fabrication de l'encre, à la teinture en noir et en gris. Les fleurs du Carthame des teinturiers, qui fournissaient des colorants rouges ou jaunes, servent maintenant à frauder le Safran.

Les stigmates du Safran ou Crocus cultivé (fig. 304) contiennent un colorant, la safranine, trop peu solide pour teindre les étoffes, mais servant à colorer en jaune les pâtes alimentaires, le beurre, les liqueurs, la pâtisserie ; leurs propriétés stimulantes les font utiliser en médecine et comme condiment. Cette plante bulbeuse était jadis cultivée sur de petites parcelles de terrain, dans le Loiret, le Gâtinais et aux environs de Carpentras; on cueillait les fleurs en octobre; les styles et stigmates étaient séparés pendant les veillées d'hiver, puis séchés au-dessus du feu dans un tamis; 140000 styles donnent I kilogramme de matière colorante. Aujourd'hui le Safran vient de l'Inde, de Turquie et d'Espagne.

Le Henné (Lawsonia blanc) [fig. 305] est un arbrisseau originaire d'Arabie et cultivé dans tout l'Orient, en Algérie et jusqu'aux Antilles. Ses feuilles, séchées et broyées, donnent une poudre employée par les femmes d'Orient pour se peindre les èvres, les paupières et les ongles en jaune brunâtre et se teindre les cheveux, auxquels il communique, suivant la dose, tous les tons, du blond doré au rouge.

La racine d'une Borraginacée, l'Orcanette (fig. 306), contient

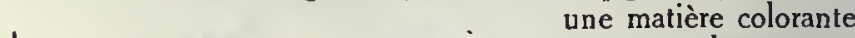

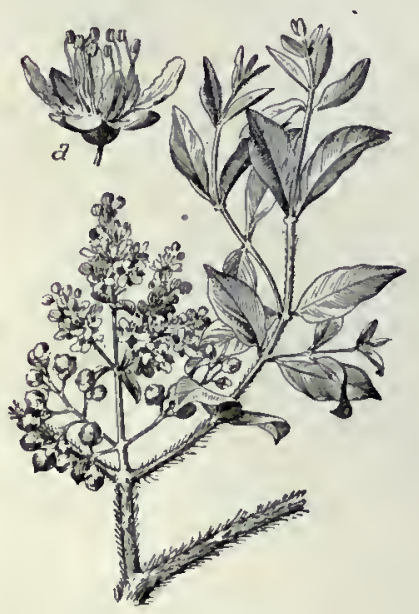

Fig. 305. - Hennè. $\alpha$, Fleur. rouge employée pour teindre les pommades.

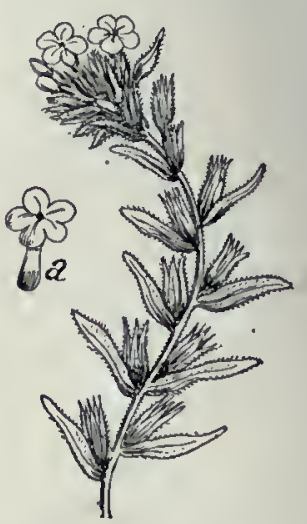

Fig. 306. - Orcanette. $a$, Fleur. 


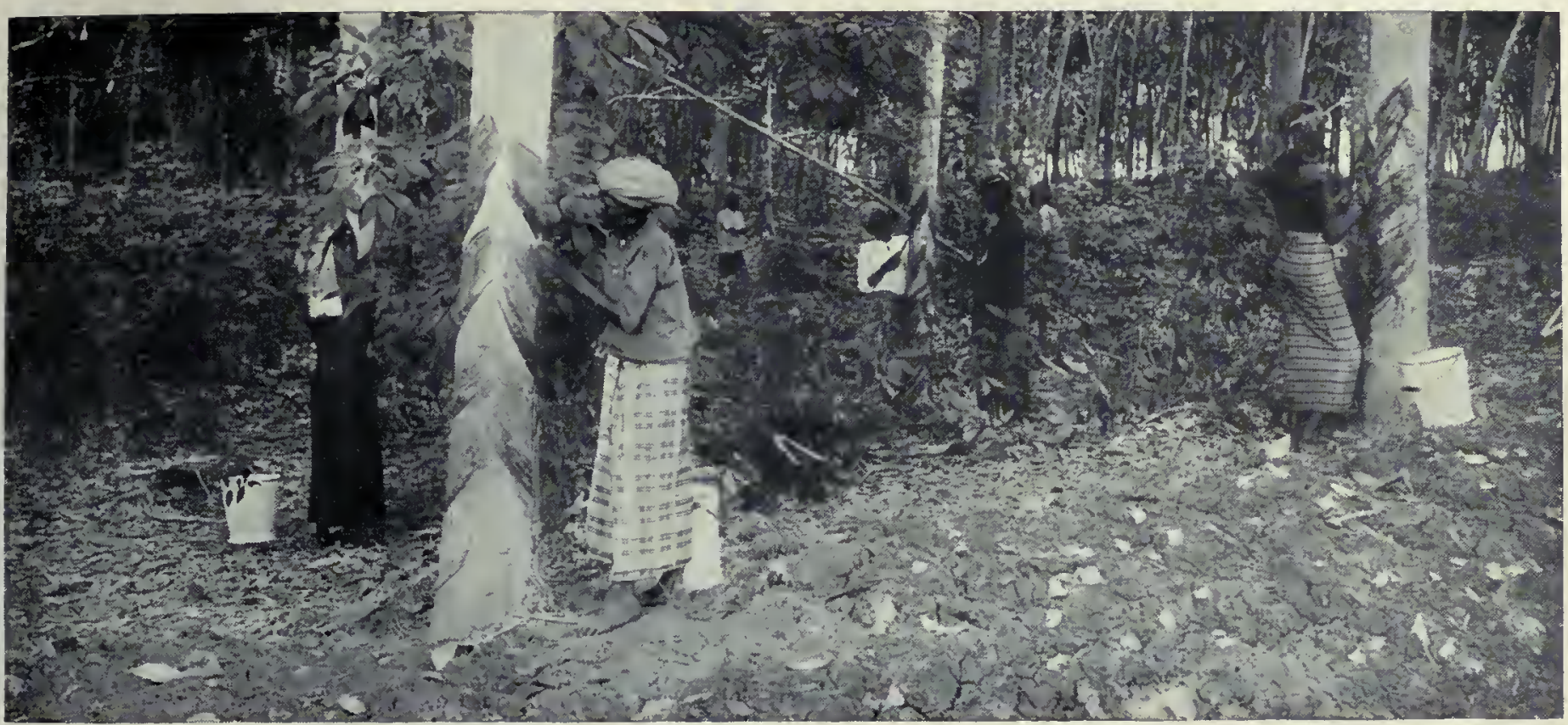

Récolte du caoutchouc d'Hevea, dans la presqu'ile de Malacca.

\section{CAOUTCHOUC, GUTTA, GOMMES, RÉSINES}

Importance du caoutchouc. - La question des plantes à caoutchouc est une de celles qui intéressent le plus vivement nos colonies à l'heure actuelle; pour se rendre compte de l'importance du produit qui nous occupe, il suffit de rappeler qu il sert à fabriquer des gommes à effacer le crayon, des manteaux, des chaussures, des vêtements de toute nature, des ballons d'enfants, des jouets de toute sorte, des bandages pour roues caoutchoutées de bicyclettes, d'automobiles et de voitures ordinaires, et ces nouveaux débouchés industriels ont donné à l'exploitation des plantes caoutchoutifères un essor incomparable. On emploie encore le caoutchouc dans l'ébonite, qui est du caoutchouc durci par 50 pour 100 de soufre $\left.(a ̀) 135^{\circ}\right)$ et que l'on peut tailler sous toutes les formes pour objets de chirurgie, tabletterie, optique, machines électriques, etc., et qui a été fabriquée pour la première fois en 1851 par Morey.

I] est intéressant de rappeler comment on a découvert un produit aussi utile. La première usine a été fondée en 1821 aux environs de Londres; c'est Hancock qui l'établit, qui créa le laminoir ou mélangeur; le ramollissement du caoutchouc à l'eau chaude qui purifie le caoutchouc brut fut trouvé en 1837; l'emploi de la benzine comme dissolvant, dû à Mac lntosch, date de 1823; mais la plus importante découverte est celle de la vulcanisation, due à l'Américain Goodyear, en 1836; elle consiste à le traiter par le soufre à $130^{\circ}$ : il acquiert de la souplesse, de l'élasticité, de la résistance au froid. Les efforts des inventeurs pour perfectionner le caoutchouc ont été extraordinaires et justifient l'immense développement de l'industrie de cette substance.

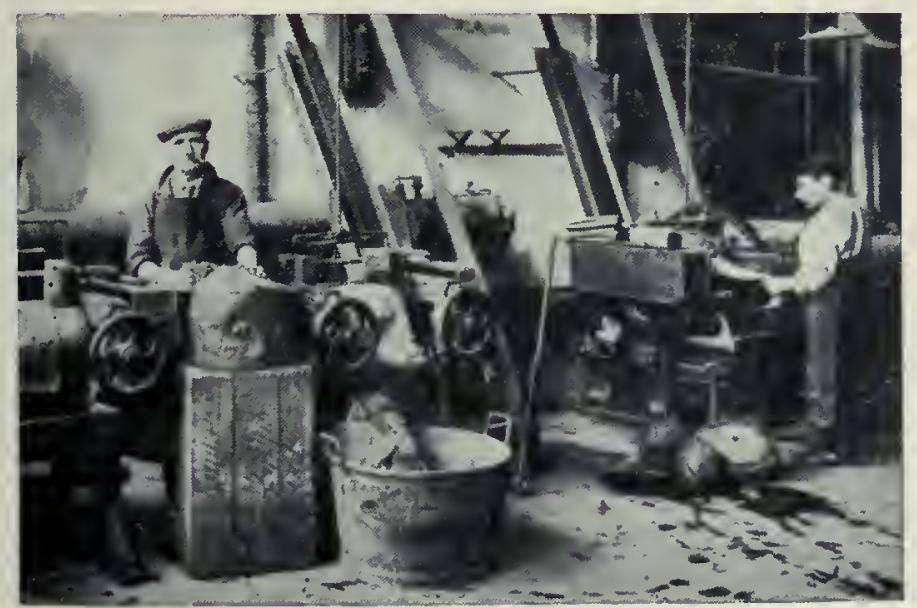

Lavage et sciage de la gomme brute.
C'est en 1525 que Pierre Martyr, dans le livre De orbe novo, parle du suc des herbes durci au feu, de manière à faire des paumes si élastiques qu' elles " bondissent en l'air et font des sauts à peine croyables "); en 1529, Sahagun a parlé cette fois d'un arbre " ulli " dont la résine devient très élastique; " on en fait des pelotes à jouer qui sautent plus que les balles faites avec du vent $n$. Enfin en 1615 , après Herrera, Torquemada signale la grande valeur de l'ulequahuitl pour faire non seulement desballes, mais des cuirasses, des chaussures. II rapporte que les indigènes le recueillent dans des calebasses rondes où il acquiert plus de consistance et se prend en masse gommeuse à laquelle on donne la forme qui convient. Il ajoute qu' un de leurs jeux consistait à faire marcher les baladins avec des chaussures d'une forme permettant difficilement l'équilibre; "la gaucherie des mouvements et les culbutes continuelles de ces pauvres gens excitaient la gaieté et les éclats de rire des spectateurs, ") dit-il. Ces remarques étaient tombées dans l'oubli quand, en 1736, La Condamine retrouva cette substance à Quito, lorsqu il était dans l'Amérique du Sud pour la mesure du méridien terrestre; il envoya à l'Académie des sciences quelques rouleaux d'une matière résineuse connue dans cette ville sous le nom de caoutchouc. C'est seulement à partir de cette époque que ce produit, maintenant si répandu, commènça à être connu en Europe.

Extraction du caoutchouc. - On apprit ainsi à utiliser une nouvelle matière que l'on pouvait trouver dans certaines plantes qui possèdent ce que l'on appelle des laticifères, grands éléments cellulaires à nombreux noyaux renfermant un liquide blanc appelé latex, parce qu'il rappelle un peu le lait. Étudié au

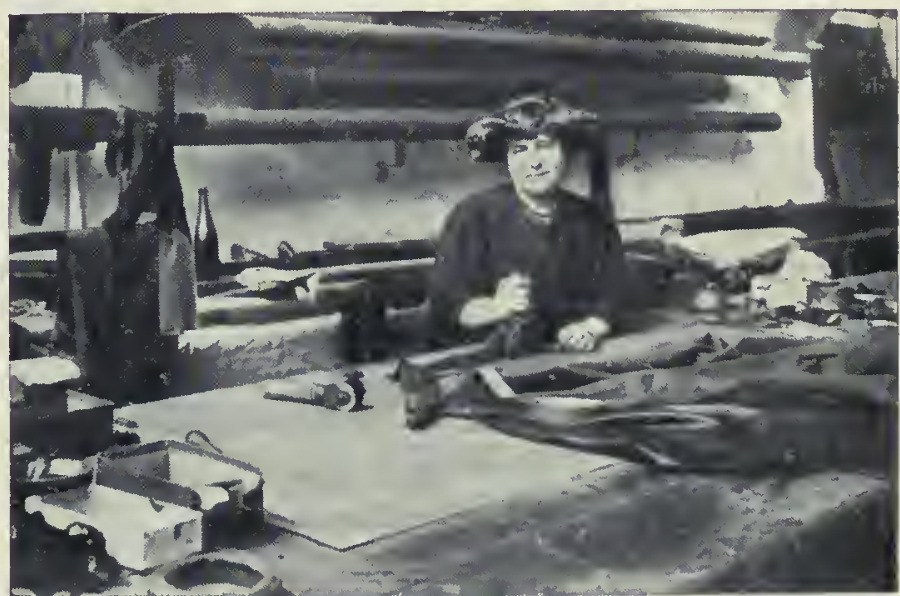

Coltage des coutures d'un vêtement de caoutchouc. 
microscope, on le voit composé d'une multitude de globules flottant dans un sérum incolore ; ce sont ces globules qui constituent le caoutchouc, lequel est un carbure d'hydrogène. Pour l'extraire dans la région de l'Amazone, des indigènes appelés " seringueros " vont chaque jour, d'arbre en arbre, sur des sentiers tracés par eux dans la forêt vierge, entailler l'écorce à l'aide d'une hache appelée "machadino "; le lait s'écoule abondamment dans des godets placés sous la blessure; les liquides de tous région de l'Angola : cette industrie est développée à Quiriri notamment. Il y a d'ailleurs un procédé de coagulation par le battage des écorces qui a été imaginé par les nègres de l'Ángola méridional, du Longa, du Kampualwe.

Toute la population se consacre presque exclusivement à la préparation du caoutchouc. Les Cafres arrivent chargés de lourds ballots de rhizomes, qui sont ficelés de manière à dépasser la hauteur d'un homme. Les rhizomes, dès l'arrivée dans le village, sont plongés

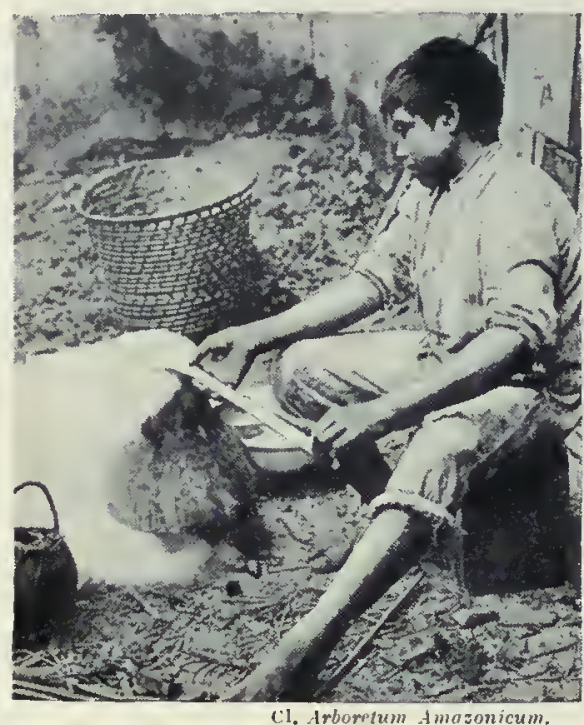

Fumigation du caoutchouc.

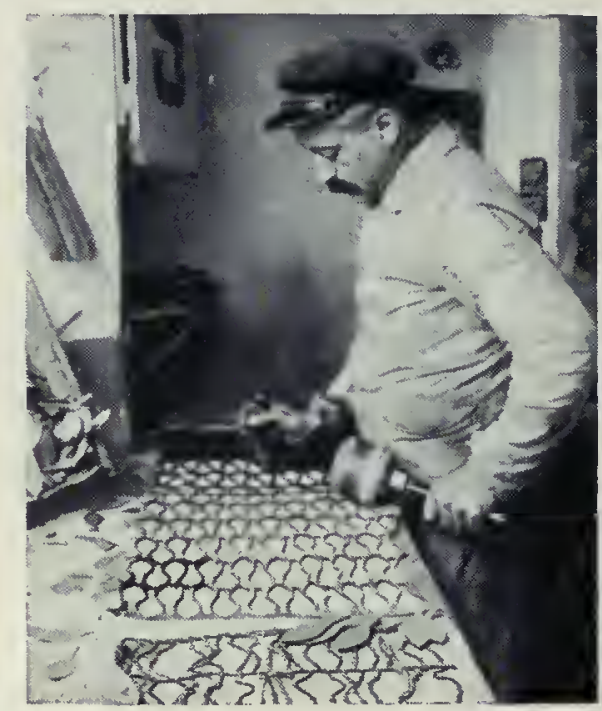

Découpage du caoutchouc.

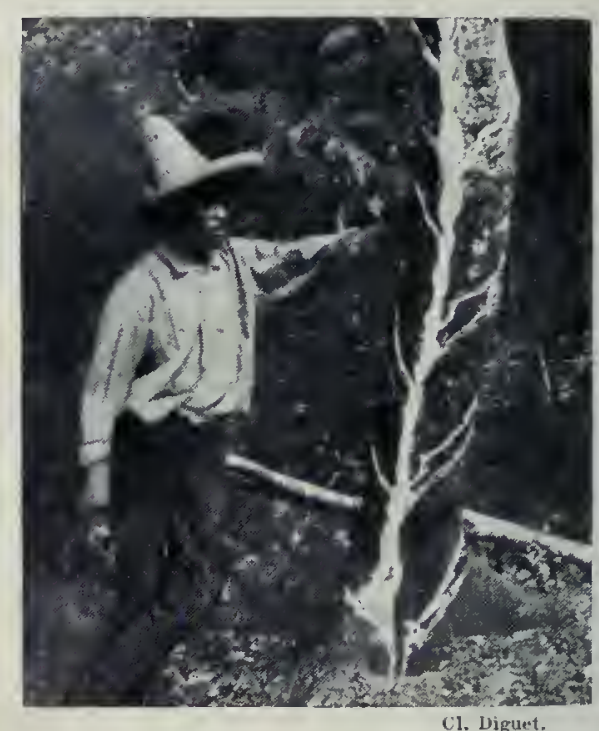

Chilté ou Jatropha de Tepic. ces godets sont ensuite récoltés et la coagulation est obtenue en exposant une sorte de palette élargie en rame, la "pala ", à la fumée produite sous un diable en terre cuite, le "buyon », où l'on fait brûler des noix de Palmiers, de préférence celles du Maximiliana princeps, et, à son défaut, des enveloppes ligneuses de " noix du Brésil ", fruits du Bertholletia excelsa. En exposant la pala enduite de gomme à la fumée du buyon, le seringuero la tourne d'une manière continue et obtient ainsi le dépôt successif de couches coagulées, qui ne tardent pas à fournir une boule de caoutchouc de Para de plusieurs kilogrammes. Ce caoutchouc est produit dans tout le bassin de l'Amazone par les saignées de l'Hevea du Brésil (fig. 308), qui est l'arbre le plus important, non seulement parce quil est le grand producteur de l'Amérique du Sud, mais parce qu'il donne le caoutchouc de première qualité.

La vie du seringuero, occupé au milieu de la forêt vierge à tracer des sentiers ou " estrada ", à inciser les arbres, à récolter le latex et à le coaguler, est très tentante pour les esprits aventureux et aimant à réaliser des gains élevés assez rapidement; aussi une séduction extraordinaire est-elle exercée depuis quelques années sur toute la population, qui draine toute la main-d'œuvre disponible vers le bassin de l'Amazone. Il y a, à l'heure actuelle, une "fièvre du caoutchouc " comme il y a eu dans certaines contrées une "fièvre de l"or "; toutes les cultures du Brésil ont été abandonnées pour l'exploitation du caoutchouc; on évalue à 150000 le nombre de seringueros de l'Amazone. La production extraordinaire du Para et autres caoutchoucs au Brésil a atteint dans ces dernières années 60000 tonnes. L'Afrique a été longtemps au second rang avec une production beaucoup plus faible. La production mondiale du caoutchouc a dépassé 100000 tonnes. L'Hevea a été transplanté par les Anglais dans les Straits settlements, dans la presquî́le de Malacca et à Ceylan, où se trouvent maintenant des cultures immenses qui rivalisent avec les forêts spontanées du Brésil. Les Anglais ont imaginé l'emploi de l'écrémeuse centrifuge, qui sépare le latex en sérum liquide coloré et une crème de caoutchouc blanc qui se solidifie par pression en faisant absorber l'eau d'interposition par un vase poreux; la couleur du caoutchouc est blanche avec une pureté inconnue précédemment; ce n'est qu'au bout d'un certain temps, par l'action des diastases, qu'il brunit à l'air. L'étude des procédés de coagulation laisse place à la découverte d'importants perfectionnements. Perkin a préconisé la coagulation par l'acide acétique.

Arnaud et Verneuil ont inventé un procédé d'extraction mécanique qui a été mis en pratique à Brazzaville, au Congo. Ce procédé de coagulation par le battage des écorces est d'ailleurs pratiqué en grand depuis quelques années par les nègres dans la dans l'eau pour rendre l'écorce plus friable, puis séchés au soleil. Les tiges sont ensuite partagées en fragments de 30 à 40 centimètres et soumises à un battage méthodique sur un tronc, de manière à séparer l'écorce du bois. Quand les deux parties sont séparées l'une de l'autre, les Cafres continuent le martelage des écorces jusqu’à former un grand gâteau qu ils soumettent ensuite à l'action de l'cau bouillante, puis achèvent la purification par un nouveau battage. La marchandise est mise en circulation sous l'aspect de bandes de l'épaisseur du doigt qui servent d'unité monétaire, soit en petits cubes, soit en bâtonnets.

Ce caoutchouc d'herbes est produit par le Landolphia de Thollon et c'est la partie souterraine qui est exploitée. En général les Landolphia, qui sont les plantes à caoutchouc africaines, sont des lianes qui, quand elles sont de la grosseur du bras, ont une centaine d'années et sont exploitées d'une manière intensive et destructive par les nègres.

Le gouvernement du Congo belge a édicté dès 1899 et en 1902 un certain nombre de mesures protectrices pour la conservation des plantes exploitées d'une manière réellement par trop sauvage. Tout concessionnaire d'une récolte de 1000 kilogrammes de caoutchouc devait planter 500 pieds nouveaux de plantes caoutchoutifères. Un service forestier bien organisé a permis d'exercer un contrôle qui est devenu pesant à la longue. Malgré des excès qui ont peut-être été regrettables, l'essor donné au commerce du caoutchouc a été considérable et a fait progresser d'une manière phénoménale l'exploitation des lianes; le développement du marché d'Anvers, qui tient à la mise en valeur des immenses territoires du Congo, a été extraordinaire.

Citons à côté des plantes à caoutchouc le Chilté (Jatropha de Tepic), parce qu'il est exploité de la même manière par saignée en arête de poisson, mais il fournit une gomme employée comme masticatoire aux Ëtats-Unis, où elle est l'objet d'un commerce assez important.

Caoutchouc des Euphorbiacées. - Le genre Hevea est le principal genre de la famille des Euphorbiacées : c'est l'H. du Brésil, qui fournit le caoutchouc de Para, qui constitue la première marque, partout appréciée; il forme d'ímmenses réserves dans les bassins de l'Amazone et de l'Orénoque; en Guyane, il y a une autre espèce, l'Hevea de Guyane, qui a été le premier Hevea trouvé par Aublet (1762). Diverses autres espèces ont été recherchées dans les forêts de l'Amérique du Sud. Labroȳ, chef des serres du Muséum, a signalé notamment aux environs de Manaos, où il a été en mission, l'Hevea discolor, qui est le caoutchoutier le plus important de la région qui s'étend entre l'Ama- 

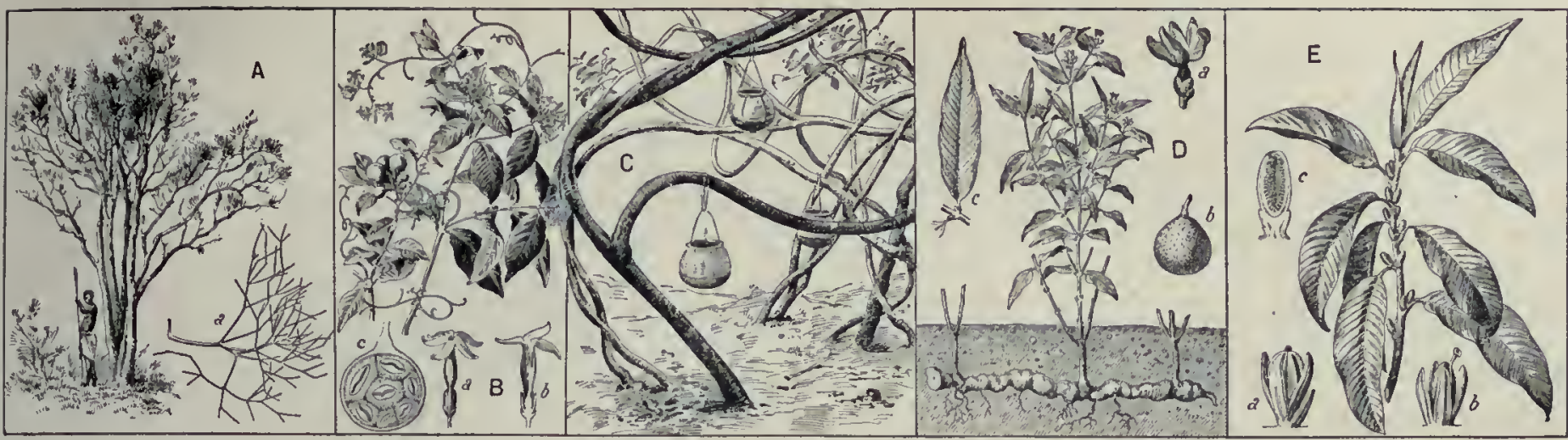

Fig. 307, - Plantes à caoutchouc.

A, Euphorbia Intisy: a, Rameau. - B, Landolphia Heudelotii : $a$, Fleur; $b$, Coupe de la fleur; $c$, Coupe du fruit. - C. Récolte du latex de Landolphia. D. Landolphia Thollonii: $a$, Fleur; $b$, Fruit ; $c$, Feuille. - E. Ficus elastica: $a$, Flenr måle; $b$, Fleur femelle ; $c$, Coupe longitudinale d'un fruit.

zone et le rio Negro, à l'endroit où ces deux cours d'eau se réunissent. L'Hevea de Spruce, signalé par le voyageur de ce nom à Santarem et qui abonde dans la vallée du rio Madeira, est de valeur secondaire. L'Hevea jaune est le Seringa amarilla du Pérou, le Seringa del Cerro; c'est une espèce de terre ferme excellente, car beaucoup de ces arbres poussent dans la région inondée. La question des espèces de ces arbres est d'ailleurs encore à l'étude.

Le Caoutchoutier de Ceara (Manioc de Glaziou) est un arbre d'une région brésilienne beaucoup plus sèche; il a été découvert par Glaziou, Français qui fut pendant longtemps le directeur du jardin botanique de Rio de Janeiro : c'est le "maniçoba ", qui est voisin du Manioc à tapioca. Son caoutchouc s'exporte surtout par le port de Ceara. Ses graines conservent beaucoup plus facilement leur pouvoir germinatif; aussi c'est l'espèce qui a été propagée avec le plus de promptitude dans toutes les régions tropicales: malheureusement elle a causé bien des mécomptes, et dans beaucoup de plantations qui ont été faites en Afrique tropicale le rendement en caoutchouc a été extrêmement faible; c'est qu'on 'l'avait planté d'une manière très inconsidérée, dans des pays qui ne lui convenaient pas par leur climat. De meilleurs rendements ont été obtenus en Afrique orientale, dans des régions sèches.

La récolte $\mathrm{du}$ latex est faite au Brésil sur des plantes sauvages pendant la saison sèche, au moment où l'arbre perd ses feuilles. Louvrier pratique sur le tronc plusieurs incisions verticales: l'arbre laisse s'écouler librement le liquide qui se coagule en longues lanières que I on recueille le surlendemain en le roulant en boules. On conçoil que cette méthode de récolte ne donne pas un caoutchcuc de première qualité. On connaît d'autres Manihots à caoutchouc: le Jequier ( $M$. dichotoma), le San Francisco (M. piauhyensis).

Enfin deux autres Euphorbiacées sont à signaler: l'Euphorbe Intisy, donnant le caoutchouc Antandroy de la brousse épineuse du sud de Madagascar, qui a malheureusement été exploité d'une manière trop intensive, ce qui a amené la destruction des plantes. Le Sapium à deux glandes est un arbre qui fournit en Colombie le "Colombie ", qui est assez apprécié.

Caoutchouc des Urticacées-Artocarpées. - Le Castilloa élastique, qui appartient aux Artocarpées, est encore un arbre qui, avec plusieurs autres espèces du même genre, abonde dans le Mexique méridional, ' 'Amérique centrale et la partie occidentale de l'Amérique du Sud située entre $25^{\circ}$ de latitude nord et $25^{\circ}$ de latitude sud : en Colombie, Equateur et Pérou. Le Castilloa de Ule a été découvert au Brésil, par Hüber, près de différents affluents de l'Amazone. C'est une des plantes à caoutchouc qui produisent le latex le plus abondant (caoutchouc caucho ou Hulé), car on a vu des arbres bien exploités fournir jusquà 90 litres de lait, ce qui donne un rendement de 22 kilogrammes de caoutchouc; mais ces rendements sont exceptionnels, et on peut évaluer à simplement 3 kilogrammes le rendement moyen annuel d'un arbre.

L'extraction du lait a lieu au début de la saison sèche; les entailles sont faites en $V$, jusqu'à I mètre, et, pour faciliter la récolte, les pointes des $\mathrm{V}$ se trouvent sur la même verticale; le lait est recueilli dans un récjpient placé au pied de l'arbre, par l'intermédiaire d'un tube quelconque. Le lait de Castilloa est acide et on le coagule par addition de liquides alcalins: on ajoute au Nicaragua du suc d'Ipomaa bonne-noix ou une solution de sel de cuisine, ou de bicarbonate de soude au Mexique. Nous avons dit plus haut que les centrifugeurs ont donné avec ce latex des produits d'une pureté extraordinaire. Le Castilloa est un grand arbre de 20 à 25 mètres de haut, à fleurs unisexuées, mais réunies sur un même pied, à feuilles grandes, entières, dont tous les organes jeunes sont couverts de poils blanchâtres. La culture peut réussir dans des régions où règne une température moyenne de $25^{\circ}$ à $30^{\circ}$, à des altitudes inférieures à 500 mètres, sur des terrains hu-

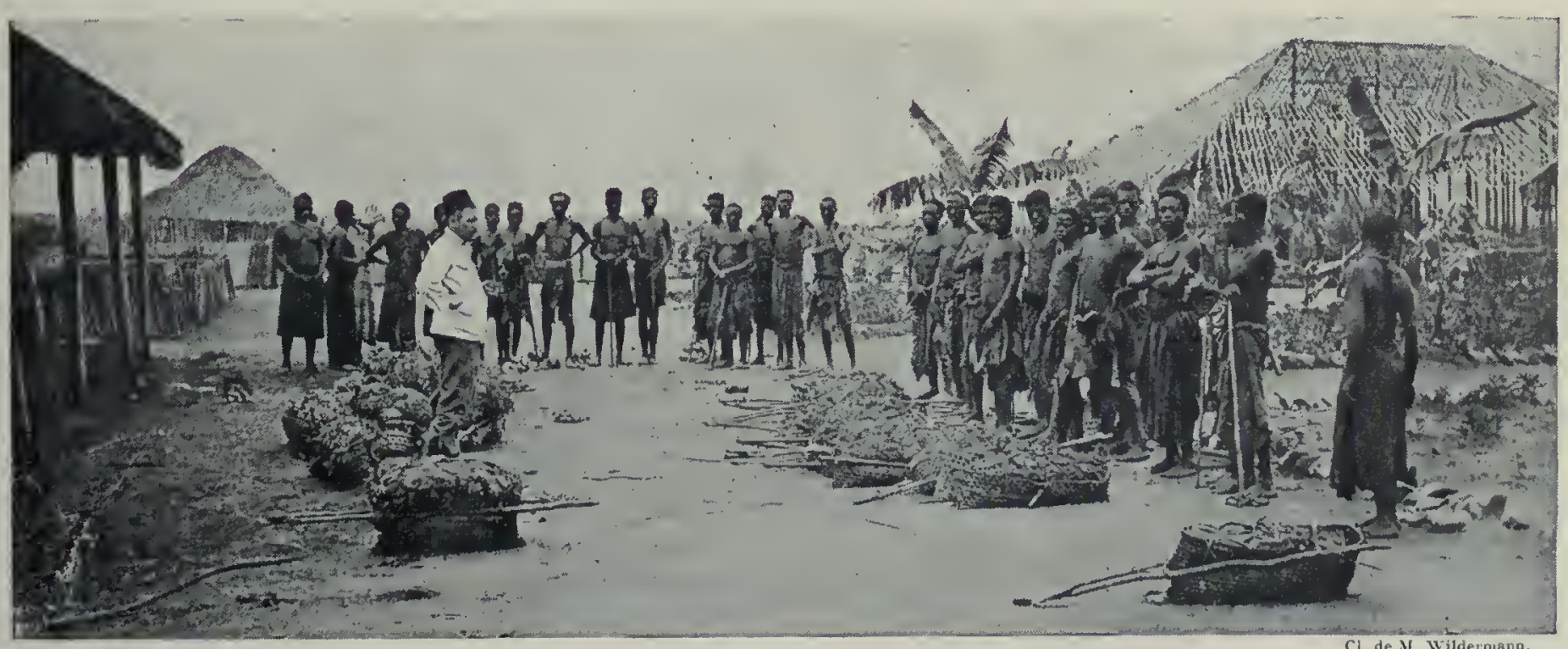

Arrivée d'un capita et de ses hommes apportant du caoutchouc au poste de Kapanga (Congo belge). 
mides, non marécageux. Les grandes plantations du Mexique n'ont d'ailleurs pas donné des résultats brillants, ce qui tient à ce que l'on n'a peut-être pas toujours employé les meilleurs types de Castilloa.

Une autre espèce importante de la même famille est le $F$ iguier élastique, le vulgaire Caoutchouc des appartements. C'est un arbre quiatteint de grandes dimensions : près de 40 mètres de haut; son tronc est couvert de racines aériennes. Il est cultivé en plantations, surtout à Java, à Sumatra, en Assam, et on lui donne vulgairement le nom de Caoutchouc de

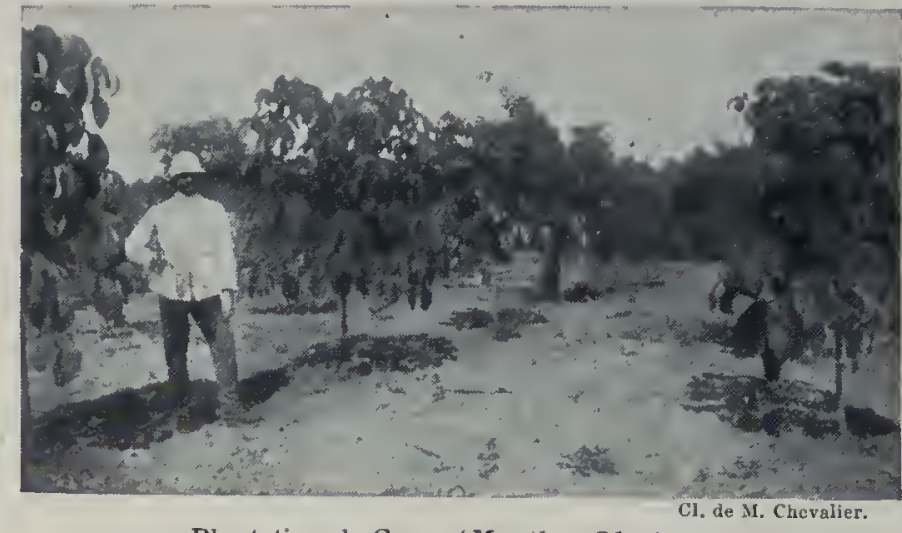

Plantation de Ceara (Manihot Glaziowii).

l'Assam. C'est seulement dans les régions tropicales qu'il peut être cultivć et donner un produit utilisable. Le rendement est d'ailleurs tardif (au bout de vingt-cinq ans), et il serait imprudent d'en entreprendre la culture en dehors de contrées très limitées. C'est aux Figuiers qu'appartient également l'espèce produisant le "Sa " de la Nouvelle-Calédonie et de Tahiti, le Figuier retus. La coagulation est opérée par l'enfumage. C'est depuis 1899 que l'explojtation de notre première colonie océanienne a commencé.

Le Tonkin peut renfermer aussi des plantes à Caoutchouc; Dubard et Eberhardt ont signalé un arbre de la même famille, voisin des Orties, qui en produit dans la, région nord de notre colonie, le Bleckroodea du Tonkin.

Caoutchouc des Apocynacées. - Le caoutchouc africain est surtout fourni par les Landolphia, dont le nom rappelle celui de Landolph, un capitaine marchand de la fin du Xvtlle siècle, énergique colonisateur qui a fondé notre colonie d'Oware et du Benin. Ce genre est formé de lianes atteignant une grande longueur, mais dont la grosseur reste en général faible. La plus importante pour les colonies de l'Afrique occidentale est la liane gohine ou Landolphia d'Heudelot, répandue dans le SénégalSoudan et surtout dans la Haute Guinée; le caoutchouc qu'elle donne est excellent quand il n'est par fraudé par les nègres. Une autre espèce à citer ensuite est le Landolphia d'Oware, du SierraLeone à l'Angola, qui entre aussi pour une part importante dans l'exploitation de l'Afrique occidentale. Le Landolphia du Père Klaine du Gabon-Congo a une certaine valeur; sa végétation est puissante : elle atteint jusqu'à 100 mètres de long. Nous avons mentionné plus haut le caoutchouc des herbes, extrait, au Congo et à l'Angola, des rhizomes du Landolphia de Thollon. A Madagascar plusieurs Landolphia ont été aussi signalés, notamment la liane vohaigne, qui est le L. de Madagascar; le Landolphia de Perrier (de la Bathie), le Landolphia à fruit rond, le L. mamolava et le $L$. mamavo, qui ont été découverts dans le sud-est de Madagascar, par Geay.

Il y a aussi des arbres caoutchoutifères appartenant à cette même famille, dont l'un au Brésil, qui donne le caoutchouc de Pernambouc ou "Mangabeira " : c'est l'Hancornia speciosa, dont
Greve, portantes est le Gonocrypta de Greve, qui donne le caoutchouc de Kompitsé ou Kopitso de Madagascar. Signalons aussi le Cryptostegia de Madagascar, connu dans ce pays sous le nom de lombir ou lombiro.

Les caoutchoucs de synthèse. - Le caoutchouc a pour formule brute $\left(\mathrm{C}^{10} \mathrm{H}^{16}\right)^{n}$; c'est un polyterpène. En distillant le caoutchouc, on peut avoir l"isoprène $\left(\mathrm{C}^{5} \mathrm{H}^{8}\right)$, découvert en 1860 . En 1892, on crut pouvoir, par action de l'acide chlorhydrique, polymériser l'isoprène et le transformer en caoutchouc, mais on n'avait qu'une huile grasse, collante et non élastique. En 1909 , Richard, puis, en 1911, les grandes fabriques de produits chimiques allemandes d'Eberfeld, de Bade (Anilin und soda), prétendent être arrivés à réaliser la synthèse, et divers brevets ont été pris. Comment obtenir l'isoprène? On ne peut songer à distiller le caoutchouc naturel ou la gutta. On peut réaliser la synthèse de l'isoprène en chauffant au rouge des mélanges d'acétone et d'éthylène ou d'acétylène et d'éthylène ou en distillant de l'essence de térébenthine. On affirme avoir pu polymériser l'isoprène sous l'influence de l'acide acétique et avoir obtenu du caoutchouc véritable et non du factice. En attendant, on a extrait l'isoprène des Xanthorrhcea (Grass Tree, Yacka). Enfin on a songé à retirer le caoutchouc, non de l'isoprène, mais de ses homologues inférieurs ou supérieurs comme le butadiène, le diméthylbutadiène. C'est là une question passionnante, car il s'agit de la destruction d'industries agricoles qui mettent en branle chaque année d'immenses capitaux. Il ne semble pas que le problème soit complètement résolu, les caoutchoucs synthétiques étant beaucoup plus oxydables et se vulcanisant plus difficilement que le produit naturel; mais il pourra l'être et ce sera une révolution économique.

Gutta-Percha. - Un autre carbure d'hydrogène, qui a les plus grandes analogies avec le caoutchouc et qui est extrait du latex de divers Palaquium (Sapotacées) [fig. 310], est la gutlapercha. Cette substance se distingue aisément du caoutchouc parce qu'elle est notamment mauvaise conductrice de l'électricité, et c'est ce qui la fait employer dans la fabrication des câbles sousmarins de télégraphie. Sa couleur est brun jaunâtre, sa plasticité est une propriété extrêmement utile qui se manifeste à une tempé-

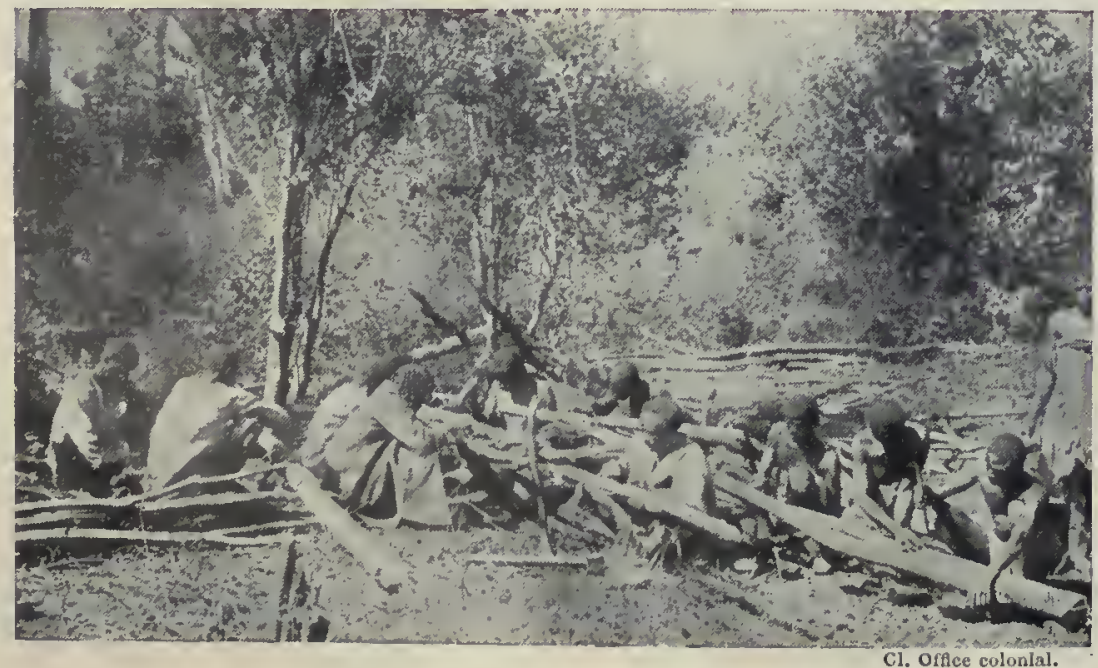

Extraction du caoulchouc Kidroa, à Madagascar.

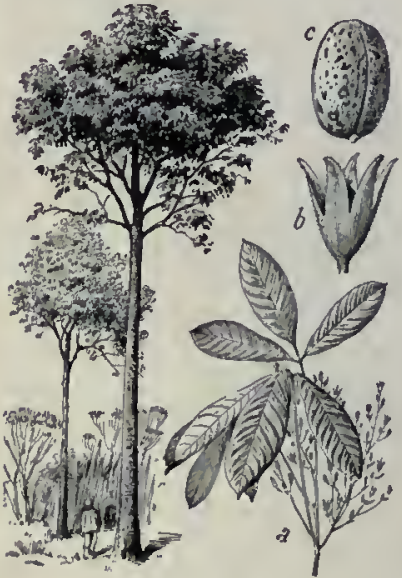

Fig. 308.

Hévea du Brésit.

$\alpha$, Rameau fleuri ; $b$, Fleur ; $c$, Graine.
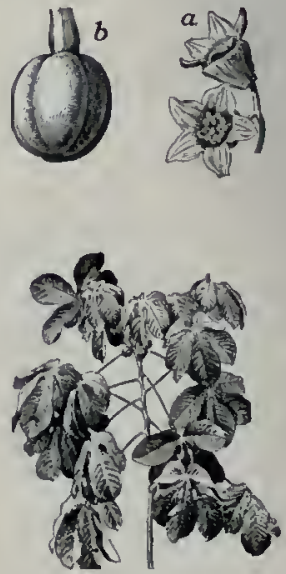

Fig. 309.

Manioc de Glaziou.

$a$, Fleurs mâles ; $b$, Fruit. 
rature de $45^{\circ}$ à $70^{\circ}$; on peut, dans ces conditions, lui donner toutes les formes que l'on désire. Avec le temps, la gutta devient noirâtre, cassante, fragile, tandis qu'à l'origine elle avait une consistance de cuir.

Les deux propriétés essentielles que nous venons de citer (malléabilité et mauvaise conductibilité de l'électricité) font employer cette substance dans la galvanoplastie, en électricité et pour la fabrication de vases, de moules, d'instruments de chirurgie divers, dentiers, etc. C'est à partir de 1851 que l'on commença à exploiter ce produit d'une manière intensive pour les câbles. C'était quelques années auparavant (1843) que le $\mathrm{D}^{\mathrm{r}}$ Montgomerie l'avait fait connaître en Europe; chi-
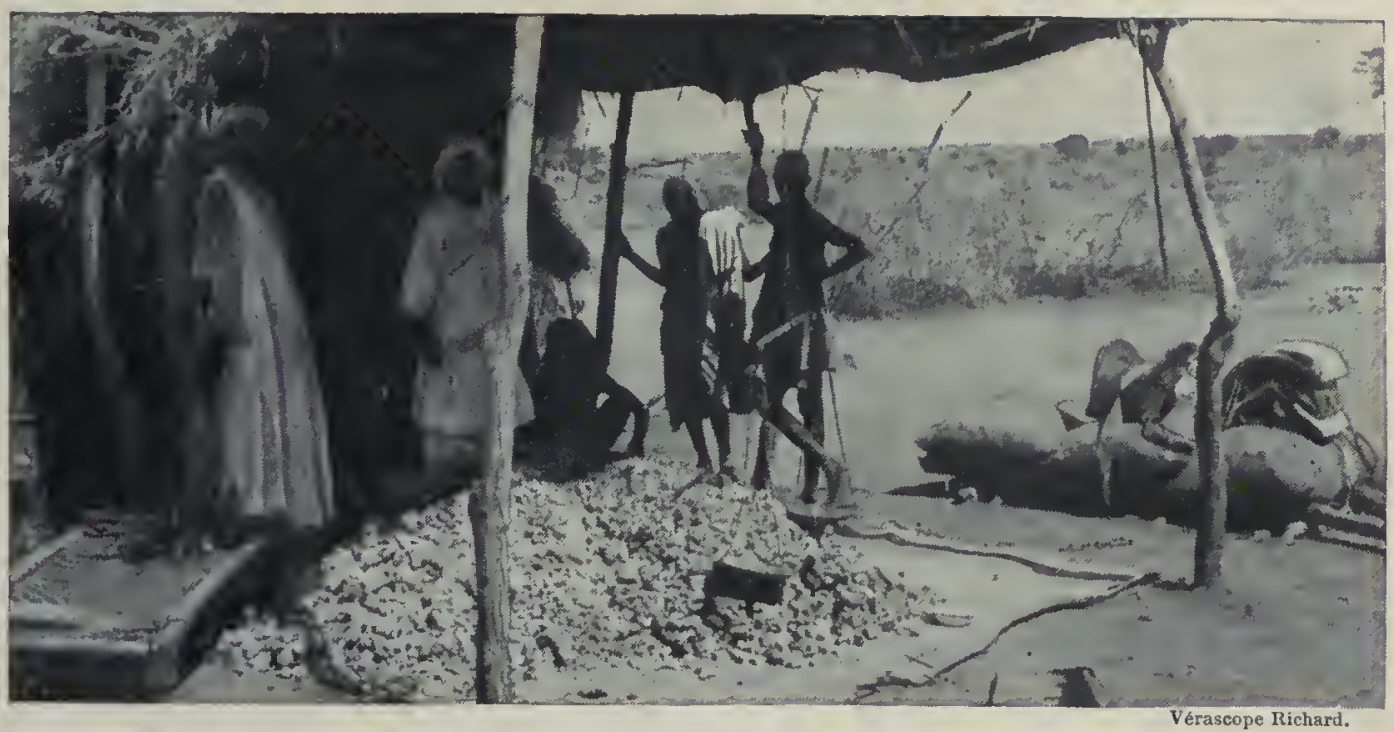

Marchand de gomme arabique, en Afrique tropicate. rurgien en Extrême-Orient, il avait vu à Bornéo, à Sumatra, et aussi dans la presqu'île malaise, où il était installé, exploiter et employer le produit de certaines plantes qui étaient absolument localisées dans le pays que nous venons de mentionner. Tout de suite l'industrie réclama des quantités énormes de gutta-percha, et l'exploitation fut faite d'une manière tellement barbare que la principale espèce, le Palaquium à feuilles oblongues, est devenue extrêmement rare; on a même prétendu quelle nexistait plus : sa culture a été heureusement entreprise par les Hollandais à Java, qui ont, dans la région de Tjipétir, plusieurs milliers d'hectares produisant maintenant.

A Sumatra, l'exploitation se fait par des indigènes qui s"installent en pleine forêt, où ils construisent une hutte pour se livrer à l'extraction du latex; la forêt est si épaisse qu"ils ne distinguent pas souvent les feuilles des arbres, et c'est en incisant le tronc qu'ils reconnaissent l'espèce, grâce à sa couleur, à son écorce, à la dureté du bois : ils l'abattent, la dépouillent de ses feuilles et recueillent le suc de blessures en cercles faites à la hache; cest le lait de Palaquium à feuilles oblongues, qui est le plus épais et se solidifie le plus vite. On exploite aussi le Palaquium Gutta et le Payena de Leer.

Les feuilles, qui ne sont pas exploitées par les indigènes, renferment cependant de la gutta-percha, et Jungfleisch et d'autres chimistes sont parvenus à l'extraire à l'aide de différents dissolvants, notamment le sulfure de carbone (Rigole), le toluène (Jungfeisch et Serullas), l'essence de pétrole bouillante (Obach), etc. Un arbre de trente ans peut foumir ainsi I kilogramme de gutta, dont malheureusement la qualité est altérée par les dissolvants. On a suggéré d'extraire la gutta par un procédé mécanique.

Diverses plantes ont été proposées comme susceptibles de fournir de lagutta : telle est une Asclépiadacée, le Calotropis gigantea; mais c'est surtout le Mimusops Balata, Sapotacée du Venezuela,

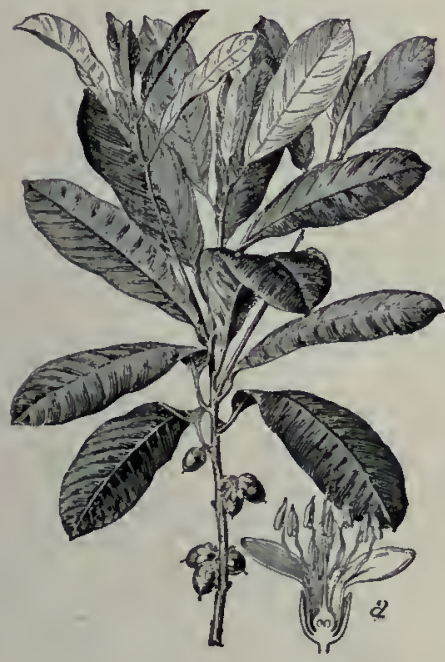

Fig. 310. - Palaquium à gutta. $a$, Coupe de la fleur. des Guyanes, du Brésil, qui est exploité. Il remplace principalement la gutta pour les câbles électriques aériens et pour les instruments de chirurgic, les courroies de transmission, les bandes minces qui, à cause de leur souplesse, peuvent être utilisées dans les pansements.

Gommes. - Un autre produit de certains arbres, notamment les Acacia, soluble dans l'eau, insoluble dans l'alcool, est la gomme, qui dérive d'une modification cellulaire d'origine surtout morbide, ou qui est un produit de sécrétion. Chacun connaît la gomme arabique et ses emplois fréquents ; elle provient d'un petit arbrisseau épineux, l'Acacia d'Arabie, qui pousse dans les régions sèches

de l'Afrique tropicale (Égypte, pays des Somalis); l'excrétion gommeuse exsude spontanément de l'arbre et se récolte surtout après la saison des pluies. Au Sénégal et au Soudan, c'est l'Acacia Sénégal qui est exploité; on trouve souvent les gommes au pied des arbres. Citons la gomme adragante, qui vient d'une Papilionacée, l'Astragale gommifère.

Les applications des gommes sont multiples : elles servent à gommer la toile, on les emploie en teinturerie, pour épaissir les mordants et les couleurs, pour fixer ces dernières dans les aquarelles, les gouaches; elles servent aussi dans la fabrication du cirage, des feutres, de l'encre. (Voir, pour le chilté, p. 268.)

Résines. - Les résines constituent une autre catégorie de sécrétions des plantes qui sont produites surtout dans des canaux sécréteurs du bois secondaire des Pins et des autres Conifères. Ces substances ainsi formées sont, au contraire des gommes, insolubles dans l'eau, mais solubles dans l'alcool, l'éther, l'essence de térében-

thine. C'est par les procédés du gemmage que l'extraction de la résine du Pin maritime se fait en France, surtout dans les régions bordelaise et des Landes. Le résinier fait des entailles appelées "carres ou quarres "), qui sont pratiquées au bas du tronc, sur 9 centimètres de large, 4 de haut et I de profondeur; la résine s'écoule dans un pot et forme la gemme. Toutes les semaines on rafraîchit l'incision en enlevant un copeau très mince ( $\mathrm{pi}$ quage), et cette opération peut se renouveler quarante fois ; l'administra tion des forêts a imposé aux adjudicataires, la première année, une hauteur de $0^{m}, 55$, la deuxième de ] $m, 30$, etc., la cinquième de $5^{m}, 80$. Les carres

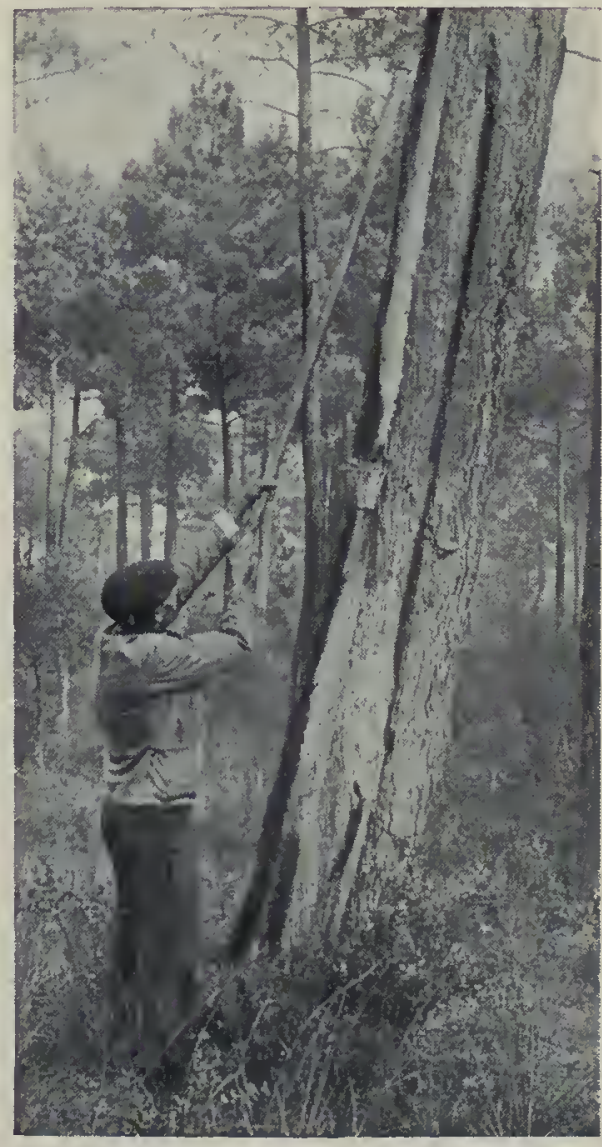

Saignée faite à un Pin, à l'aide du « abchotte ». 


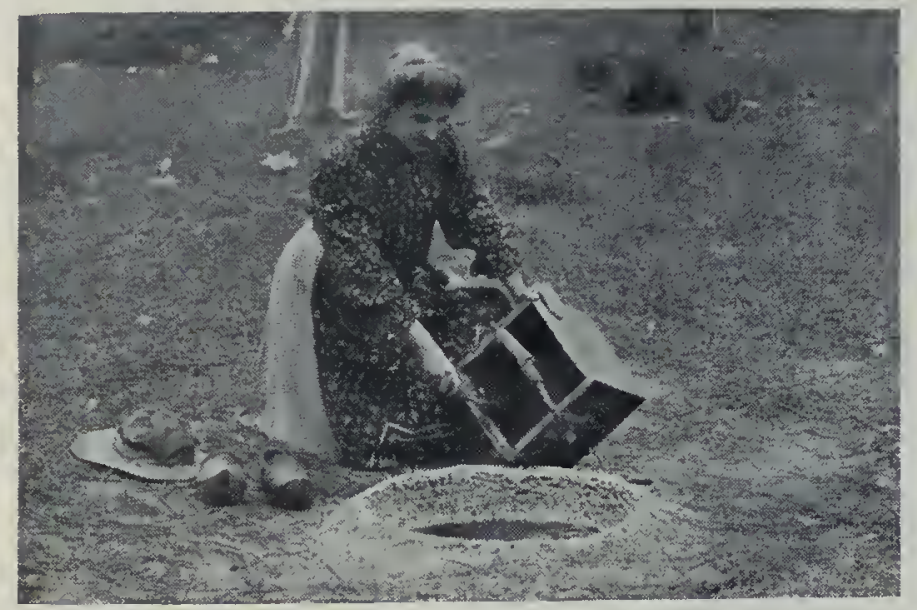

Mise de la résine dans un tonneau enterré.

se font successivement sur l'arbre : la lre carre est faite dans la partie de l'écorce la plus rugueuse, la $2^{\mathrm{e}}$ est à droite de la $\mathrm{l}^{\mathrm{re}}$, à un tiers de circonférence de distance; la $3^{e}$ est à gauche (c'est

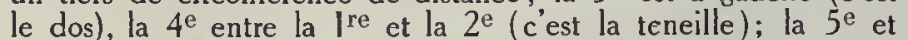
la $6^{e}$, entre la $]^{\text {re }}$ et la $3^{\mathrm{e}}$ et au delà de la $1^{\mathrm{re}}$ (ce sont les quintes de dos); la $7^{\mathrm{e}}$ et la $8^{\mathrm{e}}$ sont entre 1 et 4 et 2 et 4 (ce sont les quintes de la teneille); après la $8^{\mathrm{e}}$ carre, les parties qui restent à gemmer sont les ourets. Le gemmage à mort sapplique aux arbres destinés à être abattus, et qui sont dits Pins d'éclaircie, de 40 centimètres de tour. Le crot est le petit auget que l'on met au bas de la carre; depuis 1860 on recueille la gemme dans des pots de terre cuite et vernissée à l'intérieur, suspendus à diverses hauteurs; un crampon de lame de zinc à cinq dents est enfoncé au centre de la carre, au-dessus du pot, pour y diriger la gemme. Les instruments qui servent au résinier sont : les deux premières années, la pelle à écorcher l'arbre ; la troisième année, la barrasquite, à lame étroite recourbée, puis la pousse, qui sert à détacher le barras ou galipot, solide, jaunâtre, demi-opaque, impur, mélangé avec des copeaux de bois, et qui n'est autre que la gemme solidifiée en stalactite sous l'action de l'oxygène de l'air; il est larmeux, c'est-à-dire en larmes blanches, milarmeux ou en larmes plus petites, en sorte ou masses rousses irrégulières. Un arbre peut produire à soixante ou soixante-dix ans de 6 à 7 kilogrammes de matière résineuse brute; le tiers est formé de galipot ou de barra. On obtient avec la gemme : $1^{\circ}$ l'essence de térébenthine, utilisée pour les couleurs à huile, les vernis, les cirages, les cuirs, la dissolution du caoutchouc, pour le dégraissage, l'éclairage, la fabrication du camphre artificiel, et aussi en médecine; $2^{\circ}$ la colophane, utilisée pour le collage des papiers, la savonnerie, la fabrication des bougies, le mastic des fontainiers, le revêtement des tonneaux de bière, la cire à cacheter, la confection des tuyaux de plomb, le cirage pour voiture, les harnais, le frottage des crins d archet; 30 le brai, fournissant la résine jaune, le brai gras, l'huile de résine pyrogénée. En outre, la carbonisation, dans des fours spéciaux, des troncs d'arbres morts ou viciés, des branches, des racines donne le goudron. Le noir de fumée est le résidu charbonneux de la combustion des résines; on l'utilise dans la composition des couleurs, les crayons lithographiques, l'encre d'imprimerie, etc. La poix sobtient en brûlant les copeaux enlevés par la carre; il y en a de diverses sortes.

La colophane s'obtient aussi par la distillation de la térébenthine des Mélèzes d'Europe et des Sapins, dans les Vosges. On la tirait autrefois de Colophos, en Grèce. Le Pin austral ou Pitchpin est exploité en Amérique et fournit beaucoup de résine sur le marché mondial, en concurrence avec cellè de France. Le Pin noir d'Autriche, qui est une variété du $P$ in Laricio, donne un rendement moindre que le Pin maritime. Les Dammara de la Nouvelle-Zélande et de la Nouvelle-Calédonie fournissent le dammar ou kaur.

Citons, en terminant, la résine du Thuya (Callitris quadrivalvis), de l'Algérie, fournis- sant la sandaraque, utilisée en médecine et pour saupoudrer sur le papier qui a été gratté (pourqu'il neboive pas); celle du Calamus ou Rotang Dragon, Palmier grimpant de la $\mathrm{Ma}$ laisie, donnant le sangdragon, utilisé dans les vernis; celle de l'Hymancea Courbaril (Légumineuse) ou animé, ou copal d'Algarobo; celle du Trachylobium verrucosum (souvent enfouie sous terre), ou animé d'Orient. L'exportation de ce dernier se fait de Zanzibar et de Madagascar. Plu-

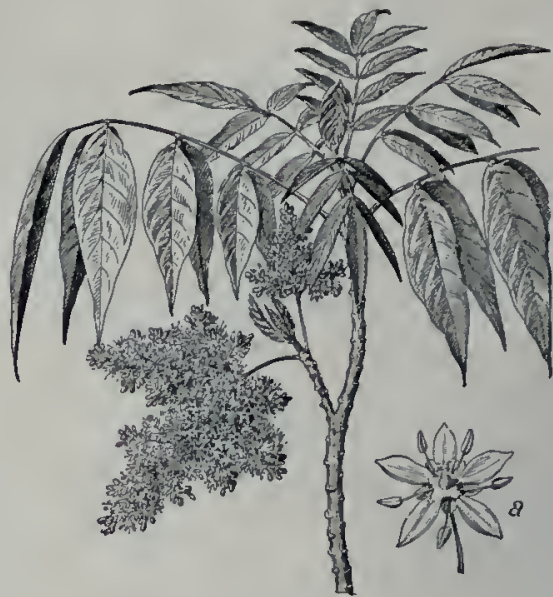

Fig. 311. - Sumac à laque. a, Fleur. sieurs autres résines ou copals de Copaifera doivent être mentionnés, notamment le Copaifera de Guibourt : des quantités importantes sont exportées par la Guinéc et le Congo. Les Guttifères donnent la gomme gutte du Siam et du Cambodge (Garcinia Hanburvi), servant en peinture jaune et en vernis; les Anacardiacées fournissent le mastic de Chio (Pistacia Lentiscus).

Laque de Chine. - La laque de Chine ou vernis du Japon provient du latex de plusieurs Sumacs (fig. 3ll), surtout du Sumac vernis (Rhus vernicifera, $R$. succedanea var. Dumortieri, et Melanorrhoa laccifera). La saignée se pratique sur des arbustes de sept ans au moins; les incisions sont répétées trois fois par mois; le latex est recueilli dans de petits godets de fer. La laque brute est crémeuse, presque blanche; on la filtre et on la conserve dans des baquets en bois recouverts d'une épaisse feuille de papier huilé, puis d'un couvercle. Ainsi que l'a montré Gabriel Bertrand, elle se compose d'un acide, le laccol, et d'un ferment oxydant, la laccase, qui fixe l'oxygène de l'air sur le laccol en le résinifiant et en le colorant en brun.

La laque, additionnée d'huiles indigènes siccatives, constitue le vernis-laque que l'ouvrier superpose par couches, l'une n'étant posée qu'après dessiccation parfaite et polissage de la précédente. Certaines couches sont appliquées avec du vernis-laque mélangé de couleurs finement pulvérisées, de charbon, de poudre d'or ou d'argent; chaque couche doit sécher à l'abri de la lumière et des poussières, dans des armoires à parois doublées intérieurement de draps mouillés. Le temps nécessité par les opérations successives explique le prix élevé atteint par les produits de cette industrie.

Le vernis-laque s'applique sur les métaux, l'os, le cuir, mais surtout sur le bois. En dehors du travail artistique auquel il se prête, il est supérieur à tous les vernis par sa grande dureté, son peu de fragilité, la conservation indéfinie de son brillant : c'est pourquoi il est utilisé pour recouvrir les pales des hélices d'avions.

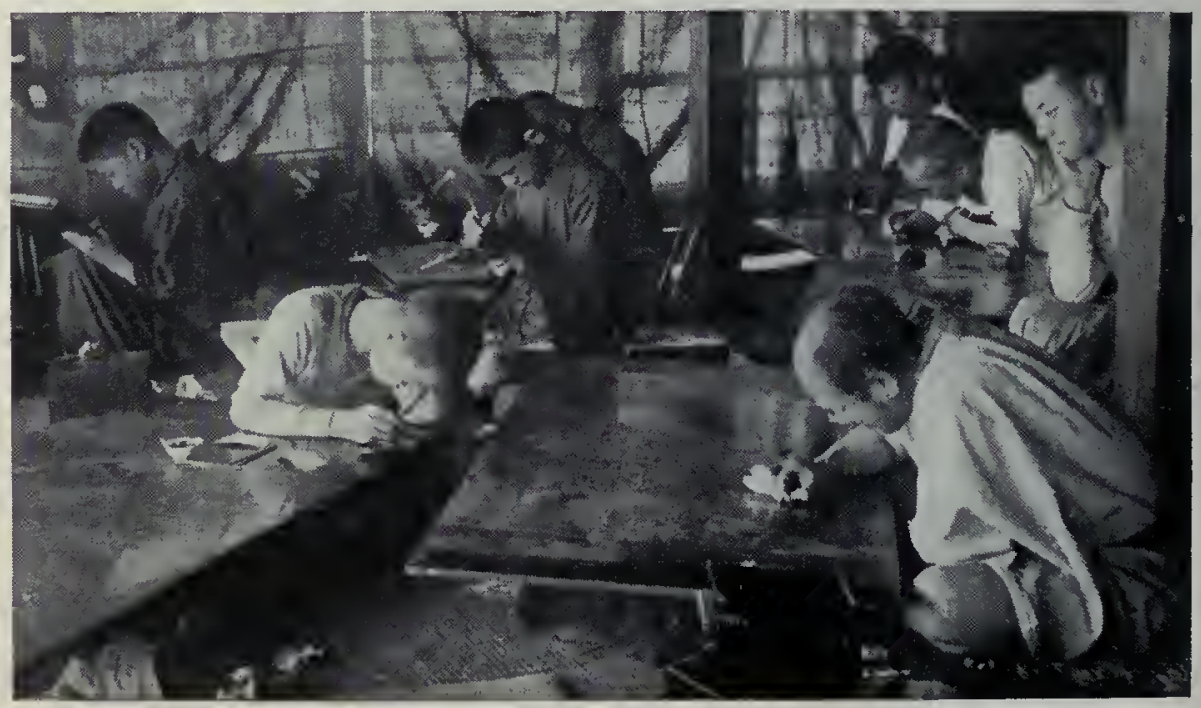

Un atelier de laqueurs, au Japon. 


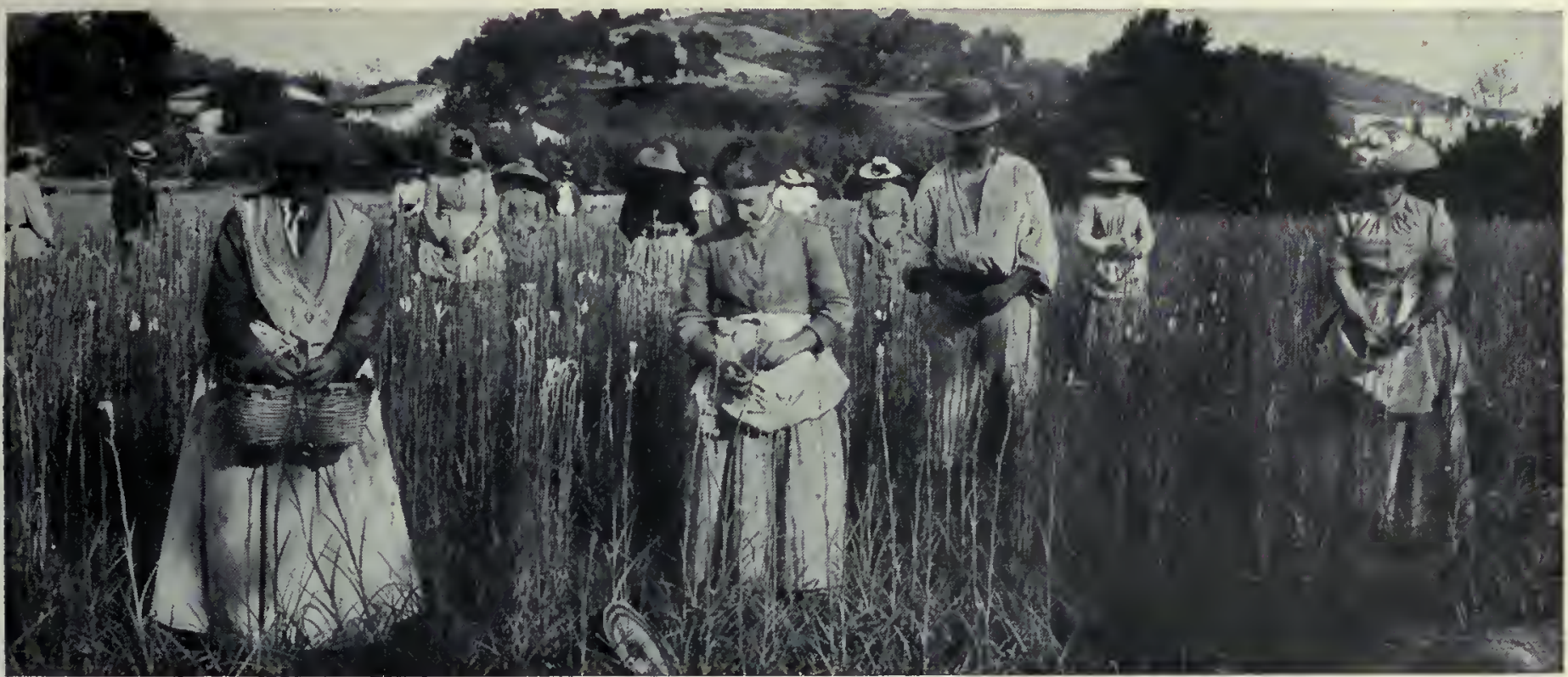

La cueillette des Tubéreuses, à Grasse.

\section{LES PLANTES A PARFUMS}

Les parfums d'origine animale : musc, civette, ambre gris, sont en très petit nombre; l'immense majorité provient des plantes. L'usage des parfums est répandu dans tout l'Orient depuis une époque reculée; ils servaient dans les cérémonies religieuses ou funéraires, pour l'embaumement des cadavres et en médecine.

Mais de tout temps c'est dans la toilette que les parfums ont trouvé leur plus important emploi. La Bible, l'lliade, les auteurs latins nous montrent leurs usages variés chez les Israélites, les Grecs et les Romains de l'antiquité. Les Grecs utilisèrent les premiers l'lris, la Violette, la Rose, la Marjolaine et les fruits. L invasion de l'Espagne par les Arabes, puis les Croisades et, plus tard, la découverte de l'Amérique firent connaitre à l'Europe des parfums nouveaux. En France, leur usage ne prit d'importance quaprès les Croisades et leur commerce se concentra entre les mains des maîtres gantiers. A l'époque des Valois et sous Louis XIII, on abusa des parfums; sous Louis XV, le goût s'affine et l'on commence à préférer les odeurs légères, délicates, aux senteurs trop violentes. C'est vers la fin du XVII' ${ }^{\circ}$ siècle que l'industrie et le commerce de la parfumerie, pour lesquels nous tenons le premier rang dans le monde entier, prirent en France une grande extension.

Essences odorantes des plantes. - Des essences odorantes se forment chez beaucoup de plantes, soit dans tous leurs organes, comme chez la Lavande, la Menthe, soit dans les feuilles, tel le Patchouli; dans les fleurs, comme la rose; les fruits (orange), les graines (anis), les sucs résineux (tolu), soit enfin dans le bois, comme chez le Santal. Ce sont ordinairement des gouttelettes contenues dans de petites cellules spéciales, véritables glandes que l'on distingue fort bien en interposant un pétale de fleur d'Oranger entre l'œil et une lumière vive. Les essences peuvent aussi s'accumuler dans des réservoirs ou canaux sécréteurs. Chez la rose, la fleur d'Oranger, il existe une notable réserve de parfum; chez la plupart des fleurs, au contraire, comme le Jasmin, le Muguet, le Réséda, le parfum se volatilise dans l'air au fur et à mesure de sa formation. Vers le milieu du XIX ${ }^{e}$ siècle, les essences odorantes furent considérées comme de composition très simple : on prenait la plupart d'entre elles pour des carbures d'hydrogène, les terpènes, tous isomères de l'essence de térébenthine. On sait aujourd'hui que ce sont, en réalité, des mélanges d'un ou de plusieurs terpènes avec des principes oxygénés divers: des alcools, comme le linalool, le géraniol, etc., qu'on retrouve isolés ou associés dans une foule d'essences (rose, géranium, linaloé, lavande, etc.); des aldéhydes, tels que le citral et le citronellal de la mélisse, du citron, de l'eucalyptus, etc.; des cétones, comme l'eugénol de la girofle, l'irone de l'iris, le safrol du sassafras; des phénols, par exemple le thymol du thym et de l'origan, l'anéthol de l'anis, etc., etc. Le parfum d'une essence végétale résulte parfois du mélange harmonieux de huit ou dix de ces composés.
Extraction des parfums. - L'extraction des essences odorantes des plantes est un art délicat et complexe. Les matériaux mis en œeuvre par nos usines françaises sont, d'une part, lesgraines et plantes sèches d'importation, comme anis, bois de Santal, clous de girofle, feuilles de Patchouli, racines de Vétiver, qui sont généralement travaillées pendant l'hiver, et, d'autre part, des plantes et fleurs qui doivent être traitées dans le plus grand état de fraîcheur possible : d'où l'obligation d'installer les usines au voisinage immédiat des centres de culture. Les méthodes d'extraction sont l'infusion, l'expression, la distillation et la dissolution.

L'infusion n'est employée que pour le rhizome d'Iris, le benjoin, qu'on fait macérer dans l'alcool pour obtenir une teinture odorante. L'expression s'applique à l'orange, au citron, à la bergamote. La distillotion est un procédé plus général : la plante est introduite avec de l'eau dans un alambic; on chauffe à $100^{\circ}$; l'eau bouillante gonfle et déchire les cellules; les vapeurs d'essence mises en liberté sont entraînées avec la vapeur d'eau et se condensent en même temps quelle dans un serpentin refroidi; leur différence de densité permet de les séparer; toutes les essences, sauf celles de cannelle et de girofle, sont plus légères que l’eau. Dans les grandes usines, les alambics sont chauffés à la vapeur; le chauffage à feu nu est encore employé dans beaucoup de petites exploitations exotiques.

On ne peut distiller que les plantes dont les essences ne sont pas sensiblement altérées par la chaleur; par exemple, le Thym, les fleurs de Rosier, d'Oranger, le bois de Santal, etc., mais malgré tout la chaleur entraîne des modifications des composés odorants et leur enlève une grande partie de leur finesse. La dissolution dans un solvant approprié est plus longue, plus coûteuse, mais conserve intégralement les parfums. On utilise des dissolvants

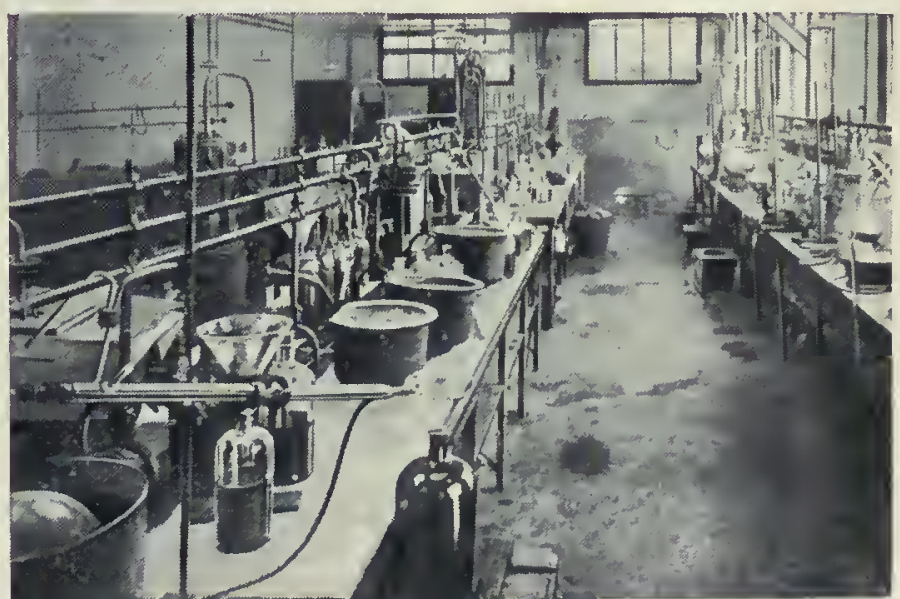

Laboratoire d'une maison de parfumerie, à Argenteuil. 


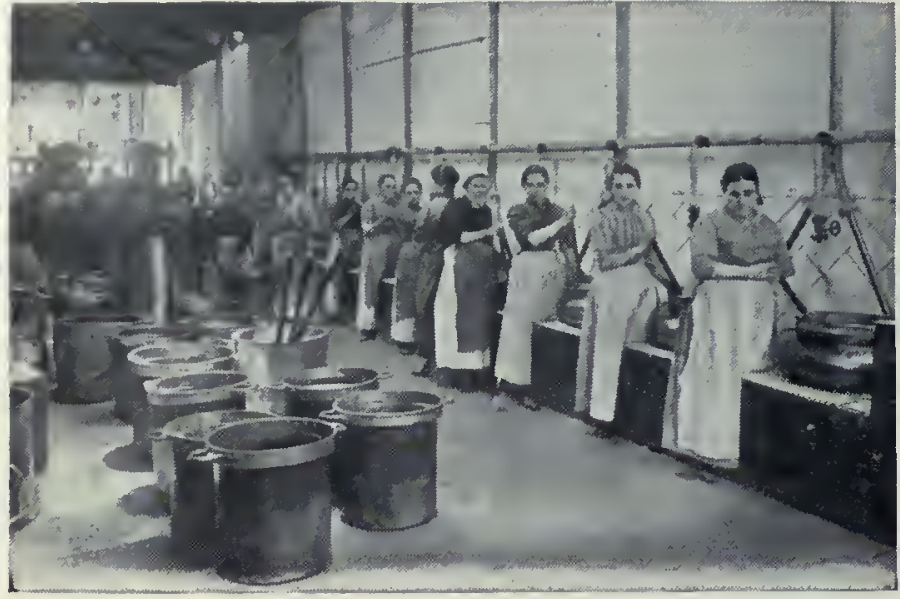

Bains-marie ou « bugadiers 》 d'une parfumerie.

fixes comme l'huile, la vaseline, la glycérine, la graisse, absolument épurés et sans aucune odeur, ou des dissolvants volatils tels que le pétrole léger, le chlorure de méthyle, etc.

A Grasse, on emploie surtout un mélange de graisses de porc et de bœuf, soit à chaud par macération, soit à froid par enfleurage. La macération s'applique à la rose, à la fleur d'Oranger, à la violette, à la cassie et à la jonquille. La graisse est chauffée entre $60^{\circ}$ et $70^{\circ}$ dans des bassines ou bugadiers; on y jette les fleurs et on brasse avec de grandes spatules; au bout de quelques heures, on verse sur des passoires; on presse les pétales qui restent pour en retirer la graisse. On recommence avec la même graisse une nouvelle opération et ainsi de suite pendant quinze à vingt jours. On obtient une pommade très parfumée dont une partie est utilisée telle quelle; le reste est mis dans une batteuse avec de l'alcool de grain absolument neutre et sans odeur; le parfum abandonne la graisse et passe dans l'alcool, qui donne ainsi un extrait.

L'enfleurage est utilisé pour le jasmin, la tubéreuse, le réséda, Heurs ne possédant pas de réserves de parfum, mais le produisant tant qu'elles sont vivantes. Le matériel consiste en châssis rectangulaires, cadres de bois hauts de 8 centimètres et dont le fond est une vitre. Les deux faces de celle-ci sont enduites d'une couche de graisse sur laquelle on jette des fleurs; on met les châssis en pile : ils deviennent autant de boîtes closes dans lesquelles la graisse absorbe le parfum. Le lendemain, on enlève les fleurs et on les remplace par d'autres, et cela pendant toute la durée de la récolte, soit deux à trois mois. La graisse parfumée est traitée comme précédemment.

Parfums artificiels. - Lindustrie des parfums artificiels, née en France, a pris un grand essor dans notre pays et plus encore en Allemagne. Elle emploie deux méthodes distinctes: $1^{\circ}$ l'une de synthèse ou formation du parfum de toutes pièces; $2^{\circ}$ l'autre d'analyse ou extraction de principes purs des essences naturelles, principes qui, par une série de réactions, deviennent la base de produits nouveaux. Les progrès de cette industrie chimique, qui ont permis de créer la parfumerie à bon marché, ont un grand retentissement sur l'extraction des parfums des plantes; mais cette dernière n'est pas aussi menacée que l'est l'industrie des plantes tinctoriales par les couleurs d'aniline; les essences odorantes sont, en effet, des corps complexes autrement difficiles à reproduire par synthèse que les matières colorantes; de plus, l'industrie chimique des parfums a presque toujours comme matière première des essences naturelles à bon marché dont elle fait dériver des produits de grande valeur. La plupart des parfums artificiels sont tellement puissants quil est presque impossible de les utiliser à l'état pur et que beaucoup d'entre eux sont vendus en mélange avec 90 pour 100 de matière inerte. Malgré leur prix élevé qui, pour certains, atteignit, lors de leur apparition, jusqu'à 25000 francs le kilogramme à l'état pur, leur emploi est très économique, tellement est minime la quantité nécessaire pour parfumer un produit. Les parfums ainsi obtenus n'ont ni la finesse ni les nuances des produits naturels.

L'industrie des parfums artificiels date de 1874; auparavant, on ne connaissait comme parfums de laboratoires que l'essence de Reine des prés, obtenue par l'oxydation de la salicine contenue dans l'écorce du Saule; la nitrobenzine, qui, sous le nom d'essence de Mirbane, sert à parfumer, aux amandes amères, les savons et

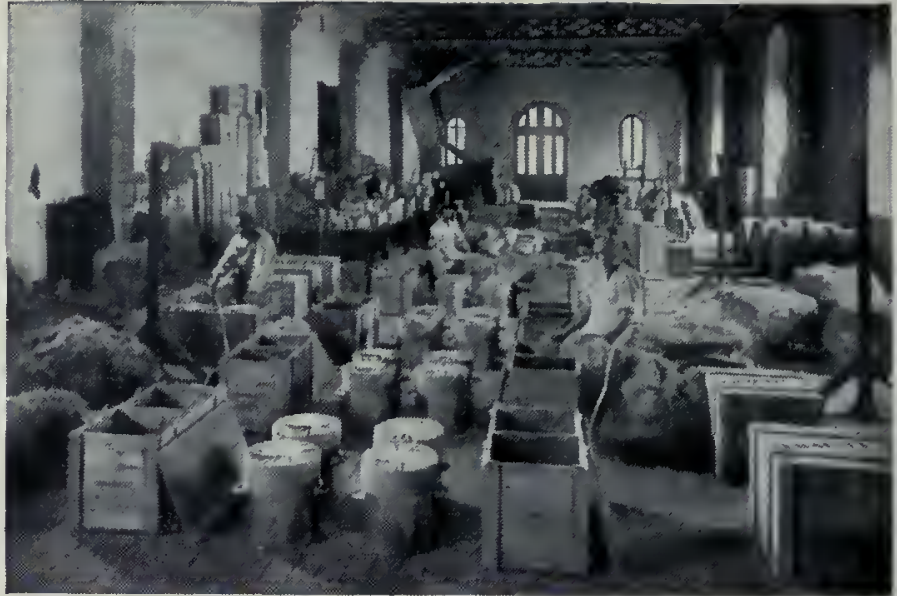

Satle d'embatlage d'une parfumerie.

crèmes, et, enfin, quelques éthers à odeurs de fruits. En 1874, la vanilline, principe odorant de la vanille et du benjoin, fut obtenue en Allemagne par Tiemann et Haarmann en partant de la coniférine, tirée du bois de Pin; en 1876, de Laire la prépare en partant de l'eugénol contenu dans l'essence de girofle; aujourd'hui, on l'obtient en Allemagne avec l'anthracène comme matière première; elle remplace en partie la vanille en pâtisserie, en confiserie et en parfumerie. Depuis, ces découvertes sont devenues très communes; bornons-nous à citer la synthèse de la coumarine, parfum de la fève Tonka, du Mélilot et de la Flouve odorante, obtenue en partant de l'acide salicylique; celle de l'héliotropine, en partant de l'essence de sassafras; celle du terpinéol, tiré de l'essence de térébenthine; enfin, celle de l'ionone, essence de violette artificielle, obtenue en partant du citral, contenu dans les essences de citron et de lemon-grass.

Les produits de la parfumerie. - Les matières premières pour la parfumerie sont, d'une part, les produits résultant du traitement des plantes à parfums : essences, eaux odorantes, extraits alcooliques, pommades et huiles parfumées, extraits concrets ou absolus obtenus à l'aide de dissolvants vo!atils appropriés, et, d'autre part, les corps odorants concentrés préparés dans les usines. Les parfumeurs transforment ces produits en eaux et vinaigres de toilette, lotions pour coiffeurs, eaux dentifrices, crèmes, cosmétiques, fards, poudres, sachets odorants, etc. La partie véritablement artistique de la parfumerie est la confection des extraits d'odeur pour mouchoirs; ils résultent souvent de mélanges complexes des produits naturels de Grasse : rose, jasmin, fleur d'oranger, cassie, lubéreuse et violette, avec lesquels on arrive à imiter à peu près tous les parfums des fleurs, comme le lilas, le chèvrefeuille, la giroflée, le pois de senteur, etc., plantes qui ne sont traitées nulle part. Souvent aussi les parfums sont artificiels : l'extrait de lilas blanc ou de muguet est du terpinéol, celui d'aubépine est l'aldéhyde anisique, l'essence de violette n' est qu'une solution d'ionone et celle de rose n'est parfois que du géraniol, le " foin coupé " est à base de coumarine, etc.

Une partie considérable des matières premières de la parfumerie est utilisée en savonnerie. Une autre catégorie non moins importante est celle des parfums comestibles : vanilline, eau de fleur d'oranger, essence de menthe, etc., utilisés par les pâtissiers, les confiseurs et les liquoristes, et surtout les essences de fruits, qui ne sont que des mélanges d'éthers composés dont 3 à 4 grammes correspondent, comme saveur, à I ou 2 kilogrammes de fruits.

Les plantes à parfums de Grasse. - La petite ville de Grasse, dans les Alpes-Maritimes, est le centre le plus important du monde entier pour la parfumerie en matières premières; c'est aussi le plus renommé pour la finesse de ses produits. On y traite surtout les fleurs cultivées dans la région et dont les floraisons s'échelonnent à peu près d'un bout à l'autre de l'année : de janvier à mars, la violette, en avril la jonquille, en mai la rose et l'oranger, en juin le réséda, en août et en septembre le jasmin et la tubéreuse, en octobre la cassie. Aux alentours de Grasse, de Cannes et de Nice, les champs sont des jardins merveilleux. La cueillette se fait à l'aube, car, à l'ardeur du soleil, les fleurs perdent de leur parfum. Une coupeuse, dans les quatre heures de la matinée, peut cueillir 20 kilogrammes de roses ou bien 3 de 


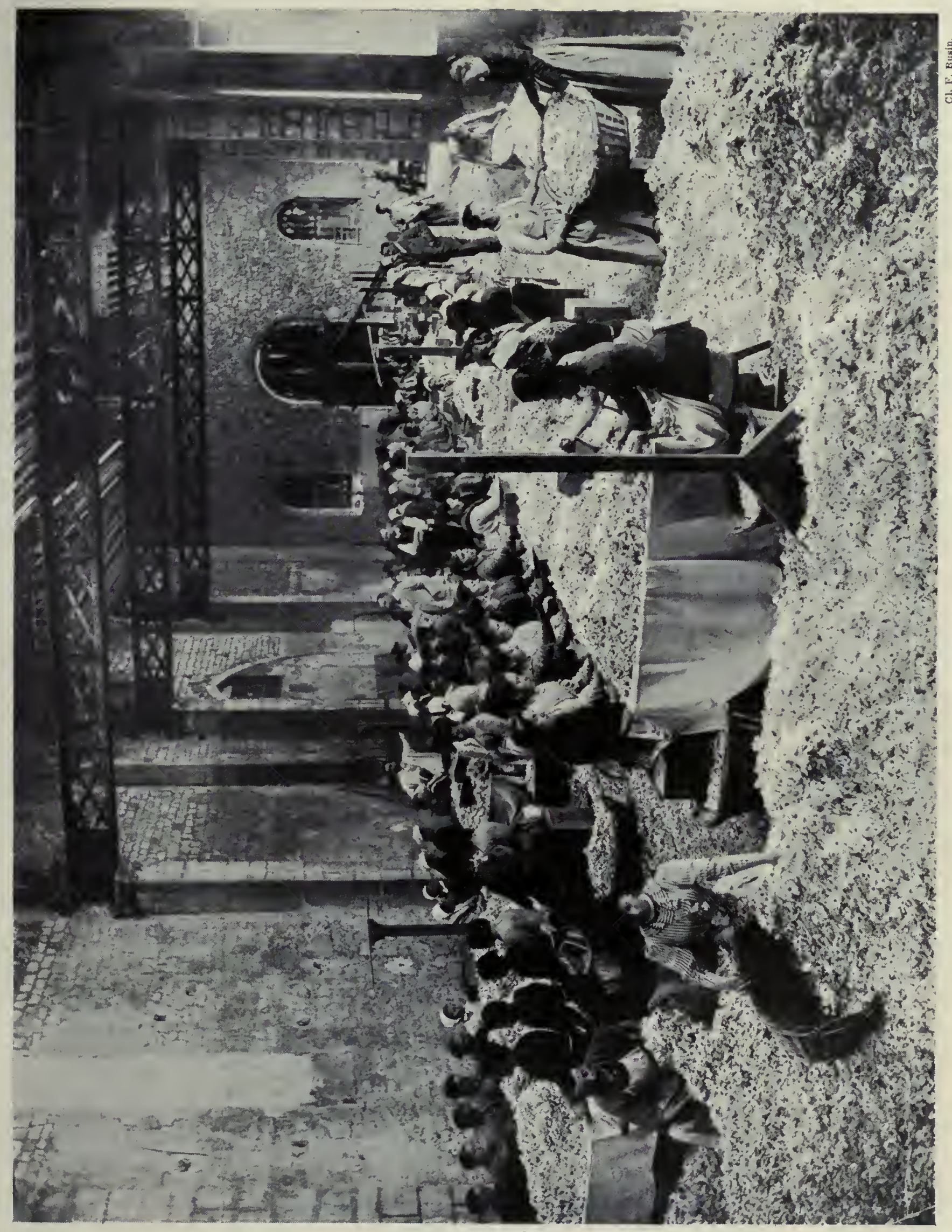





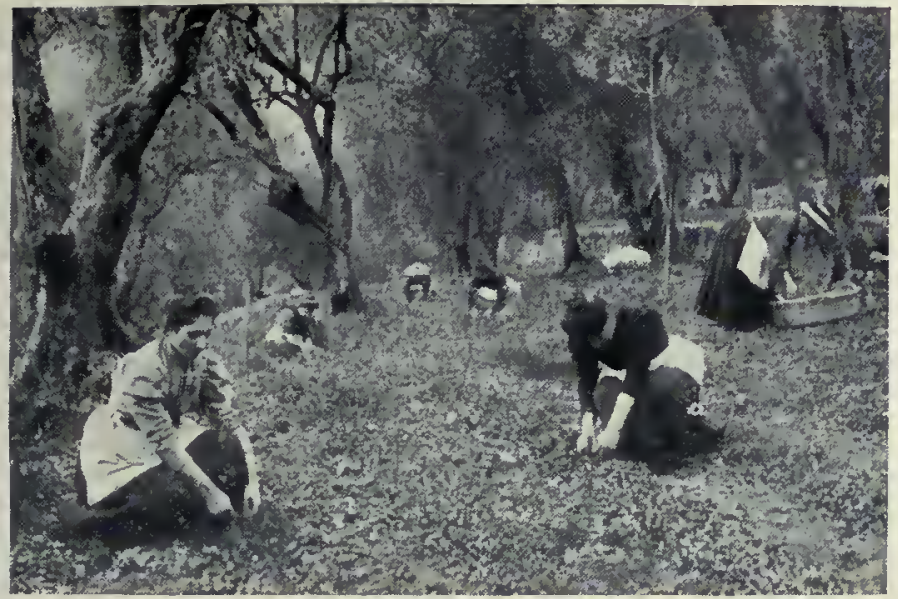

Cueillette des violettes sous tes Oliviers.

jasmin, 6 de tubéreuses, 4 de violettes. La récolte, mise en sacs, est portée de suite aux usiniers qui l'achètent; dès leur arrivée, les fleurs sont triées, puis traitées immédiatement.

La Violette est cultivée sous les Oliviers ou les Citronniers en plants renouvelés tous les cinq à six ans; I hectare fournit $10000 \mathrm{ki}-$ logrammes de fleurs, d'où l'on peut retirer environ 500 grammes de parfum concentré. La Cassie ou Acacia de Farnèse est un arbuste de 3 à 4 mètres de haut, originaire des Antilles; ses fleurs jaunes, qui rappellent celles du Mimosa des fleuristes, ont un délicat parfum; dès lâge de cinq ans, il est en plein rendement, qui est d'environ I kilogramme de fleurs chaque année. Le Jasmin $\grave{a}$ grandes fleurs ou Jasmin d'Espagne est un arbrisseau de l'Inde : 1 hectare en contient 8000 pieds et fournit 6000 kilogrammes de fleurs, d'où l'on retire 500 grammes d'extrait concentré. Le Rosier à cent feuilles est cultivé en buissons de 75 centimètres de hauteur séparés par des allées de I mètre de large, dans lesquelles on plante souvent des Oignons, pour utiliser le terrain.

La Tubéreuse ou Polianthe tubéreux est une Amaryllidacée à fleurs blanches très parfumées ; le Narcisse jonquille, le Réséda odorant sont des plantes bien connues. On estime que 15000 personnes vivent des fleurs à parfums dans les Alpes-Maritimes. On y cueille 2500000 kilogrammes de fleurs d'oranger, 2 millions de kilogrammes de roses, 200000 de jasmin, 150000 de violettes, etc.; on y fabrique 500000 kilogrammes de pommades et d'huiles parfumées, 4 millions de litres d'eaux aromatiques.

La Rose. - Les Anciens obtenaient des parfums à la rose par simple macération des pétales dans l'huile d'olive; la distillation ne semble pas remonter au delà du viIt ${ }^{\mathrm{e}}$ siècle de notre ère ; elle se pratiquait en Perse, aux Indes et jusqu'en Chine, et fournissait uniquement l'eau de rose. Lidée de séparer de l'eau de rose la petite quantité de substance huileuse surnageante, ou essence de rose, entraínée par la vapeur d'eau, ne date que de 1627. En France dans la région de Grasse, en Allemagne aux environs de Leipzig, en Angleterre, on retire de la Rose à cent teuilles de l'eau de rose avec une très petite quantité d'essence ; la Tunisie, le Caucase, les Indes, dans le district de Ghazipour, en fournissent des quantités notables tirées de la Rose musquée; maisc'est la Bulgarie qui fournit le monde entier d'essence de rose. On y cultive la Rose de Damas, d'un pourpre foncé. La vallée des roses couvre plus de 6000 hectares dans les bassins de la Toundja et de la Strema; elle se fleurit en mai-juin; la récolte a lieu avant le lever du

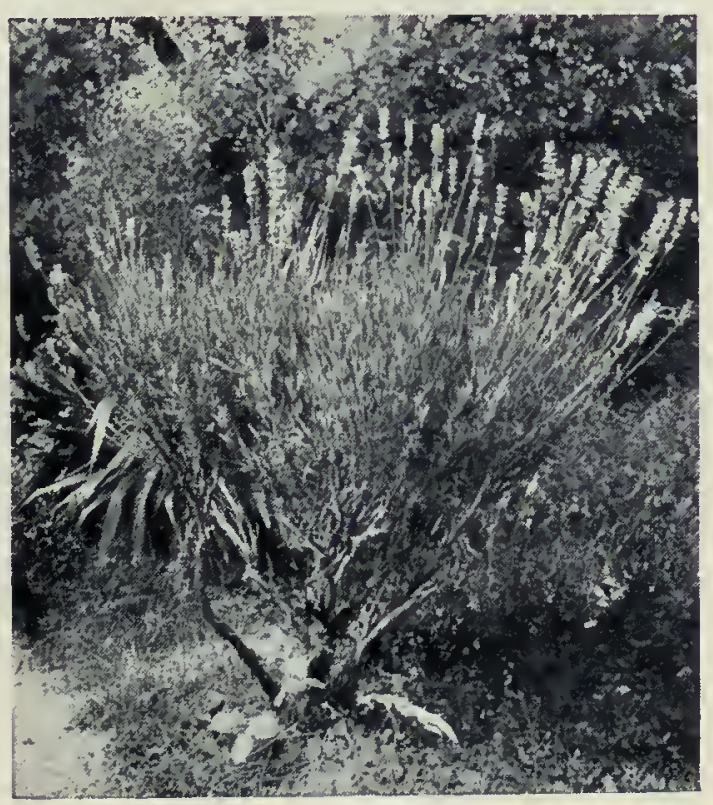

Pied de Lavande en fleurs.

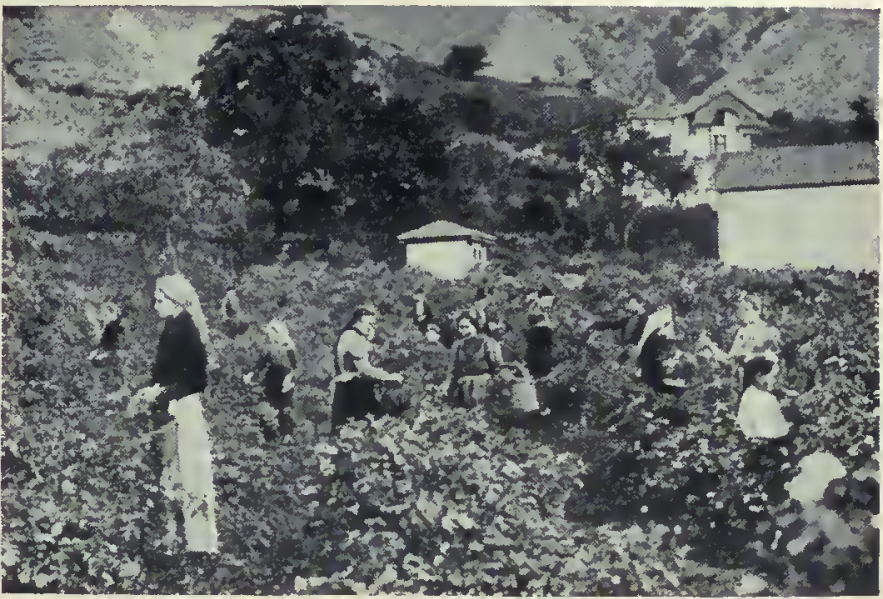

Cueillette des roses, en Bulgarie.

soleil; on ne détache que les roses incomplètement épanouies, qui sont traitées de suite dans des alambics primitifs; l'essence n'est retirée quaprès deux distillations successives de l'eau de rose. Depuis 1884, cette culture a pris une énorme extension. Un hectare donne environ 3000 kilogrammes de fleurs, d'où l'on retire I kilogramme d'essence. La production bulgare varie de 2500 à 5500 kilogrammes d'essence.

L'essence de rose est un liquide jaune pâle formé surtout d'un mélange de géraniol et de citronellol. On la falsifie avec des parfums renfermant ces corps : essence de palmarosa ou ginger grass, produite par un Andropogon; essence de santal, et surtout essence de géranium rosat, produite par les feuilles agréablement odorantes du Pelargonium capitatum, et qui se fabrique en grand dans le département des Alpes-Maritimes, en Turquie, en Algérie, à la Réunion et en Espagne.

Labiées. - La plupart des Labiées sont couvertes de poils renflés à leur extrémité en une petite glande sécrétant des principes odorants. La Lavande vraie abonde à l'état sauvage dans les régions montagneuses du midi de la France; elle y couvre des milliers d'hectares, jusqu'à 2000 mètres d'altitude. Les épis Horaux sont coupés à la faucille, réunis en bottes et portés de suite dans des alambics ambulants, car les fleurs ne supportent pas le voyage. La production française en essence de lavande atteint 100000 kilogrammes. La Lavande spic est une autre espèce du midi de la France qui fournit l'essence de spic ou d'aspic, d'une odeur moins douce; elle sert à parfumer les savons grossiers. La Lavarde vraie fait l'objet de cultures importantes en Angleterre, principalement à Mitcham et Hitchin.

La Menthe poivrée exige des sols humides, mais bien drainés. On la cultive dans la région de Sens et dans le midi de la France, en Allemagne aux environs de Leipzig, aux États-Unis dans les États de NewYork et de Michigan. L'essence la plus fine provient des cultures anglaises de Mitcham (Surrey),

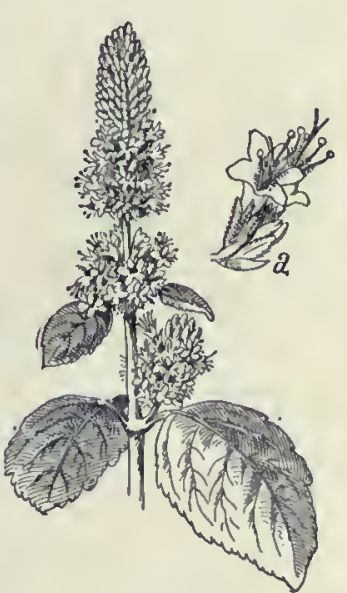

Fig. 312. - Patchouli. $a$, Fleur.

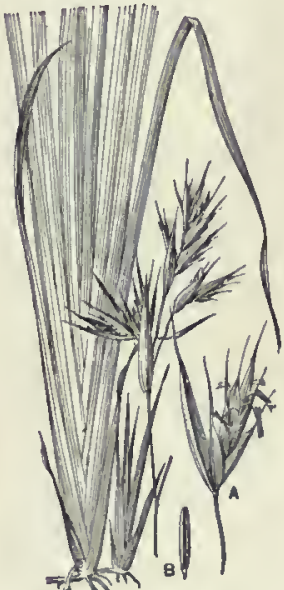

Fig. 313, - Vétiver.

A. Épillet; B, Graine. 
Visbeach (Cambridge) et Hitchin (Hertfordshire). Le Japon, très fort producteur, cultive la Menthe des chomps et en retire une essence grossière employée surtout à la préparation du menthol. Les usages de l'essence de menthe en confiserie et dans la préparation des liqueurs sont plus importantsqu'en parfumerie. Les Labiées de Provence fournissent encore l'essence de Thym, d'où l'on extrait le thymol, antiseptique agréablement parfumé, utilisé pourlessoins de la bouche; l'essence de Romarin, dont on parfume des savons; lesessences de Marjoloine et de Mélisse.

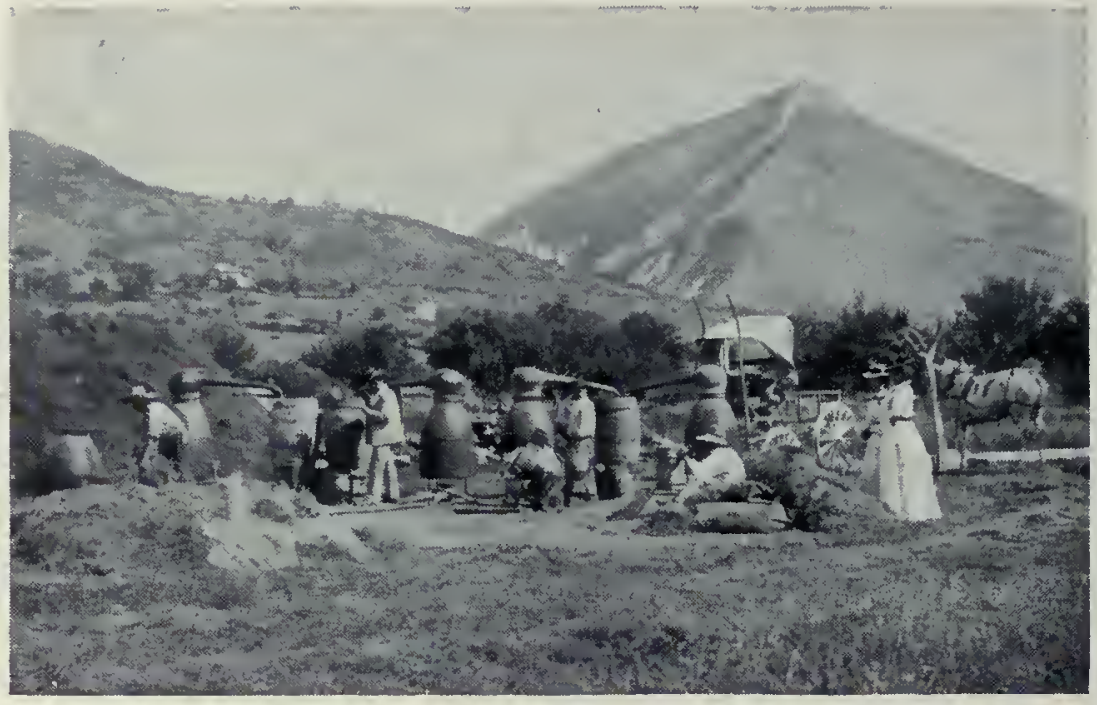

Distillation de la lavande, aux environs de Castellane.

de ginger grass, qui sert surtout à falsifier l'essence derose. Enfin, les feuilles de l'Andropogon nardus, de Ceylan et de Java, donnent l'essence de citronnelle ou de géranium indien, employée pour remplacer l'essence de rose et l'essence de géranium rosat en parfumerie. Les Anglais l'utilisent surtout en savonnerie. Cette plante est l'objet de cultures importantes à Ceylan, qui produit annuellement 1 million de kilogrammes d'essence de citronnelle; on la cultive encore en Malaisie, à Java, et un peu aussi au Tonkin. Le nard indien, parfum pénétrant non utilisé en Europe, provient de la

Le Pogostemon patchouli (fig. 312) est cultivé à Java, dans l'Inde, en Chine et dans la presqu'île de Malacca; on effeuille l'arbuste tous les six mois, et les feuilles, sèches et fermentées, sont distillées sur place ou, plus souvent, expédiées en Europe. On en fait des sachets pour éloigner les insectes des fourrures. Ce parfum, très fort, est désagréable à certaines personnes.

Racines et rhizomes. - Le rhizome de l'Iris de nos jardins acquiert en séchant une douce odeur de violette; on le coupe en tranches qu'on enfile, et de ces chapelets on parfume la lessive ou le linge dans les armoires. En Italie, on cultive depuis deux siècles l'Iris de Florence, à fleurs blanches; on arrache les rhizomes de trois ans et on les fait sécher; 1000 kilogrammes de rhizomes secs donnent par distillation ou par épuisement au sulfure de carbone 2 kilogrammes d'huile concrète. Florence et Vérone expédient en France des rhizomes secs. La découverte de l'ionone, corps artificiel à odeur de violette, a porté un coup funeste à la culture italienne de l'Iris.

Les Andropogons ou Barbons sont des Graminées répandues dans le monde entier. Le rhizome de l'Andropogon citratus, cultivé aux Indes, à Ceylan, en Cochinchine, fournit l'essence de lemon grass; on en retire le citral, avec lequel on fabrique l'ionone. La racine de l'Andropogon muricatus, de la côte de Coromandel, de la Réunion, des Antilles et des Philippines, constitue le vétiver (fig. 313), qui s'emploie en sachets et dont on retire une essence estimée; l'Andropogon Schœenanthus fournit l'essence

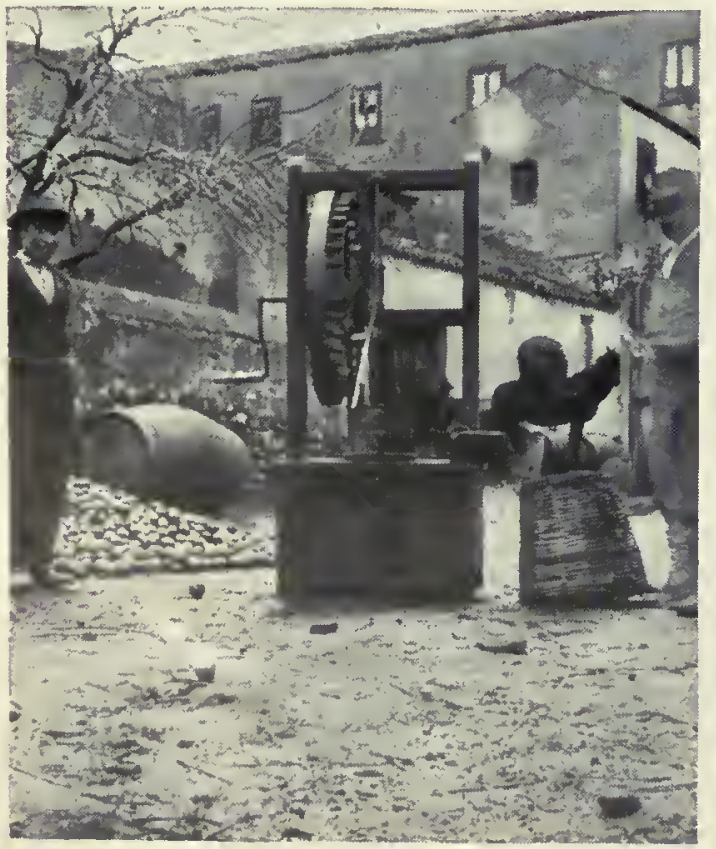

Presse à bergamote, en Sicile.

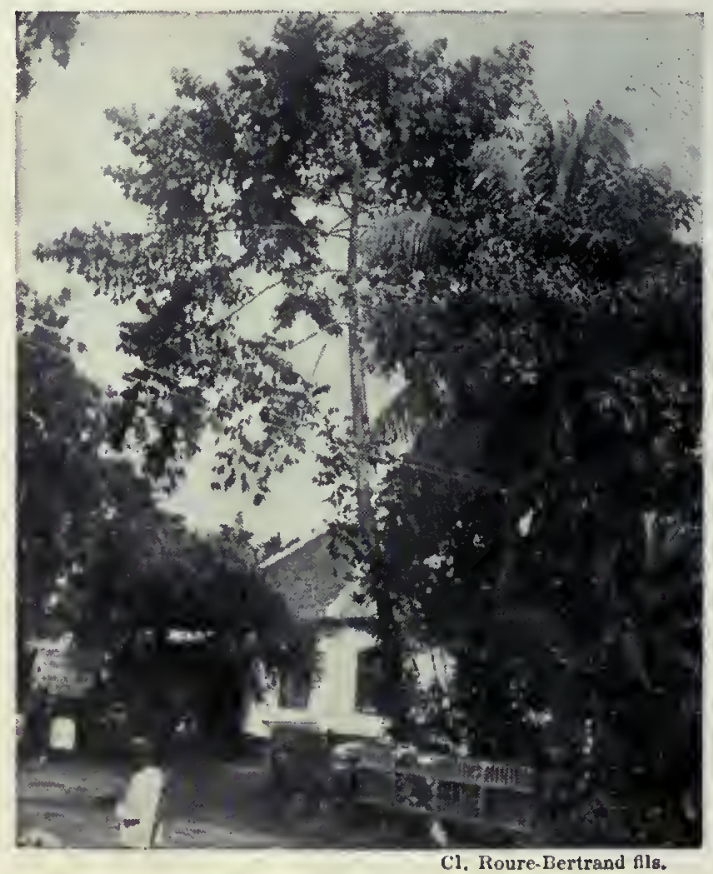

Cananga odorant, à Batavia. souche d'une Valérianacée du Népaul; le nard, l'un des parfums célèbres de l'antiquité, avait, sans doute, une origine analogue.

Hespéridées. - Les Hespéridées jouent un grand rôle en parfumerie ; on utilise, suivant les cas, les fleurs, les feuilles, les fruits ou les zestes. La Sicile et la Calabre sont les centres les plus importants de cette industrie, fort développée aussi en Provence, en Espagne et en Algérie. L'eau de fleurs d'Oranger et l'essence de néroli se préparent avec les pétales de la fleur du Bigaradier ou Oranger amer; celle de petit grain, par distillation des feuilles, branchages et fruits verts. La meilleure essence de néroli est produite en Provence par la variété de Bigaradier dite "Bouquetier de Nice ". L’essence de bergamote se prépare en Calabre par expression du zeste de ce fruit; avec l'essence de néroli, c'est un des constituants de l'eau de Cologne; l'essence de Portugal se retire par expression ou distillation des zestes des fruits de l'Oranger doux ou du Bigaradier; celle de cédrat, du zeste du fruit du Cédratier; on extrait aussi les essences de citron et de limette. L'extraction des essences de fruits se fait à l'automne; les fruits verts rendent plus que les fruits mûrs.

Plantes diverses. - L'essence d'ilong-ilang, au parfum doux et pénétrant, est extraite des fleurs d'un arbre, le Conanga odoront, de la famille des Anonacées; on le cultive aux Philippines, à la Réunion, à Madagascar et en Indochine; il produit vers l'âge de cing ans; la floraison et la cueillette durent presque toute l'année, et la distillation est immédiate. L'essence de Verveine citronnelle vient d'Espagne; elle est produite par les feuilles du Lippia à odeur de citron, arbuste de la famille des Verbénacées; sa culture industrielle est presque abandonnée. L'essence de wintergreen vient des EtatsUnis; on l'extrait des feuilles de la Gaultherio procumbens (fig. 3|4), plante voisine des Bruyères; enfin les feuilles des Eucalyptus globulus et a mygdalino d'Aus. tralie fournissent l'essence de ce nom, dont l'Algérie fabrique quelques milliers de kilogrammes. Les feuilles d'une autre Myrtacée, le Mélaleuque arbre blanc, fournissent à la NouvelleCalédonie l'essence de Cajeput ou Niaouli.

La parfumerie est redevable aux épices de quel- 


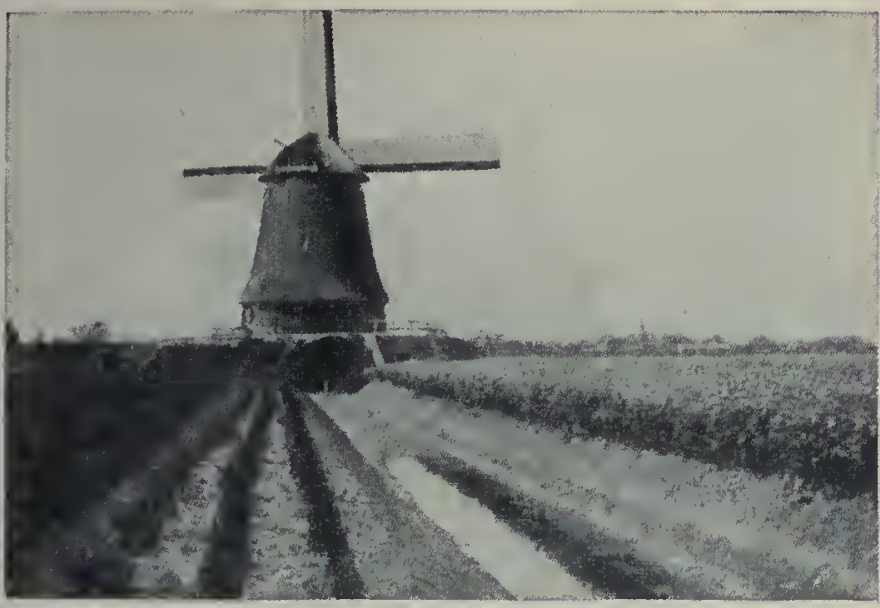

Un champ de Carvi, en Hollande.

ques essences à odeur très forte: les essences de cinnamome, de cardamome, de girofle, de toute épice, de muscade, de macis, de cannelle; cette dernière s'obtient à Ceylan et en Chine par la distillation des débris d'écorce. De l'essence de girofle on extrait l'eugénol, employé pour fabriquer la vanilline artificielle. La série des graines comprend le fenouil, le carvi, la coriandre, le cumin, l'anis, la badiane de Chine ou anis étoilé, qui entrent dans la fabrication de certains dentifrices, dans celle de l'anisette, etc., et aussi les graines d'ambrette (Hibiscus musqué) ou musc végétal des Antilles et de la Guyane, et l'amande amère, qu'on obtient en distillant le tourteau d'amande dont on a exprimé l'huile grasse.

La série des fruits comprend, outre les Hespéridées, la vanille du Mexique et de la Réunion. La coumarine est un produit qui se retirait jadis de la fève Tonka, fruit du Diptéryx odorant de la Guyane; on l'extrait aujourd'hui d'une herbe de l'Amérique du Nord, dite plante vanille (Trilisia très odorant), ou on la prépare synthétiquement.

Les bois odorants. - Des bois odorants en nombre restreint sont utilisés pour faire des coffrets inattaquables aux insectes; leur sciure est employée en sachets, ou encore, macérée dans l'alcool, elle donne des teintures qui sont la base de diverses eaux dentifrices.

L'essence de santal est un liquide jaune, épais, d'odeur agréable et très persistante, employé en parfumerie et en médecine; on l'extrait du Santal des cygnes d'Australie, du Santal Yasi des îles Fidji, du Santal rouge (Ptérocarpe de l'Inde) et surtout du Santal blanc de l'Inde, arbre abondant dans la province de Mysore; c'est le plus riche en essence et celui qui donne lieu à l'exploitation la plus importante; on ne l'abat quà partir de l'âge de cinquante ans. En ExtrêmeOrient, on brûle le bois de santal dans les cérémonies religieuses.

L'essence de cèdre, retirée autrefois du Cèdre du Liban, est préparée aujourd'hui avec le bois du Cèdre de l'Atlas et surtout du Genévrier de Virginie ou Cèdre à crayons.

L'essence de linaloé, du Mexique, introduite en Europe en 1886, provient de diverses espèces de Bursera (B. Delpechiana surtout) connues sous le nom de bois de rose femelle. Avant la guerre, la Guyane a exporté 12500 kilogrammes d'essence de linaloé, valant 312000 francs. Cayenne exporte annuellement 250 tonnes de ce bois, qui sont expédiées en Europe pour la distillation et la marqueterie. On désigne sous le nom de bois d'Agalloche, d'aloès, bois d'aigle, le bois d'une Thyméléacée, l'Aquilaria Agallocha, qui donne en brûlant un encens d'un parfum pénétrant. Ces arbres sont communs, surtout dans la province de Guerrero, au sud de Mexico; leur bois subit dans le pays même une distillation grossière.

Enfin l'essence de sassatras existe dans l'écorce d'une Lauracée de l'Amérique du Nord; elle se fabrique aux États-Unis; elle est utilisée en savonnerie et surtout elle est la base de l'héliotropine artificielle, parfum aujourd'hui très employé.

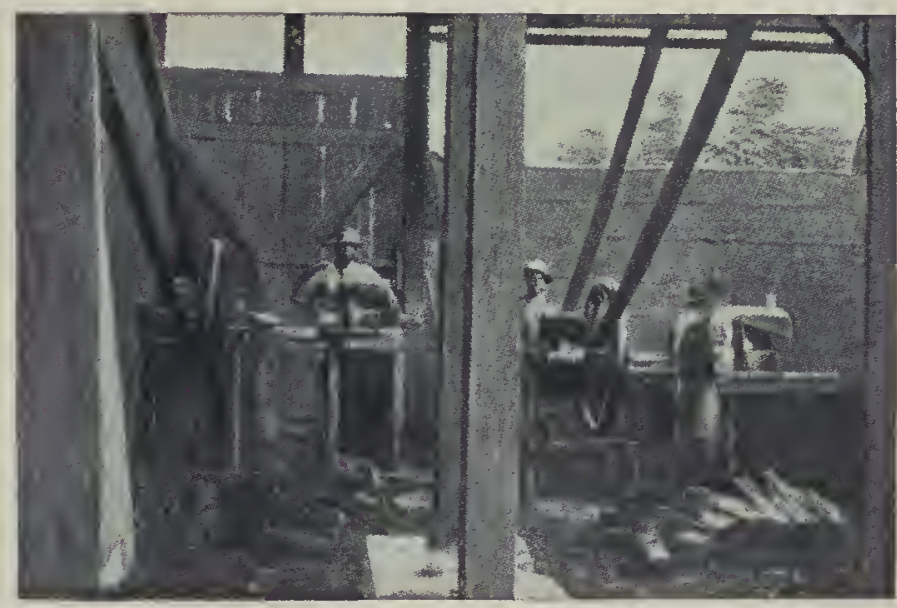

Débitage du bois de rose pour la distitlation.

Baumes et résines. - Sous le nom d'encens, on désigne plusieurs résines ou gommes-résines donnant en brûlant une odeur agréable. Le véritable encens ou oliban provient d'un petit arbre de la famille des Burséracées, le Boswellia Carterii, originaire du pays des Somalis et d'Arabie. On l'obtient à l'aide d'incisions profondes opérées sur le tronc; la gomme-résine s'écoule et se solidifie en larmes qu'on recueille. L'encens est employé dans les cérémonies religieuses; il entre dans diverses préparations pharmaceutiques. La myrrhe est produite par des arbres de la même famille et de la même région, les Commiphora d'Abyssinic et de Schimper. Comme l'encens, elle va de la côte des Somalis aux Indes et nous arrive en Europe par Bombay. La myrrhe, parfum célèbre dans l'antiquité, est encore utilisée dans la parfumerie orientale; la médecine l'emploje comme excitante et anticatarrhale. L'opoponax est produit par la distillation de la résine du Commiphora Kataf, du Somaliland. Le labdanum, employé aussi en Orient, est une résine odoriférante qui perle sur les feuilles du Ciste ladanifère de l'île de Crète.

Plusieurs baumes sont connus sous le nom de styrax. Le vrai styrax des parfumeurs provient d'un arbuste d'Asie Mineure, le Styrax officinal ou Aliboufier; il est utilisé en dissolution dans l'alcool pour fixer les parfums à essence volatile, dont il accroít la durẻe. Le benjoin, très employé en parfumerie et en médecine, est une oléo-résine fort riche en vanilline. Il s'écoule du tronc du Sturax Benjoin du Siam, de Sumatra, d'Indochine (Laos) et de Malaisie, "qui fait l'objet d'une exploitation importante. On l'exploite vers l'âge de sept ans, en pratiquant dans l'écorce des séries régulières d'incisions, dont il s'écoule bientôt un liquide jaunâtre qui se solidifie en six semaines, et qu'on enlève alors. Tous les tiois mois, on fait

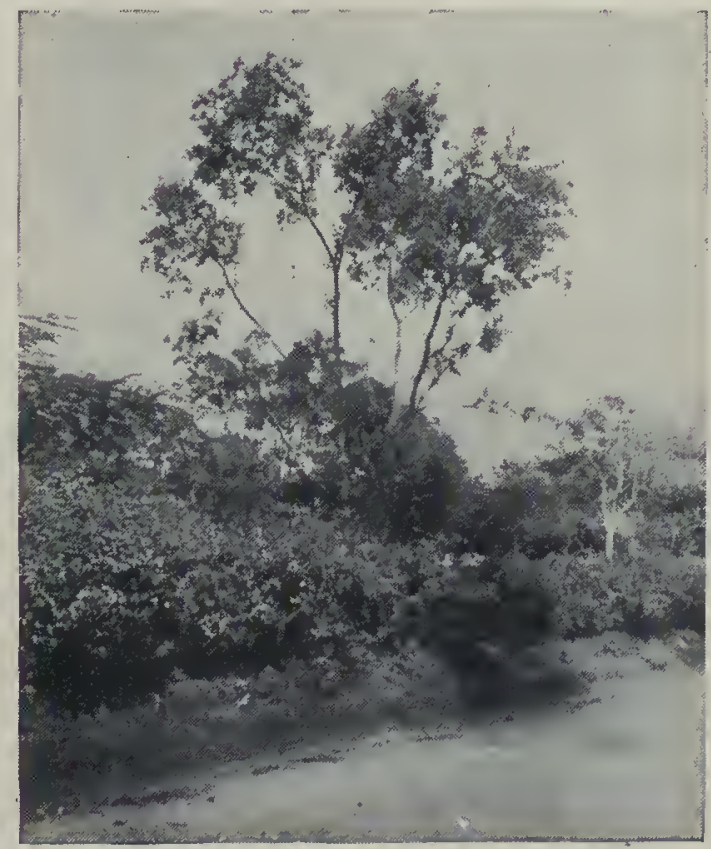

Santal blanc, de l'Inde. de nouvelles séries de blessures: l'arbre meurt épuisé après dix à douze ans de ce traitement. Le parfum est dû à l'acide benzoïque. II sert à la fabrication des pastilles du sérail et du lait virginal pour les gerçures du sein.

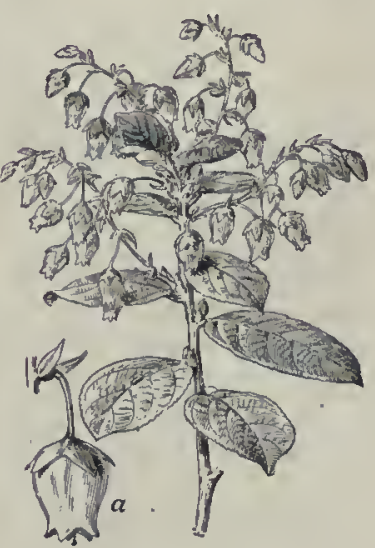

Fig. 314. - Gauthérie. $\alpha$ Fleur. 


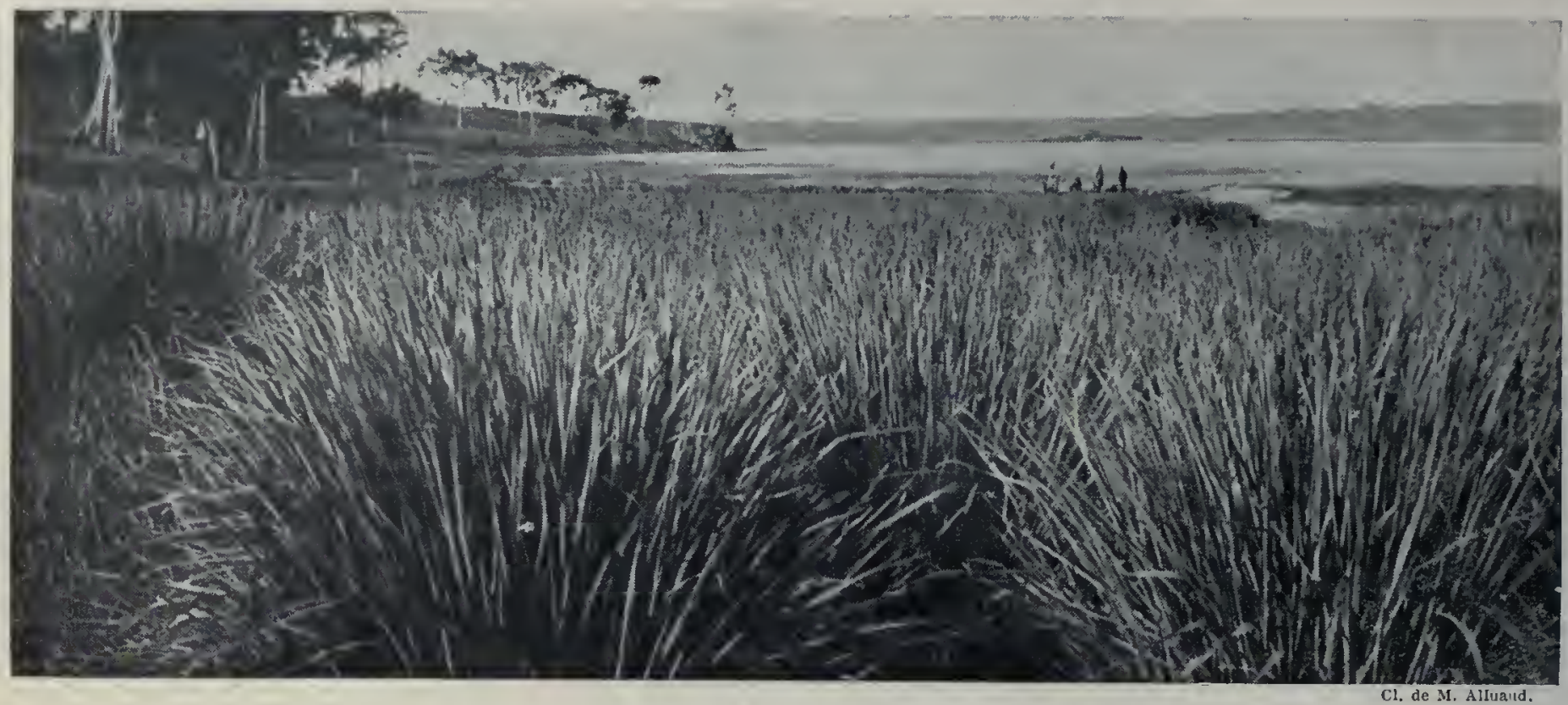

CITRONNELLE (ANDROPOGON CITRATUM) SUR LES BORDS DU LAC VICTORIA-NYANZA.

\section{VI. - PLANTES A USAGES DIVERS}

Plantes fixatrices du sol. - Les racines des plantes fixent les terrains en pente et les sols mouvants. Le principal rôle des forêts en montagne est de retenir la terre; la déforestation livre aux eaux sauvages un sol sans protection. Au-dessus de la zone des forêts, la zone des alpages ou hauts pâturages d'été joue un rôle analogue, mais moins puissant; l'abus des prairies pastorales a des conséquences aussi malfaisantes que la déforestation. Depuis 1860 , en France, la restauration des montagnes a été entreprise.

Les Saules, les Peupliers, qui aiment les lieux humides, sont à recommander pour fixer la terre des levées, des digues, les rives des cours d'eau. La Luzerne, aux très longues racines, le Baguenaudier, le Robinier, etc., maintiennent les talus des voies ferrées.

La fixation des dunes, pour arrêter leur marche envahissante vers les terres, est d'une importance capitale. Après différents travaux préparatoires, on plante généralement le Psamma des sables, nommé oyat en Picardie, gourbet dans le Médoc. C'est une Graminée à feuilles glauques, piquantes, rebutant le bétail. On la plante en poquets suivant des lignes parallèles. Lorsque le sable est fixé, on peut alors y planter des arbres. Dans les dunes de Cascogne, le Pin maritime domine, mélangé de Genêts et d'Ajoncs.

A Aïn-Sefra, à Ouargla, pour empêcher le sable d'envahir les oasis, on recouvre les dunes d'un paillis protecteur d'alfa ou de drinn, dans lequel on plante l'Opuntia, le Genêt d'Espagne, le

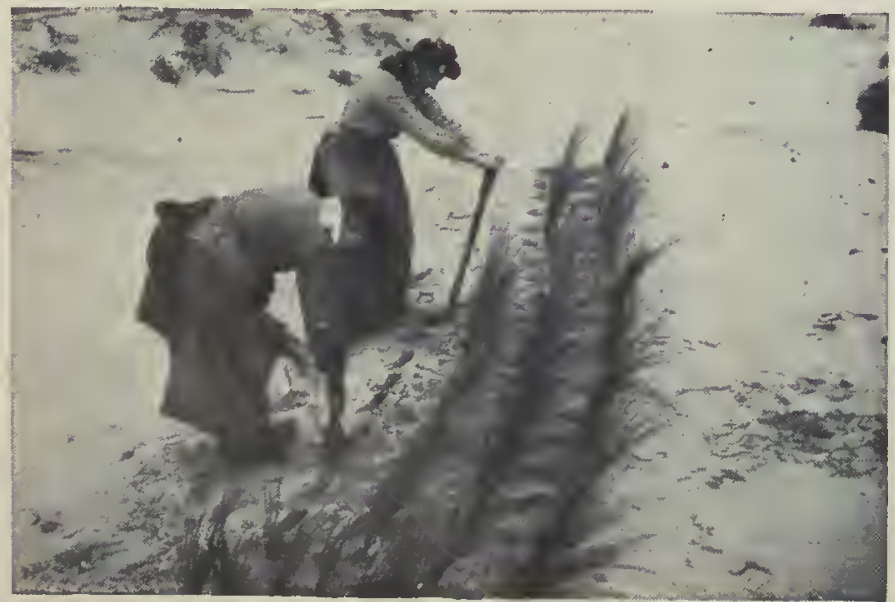

Plantation des jeunes oyats dans les dunes.
Tamarix. C'est par des plantations de Casuarina que l'on est parvenu à retenir les masses de sable qui glissaient sans cesse dans le canal de Suez.

Plantes assainissantes. - Dans les régions marécageuses, les arbres à croissance rapide ont une action assainissante marquée. Dans le marais poitevin, le Peuplier de Virginie, dit Peuplier suisse, rend de grands services; ses racines traçantes absorbent d'énormes quantités d'eau; il est, de plus, d'un bon rapport. Les plantations d'Eucalyptus globuleux, préconisées jadis en Algérie contre la malaria, agissent de la même manière, et non, comme on l'a cru, par leurs émanations aromatiques.

Diverses plantes ont été préconisées pour éloigner les moustiques des habitations; on a parlé du Basilic, du Ricin, du Papayer, du Grand Soleil, etc.; l'expérience n'a malheureusement pas confirmé cette action. Les raquettes d'Opuntia, coupées en fragments et jetées dans les eaux stagnantes, laissent exsuder un mucilage qui forme à la surface une couche isolante amenant la mort des larves de moustiques. En Afrique, on a planté la Citronnelle (Andropogon citratum) contre la maladie du sommeil; les effets avantageux obtenus sont dus à la destruction de toute la brousse littorale, asile ordinaire des larves de tsé-tsé et aussi à l'odeur très forte de la Citronnelle qui éloigne tous les insectes.

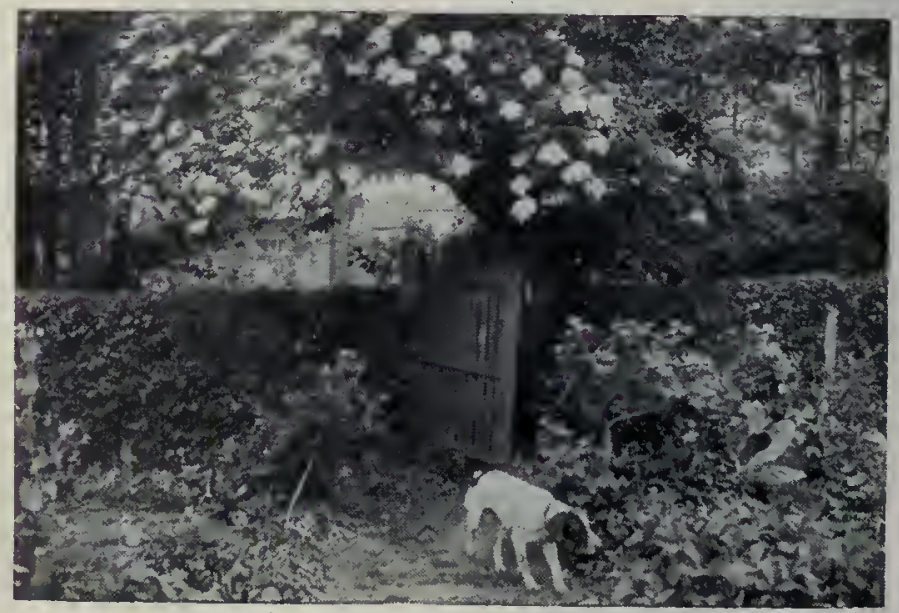

Sureau en fleur dans une haie. 


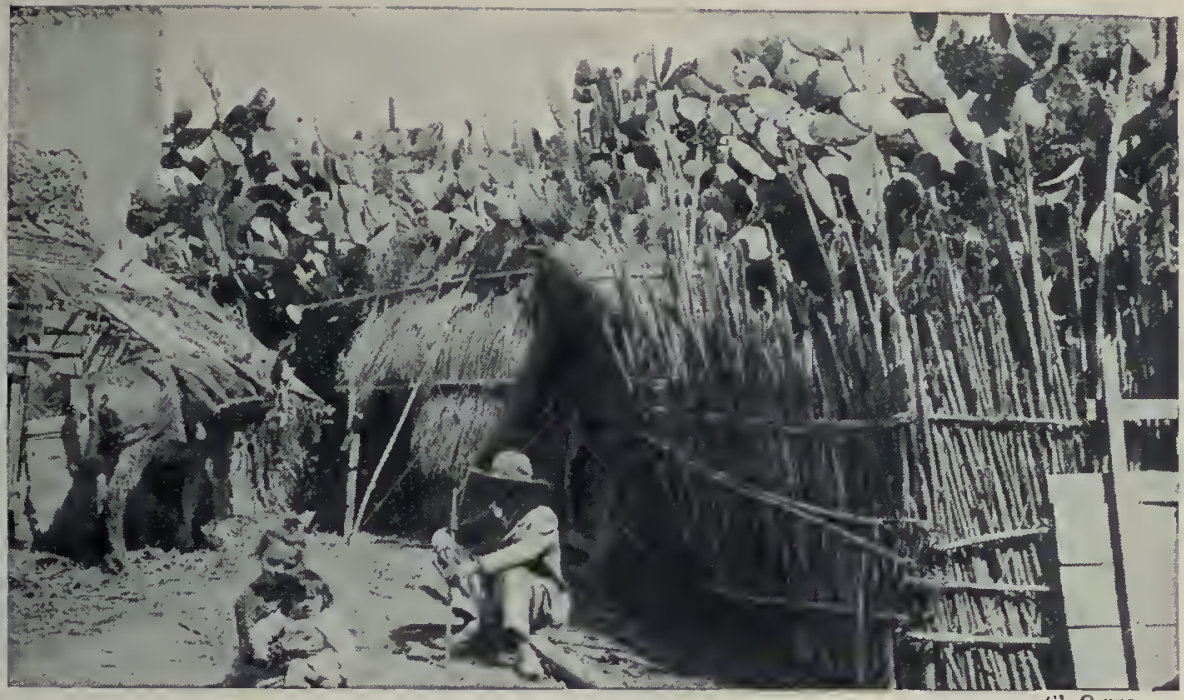

Clôture d'Opuntia dans ta campagne espagnole.

Plantes défensives. Haies. - L'homme utilise les plantes épineuses à la protection de son domaine ou de ses récoltes; il entoure son champ d'une haie, qui vaut un mur pour arrêter les malfaiteurs à deux ou quatre pattes; il couvre, dans son jardin, la semence qui lève de rameaux épineux destinés à éloigner les oiseaux et les petits rongeurs. Les haies vives de défense servent à enclore les jardins rustiques, les vergers. L'Aubépine ou Epine blanche et le Prunellier ou Épine noire sont, en France, le essences les plus employées; d'elles-mêmes elles se renforcent de nappes de Ronces et d'Eglantiers, de lianes de Clématite et de Chèvrefeuille qui les rendent impénétrables.

Le Prunellier émet des drageons et la haie se déplace peu à peu; l'Aubépine est préférable; on la recèpe après trois ans de plantation, ce qui fait naître un grand nombre de pousses propres à garnir sa base. Le Poirier et le Pommier sauvages, le Nerprun, le Lyciet d'Europe, le Genévrier, le Houx, auxquels on associe parfois des essences non épineuses, comme le Chêne, le Coudrier, l'Erable champêtre, le Charme, l'Orme, font aussi d'excellentes clôtures. En Bretagne, les haies sont d'Ajonc; dans le Midi, de Genêt d'Espagne, d'Olivier sauvage, de Grenadier, de Paliure épineux, etc. En Espagne, en Tunisie, en Algérie domine l'Opuntia, dont les raquettes inclinées en tous sens et garnies de milliers d'aiguilles constituent des barrières infranchissables. En Malaisie, on utilise le Bambou épineux. En Afrique, beaucoup de villages sont entourés de formidables haies continues, percées seulement de quelques trouées auprès desquelles veillent des sentinelles. Mais cest bien certainement au Mexique quon voit les haies les plus pittoresques et les plus redoutables; les Cierges et autres Cactus épineux dont elles sont formées sont de véritables murailles qu il est absolument impossible de traverser, ainsi que le montrent les belles photographies de M. Diguet.

Les haies d'arbres (brise-vent) sont indispensables dans les pépinières pour protéger les jeunes plantes; elles sont constituées ordinairement par un rideau d'Ifs ou de Cyprès de faible épaisseur; les rideaux de Cyprès qui abritent les riches vergers de la vallée du Rhône contre la violence du mistral sont célèbres. Au bord de la mer, les Tamarix et l'Arroche halime, qui végètent admirablement dans un milieu chargé de particules salées, sont employés comme brise-vent. On peut citer encore les plantes abris chargées de fournir de l'ombre aux jeunes Caféiers dans les cultures coloniales, les haies brisevent des cultures du Théier de Grewia. Signalons aussi les haies ignifuges d'Opuntia qui ont été proposées pour cloisonner les forêts de résineux, permettant ainsi de limiter les incendies.

Plantes engrais. - Les feuilles mortes dans les forêts, la paille des litières convertie en fumier, les mauvaisesherbes brûlées sur le champ

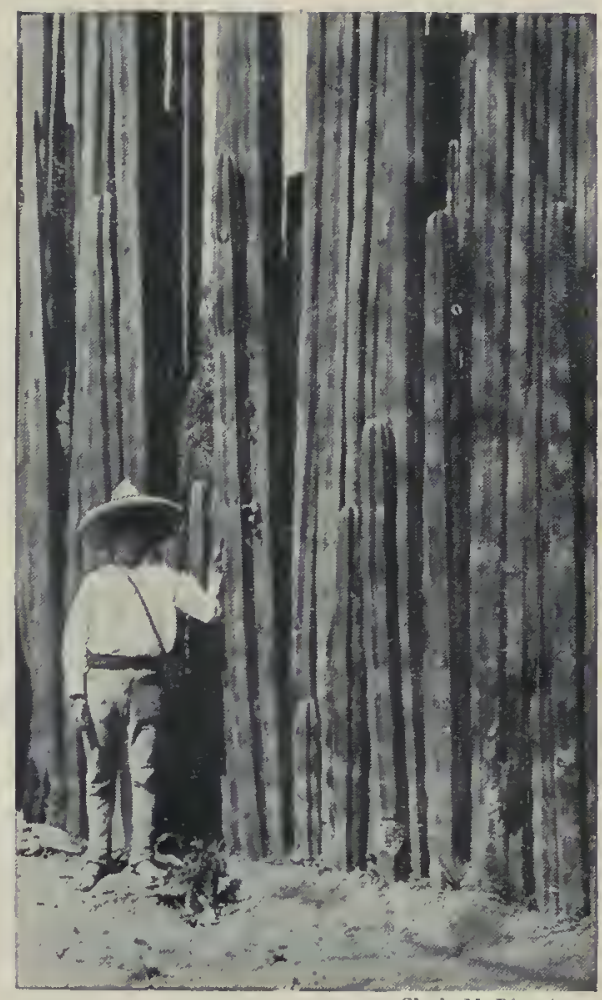

Haie de Cierges marginés (Mexique).

même, les tourteaux oléagineux, les résidus de distillerie, etc., restituent au sol des éléments utiles. Certaines plantes ne sont même cultivées que pour servir d'engrais (engrais vert); on les sème aussitôt après la moisson; elles donnent au premier printemps une récolte qui, retournée et enterrée, fournit au sol de l'ammoniaque, laquelle se nitrifie l'année suivante. Le Colza, la Vesce, les Gesses etc. font l'objet de ces cultures dites dérobées.

Pour les habitants des côtes, les Fucus, Laminaires, Ulves et autres Algues marines désignées sous les noms de goémon, varech, sart, constituent un engrais précieux. Recueille qui veut le goémon épave, mais le goémon tenant au sol est la propriété des communes riveraines; la coupe n'en peut être faite quaprès l'éclosion du frai, lorsqu'elle ne peut nuire à la reproduction des poissons qui y trouvent un abri, et aux époques fixées par l'administration de la marine. A marée basse, le goémon est coupé, placé sur des civières pour être transporté aux charrettes ou mis en tas quentourent de solides cordages et que des.canots, au moment du flot, amèneront à la côte; cette récolte est particulièrement active en hiver sur le littoral breton. Le goémon est parfois utilisé de suite, après un court séjour à l'air et un lessivage par les pluies; plus souvent, on le dispose en meules et on ne l'utilise que lorsqu'il est sec. Les pêcheurs recueillent ou draguent aussi les Lithothamnions ( $L$. calcareum) et autres Algues calcaires: c'est le maërl, qüils vendent aux paysans pour amender les terres granitiques de la

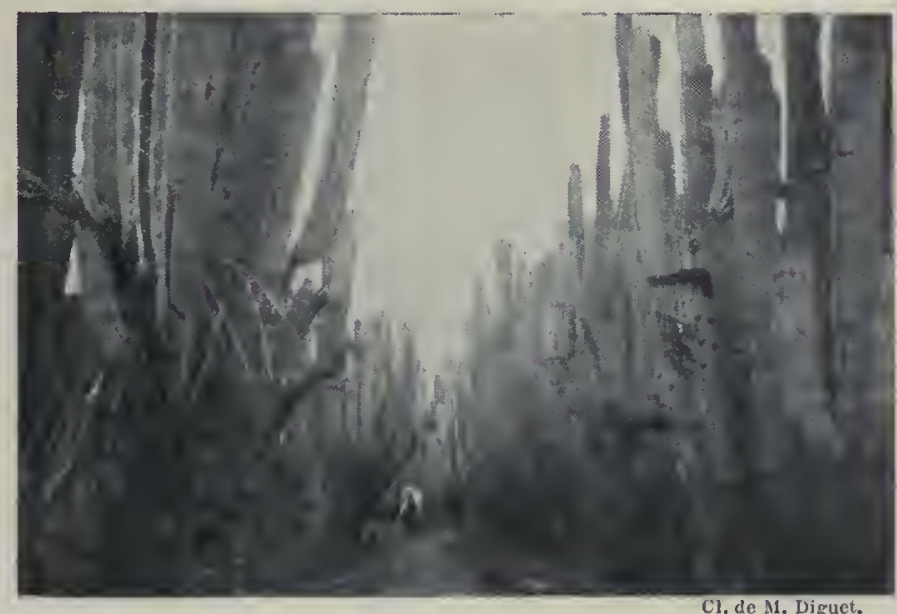

Cloture de Cierges candélabres (Mexique).
Basse-Bretagne.

Plantes pour industries chimiques. - Les plantes terrestres sont riches en tartrate et oxalate de potassium que la combustion transforme en carbonat: neutre de potassium ou potasse du commerce, qui reste dans les cendres. L'emploi des cendres de bois, à la campagne, pour lessiver le linge, est donc justifié. La potasse naturelle se prépare en brûlant le bois sur place, lessivant les cendres et flitrant la lessive obtenue. On évapore à siccité et il reste le salin, bruni par des matières organiques qu'on détruit par calcination. On obtient un corps blanc à grains 
arrondis, la potasse perlasse, produite autrefois abondamment en Russie et en Amérique. L'élévation du prix du bois, la préparation de la potasse artificielle en partant du chlorure de potassium, ont fait abandonner le lessivage des cendres. Cependant, dans la région du Caucase, la fabrication de potasse de Soleil ou Hélianthe annuel, plante cultivée pour ses graines oléagineuses, est très développée; les tiges et les feuilles sont brûlées et les cendres lessivées, produisant une potasse très pure. La calcination et le lessivage de la crème de tartre ou lie du vin, celle des vinasses de betterave, fournissent aussi de grandes quantités de potasse. Ces vinasses forment encore l'acide propionique et aussi le chlorure de méthyle, utilisé dans les industries du froid, des couleurs d'aniline, en médecine et comme dissolvant des parfums.

De même que les cendres de végétaux terrestres contiennent du carbonate de potasse, celles des plantes du bord de la mer (Soude, Salicorne, etc.) et des Algues marines sont riches en carbonate de soude. La soude artificielle, obtenue en partant du sel marin, a remplacé presque complètement la soude naturelle qui eut, pendant des siècles, une importance considérable. Après la découverte de l'iode, en 1811, et celle du brome, en 1826, l'exploitation des plantes marines devint active, car elles renferment ces deux métalloïdes, et en proportion élevée dans les Algues rouges. De nombreuses usines s'établirent dans le Cotentin et en Bretagne, mais leur prospérité fut fortement atteinte lorsqu'en 1865 on se mit à extraire le brome du gisement de Stassfurt en Allemagne ; l'extraction de l'iode, en 1875, des nitrates de soude du Chili et des phosphorites leur porta un coup funeste. Il existe cependant encore en France quelques fabriques où l'on traite les soudes de varech pour en extraire l'iode.

Les goémons secs sont brûlés dans des fosses à fond de pierre ; les cendres sagglutinent en pains de soude qui sont vendus aux usines. Celles-ci, de 10000 tonnes de soude de varech retirent 40000 kilogrammes d'iode et, de plus, de la soude, du chlorate et du sulfate de potasse.

Passons maintenant aux acides organiques. L'acide citrique est le plus important; il sert en teinture comme rongeant, en photographie pour les papiers au citrate, en pharmacie pour la préparation du citrate de magnésie. On l'obtient aujourd'hui dans les pays de production, en Sicile, en Espagne et en Tunisie. On presse des citrons bien mûrs, débarrassés du zeste et des pépins, ou des bergamotes dont on a extrait l'essence, on ajoute au jus des réactifs (procédé Restuccia) qui séparent les principes pectiques, albuminoïdes et sucrés; on décante, on filtre sous pression et on concentre. Les pulpes épuisées servent d'engrais. On a trouvé un Champignon, le Citriomyces, du groupe des Aspergilles, qui

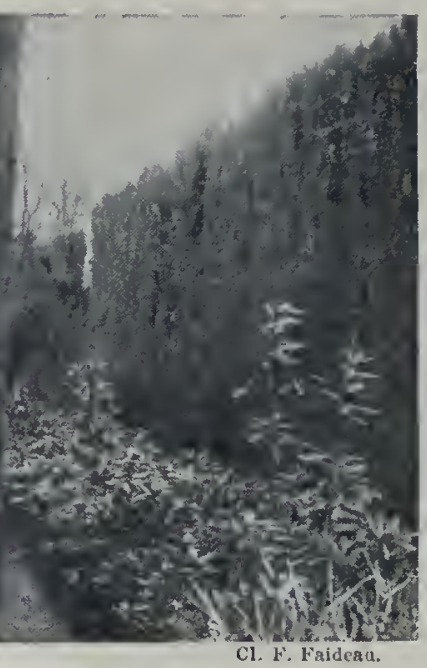

fabrique aussi l'acide citrique. L'acide tartrique est retiré du tartre ou dépôt des vins sur les parois des tonneaux; l'acide malique, des fruits du Sorbier; l'acide lactique, qui a d"importants usages en pharmacie, photographie, teinture et tannerie, s'obtient en partant des matières amylacées saccharifiées par le malt et en provoquant ensuite la fermentation lactique en présence de craie. Enfin, nous avons déjà parlé de l'acidetannique ou tanin (p.256). Signalons aussi les plantes oléagineuses (p. 230), qui fournissent des matières premières à la șavonnerie, àl'industric des bougies, etc.

Savon végétal. - Beaucoup de plantes renferment un glucoside, la saponine, soluble dans l'eau, qu'elle fait mousser et à laquelle elle communique les propriétés détergentes de l'eau de savon; étant privé d'alcali, ce savon végétal est même indiqué, de préférence, pour enlever les taches des étoffes délicates. Un autre emploi moins recommandable de la saponine est celui que lui ont trouvé les industriels peu scrupuleux pour faire mousser la bière, le cidre, le vin, falsification non sans danger, absolument interdite.

L'Arum tacheté de nos bois, la Pariétaire, le marron d'Inde et la plupart de nos Caryophyllacées indigènes : Lychnis, Gypsophile, Saponaire sont riches en saponine; la racine de la Saponaire a longtemps été utilisée dans nos campagnes; la Gypsophila Struthium, ou herbe à savon du Levant, est encore employée en Espagne. Le bois de Panama est l'écorce d'une Rosacée, le Quillai savonneux du Chili ( $f$ g. 315 ); on vend sous le même nom l'écorce d'une Sapindacée, le Savonnicr saponaire des Antilles et de l'Amérique tropicale. Semblables à de grosses cerises, les fruits de ce denier arbre, qui sont les soap-berries ou graines à savon des Américains, sont utilisés sur place pour la lessive. En Californie, le bulbe d'une Liliacée (Chlorogalum pomeridianum), et dans l'Amérique du Sud, l'écorce d'une Polygalée (Monnina polystachia) ont les mêmes applications.

Réactifs colorés. - Dans les laboratoires, les réactifs colorés sont très employés; leurs changements de couleurs indiquent si une substance est acide ou alcaline. La plupart proviennent des plantes; c'est leur matière colorante qui se modifie ainsi. Si l'on touche une rose ou un pétunia rouge avec la cendre alcaline diun cigare, on obtient une tache verte. Les fleurs violettes verdissent ou bleuissent quand on les expose aux vapeurs d'ammoniaque et rougissent sous l'action des vapeurs acides. On emploie la teinture de tournesol, celle de chou rouge, le sirop de violette. Un papier teint en jaune par la teinture du Curcuma ou de Kaempferia devient rouge sous l'action des bases. Les fleurs de Mauve, fraîches ou sèches, agitées simplement dans l'eau, donnent un liquide bleu qui rougit par les acides et verdit par les bases.

Gélatines végétales. Les matières susceptibles de se prendre en gelée avec l'eau sont nombreuses dans le monde végétal : on les nomme pectines, mucilages; on les rencontre dans les racines, les fleurs, les graines, les fruits, les gommes exsudées par certains arbres. La glu, employée surtout par les oiseleurs, est une substance visqueuse, tenace, obtenue avec les baies du Gui, avec l'huile de lin bouillie ou l'écorce intérieure du Houx pilée de manière à l'amener à l'état de pâte. On fait bouillir celle-ci avec de l'eau et on l'abandonne à elle-même : une fermentation la transforme englu. 


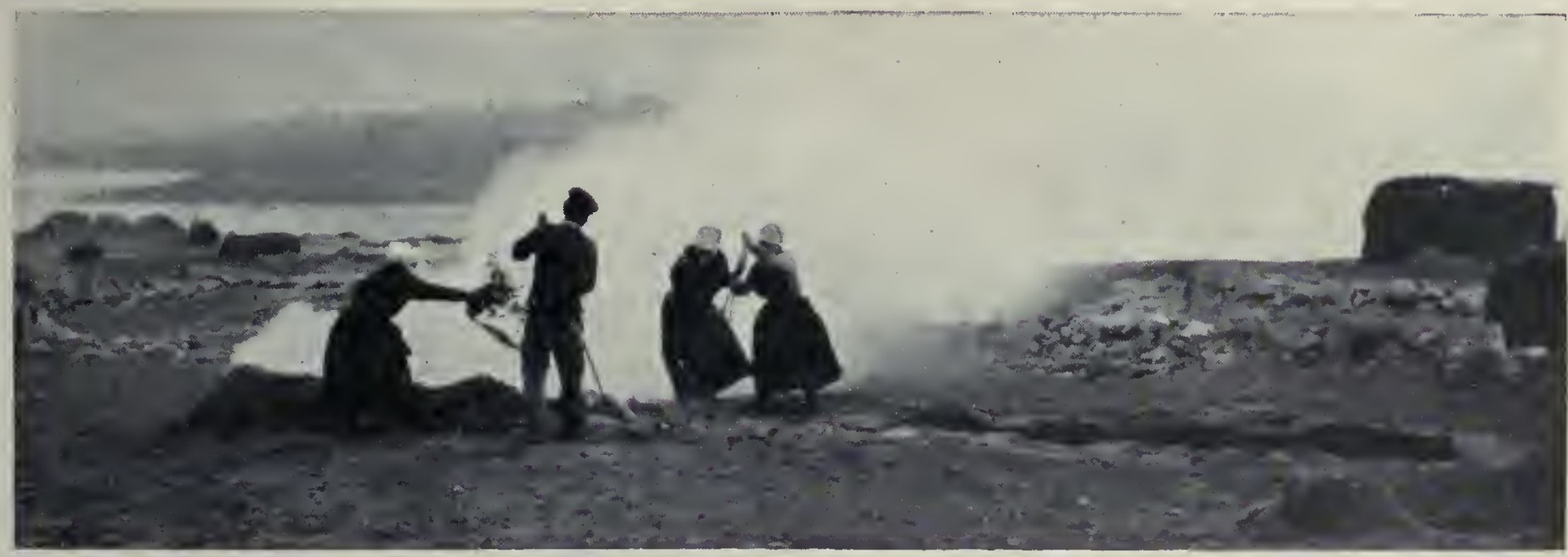

Le brûlage des goémons, au pays de Léon (Bretagne).

L'existence de la gélatine végétale dans les Algues marines est connue depuis longtemps. Les nids d'une sorte d'hirondelle, la salangane, construits avec des Algues collées par la salive de l'oiseau, font les délices des Chinois. On consommait jadis sur nos côtes de France la Laminaire sucrée, sous forme de gelée; on en a tenté l'emploi pendant la guerre à la place d'Avoine pour les chevaux (Lapicque). Les Hawaïens ne consomment pas moins de soixante espèces différentes d'Algues. Le Chondrus crispé ou mousse d'Islande, carraghean. Algue rouge fort commune, fournit des tisanes mucilagineuses; on l'emploie en Allemagne, après décoloration, pour donner aux bières une certaine viscosité.

L'extraction des gélatines végétales des diverses Algues marines est une des industries les plus anciennes du Japon. Le kanten se retire des algues du genre Gelidium, communes sur les côtes de l'île de Yeso. On les arrache au fond de l'eau avec de longues gaffes (fig. 316). La récolte est mise à sécher, puis battue, nettoyée, lavée à l'eau douce courante; enfin séchée et blanchie sur claies au soleil. Les Algues s'agglutinent en séchant; on les enroule et on les fait bouillir dans leau douce; la masse gélatineuse obtenue est filtrée à plusieurs reprises et versée dans des plateaux où elle sèche en plaques épaisses qu'on découpe en lames. Celles-ci, pressées fortement au-dessus d'un tamis métallique (fig. 318), en sortent sous forme de filaments rappelant le vermicelle. Le kanten sert à préparer des gelées alimentaires, des soupes, des sauces, des pâtisseries, à coller le saké ou vin de riz, à faire des moulages, à apprêter les étoffes, encoller le papier, à fabriquer les faux nids comestibles d'hirondelles des Chinois, à préparer l'agar-agar, milieu de culture inerte très employé en microbiologie. Une bonne partie de la production japonaise est expédiée en Europe et aux Etats-Unis pour clarifier les sirops, la bière, pour être employée en pâtisserie, en confiturerie et en cuisine.

Le funori est une gélatine plus grossière, tirée des Gloiopeltis coliformis et intricata: on l'expédie en rouleaux; on l'utilise pour
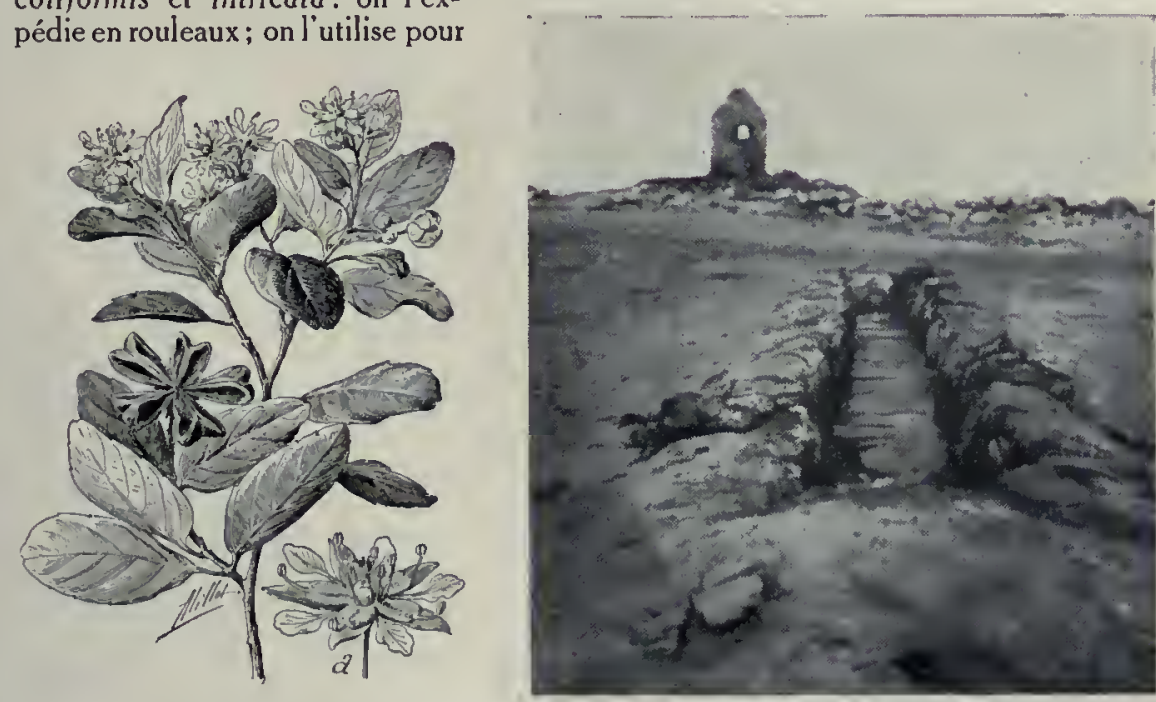

Fosse pour le brullage des goémons.
Fig. 315. - Quillai. $a$, Fleur. l'apprêt des tissus, le glaçage du papier; il est employé comme cosmétique par les Japonaises; une centaine d'établissements aux environs d'Osaka soccupent à sa fabrication. Le kombu est une gélatine préparée avec des Laminaires du nord du Japon ( $L$. japonica et religiosa). Les pêcheurs, qui sont presque tous des Aïnos, les draguent ou les arrachent avec des gaffes, les font sécher sur le rivage ( $f$ g. 317 ), puis les portent aux fabriques. Là, elles subissent l'action d'une lessive alcaline, qui est suivie de manipulations assez compliquées. Le kombu est vendu en languettes menues ou en farine; on le mange soit en potage, avec le poisson, les légumes, soit préparé avec du sucre.

Le tengusa est un autre produit comestible extrait du Gelidium Amausii. Enfin, l'amanori se prépare avec le Porphyra tenera ( fig. 320), objet d'une culture unique dans le monde. Algue mince rouge ou violette, que l'on élève spécialement dans la baie de Tokyo et auprès de lî̂le de Hiroshima, dans la Mer Intérieure. Des faisceaux de Bambou ( $f$ ig. 319), plantés en ligne dans le courant d'octobre, par des fonds vaseux, recouverts à marée haute de 3 à 4 mètres d'eau, servent à retenir et à fixer les spores de l'Algue qui se développe très vite et qu'on récolte au fur et à mesure de sa croissance, qui se fait en cinq à six mois. Ces plantes sont lavées à l'eau douce, séchées et préparées en feuilles minces qu'on fait griller avant de les consommer; elles sont utilisées avec la sauce du Soja ou Sho-you; on les vend dans les rues, dans les gares pour emporter dans les pique-niques; on en prépare le sushi, qui a la forme d'un saucisson, se coupe en tranches et s'utilise comme les sandwichs; il est formé de riz bouilli, assaisonné avec du vinaigre, du poisson, des légumes et entouré d'Algues.

Cette intéressante industrie de la gélatine végétale est aussi très développée à Ceylan, dans l'Inde et à Java. Lagar-agar de Ceylan est obtenu avec la Gracilaria lichenoides, algue dite mousse de Ceylan; l'agar de Java (macassar ou carraghean des Indes)

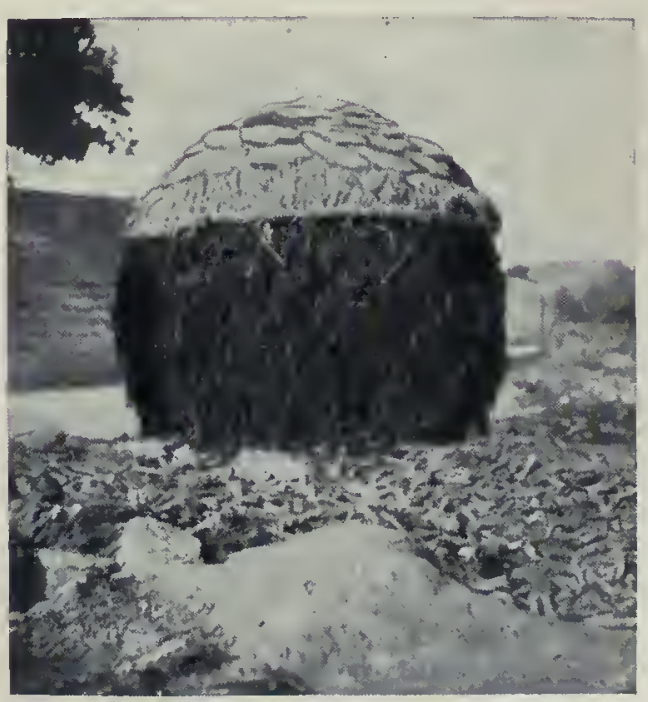

Une meule de goémon. 


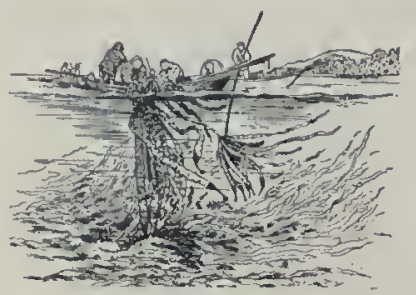

Fig. 316.

Pêche des grandes Algues.

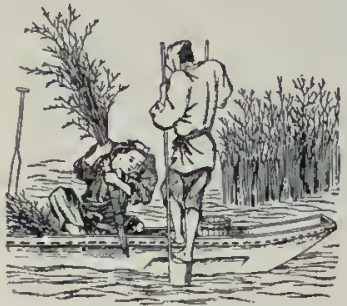
des Porphyra sur Bambou.
Fig. 319. - Culture

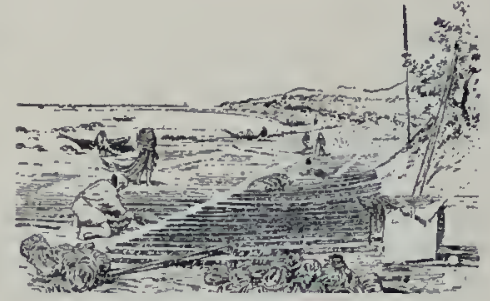

Fig. 317.

Séchage des Laminaires, au Japon.

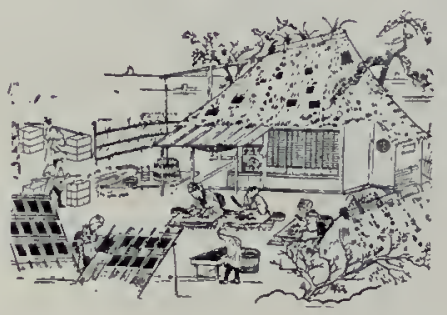

Fig. 320 .

Fabrication de l'amanori est extrait des Eucheuma. La norgine est une gélatine qui se vend en menus grains ou en écailles brunes et qui a tous les usages du kanten; elle a été préparée d'abord en Norvège; elle l'est en France, dans quelques usines, avec les Laminaires.

La valeur alimentaire de la gélatine végétale est faible, mais son usage habituel chez des populations mangeant en grande abondance du riz et du poisson est avantageux, car il facilite les fonctions intestinales et évite la constipation.

Ferments et Levures. - Tous les organismes sécrètent des principes azotés ou diastases, qui sont des ferments solubles très actifs. Aux diastases sont dus les phénomènes de digestion chez les animaux, de germination digestive chez les plantes; elles jouent un rôle immense dans les phénomènes de la vie; leurs applications dans l'industrie et dans l'économie domestique méritent aussi quelques lignes.

L'amylase de l'orge germée est utilisée en glucoserie, en distillerie et en brasserie. La laccase est une diastase oxydante très répandue qui brunit à l'air le latex de l'arbre à laque et le transforme en un vernis précieux pour l'ameublement; c'est elle aussi qui cause le brunissement des pommes broyées; le cidre lui doit sa belle coloration. Le latex du Papayer contient la papainne, qu'on utilise en médecine pour faciliter la digestion, car elle a les propriétés de la pepsine animale. Les Indiens d'Amérique, pour attendrir la viande, l'entourent pendant une nuit d'une feuille de Papayer. La diastase de la graine du Ricin (lipase ou lipaséidine de Nicloux) est utilisée dans des savonneries en Allemagne et à Marseille pour saponifier à froid les matières grasses.

La présure végétale, qui a les mêmes propriétés que la présure ou lab sécrétée par l'estomac des jeunes mammifères, est employée depuis les temps les plus reculés pour préparer le lait caillé et les

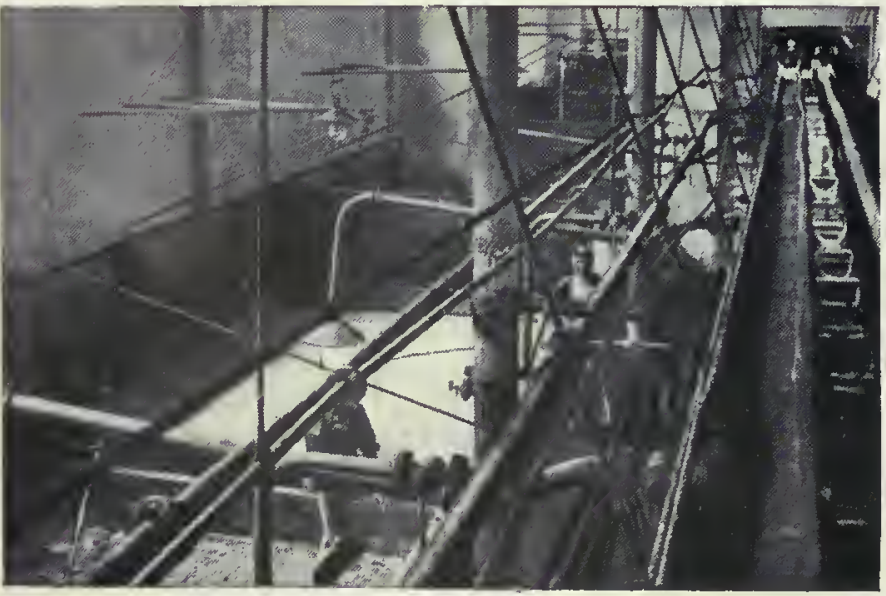

La levure dans les cuves de fermentation.

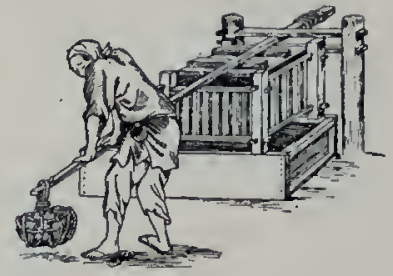

Fig. 318.

Presse à kanten. fromages: Homère en parle dans l'Iliade. Dans l'ouest et le centre de la France, les fleurs de l'Artichaut sauvage ou Chardonnette (Cynara cardunculus) sont enfermées dans un petit sachet et placées dans le lait que l'on a fait bouillir; en Angleterre, on utilise les sommités fleuries du Gaillet vrai ou Caille-lait jaune; aux îles Baléares, on remue le lait chaud, après ébullition, avec une jeune branche de Figuier fendue en croix; en Laponie et dans les Alpes italiennes, on emploie les feuilles de la Grassette vulgaire; au Japon, celles du Mûrier à papier, etc. La plupart des présures végétales, d'après Gerber, agissent plus facilement sur le lait bouilli que sur le lait cru.

L'action des Microbes, des Levures et de certaines Moisissures est due aussi à des diastases. Le koumis, le kéfir, le yoghourt, le kwas, le lebenraib sont des variétés de lait aigri sous l'influence de microbes variés; Metchnikoff a préconisé l'introduction dans l'intestin d'une flore bactérienne favorable (Bacillus bifidus) pour y éviter l'invasion d'une flore néfaste (Bacillus perfringens) qui provoque les empoisonnements et la putréfaction de l'intestin et contribue à diminuer la durée de la vie humaine (artériosclérose).

Le rôle des Microbes est considérable dans l'industrie : rouissage des textiles, fabrication du vinaigre, des fromages, etc.; celui des Levures ne l'est pas moins dans la panification et la fabrication des boissons fermentées. La Levure de bière pure, employée par les boulangers pour la fermentation des pains de luxe, se fabrique dans des usines spéciales. Il en existe une très importante à Maisons-Alfort (Seine). Le malt d'orge y est obtenu comme en brasserie; il sert à saccharifier dans les cuve-matière un mélange à proportions à peu près égales de farine d'orge, de seigle et de maïs. Les moûts sont dirigés dans des cuves quion met en train avec un levain de farine de seigle. La Levure est recueillie à la surface du liquide bouillonnant, puis refroidie, tamisée et comprimée dans des filtres-presses. Elle est ensuite piétinée par des hommes munis de sabots spéciaux, puis débitée en paquets à la machine. Les sous-produits de l'usine sont l'alcool tiré du moût fermenté, la drêche et le gaz carbonique.

La Levure constitue en brasserie un résidu d'un poids énorme (70000 tonnes par an en Allemagne). On l'emploie en médecine contre la furonculose et les bronchites chroniques; additionnée de plâtre ou de chaux, c'est un bon engrais. On en prépare des extraits dits viandine, dont la composition et la saveur sont voisines de celles des extraits de viande qüils servent à falsifier; on en fait des bouillons concentrés, des potages comprimés de peu de valeur alimentaire, mais agréables et inoffensifs. A la viandine viennent s'ajouter un peu de dextrine, des traces d'essence de carottes et d'autres légumes, des farines de pois, de haricots, des oignons hachés et grillés, etc. Dans certaines fabriques, la viandine est obtenue chimiquement, non en partant de la Levure de brasserie, mais du gluten des céréales ou même de la caséine du lait.

Pyrèthres insecticides. - Les pyrèthres insecticides sont fournis par des capitules desséchés et pulvérisés de diverses espèces

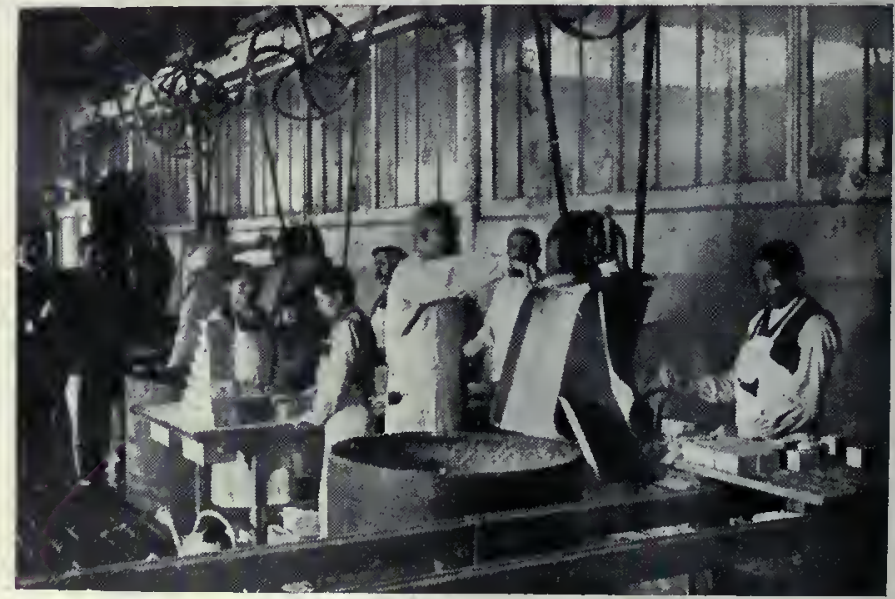

Découpage de la levure pour la boulangerie. 
de ce genre; ils doivent leur action à une huile essentielle et à une oléorésine d'odeur très forte. Le Pyrèthre rigide ou à feuilles de cinéraire est cultivé en Dalmatie et au Monténégro, le Pyrèthre du Caucase et le Pyrèthre cocciné ou rosé le sont en Perse et au Caucase. On cultive les Pyrèthres en Californie. En France, des viticulteurs les cultivent aussi et utilisent les fleurs pour combattre la cochylis. Ces plantes, au bout de trois ans, sont en plein rapport et se couvrent de fleurs qu on récolte en juin et qu'on fait sécher au soleil.

La nicotine des manufactures de tabac est fort employée comme insecticide par les horticulteurs.

Plantes à polir et plantes à carder. - Le tripoli, employé pour polir les métaux, les pierres et, mélangé avec la nitro-glycérine, pour fabriquer la dynamite, est formé de carapaces de Diatomées fossiles; on en trouve d'importants gisements en Bohême, en Auvergne, etc.

Les Prèles renferment dans leur épiderme de fortes proportions de silice; on utilise les grandes espèces, surtout la Prèle d'hiver, pour polir les bois durs. La moelle blanche et tendre du Sureau sert pour net-

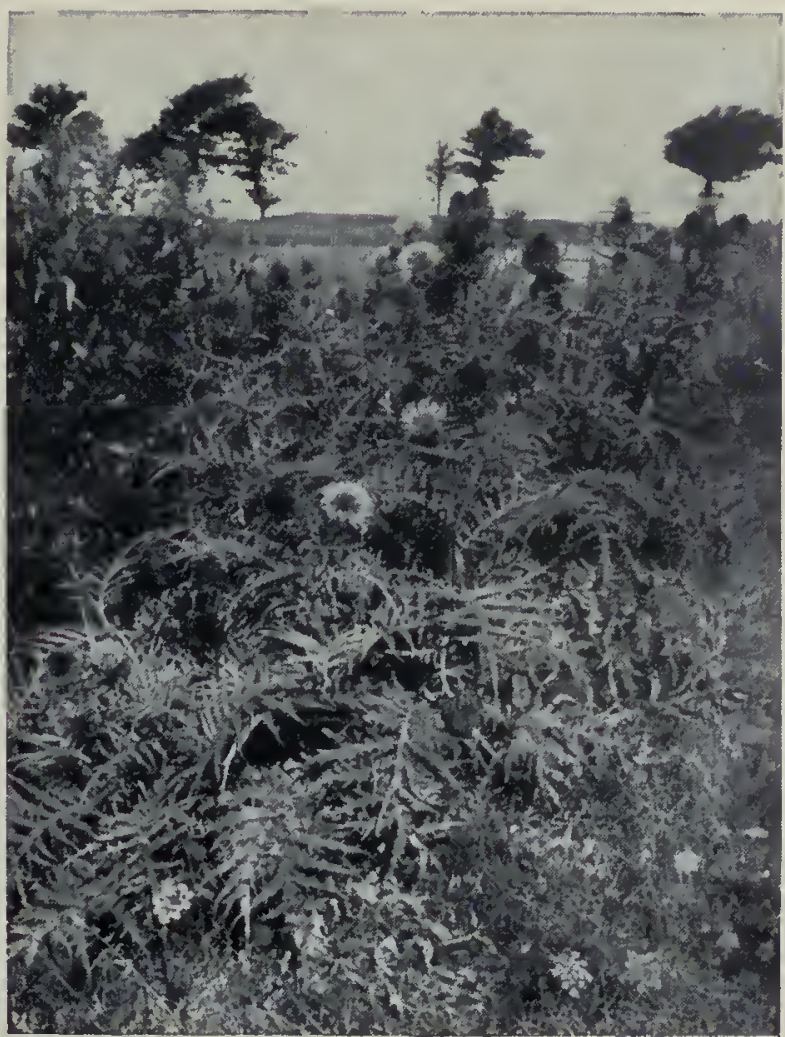

Chardonnette (Cynara cardunculus).

poussant sur les arbres : Polypore amadouvier (fig. 323), Polypore allume-feu, etc. On coupe leur chair en tranches minces que l'on fait macérer dans une eau alcaline et que l'on bat
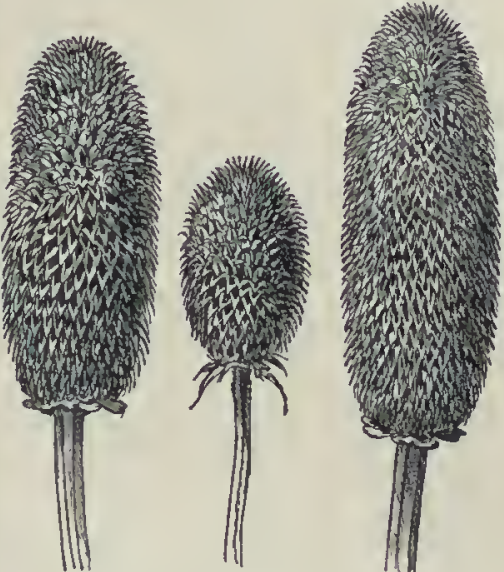

Fig. 322. - Tètes de Cardères.

De gauche à droite : Foulon, Bonnetier et Drapier.

au maillet. On obtient ainsi l'amadou des chirurgiens, employé pour arrêter les hémorragies; l'amadou des fumeurs est imprégné de salpêtre et de chlorate de potasse qui facilitent sa combustion.

L'ivoire végétal ou corozo provient toyer les rouages des montres, les verres des instruments d'optique; on en fait des pistons pour seringues, de petites boules pour les apparcils d'électricité statique; les naturalistes y plongent les fragments d'organes dont ils veulent faire des coupes au microtome. Un champignon, le Polypore du Bouleau, possède une chair blanche, coriace, qui a été utilisée pour la confection des cuirs à rasoir.

La Cardère (fig. 322) ou Chardon à foulon (Dipsacus fullonum) est une grande herbe originaire de l'Asie tempérée, mais cultivée depuis des siècles en Europe pour ses capitules ou " têtes " ovoïdes, munis de bractées élastiques, résistantes, recourbées en crochets constituant un véritable peigne pour carder la surface des draps. Cette culture, bien quayant perdu de son importance par suite de l'emploi des cardes métalliques, se pratique encore en Provence, Languedoc et Normandie, en Allemagne, aux Etats-Unis. C'est qu'en effet si les cardes métalliques suffisent au peignage des draps grossiers, seule, la cardère naturelle réunit la raideur et la souplesse indispensables pour le traitement des étoffes fines. Après la récolte qui, dans le Midi, a lieu au début de juillet, les cardères sont séchées sur une aire, puis subissent un tronçonnage qui supprime l'involucre de la base et raccourcit la queue à 10 centimètres; enfin, elles sont triées par grosseurs et qualités. Les meilleures sont presque cylindriques, à épines nombreuses, fortes, élastiques, recourbées vers le bas. Les producteurs nomment maîtres les chardons provenant de la tige principale; ailes, ceux qu'on cotipe sur les tiges secondaires; turlupins, les plus petits. Les industriels les classent en drapiers ( $7^{\mathrm{cm}}$ de long), bonnetiers $\left(5^{\mathrm{cm}}, 5\right)$ et foulons $\left(3^{\mathrm{cm}}, 5\right)$. L'expédition se fait en futailles légères. Les cultures du Nord fournissent des cardères à épines plus souples que celles du Midi et qui conviennent mieux pour certains travaux.

Amadou, ivoire végétal. - Lamadou a perdu beaucoup de son importance depuis l'invention des allumettes chimiques. Il est fourni par divers Polypores

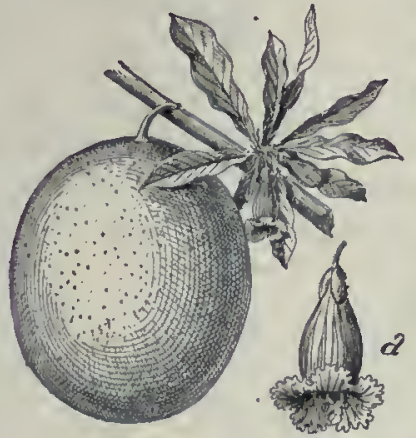

Fig. 321. - Calebassier. $a$, Fleur.

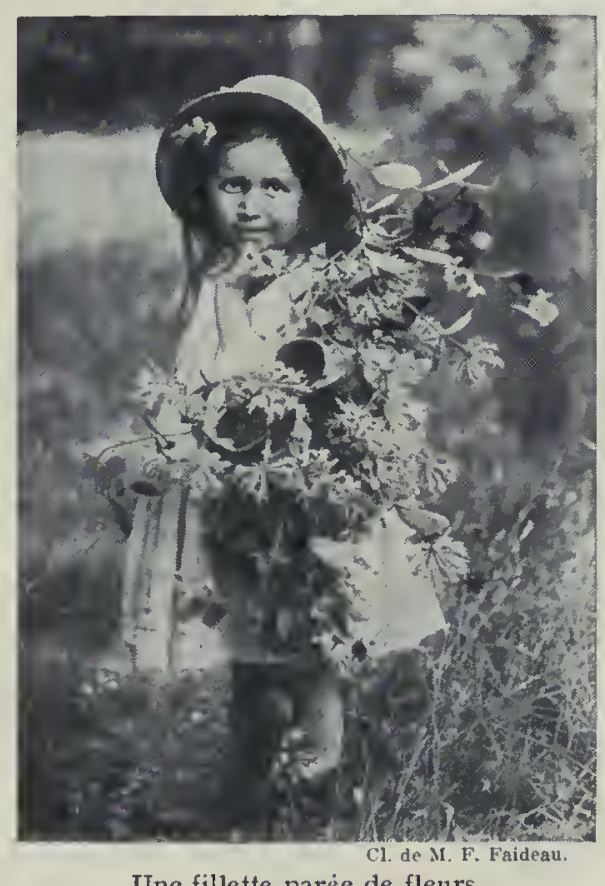

Une fillette paree de fleurs. des graines d'un petit Palmier de l'Amérique du Sud, le Phytelephas à gros fruits, commun au bord des cours d'eau. Le fruit composé pèse jusqu'à 8 kilogrammes; chaque fruit simple, individuel, renferme quatre graines de la grosseur d'un ceuf de poule. L'albumen en est corné, dur, blanc et se travaille comme l'ivoire; on en fait des boutons de vêtements, des pommes de parapluies, etc. Les graines de divers autres Palmiers, comme les Hyphæne et les Attalea, sont propres aux mêmes usages. Le Metroxylon de Viti fournit le corozo d'Australie. Les sciures provenant du travail du corozo sont employées au fleurage du pain. Le Brésil, la Colombie et l'Équateur sont les principaux pays producteurs.

Récipients, instruments de musique. - Les Gourdes (Lagenaria) sont des Cucurbitacées grimpantes qui prospèrent dans tous les pays chauds et tempérés. Leurs fruits mûrs ont un péricarpe dur et ligneux qui permet de les transformer en récipients. Le fruit de la Courde pèlerine ou Gourde bouteille présente un étranglement qui sépare deux renflements inégaux; sa contenance varie de I décilitre à 6 litres; celui de la Gourde siphon se termine par une partie étroite, droite ou

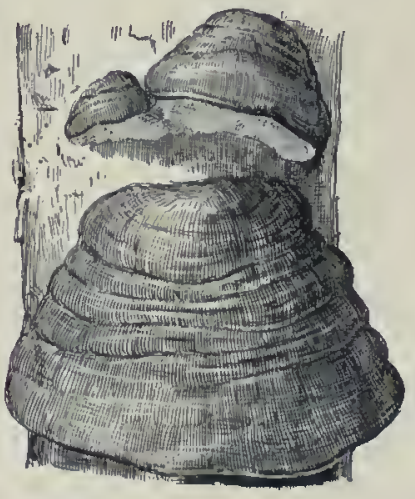

Fig. 323.

Polypore amadouvier. 
recourbée, pouvant atteindre 1 mètre de long. Suivant leur taille et leur forme, quion peut modifier par torsion, ligature, au cours du développement, on en fait des bouteilles, des poires à poudre, des tabatières ou des bonbonnières. Le vrai Calebassier (Crescentia cujele) [fig. 32I] du Mexique, des Antilles et de la Guyane, est un arbre de la famille des Bignoniacées; son fruit, dont la taille varie de celle d'un ouf à celle d'une citrouille, est beaucoup plus résistant que les Gourdes et subit aussi mille transformations.

De la coque dure des noix de coco, les indigènes de Malaisie et d'Océanie tirent leur batterie de cuisine; le Bambou fournit en Extrême-Orient des récipients variés; l'Oncoba épineux de l'Arabie est l'Arbre à tabatière, à cause de la forme de son fruit et de l'usage qu'en font les Bambaras; le petit coco (Cocos lapidea) de l'Amérique centrale sert d'œuf à repriser les bas. Le fruit du Lecythis huileux, Myrtacée de l'Amérique tropicale, est connu sous le nom de noix de sapucia ou sapokayer. Il a la forme d'une petite marmite (marmite de singe) et s'ouvre par un couvercle; il est rempli de graines oléagineuses alimentaires qui s'enflamment avec une lumière blanche et très belle : c'est la noix-bougic des indigènes de l'Amazone. Les végétaux fournissent aux peuples primitifs des instruments de musique plus originaux qu'harmonieux : fîtes en Bambou ou en Roseau, flageolets en tiges de Mil, castagnettes avec des fruits à écorce dure, tam-tams creusés dans des troncs d'arbre, trompes formées d'une courge, etc.

Colliers, passementerie. - L'emploi des végétaux dans la parure est aussi ancien que le monde. Les femmes, à Tahiti, ornent leur noire chevelure des blanches corolles du Carissa et du Gardenia. Les fillettes, dans nos champs, se parent des lianes fleuries du Chèvrefeuille, de la Clématite, du Liseron; elles en font des guirlandes; des corolles de Lilas ou de Coucou traversées d'un fil, elles façonnent des colliers somptueux mais éphémères ou tressent de gracieuses couronnes de Marguerites.

Les colliers de fruits et de graines ont été portés aux temps préhistoriques et sont encore en honneur chez bien des peuples des régions tropicales où abondent les graines à couleurs vives, les noyaux naturellement ornés et de forme gracieuse. Parfois, ils sont amulette en même temps qu'ornement. Certaines graines particulièrement jolies arrivent même jusqu'en Europe, montées en colliers, bracelets ou chapelets. Telles sont celles de l'Abrus precatorius ou arbre à chapelet, qui sont dures, rondes et d'un rouge vif brillant, avec tache noire; celles de l'Adenanthera ou fève d'Amérique, celles de Melia ou Pater noster et de Cardiosperme, les noyaux noirs des fruits du Sapindus et ceux de l'I riarté. Signalons aussi les chapelets en coiffes de boutons d'Eucalyptus, qu'on vend sur la Côte d'Azur. Les fruits élégants des Rotangs se montent comme boucles d'oreilles ou épingles de cravate.

Lutilisation des graines et des fruits secs dans la passementerie pour le vêtement et l'ameublement a été tentée en France, avec un certain succès, pour remplacer les pendeloques en bois recouvertes de soie et de velours. Des motifs fort gracieux sont obtenus en combinant, par petits groupes,

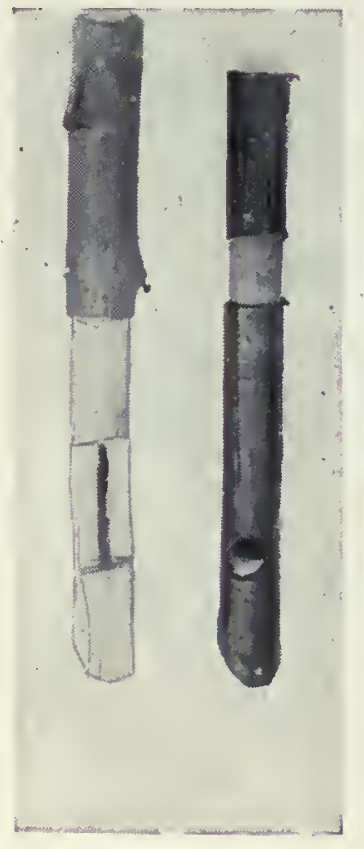

Sifftets de sureau.

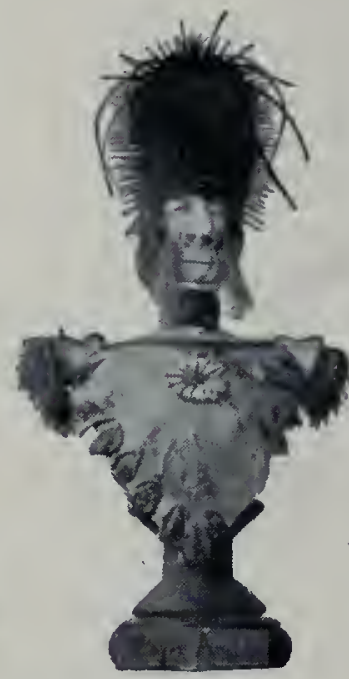

des cônes d'Aune, de Cyprès, de Casuarina, des coiffes d'Eucalyptus, des capsules de glands, des involucres de Hêtre, des noyaux d'Elæocarpus, de Melia, de Jujubier, des larmes de Job qui sont les fruits du Coix lacryma et même des akènes d'CEnanthe et de plusieurs autres Ombellifères. Tous ces fruits reçoivent au préalable par le trempé des teintes dorées, irisées, ou l'aspect du cuir, du vieil argent.

Bibelots divers. - Certains fruits à couleurs vives et tranchées à tégument résistant, comme les Coloquintes, conservent longtemps leur forme et leur aspect et sont d'élégants bibelots. Il en est de même des noyaux qu'on peut polir, tourner et sculpter: la noix de coco se prête à la confection de masques grotesques. La matière tendre et cependant résistante dont sont formés les marrons d'Inde se prête aisément à la sculpture; en vieillissant, elle durcit et se conserve indéfiniment; de plus, elle se ratatine, ce qui accentue les traits du personnage.

Un artiste, Lionel Le Couteux, a créé de petits personnages intéressants, non seulement par le marron sculpté et peint qui constitue leur tête, mais encore par leur costume, formé entièrement ou en partie par des organes végétaux. Voici, par exemple, une Danseuse siamoise; sa coiffure compliquée est formée par une capsule de Pavot incisée en avant et surmontée d'une autre capsule de Pavot plus petite et retournée que couronnent des graines de Persil; ses boucles d'oreilles sont des fruits de Bruyère; sa collerette est une feuille de Panicaut réduite à la dentelle de ses nervures; le reste du costume est constitué par des tissus. Le Major de la Garde anglaise, qui na pas l'air commode, a le chef surmonté d'un monumental bonnet à poil qui n'est qu'une tête de Cardère retournée; sa jaquette est une feuille de Châtaignier, les boutonnières et les boutons sont des graines d'Acacia, les épaulettes sont deux feurs d'Eucalyptus débarrassées de leur opercule; la décoration qui s'étale sur sa poitrine est la partie supérieure d'une capsule de Pavot, c'est-à-dire le stigmate rayonné.

Jouets. - Pour être complet, signalons, parmi ces usages divers des plantes, la place importante quelles tiennent dans les jeux des enfants de tous les pays. Elles ne coûtent rien et, par la variété infinie de leurs formes et de leurs propriétés, se prêtent à toutes sortes de petits travaux et s'adaptent à toutes les transformations. Une branche de Sureau, débarrassée de sa moelle légère, devient, à volonté, une fûte, un mirliton, une canonnière ou une seringue. D'une coquille de noix, un garçon avisé peut tirer, suivant ses goûts et son humeur présente : une balance, un cri-cri, un toton, un moulin, un bateau, une grenouille sauteuse, dix autres objets encore.

Avec une branche en sève ou un noyau d'abricot, on fait un sifflet; avec une tige de Cardère, une crécelle; avec une paille, une petite trompette; le Jonc, le Raphia se prêtent à la confection de hochets et de cent travaux de sparterie.

Les tiges du Fenouil n'ont pas de rivales pour construire un mobilier de poupée. Rigides, revêtues d'une belle écorce verte, mince et résistante, tandis que leur intérieur est formé d'une moelle blanche, très tendre, facile à travailler. 


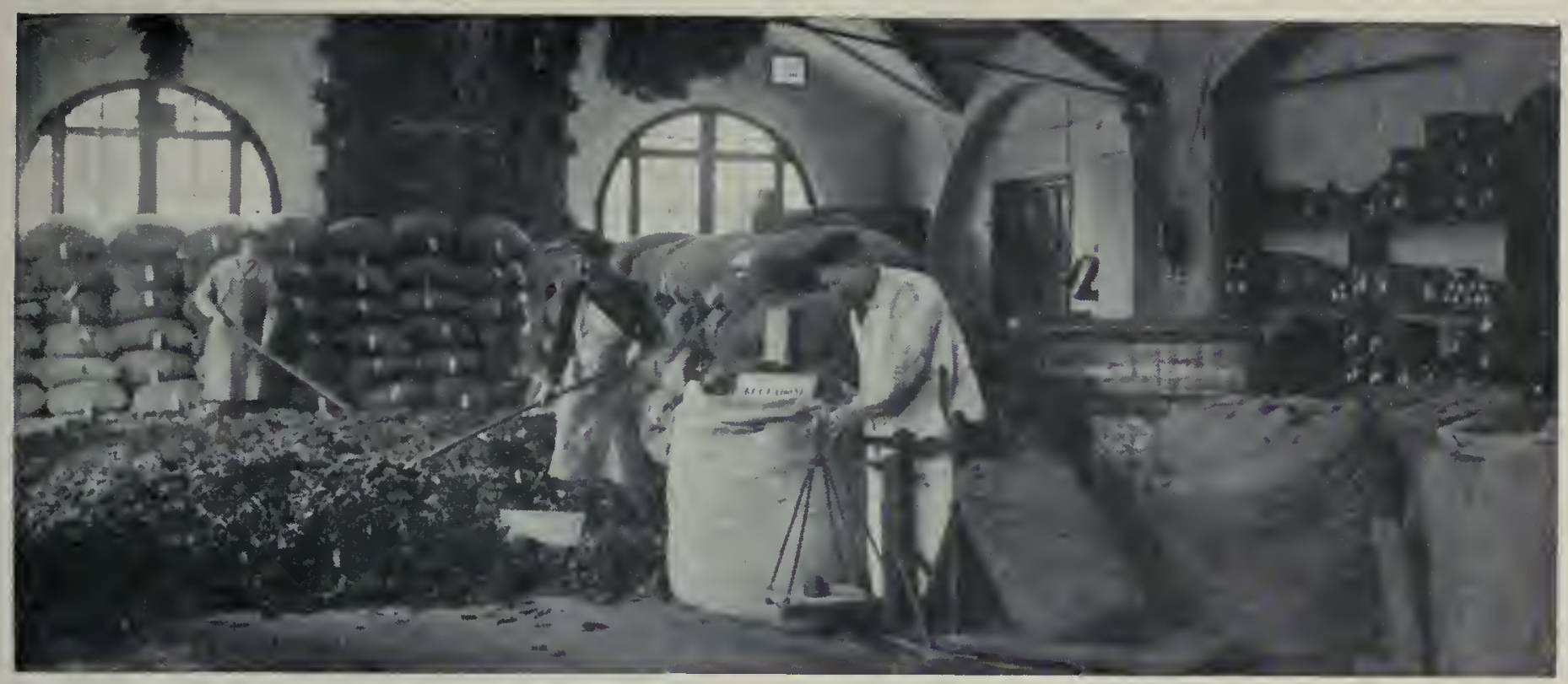

UNE HERBORISTERIE : SALLE DE SËCHAGE ET MISE EN SACS.

\section{VII. - PLANTES MÉDICINALES ET VÉNÉNEUSES}

Les connaissances que possède l'homme dans cette partie de la botanique n'ont pas été acquises sans dangers. Tout ce que savaient les Grecs de l'antiquité sur les plantes médicinales est résumé dans les écrits de Dioscoride et de Théophraste; la botanique médicale du moyen âge nous est connue par les ouvrages d'Hildegard, d'Albertus Magnus et des auteurs arabes. Paracelse, au XVt ${ }^{\circ}$ siècle, émit l'idée, qui a été appliquée de nos jours, d'extraire des plantes la quintessence, c'est-à-dire les principes actifs; mais il fut aussi le propagateur de la théorie mystique de vertu signative, d'après laquelle, en raison d'une correspondance mystérieuse entre le monde extérieur et l'organisme, les médicaments sont désignés à l'avance par leur structure ou leur ressemblance avec quelque partie du corps : la tête de Pavot, par sa forme, doit avoir une action sur la tête de l'homme; l'Hépatique doit guérir les maladies de foie, parce que ses feuilles trilobées ont, lorsqu'elles sont jeunes, la couleur brune du foie; la Pulmonaire, pour une raison analogue, convient aux maladies de poitrine, et la Ficaire, aux hémorroïdes, parce que certaines de ses racines, renfées en forme de figue, en évoquent un peu l'aspect, etc. On dira plus tard que l'action du café sur le cerveau est tout indiquée dans la forme de sa graine qui rappelle celle de cet organe. Ces singulières idées eurent cours jusquau début du $\mathrm{Xt} \mathrm{X}^{\mathrm{C}}$ siècle. Elles se relient certainement à la théorie des simulacres de Pline, des ébauches d'Empédocle et des mycéniens dont il sera parlé plus loin.

Les plantes médicinales tiennent une place considérable dans les magies et les sorcelleries de tous les peuples, soit pour les conjurations et les maléfices, soit, au contraire, pour les philtres; elles jouent également un rôle comme tal ismansou amulettes. L'Ail doré de nos jardins, le Moly d'Homère, n'avait pas son pareil pour préserver des maléfices et des enchantements. La Mandragore officinale (fig. 338) est une Solanacée à racine courte et grosse, souvent bifurquée, ayant vagusment l'aspect d'une sorte de poupée; nulle plante n'a joué un rôle aussi grand en sorcellerie. D'après Matthiole, cétait une profession en Italie que de compléter la ressem. blance humaine des organes souterrains de cette plante par un travail de sculpture et même certains individus fabriquaient de fausses racines de Mandragore avec des racines de Bryone.
Les plantes vénéneuses; leurs utilisations. - Entre une plante vénéneuse et une plante médicinale, il ny a d'autre différence qu'une question de dose. La sensibilité de l'organisme dans lequel pénètrent les poisons végétaux est aussi très variable pour chacun d'eux. Les insectes et leurs larves attaquent une foule de plantes vénéneuses pour l'homme; les limaces ne sont nullement incommodées par les Amanites les plus redoutables; le Persil, le Céleri et le Safran sont toxiques pour beaucoup d'oiseaux; les canards, les poules et les pigeons ne sont pas empoisonnés par l'ingestion d'opium; le calao mange la noix vomique; les souris, les graines d'Ivraie, de Datura ou de Ciguë. Alors que le lapin est empoisonné par la Mercuriale vivace, plante également redoutable pour le bétail et notamment pour les moutons, il peut ingérer sans inconvénient des quantités de feuilles ou de fruits de Belladone qui seraient susceptibles de tuer plusieurs hommes; on l'empoisonne cependant par injection intra-veineuse du suc de la plante.

Depuis des millénaires, la médecine tire parti des poisons végétaux. En Grèce, la Grande Ciguë était la plante justicière; les condamnés à mort buvaient le suc de cette plante, probablement additionné d'opium. Beaucoup de plantes vénéneuses servaient aux épreuves judiciaires. L'une des plus célèbres est une Asclépiadacée, le Tanghin vénéneux (Menabea venenata) [fig. 324], arbre de Madagascar dont le fruit renferme une graine toxique. On avait recours à ce poison d'épreuve dans le cas de sorcellerie, dans les complots contre l'État; on croit que les Hovas l'ont employé pour assurer leur prépondérance et ont fait périr ainsi plus de 100000 sujets. Ils l'utilisaient de même dans les procès civils, mais alors, pour simplifier les choses, chaque partie était autorisée à se faire représenter par son chien, auquel on administrait le poison; le plaideur dont le chien succombait perdait son procès.

L'écorce d'une Légumineuse, le Tali ou Bondou (Ervthrophlceum de Guinée), la fève de Calabar (Phýsostigma vénéneux) [fig. 325] ont été employés comme poisons d'épreuve par certaines peuplades d'Afrique; la première renferme un alcaloïde qui agit sur le cour à la façon de la Digitale; la seconde, un alcaloïde qui paralyse les muscles à la façon du curare. 
Nombre de plantes vénéneuses sont célèbres comme poisons de flèches pour la chasse ou la guerre. Le plus fameux est le curare des Indiens de l"Amazone, de l'Orénoque et des Guyanes; il provient des extraits de divers Strychnos; les indigènes d'Amérique utilisent aussi les fruits de Paullinia. L'extrait aqueux des graines ou des racines des Strophantes ( fig. 326) a les mêmes usages dans tout l'ouest africain; les Somalis emploient comme poison de flèche le suc de divers Adenium; les indigènes des régions africaines subdésertiques, celui des Euphorbes cactiformes; les Malais, celui de l'Upas antiar (Antiaris toxicaria)[fig.327];

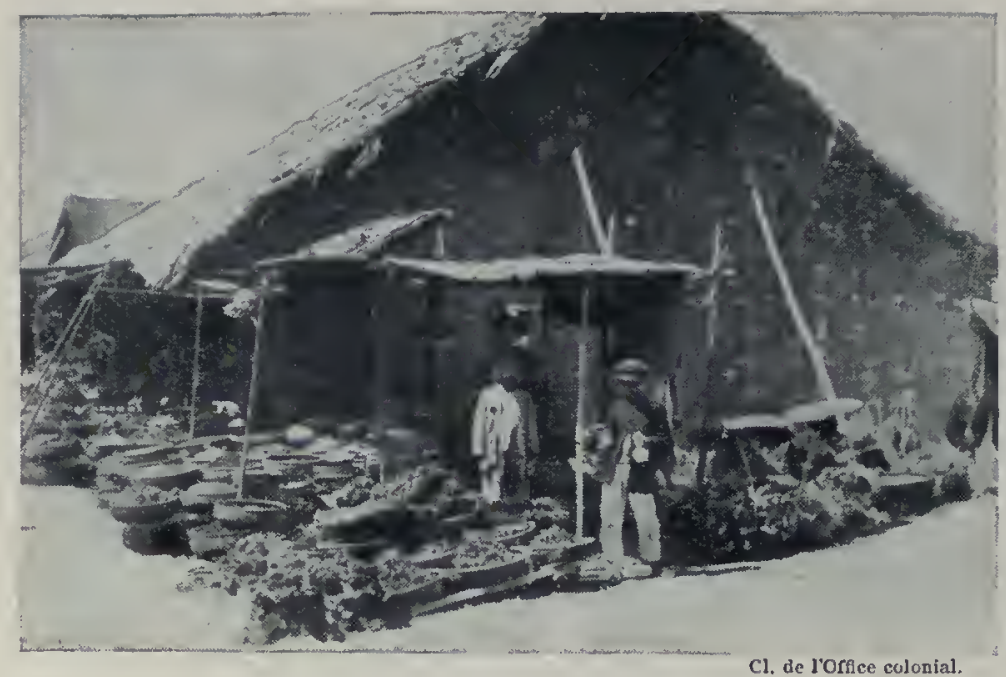

Un marché aux drogues, en Indochine. du Pêcher sont vénéneuses pour le bétail.

Les Cucurbitacées dangereuses sont la Coloquinte, et la Bryone par ses racines et ses fruits dont quinze suffsent à tuer un enfant. Les Ombellifères nous fournissent un lot malfaisant: les Enanthes et les Ciguës. L'Enanthe safranée est commune dans le marais poitevin; sa racine, arrachée et jetée sur le sol au moment où l'on refait les fossés, détermine de nombreux empoisonnements du bétail. L'CEnanthe phellandre ou Ciguë aquatique est aussi dangereuse; cependant sa toxicité est faible au printemps. Quant aux Ciguës, on en distingue trois : $]^{\circ}$ la Grande Ciguë ou Ciguë tales indigènes du Kamtchatka utilisent le suc d'Anémone, etc.

De même qu'il y a des poisons de chasse, il existe des poisons de pêche, comme l'Anamirte Cocculus, liane de l'Inde dont les fruits très toxiques, de la grosseur d'un pois, sont les coques $d u$ Levant. Certains braconniers, véritables malfaiteurs, lancent dans les rivières une pâte dans laquelle entre ce fruit; les poissons qui ont goûté à cette mixture montent, étourdis, à la surface de l'eau et peuvent être facilement capturés; la consommation en est dangereuse si l'intestin de l'animal n'a pas été enlevé aussitôt. Les fruits des Paullinia, la Téphrosic toxique et diverses Euphorbes servent au même usage.

Plantes vénéneuses indigènes. - Dans nos bois et nos champs vivent quelques espèces empoisonneuses qu'il est utile de connaître. Nombre d'accidents mortels sont causés chaque année par des Champignons du groupe des Amanites, des Volvaires, des Entolomes ou par des fruits vénéneux, charnus, de couleurs vives, qui attirent l'attention des enfants, et sont mangés par eux. Toutes nos Renonculacées renferment des principes âcres, irritants, vésicants même; il faut se méfier des Renoncules ou Boutons d'or, des Clématites, des Anémones, des Ellébores et surtout de l'Aconit. Les Pavots des jardins sont des plantes à opium; de même le Pavot Coquelicot, et lorsque ce dernier est abondant dans un champ il peut empoisonner le bétail qui mange la paille à laquelle il est mêlé. La Chélidoine, des terrains vagues, laisse écouler, quand on la froisse, un latex très vénéneux, employé jadis pour brûler les verrues. Les Rosacées sont, pour la plupart, des plantes à acide cyanhydrique : le Cerisier laurier-cerisier est très toxique et on a toujours tort d'employer ses feuilles comme

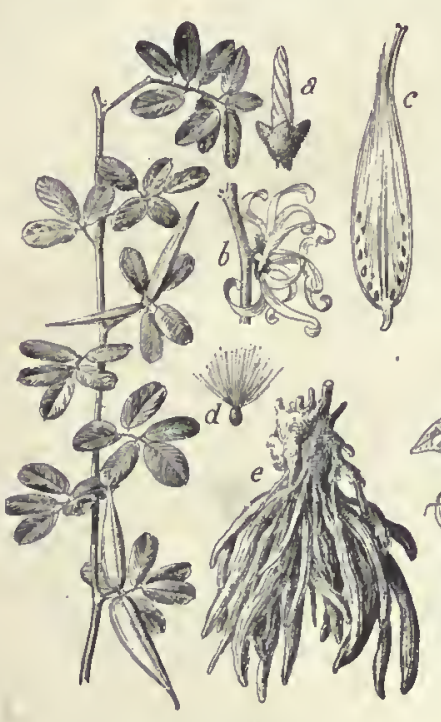

Fig. 324.

Tanghin vénéneux. $a$, Bouton: $b$, Fleurs; $c$, Fruit ouvert; $d_{1}$ Graine; $e_{1}$ Racines. condiment; on a des exemples d'empoisonnements d'enfants ayant mangé une trop grande quantité des amandes amères contenues dans nos fruits à noyau; les branches et les feuilles chetée (Conium) des lieux incultes, qui atteint 2 mètres de haut et ne peut se prêter à aucune confusion; $2^{\circ}$ la Ciguë vircuse ou Cicutaire des marais, dont les feuilles écrasées ont une odeur repoussante; sa racine, qui rappelle celle du Céleri, a souvent causé mort d'homme; $3^{\circ}$ enfin, la Petite Ciguë ou Faux persil (Ethusa cynapium), surtout dangereuse parce qu'elle croit souvent dans les jardins et, dans son jeune âge, ressemble au Persil; elle sen distingue cependant par l'odeur désagréable de ses feuilles froissées entre les doigts, par les taches brunes ou lie de vin de la base de sa tige, par ses fleurs blanches et non d'un jaune verdâtre, ses involucelles unilatéraux et pendants à deux ou trois pièces.

Toutes les Solanacées, même celles qui sont alimentaires, renferment dans l'un ou dans l'autre de leurs organes des principes vénéneux; les plus dangereuses sont le Datura, la Jusquiame et surtout la Belladone, à cause de ses baies noires et brillantes. Parmi les Scrofulariacées, la jolie Digitale est extrêmement vénéneuse; la Gratiole, les Linaires et les Pédiculaires sont suspectes. Le Colchique d'automne, dont les feuilles sont communes dans les prés en avril et les fleurs en septembre, est très vénéneux par toutes ses parties; ses feuilles nuisent à la qualité du foin. Les fruits rouges de l'Arum, du Chèvrefeuille et du Muguet, ceux des Daphnés; toutes les Euphorbiacées et la Rue du midi de la France sont toxiques. Parmi les arbustes les plus dangereux, soit pour l'homme, soit pour le bétail, il faut citer le Laurier-rose, l'If, l'Acacia jaune ou Cytise aubour, le Buis, le Genêt d'Espagne ou Spartier à tiges de Jonc, l'Ailante, les Sumacs. Les graines de la Nielle des blés et celles de l'Ivraie enivrante, mélangées au Blé, peuvent déterminer des empoisonnements par le pain.

Poisons pruritants. - Quelques végétaux, inoffensifs lorsqu'on ne les touche qu'en passant, déterminent chez les ouvriers qui les manipulent fréquemment une vive irritation de la peau, accompagnée de rougeur, de démangeaison, de manifestations eczémateuses. Le latex du Figuier commun irrite le poignet lorsqu'on cueille les fruits de cet arbre; les Conifères, par les térében- 


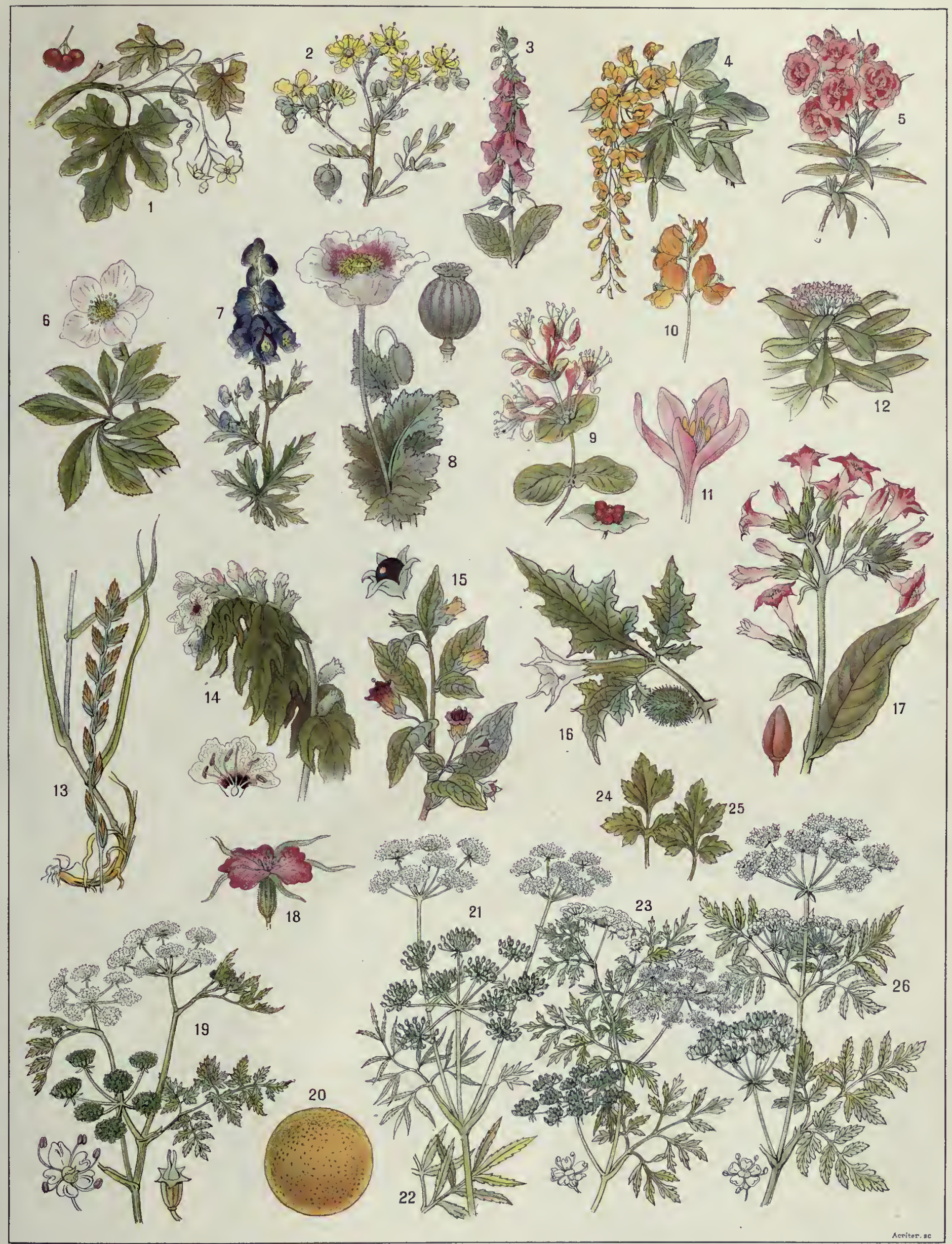

PLANTES VÉNÉNEUSES

1. Bryone dioïque ef fruit. -2 , Rue et fruit, - 3. Dígitale pourpre. -4 . Cytise Aubour, $\rightarrow 5$. Laurier-rose. -6 . Ellébore noire. -7 . Aconit napel. -8 . Pavot et fruit. 9. Chévrefeuille et fruit - 10. Genêt d'Espapne - 11. Colchique d'antomne - 12. Daphné garou - 13. Ivraie enivrante - 14. Jusquiame noire et fleur. - 15. Belladone et fruit, - 16. Datura stramoine. - 17. Tabac et fruit, -18 . Nielle des blés. -19 . Enanthe phellandre, fleur et fruit, -20. Coloqutnte (fruit). -21 . Cífuë . vireuse. 22. Ciguë vireuse, feuille de la base. - 23. Petite ciguë et fleur. -24 . Persil, feuille de la base, -25 . Petite ciǵuë, feuille de la base, -26 . Grande ciguë et fleur. 



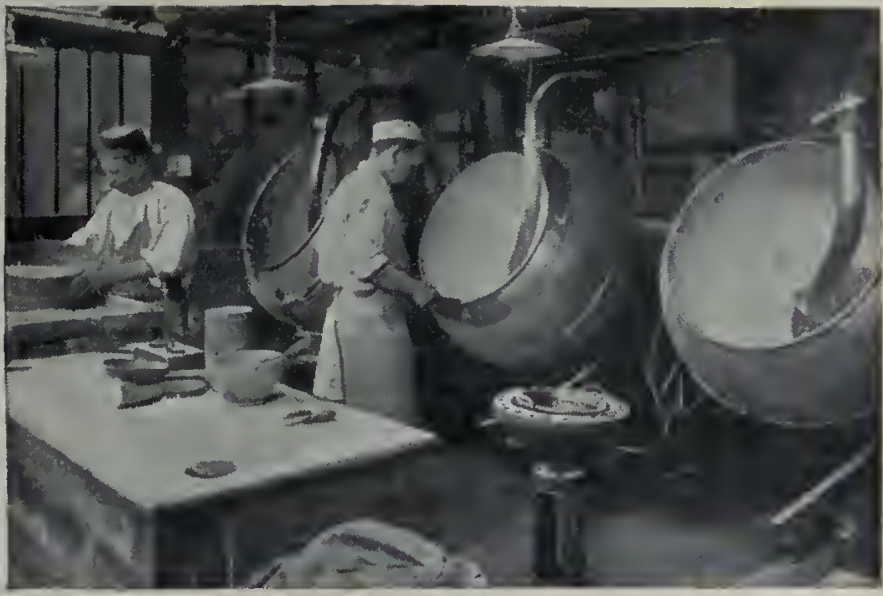

Fabrication des dragées médicinales.

thines qu'ils contiennent, agissent de même. En élaguant l'Ailante, les jardiniers peuvent attraper des pustules au visage et aux mains. Les ouvriers occupés au triage des bulbes de Jacinthe, des gousses de Vanille, à la récolte du Houblon, à l'emballage des pêches, ceux qui manient les artichauts ou les racines de Panais, les jardiniers qui cultivent la Primevère de Chine, les hommes qui pulvérisent la racine d'I péca ou manipulent les écorces de Quinquina sont souvent atteints de ces dermatites. Elles sont dues soit à la pénétration de fines aiguilles d'oxalate de chaux, soit à des poils rigides, soit à des essences ou autres principes irritants.

Les Plantes médicinales. - 11 règne encore beaucoup de préjugés sur les plantes médicinales. D'une part, des vertus innombrables sont attribuées à des espèces bien innocentes; d'autre part, on emploie souvent à tort et à travers, principalement dans les campagnes, des simples qui provoquent de graves accidents. On sait, par exemple, que les fleurs de Genêt sont purgatives : on prendra indifféremment celles du Genêt à balai, du Genêt des teinturiers ou du Genêt d'Espagne; toutes contiennent des substances très actives, mais en quantités fort inégales; les fleurs du Genêt d'Espagne (Spartium junceum) et surtout du Genêt purgatif (Cytisus purgans), gui sont les plus chargées en principes toxiques, déterminent parfois des empoisonnements.

Il $\mathrm{y}$ a cependant de bonnes plantes indigènes très utiles. On les trouve dans les champs ou dans les bois, comme la Mauve, la Guimauve, le Chiendent, le Lierre terrestre, le Lamier blanc, le Fraisier sauvage, la Tormentille, le Tussilage, la Pariétaire, la fleur de Tilleul, les cônes de Houblon, la feuille de Ronce, de Frêne ou de Noyer, ou on les cultive dans un coin du jardin, comme l'Ache, la Camomille (fig. 328), la Chicorée, la Bourrache ou la Menthe.

Dans quelques villes, surtout à l'étranger, un emplacement spécial est réservé sur les marchés aux vendeurs de plantes médicinales.

L'industrie des plantes médicinales. - Une culture rationnelle accroît la valeur des plantes médicinales : à Java, les Hollandais sont arrivés par une sélection savante à produire des écorces de Quinquina ayantl'énorme teneur en quinine de 16 pour 100. Pendant le séchage dessimples, leurs principes constituants se modifient sous l'action des ferments; il existe des différences notables dans le mode d'action de la même plante fraîche ou sèche. En plaçant les plantes dans un autoclave, en présence de la vapeur d'alcool, après les avoir incisées, on les stérilise

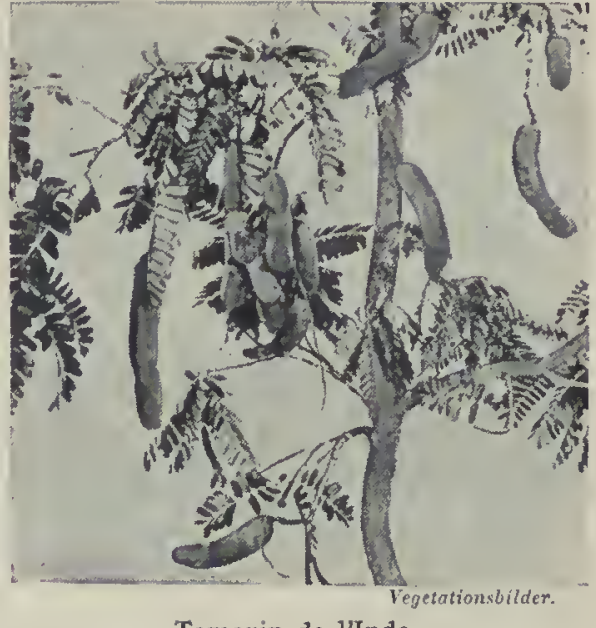

Tamarin de l'Inde. et elles peuvent conserver sans altération tous leurs éléments actifs.

Une plante médicinale renferme généralement plusieurs principes, dont l'un est dominant, mais dont l'ensemble agit. Au début du $\mathrm{XIX}^{\mathrm{e}}$ siècle, les progrès de la chimie ont permis d'extraire ces principes : quinine, morphine, digitaline, etc., qui ont l'avantage de pouvoir être parfois exactement dosés, tandis que la plante en renferme des doses variables suivant son habitat et l'époque de sa récolte. La composition de la digitaline, cependant, est bien incertaine et varie avec le mode de préparation; aussi n'est-elle pas admise par la pharmacopée anglaise. On revient cependant aujourd'hui à l'emploi des plantes, tout au moins sous forme de teintures et d'extraits qui en renferment tous les principes utiles.

Depuis 1880, les plantes médicinales, comme les plantes à parfum, sont, dans une certaine mesure, concurrencées par les médicaments de synthèse se préparant aujourd'hui par tonnes, comme l'antipyrine, le pyramidon, l'arrhénal, la stovaïne qui est un succédané de la cocaïne, etc. Quelques plantes médicinales s'utilisent en nature sous forme de tisanes, infusions, lotions, cataplasmes, etc.; le plus souvent, elles ne sont que la matière première d'où l'on extrait le médicament sous la forme pure d'alcaloïde, de glucoside, etc., ou encore de teinture, de vin, sirop, pâte, poudre. C'est là une importante industrie qui prépare d’innombrables produits, depuis les crayons antimigraine, mélange de paraffine et de menthol, jusquaux capsules, cachets, tubes d'étain à vaseline saturée de matière médicamenteuse, etc.

Pour préparer les pastilles, on triture le médicament et du sucre en poudre avec de l'eau gommée; la pâte obtenue est transformée en une galette rectangulaire qu une machine découpe et estampe. Pour faire des pilules, la matière active est mélangée avec un excipient de nature variable : gomme arabique, sucre, poudre de réglisse, huile, miel, etc., et triturée jusqu à consistance convenable, puis placée dans un pilulier à main, composé de deux pièces en bois portant chacune une règle métallique creusée de cannelures, dans lesquelles on enferme la pâte, puis l'on presse. Les pilules sont ensuite disquées dans un plateau sous la pression légère d'un disque et deviennent sphériques. Dans la grande industrie pharmaceutique, le pilulier à main est remplacé par un pilulier méca-

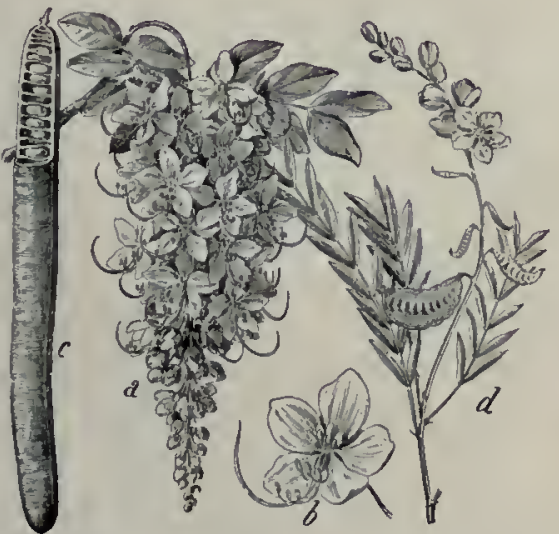

Fig. 329. - Casse.

$a$, Fistuleuse ; $b$, Fleur ; $c$, Fruit. $-d$, Lancéolée

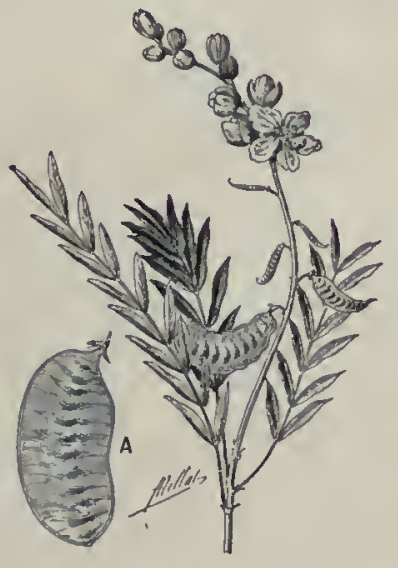

F:g. 330. - Séné. $a$, Fruit

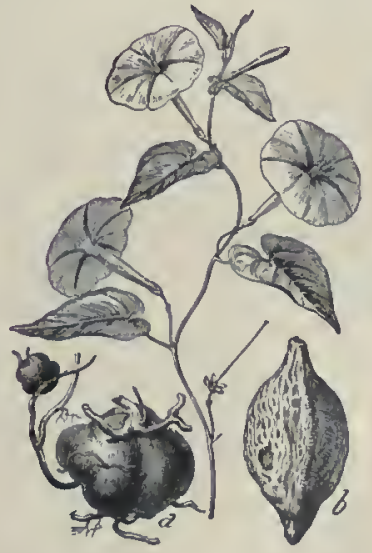

Fig. 331. - Jalap. $a$. Racine ; $b$, Fruit.

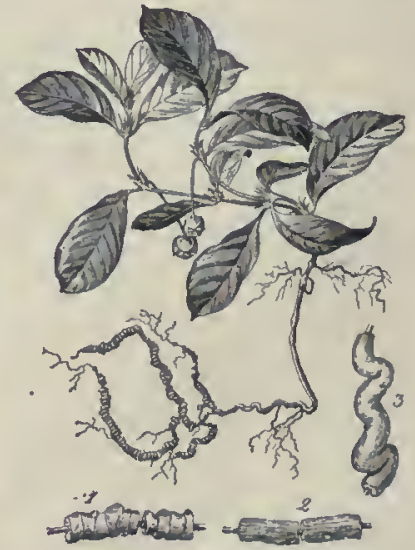

Fig. 332. - Ipécacuánha. 1, Annelé ; 2, Striẻ ; 3, Ondulé. 
nique ou magdaléonier, permettant à une ouvrière habile de fabriquer 100000 pilules par jour. Les dragées médicinales sont des pilules recouvertes de sucre comme les amandes en confiserie.

Légumes et fruits médicamenteux. - On peut accroítre la quantité des principes thérapeutiques utiles contenus dans les plantes par des arrosements appropriés. En 1860, Champouillon,

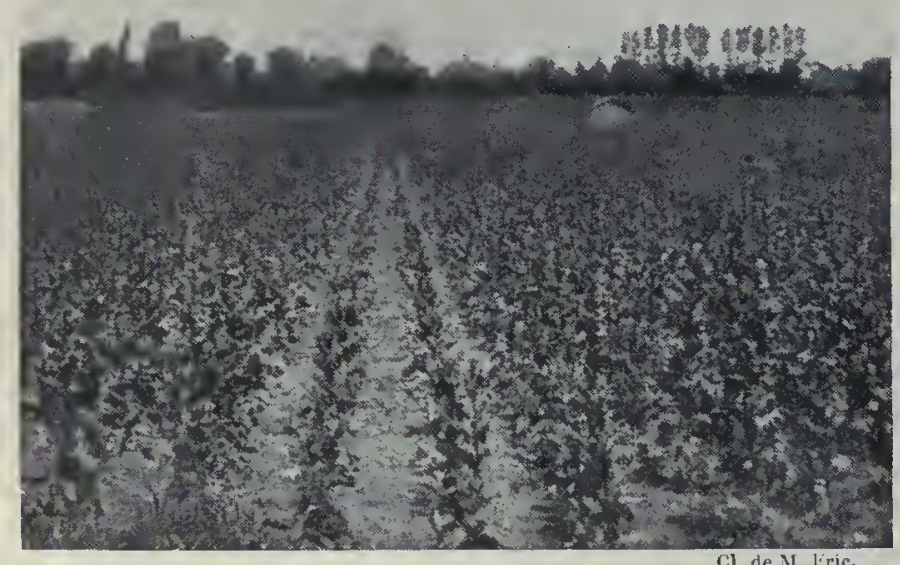

Culture de la Laitue vireuse.

en arrosant des Vignes et des Fraisiers avec de l'eau contenant du nitrate et du carbonate de potassium, a obtenu desfruits doués d'un pouvoir diurétique considérable. Cette méthode est recommandable quand il s'agit de sels de fer, si utiles pour le traitement de l'anémie et absorbables difficilement par l'organisme sous leur forme habituclle. Les Epinard's ferrugincux, obtenus à l'aide d'arrosements et de modifications dans la composition du sol, contiennent jusqu'à sept fois plus de fer que les Épinards ordinaires; ils font l'objet d'une culture spéciale aux environs de Vienne, en Autriche. La racine pulvérisée du Rumex crépu, accrue en fer par arrosements, est aussi un excellent ferrugineux employé dans les cas d'anémie et de chlorose.

Purgatifs et vomitifs. - Les végétaux fournissent à la médecine une série fort complète de purgatifs, depuis les fruits rafraîchissants comme pruneaux ou raisins frais, les graines légèrement laxatives comme celles d'Orge ou de Lin, jusqu'aux principes les plus énergiques, tels que le Jalap et la Scammonée. Les Rhubarbes sont de grandes herbes dont certaines espèces sont cultivées en Europe commes plantes potagères; le produit pharmaceutique est la racine de la Rhubarbe officinale ou celle de la Rhubarbe palmée, variété de Tangut, découverte par Prejwalsky, espèces exportées de Chine. On récolte les racines à l'âge de quatre ou cinq ans; elles pèsent jusqu'à 10 kilogrammes; on les sèche, on les écorce et on les coupe en fragments qu'on enfile en chapelets; elles constituent un laxatif doux, purgeant sans coliques.

Les graines du Ricin commun donnent une huile qui, exprimée à froid, n'est pas purgative, et qui l' est, au contraire, lorsqu' elle a été obtenue à chaud; elle n’a qu'un seul inconvénient : sa saveur désagréable. La plus grande partie des graines employées dans les pharmacies vient de l'Inde ou de Syrie. Quant aux graines, elles sont toxiques et il serait dangereux d'en broyer deux ou trois et de les ingérer sous prétexte de purgation.

Les Casses habitent les régions chaudes du globe, surtout l'Amérique; elles renferment des principes purgatifs connus et employés de temps immémorial. La Casse fistuleuse (fig. 329) est un arbre dont le fruit est une longue gousse ligneuse; ses graines sont entourées par une
pulpe d'un brun rougeâtre qui

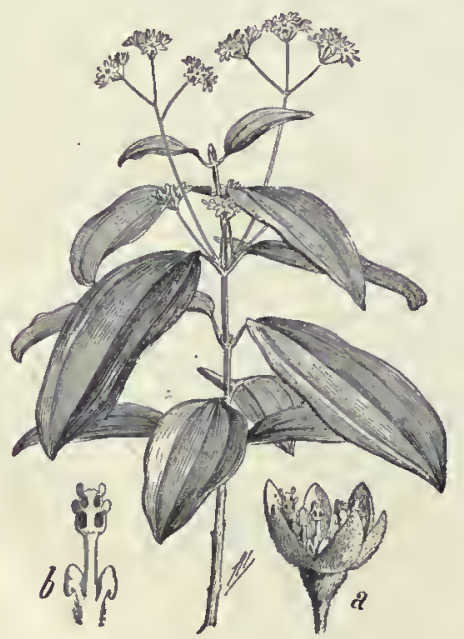
Fig. 333. - Cinnamome eamphrier. $a$, Fleur; $b$, Etamine. constitue la casse mondée qu'on emploie comme laxatif doux, tandis que les feuilles et les fruits de la Casse à feuilles aiguës d'Égypte et de plusieurs autres espèces ( $C$. angustifolia, obovata) constituent le séné des pharmaciens (fig. 330), qui est un purgatif très énergique. La pulpe de la gousse d'une autre Légumineuse, le Tamarin de l'Inde (Tamarindus indica), est un laxatif doux.

L'Amérique du Nord fournit aux officines la cascarine, matière cristallisable retirée de l'écorce d'un Nerprun (Rhammus purshiana), qui est connu dans son pays d'origine sous le nom de Cascara sagrada ou écorce sacrée; la même contrée fournit aussi le podophyllin, résine contenue dans le rhizome d'une Berbéridacée, le Podophylle pelté. La manne est un purgatif doux pour les enfants; on l'obtient en Calabre et en Sicile d'incisions pratiquées sur le Frêne orne.

Les Aloès, qu'il ne faut pas confondre avec les Agaves, sont des Liliacées à feuilles charnues, originaires de l'Afrique tropicale et introduites dans beaucoup de contrées chaudes; de leurs feuilles récemment coupées, s'écoule un suc qu'on évapore sur le feu ou

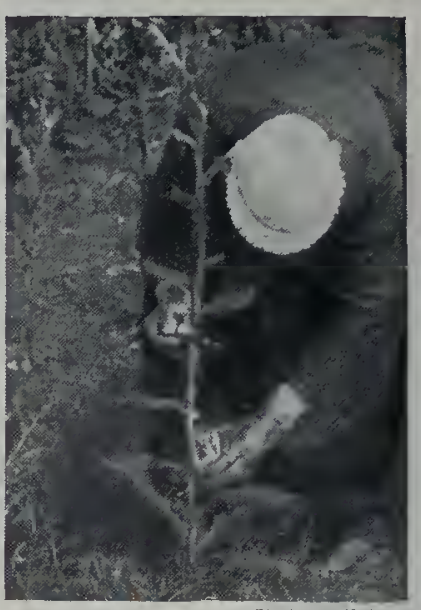

C1, Marcellet. au soleil et qui est l'aloès du commerce; il renferme un principe très actif, l'alö̈ne, accompagné d'une résine. Les espèces principales à aloès sont : l'Aloès vrai (nord de l'Afrique, Madère, Canaries), l'Aloès des Barbades, l'Aloès de Perry (Socotora).

Le jalap (fig. 33l) et la scammonée sont des résines extraites des racines de deux Convolvulacées: la première est une Exogone du Mexique; la seconde, une sorte de Liseron d'Orient; ce sont des purgatifs violents qui entrent dans la composition de l'eaude-vie allemandé. Les fleurs des Genêts, la racine de la Bryone et les fruits de la Coloquinte sont des purgatifs indigènes d'un maniement dangereux.

La racine d'une Rubiacée du Brésil, le Cephalis ipecacuanha (fig. 332), possède des propriétés émétiques qui la placent au premier rang des médicaments vomitifs. On falsifie ce produit avec la racine d'une Violacée, l'Ionidium Ipecacuanha; la racine de notre Violette indigène est douée de propriétés analogues.

Les astringents. - Les plantes riches en tanin déterminent le resserrement des tissus et diminuent la sécrétion intestinale. $\mathrm{La}$ gelée de coings, les nèfles, les feuilles de Chêne, de Ronce, d'Arbousier, de Noyer, le brou de noix, la racine de Fraisier, les pétales de la Rose de Provins sont les plus employés. Les cachous, la racine de ratanhia du Pérou (Krameria triandre) ou du Colombo (Jatrorrhize Colombo) de l'Afrique tropicale sont des remèdes des plus énergiques. La décoction d'écorce de Chêne est un contrepoison des sels de plomb, de cuivre et d'antimoine.

Les calmants. - L'eau de fleurs d'Oranger et les fleurs de Tilleul sont des calmants très populaires, sans danger et fort utiles ;

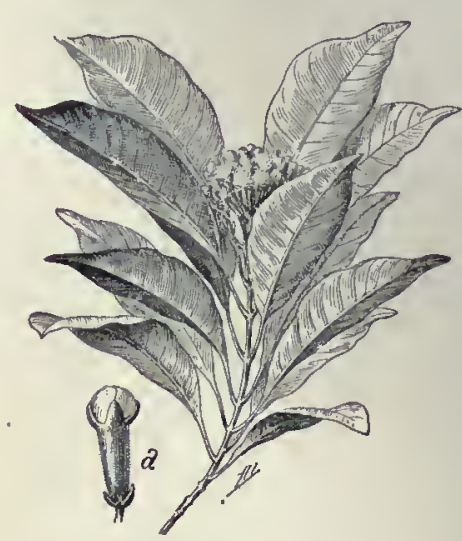

Fig. 334. - Giroflier. $\alpha$, Bouton dit : Clon de Girofle. le Tilleul fait l'objet d'un commerce important : les sortes les plus estimées sont celles du Dauphiné, de Suisse, d'Italie, du Tyrol. Le roi des calmants est l'opium, latex desséché du Pavot somnitère à graines blanches, cultivé en Perse, en Egypte, dans l'Inde et en Chine. On en retire plusieurs alcaloïdes : la morphine, la codéine, la thébaïne, etc.; ce sont des narcotiques précieux pour calmer la douleur, mais des poisons redoutables. IIs entrent dans une foule de préparations dites opiacées : laudanum, sirop diacode, pilules, etc.
On utilise la morphine en in- 


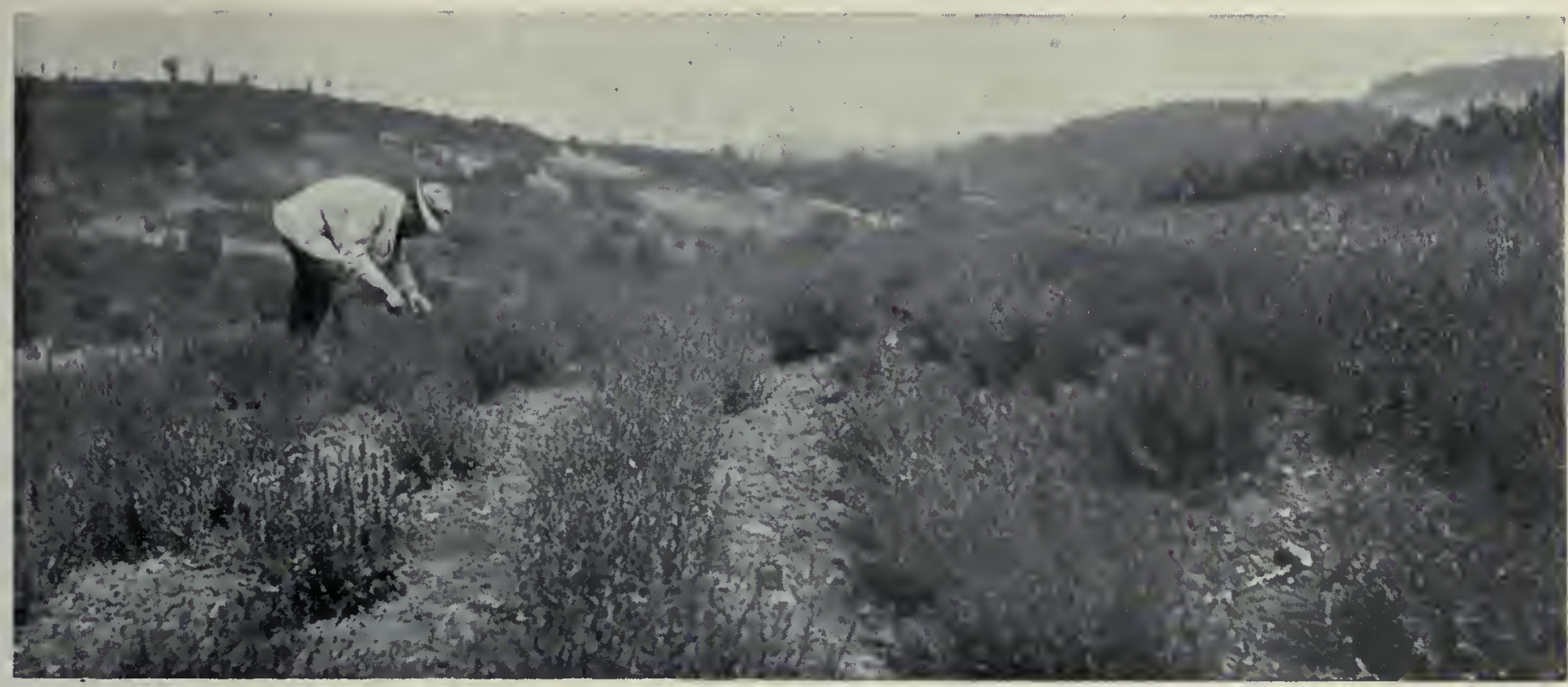

Un champ d'Hysope, dans le Var.

jections sous-cutanées. L'emploi de l'infusion de têtes de Pavot pour calmer les enfants est une pratique presque criminelle qui cause de nombreux empoisonnements.

Le lactucarium ou opium de Laitue est le latex obtenu à l'aide d'incisions pratiquées sur les tiges des Laitues cultivées ou sauvages montées; c'est un calmant, ainsi que l'eau de laitue et la thridace. obtenues par distillation; la culture des Laitues pour cet usage médicinal se pratique en grand aux environs de ClermontFerrand. L'eau de Laurier-cerise est un poison violent, renfermant de l'acide cyanhydrique; elle calme la toux; son emploi, même par les médecins, exige la plus grande prudence.

Lc camphre, dont Raspail a voulu faire une panacée, est une substance toxique à dose un peu forte, bien que son action soit fort complexe; on l'utilise à l'extérieur comme antiseptique, à l'intérieur comme calmant. On l'extrait du bois de Cinnamome camphrier (fig. 333), arbre superbe qui constitue à Formose d'immenses forêts vierges, abonde dans diverses îles du Japon et dans la Chine méridionale. On l'a introduit aux Indes; à Ceylan, en Floride et au Texas, la culture du Camphrier occupe des milliers d'hectares. On abat les arbres de quarante à cinquante ans; le bois débité en copeaux est mis dans un alambic, avec de l'eau dont la vapeur entraîne le camphre; celui-ci doit être raffiné. Les deux tiers de la production camphrière servent à la fabrication du celluloïde: le reste est utilisé en pharmacie. Depuis 1905, on fabrique du camphre de synthèse en partant soit de l"essence de térébenthine, soit du bornéol ou camphre de Bornéo, extrait du Dryobalanops aromatique; il entre en concurrence avec le camphre naturel, mais seulement pour la fabrication du celluloïde.

La racine de la Valériane officinale ou Herbe-aux-chats est employée en infusion, comme antinerveuse; on lui préfère aujour-

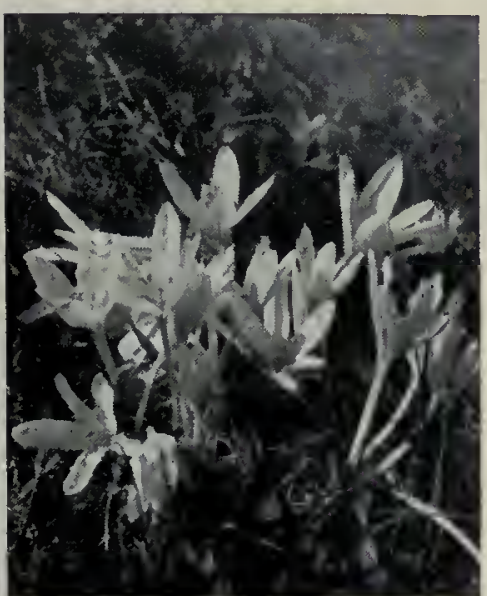

Colchique d'automne. d'hui les valérianates de quinine ou de zinc. On peut ranger aussi, dans les calmants, les adoucissants et les émollients, comme la racine de Guimauve, utilisée en -lavements ou en gargarismes, tandis que des feuilles on fait des cataplasmes; la graine de Lin : les figues agissent aussi par leurs matières mucilagineuses. Le suc de Concombre, utilisé en pommade, est adoucissant et émollient; de même, l'infusion defleurs de Surcau est regardée comme vulnéraire et résolutive. Les clous de girofle entrent dans la préparation du laudanum; lessence de girofle est un calmant des dents; on emploie aussi comme odontalgique l'extrait de la racine du Pyrèthre d'A frique (Anacycle purèthre), commun en Algérie, le Spilanthe potager ou Cresson de Para (Composée), le Clavalier frêne (Zanthoxyle), dont l'écorce mâchée calme les douleurs; c'est l'Arbre au mal de dents des Américains.

Apéritifs, digestifs. - Les médicaments apéritifs sont les amers végétaux pris une demi-heure avant le repas; ils accroissent la sécrétion de la salive, des sucs gastriques et intestinaux. La noix vomique et la fève de Saint-Ignace ou leur principe actif, la strychnine, sont employés avec prudence pour exciter les contractions musculaires d'un estomac atone. Les copeaux de Quassia amara sont fournis par le bois d'arbustes habitant l'Amérique tropicale. Le Colombo (Jatrorrhiza), le Quinquina, et, parmi nos plantes indigènes, la Gentiane, le Houblon, la Chicorće sauvage, la Potentille tormentille, l'Oranger amer, la Petite centaurée, etc., sont aussi très employés. Les pseudo-apéritifs du commerce sont des combinaisons d'herbes amères avec des essences, des liqueurs sucrées et alcooliques qui masquent l'amertume du mélange, mais produisent un résultat inverse de celui quion désire.

Les médicaments digestifs ont pour rôle de stimuler le travail trop lent de l'estomac; on emploie surtout les infusions de plantes aromatiques : graines de Carvi, d'Anis vert, de Fenouil, de Coriandre, sommités fleuries de Menthe, de Romarin, de Mélisse, de Sauge, capitules de la Camomille, fruits de Badiane ou Anis étoilé. Les élixirs digestifs du commerce sont des macérations alcooliques de ces plantes.

Sur la côte occidentale d'Afrique, on fait un usage à peu près journalier du Piment enragé en lavements, en décoctions filtrées: il agit comme un excitant très puissant de la digestion en déter-

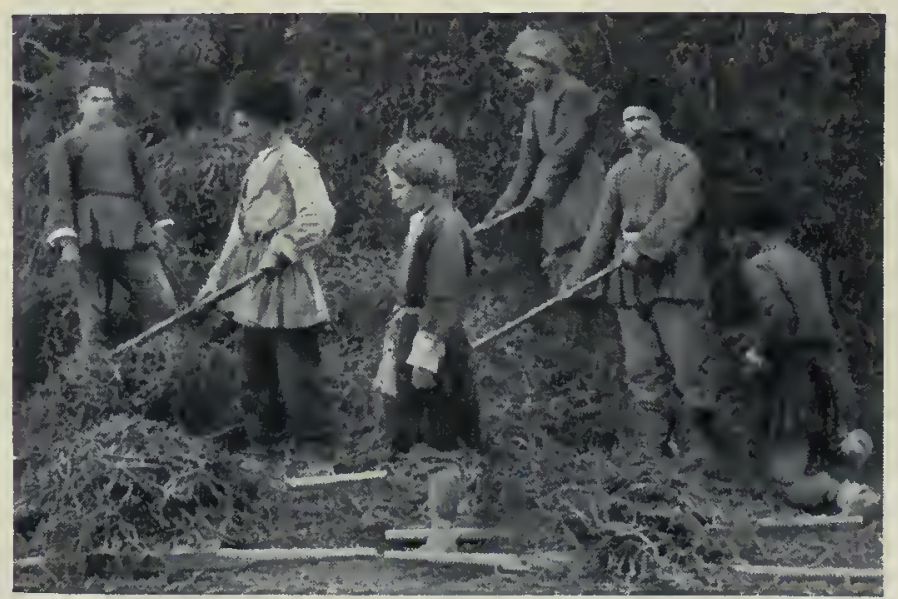

Récolte de la réglisse, dans le Caucase. 


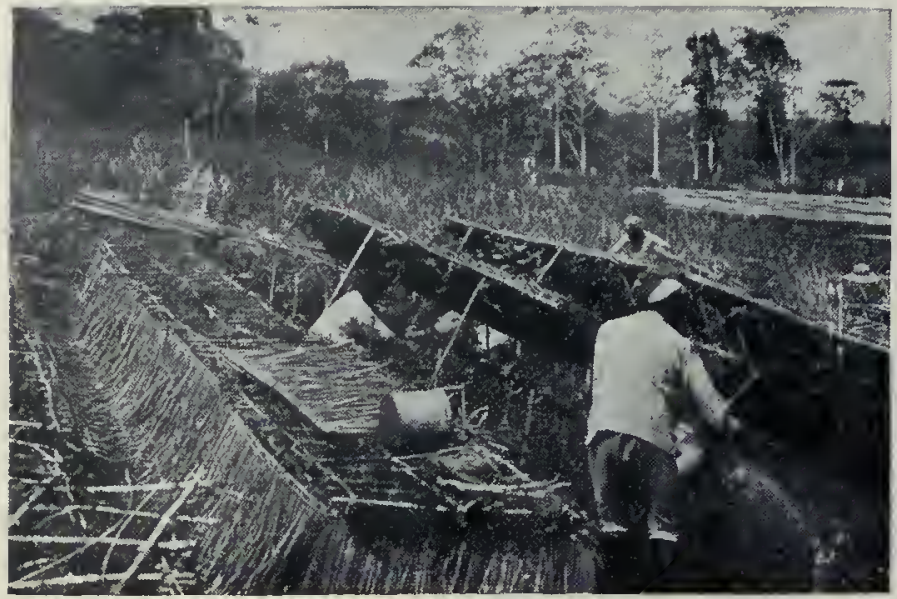

Repiquage du plant de Quinquina.

minant une hypersécrétion intestinale et ne paraît déterminer aucun effet fâcheux. Une calebasse trouée dans laquelle souffle un ami remplace l'instrument de Molière.

Dépuratifs : diurétiques, sudorifiques. - La racine de Salsepareille, qui provient de divers Smilax d Amérique, est le type des dépuratifs. Parmi nos plantes indigènes, beaucoup ont cette réputation plus ou moins justifiée, comme la Pensée sauvage, la Chicorée sauvage, le Cresson, la Fumeterre, le Houblon, le Chardon bénit (Cnicus) et la Carline.

Les diurétiques, c'est-à-dire les substances capables d'exciter la sécrétion urinaire, sont nombreux. Parmi nos plantes indigènes, il faut citer les queues de cerises, remède populaire très employé ; le Chiendent, la Polygale, l'Asperge, la Pariétaire, le Cerfeuil, la racine de Persil, les fruits du Coqueret, les fleurs de la Reine des prés ou Spirée ulmaire. Comme remèdes plus énergiques, que peut seul ordonner le médecin : la Scille maritime, le Colchique, la Digitale, la caféine et surtout la convallamarine, extraite du Muguet.

La plupart des diurétiques sont en même temps sudorifiques; mais on considère comme plus particulièrement douées de cette dernière propriété les fleurs de Bourrache et de Sureau, les rameaux ligneux de Douce-amère, les baies de Genièvre. La pilocarpine, alcaloïde extrait des Pilocarpus ou Jaborandi, de l'Amérique du Sud, a la propriété d'exagérer fortement toutes les sécrétions.

Plantes pectorales. - Les plantes pectorales sont réputées propres à guérir les rhumes et autres affections respiratoires. Les plus populaires sont les fruits pectoraux : dattes, jujubes, figues et raisins de Corinthe mélangés, et surtout les fleurs pectorales : mauve, violette, coquelicot, pied-de-chat, bouillon-blanc, tussilage et guimauve, dont les premières font partie de la fameuse tisane des quatre fleurs, chère à nos grand'mères, et qui entrent aussi dans les sirops, les pâtes pectorales, additionnées, il est vrai, de substances plus actives, comme l'opium et l'eau de Laurier-cerise.

Le rhizome de la Réglisse est utilisé en nature; on en prépare

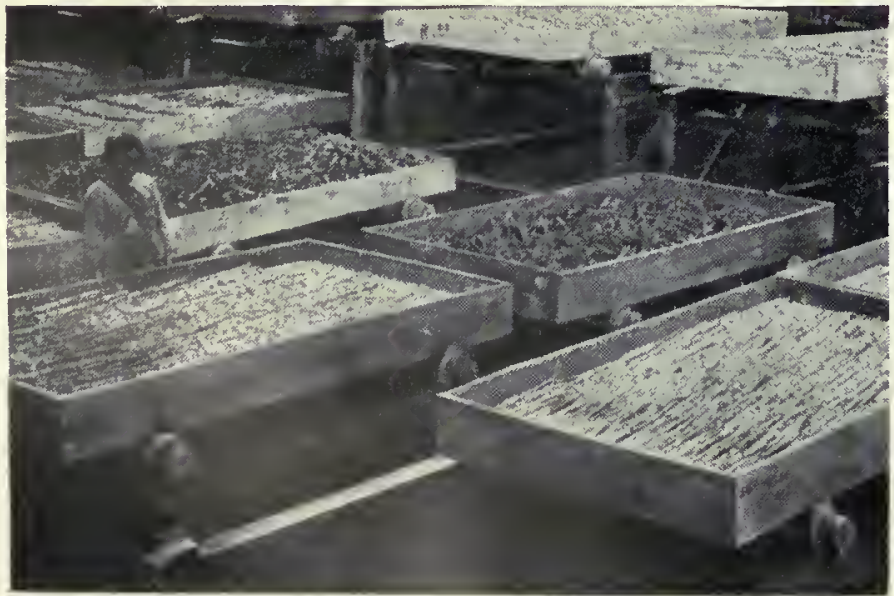

Séchage des écorces de Quinquina.

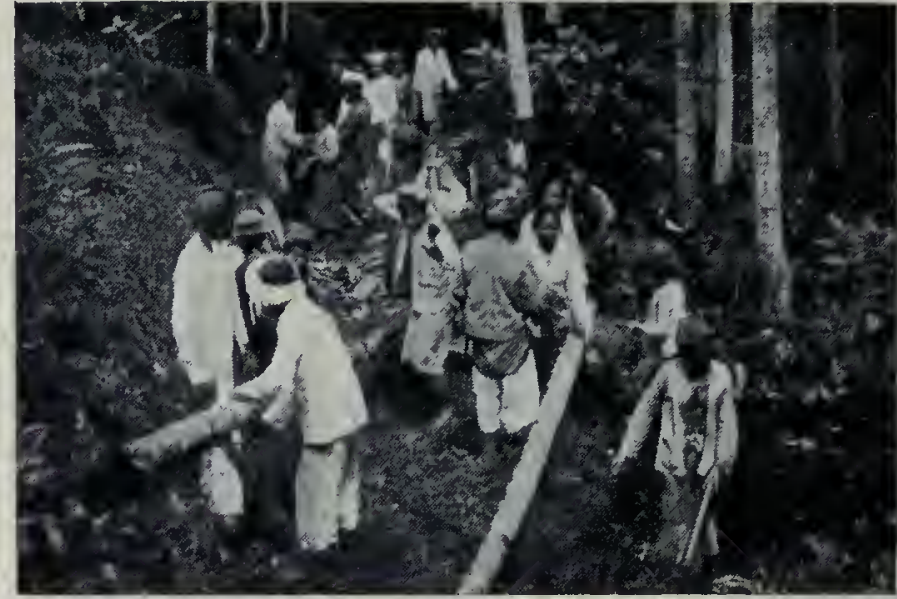

Récolte de l'écorce de Quinquina.

la boisson connue sous le nom de coco, et surtout on en extrait, principalement en Italie, le sucre noir ou sucre de réglisse, par ébullition prolongée du rhizome dans l'eau et évaporation du liquide. Cette plante est cultivée en France, à Bourgueil (Indre-et-Loire); en Floride, en Espagñe et surtout en Italie. Elle croít à l'état sauvage dans les plaines de la Russie méridionale, de l'Asie Mineure, de la Syrie et de la Mésopotamie, où elle est considérée comme une mauvaise herbe; on l'arrache chaque année avant le labourage du sol et son ensemencement en céréales. La ville russe de Tschartschui, puis Antioche, Alep, Bagdad et Damas sont les centres principaux du commerce de la Réglisse.

Les feuilles d'Eucalyptus, l'Hysope, les Grindelia (Composée de l'Amérique du Nord), la Capillaire du Canada (Adiantum pedatum) et la Capillaire de Montpellier (A. Capillus-Veneris), le Lichen d'Islande, le Chondrus crispé, ou mousse perlée des officines, qui n'est qu'une Algue de nos côtes, très riche en mucilage, sont aussi des plantes pectorales très usitées.

Les résines et les baumes agissent sur les muqueuses et facilitent l'expectoration; on emploie les bourgeons de Pin, l'essence de térébenthine, les baumes de Tolu et du Pérou.

Fébrifuges. - Le fébrifuge par excellence est l'écorce des Quinquinas, arbres dont il existe une trentaine d'espèces originaires des Andes, dans la portion qui s'étend entre $10^{\circ}$ lat. $\mathrm{N}$. et $19^{\circ}$ lat. S., à une altitude comprise entre 1100 et 2500 mètres. L'écorce de Quinquina, employée depuis des siècles par les Indiens d'Amérique, ne fut connue en Europe qu'en 1640. En 1820, Pelletier et Caventou en isolèrent la quinine. Les demandes croissantes du précieux remède amenèrent une exploitation si destructive des Quinquinas d'Amérique qu'on songea à introduire ces arbres dans différentes régions chaudes pour les cultiver et les exploiter de façon rationnelle.

En 1845, des graines envoyées par Weddell, botaniste français, furent semées au Muséum d'histoire naturelle de Paris et donnèrent des sujets qui, distribués gracieusement, furent plantés dans l'Inde anglaise, à Ceylan et à Java. Par hybridation et sélection, on est arrivé dans cette dernière île à obtenir des arbres, multipliés ensuite de greffe, dont l'écorce contient couramment 10 pour 100 , et même jusqu'à 16 pour 100 d'alcaloïde, alors que le Quinquina officinal des forêts des Andes n'en contient pas plus de 0,5 à 1 pour 100 .

Java possède aujourd'hui plus de 10 millions de Quinquinas. Comme le bois est sans usages, on enlève l'écorce par lanières, sans toucher au cambium, et une nouvelle écorce se reforme. Les quatre-vingt-cinq centièmes de la production mondiale en écorces de Quinquinas sont originaires de Java. Il existe dans le monde une vingtaine d'établissements, dont cinq en France, où l'on fabrique la quinine, le plus souvent sous forme de sulfate. On évalue à 500000 kilogrammes la production mondiale annuelle de ce médicament. L'écorce est de moins en moins employée en nature.

Les autres fébrifuges végétaux sont la salicine, tirée de l'écorce du Saule; l'esculine de l'écorce du Marronnier d'Inde, et aussi l'Eucalyptus, la Quassia amara, l'Erythrée petite centaurée de nos prés, et beaucoup d'autres amers.

Stimulants, toniques, reconstituants. - Le café, le thé, le maté, les boissons alcooliques à faible dose sont des stimu- 
lants du système nerveux; la cannelle et la vanille possèdent des propriétés excitantes accentuées; le quinquina, les amers sont des toniques.

Nous parlerons ici de la kola et de la coca, qui sont des aliments antidéperditeurs par excellence. La noix de Kola est la graine des Kolatiers, arbres de l'Afrique tropicale, dont il existe plusieurs espèces; la Cola acuminée est la plus généralement cultivée et donne presque toutes les noix commerciales. La Guinée française, la Côte d'Ivoire, le Dahomey, et surtout le Soudan anglais sont les centres les plus importants du commerce de cette substance. Les voyageurs depuis Lopez (1591) ont signalé le rôle important de la noix de Kola en Afrique, car plus de 20 millions de nègres la consomment comme masticatoire pour combattre la fatigue, la

soif, etc. Cette plante joue un rôle curieux dans les cérémonies religieuses, judiciaires, dans les mariages. Un Kola rouge signifie rupture; un Kola blanc signifie alliance. Le Kolatier est cultivé dans I'Inde, à la Jamaïque, à la Martinique et dans quelques autres régions tropicales, mais la production en est jusqu ici très faible.

Le Kolatier, qui peut vivre plus de cent ans, fleurit pour la première fois vers dix ans et est en plein rapport à vingt-cing ans. La plus grande partie de la production est consommée en Afrique. De petites quantités de noix fraîches parviennent en Europe. La noix de Kola renferme de la caféine, de la théobromine, de la kolanine, de l'amidon, etc. On l'emploie comme tonique puissant du cœur; c'est un antidéperditeur des forces; elle agit sur le système musculaire, diminue la fatigue et l'essouflement, prévient la diarrhée ; c'est, de plus, un léger excitant cérébral.

Les feuilles de l'Erythroxylon coca ou Cocaïer, arbrisseau de I à 3 mètres, des régions chaudes d'Amérique, renferment un alcaloïde, la cocaïne. Les Indiens et les métis mâchent ces feuilles, qui ont des propriétés analogues à celles de la Kola. Le Cocaïer fait l'objet de grandes cultures en Bolivie et au Pérou; ses feuilles s'emploient en poudre ou en infusion, comme toniques et stimulantes; on en extrait la cocaïne, utilisée comme anesthésique local.

Médicaments divers. - Le Kousso, fleur desséchée d'une Rosacée, le Koussotier d'Abyssinie, est un vermifuge énergique; l'écorce de Grenadier, le rhizome de la Polystic Fougère mâle, les semences de Courge et la mousse de Corse, qui est un mélange de plusieurs Algues marines, jouissent de propriétés analogues. Le semen-contra n'est autre chose que les capitules desséchés et pulvérisés des Armoises pauciflore et de Judée ou bien de, la Santoline petit cyprès, de la région méditerranéenne. On en retire la santonine, principe cristallisable utilisé le plus souvent en cachets.

Le médicament du cœur le plus employé est la Digitale; ses feuilles, ou la digitaline quion en extrait, et qui est un poison des plus violents, augmentent l'énergie des battements du cœur et en diminuent le nombre. Les feuilles et les fleurs du Muguet, ou leur extrait qui est fort toxique, la Grande Ciguë, s'emploient aussi dans les maladies de coeur.

Le Colchique, l'Aconit, l'écorce de Saule et les feuilles de Frêne sont des médicaments antirhumatismaux. La Belladone est cultivée en grand en Angleterre pour la pharmacie; on retire de ses racines et de ses feuilles un redoutable alcaloïde, l'atropine, qui ralentit les sécrétions et agrandit la pupille. La pilocarpine remplace souvent l'atropine en oculistique. Les révulsifs

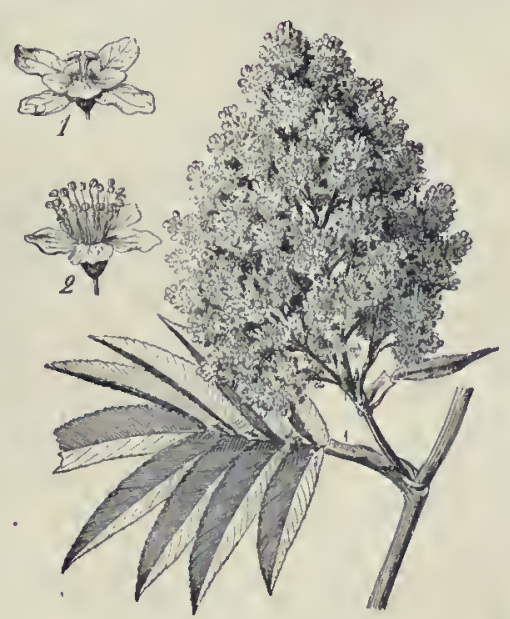

Fig. 335. - Koussotier. 1, Fleur femelle: 2, Fleur mâle.

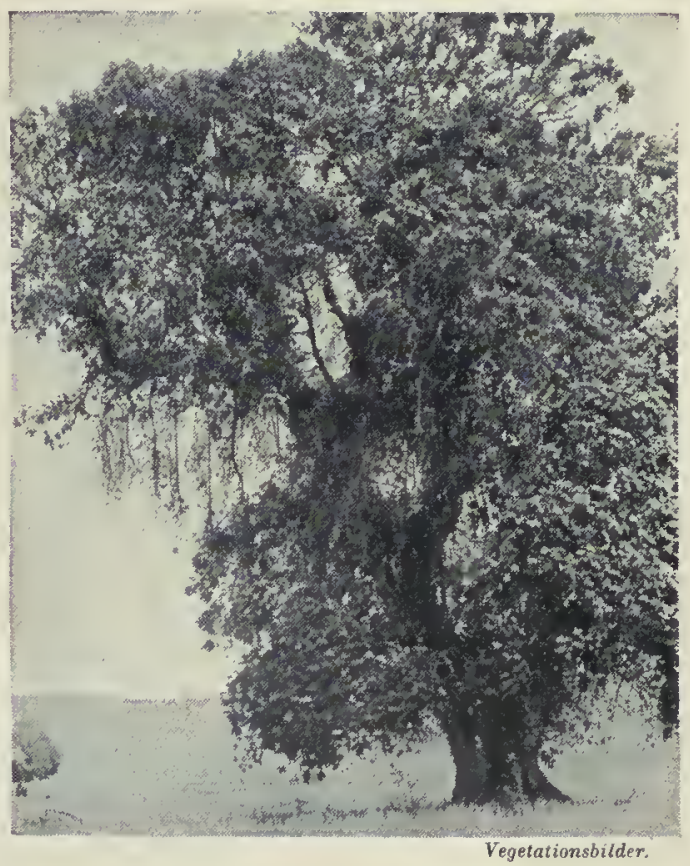

Konssotier (Hagenia abyssinica).

végétaux sont fort nombreux, depuis la racine de Thapsia, l'huile de Croton et la farine de Moutarde, dont on fait des sinapismes, jusqu'aux écorces de nos Daphnés indigènes (Garou ou Sainbois), employées jadis dans les campagnes comme vésicatoires.

Bornons-nous à citer encore les antiscorbutiques: Raifort, Cochléaria, Cresson, Houblon, Citron; les vulnéraires: Ache, Arnica, et les antiseptiques: camphre, thymol, gaïacol, menthol.

Vaccins, virus, sérums, etc. - Un certain nombre de vaccins sont d'origine végétale : ce sont des cultures atténuées de microbes par la chaleur, par l'oxygène ou par les antiseptiques, etc. Le vaccin de la variole fut le premier employé; il est dû au médecin anglais Jenner; son emploi date de la fin du $\mathrm{XVII}^{\mathrm{e}}$ siècle; le microbe est invisible. Le vaccin du charbon est, après celui du choléra des poules, le premier qui ait été trouvé (1881) et appliqué en grand par Pasteur et ses élèves, puis celui de la rage. On a trouvé des vaccins du choléra, de la typhoïde (qui a ey une importance capitale pendant la guerre : Wright, Widal et Chantemesse, Vincent), de la peste, etc.

Les sérums s'obtiennent en extrayant du sang d'un animal (cheval) qui a reçu des injections de cultures de plus en plus fortes. Le poison ou toxine développé par le microbe provoque la formation dans le sang d'une antitoxine. On emploie un sérum contre la diphtérie (1890, Behring, Roux), contre le tétanos, contre le choléra, etc.

La séro-vaccination est utilisée quand la vaccination présente des risques. On associe un vaccin et un sérum, par exemple dans la clavelée des moutons d'Algérie, maladie à microbe invisible.

Les vaccins sensibilisés s'obtiennent par immersion des microbes dans un sérum. Le microbe est débarrassé par lavage du sérum; il donne alors un vaccin plus durable (choléra, peste).

Les sérums ne sont pas employés toujours sans danger; parfois la deuxième inoculation d'un sérum provoque des troubles graves: la maladie, au lieu d'être atténuée, est exaltée : c'est l'anaphylaxie (Charles Richet).

Il $\mathrm{y}$ a encore d'autres modes de traitement fondés sur d'autres principes : sur la phagocytose ou attraction des phagocytes, qui englobent les bactéries et les digèrent : ainsi, on peut faire agir une substance comme l'iodoforme, etc., qui attire les phagocytés; sur l'étude de la flore intestinale: par exemple, introduction dans le tube digestif de bons microbes, comme le microbe bulgare; par cette méthode, Metchnikoff espérait que l'on parviendrait peut-être ainsi à atténuer les effets de l'artério-sclérose et à allonger la durée de la vie humaine. 


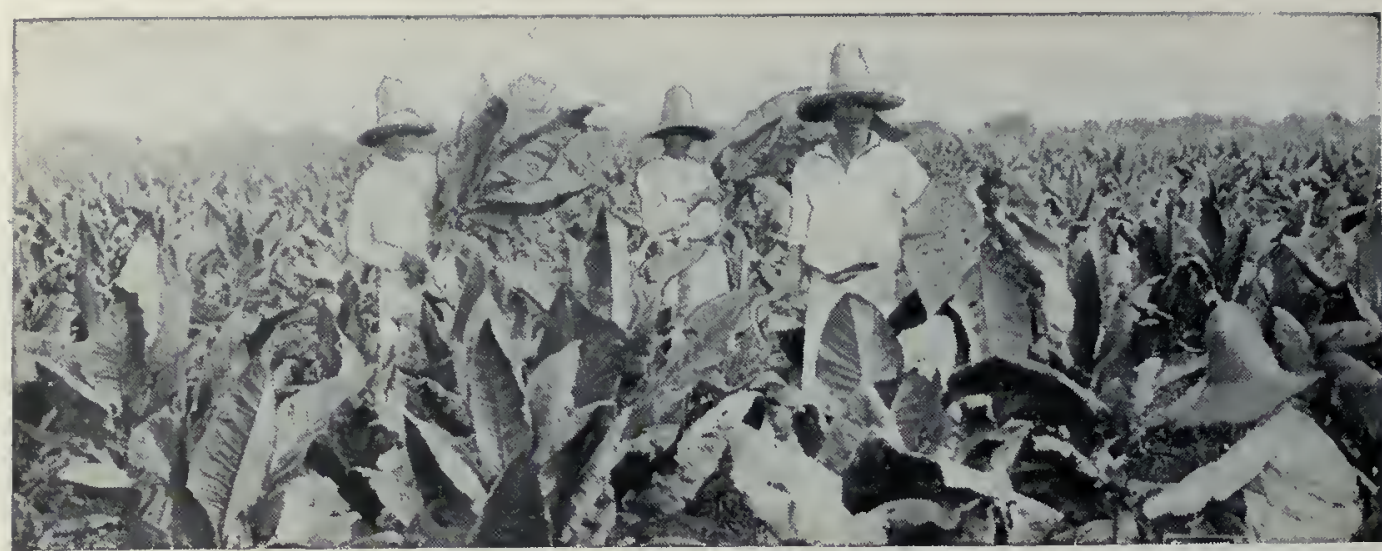

Récolte des feuiltes de Tabac, au Mexique.

Orient ou Extrême-Orient; et $2^{\circ}$ les Tabacs à fleurs jaunâtres, commele Tabacrustique ( $N$.rustica), du Brésil, d'Asie, de Hongrie et d'une partie de la France.

Le Tabac est une plante épuisante, exigeant des terres meubles, profondes, bien engraissées. En France, on sème sur couche et sous châssis vers le 15 mars; les graines sont très fines: I gramme en contient 18000 ; on repique au milieu de mai, on écime deux mois après, et on enlève ensuite les bourgeons latéraux à mesure qu'ils apparaissent. On récolte en août, feuille à feuille, quand les marbrures jaunes apparais-

\section{LES PLANTES STUPÉFIANTES}

On ne peut que constater, en le déplorant, l'usage presque universel des substances stupéfiantes dont les principes nuisibles, mis en liberté par la combustion ou l'action de la salive, pénètrent partiellement dans l'organisme. On fume le tabac, l'opium, le chanvre, et les deux premiers surtout tiennent une place trop importante dans les industries agricoles et le commerce mondial.

Tabac. - Le Tabac est une Solanacée annuelle d'origine américaine; elle était cultivée par les Indiens à l'époque de la découverte de l'Amérique; ses feuilles se prisaient, se chiquaient, se fumaient enroulées en cigares grossiers ou hachées dans des pipes, dont certaines, très ornées, ont été retrouvées dans des tombeaux de la période incasique. La plante fut importée en 1518 en Espagne. En 1560, Jean Nicot, ambassadeur de France à Lisbonne, envoya à Catherine de Médicis de la poudre de tabac destinée à guérir les migraines de la reine. Cette plante devint un remède à la mode, engouement injustifié, bientôt suivi d'une violente réaction qui la fit interdire un peu partout par des édits royaux. Nous pouvons juger aujourd'hui du peu d'effet qu'ils produisirent. Dès 1674, Colbert afferma le monopole des tabacs en France, et la plupart des gouvernements actuels tirèrent de la vente de ce produit un profit considérable.

Le Tabac est une plante très résistante; sa culture réussit aussi bien dans les pays tempérés que dans les régions tropicales, mais c'est sous les climats chauds qu'il acquiert les caractères spéciaux : élasticité, combustibilité, arome, qui font les qualités supérieures. Les anciens auteurs espagnols nous apprennent qu'il existait déjà plusieurs races de Tabac en Amérique, au moment de la conquête; elles sont aujourd'hui nombreuses et on peut les rapporter à deux groupes : $1^{\circ}$ les Tabacs à fleurs rosées ou rougeâtres, comme le Tabac commun (Nicotiana tabacum), dont les variétés sont cultivées à la Havane, en Malaisie, en France; le Tabac à larges feuilles du Maryland, de l'Ohio, du Kentucky, de Tur quie, d'une grande partie de l'Algérie; le Tabac de Virginie, le Tabac du Brésil, celui de Java et de Sumatra, cultivé en

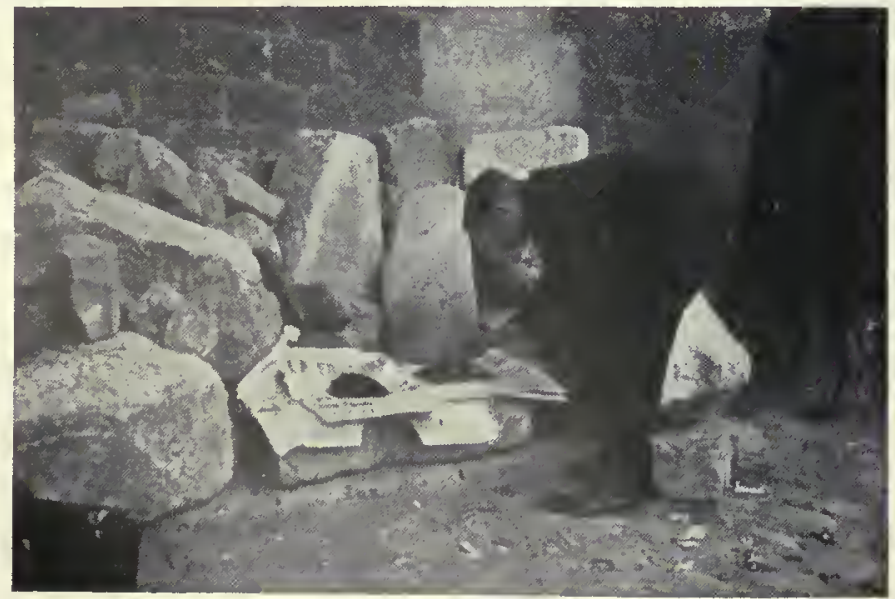

Le triage des bouts de cigares. sent. La dessiccation s'opère sous des hangars à l'air libre, et dure trois à six semaines. Les feuilles, réunies en paquets ou manoques, sont accumulées en tas, la pointe en dedans, pour la fermentation. Cette culture est autorisée dans vingt-sept de nos départements; elle est sous la surveillance de la régie, et les cultivateurs sont tenus de vendre tous leurs produits à l'État, au prix fixé chaque année par arrêté préfectoral. Le Lot-et-Garonne, la Dordogne, l'Isère, le Pas-de-Calais et la Gironde sont les plus forts producteurs.

Toute notre production française, à laquelle il faut ajouter un poids à peu près égal de tabacs achetés aux États-Unis, en Allemagne, aux Pays-Bas, en Algérie et en Turquie, est traitée dans vingt et une manufactures et, après une fermentation plus ou moins prolongée qui détruit une partie de la nicotine, transformé en scaferlati, en cigarettes, en cigares, en poudre à priser et en rôles et carottes ou tabac à chiquer. Notre tabac indigène est mélangé dans toutes ces sortes à un tiers environ de tabacs exotiques : 15000 ouvrières et ouvriers s'occupent de ce travail; 47000 buralistes en vendent les produits. Nous ne citons que pour mémoire l'intéressante corporation des ramasseurs de " mégots " qui recueillent sur le pavé des grandes villes les débris abandonnés par les fumeurs, les arrangent, les parent et les vendent à une clientèle peu aisée.

Les Etats-Unis sont parmi les plus grands producteurs de Tabac ; à la culture de cette plante, ils consacrent 300000 hectares; certaines sortes, comme le Maryland, sont peu chargées en nicotine; les Tabacs de Cuba et des Philippines sont renommés pour la finesse de leur arome; Java, Bornéo, Sumatra ont aussi une production considérable de Tabacs de qualité. L'Indochine est un pays d'avenir pour cette substance. La nicotine, dont la proportion varie de 1 à 10 pour 100 dans les feuilles de Tabac, est extrêmement toxique. L'abus du tabac amène un affaiblissement de la mémoire et de la vue, des troubles du cœur et de la laryngite.

Opium. - L'opium est le latex coagulé, retiré de la capsule du Pavot somnifère, herbe que l'on cultive en Corse, en Grèce, en Turquie, en Asie Mineure, en Égypte, en Perse, dans I'Inde, en Indochine et dans les pays d'Extrême-Orient. L'opium de

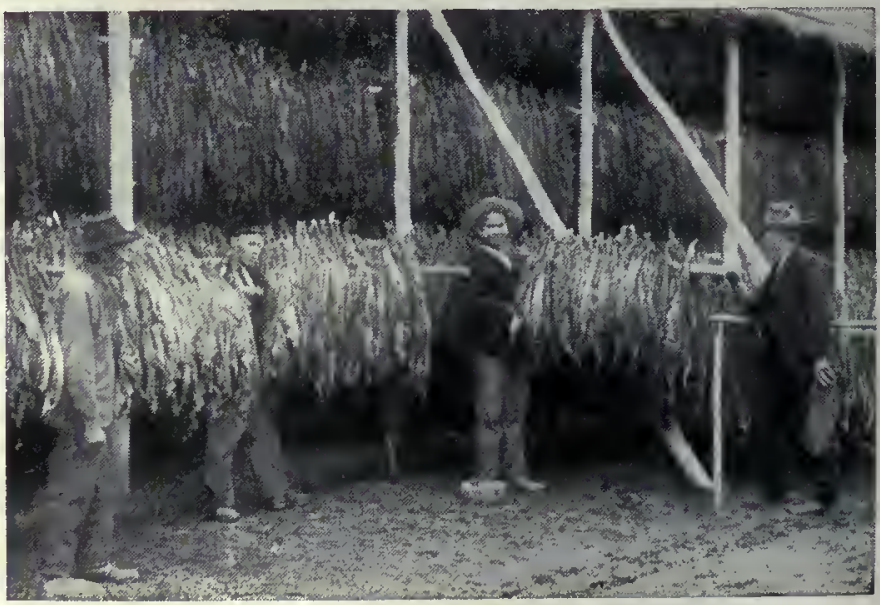

Séchage du tabac, en Australie (manoques). 
Turquie est employé pour la pharmacie; le reste est consommé par les mâcheurs et les fumeurs d'opium.

On incise la capsule encore verte avec un canif à cinq lames parallèles. Le latex s'écoule, se fige à l'air en brunissant ; on le réunit dans des cuves plates. Retourné, pétri, il perd une grande partie de son eau. D'autres manipulations, effectuées dans de grandes manufactures, comme celles de Saïgon ou de Batavia, le transforment en chandoo ou opium à fumer. Une fermentation spéciale, due à un Cham-
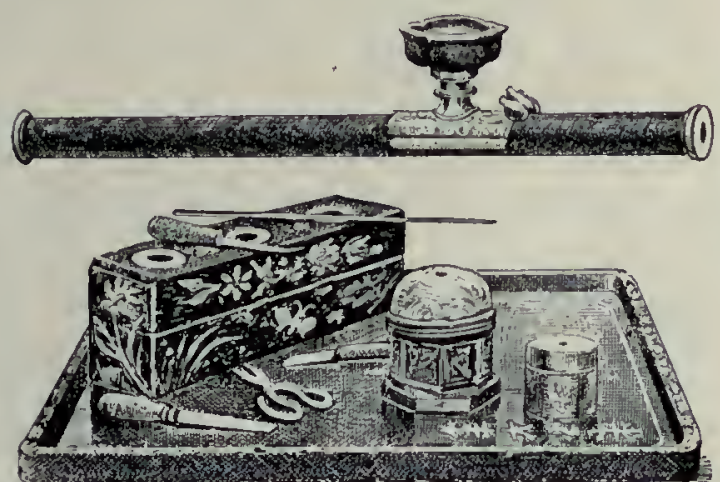

Pipe et nécessaire pour fumer l'opium.

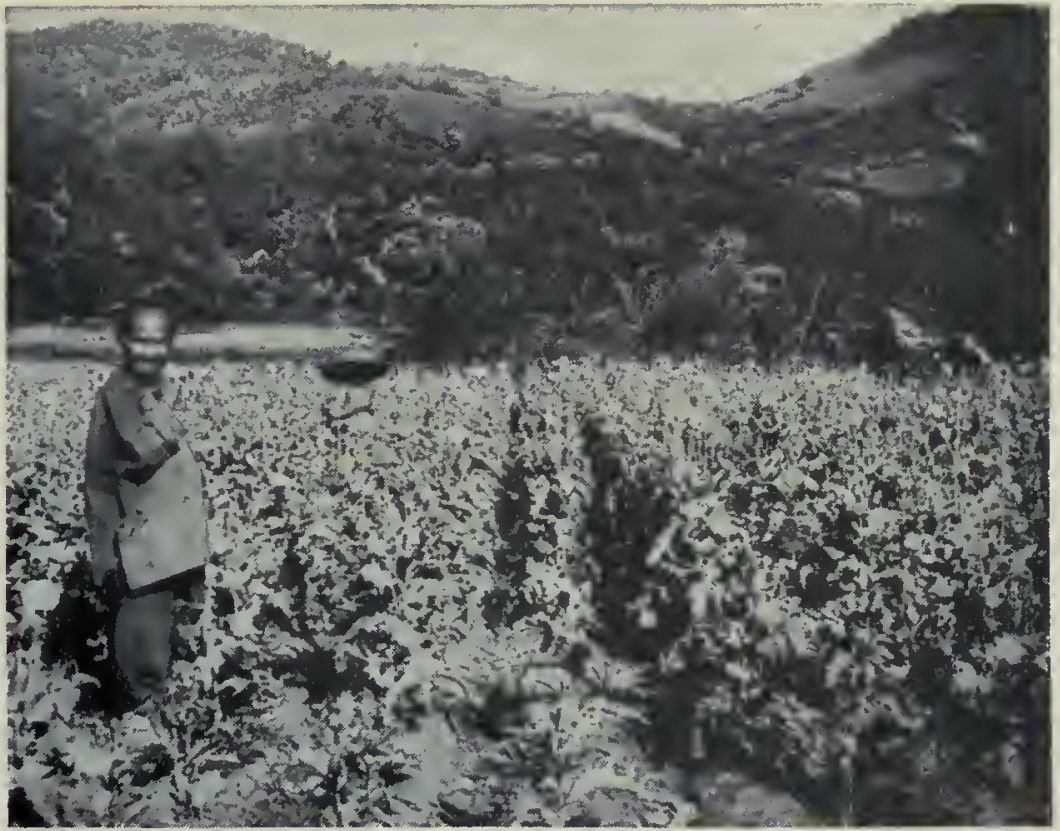

Culture du Pavot à opinm, en Chine.

Vér. Richard. pignon découvert par le $\mathrm{D}^{\mathrm{r}} \mathrm{Calmette,} \mathrm{donne} \mathrm{à} \mathrm{l'opium} \mathrm{l'arome}$ apprćcić des fumeurs. Spontanée, cette fermentation exige tout près d'une année; par l'ensemencement du Champignon, la durée en est considérablement réduite.

L'usage de l'opium est autrement dangereux que celui du tabac : il procure une lourde ivresse, dont la répétition mène à un complet abrutissement. Le gouvernement chinois a tenté à différentes reprises d'en proscrire l'usage. En 1839, il fit saisir la cargaison d'opium des navires anglais ancrés dans ses ports, soit 20000 caisses valant 50 millions de francs. De cet incident naquit la "guerre de l'opium ", après laquelle la Chine, vaincue, fut condamnée à fumer lopium des Indes. Cependant, en 1906, un édit a ordonné la réduction progressive de la culture du Pavot et la suppression complète de l'usage de l'opium dans tout l'empire chinois au bout d'une période de dix ans. Cette fois-ci, les pays importateurs d'opium en Chine : l'Inde, la Perse, l'Indochine et Java n'ont pas protesté. La lutte est entreprise un peu partout contre ce fléau qui, par les coloniaux et les marins, commence à atteindre l'Europe.

Hachisch. - Une oléo-résine sécrétée par les feuilles ou les inflorescences femelles du Chanvre indien sert à préparer le hachisch, substance enivrante qui est fumée ou mâchée dans les pays musulmans et surtout en Turquie, Perse, Arabie, Egypte et Algérie. La plus grande partie du hachisch est préparée en Grèce sous forme de gozah, qui se fume comme l'opium, dans de petites pipes spéciales, ou de dawamesk, extrait gras, sucré et aromatisé, de hachisch, cannelle, pistache, poivre, muscade, musc, cantharide, datura, qui se mâche ou se mange mélangé à des gelées de fruits. L'usage habituel du hachisch conduit très vite à l'abrutissement et à la folie, avec des crises furieuses de temps à autre.

Masticatoires. - Le bétel on pan soupary, ou byry, dans lequel entre la noix d'arec mélangée de poudre de coquillages calcinés (tchouna), additionnée de cardamome (ilatchy). le tout enveloppé par les feuilles

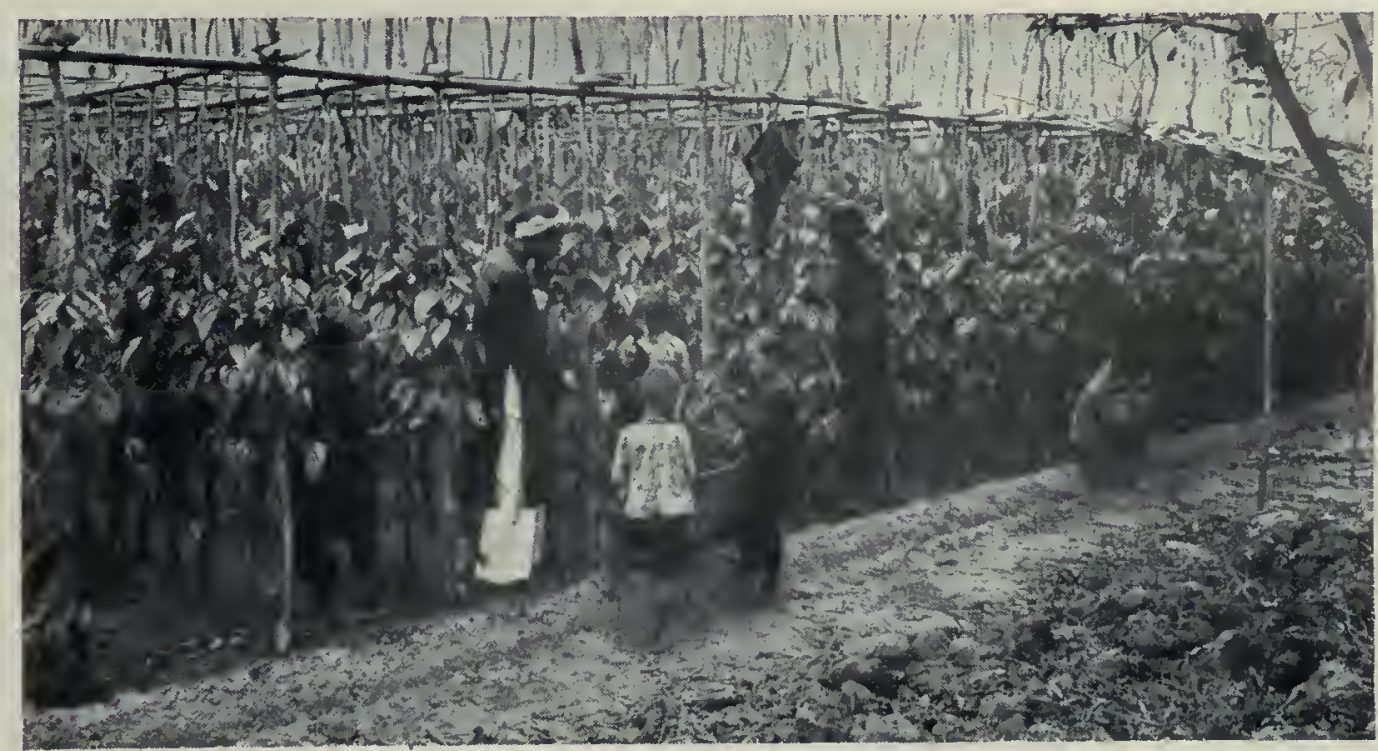

Culture du Poivrier bétel, en Indochine. du Poivrier bétel et attaché avec un clou de girofle, est un masticatoire tonique, astringent et narcotique, employé dans toute l'Asie tropicale et en Mélanésie; il rougit la salive, noircit les dents qui deviennent vacillantes, enflamme la bouche et le pharynx et émousse le goût. Il finit par produire une intoxication, avec palpitations nerveuses, paralysie des reins et aphasie. 11 contient, en effet, quatre alaloïdes (arékoline, arékaïne, arékaïdine et guvacine). Quelques autres substances utilisées pour le même usage n'ont pas d'action nuisible. Rappelons aussi l'usage très répandu, comme masticatoires, de la kola et de la coca.

En Orient, les femmes mâchent le mastic, résine extraite du Pistachier lentisque qui se ramollit sous la dent, parfume l'haleine et raffermit les gencives. Le Pistachier de l'Atlas, le Poivrier d'Amérique fournissent des substances analogues. Le cachou est aussi très employé, notamment par les fumeurs.

Le chilté est le latex qui s'écoule de divers Sapotilliers du Guatemala et du Honduras ou d'un Jatropha du Mexique (voir p. 268); on l'obtient à l'aide d'incisions en biais pratiquées sur le tronc et on le recueille dans un récipient placé au pied de l'arbre. Le chilté, filtré, puis concentré par chauffage, est façonné en pains qui sont la base de ces pâtes masticatoires ou chewing-gums dont les Américains font si grand usage. 


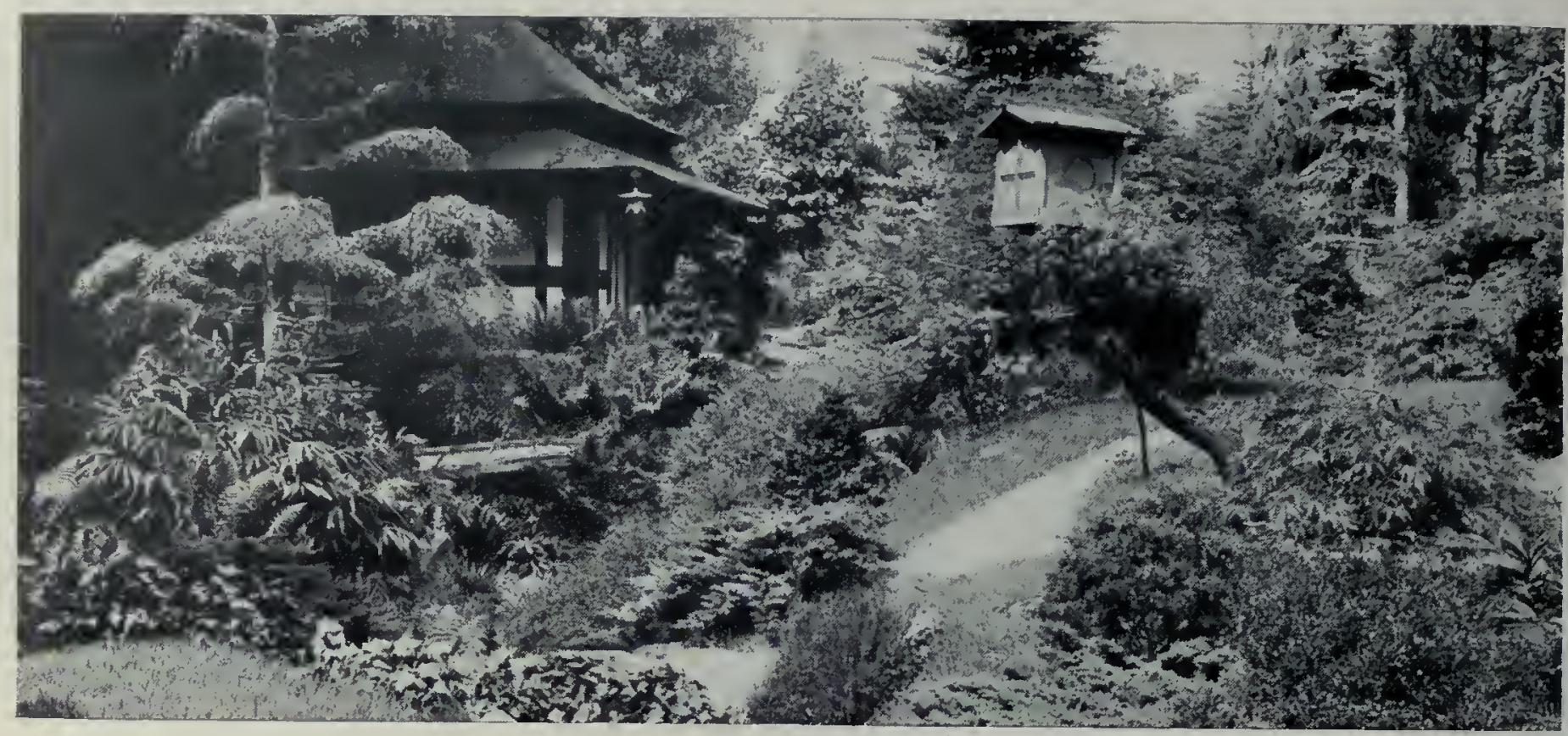

UN JARDIN JAPONAIS.

\section{VIII. - PLANTES D'ORNEMENT}

L'homme ne se borne pas, heureusement, à envisager les plantes comme des usines en raccourci, propres à lui fournir ses aliments, ses boissons, ses vêtements ou ses meubles; il les considère comme l'admirable parure de la terre; émerveillé de leur beauté, il a su de bonne heure en tirer des satisfactions d'art et d'agréables distractions. Avec les arbres, il pare et assainit les rues des cités populeuses. il rassemble dans les jardins les espèces les plus belles et les plus curieuses, il égaye de fleurs l'appartement. Tous ces emplois des plantes ont donné naissance à deux industries considérables: la floriculture et l'arboriculture d'agrément.

Les arbres d'alignement. - Pour donner aux rues parisiennes un peu d'ombre et de fraîcheur, on y a planté 90000 arbres d'alignement ; on en compte à peu près autant dans les parcs, squares, cours d'écoles et cimetières; en tout, près de 200000 arbres ; c'est un joli chiffre que bien des forêts n'atteignent pas. Parmi les arbres des avenues, à Paris, les Platanes arrivent en tête au nombre de 27000 , les Marronniers ne sont que 18000 , les Ormes 16000 : il faut y ajouter 10000 Ailantes ou Vernis du Japon, 6000 Erables planes, 5000 Sycomores, 4000 Robiniers faux Acacias, 2000 Tilleuls et 1000 Paulownia.

Les pépinières municipales du Bois de Boulogne et du Parc des Princes fournissent non seulement des jeunes sujets, mais aussi des arbres de trente à quarante ans, qu' on arrache avec un énorme cube de terre et qu'on transporte à l'aide de chariots spéciaux; un grand trou est préparé pour recevoir leurs racines et la terre qu'elles maintiennent.

Chaque année, en hiver, les arbres citadins sont taillés et élagués, principalement les Platanes, qui ont tendance à s'élever trop vite et à se dégarnir du bas; on les écime et on raccourcit leurs branches latérales qui donneront des rameaux adventifs garnis de feuilles; de plus, cette pratique est très utile contre la maladie du Platane, attaquant seulement les jeunes branches (Gloeosporium Platani). Les élagueurs sont audacieux, agiles et habiles; une large et solide ceinture de cuir, munie d'anneaux dans lesquels on passe des cordages qui sont ensuite fixés aux branches, leur laisse les mains libres pour manier la serpe. Malgré tous les soins dont on les entoure, les arbres des avenues meurent vite; leurs feuilles recouvertes de poussière sont grillées par la réverbération des rayons solaires; leurs racines, emprisonnées dans une gaine de bitume, de pavés, de tuyaux de toutes sortes, de constructions en maçonnerie, souffrent du manque de nutrition et d'aération.

Chaque région s'enorgueillit de belles allées d'arbres, Ormes ou Tilleuls centenaires, Noyers ou Peupliers géants, Palmiers superbes. Dans notre Midi, on admire de magnifiques alignements de Platanes, de Micocouliers, d'Eucalyptus; ceux de Palmiers d'Hyères et ceux de Figuiers de Roxburgh de Monte-Carlo sont célèbres à juste titre.

Parcs et Jardins. - " Le jardin, a écrit Bacon, est le plus pur des loisirs humains. C'est le plus grand délassement de la pensée de l'homme, sans lequel maisons et palais ne sont que les grossiers ouvrages de sa main. "La disposition des jardins, leur style, leur parure florale ont profondément varié au cours des siècles. Chez les Romains, ils étaient tirés au cordeau, ornés de Buis et d'Ifs, taillés parfois de façon extravagante; les statues y abondaient plus que les corolles. Au moyen âge, le jardin d'agrément consistait en petits prés ou préaux, pelouses aux lignes géométriques ornées d'arbustes et de fleurs. A la Renaissance, le jardin devient luxueux, architectural. Le jardin "à la française " en dérive avec ses parterres bordés, ses terrasses, ses quinconces et ses bassins disposés en terrain plat; il a un caractère monumental et majestueux; sa perfection fut atteinte sous Louis XIV, grâce à Le Nôtre. A cette disposition ordonnée, régulière, succède au XVIIt ${ }^{\mathrm{e}}$ siècle le jardin " paysager ", irrégulier, avec des rivières et des allées sinueuses; on y trouve des rochers, des bouquets d'arbres, et tout cela sur un terrain vallonné. De nos jours, les jardins ont autant d'art, mais plus de fleurs. Il semble que plus notre existence devient fièvreuse, fatigante, plus est grand 
notre désir d'avoir autour de nous des fleurs qui reposent la vue, nous calment et nous rappellent les campagnes lointaines où la vie est douce et paisible.

Les grandes villes dépensent des sommes considérables pour fournir à leurs habitants l'agrément de promenades, de parcs et de jardins magnifiques; le Touring-Club de France encourage et prime la floraison desgares et les villages coquets; la Société française de l'Art à l'Ecole fait une campagne fructueuse pour l'embellissement de l'école par la fleur;

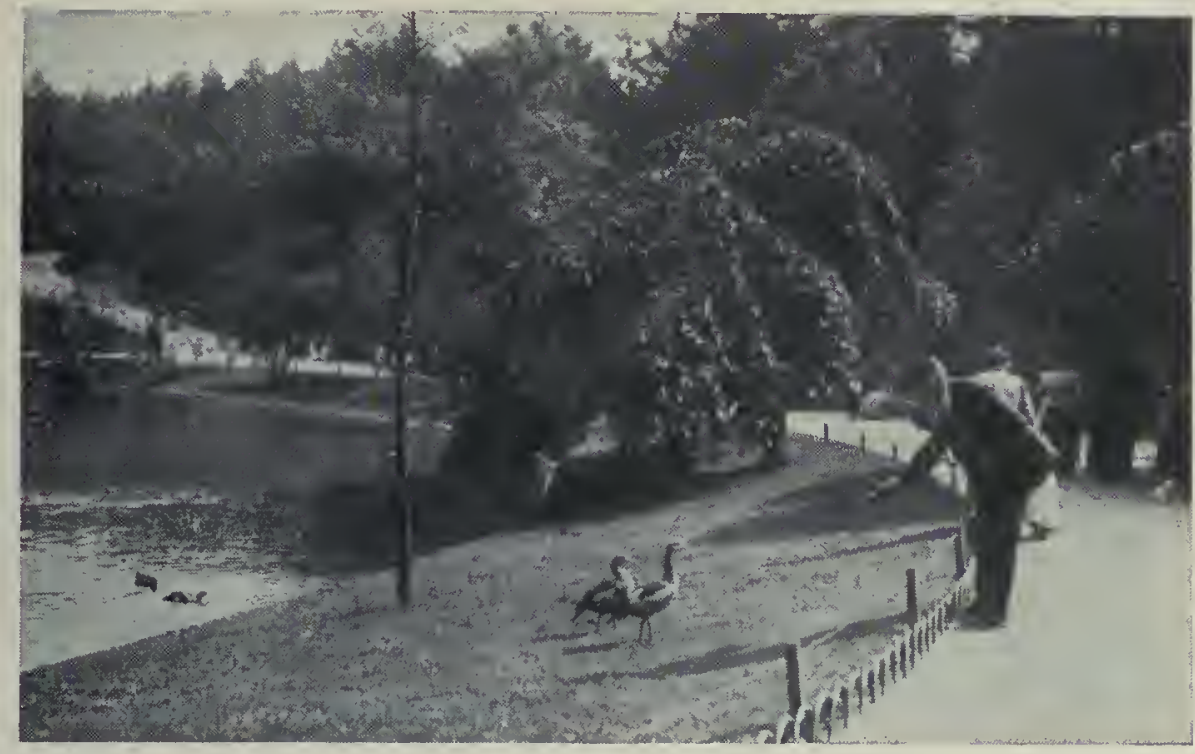

Les bords du lac, au parc Montsouris.

de Cannes, d'Antibes, d'Hyères, de Nice, un incomparable décor.

Londres dispose de 6000 hectares de parcs, jardins et squares dont certains justement célèbres : Battersea, Regent's Park, Hyde Park, le plus élégant, situé au cœur même de la ville et d'une surface considérable (240 hectares) puis, dans la banlieue, Richmond Park, avec ses 800 hectares, et le célèbre jardin botanique de Kew, aux paysages admirables, aux serres immenses, où sont réunies les plantes les plus rares.

Lestetats-Unispossèdent aussi de belles de riches directeurs d'usines en Angleterre, aux États-Unis, ont résolu le problème de transporter la ville à la campagne par la création des cités-jardins qu'habitent leurs ouvriers; un peu partout, des associations philanthropiques de jardins ouvriers procurent au travailleur un terrain où il plante des légumes et quelques fleurs.

Paris possède l'admirable Bois de Boulogne ( 850 hectares) et le Bois de Vincennes (650 hectares) situés aux deux extrémités de la ville; de nombreux parcs, jardins et squares, dont certains, comme le Parc Monceau, les Buttes Chaumont, Montsouris, sont de toute beauté, se partagent le reste. Pour garnir son immense corbeille florale et en renouveler la décoration, Paris entretient, non loin d'Auteuil, un superbe jardin fleuriste, véritable usine à fleurs, d'où sortent chaque année plus d'un million de végétaux: Pensées, Myosotis, Tulipes, Silènes, Giroflées, Pâquerettes, Aubriétia, pour la garniture d'hiver ou de printemps; Pélargonium (350000 pieds), Bégonia, Ageratum, Lobelia, Fuchsia, Héliotropes, Canna, etc., pour la garniture d'été, sans parler de 50000 arbres ou arbustes pour massifs, pris dans les pépinières du Bois de Boulogne. C'est, en même temps qu'une manufacture de fleurs, un jardin splendide renfermant de remarquables collections d'arbustes, de Chrysanthèmes, d'Azalées, de Palmiers, d'Orchidées.

Le Luxembourg et le Jardin des Plantes, où l'on trouve de si belles réunions de végétaux et de grandes serres remarquablement aménagées, sont des établissements d'Etat qui s'entretiennent eux-mêmes de fleurs. Les environs immédiats de Paris offrent aux promeneurs les beaux parcs de Saint-Cloud, de Versailles et de Trianon. Nombre de parcs et jardins de province, à Lyon, Bordeaux, Marseille, etc., et beaucoup de propriétés privées sont de véritables merveilles. Comment ne pas citer le paradis des roses : la roseraie de l'Hay, le jardin japonais de M. Kahn à Boulogne-sur-Seine, le parc de Ferrières et ces admirables jardins toujours fleuris du littoral de la Côte d'Azur où se mélangent les flores du Mexique, d'Australie, du Chili, de l'Afrique centrale : Jardins de MonteCarlo, si somptueux; de Monaco, si pittoresques, et ceux qui forment aux villas

promenades : Central Park de New-York, Prospect Park de Brooklyn, Washington Park de Chicago, etc., mais certains d'entre eux sont gâtés par l'abus de la mosaïculture et la tendance au bizarre : immenses cadrans solaires en verdure et en fleurs, gigantesque globe terrestre où les terres, en Echeveria glauque, se détachent en blanc sur des océans d'Oxalis, animaux taillés dans des arbres ou dessinés par la mosaïculture. Une mention spéciale doit être faite du Parc botanique de Boston, qui est le plus bel Arboretum du monde; il renferme plus de 2000 variétés ligneuses de tous les pays tempérés.

Jardins alpins, alpinum. - Dans les régions montagneuses, on a créé des jardins alpins, dont les uns sont purement scientifiques, tandis que d'autres ont un but ornemental. Les plus intéressants sont le jardin de la Linnea, à Bourg-Saint-Pierre, dans les Alpes du Valais, à 1700 mètres d'altitude; on y trouve, outre les espèces des Alpes, celles du Jura, des Pyrénées, du Caucase, de l'Himalaya; le jardin de la Daphnaa $(790 \mathrm{~m}$.) de Monte Baro, près du lac de Côme ; celui de la Chanousia (2 $200 \mathrm{~m}$.), au Petit-Saint-Bernard; ceux du Lautaret, qui dépend de l'Université de Grenoble; du Ballon d'Alsace, du rocher de la Naye, du Hohneck (l000 m.), à Montabey, placé sous la direction de
Élagage des arbres, à Paris.
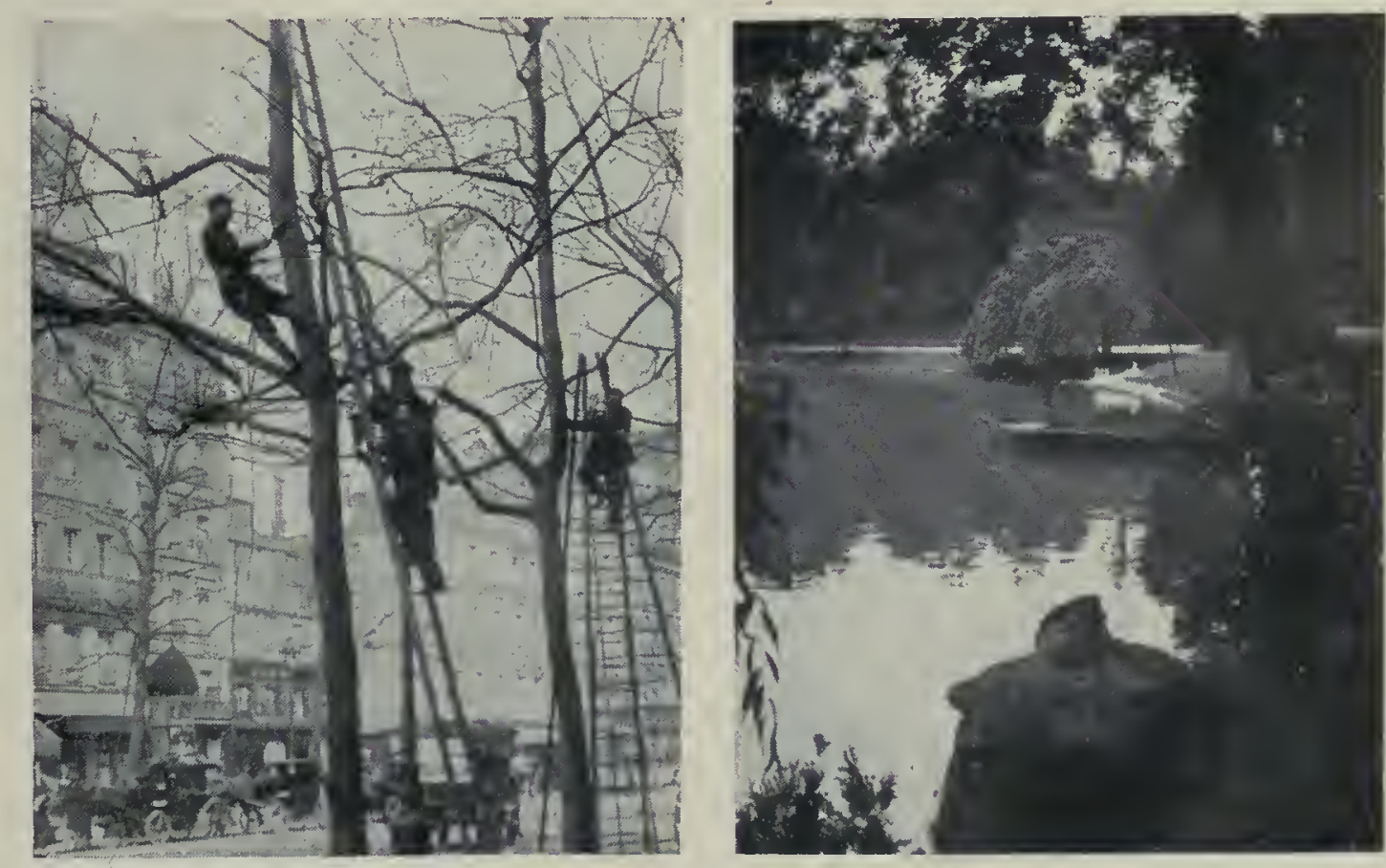

Un joli coin de parc. 


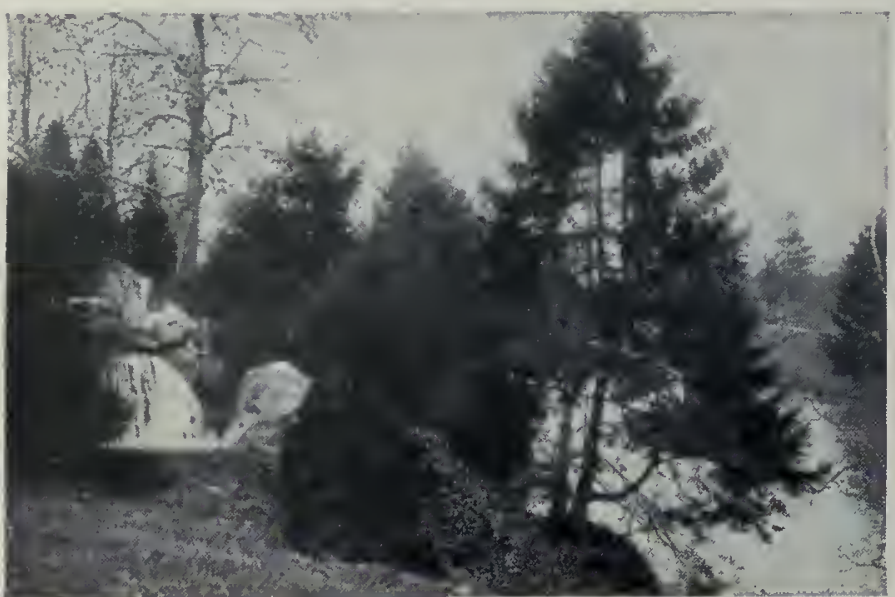

Motif de cascade dans un parc

l'Université de Nancy; du Mont-Aigoual, qui dépend de l'Université de Montpellier; du Pic du Midi de Bigorre, qui détient le record de l'altitude $(2850 \mathrm{~m}$.). La Bavière et l'Autriche ont aussi de très beaux jardins alpins. A Samoens (Haute-Savoie) est le plus merveilleux de tous les jardins alpins : celui de la Jaysinia, créé et donné à sa commune natale par $M^{\text {me }}$ Cognac-Jay, et qui a coûté plus d'un million.

La mode charmante de cultiver les plantes saxatiles et alpines sest beaucoup répandue et il est bien peu de jardins qui najent leur alpinum : c'est le nom sous lequel on désigne les jardins alpins de plaine. L'alpinum de l'Ariana, près de Cenève, est justement célèbre; le Rock garden du Jardin botanique de Kew est le modèle du genre; ceux de Batsford Park, de Kirkby Lonsdale sont aussi fort remarquables. Certains amateurs anglais ont consacré des sommes considérables à la création d'un alpinum; l'un d'eux, à Henley, près de Windsor, a reproduit en petit le massif du Cervin et l'a garni de la flore des montagnes du monde entier.

Jardins coloniaux. - La plupart des jardins coloniaux créés dans leurs colonies par les nations européennes ont un but utilitaire : ce sont des jardins d'essai où l'on étudie l'acclimatation d'espèces utiles, ou des jardins botaniques rassemblant sur un étroit espace les principales plantes de la région. Certains grands jardins coloniaux, créés depuis longtemps, sont à la fois des jardins d'essai, des jardins botaniques et des parcs d'une beauté merveilleuse.

La France peut s'enorgueillir de trois jardins coloniaux : celui de l'île de la Réunion, fondé par l'illustre Poivre; celui de Saïgon et enfin celui du Hamma, près d'Alger. Ce dernier, qui fut créé en 1832, est riche en arbres gigantesques: Eucalyptus, Conifères d'Australie et d'Amérique, magnifiques Cycas, massifs de Yucca hauts de 20 mètres. Cing allées y sont particulièrement remarquables : l'une de Rosiers grimpants, fleuris dès le mois d'avril; l'autre de magnifiques Palmiers; une troisième, de Platanes, dont ceux de nos avenues parisiennes ne donnent qu une bien faible idée; une quatrième est bordée de $F_{j}$ guiers de l'Inde (Ficus Roxburghii) aux troncs énormes; enfin une merveilleuse allée de Bambous géants.

Parmi ses nombreux jardins botaniques coloniaux, l'Angleterre en possède deux hors de pair : celui de Calcutta, créé en 1786 sur les bords de l'Hougly, et celui de Peradeniya, fondé en 1821, près de Kandy, à Ceylan. Le premier est un parc délicieux, agrémenté de plusieurs cours d'eau et de lacs artificiels ; on y trouve des fleurs superbes, des $\mathrm{Pal}$ miers et des plantes des

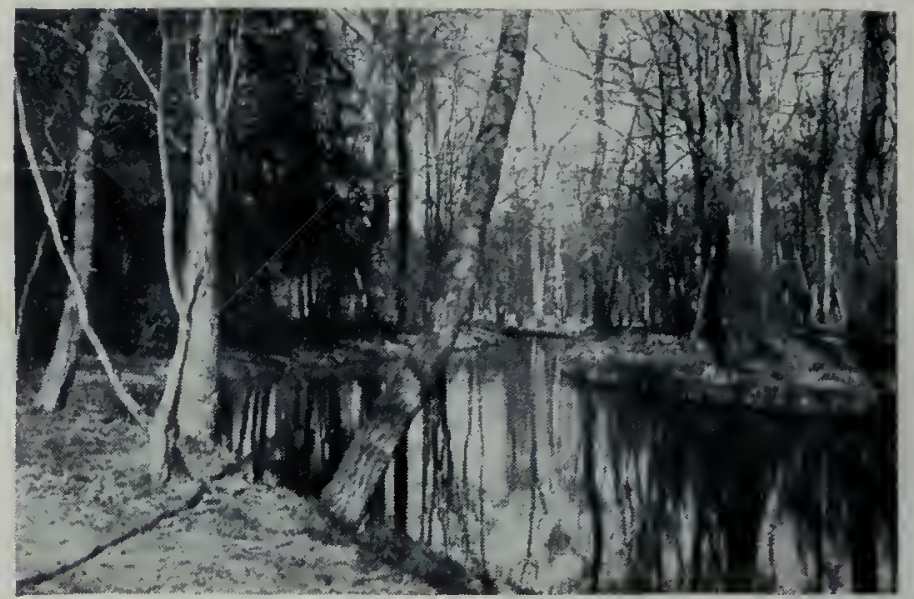

Motif de rivière dans un parc.

tropiques; l'arbre le plus imposant est un Figuier du Bengale, âgé de cent vingt ans, dont deux cent trente-deux racines-supports soutiennent les immenses branches partant d'un tronc de 14 mètres de circonférence; il forme un unique bouquet de verdure de 300 mètres de tour. Quant au jardin de Peradeniya, c'est un sćjour enchanté pour le promeneur, un paradis pour le botaniste, un établissement de première utilité pour les horticulteurs de la région qui s'y approvisionnent de boutures et de graines. Situé à 450 mètres d'altitude, baigné par la rivière de Mahaveli, il renferme presque toutes les plantes tropicales des deux hémisphères harmonieusement mêlées; on y remarque, en particulier, des Figuiers élastiques géants, qui ne ressemblent guère à leurs frères les Caoutchoucs de nos appartements, et d'impressionnantes gerbes de Bambous (Gigantochloa aspera). Peradeniya possède comme annexes une station d'essai de 120 hectares et une station de montagne à Hakgala, à 1750 mètres d'altitude.

Mais la merveille des merveilles c'est le jardin de Buitenzorg, à Java, fondé par les Hollandais en 1817. Il est pour la botanique, a-t-on dit, ce que la Grèce est pour l'archéologie et l'I talie pour l'art. Au jardin botanique proprement dit, situé au milieu de la ville et occupant 60 hectares, sont venus s'ajouter un jardin d'essai de 70 hectares et le jardin de montagne de Tjibodas, situé à 1350 mètres d'altitude, comptant 1500 espèces d'arbres et occupant 300 hectares pris sur la forêt vierge. Un musée, des laboratoires pour les travailleurs de tous les pays, une bibliothèque, un herbier annexés à cet établissement, en font un véritable Institut de botanique tropicale, qui dispose d'un budget de plus d'un million.

On ne trouve pas de serres à Buitenzorg : tout le jardin en est une où règnent une chaleur et une humidité constantes; on y rencontre seulement des sortes de hangars où l'on met certaines plantes à l'abri du soleil ou de l'humidité. Au point de vue pittoresque, rien n'y manque : une rivière naturelle le traverse, des ruisseaux courent partout; le solest vallonné ; dans un étang vit un monde

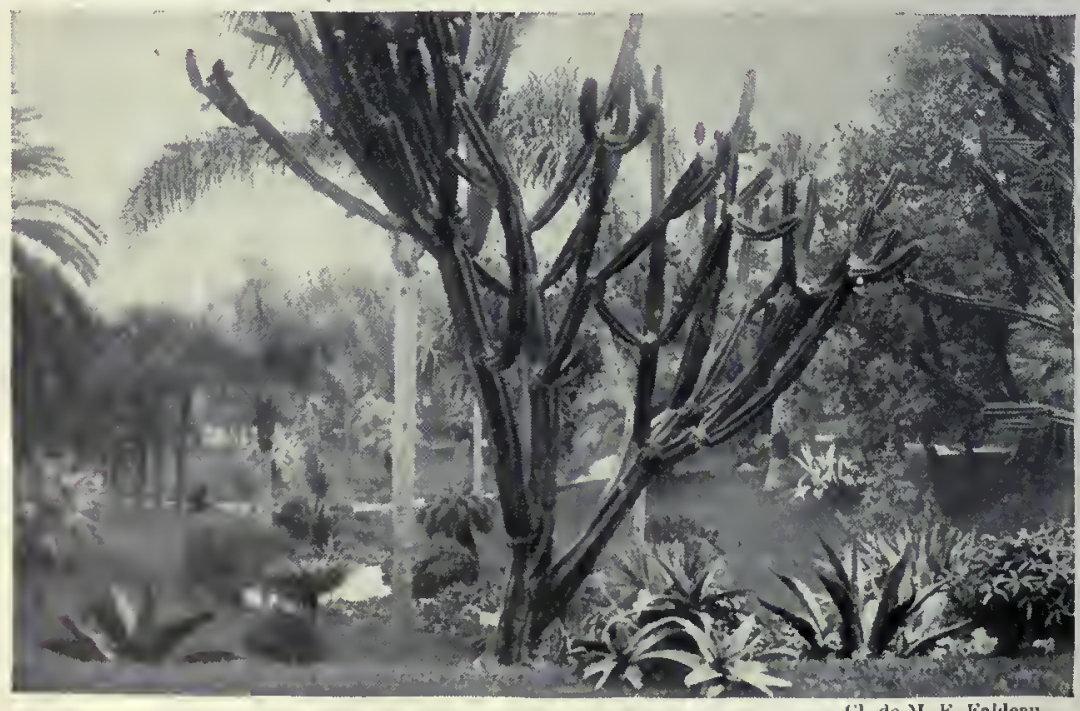

Végétation tropicale dans le jardin de Monte-Carlo. de plantes d'eau: Nénuphars, Lotus, Victoria regia. La végétation y est touffue, admirable; les collections de Palmiers, de Fougères arborescentes et de Lianes géantes dépassent en intérêt tout ce que l'on peut voir ailleurs; partout sont des groupes étonnants de plantes épiphytes.

Jardins japonais. Les Japonais, pour créer leurs jardins, s inspirent d'un tout autre idéal que le nôtre. Nous y voulons des fleurs variées, abondantes, de beaux arbres, de l'ombre et de la fraîcheur; eux, y veulent sur- 


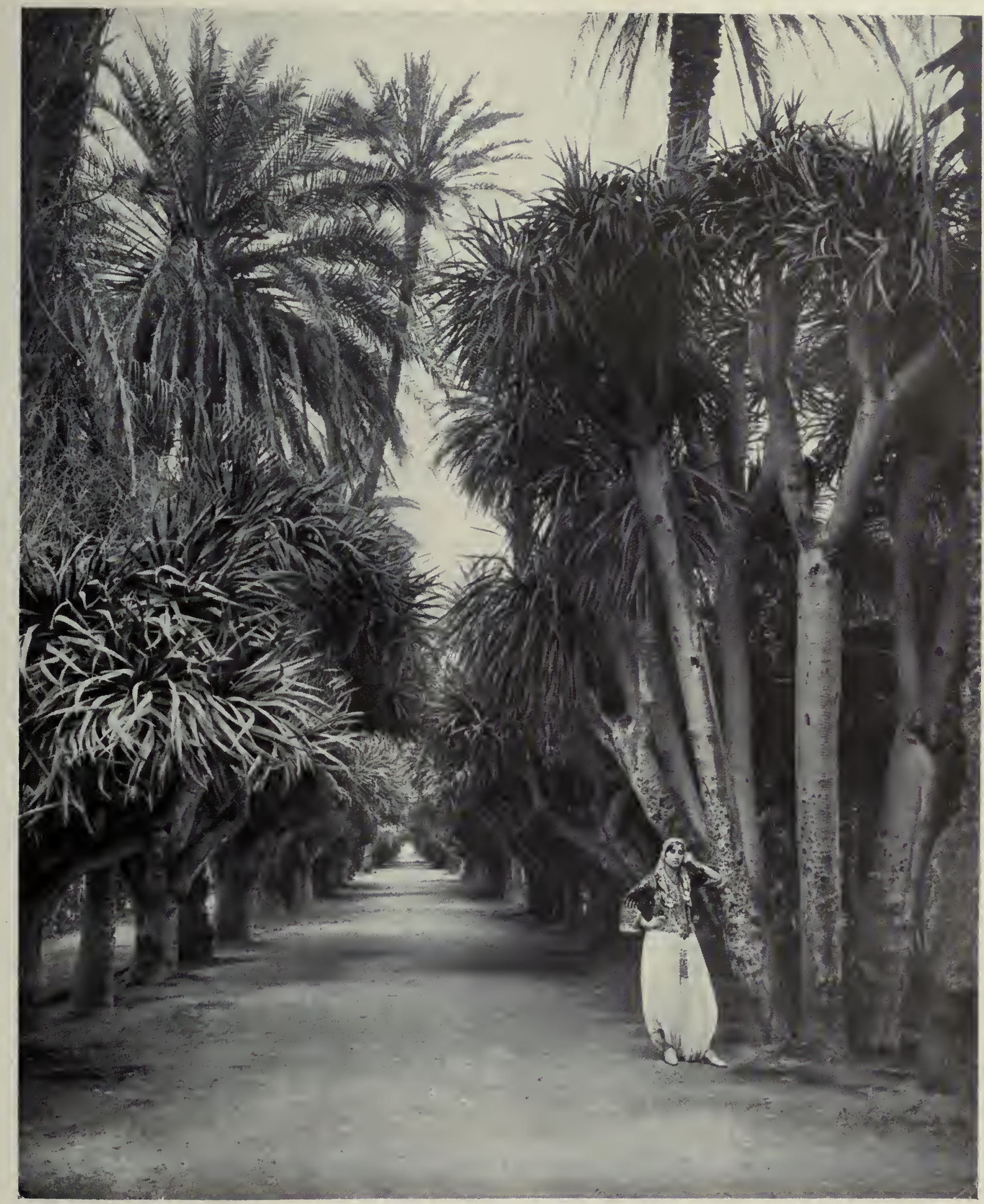

ALLEE DE DRACAENA, AU JARDIN DU HAMMA, ALGER. 



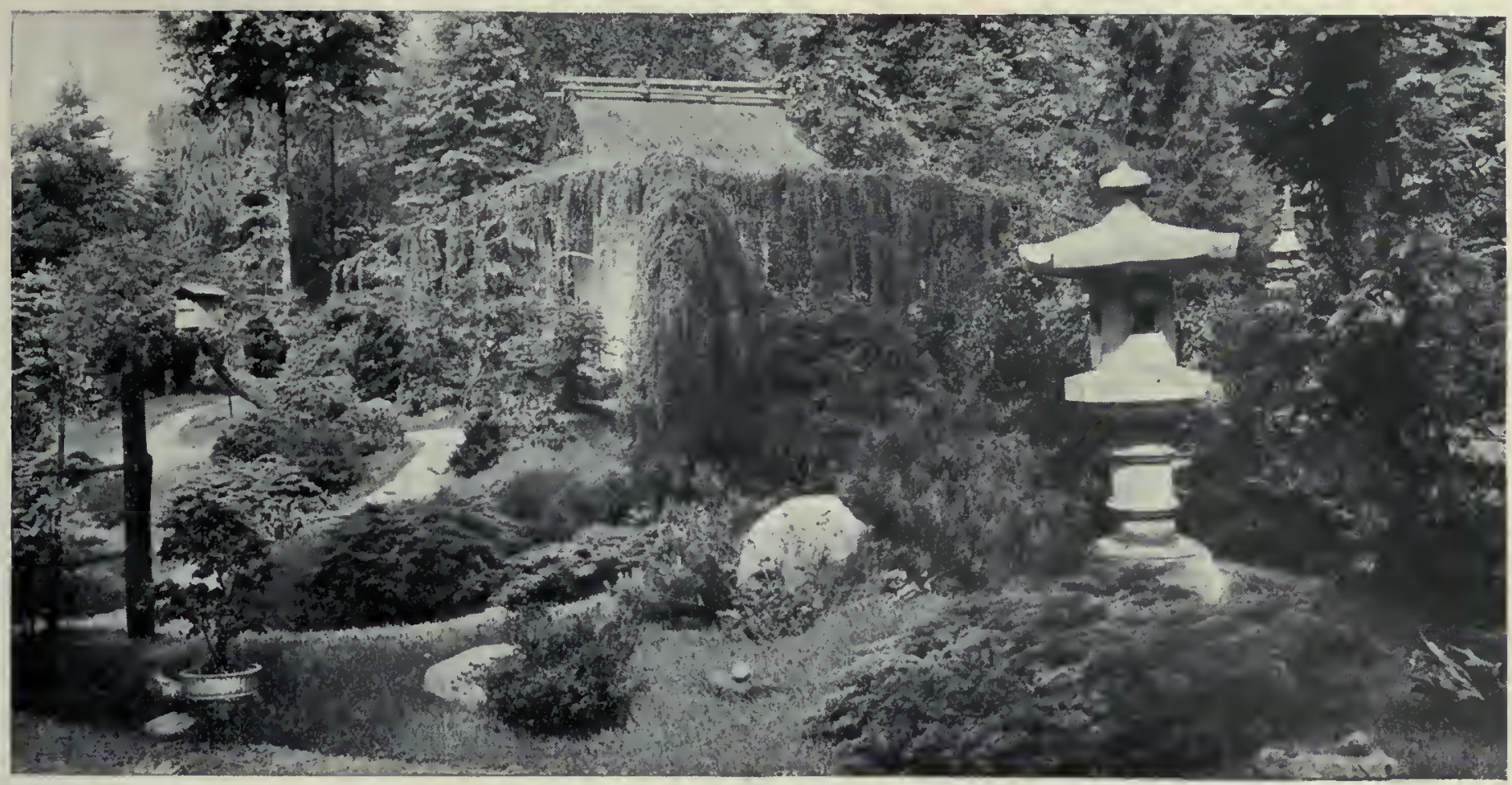

Un jardin japonais.

tout des objets rares, des " bibelots " végétaux, des plantes curieuses ou bizarres : leur jardin est un prolongement du salon. N'eut-il que quelques mètres carrés, il doit donner un résumé de tous les aspects de la nature, mais celle-ci y semble vue par le gros bout d'une lorgnette; on y admire des montagnes de trois pieds de haut, des lacs grands comme un mouchoir, de minuscules torrents roulant leurs eaux d'une façon terrible ou simplement figurés par des lignes de cailloux blancs, des arbres hauts de quelques décimètres, mais ayant l'aspect de ceux que l'on rencontre au dehors.

Les arbres nains japonais ont un aspect tourmenté, un tronc noueux et des rameaux tordus d'un effet pittoresque; certains Thuya, vieux de deux siècles, n'ont pas plus d'un mètre de haut. Pour nanifier les arbres, on les prive de nourriture; le jardinier coupe souvent les racines, supprime les bourgeons du haut, se livre à des rempotages étroits, et, en même temps, contourne les branches pour leur faire prendre des formes tourmentées. Pour parvenir au but à atteindre, il faut du temps, des soins continuels et du goût, mais il est nécessaire aussi que le sujet y mette une certaine complaisance; on réussit surtout avec les Ormes, les Glycines, les Cerisiers, les Erables, les Conifères et principalement les Pins et les Thuya. Les arbres taillés de façon bizarre : Ifs, Retinospora et autres, en pagode, en moulin, en oiseau, en chien, sont aussi des ornements indispensables du jardin japonais. On y voit encore des mannequins fleuris formés d'une carcasse en fil de fer représentant des hommes, des animaux ou des objets divers, à la base desquels on sème des plantes grimpantes; ces supports servent aussi à palisser des branches flexibles de Chrysanthèmes ou de Glycines.

Une Fougère, la Davallia bulleuse, commune dans les montagnes du Japon, fournit aussi, comme nous l'avons vu (p. 123), son contingent de bizarreries.

Les Japonais ont d'ailleurs aussi de fort beaux jardins de fleurs, principalement : lris, Amaryllis ou Chrysanthèmes, justement réputés.

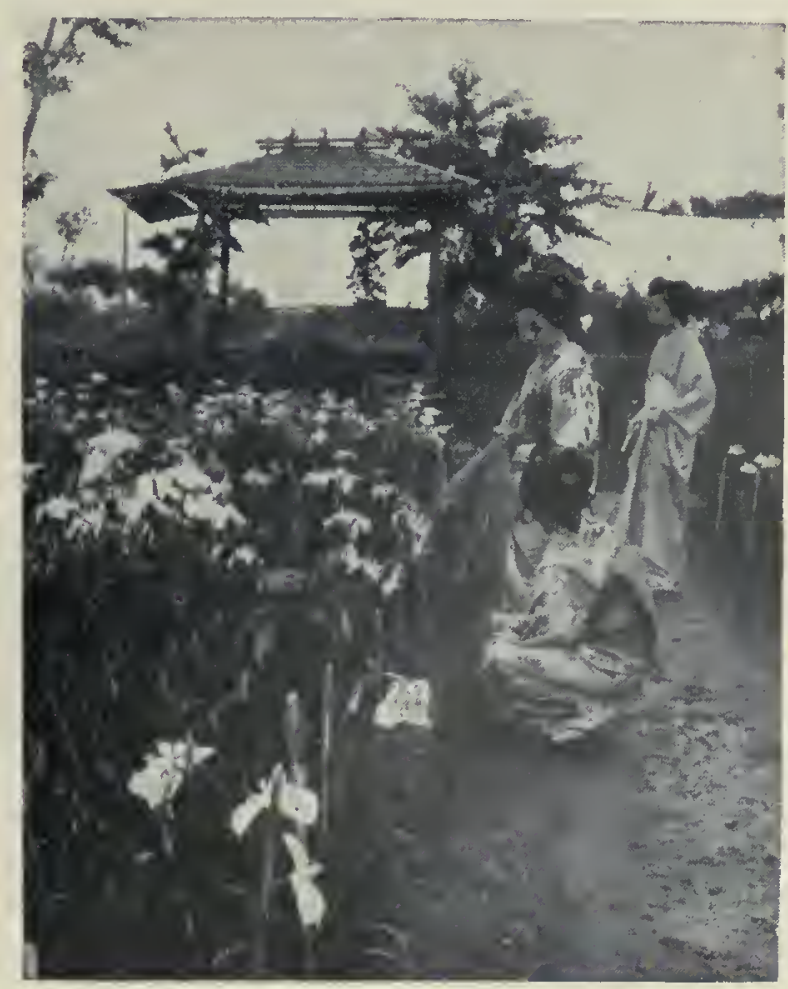

Japonaises dans un jardin d'Iris.
Décoration extérieure de l'habitation. - Une maison de campagne est tout à fait gracieuse quand elle est presque enfouie dans un écrin de verdure qui masque ses murailles et ne laisse libres que les ouvertures. Le décor floral de l'habitation peut être infiniment varié : le Lierre, la Vigne vierge, l'Aristoloche siphon forment des somptueux rideaux de verdure; les Chèvrefeuilles, les Clématites, les Rosiers sarmenteux font, à la belle saison, une parure incomparable.

Dans les villes, les habitants, ne pouvant avoir leur jardin au rez-de-chaussée, le mettent aux fenêtres. Les fenêtres fleurie sont de lointaines origines. Pline dit que le peuple de Rome " entretenait à ses fenêtres des espèces de jardins, présentant aux yeux le continuel spectacle de la campagne ". Les Parisiens du XIV siècle aimaient aussi à fleurir leur maison; plusieurs ordonnances de police parvenues jusqu à nous réglementent les jardinets aériens, en raison des plaintes des passants douchés par les eaux d'arrosage ou blessés par la chute des pots. Les pierres d'appui des croisées n'en continuèrent pas moins à se parer d'Eillets, Romarins et Marjolaines, auxquels vinrent se joindre plus tard les plantes du Nouveau Monde et des Indes orientales : CFillet d'Inde, Momordique pomme de merveille et même l'Aubergine et la Tomate ou Pommier d'amour qui ne quittaient les fenêtres pour le potager qu'au XVIt $t^{\theta}$ siècle. Plus tard encore apparurent les Tulipes, les Jacinthes, les Narcisses, les Volubilis, la Vigne vierge, les Pélargonium, les Chrysanthèmes, puis, plus près de nous, la Morelle faux piment ou Cerisier d'amour, dit plaisamment Oranger de savetier, et le Fuchsia, orgueil des fenêtres dans les quartiers populaires, et tant d'autres espèces charmantes ou curieuses.

De nos jours, les décorations florales des fenêtres et des balcons sont encouragées en Belgique, en $\mathrm{Hol}$ lande, en Angleterre, etc., par des concours. En France, l'Euure des tenêtres fleuries, la Société du Nouveau Paris, pour la capitale, les Sociétés d'Horticulture, dans les dé- 
partements, organisent des concours qui récompensent des merveilles de grâce et d'ingéniosité.

Les toitures en terrasse offrent aussi une précieuse ressource. En Orient, en Italie, en Espagne, sur les terrasses de pierre ornées de balustrades, prospèrent des Orangers, des Rosiers, des Lauriers-roses et des Myrtes. Même dans les pays du Nord, depuis quelques années, les toitures plates en béton recouvert de terre végétale permettent de réaliser la terrasse-jardin. On en voit en Allemagne, en Belgique; il y en a au sommet des maisons géantes de New-York; Paris en possède quelques-unes, dont la plus connue est celle de l'Automobile-Club, sur la place de la Concorde : cest un petit parc, avec des parterres de fleurs, des bosquets, des berceaux de verdure, un bassin avec jet d'eau et un kiosque à musique.

Les plantes dans l'appartement. - Les plantes dites d'appartement exigent beaucoup de soins pour vivre dans un milieu où l'air et la lumière leur manquent à la fois. La respiration des plantes vertes ainsi emprisonnées est toujours peu active et, pendant la nuit, elles ne dégagent que des quantités relativement faibles de gaz carbonique; il n'en est pas de même des plañtes fleuries; elles sont dangereuses la nuit, dans une pièce close, par leur respiration intense et par les essences qu'elles émettent souvent.

Les meilleures plantes à feuillage pour l'appartement sont celles qui ont des feuilles dures, lisses et d'un vert foncé; elles sont peu fragiles, facilement nettoyables et résistent au manque d'eau : Aspidistra, Caoutchouc, Dracæna, Araucaria, Palmiers et plantes grasses sont parmi les plus endurantes. Parmi les plantes à fleurs, les espèces bulbeuses constituent une précieuse ressource, grâce à la facilité de leur culture et à la beauté de leurs corolles.

Les fleurs coupées et les feuillages disposés avec goût en bouquets et en gerbes dans des vases bien choisis formeront toujours la décoration la plus belle de la demeure et celle qu'on peut le plus aisément varier et renouveler. Les cucillettes faites au cours des promenades, auxquelles s'ajoutent quelques petits achats chez la fleuriste voisine, en fournissent aux plus modestes ménages les éléments peu coûteux. Dans une maison élégante, Ja fleur peut être, au contraire, un élément im-

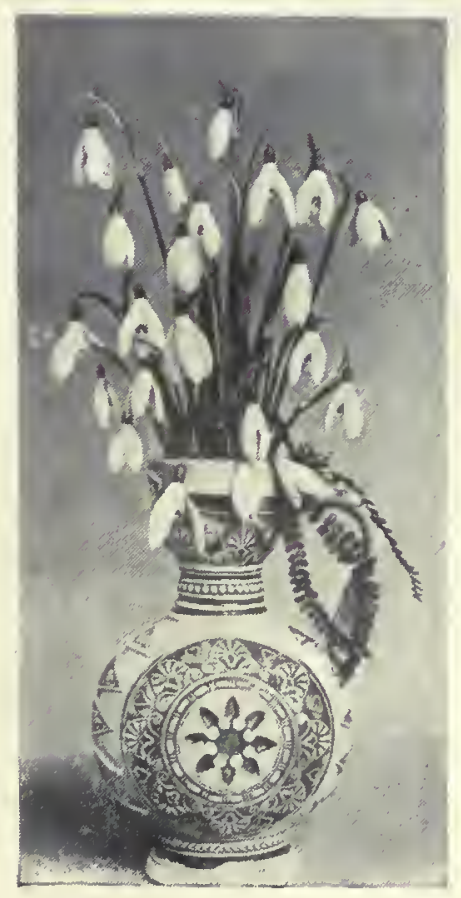

Perce-neige.

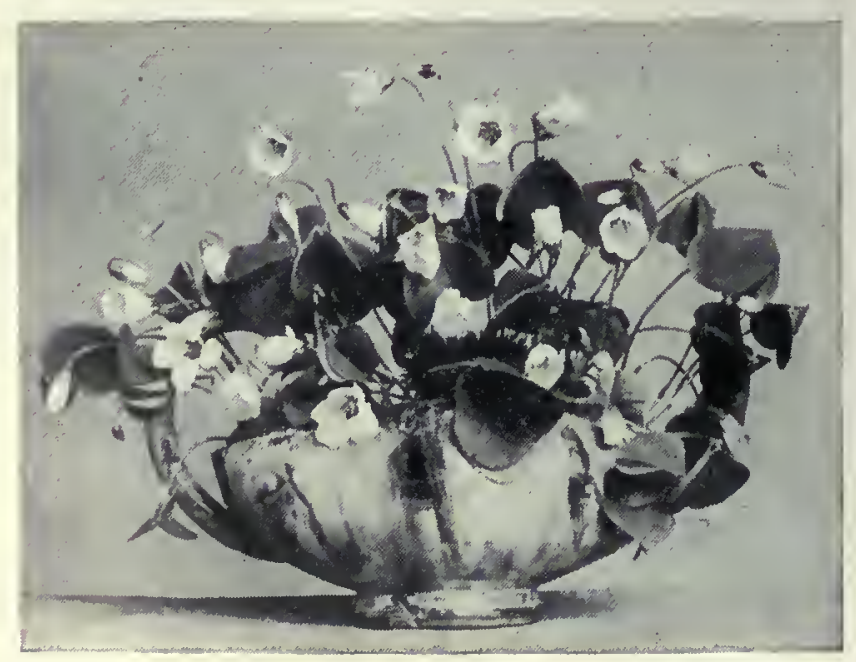

Oxalis petite-oseitle. portant de dépense : les riches New-Yorkais qui paient à leur fleuriste 25000 francs par an pour l'entretien de la décoration florale de leur maison sont plus nombreux qu'on ne l'imagine.

Au moyen âge, dans les festins, les invités s'ornaient de feurs naturelles tressées en "chapels". Aujourd hui, c'est surtout la table quel'on pare de fleurs et, danscertaines maisons, cette ornementation florale entre pour une part notable dans la dépense d'un repas.

Les Japonais ont une conception spéciale du décor par les plantes. L'art des bouquets y est complexe et nécessite une longue initiation. Avec un bouquet composé suivant les règles, on doit peindre ou indiquer la joie, la tristesse, le plaisir ou la douleur; I'harmonie des couleurs qui, chez nous, passe avant tout, a peu d'importance au pays du Soleil Levant; on ne tient compte que de l'harmonie et de la beauté de la ligne, en évitant la symétrie.

Les fleurs dans la toilette, les fêtes, les cérémonies. - Suivant les caprices de la mode, les fleurs naturelles forment une partie plus ou moins importante de la toilette féminine. Pour le bal, la coiffure, le corsage et même la jupe peuvent s'agrémenter d'une gracieuse aigrette de Muguet ou d'une guirlande d'Orchidéc. A la promenade, le bouquet de corsage, la boutonnière fleurie sont toujours de bon ton; on y glisse même un petit réservoir caché et bien clos, renfermant de l'eau pour que les fleurs se maintiennent fraîches. A Paris, les fleuristes des quartiers élégants ont un certain nombre d'abonnements de boutonnières : violettes de Parme, ceillets, gardenia, roses, petits bouquets composés, suivant la saison. Certaines " boutonnières "s sont célèbres; celles de lord Palmerston, d'Odilon Barrot, étaient d'un bout de l'année à l'autre fleuries d'une rose, celle de Disraeli d'une Primevère. A certaines époques, la fleur : violette, oeillet blanc ou rouge, bleuet, immortelle, qui orne le vêtement, est non seulement une parure, mais un emblème, et aspire à jouer un rôle politique.

Les fleurs nous accompagnent du berceau à la tombe; on les voit apparaître à tous les actes de la vie familiale ou sociale : fleurs pour les baptêmes, les mariages, les fêtes, les anniversaires, fleurs aussi pour les morts, recouvrant les corbillards ou la terre des tombeaux. Aux approches de

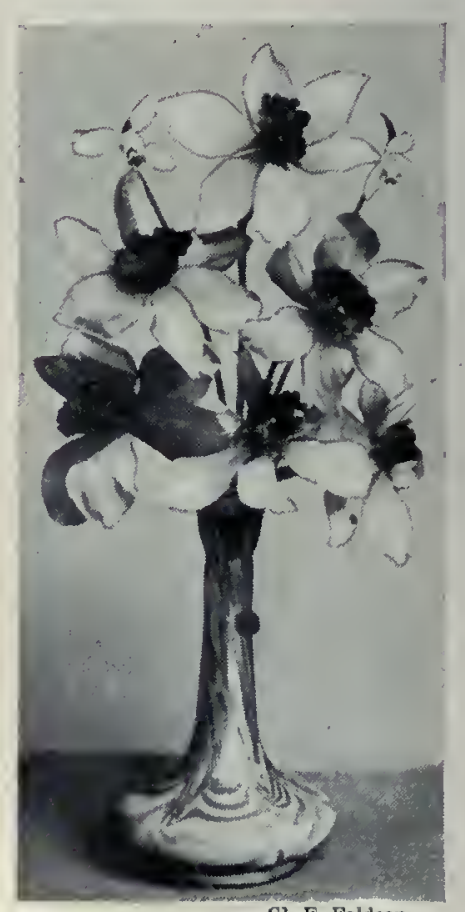

Narcisses. 
la Toussaint, le commerce des Chrysanthèmes en pots ou à planter sur les tombes prend partout une énorme extension. La valeur des fleurs qui accompagnent les morts illustres représente parfois une véritable fortune.

Les Fêtes des Fleurs, les régates fleuries comme on en voit à Venise, sont aussi l'occasion de grandes dépenses. Les fleurs collaborent aussi à la beauté des cérémonies religieuses: en Espagne, en l talie, par jonchées elles recouvrent les rues sur le passage des processions; à Orotawa, dans lî̀le de Ténériffe, les rues, lors des mêmes cérémonies, sont tapissées de mosaïques de pétales. Des cadres en bois déterminent

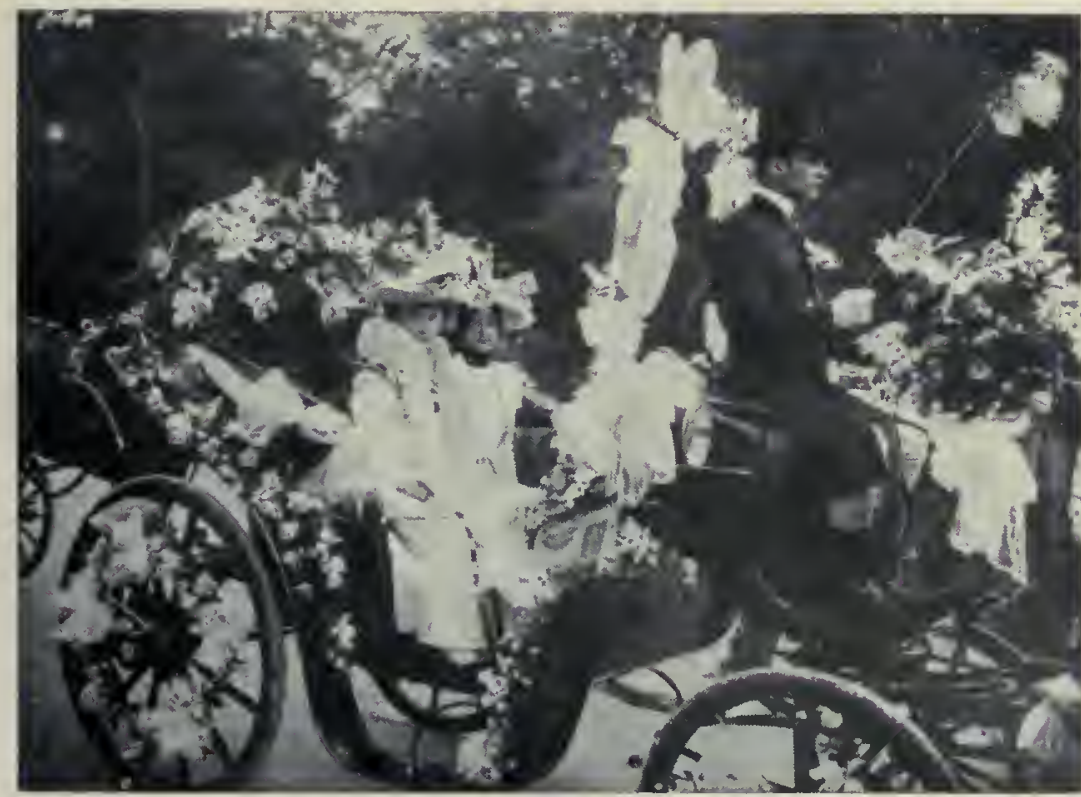

Une calèche à la Fête des Fleurs.

pes, Chrysanthèmes, etc., suivant les saisons. Mais ce n'est là qu'un faible appoint. La masse du "Paris " est fournie par quatre cents à cinq cents horticulteurs qui se spécialisent dans la culture d'un petit nombre d'espèces de plein air ou de serre.

Sans sortir de Paris, on peut voir quelques grands établissements horticoles : à Montrouge on élève les plantes bulbeuses, à Charonne et au boulevard d'Italie des horticulteurs forcent l'Oranger uniquement en vue de la production des fleurs pour bouquets de mariées, à Picpus on force le Réséda et les Giroflées, à la Glacière les Héliotropes et les Cyclamens. La banlieue compte vingt forceque l'on veut exécuter; on les remplit de pétales de la couleur voulue pour obtenir l'effet désiré; le fond de verdure est formé par des Bruyères coupées en menus morceaux.

Quelques fêtes religieuses donnent lieu à des commerces spéciaux se rapportant aux plantes. Le jour des Rameaux, c'est, à la porte de nos églises, la vente du Buis. Dans certaines parties de l'Italie et jusqu'à Nice, il est remplacé par celle des palmarelli, qui font l'objet d'une culture spéciale du Dattier sur le territoire de Bordighera. Les palmarelli sont de deux sortes : les "romains", qui servent pour la fête chrétienne des Rameaux, et les " juifs ", pour la fête des Tabernacles.

Pour obtenir les premiers, on lie les Dattiers dès le commencement de mars, de façon à faire blanchir les feuilles qu'on travaille ensuite en longues hampes tressées. Les palmarelli juifs sont verts; ils subissent la concurrence de ceux d'Alexandrie en Egypte et d'Elche en Espagne; ils s'expédient surtout en Allemagne et dans le Nord-Amérique.

Aux environs de Noël, deux productions végétales sont fort demandées : d'une part, les jeunes Pins et Sapins pour arbres de Noël, cultivés spécialement dans ce but aux environs de Paris; et, d'autre part, le Gui, plante sacrée des Druides, plante porte-veine, dont la vente à Paris est importante pendant tout l'hiver ; mais la consommation qui s'en fait en Angleterre pour les fêtes de Noël est considérable : chaque maison, même la plus humble, est ornée de sa touffe de Gui. Le Royaume-Uni ne se suffisant pas en Gui, la France lui en expédie d'énormes quantités dont la cueillette se fait sur les Pommiers de Normandie et de Bretagne. De Dinan un grand nombre de wagons chargés de Gui partent à destination de Saint-Malo; ce port, à lui seul, expédie chaque année en Angleterre un demi-million de kilogrammes de Gui ; Granville, plus de 100000 kilogrammes et Saint-Brieuc tout autant.

L'industrie horticole de la région parisienne. - Le commerce parisien de la fleur distingue deux catégories de productions: le "Paris" et le "Nice". Le "Paris " donne toute l'année; il est fourni par les départements de Seine et Seine-et-Oise; le "Nice " vient de Provence, de novembre à la fin de mai. Voyons d'abord le " $\mathrm{Pa}$ ris 11. La plupart des maraîchers parisiens, au milieu de leurs légumes, consacrent à la fleur quelques châssis ou quelques planches. Ils portent sur les marchés des plantes en pots : roses de Noël, Violettes des quatre saisons, Giroflées jaunes, Pensées, Jacinthes, Tulipes, Héliotro-

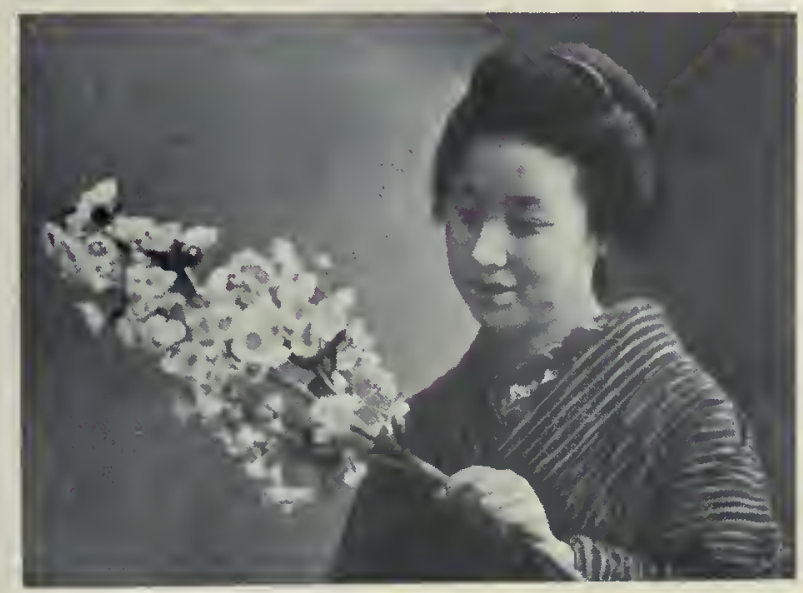

Jeune filte d'Osaka avec une branche de Cerisier. ries de Lilas, surtout à Vitry et au Grand Montrouge; Montreuilsous-Bois nous envoie ses Camelia, Gardenia, Azalées, Cycla-

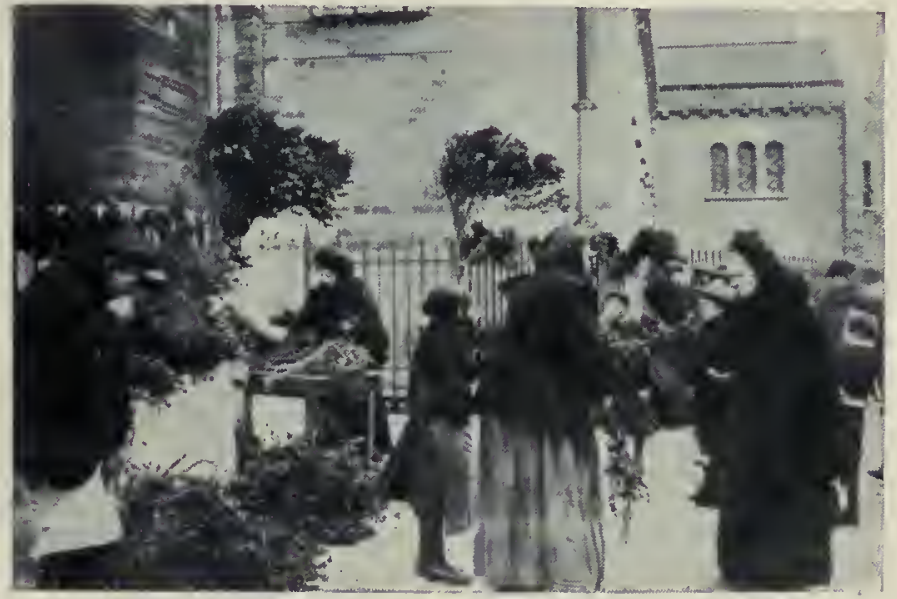

Devant une église, le jour des Rameaux.

mens et Lilas forcés; Fontenay-sous-Bois, la Primevère de Chine et les Cinéraires hybrides; Vanves, des Bouvardia; Bourg-laReine, Sceaux et Verrières se consacrent surtout aux Violettes de Parme et des quatre saisons; Ivry, aux Tulipes, Narcisses, Tubéreuses et Jacinthes. On force le Muguet à Neuilly, le Rosier un peu partout; on cultive les Fougères à Vincennes, des plantes à feuillage à Versailles, Mortefontaine; les Orchidées, à Versailles, Saint-Cloud, etc.

Beaucoup d'horticulteurs joignent à la production florale proprement dite celle des arbustes d'ornement : Clématites à grandes fleurs, Viornes, Erables, Conifères, etc. ; plusieurs grands établissements ne vendent pas seulement des fleurs, mais des graines sélectionnées, des bulbes et tubercules de choix; il en est dont les produits, renommés à juste titre, se dispersent dans le monde entier.

Le forcage et le retardage. - L'idéal' auquel tend aujourd'hui l'horticulteur est d'amener sur les marchés les plus belles plantes, produites avec le minimum de frais et en toutes saisons. On y parvient 


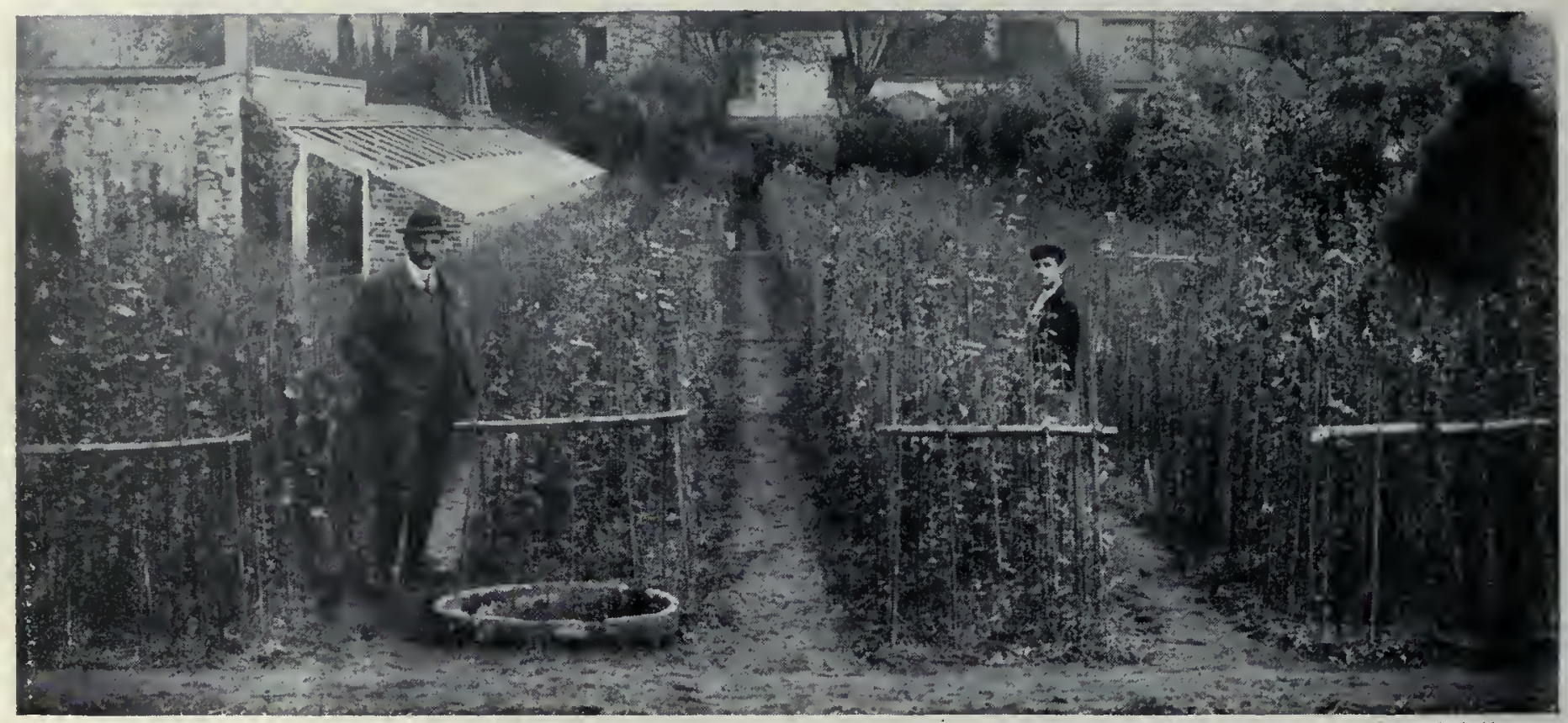

Une pépinière de Clématites à grandes fleurs.

pour un grand nombre d'entre elles : dans les grandes villes d'Europe ou des États-Unis, on peut se procurer à n importe quel jour de l'année du muguet, du lilas, des roses, des cillets, etc. Voyons comment les horticulteurs sont parvenus à supprimer les saisons. Distinguons d'abord le chauffage et le forçage. Par le chauffage, on se borne à activer en serre la montée de la sève dans les boutons déjà formés et on laisse à la fleur un temps presque normal pour s'épanouir : on ne gagne que quelques semaines sur l'époque de floraison régulière. $\mathrm{Par}$ le forçage, au contraire, on violente le végétal; on l'oblige à passer en un temps très court par toutes les phases de son développement et il meurt presque toujours de l'effort. Il est nécessaire pour forcer une plante que sa végétation soit complètement arrêtée, sinon la chaleur fait développer ses feuilles, mais ses bourgeons floraux avortent. Pour avancer cette période de repos, qui ne se fait sous nos climats que vers la fin d'octobre, on arrache de bonne heure les plantes à forcer et on les expose à l'air.

En 1893, Johannsen, de Copenhague, a montré que les vapeurs d'éther ont la même action que la gelée pour arrêter la végétation; elles font jaunir et tomber les feuilles, arrêtent la circulation de la sève et créent la période de repos. En éthérisant ou chloroformant dès le mois de juillet une plante à floraison printanière, elle entre dans la période de repos et peut être forcée de suite, alors que si l'on avait laissé faire la nature, la plante n'eut été bonne à forcer qu'à partir de novembre. C'est pendant les mois de juillet et d'août que l'éthérisation donne les meilleurs résultats. Les plantes sont mises dans de grandes caisses à la température de $18^{\circ}$, on les soumet pendant cinquante heures à l'action des vapeurs d'éther ou de

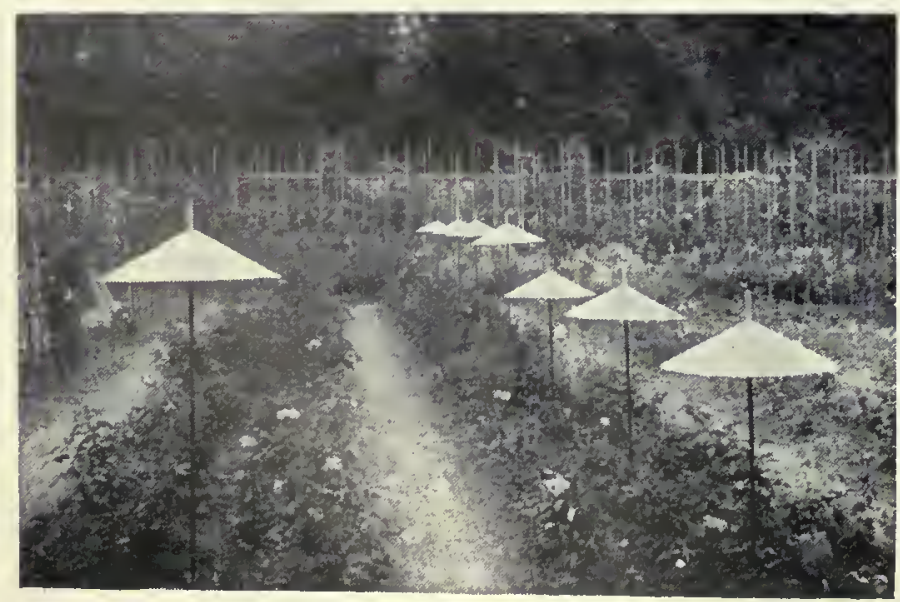

Abris pour les jeunes Rosiers, à l'Hay. chloroforme; aussitôt après, elles sont placées en serre chaude et forcées; elles fleurissent beaucoup plus rapidement que celles qui n'ont pas été éthérisées.

L'éthérisation, qui se pratique en grand dans plusieurs forceries de Berlin et de Hambourg, ne s'applique évidemment qu'aux plantes ayant fleuri au printemps et dont les bourgeons à fleurs sont formés avant l'hiver: Lilas, Boules-de-neige, Cerisier du Japon, Prunier de Chine, Azalée, Deutzia, Staphylea, Glycine, Hortensia, Hoteia, Muguet, etc.

Hans Molich, professeur à l'Université de Prague, a montré en 1908 qu'on pouvait remplacer l'éthérisation par des bains chauds, pour abréger la période de repos des plantes. On plonge l'arbuste la tête en bas, sans mouiller les racines, dans un bain d'eau tiède et on l'y maintient pendant neuf à douze heures au maximum. La température la plus convenable varie entre $30^{\circ}$ et $40^{\circ}$, suivant les espèces; on procède ensuite au forçage.

De même quion peut produire un été factice dans les forceries, on peut créer un hiver artificiel par des chambres froides et pratiquer ainsi le retardage, qui complète le forçage pour la suppression des saisons. Voici, par exemple, des Lis, des Hortensia qui, abandonnés à eux-mêmes, seraient défleuris dès la fin de juillet, alors que l'horticulteur aurait intérêt à les'avoir en fleurs le 15 août, date qui correspond

à l'une des plus grandes ventes de l'année. ll lui suffit, pour réaliser son désir, de les placer en temps utile dans une chambre aérée, maintenue, par circulation d'une solution saline refroidie, à une température voisine de $0^{\circ}$. On conserve ainsi des bulbes de Lis, de Jacinthes, de Tulipes, des griffes de Muguet, des Spirées, des Lilas, des Rosiers et autres arbustes pour les mettre en végétation quand on juge le moment favorable, et même des fleurs coupées en gerbes dans l'eau, où elles

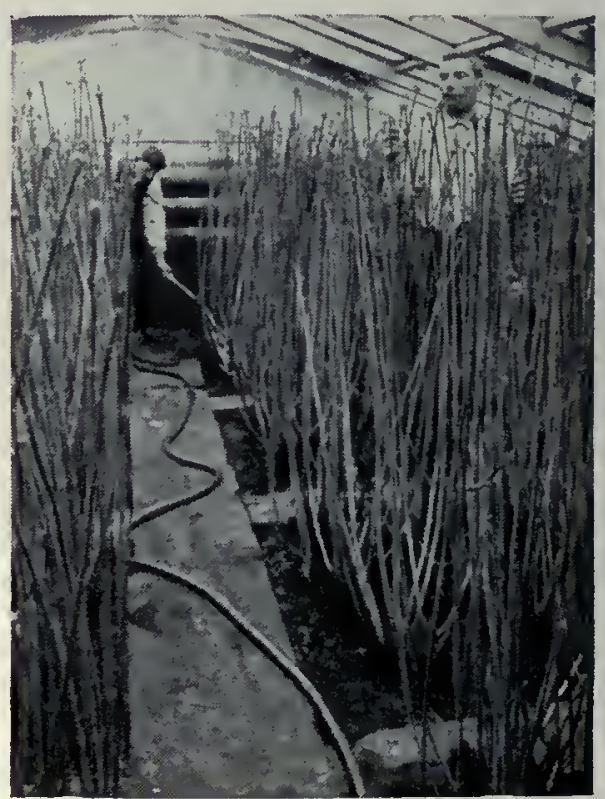

Ebourgeonnage des Boules-de-neige. 
gardent leur fraîcheur pendant une durée de vingt à soixante jours, suivant les espèces. Lors de la mise en végétation, il faut procéder progressivement et laisser dégeler les bourgeons peu à peu, avant de les soumettre au forçage.

Lindustrie du retardage, qui a pris naissance en Angleterre en 1892, est aujourd'hui fort développée dans ce pays et en Allemagne, ainsi quen Italie, au Japon et aux Etats-Unis; elle y rend des services considérables. En France, on ne pratique pas assez l'industrie du froid, laquelle cependant a vu le jour dans notre pays avec les travaux de Charles Tellier.

Forcage des Rosiers, Lilas èt Muguet. - Voyons

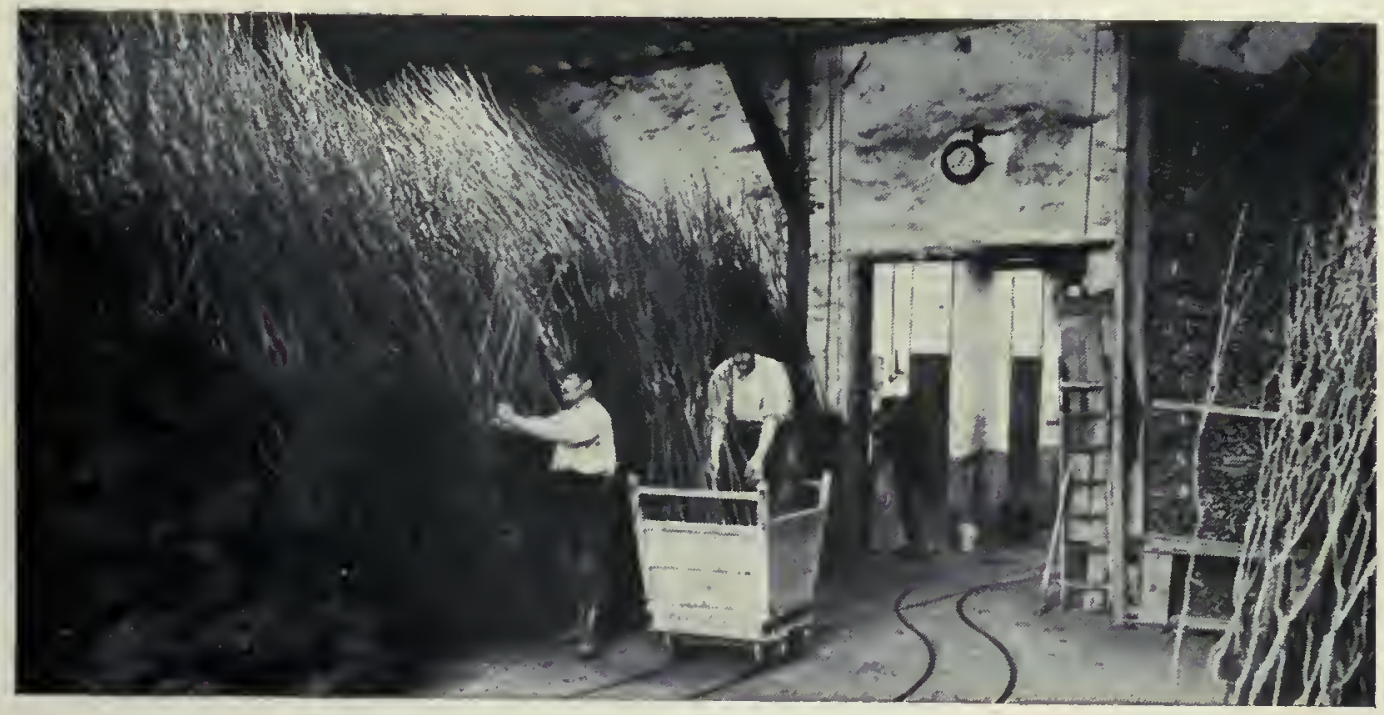

comment on applique ces méthodes dans quelques cas particuliers.

Les Rosiers de forçage des horticulteurs parisiens proviennent de la Brie où on les cultive en pleine terre et, dès la fin de l'automne, on les place dans des serres basses, fortement chauffées, très humides et bien éclairées. Deux mois après, ils sont en plein rapport; leur floraison ne dure que quelques jours; dès qu'elle est terminée, on arrache les plantes, qui sont mises en fagots pour le chauffage, et on les remplace par d'autresqu'on force de nouveau. La Reine est, par excellence, la rose de forçage; on y soumet aussi La France, la Paul Neyron, la Maréchal Niel, la Gloire de Dijon, etc.

Les pépinières qui alimentent les forceries parisiennes de Lilas occupent de vastes surfaces à Vitry. Les arbustes, appartenant aux variétés violettes, Marly ou Charles $X$, sont arrachés à l'automne, à l'âge de cing à neuf ans, le pied entouré d'une épaisse motte de terre, et on les place sous des hangars comme des fagots de bois mort. On les plante au fur et à mesure des besoins dans des serres maintenues à la température de $28^{\circ}$ à $30^{\circ}$, où l'obscurité est à peu près complète, sauf pendant quelques instants chaque jour. Au bout de trois semaines, les grappes s'épanouissent ; elles sont blanches, non à cause de leur développement à l'obscurité, mais par suite de la température à laquelle on opère; on les cueille chaque soir pour les porter aux Halles. Les forceries parisiennes fournissent le Lilas du 15 novembre au mois de mai; les forceries allemandes et anglaises, par l'éthérisation et le retardage, en produisent toute l'année.

De toutes les plantes, le Muguet est celle qui se prête le mieux au forçage. Une griffe sèche, placée en terre ou dans de la mousse et maintenue jour et nuit à la température de $25^{\circ}$ à $30^{\circ}$, donne en vingt jours une belle grappe de fleurs. En procédant ainsi par étapes régulières, la succession ininterrompue des floraisons sc prolonge jusqu en avril. Le forçage du Muguet se pratique surtout en Allemagne, en Angleterre et en Amérique. En France, Neuilly

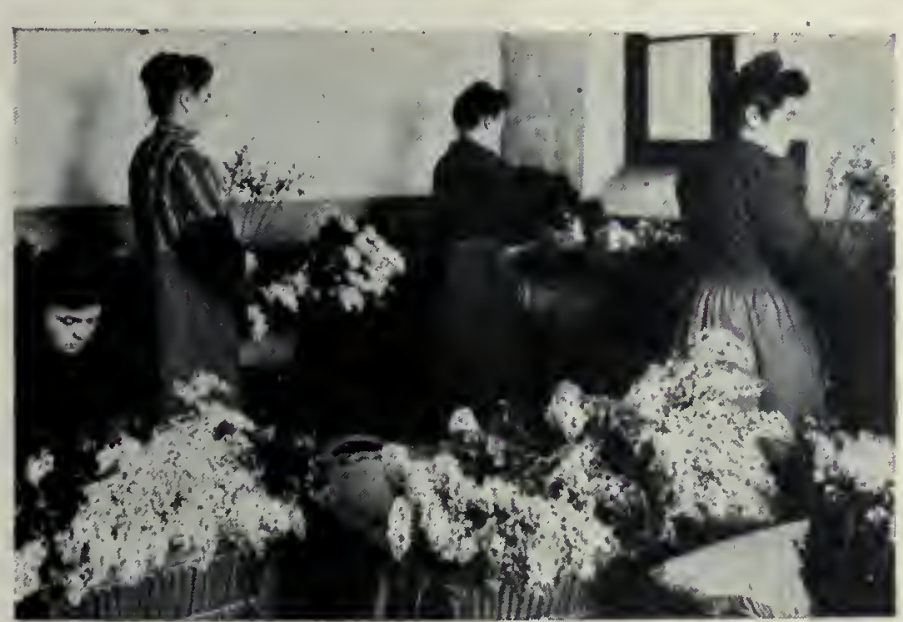

est le centre principal de cette industrie. D'autre part, la culture retardée du Muguet permet d'en obtenir en fleur de juin à novembre. Au lieu de mettre les griffes en végétation dès le mois de mars, on les conserve en caisses dans des chambres frigorifiques à $1^{\circ}$ ou $2^{\circ}$ au-dessous de zéro. On les chauffe au moment voulu. La maison Thomas Rochefort, à Cheshunt (Angleterre), est la plus importante du monde entier pour la réfrigération des plantes. $C^{\prime}$ est par centaines de mille qu'elle expédie les griffes retardées; c'est là que s'approvisionnent nos forceurs.

Production florale du midi de la France. - C'est Alphonse Karr, dit-on, qui créa l'exportation des fleurs de Nice en expédiant à Paris, avant 1870 , quelques bouquets de violettes. Depuis, la foriculture a pris sur la Côte d'Azur une vaste extension, soit pour la parfumerie, soit pour la fleur coupée. Dans le seul département des Alpes-Maritimes, 2000 hectares y sont consacrés; la production est intense d'octobre en avril. Elle a lieu surtout en plein air, sous ce climat si doux ; mais, pour certaines plantes, on utilise des bâches à châssis vitrés, sortes de petites serres rectangulaires qui recouvrent les plates-bandes; les serres chauffées sont plus rares.

Du 15 octobre au 15 mai, des marchés ont lieu dans les principales villes du littoral; les commissionnaires et expéditeurs s'y approvisionnent. Les fleurs, recouvertes de papier de soie, sont emballées dans des paniers rectangulaires en roseau. Le train des fleurs quitte Nice chaque jour vers midi et ramasse en route tous les colis postaux des Alpes-Maritimes et du Var. La plus grande partie de cette production est vendue aux Halles, à Paris; l'Allemagne, l'Angleterre et la Suisse en reçoivent aussi une portion notable. Paris reçoit du Midi chaque année des millions de douzaines de Roses, d'Cillets (principalement d'Antibes), de paquets de Violettes, puis des Giroflées, des Anémones, des Anthémis, des Narcisses, des Mimosa à pompons ou en épis, ces derniers,

Préparation et emballage des fleurs pour l'exportation.

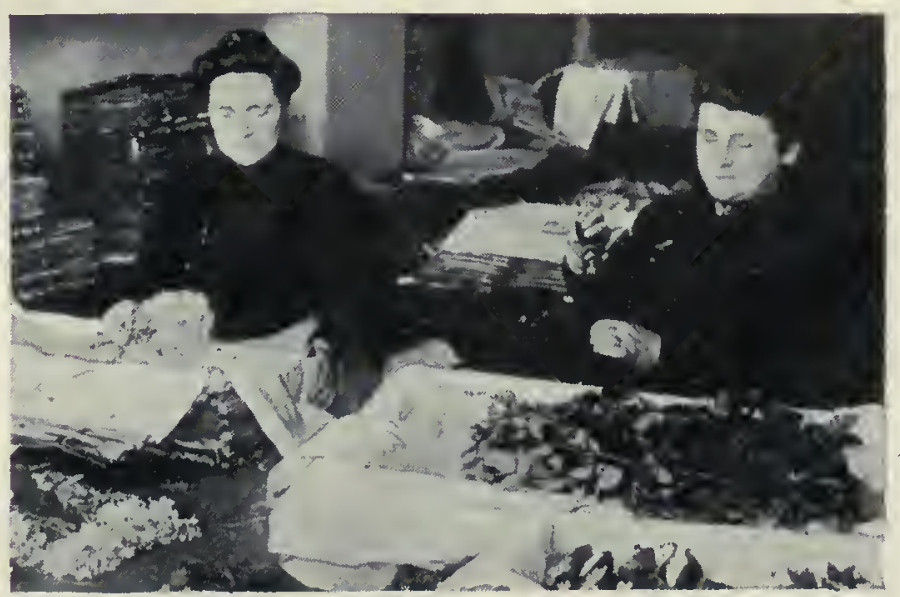




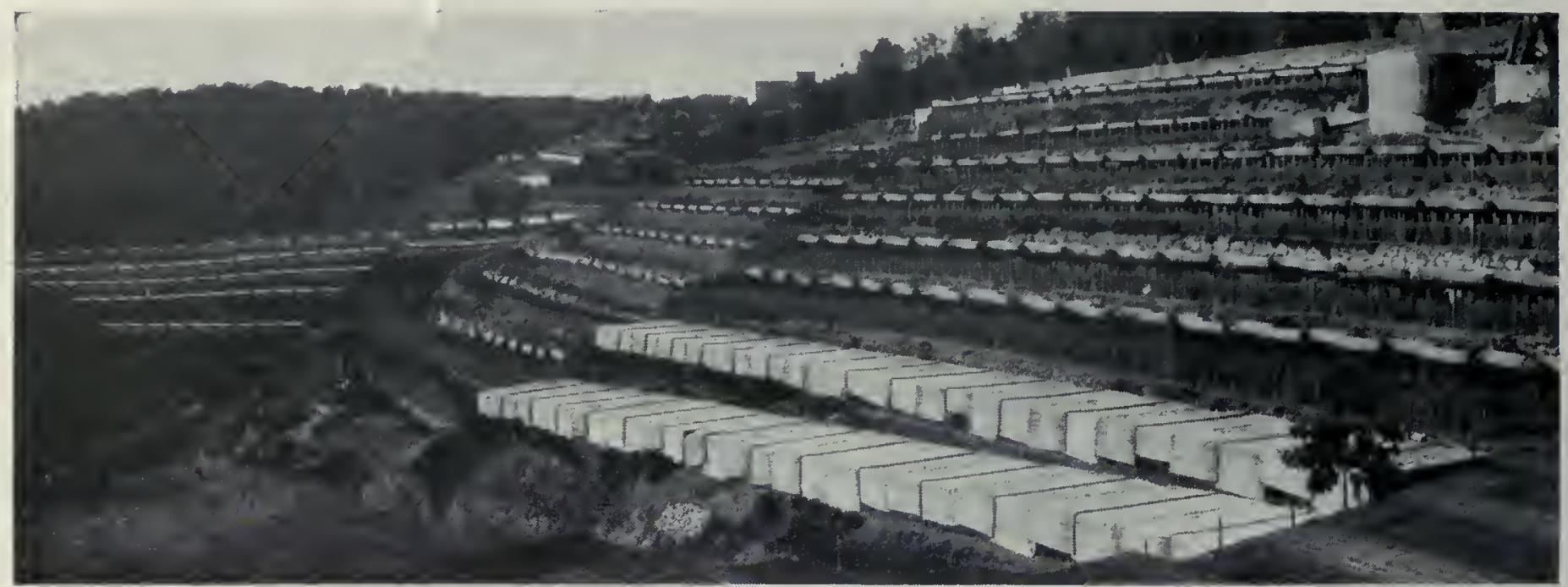

Forçage des Eillets sous abri, dans les Alpes-Maritimes.

connus des marchands sous le nom de chenilles, et, en moins grande quantité, des Freesia, Tubéreuses, Renoncules et Jacinthes.

Indépendamment du commerce de la fleur coupée, les environs de Toulon, Ollioules, Hyères, Solliès-Pont s'occupent de la production des oignons à fleurs, dont ils exportent chaque année d'énormes quantités aux États-Unis, aux Pays-Bas et en Allemagne. Depuis 1820, Ollioules et Bandol ont la spécialité de l'lmmortelle d'Orient pour couronnes funéraires et consacrent 1500 hectares à la culture de cette plante. Cueillie en juin, la plante est séchée au soleil, mise en bottes, teinte sil y a lieu et transformée sur place en couronne par application sur un toron de paille, ou bien expédiée à Paris, où on la mélange avec l'Immortelle à bractées produite aux environs de Lisieux.

Enfin, le Midi ćlève les jeunes Palmiers, les Dracæna et autres plantes vertes ornementales, et en exporte un nombre considérable. A la production florale de la Côte d'Azur, il faut ajouter les envois de la région de Toulouse en Violette de Parme et Violette dite russe. Les environs d'Orléans, de Lyon, de Tours et d'Angers surtout sont aussi des régions horticoles de premier ordre.

L'horticulture à l'étranger. - L'horticulture est fort développée en Belgique, à Bruxelles, Bruges, Liége et à Gand, la ville des fleurs. Le gros de la production comprend les Camélia, Rhododendrons, Araucaria, comme plantes de plein air en été ; les Palmiers, Fougères, Crotons, Orchidées, comme espèces de serre. Le commerce des bulbes secs de Bégonia tubéreux est
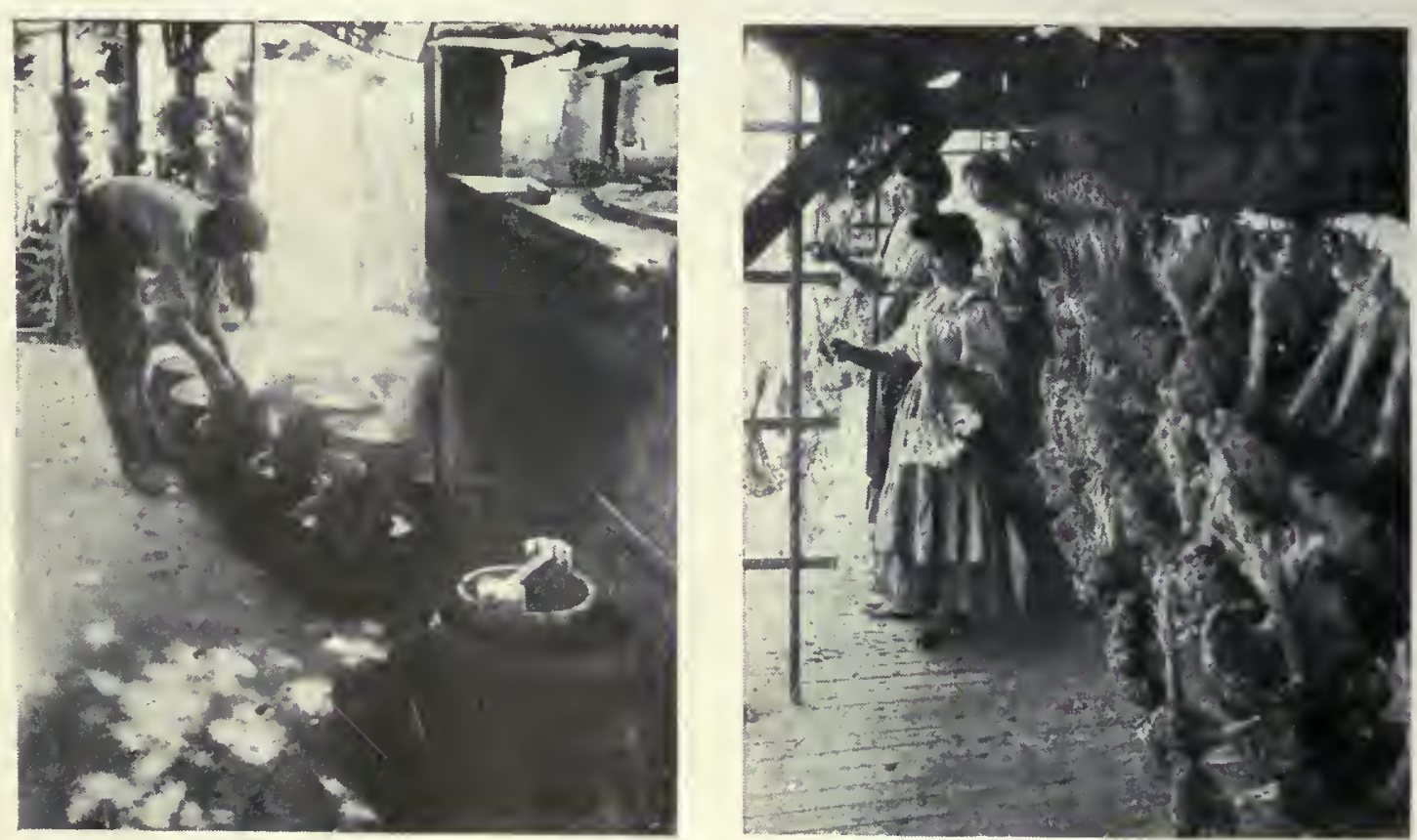

Teinture et séchage des Immortelles dans le Var. très prospère; Gand a la spécialité des Azalées, et Bruges celle des Lauriers sauce taillés en boule ou en pyramide, qui sont expédiés dans le monde entier.

La Hollande fait une énorme culture de bulbes de Tulipes, Jacinthes et Narcisses ; sans compter les colis postaux, elle en exporte annuellement 20 millions de kilogrammes, princjpalement sur l'Angleterre, l'Allemagne et les Etats-Unis. C'est un merveilleux spectacle au printemps que la vue d'immenses surfaces couvertes de plantes bulbeuses, dont la floraison couvre d'un tapis multicolore les terres d'alluvion convenant particulièrement à leur culture. Les envois de fleurs coupées de la Riviera italienne sont moins abondants que ceux de notre Côte d'Azur, mais donnent lieu cependant à un grand commerce.

Les Etats-Unis, l'Allemagne, l'Angleterre ont une industrie horticole très importante, très avancée et tenue au courant de tous les progrès de la science. Les forceries de Berlin, Dresde, Hambourg ont presque le monopole du Muguet; l'Angleterre, celui des bulbes de différentes espèces de Lis, dont beaucoup sont importés du Japon par navires frigorifiques; elle a aussi la spécialité des Muguets retardés.

Le Japon est une grande contrée horticole. Une foule de petits marchands au détail circulent dans les rues des villes et ne sollicitent pas en vain la clientèle; ils nutilisent pas, comme nos marchands parisiens, la petite voiture à bras; jls portent sur ['épaule une forte perche aux extrémités de laquelle sont équilibrés deux plateaux chargés des plantes en pots ou des fleurs coupées, qui plongent dans des tubes de Bambou remplis d'eau.

La vente des fleurs à Paris. - Quelques horticulteurs de la banlieue parisienne portent directement leur production dans les marchés aux fleurs; un certain nombre de fleuristes reçoivent des colis postaux du Midi, mais c'est par les Halles centrales que passe la plus grande partie de la fleur utilisée par Paris. Elle arrive la nuit, apportée par les grandes voitures fermées des horticulteurs ou par les lourds camions de la gare de Lyon. La vente à la criée commence à trois heures du matin en été, à quatre heures en hiver et porte journellement sur plusieurs milliers de paniers. Là viennent s'approvisionner les fleuristes, les commissionnaires qui achètent pour réexpédier 

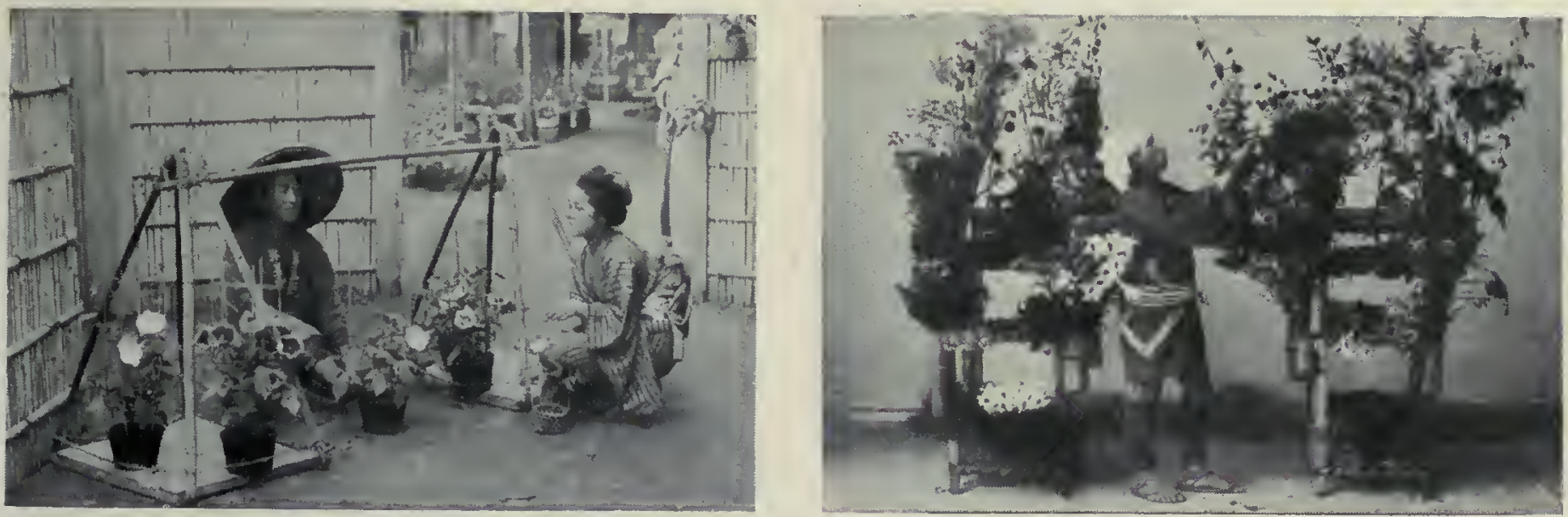

Marchands de fleurs ambulants, au Japon.

vers la province ou l'étranger. Les " regrattiers" revendront quelques heures plus tard, sur le carreau, aux fleuristes des kiosques et aux ambulants qui, le panier au bras, la hotte sur le dos, ou poussant devant eux la voiture à bras, parcourront tout le jour les quartiers de la capitale en lançant à pleine voix leur cri d'appel : "Fleurissez-vous, Mesdames!"

A côté de ces ambulants, qui vendent la fleur achetée aux Halles, une autre catégorie est celle des camelots, véritables juifs errants de la fleur, qui, d'un bout à l'autre de l'année, courent les bois des environs de Paris, à la recherche des plantes bonnes à vendre, procèdent à la cueillette et reviennent ensuite l'offrir aux fleuristes ou aux passants. En février, ils vont cueillir les Perce-neige dans les bois de Versailles; en mars, le Narcisse jaune dans la forêt de Sénart, la Pervenche, les Primevères ou Coucous; on avril, l'Anémone des bois et la Jacinthe sauvage; en mai, le Muguet, l'Aubépine, la Grande Marguerite; en juin, les charmantes plantes des moissons; en juillet et août, les Bruyères; en septembre, les Roseaux à balais et les Massettes. L'automne leur apporte les branches de Houx, de Fusain, d'Asperge chargées de fruits aux couleurs vives, le Lierre, les Cardères, les branches d'arbres avec leurs feuilles nuancées de jaune ou de pourpre. Pendant tout le mois de décembre, on voit par les rues le marchand de Gui, portant surl'épaule ses boules de verdure attachées à une forte branche ou roulant son étalage dans une charrette à bras.

Les verduriers se spécialisent dans la cueillette des feuilles pour garnitures: Platane, Sycomore, Ronce, Lierre, Fougères, Pervenche, Mousse, etc., qu ils disposent en paquets et portent aux Halles ou à des clients attitrés. C'est aux Halles que vont s'approvisionner de verdure, d'une part les bouquetières, d'autre part les restaurateurs, crémiers et fruitiers. Le marché à la verdure est encore alimenté par les horticulteurs et les marâ̂chers qui apportent la feuille de Vigne ou de Mahonia.

Pour cueillir les feuilles des arbres dans les forêts de l'Etat, une demande sur papier timbré est nécessaire; la permission n'est accordée que contre redevance annuelle et ne donne droit quau seul genre de verdure indiqué sur la demande.

\section{Les marchés et les fleuristes.} - Les marchés aux fleurs ne font pas double emploi avec les Halles, car ils ont surtout pour objet la vente des plan-

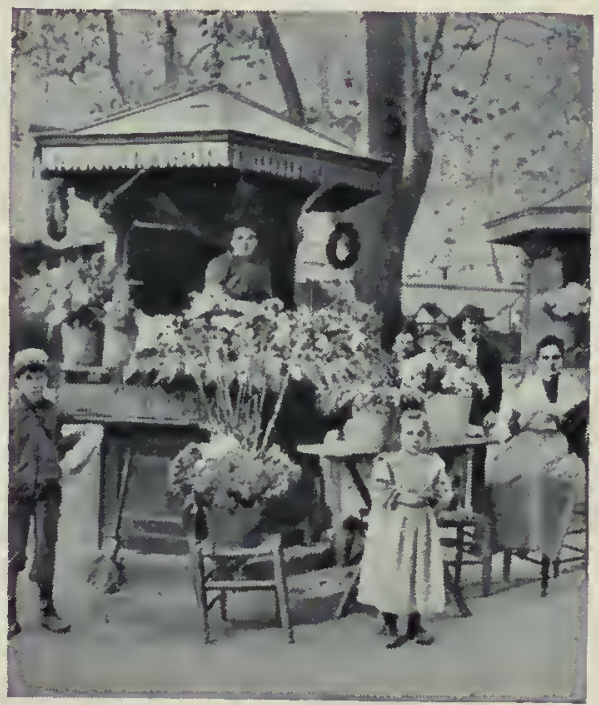

Un kiosque de fleuriste, à Marseille. tes en pots ou en mottes. II en existe onze à Paris; ils offrent un coup d'œil animé et des plus gracieux, surtout aux approches des grandes fêtes de l'Église et à celle des saints dont les noms sont populaires.

Le marché aux fleurs coupées de Marseille, non loin de la Cannebière, est très curieux avec ses kiosques symétriques où les vendeuses, perchées sur un siège surélevé, dominent de haut la clientèle.

Paris a aussi ses kiosques à fleurs, qui sont une des notes gaies de ses avenues; mais cest surtout aux devantures des grands fleuristes qu'on peut admirer d'un bout à l'autre de l'année des chefs-d'ceuvre d'art floral. Le personnel des fleuristes parisiens comprend d'ailleurs toute une hiérarchie : toupillonneuses, gerbeuses, monteuses et, enfin, au sommet, la coloriste, chargée de mettre en valeur, par le voisinage, l'aménagement et le contraste, toute la beauté et l'harmonie incluses dans les fleurs.

L'industrie des feuillages naturalisés et des plantes desséchées pour bouquets perpétuels est une annexe de l'industrie florale, qui a pris, de nos jours, une certaine importance; des magasins spéciaux, de plus en plus nombreux, en vendent les produits fort bien préparés.

Les plantes peu riches en eau, comme les Chardons et les Bruyères, n'ont besoin que d'une simple dessiccation à l'air, dans une

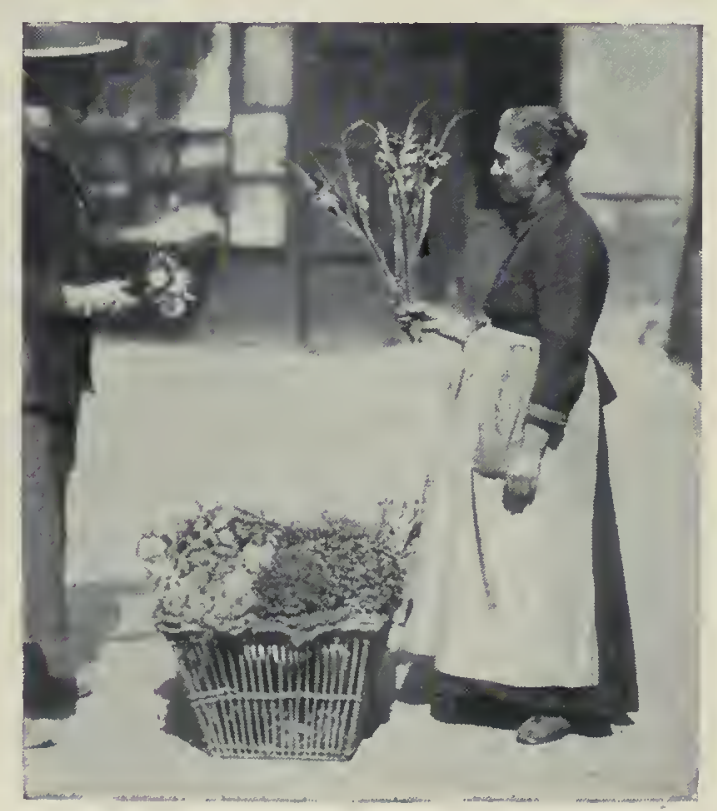

Fleuriste ambutante, à Paris. chambre peu éclairée. On conserve encore avec une grande facilité d'autres éléments de la flore indigène, comme les Immortelles, la Lunaire en fruits ou Monnaie de pape, certaines Graminées (Lagure ovale, Lamarkie dorée, etc.). des Ombelliferes en fruits, les Statices. Les autres plantes sont desséchées dans un sable spécial; on l'obtient avec du grès finement pilé, chauffé à $150^{\circ}$ et auquel on mélange un peu de blanc de baleine et d'acide stéarique; on broie le tout dans un morticr. Dans des caisses contenant un lit de ce sable, on place les plantes et on tamise doucement du sable au-dessus jusqu’à enfouissement. Les caisses sont mises pendant douze heures dans un four chauffé à $50^{\circ}$; on laisse ensuite refroidir vingt-quatre heures, de façon à ce que les plantes reprennent une certaine humidité qui les rend moins cassantes. On détache alors avec soin le sable qui y adhère et on dispose ces fleurs en bouquets. gracieux composés principalement de Bruyères, Chardons, Immortelles, Graminćes, avec des feuilles de Fougc̀res ou de Palmiers. 


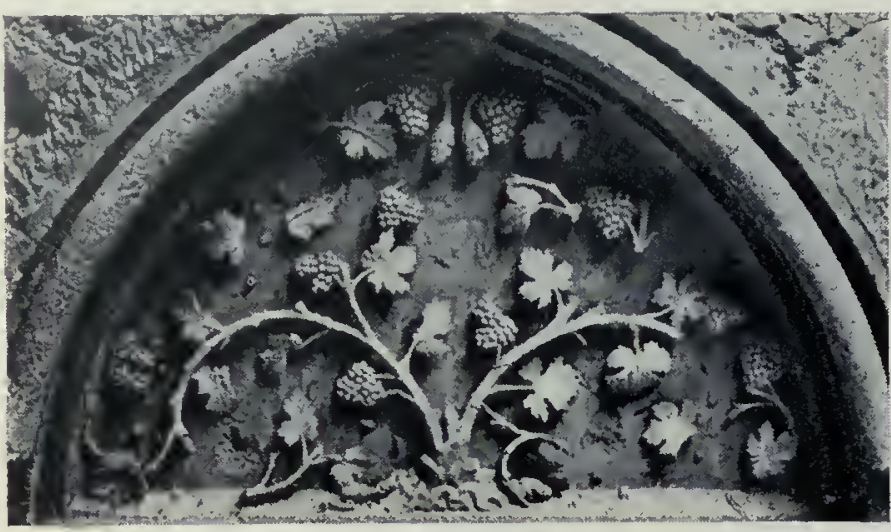

Maison à Chartres : Tympan d'une fenètre (XIIr ${ }^{\mathrm{e}}$ siècle).

\section{LA PLANTE DANS L'ART}

La beauté des plantes. - La plupart des vćgétaux présentent un ensemble harmonieux de formes, de proportions et de coloris qui éveille en nous le sentiment du plaisir et de l'admiration. Cette beauté est déjà frappante chez les plantes inférieures; rien n'est aussi charmant que les Mousses lorsqu’à la fin de l'hiver elles dressent, au sommet de leur tige délicate, le fin filament que termine la mignonne capsule sphérique ou ovoïde; les Algues, les Champignons offrent aussi à l'artiste des aspects intéressants. Quant aux Fougères de nos pays, clles sont la grâce même : avec un seul organe visible, la feuille, une seule couleur, le vert, elles réalisent ce miracle d'être variées à l'infini dans leur port, dans leurs contours et dans leurs nuances.

Avec le perfectionnement et la différenciation de ses organes, la beauté du végétal s'ćpurc et s'affine, soit qu'on en considère l'ensemble, soit qu'on en contemple les détails. "Les feuilles des plantes que nous foulons aux pieds, dit Ruskin, présentent les formes les plus bizarres et semblent ainsi nous inviter à les examiner. Elles sont étoilées, cordées, lancéolées, sagittées, découpées, dentelées. Elles prennent l'aspect de spirales, de guirlandes, d'aigrettes. En un mot, elles varient à l'infini et, tour à tour expressives, décevantes, fantastiques même, elles semblent avoir été créées pour tenter notre curiosité et pour exciter continuellement notre étonnement et notre admiration. "

"La beauté et la variété sont partout dans la plante : dans la disposition et le mouvement des branches, dans la forme des bourgeons et leur mode d'épanouissement, dans les découpures de la fenille et surtout dans la fleur, qui est le plus pur et le plus bel ouvrage de la terre. i) De toutes les parties du végétal, c'est elle qui exerce sur l'homme le plus de séduction. Les fleurs sont belles, non seulement par leurs couleurs vives, leurs formes élégantes et régulières, mais encore par leur port et leur mode de groupement, comme on peut l'observer chez le Muguet, la Fritillaire couronne impériale, le Lilas et tant d'autres.

Beaucoup de plantes, d'ailleurs, au lieu de former un petit nombre de grandes fleurs, portent une quantité de petites fleurs qui, insignifiantes par elles-mêmes, ne doivent d'être remarquées qu'à leur mode d'inflorescence. Celles du Coudrier, de l'Aune, du Châtaignier, du Peuplier, sont verdâtres, fort petites, mais groupées en chatons allongés qui pendent ou se dressent; elles forment à l'arbre une parure, surtout quand elles apparaissent de bonne heure et ne sont pas enfouies sous des masses de verdure. Les fleurs des Graminées sont minuscules, à peine colorées, mais leurs épillets se disposent en épis, en grappes, en panicules, en panaches d'une étonnante légèreté. Les petites

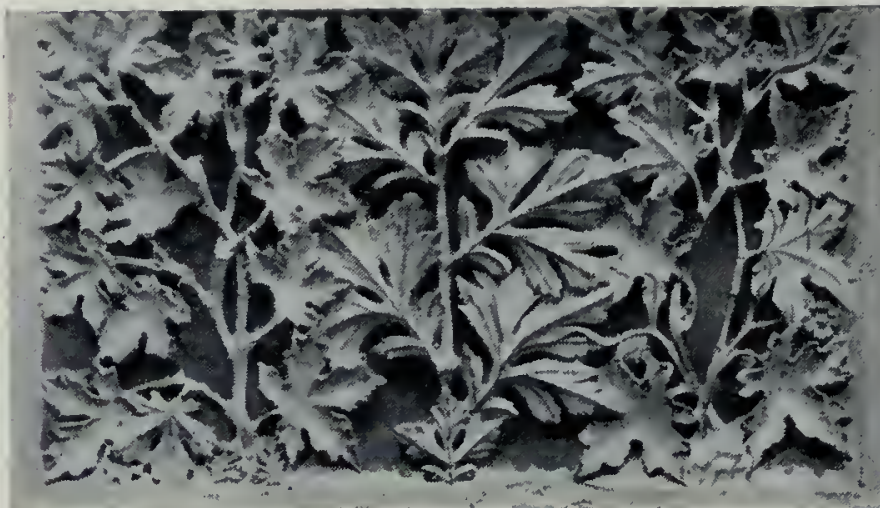

Cathédrale de Chartres : Panneau d'ornementation (xire siẻcle).

Mleurs blanches ou jaunes de la Carotte, du Fenouil et des autres Ombellifères ne sont intéressantes que grâce à leur groupement en ombelles composées dont le double étage des rayons réguliers est plaisant à l'oeil.

Comme la fleur quil continue, le fruit est gracieux et divers. Tandis que les fruits charnus nous offrent la magie de leurs couleurs, les capsules ont l'élégance et les formes pures des beaux vases. Les akènes eux-mêmes, d'ordinaire trop petits pour attirer l'attention, peuvent réaliser des dispositions extrêmement gracieuses par leur groupement en mosaïque, comme chez le Grand Soleil, ou par leur suspension, comme des pierreries à une pendeloque, à l'extrémité de longs pédoncules, ainsi qu'on peut l'observer chez le Tilleul. Les annexes du fruit contribuent souvent aussi à sa parure: tels lề longs styles persistants de l'Anémone pulsatile ou des Clématites; les blancs filaments, pompons minuscules ou vaporeuses aigrettes, qui accompagnent le fruit de nombre de Composées ou, enfin, l'ample sac écarlate des Coquerets.

Tous les principes de la composition décorative, symétrie, rayonnement, répétition, alternance, gradation, sont représentés dans les plantes par les plus admirables modèles. Il nous suffira d'évoquer, parmi tant d'autres exemples, la corolle de l'Eglantine ou de la Passiflore, l'éventail superbe des feuilles du Ravenala ou des nervures du Latanier, l'impressionnante inflorescence de l'Agave, candélabre géant chargé de milliers de fleurs surgissant du centre de la rosace foliaire.

La flore sculpturale. - De bonne heure, l'ornementation sest inspirée des formes gracicuses des corolles, des fruits, des feuillages, qu'on retrouve, sculptés suivant leur forme naturelle ou adaptée par l'artiste, sur les monuments les plus anciens. L'art égyptien a simplifié la fleur et la feuille du Lotus, qui sont représentées sur les monuments, les vases, les bijoux, les monnaies. Dans les monuments de l'Inde, le Lotus joue aussi un rôle très important.

La feuille d'Acanthe a été pendant longtemps l'élément le plus employé de la flore ornementale. Suivant une gracieuse légende, rapportée par Vitruve, c'est elle qui donna naissance au chapiteau corinthien. Cet élément ornemental a été utilisć par tous les décorateurs de l'antiquité gréco-romaine. La feuille de l'Acanthe molle se retrouve sur les vases, les coupes et les bijoux de cette époque.

Au moyen âge, cette feuille ample, à bords festonnés et légère-

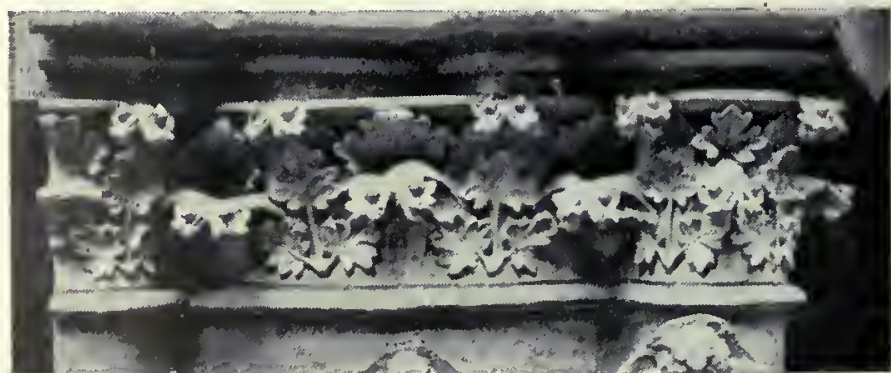

Cathédrate de Nevers: Chapiteau du XıII ${ }^{\mathrm{e}}$ siècle. ment recourbés en ourlets, cède le pas à l'Acanthe épineusc, plus maigre, plus étroite, à découpures plus raides. La Renaissance est signalée par la réapparition de l'Acanthe classique, qui, sous Louis XIV, prend encore plus d'ampleur. Plus tard, sa largeur diminue; ses découpures deviennent très aiguës; elle se rapproche de la feuille de Céleri et caractérise le style 
Louis XV, où elle se combine aux rocailles, aux coquilles en faveur à l'époque; mais la persistance, à travers de longs siècles, de ce motif décoratif est des plus remarquables.

Dans deux intéressants ouvrages, la Flore gothique et la Flore des vieilles cathédrales, Lambin a montré que, dès le $X 1^{\mathrm{e}}$ siècle, nombre de feuilles indigènes, interprétées et simplifiées, viennent se mélanger à l'Acanthe, seul sujet reproduit à profusion jusque-là. $\mathrm{Ce}$ sont d'abord l'Arum, le Nénuphar, qu'on retrouve à Notre-Dame-deParis, à Saint-Julien-le-Pauvre : l'Iris, qui abonde à SaintGermain-des-Prés, puis la Sagittaire, le Plantain, lesFougères, surtout à l'état jeune, lorsquelles sont encore gracieusement enroulées en crosses; plus tard enfin, la Vigne, le Trètle, la Chélidoine, la Cymbalaire, la Bryone, l'Ache, la Mauve, etc. La fleur, au contraire, est rarement reproduite aux $\mathrm{X}^{\mathrm{\theta}}$ et $\mathrm{X} 11 \mathrm{t}^{\theta}$ siècles, à part la Rose, la Violette, la Renoncule bouton d'or et le Muflier.

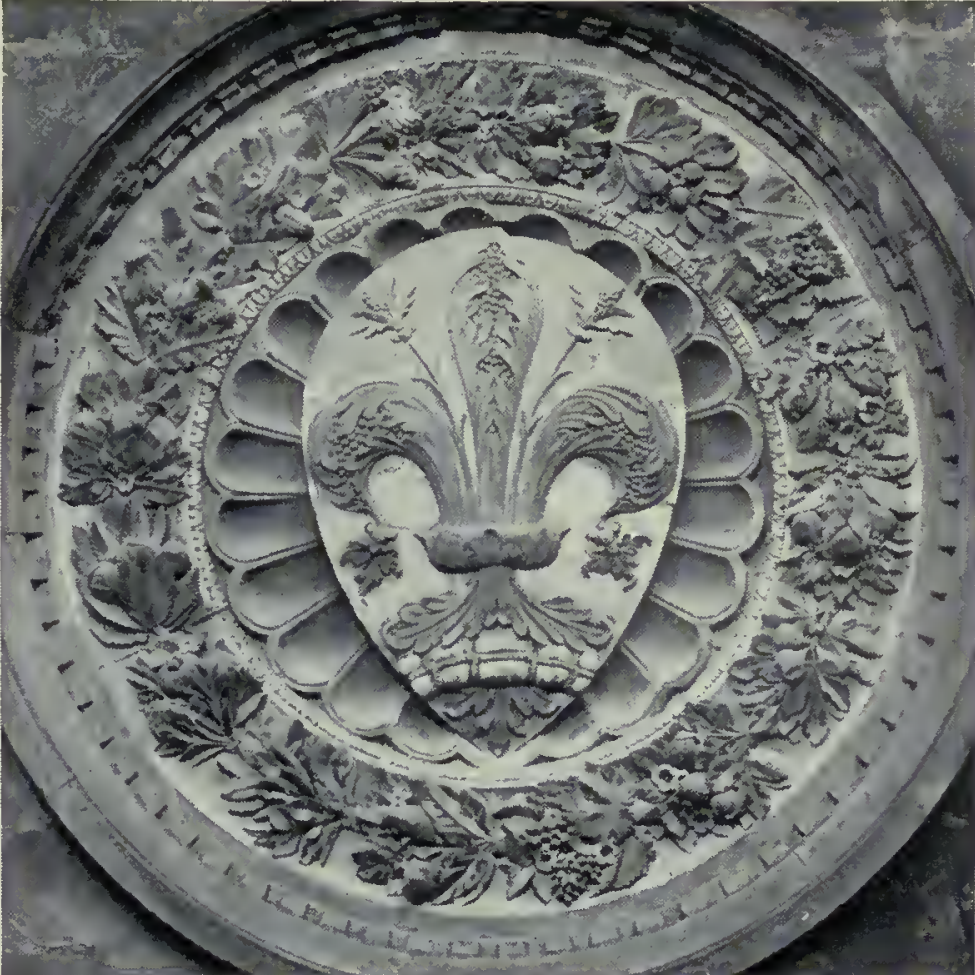

Église Or S. Michele, à Florence : Armoiries de la ville, par Della Robia (Renaissance italienne). ornemental a pris naissance: elle puise son inspiration dans la nature et trouve dans la plante, stylisée avec une remarquable science de la composition, ses principaux éléments. Ses productions sont innombrables dans les domaines les plus divers. Il nous suffira de citer ici les décors céramiques de Delaherche, de Decour, de Lenoble, de Metthey; les verreries et émaux de Gallé, de Marinot; les reliures de Marius Michel, de Kieffer, de Marc; les compositions décoratives de Grasset, de George Auriol, de Giraldon, de Paul Vera, de Bonfils; et, en Angleterre, les papiers peints de William Morris et les ornements du livre de Walter Crane.

Les Japonais sont les premiers décorateurs du monde; tous les objets qui garnissent l'habitation aisée : poteries, grès, porcelaines, bronzes, meubles, estampes, sont ornés d'une façon admirable, surtout avec le concours de la flore indigène. Dans les compositions japonaises, la plante n'apparaît jamais sous forme

Au XIV siècle, l'ornementation se modific, l'artiste interprète la nature moins librement, il la copie; il s'attaque surtout aux grands végétaux; la flore ornementale n’est plus herbacée, mais arbustive. Le Chêne, l'Érable, l'Aune, le Hêtre, le Châtaignier, le Lierre, le Saule, admirablement reproduits, abondent à la cathédrale de Bourges. Les plantes herbacées, comme la Sauge, le Liseron, l'Ellébore rose de Noël y sont beaucoup plus rares.

Le $X V^{e}$ siècle est le déclin de l'art ogival et, en même temps, de l'ornementation florale; celle-ci n'occupe plus que de faibles surfaces; la feuille n'est plus représentée isolée, mais avec ses rameaux. La Vigne et le Chêne persistent les derniers; on voit apparaître l'Armoise, le Houblon, l'Aubépine, la Chicorée.

La plante et les arts décoratifs. - Dans tous les arts décoratifs : céramique, tissus brochés, broderies, dentelles, tapisseries, papiers peints, ornements du livre, reliure, ferronnerie, etc., la plante joue un rôle aussi considérable qu'en architecture. Feuillages, fleurs, fruits sont imités, reproduits en des matières les plus différentes et interprétés suivant des tendances variables avec chaque époque, soit disposés en semis, en guirlandes, soit groupés en bouquets comme les gracieux décors à la rose des étoffes Louis XV.

Après une longue période de stagnation qui dura de la Révolution jusque vers la fin du XiX ${ }^{e}$ siècle, une admirable rénovation de l'art

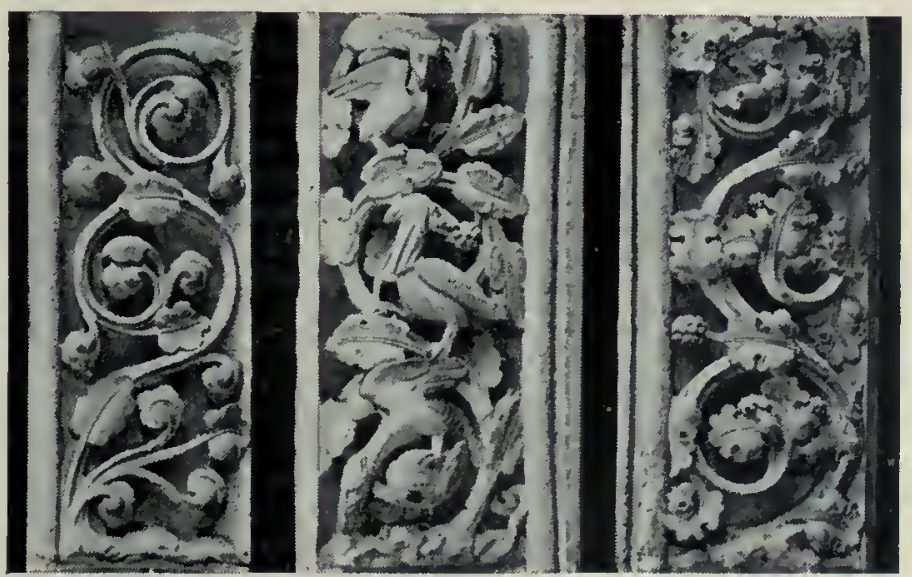

Notre-Dame de Paris : Encadrements de porte. de gerbes, de bouquets, de guirlandes; elle est libre, sans apprêt, figurée avec une vérité extraordinaire dans le rendu. Le Bambou, les branches fleuries de Cerisier et de Pêcher y jouent un rôle dominant, puis ce sont les Lotus, les Camélia, les Paulownia, les Glycines, les Magnolia, les Chrysanthèmes.

Les plantes emblèmes. - Certaines plantes figurant sur les blasons, les drapeaux, reproduites sur les monuments, sont caractéristiques d'une époque ou d'une région. La plus célèbre de ces plantes emblèmes est le Lis héraldique, dont l'origine est fort discutée : pour certains auteurs, il proviendrait de la transformation de la fleur d'Iris ou même de la fleur de Lotus.

Le Shamrock ou Petit trèfle blanc est en bonne place dans les armes d'lrlande, le Chardon dans celles d'Ecosse, la Rose dans celles d'Angleterre. Sur l'écu du royaume de Grenade, le fruit du même nom figurait comme armes parlantes; un Oranger taillé géométriquement se voyait aussi dans les armoiries de la République d'Orange, dans l'Afrique du Sud.

L'Hélianthe annuel ou Grand Soleil étaitl'emblème du roi soleil, Louis XIV; cette plante se retrouve sur beaucoup de monuments du grand siècle. Le Chrysanthème, plante nationale des Japonais, est reproduit sur les armoiries de ce pays, sur ses monnaies, et même sur ses timbresposte, où il est accompagné d'autres plantes indigènes : l'arbuste à thé, le Camélia, le Mûrier à papier, etc. A l'imitation du Japon, quelques États font figurer sur leurs timbres-poste des spécimens de leur flore.

Les vignettes postales chinoises nous offrent l'Immortelle de Chine, la Pivoine, la Passifore; des Palmiers figurent sur les timbres des Samoa, de Bornéo, de Libéria et de divers pays tropicaux.

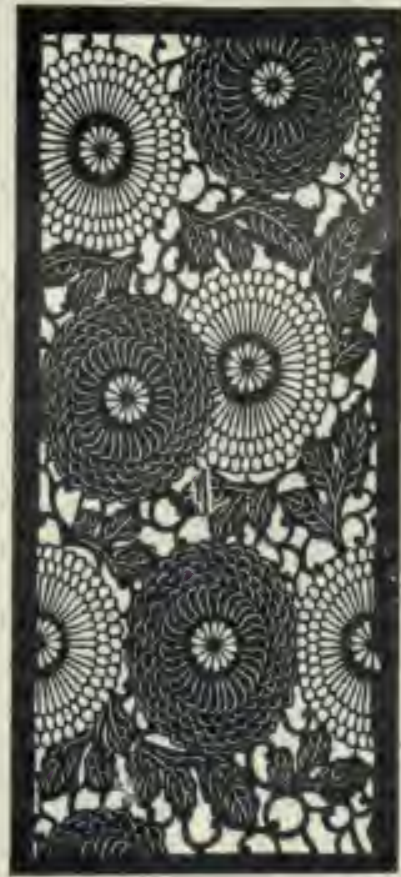

Chrysanthèmes (pochoir japonais). 


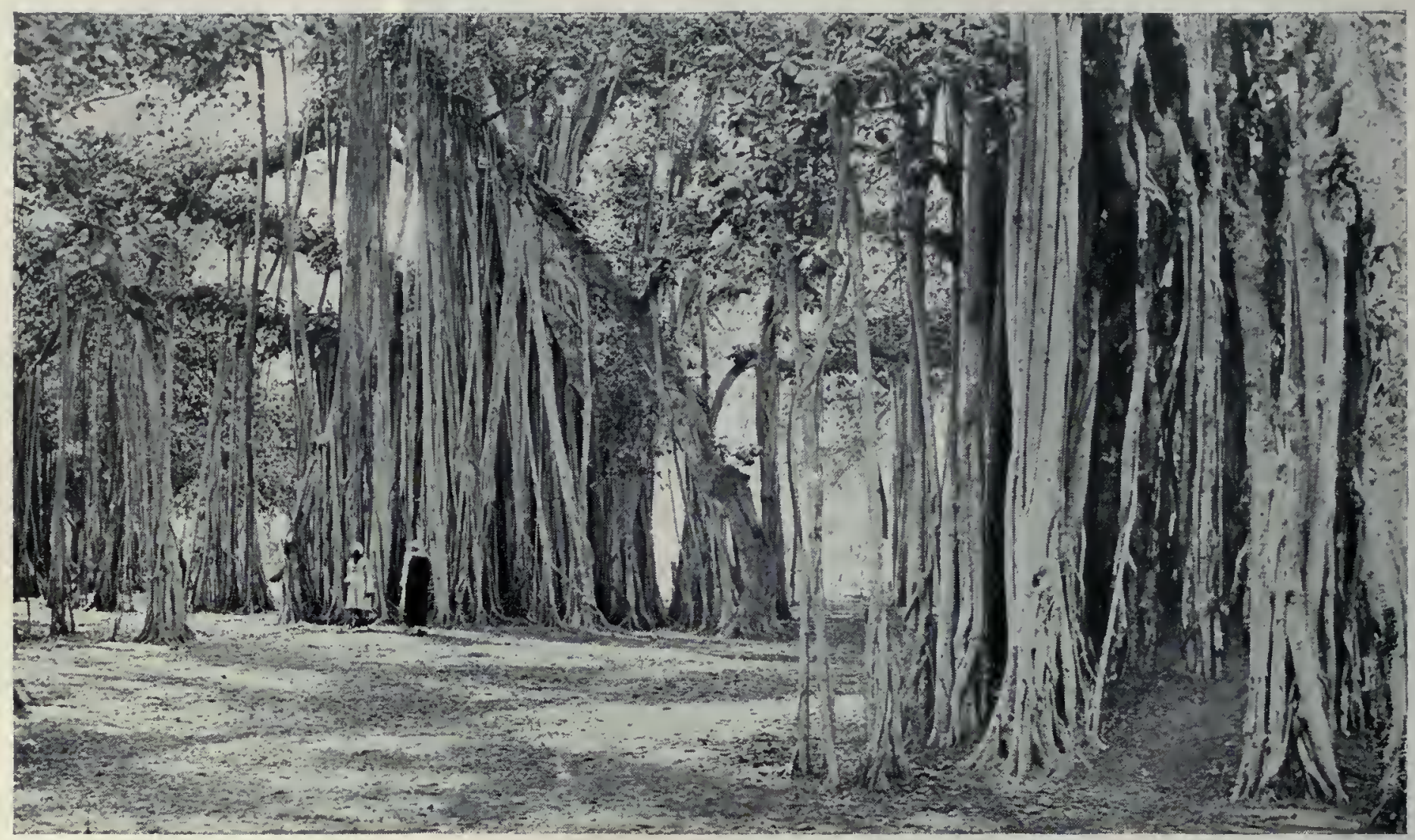

LE FIGUIER DES PAGODES, AUX INDES.

\section{IX. - FOLKLORE, MYTHES ET LÉGENDES}

L'étude des légendes et du folklore, les contes populaires où les plantes tiennent une place, méritent de nous arrêter, car ce sujet touche à l'histoire la plus lointaine de l'espèce humaine. Cubernatis a pu dire : " Les superstitions botaniques sont aussi vieilles que l'esprit humain ") ; elles bravent les philosophies, la science et les religions (1).

Le Gui. - Un premier témoignage à citer à ce propos est celui de Pline qui, dans un texte célèbre, parle du rôle que jouait le Gui chez nos pères, les Gaulois : "Aux yeux des druides, dit-il, rien n'est plus sacré que le Gui et l'arbre qui le porte, si toutefois c'est un Chêne Rouvre. Le Rouvre est déjà par lui-même l'arbre dont ils lorment les bois sacrés; ils n’accomplissent aucune cérémonie sous le feuillage de cet arbre. Tout Gui venant du Rouvre est regardé comme un envoyé du ciel; ils pensent que c'est un signe d'élection que le dieu même a faite de l'arbre. Le Gui du Rouvre est extrêmement rare et, quand on le trouve, on le cueille avec un très grand appareil. Avant tout, il faut que ce soit le sixième jour de la lune, jour qui est le commencement de leurs mois, de leurs années, de leurs siècles qui durent trente ans. Ils l'appellent d'un nom qui signifie remède universel. Ayant préparé, selon les rites, sous l'arbre, des sacrifices et un repas, il font approcher deux taureaux de couleur blanche, dont les cornes sont attachées pour la première fois. Un prêtre vêtu de blanc monte sur l'arbre et

(1) Voir Costantin : Biologie et Religion chez les primitits. " Revue Encyclopédique o, 28 oct. 1899.

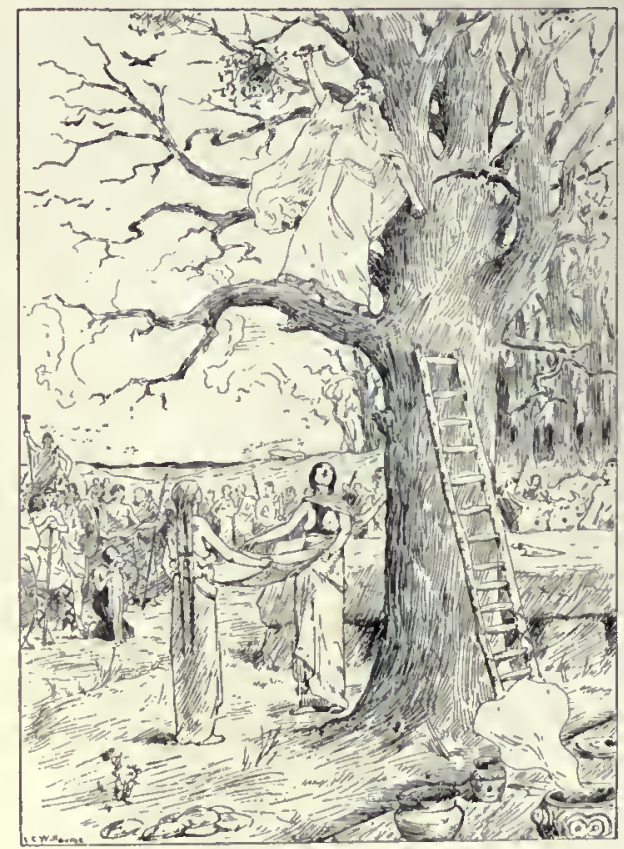

Druide récoltant le Gui. coupe le Gui avec une serpe d'or: on le reçoit dans une saie blanche; puis on immole les victimes, en priant que leur dieu rende le don quili a fait propice à ceux auxquels il l'accorde. On croit que le Gui pris en boisson donne la fécondité à tout animal stérile et quïl est un remède contre les poisons. "Le Gui sur le Chêne est, en effet, très rare; on l'a cependant trouvé plusieurs fois au $\mathrm{XIX}^{0}$ siècle : dans le Doubs, en 1859; dans la forêt de Jeugny, en 1878.

Les peuples méditerranéens avaient des notions sur l'origine de ce Gui, car on connaît un proverbe latin qui dit d'une manière un peu grossière que les grives déposent sur les arbres la glu qui doit servir à les prendre, car le fruit du Gui contient une matière agglutinante qui est employćc depuis longtemps par les oiseleurs pour capturer les oiseaux (turdus ipse sibi perniciem cacat). Gaidoz a trouvé aux environs de Coulommiers ce dicton : "Le Gui vient de la chiasse des oiseaux. " Les Gaulois évidemment savaient aussi bien que les Romains que la germination de cette plante ne se produisait qu'après le passage de fruits au travers du tube digestif des grives et des merles. II est très vraisemblable de croire que, pour nos ancêtres, lorsqu'il s'agissait du Gui du Chêne, l'ensemencement avait dû être fait par un oiseau mystérieux, probablement prophétique et divin. Les légendes relatives au Gui paraissent particulièrement vivaces en France, en Angleterre, en Scandinavie. La chanson du "Gui l'an neuf " a longtemps retenti au premier janvier dans toutes les provinces de la vieille France; le marchand de Gui 


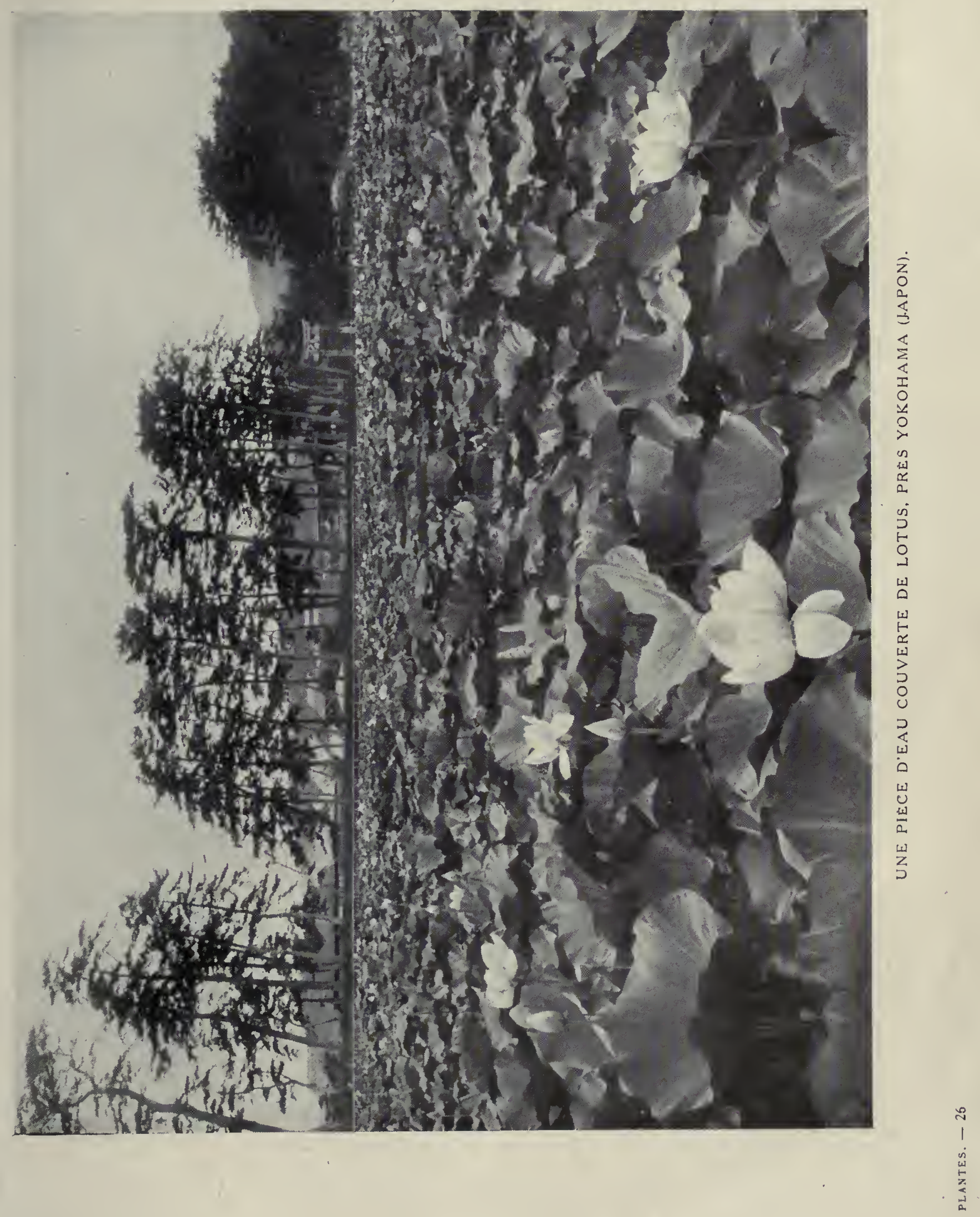





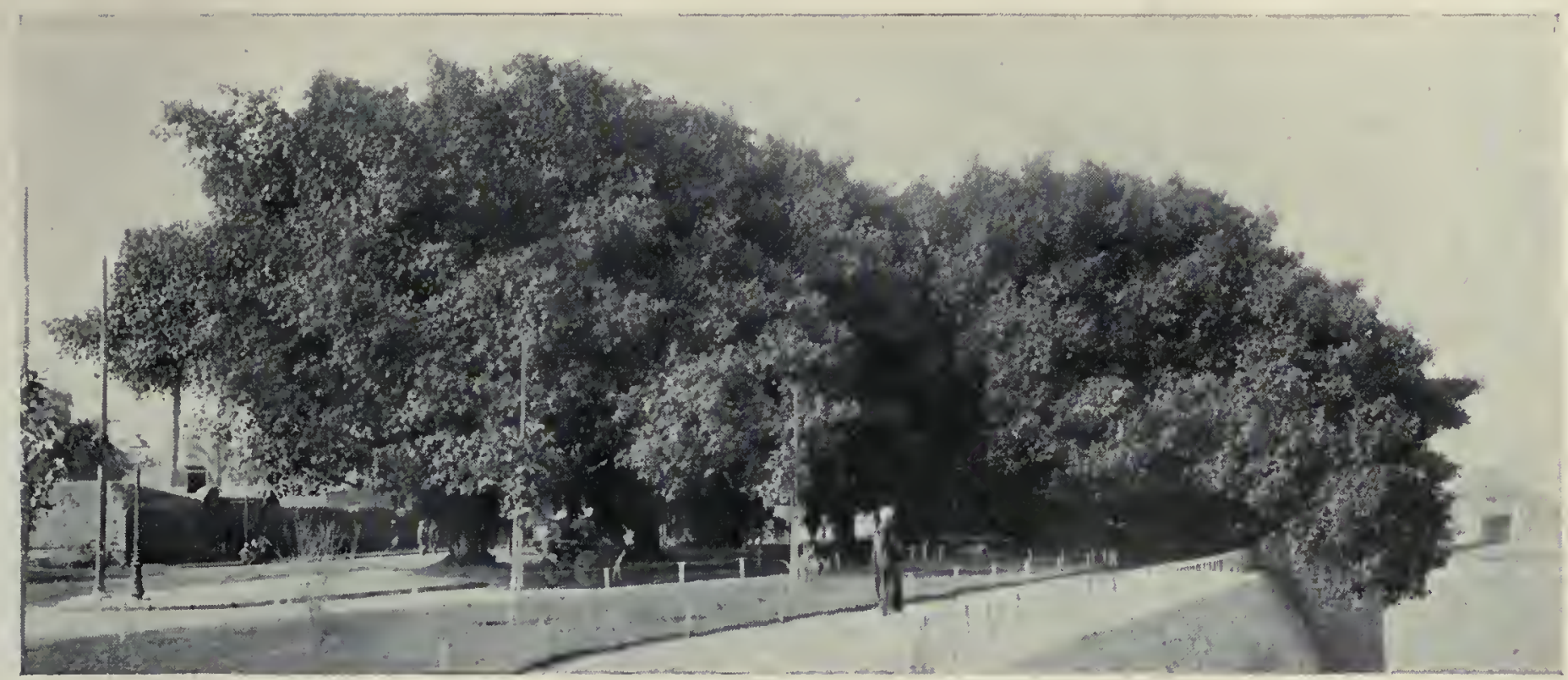

Figuier sycomore centenaire du vieux Caire.

est accueilli aujourdhui vers Noël avec bienveillance, car il apporte un signe de bonheur; le baiser sous le Gui se pratique encore dans certaines familles.

Figuiers, Sorbiers et Chênes. - La conception des druides sur le Gui paraît, au premier aspect, très différente de celle qui a contribué à faire attribuer dans l'Inde un caractère divin au Figuier des pagodes, mais cependant il semble qu'il y ait un point commun dans l'origine de ces mythes religieux, car le Figuier n'acquiert son caractère sacré que lorsqu'il pousse sur un autre arbre (Acacia suma) ou sur une muraille. Le développement extraordinaire de ce Figuier qui, par sa végétation puissante, arrive à submerger tout le support sur lequel sa graine est déposée, était bien susceptible de frapper des esprits très attentifs à l'apparition de tous les phénomènes naturels, auxquels ils donnaient unc signification mystique.

Les anciens Germains avaient déjà constaté des cas d'épiphytisme accidentel pour le Sorbier et, quand ils observaient la présence de cette plante sur un autre arbre, ils lui attribuaient des propriétés merveilleuses; d'après Adalbert Kuhn, on célébrait encore en Westphalie, au début du XIX ${ }^{\theta}$ siècle, et en Scandinavie, au XVIII ${ }^{\circ}$ à l'aide des baguettes de cette plante des cérémonies de sorcellerie quand le Sorbier avait poussé «sur un mur ou dans le creux d'un arbre ». La semence était encore apportée par " un oiseau " l'ayant laisser " tomber de son bec ".

Dans tous ces exemples, on voit que les légendes des arbres sacrés sont liées à celles des oiseaux divins. Ce lien se manifeste d'une façon particulièrement saisissante dans les traditions reli-

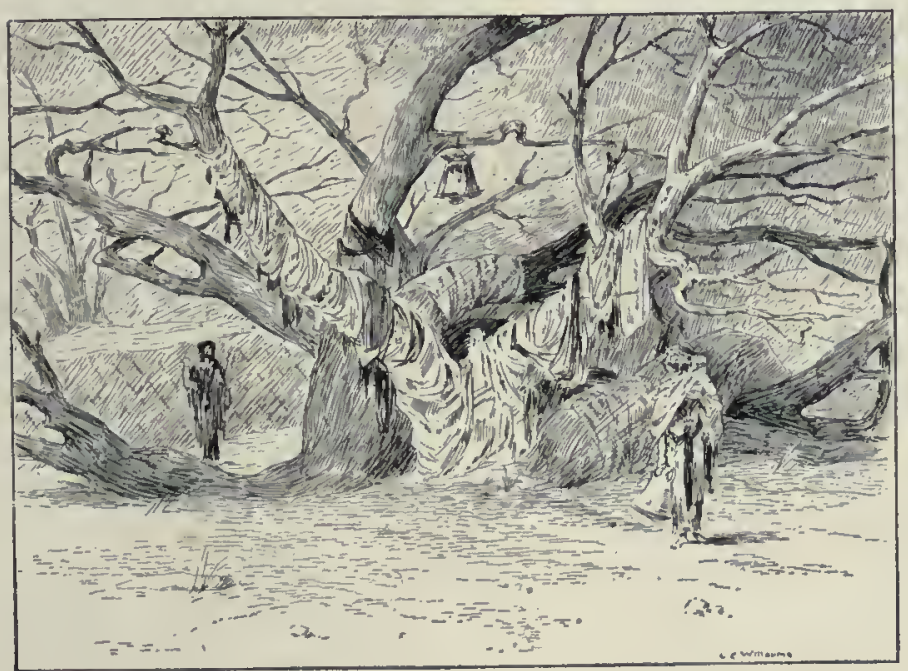

Arbre sacré, vénéré par les fellalıs, au Caire. gieuses de l'Inde. On a souvent confondu l'açvattha ou pippala ( $F$ icus religiosa) avec le vata ou nyagrodha ( $F$ icus indica), dont l'un des noms sanscrits est bahupâdah, c'est-à-dire " qui a beaucoup de pieds ". L'açvattha est l'arbre qui n'a " ni commencement, ni fin ", l'arbre de la sagesse par excellence, adoré par les Bouddhistes. Al'heure où naquit le Bouddha, une tige prodigieuse de l'arbre açvattha poussait au centre de l'univers. Dans le Rig Véda, il est question de " deux oiseaux amis et compagnons, qui tiennent embrassé un même arbre, et l'un mange la figue succulente "); il s'agit probablement de l'açvattha ou pippala. Gubernatis dit que le pippala ou açvattha est hanté par les oiseaux qui mangent les douces figues, qui chantent que la figue suave ne peut être mangée que par ceux qui connaissent le mystère de la génération. Il y a là, semble-t-il, une double allusion au culte du " soma ", la liqueur enivrante qui joue encore à l'heure actuelle un rôle si important dans les religions de l'Inde, et aux phénomènes de la caprification.

Ces cultes dérivés de la plante passent de l'un à l'autre et celui de la liqueur ambroisie est lié à celui d'Agni ou du feu. Les deux bâtons qui, par leur friction l'un contre l'autre, engendrent la flamme sacrée sont appelés les aranis. L'un, le pramantha (le bâton qui tourne), est formé d'açvattha ( $F$ icus religiosa); l'autre, l'arani (le disque qui reçoit le premier dans un trou qui y a été pratiqué), est le çami (l'Acacia suma); les aranis sont donc formés de l'arbre et de son parasite. Allumer le feu est une cérémonie religieuse et le procédé que l'on doit employer est minutieusement décrit dans les sutras védiques. Pramathys, " celui qui a obtenu le feu par le frottement ", est devenu le Prométhée des Grecs, celui qui fend le crâne de Zeus pour en faire sortir Athêné, déesse de l’éclair.

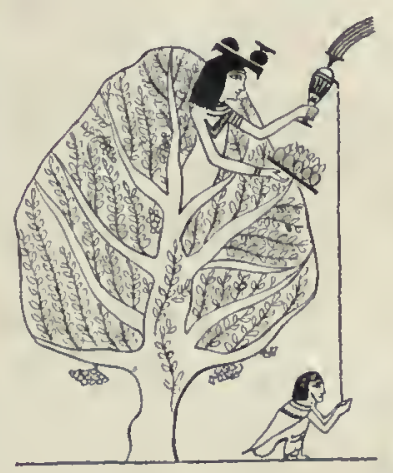

Fig. 337. La déesse Nouit sortant du sycomore et tenant l'eau de vie, qui donne l'inumortalitè.

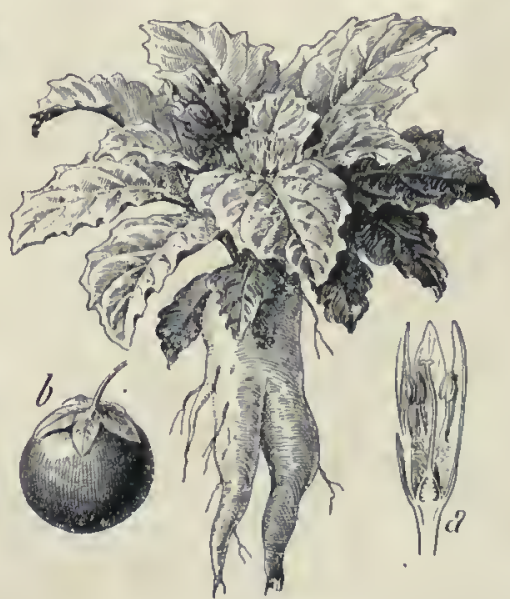

Fig. 338. - Mandragore. $a$, Fleur: $b$, Fruit. 
Or il est des traditions de l'ancienne Grèce qui nous font entrevoir les liens du culte du Figuier de l'Inde et du culte du Chêne en Gaule. Pausanias nous dit que Plutarque avait une théorie abstruse pour expliquer une légende singulière, celle de la bûche de bois de Chêne que Zeus prétendait épouser alors quil était en désaccord avec Hera; cette bûche, que l'on appelait la femme muette, signifiait un arbre qui émergeait des flots. Ces légendes bizarres des anciens nous apprennent, ce qui est confirmé par d'autres sources, que Zeus à l'origine a été un arbre

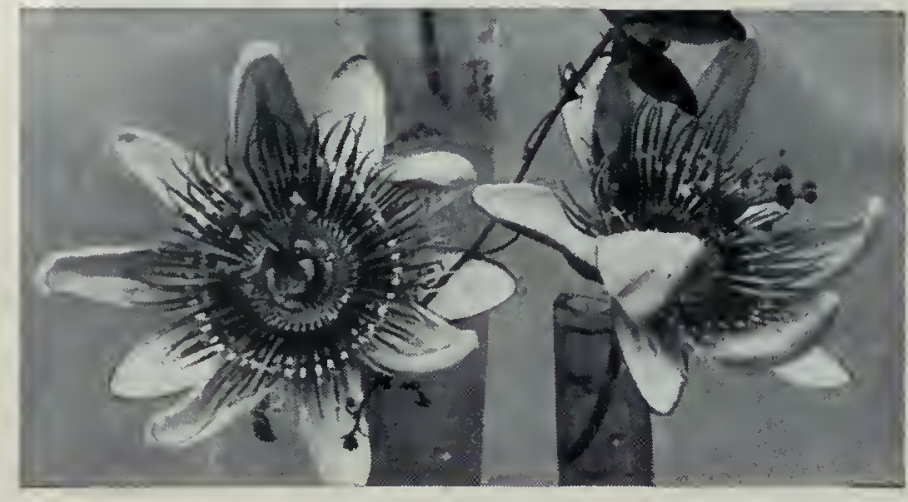

Fleurs de Passiflore.

sorcières l'employaient dans leurs philtres d'amour. En Silésie, en Thuringe, en Bohême, la Mandragore est associée à la décollverte des trésors cachés.

Pour frapper l'imagination des peuples primitifs, il suffit d'ailleuns d'un fait insignifiant, d'une simple apparence. Croyez-vous qu une figure grimaçante, comme celle que notre photographie reproduit, apparaissant sur la coupe d'un tronc, ne donnerait pas prétexte, dans un tel milieu, à bien des légendes? Et, cepcndant, il sagit simplement d'une disposition singulière des zones ligneuses d'accroissement d'un tronc, avec et probablement un Chêne. Cet arbre cosmogonique avait la propriété d'engendrer les hommes. On ne doit pas oublier l'opinion d'Homère qui dit que les hommes " sont nés de la pierre et du Chêne ". On conçoit donc que Baudry, dans son étude si curieuse sur les mythes du feu, ait pu dire : "Le feu céleste est le fruit (de l'arbre céleste) ou son rameau enflammé; et un oiseau divin, qui a son nid dans la branche, dérobe le feu et l'apporte à son bec sur la terre. "

Le rôle des plantes dans les conceptions religieuses se manifeste encore par la place extraordinaire que tiennent quelques arbres dans les religions anciennes, notamment dans celle de l'Égypte. Le Figuier Sycomore poussant à la limite du désert paraissait une plante miraculeuse par sa ramure impénétrable; on le croyait animé d'un esprit qui se cachait en lui et qui, dans certaines circonstances, se manifestait. On sait que, dans leur voyage aux champs mystérieux d'lalou, le paradis des Égyptiens, les âmes rencontraient dans le désert où elles s'enfonçaient un Sycomore toujours vert. Les peintures égyptiennes nous représentent cet arbre et, au milieu du feuillage, la déesse Nouit ou Hathor sort pour tendre à l'âme ćplorée l'eau de vie qui doit lui assurer l'immortalité. Le Papyrus d'Ani dit: "O Sycomore de Nouit, donne moi l'eau et le souffle de vie qui procède de toi! "On conçoit, d'après cela, que l'Égypte ait été appelée la terre du Sycomore et que cet arbre ait conservé ses fidèles qui viennent encore, à l'heure actuelle, aux environs du Caire, lui rendre un culte pieux en le recouvrant d'offrandes et d'étoffes.

Lotus, Mandragore. - Le Lotus a été ćgalement l'objet d'un culte important, et souvent la divinité Horus ou $R$ a naît d'une fleur de Lotus. Ce culte existe encore dans l'Inde et en Extrême-Orient, et il n'est pas rare de voir l'ouf du monde dans le sein de l'Océan primordial engendrant une plante se terminant par un Lotus, lequel produit un dieu.

Le rôle des arbres s'est maintenu à travers les âges. Dans les premiers siècles de notre ère, les conciles d'Arles, de Tours, ont dénoncé le culte des plantes. Mais ces conceptions sont très vivaces et réapparaissent dans les histoires de sorcellerie à travers le moyen âge. Les légendes sur la Mandragore méritent d'être rapportées à ce propos. La racine tuberculeuse de cette plante affecte des aspects bizarres et elle rappelle souvent par ses formes les jambes et les bras d'un homme ou d'une femme. On en faisait des amulettes. On ne la déterrait pas sans dangers, et il est communément rapporté qu'un cri perçant retentissait à sa sortie de terre, et les mortels qui l'entendaient devenaient fous. Elle naissait là où la présence d’un criminel avait pollué le sol ou au voisinage des gibets. Cette plante mystique était vendue pour ses propriétés médicinales : elle servait à guérir de la stérilité, et la fable de La Fontaine "la Mandragore" repose sur son pouvoir de prolification. Les

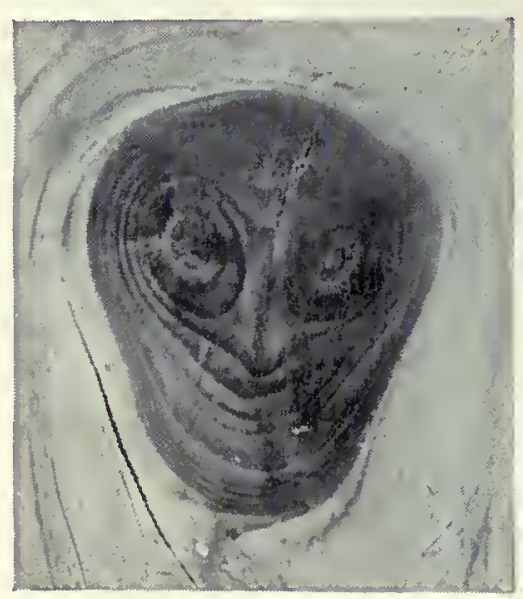

Nouds du bois

simulant une face humaine.
Plantes américaines. - Toute plante ayant des caractères particuliers, nocifs, narcotiques, par exemple, acquiert un rôle mystérieux et divin. Dans la région du Darien (isthme de $\mathrm{Pa}$ nama), les Indiens se servaient des graines de Datura sanguinea pour produire chez les enfants un délire prophétique dans lequel ils révélaient les points où se trouvent cachés des choses précieuses.

L'Erythroxylon coca, qui donne la Coca, a été autrefois considéré au Pérou comme une plante sacrée par les Incas, qui la brûlaient sur les autels des temples du Soleil. Elle jouit, en effet, de propriétés très remarquables, car c'est un excitant qui joue le rôle d'anesthésique local et qui peut supprimer la sensation de faim; aussi les Incas l'employaient-ils pour se soutenir sans nourriture pendant les marches les plus pénibles et au cours des travaux les plus fatigants.

Au Mexique, toutes les plantes extraordinaires avaient attiré l'attention des sujets de Montezuma, et le culte des fleurs y était extrêmement répandu; il semble avoir été dévié vers le christianisme par les efforts des missionnaires espagnols. Selon Bateman, " pas d'enfant n'est baptisé, pas de mariage célébré, pas de mort enterré, sans que les Orchidées ne soient appelées à exprimer les sentiments si divers relatifs à ces circonstances 1. C'est en tenant compte de ces sentiments, qui tirent leur origine de traditions antérieures à la conquête espagnole, qu il faut expliquer les noms vulgaires de plusieurs de ces fleurs admirables : flor de los muertos (fleur des morts), qui est l'Oncidium tigrinum; flor del paradiso (Aleur du paradis), qui est le Sobralia dichotoma; boca del Dragon (gueule du Dragon), qui est l'Epidendrum atropurpureum. Ce sont évidemment les prêtres espagnols qui ont imaginé les noms de flor de Jesus (Lelia acuminata) et flor de Espiritu santo (Peristeria clata). Ce sont eux également qui ont cru retrouver dans les Passiflores (fleurs de la Passion) tous les objets qui ont joué un rôle dans la mort de JésusChrist: la collerette de staminodes représente la couronne d'épines; les styles sont les clous; les étamines, les marteaux; enfin la feuille est la lance, et la vrille, le fouet.

C'est à des traditions plus anciennes qu'il faut rapporter le nom espagnol du Cheirostemon platanoides, "flor ou arbol de las manitas ", à cause de la forme étrange de la fleur qui rappelle une main. Cette plante a probablement jouć un rôle fantastique analogue à celui qu'on a attribué aux " mains de gloire " en Europe, c'est-à-dire à la Mandragore.

En somme, les noms des plantes, comme le langage des fleurs, nous renseignent d'une manière très curieuse sur le rôle considérable qu'ont joué les végétaux aux temps passés dans les conceptions humaines; ces appellations se rattachent à la cosmogonie, à la fable, à la sorcellerie, à la médecine, en un mot à la science des hommes primitifs et barbares. 


\title{
INDEX ALPHABÉTIQUE
}

\author{
DES TERMES BOTANIQUES, NOMS ET FIGURES
}

Abaca, 260

Abiétinées, 126, 127

Abrasin (Aleurites), 3, 232.

Abricotier (Armenica vulga ris). 28, 40, 41, 195, 208 , $222,223,231,284$

Abrus precatorius, 192, 284.

Absinthe (Artemisia Absin-

thium), 4, 165, 166

Abutilon, 180

Acacia, 194, PI, 16, 256, 271,

284; - helerophylla, 194:

à fourmis, 66:- longi-

folia, 194; - giraffa, 194;

Calechu, 194, 217, 226;

- Farnesiana, 194.275; -

harpophylla, $97 ;-$ fistula,

194; - spherocephala, 65:

- Senegal, 271:- suma,

binia, 191,294; - Cytisus,

binia, 191,294:-Cytisus,
191, 286:-- Albizzia Julibrissin), 194 .

Acajou, 187, 188, 252, 253

254; - (Swietinia), 254.

Acanthus, 175; - spinasus,

304; - mollis, 304, 305.

Acanthephippium, 153.

Acène (Acana adscendans).

74. 77 ; - pinnalifida. 84.

Aceras, anthropophora, 154.

Acetabularia, 109, 206.

Ache odarant (Apium grave-

Achillea Millefolium, 81, 166.

245.

Achimenes, 175.

Acineta, 153.

Acanilum Napellus, 38, 41.

178, Pl. 24, 286, 291

Acorus gramineus, 135.

Acroclinium roseum, 166.

Acrostichum, 122.

Acrostichum,
Ada, 94, 152

Ada, 94, 152 . 180; - digi-

tata, 180; - Madagasca-

riensis, 180

Adenanihera, 284

Adenium 87, 173, 286.

Adenocystis Lessonii, 77.

Adiantum, 122; - capillus

Veneris, 290;- pedatum. 290.

Adonis, 177, 178.

Echmea, 147, 148 .

Echynomene, 192, 257.

Aerides, 152.

Ėsculus Hippocastanum, 188.

Ethusa cynapium, 286.

Agapanthus umbellatus, 143, PI 12.

Agancinées, 112,113, 114, 118.

Agarum Gmelini, 77, 111.

Agave, 26, 30, 145, 146, 147.

$257,260,288,304$; -

miana, 145, 238, 239, 240;

- Sisalama et heteracan-

tha, $145,260,262$; rigida, $145,260$.

Ageratum. 164, 295.

Agrimonia Eupatoria, 7, 68. 197.

Agripaume (Leanurus cardiaca), 175.

Agropyrum cristalum, 133; - repens. 133

Agrostis, 131, 132, 245; -

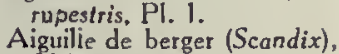

204.
Ail (Allium), 143; - azureum, 143; - sativum, 143 , 208.219.245:-Crameri, 86: - neapolitanum, 143 . - vineale, 33,$34 ;-M o l y$. 143,285 .

Ailanius glandulosa, 188, 247. 286, 287, 294 .

Aira antarctica, 77

Airelle mystille (Vaccinium Myrtillus), 170; - uliginasum, 75.

Aizoon canariensis, 86.

Ajonc (Ulex europaus), 190, $247,255,278,279$.

Ajuga, 176.

Alaria, 77.

Albizzia Julibrissin, 90, 194. Alchimille (Alchimilla), 97.

Alcool, 4, 142, 145, 212, 229,

$234,239,240,250,251$

Aldravandia, 69, 71,184 .

Aleurites, 3, 85:- cordata,

232: - trilaba, 181, 223.

$258,260,262,263,274$.

Algues, 9, 10, 50, 51, 59, $60,74,75,77,107,108$ à

112. 119, 200, 206, 279

$280,281,282,290,291$.

Alhagi Maurorum, 86, 87.

Aliboufier (Styrax officinalis), $170,277$.

Alisier (Sorbus latifolia), 198. 224, 253, 254

Alisma Plantago, PI. 6, 144.

Alkana linctoria. 172

Allouchier (Sorbus ou Aria nivea), 198.

Alluaudia procera, 96.

Alocase (Alocasia), 134, 135.

Aloès (Alae), 7, 9, 144, 288 - Perryi, 144, 288; succotrina,

Aloès pitte (Fourcroya), 260

Aloès pitte (Fourcroya), 260.

Alopecurus 132.
Alpiste (Phalaris), 131, 247.

Alsinées, 185

Alsophila. 90, 124.

Althea, 179:- rosea, 180.

Althernanthère, 158.

Altingia, 21.

Alysson (Alyssum), 183.

Amandier (Amygdalas communis), 42, 195, Pl. 16,223. 226. 231.277

Amanita, 113, 117, 285, 286

Amarantus caudatus, 158.

Amaryllidacées, 90, 145, 146, 235. 275

Amaryllis, PI 12, 145, 297.

Ambrette (Hibiscus Abelmoschus). 180,277.

Ambrevade, 192, 247.

Amentacées, 155, $158^{\circ}$ à 161 .

Amherstia nobilis. 29.

Amidon, 32, 46, 47, 49, 148 ,

149, 159, 221, 223, 234

$$
235236 \text {. }
$$

Ammi majus, 204.

Amonum, 221.

Amorphophallus, 135.

Ampélidées, 189

Ampelopsis, 189.

Amyodalus, 195.

Amylomyces de Roux, 285.

Anacamptis pyramidal, 154

Anacardiacées, 186, 187, 257. 272.

Ancordium occidentale, 187 Anacyclus Pyrethrum, 289 Anagallis, 170.
Anamirte cocculus, 178, 286. Ananassa sativa, 106. 147.

148, P1. 19,225, 226.

Anaptychia ciliala, 119

Anastatica, 86, 183.

Anchomanes difforme, 135.

Anchusa, 172

Ancolie (Aquilegia), 39, 178 . - alpina 9. PI. I.

Ancylonema, 77

Aadira, 193.

Andropogon, 262, 275, 276 ;

- citralum, 276.

Androsace, 8, 170; PI. 1.

Anactochilus, 154.

Aneimie (Aneimia), 124

Anemone, 37, 80, 84, 177

$245,286,301$; - Japonica,

177, 178; - narcissiflora, 9,

Pl. 1;-coronaria, 177:-

sylvestris, 6 : - pulsatilla

177,$304 ;$ - ranunculoides. 177 .

Anethum graveolens, 203

Angelico Archangelica, 203.

Angelin, 193.

Angiopleris, 123, 124.

Angiospermes, 39.85, 107

125. 129 à 204, 206 .

Angrecum, 37, 151, 242; -

sesquipedale, 151, P1. 31

Anguloa, 152

Anis étoilé (Illicium verum)

178. 277, 289: - Anis

vert (Pimpinella anisum)

178, 204, 273, 289.

Annularia, 205

Anomozamiles, 206

Anonacées, 178, PI. 19, 221. 276

Anona Cherimalia, 208, 226.

Ansérine amarante, 215

Antarctique (Flore), 76, 77.

Antennaria margarilacea, 166.

Anthemis, 165, 301; - no-

bilis, 165; - en arbre (Chry

santhemum frutescens), 165

Anthoxanthum. 13i.

Anthriscus cerefolium, 204.

Anthurium, 37, 93.

Anthyllis vulneraria, 245.

Antiaris toxicaria, 156, 286.

Antirrhinum majus, 174.

Apétales, 155 à $16 \%, 168$

Apios tuberosa, 192.

Apium gravealens, 204.
Apocynacées, 96, 173, 270

Apodanthes Flacourtiana, 57

Aponogeton, PI. 6.

Aquilaria Agallocha, 277.

Aquilegia, 178.

Arabis alpina, 183.

Arachis hypogea, 3, 193, 208.

226. 232, $233,247$.

Arack, 136, 142, 240

Aralia cordata, 216.

Araucaria, 21, 96, 97, 125

$127,206,298,302$

Arbousier (Arbutus), 83, Pl.

$19,169,226,247,288$.

Arbre, 89,90 ; - à beurre

170, 233: - à chapelet,

284 ; - à huile, 232; -

au mal de dents, 186, 289;

-à lait ou à la vache, 156,

233 ; - à melons, 182 ; -

à noix $158 ;-$ à pain, 43 .

$90,155,156, \mathrm{Pl}, 19 ;-$ à

papier, 85: - à perruque.

187:- à saucisson, $7:-$

tière, $284 ;-$ à thé, 85 ,

96; - au chapeau, 189 ;

- aux fraises, 169 ; - aux quarante écus, 46,128 ; aux vessies, 191. - bouteille, 97:- de Judée. 192. 193, 206; - de soie, 194; 7 du voyageur, $28,96$. 84, 128: - siffleur, 194. Arbulus, 169

Arctique (Flore), 74 à 76.

Areca Calechu, $90,141,257$.

265: - oleracea, 216.

Arécinées, 137, I41, 142

Arenaria, 72, 185

Arenga saccharifera, 141, 229. 235, 262.

Aréquier(Areca), 90, 141, 216.

Argalou (Paliurus), 189.

ArganiaSideroxylan, 170, 233.

Aristolochia, 61, 62, 161, 297.

Armeniaca, 195.

Armeria maritima, 170.

Armoise (Artemisia), 8, 87.

165, 166, 305; - absin-

thium, 165; - vulgaris,

165; - Dracunculus, 165

- pauciflora, 165, 291.

Arnica montana, 166, 291.

Aroidées, 19, 37, 58, 59, 67 .

$93,134,135,216,235$.

Aromates, 220, 221.

Arondinaire (Arundinaria),

133,134

Arroche (Atriplex halimus),

87, 279; - (horlensis), 158.

Arrow-root, 149, 235

Artichaut ( $C$ ynara Scolymus).

$164,165,216$.

Arlocarpus, 135, 155, 156.

Artocarpées, 155, $269,270$.

$134,135,280,286,305$.

Aruado, 9, 10, 70, 132, 256. 263.

Asaret (Asarum), 161

Asclépiadacées, 25, 38, 45

$87,93,96,173,270,271$.

Asclepias cornuti, 173

Ascomycètes, 115, 116, 119. 
Bergamote, Bergamotier, 186, Pl. $19,225,273,276$.

Berle (Sium), 204

Bertholletia excelsa, 201

Bétel (Piper Bettle), 293

Bette, 215.

Betterave (Beta vulgaris), 47

98, $100,158,227,228$

229. 236. 240. 241, 245 ,

245, 246, 247, 280

Bétulées, 157, 158, 160.

Beurres végétaux, 170,188 223.

Bibace, Bibassier (Eriabotryo

japonica). 198. Pl. 19,226.

Bidens Beckii, 70.

Bière, 49.156, 212, 221, 229. $239,280$.

Bigaradier, 186, 225, 276;

- bizarrerie. 102. 103.

Bignoniacées, 46, 55, 67, 175 . 284.

Billbergia, 93, PI. 12, 147.

Biota, 128.

Biscutella, 183.

Bixacées, 181, 182.

Blé (Triticurm), 2, 7, 24, 27. 37, 44, 46, 47, 104, 115, $129,133,178,208,210$, $211,234,235,247,258$, 263, 264, 286; - de Cafrerie, 131,213 ; - du Dekkan, 2i2; - de Guinée, 213; - de Turquie. 212; - noir. 157, 213.

Blechnum, 122

Bleckroodea, 255, 266.

Bletia, 153.

Bleuet, 7, 163. 298.

Bæhmeria, 155

Bois 4, 17, 21, 22, 248 à 257 ; d damarante, 253; d'agalloche, 277:-d'Ambatsch, 195; - d Amboine. 188, 253: - du Brésil. 193; - de Campêche, 22 . $194,265,266$; - de fer, 17253; - de Fernam(etPanama, 196, 280; - de Perpignan. 254; - de résonance, 255 ; - de de rose, 253, 277; - de Santal, jaune, 266:- odorants. tinctoriaux. 265, 266.

tinctoriaux. 265, 266.

Bolet (Bolet us). 114, 118.

Bombax, 180, 262

Borassinées. 137, 140, 141.

Borassus, $238 ;-\frac{1}{8}$ éventail

(flabelliformis), 8, 262.

Borraginacées, $66,68,86$. $172,173,175,266$.

Bosweillio, 187, 188, 277. Bougainvillea, 158.159. Bouillonblanc.6, 174, 255,290. Bouleau (Betula), 6, 8, 28 , $208,247,250,251,253$. 254, 262, 283

Bourdaine, 38, 189

Bourrache (Borrago), 38, 68, 172. $215,287,290$

Boussingaultia, 158.

Bouturage, $19,33,34,119$.

Brachychiton (Stercalia: 180

Brassia verrucosa, 151 .

Brassia verrucos

Brayère (Hagenia), 197

Brésillet, 193, 266.

Brize (Briza), 132, 245

Brome. 132, 24

Broméliacées, 7, 45, 58, 59 , $67,84,93$, PI. 12, 145, 147. 148.

Brosimum, 156, 233.

Broussonetia, 85, 155, 256.

Brugmansia Zipellii, 57. Bruguiera, 94.

Brunelle (Brunella), 176.

Bruyère, $6,26,38,80,83$,

$84,85,94,169,186,254$,

$255,262,284,299,303$.
Brye (Bryom), 77, 120. Bryonio dioica, 8, 54, 92 168. PI. 24, 286, 288. Buchloe dactylis, 86. 88. Bugle (Ajuga), 170, 245.

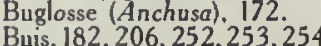
286, 294, 299

Bulbophyllum, 153.

Buplèvre (Buplevrum), 204.

Burmanniacées. 59.

Bursera. 58, 188, 277.

Butome, PI. 6, 144.

Butyrospermum, 171, 233.

Buxées, 182

Cacao, 149, 233, 241, 242.

Cacaoyer (Theobroma cacao). $180.241 .242,243$.

Cachou, 257, 266, 293

Cachoutier (Acacia), 194.

Cactacées, 25, 30, 73, 83. $199,202,203$

Caféier (Coffea). 163. 164.

240, 241, 279, 285, 290.

\section{Cailcédrat, 253}

Caille-lait, 55, 163, 282.

Cajanus indicus, 192, 247.

Cokile maritima. 183

Caladium, 26, 31, 134, 135.

Calamées, 137.

Calamintha, 176

Calamite, 205.

Calamus, 92, 96, 139, 140, 272.

Calanthe, 153.

Calathea, 11, 17.

Calceolaria, 174

Calebasse (Lagenaria), 168.

Calebassier (Crescentia), 175 176, 284.

Calendulées, 164, 166.

Calirthoe, 180

Calla, 135

Calliandra, 27

Callistephus chinensis, 164 .

Callithamnie, 112.

Callitrique, 200.

Callitris, 128, 272.

Calluna vulgaris, 169

Callymenia antartica, 77.

Calotropis gigantea, 271 .

Caltha, 70; Pl. 6, 177, 178.

Calycanthe, 80.

Calystégie (Calystegia), 172.

Camarine, 80.

Cameline, 184, 231, 247

Camellia, $85,186,233,242$, 299, 302, 305

Camerisier (Lonicera), 162.

Camomille d"Alle magne, 165

- ordinaire, $165,286,287$.

289: - puante.

Campanule, 7, 9, 167 ; PI. 1.

Campêche (Bois de), 22

Camphre, 180, 289, 291.

Camphrier, 178.

Campsiandra laurifalia, 93

Canaigre (Rumex hymeno-

sepalo), 4, 158, 257 .

Cananga cdarata. 178, 276.

Canéficier (Cassia), 194.
Canna, Pl. 12, 149, 217, 235.

295.

Cannobis sativa, 260.

Canno indico, 149

Canne à sucre (Saccharum), 92, 96, 129, 130, 208 Canne de Provence, 132.

Canne de Prove

Cannées, 149.

Cannellier, 178, 206, 208.

220,221

Caoutchouc, 3, 156, 173, 181, 267 à $270,296,298$.

Capillaire (Adiantum), 121;

Capparis. 184.

Caprier, 184, 219, 247

Caprification, Caprifguier $63,64,65,156,225$

Caprifoliacées, 162.

Capsella Bursa pastaris, 183.

Capsicum, 171, 219, 220 .
Capucine (Tropeolum), 27.

$54,185,217$

Caraguata cardinolis, 67, 147

Carambolier (Averrhoa), 185.

Carapa. 94

Cardamine pratensis, 7, 70,

Pl. 6, 183, 215, 245. 293

Cardère (Dipsacus), 163, 255. $283,284,303$

Cardiosperme, 284.

Cardon (Cynana) 158, 216.

Cardulovice, 90, 263, 264

Carduus nutans, 164

Carex. 9, 24, 134, 262, 263.

$264 ;$ - stricta, 264

Carica, 41, 182

Carissa, 284.

Carline, $137,164,290$

Carnivores (Plantes), 53, 68

$69,174,175,174,198$.

Carotte (Daucus Caroto), 2 , $217,241,282,304$.

Caroube, Caroubier. 193

Pl. 19,242, 243, 247.

Corpinus, 160

Carthamus, 208, 266

Carum carvi, 204, 277, 289.

Carya, 85, 161, 252. 77.

$170,185,280$.

Caryaphyllus aromaticus, 201. Caryota, $140,141,262$.

Cassia, $90,191,194,287,288$.

Cassie, 194, 274, 275

Cassis, Cassissier (Ribes), 224.

Castanopsis, 156, 160, 206.

Castelnavia, 72

Castilloa, 156, 269, 270

Casuarina. 157, 278, 284

Catalpa, 175

Catananche, 167

Catasefum. 152, 153

Catha comestible. 189. 243.

Cattleya, 59, 92, 152, 153; -

citrina, Pl.13;-Dowiana,

Cavlerpa, 109.

Ceanothus cuneatus, 84, 189.

Cecropia, 65, 66, 68, 156

Cédratier, 187, PI. 19, 276.

Cèdre (Cedrus).

Cèdre rouge $d^{*}$ Amérique $(J a-$

niperus) 254,277

Célastre, 189

Céleri (Apium graveolens),

$204,215,285,286,304$.

Celosia cristata, $98,158$.

Celtis oustralis. 157.

Centaurea, $163,164,245$.

Centaurée (Petite), 289, 290.

Centranthus ruber, 38, 162.

Cèpe (Boletus), $114,118$.

Cephalis, 163, 288

Cephalanthera, 63,154, P1.13.

Cephalopitcairnia, 147.

Cephalotus, 69, 198.

Céraiste (Cerastium), 36, 185.

Cerasus, 195, 196.

Ceratanthera Beaumetzi, 221

Ceratonia, 193. 70, 71, 200.

Ceratazamia, 90.

Cercis accidentalis, 84, 193.

Céréales. 2, 7, 44, 60, 101

$104,208,210$ à $215,234$.

Céréoidées, 202.

Cereus, 25, 52, 68, 202, 203.

Cerfeuil commum (Anthriscus), 204, 219.290; - bulbeux (Chorophyllum), 204, 217. Cerise, $2,3,41,207,208$,
222, $223,238,290$.

Cerisier (Cerasus vulgaris),

$253,297,305$; - padus

195; - 297. $305 ;$; 195 padus,

Mahaleb. 36,195 .

Ceroxilées, 173

Ceroxylon, 90, i41, 233.

Cesalpinia, 257, 266 .

Césalpinées 190, 193.

Ceterach officinorum, 122.

Cetraria Islandica, 119

Chamæcyparis, 128.

Chamedora, 141.

$83,138,262,264$ hamilis

Champignons, $4,10,25,33$

$49,59.60,72,81,93,107$

112 à 118, $119,150,151,159$ $280,286,304$

Chanvre (Cannabis sativa) 3 $35,39156,175,232,258$ $259,260,261,292,293$.

Chanvre du Bengale, 180 260: — de Manille, 148 260; - de Maurice, 260 : 
Cornichon (Cucumis sativus), $168,219$.

Cornifle (Ceratophyllum), 70 , 71, 200, PI. 6.

Cornouiller (Cornus), 180 ,

Caranilla $192 \mathrm{Pi}$

Corossolier (Anona), 178.

Corrète (Corcharus), 180.260

Corroyère à feuille de Myste

(Coriaria myrtifolia), 185.

Corydale (Corydallis), 182

Corypha, 138, 235, 264.

Cosmarium, 77

Coton, 258, 259, 260, 261.

Cotoneaster, 198

Cotonnier (Gossypium) , 3, 45 $180,208,232,259,260$, 261.

Catyledon gibbiflora, 30.

Coudrier (Corylus Avellana).

$160,226,279,304$

Courbaril (Hymenea), 194

Courge (Curcubita), 41, 168

218. 291

Crambe maritima, 183, 215.

Cranson (Cachlearia), 183.

Crassulacées, Pl. 16, 198.

Crategus, 198

Crépide (Crepis), 167.

Crescentia cujete, 175, 281.

Cresson de fontaine (Nosturtium officinale), 183, 215, 216, 289, 290, 291.

Cretelle (Cunosurus). 245.

Crin végétal, 141, 145, 261.

Crithmum maritimum, 203.

266.

Crosne du Japon (Stachys affinis), 24 , 176. 217.

Croton (Codicum). 31, 181. 233, 291, 302 .

Croton des teinturiers (Chrazophora tinctoria), 266.

Crucifères, $38,44,51,76$

77, 86, 183, 184, 231.2 256 .

Cryptanthus, 147

Cryptogames, 10, 35, 107, 121

à 124.

Cryptophoranthus, 153.

Cryptostegia, 270.

Cucumis, 168

Cucurbitacées, 30, 41.55, 92 162 , 167. $168,218,263$, 283, 286.

Cimminum, 203, 277

Cuphéa, 200

Cupressus, 128, P1. 11.

Cupulifères 158,159 .

Curare, 174, 285, 286.

Curcuma, 149, 221, 280.

Cuscuta, 56, 58, 81,175 246.

Cyomapsis psaraloides, 246.

Cyathea, 90, 96, 97, 124 .

Cyathium, 181

Cycadées, 85, 90, 125, 128 ,

205, 206, 235.

Cycadospadix. 206

Cycas, 90,128

Cyclamen, 170, 299

Cyclanthacées, 90.

Cydonia. 198

Cymbidie (Cymbidium), 152.

Cymodoce, 134.

Cymopolie, 109

Cynara, 164,282, 283

Cynodon dactyle. 132. 262.

Cynoglassum, 172

Cyperus, 134, 263, 264, 258.

Cyprès (Cypressus). 84, $254,279,280,284:-$ sempervirens. PI. 11.

Cyprès chauve (T axodium),

127.

Cypripedium, 3, 154, PI. 13.

Cytinus, 161.

yftisus, 44, 190, PI. 16

PI. 24, 247, 286, 287.

Dactylis glomerata. 132, 245.

Dahlia. 3. 19, 165, 166.

Daikon, 217.

Dalbergiées, $190,192,193$.

Dammara, 97,272

Daphne, 83,286, 291; Gnidium. PI. 24. Darlingtoma californica, 69, Edelweiss (GnaphaliumLeon-
topodium), 8, PI. I, 81,

Dasylirion, 90.

Dasypogon, 97.

Dattier (Phanix dactylifera)

39, 45. Pl. 4.61, 102,136,

137. 138, 208, 226, P1. 19

Datura, 172, 285, 286, 308. PI. 24.

Daucus Carota, 203.

Dauphinelle, 45,178

Davallia, 123, 297.

Delesseria sanguinea, 112 ,

113.

Delimopsis, 55

Dendrobirm, 152,153, P1. 13

Dendroseris, 95, 96.

Deodora, 127.

Desmodium oyrans, 53, 192

Desmuncus, 54, 92.

Deutzia, 199, 300 .

Dialypétales, 155, 172, 177 à

Dianthus, 185

Diatomées. 111, 112, 283.

Dicentra, 182

Dicksania, 96, 123, 124.

Dicotylédones, $26,38,49$. $107,125,155$ aे 204.

Dicrea, 71.

Dicrane (Dicranum), 75.

Dictamnus Fraxinella, 186

Dictyota atomaria, 111 .

Didiéréacées, 96.

Didymochlène, 123.

Dieffenbachia, 135.

Diervillea, 162, 163

Digitalis, 6, 61, 174, 175

PI. 24, 285, 286, 287, 290 291.

Dilléniacées, 55.

Dionaa muscipula. 69, 184

Dioscorea, 146. 217.

Diosmée, 186.

Diospyros, 170, 253.

Dipsacées, 163, 164.

Dipsacus, 163, 283.

Diptérocarpées, 180, 233

Dipteryx odarata. 193.

Disa grandiflara, 154, Pl. 13.

Discomycètes, 116, 119.

Diss (Festuca patula), 263.

Dissolis grandiflora, 240

Dolichos Lablab, 246.

Dompte-venin (Cynanchum vinceloxicum). 173.

Doradille (Asplenium), 58,

92, 123.

Dorema Ammoniacum, 203.

Dorine, 199.

Dossinia, 154.

Doum (Hyphane thebaica).

$20,90,140,141$

Doura (Sorghum) 131, 213.

Draba, 73, 76, 183

Dracena, 7, 8, 144, Pl. 25.

298.

Dracuntium, 26, 135.

Dragonnier (Draceena), 21 22. 84, 90, 97.

Drave (Draba), 8, 76, P1. 1

Drepanocladus uncinatus, 77.

Drimys, 97, 221.

Drinn (Stipa). 263, 278.

Drosera, 68, 69. 184.

Drosaphyllum, 69. 184

Dryas, 76, 196, 206

Dryobalanaps, $180,288$.

Dupontia. 76.

Duroia, 66.

Dyckie (Dyckia), 147.

Ebénier (Diospyras Ebenum),

$22,170,253,255$

Ecballium elastica, 168.

Echalote (Allium ascalonicum). 143, 219.

Echeveria. PI. 16. 198; -

glauca. 198, 295.

Echinacactus, 13, 73, 87

$88,202,203$.

Echinope, 164.

Echinopsis, 202, PI. 16

Echium, 172.

Ecklonia, 77

Ectozoma d'Ule, 66, 67.
166.

Edgeworthia Gardneri. 258.

Eglantier (Rosa), 8, 61, 65,

$196,197,279$

Eichhornia, 70, 144

Eleis, 90, 136, 142, 231

Elcocarpus, 180, 284.

Elcodendran orientale, 171.

Elettaria, 149, 221.

Eleusine, 133, 213, 246.

Ellébore (Hellebartus), 37, 38 ,

177, 286, PI. 24, 305 .

Elodea canadensis, 148.

Encalypta vulgaris, 120

Eacens 106, 187. 277

Encephalartos, 128.

Endymian nutans, 143, 144.

Engrain (Triticum monococ-

cum), 133.

Entolama lividum, 117, 286.

Épeautre (Triticum spelta). 133

Épervière (Hieracium), 167

Ephèdre (E\&hedra). 128.

Ephémérine (Tradescantia),

144.

Épiaire (Stachys), 176.

Épicea élevé (Picea excelsa).

127, 255, 258.

Épices, 106, 220, 22l, 276.

Epidendrum. 152.308, PI. 13.

Epilabium, 61, 75, 81, 200.

Epimède (Epimedium), 178.

Epinard potager (Spinacia oleracea), $158,215,288$; - des Indes, 158; - de la

Epine-vinette (Berberis), 38 ,

$39,53,80,115,178$

Epiphyllum, 13, P1. 16. 202.

Epiphytisme. $7,8,19.45$. $92,94,122,147,151,180$, 307.

Epipogon, 80.

Épurge (Euphorbia Lathyris), 181

Equisétinées, 107, 121, 124 ,

Érable (Acer), 17, 28, 36, 43 ,

$44,48,49,54,85,188$,

189,225 , 227, 229, 236 ,

$250,252,253,254,255$,

279. 294.297, 299, 305

Eragrostis, 213.

Ergot (Claviceps), 60, 116.

Ericacées, 76, 96, 169, 170.

Erigeron canadensis, 164.

Eriadendran, 45, 88, 90, 180.

233. 262.

Eriophorum, 75, 81, 134

Erodium, 5i, 86, 184.

Eryngium, 96, 204

Erythrea, 174, 289. 290

Erythrina,192, PI. 16.

Erythrophlaum, 285. 308

Erythroxylon, 185, 291, 308.

ticum), 133.

Esérine, 192

Esparcette 192, 246

Estragon (Artemisio Dracun-

culus). 165.

Eucalyptus, 21, 96, 97, 201. $215,252,273,276,278$, $284,290,294,296$.

Euchema, 282

Euchlène mexicain, 130, 246.

Eugenia, 201.

Eulophie (Eulophia), 152.

Eupatoire bleue (Ageratum). 64 ; - chanvrine (Eupatorium) 164:

Euphorbe (Euphorbia), 25. $60,68,87,96,181,233$, 235. 269. 286; - (Poinsettia). $18 \mathrm{i}$

Euphorbiacées, 91, 93, 181. $232,233,268,269,286$.

Euphraise, 56, 73, 174 .

Euterpe (Euterpe), 93.

Euterpe (Euterpe), 93.

Evonymus, 189.

Excoecaria Agallocha, 182.

Exoacus pruni, 60, 116.
Epipoctis latifolia, 61.

Eremurus spectabilis, 84,144.

Faba, 191

Fagus, 160

Fatsia, 44, 80, 204

Fegatella conica, 120. 
Comme, 180, 19], 194, 203 271,272 ; - ammoniaque. 203: - laque, 247; résine, 203, 277

Gommier blanc, 201:- bleu, 201.

Gomphocarpus, 173.

Gonocrypta Grevii, 3,96,270.

Gossupinm, 180, 261.

Gouet (Arum), 84, 135.

Gourde calebasse (Lagenaria vulgaris), 168, 208, 283.

Goyavier ( $P$ sidium Goyavia) 201, 226, Pl. 19, 255

Gracillaria, 77.

Graine, 41, 42, 45 à 49,51. $58,59,67,68,125,137$ $140,150,220,227,284$.

Graminées, $6,7,26,3 \%, 44$. $56,60,61,76,77,81,84$ $86,88,91,93,97,129$ a
$134,174,210,229,244$, $245,246,247,262,263$, $278,303$.

Graminidées, 129 à $l 35$.

Grammataphyllum, 52, 93.

Graphis, 119.

Grasses (Matières), 230 à 233.

Grassette commune (Pingui-
colavulgaris), 69, 174,282.

Gratiole (Gratiola). 286.

Greffage, 34, 35, 102.

Grémil (Lithospermum), 172.

Grenadier (Punica granatum), $222,225,279,291,305$.

Grenadille. Pl. 19.

Grevillea, 96, 97, 158.

Grimmia pulvinata, 120.

Grindelia, 290.

Groseillier (Ribes), 36, 199 ,

Grossulariées, 199, 200, 202. 203.

Gueule-de-loup, 174.

Gui (Viscum album), 18, 19 $-57,67,81,93,161,280$ 299, 303, 306, 307.

Guimauve officinale (Althea officinalis), $38,179,258$ $287,289,290$

Guimauve en arbre, 180.

Guinche (Molinia), 262.

Guizotie d'Abyssinie. 232.

Gutta-percha, 3, 170, 270. 271.

Guttier, 180.

Guzmannia, 147.

Gymnadenia, 154

Gymnoclados, 193.

Gymnogramme, 122.

Gymmospermes, $39,85,87$.

107,125 à $128,206$.

Gymnostome, 120 .

Gynérie argentée 132

Gypsophila, 73, 185, 280.

Habenaria, 154.

Hæmanthus, 145.

Hagenia abyssinaca, 197, 291

Haloragées, 200.

Haloxylon, 86, 158.

Hamamelis, 200.

Hancornia speciosa. 173,270

Haricot (Phaseolus), 44, 45 $46,48,106,192,208$,
$217,218,235,247,282$.

Haricot-pistache (Voandzeia), 192.

Hedera, 204.

Hédysarées, 190, 192

Hélénie (Heleniom), 165

Héléocharis tubuleux, 134.

Heliamphora, 184.

Helianthus, 164, 165, 217. $232,280,305$.

Hélianti (Helianthus decapetalus). 217

Héliconie (Heliconia), 148

Heliatropium, 86, 172

Hellébore. Voir Ellébore.

Helosis guyanensis, 57.

Helvelle (Helvella) 118

Helychrysum, 85, 166.

Hematoxylon campechianum
$22,90,194,265,266$.
Hemerocallis, 144.

Hemileia, 241.

Henequen, 260, 262.

Henné (Lawsania alba), 200. 208, 266

Hepatica, 80,177, 285.

Hépatiques, 35, 81, 107, 120. Heracléum, 204.

Herbe aux chats (Nepeta, Valeriana), 162, 176, 289; - aux écus (Lysimachia), 170: - aux mites (Tanacefum), 166; - au musc (Hibiscus), 180; $\overline{173}$ à la à plumet (Gynerium), 132; - als porc-épic (Triodia) 97: - à savon (Gypsophila). 280 ; - des bufles (Buchloe), 88; - de Guinée (Panicum), 246

Herminiera, 257.

Hespéridées, 276

Hêtre (Fagus), 6, 8, 12, 23.

$24,26,28,29,35,44$

$48,78,79,80,82,85,96$

$97,103,104,206,208,218$

$249,250,251,252,253$

$255,258,284,305$

Hevea, 47, 93, $181,267,268$. 270.

Hibiscus, 180.

Hickory (Carya), 161, 252

Himanthalia, 12, 13, 108,110.

Himpeastrum. $145, \mathrm{Pl}$. 12.

Hippocastanées, 188.

Hippocrépis, 192.

Hippomanées, 18]

Homaria 154

Homoxylées, 97, 206.

Hopea, 233.

Hordées, Hordeum, 130, 133.

Hortensia, Pl. 16, 199, 300.

Hoteia du Japon (Astilbe

japonica), 199. 300

Hottonie (Hottonia), 70, 170.

Houblon, 54, 55, 80, 156.

$157,239,287,289,290$

Houlque (Holcus), 132, 245.

Houx (llex) $67,80,82,173$

$243,253,254,255,279$

280,303 .

Houx (Petit) [Ruscus], 144.

Hovenia dulcis, 189.

Howea, 141

Huile, 157, 160, 170, 171 181. 192, 208, 230 à 233.

Huntleya, 152

Hura crepitans, 181.

Hydnophytum, 65, 66.

Hydnoracées, 57.

Hydnum repandum, 114.118.

Hydrangea hortensia, 199.

Hydrocharis, 35, 71, 148.

Hydrocleis, 70 .

Hydrodictyon, 109.

Hydrosome, 135.

Hydrotropisme, 19, 51.

Hygrophore, 114.

Hymenæa, 194, 272 .

Hymenocallis, $145,146$.

Hyménophylle, 58, 124.

Hyménophyllite, 205.

Hypericum perforalum, 181.

Hyphane, 20, 90, 141.

Hypnum, 120, 264.

Hyssopus officinalis, 176

Icaquier (Chrysobalanus), 196.

Idria, 11, 12, 106, 182

If ( $T$ axus $), 46,128,247,279$.

$286,294,297$.

Igname (Dioscorea), 146, 217

llang-ilang, 276.

llex aquifoliom, 172.

Imantophyllum, 145.

303: - à bractées (Heli-

chrysum bracteatum), 166.

$302 ;-$ annuelle (X'Xeran-

themum), 166: - blanche

d'Orient (Helichrysum

orientale), 166.
Indigotier (Indigofera), 90. 191, 265

Inula Helenium. 166.

Ionidinm lipecacuanha, 288.

pecacuanha (Cephceisis), 163 $184,287,288$.

lpomcea, 173, 288.

résine (Tresine) 158.

riarté, $140,142,284 . \quad 145$

ridinées, 129,145 à 154.

lris, $24,29,43,70,145$

$46,148,273,297,305$.

Pl. 6. Pl. 12.

Irvingia, 188, 232, 233.

1satis, 184.

Ivraje (Lolium), 81, 133, 245 $285,286, P j .24$

Ixla maculata, i46, PI. 12 Ixtle, 260.

Jaborandi (Pilocarpus pennatifolios). 186, 290.

Jacée (Centaurea Jacea), 7.

Jacinthe sauvage (Endymion

nulars), $6,80,143,303$.

Jacinthe d'Orient (Hyacinthus orientalis), 143, PI. 12, 287. 297. 299, 300,302 .

Jacquier (Artocarpus integrifolia) 42, 90, 156

Jalap (Ipomaa Jalapa), 173. 187, 288

Jambosa, P]. 19. 201.

Jarrah, 201, 25i.

Jasminum, 171, 242,254, 275.

Jatropha, 181, 233, 268.

atrorrhiza, 178; - Colombo, $288,289$.

Johnsoniées, $97.9,14,68,70$,

$136,263,264$.

Joncinées, 129,136 à 142 . la), 274 .

Joubarbe des toits (Sempervi-

vum tectorum), $5,30,178$

Juba spectabilis, 84, 85, 142

Juglans, 160

Jujubier (Zizyphus), 189.

PI. 19, 226, 284, 290.

Julienne Hesperis, 183.

Juniperus, 128, 254.

Jusquiame (Hyoscyamus), 43.

172, PI. 24, 286

Jussiée, 200.

Jute (Corchorus capsularis).

$25,180,258,260$

Kampferia, 149, 280

Kaki (Diospyros Kaki), 170, Pl. 19, 226.

Kalanchoe, 198

Kapok, 45, 180, 262, 263.

Kapoquier (Eriodendron an

fractuosum), 233. 262.

Karité (Butyrospermum) 170, 233.

Karri, 201, 252.

Kentia, 96, 14

Kerria japonica, 196, Pl. 16.

Keteleeria de Fortune, 127

Ketmie (Hibiscus), 85, 180 260.

Khât, 189.
Khaya, 253.

Kigelia, 17, 44, 175

Kingia, 97.

Knightia excelsa, 97

Kniphofia, 144.

Kœlérie (Kcleria), 132.

Kola, Kolatier (Cola acuminata), 90, 180, 291, 293.

Kousso, Koussotier (Hagenia

Kameria triandra, 288.

Labiées, 38, 61, 84, 87, 91 , 175, 176,275

Lelia, 92, 94, i53, 308 ;

purpurata, PI. 13.

Lagenaria, 168, 283.

Lagerstroemia, 96.

Lagurus ovatus, 132, 303.

Laiche (Carex), 81, 97.

Lait végétal, 156, 192, 233.

Laiteron (Sonchus), 81, 96. 167.

Laitue (Lactuca), 52, 163

167, 215, 288, 289 .

Laitue de mer (Ulva), 9, 109

Lamarkia aurea, 132, 303.

Lamier (Lamiam), 6, 38, 99.

$100,175,176,287$

Laminaria, $9,12,13,77,110$.

227, 279. 281, 282

Lampsana communis, 167.

alphia, 173, 268, 269 270.

Langsdorfia hypogea, 57.

Lnportea moroides, 68, 96.

Lappa, 164

Laque de Chine, 187, 272 
Manicaria. 26, 140, 142. Manihot, 181, 208, 235, 239, 269, 270.

Manne, 171, 182, 201, 227. 288,290

Maquis, 83. $39,217,235$

Marasmius Oreades, 114, 118.

Marattiacées, 124, 205.

Marchantia polymorpha, 120.

Marckea des fourmis, 66, 67 .

Marea, 257.

Margousier (Melia Azedaroch), 188.

Marguerite. 7. 165 ; - grande (Leucanthemum vulgare), (Chrysanthemum segetum). 165 ; - en arbre, $165 ;-$ petite (Bellis perennis), 6 ,

Marjolaine (Origanum vulgore), 176, 273, 276, 297. Marronnier d'Inde (Esculus Hippocastonum), 27, 28 , 280. 281, 290, 294.

Marsilie (Marsilia), 124.

Martynia, 175.

Mascarenhasia, 173, 270.

Masdewallia, PI. 13,153

Massette(Typha), 70, 98,99, $135,262,264,303$.

Maté (Vlex paraguayensis). 172,290 .

Matricaria camomilla, 17,165.

Matthiala, 9, 86, 183

Maurandia scandens, 174.

Maurelle (Chrazophara), 266. vinifera, $90,138,139 ;=$ flexuasa, 139.

Mauve (Malva), 179, 180,

280, 287, 305.

Moxillaria, 152. Pl. 13.

Maximiliano princeps, 268.

Maydées, 130.

Medicago, 191.

Megaclinium, 153.

Melampyrum, 56, 174.

Melandrium apetole, 76 .

Melanorrheo, 187, 272.

Melastomacées, 66, 67, 92. 201.

Mélèze (Larix), 8, 79, 126, 187, 252,272

Melio azedorach, 188, 284.

Méliguette. 221.

Melilotus afficinalis, 191, 274. Melissa officinalis, 176, 273. 276, 289.

Melon (Cucumis Melo), 55 . 167, 168,218

Menabea venenata, 285.

Menispermum, 80, 178.

Mentha, 28. 176, 273, 275. 276, 287, 289, 291.

Menyanthes, Pl. 6. 174

Meniésie, 80.

Mercurialis, 101, 181; - annua, 101 ; - perennis, 285
Merisier (Cerasusavium), 195 . $196,249,254,255$.

Mesembrianthemum, $52,203$.

Mespilus, 198.

Metraxylon, 90, 139. 283.

Mibara verna, 129, 132.

Micocoulier (Celtis australis) $157,252,254,255,294$

Microbes. 4, 33, 237, 282

Millefeuille (Achillea), 7.

Millepertuis (Hypcricum), 38 . $39,181$.

Millet à chandelle (Pennisetum typhoideum). 131, 212 . - commun (Panicum miliaceum), 131, 208, 222, 246, 247; - d'Italie (Setario italica), 208, 212; - indien (Sarghum vulgare)

Miltonia, 152, PI. 13.

Mimosa, 275, 301; - tenuifolia), 255 :- pudica, 194. Mimosa des fleuristes (Acacio dealbata, etc.). Pl. 16, 194 Mimosées, 90, 190.

Mimule (Mimulus), 174

Mimusops, 93, 170, 271

Mirabilis, 103, 104, 158.
Mnie (Mnium), 120.

Moisissures, 4, 113, 116, 282.

Molène, 174, 255

Molinia carulea, 262.

Momordico, 168, 297.

Monbin (Spondios purpurea), 187. Pl. 19.

Monnina polystachya, 280. 107, 129 à 154, 155.

Monodora Myristica, 221.

Monostroma Hariotii, 77.

Monotropées, 170.

Monstera, 29. 58, 93, 135.

Montbretia, 146.

Morées, 67, 155.

Morelle (Solanum), 52, 171 297.

Morène (Hydracharis), 148.

Moréniées, 92.

Moringa ptérygosperme, 233.

Morus, 266.

Mourera Weddeliona, 72.

Mouron commun ou des oiseaux (Stclloria media), 43 Anagollis). 44, 52,170

Mousses, 5, 6, 9, 50, 51,71. $75,77,80,81,83,107$ $120,121,122,125,303$ 304; - de Ceylan, 281: - de Corse, 291:- d'Is lande, 281 ; - perlée, 291

Moutarde (Sinapis). 183,219

Mouvements, 51, 52, 194

Mucorinées,112, 113,116,236.

Macuna, 192.

Muflier (Antirrhinum majus), 43, 44, 174, 305 .

Muguet (Convallaria), 6, 28, $80,144,273,274,286$ $290,291,298,299,300$, $301,302,303,304$.

Mârier (Marus), 196, 255. - olba, 43, 155, 208, 247 252: - Cudrania tinctorio javanensis, 266; - nigra, 43, 155, 225; - papier (Braussanetia papyrifera).

Muse, 148,260

Muscade, 221, 233, 277.

Muscadier (Myristica), 93.

$178,220$.

Muscari, 84. PI. 12, 143.

Muscinées, 35, 107, 108, 120 .

Musées, 148, 149.

Mycaconthococcus antarcti-

cus, 77:- ovalis, 77

Myosotis, 36, 172, 295.

Myrceugenia. 95, 96.

Myrica, 80, 232, 233.

Myriophyllum verticillotum. 29, 30, 70, Pl. 6, 200

Myristicacées, 93, 178.

Myroxylon, 193.

Myrtacées, 200, 20l, 276. 284.

Myrte (Myrtus), 84, 85, 97 200255,298

Myrtille (Vaccinium Myrtillus), '170, 238

Myxamibes, 50 .

Myxomycètes. 50, 116.

Myzodendron, 82.

Naiadacées. 134.

arcissus. 8, 9, Pl. 6, 145 275. 297, 298, 299, 301 $302,303, \mathrm{P1} 12$.

Nasturtium, 183.

Natrices, $125,128$. 183, 217, 247.

Navicula, i11, 1i2.

Néflier (Mespilus), 42, 102. 197, 198, 224.

Néflier du Japon (Eriobotryo japonico). Pl. 19, 198, 226.

Negondo, 189

Nelumbium P1 6, 179

Nénuphar, 9, 36, 38, 52, 70 .

178, P1. 6, 296, 305.

Neottio $59,80,150,151$.

Népenthès, 69, 184.

$\begin{array}{ll}\text { Nepeta cataria, } 176 . & 176 . \\ \text { Nephelium, } 85,188 .\end{array}$

Néphrodie (Neprodium), 123.
Nephrolepis, 123.

Nerism Oleander, 173.

Nerocystis, 75.

Nerprun (Rhommus), 189

Niaouli cajeput, 201, 276.

Nicotiona, 172, 292.

Nidularia, 66, 93, 147.

Nielle (Lychnis Githogo), 7.

185, Pi. 24, 286.

Nierembergia, 172.

Nigella), J, I77.

Nigritella angustifol

Noilssonia, 206.

Avellana), 27, 39,160
A

$206,226,231,247,255$

- Colurna. 252.

Noisette, 207. 226. 231.

Noix, 42, 207, 208, 284 .

- bougie, 284 ; - d'aca-

jou, 187 , Pl. $19 ;$ - darec.

136, $\mathrm{PI}$. 19, 260. 262

264, 284: - de galle, 65 ,

kory, 226; - de kola. 291.

- de muscade. 221 ; -

de Para. 201:- de Sa

pucia, 284 ; - pacane, 161

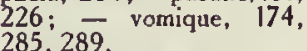

Nombril de Vénus (Umbili-

cus pendulinus), 198.

Nopal (Opuntia), 87, 88,

$202,247$.

Nostoc, 77, 109, 110, 119

Nathafagus, $29,78,82$

Noyer (Juglons), 22, 49, 160 ,

$161,206,226,231,252$,
$253,254,287,288,294$.

Nuphar luteum, i78.

Nyctaginacées, 158.

Nymphaa, 70, 179, 206.

Oca, 185, 217

Ocimum basilicum, 176.

Octojuga variabilis, 59.

Odonthalia dentata, 113.

Odontites, 174.

Odontoglossum. 50, 93, 94 ,

152, 154, PI. 13.

Odontopteris, 205.

Edogone, 50, 109.

Eillet (Dianthus), 29, 43,

$185,297,298,300,302$.

Eillet d"lnde (Tagetes pa-

tula), 165, 297

Enanthe, 70, 203, 284, 286, Pl. 24.

Enocarpe, 93.

Oidium, 116,237

Oignon (Allium Cepa), 2, 24,

$143,208,219,275,282$.

Olea, 171 .

Olive, 4i, 171, 219, 230.

Olivier (Olea) 83, 84, 169 .

$170,208,227,230,251$,

$255,275,279$; - odorant (Osmanthus) 242

Ombellifêres, $26,61,68,77$,

164. 199, 203, 204, 284.

Ombilic (Umbilicus), 198.

Onagre (Enothera), 38:-

biennis, 200; - Lamarc-

kiana, 101; - nana, 101, 102

Oncidium, 93, 152, Pl. 13,

Oncoba épineux, 284

Oncocalamus, 140.

Onabrychis sativa, 192

Onopordon acanthe, 164.

Oomycètes, 116.

Ophioglossum, 124, 154, Pl. 13.

Ophrys, 19,72,84,

Opopanax, 203. 204, 277.

Opoponax, 203, 204, 277
Opuntia, 31, 40, 46, P1. i6 $247,264,278,279$; monacantha, 82 ; - Ficus indica, 202, 247.

Oranger (Citrus Aurantium).

$38,66,83,84,186,208$, $224,225,273,274,275$ $276,288,289,298,299$,
305.

Orcanette (Alkanna), 172, 266.

Orchidées, $3,7,8,19,38$, $39,58,59,62,63,67,80$, $84,92,93,94,99,120$,

$121,129,145$, PI. 13,150 à $154,264,298,299,302$, 308.

Orchis, 19, 63, 72, 84, 150 , 153, 154, 235, P1. 13.

Oreille-d'ours (Primula auri-

cula), 170.

Oreodaxa, 90, 140, 141, 142. 
Phytophthora, 117, 216.

Picea, 127, 252, 258.

Picrémie élevée, 188.

Picride (Picris), 167.

Pied-d'alouette (Delphinium) 7. 178.

Pignon d'Inde (Jatropha Curcos), 181.

Pilocarpus, 186, 290.

Pilocerens lateralis, 11.

Pilostyles, 57. 58 .

Piment annuel (Capsicum annum 219,220:- fastigié. 230; - frutescens. 220, 280

Piment yrai (Myrtus Pimenta), 255

Piment de la Jamaïgue ( $P{ }_{i}$ mento acris), 201, 220.

Pimpinella anisum, 204.

Pimprenelle (Poterium), 197

$P_{\text {in }}\left(\dot{P}_{\text {inus }}\right), 6,8,20,22$ $23,26,40,58,79,83,84$ $85,86,109,118,126,206$, $250,252,254,255,258$ 271, 272, 278, 297,

Pinguicula vulgaris. 69, 174.

Pinnularia lata. 111 .

Pipéracées, 67, 92, 155 .

Piratinera guyanensis, 253.

Pirole, Pirolées, 170.

Pirus, 198.

Pissenlit (Taraxacum Dens leonis) $43,45,52,101$ $166,167,215$

Pistachier (Pistacia) , 82, 83 $84,187,226,272,293$. 193.

Pistia, 135.

Pisum sativum, 192.

Pitcairnia. Pitcairniées, 147.

Pitchpin (Pinus oustralis). 252, 272.

Pithe cothe nium, 54.

Pitoxylon, 206.

Pit si (Heleocharis), 134.

Pittosporum, 204.

Piroine (Pconio), 44, 178. 305.

Placenta, 40, 44.

Planera, 85, 157.

Plankton, 112.

Plantain (Plantago), 7, 37. $61,98,176,247,305$

Plaqueminier (Diospyros), 22. 170, 253.

Plasmode, 50.

Plasmopora viticola, 116

Platanthera, 154

Platanus, 23, 157, 158, 254, $294,296,303$

Platycerium, 58, 92, 122.

Pleurococcus, 13, 109.

Pleuropogon. 76.

Plenrosigma 111, 112.

Pleurote (Pleurotus), 10, 113

Pleurothallinidées, 153.

Plocamium coccinium. 77.

Plombaginacées, 88, 170.

Poa, 77, 132.

Poacinées, 130.

Podocarpus macrocarpa, 85

Podophyllum peltotum, 288.

Podostémacées, 71, 72.

Pogonate (Pogonatum), 120.

Pogostemon. 176, 276.

Poinsettia, 181.

Poire, 2, 3, 42, 222, 224, 238 ; - d'avocat, PI. 19 - de terre, 217.

Poireau (Allium Porrum), 37

38, 143, 215,

Poirée à carde (Beto vulga. ris). $158,215$.

Poirier commun (Pirus communis), 28, 37, 38, 39 $279^{\circ}$

Pois (Pisum) , 3, 37, 38, 39 $44,45,48,49,60,103$ $104,105,190,192,217$. 246, 282.

Pois carré, 246: - cornu 246; - d'Angole, 192; manioc, 246; - patate,
Pois chiche (Cicer arietinum), 51, 192, 218, 241 .

Pois del senteur (Lathyrus odoratus), 104, 105, 192 274.

Poivre, 149 ; - des Achantis ou de Guinée, 220; - de Cayenne, 220; - long, 220.

Poivrier (Piper), 157; - betel, 293:- - offcinarum.

Poivrier d'Amérique (Schinus

molle) Amérique (15

Polemonium, 76, i73

Polémoniacées, 172, 173.

Polianthe. 146, 275.

Pollen, 38, 40, 61, 62, 104.

Pollinie, $38,63,150,151$.

Polygalo, 188, 189, Pl. 1.

Polygalées, 189, 280

olygonacées, 96, 155, 157 ,

Polygonatum, 149.

Polymnia edulis, 217. $122,157$.

Polypodiacées, 122, 124, 206.

Polyporus, 114, 115, 283.

Polyporées, $114,118$.

Polysiphonia fastigiata, 112.

Polystic fougère mâle (Polys-

ticum Filis-mas), 291.

Polytrichum strictum.

Pomme, 2, 3, 42, 43, 198 , $222,223,224,238,239$, 247: - cannelle, 178 : d'acajou, 187; - de chêne 61, 65:- de Cythère.187. PI. 19; - de merveille,

168: - épineuse, 172.

tuberosum), 2, 24,38, 39 . $51,52,72,106,116,171$. $172,173,216,217,229$, $234,235,247$.

Pommier (Malus), 18, 35.

197, 198, 224, 279.

Pontederia, 70, Pl. 6.

Pontederiacées, 142, 144.

Populage (Caltha palustris),

70, Pl. 6. 178

Porcelle (Hypochocris), 167.

Porphyra, 112, 113, 281.

Porte-chapeau (Poliurus), 44.

Portulacées, 185.

Posidonie. 134.

Potamot (Potamogeton), 70,

$134,135$.

Potentillo, 196, 289.

Poterium sanguisorba, 196. 197.

Pothos. 135

Potiron (Cucurbita maxima), $41,168,218$.

Pourpier (Portulaca) , 43, 185. Pratelle (Psalliota), 117

Prèle (Equisetum), 124, 128. 283.

Prenanthes purpurea, 80 .

Primevère (Primula) 36,38 ,

287, 298, 299, 303, Pl. I.

Primula. Primulacées, 170

Pringlea, 77, 183.

Pritchardia, 139

Prosopanche, 67

Protea orgentea, 85. 158.

Protéacées, 85, 96, 97, 158.

Prothalle, 121,122, 128.

Protonéma, 120.

Protoplasma, 14, 50.

Proto, $-41,207,208,222$, $223,240,288$; - datte,

170 ; - coton, 196.
Prunées, 195, 196.

Prunellier (Prunus spinosa). $8,60,67,68,119,195$,

Prunier (Prunus domestica) $23.28,80,84,195,195$, $223,253,310$

Prunier mirobolan (Spondias),

Psalliota campestris, 35, 112. 113, 117.

Psamma arenaia, 278.

Pseudotetraspora Gainii, 77.

Psoralea glondulosa,
Ptelea trifoliata, 186.
Pteris, 80, 122; - aquilina, 122 ; - cretica, 122; serrulata, 122.

Ptéridospermées, 205206.

Pterocarpus, 193, 297.

Pterophyllum, 206.

Puccinio graminis, 60, 115.

Pulmonaria. 172, 285.

Pulque, 212, 238.

Punica Gronatum, 201.

Purgatives (Plantes), 171, 172. $173,288$.

Pusæetha scandens, 91

Pyrénacanthe à feuilles de mauve, 87

Pyrethrum, 165; - d'Afri-

gue, 289; - insecticide,

282, 283.

Pyxide, 44.

Quarantaine (Mathiola an nua), 104.

Quassio amaro, 188, 289, 290.

Quatre-épices (Pimenta offcinalis). 220

Quebracho colorado (Quebraciha Lorentzii), 257.

Quercitron (Quercus discolor). 159.266

Quercus, 65, 158, 266.

Quillaja saponario $196,280$. 281.

Quinoa (Chenopodium), 158 , $217,218$.

Quinquina (Cinchono), 4, 163. $164,287,289,290,291$

Racine, 16 à $19,33,51,52$, $56.71,94,121,127,204$ $276,278$.

Radiées, 163, 164 à 166

Radis (Raphonus sativus), 72. 183. 217

Rafflesia, 57, 58, 93, 161.

Raifort sauvage (Cochlearia

Aaimonce (Companula Ra

punculus), 167, 215.

Raisin, 41. 222, 224, 225. 247, 288, 290

Ramaline (Ramalina) 119.

Ramie (Bchmeria), 25, 155 $258,260,263$.

Raphia, 90, 96. 139, 235 $260,262,263,264,262$.

Raphiées, 92, 137.

Ratanhia (Kramerio), 288.

Ravenalo modagoscariensis

$26,28,96,148,149,304$

Ravenelle (Raphanus rapha-

nistrum, 183

Ravison, 231, 247

Ray-grass anglais (Lolium perenne), $47,138,245,246$;d'ltalie (multiflorum), 245.

Reanna, 246.

Redoul (Coriara), 185, 266.

Réglisse (Glycyrrihza glabra), 289, 290.

Reine des prés (Spirca ulmaria). 196, 199. 290

Reine-Marguerite (Callistephus chinensis), 164.

Renoncule (Ronunculus), 29 $83,70,177,245,286,302$ 305, Pl. 6.
Renonculacées, 76, 177, 178. 286

Renouée (Polygonum), 70, 96, 157.

Réseaud'eau(Hydrodyction), 109. 184,266, 273, 275

Resedo. 299.

Résines, 164, 206, 271, 272, 288, 290.

Retinospora, 297.

Retios

Rhaphidonema nivale, 77

Rhapis flabelliformis, 138 .

Rhinanthus, $56,174$.

Rhizocarpées, 124.

Rhizocarpon, 119

Rhizome, 23, 121, 149, 221 276.

Rhizophora, 93, 94, 202; mangle, 93.

Rhodante de Mangles, 166.

Rhododendron, 81, 170, 302.

Rhodymenia palmata, 113 .

Rhopalocnemis phalloides, 57.

hubarbe (Rheum), 157, 215 , 288

Rhus, 187, 233, 257, 272.

Ribésiées, 199.

Ricinus, 3, 28, 45, 47, 48, 
Scolopendrium, 122.

Scolymus hispanicus, 167, 217

Scorpiure (Scorpiurus), 192

Scorzonera, 167, 217

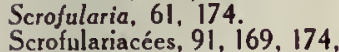
175. 286

Scutellaire (Scutellorio), 176 Scybalium fungiforme, 57 .

Scytonème. 119.

Sédum (Sedum), 5, 31, 36, 198.

Seigle (Secale), 47, 60, 133

210. 211, 212, 239, 240 , 241, 246, 247, 258, 263 . 264.

Selaginella, 50, 51, 124

Sélection, 99, 100

Sélénipedde chica, 154.

Semen-contra, 165

Sempervivum, 30. 198

Sené (Cassia ocutifolig et on-

gustifolia), 194, 287, 288.

Senecinoidées, 164, 166.

Senecions (Senecio), 94, 106.

166,247 .

Sénevé, 183. 53, 194.

Sépale. 37

Séquoia (Wellingtonio), 21 22, 84, PI. 7, 127, 128, 206, 249.

Serapias neglecta, 154, PI. 13.

Seringat (Philadelphus), 199.

Serjania, 188

Serpolet, 176.

Sesomum orientale, 175.

Sésélinées, 203.

Setaria italica, 212.

Sezanella, 206.

Sideroxylon, 170, 171.

Sideroxyllon, 205

Sigillaria, 205, 185, 295, P1.1.

Silique, 44, 183.

Silybum Marionum, 164, 165.

Simaruba, 186, 188, 233.

Sinapis, 183.

Sinningia, 175.

Siphonées, $109,206$.

Sisal, 260.

Sium sisarum, 204.

Smilax, 23, 55, 84, 290.

Smilacées, 92,144

Smurnium olusatrum, 204.

Sobralia dichotoma, 153, 308.

Soja. 192, 218, 219, 233.

Sojai.

Sola Æschynomena, 192, 257.

Solanacées, 67. 169, 171 .

$172,174,285^{\circ}, 286$.

Solanum, 24, 171 .

Soldanello olpina, PI. I, 170

Soleil (Grand) Helionthus

annuus $, 52,164,232,247$.

278, 280, 304, 305 .

Solidago, 164.

Sommeil (Mouvements de) $52,53,194$.

Sonneratia, 16, 19

Sophora joponico, 103, 104. 192, 193.

Sophronitis, 153. 197, 198. $247,254,255,280.307$ Sorgho (Sorghum), 130, 131 210. 213,229, 262

Souchet (Cyperus), 81, 134 $230,243,258$.

Souchet des Indes (Curcuma longa), 221.

Souci (Calendula), 7,52,166. Souci deau (Caltha), 178.

Sparganier (Spargonium), 318.

Sparmannia, 180.260.

Spart, Sparterie, 263

Spartium, 191, 286. 287.

Spathiphyllum, 135.

Speculario, 7, 167.

Sphacelaria, ill.

Spherophorus. 77.

Sphæroplea, 50.
Sphaigne (Sphagnum), 74, Tapioca, 235

120, 151,206, 264. Taro, 217, 235

Sphenopteris, 205.

Spherelle (Spharella) 13

Spilanthus oleracea, 289.

Spinifex, 97

Spiranthes. 153, 154.

Spirca, 300:- ulmaria, 70.

PI. $6,196,290$.

Spirille, 109, 110

Spirochète, 110.

Spirogyre, 108.

Splachnum, 120

Spondios cythereo, 187.

Sporange-spore, $15,51,112$

$114,116,121,122,123$,

$124,205$.

Squamaire (Lathrea), 56.

Stochys, 24, 176, 217.

Stanhopea, $152, \mathrm{Pl}, 13$.

Staphylea, 188. 255, 300

Staphylées, 188.

Statice, 9, 170, 303.

Stellaria, $6,170,185$.

Stellingia sebifera, 233.

Sterculio, 180, 206.

Sterculiées, 179, 180.

Steppe, 76, 88.

Stéréocaulon. 77.

Stérigmatocyste, 13.

Stichococcus bacillaris, 77.

Sticta pulmonacea, 119.

Stigmatées, 129

Stipa, 51, 88, 132, 263.

Stomate, 22, 30, 31, 71

120 ; - aquifère, 32 .

Storax, 170 .

Stratiotes oloides, 7, PI, 6,148.

Strelitizie (Strelitzio), 148

$149, \mathrm{PI} .12$.

Streptocoque, 109, 110.

Strophaire (Stropharia), 114

Strophantus, 173, 286.

Struvea plumosa, 109.

Strychnine, 289.

Strychnos, 174, 286.

Stupéfiantes (Plantes), 292. 293.

Stypaucaulon scoparium, 111.

Styracées, 170.

Styrax, 170, 277

Submergées (Plantes), 70, 71

Succin, 206

Sucrières (Plantes) 141, 142.

160,227 à 229.

Suifs végétaux, 233.

Sulla, 246.

Sumac (Rhus), 187, 233, 247. $266,272,286$

Sureau (Sambucus), 67. 162

278, 283, 284, 289, 290

Surelle (Oxalis) 185 .

Surirella splendida, 111.

Swietina Mahagon, 188,253

294,303;-(Figuier), 307

Symbiose, 59.

Symphoricatpos racemosa, 162.

Synanthérées, 38, 163.

Synedra, 112;-radions, 111.

Syringa, 170.

Tabac (Nicotiana Tabacum),

4. 155, 172, 175, Pl. 24, 193. 292 .

Tabitnamontana utilis, 173. 232,233 .

Taboure: (Thlaspi) 183.

Tacca pinnatifida, 235 .

Tagetes, 165.

Tamaricacées, 182

Tomorindus, 193, 194, 287.

288.

Tamaris (Tamarix), 9. 26. $87,88,227,278,279$; mannifera, 182

Tampico, 260, 262.

Tanaisie (Tanacetum), 7, 166 . Tanghinio, 285, 286

Tannintes (Matières). 4. 256.

257, 280 .
Taxinées, 126, 128, 205

Taxodium distichum, 127

Taxus baccata, 46, 128.

Teck (Teciona), 176, 251, 252.

Tecoma, 175

Tef (Poa abyssinica), 132, 213.

Teigne (Lappa), 164.

Tengusa, 281 .

Téosinthe (Euchlana mexi-

cana), 130, 246.

ephrosia, 286, $26,187,270$,

$271,274,286$.

Térébinthacées, 187

Tetragonia expanso, 215.

Teucrium, 176.

Textiles (Plantes), 3, 173. 259 à 261.

Thalassia, 148.

Thalia dealbata, 149.

Thalle, 71, 107, 110, 111, 119,134

Thallophytes, 107, 108 à 119 .

Thapsia, 203, 291.

Théerer (Theo chinensis), 154 , $169,180,208,241,242$, 290. 305: - de Grewia, 279.

Théier du Paraguay (llex poroguayensis) $172,243$.

Theobroma, 186.

Thermopsis. 193.

Thesium, 161.

Thlaspi, 183.

Thrysopteris, 206.

Thunia, 153

Thuya, 21, 127, 128, 272. 297: - de Barbarie (Cal. litris), 252, 253.

Thymus vulgaris, 84,176 , 219:- Serpyllum, 176.

Thymélacées, 227.

Tige, 20 aे 25,52 .

Tigridia pavonia, 146, 147, P]. 12.

Tiliées. 179, 180.

Tillandsia. 45, 58, 93, Pl. 12.

$147,148,149$

Tilleul (Tilia), 21, 33, 40, 43. $64,65,85,180,206,247$. $250,253,254,255,260$. $287,288,294,304$

Tinctoriales(PI.) 4, 265, 266.

Tinospora crispa, 55

Tococa lancifolia, 65, 66, 67.

Tocusso d'Abyssinie (Eleu-

sine Coracana). 133, 246.

Toddy, 140,141, 142, 238.

Todea, 96, 123,124

Tomate (Lycopersicum), 102. $171,218,297$

Topinambour (Helianthus (uberosus). 73, 165, 166 $217,247$.

Toque (Scutella), 176.

Torreya, 206.

Toundra, 74, 75, 79

Tourbe, 120, 206, 247, 262.

Tourresol (Helionthus onnuus), 165; - (Chrozophora tinctoria), 181, 266.

Tout épice (Pimenta officinalis). 220.

Trachycarpus, 137, 138, 262.

Tradescantia, 144.

Transformisme, 98 à 105.

Transpiration, 32, 52.

Trapa natans, 200.

Trèfle (Trifolium), 26, 47. 2. $98,99,175,191,245$ $246,305$.

Trèfle aigre (Oxolis acetosel-

la) 185 .

Trèfle d'eau (Menyanthes trifoliata), 174.

Tremble (Populus Tremula),
161, 206, 247, 253, 258. Tremellinées, 115.

Trichocolées. 120.

113.114, 118 (c)

Trichomanes, 58, 92, 124.

Trichopilia, 152 .

Triglochin, 136.

Trigonello, 191.

Triodie (Triodia), 97.

Tripoli, 112, 253

Trisète (Trisetum), 132.

Triticum, $133.12,143,144$.

Tritonia, 146

Triuriacées, 59.

Troscart (Triglochin), 136.

Troène (Ligustrum), 171, 249. 254.

Trollius europaus, 9. Pl. 1.

Tropaolum, 184, $185^{\circ}$.

Tropicale (F́lore), 89 à 94.

Tropismes, 51.

ruffe comestible (Tuber).

$115,116,159,219$. 


\section{TABLE DES MATIÈRES}

INTRODUCTION.

Pager.

I VIl. - Gamopétales supérovariées . . . . . . . . . 169

VIII. - Dialypétales supérovariées . . . . . . . 177

\section{LA VIE VÉGÉTALE}

I. - Les Organes de la plante .......... II

II. - Rapports des plantes avec les organismes. . . . 54

III. - Rapports des plantes avec le milieu . . . . 70

IV. - Le Transformisme. . . . . . . . . . . . 98

IX. - Dialypétales inférovariées. . . . . . . . . 199

X. - Les Plantes fossiles ............ 205

\section{LA CLASSIFICATION BOTANIQUE}

1. - Les Voyages et la botanique . . . . . . . 106

II. - Les Plantes sans fleurs . . . . . . . . 108

III. — Les Plantes à fleirs : Gymnospermes. . . . .. 125

IV. - Monocotylédones . . . . . . . . . . . 129

V. - Dicotylédones apétales .......... 155

Vl. - Gamopétales inférovariées. . . . . . . . . 162

\section{UTILITÉ DES VÉGÉTAUX}

1. - La Culture du sol ............ 209

II. - Les Plantes alimentaires . . . . . . . . 210

III. - Les Plantes pour boissons . . . . . . . . 236

IV. - Les Plantes fourragères. . . . . . . . . . . 244

V. - Les Plantes industrielles . . . . . . . . . 248

Vl. - Plantẹs à usages divers. . . . . . . . 278

VII. - Plantes médicinales et vénéneuses . . . . 285

VIll. - Plantes d'ornement . . . . . . . . . . 294

IX. - Folklore, mythes et légendes . . . . . 306

INDEX . . . . . . . . . . . . . . . . . 309

\section{HORS-TEXTE EN COULEURS}

Pages.

Plantes alpines .................. 8

Plantes deau. . . . . . . . . . . . 70

Planisphère de la distribution des fores naturelles . . . 90

Principales variétés de Champignons......... 118

Broméliacées, Liliacées, Iridées, etc. . . . . . . . . 144

Plantes vénéneuses . . . . . . . . . . . . 286

Orchidées. .......

Rosacées, Légumineuses, Crassulacées, etc. . . . . . . 192

Fruits exotiques. . . . . . . . . . . . . . . . . . 224

Planisphère des principales cultures du globe. . . . . . . 244

Carte des cultures et productions des colonies françaises . 260

\section{HORS-TEXTE EN NOIR}

\begin{tabular}{|c|c|c|c|}
\hline & Pages. & & Pages. \\
\hline Figuier banian et ses racines adventives & 18 & Un Ombu en République Argentine & 158 \\
\hline Les Jardins de la villa Tasca, à Palerme. & 28 & Les Victoria regia, à Buitenzorg (Java). & 178 \\
\hline Après la récolte des dattes (Sud Algérien). & 42 & Un Détail de la roseraie de l'Hä̈ (Seine). & 196 \\
\hline Lianes en forêt, à Madagascar. & 54 & Disposition d'une rizière, au Mexique. & 21 \\
\hline Hôtel dans une forêt de Sequoia gigantea. & 84 & Un Vignoble à Cochem, vallée de la Moselle. & 2 \\
\hline Fougères arborescentes dans une forêt australienne & 96 & Le Triage des roses, à Grasse. & 274 \\
\hline Cyprès sur les bords du lac de Garde & 128 & Allée de Dracana, au jardin du Hamma (Alger). & 296 \\
\hline
\end{tabular}

Une Pièce d'eau couverte de Lotus (Japon). . . . . . 306

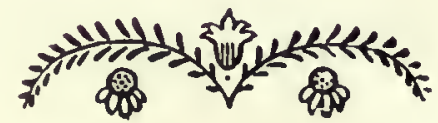






\section{0 - Ho - n}

in

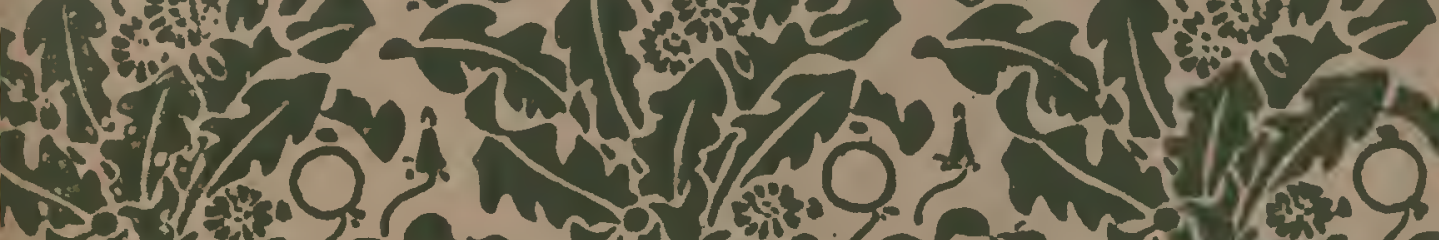

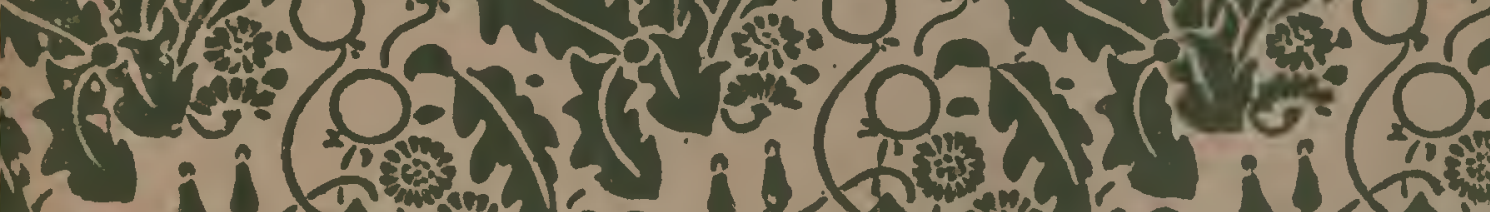

11

n. 10.12

o.

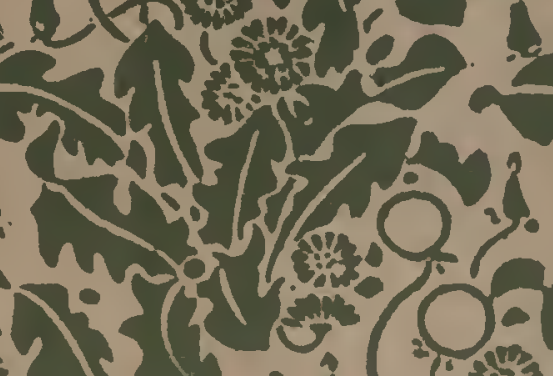

\section{nillo}

(1) 2. 15 $y$

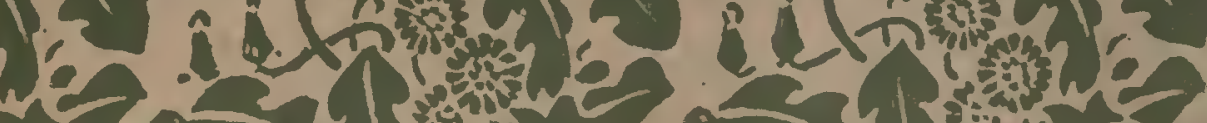

ans

Nin $3.1 \%$

(2)

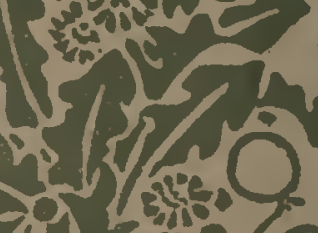

61 an:

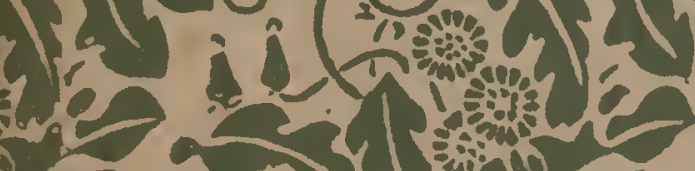

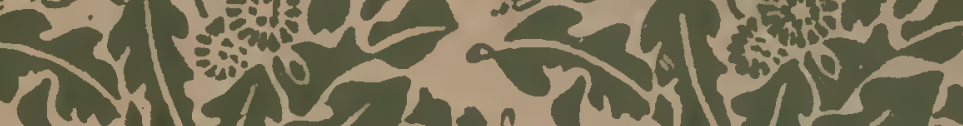

$32\left(\frac{\pi}{4}\right)$

3 .

ons

$\mathrm{Sim}^{2}$

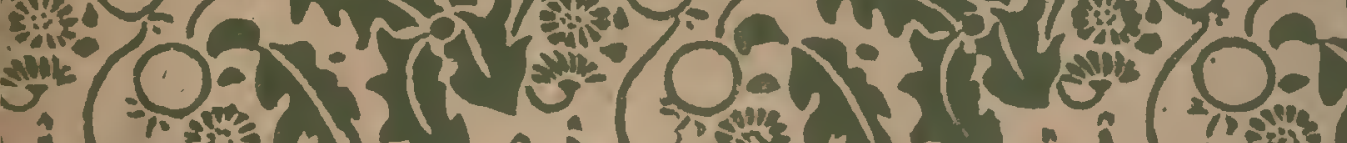

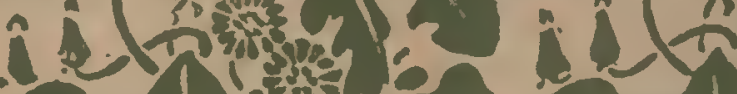

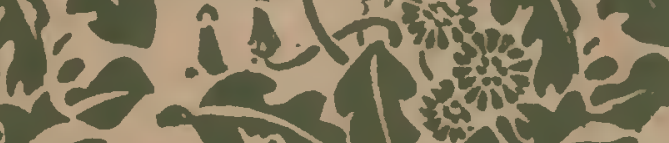

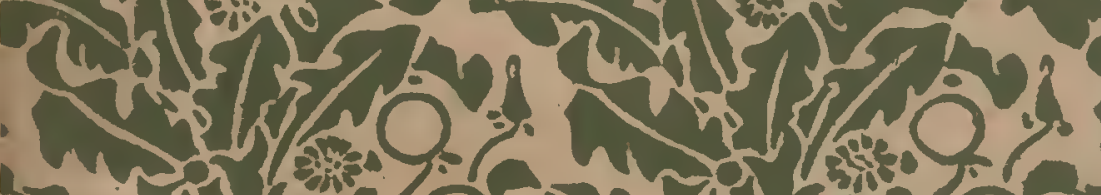

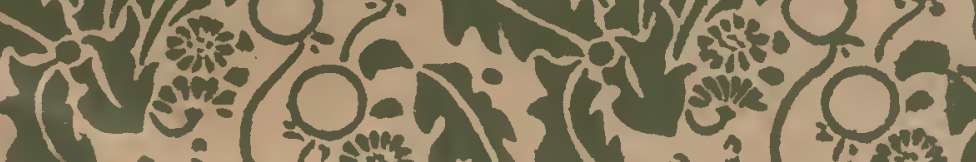

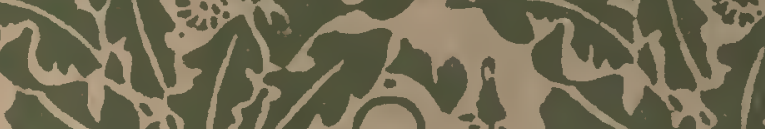

2

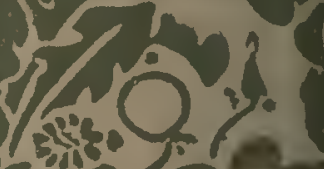

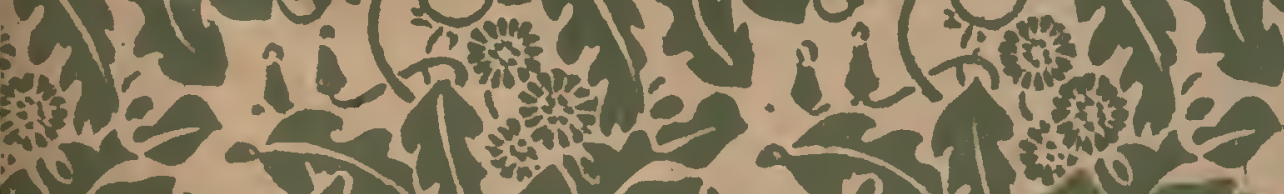

(3)

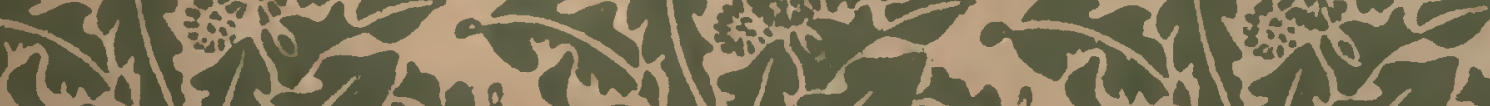

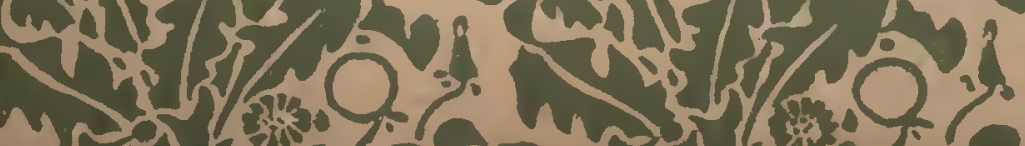

. 13120

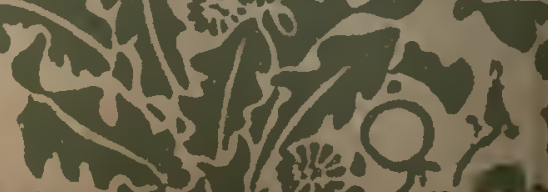

sink $O$

3. $\frac{\text { nthe }}{10}$

21 s?

(iv)

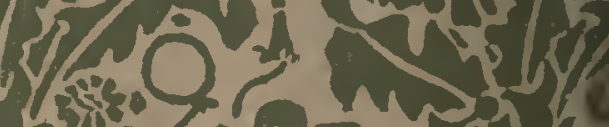
$-210-12$ 
Iy,..

1) $2 x+5=0$

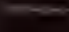

$\boldsymbol{N}_{\mathrm{n}}$ 